
2. (6): monIt:

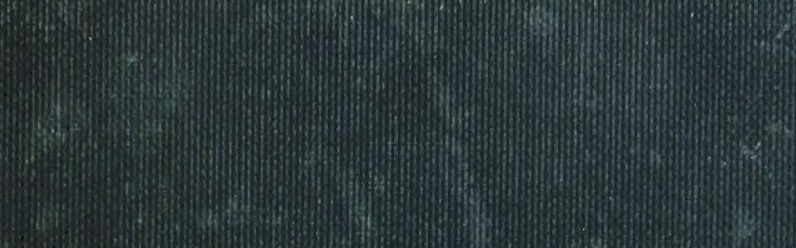

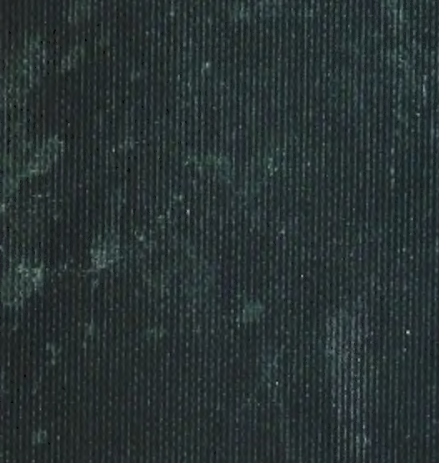

19.

3.

iftisis

6.

H)

nom Don219.

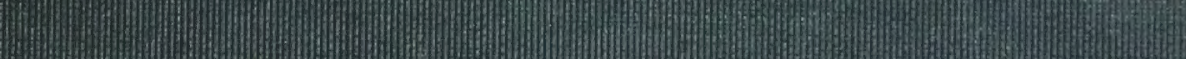
16: 


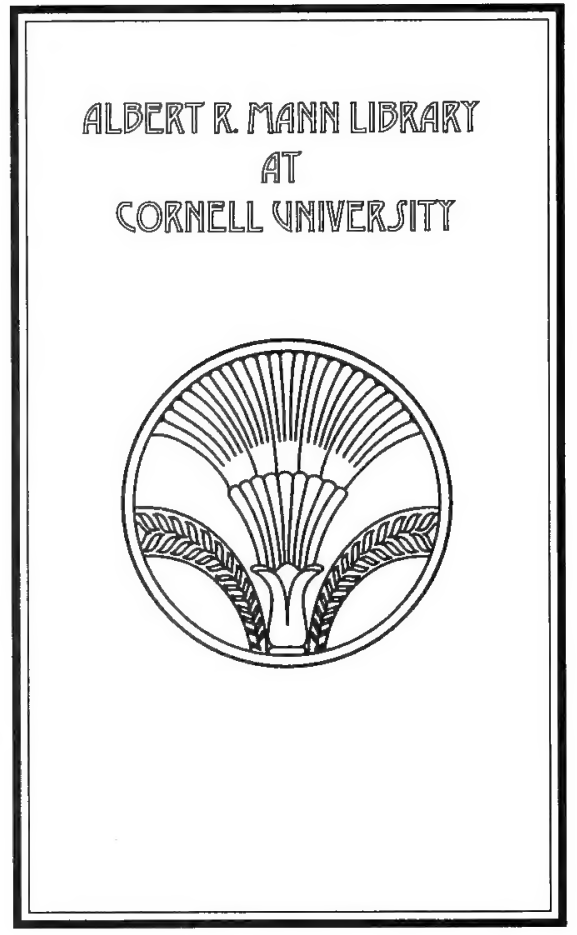




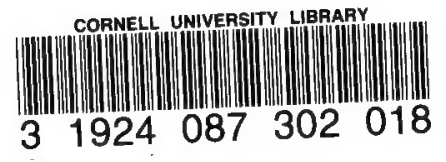

All books are subject to recall after two weeks DATE DUE

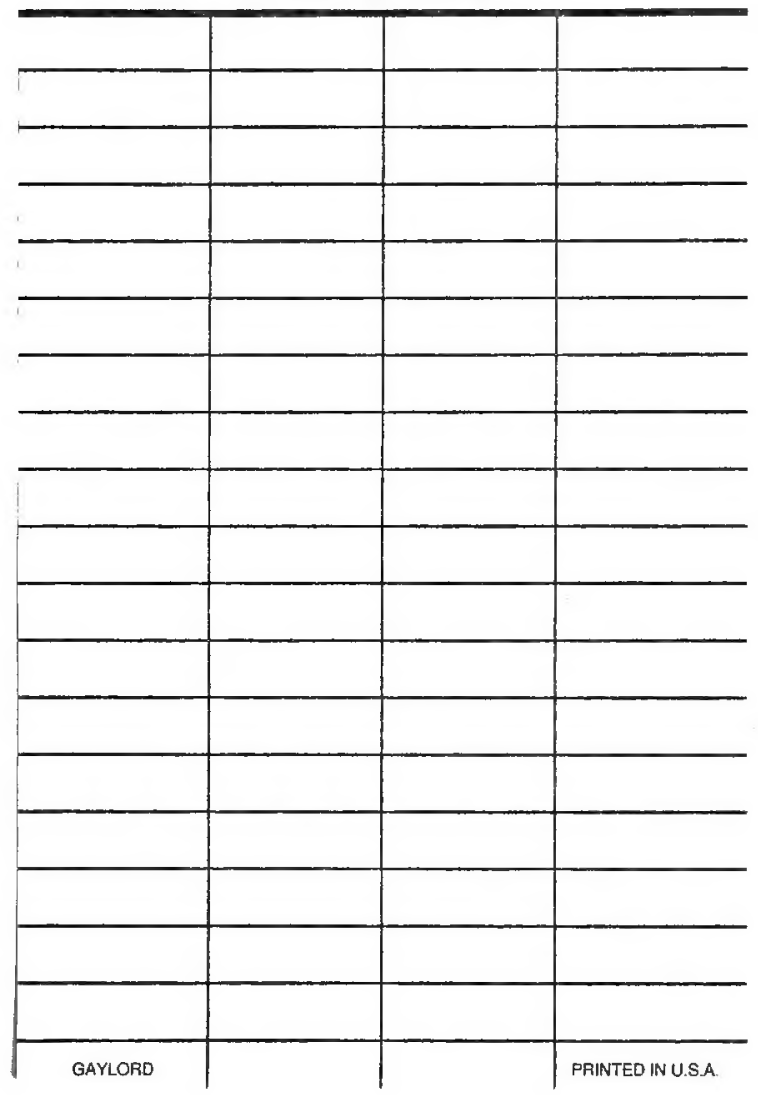




\section{Cornell University Library}

The original of this book is in the Cornell University Library.

There are no known copyright restrictions in the United States on the use of the text.

http://www.archive.org/details/cu31924087302018 
THE STRUCTURE AND DEVELOPMENT OF MOSSES AND FERNS 


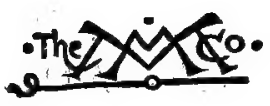




\title{
The Structure and Development
}

\section{of \\ Mosses and Ferns}

(Archegoniatae)

THIRD EDITION, REVISED AND ENLARGED

\author{
BY \\ Douglas houghton CAMPBell, Ph.D. \\ PROFESSOR OF BOTANY \\ IN THE \\ LELAND STANFORd JUNIOR UNIVERSITY
}

few 骡ork

THE MACMILLAN COMPANY

London: Macmillan \& Co., Ltd.

1918

All rights reserved 


\section{COPYRIGHT, 1905}

\section{By THE MACMILLAN COMPANY}

Set up and electrotyped

Published, September, I905

Reprinted July, I9:3 


\section{PREFACE TO THE SECOND EDITION}

Since the first edition of the present work was published, the number of important investigations on the structure and development of the Archegoniatæ has been so great that it has been found necessary to recast entirely certain portions of the work, this being especially the case with the chapters dealing with the eusporangiate Ferns. The whole book, however, has been carefully revised, and a good deal of new matter introduced, including two special chapters on the geological history of the Archegoniates, and the significance of the alternation of generations.

Some of the new material incorporated in the present work is published for the first time; but much of it is based upon papers published by the writer since the first edition was published. The work of other investigators has been freely drawn upon, and acknowledgment has been made in all cases where statements or illustrations have been borrowed from other sources than the writer's own investigations.

The large number of recent books and papers on the Archegoniates has involved an entire revision of the bibliography, which has been materially augmented. It is hoped that it will be found to be a fairly complete list of the more recent works bearing upon the structure of the Archegoniates.

The results of more recent investigations have necessitated, in some cases, a modification of certain views expressed by the author in the earlier edition. In other cases, however, his views have been confirmed as the result of more complete knowledge of certain forms. 
In view of the decidedly unsettled state of nomenclature at the present time, it has seemed best to maintain a somewhat conservative attitude in this matter, and this will explain the retention of some familiar names, which perhaps are not in accord with a strict law of priority.

The author is especially indebted to Professor E. C. Jeffrey and to Dr. W. R. Shaw, for valuable preparations which were of great assistance in the preparation of the chapters on the Ferns. Thanks are also due one of my students, Mr. H. B. Humphrey, for the preparation of the drawings for figures 43,44 and 47 .

The author also would express his thanks to Professor D. S. Johnson of Johns Hopkins University for kindly revising a portion of the bibliography, and to Professor G. J. Peirce of Stanford University for valuable assistance in reading part of the proof.

DOUGLAS HOUGHTON CAMPBELL.

Stanford University,

April, I905. 


\section{PREFACE TO THE THIRD EDITION}

IN the second edition of the "Mosses and Ferns," the original text was carefully revised, and a good deal of it was rewritten. At the same time considerable new matter was added. In preparing the present edition of the book, it has not seemed necessary to change the body of the text, the new material being given in the form of an appendix.

Since the publication of the last edition, as might be expected, numerous contributions have been made to the literature of the Morphology and Classification of the Archegoniates. Among these contributions are several publications by the writer. These are for the most part based upon collections of tropical Liverworts and Ferns made by the writer, including some new and rare species of the Indo-Malayan region.

A summary of the more important results of these studies as well as those of other investigators is added to the text in the form of an appendix, in which the new material is arranged under the Chapter headings which deal with the allied topics in the main text. In the appendix, also, certain errors of statement and reference in the original text have been corrected.

The numerous additions in the literature on the subject have necessitated a complete revision of the bibliography, which has been very considerably enlarged.

It is hoped that with the appendix and augmented bibliography the book will prove a satisfactory statement of our present knowledge of the structure and development of the Archegoniate Plants.

Stanford University,

DOUGLAS HOUGHTON CAMPBELL. January, I9I8. 



\section{CONTENTS}

CHAPTER I

INTRODUCTION

CHAPTER II

Muscinee (Bryophyta)-Hepatic E-Marchantiales

CHAPTER III

The Jungermanniales

CHAPTER IV

The ANTHOCEROTES 120

CHAPTER V

The Mosses (Musci) : Sphagnales-Andrefeales.............. i6o CHAPTER VI

The Bryales I88

CHAPTER VII

The Pteridophyta-Filicinex-Ophioglossacex 229

CHAPTER VIII

Marattiales 273

CHAPTER IX

Finicinea Leptosporangiate 305

CHAPTER $\mathrm{X}$

The Homosporous Leptosporangiatex (Filices) 346

CHAPTER XI

Leptosporangiate Heterosporexe (H ydropterides) $\ldots \ldots \ldots \ldots \ldots \ldots, 396$ CHAPTER XII

EquiseTINEA 443

CHAPTER XIII

LYCOPODINEA 483

CHAPTER XIV

ISOETACE $\mathbb{E}$ 536

CHAPTER XV

The Nature of the Alternation of Generations............. 562 CHAPTER XVI

Fossil ARchegoniates 576

CHAPTER XVII

Summary and Conclusions 592 


\section{CONTENTS}

APPENDIX

Bibliography

INDEX. 


\section{CHAPTER I}

\section{INTRODUCTION}

UNDER the name Archegoniatæ are included a large number of plants which, while differing a good deal in many structural details, still agree so closely in their essential points of structure and development as to leave no room for doubting their close relationship. Besides the Bryophytes and Pteridophytes, which are ordinarily included under this head, the Gymnospermæ or Archespermæ might very properly be also embraced here, but we shall use the term in its more restricted meaning.

The term Archegoniatæ has been applied to these plants because the female reproductive organ or archegonium is closely alike, both in origin and structure, in all of them. This is a multicellular body, commonly flask-shaped, and either entirely free or more or less coherent with the tissues of the plant. In all cases there is an axial row of cells developed, of which the lowest forms the egg. The others become more or less completely disorganized and are discharged from the archegonium at maturity. Among the Algæ there is no form at present known in which the female organ can be certainly compared to the archegonium, although the oogonium of the Characeæ recalls it in some respects.

The antheridium or male organ of the Archegoniatæ, while it shows a good deal of similarity in all of them, still exhibits much more variation than does the archegonium, and is more easily comparable with the same organ in the Algæ, especially the Characea. Like the archegonium it may be entirely free, or even raised on a long pedicel; or it may be completely sunk in the tissue of the plant, or even be formed endogenously. It usually consists of a single outer layer of cells containing 
chlorophyll, and these enclose a mass of small colourless cells, the sperm cells, each of which gives rise to a single ciliated spermatozoid. The development of the latter is very uniform throughout the Archegoniatæ, and differs mainly from the same process in the higher green Algæ, especially the Characeæ, in the larger amount of nuclear substance in the spermatozoids of the former.

Fertilisation is only effected when the plants with ripe sexual organs are covered with water. The absorption of water by the mature sexual organs causes them to open, and then, as the spermatozoids are set free, they make their way through the water by means of their cilia and enter the open archegonium, into which they penetrate to the egg. The sexual cells do not differ essentially from those of the higher Algæ, and point unmistakably to the origin of the Archegoniatæ from similar aquatic forms. Indeed all of the Archegoniatæ must still be considered amphibious, inasmuch as the gametophyte or sexual plant is only functional when partially or completely submerged.

Non-sexual gonidia are known certainly only in Aneura, one of the lower Liverworts, but special reproductive buds or gemmæ, both unicellular and multicellular, are common in many forms.

A very marked characteristic of the whole group is the sharply-marked alternation of sexual and non-sexual stages. The sexual plant or gametophyte varies much in size and complexity. It may be a simple flat thallus comparable in structure to some Algæ, and. not superior to these in complexity so far as the vegetative parts are concerned. In others it becomes larger and shows a high degree of differentiation. Thus among the Liverworts the Marchantiaceæ, while the gametophyte still retains a distinctly thalloid form, still show a good deal of variety in the tissues of which the thallus is composed. In others, e.g., the true Mosses, the gametophyte has a distinct axis and leaves, and in the higher ones the tissues are well differentiated for special functions. The gametophyte itself may show two well-marked phases, the protonema and the gametophore. The former is usually filamentous, and arises directly from the germinating spore; and upon the protonema, as a special branch or bud, the much more complex gametophore is borne. Often, however, as in many thallose 
Liverworts and Pteridophytes, the protonema is not clearly distinguishable from the gametophore, or may be completely suppressed. In the Pteridophytes the gametophyte is, as a rule, much simpler than in the Bryophytes, resembling most nearly the less specialised forms of the latter. In the so-called heterosporous Pteridophytes the gametophyte becomes extremely reduced and the vegetative part almost entirely suppressed, and its whole cycle of development may, in extreme cases, be completed within twenty-four hours or even less.

The non-sexual generation, or "sporophyte," arises normally from the fertilised egg, but may in exceptional cases develop as a bud from the gametophyte. In its simplest form all the cells of the sporophyte, except a single layer upon the outside, give rise to spores, but in all the others there is developed a certain amount of vegetative tissue as well, and the sporophyte becomes to a limited extent self-supporting. "In the higher Bryophytes the sporophyte sometimes exceeds in size the gametophyte, and develops an elaborate assimilative system of tissues, abundantly supplied with chlorophyll and having an epidermis with perfect stomata; but even the most complex moss-sporogonium is to a certain extent dependent upon the gametophyte with which it remains in close connection by means of a special absorbent organ, the foot. In these highly developed sporogonia the sporogenous tissue occupies but a small space, by far the greater part of the tissue being purely vegetative.

In the Pteridophytes a great advance is made in the sporophyte beyond the most complex forms found among the Bryophytes. This advance is twofold, and consists both in an external differentiation and a more perfect development of the tissues. The earliest divisions of the embryo resemble very closely those of the Bryophyte sporogonium, but at an early stage four distinct organs are usually plainly distinguishable, viz., stem, leaf, root, and foot. The last corresponds in some degree to the same organ in the moss-sporogonium, and like it serves as an absorbent organ by which the young sporophyte is supplied with nourishment from the gametophyte. In short, the young sporophyte of the Pteridophyte, like that of the Bryophyte, lives for a time parasitically upon the gametophyte. Sooner or later, however, the sporophyte becomes entirely independent. This is effected by the further growth of the 
primary root, which brings the young sporophyte into direct communication with the earth. The primary leaf, or cotyledon, enlarges and becomes functional, and new ones arise from the stem apex. Usually by the time this stage is reached the gametophyte dies and all trace of it soon disappears. In some of the lower forms, however, the gametophyte is large and may live for many months, or even years, when not fecundated, and even when the sporophyte is formed, the prothallium (gametophyte) does not always die immediately, but may remain alive for several months. The spore-forming nature of the sporophyte does not manifest itself for a long time, sometimes many years, so that spore-formation is much more subordinate than in the highest Bryophytes. With few exceptions the spores are developed from the leaves and in special organs, sporangia. In the simplest case, e. g., Ophioglossum, the sporangia are little more than cavities in the tissue of the sporiferous leaf, and project but little above its surface. Usually, however, the sporangia are quite free from the leaf and attached only by a stalk. These sporangia are in the more specialised forms of very peculiar and characteristic structure, and are of great importance in classification.

Corresponding to the large size and development of special organs in the sporophyte of the Pteridophytes, there is a great advance in the specialisation of the tissues. All of the forms of tissue found in the Spermaphytes occur also among the Pteridophytes, which indeed, so far as the character of the tissues of the sporophyte is concerned, come much nearer to the former than they do to the Bryophytes. This is especially true of the vascular bundles, which in their complete form are met with first in the sporophyte of the Pteridophyta. In size, too, the sporophyte far exceeds that of the highest Mosses; while in these the sporogonium seldom exceeds a few centimetres in extreme height, in some Ferns it assumes tree-like proportions with a massive trunk Io to 15 metres in height, with leaves 5 to 6 metres in length.

In the formation of the spores all of the Archegoniatre show great uniformity, and this extends, at least as regards the pollen spores, to the Spermatophytes as well. In all cases the spores arise from cells which at first form a solid tissue arising from the division of a single primary cell, or group of cells (Archesporium). These cells later become more or less 
completely separated, and each one of these so-called "spore mother cells," by division into four daughter cells, forms the spores. The young spores are thin walled, but later the wall becomes thicker and shows a division into two parts, one inner layer, which generally shows the cellulose reaction and is called the endospore (intine), and an outer more or less cuticularised coat, the exospore (exine). In addition a third outer coat (perinium, epispore) is very generally present. As the spore ripens there is developed within it reserve food materials in the form of starch, oil, and albuminous matter, and quite frequently chlorophyll is present in large quantity. Some spores retain their vitality but a short time, those of most species of Equisetum and Osmunda, for example, germinating with difficulty if kept more than a few days after they are shed, and very soon losing their power of germination completely. On the other hand, some species of Marsilia have spores so tenacious of life that they germinate perfectly after being kept for several years.

From the germinating spore arises the gametophyte bearing the sexual organs. Both archegonia and antheridia may be borne upon the same plant, or they may be upon separate ones. From the fertilised egg within the archegonium is produced the sporophyte or non-sexual generation, and from the spores which it produces arise the sexual individuals again, thus completing the cycle of development.

On comparing the lower Archegoniates with the higher ones, it is at once evident that the advance in structure consists mainly in the very much greater development of the sporophyte. In the Bryophytes, as a class, the gametophyte is more important than the sporophyte, the latter being, physiologically, merely a spore-fruit, which in many forms, e. g., Sphagnum, is of relatively rare occurrence. The gametophyte in such forms is perennial, and the same plant may produce a large number of sporogonia, and at long intervals. The sporophyte in such forms is small and simple in structure, and its main function is spore formation, as it has but little power of independent growth. In the Pteridophytes, on the other hand, the gametophyte (prothallium) rarely produces more than one sporophyte, and as soon as this, by the formation of a root and leaf, becomes self-supporting, the gametophyte dies. In short, the sole 
function of the latter in most of them is to support the sporophyte until it can take care of itself.

When the lower Pteridophytes are compared with the more specialised ones, a similar difference is found. In the lower forms, like the Marattiaceæ and Equisetaceæ, the gametophyte is relatively large and long-lived, and closely resembles certain Liverworts. In these forms a considerable time elapses before sexual organs are produced, and in artificial cultures of the Marattiacea a year or more sometimes passes before archegonia are formed. These prothallia, too, multiply by budding, much as the Liverworts do. In case no archegonia are fecundated the prothallium may grow until it reaches a length of three or four centimetres, and resembles in a most striking manner a thallose Liverwort. In such large prothallia it is not unusual for more than one archegonium to be fecundated, although usually only one of the embryos conies to maturity, and the prothallium may continue to live for some time after the sporophyte has become independent. Usually, however, as soon as an archegonium is fertilised, the formation of new ones ceases, and as soon as the sporophyte is fairly rooted in the ground the prothallium dies.

In most of the lower Pteridophytes the prothallia are monœcious, but in the more specialised ones are markedly diocious. When this is least marked the males and females differ mainly in size, the latter being decidedly larger; in the more extreme cases the difference is much more pronounced and is correlated with a great reduction in the vegetative part of the gametophyte of both males and females. This reaches its extreme phase in the so-called heterosporous forms. In these the sex of the gametophyte is already indicated by the character of the spore. Two sorts of spores are produced, large and small, which produce respectively females and males. In all of the heterosporic Pteridophytes the reduction of the vegetative part of the gametophyte is very great, especially in the male plants. Here this may be reduced to a single quite functionless cell, and all the rest of the plant is devoted to the formation of the single antheridium. In the female plants the reduction is not so great; and although sometimes but one archegonium is formed, there may be in some cases a considerable number, and owing to the large amount of nutritive material in the spore, in case an archegonium is not fertilised, 
the prothallium, even if it does not form chlorophyll, may grow for a long time at the expense of the food materials that normally are used by the developing embryo. In strong contrast to the slow growth and late development of the reproductive organs in the homosporous forms, most of the heterosporous Pteridophytes germinate very quickly. The Marsiliaceæ, in which the female prothallium is extremely reduced, show the opposite extreme. Here the whole time necessary for the germination of the spores and the maturing of the sexual. organs may be less than twenty-four hours, and within three or four days more the embryo is completely developed.

That heterospory has arisen independently in several widely separated groups of Pteridophytes is plain. The few genera that still exist are readily separable into groups that have comparatively little in common beyond possessing two sorts of spores; but each of these same forms shows much nearer affinities to certain widely separated homosporous groups.

In some of the heterosporous forms the first divisions in the germinating spore take place while it is still within the sporangium, and may begin before the spore is nearly fully developed. In other cases the sporangia become detached when ripe, and the spore (or spores), still surrounded by the sporangium, falls away from the sporophyte before germination begins. In these respects the heterosporous Pteridophytes show the closest analogy with the similar processes among the lower Spermatophytes, where it has been shown in the most conclusive manner that the ovule with its enclosed embryo-sac is the exact morphological equivalent of the macrosporangium of Selaginella or Azolla, for example, and that the seed is simply a further development of the same structure. 


\section{CHA P T E R II}

\section{MUSCINAE (BRYOPHYTA)-HEPATICAE-MARCHANTIALES}

The first division of the Archegoniatæ, the Muscineæ or Bryophyta, comprises the three classes, Hepaticæ or Liverworts, the Musci or Mosses and the Anthocerotes. In these as a rule the gametophyte is much more developed than the sporophyte, and indeed in many forms the latter is very rarely met with. They are plants of small size, ranging in size from about a millimetre in length to 30 centimetres or more. A few of them are strictly aquatic, i. e., Riella and Ricciocarpus among the Hepaticæ, and Fontinalis of the Mosses; but most of them are terrestrial. A favourite position for many is the trunks of trees or rocks. Many others grow upon the earth. They vegetate only when supplied with abundant moisture, and some forms are very quickly killed if allowed to become dry; but those species which grow in exposed places may be completely dried up without suffering, and some of those that inhabit countries where there are long dry periods may remain in this condition for months without losing their vitality, reviving immediately and resuming growth as soon as they are supplied with the requisite moisture.

The germinating spores usually produce a more or less well-marked "protonema," from which the gametophore arises secondarily. The protonema sometimes is persistent and forms a dense conferva-like growth, but more commonly it is transient and disappears more or less completely after the gametophore is formed. No absolute line, however, can be drawn between protonema and gametophore, as the former may arise secondarily from the latter, or even from the sporophyte. With very few exceptions, e.g., Buxbaumia, the gametophyte of the Muscineæ is abundantly supplied with chloro- 
phyll, and therefore capable of entirely independent growth. No true roots are found, but rhizoids are generally present in great numbers, and these serve both to fasten the plant to the substratum and also to supply it with nutriment.

The form of the gametophyte varies much. In the simplest Hepatica, like Aneura and Pellia, it is a flat, usually dichotomously branched thallus composed of nearly or quite uniform cells, without traces of leaves or other special organs. From this simplest type, which is quite like certain Algæ, differentiation seems to have proceeded in two directions; in the first instance the plant has retained its thallose character, but there has been a specialisation of the tissues, as we see in the higher Marchantiaceæ. In the second case the differentiation has been an external one, the thallose form giving place to a distinct leafy axis. This latter form reaches its completest expression in the higher Mosses, where it is accompanied by a high degree of specialisation of the tissues as well. The growth is usually from a single apical cell, which varies a good deal in form among the thallose Hepaticx, but in the foliose Hepaticæ and Mosses is with few exceptions a three-sided pyramid.

The gametophyte of the Muscineæ frequently is capable of rapid multiplication, which may occur in several ways. Where a filamentous protonema is present this branches extensively, and large numbers of leafy axes may be produced as buds from it. Sometimes these buds are arrested in their development and enter a dormant condition, and only germinate after a period of rest. Another very common method of multiplication is for the growing ends of the branches of a plant to become isolated by the dying away of the tissues behind them, so that each growing tip becomes the apex of a new plant. Very common in the Hepatica, but less so in the Mosses, is the formation of gemmæ or special reproductive buds. These are produced in various ways, the simplest being the separation of single cells, or small groups of cells, from the margins of the leaves. In the case of Ancura multifida they are formed within the cells and discharged in a manner that seems to be identical with that of the zoospores of many Algæ. Again, multicellular gemma of peculiar form occur in several of the Hepaticæ, e.g., Blasia, Marchantia, where they occur in special receptacles, 
and amons the Mosses similar ones are common in Tetraphis and some uther genera.

The archegonia of all the Muscinex agree closely in their earlier stages, but differ more or less in the different groups at maturity. In all cases the archegonium arises from a single superficial cell, in which three vertical walls are formed that intersect so as to form an axial cell and three peripheral ones. From the axial cell develop the egg, canal cells, and cover cells of the neck, and from the peripheral cells the wall of the venter and the outer neck cells. In all Muscineæ except the Anthocerotes the archegonium mother cell projects above the surrounding cells, but in the latter the mother cell does not project at all, and the archegonium remains completely sunken in the thallus. In all other forms the archegonium is nearly or quite free, and usually provided with a short pedicel. This is especially marked in the Mosses, where the lower part of the archegonium is as a rule much more massive than in the Hepaticæ.

The most marked difference, however, between the archegonium of the Hepaticæ and Mosses is in the history of the cover cell or uppermost of the axial row of cells of the young archegonium. This in the former divides at an early period into four nearly equal cells by vertical walls, the resulting cells either remaining undivided, or undergoing one or two more divisions; but in the Mosses this cell functions as an apical cell, and to its further growth and division nearly the whole growth of the neck is due.

The antheridia, except in the Anthocerotes, also arise from single superficial cells, and while they differ much in size and form, are alike in regard to their general structure. The antheridium always consists of two parts; a stalk or pedicel, which varies much in length, and the antheridium proper, made up of a single layer of superficial cells and a central mass of small sperm cells. The former always contain chloroplasts, which often become red or yellow at maturity. The sperm cells have no chlorophyll, but contain abundant protoplasm and a large nucleus, which latter forms the bulk of the body of the spermatozoid found in each sperm cell of the ripe antheridium. The spermatozoids are extremely minute filiform bodies, thicker behind and provided with two fine cilia attached to the forward end. Adhering to the thicker posterior end there may usually be seen a delicate vesicle, which represents the 
remains of the cell contents not used up in the formation of the spermatozoid.

When the ripe sexual organs are placed in water their outer cells absorb water rapidly and become strongly distended, while the central cells, i.e., the canal cells of the archegonium, and the sperm cells, whose walls have become mucilaginous, have their walls dissolved. The swelling of the mucilage derived from the walls of the central cells, combined with the pressure of the strongly distended outer cells, finally results in the bursting open of both archegonium and antheridium. In the former, by the forcing out of the remains of the canal cells an open channel is left down to the egg, which has been formed by the contracting of the contents of the lowest of the axial cells. In the antheridium the walls of the sperm cells are not usually completely dissolved at the time the anther idium opens, so that the spermatozoids are still surrounded by a thin cell wall when they are first discharged. This soon is completely dissolved, and the spermatozoid then swims away. The substance discharged by the archegonium exercises a strong attraction upon the spermatozoids, which are thus directed to the open mouth of the archegonium, which they enter. Only a single one actually enters the egg, where it fuses with the egg-nucleus, and thus effects fertilisation. The egg immediately secretes a cellulose wall about itself, and shortly after the fusion of the nuclei is complete the first segmentation of the young embryo takes place.

The origin of the sexual organs is from a single cell, but the position of this cell varies much. In the thallose Hepaticæ it is a superficial cell, formed from a segment of the apical cell either of a main axis or of a special branch. In most of the foliose Hepaticæ and the Mosses, the apical cell of the shoot becomes itself the mother cell of an archegonium, and of course with this the further growth of the axis is stopped. The antheridia in the foliose Hepaticæ are usually placed singly in the axils of more or less modified leaves, but in most Mosses the antheridia form a terminal group. Mixed with the sexual organs are often found sterile hair-like organs, paraphyses, often of very characteristic forms. In the foliose Hepaticæ and most Mosses, the archegonia are often surrounded by specially modified leaves, and in the former there is also an inner cup-like perichætium formed from the tissue surrounding 
the archegonia. In the thallose Hepaticæ, both antheridia and archegonia are generally enclosed by a sort of capsule, similar to the perichætium of the foliose forms formed by the growth of the tissue of the thallus immediately surrounding them.

\section{The Asexual Generation}

\section{(Sporophyte, Sporophore, Sporogonium)}

The sporophyte of the Muscinex is usually known as the sporogonium, and, as already stated, never becomes entirely independent of the gametophyte. After the first divisions are completed there is at an early period, especially in the Hepaticæ, a separation of the spore-producing tissue or archesporium, all the cells of which may produce spores, as in Riccia and the Mosses, or a certain number form special sterile cells which either undergo little change and serve simply as nourishment for the growing spores, as in Sphcrocarpus, or more commonly assume the form of elongated cells,-elaters, which assist in scattering the ripe spores.

\section{Classification}

\section{Class I. Hepatice (Liverworts)}

The protonema is either rudimentary or wanting, and usually not sharply differentiated from the gametophore. The gametophore is, with the exception of Haplomitrium and Calobryum, strongly dorsiventral, and may be either a (usually dichotomously) branched thallus or a stem with two or three rows of leaves. Non-sexual multiplication of the gametophyte by the separation of ordinary branches, or by special reproductive bodies, gonidia (Aneura multifida) or gemmæ-(many foliose Jungermanniaceæ, Blasia, Marchantia, etc.). The sporogonium (except in Anthocerotes) remains within the enlarged venter (calyptra) of the archegonium until the spores are ripe. Before the spores are shed the sporogonium generally breaks through the calyptra by the elongation of the cells of the stalk or seta. All the cells of the archesporium may produce spores, or part of them may produce sterile cells or elaters. 
Class II. Anthocerotes.

Gametophyte, a simple thallus, or sometimes showing a trace of leaf-formation in Dendroceros; a single large chloroplast, containing a pyrenoid, in each cell; archegonium sunk in the thallus, the antheridium endogenous; sporophyte large, with long continued basal growth; sporogenous tissue derived from the outer tissue (amphithecium) of the embryo.

\section{Class III. Musci (Mosses)}

The gametophyte shows a sharp separation into protonema and gametophore. The protonema arises primarily from the germinating spore, and may be either a flat thallus or more commonly an extensively branching confervoid growth. Upon this as a bud the gametophore arises. This has always a more or less developed axis about which the leaves are arranged in two, three, or more rows. A bilateral arrangement of the leaves is rare, and the stems branch monopodially. The asexual multiplication is by the separation of branches through the dying away of the older tissues, or less commonly by special buds or gemmæ. Both stem and leaves have the tissues more highly differentiated than is the case in the Hepatica. The archesporium is developed as a rule later than is the case in the Hepaticæ, and within is a large central mass of tissue, the columella, which persists until the capsule is ripe. In most cases there is a large amount of assimilative tissue in the outer part of the capsule, and the epidermis at its base is provided with stomata. The growing embryo breaks through the calyptra at an early stage, and the upper part is in most cases carried up on top of the elongating sporogonium. In very much the greater number of forms the top of the capsule comes away as a lid (operculum).

\section{THE HEPATIC正}

The Hepaticæ show many evidences of being a primitive group of plants, and for this reason a thorough knowledge of their structure is of especial importance in studying the origin of the higher plants, as it seems probable that all of these are derived from Liverwort-like forms. On comparing the 
Hepaticæ with the Mosses one is at once struck with the very much greater diversity of structure shown by the former group, although the number of species is several times greater in the latter. On the one hand, the Hepaticæ approach the Algæ, the thallus of the simpler forms being but little more complicated than that of many of the higher green Alga. On the other hand, these same simpler Liverworts resemble in a most striking manner the gametophyte of the Ferns. The same difference is observed in the sporophyte. This in the simplest Liverworts, e. g., Riccia, is very much like the spore-fruit of Coleochete, one of the confervoid green Algæ; on the other hand, the sporogonium of Anthoceros shows some most significant structural affinities with the lower Pteridophytes. The simplest form of the gametophyte among the Hepatica is found in the thallose Jungermanniacex and Anthocerotes. In such forms as Aneura (Fig. 38) and Anthoceros (Fig. 55) the thallus is made up of almost perfectly uniform chlorophyllbearing tissue, fastened to the earth by means of simple rhizoids. In forms a little more advanced, e. g., Metzgeria, Pallavicinia (Fig. 38), there is a definite midrib present. From this stage there has been a divergence in two directions. In one series, the Marchantiacex, there has been a specialisation of the tissues, with a retention of the thallose form of the plant. In Riccia (Figs. I-9) we find two clearly marked regions, a dorsal green tissue, with numerous air-spaces, and a ventral compact colourless tissue. In the higher Marchantiaceæ (Fig. I6) this is carried still further, and the air-chambers often assume a definite form, and a distinct epidermis with characteristic pores is formed. In the Marchantiacere also ventral scales or leaf-like lamellæe are developed, and rhizoids of two kinds are present. Starting again from the flat, simple thallus of Ancura there has been developed the leafy axis of the more specialised Jungermanniaceæ. Between the latter and the strictly thallose forms are a number of interesting intermediate forms, like Blasia and Fossombronia, where the first indication of the two dorsal rows of leaves is met with; and in Blasia at least the rudiments of the ventral row of small leaves (amphigastra) usually found in the foliose forms are present.

The tissues of the Liverworts are very simple, and consist for the most part of but slightly modified parenchyma. Occasionally (Preissia) thickened sclerenchyma-like fibres occur, 
but these are not common. Mucilage cells of various kinds are common. The secreting cells may be hairs on the ventral surface, and especially developed near the apex, where the mucilaginous secretion serves to protect against drying up; or they may be isolated (Marchantia) or rows of cells (Conocephalus) within the tissue of the thallus.

The growth of the gametophyte is usually due to the division of a single apical cell. In some of the thallose forms, e.g., Marchantiacer, Anthocerotes, a single initial cell is not always to be recognised in the older thallus, but in these forms a single initial always appears to be present in the earlier stages. In the Jungermanniacex, however, a single apical cell is always distinguishable, but varies a good deal in form in different genera, at least among the thallose forms, or even in the same genus. Among the foliose Jungermanniaceæ it always has the form of a three-sided pyramid. From the apical cell segments are cut off in regular succession, and the first divisions of the segments also show much regularity, and often bear a definite relation to the tissues of the older parts.

\section{The Sexual Organs}

The archegonium is always traceable to a single cell, but the position of the mother cell is very different in different genera. In the simplest cases, e.g., Riccia, Spharocarpus (Figs. 2, 29), the mother cell is formed from a superficial cell of one of the youngest dorsal segments of the apical cell, close to the growing point of an ordinary branch of the thallus, whose growth is in no way affected by the formation of archegonia. In such forms the archegonia stand alone, and about each is developed a sort of involucre by the growth of a ring of cells immediately surrounding the archegonium rudiment. In other cases the archegonia are found in groups, e. g., Pallavicinia (Fig. $3^{8}$ ), separated by spaces where no archegonia are found. Here each group of archegonia has a common involucre. In Aneura and most of the higher Marchantiacex the archegonia are found in the same way, but upon special modified branches. In the foliose Jungermanniaceæ the origin of the archegonia is somewhat different. Here they are formed upon short branches, where, after a small number of perichætial leaves have been formed, the subsequent segments of the apical 
cell develop archegonia at once, and finally the apical cell itself becomes the mother cell of the last-formed archegonium, and, of course, with this the growth in length of the branch ceases. With the exception of the Anthocerotes, where the archegonium mother cell does not project at all, it quickly assumes a papillate form and is divided by a transverse wall into a basal cell, and an outer one from which the archegonium itself develops. The divisions in this outer cell are remarkably uniform. Three vertical walls are first formed, intersecting so as to enclose a central cell (Fig. 2, G). In this central cell a transverse wall next cuts off a small, upper cell (cover cell) from a lower one. Subsequently the three (or in the Jungermanniaceæ usually but two) first-formed peripheral cells divide again vertically, and by transverse walls in all of the peripheral cells, and somewhat later in the central one also, the young archegonium is divided into two tiers, a lower one or venter, and an upper one, the neck (Fig. 2, F). The middle cell of the axial row, by a series of transverse walls, gives rise to the row of neck canal cells, and the lowermost cell divides into two an upper one, the ventral canal cell, and a larger lower one, the egg.

The antheridium shows very much greater diversity in its structure, and equally great difference in its position. The origin in the thallose forms is usually the same as that of the archegonium, and indeed where the two grow mixed together, as in many species of Riccia, it is sometimes difficult to distinguish them in their earliest stages. Usually, however, the antheridia are borne together, either on special branches (Marchantia, species of Aneura), or they are produced in a special part of the ordinary thallus, which usually presents a papillate appearance (e.g., Fimbriaria). In the foliose Jungermanniaceæ the antheridia are often borne singly in the axils of slightly modified leaves, but in no case does the apical cell of the shoot become transformed into an antheridium. The antheridium, like the archegonium, arises from a single superficial cell. The first division usually divides the primary cell into a stalk cell and the body of the antheridium. The first may remain very short and undergo but few divisions, or it may develop into a stalk of considerable length. The first division in the upper cell may be either transverse (Marchantiaceæ, Sphcrocarpus) or vertical (Jungermanniaceæ). 
Later, by a series of periclinal walls, a central group of cells is separated from an outer single layer of cells. The latter divide only a few times, and develop chlorophyll, which sometimes changes into a red or yellow pigment at maturity. The inner cells give rise to a very large number of sperm cells, which in most Hepaticæ are extremely small, and consequently not well adapted to studying the development of the spermatozoids. In a few forms, however, they are larger; and in Pellia especially, where the sperm cells are relatively large, the development has been carefully studied by Guignard (I), Buchtien (I), and others of late years, as well as by many of the earlier observers, and a comparison with other Hepaticæ shows great uniformity in regard to the origin and development of the spermatozoid. After the last division of the central cells the nuclei retain their flattened form, and thus the sperm cells or spermatids remain in pairs, an appearance very common in the ripe antheridium of most Liverworts. Just before the differentiation of the body of the spermatozoid begins, the nucleus has the appearance of an ordinary resting nucleus, but no nucleolus can be seen. The first change is an indentation in the edge of the discoid nucleus, and this deepens rapidly until the nucleus assumes a crescent form. One of the ends is somewhat sharper and more slender than the other, and this constitutes the anterior end. As the body of the spermatozoid grows in length it becomes more and more homogeneous, the separate chromosomes apparently fusing together as the body develops. The body of the spermatozoid increases in length until it forms a slender spiral band coiled in a single plane, lying parallel with the one in its sister cell. The full-grown spermatozoid in Pellia epiphylla has, according to Guignard ( ( I), p. 67) from three to four complete coils. Usually when the spermatozoid escapes, it has attached to the coil a small vesicle which swells up more or less by the absorption of water. This vesicle is the remains of the cytoplasm of the cell, and may, perhaps, contain also some of the central part of the nucleus. Guignard ( ( 1$),$ p. 66) asserts that sometimes the cytoplasm is all used up during the growth of the spermatozoid, and that the free spermatozoid shows no trace of a vesicle.

In the Ricciaceæ and in Spharocarpus new archegonia continue to form even after several have been fertilised, so that numerous sporogonia develop upon the same branch of the 
thallus; but in most Liverworts the fertilisation of an archegonium checks the further formation of archegonia in the same group, and only those that are near maturity at the time reach their full development; and even if more than one archegonium of a group is fecundated, as a rule but one embryo comes to maturity.

\section{The Sporophyte}

Unquestionably the lowest type of sporogonium is found in Riccia (Fig. 6). Here the result of the first divisions in the embryo is a globular mass of cells, which a little later shows a single layer of peripheral cells and a central mass of spore mother cells, all of which produce spores in the usual way. The sporogonium remains covered by the venter of the archegonium until the spores are ripe, and never projects above the surface of the thallus. The spores only escape after the thallus (or at least that part of it containing the sporogonia) dies and sets them free as it decays. In the genus Sphcrocarpus (Fig. 30), which may be taken to represent the next stage of development, we notice two points in which it differs from Riccia. In the-first place there is a basal portion (foot), which is simply an absorbent organ, and takes no part in the production of spores. Secondly, only a part of the archesporium develops perfect spores. A number of the spore mother cells remain undivided, and serve simply to nourish the growing spores. In the majority of the Hepaticæ the sporogonium shows, besides the foot and the capsule, an intermediate portion, the stalk or seta, which remains short until the spores are ripe, when, by a rapid elongation of its cells, the capsule is forced through the calyptra and the spores are discharged outside. In these forms, too, some of the cells of the archesporium remain undivided, and very early are distinguished by their elongated shape from the young spore mother cells. These elongated cells later develop upon the inner surface of the cell wall peculiar spiral thickened bands, which are strongly hygroscopic. These peculiar fusiform cells, the elaters, are found more or less developed in all the Hepaticæ except the lowest ones.

The dehiscence of the sporogonium is different in the different orders. In the Ricciaceæ and some Marchantiacex the ripe sporogonium opens irregularly; in a few cases (species of Fimbriaria) the top of the capsule comes off as a lid; in 
most Jungermanniales the wall of the capsule splits vertically into four valves.

The spores are always of the tetrahedral type, i.e., the nucleus of the spore mother cell divides twice before there is any division of the cytoplasm, although this division may be indicated by ridges projecting into the cell cavity, and partially dividing it before any nuclear division takes place. The four nuclei are arranged at equal distances from each other near the periphery of the mother cell, and then between them are formed simultaneously cell walls dividing the globular mother cell into four equal cells having a nearly tetrahedral form. These tetrads of spores remain together until nearly full grown, or in a few cases until they are quite ripe. In the ripe spore two, sometimes three, distinct coats can be seen, the inner one (endospore, intine) of unchanged cellulose, the outer one (exospore, exine), strongly cutinized and usually having upon the outside characteristic thickenings, ridges, folds, spines, etc. Where these thickenings are formed from the outside they constitute the third coat (perinium, epispore). The exospore is especially well developed in species where the spores are exposed to great heat or dryness, and which do not germinate at once. In those species that are found in cooler and moister situations, especially where the spores germinate at once, the exospore is frequently thin. The nucleus of the ripe spore is usually small. The cytoplasm is filled with granules, mostly albuminous in nature, with some starch and generally a great deal of fatty oil that renders the contents of the fresh spore very turbid. Some forms, especially the foliose Jungermanniaceæ, have also numerous chloroplasts, but these are lacking usually in those forms that require a period of rest before germination. In Pellia and Conocephalus the first divisions in the germinating spore take place while the spores are still within the sporogonium.

The germination of the spores begins usually by the formation of a long tube (germ-tube, "Keimschlauch" of German authors), into which pass the granular contents of the spore. At the same time there may be formed a rhizoid growing in a direction opposite to that of the germinal tube, although quite as often the formation of the first rhizoid does not take place until a later period. If the spore does not contain chlorophyll before germination, it is developed at an early stage, before any 
cell-divisions occur. Often the formation of a germ-tube is suppressed and a cell surface or cell mass is formed at once, and all these forms may occur in the same species. The germination only takes place when the light is of sufficient intensity, and the amount of light is a very important factor in determining the form of the young plant. Thus if the light is deficient, the germ-tube becomes excessively long and slender, and divisions may be entirely suppressed. An excess of light tends to the development at once of a cell surface or cell mass. In the simpler thallose forms the first few divisions in the young plant establish the apical cell, and we cannot properly speak of the gametophore as arising secondarily from a protonema; in other cases, however, the young plant does arise as an outgrowth or bud from a protonema, which only rarely has the branching filamentous character of the Moss protonema.

\section{Classification of the Hepaticae}

The Hepatica are readily separated into the two following well-marked orders :

Order I Marchantiales.

Order II. Jungermanniales.

The following diagnoses are taken, with some modifications from Schiffner ( ( I), p. 5):

\section{ORDER I. Marchantiales.}

Gametophyte always strictly thallose, composed of several distinct layers of tissue, the uppermost or chlorophyll-bearing cells usually containing large air-spaces. The dorsal epidermis usually provided with pores, ventral surface with scales arranged in one or two longitudinal rows. Rhizoids of two kinds, those with smooth walls, and papillate ones; sexual organs, except in the lowest forms, united in groups which are often borne on special stalked receptacles. The first divisions of the embryo are arranged like the quadrants of a sphere. Sporogonium either with or without a stalk, and all the inner cells forming spores, or some of them producing elaters. No columella present. 


\section{Fam. I. Ricciacea}

Chlorophyll-bearing tissue with or without air-chambers, and, where these are present, they never contain a special assimilative tissue. Epidermal pores wanting or rudimentary. Sexual organs immersed in open cavities upon the dorsal surface. Sporogonium without foot or stalk, and remaining permanently within the venter of the archegonium. All the cells of the archesporium produce spores.

\section{Fam. 2. Corsiniacece.}

Air-chambers well developed; epidermis with distinct pores; sexual organs in distinct groups, but the receptacles always sessile; sporogonium with a short stalk, producing besides the spores sterile cells, which may have the form of very simple elaters.

\section{Fam. 3. Marchantiacea.}

Air-chambers usually highly developed, and the chambers often containing a loose filamentous assimilative tissue. Pores upon the dorsal surface always present (except in Dumortiera and Monoclea) and highly developed, ring-shaped or cylin drical. Sexual organs always in groups, ustally upon special long-stalked receptacles. Sporophyte stalked and when ripe breaking through the calyptra, opening by teeth or a circular cleft, more seldom by four or eight valves. The archesporium develops sterile cells, in the form of elaters, as well as spores.

The Marchantiales constitute a very natural order of plants, all of whose members agree very closely in their fundamental structure. The separation of the Ricciaceæ as a group co-ordinate with the Jungermanniales and Marchantiales is not warranted, as more recent investigations, especially those of Leitgeb ((7), vol. iv.) have shown that the two groups of the Marchantiaceæ and Ricciaceæ merge almost insensibly into each other.

They are all of them strictly thallose forms, the thallus being unusually thick and fleshy, and range in size from a few millimetres in some of the smaller species of Riccia, to Io to 20 centimetres in some of the larger species of Dumortiera and Conocephalus. In most of them branching is prevailingly 
dichotomous, and as this is rapidly repeated, it often causes the thallus to assume an orbicular outline. Some forms, however,
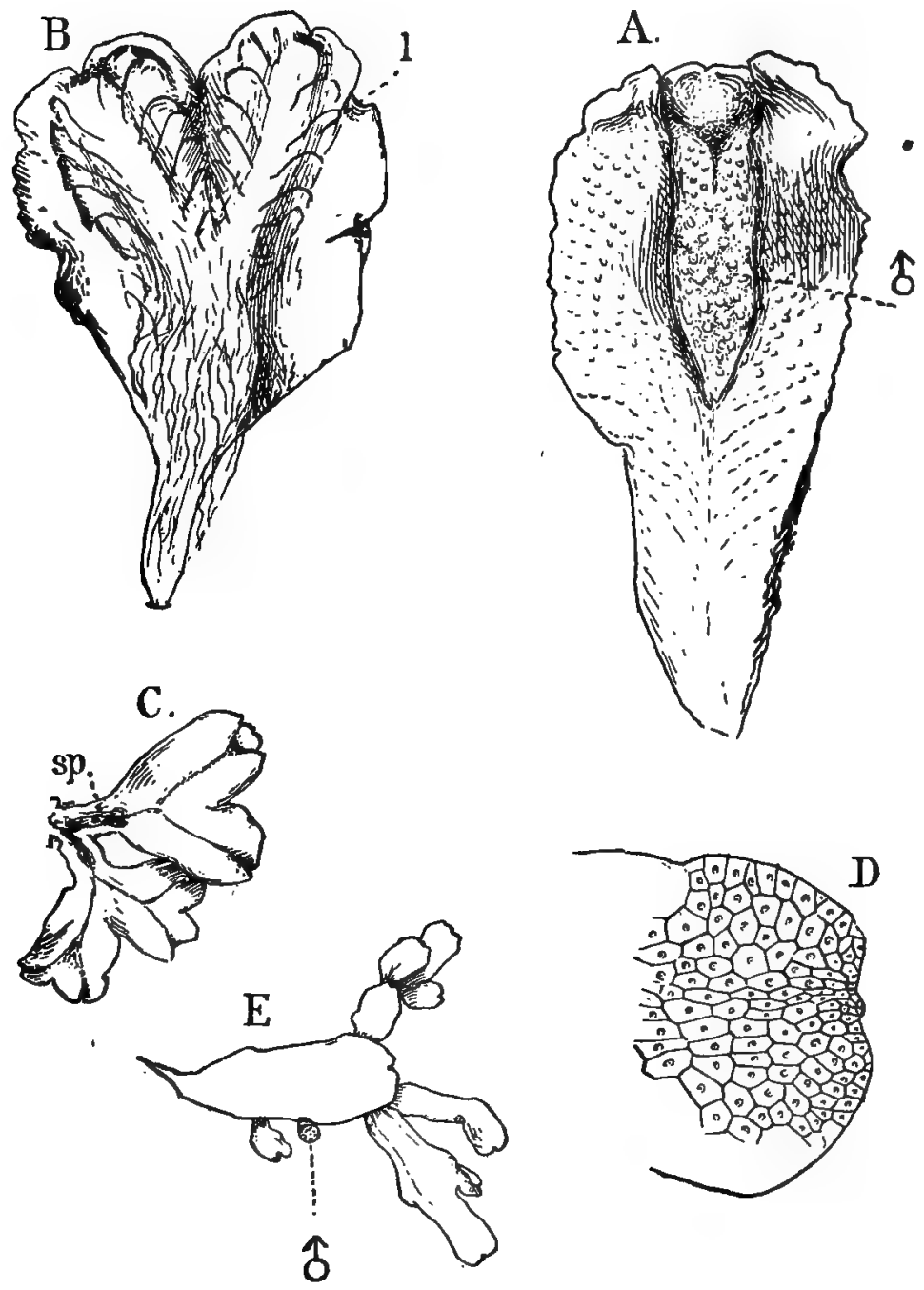

FIG. 1.-Marchantiales. A, B, Male plants of Fimbriaria Californica. A, from above; $\mathrm{B}$, from below; $\delta$, antheridial receptacle; $l$, ventral lamellæ, $\times_{4}$; C, Riccia glauca, $X_{6} ; s p$, sporogonia; $\mathrm{D}$, Conocephalus conicus, $\mathrm{X}_{4} ; \mathrm{E}$, Targionia hypophylla, $\mathrm{X}_{2}$; $\delta$, antheridial branch.

e.g., Targionia (Fig. I, E), may fork comparatively seldom, and the new branches are for the most part lateral. The thallus 
is fastened to the substratum by rhizoids, which are unicellular and usually of two kinds, those with smooth walls and those with peculiar papillate thickenings or teeth that project inward (Fig. I2). The cells of the lower layers of tissue are usually nearly or quite destitute of chloroplasts, which, however, occur in large numbers in the so-called chlorophyll-bearing layer, just below the dorsal epidermis. This chlorophyll-bearing layer contains air-spaces in all forms except some species of Dumortiera and Monoclea, and these spaces are either simple narrow canals, as in Riccia glauca, or they may be large chambers separated by a single layer of cells from their neighbors. Such forms occur in most of the higher Marchantiaceæ.

The growth of the thallus is due to the division of a small group of cells occupying the bottom of the heart-shaped indentation in the forward part of the thallus. Sections parallel to the surface, cutting through this group, show a row of marginal cells that appear very much alike, and it is impossible always to tell certainly whether or not there is a single definite initial cell. Such a single initial is unquestionably present in the earlier stages, and it is quite possible that it may persist, but owing to its small size and its close resemblance to the adjoining cells, this cannot be positively asserted. In vertical sections the initial cell (or cells) appears nearly triangular, with the free outer wall somewhat convex. From this cell two sets of segments are cut off, the dorsal segments giving rise to the green tissue, and the lower segments producing the ventral lamellæ and colourless lower layers of cells of the thallus.

The plants multiply asexually either by the older parts of the thallus dying away and leaving the growing points isolated, or lateral branches, which are often produced in great numbers from the lower surface of the midrib, become detached and each branch forms a separate plant. The well-known gemmæ of Marchantia and Lumularia are the most striking examples of special asexual reproductive bodies.

The sexual organs are always derived from the dorsal segments of the apical cell, either of the ordinary branches or of special shoots. The archegonium is of the typical form, and the antheridium always shows a series of transverse divisions before any longitudinal walls are formed in it.

While the gametophyte may reach a very considerable degree of specialisation, the sporophyte is relatively insignifi- 
cant even in the higher forms, and has the foot and stalk poorly developed. While the Marchantiales grow for the most part in moist situations, and some of them, e.g., Marchantia polymorpha, are very quickly killed by drying, some species, e.g., Riccia trichocarpa, a common California species, grow by preference in exposed rocky places exposed to the full force of the sun. This latter species as well as several others of the same region, e.g., Fimbriaria Californica, Targionia hypophylla, do not die at the end of the rainy season, but become completely dried up, in which condition they remain dormant until the autumn rains begin, when they absorb water and begin to grow again at once. In these cases usually only the ends of the branches remain alive, so that each growing tip becomes the beginning of a new plant.

\section{The Ricciaceze}

As a type of the simplest of the Marchantiacex, we may take the genus Riccia, represented, according to Schiffner ( ( I ), p. I4), by IO7 species, distributed over the whole earth. Most of them are small terrestrial plants forming rosettes upon clay soil or sometimes in drier and more exposed places. A few species, e.g., $R$. fuitans, are in their sterile condition submersed aquatics, but only fruit when by the evaporation of the water they come in contact with the mud at the bottom.

The dichotomously branched thallus shows a thickened midrib, which is traversed upon the dorsal surface by a longitudinal furrow which in front becomes very deep. At the bottom of this furrow, at the apex of the thallus, lies the growing point. A vertical section through this shows a nearly triangular apical cell which lies much nearer the ventral than the dorsal surface (Fig. $2, x$ ). From this are cut off successively dorsal and ventral segments. Each segment next divides into an inner and an outer cell. From the outer cells of the dorsal segments the sexual organs arise, and from those of the ventral segments the overlapping lamellæ upon the lower surface of the thallus, and also the rhizoids. The rapid division of the inner cells of the segments, especially those of the dorsal ones, causes the thallus to become rapidly thicker back of the apex. Sections made parallel to the surface of the thallus, and passing through the growing point (Fig. 3), show 
that the margin is occupied by a group of cells that look very much alike. Sometimes one of these cells is somewhat larger than the others, but more commonly it is impossible to decide with certainty that a single initial is present. From a comparison of the two sections it is at once evident that the initial cells have nearly the form of the segment of a disc, and that in addition to the dorsal and ventral segments lateral ones are cut off as well. In the region just back of the apex the tissue of

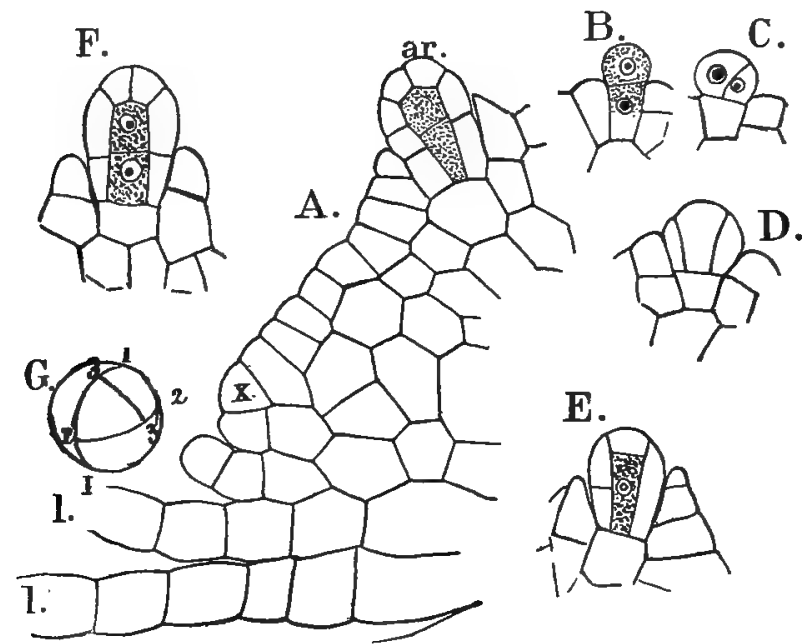

FrG. 2.-Riccia glauca. Development of the archegonium, $\times 525$. A, Vertical section through the growing point; $x$, apical cell; ar, young archegonium; $l l$, ventral lamellx; B-F, successive stages in the development of the archegonium, seen in longitudinal section; G, cross-section of young archegonium (diagrammatic).

the thallus is compact, but in the older parts a modification is observable both on the dorsal and ventral surfaces. In the former, a short distance from the growing point, the superficial cells project in a papillate manner above the surface. This causes little depressions or pits to be formed between the adjacent cells (Fig. 3, C). The subsequent divisions in the papillæ are all transverse, and this transforms each papillate surface cell into a row of cells which, as it elongates, causes the pits between it and the adjacent ones to become deep but narrow air-channels, so that in the older parts of the thallus the upper portion is composed of closely-set vertical rows of chlorophyllbearing cells separated by narrow clefts opening at the surface. 
In Riccia glauca, as well as other species, the uppermost cell of each row often enlarges very much, and with its fellows in the other rows constitutes the epidermis. According to Leitgeb's researches this epidermal cell is formed by the first division in the outer cell of the segment, and either undergoes no further division, or by dividing once by a transverse wall forms a twolayered epidermis ( $R$. Bischoffii). On the ventral side the outer cells of the segments project in much the same way, but
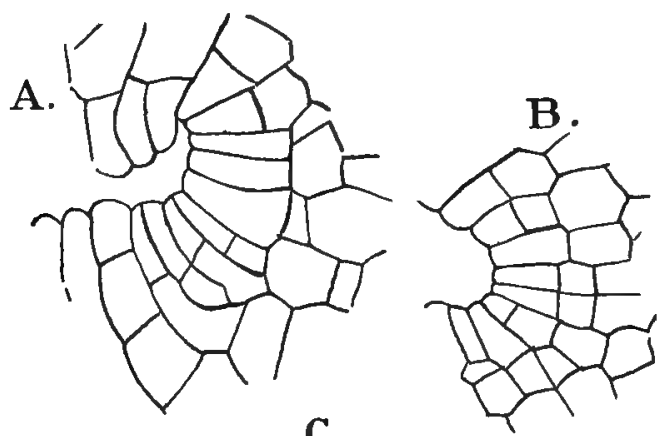

C.

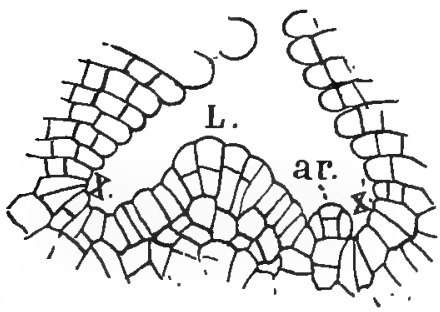

FIG. 3.-Riccia glauca. Horizontal sections of the growing point. A, B, $\times 525$; C, $X$ about 260 . C shows the dichotomy of the growing point; $x, x^{\prime}$, the two new growing points; $L$, the lobe between them; ar, a young archegonium.

they remain in close contact laterally with the neighboring cells, so that instead of forming isolated rows of cells, transverse plates or lamellæ, occupying the median part of the lower surface of the thallus, are formed. These remain but one cell thick, and grow very rapidly, and bend up so as to completely protect the growing point. With the rapid widening of the thallus in the older parts these scales are torn asunder, and the two halves being forced apart constitute the two rows of ventral scales found in the older parts. Later these scales dry up and 
are often scarcely to be detected except close to the growing point.

In the case of Ricciocarpus natans (Leitgeb (7), iv., p. 29) instead of a single scale being formed, each cell of the horizontal row, which ordinarily gives rise to a single scale, grows out independently, much as do the dorsal surface cells in the other species, and the result is a horizontal series of narrow scales, each one corresponding to a single cell of the original row. These later are displaced by the subsequent growth of the thallus, and their arrangement in transverse series can only be seen in the younger parts. The very rapid increase in length of the dorsal rows of cells as they recede from the growing point soon causes them to overarch the latter, which thus comes to lie in a deep groove; indeed not infrequently the end cells of the rows on opposite sides of the groove actually meet, so that the groove becomes a closed tube.

$R$. Auitans (Leitgeb ( 7 ), iv. P. II) and R. crystallina differ in some respects from the other forms. In these, owing to a greater expansion of the tissues of the older parts of the thallus, the air-spaces are very much enlarged. In the former they are almost completely closed above, as the epidermal cells, by repeated vertical divisions, keep pace with the growth of the thallus and form a continuous epidermis, with only a smail central pore over each of the large air-chambers. In $R$. crystallina, however, there is no such secondary growth of the epidermal cells, and in consequence the cavities are completely open above, so that the surface of the thallus presents a series of wide depressions separated by thin lamellæ. These two species also show some difference as to the ventral scales. Those of $R$. fuitans are small and do not become separated into two, and in $R$. creystallina they are wanting entirely.

Most of the Ricciaceæ multiply by special adventive shoots that arise from the ventral surface of the midrib. These become detached and form new individuals. According to Fellner ( $\mathrm{I}$ ) the rhizoids develop at the apex a young plant in a manner entirely similar to that by which the young plant arises from the germ tube of the germinating spore.

By far the commonest method of branching in most species of Riccia is a true dichotomy. The first indication of this process is a widening of the growing point and a correspond- 
ing increase in the number of the marginal cells. The central cells of the marginal group now begin to grow more vigorously than the others and to project as a sort of lobe (Fig. 3, C, L), and this lobe divides the initial cells into two groups lying on either side of it. As soon as this is accomplished each new group of initial cells continues to grow in the same manner as the original group, and two new growing points are established, each of which develops a separate branch. The growth of the middle lobe is limited, and it remains sunk in the fork between the two new branches.

The thallus is attached to the substratum by rhizoids of two kinds. The first are smooth-walled elongated cells, with colourless contents, the others much like those of the higher Marchantiaceæ. Their walls are undulating, and projecting inward are numerous more or less developed spike-like protuberances. The rhizoids arise from large superficial cells of the ventral part of the midrib. They are readily distinguished from the adjacent cells by their much denser contents, even before they have begun to project.

The arrangement of the tissues of the fully-developed thallus is best seen in vertical cross-sections. In $R$. glauca and allied forms four well-marked tissue zones can be readily recognized in such a section. The lowest consists of a few layers of colourless rather loose parenchyma, from which the rhizoids arise, and to which the ventral lamellæ are attached. Above this a more compact, but not very clearly limited region, the midrib. The elongated form of the midrib cells, which contain abundant starch but no chlorophyll, is, of course, not evident in cross-section. Radiating from the midrib are closely-set rows of chlorophyll-bearing cells with the characteristic narrow air-spaces between. The median furrow is very conspicuous in such a section, and extends for about half the depth of the thallus. Terminating each row of green cells is the enlarged colourless epidermal cells, often extended into a beak-like appendage. In some species, e.g.; $R$. trichocarpa, some of the surface cells grow out into stout thick-walled pointed hairs.

\section{The Sexual Organs}

In Riccia the sexual organs are formed in acropetal succession from the younger segments of the initial cells, and 
continue to form for a long time, so that all stages may be met with upon the same thallus. While both antheridia and archegonia may be found together, in the two species $R$. glauca and $R$. trichocarpa, mainly studied by myself, I found that as a rule several of one sort or the other would be formed in succession, and that not infrequently antheridia were quite wanting upon plants that had borne numerous archegonia. Both archegonia and antheridia arise from single superficial cells of the younger dorsal segments of the initial cells. In their earliest stages they are much alike, the mother cell of the antheridium being, however, usually somewhat larger than that of the archegonium. The cell enlarges and projects as a papilla above the surface, when it is divided by a transverse wall into an outer cell and an inner one. The latter divides but a few times and forms the short stalk; the outer cell, which has dense granular contents, develops into the archegonium or antheridium as the case may be. In the former case the divisions follow the order already indicated for the typical Liverwort archegonium. In the outer cell, which continues to enlarge rapidly, a nearly vertical wall is formed (Fig. 2, C), which divides the cell into two very unequal parts. This wall is curved and strikes the periphery of the mother cell at about opposite points (Fig. 2, $G, I)$. A second wall of similar form is next formed in the larger cell $(G, 2)$, one end of which intersects the first wall, and finally a third wall (3) intersecting both of the others is formed. The young archegonium seen in vertical section at this stage (Fig. 2, D) shows a large central cell bounded by two smaller lateral ones; in cross-section the central one appears triangular. Each of the four cells of which the archegonium rudiment is now composed divides into two. The outer ones each divide by radial walls into equal parts, and the central one divides into an upper smaller cell (cover cell) and a lower larger one (Fig. 3, E). The next divisions are horizontal and divide the young archegonium into two tiers of cells. The lower one forms the venter, and the upper one the neck, and next the cover cell divides into four nearly equal cells by intersecting vertical walls. The archegonium at this stage (Fig. 2, F) is somewhat pear-shaped, being smaller at the bottom than at the top, and the basal cell is still undivided. It now rapidly increases in length by the transverse division and growth of all its cells, and there is at the same time a 
marked increase in diameter in the venter, which finally becomes almost globular (Fig. 4). The axial cell of the neck, the neck canal cell, divides, according to Janczewski ( I), always into four in $R$. Bischoffii, and the same seems to be true for $R$. trichocarpa (Fig. 4, A), and probably is the same in other species. The number of divisions in the outer neck cells is various, but is most active in the lower part, but in the central cell of the venter there is always but a single transverse division which


FIG. 4.-A, Archegonium of Riccia trichocarpa, showing the ventral canal cell (v), $\times 525 ; \mathrm{B}$, ripe archegonium of $R$. glauca, longitudinal section, $\times 260$.

separates the ventral canal cell from the egg. The four primary cover cells enlarge a good deal as the archegonium approaches maturity, and divide by radial walls usually once, so that the complete number is normally eight-Janczewski gives ten in $R$. Bischoffi. The basal cell finally divides into a single lower cell which remains undivided, completely sunk in the thallus, and an upper cell which divides into a single layer of cells forming part of the venter, and continuous with the other peripheral cellș. The mature archegonium (Fig. 4) 
has the form of a long-necked flask with a much enlarged base. The canal cells are completely indistinguishable, their walls having become absorbed and the contents run together into a granular mass. The nuclei of the neck-canal cells are small and not readily recognisable after the breaking down of the cell walls, but from analogy with the higher forms it is not likely that they completely disappear in the ripe archegonium. The cytoplasm of the central cell contracts to form the naked globular egg. The cytoplasm is filled with granules, and the nucleus, which is of moderate size, shows a distinct nucleolus, but very little chromatin. A special receptive spot was not certainly to be seen.

Almost coincident with the first cell division in the archegonium rudiment ther $\epsilon$ is a rapid growth of the cells immediately surrounding it. These grow up as a sort of ring or ridge about the archegonium, which is thus gradually immersed in a cup-shaped cavity, and the growth of the cells about this keeps pace with the increase in length of the archegonium, so that even when fully grown only the very extremity of the neck projects above the level of the thallus. The whole process is undoubtedly but a modification of the ordinary growth of the dorsal part of the thallus, and the space about the archegonium is the direct equivalent of the ordinary air-spaces.

The first division in the primary antheridial cell is the same as in the archegonium, but the later divisions differ much and do not show such absolute uniformity. The first division wall in the upper cell (Fig. 5, B) is always transverse, and this is followed by a second similar wall, but the subsequent divisions show considerable variation even in the same species. After a varying number of transverse walls have been formed, in most cases the next divisions, which are formed only in the middle segments, are vertical, and divide the segments into quadrants of a circle when seen in transverse section. Occasionally a case is met with where the division walls are inclined alternately right and left, and the divisions strongly recall those of the typical Moss antheridium (Fig. 5, D).

The separation of the sperm cells is brought about by a series of periclinal walls in a number of the middle segments, by which four central cells in each segment (Fig. 5, G) are separated from as many peripheral cells. These central cells 
have, as usual in such cases, decidedly denser contents than the peripheral ones.

The lower one or two segments and the terminal ones do not take part in the formation of sperm cells, but simply form
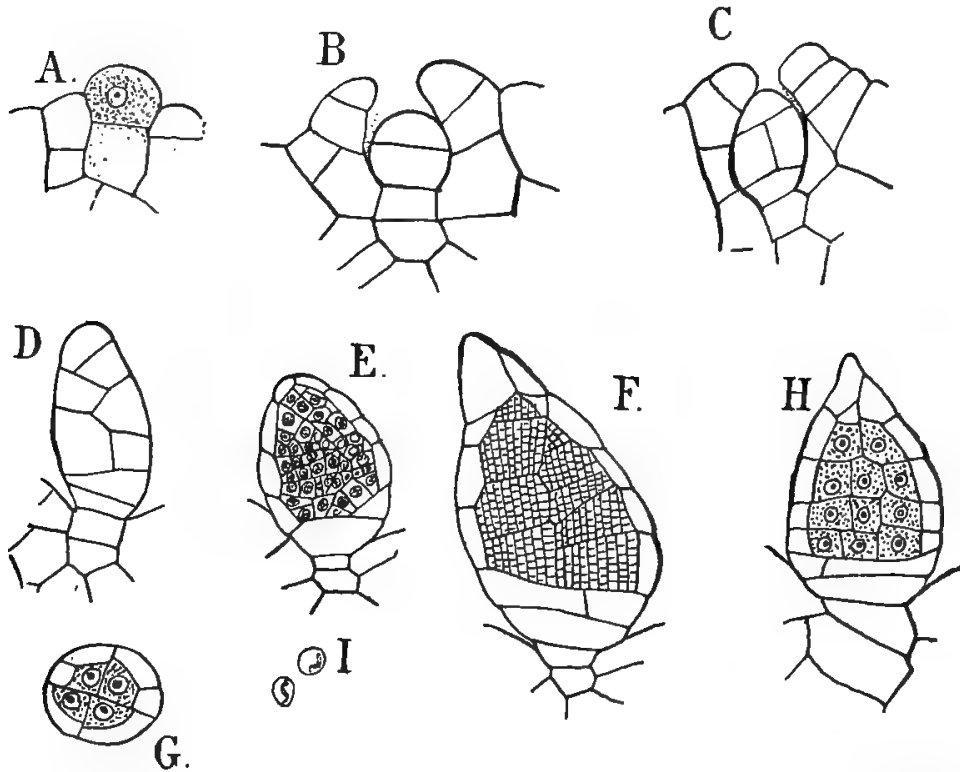

FIG. 5.-A-F, Development of the antheridium of $R$. glauca, seen in longitudinal section; $G$, cross-section of a young antheridium of the same; $H$, antheridium of $R$. trichocarpa; I, sperm cells of $R$. glanca. Figs. E, F, $\times 150 ; \mathrm{I}, \times 600$, the others $\times 300$.

part of the wall of the antheridium. The central cells now divide with great rapidity, the division walls being formed nearly at right angles to each other, so that the central part of the antheridium becomes filled with a very large number of nearly cubical cells. The divisions are formed with such regularity that the boundaries of the original central cells remain very clearly marked until the antheridium is nearly mature. The basal cell of the antheridium rudiment in $R$. glauca divides once by a horizontal wall (Fig. 5, B, D) and forms the short stalk of the antheridium, which, however, is almost completely sunk in the thallus. Between this stalk and the central group of cells there are usually two layers of cells, so that the wall of the antheridium is double at the base, while it has but a single layer of cells in the other parts. The 
uppermost cells are often, although not always, extended into a beak. The spermatozoids do not seem to differ either in their method of development or structure from those of other Hepaticæ, but their excessively small size makes it extremely difficult to follow through the details of their development. When ripe the wall cells are much compressed, but are always to be distinguished.

Like the archegonia, the antheridia are sunk separately in deep cavities, which are formed in exactly the same way. Unlike the archegonia, however, the antheridium does not nearly reach to the top of the cavity, whose upper walls are in many species very much extended into a tubular neck, which projects above the general level of the thallus, and through which the spermatozoids are discharged.

\section{The Sporophyte.}

After fertilisation is effected the egg develops at once a cell-membrane and enlarges until it completely fills the cavity of the venter. The first division wall is more or less inclined to the axis of the archegonium, but approaches usually the horizontal. The lower of the two cells thus formed divides first by a wall at right angles to the first formed, but this is followed in the upper half of the embryo by a similar division, so that the embryo is divided into nearly equal quadrants. In each of the quadrants a wall meeting both of the others at right angles next appears (Fig. 6, C, III), and the embryo at this stage consists of eight nearly equal cells. The next walls are not exactly alike, but the commonest form is a curved wall (Fig. 6, C), striking two of the others, usually walls II and III, and intersecting the surface of the embryo. This wall divides the octants into two cells, which appear respectively triangular and quadrilateral in section. By the next division the archesporium is separated from the wall of the sporogonium. These walls are periclinal, and by them a single layer of outer cells is separated from the central mass of cells which constitutes the archesporium (Fig. 6, B, D).

At first the cells of the embryo are much alike, but as it grows the inner cells increase in size and their contents become densely granular, while the outer cells grow only in breadth, and not at all in depth, assuming more and more a tabular 
form, and for the most part undergo divisions only in a radial direction so that the walls remain but one cell thick in most places. As the sporogonium increases in diameter the central cells begin to separate and round off. Their walls become partially mucilaginous, and in microtome sections stain strongly with Bismarck-brown or other reagents that stain mucilaginous membranes. With this disintegration of the division walls the cells separate more and more until they lie free within the cavity of the sporogonium. Each of these spore mother cells is a large globular cell with thin membrane
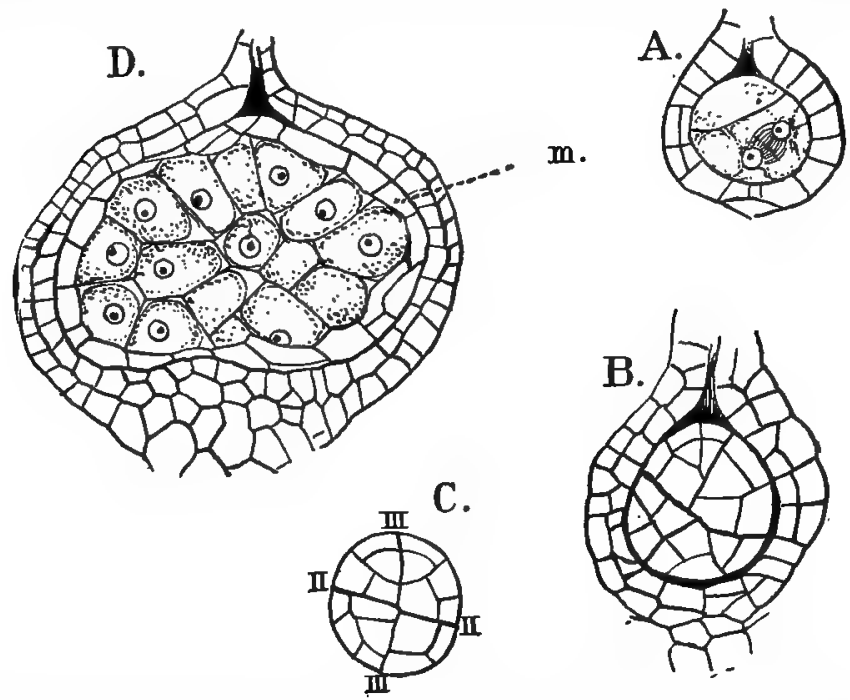

FIG. 6.-A, B, Young embryos of $R$. glauca in longitudinal section, showing the venter of the archegonim, $\times 260 ; C$, transverse section of a similar embryo, $\times 260 ; \mathrm{D}$, longitudinal section of the archegonium and enclosed embryo of $R$. trichocarpa at a later stagc, $X_{220} ; m$, the sterile cells of the sporogonium.

and densely granular contents. The nucleus is not so large as is usually the case in cells of similar character, and, except the nucleolus, stains but slightly with the ordinary nuclear stains. In the fresh state these spore mother cells are absolutely opaque, owing to the great amount of granular matter, largely drops of oil, that they contain. In embedding these in paraffine, however, the oil is dissolved and removed, and microtome sections show the fine granules of the cytoplasm arranged in a net-like pattern, the spaces between probably being occupied by oil in the living cells. 
Fig. 7, A shows the nucleus of the mother cell undergoing the first division. The small size of the nuclei, and the small amount of chromation in them, make the study of the details of the nuclear division difficult here, and as there was nothing to indicate any special peculiarities these were not followed out. After the first nuclear division the daughter nuclei divide again, after which the four nuclei arrange them-

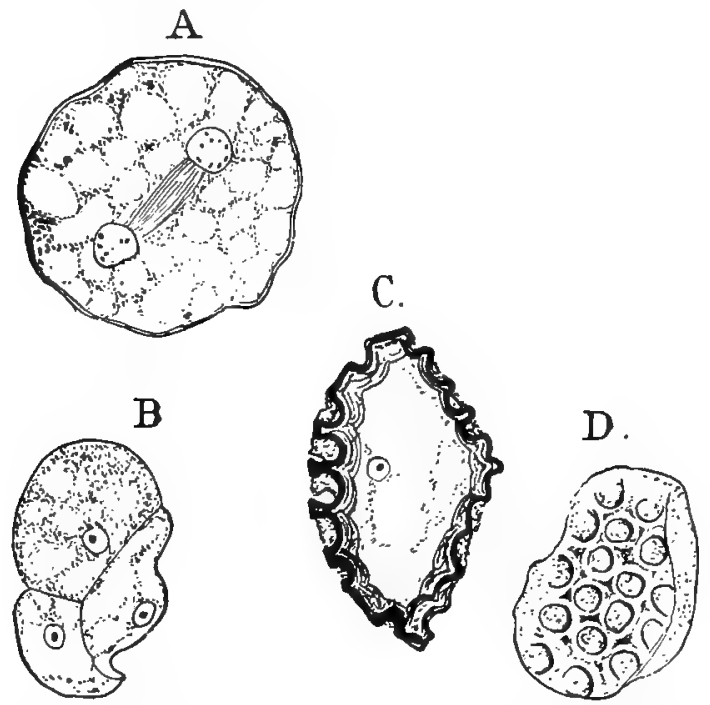

Frc. 7.-Riccia trichocarpa. A, Section of a spore mother cell undergoing its first division, $\times 600 ; B$, section of young spore tetrad, $\times 300$; $C$, section of ripe spore, $\times 300 ; D$, surface view of the exospore of a similar stage, $\times 300$.

selves at equal distances from each other, the division walls form simultaneously between them, dividing the spore mother cell into the four tetrahedral spores. A section through such a young spore-tetrad is shown in Fig. $7, \mathrm{~B}$, where one of the cells is somewhat shrunken in the processof embedding. The cell walls at this stage are very delicate and of unchanged cellulose; but as they grow older the wall soon shows a separation into endospore and exospore. The latter in $R$. trichocarpa, which was especially studied, is very thick, at first yellowish in colour, but deepening until when ripe it is black. Sections parallel to the surface show in this species what appear to be regular rounded pits, but vertical sections of the spore-coat show that this appearance is due to a peculiar fold- 
ing of the exospore, which also shows a distinct striation, the outer layer being much thicker and denser than the inner ones. The nucleus of the ripe spore is remarkably small, and it is evident that the dense contents of the ripe spore are largely oil or some similar soluble substance, as in microtome sections there is very little granular matter visible.

At the same time that the first division wall forms in the embryo, the outer cells of the venter begin to divide by periclinal walls, so that the single layer of cells in the wall of the unfertilised archegonium becomes changed into two, and the basal portion becomes still thicker; the neck takes no part in this later growth. The cells of the venter develop a great deal of chlorophyll, which is quite absent from the sporogonium itself, and before the spores are ripe the inner layer of cells of the calyptra (venter) becomes almost entirely absorbed, so that only traces of these cells are visible when the spores are ripe. The wall of the sporogonium also disappears almost completely as the latter matures, but usually in microtome sections traces of this can be made out in the ripe capsule, although the cells are very much compressed and partially disorganised. The contents of these cells, as well as the inner calyptra cells, no doubt are used up to supply the growing spores with nourishment. Thus, when ripe, the spores practically lie free in the cavity surrounded only by the outer layer of calyptra cells. The neck of the archegonium persists and is made conspicuous by the dark brown colour of the inner walls of the cells.

Hitherto the germination of the Ricciaceæ was only known in $R$. glauca (Fellner ( $\mathrm{I}$ ) ). The account here given is based upon observations made upon $R$. trichocarpa-a very common Californian species. It fruits in winter and early spring, and the spores remain dormant during the dry summer months. If the spores are sown in the autumn they germinate within a few days by bursting the massive black exospore, through which the colourless endospore enclosing the spore contents projects in the form of a blunt papilla. This rapidly grows out into a long club-shaped filament (Fig. 8, A), much less in diameter than the spore, and into this the spore contents pass. These now contain albuminous granules and great numbers of oil-globules, and some chlorophyll bodies, which at first are small and not very numerous. They, however, increase rapidly in size, and divide also, so that before the first cell division 
takes place the chloroplasts are abundant and conspicuous. The formation of the first rhizoid does not take place usually until a number of divisions have been formed in the young thallus. The first rhizoid (Fig. 9, r) arises at the base of the germinal tube, and is almost free from granular contents. It, usually at least, is separated by a septum from the germ-tube. The first wall in the latter is usually transverse, although in exceptional cases it is oblique (Fig 8, C), and this is followed by a second one parallel to the first (Fig. 8, C). In each of these cells a vertical wall is formed, and then a second at right angles to this, so that the nearly globular mass of cells at the

A.

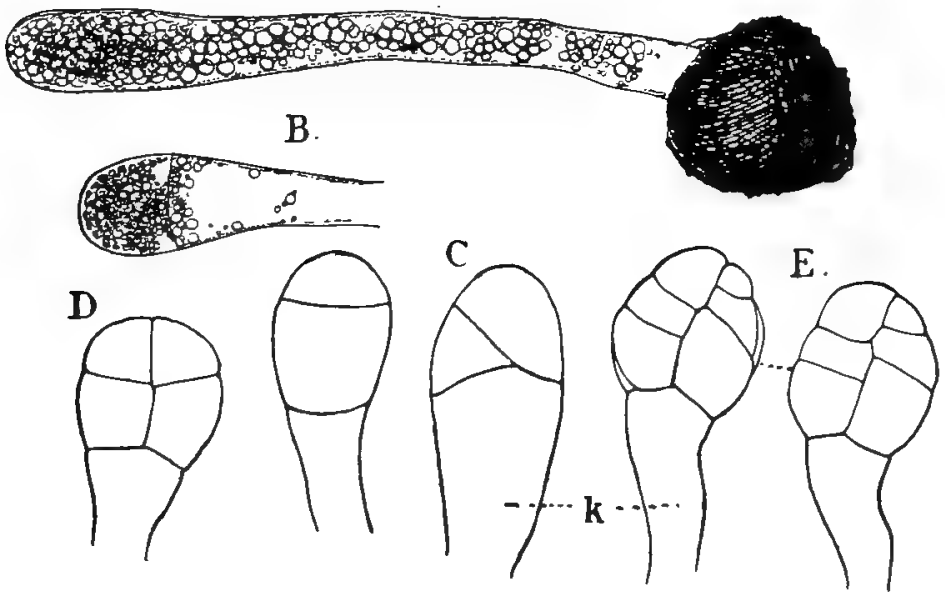

FIG. 8.-Riccia trichocarpa. Germination of the spores, XIgo. In $\mathrm{E}$ the figure at the left represents a surface view, the one at the right an optical section; $\mathbf{K}$, germinal tube.

end of the germ-tube is composed of eight nearly equal cells or octants. As these divisions proceed the oil drops which are so abundant in the undivided germ-tube disappear almost completely, and are doubtless used up by the growing cells.

According to Leitgeb's view, and that of other authors, the eight-celled body at the end of the germ-tube is a sort of protonema, from which the gametophore arises as a lateral outgrowth. I have seen nothing in the species under consideration which supports such a view. Here the axis of growth is continuous with that of the germ-tube, and in some cases at least, 
and probably always, a single apical cell is developed at the apex at a very early stage. Probably this initial rell is one of the four terminal octant cells resulting from the first divisions. This cell sometimes has but two sets of segments cut off from it at first, alternately right and left, but whether this form is constant in the young plant I cannot now say.
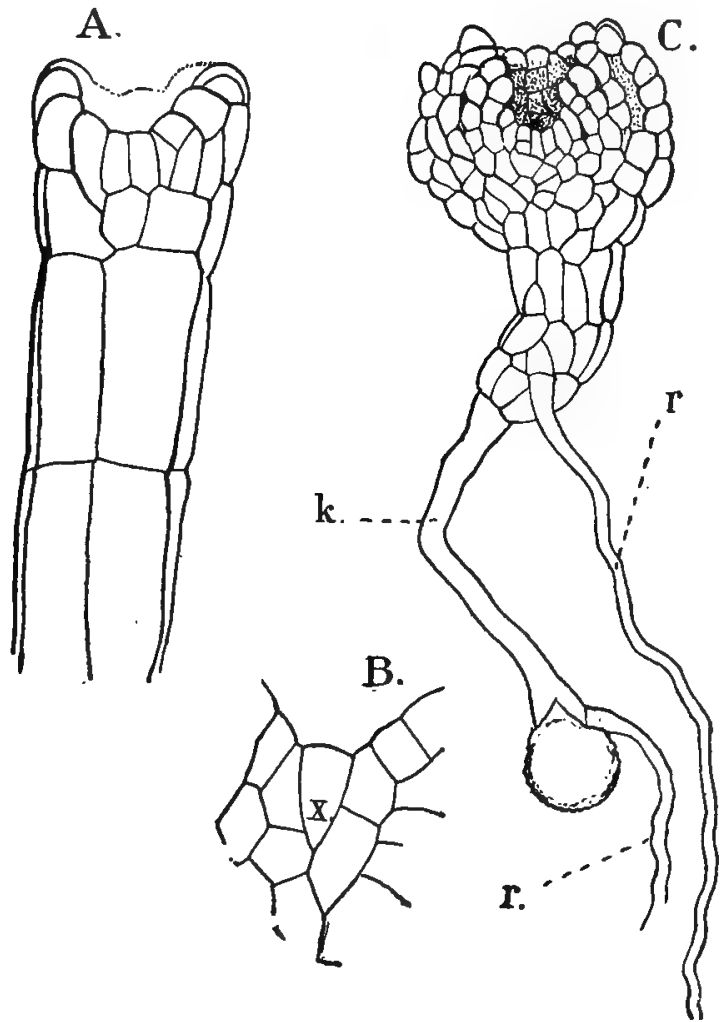

Frc. 9.-Riccia trichocarpa. Later stages of germination. A, from below, $\times 260$; B, optical section of $\mathrm{A}$, showing apical cell $x, \times_{520} ; \mathrm{C}, \times_{5} ; r$, rhizoids. Intercellular spaces have begun to develop.

The four lower quadrants also divide, at first only by transverse walls, and these cells lengthening give rise to a cylindrical body composed of four rows of cells, terminated by the more actively dividing group of cells at the summit. The single apical cell is soon replaced by the group of initials found in the full-grown gametophyte, and the method of growth from 
now on is essentially the same. The growth of the cells in the forward part of the dorsal surface of the young thallus is more active than that of the ventral side, so that they project over the growing point (Fig. 9), and as the outer cells of the lateral segments of the apical cell (or cells) also increase rapidly in size as they recede from the growing point, the forward margin of the thallus, seen from below, is deeply indented, and the forward part of the thallus is thus occupied by a deep cavity, at the bottom of which, toward the ventral side, lies the growing point. This cavity is the beginning of the groove or furrow found in the older thallus.

At first the cells of the young thallus are without intercellular spaces, but at an early period (Fig. 9, C) the outer cells of the young segments separate and form the beginnings of the characteristic air-spaces. In $R$. trichocarpa some of the dorsal cells about the same time form short pointed papillæ, the first indication of the pointed hairs characteristic of this species. As the plant grows, new rhizoids are formed by the growing out of ventral cells into papillæ, which are cut off by a partition from the mother cell. These first-formed rhizoids are always smooth-walled, and it is only at a much later stage that the other form develops, as well as the ventral lamellæ, which are quite absent from the young plant.

\section{Classification of the Ricciace}

Besides the genus Riccia, which includes all but three species of the family, there are two other genera, each represented by a single species, which undoubtedly belong here. Of these Ricciocarpus natans is of almost world-wide distribution. It is a floating form, like Riccia fluitans. Leitgeb (( 7$)$, vol. iv.) has made a very careful study of the structure and development of the thallus, which differs a good deal from that of Riccia, in which genus this plant was formerly placed. The apical growth is essentially the same, and the differentiation of the tissues begins in the same way, but the chlorophyll-bearing tissue is extraordinarily developed. The air-spaces are formed in the same way as in Riccia, but they become very deep, and at an early stage, while still very narrow, are divided by cellular diaphragms into several overlying chambers, which, narrow at first, later become very wide, so that the dorsal part of 
the thallus is composed of a series of large polyhedral airchambers arranged in several layers, and separated by walls but one cell thick. The upper chambers communicate with the outside by pores, quite like those of the Marchantiaceæ. The ventral tissue and midrib are rudimentary, and the very long pendent ventral lamellæ are produced separately in transverse rows, which, however, become displaced by the later growth of the thallus, so that their original arrangement can no longer be made out. Oil bodies like those found in the Marchantiacea occur. The terrestrial form, which grows on the margins of ponds, etc., where the floating form is found, is much more richly branched and more vigorous than the floating form (Fig. Io). The ventral scales become shorter,

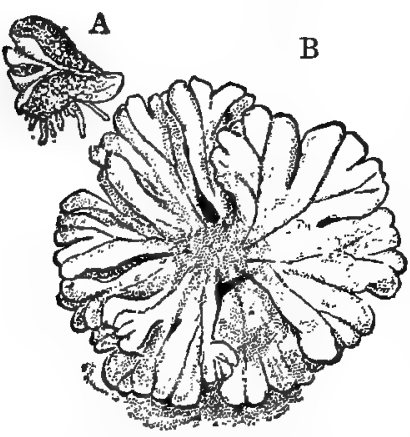

Frg. Io.-Ricciocarpus natans. A, Floating form; B, terrestrial form, $\times 2$. and numerous wide but unthickened rhizoids are formed, which are almost completely lacking in the floating form. The structure of the reproductive organs and sporogonium are essentially the same as in Riccia.

Garber (I), who has recently studied the development of Ricciocarpus, finds that it is not dicecious, as has been frequently asserted, but rather proterandrous - that is, numerous antheridia are formed, but some time before the first archegonia develop. Occasionally no archegonia are formed.

While the settling of the plant upon the mud is not a necessary condition for the development of the reproductive organs, as has been asserted by Leitgeb, still none are formed as a rule upon plants growing in permanent ponds, while those growing in temporary ponds regularly develop abundant reproductive organs. In permanent bodies of water, vegetative multiplication may be very rapid, and it has been found that after these are frozen over, a certain number of the plants survive, sometimes sinking to the bottom, and resuming growth again in the spring.

The third genus, Tesselina (Oxymitra), represented by the single species, $T$. pyramidata, is much less widely distributed, belonging mainly to Southern Europe, but also found in Para- 
guay. This interesting form has also been carefully examined by Leitgeb ( ( 7$)$, iv., p. 34), who calls attention to its intermediate position between the Ricciaceæ and the Marchantiaceæ. The thallus has all the characters of the latter: air-chambers opening by regular pores, usually surrounded by six guardcells; two rows of ventral scales, independent from the beginning; and the sexual organs united into groups upon special parts of the thallus. The sporogonium, however, is entirely like that of Riccia, so that it may properly be placed in the same family. The plants are diccious and strictly terrestrial.

A third genus, Cronisia, represented also by a single species, C. paradoxa, is placed provisionally with the Ricciacex by Schiffner ( ( I ), P. I 5), but the structure and development have not been investigated with sufficient completeness to make this certain. It has been found only in Brazil. Schiffner says of this form: "It belongs perhaps to the Corsiniex, and forms a direct transition from the Ricciaceæ to that family."

\section{The Corsiniacee (Schiffner (I), p. 26).}

The family Corsiniacea comprises but two genera, Corsinia and Funicularia (Boschia). Each genus contains but a single known species. Structurally they are intermediate in character between the Ricciaceæ and Marchantiaceæ. Corsinia differs from all the higher Marchantiaceæ in the character of the ventral scales, which are formed in more than two rows, like those of Ricciocarpus. Boschia, the other genus, has two rows of scales of the ordinary form. The archegonia are borne in a group in a depression upon the dorsal surface of the thallus, but are not formed upon a special receptacle, although after fertilisation the cells at the bottom of the cavity multiply actively and form a small prominence upon which the young sporogonia are raised, and this may perhaps be the first indication of the archegonial receptacle in the other forms.

The sporophyte resembles that of the Marchantiacer, but the sterile cells in Corsinia do not develop into true elaters, and in both genera the foot is less developed than in the true Marchantiaceæ.

\section{Marchantiaces.}

Comparing the Marchantiaceæ with the Ricciaceæ, the close similarity in the structure and development of the thallus is at 
once apparent, but the former are more highly developed in all respects. The development of definite air-chambers in the green tissue, and a continuous epidermis with the characteristic pores, is common to all of them with the exception of the peculiar genera Dumortiera and Monoclea, where the development of the air-chambers is partially or completely suppressed. The genera Ricciocarpus and Tessalina on the one hand, and Corsinia and Boschia on the other, connect perfectly Riccia with the Marchantiaceæ as regards the structure of air-spaces and epidermis, as they do in other respects. The epidermal pores in the Marchantiaceæ are sometimes simple pores surrounded by more or less symmetrically arranged guard cells (Fig. I I, D), or they are, especially upon the female receptacles, of a most peculiar cylindrical form, which arises by a series of transverse walls in the primary guard cells (Fig. I I, C). There is a good deal of difference in the character of the airchambers in different genera. In Reboulia and Fimbriaria, for instance, they resemble a good deal those of Ricciocarpus, a more or less complete division of the primary chambers being produced by the formation of diaphragms or laminæ, which give the green tissue an irregular honey-combed appearance, and in these forms there is not a sharp separation of the green tissue from the ventral colourless tissue. In other genera, Marchantia, Targionia (Fig. I8), Conocephalus, the dorsal part of the thallus is occupied by a single layer of very definite air-chambers, each opening at the surface by a single central pore. Seen from the surface the boundaries of these spaces form a definite network which in Conocephalus (Fig. I, D) is especially conspicuous. The bottom of these chambers is sharply defined by the colourless cells that lie below, and the space within the chamber is filled by a mass of short, branching, conferva-like filaments, which in the centre of the chamber have free terminal cells, but toward the sides are attached to the epidermal cells and are more or less confluent with the adjacent filaments.

As in Riccia rhizoids of two kinds are present, but the thickenings to the tuberculate rhizoids (Fig. I2) are much more pronounced, and these are not infrequently branched, and may extend nearly across the cavity of the hair. The ventral scales are not produced by the splitting of a single lamella, as in Riccia, but are separate from the first and usually arranged 
in two rows. Leitgeb ( ( 7$)$, iv., p. I7), recognises two types of these organs. In their earliest stages they are alike, and both arise from papillæ close to the growing point. In both cases this papilla is cut off from a basal cell, but in the first type (Sauteria, Targionia, Dumortiera) it remains terminal, usually forming the tip of a leaf-like terminal appendage of the scale. In the second type, represented by most of the other genera, this originally terminal papilla is forced to one side by the development of a lateral appendage to the scale, which, arising at first from a single cell, rapidly increases in

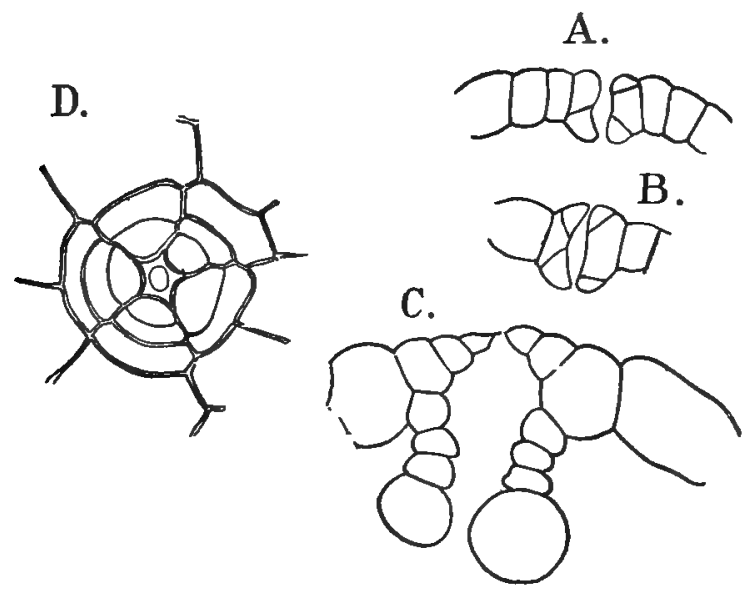

Frg. Ir.-Fimbriaria Californica. Development of the pores upon the archegonial receptacle, $\times 260 . A, B, C$, in longitudinal section; $D$, view from above.

size, and forms the overlapping dark purple marginal part of the scale so conspicuous in many species.

In different parts of the thallus are found large mucilage cells, which are usually isolated; or in Conocephalus, according to Goebel's ( I ) investigations, and those of Cavers (6), they may form rows of cells which become confluent so as to form mucilage ducts. In the earlier stages these cells have walls not differing from those of the ardjacent cells, but as they grow older the whole cell wall is dissolved, and the space occupied by the row of young cells becomes an elongated cavity filled with apparently structureless mucilage. These cells are recognisable at an early period, as their contents are much denser and more finely granular than those of the adjacent cells. 
Small cells, each containing a peculiar oil body, are found abundantly in most species, both in the body of the thallus and in the ventral scales. The structure and development of these curious bodies, which are found also in many other Hepaticæ, have been carefully studied by Pfeffer (2). The oil body has a round or oval form usually, and in the Marchantieæ usually is found in a special cell which it nearly fills. It is brown or yellowish in colour, and has a turbid granular appearance. The extremely careful and exhaustive study of these bodies by Pfeffer has shown that the oil exists in the form of an emulsion in water, and that in addition to the oil

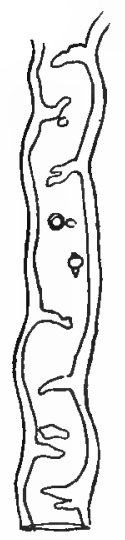

Fig. I 2.-Marchantia polymorpha. Part of a tubercul a te $\mathrm{rhizoid}$, $\times 525$. and water more or less albuminous matter is present, and tannic acid. The latter is especially abundant in the oil bodies of Lunularia, less so in Marchantia and Preissia (Cavers (6) ; Küster (I)).

The thallus of the Marchantiaceæ is made up almost entirely of parenchyma, but Goebel (3) states that in Preissia commutata there are elongated sclerenchyma-like cells in the midrib. The walls of the large colourless cells of the lower layers of the thallus are often marked with reticulate thickenings, which are especially conspicuous in Marchantia.

Most of the Marchantiaceæ have no special nonsexual reproductive organs, but in the genera Marchantia and Lunularia special gemmæ are produced in enormous numbers; and in the latter form, which is extremely common in greenhouses, the plant multiplies only by gemmæ, as the plants are apparently all female. These gemmæ, as is well known, are produced in special receptacles upon the dorsal side of the thallus. The receptacles are cup-shaped in Marchantia, and crescent-shaped in Lunularia, where the forward part of the margin of the cup is absent. These cups are apparently specially developed air-chambers, which, closed at first, except for the central pore, finally become completely open. The edge of the fully-developed receptacle is fringed. The gemmæ arise from the bottom of the receptacle as papillate hairs, and their development is the same in the other two genera where they occur. Fig. I3 shows their development in $M$. polymorpha. 
One of the surface cells of the bottom of the receptacle projects as a papilla above the surface, and is cut off by a transverse wall from the cell below. The outer cell next divides again by a transverse wall into a lower cell, which develops no further, and a terminal cell from which the gemma is formed. This terminal cell first divides into two equal cells by a cross-wall (Fig. I3, B), and in each of these cells a similar wall arises, so that the young gemma consists of four nearly

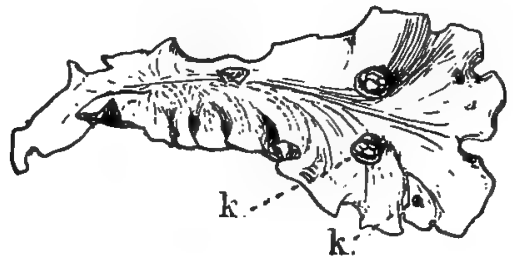

A.
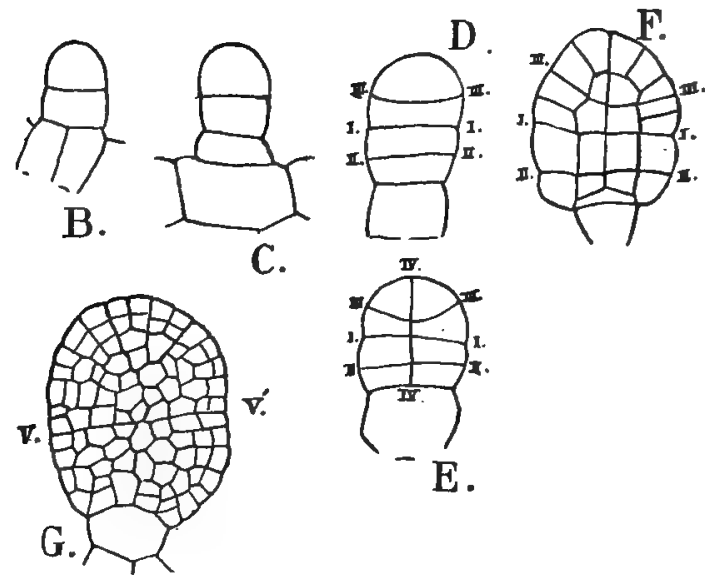

Fig. I3.-Marchantia polymorpha. A, Plant with gemma cups $(k, k), \times 2 ;$ B-F, development of the gemmx, $\times 525 ; \mathrm{G}$, an older gemma, $\times 260 ; v, v^{\prime}$, the two growing points.

equal superimposed cells (Fig. I3, D). The wall III in Fig. I3, D, arises a little later than wall II, and is always more or less decidedly concave upward. Each of the four primary cells of the gemma is divided into two by a central vertical wall, and this is followed by periclinal walls in each of the resulting cells. At first the gemma is but one cell in thickness, but later walls are formed in the central cells parallel to the surface, so that it becomes lenticular. As it grows older there 
is established on opposite sides (Fig. I3, G, v, $v^{\prime}$ ) the growing points, which soon begin to develop in the manner found in the older thallus, and come to lie in a depression, so that the older gemmæ are fiddle-shaped. The gemma stands vertically, and there is no distinction of dorsal and ventral surfaces. The cells contain chlorophyll, except here and there the cells with oil bodies, and an occasional large colourless superficial cell. Among them are small club-shaped hairs, which secrete a mucilage that swells up when wet, and finally tears away the gemmæ from their single-celled pedicels.

The further development of the gemmæ depends upon their position as to the light. Whichever side happens to fall downward becomes the ventral surface of the young plant, and the colourless cells upon this surface grow out into the first rhizoids. The two growing points persist, and the young plant has two branches from the first, growing in exactly opposite directions. As soon as it becomes fastened to the ground the dorsiventrality is established, and upon the dorsal surface the special green lacunar tissue and the epidermis with its characteristic pores are soon developed, while the ventral tissue loses its chlorophyll, and soon assumes all the characters found in the mature thallus.

The branching of the thallus is in most cases dichotomous, as in Riccia, but occasionally, as in Targionia (Fig. I, E), the growth is largely due to the formation of lateral adventitious branches produced from the ventral surface.

In structure and development the sexual organs correspond closely to those of the Ricciaceæ, but they are always formed in more or less distinct groups or "inflorescences." As might be expected, this is least marked in the lower forms, especially the Corsinieæ (Leitgeb ( 7 ), vol. iv.), where the main distinction between them and the lower Ricciacer is that in Corsinia the formation of sexual organs is confined to a special region, and that the archegonia do not have an individual envelope as in Riccia, but the whole group of archegonia is sunk in a common cavity, which is of exactly the same nature as that in which each archegonium is placed in the latter. In most of the Marchantiex, however, both antheridia and archegonia are borne in special receptacles, which in the case of the latter are for the most part specially modified branches or systems of branches, raised at maturity upon long stalks (Fig. 2I). The 
antheridial receptacles are sometimes stalked, but more commonly are sessile, and often differ but little from those of the higher Ricciaceæ.

The sporogonium shows an advance upon that of the Ricciaceæ by the development of a lower sterile portion, or foot, in addition to the spore-bearing portion or capsule, and in the latter there are always sterile cells, which in all but the lowest Corsiniea have the form of elaters. At maturity, also, the ripe capsule breaks through the calyptra, except in the Corsinieæ, where, too, the sterile cells do not develop into elaters, but seem to serve simply as nourishing cells for the growing spores. The stalk of the capsule is usually short compared with that of most Jungermanniaceæ, and the wall of the capsule remains intact until the spores are ripe.

The spores vary much in size, and in the development of the outer wall. In Marchantia polymorpha and other species where the spores germinate promptly, the ripe spore contains chlorophyll, and the exospore is thin and slightly developed. In such cases there is no distinct rupture of the exospore, but the whole spore elongates directly into the germ-tube. In Conocephalus, where the spores are very large, the first divisions occur in the spores before they are scattered. In species where the spores do not germinate at once the process is much like that of Riccia, and the thick exospore is ruptured and remains attached to the base of the germ-tube.

The apical growth of the Marchantiex is very much like that of Riccia. In Fimbriaria Californica (Fig. I4) the apical cells seen in vertical section show the same form as those of Riccia, and the succession of dorsal and ventral segments is the same; but here the development of the ventral segments is much greater, and there is not the formation of the median ventral lamellæ as in Riccia, but the two rows of ventral scales arise independently on either side of the midrib, very near the growing point, and closely overlap and completely protect the apex. The formation of the lacunæ in the dorsal part of the thallus begins earlier than in Riccia, and corresponds very closely to what obtains in Ricciocarpus. The pits are at first very narrow, but widen rapidly as they recede from the apex. In the epidermal cells surrounding the opening of the cavity, there are rapid divisions, so that the opening remains small and forms the simple pore found in this species. As in Riccio- 
carpus, the original air-chambers become divided by the development of partial diaphragms into secondary chambers, which are not, however, arranged in any regular order, and communicate more or less with one another.

In Targionia (Figs. I8, I9), where the archegonia are borne upon the ordinary shoots, the growth of the dorsal segments is so much greater than that of the ventral ones that the upper part of the thallus projects far beyond the growing point,

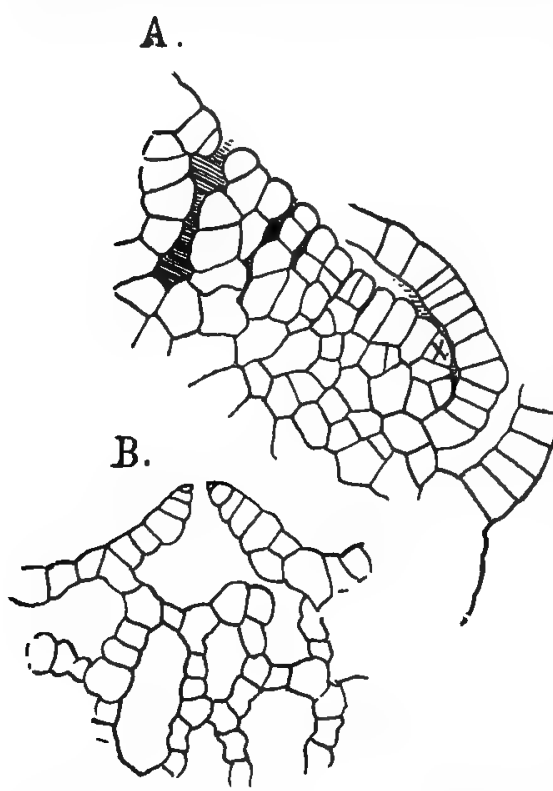

Fig. I4.-Fimbriaria Californica. A, Vertical section through the apex of a sterile shoot, show. ing the formation of the air-chambers: $x$, the apical cell, $\times_{300 ;} B$, similar section through an older part of the thallus, cutting through a pore, $X$ roo. which is pushed under toward the ventral side. A similar condition is found in the archegonial receptacles of other forms, where this includes the growing point of the shoot (Fig. 2I). In Targionia the lacunæ are formed much as in Fimbriaria, but they are shallower and much wider, and the pores correspondingly few. The assimilative tissue here resembles that of Marthantia and others of the $\mathrm{h}$ igher forms. It is sharply separated from the compact colourless tissue lying below it, and the cells form short confervoid filaments more or less branched and anastomosing, and except in the central part of the chamber united with the epidermal cells. Under the pore, however, the ends are free and enlarged with less chlorophyll than is found in other cells.

All of the Marchantiex except the aberrant genera Dumortiera and Monoclea correspond closely to one or the other of the above types in the structure of the thallus, but in the latter the air-chambers are either rudimentary or completely absent, and the ventral scales are also wanting. Leitgeb (( 7$)$, vi., p. I24) 
investigated $D$. irrigua, whose thallus is characterised by a yeculiar areolation composed of projecting cell plates, and came to the conclusion that these were the remains of the walls of the air-chambers, whose upper parts, with the epidermis, were thrown off while still very young. He had only herbarium material to work with, but in this he detected traces of the epidermis and pores in the younger parts. I examined with some care fresh material of $D$. trichocephala, from the Hawaiian Islands, and find that in this species, which has a perfectly smooth thallus without areolations, that no trace of air-chambers can be detected at any time. Vertical sections through the apex show the initial cells to be like those of other Marchantiacea, and the succession of segments the same, but no indications of lacunæ can be seen either near the apex or farther back, the whole thallus being composed of a perfectly continuous tissue without any intercellular spaces, and no distinct limit between the chlorophyll-bearing and the colourless tissue. As Dumortiera corresponds in its fructification with the higher Marchantiex, the peculiarities of the thallus are probably to be regarded as secondary characters, perhaps produced from the environment of the plant, and species like $D$. irrigua would form transitional stages between the typical Marchantiaceous thallus and the other extreme found in D. trichocephala.

\section{Sexual Organs}

The structure and development of the sexual organs are very uniform among the Marchantiaceæ. In Fimbriaria Californica, which is diøcious, the antheridial receptacle forms a thickened oval disc just back of the apex. Not infrequently (Fig. I, A), when the formation of antheridia begins not long before the forking of the thallus, both of the new growing points continue to develop antheridia for a time, and the receptacle has two branches in front corresponding to these. The receptacle is covered with conspicuous papillæ which mark the cavities in which the antheridia are situated. Vertical longitudinal sections through the young receptacle show antheridia in all stages of development, as their formation, like those of Riccia, is strictly acropetal. The first stages are exactly like those of Riccia, and the primary cell divides into two cells, a pedicel and the antheridium proper. The divisions in the lower 
cell are somewhat irregular, but more numerous than in Riccia, so that the stalk of the ripe antheridium is more massive (Fig. I6). In the upper cell a series of transverse walls is formed, varying in different species in number, but more than in Riccia, and apparently always perfectly horizontal. In Marchantia polymorpha Strasburger (2) found as a rule but three cells, before the first vertical walls were formed. In an tundetermined species of Fimbriaria (Fig. I5) probably $F$. Bolanderi, the antheridia were unusually slender, and frequently four, and sometimes five transverse divisions are formed before the first vertical walls appear. Sometimes all the cells divide into equal quadrants by intersecting vertical walls, but quite as often this division does not take place in the uppermost
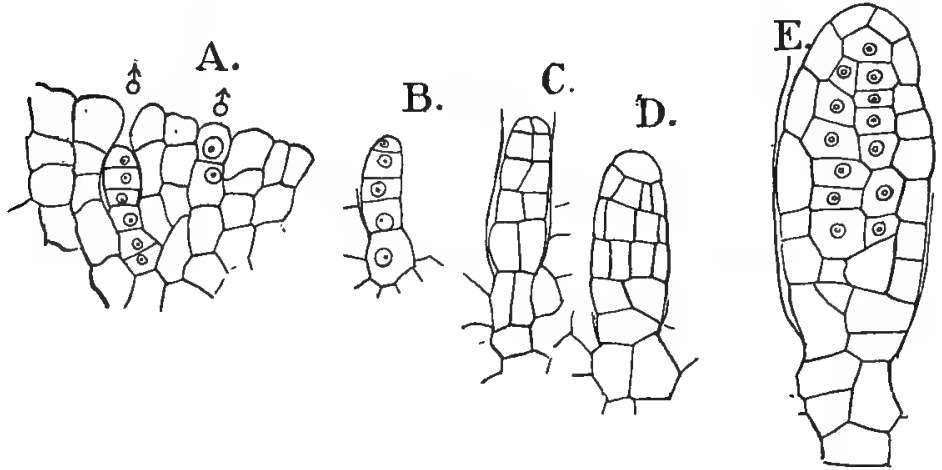

FIG. 15.-Fimbriaria sp. (?). A, Part of a vertical section of a young antheidial receptacle, showing two very young antheridia $\left(d^{*}\right), \times_{420} ; \mathrm{B}-\mathrm{E}$, older stages.

and lowest cell of the body of the antheridium, or the divisions in these parts are more irregular. The separation of the central cells from the wall is exactly as in Riccia, and the lower segments do not take any part in the formation of the sperm cells, but remain as the basal part of the wall. In Fimbriaria the top of the antheridium is prolonged as in Riccia, but in Marchantia this is not the case. The wall cells, as the antheridium approaches maturity, are often much compressed, but in Targionia hypophylla, where Leitgeb states that this compression is so great that the cells appear like a simple membrane, I found that, so far from this being the case, the cells were extraordinarily large and distinct, and filled the whole space between the body of the antheridium and the wall of the cavity, which in Leitgeb's figures ( (7), vi., P1. x., Fig. 12) is repre- 
sented as empty. The antheridium becomes sunk in the thallus precisely as in Riccia. The sperm cells are nearly cubical and the spermatozoid is formed in the usual way. The free spermatozoid (Fig. I6, D) shows about one and a half complete turns of a spiral. The cilia are very long, and the vesicle ustually plainly evident.

According to Ikeno (4), in Marchantia polymorpha the final division, resulting in the pair of spermatids, is unaccompanied by a division wall, and this seems also to be the case in
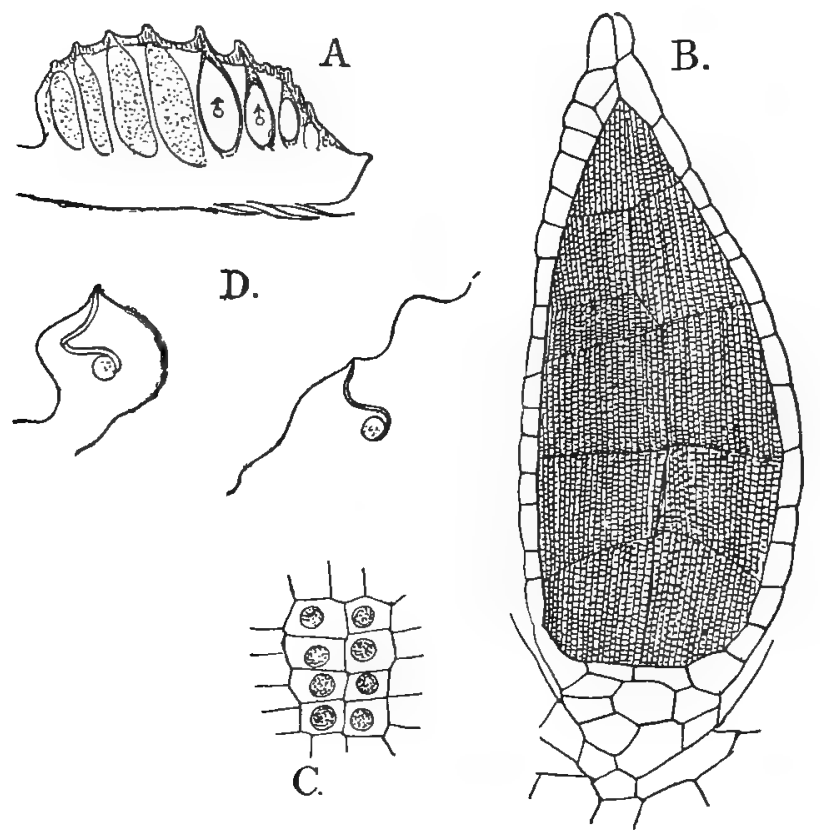

FIG. 16.-Fimbriaria Californica. A. Longitudinal section of a fully-developed male receptacle, $\times 8 ; B$, longitudinal section of a nearly ripe antheridium, $\times 100 ; C$, young sperm cells, $\times 600 ; D$, spermatozoids, $X_{1200}$

Fimbriaria. In the earlier divisions of the sperm-cells, each cell shows two centrosomes (Fig. I7, I), and Ikeno does not recognise any difference between these and the so-called "blepharoplast" of Webber and other recent students of spermatogenesis, who look upon the blepharoplast as a different organ from the centrosome. After the final division, each spermatid is provided with a single centrosome (blepharoplast), from which, later, the cilia arise. 
The young spermatid (Fig. 17,3 ) is triangular in section, and the blepharoplast is situated in the acute angle which later forms the anterior end of the spermatozoid. The blepharoplast becomes somewhat elongated, and from it grow out the two cilia before any marked change is observable in the nucleus. (Fig. I7, 5). Before the cilia can be seen, there appears in the cytoplasm a round body which stains strongly, but whose origin is not clear. This body Ikeno calls the chromatoid "Nebenkörper," and says that it does not participate directly in the development of the spermatozoid, but ultimately disappears. His figures 30 and $3 \mathrm{I}$, however, look as if the portion of the spermatozoid between the blepharoplast and the nucleus was derived from this "nebenkörper," and not from the cytoplasm, as he states is the case.

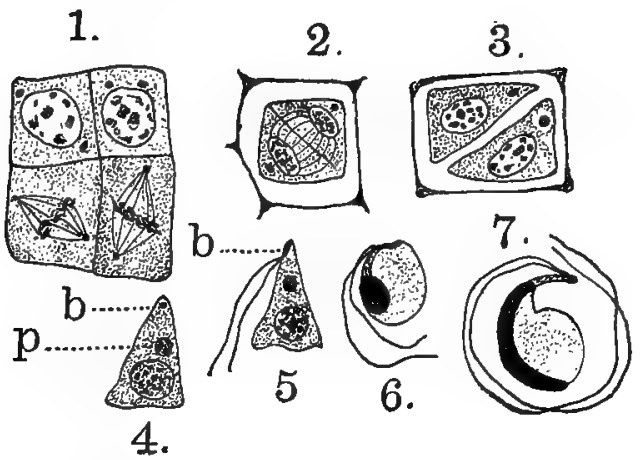

Fig, 17.-Marchantia polymorphe. Development of the spermatozoid, $x$, Sperm-cells from the young antheridium; 2 , final division of the sperm-cell to form the two spermatids; $3-7$, development of the spermatozoid; $b$, blepharoplast; $p$, "neben. körper"; (All figures after Ikeno).

Owing to the very small size of the spermatozoids in Marchantia, it could not be positively demonstrated whether there is a cytoplasmic envelope about the nuclear portion of the spermatozoid, but it was concluded that such probably is the case.

When the antheridia are borne directly upon the thallus, the apical growth continues after antheridia cease to be formed, and the receptacle is thus left far back of the growing in point. In forms like Targionia, however, where there are special antheridial branches, the growth of these is limited, and generally ceases with the formation of the last antheridia. The most 
specialised forms are found in the genus Marchantia and its allies, where the antheridial receptacle is borne upon a long stalk, which is a continuation of the branch from which it grows, and the receptacle is a branch-system. The growing point of the young antheridial branch forks while still very young, and this is repeated in quick succession, so that there results a round disc with a scalloped margin, each indentation marking a growing point, and the whole structure being equivalent to such a branch system as is found in Riccia or Anthoceros, where the whole thallus has a similar rosette-like form. The antheridia are arranged in radiating rows, the youngest one nearest the margin and the eldest in the centre. In some tropical species, e.g., M. geminata, the branches of the receptacle are extended and its compound character is evident.

The discharge of the spermatozoids from the ripe antheridium may take place with great force. In the case of Fimbriaria Californica, Peirce (I) found they were thrown vertically for more than fourteen centimetres. The mechanism involved includes not only the tissues of the antheridium itself, but also the cells below the antheridium, and those forming the walls of the chambers in which the antheridia are situated. These cells, becoming strongly distended with water, exercise great pressure upon the antheridium, whose mucilaginous contents are also strongly distended. The upper wall of the antheridium is finally burst, and the contents expelled violently through the narrow, nozzle-like opening of the antheridial chamber.

This explosive discharge was first noted by Thuret (I) in Conocephalus conicus, and has been recently studied in that species by King ( I) and Cavers (I), as well as in several other genera. It is much more marked in the diœcious species.

The archegonia are never sunk in separate cavities, but stand free above the surface of the thallus. The simplest form may be represented by Targionia. Here the archegonia arise in acropetal succession from the dorsal segments of the initial cells of the ordinary branches. A superficial cell enlarges and is divided as in Riccia into an outer and an inner cell. The latter undergoes irregular divisions and its limits are soon lost. In the outer cell the divisions occur in the same order as in Riccia, but from the first the base of the archegonium is broad and not tapering. Strasburger (2) states that in Marchantia 
there is a division of the outer of the two primary cells by a wall parallel to the first, and that the lower one forms the foot of the archegonium, and Janczewski ( I ) gives the same account of the young archegonium of Preissia commutata. This certainly does not occur in Targionia, and to judge from the later stages of Fimbriaria Californica, this species too lacks this

A.

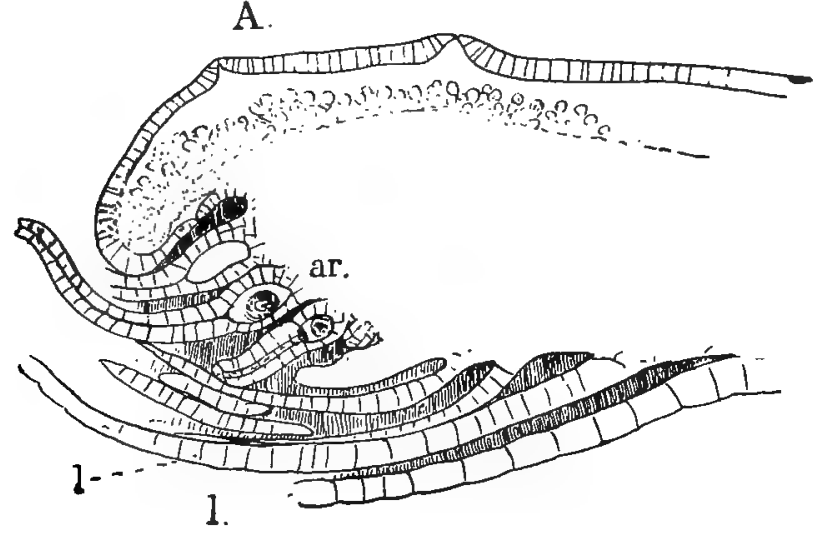

B.



FIG. 18.-Targionia hypophylla. A, Longitudinal section of the thallus, $X 100$; ar, archegonia; $l l$. ventral scales; $B$, median section through a pore, showing the assimilating cells $(\mathrm{cl})$ below, $\times_{300}$.

division. The full-grown archegonium is of more nearly uniform thickness than in Riccia, as the venter does not become so much eniarged. The neck canal cells are more numerous, about eight being the common number, but in Targionia the formation of division walls between these is sometimes sup- 
pressed (Fig. I9, C), so that this may account for Janczewski's error in stating that the number was always four, as the nuclei in unstained sections might very easily be overlooked. The cover cells are somewhat smaller than in Riccia and do not usually undergo as many divisions, there being seldom more than six in all. In Targionia (Fig. 23, A), and Strasburger ( (2I ) p. 4I8) observed the same in Marchantia, the ripe egg shows a distinct "receptive spot," that is, the upper part of the unfertilised egg is comparatively free from granular cytoplasm, while the lower part, about two-thirds in Targionia, is much more densely granular. The nucleus is not very large and has very little chromatin. The nucleolus is large and distinct and
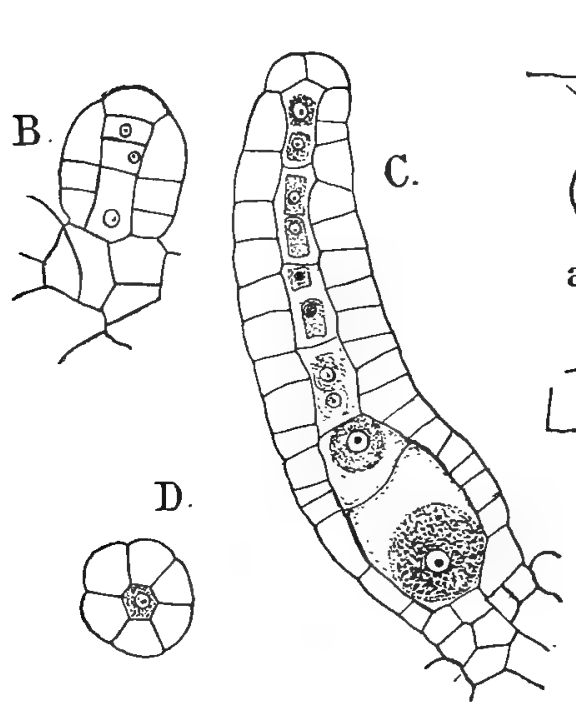

FIG. 19.- Targionia hypophylla. A, Longitudinal section of the apex of the thallus, with young archegonia (ar), $\times_{525} ; x$, the apical cell; B, young, C, older arche gonium in longitudinal section; $D$, cross-section of the archegonium neck, $\times 525$.

stains very intensely. As the archegonium of Targionia matures, its neck elongates rapidly and bends forward and upward, no doubt an adaptation to facilitate the entrance of the spermatozoid. A similar curving of the archegonium neck is observed in other forms where the archegonium is upon the lower side of the receptacle.

After an archegonium (or sometimes several of nearly equal age) is fertilised, the growth in length of the thallus stops, 
but there is a rapid lateral growth with results in the formation of two valves, which meet in front much like the two parts of a bivalve shall, and this involucre completely encloses the developing sporogonium.

In the simplest cases, where the archegonia are borne upon a receptacle ${ }^{1}$ which is raised upon a stalk, e.g., Plagiochasma, Clevea (Fig. 20, A), the receptacle does not represent, according to Leitgeb ( ( 7$)$, vi., p. 29), a complete branch, but is only a dorsal outgrowth of the latter, which may grow out beyond it, or even form several receptacles in succession. The first indi-
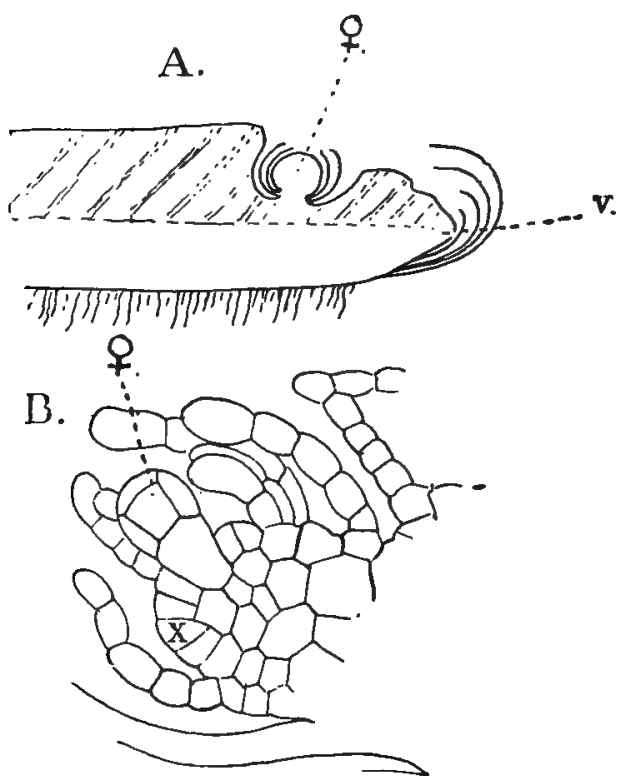

FIG. zo.-A. Clevea sp. A, longitudinal section of the thallus showing the dorsal origin of the female receptacle ( $Q$ ); $v$, the growing point (diagram after Leitgeb); B, Reboulia hemispharica (Radd.), longitudinal section of very young receptacle with the first archegonium $(\ell) ; x$, the apical cell, $\times 300$ (after Leitgeb). cation of the receptacle is a dorsal prominence which soon becomes almost hemispherical, and near the hinder margin the first archegonium arises, without, apparently, any special relation to the growing point. On the lateral margins are then formed two other archegonia, not, however, simultaneously; and finally a fourth may be formed in front: three or four archegonia in all seem to be the ordinary number. The stalk of the receptacle is also a dorsal appendage of the thallus, and not a $\mathrm{d}$ i r e c t continuation of it.

The next type is that which Leitgeb attributes to Grimaldia, Reboulia, Fimbriaria, and some others, but it is not the type found in Fimbriaria Californica. In this type the structure of

- The sporongonial receptacle of the Marchantieæ is sometimes knowi as the Carpocephalum. 
the receptacle and the origin of the archegonia are the same as in that just described; but here the growing point of the

A.

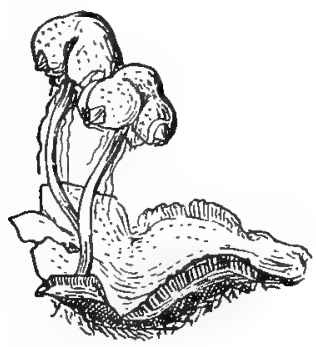

B
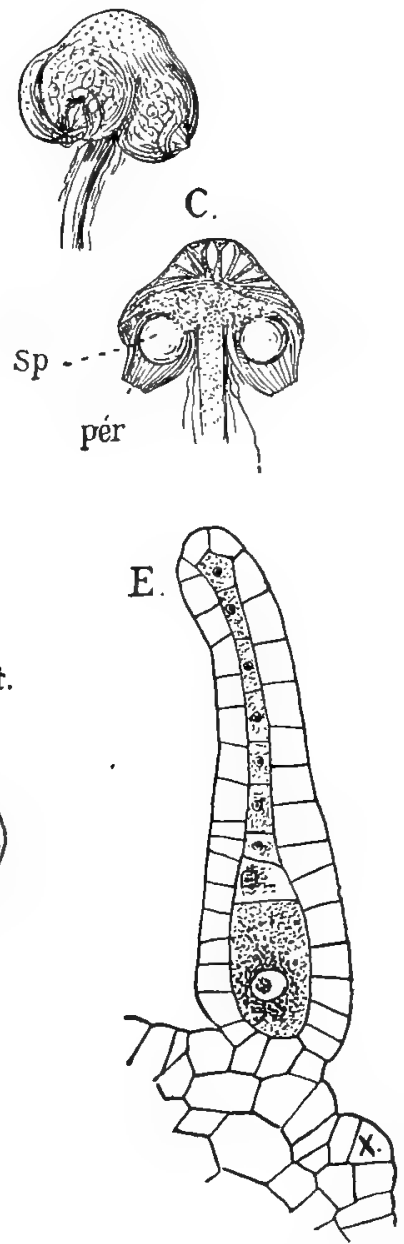

FIG. 21.-Fimbriaria Californica. A, Plant with two fully-grown sporogonial receptacles, natural size; $B$, single receptacle, $\times_{4} ; \mathrm{C}$, the same cut longitudinally, showing the sporogonium $(s p)$, enclosed in the perianth $(p e r) ; \mathrm{D}$, nearly median section of a young receptacle, showing one growing point $(x)$ and an archegonium (ar); L, air-spaces; st, a pore; $r$, rhizoids, $\times 40 ; \mathrm{E}$, the growing point of the same with an archegonium, $\times 300 ; x^{\prime}$, the apical cell.

branch forms the forward margin of the receptacle, and the stalk is a direct continuation of the axis of the branch. Upon 
its ventral surface it shows a furrow in which rhizoids are produced in great numbers, and this furrow continues along the ventral surface of the thallus.

The highest type is that of Leitgeb's "Compositæ." In this form the female receptacle is a branch system similar to that of the male receptacle of Marchantia. The branching is usually completed at a very early period, while the receptacle is almost concealed in the furrow in the front of the thallus. A simple case of this kind is seen in Fimbriaria Californica (Fig. 2I). In this case there are four growing points that have arisen from the repeated dichotomy of the primary growing point of the branch, and each of these gives rise to archegonia in acropetal succession, much as in Targionia, but the number of archegonia is small, not more than two or three being as a rule formed from each apex. The development of the dorsal tissue is excessive and the ventral growth reduced to almost nothing, and the growing apices are forced under and upward and lie close to the stalk, and the archegonia have the appearance of being formed on the ventral side of the shoot, although morphologically they are dorsal structures. In the common Marchantia polymorpha the branched character of the receptacle is emphasised by the development of the "middle lobe" between the branches. These lobes grow out into long cylindrical appendages between the groups of archegonia, and give the receptacle a stellate form. Usually in $M$. polymorpha there are eight growing points in the receptacle, and of course as many groups of archegonia, which are more numerous than in any other genus, amounting to a hundred or more in one receptacle. In Marchantia, as well as some other genera with compound receptacles, there are two furrows in the stalk, showing that the latter is influenced by the first dichotomy. While the archegonia, before fertilisation, are quite free, the whole group of archegonia, and indeed the whole receptacle, is invested with hairs or scales of various forms that originate either from the epidermis of the dorsal side, or as modifications of the ventral scales.

The peculiar American genus Cryptomitrium has been investigated by Abrams ( I) and Howe (3), who finds the development of the carpocephalum to agree essentially with that of Fimbriaria Californica. Cavers $(6,7,8)$, has recently investigated that of Conocephalus (Fegatella), Reboulia and Preissia. 
The lacunar tissue is very much developed upon the receptacles, as are to an especial degree the peculiar cylindrical breathing pores. The formation of these begins in the same way as the simple ones, being merely the original opening to the air-space. This seen from the surface shows an opening with usually five or six cells surrounding it. Vertical sections show that very soon the cells surrounding the pore become deeper than their neighbours and project both above and below. them. In these cells next arise (Fig. II, A, B) a series of inclined walls by which each of the original cells is transformed into a row of several cells, and these rows together form a curious barrel-shaped body surrounding the pore. The upper cells converge and almost close the space above, and this is still further diminished by the cuticle of the outer cell wall of the uppermost cells growing beyond the cells and leaving simply a very small central opening. The rows of cells also converge below, and in Fimbriaria Californica the lowermost cells are very much enlarged, and probably serve to close the cavity completely at times, and act very much like the guard cells of the stomata of vascular plants. In Leitgeb's group of the Astroporæ, the simple pores of the thallus have the radial walls of the surrounding cells strongly thickened, so that the pores seen from the surface appear star-shaped. The most specialised of the Marchantieæ, i.e., Marchantia, Preissia, etc., have the cylindrical pores upon the vegetative part of the thallus as well as upon the receptacle, but in the others they occur only upon the latter.

\section{The Sporophyte.}

The first divisions in the embryo of the Marchantiaceæ and Corsiniacex are the same as in the Ricciaceæ, but only the upper part (capsule) of the sporogonium develops spores, while the rest becomes the stalk and foot. The simplest form of capsule is found in the genera Corsinia and Boschia, which have been carefully studied by Leitgeb ( 7 ), iv., pp. 45-47). In these the embryo, instead of remaining globular as it does in Riccia, elongates and very early becomes differentiated into a nearly globular upper part, or capsule, and a usually narrower basal portion, the foot (Fig. 22). In the capsule at a very early period a single distinct layer of outer cells is separated from the central group of cells, and forms the wall of the 
capsule, which in Boschia at maturity develops upon the inner cell walls thickened bars. Only a portion of the cells of the central part produce spores; the remainder do not divide after the spore mother cells are formed, but remain either as simple slightly elongated nourishing cells (Corsinia) or elaters (Boschia).

The other Marchantiaceæ are much alike, and as Targionia was found to be an especially satisfactory form for study, on account of the readiness with which straight sections of the embryo could be made, it was taken as a type of the higher Marchantiales. The first division wall (basal wall) is transverse, and divides the embryo into two nearly equal parts. This is followed in both halves by nearly vertical walls (quadrant walls), and these and the basal wall are then bisected by the octant walls, so that as in Riccia the young

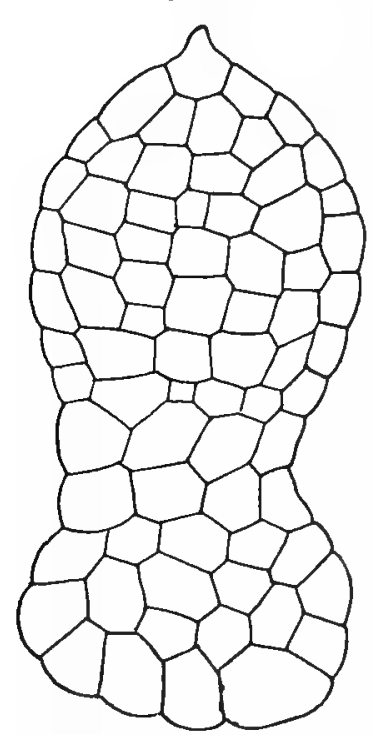

FrG. 22.-Corsinia marchantioides. Young sporogo. nium, optical section. $X_{300}$ (Leitgeb). embryo is formed of eight nearly equal cells. In Targionia, even at this period, the embryo is always somewhat elongated instead of globular. The next division walls vary a good deal in different individuals. Fig. 23, C shows a very regular arrangement of cells, where the first divisions were much the same in all the quadrants. Here all the secondary walls were nearly parallel with the basal wall, and intersected the quadrant and octant walls; but quite as often, especially in the upper half of the embryo, these secondary walls may intersect the basal wall. In no cases seen was there any indication of a two-sided apical cell such as Hofmeister figures for Targionia, and probably his error arose from a study of forms where the quadrant walls were somewhat inclined, in which case the intersection of one of the secondary walls with it might cause the apex of the embryo to be occupied by a cell that, in section, would appear like the two-sided apical cell of the Moss embryo. The regular formation of octants was observed by me in Fimbriaria Californica, and by Kienitz-Gerloff 
$(\mathrm{I}, 2)$ and others in Marchantia, Grimaldia, and Preissia, and probably occurs normally in all Marchantiaceæ.

After the first anticlinal walls are formed in the octants, no
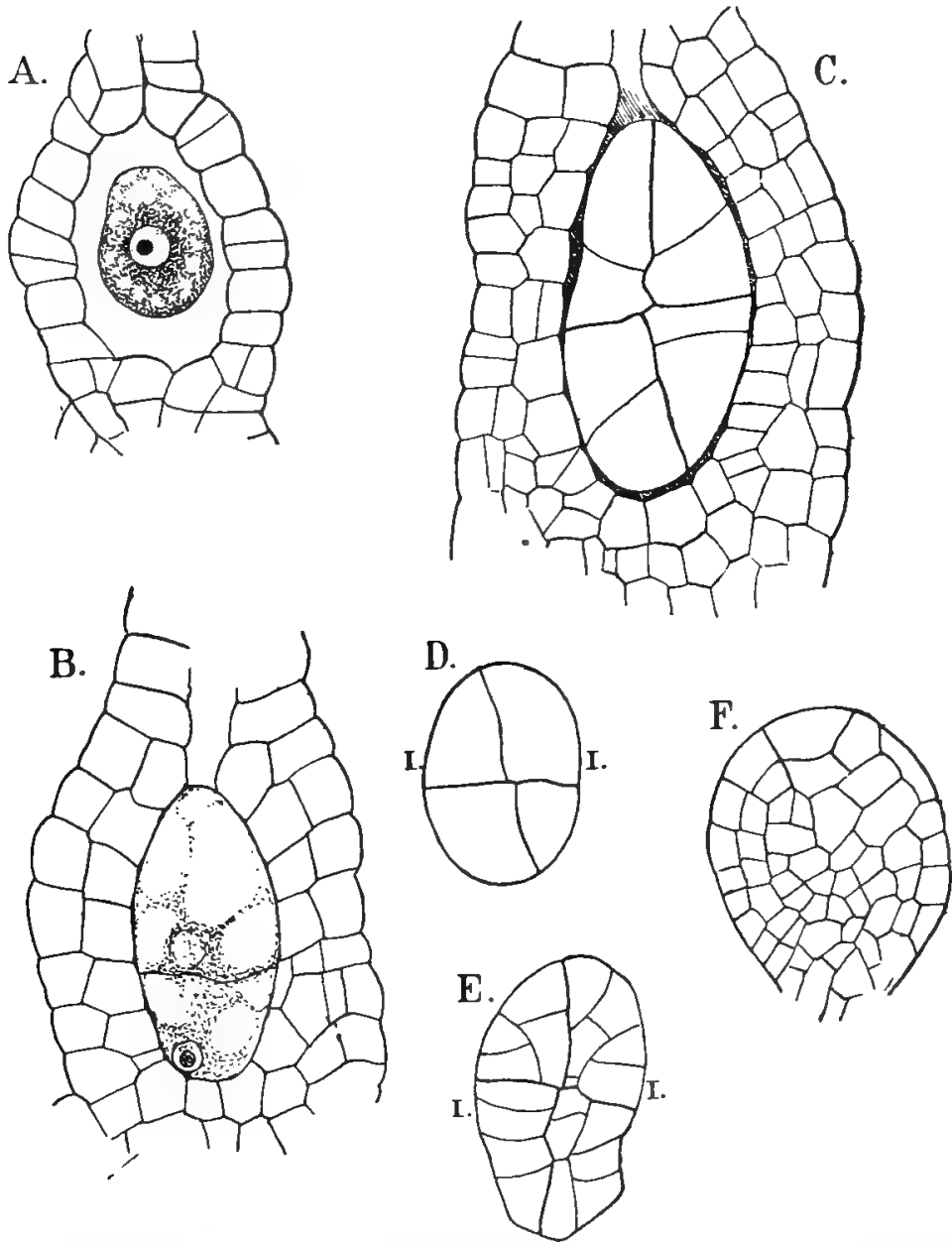

FIG. 23.-Targionia hypophylle. A, Longitudinal section of the venter of a ripe archegonium, $\times 500 ; \mathrm{B}-\mathrm{E}$, development of the embryo, seen in longitudinal median section-B, two-celled, $D$, four-celled stages, $\times 500$ except $E$, which is magnified 150 times; F, median section of the upper part of an older embryo, $\times 250$.

definite order could be observed in the succeeding cell divisions, especially in the lower half of the embryo. In the upper part 
periclinal walls appear, but not at any stated time, so far as could be made out, and the first ones do not, as Leitgeb asserts, necessarily determine the separation of the archesporium, as in the Corsiniex. The growth now becomes unequal, the cells in the central zone not dividing so actively, a marked constriction is formed, and the young sporogonium becomes dumb-bell shaped. By this time a pretty definite layer of cells (Fig. 23, F) is evident upon the outside of the capsule, but the cells of the globular lower part, or foot, are nearly or quite uniform. They are larger than those of the capsule, and more transparent.
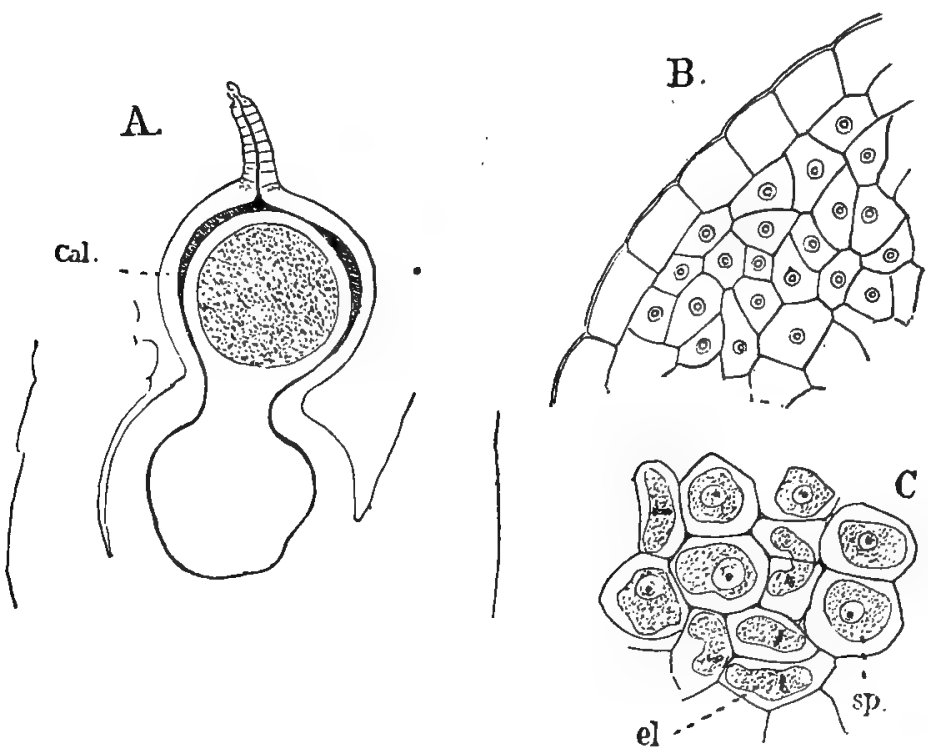

FIG. 24-Targionia hypoplyylla. A, Median longitudinal section of older embryo enclosed in the calyptra $(\mathrm{cal}), \times 80 ; \mathrm{B}$, a portion of the upper part of the same embryo, $\times 480$; the nucleated cells represent the archesporium; $C$, part of the archesporium of a still later stage; el, elaters; $s p$, sporogenous cells, $\times 480$.

In the latter the wall becomes later more definite, and remains but one cell thick until maturity. The arrangement of the cells of the archesporium is very irregular, and until the full number of these is formed they are all much alike. Just before they separate, however, careful observation shows that two wellmarked sorts of cells are present, but intermingled in a perfectly irregular way A part of these cells are nearly isodiametric, the others slightly elongated, and the nuclei of the former cells 
are larger and more definite than those of the latter. At this stage the cells begin to separate by a partial deliquescence of their cell walls, and when stained with Bismarck-brown these mucilaginous walls colour very deeply, and the cells are very distinct in sections so treated. They finally separate completely, and the much-enlarged globular capsule now contains a mass of isolated cells of two kinds, globular sporogenous cells and elongated elaters. The former now divide into four spores, but before the nucleus divides the division of the spores is indicated by ridges which project inward and divide the cavity of the mother cell much as in the Jungermanniacex.

With the first divisions in the embryo the venter of the

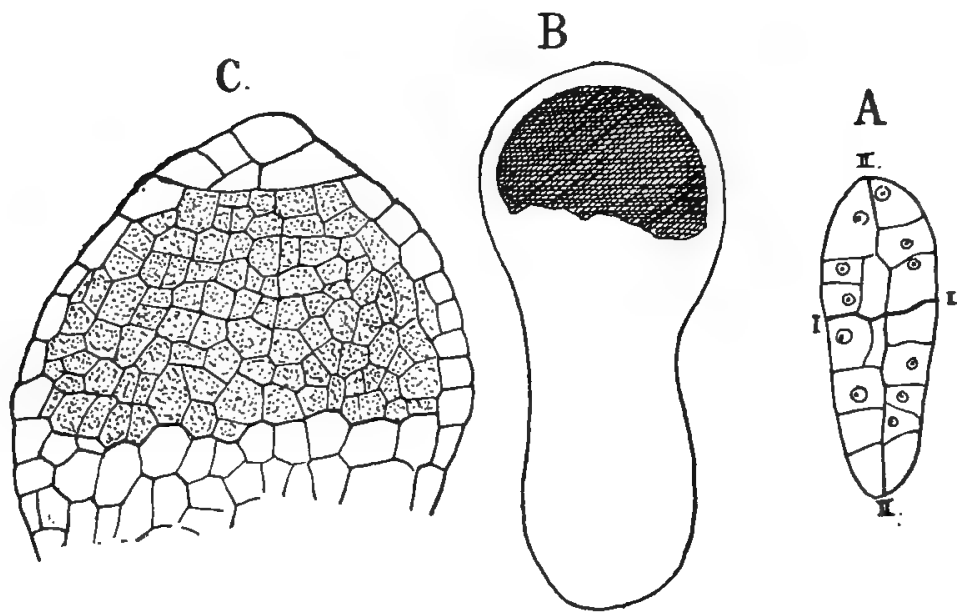

Fig. 25.-Fimbriaria Californica. A, Young, B, older embryo in median section. A, $X_{300} ; \mathrm{B}, \mathrm{X}_{100} ; \mathrm{C}$, upper part of a sporogonium, after the differentiation of the archesporium, $\times 200$.

archegonium, which before was only one cell thick, divides by a series of periclinal walls into two layers of cells, which later undergo further divisions, so that the calyptra surrounding the older capsule may consist of four or more layers of cells. The neck of the archegonium remains unchanged, but the tissue of the thallus below the archegonium grows actively, and surrounds the globular foot, which has grown down into the thallus for some distance, and only the capsule remains within the calyptra. This large growth of the foot is at the expense of the surrounding cells of the thallus, which are destroyed by its 
growth, and through the foot nourishment is conveyed from the thallus to the developing capsule. That is, the sporogonium is here a strictly parasitic organism, growing entirely at the expense of the thallus.

The further growth of the spores and elaters was studied in Fimbriaria Californica. The spores remain together in tetrads, until nearly ripe. In sections parallel to the surface of the younger spores (Fig. 26, C) the outer surface of the exospore is covered with very irregular sinuous thickenings, at first projecting but little above the surface, but afterward becoming in this species extraordinarily developed. In sections of the
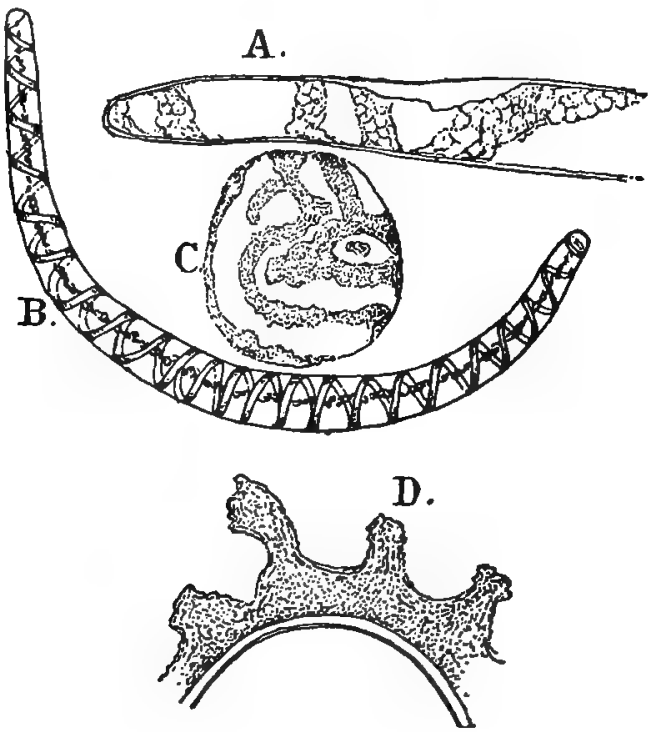

FrG. 26.-Fimbriaria Californica. A, Young elater $\times 600 ; B$, a fully-grown elater, $X_{300}$; C, surface view of the wall of a young spore, showing the developing episporic ridges, $\times 600 ; \mathrm{D}$, section of a wall of a ripe spore, $\times 300$.

ripe spore (Fig. 26, D) three distinct layers are evident, the cellulose endospore, the thick exospore, and this outer thickened mass of projecting ridges which has every appearance of being deposited from without, and must therefore be characterised as epispore (perinium) ; Leitgeb ( ( 7$)$, vi., p. 45) distinctly states that thickenings of this character do not occur in the Marchantiea, but that the thickenings are always of the character of those in Riccia. 
The elaters are at first elongated thin-walled cells with a distinct although small nucleus, and nearly uniformly granular cytoplasm. As they grow the cytoplasm loses this uniform appearance, and a careful examination, especially of sections, shows that the granular part of the cytoplasm begins to form a spiral band, recalling somewhat the chlorophyll band of Spirogyra. This is the beginning of the characteristic spiral thickening of the cell wall, and while at first irregular, the arrangement of the granular matter becomes more definite, and following the line of this spiral band of granules in the cytoplasm, there is formed upon the inner surface of the wall the regular spiral band of the complete elater. This band, which is nearly colourless at first, becomes yellow in the mature elater, and in Targionia, where there are generally two, they are almost black. Not infrequently branched elaters are found, but these are unicellular, and no doubt owe their peculiar form to their position between the spore mother cells in the young archesporium. An axial row of granules, which seem to be of albuminous nature, remains in the elaters of Fimbriaria until maturity.

The differences in the structure of the sporogonium in different genera of the Marchantieæ are slight. In Marchantia polymorpha, the young sporogonium is nearly globular, and even when full grown it is ellipsoid with the stalk and foot quite rudimentary. Most forms, however, have the foot large, but the stalk, compared with that of most Jungermanniaceæ, is short. In most of them the whole of the upper half of the young embryo develops into the capsule, but in Fimbriaria Californica I found that the archesporium was smaller than in other forms described, and that sometimes the apical part of the sporogonium was occupied by a sort of cap of sterile cells (Fig. 25, C).

When ripe, the cells of the capsule-wall in Targionia develop upon their walls dark-colored annular and spiral thickenings much like those of the elaters. These thickenings are quite wanting in Fimbriaria.

The dehiscence of the capsule is either irregular, e.g. Targionia, or by a sort of lid, e.g., Grimaldia, or by a number of teeth or lobes, e.g., Lumularia, Marchantia. In some forms after fertilisation there grows up about the archegonium a cupshaped envelope, "perianth, pseudoperianth," which in Fim- 
briaria especially is very much developed, and projects far beyond the ripe capsule (Fig. $2 \mathrm{I}$ ).

The germination of the spores corresponds in the main with that of Riccia. Except in cases where the exospore is very thin, in which case it is not ruptured regularly, the exospore either splits along the line of the three converging ridges upon


FIG. 27.-Targionia hypophylla. Germination of the spores, $X$ about 200. In $B$ two germ tubes have been formed; $\mathrm{C}$ and $\mathrm{E}$ are optical sections; $x$, apical cell; $r$, primary rhizoid; $s p$, spore membrane.

the ventral surface, and through this split the endospore protrudes in the form of a papilla, as in Riccia; or in Targionia (Fig. 27) the exospore is usually ruptured in two places on opposite sides of the spore, and through each of these a filamient protrudes, one thicker and containing chlorophyll, the other more slender and nearly colourless. The first is the germ tube, the second the first rhizoid. In Fimbriaria Californica the first rhizoid usually does not form until a later period. In Targionia a curious modification of the ordinary process is quite often met with (Fig. 27, B). Here, by a vertical division in the very young germ tube, it is divided into two similar cells, which both grow out into germ tubes. Whether both of these ever produce perfect plants was not determined, but the first divisions in both were perfectly normal. The first divisions in the germ tube are not quite so uniform as in 
Riccia trichocarpa, but resemble them very closely in the commoner forms.

In Fimbriaria especially, and this has also been observed in Marchantia (Leitgeb (7), vi., Pl. ix., Fig. I3) and other genera, a distinct two-sided apical cell is usually developed at an early period, and for a time the growth of the young plant is due to the segmentation of this single cell. Finally this is replaced by a single four-sided cell (Fig. 29, C), very much like the initial cell of the mature thallus. The young plant, composed at first of homogeneous chlorophyll-bearing cells, grows rapidly. and develops the characteristic tissues of the older thallus. The first rhizoids are always of the simple form, and the



FIG. 28.-Targionia hypophylla, Germ plant in which the thallus ( $T$ ) has been formed secondarily, $\times 260$. papillate ones only arise later, as do the ventral scales. Targionia shows a number of peculiarities, being much less uniform in its development than Fimbriaria. While it often forms the characteristic germ tube, and the divisions there are the same as in Riccia and Fimbriaria, the formation of a germ tube may be completely suppressed, and the first result of germination is often a cell mass, from which later a secondary germ tube may be formed with the young plant at the apex (Fig. 28). Such cases as these are the only ones where it seems really proper to speak of the plant arising secondarily from a protonema, for in other cases, as in Riccia, the growth is perfectly continuous, and the axis of the young thallus is coincident with that of the germ tube, and in no cases observed by me could it in any sense be looked upon as a secondary lateral growth.

\section{Biology of the Marchantiaceae}

While the Marchantiaceæ are, as a rule, moisture-loving plants, still some of them are markedly xerophilous. Most of the commoner Californian species, e.g., Fimbriaria Californica, Targionia hypophylla, Cryptomitrium tenerum, dry up com- 

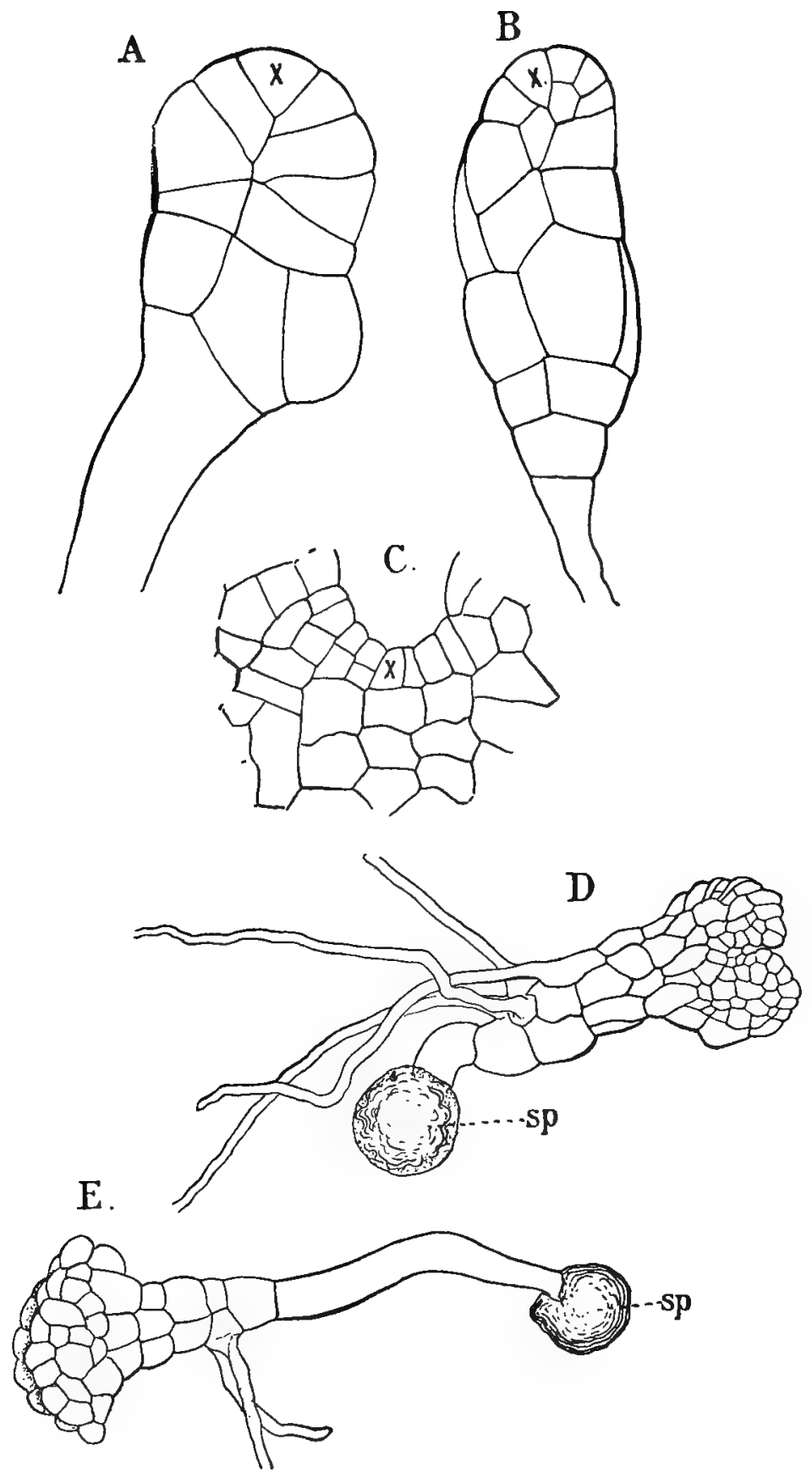

FIG. 29.-Fimbriaria Californica. A, B, Young plants in optical section, showing the single two-sided apical cell $(x), \times 260 ; \mathrm{C}$, horizontal section of an older plant with a single four-sided initial $(x), \times_{425} ; \mathrm{D}, \mathrm{E}$, two young plants, D from below, $\mathbf{E}$ from the side, $\times 85$. 
pletely during the long rainless summer, and revive immediately with the advent of the autumn rains. In these species, the growing point of the thallus, with a good deal of the adjacent tissue, survives, and at once becomes fresh and active. The scales and mucilage-cells found about the apex are doubtless water conservers, and according to $\operatorname{Cavers}(3,6,7)$, the tuberculate rhizoids are also concerned in holding water. In Fimbriaria Californica, even the young antheridia survive the long summer drought.

It has been shown (Cavers $(6,7)$ ), that the large hyaline cells terminating the green assimilating filaments in the airchambers of such forms as Conocephalus and Targionia are the principal agents in the transpiration of water from the underlying tissues.

Besides the formation of definite gemma like those of Marchantia and Lunularia, the thallus in most Marchantiaceæ is capable of extensive regeneration, even from small fragments. In Conocephalus there have also been found tuberous outgrowths, which are formed under certain conditions and are doubtless for propagation (Cavers (6)).

The Marchantiaceæ are readily separable into two subfamilies, the Targionieæ, and the Marchantieæ. Leitgeb has made a further division of the latter family, but some of the characters given are not sufficiently constant to warrant his division, and for that reason it has been thought best not to accept them. Thus Fimbriaria Californica, which is, in regard to its fructification, typical, has the female receptacle of the composite type, a character which, according to Leitgeb, not only does not belong to the genus Fimbriaria, but is not found in any genus of the group (Operculatæ) to which he assigns it. This species too does not have the capsule operculate, but opens irregularly.

The Targioniex include the two genera Targionia, which has been already described at length, and Cyathodium (Leitgeb (7), vi., p. I36), whose development is not sufficiently known to make its systematic position quite certain. In the position of the sexual organs, and the formation of the two-valved involucre about the fruit, as well as the position of the latter, it corresponds closely to Targionia, but the structure of the thallus is extraordinarily simple, there being practically but two layers of cells with large irregular air-chambers between. While two 
sorts of rhizoids are present, those that represent the papillate type of the other Marchantiaceæ, while thicker walled than the others, do not develop the projecting prominences. Indeed the whole structure of the plant is curiously reduced, and Leitgeb describes it as resembling the young plants of Marchantia or Preissia. The development of the sexual organs is but imperfectly known, and the suggestion of Leitgeb's that possibly the antheridium is reduced to a single cell, seems hardly probable in view of the structure of the rest of the plant. The sporogonium has the stalk and foot exceedingly rudimentary, but the upper part of the capsule shows a zone of cells whose walls are marked by peculiar ring-shaped thickenings, and opens regularly by a number of teeth, which on account of the thickened bars upon the cell wall offer a superficial resemblance to the peristome of the Bryales. As in Targionia the archegonia arise near the apex of the ordinary shoots, and no proper receptacle is formed.

All of the other forms have the archegonia borne upon a special receptacle, which, as the sporogonia develop, is raised upon a stalk. Here belong, according to Schiffner (I) sixteen genera with about I 50 species. The receptacle may be, as we have seen, strictly dorsal in origin, or if may include the growing point of the archegonial branch, or finally it may be a branch system arising from the repeated dichotomy of the original growing point.

\section{Monoclea}

The genus Monoclea includes two known species, $M$. Forsteri, found in New Zealand and Patagonia, and $M$. Gottschei, of Tropical America, said also to occur in Japan. This genus has been usually associated with Jungermanniales (Leitgeb (7), vol. iii., Schiffner (I)), but a more complete study of the plant has shown that its affinities are undoubtedly more with the simpler Marchantiaceæ. The structure and position of the sexual organs, especially the antheridia, and the development of the sporophyte, so far as it has been made out (Cavers ( 7 ), Johnson (3)), all point unmistakably to a relationship with the Marchantiaceæ.

Two kinds of rhizoids are present, although not so marked as in the typical Marchantiaceæ, but the thallus lacks the char- 
acteristic lacunar tissue of these forms. In the latter respect Monoclea closely resembles Dumortiera, and as in that genus, the absence of the air-chambers may be attributed to the semiaquatic habit of the plant. Monoclea evidently belongs to the lower series of Marchantiacex, and may perhaps be compared to Targionia. See Ruge (I), Cavers (7), Campbell (19).

\section{Résumé of the Marchantiales}

Comparing the different members of this order, one is struck by the almost imperceptible gradations in structure between the different families, and this accounts for the difference of opinion as to where certain genera belong. That the Ricciaceæ cannot be looked upon as a distinct order is plain, and they may perhaps be best regarded as simply a family co-ordinate with the Corsinieæ and Targionieæ, and not a special group opposed to all the other Marchantiacex. The gradual increase in complexity of structure is evident in all directions. First the thallus passes by all gradations from Riccia-with its poorly defined airchambers with no true pores and single ventral lamellæ, through Ricciocarpus and Tessalina, where definite air-chambers are present, opening by pores of the same form as those of the lower Marchantieæ, and separate ventral scales occur-to forms like Marchantia, where the air-chambers are very definite and contain a special assimilating tissue, and the pores are of the cylindrical type. With this differentiation of the thallus is connected the segregation of the sexual organs and the development of special receptacles upon which they are borne. Finally, in the development of the sporogonium, while there is almost absolute uniformity in the earlier stages, we find a complete series of forms, beginning with Riccia, where no stalk is developed and all the cells of the archesporium develop spores, ascending through Tessalina, with a similar absence of a stalk, but the first indication of sterile cells, through the Corsiniea, to forms with a massive foot and elaters fully developed. It may be said, however, that there is no absolute parallelism between the development of the gametophyte and that of the sporophyte; for in Marchantia, the most specialised genus as to the gametophyte, the sporogonium is less developed than in the otherwise simpler Targionia and Fimbriaria. 


\section{CHAPTER III}

\section{THE JUNGERMANNIALES}

A VERY large majority of the Hepaticæ belong to the Jungermanniales, which show a greater range of external differentiation than is met with in the Marchantiacex, but less variety in their tissues, the whole plant usually consisting of almost uniform green parenchyma. In the lowest forms, e.g., Aneura and Metzgeria, the gametophyte is an extremely simple thallus, in the former composed of almost perfectly similar cells, in the latter showing a definite midrib. Starting with these simplest types, there is a most interesting series of transitional forms to the more specialised leafy ones, where, however, the tissues retain their primitive simplicty. All of the Jungermanniales grow from a definite apical cell, which differs in form, however, in different genera, or even in different species of the same genus. Rhizoids are usually present, but always of the simple thin-walled type.

The gametophyte, with the exception of the genera Haplomitrium, and Calobryum, is distinctly dorsiventral, and even when three rows of leaves are present, as in most of the foliose forms, two of these are dorsal and lie in the same plane, while the third is ventral. In the thallose forms, while the bilaterality is strongly marked, there is not the difference between the tissues of the dorsal and ventral parts which is so marked in the Marchantiales. In the lowest forms the gametophyte is a simple flat thallus fastened to the substratum by simple rhizoids, and develops no special organs except simple glandular hairs which arise on the ventral side near the apex, and whose mucilaginous secretion serves to protect the growing point. In Blasia and Fossombronia we have genera that while still retaining the flattened thalloid character, yet show the first formation 
of lateral appendages which represent the leaves of the true foliose forms. In the latter the axis is slender, and the leaves usually in three rows and relatively large.

The archegonia correspond closely in their development to those of the Marchantiaceæ, and in the lower (anacrogynous) forms arise in much the same way from surface cells of the dorsal part of the younger segments, and the apical cell is not directly concerned in their formation. The archegonia in these thus come to stand singly or in groups upon the dorsal surface of the thallus, whose growth is not interrupted by their development. In the higher leafy forms (Jungermanniaceæ acrogynæ) they occur in groups at the end of special branches, whose apical cell finally itself becomes the mother cell of an archegonium, and with this the growth in length of the branch ceases.

The antheridia in most cases differ essentially in their first divisions from those of the Marchantiaceæ. After the first division in the mother cell, by which the stalk is cut off from the antheridium itself, the first wall in the latter, in all forms investigated except Spharocarpus, Riella and Geothallus, is vertical, instead of horizontal, and the next formed walls are also nearly vertical. The ripe antheridium is usually oval in outline and either nearly sessile or provided with a long pedicel. The spermatozoids are as a rule larger than in the Marchantiales, and show more numerous coils, but like those of the latter, are always biciliate.

The embryo differs in its earliest divisions from that of the Marchantiacex. The first transverse wall divides the embryo into an upper and lower cell, but of these the lower one usually takes no further part in the development of the sporogonium, but either remains unclivided or divides once or twice to form a small appendage to the base of the sporogonium. In the upper cell the first wall may be either vertical (e. g., Pellia and most anacrogynous forms), or it may be transverse. From the upper of the two primary cells not only the capsule but the seta and foot as well are formed. The development of these different parts varies in different forms, and will be taken up when considering these.

All of the Jungermanniales, except the Anelaterex, possess perfect elaters, but in the latter these are represented merely by sterile cells that probably serve simply for nourishing the grow- 
ing spores. The sporogonium remains within the calyptra until the spores are ripe, when by a rapid elongation of the cells of the seta it breaks through the calyptra, which is left at its base, and the capsule then opens. The opening of the capsule is usually effected by its walls splitting into four valves along lines coincident with the first formed vertical cell walls in the young embryo. These valves, as well as the elaters, are strongly hygroscopic, and by their movements help to scatter the ripe spores. The latter show much the same differences observed in the Marchantiaceæ. When the spores germinate at once they have abundant chlorophyll and a thin exospore, but where they are exposed to drying up, they have no chlorophyll and the exospore is thick and usually with characteristic thickenings upon it. From the germinating spore the young gametophyte may develop directly, or there may be a wellmarked protonemal stage. This latter is always found in the foliose forms, and is either a flat thallus, like the permanent condition of the lower thallose genera, or sometimes (Protocephalozia) it is a branched filamentous protonema, very much like that of the Mosses, and sometimes long-lived and producing numerous gametophores.

Non-sexual reproductive bodies in the form of unicellular gemmæ are found in many species, and in Blasia special receptacles with multicellular gemmæ something like those of Marchantia occur.

The Jungermanniales naturally fall into two well-marked series, ${ }^{1}$ Anacrogynæ and Acrogynæ, based upon the position of the archegonia. These in the former are never produced directly from the apical cell of a branch, in the latter group the apical cell of the archegonial branch always sooner or later becomes transformed into an archegonium. The Haplomitrieæ show some interesting intermediate forms between the two groups, but all the other Jungermanniales examined belong decidedly to one or the other. As a rule the Anacrogynæ are thallose (the "frondose" forms of the older botanists), but a few genera, especially Fossombronia, show a genuine formation of leaves. All the Acrogynæ have a distinct slender stem with large and perfectly developed leaves.

1 Prof. L. M. Underwood proposes the name Metzgeriaceæ for the Anacrogynæ, reserving the name Jungermanniaceæ for the Acrogynæ. These two groups he considers co-ordinate with the Marchantiales and Anthocerotes. 


\section{ANACROGYNÆ}

Jungermanniales Anacrogynæ. Apical cell of female axis never becoming transformed into an archegonium.

A. Anelatereæ. No true elaters, but sterile cells representing these. Capsule cleistocarpous. Four genera, Thallocarpus, Sphcerocarpus, Riella, Geothallus.

B. Elatereae. Capsule opening either by four valves or irregularly. Elaters always developed.

a. Gametophore always dorsiventral, either strictly thallose or with more or less developed leaves. Families,-Metzgerieæ, Leptotheceæ, Codonieæ.

b. Gametophore upright with three rows of radially arranged leaves. Fam. I., Haplomitrieæ.

\section{Anelatereæ}

The simplest form belonging here is Spharocarpus, a genus that shows certain affinities with the Ricciaceæ, but on the whole seems to be more properly placed at the bottom of the series of the Jungermanniales.

Spharocarpus terrestris occurs in Europe and the southeastern United States. In California it is replaced by two species, $S$. Californicus and $S$. cristatus, which until recently (Howe (3)) were not recognised as distinct, and were considered to be a variety of $S$. terrestris. They are small plants growing upon the ground, usually in crowded patches, where, if abundant, they are conspicuous by the bright green colour of the female plants. The males are very much smaller, often less than a millimetre in diameter, and purplish in colour, so that they are easily overlooked. The thallus is broad and passes from an indefinite broad midrib into lateral wings but one cell in thickness (Fig. 30). The forward margin is occupied by a number of growing points formed by the rapid dichotomy of the original apex, and separated only by a few rows of cells. From the lower side of the thallus grow numerous rhizoids of the thin-walled form. The whole upper surface is covered with the sexual organs, each of which is surrounded by its own very completely developed envelope.

A vertical section passing through one of the growing points (Fig. 30, C) shows a structure closely like a similar section of Riccia. The apical cell $(x)$ produces dorsal and 
ventral segments, and from the outer cells of the former the sexual organs arise exactly as in Riccia. On the ventral surface the characteristic scales of Riccia are absent, and are replaced by the glandular hairs found in most of the anacrogynous Jungermanniales.

The development of the archegonium shows one or two peculiarities in which it differs from other Hepaticæ. The mother cell is much elongated, and the first division wall, by

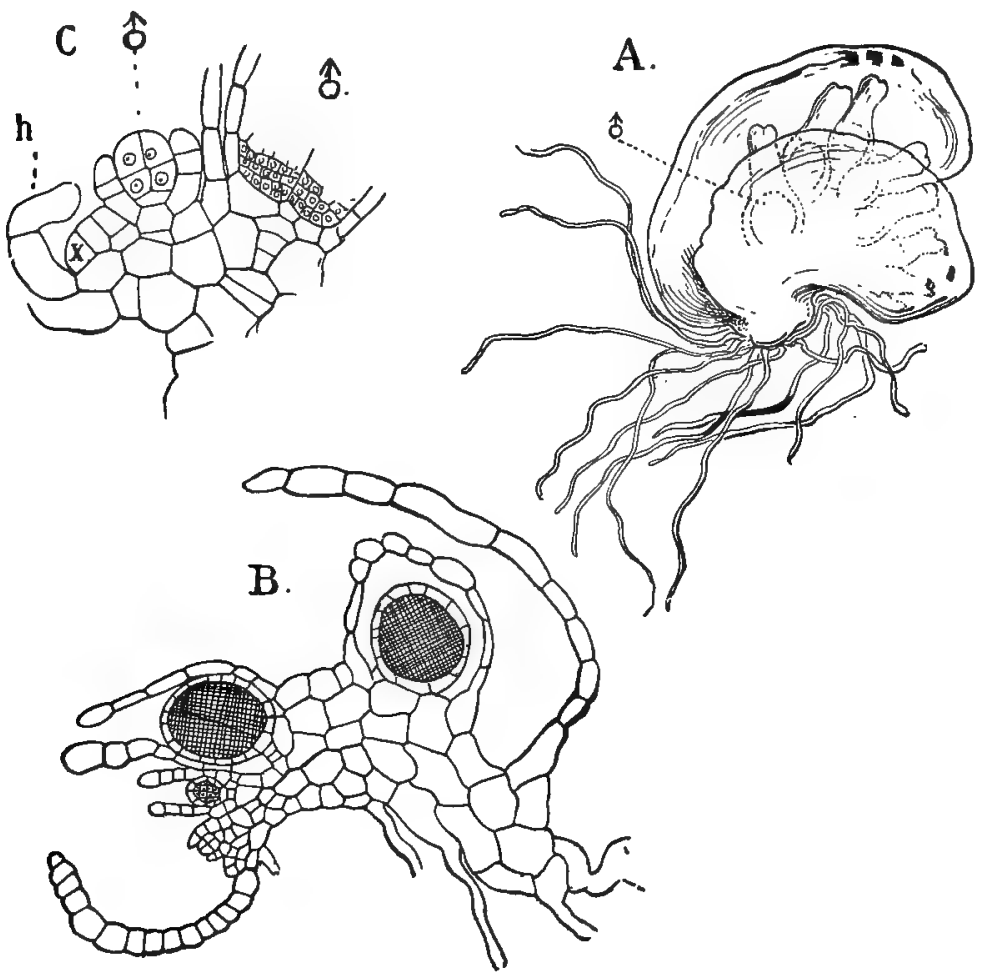

Fic. 30.-Spherocarpus Californicus (?). A, Male plant, $\times 40$; $\sigma^{3}$, antheridia; B, median section of a similar plant, $\times 80 ; \mathrm{C}$, the apex of the same section, $\times 240$; $h$, ventral hair.

which the archegonium itself is separated from the stalk, is some distance above the level of the adjacent cells of the thallus, so that the upper cell is very much smaller than the lower one. The upper cell has much denser contents than the lower one, which instead of remaining undivided as in Riccia, divides into two nearly equal superimposed cells, this division 
taking place about the same time as the first division in the archegonial cell (Fig. 3r, B). The divisions in the latter are the same as in Riccia, and the general structure of the archegonium offers no noteworthy peculiarities. The number of neck canal cells is small, probably never exceeding four, and in this respect recalls again Riccia. The central cell is relatively large, and the ventral canal cell often nearly as large as the egg. As the archegonium develops, its growth is stronger on the posterior side, and it thus curves forward. At first the young archegonium projects free above the surface, but pres-

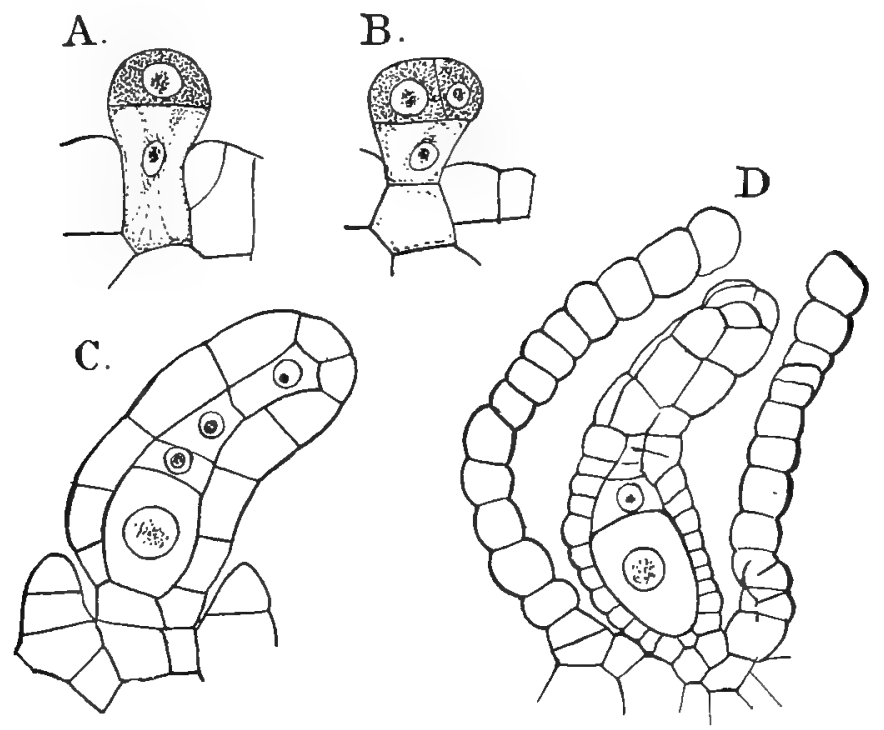

FIG. 3r.-Spharocarpus sp. (?). Development of the archegonium. A-C, Longitudinal sections, $\times 600 ; \mathrm{D}, \times 300$.

ently an envelope is formed about it exactly as in Riccia, but arising at a later stage. After this has begun to form, its growth is very rapid, and it soon overtakes the archegonium and grows beyond it, and finally forms a vesicular body, plainly visible to the naked eye, at the bottom of which the archegonium lies. The formation of this involucre is quite independent of the fertilisation of the archegonium, and as these peculiar vesicles cover completely the whole dorsal surface of the plant, they give it a most characteristic appearance. Usually each archegonium has its own envelope, but Leitgeb ( ( 7$)$, 
iv., p. 68) states that two or even more may be surrounded by a common envelope. When ripe, the venter of the archegonium is somewhat enlarged, but not so much as in Riccia. The egg-cell is very large, oval in form, and nearly fills the cavity of the single-layered venter.

The first wall in the embryo is transverse, and divides the egg cell, which before division becomes decidedly elongated, into two nearly equal cells. Ordinarily in each of these cells similar transverse walls are formed before any vertical walls appear, so that the embryo consists of a simple row of cells. As in the Marchantiaceæ the first wall separates the future capsule from the stalk, and in this respect Sphorocarpus approaches the Marchantiales rather than the Jungermanniales. Following the transverse walls there are formed in all the upper cells nearly median vertical ones, which are intersected by similar ones at right angles to them, so that in most cases, (although this is not absolutely constant) the upper half of the young sporogonium at this stage (Fig. 32, A) consists of two tiers, each consisting of four cells. The lower part of the embryo is pointed, and the basal cell either undergoes no further division or divides but once by a transverse wall, and remains perfectly recognisable in the later stages (Fig. 32, B, C). The other cells of the lower half divide much like those of the upper half, but the divisions are somewhat less regular.

There next arise in all the cells of the upper half periclinal walls, which at once separate the wall of the capsule from the archesporium. This wall in the later stages (Fig. 32, C, D) is very definite, and remains but one cell thick up to the time the sporogonium is mature. The further divisions in the capsule are without any apparent order, and result in a perfectly globular body composed of an outer layer of cells enclosing the archesporium, which consists of entirely similar cells with rather small nuclei and dense contents. While these changes are going on in the capsule, the lower part of the embryo loses its originally pointed form, and the bottom swells out into a bulb (the foot), which shows plainly at its base the original basal cell of the young embryo. This bulb is characterised by the size of the cells, which are also more transparent than those of the other parts of the embryo.

Owing to the development of the stalk of the archegonium, after fertilisation the whole embryo remains raised above the 
level of the thallus, instead of penetrating into it, as is usually the case. The stalk or portion between the capsule and foot remains short, and in longitudinal section shows about four
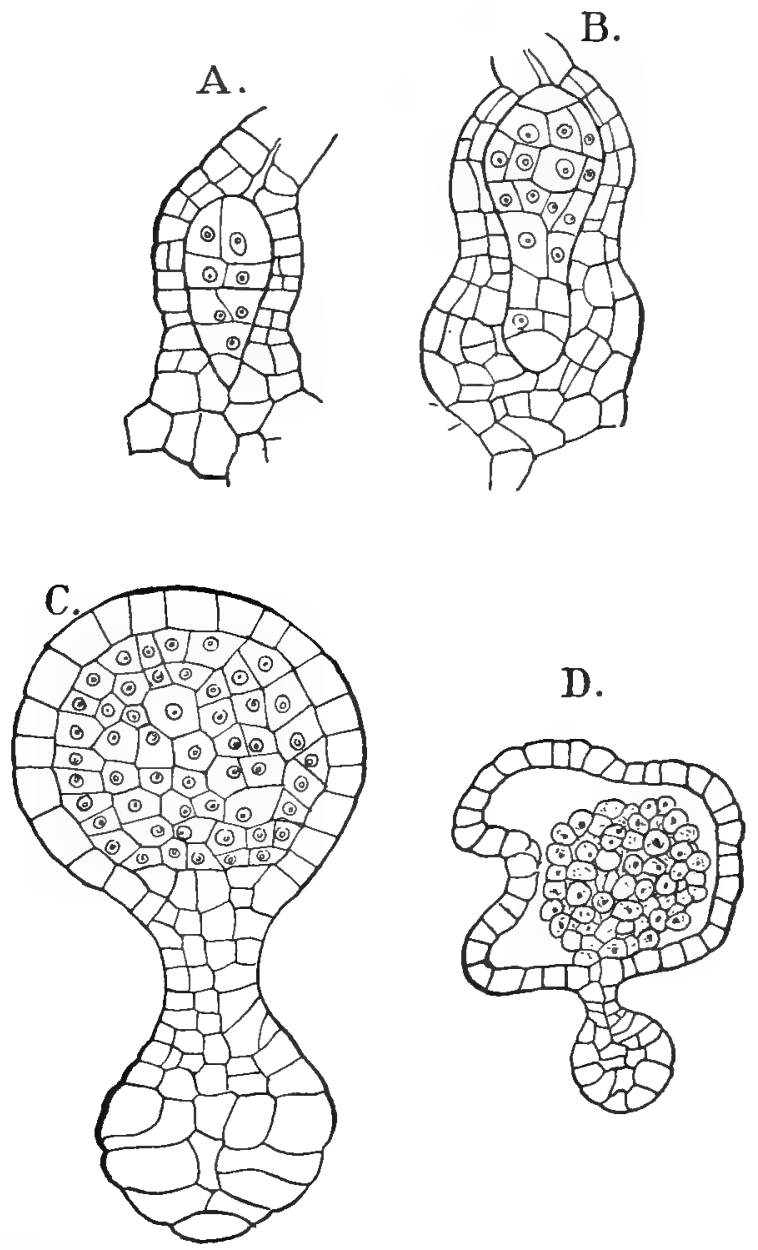

Fig. 32.-Spherocarpus sp (?). A, B, Median longitudinal sections of the archegonium venter, with enclosed embryos, $\times 260 ; C$, an older sporogonium in median section, $\times 260 ; \mathrm{D}$, a still later stage, showing the large space between the archesporial cells and the wall, $\times 85$.

rows of cells. As the calyptra grows the upper part becomes divided into two layers, the part surrounding the foot into three. Instead of breaking through the calyptra at maturity, 
the capsule grows faster than the calyptra long before it is mature, and the upper part of the calyptra is first compressed very much and finally completely broken through by the enlarging capsule.

Leitgeb calls attention to the fact that soon after the cells of the archesporium begin to separate, the whole mass of cells becomes completely separated from the wall of the capsule, which grows rapidly until the cavity within is much larger than the group of archesporial cells, which thus float free in the large cavity. Fig. 32, D shows a section through a sporogonium at this stage. The cells making up the central mass are apparently alike, but in the living sporogonium part of the cells have abundant starch and chlorophyll, while in the others these are wanting or present in much less quantity, while their place is taken by oil, but no rule could be made out as to the distribution of the two sorts of cells. The latter are the spore mother cells, while the others are gradually used up by the developing spores. The spores in S. terrestris remain united in tetrads, and escape from the capsule by the gradual decay of its wall and of the surrounding tissue of the gametophyte.

The male plants are very much smaller than the females, with which they grow and under which they are at times almost completely hidden. The cell walls of the antheridial envelopes are often a dark purple-red colour, and this makes them much harder to see than the vivid green female plant. The apical growth and origin of the antheridium is the same as in Riccia. The first division in the primary antheridial cell is the same as in that of the archegonium, but the basal cell is smaller, and does not divide again transversely, and takes but little part in the formation of the stalk. In the antheridium mother cell are next formed two transverse walls, dividing it into three superimposed cells. The two uppermost divide, as in the Marchantiaceæ, by vertical median walls into regular octants, the lower by a series of transverse walls into the stalk, which consists of a single row of cells sunk below the level of the thallus. After the division of the body of the antheridium into the octant cells, periclinal walls are formed in each of these, so that the body of the antheridium consists of eight central cells and eight peripheral ones, and the stalk of two cells, of which the upper one forms the base of the 
antheridium body (Fig. 33, D). At this stage and the one preceding it Sphcrocarpus recalls the structure of the antheridium of the Characeæ, although the succession of walls is not exactly the same. The divisions of the central cells are extremely regular, walls being formed at right angles, so that the sperm cells are almost perfectly cubical, and the limits of the primary central cells are recognisable for a long time.

The development of the antheridial envelope begins much earlier than that about the archegonium, but in exactly the same way. By the time that the wall of the antheridium is formed the envelope has already grown up above its summit, and as the antheridium develops it extends far beyond it like a flask, at the bottom of which the antheridium is placed, and through whose neck the spermatozoids escape. These are

A
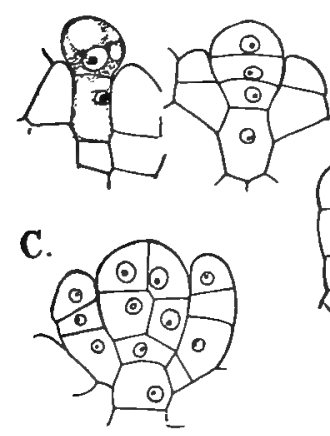

Fig. 33.-Spherocarpus sp (?). Development of the antheridium. A-D, Median longitudinal sections, $\times 450$; E, an older one, $X_{225}$; F, a spermatozoid, killed with osmic acid, $\times 900$.

very much like those of the other Hepaticæ, and in size exceed those of most of the Marchantiaceæ, but are smaller than is usual among the Jungermanniales.

Leitgeb studied the germination of the spores in $S$. terrestris, which remain permanently united in tetrads. He found that all the spores of a tetrad were capable of normal development, which does not differ from that of Riccia or other thallose Liverworts. A more or less conspicuous germ tube is found at the end of which the young plant develops, one of the octants of the original terminal group of cells becoming, apparently, the apical cell for the young plant. The latter rapidly grows in breadth and soon assumes all the characters of the 
older plant. Leitgeb (Fig. I7, Pl. IX.) shows a condition that looks as if at an earlier stage a two-sided apical cell had been present, but he says nothing in regard to this. The sexual organs appear while the plant is extremely small. Leitgeb says he observed the first indications of them on individuals only one millimetre in diameter, and before the first papillate hair on the ventral surface had been formed.

In the commonest Californian species, $S$. cristatus the spores separate completely at maturity. The early stages of germination are like those in $S$. terrestris. There is usually a two-sided apical cell at first, which later is replaced by the type found in the adult thallus.
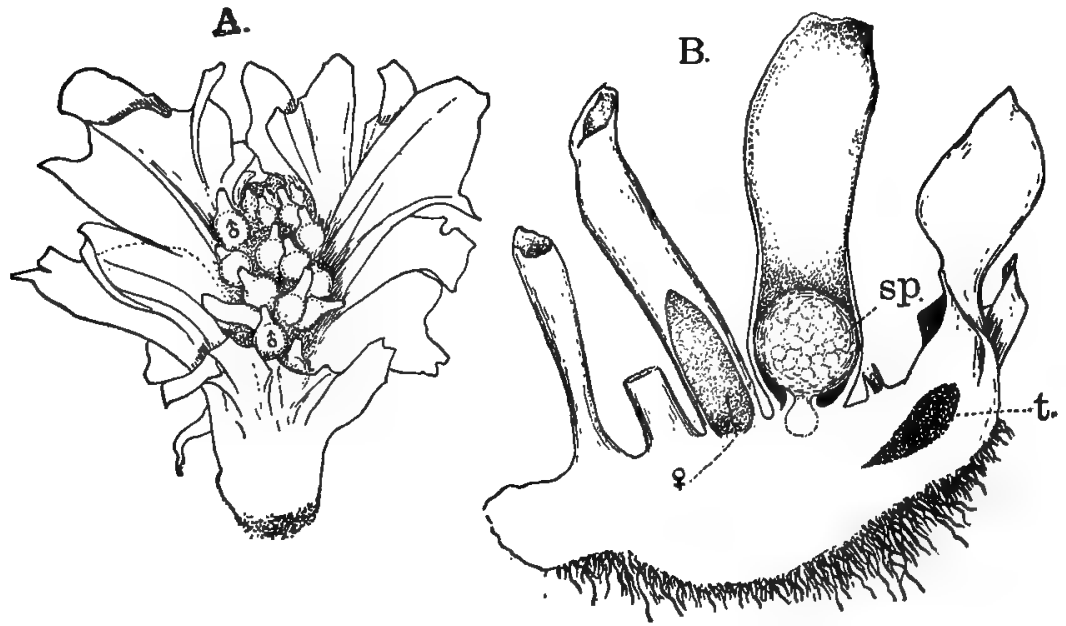

Fig. 34-Geothallus tuberosus. A, Male plant, $X_{15}$; B, section of female plant, $X_{15}$; t. young tuber.

Where there is an excess of moisture the thallus may become much larger than usual, this being especially noticeable in the male plants. There is often, under these conditions, a development of leaf-like marginal lobes. This excessive vegetative development of the thallus is accompanied by a marked diminution in the number of the sexual organs. (Campbell (I7)).

\section{Geothallus.}

Evidently closely allied to Spharocarpus is a remarkable Liverwort, as yet found only near San Diego, in Southern 
California (Campbell (18)). Geothallus tuberosus (Figs. 34, 35), differs from Sphcrocarpus in its much larger size, the development of leaf-like organs, much like those of Fossombronia and by the very much larger size of the spores. There are also some minor differences in the structure of the reproductive organs, the antheridia having a more massive pedicel than that of Sphcrocarpus. The plants are perennial, and at the end of the growing season the younger parts of the thallus become changed into a tuber with a thick black covering. The tubers are buried in the earth during the dry season.
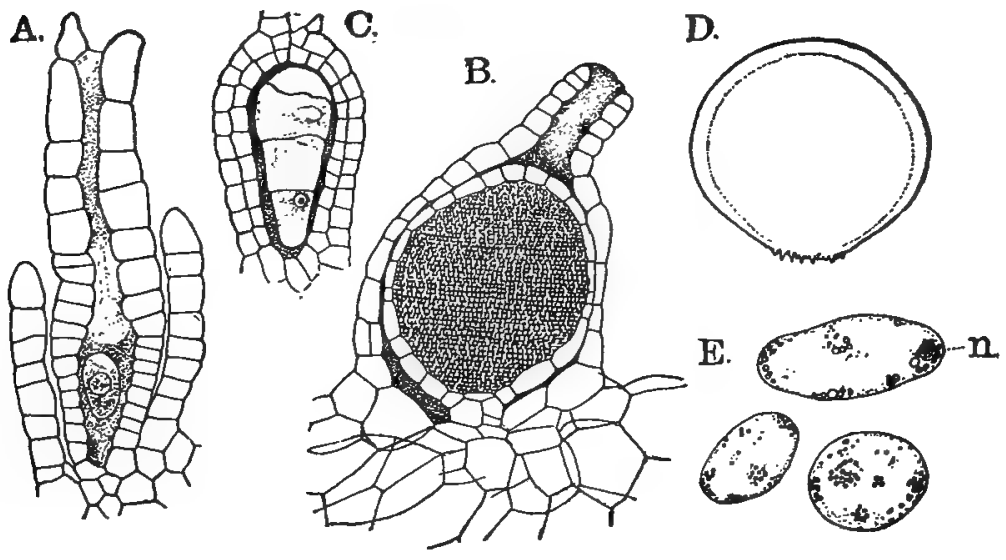

Fig. 35.-Geothallus tuberosus. A, Archegonium, $\times 200 ; B$, ripe antheridium, $X$ about 65 ; C, a four-celled embryo, $\times 200 ; D$, ripe spore; $E$, sterile cells, $\times 100$.

The apex of the shoot persists and resumes growth as soon as the conditions are favorable.

\section{Riella.}

The peculiar genus Riella (Goebel (I7), Leitgeb (7), Porsild (I)), while it closely resembles Sphcrocarpus in the structure of the reproductive organs and sporophyte, differs very much in the habit of the gametophyte. Until very recently (Howe and Underwood (3)), all the species known were from the regions adjacent to the Mediterranean, but one species has since been found in the Canary Islands, and another in the United States. They are all submersed aquatics. The thallus shows a cylindrical axis, from which grows a thin vertical 
dorsal lamina or wing, which may be more or less spirally placed, owing to torsion of the axis, but this torsion was much exaggerated in the early figures of the original species, $R$. helicophylla. According to Goebel's investigations, the growing point is formed secondarily, and this statement is confirmed by Howe's studies. The latter writer has studied the germination of the spores and has described the formation of gemmæ in $R$. Americana.

The latest contribution to our knowledge of Riella is that of Porsild (I). He confirms Howe's statements and has'

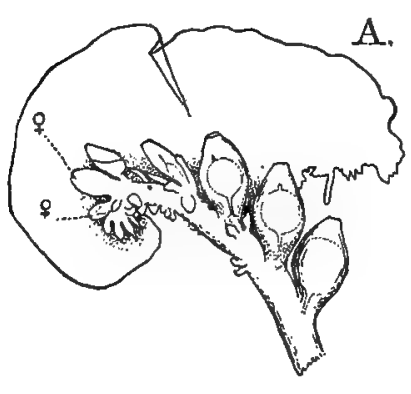

D.

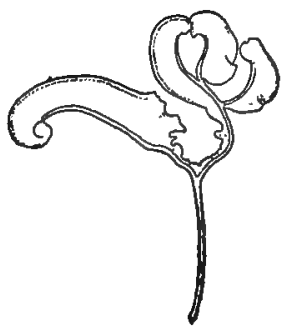

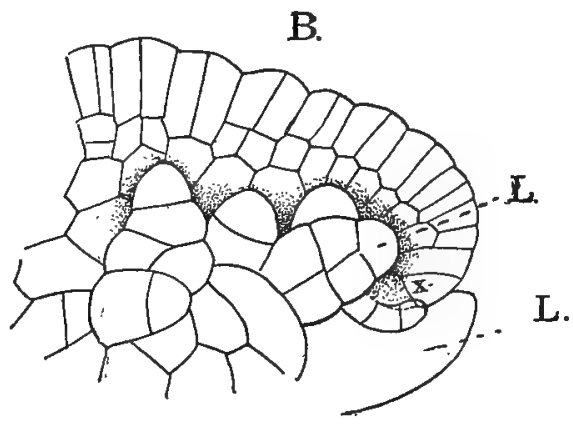

C.

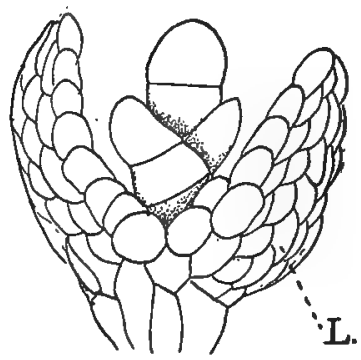

FIG. 36.-A, D, Riella Americana; B, C, R. helicophylla; A, Apex of female plant, $\times 8$; $B, C$, lateral and ventral view of the growing point, $\times 500 ; x$, apical cell; $L$, leaves. D, male plant, $X_{I} 1 / 2$; (A, D, after Howe; B, C, after Leitgeb.)

further investigated the question of the growing point. $\mathrm{He}$ finds that while an apical cell is absent in the younger stages, it is formed later in normal plants.

Both archegonia and antheridia resemble those of Spharocarpus very closely, and the structure of the sporophyte is also the same, no true elaters being developed, but instead there are simply sterile cells. 


\section{Elatereae}

Aneura and Metzgeria represent the simplest of the typical anacrogynous Jungermanniales. In the former the thallus is composed of absolutely similar cells, all chlorophyll-bearing, and in each cell one or more oil bodies, like those of the Marchantiaceæ. In Metzgeria (Fig. 37) the wings of the thallus are but one cell thick, and there is a very definite midrib, usually four cells thick. The apical growth in both genera is
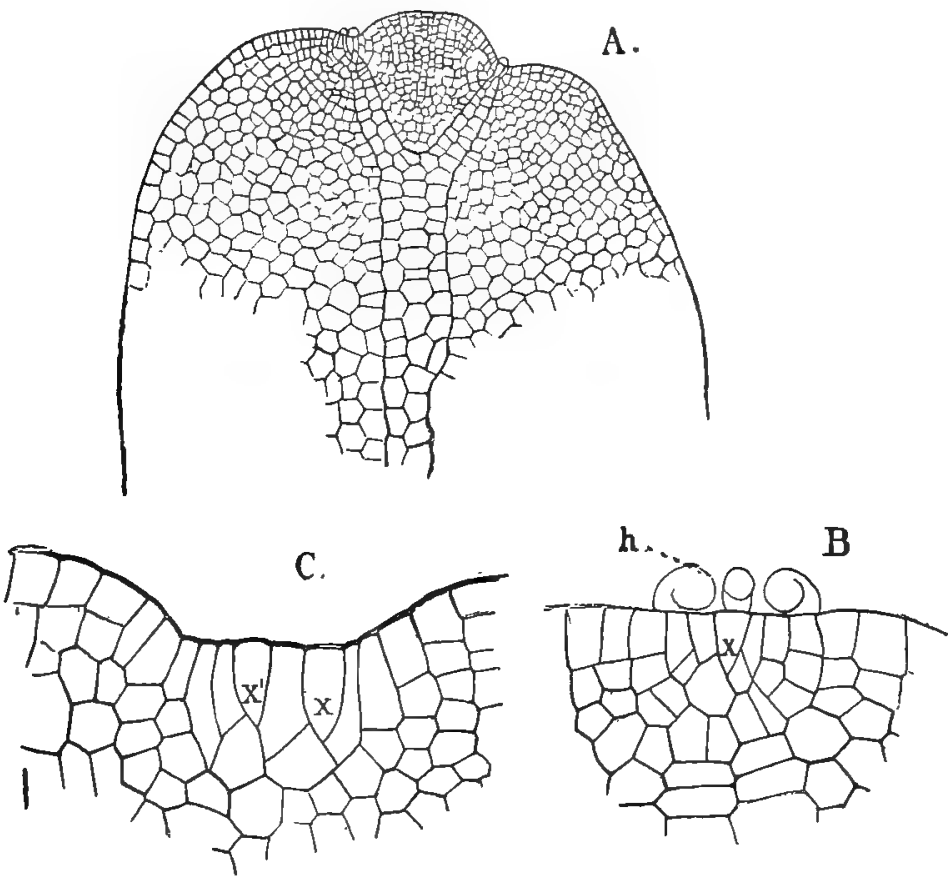

FIG. 37-Metzgeria pubescens. A, Surface view of the thallus in process of division, $X 80 ; \mathrm{B}$, growing point of a branch showing the two-sided apical cell $(x)$ and the ventral hairs $(h), \times 240 ; \mathrm{C}$, the growing point in process of division, $x, x^{\prime}$, the apical cells of the two branches, $\times 480$.

the same, and is effected by the growth of a "two-sided" apical cell. ${ }^{1}$ The segmentation is very regular, especially in Metzgeria (Fig. 37), where each of the segments divides first into an inner and an outer cell, the former by subsequent divisions parallel to the surface of the thallus producing the thick- 
ened midrib, the outer cells dividing only by perpendicular walls, forming the wings. From the ventral surface of the young midrib papillæ project, which curve up over the growing point, in the form of short two-celled hairs, whose end cells secrete mucilage for its protection. In Aneura the growth is very similar, but all of the cells divide by walls parallel to the surface of the thallus, and no midrib is formed, and the thallus is several cells thick in all parts. In both genera numerous delicate colourless rhizoids are developed from the ventral surface, especially of the midrib, when that is present.

Aneura is of interest as showing the only case among the Bryophytes of structures that may be compared to the zoo-
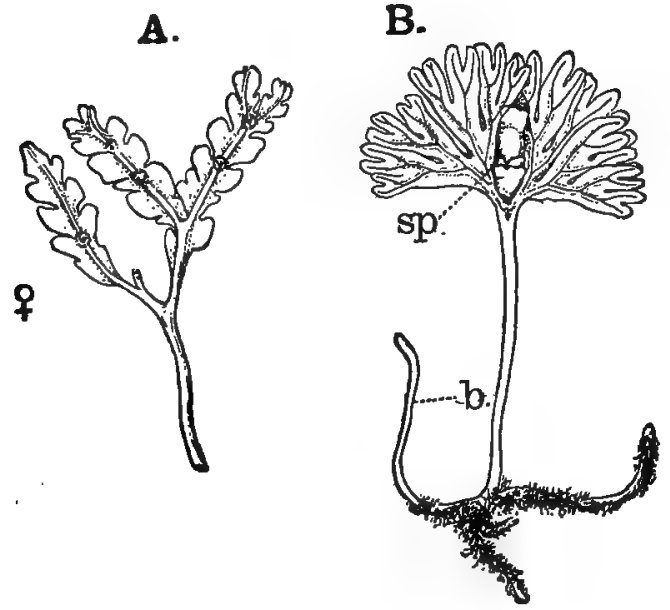

Fic. 38.-A, Symphyogyna sp.; B, Hymenophyton flabellatum, $X_{1} 1 / 2 ; s p$. , young sporophyte; $b$, young shoot.

spores of the Green Algæ. In A. multifida Goebel ((8), p. 337 ), discovered that the two-celled gemmæ which had been described as formed simply by a separation of the cells of the thallus, were really formed within the cells and expelled from them through an opening, after which they divided into two cells and ultimately developed a young plant, much as an ordinary spore would do. The absence of cilia from these cells, which probably are the last reminiscences of the ciliated gonidia of the aquatic ancestral forms, is to be accounted for by the terrestrial habit of Aneura.

The branching is dichotomous, and is brought about by 
the formation of a second apical cell in one of the youngest segments. This apical cell is formed by a curved wall, which strikes the outer wall of the segment (Fig. 37, C). Thus two apical cells arise close together, and as segments are cut off from each, they are forced farther and farther apart, and serve as the growing point of two shoots, which may continue



Frc. 39.-Aneura pinnatifida. A, Part of a thallus with two antheridial branches, slightly magnified; $B$, an archegonial branch, $\times 40 ; C$, cells from the margin of the archegonial branch showing the oil bodies $(o), \times 300$.

to grow equally, when the thallus shows a marked forking (M. furcata), or one of the branches grows more strongly than the other, which is thus forced to one side and appears like a lateral branch (Aneura pinnatifida, Fig. 41, B).

In certain species of Pallavicinia and Symphyogyna, and especially in Hymenophyton (Fig. $38, \mathrm{~B}$ ), the gametophyte shows a differentiation into a prostrate thizome-like sten, 
from which arise upright flattened shoots which are repeatedly forked, so that there is a remarkably close superficial resemblance to the fan-shaped leaves of certain Ferns, especially some of the smaller Hymenophyllaceæ. This resemblance is heightened by the very distinct midrib traversing each thallussegment.

\section{Sexual Organs.}

The sexual organs in both Aneura and Metzgeria are borne on short branches, which in the latter arise as ventral struc-

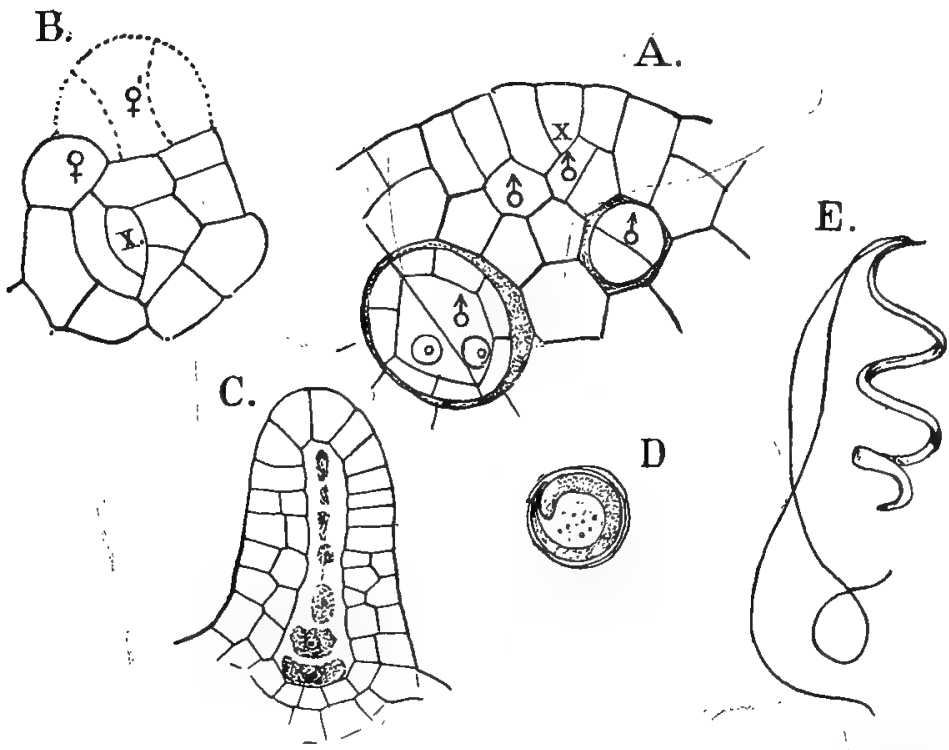

Fig. 40.-Aneura pinnatifida. A, Horizontal section of the apex of a young antheridial branch, $\times{ }_{5} 65 ; x$, the apical cell; $\delta$, antheridia; $B$, transverse section of a young archegonial branch, passing through the apical cell $(x)$; 9 , young archegonia, $\times 525$; C, longitudinal section of a nearly ripe archegonium, $\times 262 ; D, E$, spermatozoids of Pellia calycina, $\times 1225$ (D, E, after Guignard).

tures, but in Aneura are simply ordinary branches that are checked in their growth by the production of the sexual organs, and not infrequently may grow out into ordinary branches after the formation of the sexual organs has ceased. In $A$. pinnatifida (Fig. 39, B), archegonia and antheridia are usually produced upon separate branches, but may occur together.

The origin of the antheridia can be readily followed in 
sections -made parallel to the surface of the male branch. The apex is occupied by an apical cell of the usual form, and the cell divisions in the young segment are extremely regular. The segment first divides into an inner and an outer cell, and the former probably next into a dorsal and a ventral one. The dorsal cell divides by a longitudinal wall into two nearly equal cells, of which the inner one, dividing by a wall perpendicular to the first, gives rise to the primary cell of the antheridium (Fig. 40, A $\delta^{\prime}$ ). This cell now projects above the surface of the thallus, and divides into a single stalk cell, which undergoes no further divisions, and the antheridium mother cell. The divisions in the latter correspond to those in the other Jungermanniales: First a vertical wall is formed, dividing the young antheridium into two equal parts. Next, in each of these, two walls arise intersecting each other as well as the median wall, and dividing each half of the antheridium into three cells, two peripheral ones and a central one. (A somewhat later stage than this is shown in Fig. 40, A.) The peripheral cells do not reach to the top of the antheridium, and next a periclinal wall is formed near the top of the central cells, by which a third peripheral cell is formed in each half of the antheridium, which now consists of two central cells and six peripheral ones. The further divisions were not followed in detail, but seem to correspond with those in the higher forms.

Of the two first cells into which the dorsal cell divides, the one which does not produce the antheridium together with the inner of the two into which that cell first divides, form a partition which rapidly increases in height with the growth of the antheridia, and separates each from its neighbour by a single layer of cells, so that the antheridia are sunk in chambers, arranged in two rows, corresponding to the two series of segments of the apical cell.

In the other thallose anacrogynous forms, e. g., Pallavicinia (Fig. 4I, A), the sexual organs are borne upon the dorsal surface of the ordinary shoots, usually surrounded by a sort of involucre. In most of these forms the apical cell is of a different type from that of Ancura, but is variable even in the same species. Thus in Pallazicinia cylindrica, while the commoner form is nearly wedge-shaped, appearing foursided seen from the surface, and triangular in vertical section, it may approach very nearly the two-sided type (Fig. 42, C). 
In the ordinary form four sets of segments are cut off,- dorsal and ventral, as in Riccia or Sphcrocarpus, and two sets of lateral ones. In Pellia calycina the apical cell shows a similar form, but in $P$. epiphylla (Fig. 42, D, E), another type is seen. Here, while the surface view is the same as in $P$. caly-

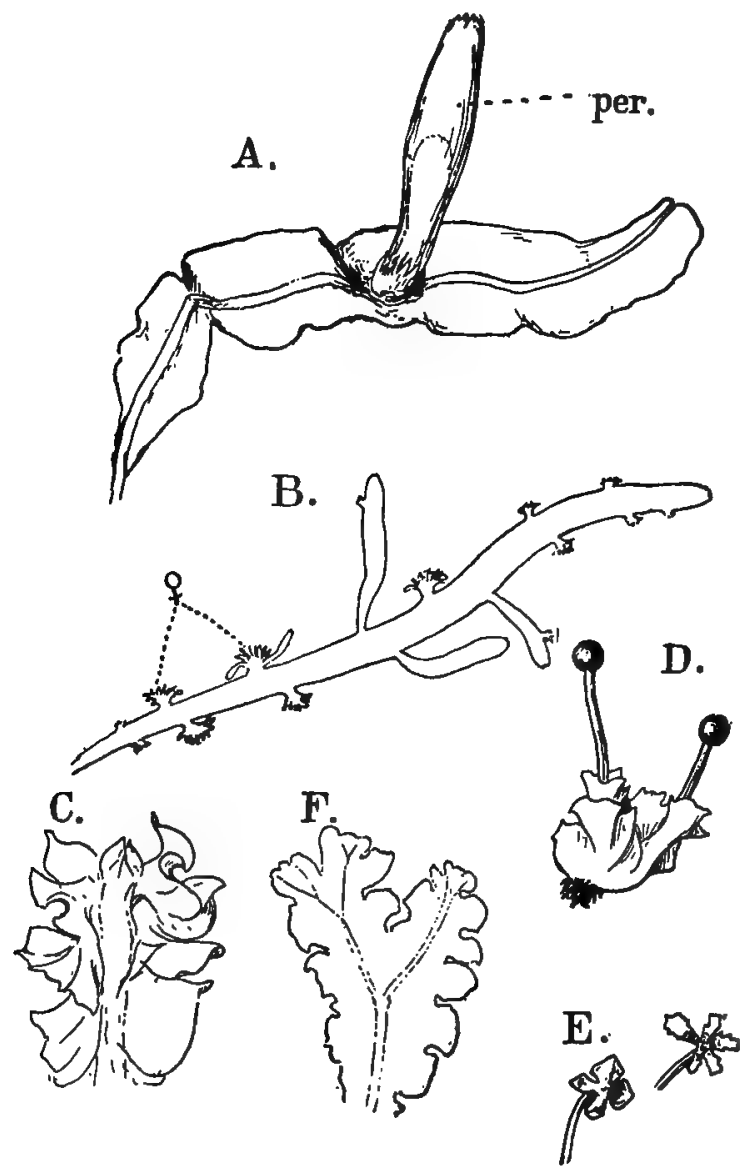

Fig. 4I.-A, Pallavicinia cylindrica, $X_{4}$; per, the elongated perianth; B, Aneura pinnatifida, $\times 6$; , archegonial branches; C-E, Fossombronia longiseta, $\times_{4} ; \mathrm{F}$, Blasia pusilla, $\times 4$.

cina, in vertical section the cell is nearly semicircular, i. e., here there are but three sets of segments, two lateral ones and a basal one, extending the whole depth of the thallus, and only 

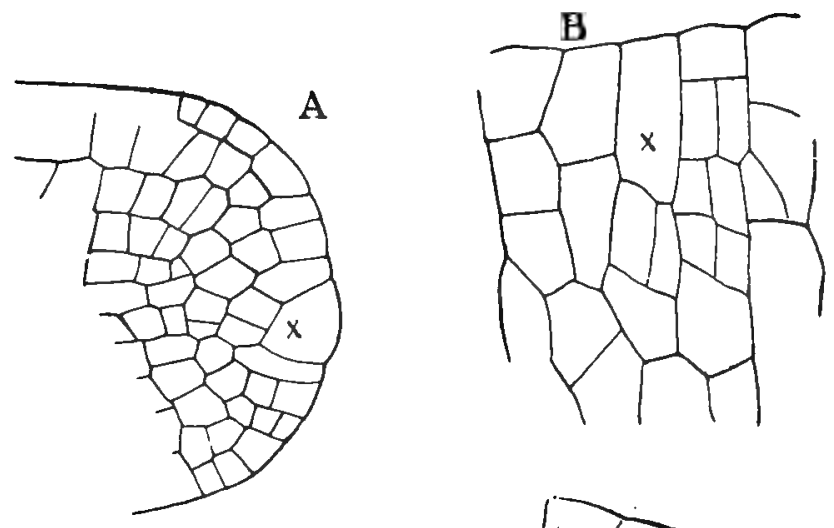

C.
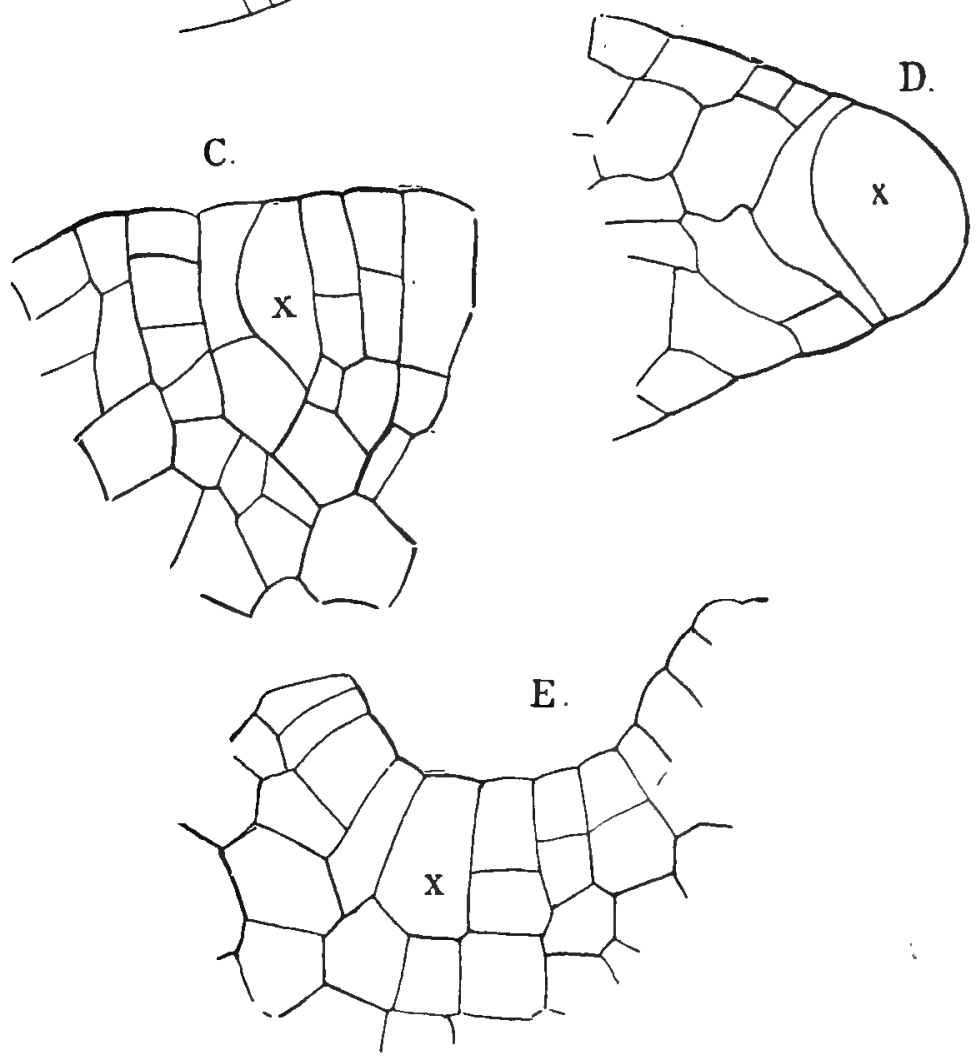

Fic. 42.-A, Vertical, B, C, horizontal sections through the apex of Pallavicinia cylindrica; $九$, apical cell, A, $\times 225 ; \mathrm{B}, \mathrm{C}, \times 450 ; \mathrm{D}, \mathrm{E}$, Pellia epiphylla; D, vertical section; $E$, horizontal (optical) section, $\times 450$. 
later showing a division into ventral and dorsal cells. Probably this type has been derived from the former by a gradual increase in the size of the angle formed by the dorsal and ventral walls of the apical cell, which finally became so great as to practically form one plane.

The antheridium of Pellia is larger than that of Aneura, but its' development is very similar except that the stalk is multicellular, as it is in the other Anacrogynæ. The spermatozoids of Pellia (Fig. 40, D, E), are much larger than those of Aneura, but are exceeded in size by those of the allied genus Makinoa (Miyake (2)).
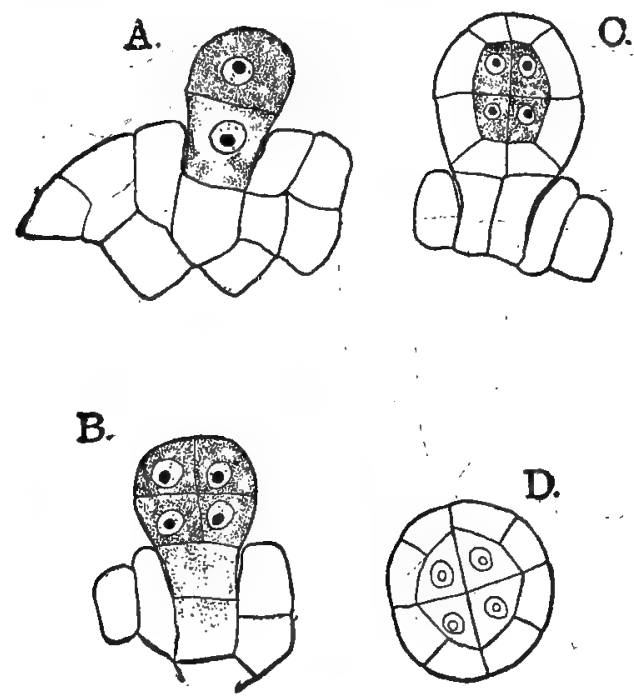

Frc. 43--Fossombronia longiseta; early stages in the development of the antheridium, $X_{525}$; drawings made by Mr. H. B. Humphrey. D, cross-section.

In Fossombronia (Fig. 43), which in several respects recalls Sphcrocarpus or Geothallus, the first divisions in the antheridium are median ones, so that in both longitudinal and transverse sections the antheridium appears to be divided into equal quadrants. The first division, however, is vertical, as it is in Aneura.

The archegonia are borne upon similar but shorter branches and their development also is very regular. In Fig. 40, $\mathrm{B}$, a vertical section through the end of a young female branch is shown with the apical cell $(x)$. Segments are here, too, cut 
off alternately right and left, and from each segment an archegonium develops. The segment is first divided, probably, as in the male branch and the vegetative ones, into an inner and an outer cell, but I did not succeed in getting satisfactory longitudinal sections parallel to the surface, so cannot speak positively on this point. The youngest segment, in which the archegonium mother cell is recognisable, shows in vertical section three cells, a small ventral one, a middle larger one, and a dorsal one-the archegonium mother cell. The latter does not form any stalk, but divides at once by the three intersecting walls, as in other Hepaticæ, and the further development corresponds with these, except that the base of the archegonium

A.

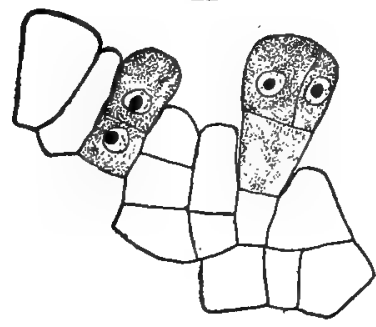

B.

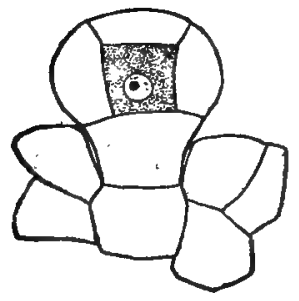

C.



Frg. 44-Fossombronia longiseta. Development of the archegonium, longitudinal section, X525; drawings made by Mr. H. B. Humphrey.

is not free, and the central cell is below the level of the superficial cells of the thallus. The archegonium neck is short, and the basal part as well as that part of the venter which is free, two cells thick (Fig. 40, C). The number of neck cells is small (apparently about four), but whether the number is constant cannot be stated positively. The female branch remains 
very short, and the archegonia, which are only produced in small numbers (usually not more than six to eight), are close together and surrounded by an irregular sort of envelope formed by the more or less incurved and very much laciniated margins of the branch. Secondary hair-like growths are also formed, so that to the naked eye the archegonial receptacles appear as densely fringed and flattened tufts upon the sides of the larger branches.

The archegonium of Fossombronia (Fig. 44) closely resembles that of Sphcrocarpus, but it ordinarily has but five peripheral rows of neck-cells, as in most of the Jungermanniales. Occasionally, however, there may be six rows, as in Spherocarpus.

Janczewski (I) followed very carefully the development of the archegonium in Pellia epiphylla, which differs a good deal from that of Aneura. The archegonia are formed in groups just back of the apex, but he does not seem to have been able to detect any relation between them and the segments of the apical cell such as obtains in Aneura, but it seems probable that such a relation does exist. After the archegonium mother cell is cut off, it does not at once divide by vertical walls, but there is first cut off a pedicel, after which the upper cell undergoes the usual divisions. Of the three peripheral cells one is much smaller and does not as a rule divide longitudinally, so that the neck has normally but five rows of cells instead of six, as in the Marchantiaceæ. Owing to the formation of the pedicel, the archegonium is quite free at the base, and like that of Aneura the wall of the venter is two-layered. The neck becomes very long, and, according to Janczewski, the number of neck canal cells may reach sixteen or even eighteen.

\section{The Sporophyte}

The earliest stages in the embryo are not perfectly known. Kienitz-Gerloff ( I ) investigated Metzgeria furcata and Leitgeb ( ( 7$)$, III) species of Aneura. In both of these the first division in the embryo separates an upper cell, from which capsule and seta develop, from a lower cell, which forms a more or less conspicuous appendage at the base of the foot. The earliest divisions in the upper part are not known, but it soon becomes a cylindrical body consisting of several tiers of 
cells, each composed of four equal quadrant cells. According to Leitgeb ( I ), the upper tier, from which the capsule develops, is formed by the first transverse wall in the upper part of the embryo. This upper tier is next divided by nearly transverse walls into four terminal cover cells, and four larger ones below, and these latter are again divided each into three cells, an inner one and two outer ones, so that the capsule consists of four central cells, the archesporium, and twelve wall cells (Fig. 45, A). A similar division in the lower tiers results in the formation of four axial rows and a single outside layer of cells in the stalk. In the lowest tiers the divisions are much less regular, and the foot, which is not very largely developed, shows
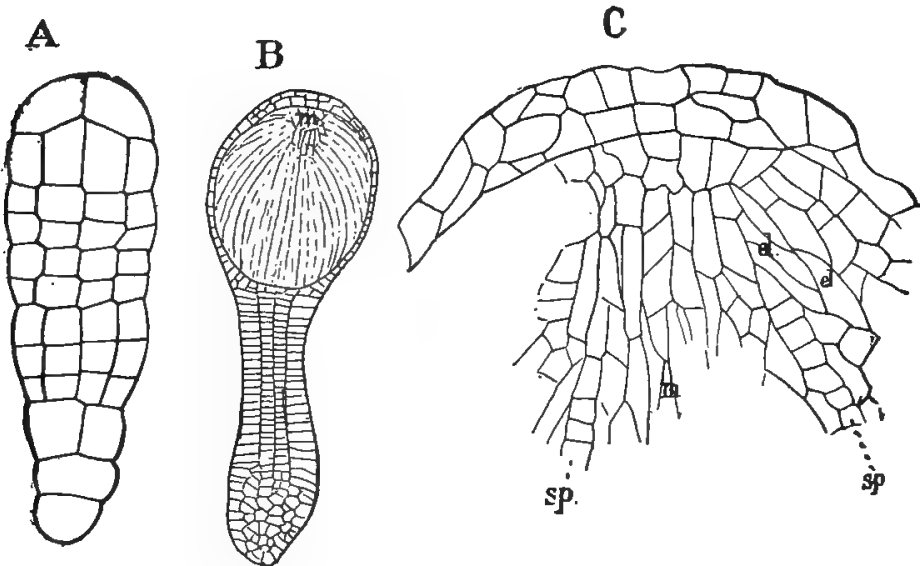

Fig. 45.-A, Young embryo of Aneura multifda, optical section, $\times 235$ (after Leitgeb) ; $\mathrm{B}$, median longitudinal section of an older sporogonium of $A$. pinguis, $\times 35$; C, upper part of $\mathrm{B}, \times 200 ; s p$, sporogenous cells; $e l$, young elaters; $m$, apical group of sterile cells.

no definite arrangement of the cells. The part of the wall of the capsule formed from the four cover cells later become twolayered, but the rest remains but one cell thick. In Metzgeria (Leitgeb (7), III.) the wall becomes later two-layered. The archesporium divides first into two layers. In the upper cells the divisions are more regular than in the lower one, and later the archesporium is made up of cells arranged in more or less regular lines, starting from just below the apex and radiating from this point, extending to the base of the capsule. These cells are at first of similar form, and with 
the growth of the capsule become elongated with pointed ends that fit together without any spaces between. Some of these cells, however, divide rapidly by transverse walls and give rise to rows of isodiametric cells (Fig. 45, sp), wedged in between others that have remained undivided $(e l)$.
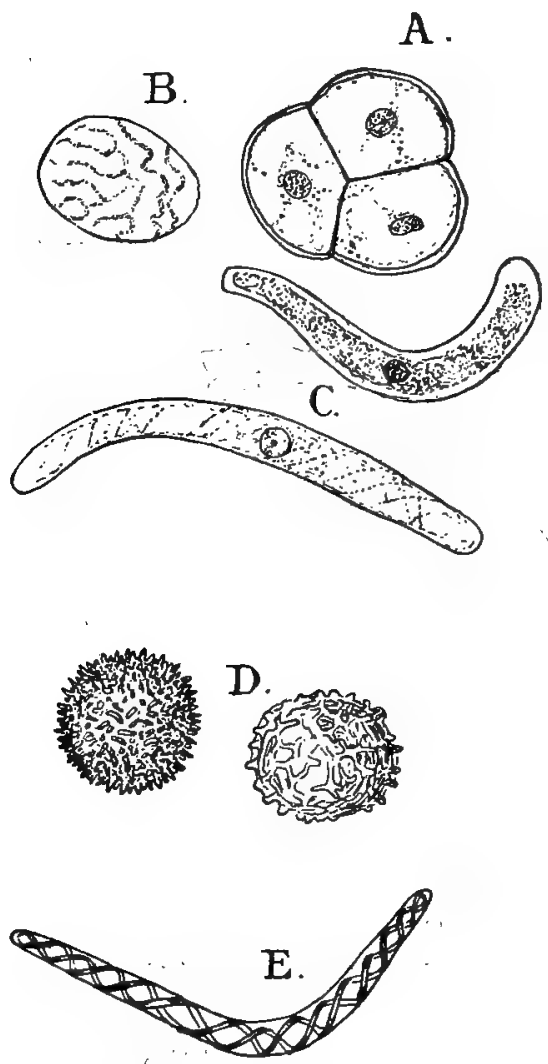

FIG. 46.-Fossombronia longiseta. A, Section through a young tetrad of spores; B, surface view of the wall of a young spore; $C$, two young elaters, $\times 600 ; D$, two ripe spores; $E$, elaters, $\times 300$.

The former are the young sporogenous cells, the latter the elaters. A mass of cells lying just below the apex, and belonging to the archesporium, remains but little changed, and forms the point of attachment for the elaters after the capsule opens (Fig. 45, B, C, $m$ ). See àlso Goebel ( $(2 \mathrm{I})$, ' pp. 325-327.

The further development of spores and elaters is similar to that in the higher Marchantiacer, and when, the capsule is mature it opens by four valves which extend its whole length.

The first division-wall in the embryo of Fossombronia longiseta. is transverse and divides it into two somewhat unequal cells, of which the lower and smaller one gives rise to the foot, and not merely to the appendage of the foot, as is the case in Aneura. From the upper cell arise the seta and the capsule. A second transverse wall (Fig. 47, II.) is formed before any longitudinal walls appear. The upper of the three cells gives rise, not only to the capsule, but to part of the seta as well. The separation of the primary archesporial cells is 
brought about by a periclinal wall in each of the four terminal cells, dividing each into an inner archesporial cell, and an outer wall-cell. (Fig. 47, D.)

The capsule wall in Fossombronia is two cells in thickness, except at the apex, where it may be three cells thick. The inner layer of cells, when the capsule is ripe, have irregular thickened bars developed upon the surface of the radial cellwalls.

The development of the sporogonium is best known in Pellia epiphylla (Kienitz-Gerloff (I), Hofmeister (I) ). Here the first wall, as in Aneura, separates a lower cell, which simply forms an appendage, from the upper cell, from which the
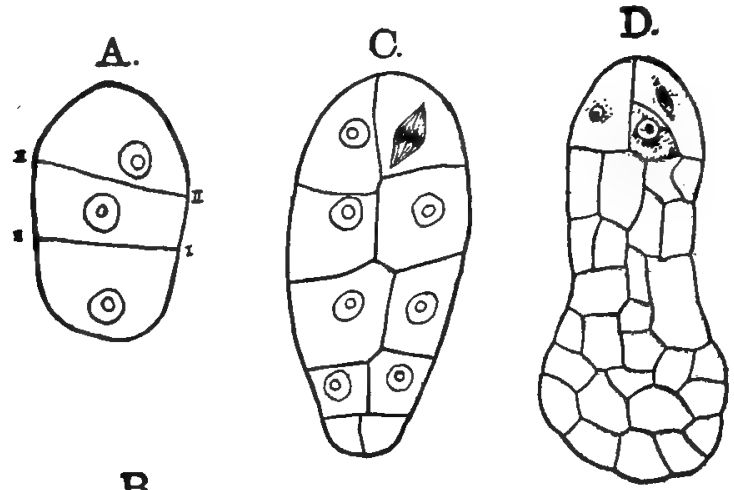

B.
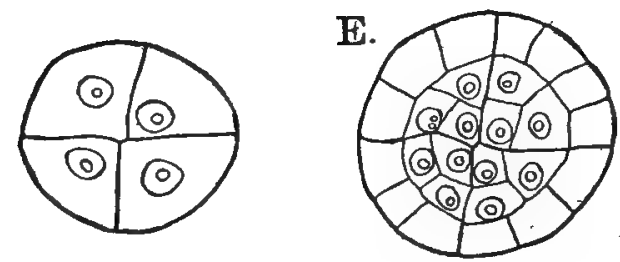

FrG. 47.-Fossombronia longiseta. Development of the embryo, $\times 525 ; B, E$, cross̄sections; D, shows one of the primary archesporial cells. Figures drawn by Mr. H. B. Humphrey.

stalk and capsule develop. In the latter the first wall is vertical, and is followed in each of the resulting cells by horizontal walls, by which the separation of the capsule from the seta is effected. These four cells are now divided by vertical walls, so that two layers of four cells each are present. The first periclinal walls in the apical group of cells separate the archesporium from the wall of the capsule. 
The differentiation of the capsule and seta follows as in 'Aneura, and the arrangement of the cells of the archesporium is much the same except that the rows of cells radiate from the base of the capsule and not from the summit. The foot is very distinct and forms a pointed conical cap, whose edges overlap the base of the seta.

\section{Spore-division in 'Anacrogyne}

According to Farmer (4), in Pallavicinia decipiens there is formed, previous to the division of the nucleus, a "quadripolar" nuclear spindle, extending into each of the four lobes of the spore mother-cell. Then follows a double division of the chromosomes, resulting in sixteen, of which four move to each pole of the spindle to form at once the four nuclei of the spore tetrad. In Aneura multifida the formation of a quadripolar spindle was also found, but there were subsequently two successive nuclear divisions of the usual type. From his study of Pellia epiphylla, Davis (3) has questioned the accuracy of Farmer's statements, and Moore's ( I) studies on Pallavicinia Lyalii show that in this species, although a structure which might be interpreted as a quadripolar spindle is present, there are two successive divisions of the nucleus with bi-polar spindles. However, the second mitosis follows without an intervening resting stage of the nucleus.

The growth of the seta after the spores are ripe is extremely rapid, but consists entirely in a simple elongation of the cells. Askenasi (I) has investigated this in Pellia epiphylla, and states that in three to four days the seta increases in length from about I mm. to in some cases as much as 80 $\mathrm{mm}$, and that this extraordinary extension is at the expense of the starch which the outer cells of the young seta contain in great abundance, but which disappears completely during the elongation of the seta. The growing sporogonium here as well as in other species is strongly heliotropic.

The calyptra in the thallose Anacrogynæ is usually massive, and in addition there is formed about the growing sporogonium a special envelope inside the involucre, which in Pallavicinia especially (Fig. 4I, A) becomes prolonged into a tube which completely encloses the sporogonium until just before its dehiscence. 
The further development of the spores and elaters corresponds with that of the Marchantiacer (Fig. 46), and there is the same method of the development of the thickenings upon the walls of the elaters and the spores. In cases where the spores germinate immediately, chlorophyll is developed and no proper exospore is formed, although the outer layer of the cell wall is more or less cuticularised.

In the germination of the spores Pellia offers an exception to the other Jungermanniales, in that the spores divide into a multicellular body before they are discharged from the capsule. The presence of centrospheres in the dividing nuclei has been demonstrated by Farmer ( 5 ), and recently Chamberlain (2) has studied these bodies very thoroughly in Pellia. The ripe spore here is an oval body which consists of several tiers of cells, the end cells being usually undivided, and the middle ones each consisting of four equal quadrant cells. There is some disagreement as to the earliest stages in the germination and the establishment of the apical growth. Hofmeister ( (I), p. 2I) states that in P. epiphylla one end cell of the spore grows out into the first rhizoid, while the other develops into the growing point of the young plant. Müller, N. J. C. ( ( I ) p. 257), on the other hand, states that in P. calycina both ends of the spore develop rhizoids while the growing point, which at first has a two-sided apical cell, like that of Metzgeria, arises laterally.

The germination of the spores of Aneura has been studied by Kny (I) in A. palmata, and by Leitgeb ( ( 7$)$, III., p. 48) in $A$. pinguis, which agrees in all respects with the former. The spores, as is usual in the Jungermanniales, have a poorly-developed exospore, and contain chlorophyll when ripe. Before any divisions take place, the spore enlarges to two or three times its original volume, and then elongates and by repeated cross-walls forms a filament of varying length. In the end cell next an inclined wall arises, which is met by another nearly at right angles to it, and thus the two-sided apical cell is established, and the thallus gradually assumes its complete form (Fig. 48, A).

Connecting the strictly thallose anacrogynous Hepaticæ with the foliose acrogynous ones, are a number of most instructive intermediate forms. Of these Blasia (Fig. 4r, F) is perhaps the simplest. Here the margin of the thallus is lobed, 
and these lobes, according to Leitgeb's view, are very simple leayes.' In Fossombronia (Fig. 4I, C, D), while the general thallose form is more or less evident, the leaves are unmistakable, and as their development shows, morphologically the same as the leaves of the acrogynous forms. The most remarkable form, however, is Treubia insignis, a very large foliose Liverwort discovered by Goebel in Java. This has all the appearance of a very large acrogynous form, and also the

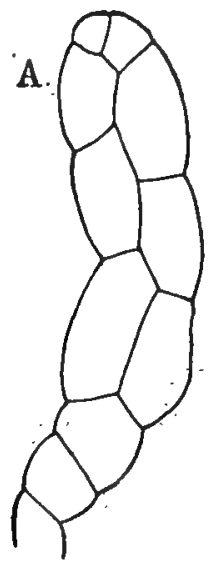
typical three-sided apical cell; but in regard to the position of the sexual organs it is typically anacrogynous. These and the Haplomitrieæ form a perfect transition from the Anacrogynæ to the Acrogynæ.

The multicellular gemmæ of Blasia have been alluded to. They are pro duced in long flask-shaped receptacles, and when mature form nearly globular

B.



1



2

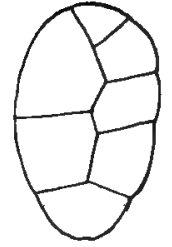

3
Fig. 48.-A, Young plant of Aneura palmata $\times 265$ (after Leittgeb); $B$, three views of a young plant of Pellia calycina, $X_{420}$ (Leitgeb).

brownish bodies whose cells contain much oil, and whose stalk consists of a simple row of cells. Among them are glandular hairs, which secrete mucilage, by the swelling of which the gemmæ are loosened from their pedicels, as in Marchantia. Similar but simpler gemmæ having usually three cells occur in Treubia

(Goebel (I3)). Blasia is also characterised by the presence of colonies of Nostoc within the thallus. These occupy cavities in the bases of the leaves and are normally always present.

The Haplomitriece

The two genera, Haplomitrium and Calobryum, which con- 
stitute this family, differ from all other Hepaticæ in having the leaves radially arranged, and not showing the dorsiventral form that characterises all the others. The plants are completely destitute of rhizoids but possess a rhizome-like basal part, from which the leafy axes arise. The latter have welldeveloped leaves arranged more or less distinctly in three rows. The stem grows from a tetrahedral apical cell, as in the acrogynous forms, but in Haplomitrium at least the apical cell does not develop into an archegonium. The archegonia are in this genus borne at the end of ordinary shoots, but in Calobryum the end of the female branch becomes much broadened and the numerous archegonia stand crowded together. In this case it is possible that the apical cell of the stem may finally produce an archegonium. Much the same difference is observable in the arrangement of the antheridia.

\section{The Acrogyna}

Treubia and Haplomitrium, as we have seen, connect almost insensibly the anacrogynous with the acrogynous Jungermanniales. The latter are much more numerous than the former, but much more constant in form, and are doubtless a later specialized group iderived from the former. While differing in the form and arrangement of the leaves and other minor details, they are remarkably constant in their method of growth and in the position of the sexual organs, especially the archegonia. These are always formed upon- speeial branches, where, after a varying number of segments are cut off, the apical cell becomes the mother cell of an archegonium. The study of any typical form will illustrate the principal characters of the group. The species selected, Porella ( $M a$ dotheca) Bolanderi, is very like the common and widely distributed $P$. platyphylla, which corresponds with it in all structural points.

The plant grows upon rocks, especially, but also upon the trunks of trees, and forms dense mats closely covering the substratum. It branches extensively, but always monopodially, dichotomous branching never occurring in the acrogynous Jungermanniales. The slender stem is completely hidden above by the two rows of closely-set, overlapping, dorsal leaves. Upon the ventral side, which is fastened by. scattering 
rhizoids to the substratum, there is a row of much smaller leaves (amphigastria), more or less irregularly disposed. The dorsal leaves, seen from above, are nearly oval in outline, but each has a smaller ventral lobe, pointed at the tip, and closely appressed to the lower surface of the much larger dorsal lobe. The ventral lobes closely resemble the amphigastria, both in form and size, and with the latter form apparently three rows of leaves upon the ventral side of the stem. The structure of the leaf is of the simplest character, consisting of a single layer of polygonal cells containing numerous chloroplasts.

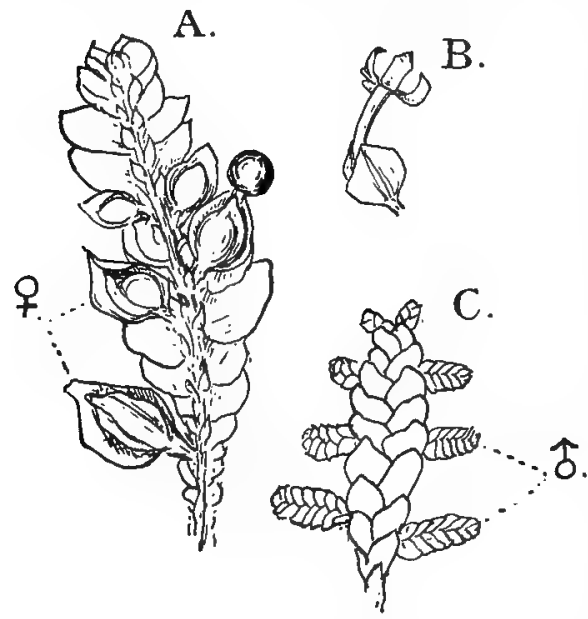

FiG. 49.-Porella Bolanderi. A, Female plant, $\times 4$; O archegonial branches; $B$, an open sporogonium, $\times_{4} ; C$, a male plant, $\times_{4}$; $\delta^{x}$, the antheridial branches.

The plants grow where they are exposed to alternate wetting and drying up. They may at any stage become completely dried up, and on being moistened will resume at once their activity. In the dried condition, the species under consideration often re$\mathrm{ma}$ in $\mathrm{s}$ for severa 1 months without apparently being injured in the least, and this power is shared to a considererable degree by most of the acrogynous forms, whose favourite habitat is the trunks of trees.

The apical growth of the stem is extremely regular, and as in all the other acrogynous Hepatica, the apical cell is a threesided pyramid (Fig. 5O, A). In longitudinal section it is much deeper than broad, and its outer face is almost flat. In cross-sections (Fig. 50, B) it has the form of an isosceles triangle, the shorter side turned toward the ventral surface of the plant. From this cell three sets of lateral segments are cut off, two dorsal and one ventral, and each of these gives rise to a row of leaves, a leaf corresponding to each segment of the apical cell. The first division wall in each segment is at right angles to its broad faces and divides it into two cells of some- 
what unequal size. The next wall formed divides the larger of the two primary cells into an inner and an outer cell (Fig. 5o, A), so that the young segment now consists of three cells, an inner one and two outer; the latter in the dorsal segments correspond to the two lobes usually found in the dorsal leaves. The two outer cells now divide by walls in two planes, and rapidly grow out above the level of the apical cell and form
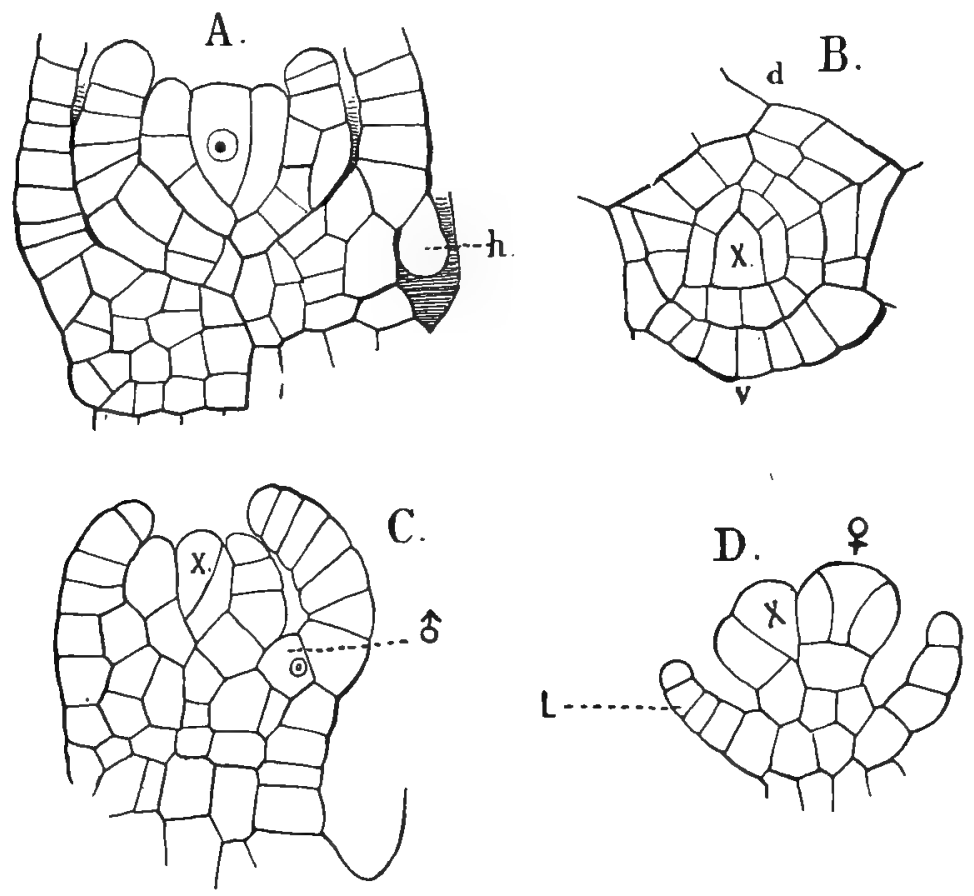

FrG. 50.-Porella Bolanderi. A, Median longitudinal section of a vegetative axis: $\mathrm{B}$, a cross-section of the apex of a similar one, $\times 500 ; x$, the apical cell; $h$, hair; $d$, dorsal surface; $v$, ventral surface; $\mathrm{C}$, male; $\mathrm{D}$, female branch.

lamellæ which remain single-layered, and undergo but little further modification beyond an increase in size. From the base of the young leaves simple hairs develop, but remain small and inconspicuous. The inner of the three first formed cells of the segment, by further division and growth in all directions, produces the axis of the plant. This in cross or longitudinal section shows almost perfectly uniform tissue. No distinct epidermis, or central strand, like that found in most Mosses, can be seen. 
The branching is monopodial and the branch represents the ventral lobe of a leaf. After the first division by which the two lobes of the leaf are separated, only the dorsal one develops into the lamina of the leaf, which is thus in the segment from which a branch is to form, only one-lobed. In the ventral cell three walls arise (Fig. 5I), intersecting so as to cut out a pyramidal cell of the same form as the apical cell of the main axis, and the cell so formed at once begins to divide

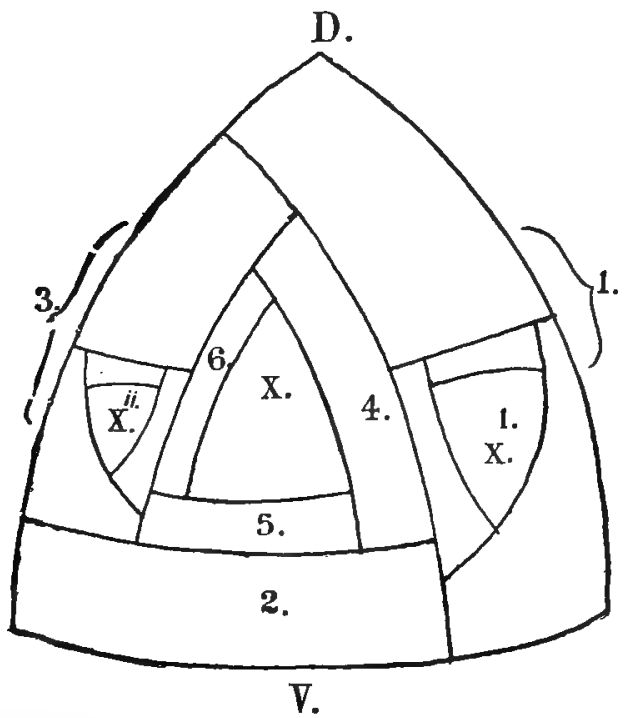

FIG. 51.-Diagram showing the ordinary method of branching in the acrogynous Jungermanniacez (after Leitgeb). D, Dorsal; V, ventral side of stem; $\mathrm{X}^{\prime} \mathrm{X}^{\prime \prime}$, apical cells of the branches. The segments are numbered.

in the same way, and forms a lateral axis of precisely the same structure as the main one.

The genus Physiotium differs from all other known Acrogynæ in having a two-sided apical cell, instead of the typical tetrahedral one-(Goebel (2I), p. 287).

\section{The Sex-organs}

The plants in Porella are strictly dioecious and the two sexes are at once recognisable. The males are smaller, and bear special lateral branches which project nearly at right angles from the main axis, and whose closely imbricated light green 
leaves make them conspicuous. At the base of each of the leaves is a long-stalked antheridium, large enough to be readily seen with the naked eye.

The development of the antheridium may be easily traced by means of sections made parallel to the surface of the branch. At the apex (Fig 5o, C) is an apical cell much like that in the sterile branches, but with the outer face more convex. The divisions in the segments are the same as there, but the whole branch remains more slender, and the hairs at the base of the leaves are absent. The antheridia arise singly from the bases

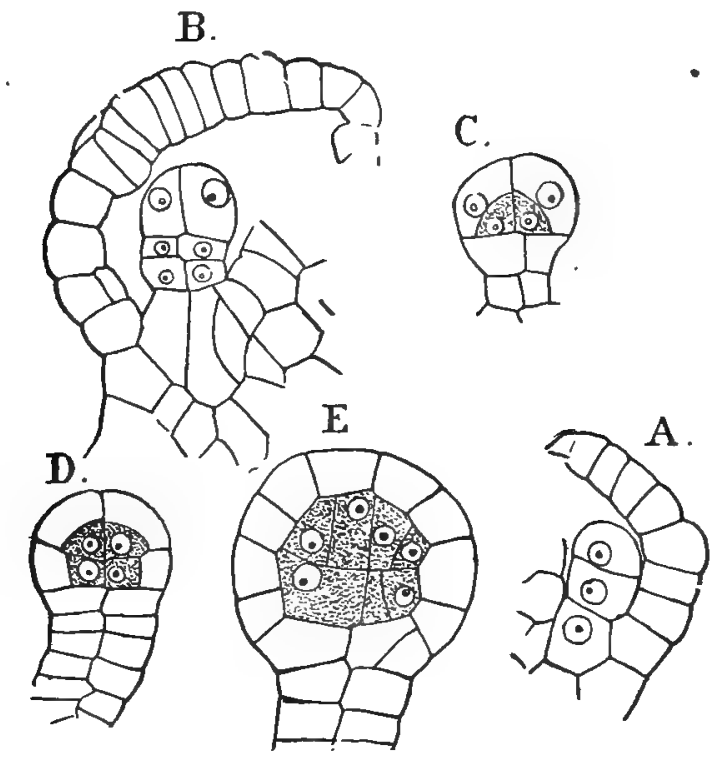

FIG 53.-Porella Bolanderi. Successive stages of the young antheridium in median longitudinal section, $\times 600$.

of the leaves, close to where they join the stem, and are recognisable in the fourth or fifth youngest leaf (Fig. 50, C, $\delta^{\circ}$ ). The antheridial cell assumes a papillate form, and divides by a transverse wall into an outer and inner cell, and the former divides by a similar wall into two cells, of which the upper one is the mother cell of the antheridium, and the other the stalk. The first wall in the antheridium itself is vertical (Fig. 52, B), and divides it into two equal parts. Each of these is now divided by two other intersecting walls, best seen in cross-sec- 
tion (Fig. 53, A), which separate a central cell, nearly tetrahedral in form, from two outer cells. In the complete separation of the central cell by these first two walls, Porella appears to differ from the other Jungermanniaceæ examined, (Leitgeb (7), ii., p. 44), where these first two peripheral cells do not reach to the top of the antheridium, and a third cell is cut off before the separation of the central part of the antheridium from the wall is complete. It is possible, too, that in Porella this may be sometimes the case. The antheridium in crosssection at this stage shows two perfectly symmetrical halves

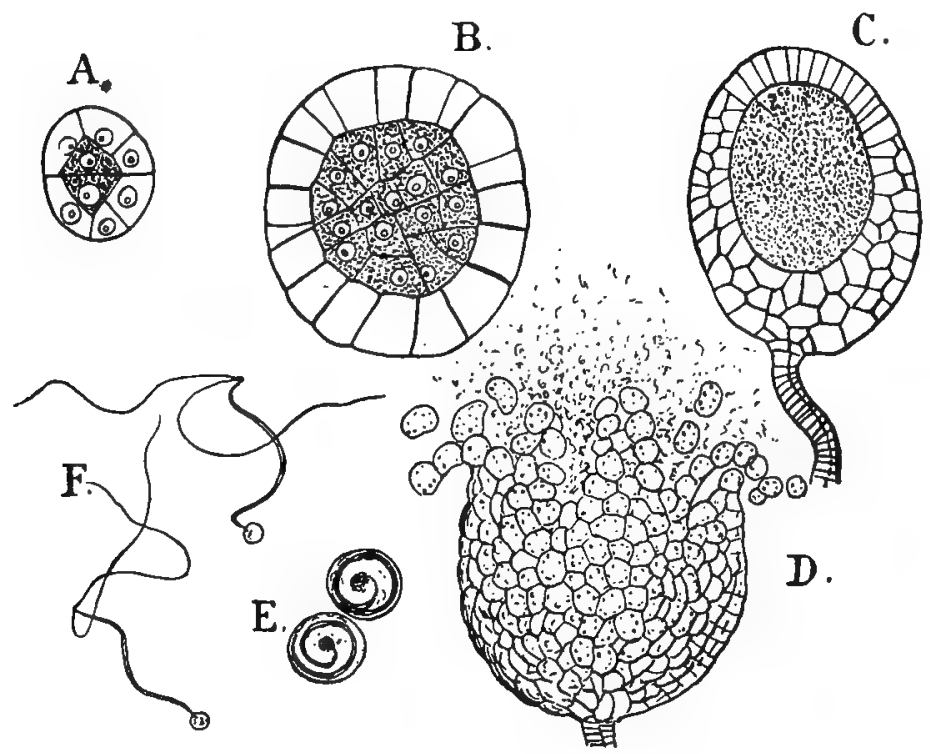

Fig. 53. - Porella Bolanderi. A, B, Cross-sections of young antheridia, $\times 600$; $C$, longitudinal section of nearly ripe antheridium, $\times 100 ; D$, ripe antheridium in the act of opening, $\times 50 ; E, F$, spermatozoids, $\times 1200$.

(Fig. 53, A). The two central cells form a rhomboid surrounded by six cells, the first of the primary peripheral cells being in each case divided into two. The divisions proceed rapidly in both the central cells and in the peripheral ones. In the latter they are for a long time always radial, so that the wall remains but one cell thick; but as the antheridium approaches maturity periclinal walls also form in the lower part, which thus becomes double, and at places even three cells thick. After the division of each primary central cell into equal 
quadrants, a series of curved walls intersecting the inner walls of the peripheral cells arise, and then periclinal walls (Fig. $53, \mathrm{~B}$ ), but beyond this no definite succession of walls could be traced.

The development of the spermatozoids is the same as in other Liverworts. The slender body shows about two complete coils; the vesicle is small, but always present, and the cilia somewhat longer than the body (Fig. 53, F). The stalk of the antheridium is long and at maturity composed of two rows of cells. Before the central cells of the antheridium are separated from the peripheral ones, the stalk shows a division into two tiers of two cells each (Fig. 52, B), but it is only the lower one that forms the real stalk; the other forms the base of the antheridium itself. The cells of the walls have numerous chloroplasts, but the great mass of colourless sperm cells within make the ripe antheridium look almost pure white. If one of these is brought into water it soon opens in a very characteristic way. The cells of the wall absorb water with great avidity, and finally the upper part bursts open by a number of irregular lobes which curl back so strongly that many of the marginal cells become completely detached. The whole mass of sperm cells, with the included spermatozoids, is forced out into the water, and if they are perfectly mature, the spermatozoids are quickly liberated and swim away (Fig. 53, D.)

The female plants are decidedly larger than the males, but the archegonial branches are much less conspicuous than the antheridial ones. The older ones, which either contain a young sporgonium or abortive archegonia, are readily distinguished on account of the large perianth (Fig. 49, A), but those that contain the young archegonia are situated very near the apex of the main shoot, and are scarcely to be distinguished from the very young vegetative branches. However, a plant with the older perichætia, or very young sporogonia, will usually show young archegonial branches as well.

The archegonial branch originates in the same way as the vegative branches, and the first divisions of its apical cell are the same; but only two or three segments develop leaves, after which each young segment divides into an inner and an outer cell; the latter becomes at once the mother cell of the young archegonium. The inner cell divides further by a transverse wall, and the outer of the two cells thus formed gives rise to 
the short but evident pedicel of the archegonium. The latter is very like that of the anacrogynous Liverworts. Of the three first walls (Fig. 54, C), the last formed one is much shorter, so that one of the three peripheral cells is much smaller, and does not divide by a vertical wall, and the neck has but five rows of cells, as in Pellia. This appears to be universal among the acrogynous Jungermanniales examined. Often in Porella the three primary walls converge at the bottom so as to almost meet, in which case the central row of cells is narrower at the base (Fig. 54, D). The rest of the development
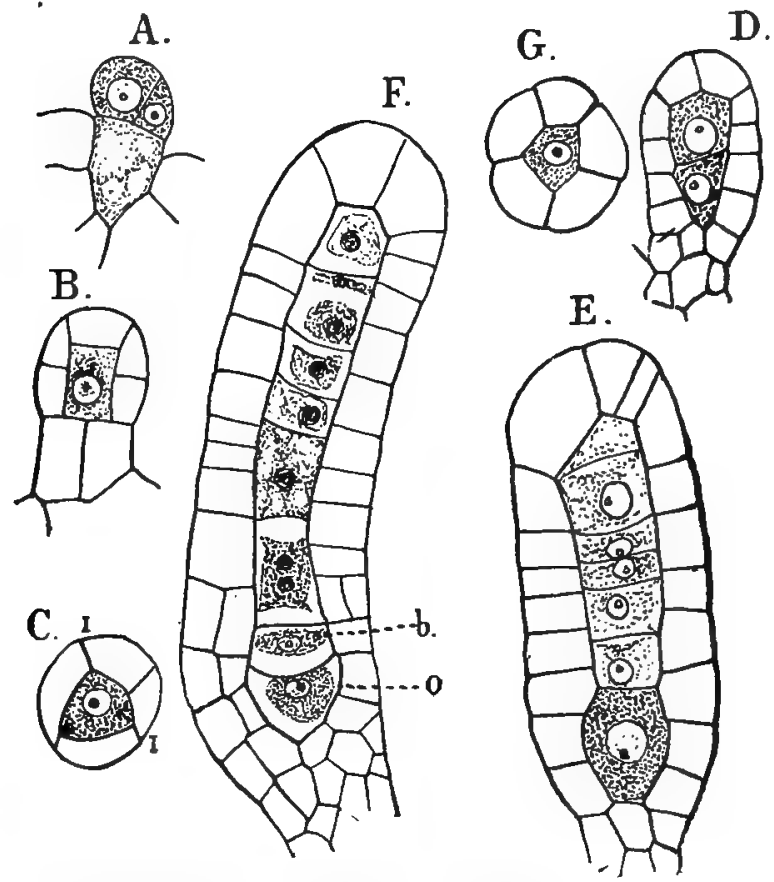

F16. 54-Porella Bolanderi. Development of the archegonium, $\times 600 ; C$, cross-section of young archegonium; G, cross-section of the neck of an older one. The others are longitudinal sections; $b$, ventral canal cell; $v$, the egg.

is exactly as in the other Hepaticæ. The number of neck canal cells in the full-grown archegonium is normally eight. The archegonium (Fig. 54, F), at maturity is nearly cylindrical, with the venter but little enlarged. The canal cells are broad, but the egg small. The venter has a two-layered wall.

The first-formed archegonia arise in strictly acropetal suc- 
cession, and finally the apical cell divides by a transverse wall, and the outer cell so formed becomes transformed into an archegonium. In a number of cases observed, young archegonia were noticed among the older ones, apparently formed secondarily from superficial cells between them, and not from the younger segments of the apical cells.

A perianth is formed about the group of archegonia, much as in the anacrogynous forms..

Gayet (I) has asserted that in the Liverworts, as well as in the true Mosses, the growth of the archegonium is largely apical. This point has been examined again by the writer (Campbell (2I)), but Gayet's conclusions were not verified.

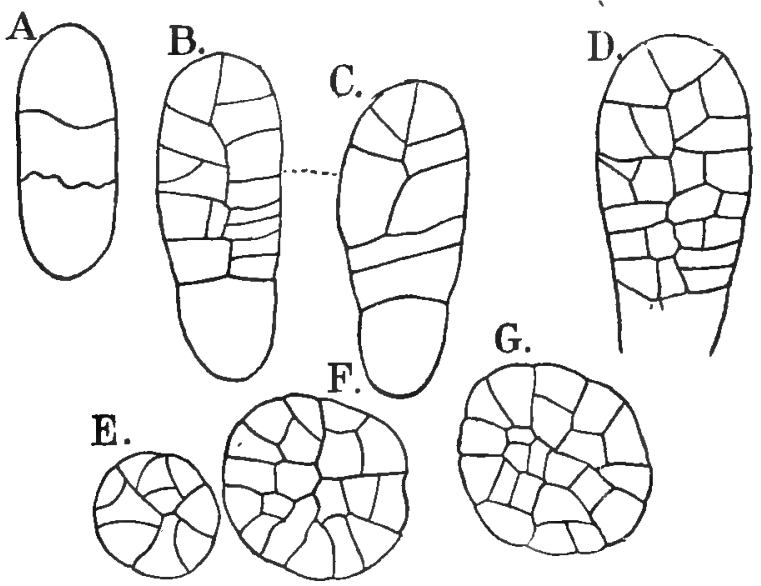

Frg. 55.-Porella Bolanderi. Development of the embryo. A-D, in longitudinal section; E.G, transverse sections. $B$ and $C$ are sections of the same embryo, and $E, F, G$ are successive sections of a single embryo, $\times 525$.

\section{The Sporophyte}

The early divisions in the embryo of Porella are less regular than those in some others of the foliose Liverworts. The embryo at first is composed of a row of cells, of which the lowest, cut off by the first transverse wall, undergoes here no further development. In Jungermannia bicuspidata (Hofmeister, Kienitz-Gerloff, Leitgeb) this lower cell undergoes further divisions to form the filamentous appendage at the base of the sporogonium. The next divisions in the upper part of the embryo correspond closely: to those described in Pellia and Aneura, but the succession of the walls is more variable and 
CHAP.

the limits of the primary cells more difficult to follow. The number of the cells, too, that contribute to the formation of the capsule, cannot be determined exactly, and there is evi-
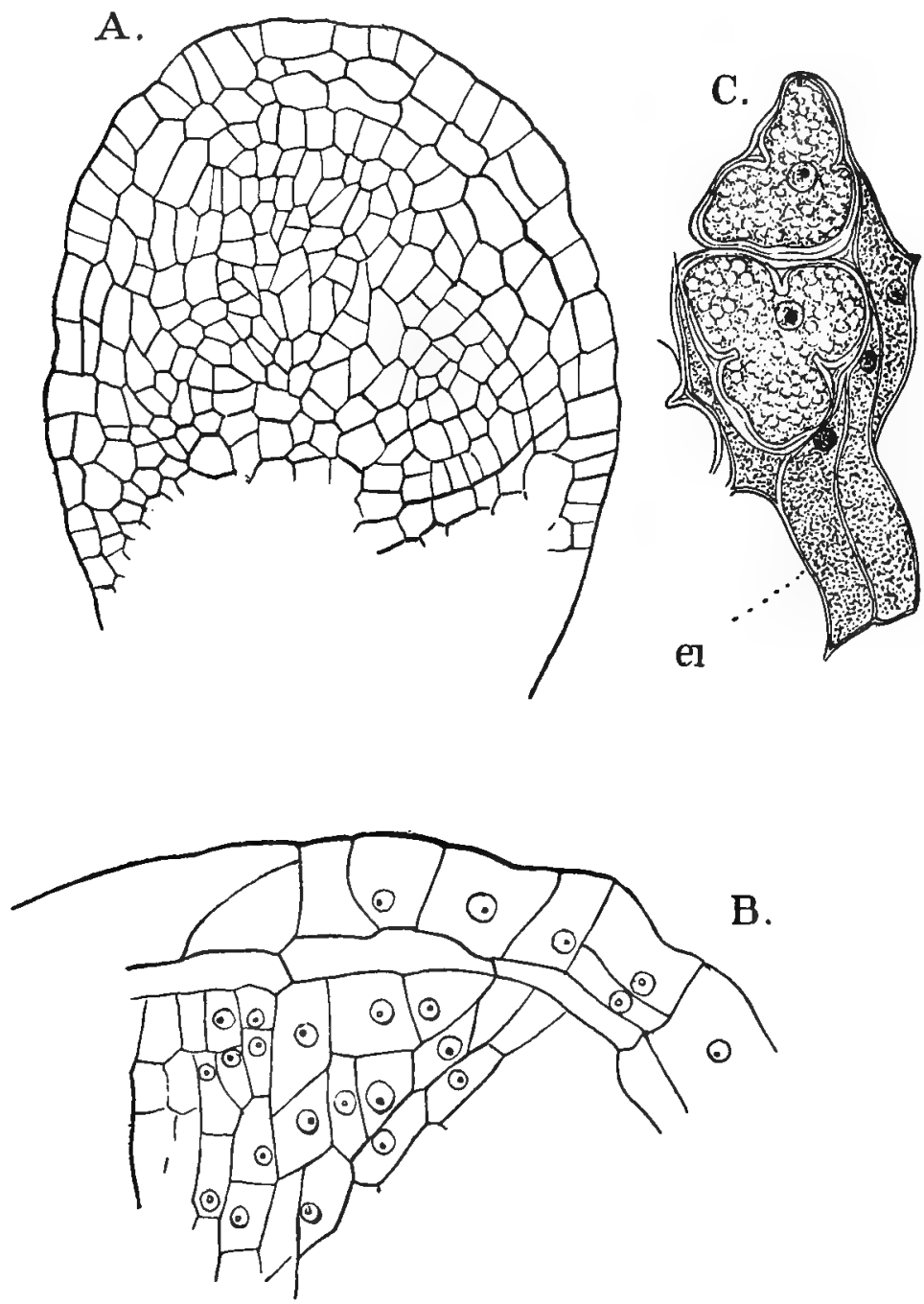

Fic. 56.-Porella Bolanderi. A, Nearly median longitudinal section of an advanced embryo, $X 260 ; B$, the upper part of a similar embryo, $X_{525}$; , sporogenous cells and elaters from a still older sporogonium, $\times 525$.

dently some variation in this respect, as there is in the time of the separation of the capsule wall from the archesporium. 
Both longitudinal and transverse sections of the sporogonium at this stage (Fig. 55, D) show a good deal of irregularity in the arrangement of the cells, and the first periclinal walls form at very different distances from the surface, so that it is clear that the wall cannot be established, as in Radula for instance, by the first periclinals.

The cells of the older archesporium are arranged in more or less evident rows radiating from the base (Fig. 56, A). No definite relation of spores and elaters can be made out, the two sorts of cells being mingled apparently without any regular order. Some of the cells cease dividing and grow regularly in all directions, while others may divide further and grow mainly in the plane of division, so that they become elongated. The former are the young spore mother cells, the latter the elaters (Fig. 56, C). The division of the spores begins while the cells of the archesporium are still united, although at this time the swollen and strongly striated cell walls of the mother cells (Fig. 56, C) show that they are becoming mucilaginous. At this stage sections through the archesporium show the deeply-lobed spore mother cells with the elongated elaters packed in between them, the pointed ends of the latter fitting into the interstices between the spore mother cells. The latter are somewhat angular and the wall distinctly striated. It is the inner layer only of the wall that projects into the cavity of the cell and forms the characteristic lobes marking the position of the four spores. The cell cavity is filled with crowded granules, some of which are chloroplasts. The nucleus, which is of moderate size, and rich in chromatin, has a distinct nucleolus. The elaters have thinner walls than the spore mother cells, and the contents are more finely granular. A distinct nucleus staining strongly with the usual reagents is present. The further history of spores and elaters corresponds closely with that of the forms already described. The ripe spores have only a thin wall, which is coloured brown, and has delicate granular thickenings.

In a paper by Le Clerc du Sablon (3) the statement is made, and figures are given, showing that at an early stage in the development of the spores and elaters of a number of $\mathrm{He}$ paticæ the walls of the cells are completely destroyed, so that the young spore mother cells and elaters are primordial cells. A great many carefully stained microtome sections of a large 
number of Liverworts belonging to all the principal groups have been examined by me, and invariably the presence of a definite cell wall could be demonstrated at all stages.

Many of the foliose Hepaticæ show much greater regularity in the early divisions of the embryo, and in the establishment of the archesporium and the arrangement of its cells. This is especially marked in Frullania (Leitgeb ( 7$)$, II.).

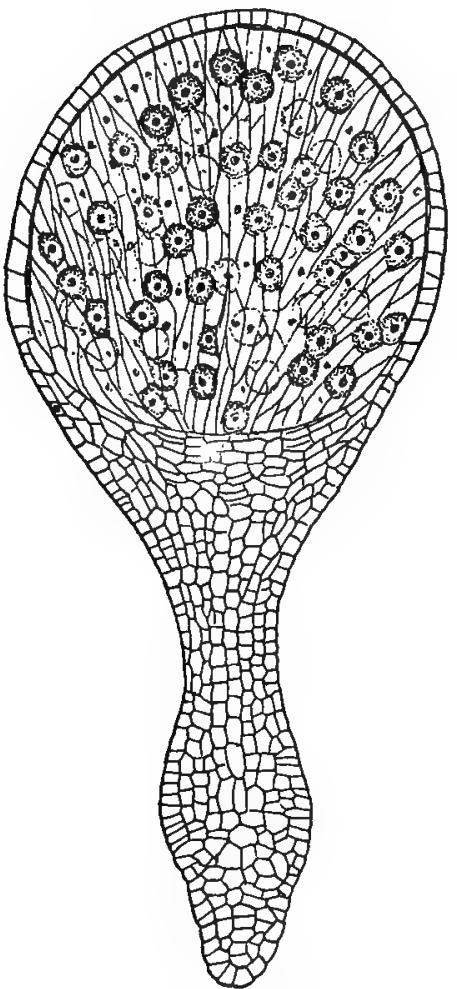

Fig. 57.-Porella Bolanderi. Loneitudinal section of a sporogonium after the final division of the archesporial cells, $\times 85$.

growth of the capsule. The degree to which the seta and foot are developed varies. In Porella there is not a distinctly marked foot, the lower part of the seta being simply somewhat enlarged, but in others, like Jungermannia bicuspidata, there is a large heart-shaped foot, very distinct from the seta. In Porella the seta is short, projecting but little beyond the 
perianth; but in others it may reach a length of several centimetres.

The development of the perianth is quite independent of fertilisation, and not infrequently it contains, although fully developed, only abortive archegonia. It is not always formed, but when present, according to Leitgeb, it is the product of the older segments of the apical cell from which archegonia are formed, and arises as a sort of wall about the whole group of archegonia. In Porella, as well as most of the foliose $\mathrm{He}$ paticæ, the capsule opens by four equal valves, the lines of splitting corresponding, according to Leitgeb, to the first quadrant walls in the young embryo.

The germination of the spores shows a great deal of variation, and has been studied in a large number of forms by several observers. Recently a number of tropical species have
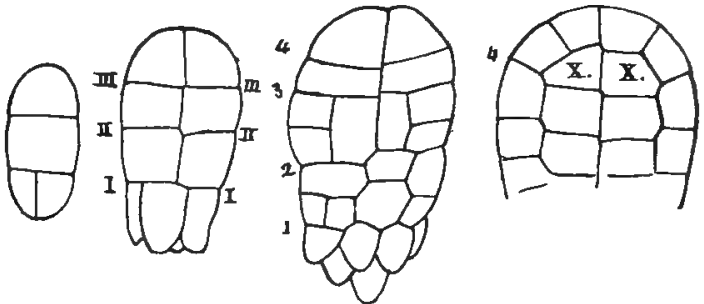

FiG. 58.-Frullania dilatata. Development of the embryo, $\times_{300}$ (after Leitgeb) ; $x, x$, the archesporial cells. The numbers indicate the primary transverse divisions.

been investigated, especially by Spruce (2) and Goebel (12), and some extremely interesting variations have been discovered. In these forms and when the exospore is not strongly developed, it is simply stretched by the expanding endospore, and finally becomes no longer discernible; but when it is clearly differentiated, it splits with the swelling of the endospore and then remains unchanged at the base of the young plant. The germinating spore may give rise to a cell mass immediately, which develops insensibly into the leafy axis, or it may form a simple or branched protonema of very different form, which sometimes reaches a large size and upon which the leafy axis arises as a bud.

The simplest form may be illustrated by Lophocolea, in which the germinating spore divides by a transverse wall into two equal cells, one of which continues to grow and divide 
until a short filament is formed. After a varying number of transverse divisions an oblique wall is formed in the terminal cell, and a second one nearly at right angles to it. By these divisions the dorsiventral character is established, the firstformed segment being ventral. A third oblique wall now arises, intersecting both of the others, and the three include a tetrahedral cell which is the permanent apical cell of the young plant. The ventral segments do not at first form any trace of leaf-like structures, and in the dorsal segments the leaves are at first simple rows of cells; but a little later the leaves show plainly their two-lobed character, each being made up of two rows of cells united at the base. From the ventral segments the amphigastria develop gradually, being quite absent in the earlier ones. Chiloscyphus closely resembles Lophocolea, but
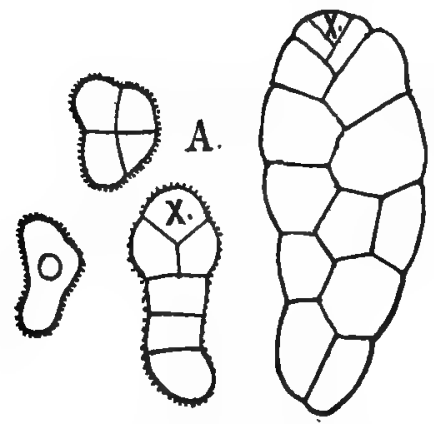

B.

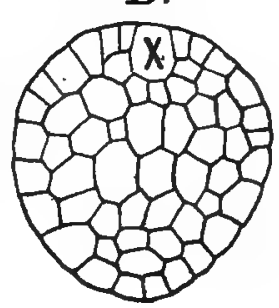

FIG. 59.-A, Germination of Lejeunia serpyllifolia; B, young plant of Radula com. planata; $\pi$, the optical cell (all the figures after Goebel).

the filamentous protonema is longer, and is often branched. A similar filamentous protonema is present in Cephalozia (Jungermannia) bicuspidata and other species.

Lejeunia (Goebel (I3)) shows a most striking resemblance in its early stages to the simple thallose Jungermanniaceæ. The germinating spore forms either a short filament or a cell surface (Fig. 59, A). In either case, at a very early stage, a two-sided apical cell is established, and for a time the young plant has all the appearance of a young Metzgeria or Aneura. This two-sided apical cell gives place to the threesided one found in the older gametophyte, and the leaves and stem are gradually developed as in Lophocolea.

In Radula (Hofmeister (I), p. 55), and according to 
Goebel, much the same condition occurs in Porella, the first divisions of the spore give rise to a disc, and the formation of a filament is completely suppressed. This disc is nearly circular in outline, and at its edge a single large cell appears (Fig. $59, \mathrm{~B})$, whose relation to the primary divisions of the spore is not quite clear. This cell forms the starting-point for the

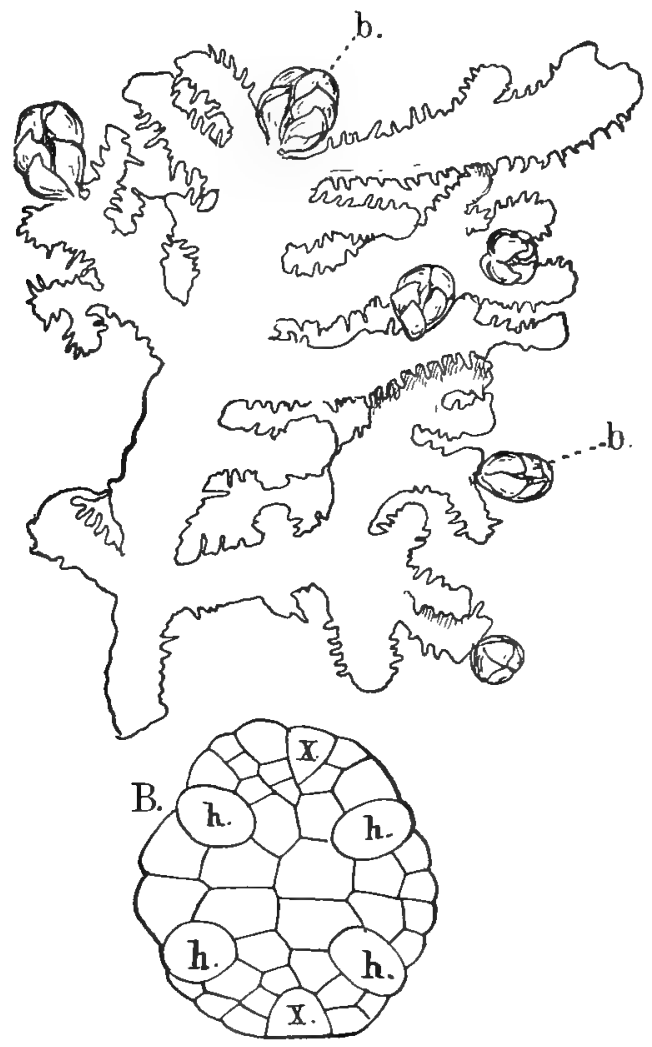

FIG. 6o.-A, Lejeunia metzgeriopsis, showing the thalloid protonema with terminal leafy buds (b), $\mathrm{X}_{44}$ (after Goebel). B, Gernma of Cololejeunia Goebelii.

growing apex of the gametophore. As in the other forms, the first leaves are extremely rudimentary, and only gradually is the complete gametophyte developed.

How far this variation in the form of the protonema is of morphological importance is a question, as the same species may show both a filamentous protonema and the discoid form. 
According to Leitgeb this is the case in several species of Jungermannia, and he suggests that the conditions under which germination takes place probably affect to a considerable extent the form of the protonema. This is well known to be the case in Ferns.

The very peculiar modifications observed in certain tropical Hepaticæ, especially by Spruce and Goebel, should be mentioned in this connection. In these forms the protonema is permanent and the leafy gametophore only an appendage to it. In Protocephalozia ephemeroides, a species discovered by Spruce in Venezuela, the plant forms a dense branching filamentous protonema much like that of the true Mosses, which it further resembles by having a subterranean and an aerial portion. Upon this confervoid protonema are borne the leafy gametophores, which are small and appear simply as buds. Among the other remarkable forms is Lejunia metzgeriopsis, a Javanese species discovered by Goebel growing upon the leaves of various epiphytic Ferns. It has a thallus much like that of Metzegeria, and like it has a two-sided apical cell. This thallus branches extensively (Fig. 6o, A), and propagates itself by numerous multicellular gemmæ. This thallose condition is, however, only maintained during its vegetative existence. Previous to the formation of the sexual organs, the two-sided apical cell of a branch becomes three-sided, as in the young plant of other species of Lejeunia, and from this three-sided apical cell a short leafy branch, bearing the sexual organs, is produced. ${ }^{1}$

Considerable variety is exhibited by the leaves of the Acrogynæ as to their form and position, but all agree in their essential structure and early growth. The two lobes may be either equal in size or unequal. In the latter case either the dorsal or ventral lobe may be the larger, when the leaves are overlapping, as occurs in most genera. Where the dorsal half is the larger it covers the ventral lobe of the leaf in front of it, and the leaves are said to be "incubous"; where the reverse is the case, the leaves are "succubous." These differences are of some importance in classification.

In many species, especially the tropical epiphytic forms, one lobe of the leaf frequently forms a sac-like organ, which ap-

${ }^{2}$ For a complete account of these forms as well as others, see Goebel's papers in the Annals of the Buitenzorg Botanical Garden, vols. vii. and ix., and in Flora, I889 and I893 
pears to serve as a reservoir for moisture. These tubular structures sometimes have the opening provided with valves, which open readily inward, but not from the inside, and thus securely entrap small insects and crustaceans which find their way into them. Schiffner ( ( ) , p. 65) compares them to the pitchers of a Sarracenia or Darlingtonia, and suggests that they may serve the same purpose.

The branching of the foliose Jungermanniaceæ has been carefully investigated by Leitgeb, and will briefly be stated here. Two distinct forms are present, terminal branching and intercalary. The former has already been referred to, but it shows some variations that may be noted. In most cases the whole of the ventral part of a segment, which ordinarily would produce the ventral lobe of a leaf, forms the rudiment of the branch. so that the leaf, in whose axil the branch stands, has only the dorsal lobe developed. In the other case, only a part of the cell is devoted to forming the branch, and the rest forms a diminished but evident ventral leaf-lobe, in whose axil the young branch is situated. The formation of the intercalary branches, which

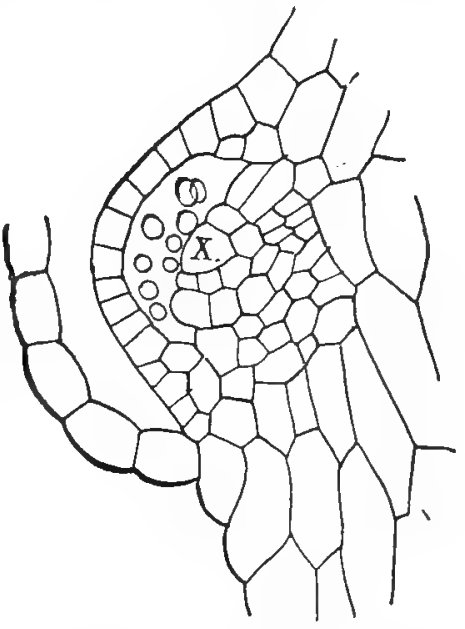

FIG. 61.-Mastigobryum trilobatum. Longitudinal section of the stem, showing the endogenous origin of the branches; $x$, the apical cell of the branch, $\times 245$ (after Leitgeb).

are for the most part of endogenous origin, may be illustrated by Mastigobryum, where the characteristic flagellate branches arise in this manner. The apical cell of the future branch (the branches in this case arise in strictly acropetal order) springs from the ventral segment, and exactly in the middle. It is distinguished by its large size, and is covered by a single layer of cells (Fig. 6I). In this cell the first divisions estabiish the apical cell, which then grows in the usual way. The young bud early separates at the apex from the overlying cells, which rapidly grow, and form a dome-shaped sheath, between 
which and the bud there is a space of some size. Later the young branch grows more rapidly than the sheath and breaks through it.

The non-sexual reproduction of the acrogynous Hepaticæ may be brought about either by the separation of ordinary branches through the dying away of the older parts of the stem, or in a few cases observed (Schiffner (I), p. 67) new plants may arise directly from almost any point of a leaf or
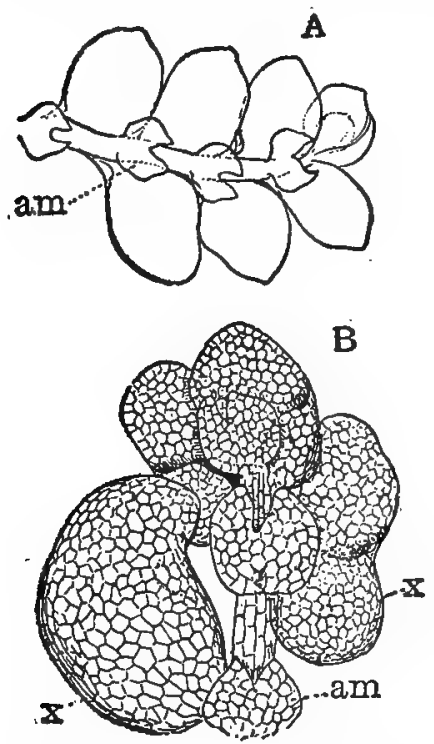

FiG. 62.-A, Lejeunia sp., showing the ventral leaves, or amphigastria, am $(X$ about 40 ). B, a West Indian Lejeunia, the lower leaf-Iobes. X, modified as water-sacs $(\times 75)$. stem. Gemmæ are known in a large number of species. These in most of the better known cases are very simple unicellular or bicellular buds arising often in great numbers, especially from the margins and apices of leaves. Curious discoid multicellular gemmæ have been dis. covered in a number of species, especially in several tropical ones investigated by Goebel (I6). Gemmæ upon the thallus of $L e-$ jeunia metzgeriopsis are of this character, and similar ones are found in Cololejeunia Goebelii. In the latter (Fig. 6o, B). the gemma is a nearly circular cell plate attached to the surface of the leaf by a stalk composed of a single cell. The first wall in the young gemma divides it into two nearly equal cells, in each of which a two-sided apical cell is formed, so that like the gemma of Marchantia there are two growing points. There are usually four cells that differ from the others in their thicker walls and projecting on either side of the gemma above the level of the other cells. These serve as organs of attachment, perhaps by the secretion of mucilage, and by them the young plant adheres to the surface of the fern leaf upon which it grows. The development of the gemmæ, whether unicellular or multicellular, resembles very closely that of the germinating spores. 
Representatives of the Acrogynæ are found in all parts of the world, and many of the larger genera are cosmopolitan. It is in the wet mountain forests of tropical and subtropical regions that they reach their greatest development, both as to size and numbers. In these regions they replace to a great extent the Mosses of the more northern forests. Some of them are extremely minute, and grow as epiphytes upon the leaves and twigs of trees and shrubs, or even upon the leaves of ferns, or of larger Liverworts. Some of the larger forms, like species of Bazzania or Schistochila (Fig. 63) are conspicu-

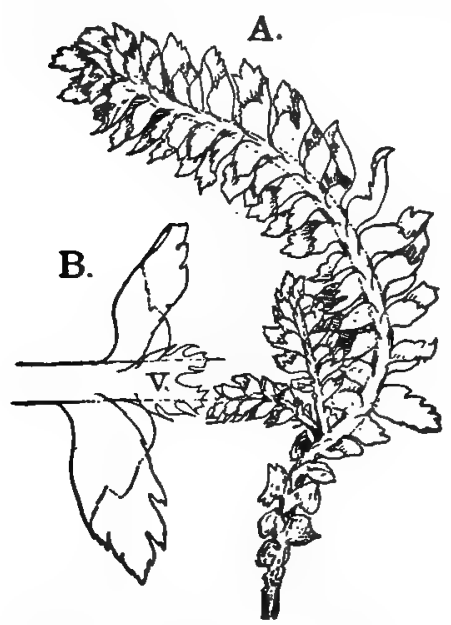

FIG. 63.-Schistochila appendiculata. A plant of the ratural size; $B$, two dorsal and one ventral leaf $(v), X_{2}$. ous and characteristic plants.

Classification of the Acrogyne

In attempting to subdivide this very large family, numerous difficulties are encountered. Their affinity with the Anacrogynæ is unmistakable, but it is highly improbable that the family, as a whole, has had a common origin. It is much more likely that different types of leafy Liverworts have originated quite independently from different anacrogynous prototypes. While the Acrogynæ show a good deal of variation, the differences are not constant, and the different groups or sub-families merge so into each other as to make a satisfactory division of the family almost hopeless. According to Schiffner (I), the only one of the subfamilies which he recognizes, which is clearly delimited, is the Jubuloidex. He recognizes the following sub-families (Schiffner (I), p. 74):

I, Epigoniantheæ; II, Trigonantheæ; III, Ptilidioideæ ; IV, Scapanioideæ; V, Stepaninoideæ ; VI, Pleurozioideæ ; VII, Bellincinioideæ; VIII, Jubuloideæ. 


\section{CHAPTER IV}

\section{THE ANTHOCEROTES}

THIs group contains but three genera, Anthoceros, Dendroceros, and Notothylas, and differs in so many essential particulars from the other Hepaticæ that it may be questioned whether it should not be taken out of the Hepaticæ entirely and given a place intermediate between them and the Pteridophytes. All the members of the class correspond closely in the structure of the gametophyte, and while showing a considerable variation in the complexity of the sporophyte, there is a perfect series from the lowest to the highest in regard to the degree of development of the latter, so that the limits of the genera; are sometimes difficult to determine. The Anthocerotes are of extraordinary interest morphologically, as they connect the lower Hepaticæ on the one hand with the Mosses, and on the other with the vascular plants. Leitgeb ( ( 7$)$, v., p. 9) has endeavoured to show that they are sufficiently near to the Jungermanniales to warrant placing them in a series with that order opposed to the Marchantiales, but a careful study of both the gametophyte and the sporophyte has convinced me that this view cannot be maintained; and that while probably the affinities of the Anthocerotes are with the anacrogynous Jungermanniales rather than with the Marchantiales, nevertheless the two latter orders are much nearer each other than the former is to either of them.

The gametophyte in all the forms is a very simple thallus, either with or without a definite midrib. Of the three genera Dendroceros is confined to the tropical regions, while the other genera occur in the temperate zones, but are more abundant in the warmer regions, where they also reach a greater size. The species of Anthoceros and Notothylas grow principally upon 
the ground in shady and moist places, and are usually not well adapted to resist dryness.

The chloroplasts in the Anthocerotaceæ resemble those in certain confervoid Algæ, e. g., Stigeoclonium, Coleochate. Each cell in most species shows a single large chloroplast containing a pyrenoid. In sterile specimens of an undetermined species of Anthoceros from Jamaica, two chloroplasts were found in each cell, and a doubling of the chloroplast is not uncommon in the more elongated thallus-cells of other species, while in the sporophyte there seem to be regularly two chloroplasts in each cell. Simple thin-walled rhizoids are formed abundantly upon the ventral surface, where there are in many species curious stoma-like clefts which open into cavities filled with a mucilaginous secretion, and in some of which, in all species yet examined, are found colonies of Nostoc which form dark blue-green roundish masses, often large enough to be readily detected with the naked eye, and which were formerly (Hofmeister ( I ), p. I8) supposed to be gemmæ.

The sexual organs are very different from those of the true Hepaticæ, and are more or less completely sunk in the thallus from the first. While the first divisions in the archegonium are much like those in the Hepaticæ, the subsequent ones are much less regular except in the axial row of cells, and the limits of the outer neck-cells are in the subsequent stages difficult to determine, and the archegonium projects very little above the surface of the thallus, even when full grown. The divisions in the axial row of cells correspond to those in the other Archegoniatæ.

The origin of the antheridium is entirely different from that of all other Bryophytes, but shows, as will be seen later, certain suggestive resemblances to that of the lower Pteridophytes. Instead of arising from a superficial cell, as in all of the former, the antheridium, or in most cases the group of antheridia, is formed from the inner of two cells arising by the division of a superficial one. The outer one takes no part in the formation of the antheridia, but simply constitutes part of the outer wall of the cavity in which they develop.

While the gametophyte is extremely simple in structure, being no more complicated than that of Aneura or Metzgeria, the sporophyte reaches a high degree of complexity. Here, instead of the greater part of the sporophyte being devoted to 
spore formation, and dying as soon as the spores are scattered, the archesporium, especially in the higher forms, constitutes but a small part of the sporogonium, which develops a highly differentiated system of assimilating tissue, with complete stomata of the same type as those found in vascular plants; and in addition a central columella is present whose origin and structure point to it as possibly a rudimentary vascular bundle. In all of them this growth of the sporophyte is not concluded with the ripening of the first spores, but for a longer or shorter time it continues to grow and produce new spores. This reaches its maximum in some species of Anthoceros, where the sporogonium may reach a length of several centimetres, and continues to grow as long as the gametophyte remains alive. In these forms the foot is provided with root-like processes, which are closely connected with the cells of the gametophyte, from which nourishment is supplied to the growing sporophyte.

The archesporium produces spores and elaters, but the latter are not so perfect as in most of the Hepaticæ. They often show a definite position with regard to the spore mother cells; this is especially marked in Notothylas. The archesporium in all forms that have been completely investigated arises secondarily from the outer cells of the capsule. Leitgeb's ( ( $)$, v. p. 49) conjecture that in Notothylas the whole central part of the capsule is to be looked upon as the archesporium, is not confirmed by my observations on $N$. valvata (orbicularis), where the formation of a columella and the secondary development of the archesporium are exactly as in Anthoceros. ${ }^{1} \quad$ It is hardly likely that in the other species there should be so essential a difference as would be implied by such an assumption. The development of the spores and their germination show some peculiarities which will be considered when treating of these specially. The sporogonium shows no clear separation into seta and capsule, all except the foot and a very narrow zone above it producing spores. At maturity it opens longitudinally by two equal valves, between which the columella persists. The splitting is gradual and progresses with the ripening of the spores.

The genus Anthoceros includes about twenty species, widely distributed, but most abundant in the warmer parts of

'See also Mottier (2). 
the world. The species that has been most frequently studied is $A$. levis. The related $A$. Pearsoni has been carefully investigated by the writer, and also the larger $A$. fusiformis, a common Californian species allied to $A$. punctatus.

The gametophyte in all species is a dark green or yellowish green fleshy thallus, branching dichotomously so that it may form orbicular discs not unlike those of the Marchantiaceæ in shape; but owing to the rapid division of the growing point, and the irregular margin of the thallus, the separate growing points are not readily made out. The surface of the thallus may be smooth as in $A$. lavis, or much roughened, with ridges and spines as in $A$. fusiformis. The thallus may be quite compact, or there may be large intercellular spaces or chambers. The latter are not filled with air, as in the similar chambers of the Marchantiaceæ, but with a soft mucilage. Here and there, imbedded in the thallus, are small dark blue-green specks, which a closer examination shows to be colonies of Nostoc, which are invariably found in the thallus. Colourless rhizoids fasten the thallus to the ground. Sometimes the yellowish antheridia can be detected with the naked eye, but there is no indication visible of the archegonia, which are very inconspicuous and completely sunk in the thallus, and their presence can only be detected by sectioning.

The sporophytes are relatively large and may be produced in great numbers, this being especially conspicuous in $A$. fusiformis, where they may reach a length of six or seven centimetres, and stand so close together that a patch of fruiting plants looks like a tuft of fine grass.

Both of the common Californian species, A. Pearsoni and $A$. fusiformis are perennial. The growing point of the shoot, with a certain amount of the adjacent tissue, remains alive and persists through the summer, after the rest of the plant has dried up. Probably the great amount of mucilage in the thallus helps to check the loss of water, and enables the plant to survive the long summer drought.

Growth begins promptly with the first autumn rains, and by mid-winter, or sometimes earlier, the reproductive organs mature. The sporophyte continues to grow in length as long as the thallus receives the necessary moisture. New sporogenous tissues develops at the base of the sporophyte long after the first spores have been shed. With the cessation of its 


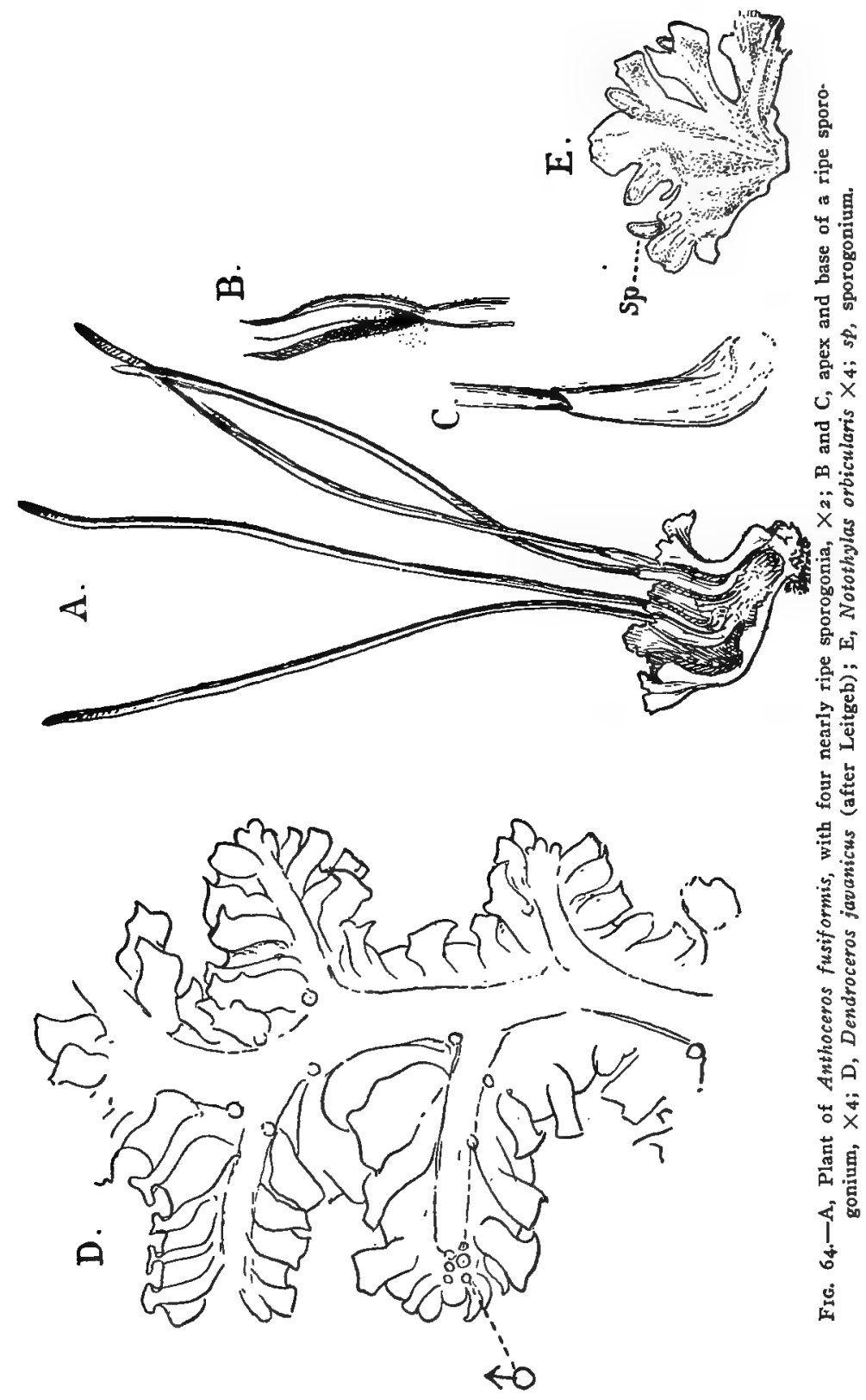


water-supply through the drying up of the thallus, the sporophyte finally dies.

In order to study the apical growth satisfactorily, young plants that show no signs of the sporogonia should be selected. In $A$. fusiformis such a plant will show the margin of the thallus occupied by numerous growing points separated by a greater or smaller number of intervening cells. It is somewhat difficult to determine positively whether one or more apical cells are present. In sections parallel to the surface the initial cells are seen to occupy the bottom of a shallow depression (Fig. 65, C). In the case figured, $x$ probably is the single apical cell, and it seems likely that this is usually the case, although Leitgeb was inclined to think that there were several marginal cells of equal rank. The outer wall of the cells shows a very marked cuticle. A vertical section passing through one of the growing points (Fig. 66) shows that the apical cell is much larger than appears from the horizontal section. On comparing the two sections it is evident that its form is the same as in the Marchantiaceæ or Pallavicinia. Two sets of lateral segments, and two sets of inner ones, alternately ventral and dorsal, are cut off, and the further divisions of these show great regularity, this being especially the case in the dorsal and ventral segments. Each of these first divides into an inner and an outer cell. The former divides repeatedly and in both segments forms the central part of the thallus. It is these cells that, according to Leitgeb, later show thickenings upon their walls somewhat like those met with in many Marchantiaceæ. From the outer cells are developed the special superficial organs both on the ventral and dorsal sides. From the former arise the colourless delicate rhizoids and peculiar stoma-like organs, the mucilage clefts, first described by Janczewski ( I), who also pointed out the true nature of the Nostoc colonies found within the thallus. These mucilage clefts, especially in their earlier stages, resemble closely the stomata of the higher plants. They arise by the partial separation of two adjacent surface cells close to the growing point, and often at least, the two cells bounding the cleft are sister cells. However, the same division of the neighboring cells frequently occurs without the formation of a cleft, and there is nothing to distinguish the two cells bounding the cleft from the adjacent ones, and a homology with the real stomata 
on the sporogonia is not to be assumed. The mucilage slit becomes wider, and beneath it an intercellular space is formed which widens into a cavity whose cells secrete the abundant
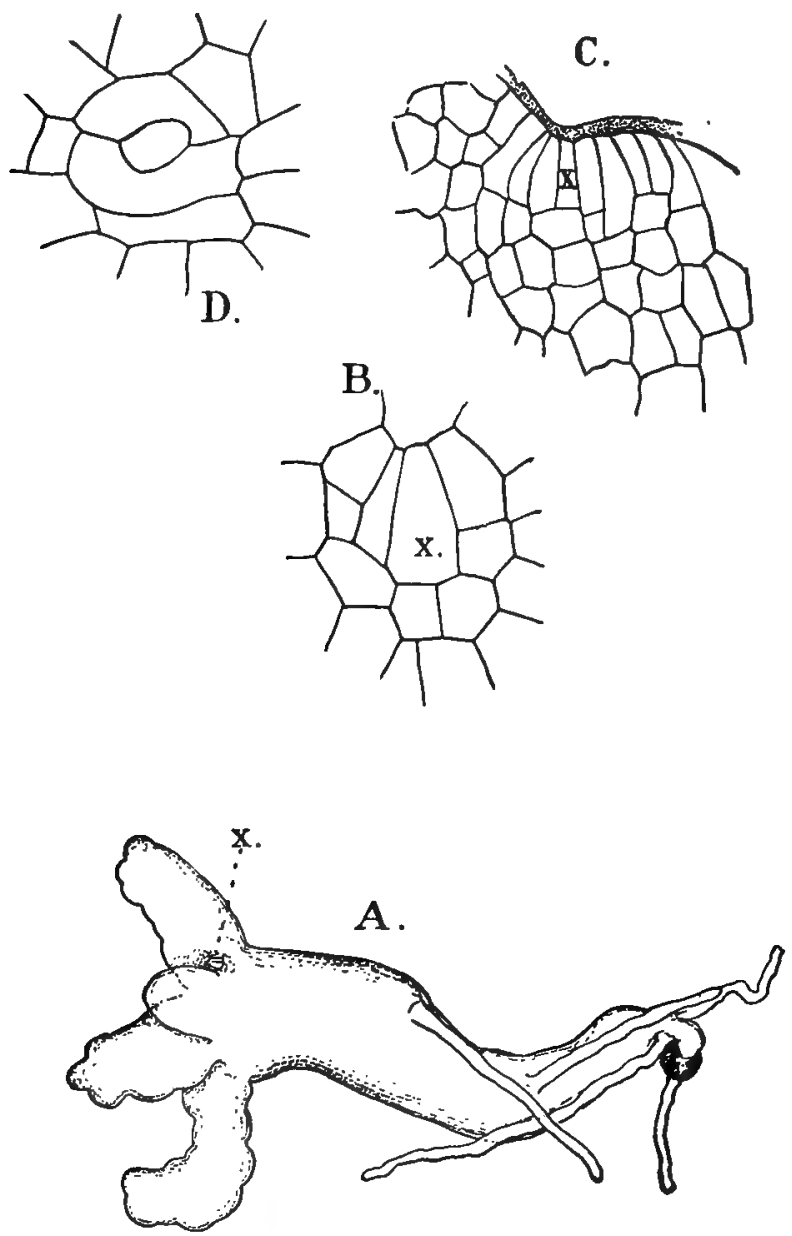

Fic. 65.-Anthoceros fusiformis. A, Young plant with single growing point $(x), \times 85$; $B$, horizontal section of the growing point of a similar plant, $\times 525 ; x$, the single apical cell; C, similar section of a growing point from an older plant, with possibly more than one initial cell, $\times 260 ; \mathrm{D}$, a mucilage slit from the ventral side of the thallus, $\times 525$.

mucilage filling it. This mucilage escapes through the clefts and covers the growing point in the same way as that secreted by the glandular hairs in the Jungermanniaceæ. 


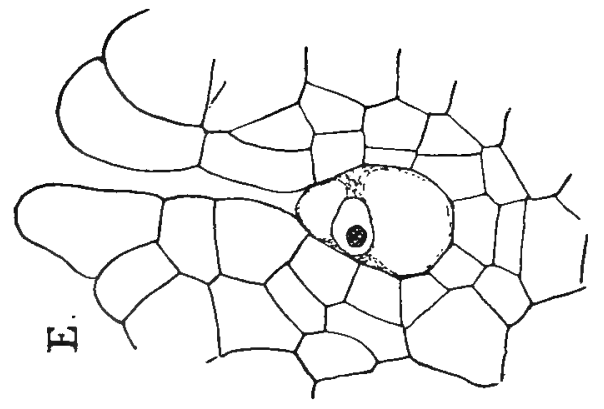

岁毒

壱

号导

送

คิ

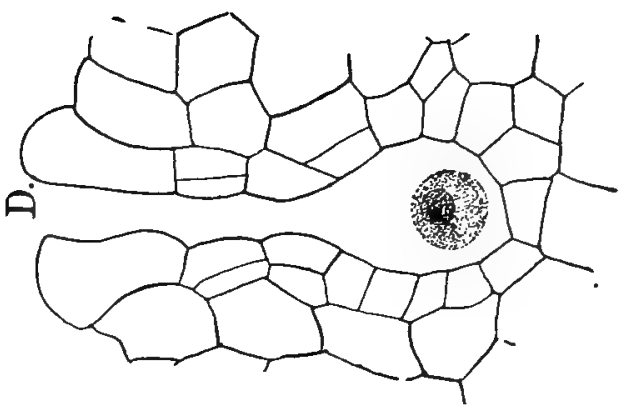

के

욤

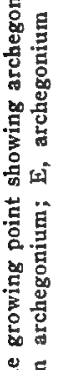

卷

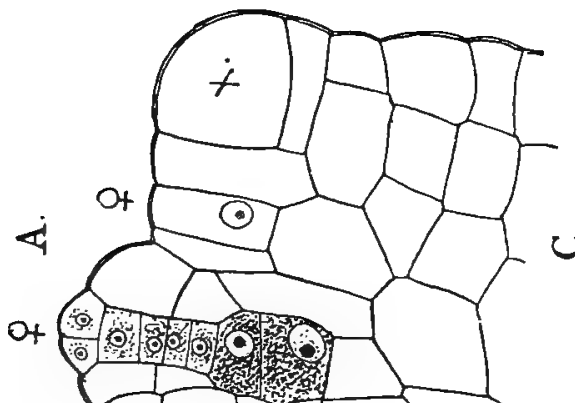

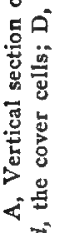

S1

ชी

窟要

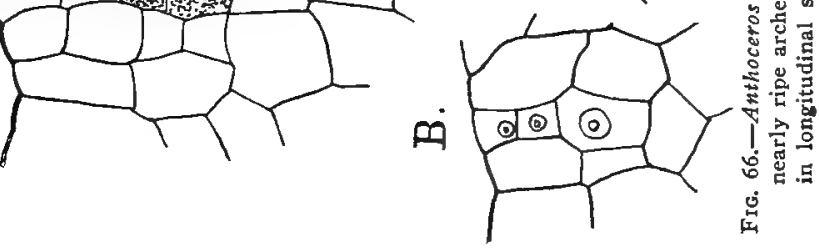


Each cell of the thallus contains a single chloroplast which may be either globular or spindle-shaped, or more or less flattened. The nucleus of the cell lies in close contact with the chloroplast, and usually partly or completely surrounded by it. There is no separation of the tissues into assimilative and chlorophylless, as in the Marchantiacer, and in this respect Anthoceros approaches the simplest Jungermanniaceæ, as it does in the complete absence of ventral scales or appendages of any kind, except the rhizoids.

The infection of the plant with the Nostoc has been carefully studied by Janczewski and Leitgeb ( ( 7$)$, v., p. I 5 ). The infection takes place while the plant is young, and is usually brought about by a free active filament of Nostoc making its way into the intercellular space below the mucilage slit, through whose opening it creeps. Once established, the filament quickly multiplies until it forms a globular colony. The presence of the parasite causes an increased growth in the cells about the cavity in which it lies, and these cells grow out into tubular filaments which ramify through the mass of filaments, and becomes so interwoven and grown together that sections through the mass present the appearance of a loose parenchyma, with the Nostoc filaments occupying the interstices. Other organisms, especially diatoms and Oscillarea, often make their way into the slime cavities, but according to Leitgeb's investigations their presence has no effect upon the growth of the thallus.

\section{Sexual Organs.}

The plants are monocious in $A$. fusiformis, and this is true of other species observed. In the former, however, the antheridia appear a good deal earlier than the archegonia. I observed them first on young plants grown from the spores, that were not more than $3 \mathrm{~mm}$. in length. The exact origin of the cell which the antheridia develops could not be made out, as none of my sections showed the youngest stages. Waldner's (2) observations upon $A$. lavis, however, and my own on $A$. Pearsoni and Notothylas valvata, as well as a study of the older stages in $A$. fusiformis, leave no doubt that in this species as in the others the antheridia are endogenous, and the whole group of them can be traced back to a single cell. They arise close to the growing point, and the cell from which they 
arise is the inner of two cells formed by a transverse wall in a suriace cell. The outer cell (see Figure 67, B) divides almost immediately by another wall parallel with the first, so that the group of antheridia is separated by two layers of cells from the surface of the thallus. The inner cell in $A$. Pearsoni at once develops into an antheridium; but in most species the cell divides first by a longitudinal wall into two, each of which
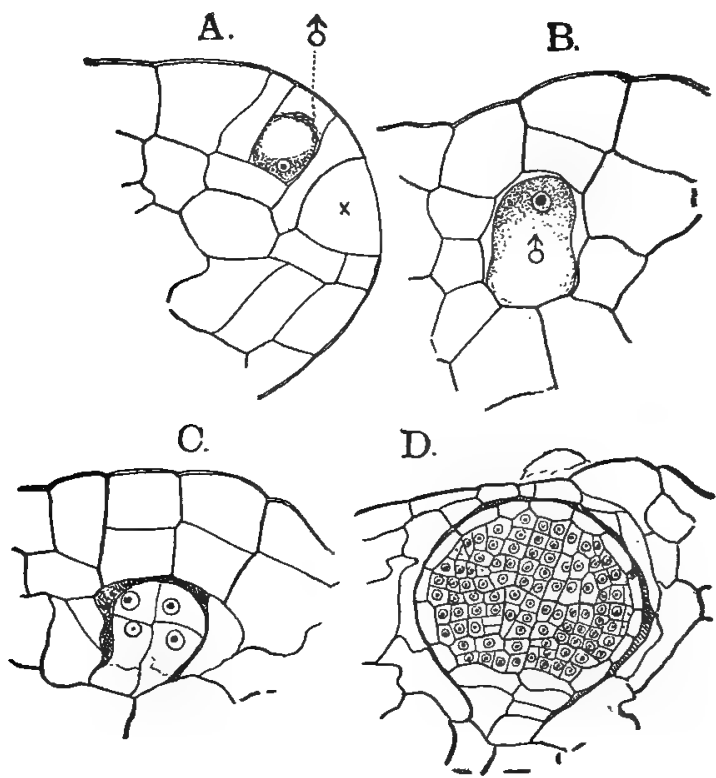

Fic. 67.-Anthoceros Pearsoni. Development of the antheridium: A, apex of the thallus, with very young antheridium, $X$ about $500 ; \mathrm{B}$, a somewhat older stage; C, still older stage, somewhat less highly magnified; D, an older, but still immature antheridium, $X$ about 200 .

generally divides again, so that there are four antheridium mother cells, all, however, unmistakably the product of a single cell, and if a comparison is to be made with the antheridium of any other Liverwort, the antheridium in the latter is homologous, not with the single one of Anthoceros, but with the whole group, plus the two-layered upper wall of the cavity in which they lie.

The first divisions in the antheridium are the same as those in the original cell, i.e., the young antheridium is divided longitudinally by two intersecting walls, and the separation of the 
stalk from the upper part is secondary; indeed in the earliest stages it is difficult to tell whether these longitudinal divisions will result in four separate antheridia or are the first division walls in a single one. Secondary antheridia arise later by budding from the base of the older ones, so that in the more advanced conditions the antheridial group consists of a varying number, in very different stages of development (Fig. 68, A).

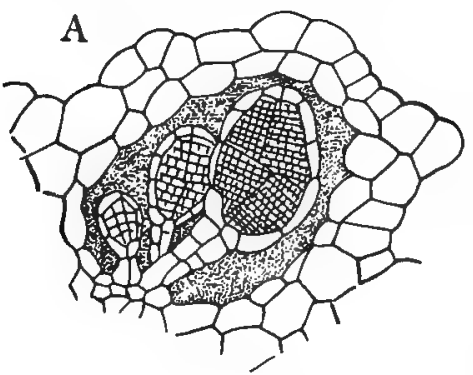

B.
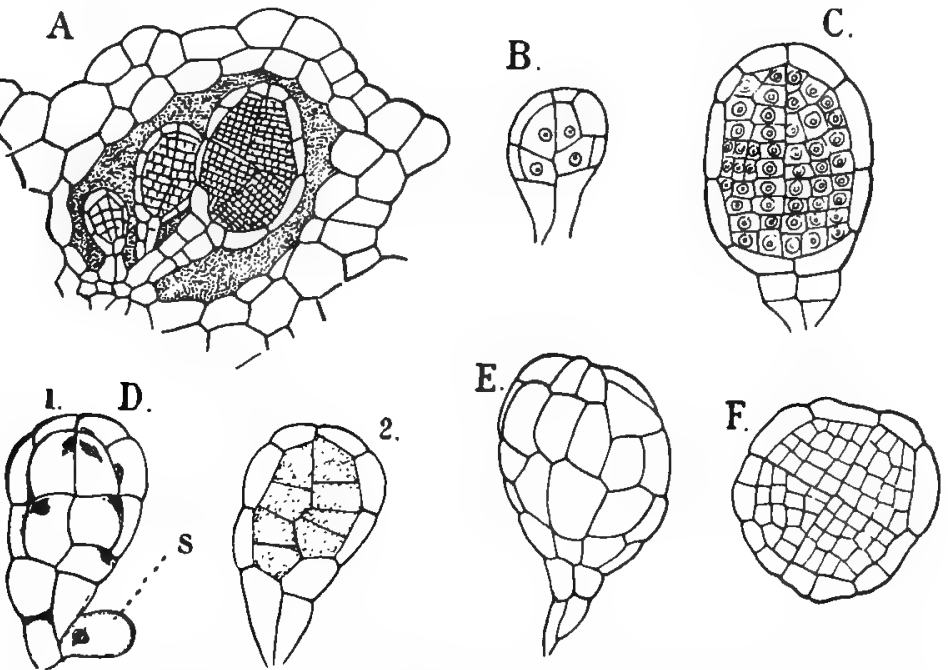

F1G. 68.-Anthoceros fusiformis. Development of the antheridium; D, E, drawn from living specimens, the others microtome sections; $\mathrm{D}, 1$, shows the single chloroplast in each of the wall cells, and the secondary antheridium $(s)$ budding out from its base; 2 is an optical section of the same; E, surface view of full-grown antheridium; F, cross-section of a younger one. Figs. A, $E \times 225$, the others $\times 450$.

After the first transverse walls by which the stalk is separated, the next division in each of the upper cells is parallel to it, so that the body of the antheridium is composed of nearly equal octant cells. Then by a periclinal wall each of these eight cells is divided into an inner and an outer cell, and the eight central ones then give rise to the sperm cells, and the outer ones to the wall. The four stalk cells by repeated transverse divisions form the four-rowed stalk found in the ripe antheridium. The uppermost tier of the stalk has its cells also divided by vertical walls and forms the basal part of the antheridium wall. The transverse and vertical division walls in the central cells alternate with great regularity, so that there is little displacement of the cells, and up to the time of the separation of the sperm 
cells the four primary divisions are still plainly discernible, and the individual sperm cells are cubical in form. In the peripheral cells hardly less regularity is observable. Except near the apex none but radial walls are formed after the first transverse wall has divided the body of the antheridium into two tiers, and when complete the wall consists of three wellmarked transverse rows of cells, the lower being derived from the uppermost tier of stalk cells. At the apex the cells are not quite so regular (Figs. D, E). In its younger stages the antheridium is very transparent and perfectly colourless. In each peripheral cell a chloroplast is evident, but at this stage it is quite colourless and the nucleus is very easily seen in close contact with it. As the antheridium grows the chloroplasts develop with it, becoming much larger and elongated in shape, and at the same time develop chlorophyll. The mature chloroplast is a flattened plate that nearly covers one side of the cell, and its colour has changed from green to a bright orange as in the antheridium of many Mosses. The sperm cells are discharged through an opening formed by the separation of the apical cells of the antheridium. These cells do not become detached, but return to their original position, so that the empty antheridium has its wall apparently intact. The spermatozoids are small and entirely like those of the other Hepaticæ.

Leitgeb ( ( 7$)$, v., p. I9) found in abnormal cases that the antheridia may arise superficially, as in the typical Hepaticæ. Lampa (I) describes a similar exogenous origin for the antheridium, but Howe (5) has questioned the accuracy of her statements, and thinks that the supposed antheridia were tubers, as Frau Lampa's figures do not agree with the structure of the typical antheridium. Whether this exogenous development of the antheridium is a reversion to a primitive condition is impossible to decide, but it is possible that such is the case.

At first the cell from which the antheridial complex arises is not separated from its neighbours by any space. About the time that the first divisions in it are formed, the young antheridial cells begin to round off and separate from the cells above them. With the growth of the surrounding cells this is increased, so that before the divisions in the separate cells begin, the group of papillate cells is surrounded by a cavity of considerable size. To judge by the readiness with which the walls of the cavity stain, it is probable that the 
separation of the cells is accompanied by a mucilaginous change in their outer layers.

The first account of the archegonium was given by Hofmeister, who, however, overlooked the peripheral cells and only saw the axial row. Later Janczewski (2) showed that Anthoceros did not differ essentially in the development of the archegonium from the other Hepaticæ, and his observations were confirmed by the later researches of Leitgeb and Waldner (2). The formation of archegonia does not begin until the older antheridia are mature, and very often, especially in $A$. Pearsoni, few or no antheridia were found on the plants with well-developed archegonia. After the formation begins, each dorsal segment gives rise to an archegonium, so that they are arranged in quite regular rows, in acropetal order. After the transverse wall by which the segment is divided into an inner and an outer cell is formed, the outer cell becomes at once the mother cell of the archegonium, much as in Aneura. In this cell next arise three vertical intersecting walls, by which a triangular (in cross-section) cell is cut out as in the other Hepaticæ. Sometimes it looks as if one of these walls was suppressed, but even in such cases the triangular form of the central cell is evident. The main difference between the archegonium at this stage in Anthoceros and the Hepatica lies in the complete submersion of the archegonium rudiment in the former. In this respect Aneura, where the base of the archegonium is confluent with the cells of the thallus, offers an interesting transition between the other Hepaticæ, where the base of the archegonium is entirely free, and Anthoceros.

The archegonium rudiment divides into two tiers as in the other Liverworts, and the peripheral cells divide longitudinally, and the neck shows the six vertical peripheral rows although it is completely sunk. Later, the limits of the neck become often hard to determine, although by later divisions the central cell is surrounded by a pretty definite layer of cells. The axial cell divides into two of nearly equal size, but the inner one soon increases in breadth more than the upper one. The latter divides again by a transverse wall into an outer cell corresponding to the cover cell of the ordinary hepatic archegonium, the other to the primary neck canal cell. The cells of this central row soon become clearly different from the other through their more granular contents. The lower cell grows much 
faster than the others and divicles into the egg cell and the ventral canal cell. The cover cell divides by a vertical wall into two nearly equal cells, and these usually, but not always, divide again, so that four cells arranged cross-wise form the apex of the archegonium. In $A$. fusiformis in nearly ripe archegonia I have sometimes been able to see but two of these cover cells, but ordinarily four are present. The neck canal cell divides first into two, and these then divide again, so that four cells are formed. This was the ordinary number in $A$. fusiformis. In a nearly ripe archegonium of $A$. Pearsoni five neck canal cells were seen, but in no cases so many as

A

B.

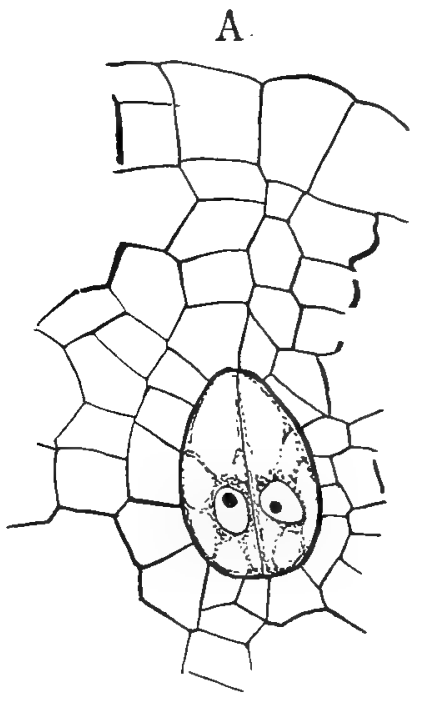

Frg. 69.-Anthoceros fusiformis. A two-celled embryo within the archegonium venter, $X 600 ; B, C$, two longitudinal sections of a four-celled embryo, $\times 600$.

Janczewski describes for $A$. lavis, where he says as many as twelve may be present.

If the earlier divisions in the archegonium of Anthoceros are compared with those of the other Hepatica, the most striking difference noticed is the separation of the cover cell. In the latter the first division of the axial cell separates the cover cell from an inner one, and by the division of the latter the primary neck canal cell is cut off from the central cell. In Anthoceros the neck canal cell is cut off from the outer, and not from the inner cell. 
As the archegonium approaches maturity the cover cells become very much distended and project strongly above the surrounding cells. In stained microtome sections their walls colour very strongly, showing that they have become partially mucilaginous. This causes them to separate readily, and they are finally thrown off, so that in the open archegonium no trace of them is to be seen. The walls of the canal cells and the central cell undergo the same mucilaginous change, but here it is complete, and before the archegonium opens the partition walls of the canal cells completely disappear, and the neck contains a row of isolated granular masses corresponding in number to the canal cells. The ventral canal cell is quite as large as the egg, which consequently does not nearly fill the cavity at the base of the open archegonium (Fig. 66, D) after the canal cells have been expelled. The egg did not, in any sections studied, show clearly a definite receptive spot, but appeared to consist of uniformly granular cytoplasm with a nucleus of moderate size. The upper neck cells in the open archegonium become a good deal distended, and the canal leading to the egg is unusually wide. Surrounding the central cavity the cells are arranged in a pretty definite layer.

Miss Lyon ((2), p. 288) states that she has frequently found archegonia in $A$. lavis, produced upon the ventral side of the thallus.

\section{The Sporophyte}

Hofmeister was the first to study the development of the embryo in Anthoceros, and described and figured correctly the first divisions, but his account of the apical growth, which he supposed was due to a single apical cell, and the differentiation of the archesporium, was shown by the careful investigation of Leitgeb $((7), v$.$) to be erroneous. The following account$ is based upon a large series of preparations of $A$. Pearsoni and $A$. fusiformis, which seem to agree in all respects. After fecundation the egg at once develops a cellulose wall and begins to grow until it completely fills the centre cavity of the archegonium. As it grows the uniformly granular appearance of the cytoplasm disappears, and large vacuoles are formed, so that the whole cell appears much more transparent. The granular cytoplasm is now mainly aggregated about the nucleus, which has also increased in size (Fig. 66, E). The 
first division wall is parallel with the axis of the archegonium and divides the embryo into two equal parts, in which the character of the cells remains much as in the undivided egg. Here too the granules are most abundant about the nucleus, from which radiate plates that separate the vacuoles. The next divisions are transverse and divide the embryo into two upper large cells and two lower smaller ones. The embryo at this stage is oval and more or less pointed above. In each of the four primary cells vertical walls arise that divide the embryo into octants, but the upper octants are decidedly larger than the lower. Next, in the upper cells, transverse walls are formed and the embryo then consists of three tiers of four cells each. Of these the cells of the upper tier are decidedly the larger. At this stage, in neither species examined by me, were any traces present of the projection of the basal cells figured by Leitgeb (1. c. P1. I.). As his drawings were made from embryos that had been freed from the thallus, probably with the aid of caustic potash, it is quite possible that this appearance was due in part at least to the swelling of the cell walls through the action of the potash. At any rate in microtome sections of both species in these early stages, the basal cells do not project in the least (Fig. 70, A). The next divisions are very uniform in the upper tier of cells, from which the capsule develops, but less so for the two lower ones. In the upper tier, seen in cross-section (Fig. 70, B I), a slightly curved wall running from the median wall to the periphery forms in each quadrant, which thus viewed is divided into an inner four-sided and outer three-sided cell. In the former a periclinal wall next forms, which cuts off an inner square cell (Fig. 70, D). In longitudinal section these periclinal walls are seen to be concentric with the outer walls of the cells, and to strike the median and quadrant walls at some distance below the apex of the sporogonium so as to completely enclose the central cells (Fig. 7o, C). By the formation of these first periclinal walls the separation of the columella from the wall of the capsule is completed, and this is not unlike what obtains in the sporogonium of many other Hepaticæ; but an essential difference must be observed. In the latter the central group of cells forms the archesporium; here these cells, as we shall see, take no part in spore formation. In the lower tiers of cells similar but less regular divisions occur (Fig. 70, D 2), 
and the outer cells begin to grow out into root-like processes which push down among the cells of the thallus and obviously serve the purposes of haustoria. Leitgeb states that the foot arises only from the lowest of the primary tiers of cells, but in most of my sections of the earlier stages the fact that the foot was composed of two distinct layers of cells, corresponding in position to the two lower tiers of cells in the embryo, was very obvious (Fig. 7o, E).
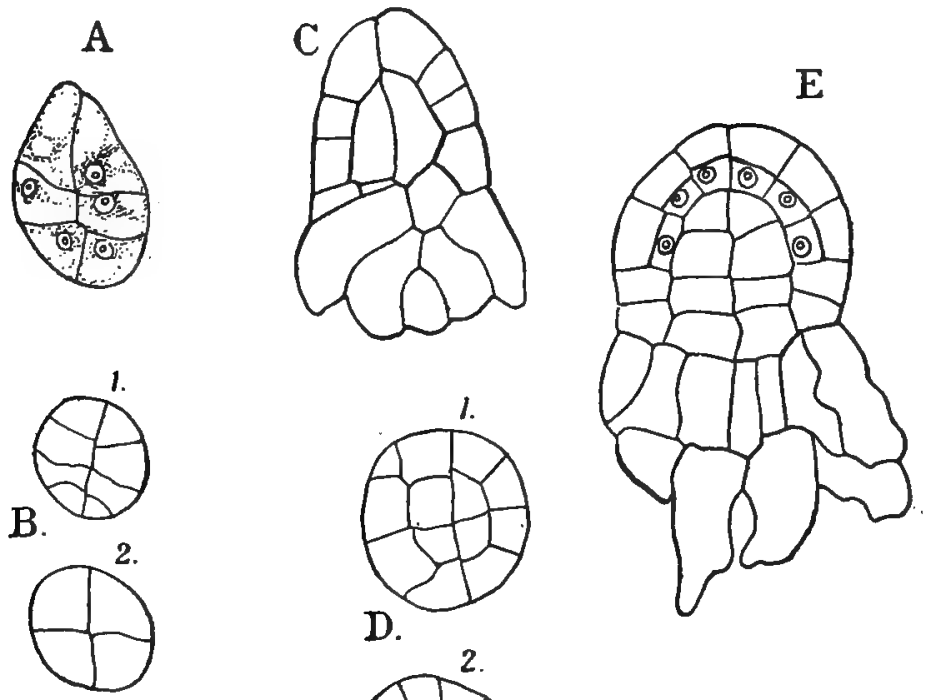

D.
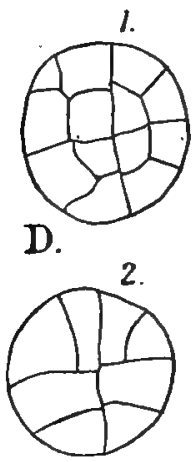

FiG. 7o.-Anthoceros Pearsoni. Development of the embryo $\times_{300} ; \mathrm{A}, \mathrm{C}, \mathrm{E}$, median longitudinal sections; $B$ and $D$, successive cross-sections of embryos of about the age of $\mathrm{A}$ and $\mathrm{C}$ respectively. In $\mathrm{E}$ the archesporium is differentiated.

The origin of the archesporium in Anthoceros was in the main correctly shown by Leitgeb, but I find that the extent of the archesporium is less than he represents. In Pl. I. Figs. 3 and Io of his monograph on the Anthoceroteæ, he figures the archesporium as extending completely to the base of the columella. A large number of sections were examined, and in no case was this found to be so. Instead, it was only from the cells surrounding the upper half of the columella that the archesporium was formed. Previous to the differentiation of 
the archesporium the four primary cells of the columella divide by a series of transverse walls until there are about four cells in each row. Radial walls also form in the outer cells so that their number also increases, and the young capsule consists of the central columella composed of four rows of cells and a single layer of cells outside. The archesporium now arises by a series of periclinal walls in the peripheral cells of the upper half only of the capsule, and is thus seen to arise from the peripheral cells of the capsule, and not from the central ones. Fig. 70, E shows a longitudinal section of the sporogonium at this stage. Three parts may be distinguished-the foot, the capsule, and an intermediate zone between. The latter is important, as it is from this that the meristematic part of the older sporogonium is formed. With the separation of the archesporium the apical growth ceases, and the future growth is intercalary.

In the capsule cell divisions proceed rapidly in all its parts. The original four rows of cells forming the columella increase to sixteen, which is the normal number in the fully-developed sporogonium. The archesporium, by the formation of a second series of periclinal walls, becomes two-layered, and the wall outside the archesporium becomes about four cells thick, the outermost layer forming a distinct and well-developed epidermis.

The foot grows rapidly in size, but the divisions are very irregular, and finally it forms a large bulbous appendage to the base of the sporogonium. The cells are large and the outer ones develop still further the root-like character of those in the young foot. The tissues of the thallus about the base of the sporogonium grow rapidly with it, and the connection between the surface cells of the sporogonium foot and the adjacent cells of the thallus is very intimate.

The subsequent growth of the capsule is entirely dependent upon the activity of the zone of meristem at its base. This divides very actively, and the divisions correspond exactly with the primary ones in the young embryo, so that the completed portions of the older parts of the capsule are continuous with the forming tissues at the base. A series of cross-sections at different points, compared with a median longitudinal section, shows in a most instructive way the gradual development of the different parts of the mature capsule (Fig. 72). The centre 
of the sporogonium is occupied by a columella composed of sixteen rows of cells, which in cross-section form a nearly perfect square. At the base these cells are thin-walled and show no intercellular spaces, but farther up their walls begin to thicken and the rows gradually separate until in the upper part the columella has somewhat the appearance of a bundle of isolated fibres. The archesporium is constantly growing from below, and the new cells are cut off from those surrounding the

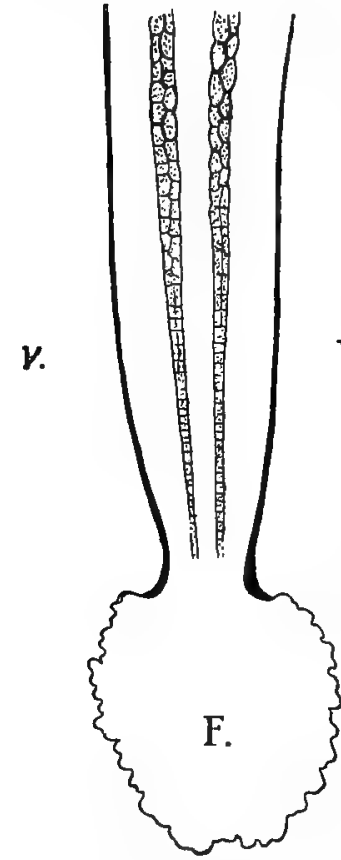

Fig. 71.-Anthoceros Pear. soni. Median longitudinal section through the base of the sporogonium. The archesporium is shaded. F, Foot; $v, v$, basal sheath of calyptra, $X$ Ioo. columella in the same way as at first. The archesporium, as well as the columella, can be traced down nearly to the base of the capsule, and its cells are very early recognisable both by their position and by their contents. At first but one cell thick, the archesporium soon becomes double, but does not advance be$v$ yond this condition. As the archesporium is followed from the base towards the apex of the capsule the cells begin to show a differentiation. $U_{p}$ to the point where the archesporium becomes divided into two layers the cells appear alike; but shortly after this their walls begin to separate, and two distinct forms are recognisable, arranged with much regularity in many cases, although this arrangement is not invariable. Pretty regularly alternating are groups of oval, swollen cells, with large nuclei and abundant granular cytoplasm, and much more slender ones, that may undergo secondary longitudinal divisions. The latter have smaller nuclei and more transparent contents. Examination higher up shows that the former are the spore mother cells, the others the elaters, which here have the character of groups of cells, and do not develop the spiral thickenings found in most Hepaticæ. As these two sorts of cells grow older they separate completely, and the spore mother cells become perfectly globular. The sterile cells remain more 
or less united, and form a sort of network in whose interstices the spores lie.

The development of the spores can be easily tollowed, at least in most of the details, in fresh material, and on this account it was among the first plants in which cell division was studied. The mother cells in all stages can be found in the same sporogonium, and on account of their great transparency show the process of cell division very satisfactorily. The nucleus, however, is small, and its behaviour during the cell division is not so easy to follow. The mother cell, just before division, is filled with colourless cell sap, and the cytoplasm is confined to a thin film lining the cell wall. This cytoplasmic layer is somewhat thicker on one side, and here the nucleus is situated (Fig. 73, A). Lying close to the nucleus is a roundish body, of granular consistence and yellowish green in colour. This is a chloroplast, which at this stage is less deeply coloured than later. The chloroplast contains a number of granules, some of which are starch. The cell increases rapidly in size, and the nucleus, together with the chloroplast, move away from the wall of the cell toward the centre, where they are suspended by cytoplasmic threads. The chloroplast next divides into two equal portions, which move apart (Fig. 73, B), but remain connected by the cytoplasmic filaments. They approach again, and each dividing once more, the four resulting chloroplasts remain close together with the nucleus, in the centre of the cell.

Davis (I) has made a very complete study of the spore division in $A$. levis. In this species the archesporium is less massive than in $A$. Pearsoni or $A$. fusiformis, and the arrangement of the sporogenous and sterile cells less regular. Davis found that the sporophytic nuclei had regularly eight chromosomes, those of the gametophyte four.

Owing to the small amount of chromatin in the nucleus, the karyokinetic figures are small and the changes difficult to follow satisfactorily. Enough can be easily made out, how. ever, to show that the process is in no way peculiar. There is first a nuclear spindle of the ordinary form, and the resulting nuclei assume the resting stage before dividing again. Each then divides, and the four nuclei move to points equidistant from each other, and which are already occupied by the four chloroplasts. After this is accomplished, cell walls arise 


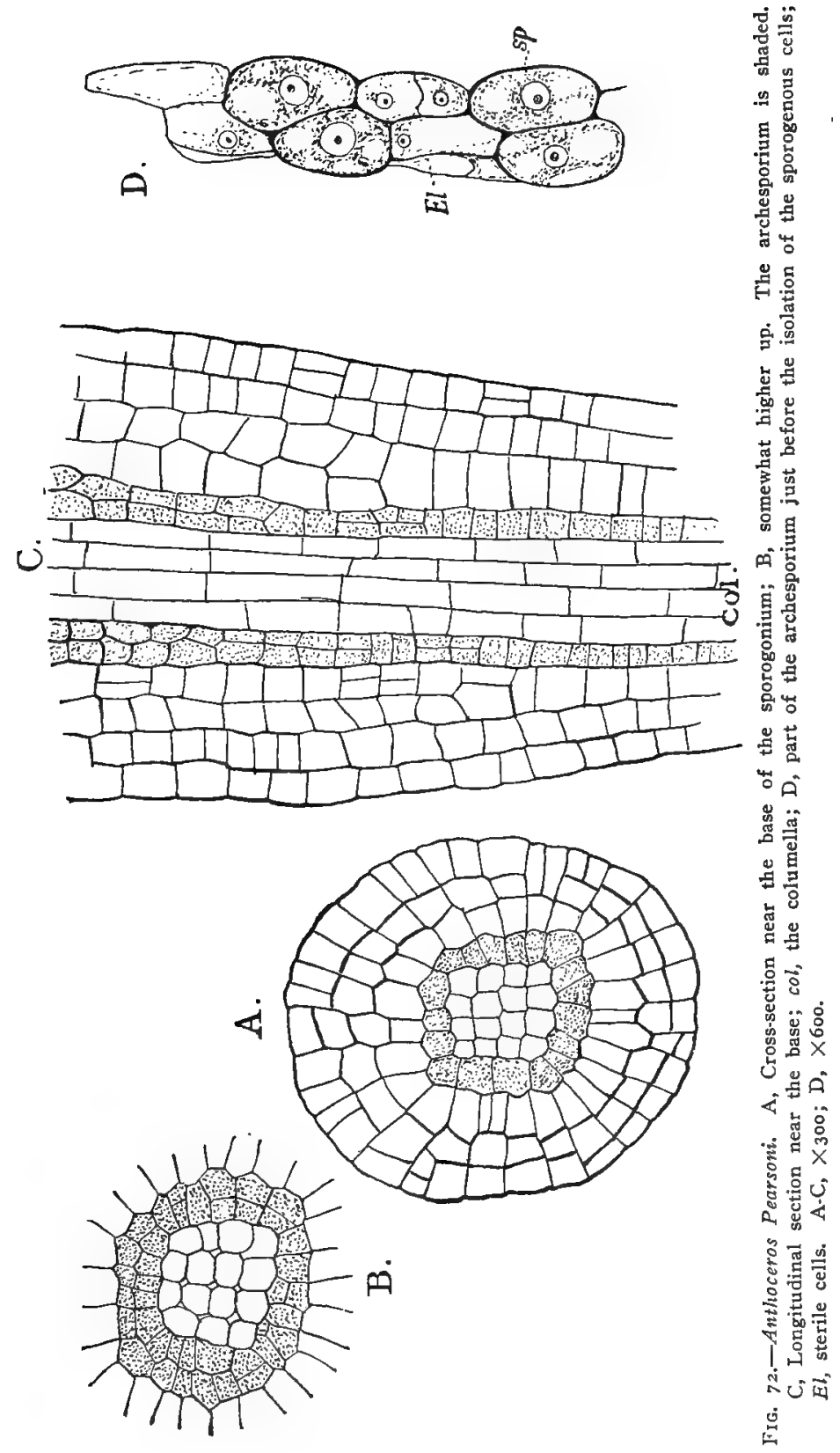


simultaneously between the four nuclei dividing the mother cell into four tetrahedral cells, - the young spores. The wall of the mother cell becomes thicker, and in the later stages swells up on being placed in water, so that it interferes a good deal with the study of the spores in the fresh condition. As the spores ripen they develop a thick exospore, which is yellow in colour and irregularly thickened in $A$. Pearsoni, and in $A$. fusiformis black and covered with small tubercles. The chlorophyll disappears and the spore becomes filled with oil and other food materials. The spores remain together until nearly ripe. The elaters, if this name can properly be applied to the sterile cells, at maturity consist of simple or branching rows of cells, which in some cases arise from the division of a single one; but more commonly, at least in $A$. Pearsoni, where they branch, it is probable that they are to be looked upon as merely fragments of the more or less continuous network of sterile cells. The contents mainly disappear from the older elaters, and their walls become thick and
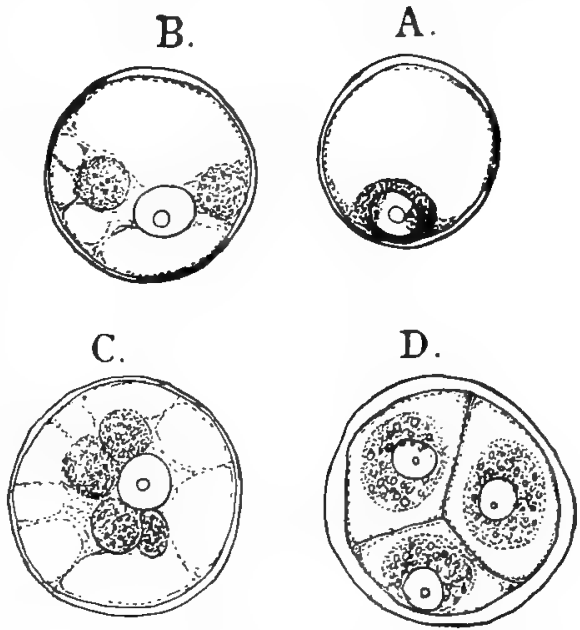

Fig. 73.-Spore division in A. fusiformis; optical sections of living cells, $\times 600$. in colour like the wall of the spores. In $A$. fusiformis they are longer and more symmetrical than in $A$. lcevis, and in one group of the genus, according to Gottsche (2), the elaters, which consist of a row of five to six cells, have a distinct spiral band as in Dendroceros. Leitgeb thinks, however, that this group is more nearly related to the latter genus than to Anthoceros proper, inasmuch as in addition to the peculiar elaters the epidermis of the capsule has no stomata, which are always present in typical species of Anthoceros.

If the epidermis from the young capsule is examined it is seen to be composed of elongated narrow cells much like those 
in the epidermis of elongated leaves of Monocotyledons. In the older parts some of these cells cease to elongate, and become more nearly oval (Fig. 75, A). These are the young stomata, and exactly as in the vascular plants, each divides longitudinally by a septum which later separates in the middle and forms the pore surrounded by its two guard cells. The walls of the other epidermal cells become much thickened and distinctly striated. Each epidermal cell contains two large chloroplasts like that in the cells of the gametophyte, and between the cells are well-developed air-chambers communicating with the stomata, so that there is here a typical assimilative system of tissues.

The doubling of the chloroplast in the cells of the sporophyte has been noted by Schimper (A. F. W. Schimper (2)), and

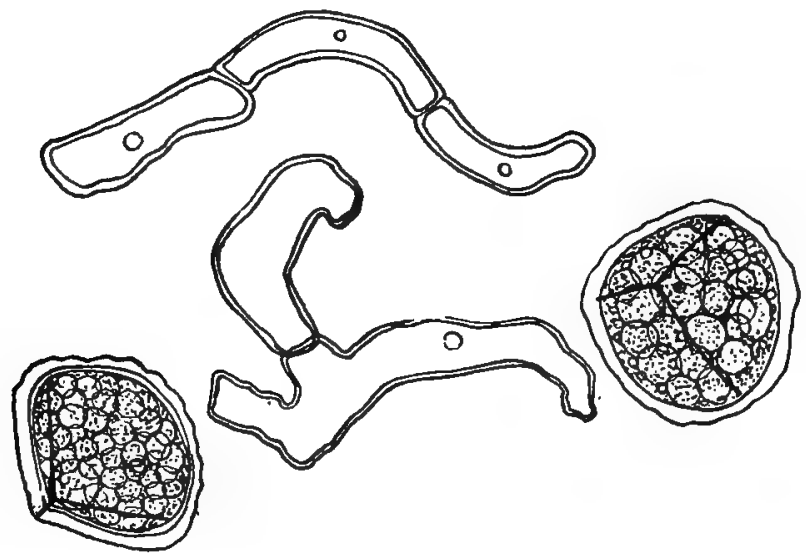

FIG. 74-Ripe spores and elaters of A. Pearsoni, $\times 600$.

this was observed by the writer in both $A$. fusiformis and $A$. Pearsoni.

About the base of the growing sporogonium is a thick tubular sheath representing in part the calyptra of the other Hepaticæ, but involving, besides the archegonium venter, also the surrounding tissue of the gametophyte. This sheath keeps pace with the growth of the sporophyte for a long time, but finally the sporogonium grows more rapidly and projects far beyond it, and this remains as a tube surrounding its base. The growth of the sporogonium continues as long as the gametophyte remains alive, and in $A$. fusiformis is often 6 
centimetres or more in length, and reaches nearly this length before the first spores are ripe and the capsule opens. This it does by splitting at the top into two equal valves between which the dried-up columella protrudes. The split deepens as the younger spores ripen, and may finally extend nearly to the base. It is quite possible, although this point was not investigated, that the line of dehiscence corresponds to the primary vertical wall in the embryo, as is the case in the Jungermanniaceæ.

The germination of the spores $^{1}$ has hitherto been observed only in $A$. lavis. A study of the germination in $A$. fusiformis shows a general correspondence with the results of other observers, but certain points were brought out that do not seem to have been observed in $A$. lavis. The spores of $A$. fusiformis are protected by a perfectly opaque black exospore,

B.
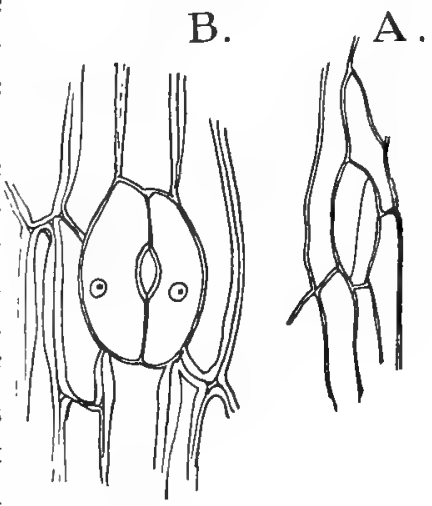

Fig. 75.-A, Young : B, fully developed stoma from the epidermis of the sporogonium of $A$. Pearsoni, $\times 250$. which is covered with small spines or tubercles. These spores will not germinate readily when fresh, but after resting for a few months grow freely. As in other similar spores, the exospore is ruptured along the three ridges upon the ventral side ( $i$. e., that with which it was in contact with the other spores of the tetrad), and through this cleft the endospore protrudes as a papilla which sometimes grows into a very long germ tube, or more commonly divides before it reaches a great length. Into this tube passes the single chromatophore which, during the early period of germination, has resumed its green colour, and with it the oil drops and other contents of the spore. A good deal of variation was observed here in the first divisions, as is the case in A. laevis. The first division wall is, in most cases at least, transverse, and is usually followed by a second similar one, before any longitudinal walls appear. Then in the end cell two intersecting walls and the formation of four terminal quadrant cells are often seen (Fig. 76, D), as in other Hepatica. Variations from this type are often met

${ }^{1}$ Hofmeister (I); Grönland (I); Leitgeb (7), vol. v. p. 29. 
with, and some of these are shown in the figures. Very commonly a second cell is cut off by an oblique wall from the germ tube subsequent to the first transverse wall, but this does not, at least in the early stages, develop into a rhizoid, the first rhizoid being met with only after the young plant has become a cell body of considerable size (Fig. 77).

Whether the young plant regularly grows from a single apical cell is difficult to say, but it seems probable, and numerous forms like Fig. 76, B were encountered where there certainly seemed to be a two-sided apical cell, such as occurs so often in

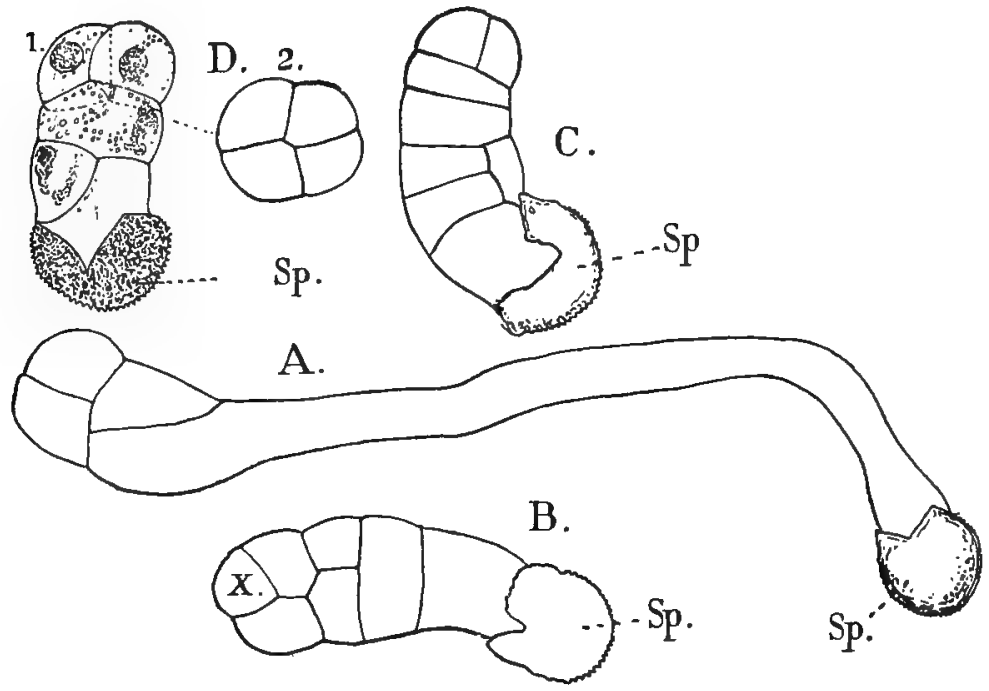

FIG. 76.-Anthoceros fusiformis. Germination of the spores, $\times 250$. A shows a form with very long germ tube; in B there seems to be a definite apical cell; Fig. D, 2 , is an apical view of $D, I$.

other Hepaticæ. At a later stage (Fig. 77, B) a single apical cell of the form found in the mature thallus is unmistakably present. By this time the marginal lobes that give this species its peculiar crimped appearance begin to develop. They arise close to the growing point, and grow rapidly beyond it, but do not show any definite apical growth. The plant at this stage has a striking resemblance to the prothallium of Equisetum. With the appearance of the marginal lobes, the first of the mucilage slits appears upon the vental surface (Fig. 77), and from time to time surface cells grow out into the delicate 
rhizoids, and a little later the first dichotomy of the growing point takes place. Up to this time the young plants appeared entirely free from Nostoc, but soon after they were found to be infected, which no doubt was connected with the formation of the mucilage slits through which the Nostoc enters the thallus.

In several species of Anthoceros, especially those inhabiting regions with a marked dry season, tubers are developed by means of which the plants are perennial. Howe (3) finds such tubers developed in $A$. phymatodes, of California, and they are found in $A$. dichotomus, of Southern Europe, and in A. tuber-
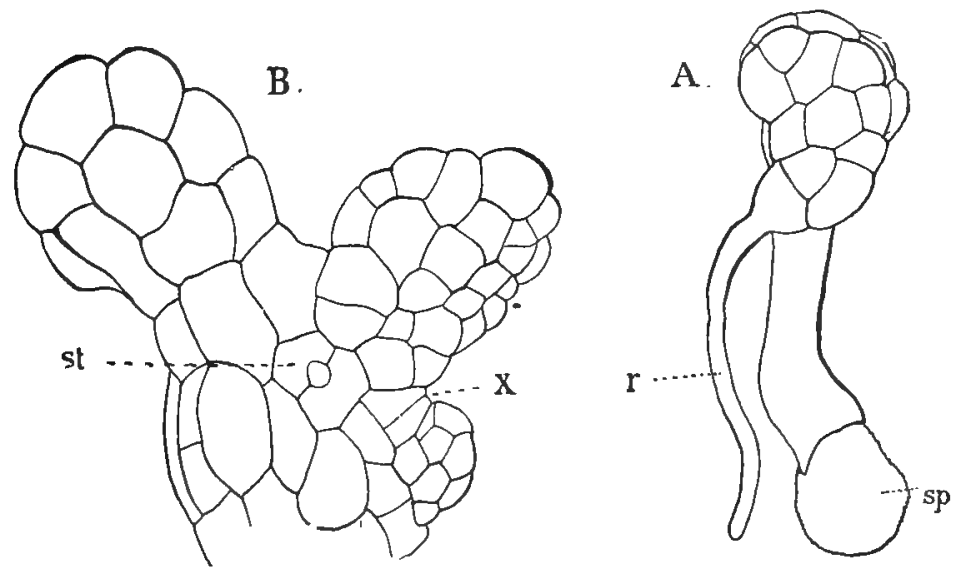

FIG. 77.-Anthoceros fusiformis. A, Young plant showing the first rhizoid $(r) ; \mathrm{B}$, upper part of an older one with the first mucilage cleft $(s t) ; x$, the growing point, $\times 215$.

osus of Australia (see also Goebel (22), p. 293). The structure of these tubers has been studied by Ashworth (I), in A. tuberosus.

\section{Dendroceros}

Dendroceros includes about a dozen species of tropical Liverworts, which are distinguished at once from Anthoceros by the very characteristic form of the thallus. This has a massive midrib, projecting below, but the rest of the thallus is but one cell thick and forms lateral wings which are much folded and lobed, so that the aspect of the plant is somewhat like a Fossombronia. As in Anthoceros, some species have a perfectly com- 
pact thallus without intercelluar spaces ( $D$. cichoraceus), while in others these are very much developed and the thallus has a more or less spongy texture, e. g., D. Javanicus. The development of the thallus and sporogonium has been studied by Leitgeb ( ( 7$)$, v., p. 39), and in the main corresponds very closely to Anthoceros. A difference may be noted, however, in some details. Thus the form of the apical cell is like that of Pellia epiphylla, where the inner segments extend the whole depth of the thallus, and the division into dorsal and ventral segments is secondary. The formation of the wings begins near the apex and is the result of the growth of the marginal cells, which project strongly and divide rapidly by vertical walls only. The walls of the cells are thickened at the angles, and the surface view is curiously like a cross-section of the collenchyma of many vascular plants. As in Anthoceros mucilage slits are formed, sometimes on both surfaces of the thallus, and through these the plant is infected with Nostoc, as in the other Anthocerotes. In Dendroceros the Nostoc colonies are very large and cause conspicuous swellings upon the thallus. All the species of Dendroceros that have yet been examined are monœcious.

The antheridia of Dendroceros (Campbell (20)), which are larger than those of the other two genera, are developed singly in strict acropetal succession, forming a row on each side of the midrib. The youngest ones occur very near the apex of the shoot. The mother cell arises exactly as in Anthoceros and Notothylas, and the periclinal division of the cell lying outside it takes place very early, so that almost from the beginning there are two layers of cells above the antheridial chamber. In all the younger stages met with by the writer, the antheridium lay horizontally nearly parallel with the axis of the shoot, and was attached to the back of the antheridal chamber, instead of at its base, as in the other genera. (Fig. 78, D.)

The first division in the antheridium is transverse, and separates the upper part from the stalk. The next divisions may be alike in both of these cells, being vertical walls intersecting so as to divide both cells longitudinally into four similar cells. In the stalk, however, one of these divisions may be suppressed, and in such cases, the stalk has but two rows of cells instead of four. In the ripe antheridium the stalk becomes very long, and is coiled up in the large antheridial chamber. 
IV.

The archegonium of Dendroceros is much like that of the other genera, perhaps more nearly approaching that of Anthoceros.

The embryo of Dendroceros resembles more nearly that of Anthoceros than it does Notothylas. The archesporium is less

$\cdot \mathbf{A}$
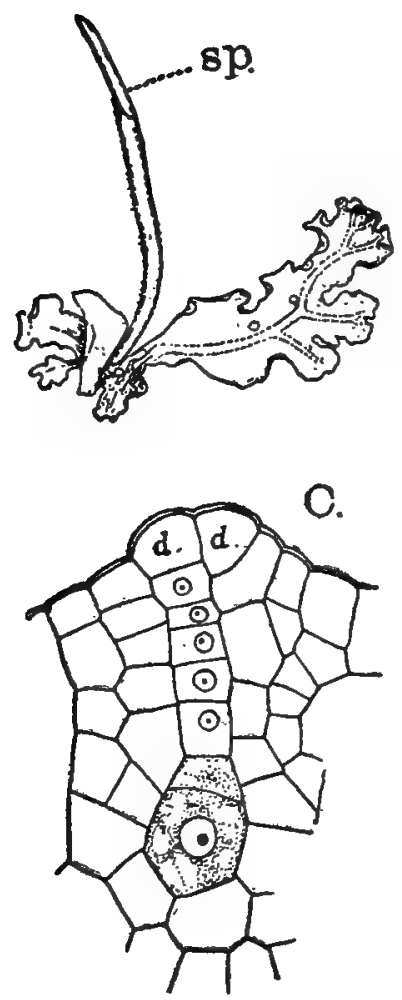

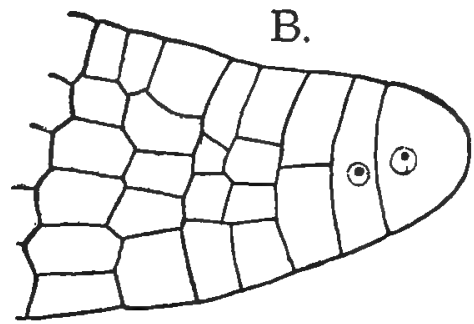

D.
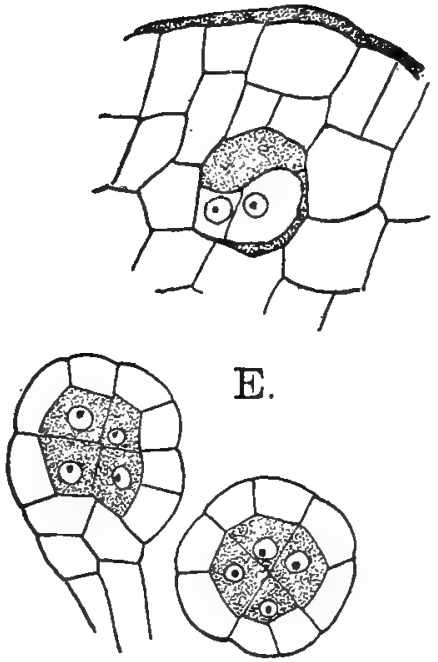

a.

Fic. 78.-Dendroceros Breutelii. A, Thallus with sporophyte attached, $\times 4 ; \mathbf{B}$, apex of the thallus $\times 600 ; C$, archegonium, $\times 600 ; D, E$, young antheridia, $\times 600$.

developed than in either species of Anthoceros that were studied by the writer, showing only an imperfect division into two layers when seen in section. No stomata are developed in the epi- 
dermis of the mature sporophyte, which otherwise closely resembles that of Anthoceros.

The spores may remain undivided, as in Anthoceros, or in some species, e.g., D. crispus, they become multicellular before they are discharged. In this respect these species of Dendroceros recall Conocephalus and Pellia, where germination begins before the spores are set free.

\section{Notothylas}

The third genus, Notothylas, is of especial interest, because it was largely upon the results of his investigations upon this


FiG. 79.-Dendroceros Breutelii. A, section of young sporophyte, $X_{250}$; , section of mature sporophyte showing spores and elater-like, sterile cells; $C$, single elater, $X_{250}$.

plant that Leitgeb ( $(7)$, v., p. 39) based his theory of the close relationship of the Anthocerotes and Jungermanniales. All of Leitgeb's observations on the young capsule were made from herbarium material, and, as he himself admits, were in all cases embryos that had not fully developed. The writer has made a very complete examination of the commonest American species, $N$. orbicularis (valvata), and the results of the study of the development of the sporogonium differ so much from those of Leitgeb that they will be given somewhat in detail. Mottier 
(2) has also studied this species, and his results agree entirely with those of the writer.

The thallus much resembles a small Anthoceros, and sections through it show that in its growth and the development and structure of the sexual organs there is close correspondence. The thallus contains very large lacunæ, which are formed in pretty regular acropetal order, and vertical sections show these large cavities increasing regularly in size as they recede from the apex. Similar but less regular lacunæ occur in $A$. fusiformis. The antheridia arise as in Anthoceros, endogenously. The youngest stage found is shown in Fig. 80, A. Here evi-
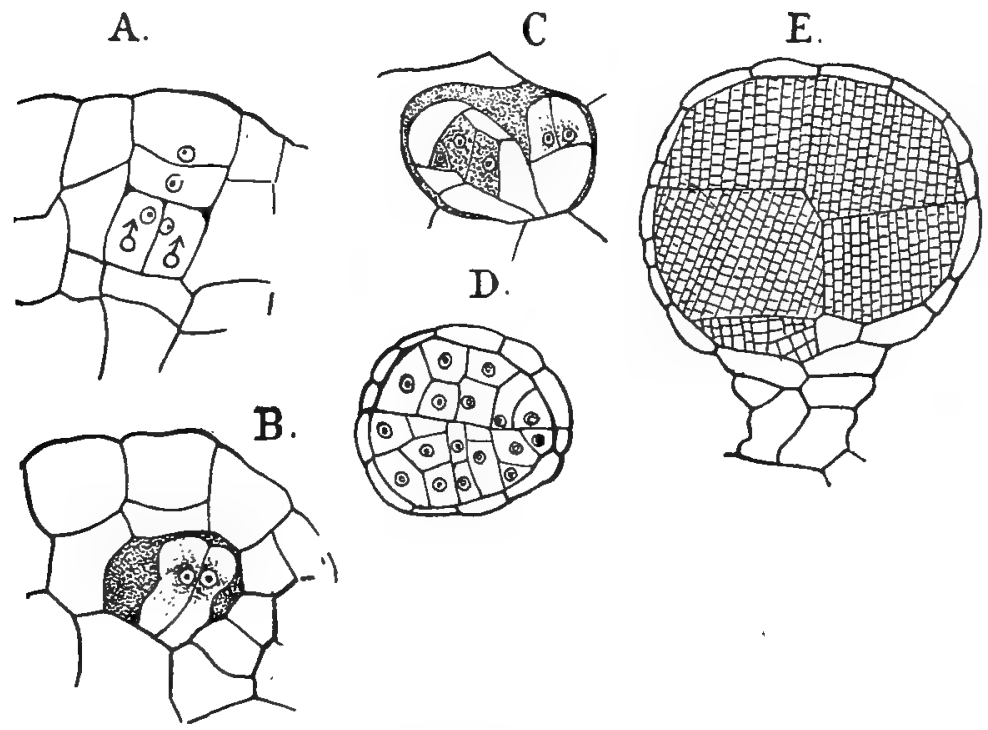

Fug. 80.-Notothylas orbicularis. Development of the antheridium. D, cross-section, the others longitudinal sections; E, nearly ripe antheridium, $X_{3} 00$, the other figures $\times 600$; $\delta$, A, the primary antheridial cells.

dently the young antheridia $\left({ }^{*}\right)$ have been formed by the longitudinal division of a single hypodermal cell, whose sister epidermal cell has divided again by a transverse wall to form the outer wall of the antheridial cavity (Figs. A, B). The commonest number of antheridia formed is four.

Less regularity is found in the next divisions than in Anthoceros, although in the main they are the same. This is observable both in longitudinal and cross-sections (see Fig. 80, D). 
The full-grown antheridium is more flattened than in either species of Anthoceros examined by me, and the stalk shorter and thicker, but otherwise closely resembles it, although the extremely symmetrical arrangement of the cells, especially of the wall, is much less noticeable.

The archegonia correspond very closely, both in position and structure, with those of the other genera, the most marked peculiarity being the more nearly equal diameter of the cover cell and central cell, and a corresponding increase in the breadth

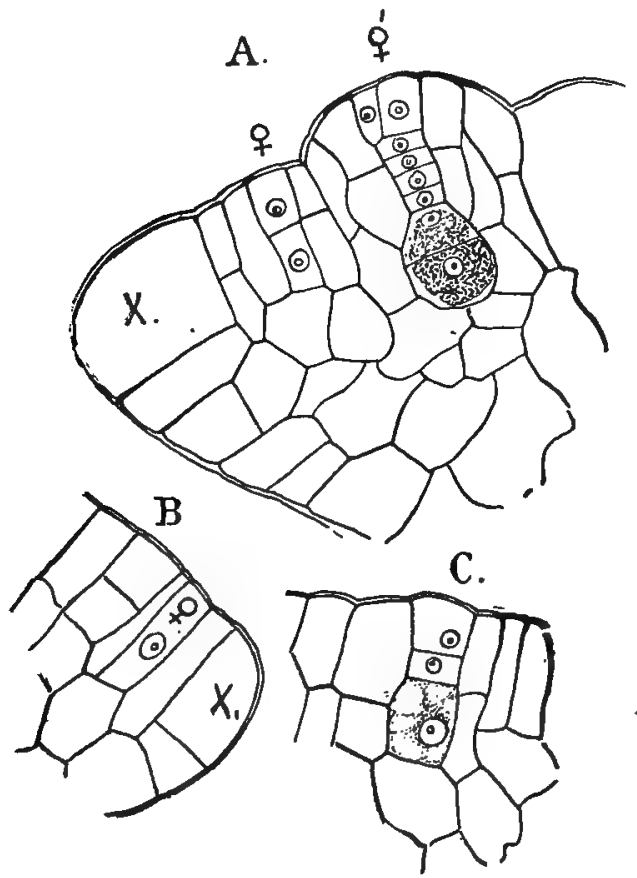

FIG. 81.-Notothylas orbicularis. Development of the archegonium, $\times 600 ; x$, the apical cell.

of the neck canal cell. Subsequently the central cell becomes much enlarged and the appearance of the fully-developed archegonium is very much like that of Anthoceros (Fig. 8I, A). As in $A$. fusiformis, the usual number of neck canal cells seems to be four, and in no case did the number exceed five. The cover cells were four in number in all the archegonia studied, 
and are larger than in Anthoceros. As in that genus, they are thrown off when the archegonium opens.

The youngest embryo found was composed of four cells, and presented quite a different appearance from the corresponding stage in Anthoceros. It is impossible from this stage to tell whether the first wall in the embryo is vertical or transverse. This embryo consisted of four nearly equal quadrants, instead of having the two upper cells larger than the lower ones. By comparison with the older stages there is little doubt that here the first transverse wall separates the foot from the capsule, as in Sphcrocarpus, and that the upper cell develops directly into the capsule instead of the latter being determined by the second transverse walls. In the next youngest stages
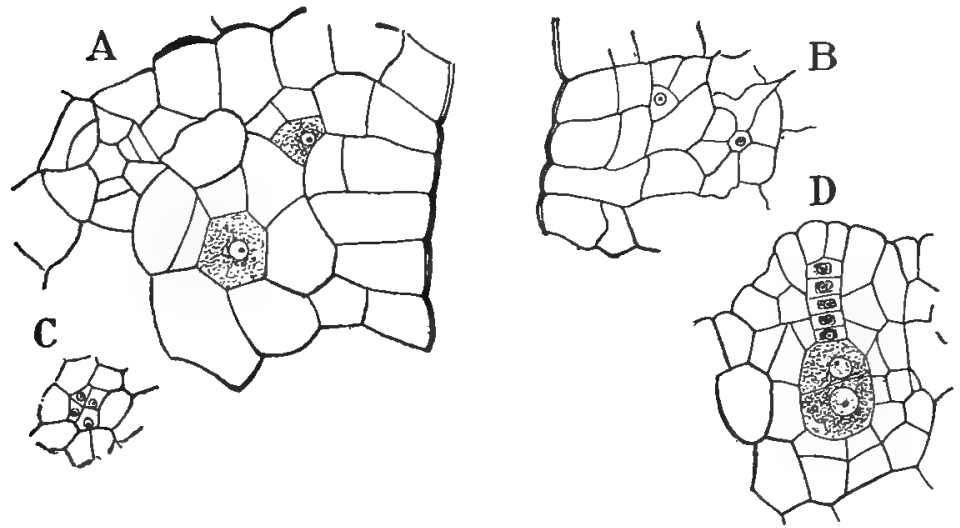

FIG. 82.-Notothylas orbicularis. A, B, Horizontal sections of the growing point with young archegonia; C, cross-section of the apex of an archegonium, showing the arrangement of the cover cells; $\mathrm{D}$, longitudinal section of a nearly ripe archegonium, $\times 400$.

found (Fig. 83, B) the archesporium was already differentiated. A comparison of this with the corresponding stage of Anthoceros shows conclusively that the two are practically identical in structure. The columella, evidently formed as in Anthoceros, and as there made up of four rows of cells, is surrounded by the archesporium cut off from the peripheral cells. Leitgeb's surmise that the columella is a secondary formation is, therefore, for $N$. orbicularis at least, entirely erroneous, and it is extremely likely that when normal specimens of the other species are examined from microtome sections, in the young 
stages at least, a similar columella will be found. The single embryo that Leitgeb (1. c. P1. IV., Fig. 77) figures of N. orbicularis (valvata) is at once seen to be abnormal, and as his conclusions were drawn from a study of similar dead embryos in the other species, they cannot be accepted without more satisfactory evidence. While in the main corresponding to the embryo of Anthoceros there are some interesting differences which are closely associated with the structure of the older sporogonium. The foot is smaller than in Anthoceros and derived only from the lowest tier of cells. The columella is decidely smaller, and the archesporium, as well as the young sporogonium wall, relatively much thicker. As in Anthoceros, the archesporium does not extend to the foot, but is separated by the zone of
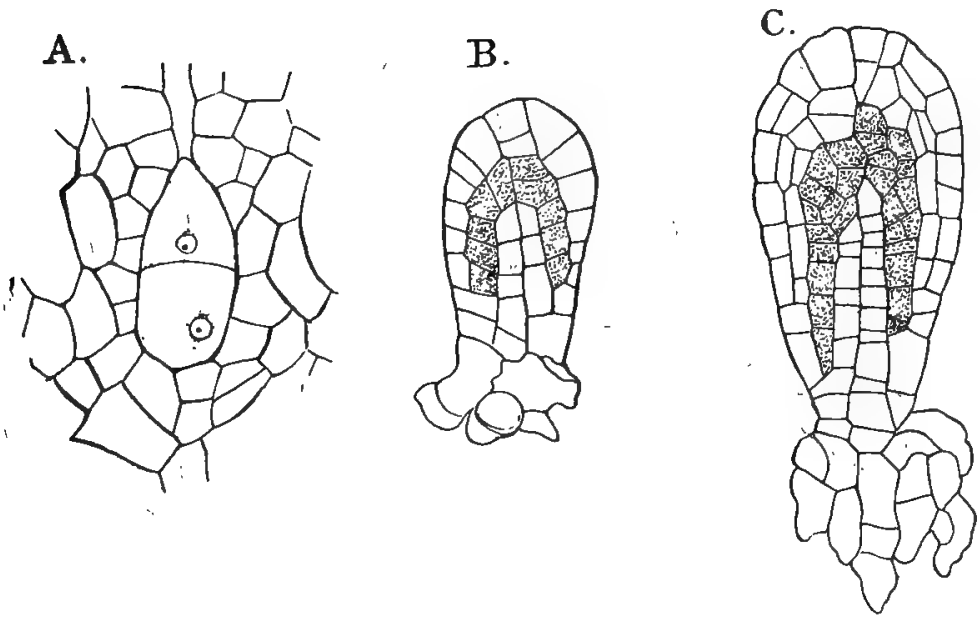

Fig. 83.-Notothylas orbicularis. A, Four-celled embryo; B, C, older embryos, in longitudinal section. The archesporial cells are shaded. A, $\times_{450} ; \mathrm{B}, \mathrm{C}, \times_{225}$.

cells which there give rise to the meristem at the base of the capsule. The form of the embryo is different too. It is pearshaped and more elongated than in Anthoceros.

As the embryo develops these differences become more apparent and others arise. Fig. 83, C shows a stage where the division of the archesporial cells has begun, and it is at once apparent how much more conspicuous they are. It is seen too that the outer cells of the upper part of the capsule are also dividing actively, and that, compared with Anthoceros, the 
apical part of the capsule retains its meristematic character for a much longer period. Corresponding with this, the growth at the base of the capsule is much less marked. The divisions in the archesporium are much more active than in Anthoceros, and the apical part of the capsule retains its meristematic character for a much longer period. Corresponding with this, the growth at the base of the capsule is much less marked. The divisions in the archesporium are much more active than in $A n$ thoceros, and also less regular. At first divisions occur in the upper portion in all directions, so that above the columella there is a mass of archesporial tissue much thicker than that below, and occupying very much more space than the corresponding tissue in Anthoceros. Longitudinal sections through the basal part of the older sporogonium show an arrangement of tissues similar to those in Anthoceros, but there are differences corresponding to those in the young stages. The foot (Fig. 84, A) is much smaller and flatter, and sometimes shows a very regular structure. The central part is composed of a compact mass of rather large cells, between which and the base of the capsule is a narrow zone of meristematic tissue. The superficial cells do not always grow out into the root-like processes found in Anthoceros and Dendroceros, but may remain short and project but slightly. The cells are characterised by abundant granular cytoplasm and conspicuous nuclei, showing that they are probably not only absorbent cells, but also elaborate the food materials taken in from the gametophyte. The gradual transition of the differentiated tissues above into the meristem at the base, is precisely as in Anthoceros, and sections at that point in the two genera can scarcely be distinguished from one another. The columella (in longitudinal section) in both shows four parallel rows of cells, outside of which lies the single row of archesporial cells, and four rows of cells belonging to the wall of the capsule.

As the section is examined higher up, however, there are marked differences, especially in the divisions of the archesporium. The first divisions in the archesporium of Notothylas are periclinal, and for a short distance it is two-layered, as it is permanently in Anthoceros; but still further up it widens verv rapidly by the formation of repeated periclinal walls, and soon comes to be much thicker than either the columella or the capsule wall. A further study of the developing archesporium shows 


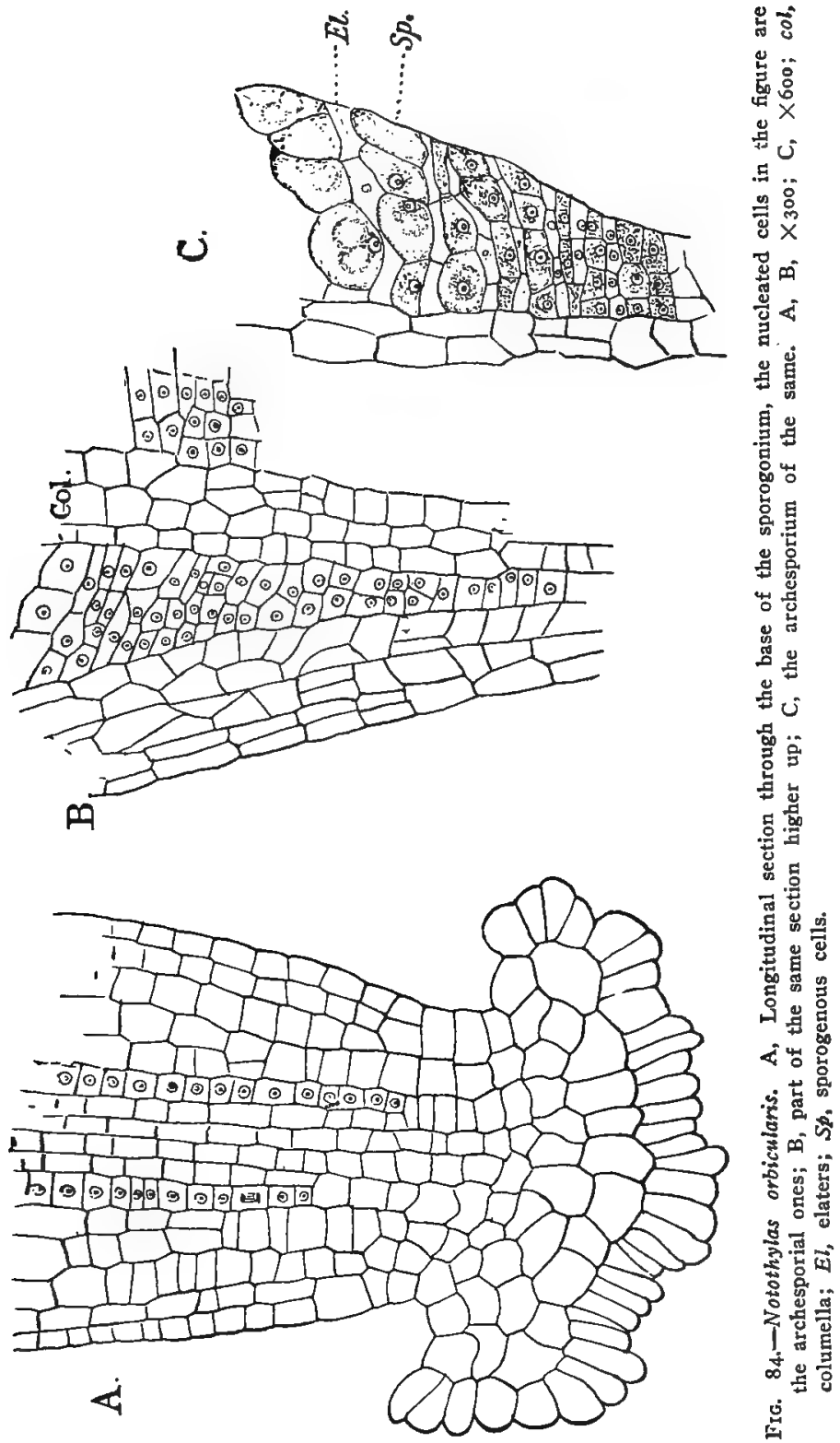


that the divisions occur with a good deal of regularity. The archesporial cells are divided by alternating vertical and transverse walls into four layers of cells instead of two, as in Anthoceros, and these cells are arranged in regularly placed transverse rows. At first the cells appear alike, but later there is a separation into sporogenous and sterile cells as in Anthoceros. Each primary transverse row of cells becomes divided into two. The upper row grows much faster, and its cells become swollen and the cytoplasm more granular, while the lower row has its cells remaining flattened and more transparent, $i$. e., there is a separation of the archesporium into alternate layers of sporogenous and sterile cells as in Anthoceros, but here the number of cells is double that in the latter, and the longer axis of the cells is transverse instead of vertical. In the portion of the archesporium above the columella these alternate layers of spore mother cells and sterile cells extend completely across, and Leitgeb has correctly figured this, although he probably was mistaken in assuming that this arrangement extended to the base of the capsule.

The further development of the capsule is much like that of Anthoceros, but the division of the chloroplast takes place before the spore mother cells are isolated, and the primary chloroplast is evident almost as soon as the sporogenous cells are recognisable as such. The cells of the columella do not become as elongated as in Anthoceros, and develop thickenings much like those of the sterile cells of the archesporium; and it was this partly that led Leitgeb to the conclusion that even where a definite columella was present it probably arose as a secondary formation in the archesporium, similar to the formation of the axial bundle of elaters in Pellia, and that in Notothylas as in the Jungermanniales, the archesporium arose from the inner of the cells formed by the first

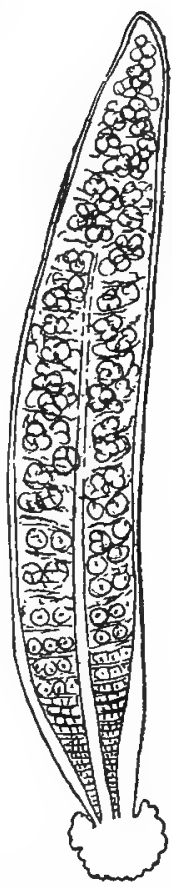

FiG. 85. - Longitudinal section of a nearly ripe sporogonium of $N$. or bicularis, $\times 50$. periclinal walls, and not from the outer ones. That this is not true for $N$. oribicularis is shown beyond question from sections of both the older and younger sporogonium, and it would be 
extremely strange if the other species should differ so radically from this one as would be the case were Leitgeb's surmise correct.

The wall of the capsule does not develop the assimilative apparatus of the Anthoceros capsule, and stomata are completely absent from the epidermis. The inner layers of cells are more or less completely disorganised, and they probably serve to nourish the growing spores, which here, of course, are correspondingly more numerous than in Anthoceros. As in the latter the sterile cells from a series of irregular chambers in which the spores lie. At maturity these sterile cells separate into irregular groups. Their walls are marked with short curved thickened bands, yellowish in colour like the wall of the ripe spores. At maturity the capsule projects but little beyond its sheath, and opens by two valves. In some species, $e . g ., N$. melanospora, the capsule often opens irregularly.

\section{The Evolution of the Anthocerotes}

The Anthocerotes form a most interesting series of forms among themselves, but are also of the greatest importance in the study of the origin of the higher plants. Unquestionably Notothylas represents the form which most nearly resembles the other Liverworts, but until the other species are investigated further we shall have to assume that the type of the sporogonium is essentially different from that of the lower Hepaticæ, and corresponds to that of the other Anthocerotes. The primary formation of the columella and the subsequent differentiation of the archesporium occur elsewhere only in the Sphagnaceæ. From Notothylas, where the archesporium constitutes the greater part of the older sporogonium, and the columella and wall are relatively small, there is a transition through the forms with a relatively large columella to Dendroceros, where the spore formation is much more subordinated and a massive assimilative tissue developed. In Notothylas the secondary growth of the capsule at the base, while it continues for some time, is checked before the capsule projects much beyond its sheath. In Dendroceros the growth continues much longer, although it does not continue so long as in Anthoceros. The assimilative system of tissue in the latter is finally completed by the development of perfect stomata, and the growth of the 
capsule is unlimited. All that is needed to make the sporophyte entirely independent is a root connecting it with the earth.

\section{The Inter-relationships of the Hepatice}

From a review of the preceding account of the Liverworts, it will be apparent that these plants, especially the thallose forms, constitute a very ill-defined group of organisms, one set of forms merging into another by almost insensible gradations, and this is not only true among themselves, but applies also to some extent to their connection with the Mosses and Pteridophytes. The fact that the degree of development of gametophyte and sporophyte does not always correspond makes it very difficult to determine which forms are to be regarded as the most primitive. Thus while Riccia is unquestionably the simplest as regards the sporophyte, the gametophyte is very much more specialised than that of Aneura or Spherocarpus. The latter is, perhaps, on the whole the simplest form we know, and we can easily see how from similar forms all of the other groups may have developed. The frequent recurrence of the two-sided apical cell, either as a temporary or permanent condition in so many forms, makes it probable that the primitive form had this type of apical cell. From this hypothetical form, in which the thallus was either a single layer of cells or with an imperfect midrib like Spharocarpus, three lines of development may be assumed to have arisen. In one of these the differentiation was mainly in the tissues of the gametophyte, and the sporophyte remained comparatively simple, although showing an advance in the more specialised forms. The evolution of this type is illustrated in the germinating spores of the Marchantiaceæ, where there is a transition from the simple thallus with its single apical cell and smooth rhizoids to the complex thallus of the mature gametophyte. In its earlier phases it resembles closely the condition which is permanent in the simpler anacrogynous Jungermanniacea, and it seems more probable that forms like these are primitive than that they have been derived by a reduction of the tissues from the more specialised thallus of the Marchantiaceæ. Spherocarpus, showing as it does points of affinity with both the lower Marchantiales and the anacrogynous Jungermanniales, probably represents more nearly than any other known form this hypothetical type. Its 
sporogonium, however, simple as it is, is more perfect than that of Riccia, and if our hypothesis is correct, the Marchantiales must have been derived from Spharocarpus-like forms in which the sporophyte was still simpler than that of existing species. Assuming that this is correct, the further evolution of the Marchantiales is simple enough, and the series of forms from the lowest to the highest very complete.

In the second series, the Jungermanniales, starting with Sphcerocarpus, the line leads through Aneura, Pellia, and similar simple thallose forms, to several types with more or less perfect leaves-e.g., Blasia, Fossombronia, Treubia, Haplomitrium. These do not constitute a single series, but have evidently developed independently, and it is quite probable that the typical foliose Jungermanniaceæ are not all to be traced back to common ancestors, but have originated at different points from several anacrogynous prototypes.

The systematic position of the Anthocerotes is more difficult to determine, and their connection with any other existing forms known must be remote. While the structure of the thallus and sporogonium in Notothylas shows a not very remote resemblance to the corresponding structures in Spharocarpus, it must be remembered that the peculiar chloroplasts of the Anthocerotes, as well as the development of the sexual organs, are peculiar to the group, and quite different from other Liverworts. To find chloroplasts of similar character, one must go to the green Algæ, where in many Confervaceæ very similar ones occur. It is quite conceivable that the peculiarities of the sexual organs may be explained by supposing that those of such a form as Sphcrocarpus, for example, should become coherent with the surrounding envelope at a very early stage, and remain so until maturity. In Aneura we have seen that the base of the archegonium is confluent with the thallus, in which respect it offers an approach to the condition found in the Anthocerotes; but that this is anything more than an analogy is improbable. The origin of the endogenous antheridium must at present remain conjectural, but that it is secondary rather than primary is quite possible, as we know that occasionally the antheridium may originate superficially. In regard to the sporogonium, until further evidence is brought forward to show that Notothylas may have the columella absent in the early stages, it must be assumed that its structure in the Anthocerotes 
is radically different from that of the other Liverworts. Of the lower Hepaticæ Sphcerocarpus perhaps offers again the nearest analogy to Notothylas, but it would not be safe at present to assume any close connection between the two. Of course the very close relationships of the three genera of the Anthocerotes among themselves are obvious.

On the whole, then, the evidence before us seems to indicate that the simplest of the existing Hepaticæ are the lower thallose Jungermanniales, and of these Sphcrocarpus is probably the most primitive. The two lines of the Marchantiales and Jungermanniales have diverged from this common ancestral type and developed along different lines. The Anthocerotes cannot certainly be referred to this common stock, and differ much more radically from either of the other two lines than these do from each other, so that at present the group must be looked upon as at best but remotely connected with the other Hepaticæ, and both in regard to the thallus and sporophyte has its nearest affinities among certain Pteridophytes. The possibility of separate origin of the Anthocerotes from Coleochate-like ancestors is conceivable, but it seems more probable that they have a common origin, very remote, it is true, with the other Liverworts. They may probably best be relegated to a separate class, coördinate with the Hepaticæ and Musci. 


\section{CHAPTER V}

THE MOSSES (MUSCI) : SPHAGNALES-ANDREÆALES

THE Mosses offer a marked contrast to the Hepaticæ, for while the latter are pre-eminently a generalised group, the Mosses with a very few exceptions form one of the most sharply defined and specialised groups of plants known to us. Although much outnumbering the Liverworts in number of species, as well as individuals, the differences in structure between the most extreme forms are far less than obtain among the Liverworts. While the latter occur as a rule in limited numbers, and for the most part where there is abundant moisture, the Mosses often cover very large tracts almost to the exclusion of other vegetation, especially in northern countries. In more temperate regions, the familiar peat-bogs are the best known examples of this gregarious habit. Mosses are for the most part terrestrial, and are found in almost all localities. Some grow upon organic substrata, especially decaying wood, and are to a greater or less extent saprophytic. Haberlandt (4) first called attention to this, and investigated a number of forms, among them Rhynchostegium murale, Eurynchium pralongum, Webera nutans, and others, and in these found that the rhizoids had the power of penetrating the tissue of the substratum, much as a fungus would do. The most remarkable case, however, is Buxbaumia, where the leaves are almost completely absent and the saprophytic habit very strongly pronounced. Most of the Mosses, however, are abundantly provided with assimilative tissue, and grow upon almost every substratum, although most of them are pretty constant in their habitat. A number of species are typically aquatic, e. g., Fontinalis and many species of Sphagnum and 
Hypmum; others grow regularly in very exposed situations on rocks, e. g., Andrecea. Very many, like Funaria hygrometrica and Atrichum undulatum, grow upon the earth; and others again, like species of Mnium and Thuidium, seem to grow exclusively upon the decaying trunks of trees. Indeed Mosses are hardly absent from any locality except salt water. With the exception of the Sphagnaceæ and Andreæaceæ, and possibly Archidium, the type of structure found among the Mosses is extraordinarily constant, and they may all be unhesitatingly referred to a single order, the Bryales, which includes within it an overwhelming majority of the species.

The gametophyte of the Musci always shows a wellmarked protonema, which in most cases has the form of an extensively branching alga-like filamentous structure, from which later a distinct leafy axis arises as a lateral bud. In Sphagnum this protonema is a flat thallus, and the same is true of Tetraphis and a few other forms, but the filamentous protonema is very much more common. The gametophore arises from this protonema as a lateral bud, which develops a pyramidal apical cell, from which three sets of segments are cut off, each segment producing a leaf. The only exception to this, so far as is known at present, is the genus Fissidens (Leitgeb (2)), where the apical cell is wedge-shaped, and only two sets of segments are formed. Upon these leafy branches the sexual organs are borne. The relative degree of development of the protonema and the gametophore differ much in different forms. Thus in the Phascaceæ the protonema is permanent, and the gametophore small and poorly developed. In the higher Mosses the protonema disappears more or less completely, and the assimilative functions are entirely assumed by the large highly developed gametophore, which is capable of reproducing itself by direct branching without the intervention of the protonema. The commonest type of gametophore is the upright stem with the leaves arranged radially about it, but in many creeping forms, such as some species of Mnium, Hypumm, etc., the gametophore is more or less dorsiventral; but in these the apical cell is pyramidal, and produces three rows of leaves. Growing out from the base of the stem in most Mosses, and fastening it to the substratum, are numerous brown rhizoids which are not, however, morphologically distinct from the protonema. Thus if 
a turf of growing Moss is turned upside down, the rhizoids thus exposed to the light very soon develop chlorophyll, and grow out into normal protonemal filaments.

In most of the Mosses the leaves show a one-layered lamina traversed by a midrib, which may be quite small or very massive. This midrib is made up in part of elongated thickwalled sclerenchyma, and contains a conducting tissue. The highest grade of development of the leaf is met with in the Polytrichacea, where the midrib is very massive and peculiar vertical laminæ of chlorophyll-bearing cells grow out from the surface of the leaf. In Buxboumia the leaves are almost entirely abortive. The peculiar leaves of Sphagnum will be referred to later, as well as the details of structure of the leaves of other forms.

The stem, except in the lowest forms, is traversed by a well-defined central strand of conductive tissue, and in a few of the highest ones, e. g. Polytrichum, there are in addition smaller bundles, continuations of the midribs of the leaves, recalling the "leaf-traces" found in the stems of Spermatophytes.

The types of non-sexual reproduction among the Musci are extraordinarily various, and a careful study of them shows that the morphological connection between the protonema and gametophore is a very intimate one, as they may arise reciprocally one from the other. With the exception of certain resting buds developed from the protonema it appears (Goebel (Io), p. I7o) that the formation of the leafy stem is always preceded by the protonema. The latter arises primarily from the germinating spores, but may develop secondarily from almost any part of the gametophore or even in exceptional cases from the cells of the sporophyte (Pringsheim (2); Stahl (I)). From these protonemal filaments new gametophores arise in the usual way. The gametophore itself, especially where it is large and long lived, by the separation of its branches rapidly increases the number of new individuals. This is especially marked in Sphagnum, where this is the principal method of propagating the plants. Special organs of propagation in the form of gemmæ also occur, and these may develop from the protonema or from the gametophore Tetraphis pellucida (Fig. I 18 ) is a good example, showing these specialised gemmæ which after a time germinate by 
giving rise to a protonema upon which, as usual, the gametophore arises as a bud. In size the gametophore of the Mosses ranges from a millimetre or less in height in Buxbaumia and Ephemerum to 30 to $50 \mathrm{~cm}$. in the large Polytrichaceæ and Fontinalis. The branching of the gametophore is never dichotomous, and so far as is known the lateral branches arise, not in the axils of the leaves, but below them. Underground

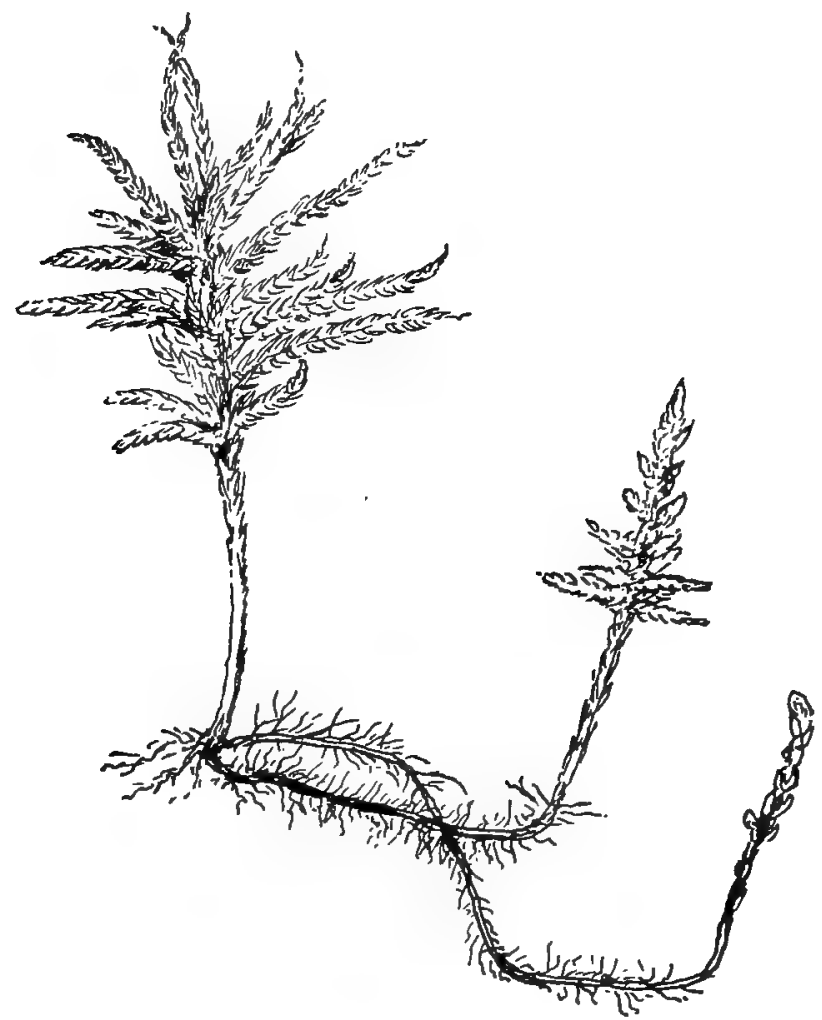

FIG. 86.-Climocium Americanum, showing the formation of stolons, $\times \mathbf{2}$.

stems or stolons, which afterwards develop into normal leafy axes, are common in many forms, e. g., Climacium (Fig. 86).

The sexual organs are borne either separately or together at the summit of the gametophoric branches. Where the plants are dicecious, it sometimes happens that the two sexes do not grow near together, in which case, although archegonia 
may be plentiful, they fail to be fecundated and thus no capsules are developed. This no doubt accounts for the extreme rarity of the sporogonium in many Mosses, although in other cases, e. g., Sphagnum, it would appear that the formation of the sexual organs is a rare occurrence. These resemble in general those of the Hepatica, but differ in some of their details. The leaves surrounding them are often somewhat modified, and in the case of the male plants (Atrichum, Polytrichum) different in form and colour from the other leaves, so that the whole structure looks strikingly like a flower. As a rule, the archegonial receptacles are not so conspicuous. The early divisions of the archegonium correspond closely with those of the Liverworts, but after the "cover cell" is formed, instead of dividing by cross walls into four cells, it functions for some time as an apical cell, and to its activity is largely due the further development of the neck. The venter is usually very much more massive than in the Hepaticæ, and the egg small.

The antheridia, except in Sphagnum, are borne also at the apex of the stem, whose apical cell does not always, at any rate, become transformed into an antheridium, as we sometimes find, especially in species of Atrichum and Polytrichum, that the axis grows through the antheridial group and develops a leafy axis, which later may form other antheridia at its apex. Where the plants are diœcious the males are usually noticeably smaller than the females. The antheridia, except in Sphagnum, are very uniform in structure, and like the archegonium exhibit a very definite apical growth (Fig. I02). The wall remains one-layered, as in the Liverworts, and often the chromatophores in its cells become red at maturity, as in some Liverworts, e. $g$., Anthoceros. The ripe antheridium is in most Mosses clubshaped, and the sperm cells are discharged while still in connection, the complete isolation of the sperm cells only taking place some time after the mass has lain in water. In Sphagnum the antheridia are much like those of certain leafy Liverworts, and stand singly in the axils of the leaves of the male branches.

Holferty ( I) describes and figures a number of interesting abnormalities in Mnium cuspidatum in which organs are sometimes developed which are intermediate in character between archegonia and antheridia.

The sporophyte of the Mosses reaches a high degree of 
development in the typical forms, and shows great uniformity, both in its development and in the essential structure of the full-grown sporophyte. With the exception of Sphagnum, which will be referred to more specially later, the early growth of the sporogonium is due to the segmentation of a two-sided apical cell. The separation of the archesporium takes place at a late period, and like that of Anthoceros it occupies but a very small part of the sporogonium, which in all the higher forms attains a considerable size and complexity. All the archesporial cells form spores, and no trace of elaters can be found.

In all but the lower types, the sporogonium becomes differentiated into a stalk (seta) and a capsule. This differentiation is gradual, and the elongation of the seta is not a rapid process, due simply to an elongation of the cells, but is caused by actual growth and cell division. In Sphagnum and Andrecea, where no seta is present, the axis of the gametophore elongates and forms a sort of stalk (pseudopodium), which carries up the capsule above the leaves.

The formation of the capsule and seta takes place by a rapid enlargement of the upper part of the very much elongated embryo about the same time that the archesporium becomes recognisable. This enlargement is accompanied by a separation of the cells of two layers of the wall, by which an intercellular space is formed which later may become very large (Figs. IO9-I 12). A second similar space may be developed inside the archesporium, but this is found only in the Polytrichaceæ. In the Sphagnaceæ and the Andreæaceæ this space is not developed. These lacunæ are traversed by protonema-like filaments of chlorophyll-bearing cells, and the cells of the massive wall of the capsule also contain much chlorophyll, so that there is no question that the sporogonium is capable of assimilation. Stomata, much like those of Anthoceros or the vascular plants, occur upon the basal part of the capsule in many species, but are not always present.

In Sphagnum and all the higher Bryales the capsule opens regularly by means of a circular lid or operculum. This in the latter group is a most characteristic structure, and with its accompanying structures, the "annulus" and "peristome," form some of the most important distinguishing marks of different genera and species. When ripe, the operculum falls off and the ripe spores are set free. The teeth of the peristome, by. 
their hygroscopic movements, play an important part in scattering the spores, and physiologically take the place of the elaters of the Hepaticæ.

Some Mosses live but a few months, and after ripening their spores, die. This is the case with Funaria hygrometrica, at least in California. Other Mosses are perennial, and some species of peat or tufa-forming Mosses seem to have an unlimited growth, the lower portions dying and the apices growing on until layers of peat or tufa of great thickness result, covered over with the still living plants whose apices are the direct continuation of the stems which form the basis of the mass.

With the exception of a very few forms all the Mosses are readily referable to three orders. The first two, the Sphagnales and the Andreæales, are represented each by a single genus, and are in several respects the types that come nearest the Liverworts. All the other Mosses, except perhaps Archidium and Buxbaumia, conform to a very well-marked type of development, and may be referred to a common order, the Bryales. The Phascacere or cleistocarpous Mosses are sometimes separated from the higher Bryales as a distinct order, but a study of their development shows that they belong to the same series, and only differ in the degree of development from the more specialized stegocarpous forms.

\section{ORDER I.-Sphagnales}

The Sphagnales, or Peat-Mosses, are represented by the single genus Sphagnum. They are Mosses of large size, which, as is well known, often cover large tracts of swampy land and about the borders of lakes, forming the familiar peatbogs of northern countries. Owing to the empty cells in the leaves and outer layers of the stem, they suck up water like a sponge, and the plants when growing are completely saturated with water. The colour is usually pale green, but varies much in depth of colour, and in many species is red or yellow. When dry the colour is much duller, largely owing to the opacity of the dry, empty cells which conceal to a great extent the colour of the underlying tissues. They branch extensively, and, according to Schimper, a branch is always formed corresponding to every fourth leaf; but Leitgeb has shown that although this 
is the rule numerous exceptions to it occur. In sterile plants the branches are of two kinds, long flagellate branches which hang down almost vertically and are applied to the stem, and much shorter ones that are crowded together at the apex and have only a limited growth. The leaves are inserted on the

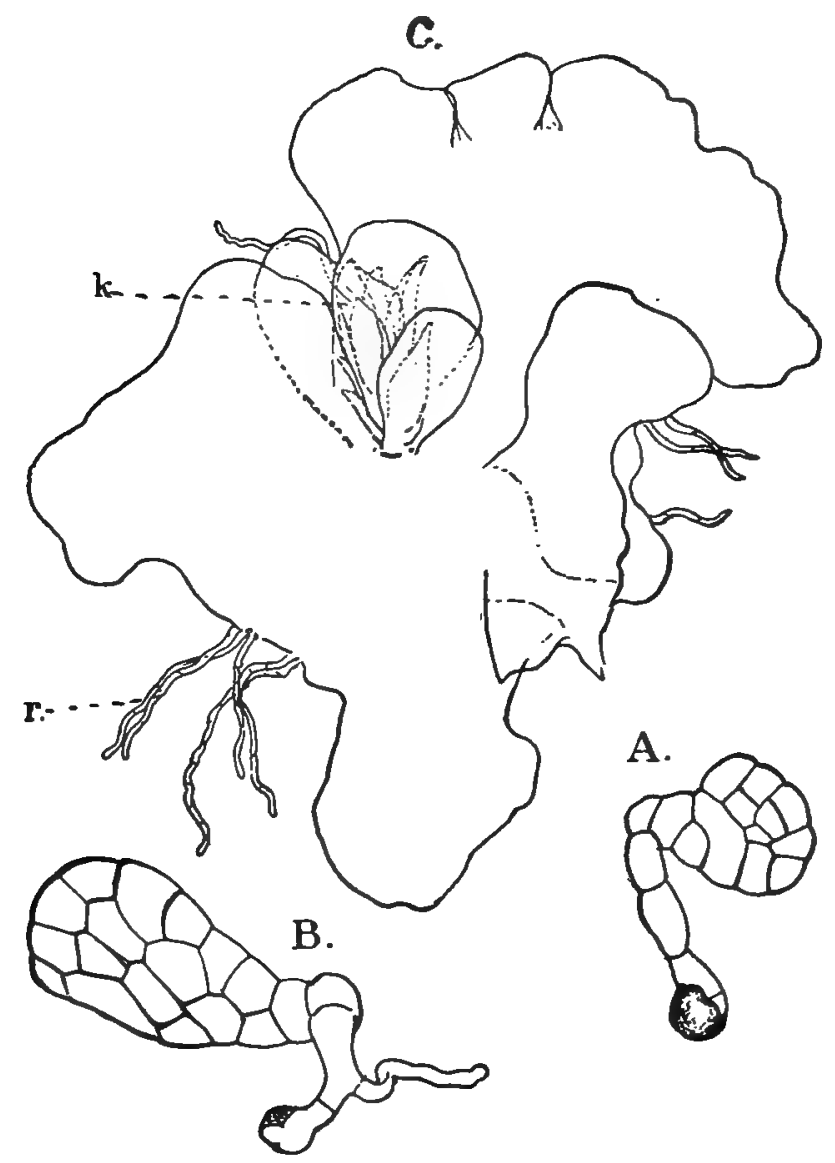

Fic. 87.-Sphognum (sp); A, B, Young protonemata, $\times 262 ; C$, an older protonema with a leafy bud $(k), X$ about $40 ; r$, marginal rhizoids.

stem by a broad base, and taper to a more or less well-marked point. According to Schimper, the divergence of the leaves of the main axis is always two-fifths, but on the smaller branches variations from this sometimes occur. The leaves 
show no trace of a midrib. As the axis elongates the leaves become separated, as well as the lower branches, but upon the smaller branches they remain closely imbricated. Rhizoids are present only in the earlier stages of the plant's growth, and are only occasionally found in a very rudimentary condition in the older ones.

The spores of Sphagnum on germination form first a very short filament, which soon, at least when grown upon a solid substratum, forms a flat thallus, which at first sometimes grows

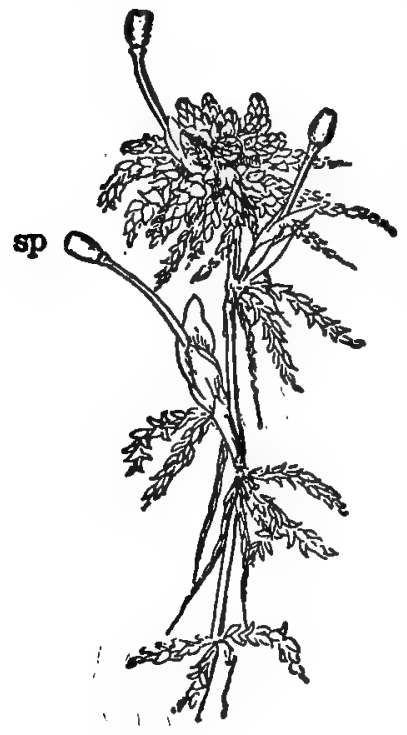

FiG. 88. - Sphagnum squarrosum. Leafy shoot with sporophytes $(s p)$, borne at the end of leafless branches, or "pseudopodia," $\times 2$.

Schimper (I), produce a flattened thallus at their extremity, and thus the number of flat thalli may be increased. Schimper states that if the germination takes place in water, the formation of a flat thallus is suppressed and the protonema remains filamentous, but Goebel disputes this.

In the few cases observed by me, only one leafy axis arose from each thalloid protonema, and although this is not expressly stated by Hofmeister and Schimper, their figures would indicate it. At a point, usually near the base, a protuberance is 
formed by the active division of the cells, in a manner probably entirely similar to that in other Mosses, and this rapidly assumes the form of the young stem. The first leaves are very simple in structure, and are composed of perfectly uniform elongated quadrilateral cells, all of which contain more or less chlorphyll. Like the older ones, however, they show the characteristic two-fifth divergence. Schimper states that the fifth leaf, at the latest, shows the differentiation into chlorophyll-
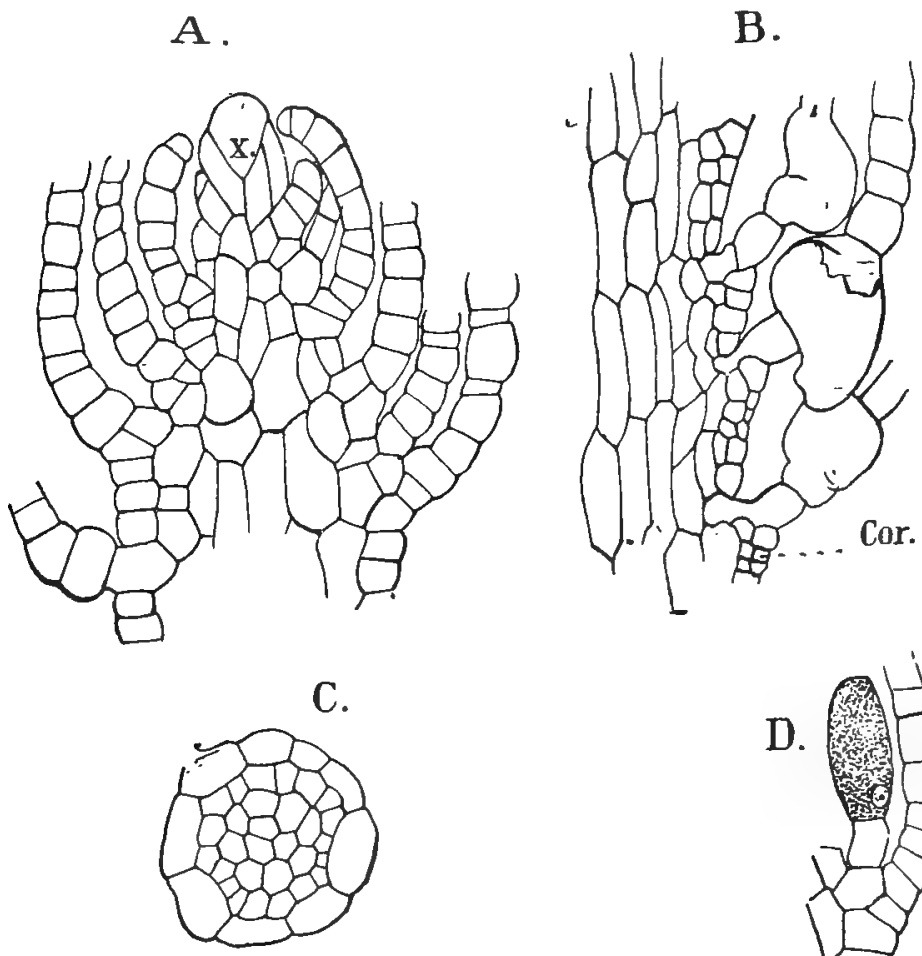

FiG. 89.-Sphagnum cymbifolium. A, Median longitudinal section of a slender branch; $x$, the apical cell; $B$, part of a section of the same farther down, showing the enlarged cells at the bases of the leaves, and the double cortex (cor); C, crosssection near the apex of a slender branch; D, glandular hair at the base of a young leaf-all $\times 525$.

bearing and hyaline cells, found in the perfect leaves. The first leaves in which this appears only show it in the lower part. the cells of the apex remaining uniform. 
At the base of the young plant very delicate colourless rhizoids are developed, and these show the oblique septa so general in the rhizoids of other Mosses. As the plant grows older these almost completely disappear.

The apex of the stem and branches is occupied by a pyramidal apical cell with a very strongly convex outer free base. From the lateral faces of the apical cell, as in the acrogynous Liverworts, three sets of segments are formed. The whole vegetative cone is slender, especially in the smaller branches. The first division in the young segment is parallel to its outer face, and separates it into an inner cell, from which the central part of the axis is formed, and an outer cell which produces the leaves and cortex.

The second wall, which is nearly horizontal, divides the outer cell of the segment into an upper and a lower cell, the former being much broader than the latter, which is mainly formed from the kathodic half of the segment, which is higher than the anodic half (Leitgeb (I)). The next wall divides the upper cell into an upper and a lower one, the former being the mother cell of the leaf, the lower, with the other basal cell, giving rise to the cortex. Growth proceeds actively in the young leaf, which soon projects beyond the surface of the stem, and by the formation of cell walls perpendicular to its surface forms a laminar projection. The position of the cell walls in the young leaf is such that at a very early period a two-sided apical cell is established, which continues to function for a long time, and to whose regular growth the symmetrical rhomboidal form of the cells of the young leaf is largely due (Fig. 90). The leaves do not retain their original three-ranked arrangement, but from the first extend more than one-third of the circumference of the stem, so that their bases overlap, and the leaves become very crowded, and the two-fifth arrangement is established. The degree to which the central tissue of the stem is developed varies with the thickness of the branch. In the main stem it is large, but in the small terminal branches it is much less developed, as well as the cortex, which in these small branches is but one cell thick. Later the cortex of the large branches becomes two-layered (Fig. 89, B), and is clearly separated from the central tissue, whose cells in longitudinal section are very much larger. In such sections through the base 
v.

of very young leaves characteristic glandular hairs are met with. They consist of a short basal cell and an enlarged ter-
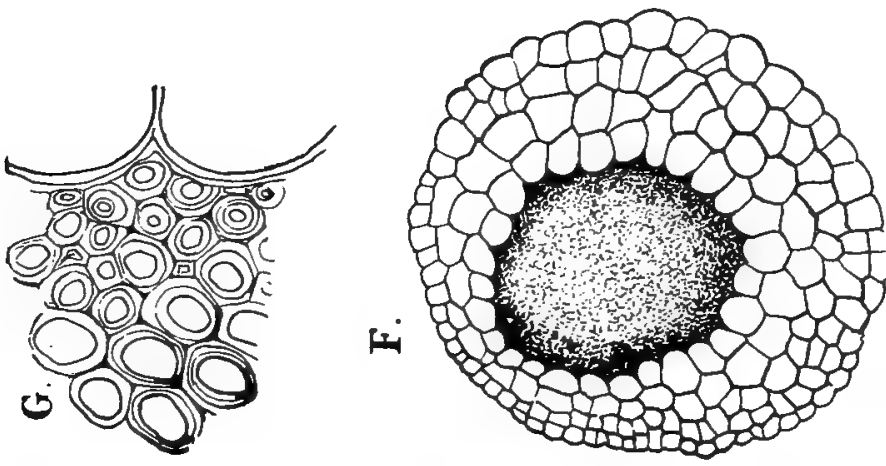


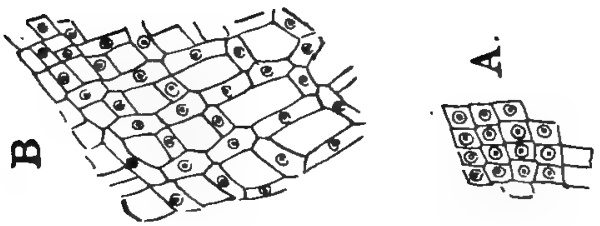

要

$\rightarrow$

bo

承.

은

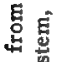

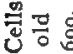

ن대 $X$

लํํㅇ

뎐

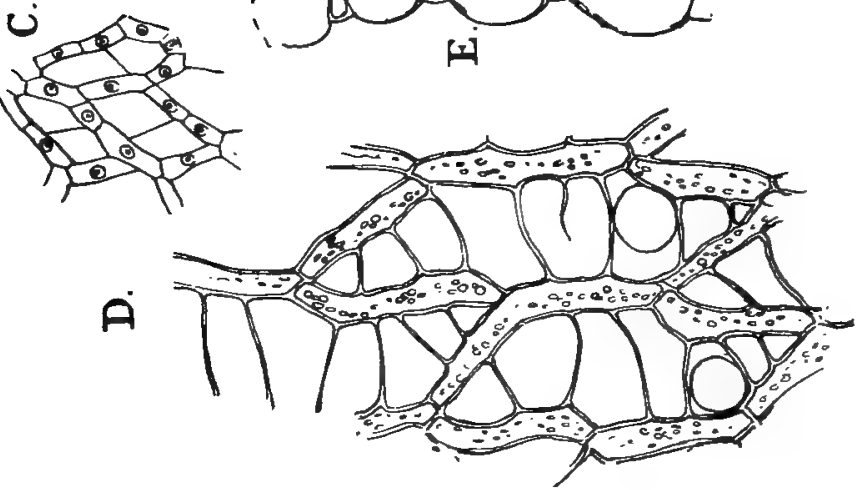

4.

寒

$\because 5$

舟

응

$\pm \times$

엉

원

祭票

空

要

minal cell containing a densely granular matter, which from its behaviour with stains seems to be mucilaginous. The form 
of the secreting cell is elongated oval (Fig. 89, D), and the hair is inserted close to the base of the leaf, upon its inner sur. face.

The young leaf consists of perfectly uniform cells of a nearly rhomboidal form (Fig. 90, A), and this continues until the apical growth ceases. Then there begins to appear the separation into the chlorophyll-bearing and hyaline cells of the mature leaf. This can be easily followed in the young leaf, where its base is still composed of similar cells, but where toward the apex the two sorts of cells become gradually differentiated. The future hyaline cells grow almost equally in length and breadth, although the longitudinal growth somewhat exceeds the lateral. These alternate regularly with the green cells, which grow almost exclusively in length, and form a network with rhomboidal meshes, whose interstices are occupied by the hyaline cells. The latter at first contain chlorophyll, which soon, however, disappears; and finally, as is well known, they lose their contents completely, and in most cases round openings are formed in their walls. The protoplasm is mainly used up in the formation of the spiral and ring-shaped thickenings upon the inner surface of the wall, so characteristic of these cells (Fig. 90, D). The chlorophyll cells are sometimes so crowded and overarched by the hyaline ones that they are scarcely perceptible, and of course in such leaves the green colour is very faint. Cross-sections of the leaves show a characteristic beaded appearance, the large swollen hyaline cells regularly alternating with the small wedge-shaped sections of the green cells (Fig. 90, E). Russow (4) has shown that the leaves of the sporogonial branch retain more or less their primitive character, and the division into the two sorts of cells of the normal leaves is much less marked. $\mathrm{He}$ connects this with the necessity for greater assimilative activity in these leaves for the support of the growing sporogonium. From his account too it seems that the stem leaves lose their activity very early.

The degree of development of the thickenings upon the walls of the hyaline cells varies in different species, and in different parts of the leaf. It is, according to Russow, best developed in the upper half of the leaf, where these thickenings have the form of thin ridges projecting far into the cell cavity.

The development of the central tissue of the stem varies. 
The central portion usually remains but little altered and constitutes a sort of pith composed of thin-walled colourless parenchyma, which merges into the outer prosenchymatous tissue of the central region. The cells of the latter are very thicl: walled, and elongated, and their walls are usually deeply staincd with a brown or reddish pigment. In their earlier stages, according to Schimper ( ( I), p. 36), the prosenchyma cells have regularly arranged and characteristic pitted markings on their walls, but as they grow older and the walls thicken, these become largely obliterated. Cross-sections of these prosenchyma cells show very distinct striation of the wall (Fig. 90, G), which become less evident as they approach the thinner-walled parenchyma of the central part of the stem. No trace of a central cylinder of conducting tissue, such as is found in most of the Mosses, can be found in Sphagnum, and this is correlated with the absence of a midrib in the leaves.

The cortex at first forms a layer but one cell thick, but is from the first clearly separated from the axial stem tissue. In the smallest branches it remains one-layered (Fig. 89, C), but in the larger ones it early divides by tangential walls into two layers, which at this stage are very conspicuous (Fig. 89, B). Later there may be a further division, so that the cortex of the main axes frequently is four-layered. While the cells of the young cortex are small, and the tissue compact, later there is an enormous increase in the size of the cells, which finally lose their protoplasmic contents and resemble closely the hyaline cells of the leaves. Like the latter, the cortical cells are perfectly colourless, and usually have similar circular perforations in their walls. The resemblance is still more marked in $S$. cymbifolium, where there are spiral thickened bands, quite like those of the hyaline leaf cells. On the smaller branches the cortical cells (Schimper (I), p. 39), have been found to be of two kinds-the ordinary form and curious retort-shaped cells with smooth walls and single terminal pore.

\section{The Branches}

Leitgeb (I) has studied carefully the branching of Sphagnum, which corresponds closely to the other Mosses investigated. The branch arises from the lower of the two cells into 
which the outer of the two primary cells of the segment is divided. In this cell, which ordinarily constitutes part of the cortex, walls are formed in such a way that an apical cell of the ordinary form is produced. These lateral branches themselves branch at a very early period, and form tufts of secondary ones. Schimper was unable to make out clearly what the nature of this branching was, but suggested a possible dichotomy. Leitgeb, however, concludes that it is monopodial, and that each branch corresponds to a leaf, as do the primary branches. The growth of all the lateral branches, both the descending flagellate ones and the short upright ones at the top of the stem, is limited, and lasts through one vegetative period only. This, however, is not true of the branches that are destined to continue the axis These are apparently morphologically the same as those whose growth is limited, but they continue to grow in the same manner as the main axis.

\section{The Sexual Organs}

The sexual organs in Sphagnum are produced on branches that do not differ essentially from the sterile ones. The leaves of the antheridial branches are usually brightly coloured,-red, yellow, or dark green, and are closely and very regularly set so that the branch has the form of a small catkin (Fig. 9I, A). The antheridia stand singly in the axils of the leaves, and Leitgeb states that their position corresponds with that of branches, with which he regards them as homologous, having observed in some cases a bud occupying the place of an antheridium. $\mathrm{He}$ studied in detail their development, which differs considerably from that of the other Mosses. The antheridium arises from a single cell whose position corresponds to that of a lateral bud on an ordinary branch. This cell grows out into a papilla and becomes cut off by a transverse wall. The outer cell continues to elongate without any noticeable increase in diameter, and a series of segments are cut off from the terminal cell by walls parallel to its base, so that the young antheridium consists of simply a row of cells, comparable to the very young antheridium of the Marchantiaceæ. Intercalary transverse divisions may also arise, and later some or all of the cells, except the terminal one, divide by longitudinal walls, usually two intersecting ones in each cell, so that the antheridium rudiment at this 
stage is composed of a long stalk composed of several rows of cells, usually four, and a terminal cell which later gives rise to
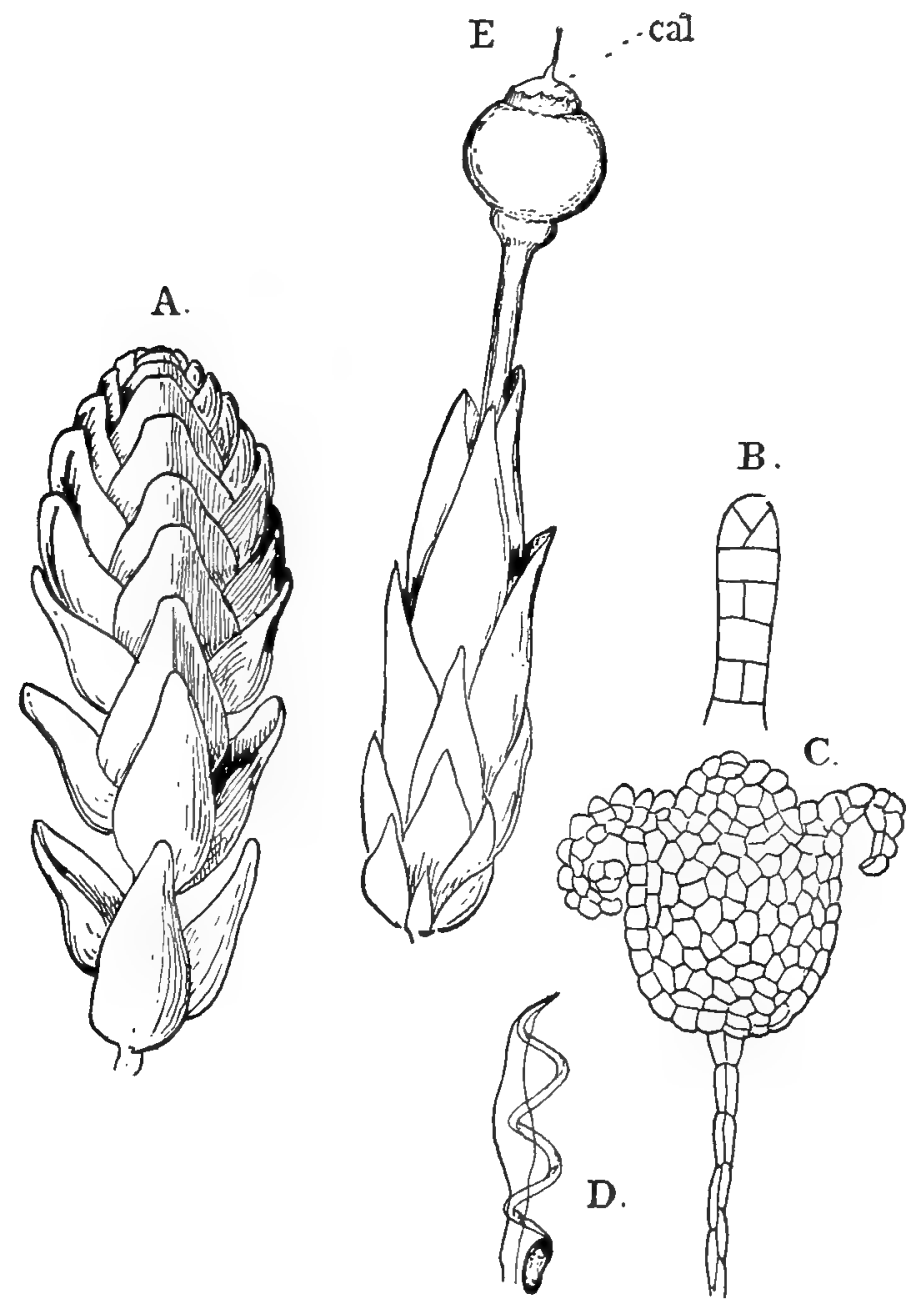

FrG. 9r.-A, Male catkin of Sphagnum cymbifolium, $\times 50 ; B$, young antheridium of S. acutifolium, $\times 350 ; C$, opened antheridium of the same species; D, spermatozoid, $\times 1000$ (about); E, female branch with sporogonium of $S$. acutifolium, slightly magnified; cal, calyptra. A, C, E, after Schimper; B, after Leitgeb.

the body of the antheridium. The first divisions in the body of the antheridium only take place after the stalk has become 
many times longer than the terminal cell, and is divided into many cells.

The account of the development of the antheridium given by Hofmeister and Schimper is incomplete, and differs in some respects from that of Leitgeb. Neither of the former observers seems to have clearly recognised the presence of a definite apical cell from the first. Schimper ( ( I), p. 45), states that after the stalk has been formed four rows of segments arise from the terminal cell; to judge from the somewhat vague statements of Hofmeister ( ( I), p. I 54), it appears that he regarded the terminal growth as taking place by the activity of a two-sided apical cell, as in other Mosses. Leitgeb states that, while this form of growth does frequently occur, usually the divergence of the segments is not exactly half, and the segments do not stand in two straight rows, but some of them are intercalated between these, forming an imperfect third row. Each segment is: first divided by a radial wall into nearly equal parts, and these are then divided into an outer and an inner cell, and from the latter by repeated divisions the sperm cells are formed. The body of the full-grown antheridium is broadly oval, and both in its position and shape recalls strongly that of such a foliose Liverwort as Porella.

The development of the spermatozoids has been carefully followed by Guignard ( ( ) , p. 69), and corresponds in the main with that of the Hepaticæ. A peculiar feature is the presence of a pear-shaped amylaceous mass, firmly attached to the posterior coil. This becomes evident at a very early stage in the development and remains unchanged up to the time the spermatozoids are liberated (Fig. 9I, D). The vesicle in which it is enclosed collapses, leaving only the large starch granule, which finally becomes detached. The free spermatozoid has about two complete coils, and in form recalls that of Chara. The cilia are two and somewhat exceed in length the body.

The ripe antheridium is surrounded by a weft of fine branching hairs, which Schimper suggests serve to supply it with moisture. ${ }^{1}$ It opens by a number of irregular lobes (Fig. 9I, C), precisely as in Porella, and, like that, the swelling of the cells is often so great that some of them become entirely

1 These are probably the hyphæ of a fungus. 
detached. Schimper states that antheridia may be formed at any time, but they are more abundant in the late autumn and winter.

The archegonia are found at the apex of some of the short
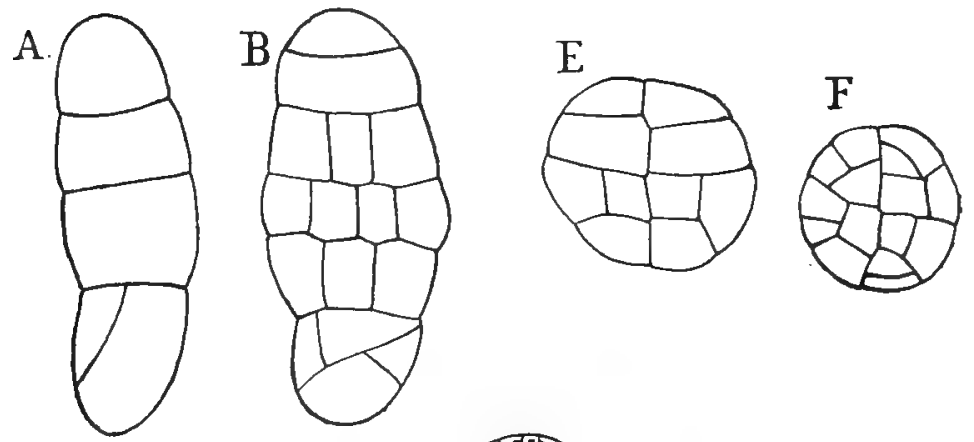

C
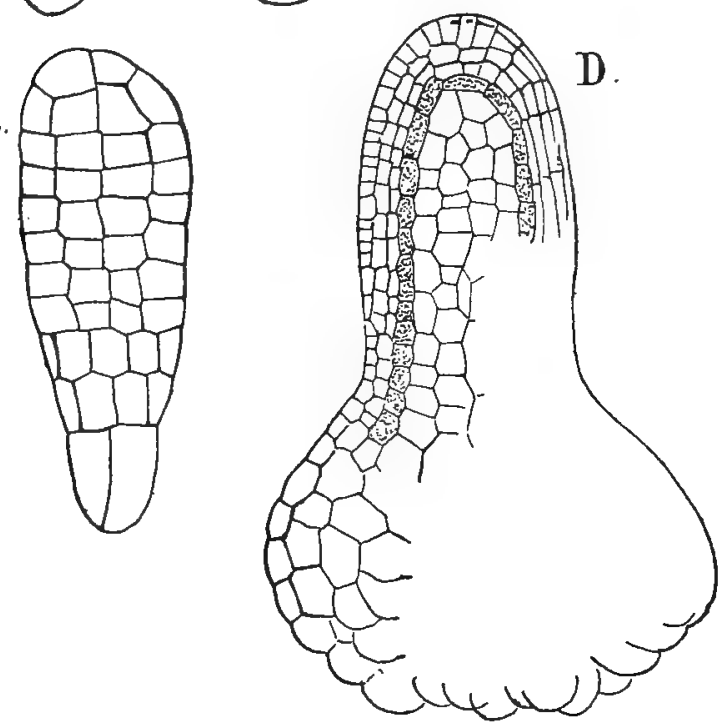

FIG. 92.-Sphagnum acutifolium. Development of the embryo (after Waldner). A-D, Median optical section; E, F, cross-sections. A, D, E, F, $\times_{360 ;}$ C, $\times 315 ; D$, XI53.

branches at the summit of the plant, which externally are indistinguishable from the sterile branches. The development of the archegonia has not been followed completely, but to judge from the stages that have been observed and the mature arche- 
gonium, its structure and development correspond closely to that of the other Mosses. As in these, and the acrogynous Hepaticæ, the apical cell of the branch becomes an archegonium, and a varying number of secondary archegonia arise from its last-formed segments. The mature archegonium has a massive basal part and long somewhat twisted neck, consisting of six rows of cells. As in the other Mosses, the growth of the young archegonium is apical, and probably as there the neck canals are formed as basal segments of the apical cell, and the ventral canal cell is cut off from the central cell in the usual way. The venter merges gradually into the neck above and the pedicel below, and at maturity its wall is two or three cells thick. The egg (Waldner (2)) is ovoid, and the nucleus shows a distinct nucleolus. Whether a receptive spot is present is not stated. Mixed with the archegonia are numerous fine hairs like those about the antheridium. The leaves immediately surrounding the group of archegonia later enlarge much and form a perichrtium. By the subsequent elongation of the main axis both archegonial and antheridial branches are often separated by the growth of the axis between them, although at first they are always crowded together at the top of the main stem.

\section{The Sporophyte}

Waldner (2) has recently studied carefully the development of the embryo of Sphagnum, which differs essentially from all the other Mosses, and has its nearest counterpart in the Anthocerotes. In the species $S$. acutifolium, mainly studied by Waldner, the sexual organs are usually mature in the late autumn and winter, and fertilisation occurs early in the spring. The ripe sexual organs are found in a perfectly normal condition in mid-winter, under the snow, and apparently remain in this condition until the first warm days, when they open and fertilisation is effected. The first embryos were found late in February, and development proceeded from that time.

The first division in the embryo is horizontal and divides it into two cells. In the lower of these the divisions are irregular, but in the upper one the cell walls are arranged with much regularity. The upper cell is the apical cell of the young embryo, and from it, by walls parallel to the base, a series of seg- 
ments is formed (Fig. 92, A). These are usually about seven in number, and each of these segments undergoes regular divisions, these beginning in the lower ones and proceeding toward the apical cell, which finally ceases to form basal segments and itself divides in much the same way as the segments. The latter first divide by two vertical divisions into quadrants, and in each quadrant either directly by periclinal walls, or by an anticlinal wall followed by a periclinal wall in the inner of the two cells (Fig. 92, E), four central cells in each segment are separated from four or eight peripheral ones. The terms endothecium and amphithecium have been given respectively to these two primary parts of the young Moss-sporogonium. By the time that the separation of endothecium and amphithecium is completed, a division of the embryo into two regions becomes manifest (Fig. 92, C). Only the three upper segments, including the apical one, give rise to spores; the lower segments together with the original basal cell of the embryo form the foot, which in Sphagnum is very large. The cells of the foot enlarge rapidly and form a bulbous body very similar in appearance and function to that of Notothylas or Anthoceros. The next divisions too in the upper part of the sporogonium find their nearest analogies in these forms. The central mass of cells, both in position and origin, corresponds to the columella in these genera, and the archesporium arises by the division of the amphithecium into two layers by tangential walls, and the inner of these two layers, in contact with the columella, becomes at once the archesporium. By rapid cell division the upper part of the sporgonium becomes globular, and is joined to the foot by a narrow neck, much as in Notothylas (Fig. 93). The single-layered wall of the young sporogonium becomes six or seven cells thick, and the columella very massive. The onelayered archesporium also divides twice by tangential walls, and thus is four-layered at the time the spore mother cells separate. All the cells of the archesporium produce spores of the ordinary tetrahedral form. The so-called "microspores" have been shown conclusively to be the spores of a parasitic fungus (Nawaschin (I)). The layer of cells in immediate contact with the archesporium on both inner and outer sides has more chlorophyll than the neighbouring cells, and forms the "spore-sac." 
The ripe capsule opens by a circular lid which is indicated long before it is mature. The epidermal cells where the opening is to occur grow less actively than their neighbours, and thus a groove is formed which is the first indication of the operculum. The cells at the bottom of the groove have thinner

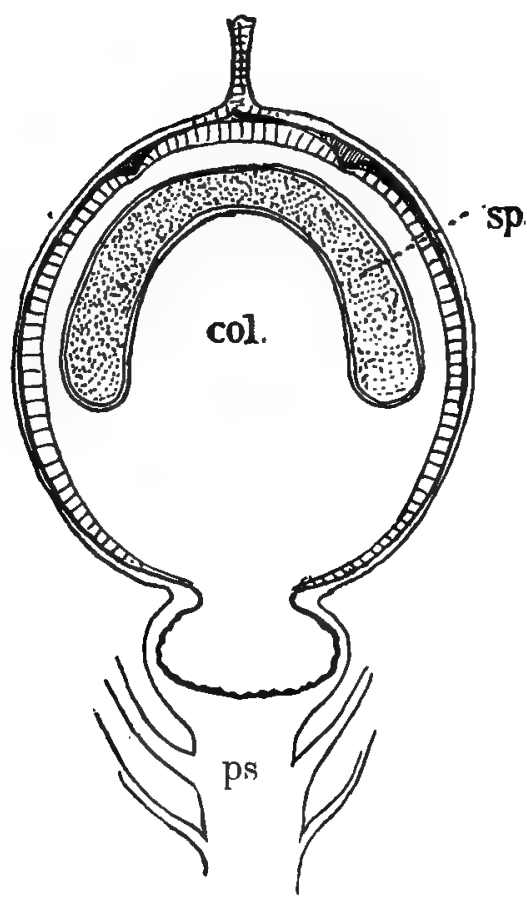

FIG. 93.-Median longitudinal section of a nearly ripe sporogonium of $S$. acutifoli$u m, \times 24 ; p s$, pseudopodium; $s p$, spores; col, columella (after Waldner).

walls than the other cells of the capsule wall, and when it ripens these dry up and are very readily broken, so that the operculum is very easily separated from the dry capsule. Stomata, according to Schimper, always are present, sometimes in great numbers; but Haberlandt ((4), p. 475), states that these are always rudimentary, and he regards them as reduced forms. No seta is formed, but its place is taken physiologically by the upper part of the axis of the archegonial branch, which grows up beyond the perichætium, carrying the ripe sporogonium at its top (Fig. 9I, E). The upper part of this "pseudopodium" is much enlarged, and a section through it shows the bulbous foot of the capsule occupying nearly the whole space inside it. The ripe capsule breaks through the overlying calyptra, the upper part of which is carried up somewhat as in the higher Mosses, while the basal part together with the upper part of the pseudopodium forms the "vaginula."

The disorganised contents of the canal cells, which are usually ejected from the archegonium, in Sphagnum remain in a large measure in the central cavity, and on removing the 
young embryo from the venter of the archegonium, this mucilaginous mass adheres to it and forms a more or less complete envelope about it, in which are often found the remains of spermatozoids.

The species of Sphagnum are either monccious or diøcious, but in no cases do archegonia and antheridia occur upon the same branch.

\section{The Andrefales}

The second order of the Mosses includes only the small genus Andreca, rock-inhabiting Mosses of small size and dark

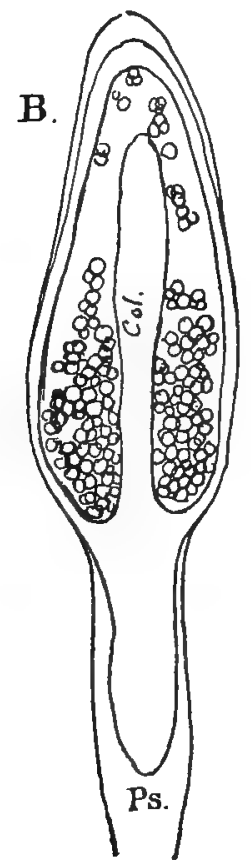

A.

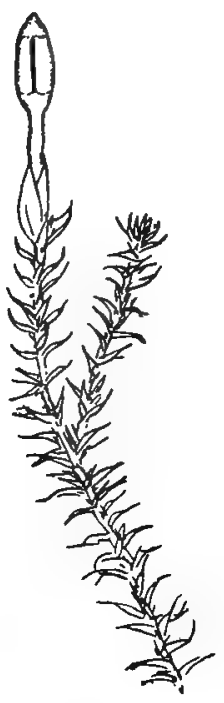

FIG. 94-Andreze petrophila. A, Plant with ripe sporogonium, $\times$ ro; $\mathrm{B}$, median section of nearly ripe capsule, $\times 80 ; p s$, pseudopodium; col, columella.

brown or blackish colour. In structure they are intermediate in several respects between the Sphagnales and the Bryales, as has been shown by the researches of Kühn (I), and Waldner (2), to whom we owe our knowledge of the life-history of Andreaa. They all grow in dense tufts upon silicious rocks, 
and are at once distinguished from other Mosses by the dehiscence of their small capsules. These, like those of Sphagnum, are raised upon a pseudopodium, and are destitute of a true seta. The capsule opens by four verticai slits, which do not, however, extend entirely to the summit (Fig. 94). This peculiar form of dehiscence recalls the Jungermanniaceæ, but is probably only an accidental resemblance. The closely-set stems branch freely; the leaves, with three-eighth divergence, are either with a midrib ( $A$. rupestris) or without one ( $A$. petrophila).

The growth of the stem is from a pyramidal apical cell, as in Sphagnum, and probably the origin of the branches is also the same as in that genus. The growth of the young leaves is usually from a two-sided apical cell, but another type of growth is found where the apical cell is nearly semicircular in outline, and segments are cut off from the base only. These two forms of apical growth apparently alternate in some instances in the same leaf. The originally thin walls of the leaf cells later become thick and dark-coloured, whence the characteristic dark colour of the plant.

The stem in cross-section shows an almost uniform structure, and no trace of the central conducting tissue of the higher Mosses can be found. The outer cells are somewhat thickerwalled and darker-coloured, but otherwise not different from the central ones. Numerous rhizoids of a peculiar structure grow from the basal part of the stem, and from these, new branches arise, which replace the older ones as they die away. These rhizoids are not simple rows of cells as in the Bryales, but are either cylindrical masses of cells or flattened plates. They penetrate into the crevices of the rocks, or apply themselves very closely to the surface, so that the plants adhere tenaciously to the substratum (Ruhland (2)).

\section{Spores and Protonema}

The germination of the spores and the development of the protonema show numerous peculiarities. The spores may germinate within a week, or sometimes remain unchanged for months. They have a thick dark-brown exospore and contain chlorophyll and oil. The first divisions take place before the exospore is ruptured, and may be in three planes, so that the 
young protonema then has the form of a globular cell mass (Fig. 95, A). This stage recalls the corresponding one in many of the thallose Hepaticæ, e. g., Pellia, Radula, and is entirely different from the direct formation of the filamentous protonema of most Mosses. Some of the superficial cells of this primary tubercle grow out into slender filaments, either with straight or oblique septa, and these later ramify extensively. Where there are crevices in the rock, some of these branches grow into them as colourless rhizoids, but, as in the Bryales, there is no real morphological distinction between rhizoid and protonema. Most of the filamentous protonemal branches do not remain in this condition, but become transformed into cell plates or cylindrical cell masses, like the stem-
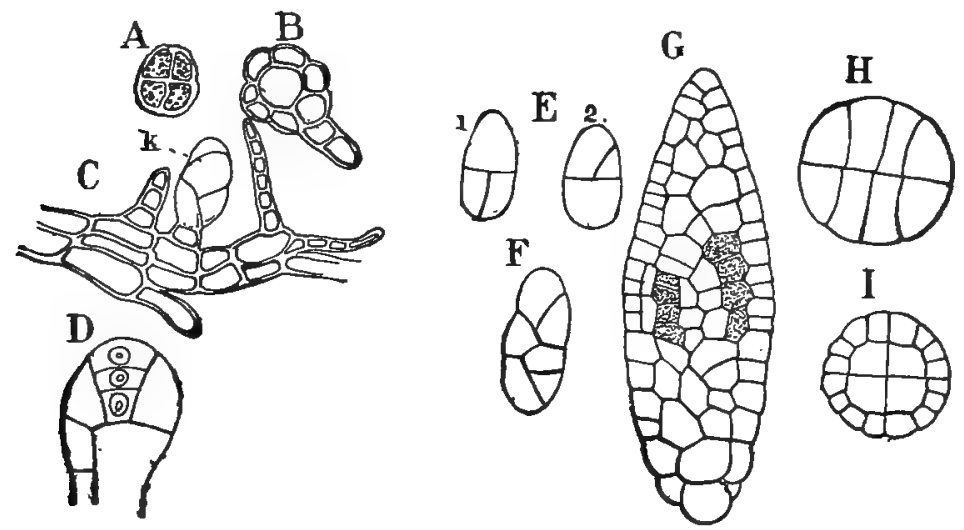

FrG. 95.-A, B, Germinating spores of A. petrophila, $\times 200$; C, protonema with bud $(k)$; D, young archegonium in optical section; $\mathrm{E}, \mathrm{x}, 2$, two views of a very young embryo of $A$. crassinerva, $\times 266 ; \mathrm{F}$, somewhat older embryo of $A$. petrophila; $\mathrm{G}$, older embryo showing the first archesporial cells; H, I, cross-sections of young embryos, Xz200. A-D, after Kühn; E-I, after Waldner.

rhizoids. The flat protonema recalls strongly that of Sphagnum, and is probably genetically connected with it. All of the different protonemal forms, except what Kühn calls the "leaflike structures," vertical cell surfaces of definite form, can give rise to the leafy axes. The development of these seems to correspond exactly with that of the other Mosses, and will not be further considered here. 


\section{The Sexual Organs}

The species of Andrecea may be either monœcious or dicecious. Archegonia and antheridia occur on separate branches, but their origin and arrangement are identical. The firstformed antheridium develops directly from the apical cell of the shoot, and the next older ones from its last-formed segments, but beyond this no regularity can be made out. In the first one the apical cell projects, and its outer part is separated from the pointed inner part by a transverse wall. This is followed by a second wall parallel to the first, so that the antheridium rudiment is composed of three cells. Of these the lower one takes little part in the future development. Of the two upper cells the terminal one becomes the body of the antheridium, the other the stalk. In the former, by two inclined walls, a two-sided apical cell is developed, and the subsequent growth is the same as in the Bryales. The middle cell of the antheridium rudiment divides repeatedly by alternating transverse and longitudinal walls, and forms the long two-rowed stalk of the mature antheridium. On comparing the antheridium with that of the other Mosses, we find that it approaches Sphagnum in the long stalk, but in its origin and the growth of the antheridium itself, it resembles closely the higher Mosses.

The first archegonium also is derived immediately from the apical cell of the female branch, and the first divisions are the same as in the first antheridium. Here, too, the subsequent development corresponds exactly with that of the higher Mosses, and will be passed over. The ripe archegonium shows no noteworthy peculiarities, and closely resembles in all respects that of the other Mosses.

\section{The Sporophyte}

The more recent researches of Waldner (2) on the development of the sporogonium of Andreaa have shown clearly that in this respect also the latter stands between the Sphagnaceæ and the Bryales. The first division in the fertilised ovum is transverse and divides it into two nearly equal parts. The lower of these divides irregularly and much more slowly than the upper one. In the latter (Fig. 95, E), the first division wall is inclined, and is followed by a second one which meets it nearly at right angles, and by walls inclined alternately right 
and left-in short, has the character of the familiar "two-sided" apical cell. The number of segments thus formed ranges from eleven to thirteen. Each segment is first divided by a vertical median wall into equal parts, so that a cross-section of the young embryo at this stage shows four equal quadrant cells. The next divisions correspond to those in Sphagnum, and result in the separation of the endothecium and amphithecium. The formation of the archesporium, however, differs from Sphagnum, and is entirely similar to that of the higher Mosses. Instead of arising from the amphithecium as in the former, the archesporium is formed by the separation of a single layer of cells from the outside of the endothecium. All of the segments do not form spores, but only three or four, beginning with the third from the base. The two primary segments of the upper part of the embryo, like the corresponding ones in Sphagnum, go to form the foot, which is not so well developed, however, as in the latter. The originally one-layered archesporium later becomes double, and as in Sphagnum extends completely over the columella, which is thus not contintous with the tissue of the upper part of the sporogonium. As in Sphagnum also, no trace of the intercellular space formed in the amphithecium of the Bryales can be detected. A section of the nearly ripe capsule shows the club-shaped columella extending nearly to the top of the cavity. With the growth of the capsule the space between the inner and outer spore-sacs becomes very large to accommodate the growth of the numerous spores. The pseudopodium is exactly the same as in Sphagnum, and the vaginula and calyptra are present. The latter is much firmer than in Sphagnum, and like that of the Bryales.

\section{ARCHIDIUM}

The genus Archidium is one whose systematic position has been long a subject of controversy. It has usually been associated with the so-called cleistocarpous Bryales, but the researches of Leitgeb (8) seem to point to a nearer affinity with Andreaa.

The species of Archidium are small Mosses growing on the earth, and especially characterised by the small number, but very large size, of the spores contained in the sessile globular sporogonium. Hofmeister ( ( I), p. I60), was the first to study the development, and his account agrees in the main with Leit- 
geb's, except as to the relation of the columella and outer sporesac. The first divisions in the embryo correspond exactly to those in Andrea and the Bryales, and for a time the young embryo grows from a two-sided apical cell. The secondary divisions in the segments, however, are quite different from that observed in any other Moss, and are like those in the antheridium. Instead of the first wall dividing the segment into equal parts, it divides it very unequally. The second wall strikes this so as to enclose a central cell, triangular in cross-

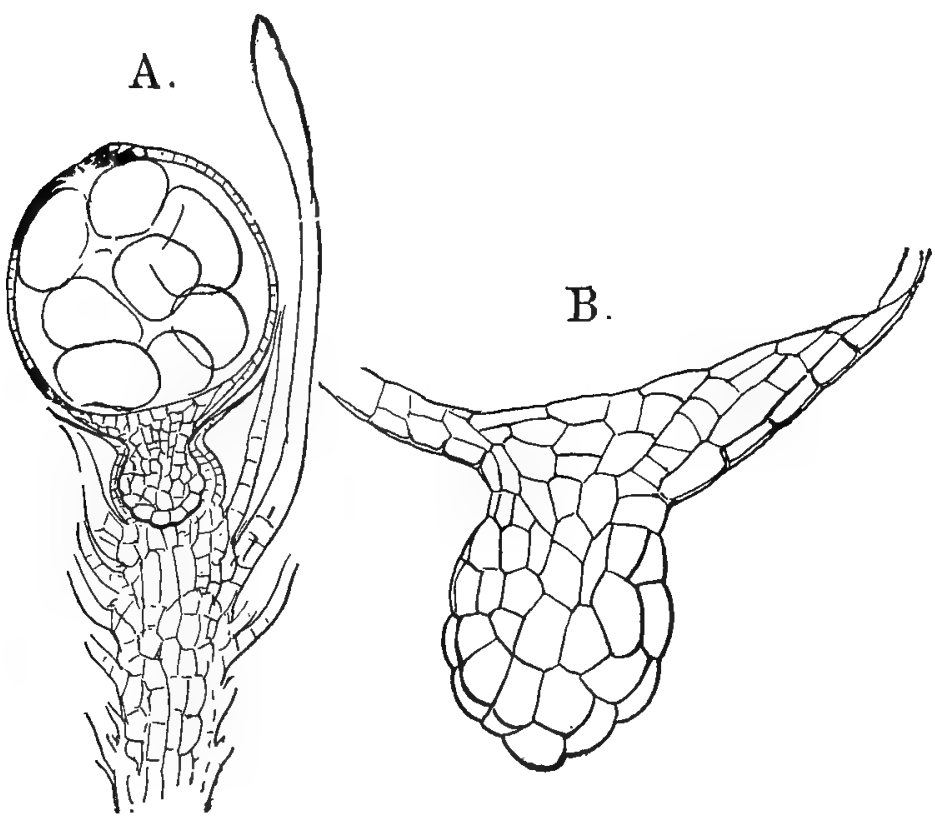

FIG. 96.-Archidium Ravenelii. A, Median section through a nearly ripe sporogonium, $X_{90} ; B$, base of the sporogonium, $\times 270$.

section, which with the corresponding cell of the adjacent segment forms a square. This square, the endothecium, does not therefore at first show the characteristic four-celled stage found in all other Mosses. The amphithecium becomes ultimately three-layered, and between the second and third layers an intercellular space is formed, as in the Bryales, but this extends completely over the top of the columella. The most remarkable feature, however, is that no archesporium is differentiated, but any cell of the endothecium may apparently become a spore 
mother cell. The number of the latter is very small, seldom exceeding five or six. They become rounded off, and gradually displace the other endothecial cells, which doubtless serve as a sort of tapetum for the nourishment of the growing spores. Each spore mother cell as usual gives rise to four spores, which are very much larger than in any other Moss. A section of the ripe sporogonium (Fig. 96), shows that only one of the primary three layers of amphithecial cells can be recognised except at the extreme apex and base. No seta is present, and a foot much like that of Andreaa, and penetrating into the tissue of the stem apex, is seen.

Leitgeb is inclined to look upon Archidium as a primitive form allied on the one hand to Andreaa and on the other to the Hepaticæ, possibly Notothylas. However, as his assumption that the latter has no primary columella has been shown to be erroneous, his comparison of the whole endothecium of $A r$ chidium with that of Notothylas cannot be maintained, as we have shown that in the latter, as in Anthoceros, the archesporium arises from the amphithecium, and not from the endothecium, as is the case in Archidium. Inasmuch as the gametophyte and sexual organs of Archidium are those of the typical Mosses, it seems quite as likely that the older view that $A r$ chidium is a degenerate form is correct. At any rate, until more convincing evidence can be brought forward in support of a direct connection between it and the Hepaticæ than the formation of the spores directly from the central tissue of the sporogonium, it cannot be said that the question of its real affinities is settled. 


\section{CHAPTER VI}

\section{THE BRYALES}

UNDER the name Bryales may be included all the other Mosses; for although the so-called cleistocarpous forms are sometimes separated from the stegocarpous Mosses as a special order, the Phascaceæ, the exact correspondence in the development of both the gametophyte and sporophyte shows that the two groups are most closely allied, the former being either rudimentary or degraded forms of the others.

With few exceptions the protonema is filamentous and shows branches of two kinds, the ordinary green ones with straight transverse septa, and the brown-walled rhizoids with strongly oblique ones, but the two forms merge insensibly into one another, and are mutually convertiblc. In a few forms, notably the genus Tetraphis, the protonema is thalloid, and as in Splagnum these flat thalli give rise to filamentous protonemal threads, which in turn may produce secondary thalloid protonemata. The genus Diphyscium (C. Muller (3), pp. I69, I70), develops upon the protonema solid, trumpet-shaped bodies. In some of the simpler forms, e. g., Ephemerum, the protonema is permanent, and the leafy buds appear as appendages of it; but in most of the larger Mosses the primary protonema only lives long enough to produce the first leafy axes, which later give rise to others by branching, or else by secondary protonemal filaments growing from the basal rhizoids. The early stages of development of the primary protonema are easily traced, as the spores of most Mosses germinate readily when placed upon a moist substratum. The ripe spores usually contain abundant chlorophyll and oil, and the thin exospore is brown in colour. The spore absorbs water and begins to enlarge until the exospore is burst, when the endospore protrudes 
as a papilla which grows out into a filament; or the endospore soinetimes grows out in two directions, and one of the papillæ remains nearly destitute of chlorophyll and forms the first rhizoid. The growth of the protonemal filaments is strictly apical, no intercalary divisions taking place except those by which lateral branches arise. If abundant moisture is present, the protonema grows with great rapidity and may form a dense branching alga-like growth of considerable extent. Sooner or later upon this arise the leafy gametophores. The development of the latter, as we have seen, also takes place abundantly

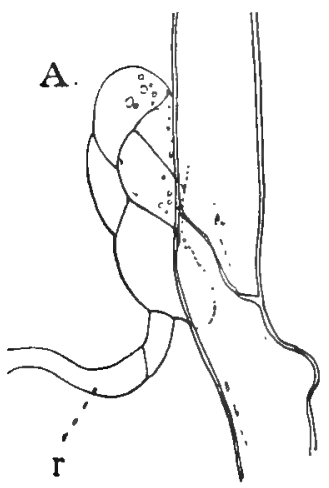

B.
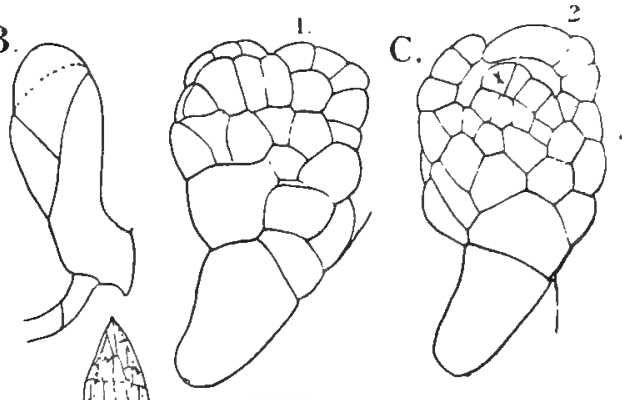

$\mathrm{D}$

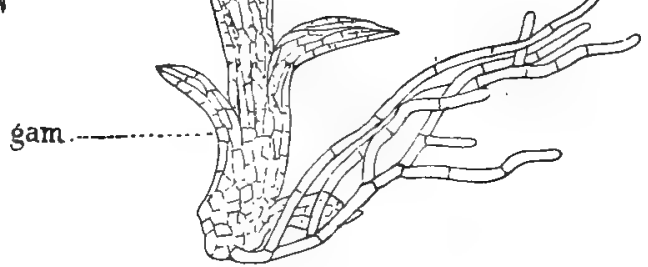

FiG. 97.-Funaria hygrometrica. A, Fragment of a protonemal branch with a young gametophoric bud; $r$, rhizoid; B, median optical section of the bud; C, older budI, surface view; 2, optical section; $x$, apical cell; D, protonema with a still older gametophore $(\mathrm{gam})$ attached. A-C, $\times 225 ; \mathrm{D}, \times 36$.

from the secondary protonemal filaments which may be made to grow from almost any part of the gametophore.

The development of the bud is as follows. From a cell of the protonema a protuberance grows out near the upper end. This is at first not distinguishable from a young protonemal branch, but it very soon becomes somewhat pear-shaped, and instead of elongating and dividing simply by transverse walls, the division walls intersect so as to transform it into a cell mass. 
After the cell is separated it is usually divided at once by a strongly oblique wall, which is then intersected by two others successively formed and meeting each other and the first-formed one at nearly equal angles, so that the terminal cell of the young bud (Fig. 97, A), has the form of an inverted pyramid; that is, by the first divisions in the bud the characteristic tetrahedral apical cell of the gametophore is established. From now on the apical cell divides with perfect regularity, cutting off three sets of lateral segments. From the base of the young gametophore the first rhizoid (Fig. 97, A, r), is formed at a very early period. The first two or three segments do not give rise to leaves, and the leaves formed from the next younger segments remain imperfect. Thus in Funaria hygrometrica these earliest formed leaves show no midrib. The young leaves rapidly elongate and completely cover up the growing point of the young bud, and are at first closely imbricated. Later, by the elongation of the axis, the leaves become more or less completely separated (Fig. 97, C, D). In Funaria, as well as in many other Mosses, buds are often met with that have become arrested in their development, lost their chlorophyll, and assumed a darkbrown colour. This arrest often seems to be the result of unfavourable conditions of growth, and under proper conditions these buds probably always will develop either directly or by the formation of a secondary protonema into perfect plants.

\section{Apical Growth of the Stem}

The growth of the stem of the fully-developed gametophore is better studied in one of the larger Mosses. The growth of the gametophore is so limited in length in Funaria that it is not so well adapted for this. Perhaps the best species for this purpose is the well-known Fontinalis antipyretica, which has already been carefully studied by Leitgeb (I). Amblystegium riparium, var. fluitans, was examined by me and differed in some points from Leitgeb's figures of Fontinalis. Fig. 98, A shows an exactly median longitudinal section through a strong growing point. Compared with Leitgeb's figures the apical cell is much deeper than in Fontinalis, and in consequence the young segments more nearly vertical. Here, as in Sphagnum, the first wall in the young segment divides it into an inner and an outer cell, from the latter of which alone are formed the lateral 
appendages of the stem. The inner cells of the segments by repeated longitudinal and transverse divisions form all the tissues of the axis. The second division wall in the segment, like that in Sphagnum, is at right angles to the first, but in Amblystegium it extends the whole breadth of the segment. By this division the outer of the two primary cells of the segment is divided into an upper cell, from which the leaf develops, and a lower one from which the outer part of the stem and the buds are formed. The leaves grow from a two-sided apical cell
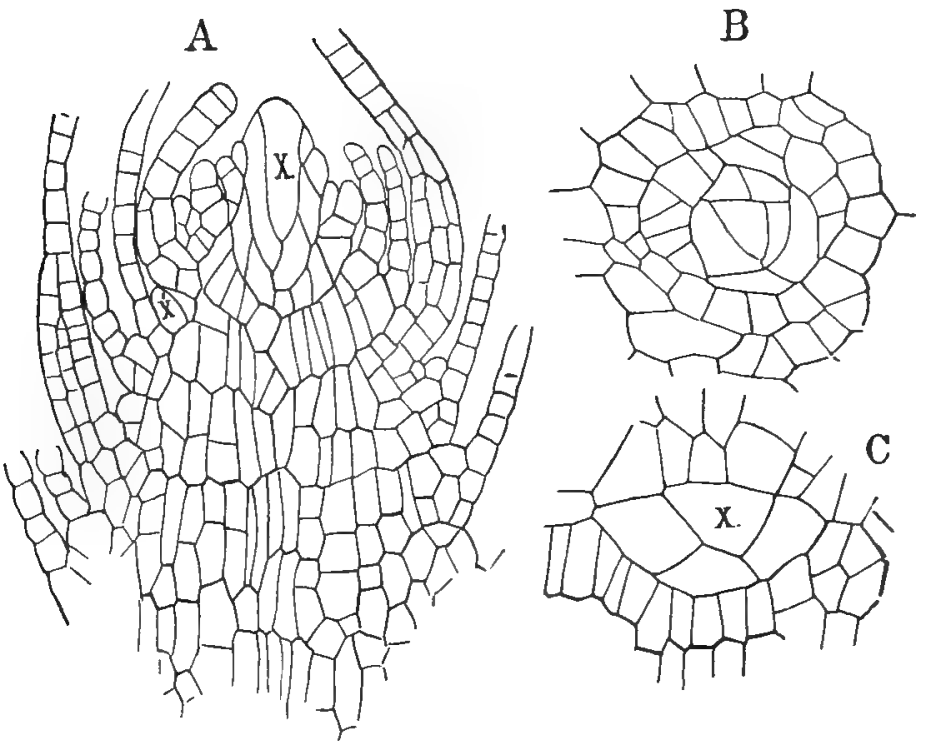

FIG. 98.-Amblystegium riparium, var. fuitans. A, Median longitudinal section of a strong shoot; $x$, apical cell; $x^{\prime}$, initial of a lateral branch, $X 250 ; \mathrm{B}$, transverse section through the apex, $\times 250 ; C$, similar section through a young branch, $\times 500$.

(Fig. 99), as indeed they seem to do in all Mosses, and the divisions proceed with great rapidity and the young leaves quickly grow beyond and surround the growing point. In Amblystegium, as in all the typical Bryales, the leaf has a welldeveloped midrib. The formation of this begins while the leaf is very young and proceeds from the base. In the middle row of cells (Fig. 99, C), a wall first arises parallel to the surface of the leaf, and this is followed by a wall in the cell on the lower side of the leaf (Fig. 99, D). By further divisions in all the 
cells of this central strand the broad midrib found in the mature leaf is developed. In Amblystegium all the cells of the midrib are alike and have thickened walls. The midrib projects on both sides of the leaf, but rather more strongly upon the lower side. In Funaria (Fig. IOO), the structure of the midrib is more definite. Here two rows of cells take part in the formation of the midrib. Each of these first divides as in Amblystegium by a wall parallel to the surface of the leaf, so that in cross-section the central part of the leaf shows a group of four cells, those
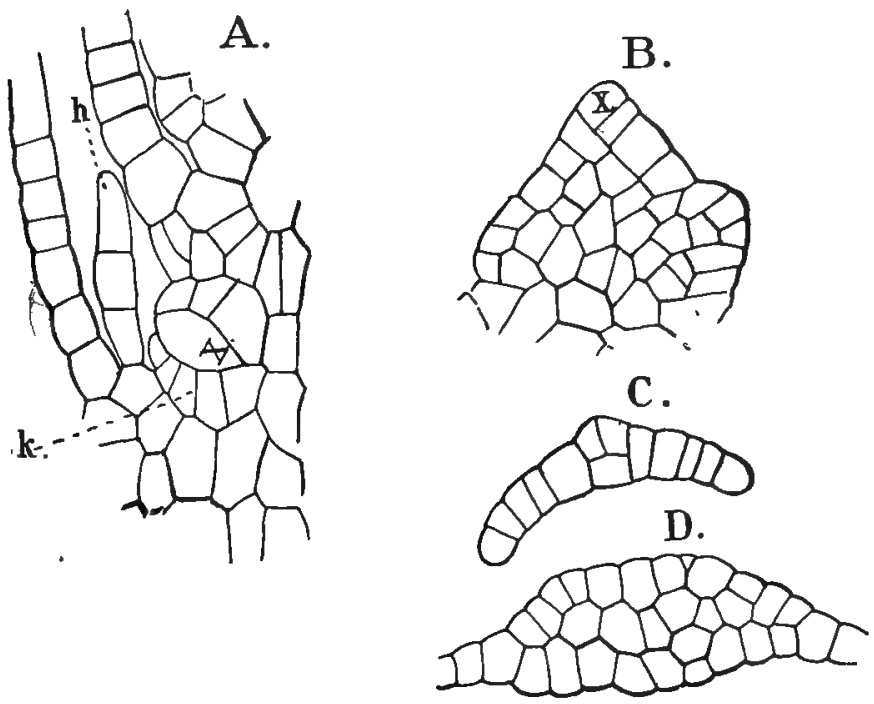

FIG. 99.-Amblystegium riparium, var. fuitans. $\mathrm{A}$, Longitudinal section of the stem passing through a young lateral branch $(k) ; h$, hair at the base of the subtending leaf; $\mathrm{B}$, horizontal section of a very young leaf, showing the apicai cell $(x)$; $\mathrm{C}$, $D$, transverse sections of young leaves, showing the development of the midrib. All the figures $\times 525$.

on the outer side being larger than the others. In the former the next wall is a periclinal one and divides the cell into an inner and an outer one. From the two inner cells by further division is formed the group of small conducting cells that traverse the centre of the midrib, while the outside cells together with those on the inner side of the midrib become much thickened and serve for strengthening the leaf. As in Amblystegium the lamina of the leaf remains single-layered, and its cells contain numerous large chloroplasts which, as is well-known, continue 
to multiply by division after the cells are fully grown. The marginal cells in the leaf of Funaria are much narrower than those between them and the midrib, and their forward ends
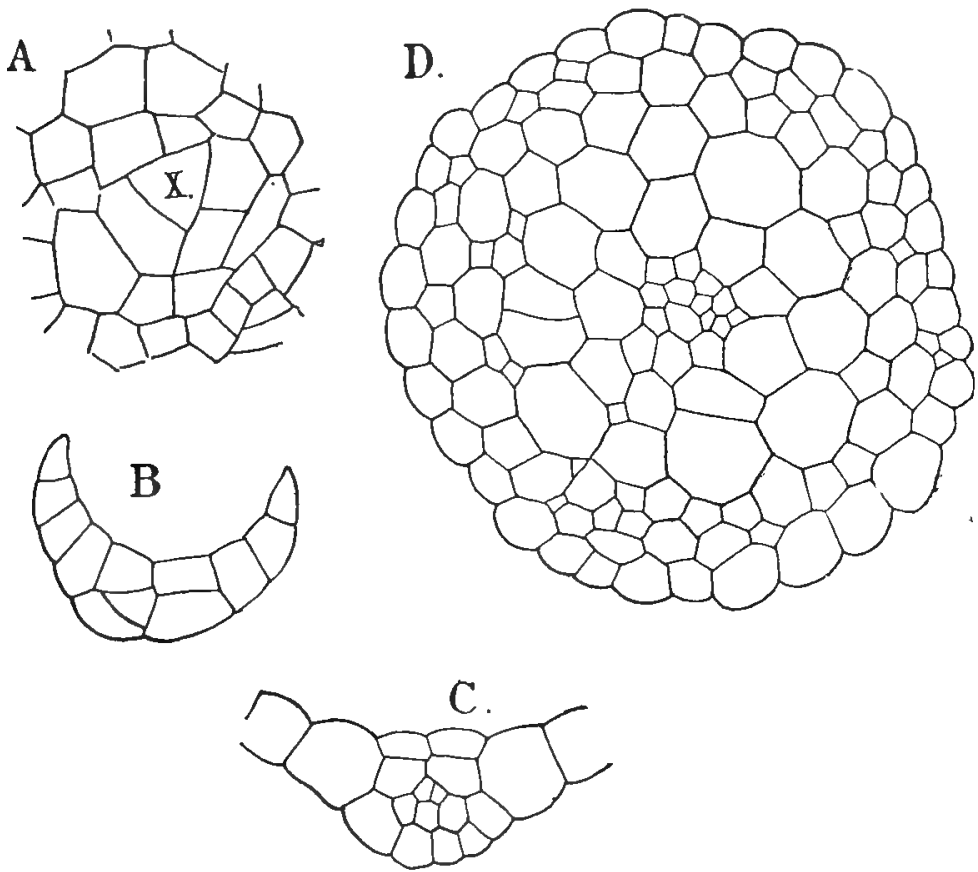

FIG. 100.-Funaria hygrometrica. A, Transverse section of the apex of a young shoot, $\times 515 ; \mathrm{B}, \mathrm{C}$, cross-sections of young leaves, $\times 515 ; \mathrm{D}$, cross-section of the stem, $\times 257$.

often project somewhat, giving the margin of the leaf a serrate outline, which is also common in many other Mosses.

\section{The Branches}

For the study of the branching of the stem, Amblysteginm again is much better than Funaria, whose short stem and infrequent branching makes it difficult to find the different stages. In Amblysteginm, however, every median section will show some of the stages, and it is easy to follow out all the details, as has already been done in Fontinalis by Leitgeb. The lateral shoot originates from a basal cell of the segment below the middle of the leaf. It is very easily seen that it belongs to the 
same segment as the leaf standing above it, and therefore is not axillary in its origin. The mother cell of the young branch projects above the surrounding cells, and in it are formed in succession three oblique intersecting walls which enclose the narrow pyramidal apical cell (Figs. 98, 99). The secondary divisions in the first set of segments are not so regular as in the later ones, but the bud rapidly grows, and very soon the perfectly regular divisions of the young segments are established. So far as investigations have been made upon other genera, they follow the same line of development as Amblystegium, Fontinalis, and Sphagnum.

Where the growth of the main axis is stopped by the formation of sexual organs, a lateral branch frequently grows out beyond the apex of the main axis, as in Sphagnum, and thus sympodia arise. In other cases, where the growth of the lateral branches is limited, characteristic branch systems arise, such as we find in Thuidium or Climacium (Fig. 86).

Compared with Amblystegium, the growing point of Funaria and other Mosses of similar habit is much broader. and the apical cell not so deep. The arrangement of the segments is much the same, except that the original threeranked arrangement of the segments which is retained in Fontinalis $^{1}$ is replaced in most Mosses by a larger divergence, owing to a displacement like that in Sphagnum.

A cross-section of the older stem (Fig. Ioo, D), shows in most Bryales a central cylinder of small thin-walled cells surrounded by a large-celled cortical tissue, which in the older parts of the stem often has its walls strongly thickened and reddish brown in colour. An epidermis, clearly recognisable as such, cannot usually be detected. The outer cells contain chlorophyll, which is wanting in the central cylinder.

The rhizoids in Funaria grow mainly from the base of the stem, and the first ones arise very soon after the young bud is formed. Their growth, like that of the protonemal branches, is strictly apical, and they branch extensively. The young ones are colourless, but as they grow older the walls assume a deep brown colour. Usually the division walls in the rhizoids are strongly oblique. Their contents include more or less oil, and where they are exposed to the light, chlorophyll.

${ }^{1}$ This is only strictly true in the smaller branches. 
VI.

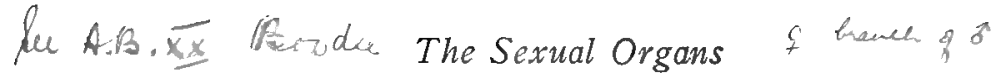

I Funaria is strictly dioecious. The male plants (Fig. IOI, A) are easily distinguished by their form. They are about I $\mathrm{cm}$. in height, with the lower leaves scattered, but the upper
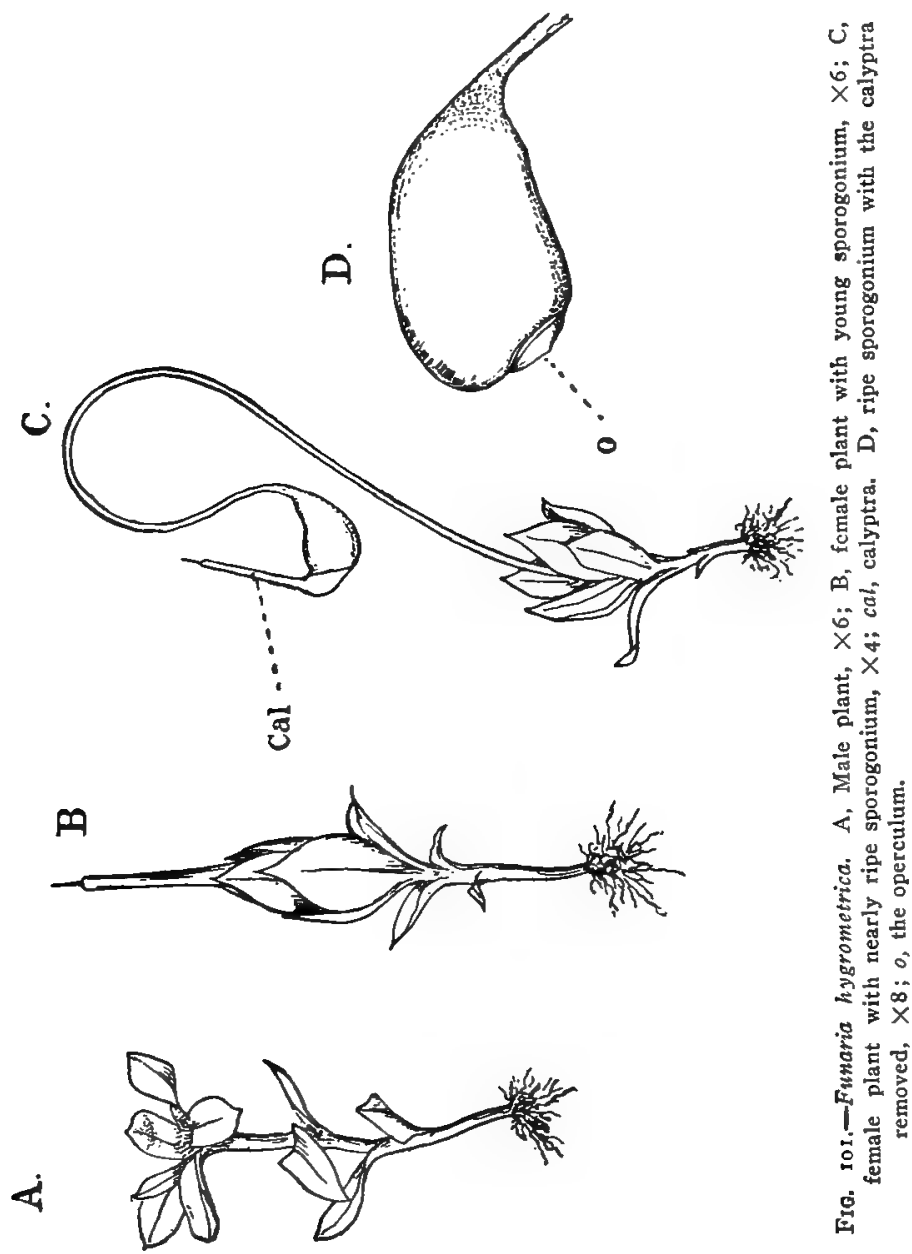

ones crowded so as to present much the appearance of a flower whose centre forms a small reddish disc. These male plants either grow separately or more or less mixed with the females. 
Whether the first antheridium, as in Andreca and Fontinalis, arises from the apical cell is doubtful, and it is impossible to trace any regularity in the order of formation of the very numerous antheridia. Except in old plants, all stages of development are found together, and the history of the antheridium may be easily followed. A superficial cell projects above its neighbours, and this papilla is cut off by a transverse wall.
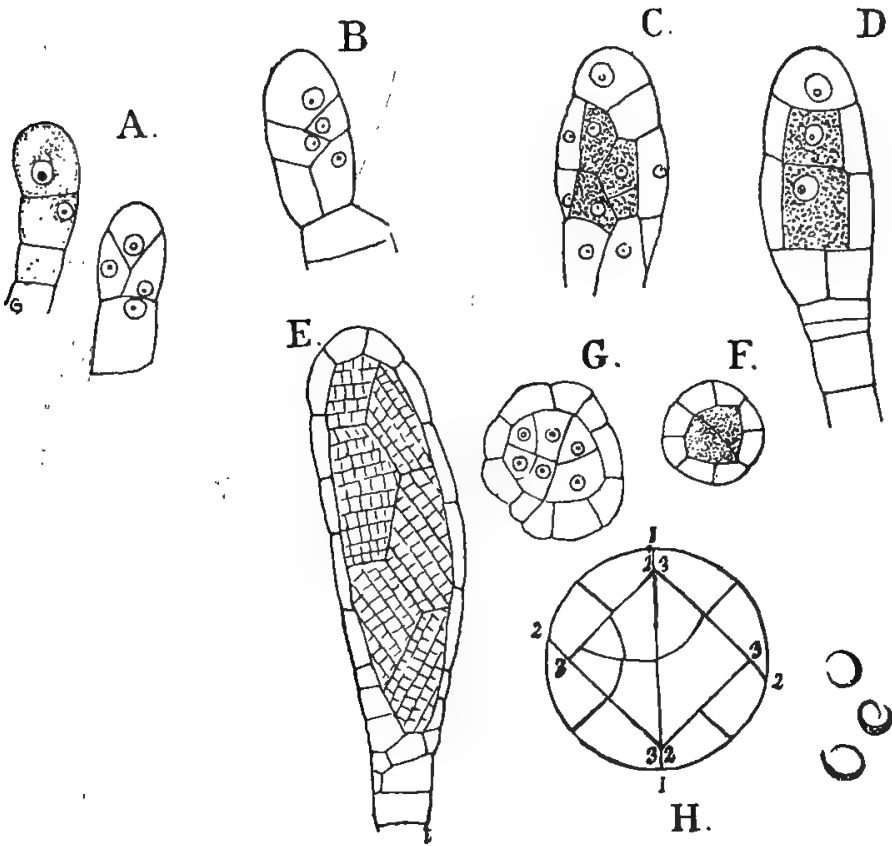

$\mathrm{D}$

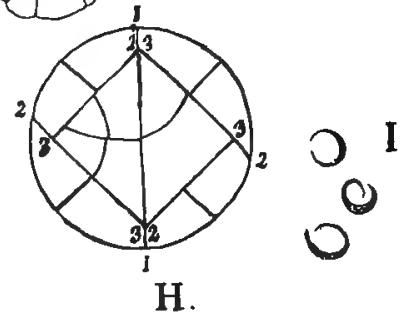

FIG. 102.-Funaria hygrometrica. Development of the antheridium. A-D, Longitudinal sections of young stages, $\times 600 ; D$ is cut in a plane at right angles to $C$; $E$, optical section of an older stage, $\times 300 ; G, F$, cross-sections of young antheridia, $\times 600$; $H$, diagram showing the first divisions in the antheridium; $I$, young spermatozoids, $\times 1200$.

The outer cell either becomes at once the mother cell of the antheridium, or other transverse walls may occur, so that a short pedicel is first formed (Fig. I02, A). Finally in the terminal cell, as in Andreaa, two intersecting walls are formed enclosing a two-sided apical cell, from which two ranks of segments are cut off in regular succession (Figs. A, B, C). The number of these segments is limited, in Funaria not often exceeding seven, and after the full number has been formed, the 
apical cell is divided by a septum parallel with its outer face into an inner cell, which with the inner cells of the segments forms the mass of sperm cells, and an outer cell which produces the upper part of the wall. Before the full number is completed, the secondary divisions begin, proceeding from the base upward. These are very regular, and correspond closely to those in the antheridium of the Jungermanniaceæ, and can only be clearly made out by comparing transverse and vertical sections of the young antheridium. Fig. I02, $\mathrm{H}$, shows a diagram illustrating this: $I$ is the wall separating two adjacent segments, and 2 the first wall formed in the segment itself. The wall 2 , it will be seen, starts near the middle of the periphery of the segment and strikes the wall I far to one side of the centre, so that the segment is thus divided into two cells of very unequal size, although their peripheral extent is nearly equal. The next wall (3) strikes both the wall I and 2 at about equal distances from the periphery, and thus each segment is divided into an inner cell which in cross-section has the form of a triangle, and two peripheral cells. The latter divide only by radial walls, and give rise to the single-layered wall of the antheridium. The inner cells of the segments by further division in all directions form the mass of sperm cells. The first division wall in the central cell starts from near the middle of the segment wall and curves slightly, so that the two resulting cells are unequal in size. From this first division wall usually two others having a similar form extend to the peripheral cells, and these are next followed by others nearly at right angles to them. After this transverse and longitudinal walls succeed with such regularity that the limits of the primary segments remain perfectly evident until the antheridium is nearly full grown.

The central cells in the fresh antheridium are strongly refringent and in stained sections show a much more granular consistence than the outer ones. The nucleus, as in other cases studied, loses its nucleolus before the formation of the spermatozoids begins. The latter in their structure and development correspond with those of Sphagnum, but owing to their smaller size are not favourable for studying the minute details of development.

In the peripheral cells are numerous chloroplasts which in the ripe antheridium lie close to the inner wall of the cell. As 
the antheridium ripens, these gradually assume a bright orangered colour. The development of the stalk varies in different cases. Sometimes it consists of a row of several cells, sometimes the antheridium is almost sessile. The lowermost seg-
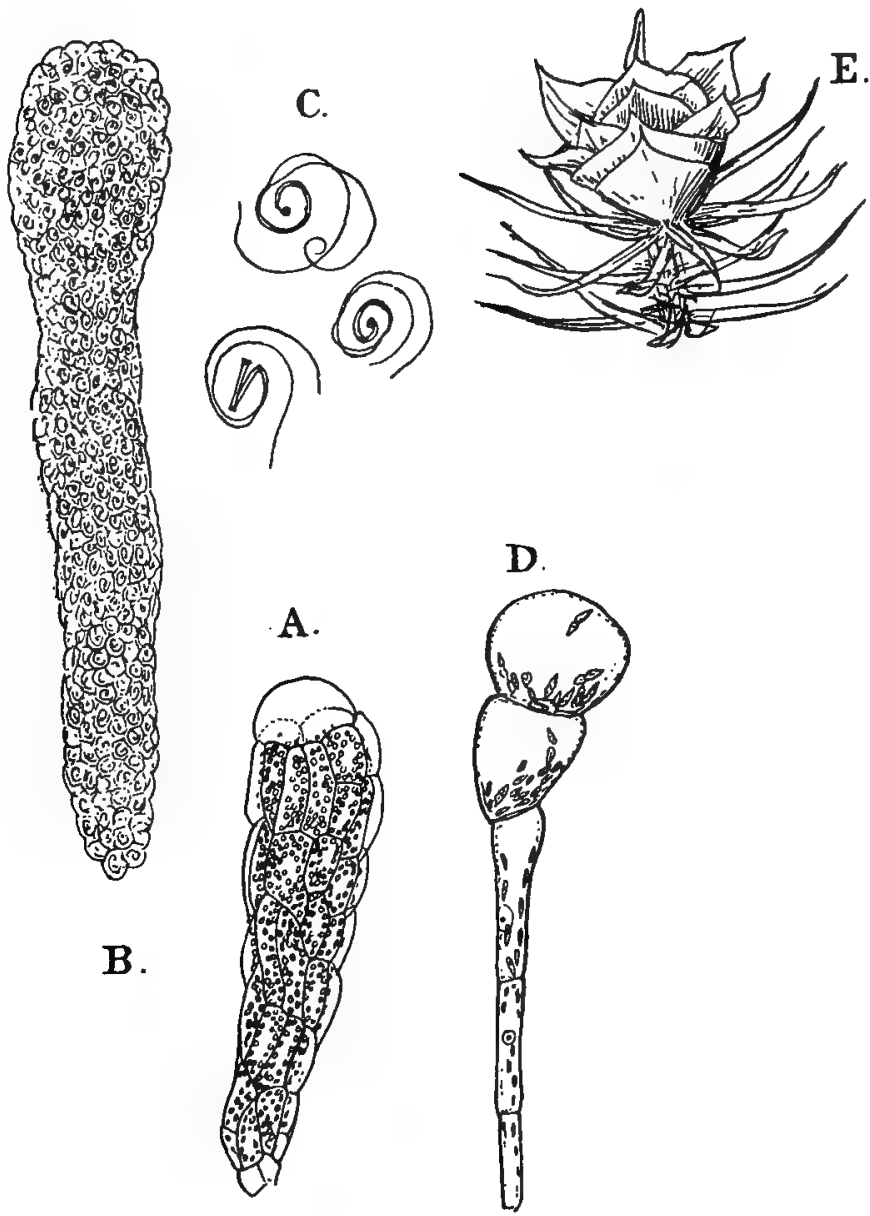

Fig. 103.-Funaric hygrometrica. A, Antheridium that has just discharged the mass of sperm cells (B), $X_{300 ; C}$, spermatozoids, $X_{13} 00 ; D$, paraphysis, $\times 300 ; E$, male "flower" of Atrichum undulatum, $\times 6$.

ments of the apical cell help to form the upper part of the stalk, and sometimes the two lowest seem to take no part in the formation of the sperm cells. There is no absolute uniformity in the cell divisions of the stalk, which varies in the arrange- 
ment of the cells in different individuals in the same inflorescence.

The ripe antheridium opens promptly when placed in water. At the apex there is usually present a single cell decidedly larger than its neighbours (Fig. IO3, A), or sometimes there are two opercular cells (Goebel (22), p. 239). All of the parietal cells become strongly turgescent and this is especially the case in the terminal cell, which finally bursts and forms a narrow opening through which the mass of sperm-cells is forced out by the pressure of the distended parietal cells, and the swelling of the mucilage derived from the disintegration of the walls of the sperm-cells. The opercular cell in Funaria is not destroyed, as a rule, and is still very conspicuous after the spermcells have been discharged, so that the empty antheridium, except for a slight contraction of its lower part, looks very much as it did before the escape of the sperm-cells. In some other Mosses, e. g., Polytrichum, Catharinia, the opercular cap consists of several cells (Goebel, 1. c.). The whole mass of spermcells is thrown out without separating the cells, and in this stage the walls of the sperm-cells are still very evident. It sometimes happens that the mass is thrown out before the spermatozoids are complete, in which case they never escape. If, however, the spermatozoids are mature, they show active motion within the sperm-cells while these are still in connection, and are set free by the gradual dissolution of the mucilaginous walls. The free spermatozoid is much like that of Sphagnum, but the body is somewhat shorter. The cilia are relatively very long and thick, and as in all Bryophytes but two in number. A small vesicle can usually be seen attached to the posterior end.

Growing among the antheridia are found peculiar sterile hairs, or paraphyses. These in Funaria are very conspicuous, and consist of a row of cells tapering to the base, and very much larger at the apex. The terminal cell, or sometimes two or three of them, are almost globular in form and very much distended. All the cells of the paraphyses contain large chloroplasts, which in the globular end cells are especially conspicuous and are often elongated with pointed ends.

The archegonia are formed while the female plant is still very small, and it is much more difficult to recognise the female plants than the males. The archegonia are ripe at a time when 
the female plant is still but a few millimetres in height. In this case there is no doubt that the apical cell forms an archegoniun directly, but not necessarily the first one, which arises usually from one of the last-formed segments. The elongation of the axis of the female branch is but slight, even in the later stages,

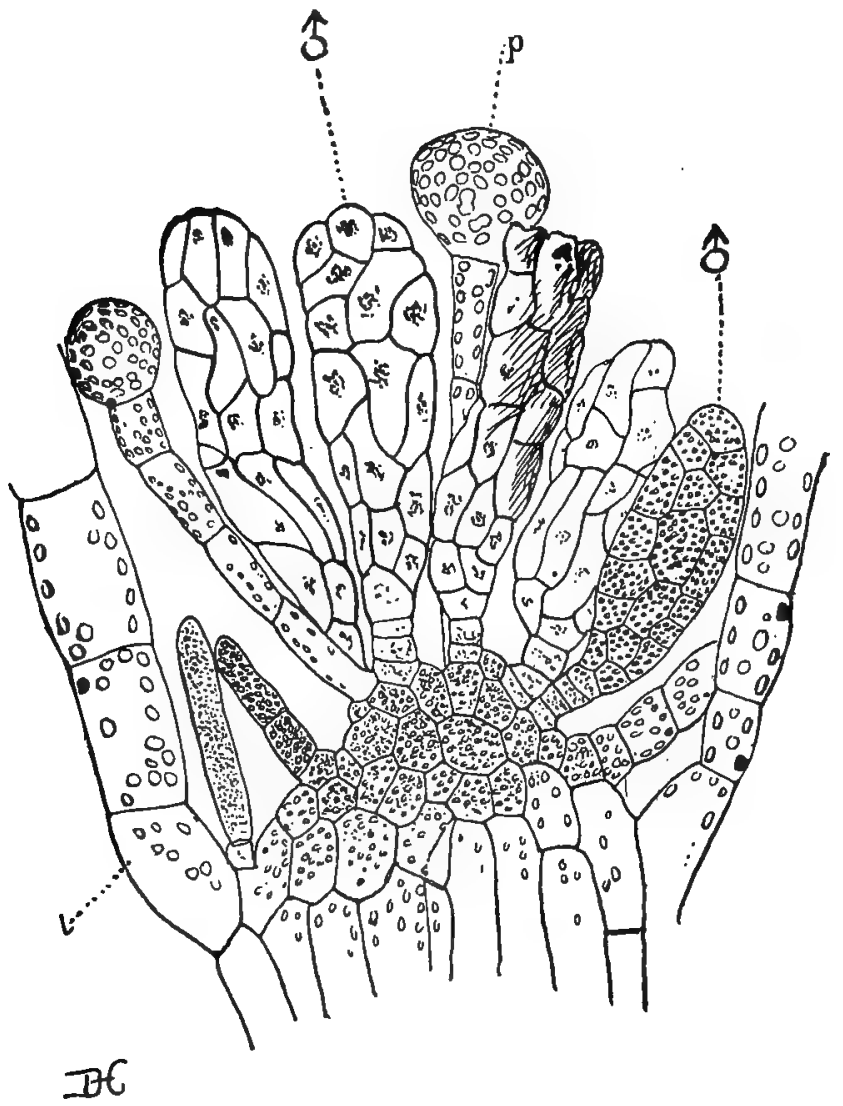

Fig. 104-Longitudinal section through the apex of a male plant of $F$. hygrometrica, $\times 300 ; L$, leaf; $\delta$, antheridia; $p$, paraphyses.

and the plant remains bud-like even after the sporogonium is developed. In regard to the development of the leafy axis, or gametophore, therefore, Funaria offers a very marked contrast to Fontinalis or Sphagnum, where the gametophore reaches such a large size and has practically unlimited growth.

The young archegonia are quite colourless, and the details 
of their structure may be made out without difficulty. The first division separates a basal cell from a terminal cell, which is the mother cell of the archegonium. In the latter three walls



now arise, as in the Hepaticæ and Andrece, but in Funaria these do not all reach to the basal wall, but intersect at some distance above it, so that they enclose a tetrahedral cell, pointed 
below instead of truncate. The tetrahedral cell now divides by a transverse wall into an upper cell, corresponding to the "cover cell" of the Liverwort archegonium, and an inner one (Fig. I05, A), which gives rise to the primary neck canal cell, the egg, and the ventral canal cell. From this point, however. the development proceeds in another way, and follows the course observed in Andrecea. The cover cell, instead of dividing by quadrant walls, has a regular series of segments cut off from it, and acts as an apical cell. These segments are cut off parallel both to its lateral faces and base, and thus form four rows of segments, the three derived from the lateral faces forming the outer neck cells, and the row of segments cut off from the base constituting the axial row of neck canal cells. Each row of lateral segments is divided by vertical walls, and forms six rows, which later divide by transverse walls as well so that the number of cells in each row exceeds the original number of segments. This is not the case with the canal cells, which, so far as could be determined, do not divide after they are first formed. The wall of the venter owes its origin entirely to the three peripheral cells formed by the other primary walls in the archegonium mother cell. This becomes two-layered before the archegonium is mature, and is merged gradually into the massive pedicel, which in the Mosses generally-is much more developed than in the Hepaticæ. In the older archegonia the neck cells do not stand in vertical rows, but are somewhat obliquely placed, owing to a torsion of the neck during its elongation. From the central cell the ventral canal cell is cut off, as usual, but is relatively smaller than is usual among the Hepaticæ. The egg shows a distinct receptive spot, which is not, however, very large. The rest of the egg shows a densely granular appearance, and the moderately large nucleus shows very little colourable contents, beyond the large central nucleolus. The terminal cells of the open archegonium diverge widely, giving the neck of the archegonium a trumpet shape (Fig. I05, F). Usually some of the cells become detached and are thrown off.

Holferty (I) has made a careful study of the archegonium in Mnium cuspidatum and finds that the archegonium in its earliest stages grows from a two-sided initial cell like that of the antheridium. This is later replaced by the usual tetrahedral apical cell found in other species. After a more or less 
massive pedicel is formed, the apical cell divides, as in Funaria, into an inner and an outer cell. The former, as usual, gives rise to the central cell, from which later arise the egg and ventral canal cell, and a second cell, which is the primary neck canal cell. The latter, according to Holferty, undergoes further divisions and the secondary canal cells, cut off from the base of the apical cell, also undergo further divisions. There may be as many as ten neck canal cells finally developed.

Holferty also describes and figures several abnormal structures, intermediate in character between the archegonium and antheridium.

While in Funaria and Polytrichum the plants are regularly diøcious, in many Mosses this is not the case. Both antheridia and archegonia may occur in the same "inflorescence," or they may be in separate groups upon different parts of the same plant. Some doubt has been thrown upon the nature of the socalled hermaphrodite inflorescences, and it is possible that they are really composed of distinct but closely approximated inflor, escences. (Satter (2) ; ' see Ruhland (I), pp. 204, 205.)

\section{The Sporophyte}

The first (basal) wall in the fertilised ovum divides it into an upper and lower cell, as in Sphagnum and Andreaa, and the next divisions correspond closely to those in the latter. In both cells a wall is formed intersecting the basal wall, but not at right angles. This is especially the case in the upper cell, where a second wall strikes the first one nearly at right angles, and establishes the two-sided apical cell by which the embryo grows for a long time. In the lower cell the divisions are somewhat less regular, but here also it is not uncommon to find a somewhat similar state of affairs, so that the embryo may be said to have two growing points, although the lower end shows neither such regular nor so active growth as the upper one. In the latter the divisions follow each other with almost mathematical precision. There seems to be no rule as to how many segments are cut off from the apical cell before it ceases to function as such, but there are more than in Andreaa, and the embryo soon becomes extremely elongated. A series of transverse sections of the young sporogonium shows very beatifully the succession of the first walls in the young segments. In a section just below the apex (Fig. 107, A), each segment is seen to 

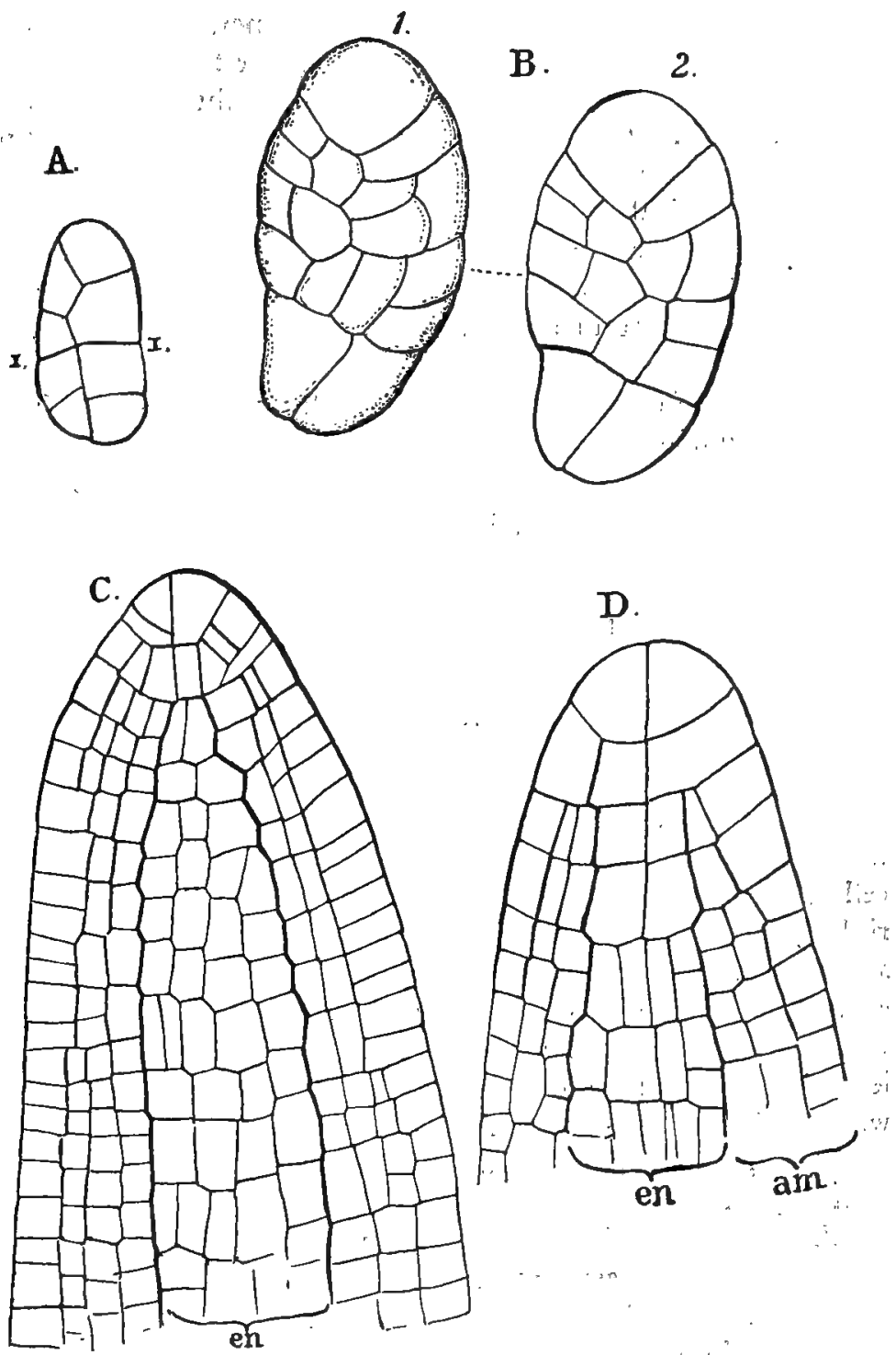

Fig. 106.-Funaria hygrometrica. Development of the embryo., A, Optical section. of a very young embryo; B, C, surface view and optical section of an older one, $\times 600 ; C, D$, longitudinal sections of the apex of older embryos, $\times 600$; $e n$, endothecium; am, amphithecium. 
be first divided by a median wall into two equal cells. In Funaria usually the next division wall is periclinal, and at once separates endothecium and amphithecium. In most other Bryineæ that have been examined, however, and this may also occur in Funaria (see Fig. I07, A), the second walls formed in the young segments are anticlinal, and it is not until the third set of walls is formed that the separation of endothecium and amphithecium is complete. The next divisions (Fig. IO7, C), are in the amphithecium, and separate it into two layers. In the endothecium a series of walls is next formed, almost exactly repeating the first divisions in the original segment (Figs. D,



FIG. 107.-Five transverse sections of a young embryo of $F$. hygrometrica. A, Just below the apex, the others successively lower down; en, endothecium, $X_{450}$,

E), and transforming it into a group of four central cells and eight peripheral ones. Each of the latter divides twice by intersecting walls, so that a group of about sixteen cells (Fig: I08, A), occupies the middle of the endothecium. The eight peripheral cells divide by radial walls, after which each of these cells is divided by a periclinal wall into an outer and an inner cell (Fig. Io8, B), and the outer cells divide rapidly by radial walls and form the archesporium. The single layer of cells immediately within, and therefore sister cells of the primary. archesporial ones, is the inner spore-sac.

The account of the development of the endothecium here given differs slightly from the account of Kienitz-Gerloff (2). 
It was found first that there was not the absolute constancy in the number of cells given by him; thus in Fig. I08, A there are only fourteen cells in the inner part of the endothecium, and although there are sixteen cells in the outer row their position is not perfectly symmetrical. Again the periclinal division of the cells of the inner spore-sac takes place later than he states is the case.

In the eight primary cells of the amphithecium there first arise periclinal walls that divide each cell into an inner small cell in contact with the endothecium, and an outer larger one.

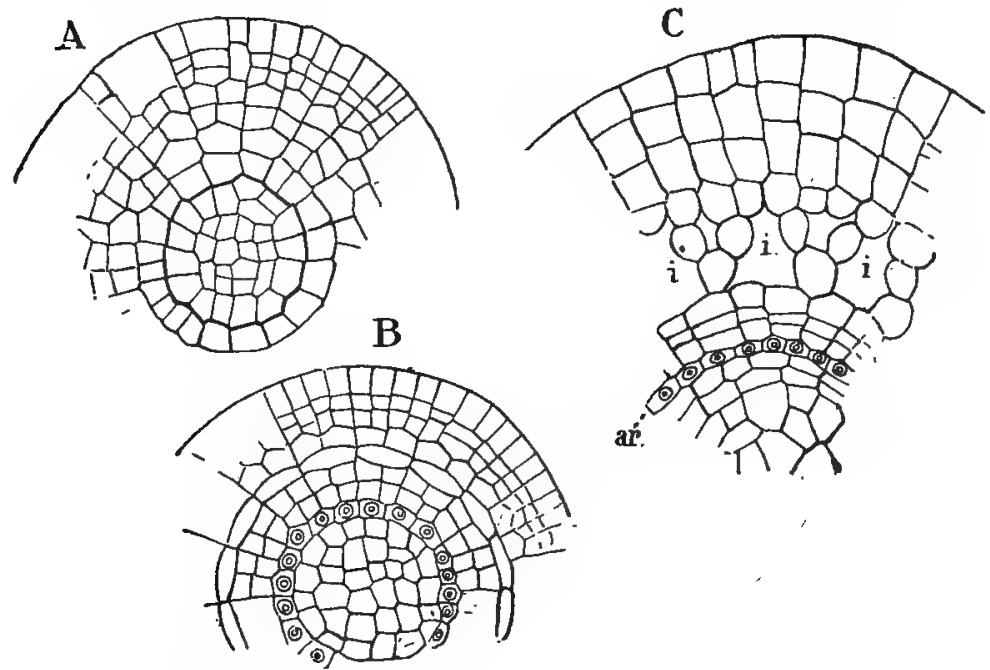

Fic. 108. -Three transverse sections of an older sporogonium of $F$. hygrometrica, $\times 400$; $a r$, archesporium; $i$, intercellalar spaces.

This first division separates the wall of the capsule from the outer spore-sac. The latter next divides by radial and transverse walls, and later by periclinal walls into two layers (Fig. I08). Almost coincident with the latter, the rows of cells lying immediately outside it show a very characteristic appearance. They cease to divide, and with the rapid growth in diameter of the capsule become much extended both vertically and laterally, but are compressed radially. It is between these cells and the spore-sac that the characteristic air-space found in the capsule is formed. This is first evident shortly after the enlargement of the base of the capsule begins. The devel- 
opment can be very easily followed in longitudinal sections made at this stage. The formation of the space begins at the base of the capsule and proceeds toward the top. The line of cells bordering on the spore-sac is very easily followed, owing to their being so much larger than the neighbouring ones. As this is followed down, it is found that at the base of the capsule the cells are separated by large intercellular spaces, which become less marked toward the apex. With the rapid enlargement of the capsule these spaces become very large, and sections made a little later show that during this process the cells remain in contact at certain points, and form short filaments that extend across the space and unite the wall of the capsule with the outer spore-sac. At the base of the capsule the formation of intercellular spaces is not confined to the single layer of cells but involves the whole central mass of tissue, which becomes thus transformed into a bundle of filaments connecting the columella with the basal part (apophysis) of the capsule. The innermost of the two layers of cells between the archesporium and the air-space finally undergoes a second periclinal division, and in the full-grown sporogonium the archesporium is bounded on the outside by three layers of cells.

The differentiation into seta and capsule takes place late in Funaria, and the first indication of this is the enlargement of a zone between the two, forming the apophysis, which at this stage (Fig. I09), is much greater in diameter than the upper part of the capsule. Sections through the apophysis and seta show a less regular arrangement of the cells than in the sporiferous part of the capsule, but the general order of cell-succession is the same, except for the formation of the archesporium. Almost as soon as the capsule is recognisable, . the first indication of the operculum or lid becomes evident. About half-way between the extreme apex of the sporogonium and the top of the apophysis, a shallow depression is noticed extending completely round the capsule and separating the sharply conical apex from the part below. An examination of a longitudinal section at this point shows that at the point of separation the epidermal cells of the opercular portion are much narrower than those immediately below. Examining the tissues farther in, the archesporium is seen to extend only to a point opposite the base of the operculum, and the same is true of the row of large cells where the air-space is formed. If a 


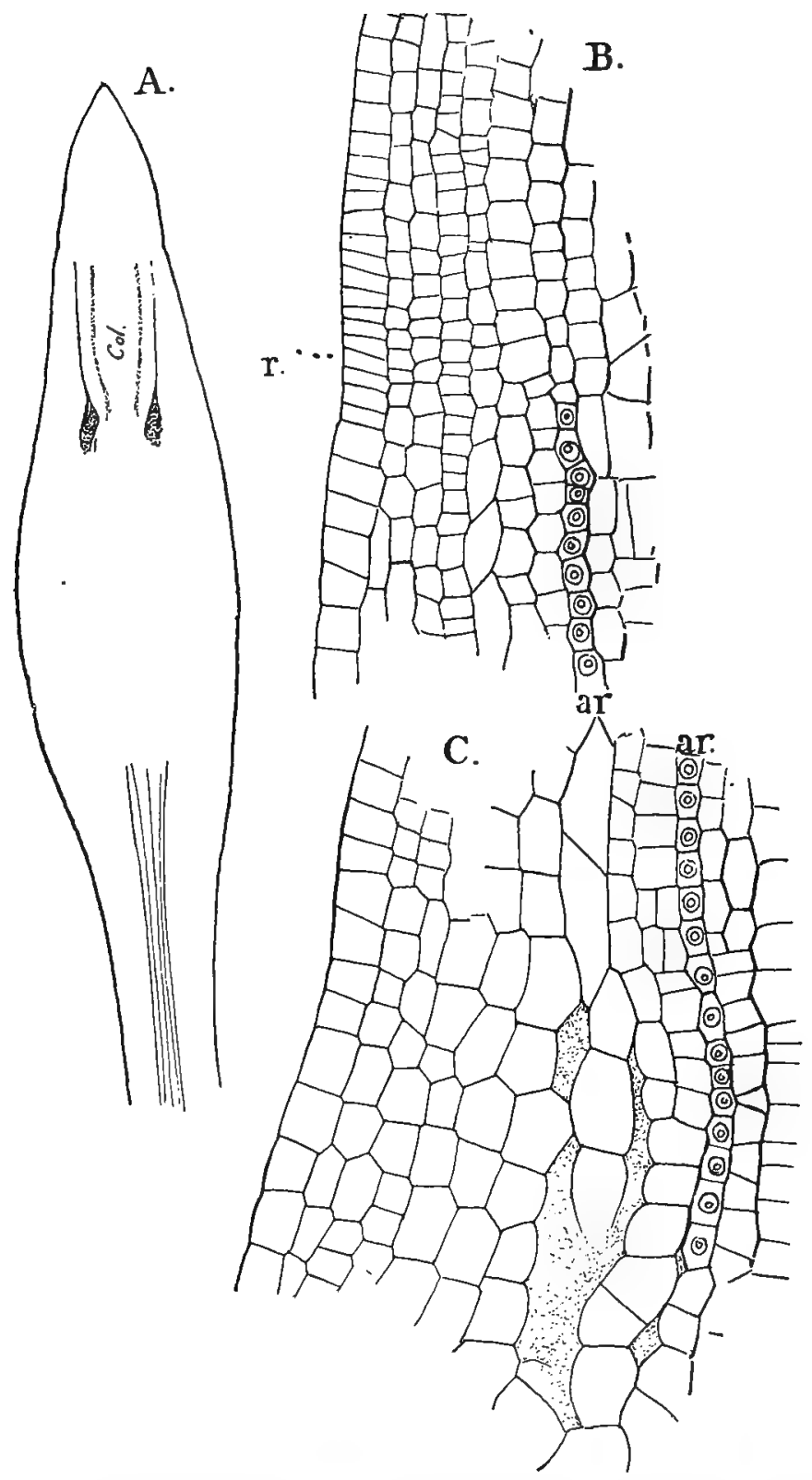

Frg. 10g.-Funaria hygrometrica. A, Longitudinal section of a sporogonium showing the first differentiation of its parts, $X$ about $96 ; B$, the upper part of the same, $X 600 ; r$ marks the limits of the theca and operculum; $C$, basal part of the capsule of the same, $\times 600$. The intercellular spaces are beginning to form; $a$, archesporium; col, columella. 
similar section is made through an older capsule (Fig. I IO), it is evident at once that the enlargement takes place mainly below the junction of the operculum, and there is also a similar but less pronounced increase in diameter in the operculum itself ; but there is a narrow zone at the junction of the operculum and capsule, where the epidermal cells increase but little in depth, while those above this point become very much larger and project beyond them. This narrow zone of cells marks the point where when ripe the operculum becomes detached. The latter,



FIG. rro.-Longitudinal section of an older capsule of $F$. hygrometrica; $i$, intercellular spaces; sp, archesporium; $r$, cells between operculum and theca, $\times 525$.

up to the time the sporogonium is ripe, is composed of a close tissue without any intercellular spaces. The epidermal cells. seen from the surface, are seen to be arranged in spiral rows running from the base to the apex. Its central part is made up of large thin-walled parenchyma, continuous with the tissue of the columella. The archesporium, therefore, is not continuous over the top of the columella, as in Sphagnum and Andrexa, but is cylindrical. The archesporium forms simply a single layer of small cells, and occupies a very small part of the sporo- 
gonium, much less, relatively, than in any of the forms hitherto described. Before the final division of the spores it divides more or less completely into two layers. The cells resulting from this last division are the spore mother cells, which separate soon after their formation and lie free in the space between the inner and outer spore-sacs, where each one divides into four tetrahedral spores.

In the operculum, as the capsule approaches maturity, the differentiation of annulus and peristome takes place. The annulus consists of five or six rows of cells that occupy the
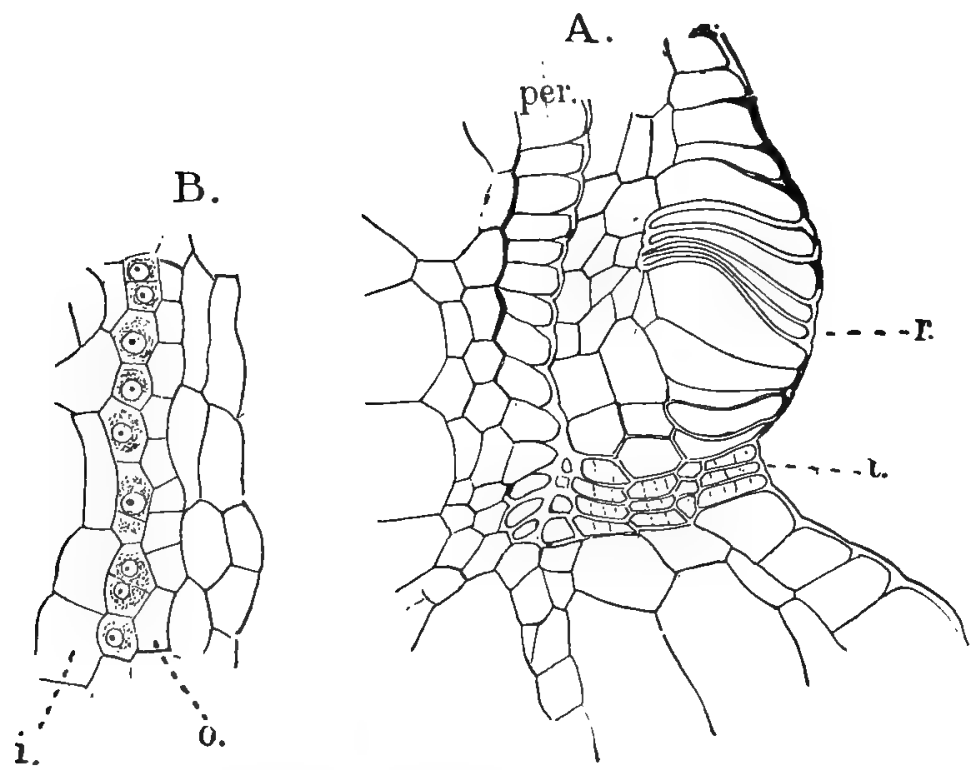

FIG. II1.-A, Longitudinal sections of a nearly ripe capsule of $F$. hygrometrica, $\times 260$; per, peristome; $r$, annulus; $t$, thickened cells forming the margin of the theca; $\mathbf{B}$, the sporogenous cells shortly before the final divisions; $i$, inner; 0 , outer sporesac, $\times 525$.

periphery of the broadest part of the operculum. The upper rows of cells are very much compressed vertically, but are greatly extended radially and have their walls thicker than those of the neighbouring cells. These thickened annulus cells form the rim of the loosened operculum. The two lower rows of annulus cells-the annulus proper-have thin walls and finally become extremely turgescent. It is the destruction of these 
cells, when the capsule is ripe, that effects the separation between the operculum and theca.

The peristome arises from the fifth layer of cells from the outside of the operculum. If a median longitudinal section of a nearly ripe capsule is examined, the row of cells belonging to this layer (Fig. I I I, per), is at once seen to have the outer walls strongly thickened, and this thickening extends for a short distance along the transverse walls. The inner walls of the cells also show a slight increase in thickness, but much less marked than the outer ones. A similar thickening of the cell walls occurs also in about three rows of cells which run from

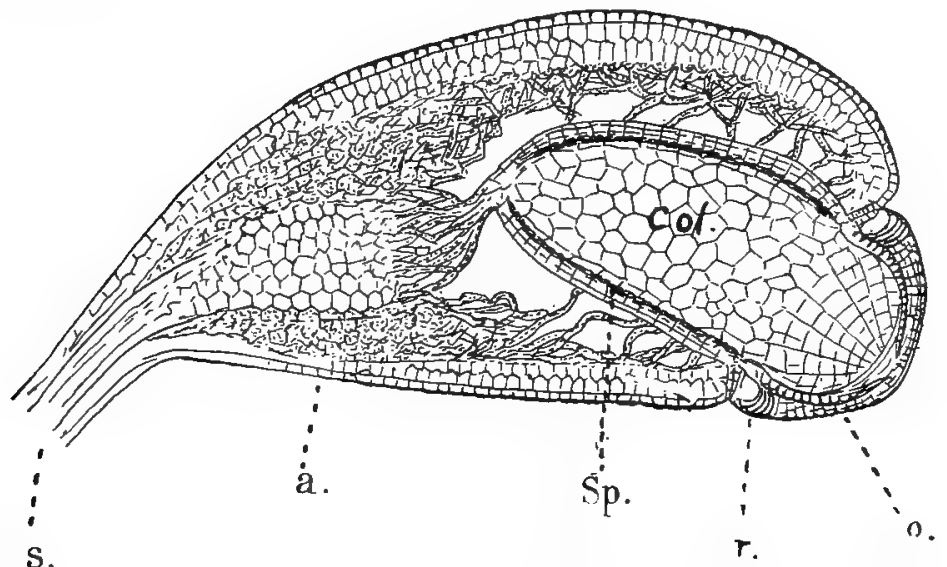

FIG. 112.-Longitudinal section of a fully-developed sporogonium of Funaria hygrometrica, $\times$ about $40 ; s$, seta; $a$, apophysis; $s p$, spores; col, columella; $r$, annulus; $v$, operculum.

the outside of the capsule to the base of the peristome, and form the rim of the "theca" or urn.

The epidermis of the whole capsule has its outer walls very much thickened, and upon the apophysis are found stomata quite similar to those found upon the sporogonium of Anthoceros or upon the leaves of vascular plants. Haberlandt ((4), p. 464), showed that while the form of the fully-developed stoma in Funaria differs from that of most vascular plants, this difference is secondary, and that in its earlier stages no difference exists. This can be easily verified, and with little difficulty all the different stages found. The young stoma (Fig. I I3), has the division wall extending its whole length, 
as is the case in stomata of the ordinary form. As the stoma

C.

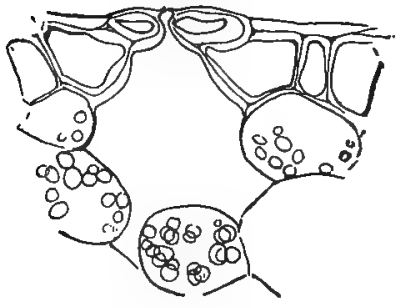

A.

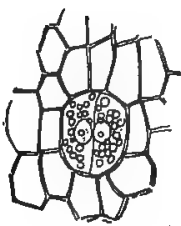

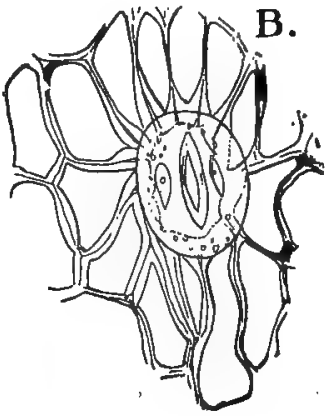

FIG. I13.-Funaria hygrometrica. A, Young; $\overrightarrow{\mathrm{B}}$, older stoma, from the base of the capsule; $C$, vertical section, $\times{ }_{3} 60$.

grows larger, however, the median wall does not grow as fast as the lateral walls, and a space is left between its extremities,

B.
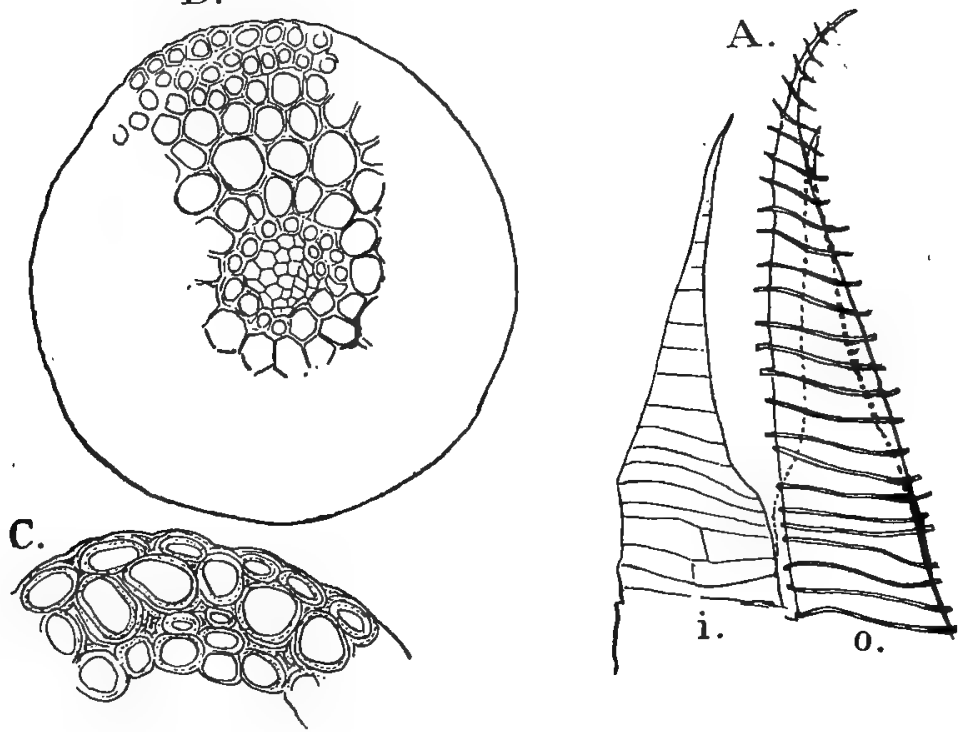

FIG. II4.-Funaria hygrometrica. A, Part of the peristome; $o$, an outer tooth; $i$ one of the inner teeth, $\times 85 ; \mathrm{B}$, section of the seta, $\times 260 ; \mathrm{C}$, cross-section of upper part of calyptra, $\times 525$.

so that the two guard cells have their cavities thrown into communication, and the division wall forms a cellulose plate 
extending from the lower to the upper surface of the stoma, but with its ends quite free. The formation of the pore by the splitting of the middle lamella of the division wall takes place in the ordinary way. Later the walls of the epidermal cells become very thick and show a distinct striation (Fig. I 3 ). By the formation of the stomata the green assimilating tissue of the apophysis and central part of the capsule is put into direct communication with the external atmosphere.

The lower part of the seta grows downward and penetrates the top of the stem of the gametophyte, from which, of course, it derives a portion of its sustenance. The centre of the seta is traversed by a well-marked central cylinder, whose inner cells are small and thin-walled, and are mainly concerned in conducting water; immediately outside of this is a circle of thick-walled brown cells (leptome of Haberlandt), and the rest of the seta is made up of nearly similar thick-walled cells which grow smaller toward the periphery.

At maturity, as the supply of water is cut off from below, the capsule dries up, and all the delicate parenchyma composing the columella and inner part of the operculum, as well as that between the spore-sac and the epidermis of the theca, completely collapses, leaving little except the spores themselves, and the firm cell wells of the peristome, and the cells connecting the latter with the wall of the capsule. By the breaking down of the unthickened lateral and transverse walls of the peristomial cells, the outer and inner thickened walls are separated and form the two rows of membranaceous teeth that surround the mouth of the urn (Fig. II4). By the drying up of the thin-walled cells between the annulus and the margin of the theca the operculum is loosened and is very easily separated. The teeth of the peristome are extremely hygroscopic, and probably assist in lifting off the operculum as well as removing the spores from the urn. When wet they bend inward, extending into the cavity of the urn. As they dry they straighten out and lift the spores out. The marked hygroscopic movements of the seta also are no doubt connected with the dissemination of the spores.

The calyptra in the Bryales is very large and is carried up on the top of the sporogonium in the form of a conspicuous membranaceous cap. As in other forms it is the venter alone that shows secondary growth. In Funaria it increases very 
much in diameter at the base, where it is widened out like a bell, and far exceeds in diameter the enclosed embryo. Above it is narrow and lies close to the embryo. After a time the embryo grows more rapidly in length than the calyptra, which then is torn away by a circular rent about its base, and is raised on top of the elongating sporogonium. The lower portion remains delicate and nearly colourless, but the upper part has its cells thick-walled and dark-brown in colour (Fig. I I4, C). Tipping the whole is the persistent dark-brown neck of the archegonium.

\section{Classification of the Bryales}

\section{Cleistocarpe}

The simplest of the Bryales are the Cleistocarpe or those in which there is no operculum developed, and in consequence the capsule opens irregularly. If Archidium is removed from this group the simplest form known is Ephemerum. In this genus, from a highly-developed filamentous protonema are produced the extremely reduced gametophores. According to Müller, (2) who has studied the life-history of this genus, both male and female branches arise from the same protonema, and are only distinguishable by the smaller size of the former. The axis of the branch is scarcely at all elongated, and the leaves therefore appear close together. The sexual organs correspond closely in origin and structure to the other Bryales. The development of the sporogonium in its early phases is also the same, and the differences only appear at a late stage. The separation of endothecium and amphithecium is apparently exactly the same as in other Bryales, and from the former is derived the archesporium, which like that of Funaria has the form of a hollow cylinder through which the columella passes. Between the outer spore-sac and the wall of the sporogonium an intercellular space is also formed, but the separation of the cells is complete, and there are no filaments connecting the spore-sac and the sporogonium wall as in Funaria. The cells of the archesporium are few in number and correspondingly large (Fig II5, E), and before the division into the spores takes place all the central tissue of the columella is absorbed, and the spore mother cells occupy the whole central space, where the division of the spores is completed, and at maturity the 
B.

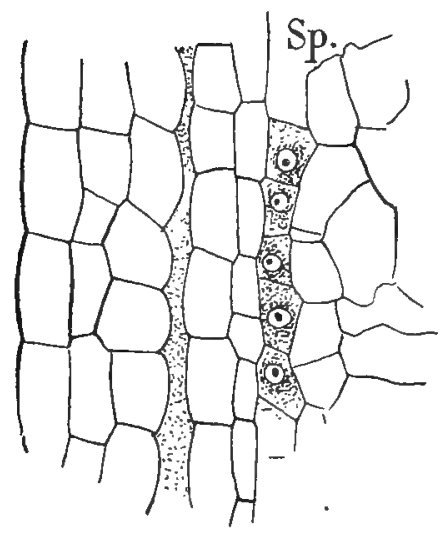

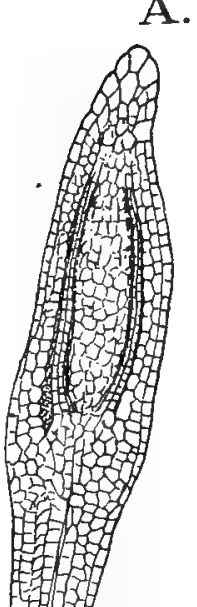

$\mathrm{Sp}$.
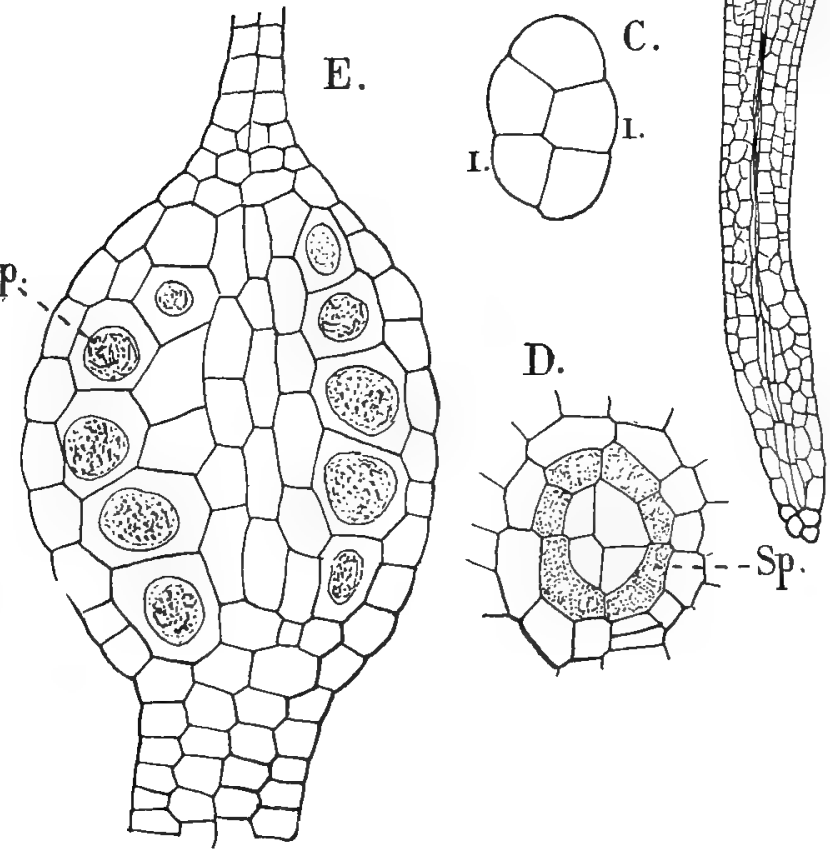

FIG. I15.-A, Longitudinal section of the young sporogonium of Pleuridium subulatum, $\times 80 ; \mathrm{B}$, part of the same, $\times 600 ; s p$, archesporium; C, young embryo of Phascum cuspidatum, optical section, $\times 175 ; D$, cross-section of an older embryo of the same, $\times 350 ; s p$, archesporium; $E$, longitudinal section of the central part of the young sporogonium of Ephemerum phascoides, $\times_{350} ; s p$, archesporium. $\mathrm{C}, \mathrm{D}$, after Kienitz-Gerloff; E, after Müller. 
whole of the capsule is filled with the large spores, and no trace of the columella remains.

Nanomitrium (Goebel (22), p. 374), closely resembles Ephemerum in the development of the sporophyte.

The highest members of the Cleistocarpæ, such as Phascum and Pleuridium (Fig. I 16), approach very closely in struçture the stegocarpous Bryales. In these the gametophore is much better developed than in Ephemerum, and the protonema not so conspicuous. The leaves also frequently have a welldeveloped midrib which is wanting in the leaves of Ephemerum.

Kienitz-Gerloff (2) has carefully studied the embryogeny of Phascum cuspidatum, and except in a few minor details it

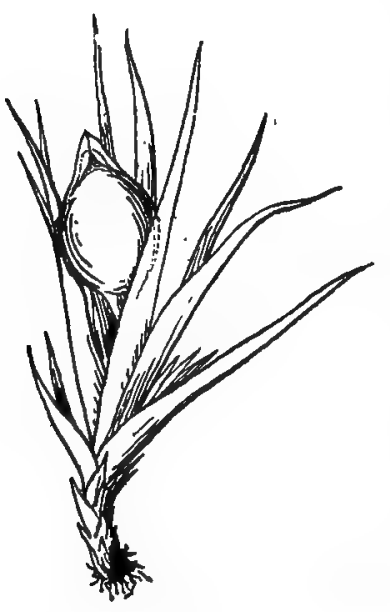

Fig. II6.-Pleuridium subulatum, $\times 20$. corresponds verv closely to that of Funaria, except, of course, as regards the operculum and peristome, which are absent. In Phascum, however, the archesporium is differentiated earlier than in Funaria. In each of the four primary cells of the endothecium, as seen in transverse section, a periclinal wall arises which at once separates the archesporium from the columella (Fig. I I 5, D). The outer sporesac has but two layers of cells, and the capsule wall three, and between them the large lacuna is formed as in Funaria; but in Phascum as in Ephemerum, the separation of the cells is complete. In the seta a slightly-developed central cylinder of conducting tissue is developed, derived, as in Funaria, from the endothecium, but in Phascum it is much less conspicuous. Pleuridium (Fig. I I 5, A) in its later stages corresponds exactly to Phascum, except that the capsule is more slender. In both of these genera the seta remains short, but is perfectly evident. Whether the absence of a distinct operculum in the cleistocarpous Mosses is a primitive condition, or whether they are reduced forms, it is impossible to determine positively from a study of their embryogeny. 


\section{Stegocarpa}

Very much the larger number of Mosses belong to this group, which is primarily distinguished from the foregoing by the presence of an operculum. Of course among the 7000 or more species belonging here there are many differences in structure; but these are mainly of minor importance morphologically, and only the more important differences can be considered here.

As we have already seen, there is great uniformity in the growth of the stem, which, with the single exception of Fissidens, has always a three-sided pyramidal apical cell. In Fissidens this is replaced by a two-sided one, but even here it has been found (Goebel (8), p. 37I) that the underground

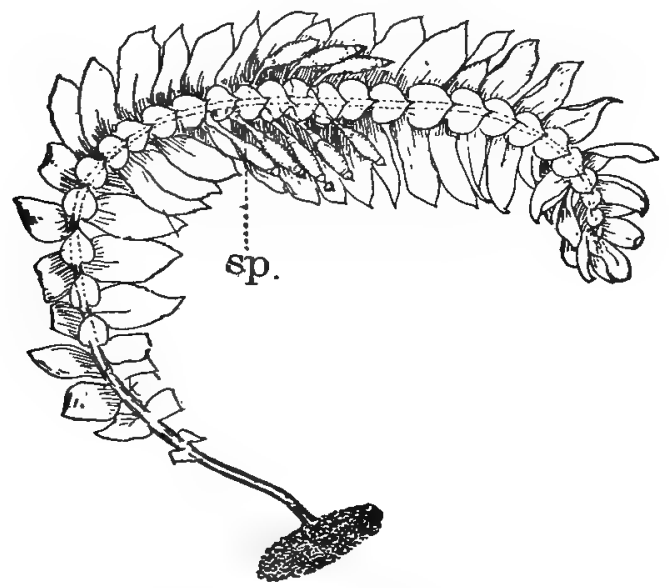

FIG. II7.-Cyathophorum pennatum, showing three rows of leaves; $s p$, sporophytes, $\times x^{2} / 3$.

stems have a three-sided initial cell, which is gradually replaced by the two-sided one after the apex of the shoot appears above ground. In Fissidens the leaves are arranged in two rows corresponding to the two sets of segments, and are sharply folded, so that the margins of the leaf are covered over by those of the rext older ones, leaving only the apex free. A similar arrangement is found in the genus Bryoziphion (Eustichia), but here there is a three-sided apical cell, and the two-ranked arrangement of the leaves is secondary. In Cyathophorum (Fig. I I7), there are two rows of large dorsal leaves and a row of much 
smaller ventral ones, so that the plant resembles very closely a foliose Liverwort. The curious genus Schistostega shows also a two-ranked arrangement of the leaves of the sterile branches, but here they are placed vertically and the bases conniverit, so that the effect of the whole is that of a pinnatifid leaf. The fertile branches, however, have the leaves spirally arranged, and in the sterile ones the three-sided apical cell is found. The leaves, with few exceptions, e. g., Fontinalis, have a wellmarked midrib, and the lamina is single-layered. Leucobryum (Fig. I2 I, A) has leaves made up of two or three layers of cells, large hyaline ones, somewhat as in Sphagnum, and small green cells. The hyaline cells, as in Sphagnum, have round holes in the walls, but no thickenings. The midrib may be narrow, as in Funaria, or it may occupy nearly the whole breadth of the leaf, as in the Polytrichaceæ, where, owing to the almost complete suppression of the lamina, secondary vertical plates of green cells are formed (Fig. I2 I, B).

The one-third divergence of the leaves found in Fontinalis ${ }^{1}$ is replaced in most other genera by a larger divergence. (Goebel (8)). Thus in Funaria hygrometrica it is $\frac{3}{8}$; in Polytrichum commune $\frac{5}{13}$; in $P$. formositm $\frac{13}{34}$.

As the archegonia are borne upon lateral branches, or upon the main axis, the stegocarpous Bryineæ are frequently divided into two main divisions, the Pleurocarpæ and the Acrocarpæ, which are in turn divided into a number of subdivisions or families. How far the division into acrocarpous and pleurocarpous forms is a natural one may be doubted, as probably the latter are secondary, and it is quite conceivable that different families of pleurocarpous forms may have originated independently from acrocarpous ones.

The simplest of the stegocarpous Mosses, while having the operculum well marked, have no peristome. Thus the genus Gymnostomum has no peristome at all, and in an allied genus, Hijmenostomum, it is represented by a thin membrane covering the top of the columella. In nearly related genera, however, e. g., Weisia, a genuine peristome is present.

The Tetraphideæ, represented by the genus Tetraphis (Georgia) (Fig. II8), are interesting as showing the possible origin of the peristome, as well as some other interesting points

1 This seems to be strictly the case only in the smaller branches; in the larges axes the leaves are not exactly in three rows. 
of structure. Tetraphis pellucida is a small Moss, which at the apex of its regetative branches bears peculiar receptacles containing multicellular gemmæ of a very characteristic form. The leaves that form the receptacle are smaller than the stem leaves, and closely set so as to form a sort of cup in which the gemmæ are produced in large numbers. These arise as slender multicellular hairs, the end cell of which enlarges and forms a disc, at first one-layered, but later, by the walls parallel to the broad surfaces, becoming thicker in the middle, and lenticular

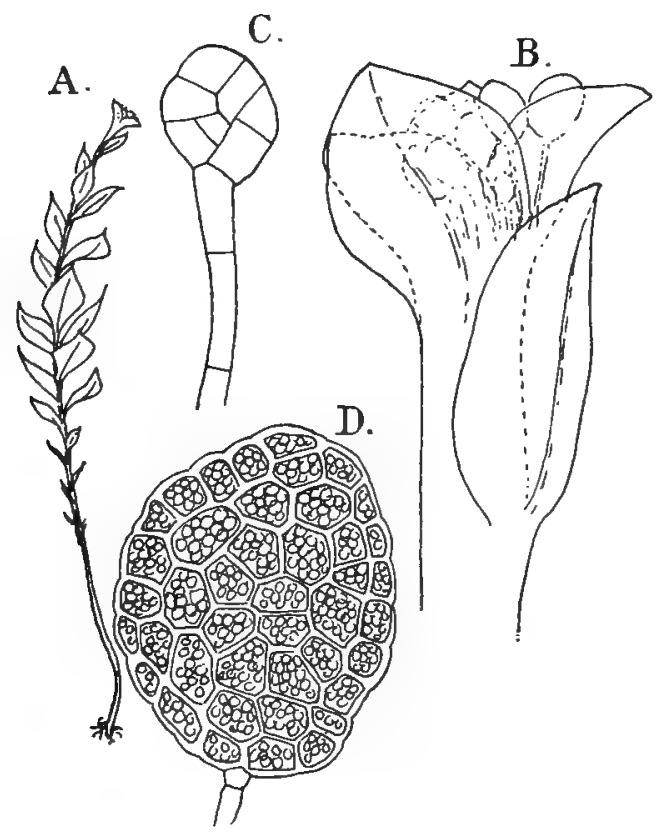

FIG. I18.-Tetraphis pellucida. A, Plant with gemmæ, $\times 6$; B, upper part of the same, $\times 50$; $C$, young gemma, $X 600 ; D$, a fully-developed gemma, $\times 300$.

in form. The arrangement of the cells in the young gemmæ looks as if the growth of the bud was due to a two-sided apical cell (Fig. I $8, \mathrm{C}$ ), but this point was not positively determined. These gemmæ give rise to a protonema of a peculiar form, from which in the usual way the leafy stems develop. The protonemal filaments grow into flat thalloid expansions that recall those of Sphagnum and Andreaa. 
The sporogonium of Tetraphis has a peristome of peculiar structure, and not strictly comparable to that of any of the other Mosses. After the operculum falls off the tissue lying beneath splits into four pointed teeth, which, however, are not, as in Funaria, composed simply of the cell walls, but are masses of tissue.

All the other higher Bryales, with the exception of the Polytrichaceæ, have the peristome of essentially the same structure as that described for Funaria. Sometimes the teeth do not separate but remain as a continuous membrane, e. $g$., the inner
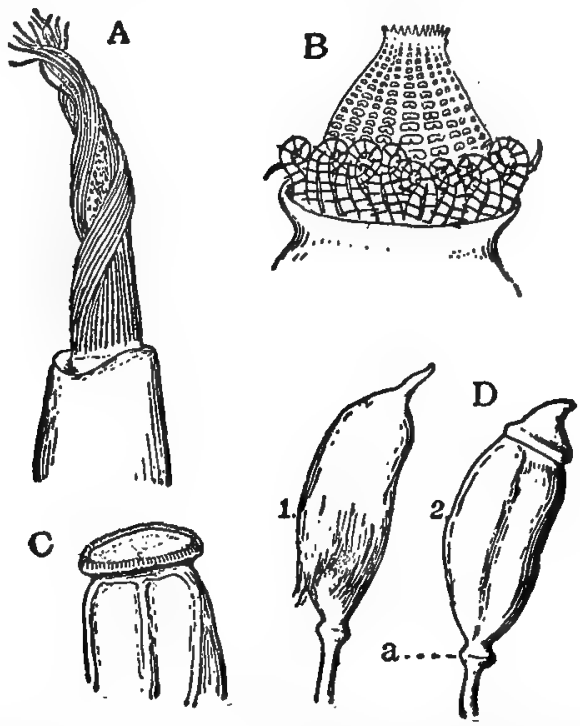

FIG. IIg.-A, Barbula fallax, upper part of the capsule, showing the slender twisted peristome teeth $X$ about 20 . B. Fontiualis antipyretica, showing double peristome (after Schimper). C, Polytrichum commune, peristome and epiphragma $\times 8$, D, $P$. commune, ripe capsule; 1 , with, $z$, without the calyptra $\times 3$.

peristome of Buxbaumia, or a perforated membrane, as in Fontinalis (Fig. I I9, B).

The base of the capsule, or apophysis, which Haberlandt (4) has shown to be the principal assimilative part of the sporogonium, and which alone is provided with stomata, sometimes becomes very large, and in the genus Splachnum (Vaizy ( I )) especially forms a largely-developed expanded body, which must be looked upon as a specially-developed assimilating apparatus. 
Undoubtedly the Polytrichaceæ represent the highest stage of development among the Musci. This is true both in regard to the gametophore and the sporogonium. The former reaches in some species, e. g., P. commune, a length of 20 centimetres and sometimes more. The stem is usually angular and the closely-set leaves thick and rigid. The numerous rhizoids are often closely twisted together and form cable-like strands. The structure of the leaves is very characteristic, and differs very much from that of the simpler type found in Funaria.

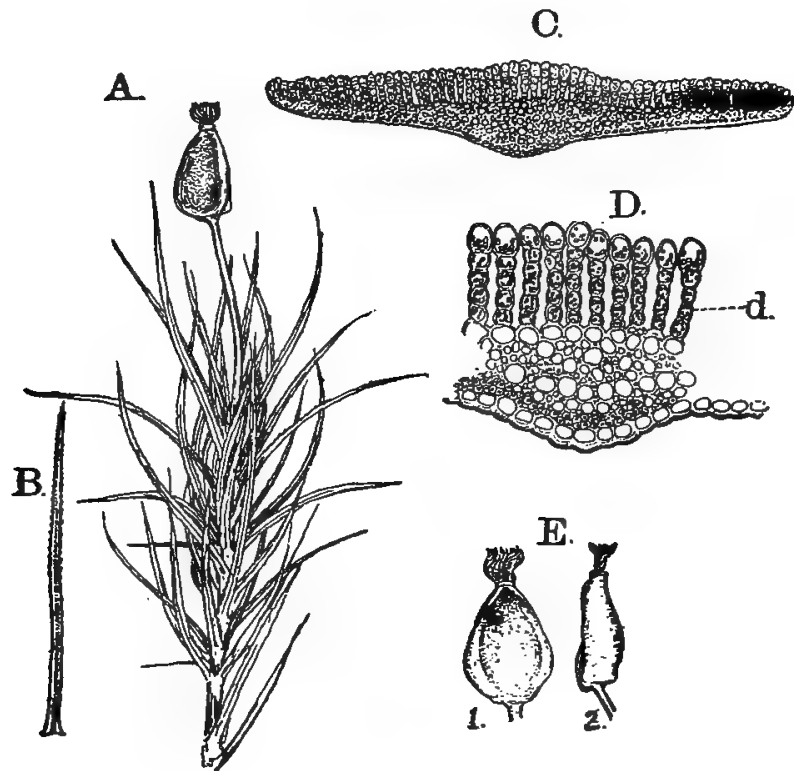

Fig. r20.-Dawsonia superba. A, upper part of female plant bearing a sporogonium, $X I ; B$, leaf, slightly enlarged; $C$, section of leaf, $X$ about $70 ; D$, part of the same more highly magnified; $E$, two views of the capsule, $\times 1 / 1 / 3$.

In the Polytrichacer (Fig. I2I) the midrib of the leaf is very broad and only at the extreme margin of the leaf is the lamina developed at all. A cross-section of the leaf shows that the midrib is greatly thickened in the centre, and gradually merges into the rudimentary lamina. In Dawesonia (Fig. I20), the leaf is almost flat, in Polytrichum (Fig. I2I), usually more or less incurved at the margin.

The outer, or dorsal, surface of the leaf is covered with a well marked epidermis, whose outer cell-walls are strongly 
thickened, and have a conspicuous cuticle. Within this epidermis are closely set, small sclerenchymatous elongated cells, among which are found more or less definite rows of large, thin-walled elements, strongly suggesting the tracheary tissue of the vascular plants, and without much question, true waterconducting structures. From the inner ventral surface there arise numerous parallel, thin, vertical laminae (cl.) composed of green cells. These extend nearly the whole length of the leaves and in section appear as rows of short cells, the outermost ones being somewhat enlarged.

The axis of the shoot in the Polytrichaceæ shows a decidedly complex structure and many reach a relatively large size. Thus in Daw'sonia superba (Figs. I2O, 122 ) it is about $1.5 \mathrm{~mm}$. in diameter, and forms an erect, densely leafy shoot 40 to 50 centimetres in height. The cross-section of the shoot in the latter species (Fig. I22) is triangular in outline. Within the firm epidermis there are several layers of somewhat similar, but more compact cells, which like the epidermal cells are thickwalled, and dark coloured. This compact hypodermal tissue passes somewhat gradually into a colourless, parenchymatous ground-tissue, which makes up the bulk of the shoot-axis. There is a very conspicuous central cylinder composed of two tissue-elements-small, dark-colored sclerenchyma or fibrous tissue, especially compact toward the centre of the cylinder; and very much larger, thin-walled cells, appearing almost destitute of protoplasmic contents, and closely resembling the vessels of true vascular plants, and like them, no doubt, true water-conducting organs. Traversing the ground tissue are slender strands of elongated cells-leaf-traces, which are structurally like the central cylinder of the shoot, but with the waterconducting cells less conspicuous. Most of the cells in the stem of Dawsonia, except the large tracheary cells of the central cylinder, contain starch, which it is stated by Goebel (8) is not abundant in the tissues of Polytrichum, where its place is taken largely by oil. Starch has been noted in Polytrichum in the outer cells of the stem and in the leaf-traces.

The leaf-traces, or continuation of the central tissue of the midribs of the leaves, bend down into the stem, and finally unite with the axial cylinder of the latter, in a manner quite analogous to that found in the stems of many vascular plants. 
Bastit ( ( I ), p. 295), who has made a comparative study of the subterranean and aerial stems of $P$. juniperinum, divides the outer tissue of the latter into epidermis, hypoderma, and cortex. In the subterranean stems he finds the construction quite different from that of the leafy branches. The section of the former is triangular, and its epidermis provided with hairs which are absent from the epidermis of the aerial parts. Rudimentary scales, arranged in three rows, are present, and corresponding to these are strands of tissue that represent the leaftraces of the aerial stems. The central cylinder is much larger relatively than in the leafy branches, and its cross-section is not continuous, but is interrupted by three "pericyclic sectors," composed of cells whose walls are but little thickened. The point of each sector is at the periphery of the medulla, or central cylinder, and the broad end toward the centre. As might be expected, intermediate conditions are found where
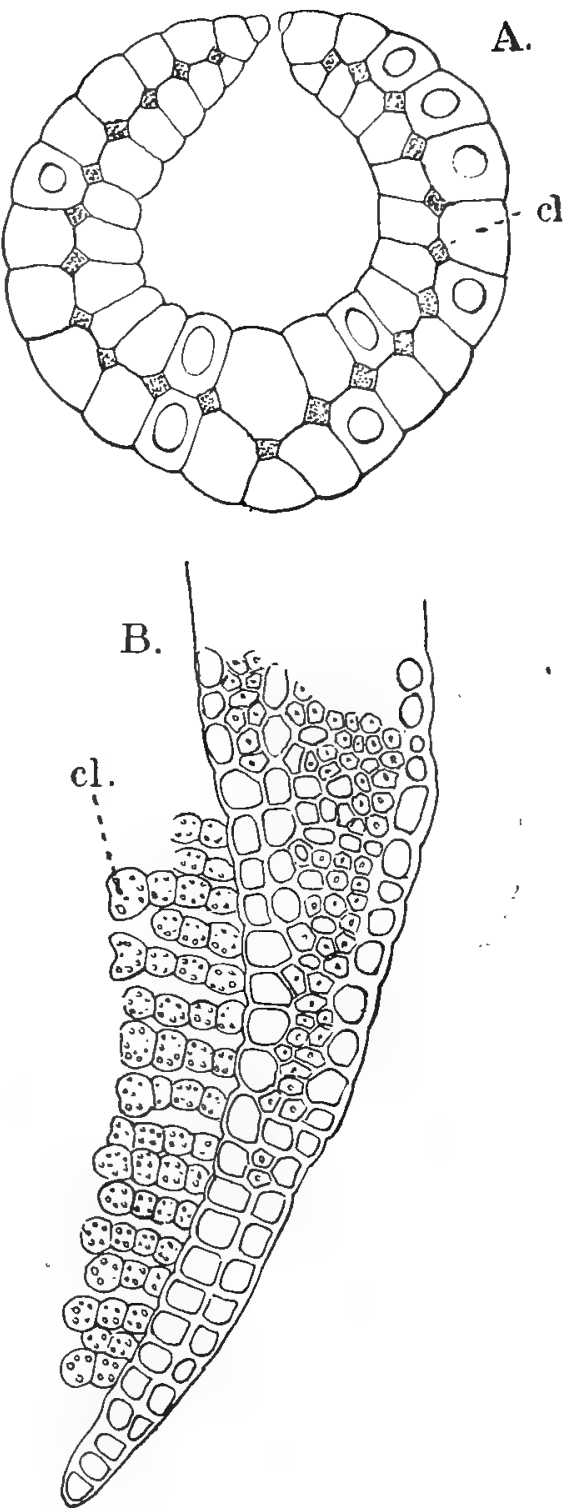

FIG. 121.-A, Transverse section of the leaf of Leucobryum; $\mathrm{B}$, similar section of the leaf of Polytrichum commune; $\mathrm{Cl}$, chlorophyll-bearing cells (after Goebel).

the rhizome begins to grow upward to form a leafy branch, 
The male inflorescence of the Polytrichaceæ is especially conspicuous, as the leaves immediately surrounding the antheridia are different both in form and colour from those of the stem. They are broad and membranaceous, and more or less distinctly reddish in colour. A well-known peculiarity of these forms is the fact that the growth of the stem is not stopped by the formation of antheridia, but after the latter have all been formed the axis resumes its growth and assumes the character of an ordinary leafy shoot. This, of course, indicates that, unlike most of the Mosses, the apical cell does not become transformed into an antheridium, and the researches of
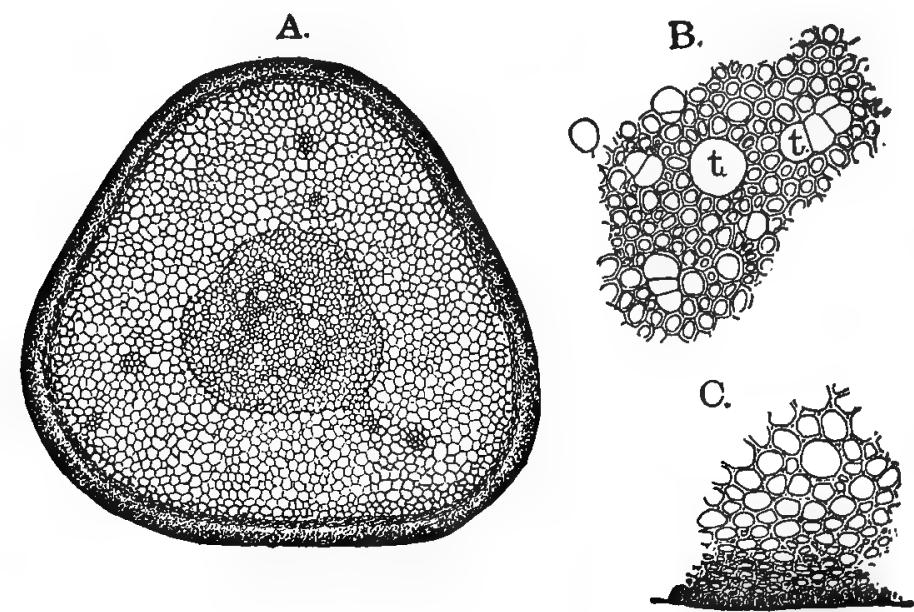

FIG. 122.-Dansonia superba. A, Transverse section of the stem, $\times 35 ; B$, part of the central cylinder, showing water-conducting elements, $t, \times_{200 ;}$, outer tissues of the stem, $\times 200$.

Hofmeister (2), Leitgeb (9), and Goebel (7) have shown that this is the case. The antheridia form groups at the base of each leaf of the inflorescence, and Leitgeb thinks it probable that each group represents a branch, $i . e$., the inflorescence is a compound structure, and not directly comparable to the simple male inflorescence of Funaria. The sporogonium in Polytrichum has a large intercellular space between the inner sporesac and columella as well as the one outside the outer spore-sac. In both cases the space is traversed by the conferva-like green filaments found in the other stegocarpous Mosses. The apophysis is well developed, especially in Polytrichum, and the 
calyptra very large and covered with a dense growth of hairs (Fig. II9, D).

The structure of the peristome in the Polytrichacea is entirely different from that of the other Mosses. It is composed of bundles of thickened fibrous cells arranged in crescent form, the ends of the crescent pointing up, and united with the adjacent end of the bundle next it. The tops of the teeth thus formed are connected by a layer of cells stretching across the opening like the head of a drum. This membrane is known technically as the "Epiphragm" (Fig. I I9, C).

\section{The Buxbaumiace}

The last group of Mosses to be considered is the very peculiar one of the Buxbaumiacea. In these Mosses the
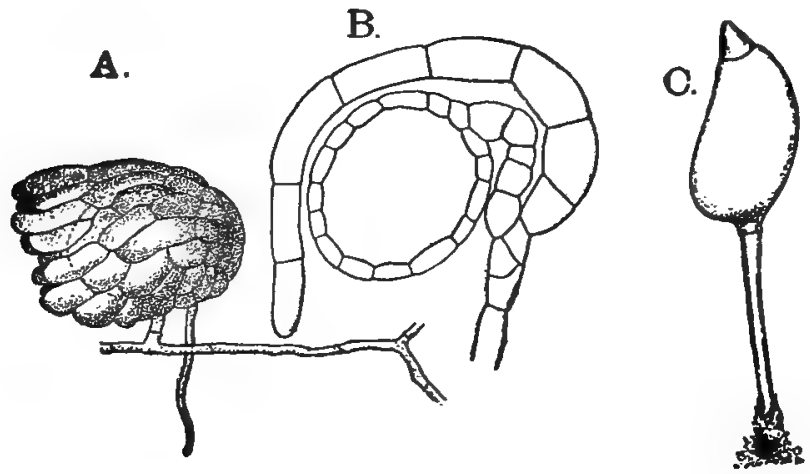

FIG. 123.-A, Protonema of Busbaumia indusiata, with the anthreidial shoot, X175: B, antheridium, seen in optical section; C, sporophyte of $B$. sp., $X_{4}$, (A, B, after Goebel.)

gametophyte is extraordinarily reduced, although the sporogonium is large and well developed. So simple is the sexual plant, that Goebel ( I6) has concluded that these ought to be taken away from the rest of the Mosses, and removed to a distinct order. According to Goebel's account, the antheridia, which are long stalked, are borne directly upon the protonema, and subtended by a single colourless bract (Fig. I23). The female branches are also very rudimentary, but less so than the male. On the strength of the extreme simplicity of these, Goebel thinks that Buxbaumia is a primitive form allied to some alga-like progenitor of the Mosses. There are, however, two very strong objections to this. First the sporogonium, which 
is extremely large, and complicated in structure, and essentially like that of the other stegocarpous Mosses; secondly, $B u x$ baumia has been shown by Haberlandt ((4), p. 480) to be distinctly suprophytic in its habits, and the extreme reduction of the assimilative tissue of the gametophyte is quite readily explicable from this cause.

\section{Fossil Muscinea}

The remains of Muscineæ in a fossil condition are exceedingly scanty; so much so indeed as to practically throw no light upon the question of their origin and affinities, as nearly all of the forms discovered belong to the later formations, and are either identical with living species or closely allied forms. No doubt the great delicacy of the tissues of most of them, especially the Hepaticæ, accounts in great measure for their absence from the earlier geological formations.

\section{The Affinities of the Musci}

It is perfectly evident that the Mosses as a whole form a very clearly defined class, and that their relationship with other forms is at best a somewhat remote one. Sphagnum, however, certainly, shows significant peculiarities that point to a connection between this genus, at least, and the Hepaticæ. It will be remembered that the protonema of Sphagnum is a large flat thallus, and not filamentous, as in most Bryales. It it noteworthy, however, that from the margin of this flat thallus later filamentous branches grow out which arè apparently identical in structure with the ordinary protonemal filaments of the Bryales. In Andreaa similar flat thalloid protonemata occur, but not so largely developed as in Sphagnum, and finally in Tetraphis a similar condition of affairs is met with. As this occurs only among the lower members of the Moss series, the question naturally arises, does this have any phylogenetic meaning? While it is impossible to answer this question positively, it at any rate seems probable that it has a significance, and means that the protonema has been derived from a thalloid form related to some thallose Liverwort, and that by the suppression of the thalloid portion, as the leafy gametophore became more and more prominent, the filamentous branches, 
which at first were mere appendages of the thallus, finally came to be all that was left of it. The view of Goebel and others that the filamentous form of the protonema is the primitive one, and indicates an origin from alga-like forms, might be maintained if the question were concerned simply with the protonema; but when the structure of the sexual organs, especially the archegonium, is considered, and the development of the sporophyte, the difficulty of homologising these with the corresponding parts in any known Alga is apparent, while on the other hand the resemblance between them and those of the Hepaticæ is obvious. It is quite probable that the development of the filamentous protonema is a provision for the production of a greater number of gametophoric branches.

As to which group of the Hepaticæ comes the nearest to the Mosses, the answer is not doubtful. The remarkable similarity in the development and structure of the sporogonium of Sphagnum and the Anthocerotes leaves no room for doubt that as far as Sphagnum is concerned, the latter come nearest among existing forms to the ancestors of Sphagnum. Of course this does not assume a direct connection between Sphagnum and any known form among the Anthocerotes. There are too many essential differences between the two to allow any such assumption: but that the two groups have come from a common stock is not impossible, and the structure of the capsule in Sphagnum points to some form which like Anthoceros had a highly-developed assimilative system. This is indicated by the presence of stomata, which, although functionless, probably were once perfect, and make it likely that with the great increase in the development of the gametophyte the sporophyte has lost to some extent its assimilative functions which have been assumed by the gametophyte.

Andreca, both in regard to the gametophyte and the sporophyte, is in many ways intermediate between Sphagnum and the other Mosses. The resemblance in the dehiscence of the sporogonium to that of the Jungermanniacex is probably accidental. It may perhaps be equally well compared to the splitting of the upper part of the capsule into four parts, in Tetraphis, although in the latter it is the inner tissue and not the epidermis which is thus divided.

If this latter suggestion proves to be true, then there would be a direct connection of Andreaa with the stegocarpous 
Bryales, and not through the cleistocarpous forms. These latter would then all have to be considered as degraded forms derived from a stegocarpous type, unless, with Leitgeb, we consider them as a distinct line of development leading up to the higher Bryales, entirely independent of the Sphagnaceæ, and with Archidium and Ephemerum as the simplest forms. His comparison of these forms with Notothylas, however, cannot be maintained with our present knowledge of that genus, and more evidence is needed before his view can be accepted; but the possibility of some such explanation of the cleistocarpous Bryales must be borne in mind in trying to assign them their place in the system.

The objections to considering Buxbaumia a primitive type have been already given, and it is not necessary to repeat them. 


\section{CHAPTER VII}

THE PTERIDOPHYTA-FILICINE

IN tracing the evolution of the Bryophytes from the lowest to the highest types the gradual increase in the importance of the second generation, the sporophyte, is very manifest. This may or may not be accompanied by a corresponding development of the gametophyte. In the line of development represented by the higher Mosses, in a general way the two have been parallel, and the most highly differentiated gametophyte bears the most complicated sporophyte, as may be seen in Polvtrichum, for example; but in the Hepaticæ this is not the case, and among the Anthocerotes much the most highly organised sporophyte, that of Anthoceros, is produced by a very simple gametophyte.

In this evolution of the sporophyte, it approaches a condition where it is self-supporting, but in no case does it become absolutely so. A special assimilative tissue, it is true, is developed, and in some of the true Mosses, such as Splachnum, this goes so far that a special organ, the apophysis, is formed; but, as we have seen, the sporogonium is dependent for its supply of water and nitrogenous food upon the gametophyte, with which it remains intimately associated, and upon which it lives as a parasite.

The type of structure found in the gametophyte of the Muscineæ seems to be imperfectly fitted for a strictly terrestrial life. The gametophyte of all Archegoniates is more or less amphibious. Free water is essential for the act of fecundation, and the gametophyte seems never to have solved satisfactorily the problem of an adequate water supply, except by returning to the aquatic condition. 
Many Bryophytes can exist only in damp, shady localities, and those which have adapted themselves to a xerophytic habit, have acquired the power of becoming completely dried up without being killed, reviving promptly when supplied with water, but remaining completely dormant during the period of drought. These plants do not depend upon their rhizoids for absorbing water, but, like Algæ, can absorb water at all points of their surface. Where the plant depends largely upon the rhizoids for water absorption, as in the Marchantiaceæ, the plant is a flat, prostrate thallus, which offers a large surface for the development of the rhizoids. In the upright stems of the larger Mosses, the rhizoids are multicellular, and sometimes twisted into root-like strands, which are of relatively large size, and are undoubtedly efficient organs for water-absorption. Still it is evident that even such strands of multicellular rhizoids would not suffice for providing the water necessary to make good the loss by transpiration in a large terrestrial plant. It is this failure to develop an adequate root system which probably explains the fact that no Bryophyte has attained the dignity of a successful upright terrestrial plant.

Among the Pteridophytes the gametophyte is equally incapable of a strictly terrestrial existence; but in these plants, the sporophyte, developing still further along lines indicated in many Bryophytes, has finally attained to the condition of an independent plant. It may be conjectured that from part of the foot, the absorbent organ of the embryo in the bryophytic sporophyte, there was developed a root, with a permanent growing point, and capable of indefinite growth in length. This, penetrating through the tissues of the gametophyte, put the sporophyte into direct communication with the water in the earth, and thus completely emancipated it from its former status of dependence upon the gametophyte.

The true root differs essentially from the rhizoids in being a massive organ capable of indefinite growth and division, which can thus keep pace in its development with the increasing size and complexity of the sporophyte. The latter from this time assumes more and more the principal rôle in the lifehistory of the organism, while the gametophyte becomes correspondingly reduced. With the development of an independent sporophyte, there appeared a plant adapted from the first to a terrestrial existence and not a modification of an originally 
aquatic organism like the gametophyte of all Muscineæ. In the few cases where true roots are absent their place is taken by other structures that perform their functions. The assimilative activity is restricted to special organs, the leaves, except in a few cases where these become much reduced, as in Psilotum or Equisetum. A main axis is present upon which the leaves are borne as appendages, and this continues to form new leaves and roots as long as the sporophyte lives.

The differentiation of these special organs begins while the sporophyte is still very young. The earliest divisions in the embryo correspond closely to those in the embryo of a Bryophyte, but instead of forming simply a capsule, as in all the Bryophytes, there is established more than one growing point, each one forming a distinct organ. In the typical Ferns there are four of these primary growing points, giving rise respectively to the stem, leaf, root and foot. The latter is a temporary structure, by which the young sporophyte absorbs food from the gametophyte, but as soon as it becomes independent the foot gradually withers away, and soon all trace of it is lost.

The originally homogeneous tissues of the embryo become differentiated into the extremely complicated and varied tissues characterising the mature sporophyte. The most characteristic of these is the vascular system of tissues. This is hinted at in the central strand of tissue in the seta of many Mosses, and the columella of the Anthocerotes; but in no Bryophyte does it reach the perfect development found in the Ferns and their relations, which are often called on this account the Vascular Cryptogams.

The gradual reduction in the vegetative parts of the gametophyte, from the large long-lived prothallium of the Marattiacer to the excessively reduced one found in the heterosporous Pteridophytes, has already been referred to in the introductory chapter.

The structure of the sexual organs of the Pteridophytes appears at first sight radically different from that of the Bryophytes, but a careful comparison of the lower forms of the former with some of the Hepatica, and especially with the Anthocerotes, shows that the difference is not so great as it at first sight appears. A further discussion of this point must be left, however, until we have considered more in detail the structure of these parts in the different groups of the Pteridophytes, 
where they are remarkably uniform. In all of them the archegonium has usually a neck composed of but four rows of peripheral cells, instead of five or six, as in the Bryophytes, and the antheridium, except in the leptosporangiate Ferns, is more or less completely sunk in the tissue of the prothallium. The spermatozoids are either biciliate, as in Mosses, or multiciliate, a condition which, so far as is known, does not exist among the Bryophytes.

The formation of spores is very much more subordinated to the vegetative life of the sporophyte than is the case among the most highly organised of the Bryophytes. Indeed it may be many years before any signs of spore formation can be seen. The spores are always born in special organs, sporangia, which are for the most part outgrowths of the leaves, but may in a few cases develop from the stem. In the simplest cases the spores arise from a group of hypodermal cells, generally traceable to a single primary cell. The cell outside of these divides to form a several-layered wall, but the limits of the sporangium are not definite, and it may scarcely project at all above the general surface of the leaf. From this "eusporangiate" condition found in Ophioglossum, there is a complete series of forms leading to the so-called leptosporangiate type, where the whole sporangium is directly traceable to a single epidermal cell, and where a very regular series of divisions takes place before the archesporium is finally formed.

With very few exceptions all of the existing Pteridophytes fall naturally into three series or classes of very unequal size. The first of these, the Ferns or Filicinea, is the predominant one at present, and includes at least nine-tenths of all living Pteridophytes. The Equisetineæ are the most poorly represented of the modern groups, and include but a single genus with about twenty-five species. The third class, the Lycopodineæ, is much richer both in genera and species than the Equisetineæ, but much inferior in both to the Filicineæ. The disproportion between these groups was much less marked in the earlier periods in the world's history, as is attested by the very numerous and perfect remains of Pteridophytes occurring especially in the coal-measures. At that time both the Equisetineæ and Lycopodineæ were much better developed both in regard to size and numbers than they are at present. 


\section{Class I. Filicine.e (Filicales)}

The Filicineæ or Filicales, as already stated, include by far the greater number of existing Pteridophytes, and are much more extended in range and abundant in numbers than either of the other classes. A marked characteristic of all Ferns is the large size of the leaves, which are also extremely complicated in form in many of them. In a few of these the leaves are simple, e. g., Ophioglossum, Vittaria, Pilularia, but more commonly they are pinnately compound and sometimes of enormous size. The stem varies a good deal in form and may be very short and completely subterranean, as in species of Ophioglossum and Botrychium, or it may be a creeping rhizome, or in some of the large tropical Ferns it is upright, and grows to a height of 8 to Io metres, or even more.

While some forms of the Ferns are found adapted to almost all situations, most of them are moisture-loving plants, and reach their greatest development in the damp mountain forests of the tropics. A few, e. g., Ceratopteris, Azolla, are genuine aquatics, and still others, e.g., species of Gymnogramme, live where they become absolutely dried up for several months each year. These latter will quickly revive, however, as soon as placed in water, and begin to grow at once. In the tropical and semi-tropical regions many Ferns are epiphytes, and form a most striking feature of the forest vegetation. With few exceptions the sporophyte is long-lived, but a few species are annual, e.g., Ceratopteris, and depend mainly upon the spores for carrying the plant through from one season to another. The sporophyte may give rise to others by simply branching in the ordinary way, or special buds may be developed either from the stem or upon the leaves (Cystopteris bulbifera).

Besides the normal production of the gametophyte from the spore, it may arise in various ways directly from the sporophyte (apospory); and conversely the latter may develop as a bud from the gametophyte without the intervention of the sexual organs (apogamy).

The Filicineæ include both eusporangiate and leptosporangiate forms, - indeed the latter occur only here. The former comprise the homosporous orders, Ophioglossales and Marattiales, and possibly the heterosporous order Isoetales, whose systematic position, however, it must be said is still doubtful. The 
Leptosporangiatæ include the single great homosporous order Filices, and the two heterosporous families, closely related to it, the Salviniaceæ and the Marsiliaceæ. These are usually classed together as a distinct order, the Hydropterides or Rhizocarpeæ.

\section{The Filicineæ Eusporangiate}

The two orders, Ophioglossales and Marattiales, show many evidences of being very ancient forms, and in several respects seem to approach more nearly to the Hepaticæ than any other Pteridophytes. While they are different from each other in many respects, still there is sufficient evidence to indicate that they belong to a common stock to warrant placing them near each other in the system.

\section{The Ophioglossales}

The three genera belonging to this order may all be united in a single family, Ophioglossaceæ.

\section{The Gametophyte}

Our knowledge of the gametophyte of the Ophioglossaceæ has been very much augmented during the past ten years. Jeffrey (I) has described very fully the gametophyte of Botrychium Virginianum, and Lang (4) and Bruchmann (5) have made out the most important facts in that of Ophioglossum and Helminthostachys. Our earlier knowledge was based entirely upon the fragmentary observations of Hofmeister (I) upon Botrychium lunaria, and those of Mettenius (2) upon Ophioglossum pedunculosum.

The writer has succeeded in securing the earliest phases of germination in two species, viz., Ophioglossum (Ophioderma) pendulum and Botrychium Virginianum, as well as the older prothallia of the latter. The germination in both cases is extremely slow, especially in the former, where a year and a half after the spores were sown the largest prothallia had but three cells. Probably under natural conditions the growth is more rapid. The spores of both forms show much the same structure. The tetrahedral spores contain granular matter, 
with numerous oil-drops, and a central large and distinct nucleus. The exospore is colourless, and upon the outside presents a pitted appearance in Ophioglossum, and irregular small tubercles in Botrychium. The perinium or epispore is not clearly distinguishable from the exospore. In both cases chlorophyll is absent in the ripe spore. The first sign of germination is the absorption of water and splitting of the exospore along the three radiating lines on the ventral surface of the spore. The spore enlarges considerably before any divisions occur, but remains globular in form, and no chlorophyll can be detected. In this condition, which was observed within two weeks after the spores were sown in Ophioglossum, it may remain for several months unchanged. The first division wall is usually at right angles to the axis of the spore, and divides it into two nearly equal cells, of which the lower has more of the granular contents than the upper one. The endospore is noticeably thickened where it protrudes through the ruptured exospore. The next wall, in all cases observed, is at right angles to the first, and always in the lower cell, which it divides into equal parts (Figs. I24, I25). In Botrychium at this stage a few large chloroplasts were seen in both upper and lower cells, but Ophioglossum showed no positive evidence of chlorophyll, although it seemed sometimes as if a faint trace of chlorophyll could be detected. As growth proceeds, the oil partially disappears, and the cells become

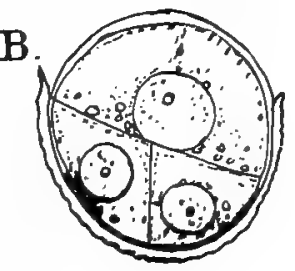
much more transparent than at first.

Lang (4) found the prothallia of Ophioglossum pendulum buried in the humus collected about masses of epiphytic ferns among which the sporophytes of the Ophioglossum were growing. The youngest ones discovered were nearly circular in outline, the older specimens more or less branched (Fig. I25, C). The branches are cylindrical and grow from a single initial cell which has the form of a four-sided pyranid. The lower half of the prothallium is infested by an endophytic fungus, while 
from the upper side of the thallus the reproductive organs are developed. Numerous rhizoids grow from the superficial cells.

Mettenius (2) has described the gametophyte in $O$. pedunculosum, which agrees in the main with that of $O$. pendulum. In this species, however, there is first developed a "primary tubercle" (Fig. I25, B), and the branches were observed in some cases to grow above the ground, where they became flattened and developed chlorophyll.
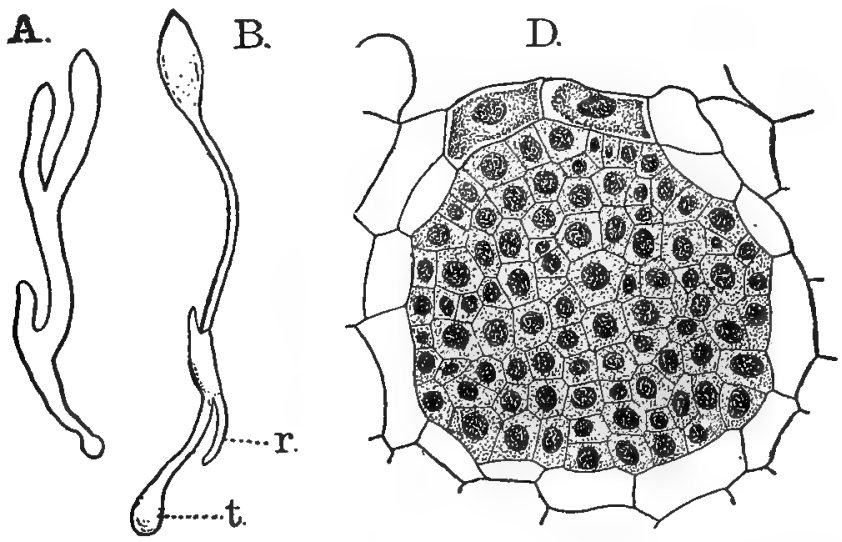

E.

C
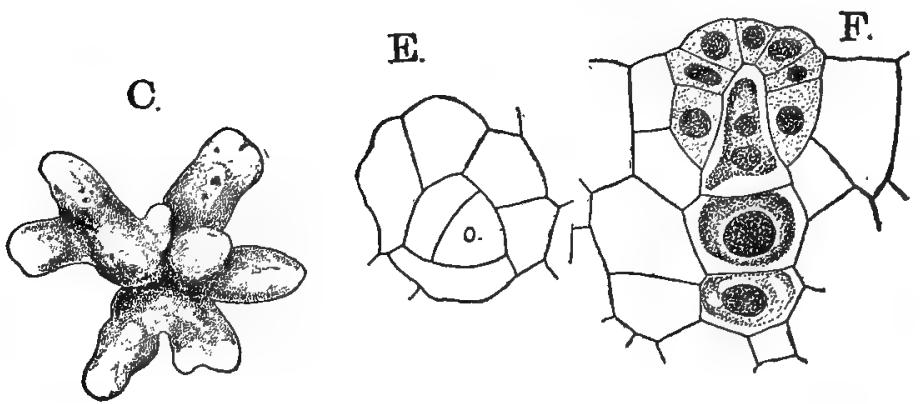

FIG. 125.-A, B, Prothallia of Ophioglossum pedunculosum, $X I 1 / 2$; $B$, shows the young sporophyte, with the cotyledon and first root, $r ; t$, the primary tubercle. C-F, O. pendulum. C, An old prothallium, $\times 6 ; \mathrm{D}$, nearly ripe antheridium; $\mathrm{E}$, surface view of antheridium, showing the opercular cell; $F$, nearly ripe archegonium; D-F, $X$ about 275; (A, D, after Mettenius; C-F, after Lang).

\section{The Sex-Organs}

The antheridium arises from a superficial cell which divides by a periclinal wall into an inner cell, from which by further divisions the mass of sperm-cells is derived, and an outer one, 
from which the cover of the antheridium is formed. The outer wall of the antheridium remains for the most part but one cell thick, in this respect more resembling Marattia than it does Botrychium. The antheridium also opens by a single, nearly triangular opercular cell (Fig. I25, E), as it does in Marattia. The spermatozoids were not seen, but probably resemble those of Botrychium or Marattia.

The first division of the young archegonium is the same as in
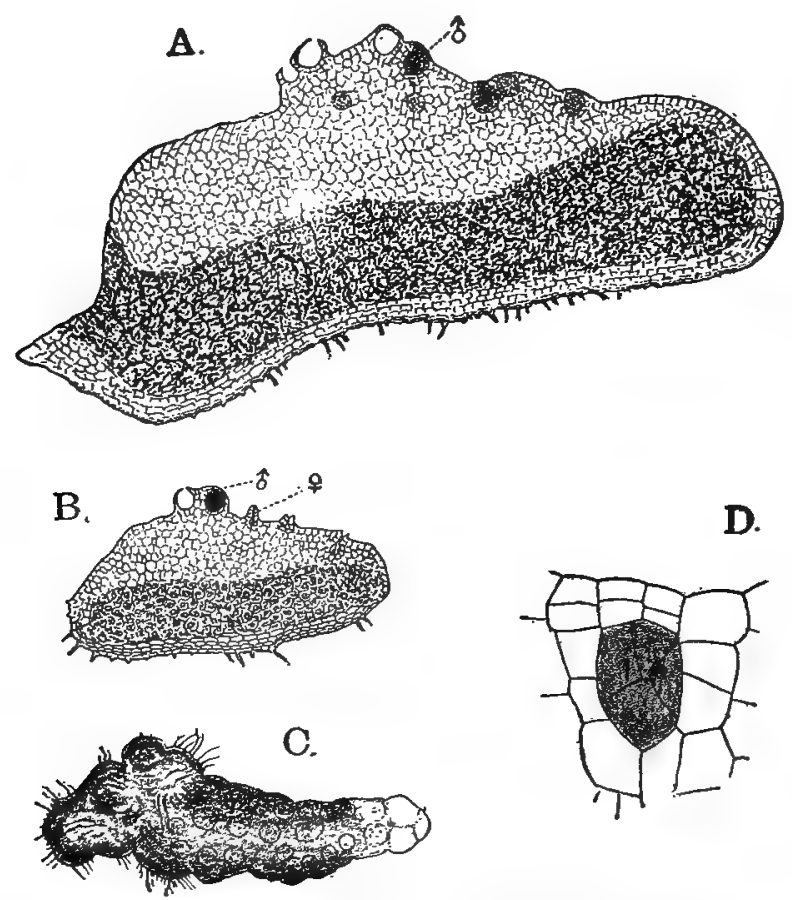

D.

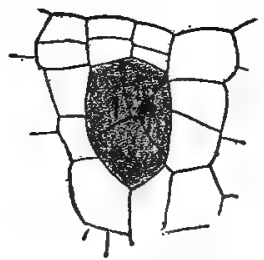

FIG. 126.-A, Longitudinal section of a large prothallium of Botrychium Virginianum, $X_{15}$; B, transverse section of a somewhat younger one, showing the antheridial ridge, and the archegonia; $\mathrm{C}$, prothallium of Helminthostachys Zeylanica, $\times 7$; D, young antheridium of Helminthostachys, $\times 225$. (C, D, after Lang.)

the antheridium. From the inner cell, after it divides into a basal and a central cell, is formed the axial row of cells-the egg cell and the canal cells. No division of the neck canal cell .. was observed beyond the division of the nucleus, and the ventral canal was not seen; but the latter is doubtless formed before the archegonium is mature.

The neck of the archegonium remains very short, scarcely 
projecting at all above the surface of the prothallium, and closely resembling in form the archegonium of the Marattiaceæ. Each of the four rows of neck cells contains three or four cells. The basal cell may undergo divisions, but its limits remain clearly visible in the ripe archegonium.

According to Mettenius ((2) P1. xxx, Figs. I8, I9), $O$. pedunculosum differs from $O$. pendulum in having the outer wall of the antheridium double, as it is in Botrychium. The neck of the archegonium is also somewhat longer than in O. pendulum. Bruchmann's account of $O$. vulgatum agrees closely with that of Lang for $O$. pendulum.

\section{Botrychium}

In July, I903, the writer found at Grosse Isle, Michigan, a number of old prothallia of Botrychium Virginianum, with the young sporophytes still attached, but nevertheless showing the older stages of the sexual organs. In I896, Jeffrey (I) was fortunate enough to secure abundant material of this species, including young prothallia, and succeeded in tracing very completely the development of the reproductive organs and embryo. Owing to the kindness of Professor Jeffrey, who sent preserved material, as well as prepared slides, I have been able to confirm the results of his investigations.

The prothallium (Figs. I26, I27) is a subterranean, tuberous body, much like that of $B$. lunaria described by Hofmeister, but is very much larger. The specimens collected by the writer were buried several centimetres below the surface, in rather dry woods ; Jeffrey's material was in part found in a sphagnum bog, partly in dryer localities.

The youngest specimens found by Jeffrey were oval, slightly flattened bodies, which bore only antheridia. These occupied the middle line of the upper surface, which later develops a median ridge upon which the antheridia are borne, while archegonia appear later on either side of the antheridial ridge. (Fig. I26, B). In B. lunaria, according to Hofmeister ( ( $\mathrm{I}$ ), p. 308 ), the archegonia are mostly formed upon the ventral surface.

A. section of the prothallium shows that the superficial tissues are composed of relatively transparent cells, while the inner tissue, especially toward the ventral side of the thallus, has very dense contents, there being an oily substance present, as well as 
granular matter. In these cells is found an endophytic fungus, which probably acts as a mycorhiza. Multicellular hairs are found growing from the upper surface of the prothallium.

The growth of the prothallium is distinctly apical, and a single definite apical cell seemed to be present, although it is possible that there may be more than one initial.

The infection of the thallus by the mycorhizal fungus is chiefly through the short rhizoids upon the inferior surface of the thallus. Jeffrey concludes that the affinities of the fungus are with the genera Pythium or Completoria.

A

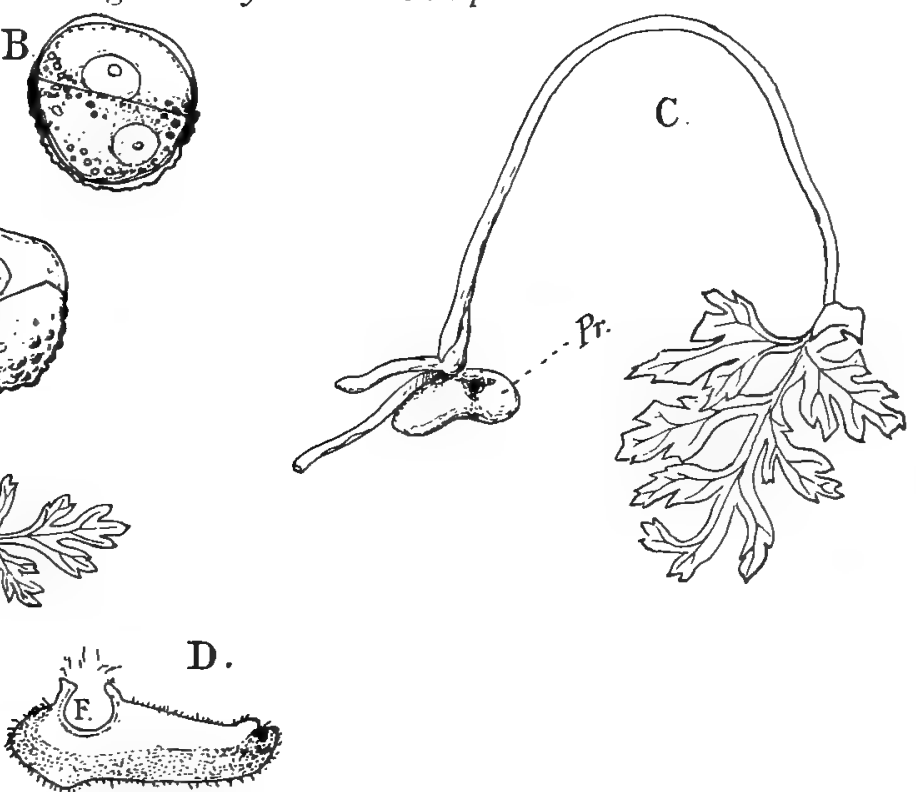

FIG. 127.-Botrychium Virginianum. A, B, Germinating spore, $\times 600 ; C$, prothallium ( $p r)$, with young sporophyte attached, $X_{2} ; \mathrm{D}$, longitudinal section of the prothallium, showing the foot of the embryo $(F), \times_{4} ; \mathrm{E}$, first (?) leaf of a young sporophyte, $\times 2$.

As the prothallium grows older-it may evidently live for several years-it becomes irregular in outline. It may finally reach a length of twenty millimetres, and occasionally shows indications of a dichotomy of the apex.

\section{Sex-Organs}

The first antheridia form a small group upon the upper surface of the prothallium while it is still very young. The later ones form only upon the median ridge already referred to. 
Still later the archegonia appear along the base of the antheridial ridge (Fig. I $26, \mathrm{~B}$ ).

The development of the antheridium (Fig. I28) is much like that of Ophioglossum, but the outer wall of the antheridium has normally two layers of cells. The spermatozoids, according to Jeffrey, probably correspond with those of the true Ferns. In a few cases observed by myself (Fig. I28, C) the primary division walls of the central part of the antheridium were not broken down by the separation of the sperm cells, but formed a number of chambers.

The complete spermatozoid has about one and a half coils,
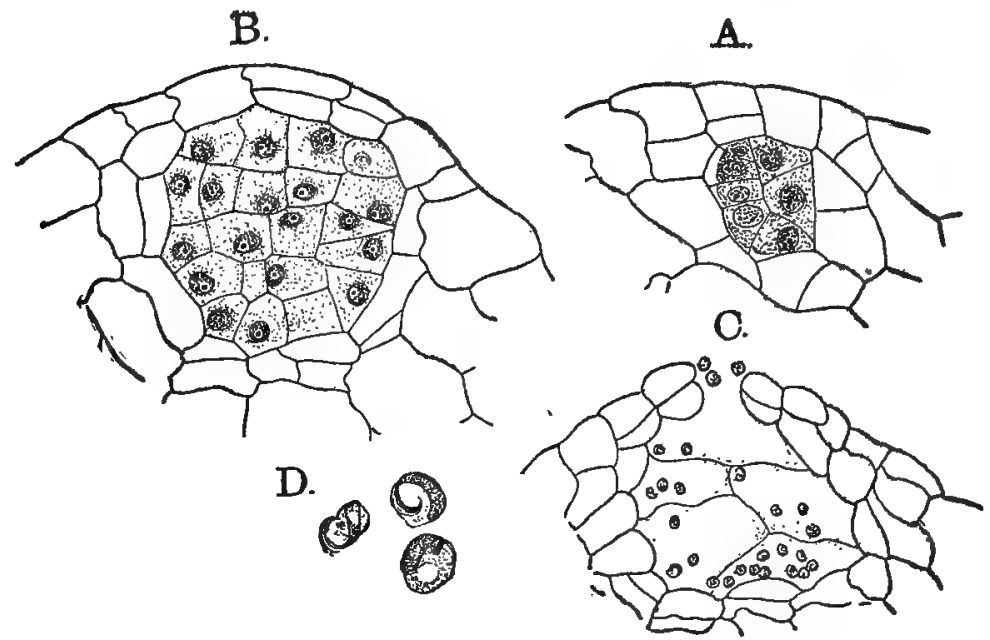

FIc. 128.-Botrychium Virgirianum. Development of the antheridium, $X$ about 450; in $\mathrm{C}$, the primary division walls within the antheridium have persisted, forming large chambers, from which the ripe sperm-cells are ejected successively.

and closely resembles that of the true Ferns and Equisetum, like them having numerous cilia. They swarm within the antheridium, and according to Jeffrey's account, escape through on opening formed by the destruction of two superimposed cells of the outer wall. They do not all escape at once, but are ejected in separate swarms. It is possible that the formation of the separate chambers, noted by the writer, may have something to do with this phenomenon.

The development of the archegonium (Fig. 129) is much like that of Ophioglossum, but the neck of the archegonium is much longer and projects conspicuously above the surface of 
the thallus. The basal cell also divides more extensively, but the group of cells derived from it is easily recognisable in the ripe archegonium.

The central cell divides transversely, the lower cell forming the egg, and the ventral canal cell, the upper one giving rise to the single neck canal cell, whose nucleus later divides as in Ophioglossum.

The mature egg cell contains dense cytoplasm, but has a vacuole within it. Jeffrey observed a spermatozoid in the act of penetrating the egg, which showed an extension toward the entering spermatozoid. The details of fertilisation, however,

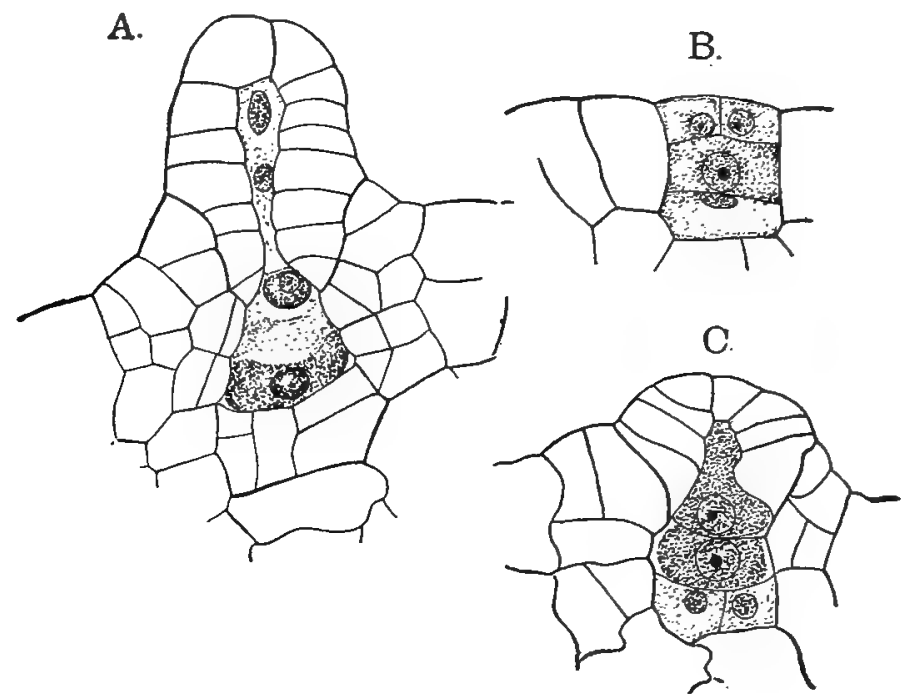

FIG. 129.-Botrychium Virginianum. Development of the archegonium, $X$ about 450 .

were not made out, but they probably correspond closely with those observed in other Ferns.

\section{Helminthostachys}

The gametophyte of Helminthostachys (Lang (4)), the third genus of the Ophioglossaceæ, does not differ essentially from the other genera, being also subterranean. It is nearly cylindrical in form (Fig. I26, C). The lower part, which is brown, and covered with rhizoids, is sterile, and contains an 
endophytic fungus. The upper portion, lighter in colour, bears the reproductive organs. Some of the prothallia bear only antheridia; the others have archegonia as well. As usual, the first antheridia appear before any archegonia are formed. Both archegonia and antheridia resemble those of Botrychium more than they do those of Ophioglossum.

\section{The Embryo}

The fertilised egg, or oöspore, becomes invested with a cellmembrane and enlarges to several times its original bulk before
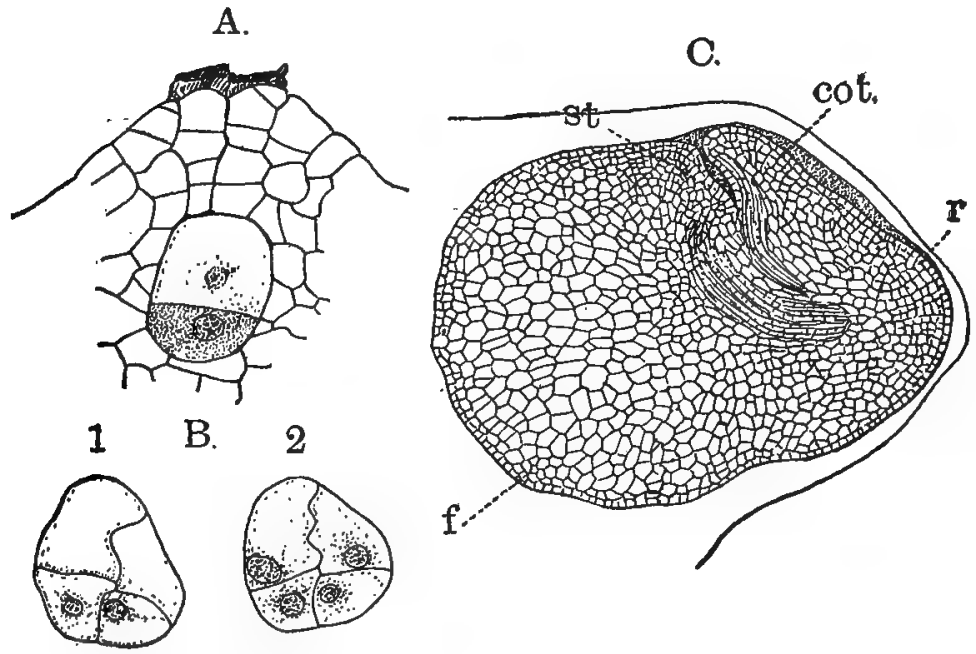

FIG, 130.-Botrychium Virginianum. A, two-celled embryo within the archegonium venter, $X$ about $300 ; B$, two sections of an 8-celled embryo; $C$, large embryo showing the primary organs, $X$ about 25 .

the first division wall is formed. This primary (basal) wall is in most cases transverse, but may be somewhat oblique. The two cells are generally more or less unequal in size, the upper or epibasal cell being larger than the lower (hypobasal) one. Each primary cell is next divided by a median vertical wall, and the young embryo shows thus a regular quadrant formation. The next divisions occur in the epibasal quadrants and are also approximately transverse ; at this stage, to judge from Jeffrey's figures 43,44 , the embryo presents a striking resemblance to a corresponding stage in Anthoceros. 
The subsequent divisions apparently show great irregularity, and the embryo does not exhibit the early development of apical initial cells so marked in the typical Ferns.

The whole part of the embryo is devoted to the formation of the foot, in this respect showing an analogy, at least with Anthoceros. From the epibasal region arise the shoot and the root, both of which later develop a definite apical cell. The initial cell of the root at once begins to form periclinal cells, which cut off the segments of the root cap from its outer face, and the apical cell thus becomes deeply sunk beneath the surface of the root-apex, which projects but little beyond the other parts of the very massive embryo-sporophyte. The primary leaf, or cotyledon (Fig. I 30 cot.), unlike that of the true Ferns, arises secondarily from the shoot.

In one instance, Jeffrey found small tracheids present in a prothallium, but the young sporophyte had been destroyed, and there was no means of determining whether this formation of tracheids was associated with apogamy, as in all other similar cases that have been observed.

The tissues adjacent to the venter of the archegonium grow rapidly, keeping pace with the developing embryo, which becomes very large before it breaks through the overlying tissues (calyptra), which protect it. At this time, the very large foot is especially conspicuous. The root is already somewhat elongated and shows a very definite arrangement of its tissues, which resembles that of the later roots. A tetrahedral apical cell is covered by a root-cap composed of several layers of cells, and the axis of the root is occupied by a strand of narrow cells, which later develop into the vascular cylinder or "stele" of the root.

The cotyledon, at this time, is relatively inconspicuous, and forms a short, incurved, conical protuberance, between which and the root lies the very slightly conical apex of the shoot. Both stem and leaf show a fairly distinct apical cell, but these apparently cannot be traced back to the original embryo-octants, as is the case in the more specialised Ferns. A very short procambium cylinder can somewhat later be seen in the axis of the stem, and from it extends a similar strand into the cotyledon. The central cylinder of the stem (Jeffrey (I), P. 2I) becomes fully dereloped below the point of origin of the cotyledon. From the first it is a hollow cylinder with a well- 
marked pith. The vascular ring is broken by a gap above the first leaf-trace (cotyledonary stele), and the pith is thus thrown into communication with the outer ground tissue, or cortex.

The first tracheary tissue appears shortly after the root has broken through the calyptra, at which time the root has the length of 5-20 millimetres. The development of the tracheary tissue in the root begins at two, or more commonly. three, points, $i$. e., the root is either "diarch" or "triarch." The innermost layer of the fundamental tissue forms the "endodermis" or bundle-sheath. As is usually the case, the endodermal cells are characterised by the peculiar thickening or foldings of the radial walls, which appear as elongated dots in transverse sections. A similar endodermis can be made out, surrounding the stelar tube of the stem.

The primary tracheids, or "protoxylem," have reticulately sculptured walls, and, except in size, closely resemble the secondary tracheary elements, or "metaxylem," which are formed centripetally, and meet in the centre of the vascular cylinder. Between the xylem masses are as many masses of phloem, or bast, made up in part of sieve-tubes with which are mingled elongated paranchyma cells. Surrounding the circle of xylem and phloem masses is the pericycle, composed of one or two layers of parenchyma.

After the young root has broken through the calyptra and penetrated the ground, the cotyledon grows upward and finally makes its appearance above the surface of the ground. It becomes differentiated into a slender, nearly cylindrical stalk (stipe) and a much-divided lamina (Fig. I27, E). The single primary vascular bundle of the leaf-rudiment divides into two within the stalk, and passes into the two lateral lobes of the lamina. From one of them a strong branch is developed which constitutes the midrib of the central segment of the lamina. The vascular bundles of the stipe approach the collateral type, rather than the concentric structure found in the later formed leaves.

Sometimes two or three roots are developed before the cotyledon unfolds, and the young sporophyte remains for a long time-probably two or three years-attached to the gametophyte, the superficial cells of the foot remaining active during this period. These cells show the dense cytoplasm and conspicuous nuclei of active cells. 
According to Mettenius, the cotyledon in Ophioglossum pedunculosum develops much earlier than is the case in Botrychinm. It appears above the ground while the primary root is still but little developed. (Fig. I25, B.)

In Botrychium lunaria, according to Hofmeister, the first three leaves are rudimentary and the first green leaf does not appear above ground until the second year.

Mettenius' account of the development of the embryo in $O$. pedunculosum is less complete. The earliest stage seen by him was already multicellular, and the young embryo had the form of an oval cell mass in which the primary divisions were not recognisable. The upper part, $i$. e., that next the archegonium. neck, grows up at once into the cotyledon, while the opposite part gives rise to the first root. These grow respectively upward and downward; and break through the overlying prothallial cells. Later, at a point between the two, the stem apex is developed. The first leaf becomes green, and develops a lamina similar to that of the later-formed ones. Usually but one embryo is developed from the prothallium, but occasionally two are formed, especially where the prothallium forks.

\section{The Adult Sporophyte}

Ophioglossum (Ophioderma) pendulum, an epiphyte common in the Eastern tropics, may be taken as a type of the simplest of the Ophioglossacex. Its short creeping stem grows upon the trunks of trees, especially tree-ferns, from which the long flaccid leaves hang down. The lamina of the leaf merges insensibly into the stout petiole whose fleshy base forms a sheath about the next younger leaf. Corresponding to each leaf is a thick unbranched root, which penetrates into the crevices of the bark and holds the plant secure. These roots are smooth, and show no trace of rhizoids. The petiole is continued up into the lamina as a very broad and thick midrib, which in the sporiferous leaves (sporophylls) is continued into the peculiar elongated spike which bears the sporangia.

The petiole if cut across shows a number of vascular bundles arranged in a single row, nearly concentric with the periphery of the section. As these enter the lamina they anastomose and form a network with elongated meshes (Fig. I33, C) and no free ends. Sections of the spike cut parallel to its broad 


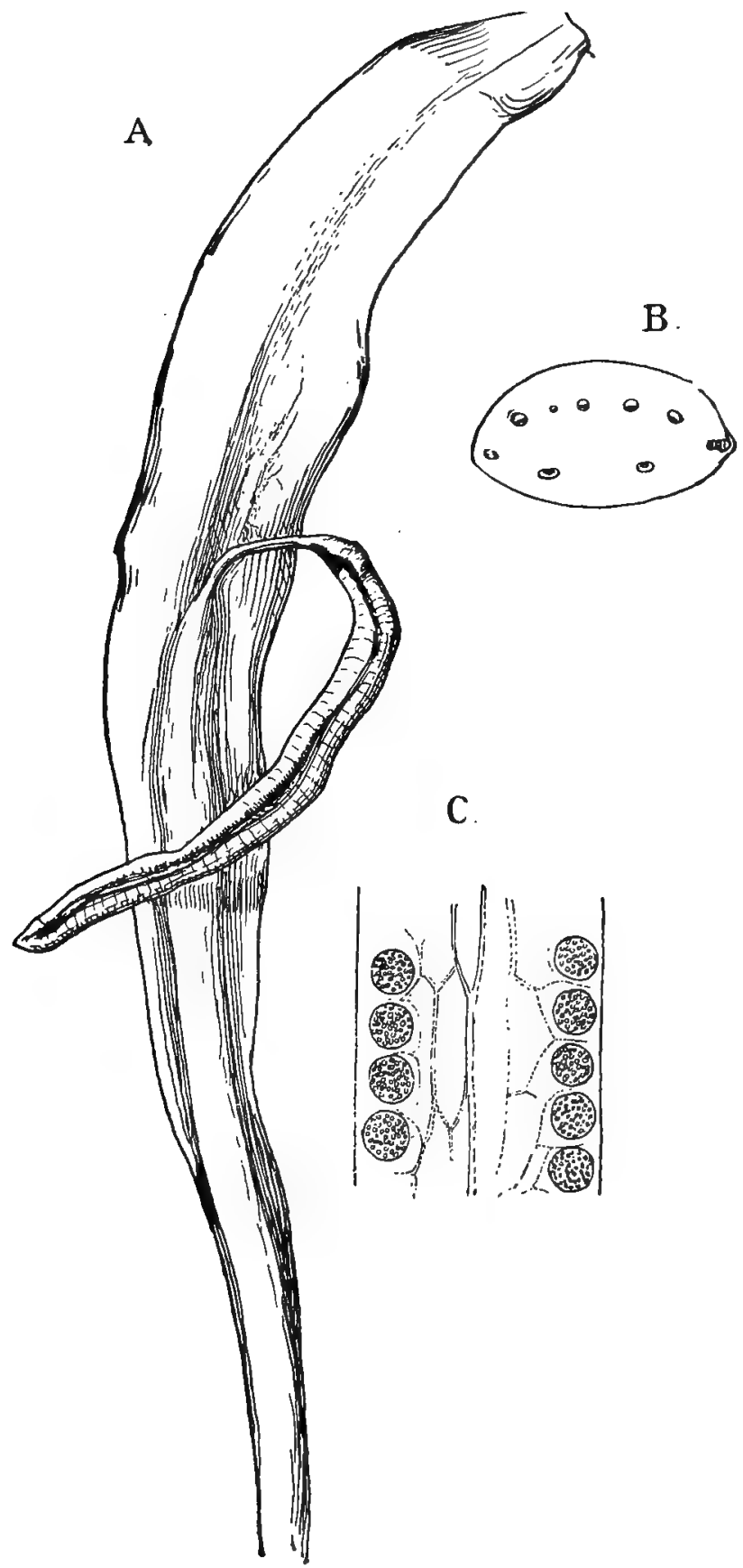

FIG. 131.-Ophioglossum pendulum. A, Leaf with sporangiophore, natrual size; B, cross-section of the petiole, $\times 6 ; \mathrm{C}$, section of the sporangiophore, parallel to th broad surface, $\times 6$. 
diameter show a somewhat similar arrangement of the vascular bundles, but here there are free branches extending between the sporangia. The relations of the bundles of the fertile and sterile parts of the leaf are best followed in the smaller species. Prantl ( ( 7$)$, p. I55) describes it as follows for $O$. Lusitanicum, and states that it is essentially the same in other species. "The primary bundle given off from the stem branches just after it enters the petiole. The main bundle gives off two smaller lateral branches right and left. The latter branch again near the base of the sporangiophore, and the upper branches from each unite to form the single bundle that enters the latter."

The sporangia are sunk in the tissue of the sporophyll, and scarcely project at all above the surface, where the position of each one is indicated by a faint transverse furrow which marks the place where it opens. Seen in sections parallel to the flat surface these appear perfectly round, but in transverse section are kidney-shaped (Fig. $\mathrm{r} 40, \mathrm{C}$ ).

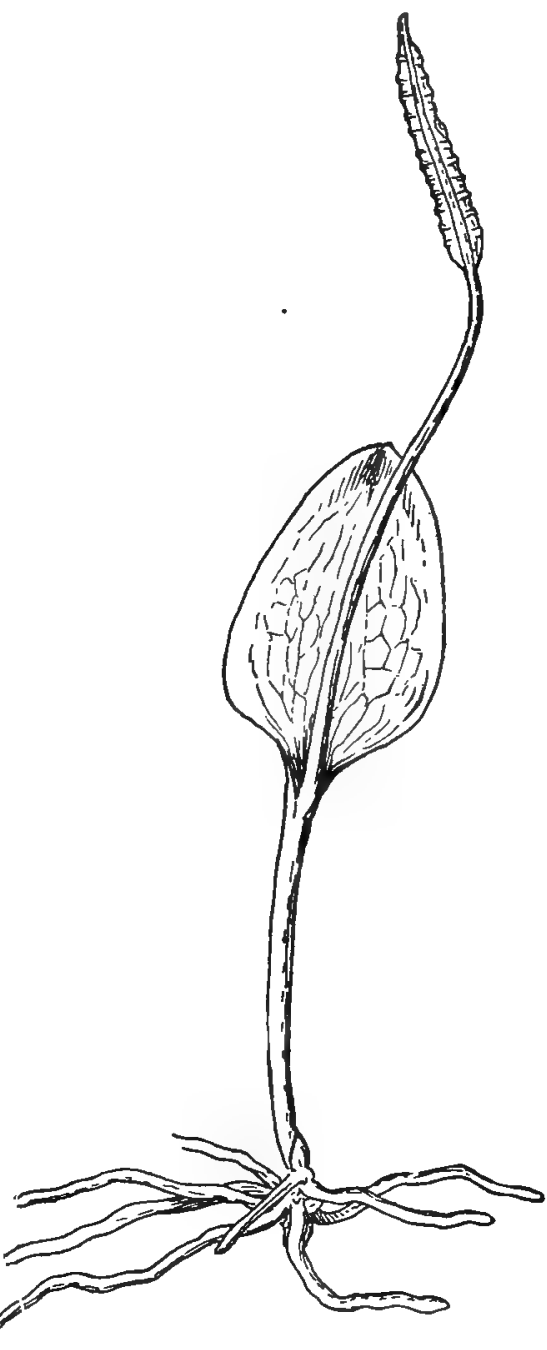

FIG. 132.-Ophioglossum vulgatum, $\times 1$.

The apex of the stem forms a blunt cone, which, however, is not visible from the outside. A longitudinal section through the end of the stem shows that it is covered by a sheath com- 
posed of several layers of cells, and this encloses a cavity in which are the growing point of the stem and the youngest leaf. The leaves here form much more rapidly than in the species of the temperate regions, as the growth continues uninterruptedly throughout the year. The real apex of the stem forms an inclined nearly plane surface, slightly raised in the centre, where the single apical cell is placed (Fig. I34,A,B). This cell is by no means conspicuous, and not always readily found, but probably

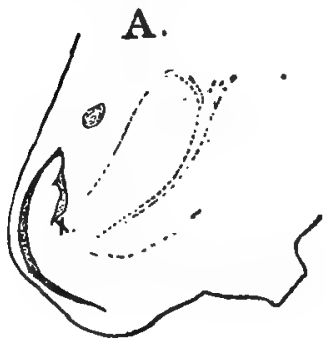

B.

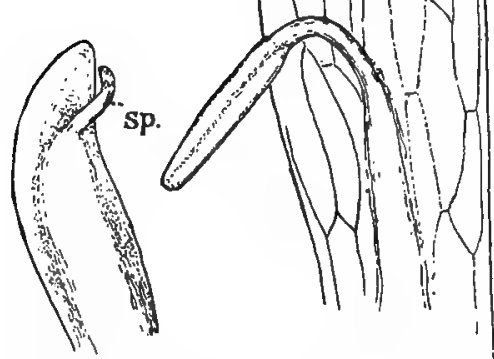

FIG. 133.-Ophioglossum pendulum. A, Me$x$, the growing point; $\mathrm{B}$, young sporophyll, $\times 2 ; s p$, the sporangiophore; $C$, an older leaf, showing the venation, $\times 2$. is always present. It has the form of an inverted three-sided pyramid, but the lateral faces are more or less strongly convex, and the apex may be truncate. From the few cases observed it is not possible to say whether in addition to the three sets of lateral segments basal segments are also formed, but it is by no means impossible that such is the case. According to investigations of Rostowzew (( I), p. 45I), the apical cell of the stem of Ophioglossum vulgatum shows considerable variation, and may be either a three or four-sided prism, $i$. e., it apparently also may have the base truncate. Holle's (I) description agrees with this except that he states that he always found the cell pointed below, not truncate. The segments cut off from the lateral faces are large, and the divisions irregular. They are apparently formed in very slow succession, and the irregularity of the succeeding divisions in the segments themselves soon makes it impossible to trace their limits. Each segment apparently gives rise to a leaf, but this is impossible to determine with certainty. The first wall in the young segment probably divides it into an inner and outer cell, but the next divisions could not be deter- 
mined positively. Probably, as in Botrychium, the outer cell is next divided by a vertical wall, perpendicular to the broad faces of the segment, into two cells, in which divisions then take place in both transverse and longitudinal direction without strict regularity.

The stem in $O$. pendulum is mostly made up of thin-walled parenchyma, and the vascular bundles are much less developed than is the case in the underground stem of $O$. vulgatum or Botrychium. The bundles are of the collateral form, $i$. e., the inner side is occupied by the xylem, the outer by the phloem,

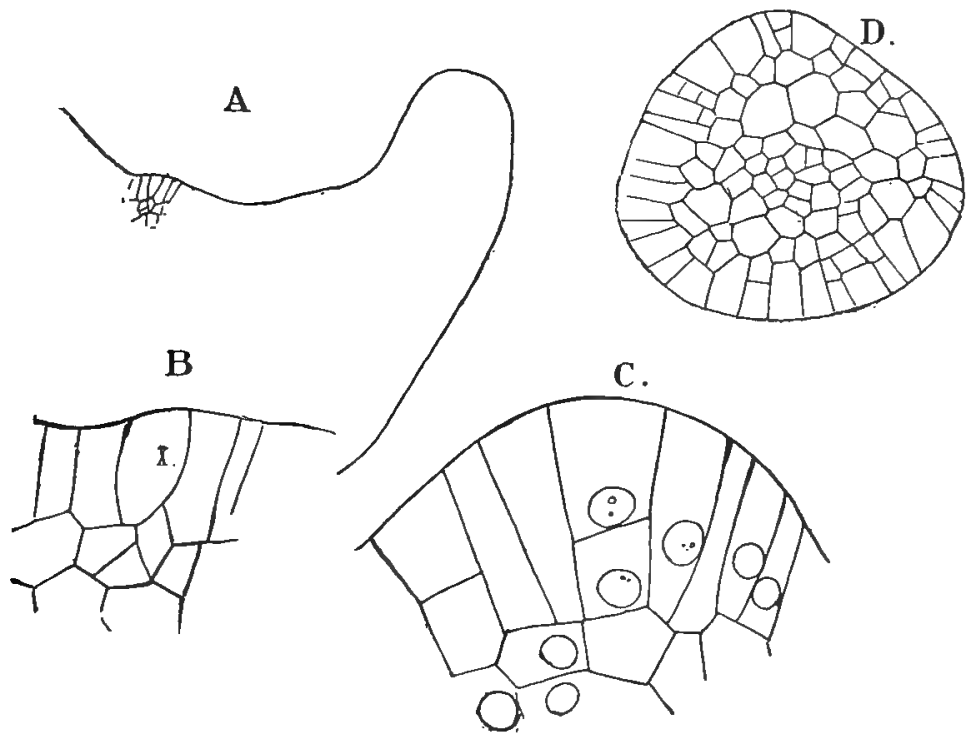

FIG. 134.-Ophioglossum pendulum. A, Longitudinal section of stem apex, $\times 60 ; \mathrm{B}$, the central part of the same section, $X 180 ; D$, longitudinal section of verg young sporangiophore, $X I 80 ; E$, cross-section of young sporangiophore, $\times 60$.

and there is no evident bundle-sheath developed. The bundles form a very irregular wide-meshed cylinder, not differing essentially from that in $O$. vulgatus

Van Tieghem (7) states that in Ophioglossum vulgatum each vascular strand is completely invested with a distinct endodermis and pericycle; but Bower (I6) found the endodermis very poorly developed in the species studied by him, especially $O$. Bergianum, a small and simple species. The stem of this form shows in transverse section two strands which may 
either be separate, or partly coherent, so as to form a single crescent-shaped bundle, when seen in section. There may be, however, even in this species, more than two strands present. Poirault (2) found a definite endodermis in the lower part of the stem, which disappears in the upper portion.

Van Tieghem asserts (see Bower (I6), p. 67) that in the young sporophyte of $O$. vulgatum, there is at first a solid axial stele, with pericycle and endodermis, and that only above the insertion of the first leaf does a pith appear.

In the bundles of the stem of $O$. pendulum, the xylem of the collateral bundle is mainly composed of short irregular tracheids, with close reticulate markings on the walls. The phloem is composed of short, thin-walled cells with large nuclei. No true sieve-tubes could be recognised.

\section{The Leaf}

The young leaf is completely concealed by the sheath formed at the base of the next older one. It is at first a conical protuberance arising close to the stem apex, around which its base gradually grows and forms the sheath about it and the next leaf rudiment. It is probable that here, as in $O$. vulgatuin, ${ }^{1}$ the young leaf grows at first by a definite apical cell. After the plant has reached a certain age, each leaf gives rise to a sporangial spike, which becomes evident while the leat is still very small. The first indication of this is a conical outgrowth upon the inner surface of the leaf, about halfway between the apex and base. A longitudinal section of this shows it to be made up of large cells, especially toward the top; but although there was sometimes an appearance that indicated the presence of a single apical cell, this was by no means certain, and if there is such an initial cell, its divisions must be very irregular.

Bower (16) found that in O. vulgatum the young sporangial spike grows from a single apical cell, which in less robust specimens persists for a long time as a four-sided, initial cell, but in the larger specimens seems to be replaced by four similar initials.

The subsequent growth of the leaf is for a long time mainly from the base, and the young sporangial spike is much nearer the apex in the next stage (Fig. I33, B). No distinct petiole ... Rostowzew (I), p. 45 I. 
has yet developed, but the centre of the young leaf, up to the point of attachment of the spike, is traversed by the thick midrib, above which the lamina is still very small. Indeed in this stage it looks as if the spike were really terminal and the lamina a lateral appendage. The young spike now forms a beakshaped body curving inward and upward, and sections of slightly older stages than the one figured show the first indications of the developing sporangia. Later still the base of the leaf becomes narrowed into the petiole, and the spike also becomes divided into the upper sporiferous portion and the short slender pedicel.

The anatomical structure of the leaf is extremely simple. The epidermis is composed of rather thick-walled cells, irregularly polygonal in outline, with large stomata at intervals, about which the cells are arranged concentrically, and frequently with a good deal of regularity. The stomata themselves (Fig. I35), seen from above, have an angular outline, but from below are perfectly oval, and cross-sections show that this appearance is due to a partial overarching of the guard cells of the stoma by the surrounding epidermal cells. The upper walls of the guard

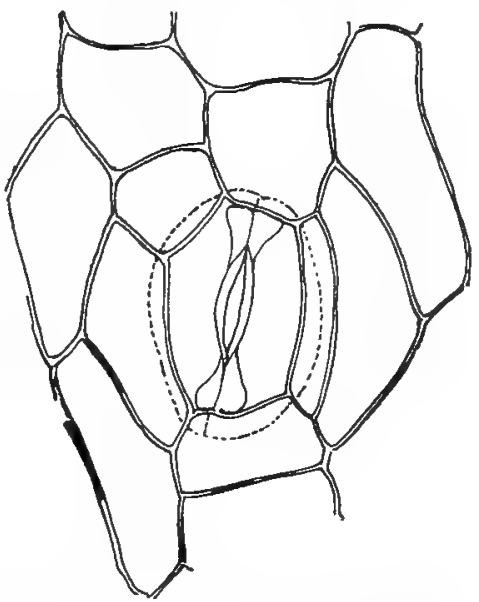

Fig. 135.-Stoma from the leaf of Ophioglossum pendulum, $\times 260$. cells are thickened unequally, giving them the appearance of being folded longitudinally. There is no distinct hypoderma formed, and the bulk of the leaf is made up of a uniform mesophyll composed of nearly globular cells with much chlorophyll, and separated by numerous intercellular spaces. In the petiole the tissues are similar, but more compact, and the walls of the ground tissue are all deeply pitted. The vascular bundles are nearly circular in section and show a compact mass of tracheary tissue (Fig. I $36, t$ ), surrounded by nearly uniform cells with moderately thick colourless walls. The limits of the bundle are not, as in the higher Ferns, marked by a distinct bundle-sheath, but are indicated simply by the 
somewhat smaller size of the cells of the bundle itself-indeed it is not always easy to say exactly where the ground tissue begins. The xylem is composed of pointed tracheids whose walls are marked with thick reticulate bands. This mass of tracheary tissue is situated near the inner side of the bundle, which like that of the stem is collateral. The rest of the bundle is composed of sieve-tubes mingled irregularly with smaller cambiform cells. Whether or not sieve-tubes occur upon the inner side of the bundle could not be positively determined. The sieve-tubes have transverse walls, and in 0 . vul-

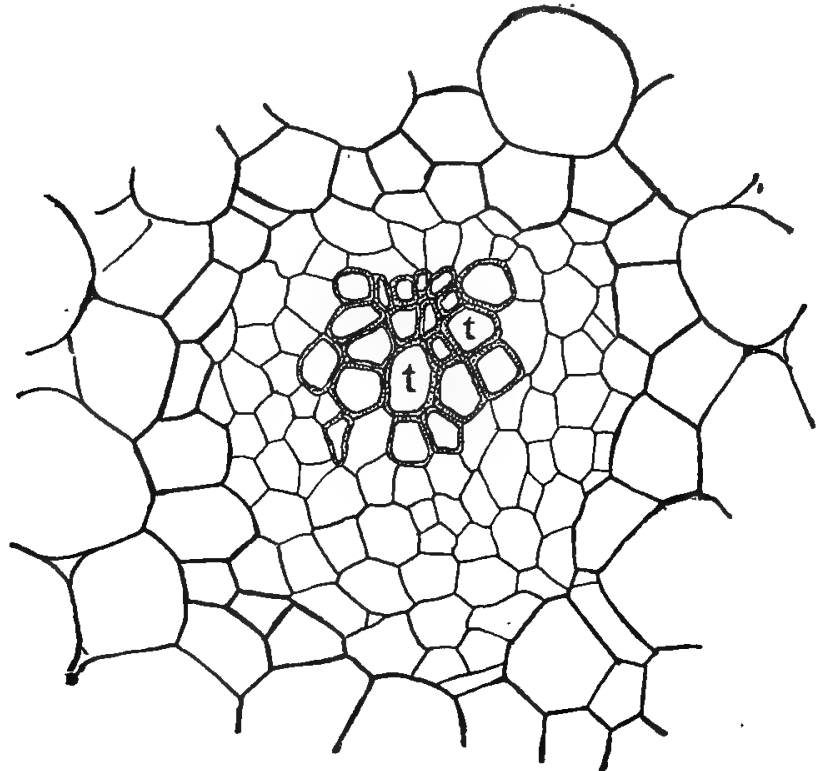

Fic. 136.-Vascular bundle of the petiole of 0 . pendulum, $\times_{260} ; t, t$, the xylem of the bundle.

gatum lateral sieve-plates have been observed. The sporangiophore has much the same anatomical structure as the rest of the leaf, but stomata are quite absent from its epidermis. In this respect $O$. pendulum differs from $O$. vulgatum and allied species, where stomata are developed upon the sporangiophore as well as upon the rest of the leaf.

\section{The Root}

The roots are formed singly near the bases of the leaves, and are light yellowish brown in colour, and so far as could be 
seen, entirely unbranched. Sections show that here, as in most vascular plants, the growing point of the root is not at the apex, but some distance below and protected by the root-cap. The growth of the root in Ophioglossum can be traced to a single apical cell (Fig. I37), which is of large size, and, like that of the stem, approximately pyramidal in form. While the divisions show greater regularity than in the stem, still they are very much less so than in the leptosporangiate Ferns. Segments are cut off not only from the lateral faces of the apical cell, but also from its outer face. These outer segments help to form the root-cap, which, however, is not derived exclusively
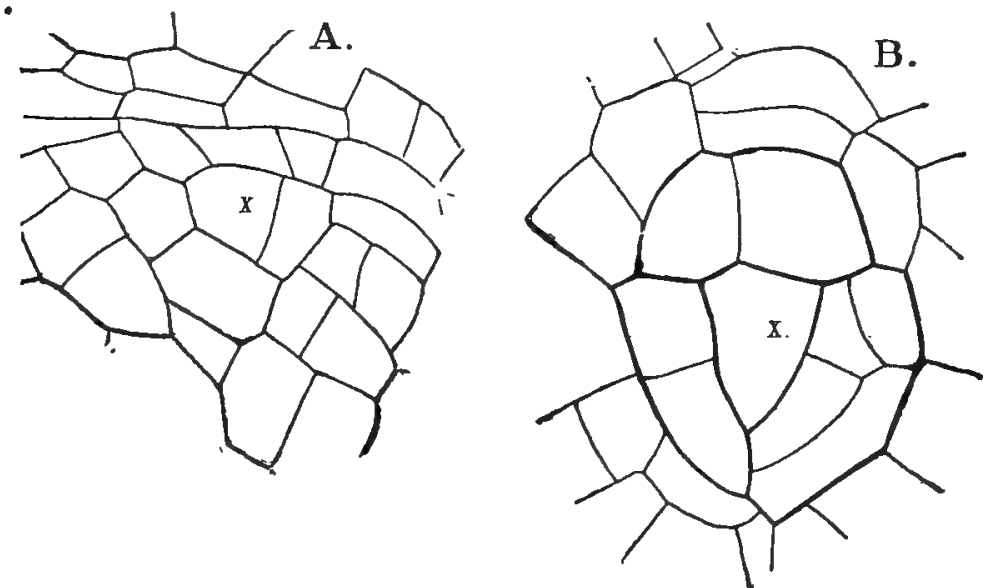

F1G. 137.-Ophioglossum pendulum. A, Longitudinal; B, transverse sections of the root apex, X.215.

from these, but in part also from the outer cells of the lateral segments. Each of the latter is first divided by a nearly vertical wall, perpendicular to its broad faces, into two "sextant cells," but beyond this no regularity could be discovered in the order of division in the segments, and the tissue at the growing point, especially in longitudinal section, presents a very confused arrangement of the cells. A little lower down two regions are discernible, a central cylinder (plerome), whose limits are not very clearly defined, and the periblem or cortex. A definite epidermis is not distinguishable.

The first permanent tissue in the plerome cylinder or stele, which is elliptical in section, arises in the form of small tracheids 
near the foci of the elliptical section. From here the formation proceeds towards the centre, and in the full-grown root the tracheary tissue forms a continuous band occupying the larger axis of the section, the last-formed tracheids being the largest. On either side of this tracheary plate is a poorly defined mass of phloem, similar to that of the stem and leaf bundles. An endodermis or bundle sheath can be made out, although it is much less prominent than in most roots. The endodermis is derived from the innermost cortical layer, and the radial cell-walls are characterised by a thickening, or folding of the wall. In $O . v u_{i}^{\prime}$ -

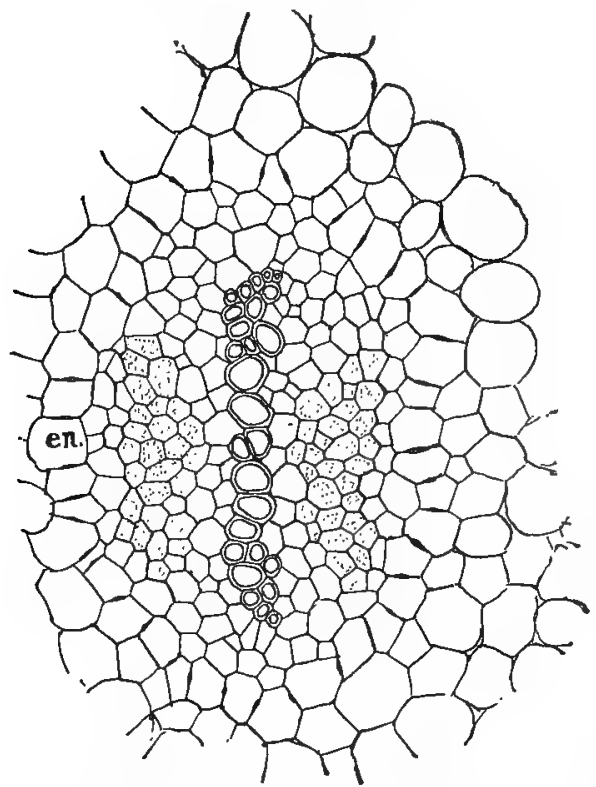

FIG. 138.-O. pendulum. Vascular bundle of the root, $\times 85$. The phloem is shaded; $e n$, endodermis. gatum the bundle of the root is diarch to begin with, but by the suppression of one of the phloem masses it becomes monarch.

\section{The Sporangium}

The development of the sporangium has been studied by Goebel ( ( I 7$)$, p. 390), in O. vulgatum, and recently by Bower (I6) in this species and in $O$. pendulum. The latter has been carefully examined by the writer, and the results confirm that of the latter investigator, except that it seems possible that the archesporium may be traced to a single cell, as Goebel asserts is probably the case in O. vulgatum.

According to Bower ( 16 ), in all species examined by him, the sporangia arise from a continuous band of superficial tissue, on each side of the spike. To this he gives the name, "sporangiogenic band." The sporangia arise from the sporangiogenic band, at more or less definite intervals, separated by intervals of sterile cells. In the sporangial areas, periclinal walls sep- 
arate an inner archesporium from the outer cells, destined to form the wall of the sporangium. Between the young sporangia the cells form sterile septa. The cell-groups which form archesporia, and those which develop into sterile septa, are sister-cell groups.

All of the sporogenous tissue cannot be traced back to the primary archesporial cell, as later secondary sporogenous tissue may be formed by further periclinal divisions in the outer cells of the sporangium.

A transverse section of the very young sporangiophore is

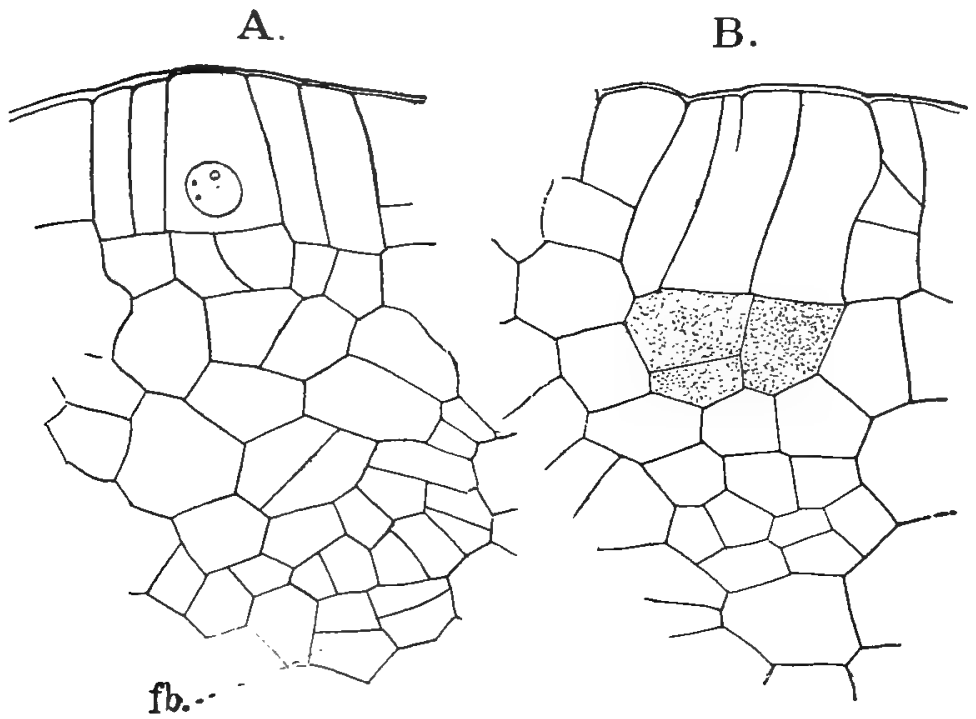

FIG. I39.-A, Very young; B, older sporangia of $O$. pendulum; transverse sections, $x=60$.

somewhat triangular, the broader side corresponding to the outer surface of the sporangiophore. The cells are very irregular in form, and no differentiation of the tissues is to be observed. Sections of somewhat older stages show in some cases, at least, a large epidermal cell occupying nearly the centre of the shorter sides of the triangular section. This cell has a larger nucleus than its neighbours, and is decidedly broader. The next stage was not observed, but a somewhat more advanced one shows a small group of inner cells (shaded in the figure), which appear to have arisen from the primary 
cell by a transverse wall, although this point is exceedingly difficult to determine on account of the great similarity of all the cells (Fig. I39). This group of inner cells (or the single one from which they perhaps come) constitutes the archesporium, and by rapid division in all directions forms a large mass of cells whose contents become denser than those of the
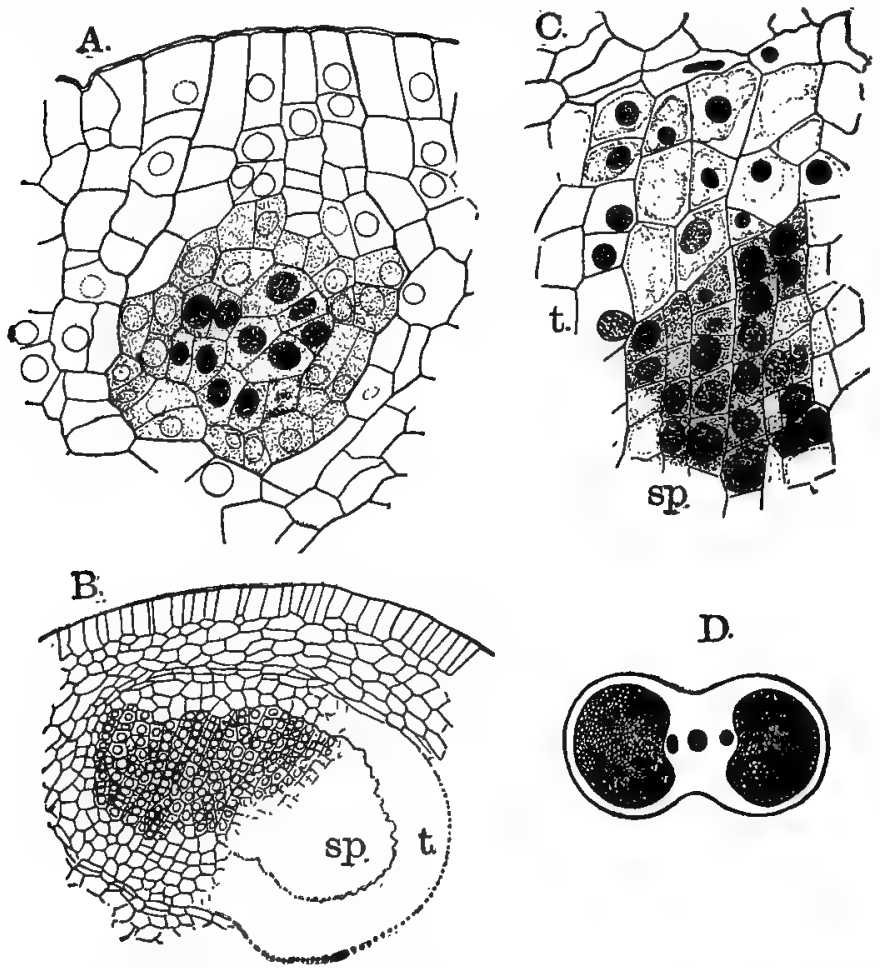

FIG. 140.-Ophioglossum pendulum. A, Section of a young sporangium, the archesporial tissue is shaded, the inner cells with dark nuclei being the definitive sporogenous cells, $\times 200 ; \mathrm{B}$, transverse section of an older sporangium; $s p$, sporangeous cells; $t$, tapetum, $X$ about $35 ; \mathrm{C}$, a portion of $\mathrm{B}$ more highly magnified; $\mathrm{D}$, section of nearly mature sporangial spike, $\times 8$.

surrounding ones, between which and these, however, the limits are not very plain. Later, when the number of cells is complete, the difference between them and the sterile tissue of the sporangiophore is much more evident.

The cells lying outside of the archesporium divide rapidly both by longitudinal and transverse walls, and form the thick outer wall of the sporangium. In longitudinal sections, two 
rows of cells may be seen extending from the mass of archesporial cells to the periphery. In these rows the vertical walls have been more numerous than in the adjacent ones, so that the number of cells in these rows is greater. It is between these rows of cells that the cleft is formed by which the ripe sporangium opens. The outer cells of the sporogenous tissue do not develop into spores, but constitute the "tapetum" (Fig. $\mathrm{I} 4 \mathrm{O}, \mathrm{B}, \mathrm{t}$ ), which serves to nourish the developing spores.

After the full number of cells is reached in the archesporium, their walls become partially disorganized, and the cells round off and separate, exactly as in the sporogonium of a Bryophyte, and each cell is, potentially at least, a spore mother cell. Bower ( I6) states that only a part of the cells produce spores, and that the rest remain sterile and serve with the disorganised tapetal cells to nourish the growing spores. The final division of the spore mother cells into four spores is identical with that of the Bryophytes.

At maturity the sporangium opens by a cleft, whose position is indicated as we have seen in the younger stages, and as the cells shrink with the drying of the ripe sporangiophore the spores are forced out through this cleft.

Ophioglossum vulgatum and the other terrestrial forms show some points of difference when compared with $O$. pendulum. These grow much more slowly, and longitudinal sections of the upper part of the subterranean stem show several leaves in different stages of development. Each leaf rudiment, as in $O$. pendulum, is covered by a conical sheath, formed at the base of the next older leaf, and these sheaths are open at the top, so that there is direct communication between the outside air and the youngest of these sheaths which encloses, as in the latter species, the youngest leaf rudiment and stem apex (Rostowzew (I), p. 45I). In these terrestrial forms, also, the sporangiophore is longer stalked, and the lamina of the leaf more clearly separated from the petiole, which is not continued into it. The lamina is relatively broader and the venation more complex, in some species showing also free endings to the ultimate branches. The sporangia, too, project more strongly and are very evident (Fig. I32). Branching of the roots occurs occasionally, and according to Rostowzew may be either spurious or genuine. In the first place an adventive bud, which ordinarily would develop into a stem, develops a single root and 
then ceases to grow. This root appears to be formed directly from the main root, and as the latter continues to grow the effect is that of a true dichotomy. The latter does occur, but not frequently.

The formation of adventitious buds upon the roots is the principal method of propagation of some species of Ophioglossum, whose prothallia, as we have seen, are apparently very seldom developed. Rostowzew states that these are not developed from the apical cell of the root, but arise from one of the younger segments, and the apical cell of the bud is produced from one of the outer cells of the young segment, but is covered by the root-cap, through which the bud afterwards breaks. The sheath covering the first leaf of the bud is formed from the cortex of the root and the root-cap.

Differing most widely from the other species in general appearance is the curious epiphytic $O$. (Cheiroglossa) palmatum. In this species the leaf is dichotomously branched, and instead of a single sporangiophore there are a number arranged in two rows along the sides of the upper part of the petiole and the base of the lamina.

According to Bitter ((I) p. 468), O. pendulum also has the sterile leaf segment dichotomously divided, but this was never the case in the specimens collected by the writer in various parts of the Hawaiian Islands. These invariably had an undivided, strap-shaped leaf.

In $O$. Bergianum the plant is very small and the sporangia are reduced in number to a dozen or less. The sterile segment is inserted very far down. A most remarkable form has been recently described from Sumatra (Bower (20)). This species, $O$. simplex, is described as having no sterile leaf-segment, or the merest rudiment of one, the sporophyll being a flattened slender body, with the sporangia closely resembling those of $O$. pendulum, to which $O$. simplex seems to be allied. $O$. simplex may be considered to represent the most primitive type of the genus yet discovered.

\section{BOTRYCHIUM}

The genus Botrychium includes several exceedingly variable species, the simplest forms, like $B$. simplex (Fig. I41, A, B), being very close to Ophioglossum, while leading from these is a 
series ending in much more complicated types, of which $B$. Virginianm is a good example. In $B$. simplex the lamina of the leaf is either entirely undivided, as in most species of Ophioglos$s u m$, or once pinnatifid. From these there is a complete series to the ample decompound leaf of B. Virginianum. When the other parts of the plant are studied we find that this greater complexity extends to them as well. Thus the sporangiophore is also decompound, and the sporangia entirely free, showing an approach to those of such Ferns as Osmunda; and the venation, which in the simpler forms is dichotomous, approaches the pinnate type in B. Virginianum. The tissues, especially the vascular bundles, are also more highly differentiated in the larger species.

Under favourable conditions well-grown plants of $B$. Virginianum reach a height of $50 \mathrm{~cm}$. or more, and the sterile lamina of the leaf, which is triangular in outline, may be 30 to $40 \mathrm{~cm}$. in breadth, and from three to four times pinnate. The texture of the leaf is membranaceous and not fleshy like that of Ophioglossum and most species of Botrychium. The sporangiophore is twice or thrice pinnate. The plant sends up a single leaf each year from the underground stem, which is upright and several centimetres in length in old specimens. The roots are thick and fleshy, and much smaller at the point of insertion. As in Ophioglossum each root corresponds probably to a leaf, but the roots branch frequently, so that the root system is much better developed than in Ophioglossum. The secondary roots of $B$. Virginianum arise laterally, and in much the same way as those of the higher Ferns. As in the terrestrial species of Ophioglossum, the development of the leaves is very slow.

In most species of Botrychinm the relation of the leaf base to the young bud and stem apex is the same as in Ophioglossum, except that the sheath is more obviously formed from the leaf base; but in B. Virginianum the sheath is open on one side, and more resembles a pair of stipules. Fig. 142, A shows the stem and terminal bud of a plant of this species with all but the base of the leaf of the present year cut away, and B the same with the bud cut open longitudinally. At this stage the parts of the leaf for the next year are well advanced, and the formation of the individual sporangia just begun. The leaf for the second year already shows the sporangiophore clearly evident, and the leaf which is to unfold in three years is evident, but the sporan- 


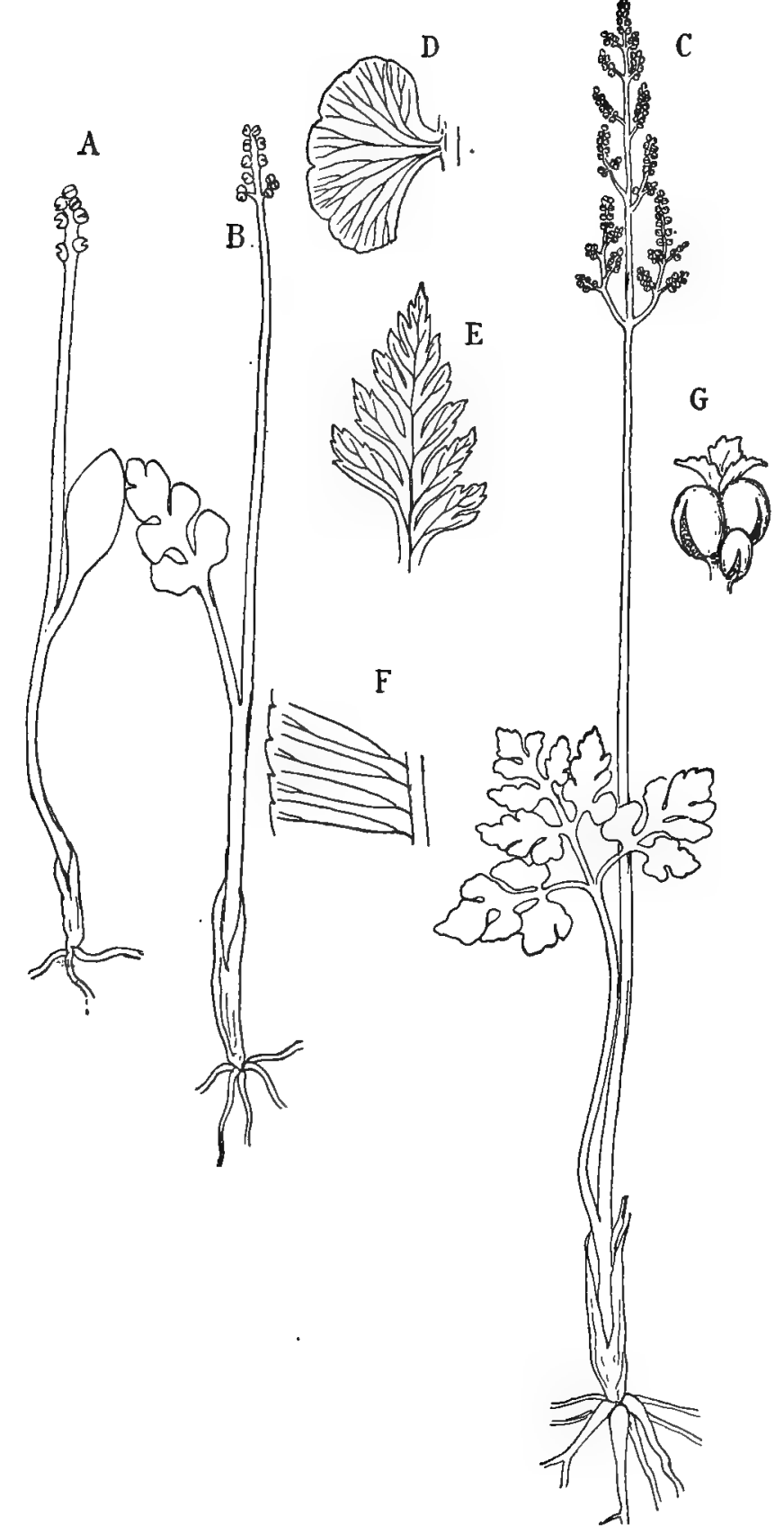

Fig. 14r.-A, B, Botrychium simplex, slightly enlarged; C, B. ternatum, $\times \frac{2}{3} ; \mathrm{D}$, leaf segment of $B$. lunaria; $\mathrm{E}$, leaf segment of $B$. Virginianum, natural size; F, portion of sterile leaf segment of Helminthostachys Zeylanica; G, fragment of the sporangiophore of the same enlarged. A, B, C after Luerssen; D, F after Hooker. 
giophore not yet differentiated. At the base of the youngest leaf is the stem apex. The whole bud is covered in this species with numerous short hairs, which are also found in $B$. ternatum and some other species; but in $B$. simplex and the other simpler species it is perfectly smooth, as in Ophioglossum. The young leaves in $B$. Virginianum are bent over, and the segments of the leaf are bent inward in a way that recalls the vernation of the true Ferns. The sporangiophore grows out from the inner surface of the lamina, and its branches are directed in the opposite direction from those of the sterile part of the leaf.

B.
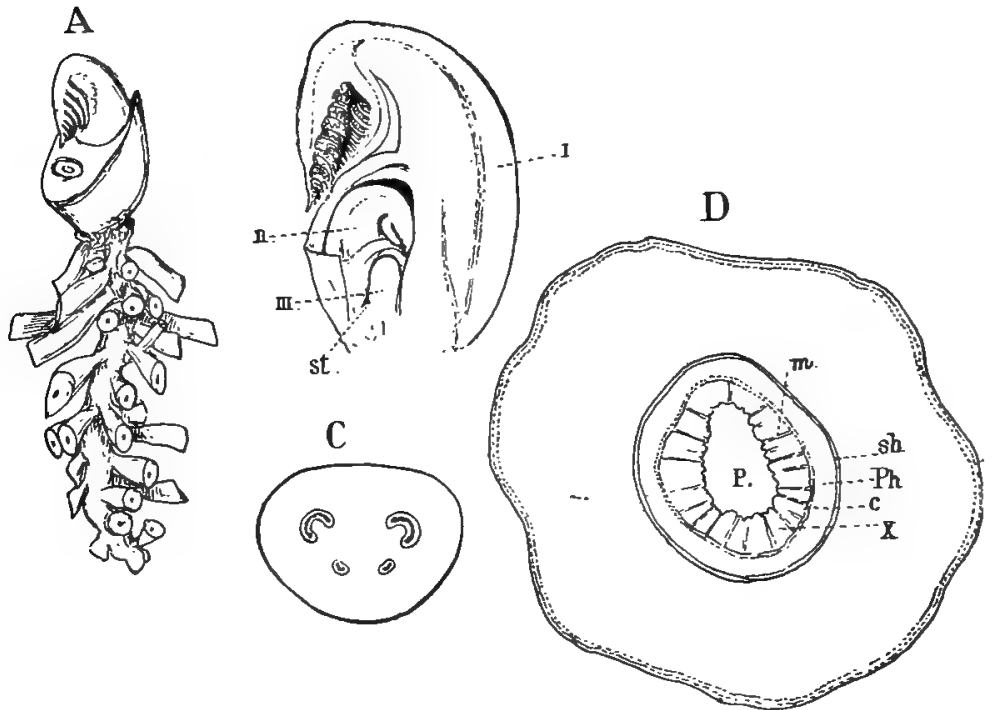

FIG. 142.-Botrychium Virginianum. A, Rhizome and terminal bud of a strong plant, the roots and all but the base of the oldest leaf removed, $X I$; $B$, longitudinal section of the bud, $X_{3}$; st, the stem apex; I. II. III., the leaves; $C$, transverse section of the petiole, $X_{4} ; \mathrm{D}$, transverse section of the rhizome, $X$ about $16 ; P$, the pith; $m$, medullary rays; $x$, xylem; $c$, cambium; $p h$, phloem; $s h$, endodermis.

The vascular bundles of the stem are much more prominent than in Ophioglossum, and form a hollow cylinder, with small gaps only, corresponding to the leaves. This cylinder shows the tissues arranged in a manner that more nearly resembles the structure of the stem in Gymnosperms or normal Dicotyledons than anything else. Surrounding the central pith (Fig. I42, P) is a ring of woody tissue $(x)$ with radiating medullary rays $(m)$, and outside of this a ring of phloem, separated from the 
xylem by a zone of cambium $(c)$, so that here alone among the Ferns the bundles are capable of secondary thickening. The whole cylinder is enclosed by a bundle-sheath (endodermis) consisting of a single layer of cells.

The cortical part of the stem is mainly composed of starchbearing parenchyma, but the outermost layers show a formation of cork, which also is developed in the cortical portions of the roots.

The free surface of the stem apex is very narrow, and the cells about it correspondingly compressed. The apical cell (Fig. I43, A, B), seen in longitudinal section, is very deep and narrow, but as comparison of cross and longitudinal sections shows, has the characteristic pyramidal form, and here there is no doubt that only lateral segments are cut off from it. Holle's ( ( I) P1. iv., Fig. 32) figure of Botrychium rutcefolium closely resembles $B$. Virginianum, and probably the other species will show the same form of apical cell. The divisions are decidedly more regular in the segments of B. Virginianum than in Ophioglossum, and can be more easily followed, although here, too, as the division evidently proceeds very slowly, it is difficult to trace the limits of the segments beyond the first complete set, which in transverse section are sufficiently clear. The first division divides the segment into an inner and an outer cell, the former probably being directly the initial for the central cylinder. The outer cell by later divisions forms the cortex, and the epidermis which covers the very small exposed surface of the stem apex. As in Ophioglossum, it is impossible to determine exactly the method of origin of the young leaves, one of which probably corresponds to each segment of the apical cell, but as soon as the leaf can be recognised as such it is already a multicellular organ. It grows at first by an apical cell which seems to correspond closely in its growth with that of the stem. From almost the very first (Fig. I43) the growth of the leaf is stronger on the outer side, and in consequence it bends inward over the stem apex.

The arrangement of the tissues of the fully-developed stem shows, as we have seen, a striking similarity to that in the stems of many Spermatophytes. The xylem of the strictly collateral bundle is made up principally of large prismatic tracheids (Fig. I44), whose walls are marked with bordered pits not unlike those so characteristic of the Conifèræ, but some- 
what intermediate between these and the elongated ones found in most Ferns. The walls between the pits are very much thickened, and the bottoms of corresponding pits in the walls of adjacent tracheids are separated by a very delicate membrane. At intervals medullary rays, one cell thick, extend from the pith to the outer limit of the xylem. The cells are elongated radially, and have uniformly thickened walls and granular contents.

The phloem consists of large sieve-tubes and similar but smaller parenchymatous cells. No bast fibres or sclerenchymatous cells are present. The whole cylinder is bounded by


FrG. 143-Botrychium Virginianum. A, Longitudinal section of the stem apex of a young plant, $\times 260 ; B$, cross-section of a similar specimen; $L$, the youngest leaf.

a single layer of cells somewhat compressed radially, forming the endodermis or bundle-sheath. Between the xylem and phloem is a well-defined layer of cambium by whose growth the thickness of the vascular cylinder is slowly but constantly added to, and as a result there is a secondary growth of the stem strictly comparable to that of the Dicotyledons.

The outer layer of the cortex (the epidermis is quite absent) develops cork, but not from a definite cork cambium (Holle, ( ), p. 249). These cork cells arise by repeated tangential divisions in cells near the periphery, and have in consequence the same regular arrangement seen in similar cells of the higher plants. 
A cross-section of the petiole of the earliest leaves of the young plant shows but a single nearly central vascular bundle, but as the plant grows older the number becomes much larger, and may reach ten (Luerssen (8), p. 58). In leaves of moderate size there are usually about four, and these are arranged symmetrically. The ground tissue is composed mainly of large thin-walled parenchyma and a well-marked epidermis. The fibrovascular bundles are arranged in two groups, right and left, and where there are four of them the inner ones are the

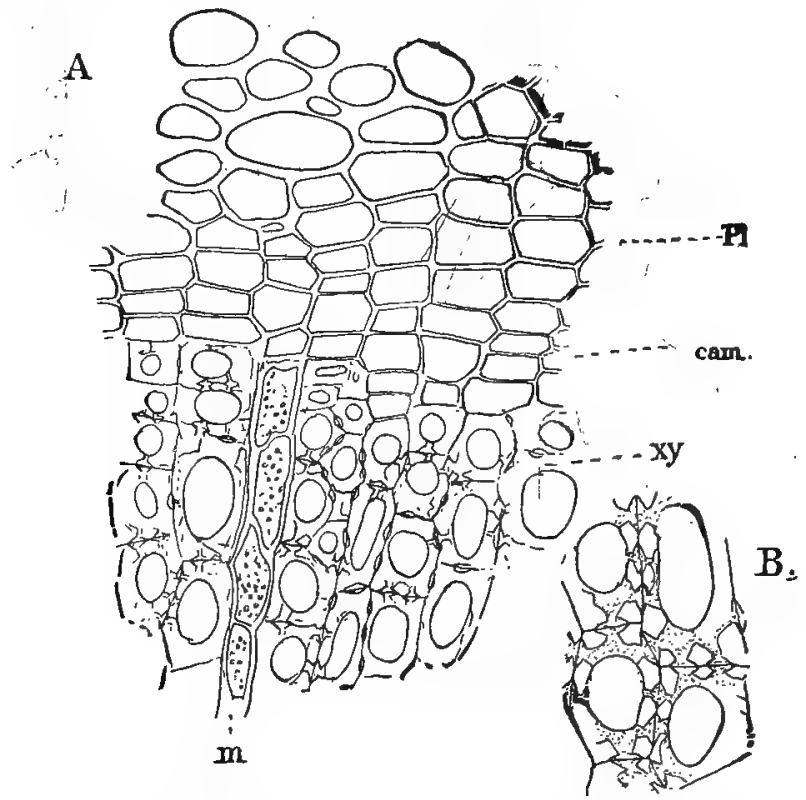

Fig. 144-A, Part of a cross-section of the stem bundle of $B$. Virginianum, $\times 200,-$ lettering as in Fig. I42; B, a portion of the tracheary tissue, showing the peculiarly pitted walls, $\times_{400}$.

larger, and in cross-section crescent-shaped. The xylem occupies the middle of the section, and is completely surrounded by the phloem, i.e., the bundle is concentric, like that of the true Ferns. In $B$. lunaria the bundle has the phloem only perfectly developed on its outer side and approaches the collateral form. $B$. ternatum and $B$. lunaria, while having concentric bundles; also have the phloem more strongly developed on the outer side. The tracheary tissue is much like that of the stem, but the tracheids are smaller and the walls thinner. The smaller tracheids show reticulate markings. 
The phloem is composed also of the same elements, large sieve-tubes, arranged in a pretty definite zone next the xylem, and smaller cells of similar appearance, but not showing the multinucleate character or perforated transverse walls of the latter. The sieve-tubes are large (Fig. I45), and in longitudinal section are seen to consist of rows of wide cells with either horizontal or oblique division walls. The transverse walls separating two members of a sieve-tube are somewhat swollen and show small perforations, which are not always
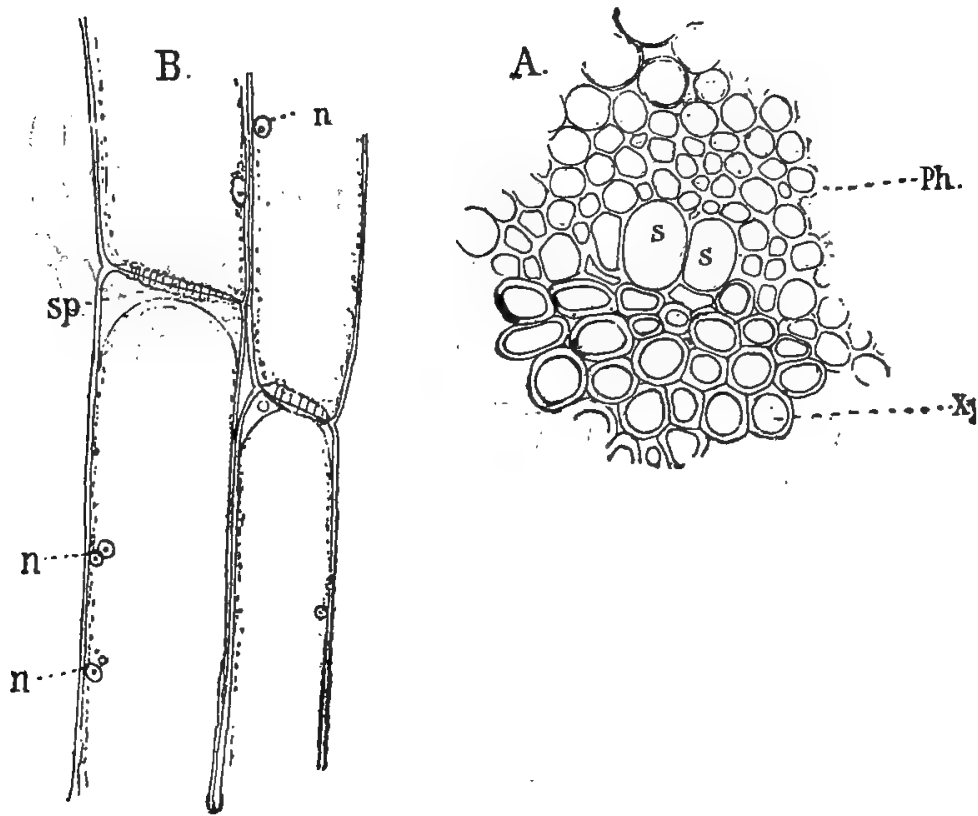

FIg. 145.-Part of a vascular bundle from the petiole of $B$. Virginianum, $\times 245 ; x y$, xylem; $p h$, phloem; $s, s$, sieve-tubes; $\mathbf{B}$, two sieve-tubes in longitudinal section, $\times 490 ; s p$, sieve-plates; $n$, nuclei.

easily demonstrated. According to Janczewski (4) these pits do not penetrate the membrane between the cells, but Russow's (5) assumption that there is direct communication between the cells is correct, although difficult to prove. Russow also states that callus is present in the sieve-plates of Botrychium, although poorly developed. According to Janczewski the pores are not confined to the transverse walls, but may also occur, but much less frequently, in the longitudinal walls. The contents of the 
sieve-tubes consist of a thin parietal layer of protoplasm in which numerous nuclei are imbedded. Little glistening globules are also found, especially close to the openings of the pores of the sieve-plates.

The lamina of the sterile segment of the leaf is composed of a spongy green mesophyll, more compact on the upper surface. The epidermal cells show the wavy outlines characteristic of the broad leaves of other Ferns, and develop stomata only upon the lower side of the leaf.
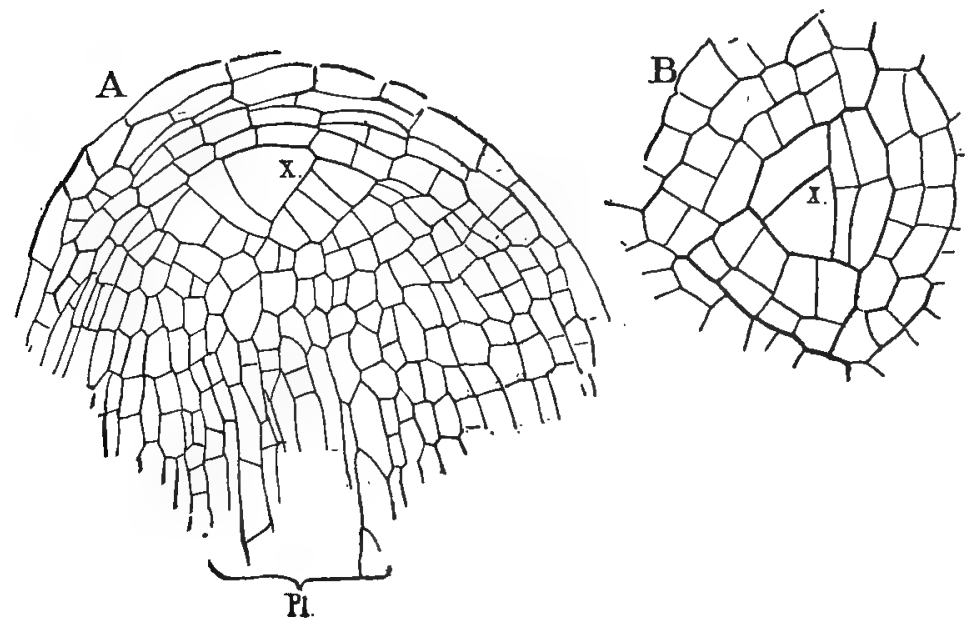

FiG. 146.-Botrychium Virginianum. A, Longitudinal; B, transverse sections of the root apex, $\times 200 ; p l$, plerome.

\section{The Root}

The roots arise singly at the bases of the leaves, and in older plants branch monopodially. Like those of Ophioglossum they have no root-hairs, but the smooth surface of the younger roots becomes often strongly wrinkled in the older ones. Sections either transverse or longitudinal, through the root tip, when compared with those of Ophioglossum, show a very much greater regularity in the disposition of the cells. This is less marked in B. ternatum, and probably an examination of such forms as $B$. simplex will show an approximation to the condition found in Ophioglossum, although Holle's figure of $B$. luna- 
ria shows even greater regularity in the arrangement of the apical meristem than is found in B. Virginianum. A careful examination of this point is much to be desired.

The first wall in the young lateral segment is the sextant wall, as in the higher Ferns, and divides the segment into two cells of unequal depth. The next wall divides the larger of these cells into an inner and an outer one, the former becoming the initial of the central plerome cylinder, the outer one, together with the whole of the smaller semi-segment, giving rise to the cortex, in which the divisions are very similar to, but

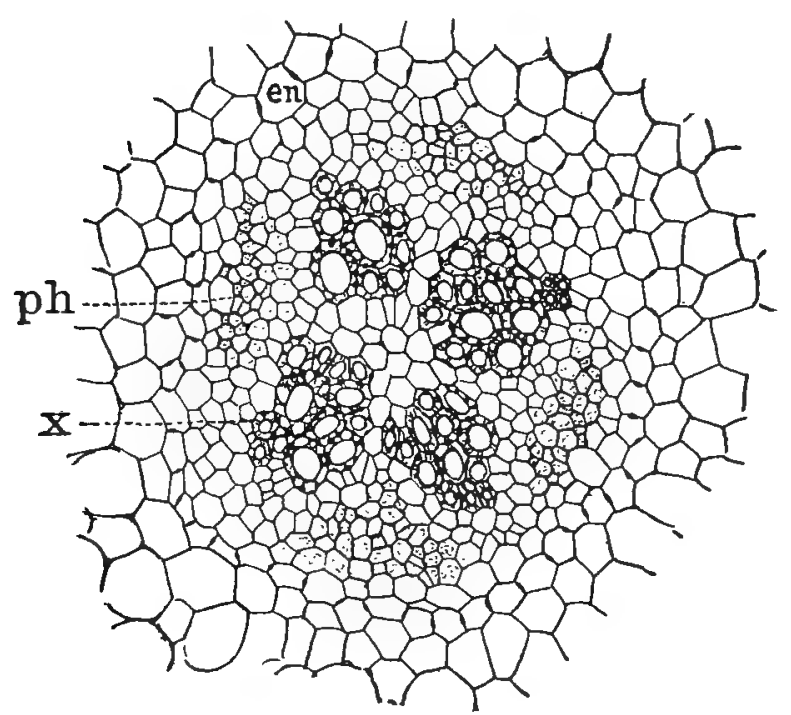

FIG. 147.-Tetrarch vascular bundle of the root of B. Virginianum, $\times 85$; en, endo. dermis; $p h$, phloem; $x$, xylem.

somewhat less regular than in Equisetum and the leptosporangiate Ferns. As usual in roots of this type, segments are also cut off from the outer face of the apical cell, but I have never seen, either in B. Virginianum or B. ternatum, any indication that the growth of the root-cap was due exclusively to the development of these segments, as Holle states both for $B$. lunaria and Ophioglossum vulgatum. In both species of Botrychium examined by me the growth of the root-cap was evidently due in part to the division of cells in the outer part of the lateral segments, so that in exactly median sections there was not the 
clear separation of the root-cap from the body of the root that is so distinct in Equisetum, for example.

The central cylinder of the root is bounded by an endodermis whose limits, however, are not so clearly defined as in the more specialised Ferns. The number of xylem and phloem masses varies, even in the same species. In $B$. Virginianum the larger roots show three or four xylem masses (Fig. I47). $B$. ternatum ${ }^{1}$ has usually a triarch bundle, while $B$. lunaria is commonly diarch (Holle (I), p. 245). The elements both of the xylem and phloem are much like those in the stem and do not need any special description. The roots increase considerably in diameter as they grow older, but this enlargement does not take place at the base, where the root is noticeably constricted. The enlargement is due entirely to the cortical tissue, and is mainly simply an enlargement of the cells. The diameter of the central cylinder remains the same after it is once formed. In the outer part of the root, as in the stem, there is a development of cork.

\section{The Sporangium}

In the simplest forms of $B$. simplex the sporangia, which are much larger than those of $B$. Virginianum, form two rows very much as in Ophioglossum; but in all the more complicated forms the sporangiophore branches in much the same way as the sterile part of the leaf, and the ultimate segments become the sporangia. In B. Virginianum the development of the individual sporangia begins just about a year previous to their ripening, and if the plants are taken up about the time the spores are shed, the earliest stages may be found. The sporangiophore is at this time thrice pinnate in the larger specimens, and an examination of its ultimate divisions will show the youngest recognisable sporangia. These form slight elevations growing smaller toward the end of the segment (Fig. I48), and exact median sections show that at the apex of the broadly conical prominence which is the first stage of the young sporangium there is a large pyramidal cell with a truncate apex. Holtzman (I) thinks the sporangium may be traceable to a single cell, and that the divisions at first are like those in a three-sided apical cell. I was unable to satisfy myself on this

${ }^{\wedge}$ B. ternatum $=$ B. obliquum (Underwood (5) p. 72$)$. 
point, but the youngest stages found by me in which the sporangial nature of the outgrowths was unmistakable, would not forbid such an interpretation, although there was no doubt that the basal part of the sporangium is derived in part from the surrounding tissue.

From the central cell, by a periclinal wall, an inner cell, the archesporium, is separated from an outer one. The outer cell divides next by cross walls, and this is followed by similar divisions in the inner cells (Fig. I48). The succeeding divi-

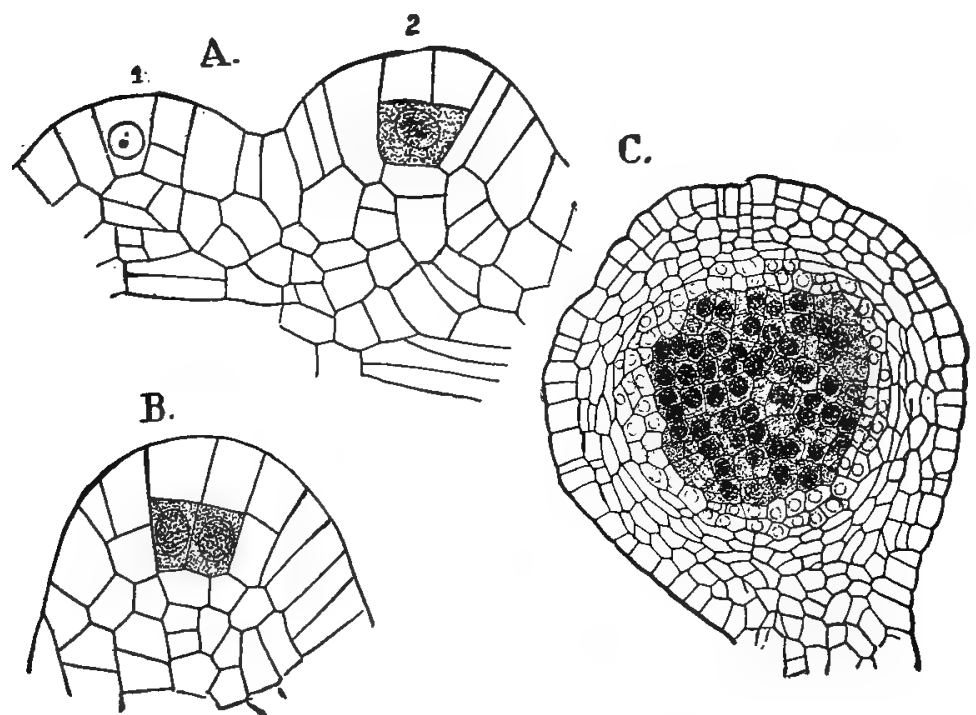

Fic. 148.-Botrychium Virginianum. Development of the sporangia. A, 1, 2, Very young sporangia; $B$, a somewhat older one, $\times 480$; $C$, older sporangium, $X 240$; all median longitudinal sections, the sporogenous cells are shaded.

sions in the outer cells are now mainly periclinal, and transform the four cells lying immediately above the archesporium into as many rows of tabular cells. Growth is active in the meantime in the basal part of the sporangium, which projects more and more until it becomes almost spherical. To judge from the account given by Goebel (3) and Bower ( I6) of B. lunaria, this species corresponds closely in its early stages to $B$. Virginianum. The later divisions in the archesporium do not apparently follow any definite rule, but divisions take place in all directions until a very large number of cells is formed. 
The cells immediately adjoining the sporogenous tissue divide into tabular cells, some of which contribute to the tapetum, which is to some extent, at least, derived from the outer cells of the sporogenous complex, as in Ophioglossum. (See also Goebel (22) p. 758). The sporangium shortly before the isolation of the spore mother cells (Fig. I48 C) is a nearly globular body with a thick, very short stalk. The central part of the upper portion is occupied by the sporogenous tissue surrounded by a massive wall of several layers of cells. The central cells, as usual, have larger nuclei, and more granular contents than the outer ones. The stages between this and the ripe sporangium were not seen, so that it cannot be stated positively whether all the cells of the definitive sporogenous tissue (which seems probable) or only a part of them, as in Ophioglossum, develop spores. The wall of the ripe sporangium has 4-6 layers of cells, and sometimes the place of dehiscence is indicated, as in Ophioglossum, by two rows of smaller cells (Fig. I 48, C).

The stalk is traversed by a short vascular bundle, which is first evident about the time that the number of sporogenous cells is complete, and joins directly with the young vascular bundle of the leaf segment (Fig. I48, C). The ripe sporangium opens by a transverse slit, as in Ophioglossum.

The presence of fungous filaments in the roots of the Ophioglossaceæ has been repeatedly observed, and has been the subject of recent investigations by Atkinson (2), who is inclined to regard them as of the same nature as the mycorhiza found in connection with the roots of many Dicotyledons, especially Cupuliferæ. Atkinson asserts that he finds them invariably present in all the forms he has examined; but Holle (I) states that, while they are usually present in Ophioglossum, he has found strong roots entirely free from them, and that in Botrychium rutcefolium they were mainly confined to the diarch roots, and that this is connected with a weakening of the growth of the root through the growth of the fungus, by which the triarch bundle of the normal fully-developed root is replaced by the diarch form of the weaker one.

\section{Helminthostachys}

The third genus of the Ophioglossaceæ, Helminthostachys, with the single species $H$. Zeylanica, is in some respects inter- 
mediate between the other two, but differs from both in some particulars. The sporophyte has a creeping fleshy subterranean rhizome, with the insertion of the leaves corresponding to Ophioglossum pendulum. According to Prantl ( 7 ), who has made a somewhat careful study of a plant, the roots do not show any definite relation to the leaves, as Holle claims is the case in the other genera. The plant sends up a single leaf, which may reach a height of 30 to $40 \mathrm{~cm}$. or more, and as in the Ophioglossum vulgatum and $B$. Virginianum, the sporangiophore arises from the base of the sterile division of the leaf. The latter is ternately lobed, and the primary divisions are also divided again. The venation is different from that of the other Ophioglossaceæ, and is extremely like that of Angiopteris or Danca. Each pinnule is traversed by a strong midrib, from which lateral dichotomously branched veins run to the margin. In regard to the structure of the sheath that encloses the young leaf and stem apex, Helminthostachys resembles Botrychium.

The apex of the stem, as in the other genera, grows from a single initial cell. The stem has a single axial stele, with the form of a hollow cylinder, interrupted upon the upper side by the leaf-gaps. In the youngest stems, the stele is solid. There is an imperfect inner, and a distinct outer endodermis. The xylem is mesarch-i.e., it begins to develop in the center of the bundle-and its differentiation goes on very slowly. There is no formation of secondary wood as in the larger species of Botrychium. (Farmer (6)).

The sieve-tubes have sieve-plates on their lateral faces, and similar sieve areas occur upon the walls of the adjacent phloem cells. The metaxylem has bordered pits, apparently similar to those of Botrychium Virginianum.

The roots resemble those of Botrychium. There are from three to seven xylem masses.

The sporangiophore is long-stalked and in general appearance intermediate between that of the other genera, but a careful examination shows that it is much more like that of Botrychium. It is pinnately branched, but in an irregular way, and the small branchlets bear crowded oval sporangia, which open longitudinally on the outer side, and not transversely as in the other genera. The tips of the branches, instead of forming sporangia as in Botrychium, develop into green leaf-like lobes, which upon the shorter branchlets are oftenn arranged in a rosette of three or 
four together, with the sporangia close below them (Fig. I4I, D). This at first sight looks as if the sporangia were produced upon the lower side of these, like Equisetum, but a very slight examination shows at once that this is only apparent, and the sporangia are undoubtedly outgrowths of the branches as in Botrychium. The green lobes are seen to be only the vegetative tips of the branches, or perhaps better comparable to such sterile leaf segments as are not uncommon in Osmunda Claytoniana. (Bower (17), Goebel (22), p. 664.)

The sporangiophore in Helminthostachys originates as in the other genera, and is bent over and protected by the sterile leaf-segment, very much as in Botrychium. There is a certain correspondence between the early stages of the sporangiophore of Helminthostachys and that of Ophioglossum, but in the former there are later developed short lateral outgrowths, or secondary sporangiophores, which bear clusters of sporangia more like those of Botrychium, but the pinnate form of the sporangiophore is much less evident.

The young sporangia project less than those of Botrychium, but otherwise closely resemble them. The archesporium is referable to a single mother-cell, but the tapetum is derived from the surrounding tissue, and not from the primary archesporium, as in Ophioglossum. Some of the sporogenous cells, as in Ophioglossum, become broken down. 


\section{CHAPTER VIII}

MARATTIALES

The Marattiace $x$

ThE Marattiaceæ, the sole existing family of the order, at the present time includes five known genera, with about twentyfive species of tropical and sub-tropical Ferns. Many fossil types are known which evidently were related to the Marattiaceæ, and they seem to comprise the majority of the Palæozoic Ferns.

Recently a good deal of attention has been paid to these Ferns, and our knowledge of their life-history and structure is fairly complete. Some of them are plants of gigantic size. Thus the stem of Angiopteris evecta is sometimes nearly a metre in height and almost as thick, with leaves 5 to 6 metres in length, and some species of Marattia are almost as large. The other genera, Kaulfussia, Archangiopteris and Danca, include only species of small or medium size. While in the structure of the tissues and the character of the sporangia these show some resemblances to the Ophioglossaceæ, their general appearance is more like that of the true Ferns, with which they also agree in the circinate vernation of their leaves. The sporangia are borne upon the lower surface of ordinary leaves, as in most leptosporangiate Ferns, but the sporangia themselves are very different, and are more or less completely united into groups or synangia, which open either by longitudinal slits or, in Dancea, by a terminal pore. The base of the leaf is provided with a pair of fleshy stipules, which possibly correspond to the sheath at the base of the petiole in Botrychium. 


\section{The Gametophyte}

The germination of the spores and development of the prothallium were first investigated by Luerssen (5) and Jonkman (I) in Angiopteris and Marattia, and later by the latter investigator for Kaulfussia (2). More recently Brebner (I) has described the prothallium and embryo in Dancea.

The spores are of two kinds, bilateral and tetrahedral, but the former are more common. They contain no chlorophyll, but oil is present in drops of varying size, as well as other granular bodies. The nucleus occupies the centre of the spore and is connected with the wall by fine protoplasmic filaments. The wall of the spore is colourless and shows three coats, of which the outer one (perinium) is covered with fine tubercles.

Germination begins within a few days and is first indicated by the development of chlorophyll. This does not, as Jonkman asserts, first appear in amorphous masses, but very small, faintly-tinted chromatophores are present between the large oildrops, and rapidly increase in size and depth of colour as germination proceeds, their number increasing by the ordinary division. In the bilateral spores the exospore is burst open above the thickened ventral ridge found in these spores, and the growing endospore slowly protrudes through this. The spore enlarges to several times its original diameter before the first division occurs, and forms a globular cell in which the large chloroplasts are arranged peripherally.

The first division takes place about a month after the spores are sown, and is perpendicular to the longer axis of the cell, dividing it either into two equal parts, or the lower may be much smaller and develop into a rhizoid. In the former case each cell next divides by walls at right angles to the first, and the resulting cells are arranged like the quadrants of a circle, and one of these cells becomes the two-sided apical cell from which the young prothallium for a long time grows (Fig. I49), much as in Aneura. This type of prothallium, according to Jonkman, is commoner in Marattia than in Angiopteris, where more commonly a cell mass is the first result of germination. This latter is usually derived from the form where a rhizoid is developed at first. In this case only the larger of the primary cells gives rise to the prothallium. In the larger cell, divisions take place in three directions and transform it into a nearly globular cell 
mass, terminated by four quadrant cells, one of which usually becomes the apical cell, much as in the flat prothallium. In exceptional cases the first divisions are in one plane and a short filament results.

As soon as the apical cell is established it grows in precisely the same way as the similar cell in the thallus of a Liverwort, and produces a thallus of much the same form and structure. As the prothallium grows older, however, a cross-wall forms in

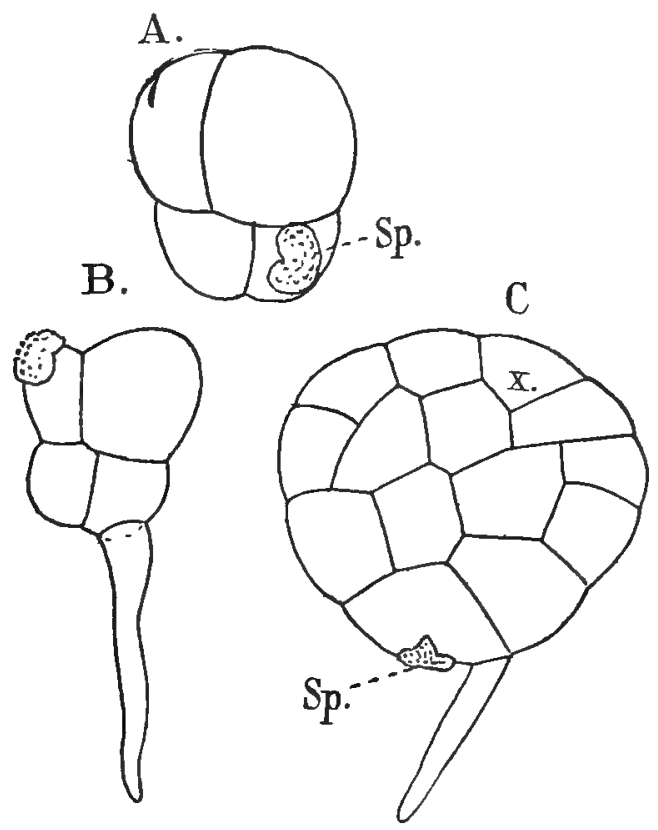

FIG. 149.-Angiopteris evecta. Germination of the spores,-A, B, $\times 220 ; C, \times 175$; $s p$, spore membrane; $x$, apical cell (after Jonkman).

the apical cell, and this is followed by a longitudinal wall in the outer one, forming two similar cells which, by further longitudinal divisions, may produce a row of marginal initials, and the subsequent growth of the prothallium is due to the divisions and growth of this group of initial cells (Fig. I 50, A).

At first the prothallium has a spatulate form, but before the single apical cell is replaced by the group of marginal initials, the outer cells of the segments grow more rapidly than the inner ones, and the segments project beyond the apical cell, 
which comes to lie in a depression between the two lobes formed by the outer parts of the segments, and the prothallium assumes the heart-shape found in most homosporous Ferns. The secondary initial cells vary in number with the width of the indentation in which they lie. Seen from the surface they are oblong in shape, but in vertical section are nearly semicircular (Fig. I 5O, B). Basal segments are cut off by a wall that extends the whole depth of the prothallium, and the segment is then divided by a horizontal wall into a dorsal and ventral cell of nearly equal size. The divisions are more numerous in the
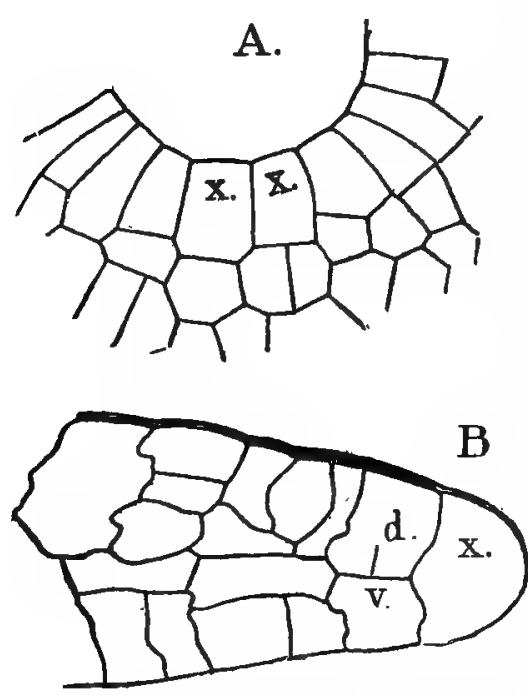

Fig. 350.-Marattia Douglasii. A, Horizontal section of prothallium apex, with two initials, $\times 160 . B$, Longitudinal section of a similar growing point; $d$, dorsal; $v$, ventral segment. ventral than in the dorsal cells of the segment, this difference first being manifest some distance back of the apex. Owing to this, a strongly projecting, nearly hemispherical cushion-like mass of tissue is formed upon the ventral surface. The superficial cells of both sides of the prothallium have a well-marked cuticle. Numerous brown rhizoids, which, like those of the simpler Liverworts, are unicellular and thin-walled, grow out from the cells of the lower surface, especially from the broad midrib. The full-grown prothallium in M. Douglasii is sometimes a centimetre or more in length (Fig. I 5I), and tapers from the broad heart-shaped forward end to a narrow base. In Angiopteris (Farmer ( 3 )) it is more nearly orbicular. In both genera it is dark-green in colour, looking very much like the thallus of Anthoceros lavis, and like this too is thick and fleshy in texture. A broad midrib extends for nearly the whole length of the thallus and merges gradually into the wings, which are also several-layered, nearly or quite to the margin.

The prothallium of Dancea (Brebner (I)) resembles more 
closely that of Angiopteris, than that of Marattia. The rhizoids are multicellular, recalling those of the gametophyte of Botrychium.

The very old prothallia sometimes branch dichotomously (Fig. I5I, B, C), and the process is identical with that in the thallose Hepaticæ. The two growing points are separated by a median lobe in the same way, and the midrib with the sexual

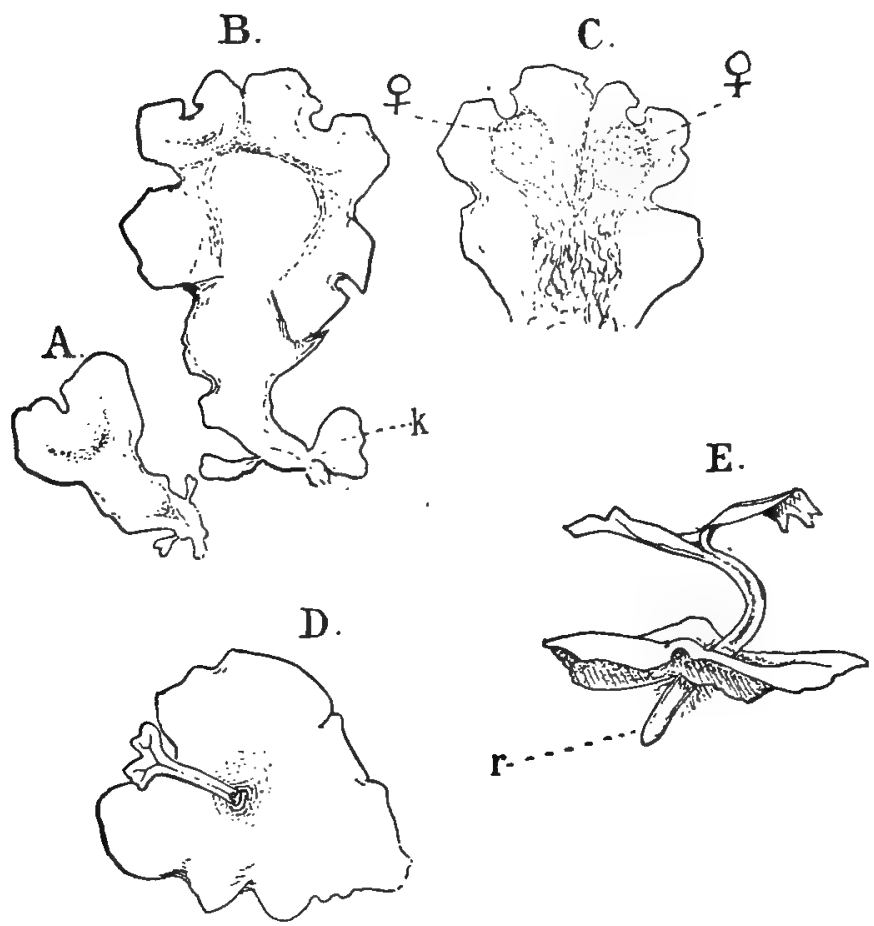

FIG. I5I.-Marattia Douglasiz. A, Prothallium about one year old, $\times 2 ; B$, the same prothallium about a year later, showing a dichotomy of the growing point; $C$, the same seen from below, showing two archegonial cushions ( () ); D, prothallium with young sporophyte, $X_{4} ; E$, a somewhat older one, seen from the side; $r$, the primary root.

organs upon it forks with it, exactly as we find, for example, the antheridial receptacle forking in Fimbriaria Californica (Fig. I, A). Besides this form of branching, which is not common, adventitious buds are produced upon the margin of the thallus very frequently. These grow in precisely the same way as the main prothallium, and after a time may become 
detached and form independent plants; or they may develop sexual organs (mainly antheridia) while still connected with the mother plant. The duration of the prothallium is apparently unlimited, so long as it remains unfecundated. The writer kept prothallia of Marattia Douglasii for nearly two years, during which they grew continuously and finally reached a length of over two centimetres. At the end of this time they were growing vigorously, and there was nothing to indicate the slightest decrease in their vitality.

The prothallia are monœcious, although not infrequently the smaller ones bear only antheridia. The latter always appear first, and are mainly found upon the lower side of the midrib, but may also occur upon the upper side. The archegonia are confined to the lower surface of the midrib, and as they turn dark brown if they are not fertilised, they are visible to the naked eye as dark brown specks studding the broad thick midrib. Both antheridia and archegonia resemble closely those of Ophioglossum.

\section{The Sex-organs}

The antheridium arises from a single superficial cell which first divides into an inner cell, from which the sperm cells are derived, and an outer cover cell (Fig. I52, A). The latter divides by several curved vertical walls (Figs. E-G) which intersect, and the last wall cuts off a small triangular cell $(0)$, which is thrown off when the antheridium opens, and leaves an opening through which the sperm cells are ejected. The inner cell, by repeated bipartitions, gives rise to a large number of polyhedral sperm cells. Before the full number of these is complete, cells are cut off from the adjacent prothallial cells, which completely enclose the mass of sperm cells. As in other Archegoniates, the nucleus of the sperm cell, after its final division, shows no nucleolus. The first sign of the formation of the spermatozoid that could be detected was an indentation upon one side, followed by a rapid flattening and growth of the whole nucleus. The cytoplasmic prominence which, according to Strasburger, is the first indication of the formation of the spermatozoid, could not be certainly detected. The main part of the spermatozoid, stains strongly with alum-cochineal, and is sharply differentiated against the colourless cytoplasm, and 
for some time shows the characteristic nuclear structure. The origin of the cilia was not clearly made out, but there is little question that they arise from a blepharoplast as in other cases that have been more recently investigated. The free spermatozoid (Fig. I 52, I), is a flattened band, somewhat blunt behind and tapering to a fine point in front; attached to a point just back of the apex are several fine cilia. The body shows only about two complete coils.

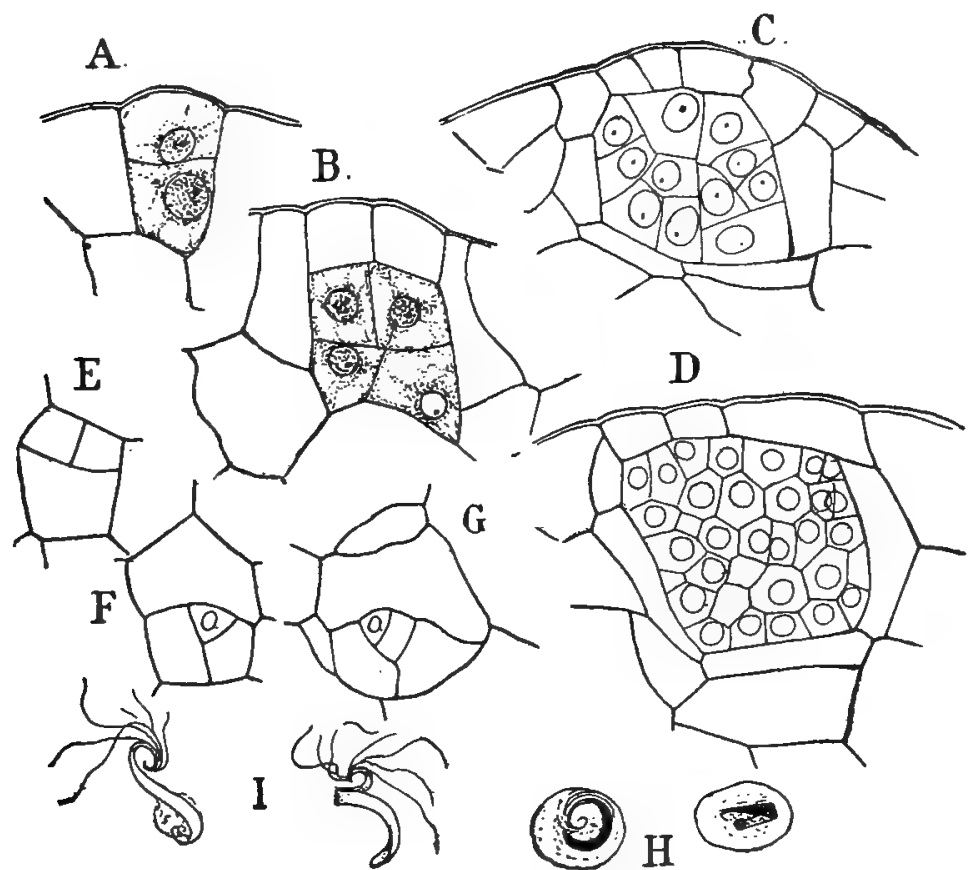

FiG. 152.-Marattia Douglasii. Development of the antheridium. A-D, Longitudinal section, $\times 515 ; E-G$, surface views, $\times 257 ; \mathrm{H}$, ripe sperm cells; I, free spermatozoids, XI030; 0 , operculum.

The youngest archegonia are met with some distance back of the growing point, and apparently any superficial cell is potentially an archegonium mother cell. The latter divides usually into three superimposed cells (Fig. I53, A), of which the lowest $(b)$ forms the base of the archegonium. The basal cell, however, may be absent in Marattia Douglasii, as is also the case in Angiopteris and Dance. From the middle cell by a transverse division are formed the primary neck canal cell and 
the central cell. Each of these divides again transversely. In the upper one this division is often incomplete and confined to the nucleus; but in the central cell the division results in the separation of the ventral canal cell from the ovum. Before the separation of the primary neck canal cell from the central cell, the cover cell divides as in the Liverworts into four cells by intersecting vertical walls, and each of these cells by further obliquely transverse walls forms a row of about three cells, and these four rows compose the short neck. The canal cells are

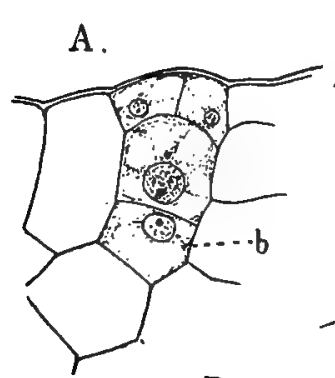

B
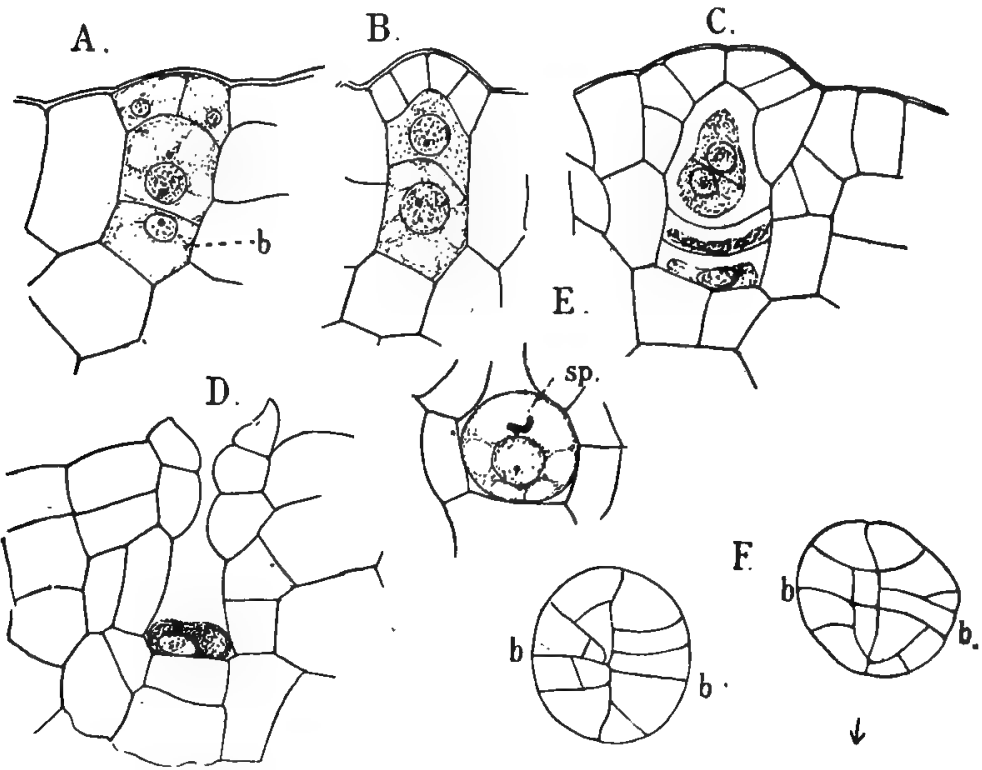

F1G. I53.-Marattia Douglasii. A.D, Development of the archegonium, $\times 450$; E, section of the fertilised egg, showing the spermatozoid $(s p)$ in contact with its nucleus, $\times 485 ; F$, successive longitudinal sections of a young embryo, $\times 225 ; b, b$, the basal wall; the arrow points towards the archegonium.

very broad and the egg cell small, so that after the archegonium opens it occupies but a small part of the cavity left by the disintegration and expulsion of the canal cells. Before the archegonium is mature, flat cells are cut off from the adjacent. prothallial tissue as in the antheridium (Fig. I53, D). The neck of the ripe archegonium projects but little above the surface of the prothallium, and in this respect recalls both the lower Ophioglossacex and the Anthocerotes. The ripe ovum is somewhat elliptical, and slightly flattened vertically. Its 
upper third is colourless and nearly hyaline. This is the "receptive spot," and it is here that the spermatozoid enters. The nucleus is of moderate size, and not rich in chromatin; a small but distinct nucleolus is present. The spermatozoid retains its original form after it first enters the egg, and until it comes in contact with the membrane of the egg nucleus. It afterwards contracts and assumes much the appearance of the nucleus of the sperm cell previous to the differentiation of the spermatozoid. The two nuclei then gradually fuse, but all the different stages could not be traced. Before the first division
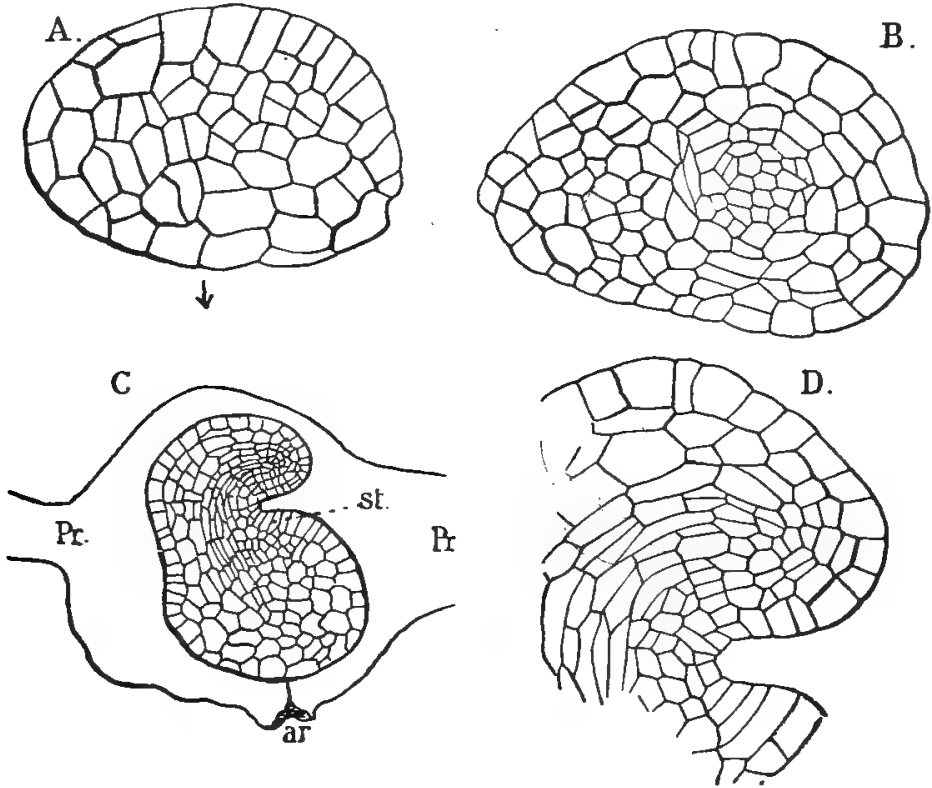

FrG. 154-Marattia Douglasii. Embryogeny. A, Longitudinal; B, transverse sections of embryos, $X_{215} ; C$, vertical section of an older embryo, showing its position in the prothallium, $\times X_{72} ; s t$, the stem; $p r$, prothallium; $D$, upper part of the same embryo, $\times 215$.

takes place, however, but one nucleus can be seen, and this much resembles the nucleus of the unfertilised egg. It is probable that the nucleus of the spermatozoid really penetrates the cavity of the egg-nucleus as has been shown to be the case in Onoclea. (See Shaw (I)).

The Embryo-(Farmer (3); Jonkman (3))

After fertilisation the egg enlarges to several times its original size before dividing. The first (basal) wall is trans- 
verse and is followed in each half by two others, the median and octant walls. The nearly globular embryo is thus divided into eight similar cells, each having the tetrahedral form of a globe octant. The next divisions are not perfectly understood, and evidently are not absolutely uniform in all cases. All the octants at first show nearly uniform growth, and the embryo retains its nearly oval form (Figs. I 53, F, I 54, A). The first division in the octants is essentially the same, and consists in a series of anticlinal walls, before any periclinal walls appear, so that we may say that for a short time each octant has a distinct apical growth, and there are eight growing points. The older
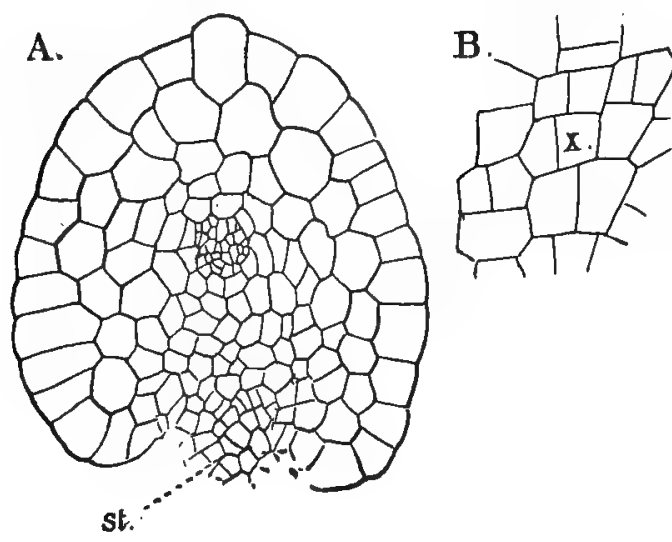

C.

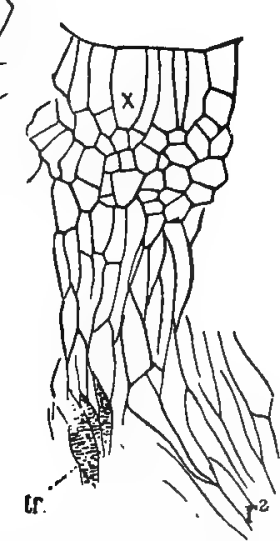

FIG. 155.-Marattia Douglasit. A, Cross-section of the young sporophyte at the junction of the cotyledon and stem; st, the apical meristem of the stem, $\times 215 ; \mathrm{B}$, the stem apex of the same, $\times 430 ; C$, longitudinal section of the stem apex of a plant of about the same age, $X_{215} ; t r$, the primary tracheary tissue; $r^{2}$, the second root.

embryo shows an external differentiation into the first leaf, stem, and root, but the foot is not clearly limited at first. The basal wall separates the embryo into two regions, epibasal and hypobasal. From the former the cotyledon and stem apex are derived, from the latter the root and foot.

The cotyledion arises from the anterior pair of epibasal octants, which are in the Marattiaceæ, unlike all the other Ferns, turned away from the archegonium opening. In the earliest stages where the cotyledon is recognisable, no single apical cell could be made out, and later the growth is very largely basal. 
At first the growth is nearly vertical, but it soon becomes stronger upon the outer side, and the leaf rudiment bends inwards. At this stage the different tissues begin to be distinguishable. Somewhat later the tip of the cotyledon becomes flattened, and still later there is a dichotomy of this flattened part which thus forms a fan-shaped lamina (Fig. I57). The
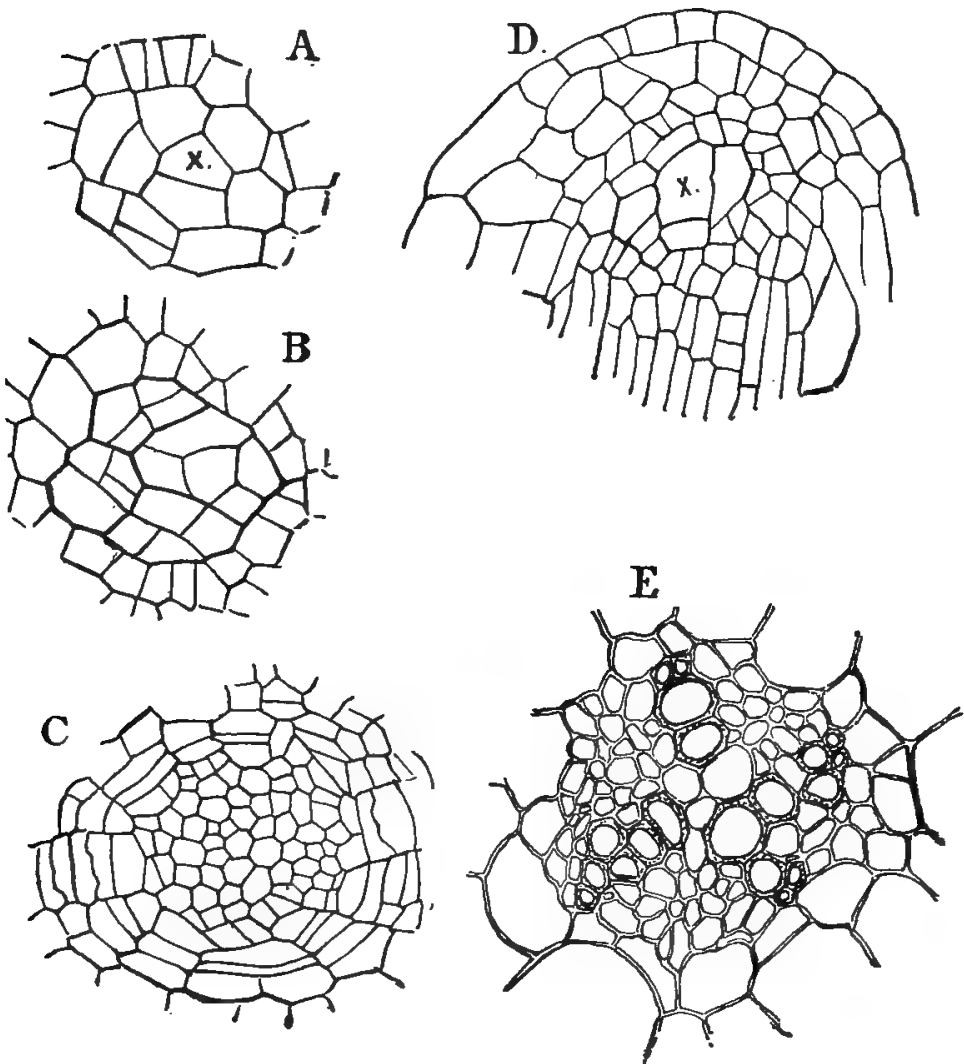

Fig. 156.-Marattia Douglasii. A, B, C, Three transverse sections of a root from the young sporophyte; A shows the apical cell $(x), X_{21} 5 ; \mathrm{D}$, longitudinal section of a similar root, $\times 260 ; E$, vascular bundle of the root, $\times 260$.

first tissue to be recognised is the vascular bundle which traverses the centre of the petiole and at first consists of uniform thin-walled elongated cells (procambium). This formation of procambium begins in the centre of the embryo and proceeds in three directions, one of the strands going into the 
cotyledon, one in an almost opposite direction to the primary root, and a very much shorter one to the young stem apex, which lies close to the base of the cotyledon. The outer layer of cells of the cotyledon forms a pretty clearly defined epidermis separated from the axial procambium strand by several layers of young ground-tissue cells.

The apex of the young stem is occupied in some cases, at least, by a single apical cell, which probably is to be traced back directly to one of the original octants of the embryo. Whether this is always the case in the youngest stages cannot be determined until further investigations are made. Farmer (3) was unable to make out a single initial in Angiopteris, which otherwise agrees closely with Marattia. Dancea, according to Brebner ( 1 ), shows a single initial cell at the stem-apex, as well as that of the primary root.

The study of the root was confined mainly to the older embryos, and although some variation is noticed, it is pretty certain that there is a single apical cell, not unlike that found in the Ophioglossaceæ. Whether this can be traced back to one of the primary hypobasal octants, it is impossible now to say; but Farmer's statement that in Angiopteris there is at first a three-sided apical cell would point to this. Unfortunately my own preparations of Marattia were too incomplete to decide this point in the latter. In the older root the form of the apical cell was usually a four-sided prism, from all of whose faces segments were cut off, although sometimes an approach to the triangular form found in the Ophioglossacer was observed.

The foot is much less prominent than in Botrychium, and in this respect the Marattiaceæ are:more like Ophioglossum (Mettenius (2), P1. xxx). In Marattia all the superficial cells of the central region of the embryo become enlarged and act as absorbent cells for the nourishment of the growing embryo.

As the embryo grows, the surrounding prothallial tissue divides rapidly, and a massive calyptra is formed which completely encloses the young sporophyte for a long time. Owing to the position of the cotyledon and stem, which grow up vertically through the prothallium, a conspicuous elevation is formed upon its upper side, through which the cotyledon finally breaks. A similar elevation is formed by the calyptra upon the lower side, through which the root finally penetrates, but not until after the cotyledon has nearly reached its full development. 
The prothallium does not die immediately after the young sporophyte becomes independent, but may remain alive for several months afterwards, much as in Botrychium.

The first tracheary tissue arises at the junction of the bundles of the cotyledon, stem, and root. These primary tracheids are short and their walls are marked with reticulate thickenings. From this point the development of the tracheary tissue, as well as the other elements of the bundles, proceeds toward the apices of the young organs. The formation of the secondary tracheids is always centripetal.

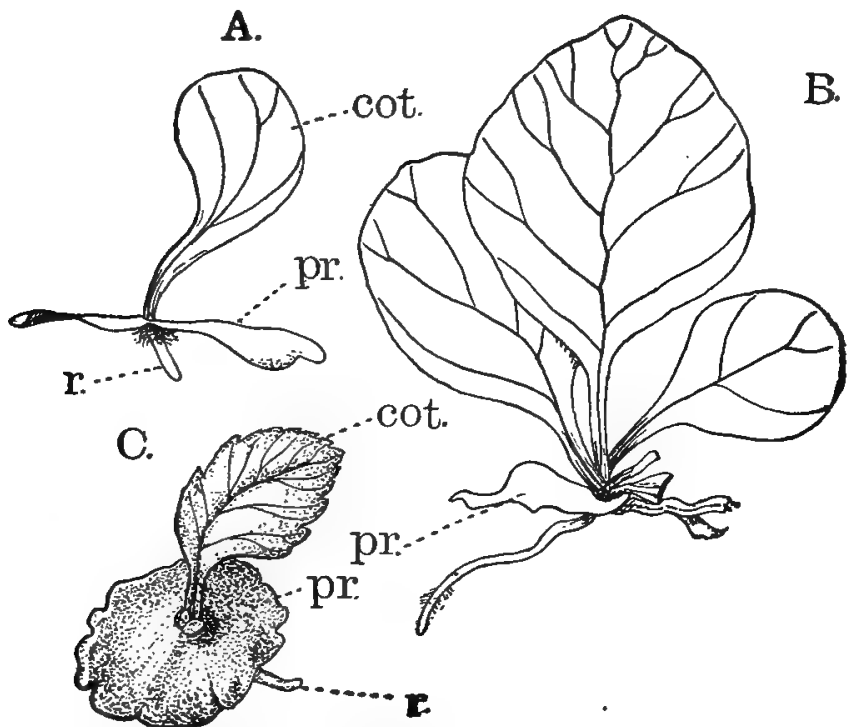

Fig. 157.-A, Young sporophyte of Daraea simplicifolia, still attached to the gametophyte, $p r ; \times 3 ; \mathbf{B}$, an older sporophyte of the same species; C, gametophyte of Angiopteris evecta, with the young sporophyte. (A, B, after Brebner; C, after Farmer.)

Jeffrey (3) states that in the young sporophyte of several species of Danca examined by him, the stele has the form of a tube with both internal and external endodermis and phloem. Both internal endodermis and phloem tend to disappear in the later-formed part of the stem. The tubular central cylinder is interrupted by the foliar gaps, and later there are formed medullary vascular strands, and the vascular system gradually assumes the very complicated form met with in the older sporophyte. Brebner (3) states that in Dance simplicifolia the 
primary vascular axis is a simple concentric stele, which is later replaced by a cylindrical stele like that of $D$. alata.

Short hairs with cells rich in tannin, and staining strongly with Bismarck-brown, occur sparingly upon the leaves and stem of the young sporophyte.

The fully-developed cotyledon has the fan-shaped lamina somewhat lobed, and the two primary veins arising from the forking of the original vascular bundle usually fork once more, so that the venation is strictly dichotomous in character. The nearly cylindrical petiole is deeply channeled upon the inner side, and the single axial vascular bundle is almost circular in section. While the crescent-shaped mass of tracheary tissue is completely surrounded by the phloem, the latter is much more

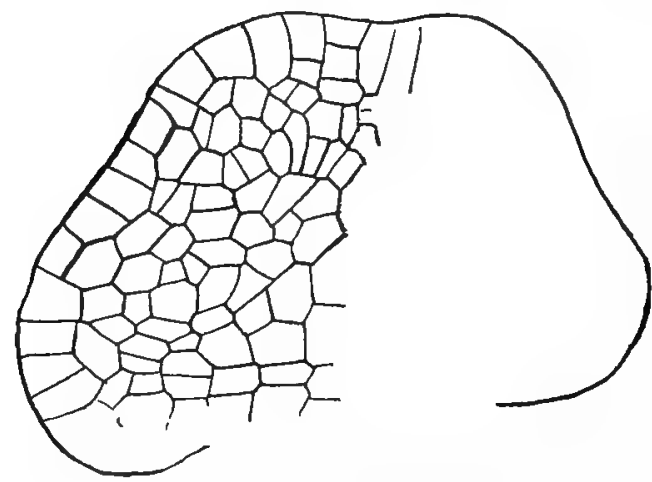

FIG. 158.- Horizontal section of the lamina of the cotyledon of $M$. Douglasii, $\times 260$. strongly developed upon the outer side, and the bundle approaches the collateral form of Ophioglossum. Indeed, if the tannin cells, which are found here, belong to the cortex, as Farmer asserts to be the case in Angiopteris, the bundle would be truly collateral, as these tannin cells are immediately in contact with the tracheids. The lamina of the cotyledon is similar in structure to that of the later leaves, and differs mainly in the smaller development of the mesophyll. The smaller veins have the xylem reduced to a few (I-3) rows of tracheids upon the upper side of the collateral bundle. Stomata of the ordinary form occur upon the lower side of the leaf.

In Angiopteris (Fig. I 57, C) and Danaa (Fig. I57, A), the cotyledon is spatulate in outline with a distinct midrib.

As the root finally breaks through the calyptra and penetrates into the earth, numerous fine unicellular root-hairs develop from the older parts, but the tip for some distance remains free from them. Owing to the numerous irregularities in the cell divisions, the exact relation of the tissues of the 
older parts of the root to the segments of the apical cell is impossible to determine, and evidently is not always exactly the same. The root-cap is derived mainly from the outer segments of the apical cell, but also to some extent from the outer cells of the lateral segments; and the central cylinder, where the base of the apical cell is truncate, is formed mainly from the basal segments, but in part as well from the inner cells of the lateral segments.

The vascular cylinder of the root is usually tetrarch. At four points near the periphery small spiral or annular tracheids appear, and from them the formation of the larger secondary tracheids proceeds toward the centre. The phloem is made up of nearly uniform cells with moderately thick colourless walls. A bundlesheath is not clearly to be made out (Fig. I56).

The cotyledon is destitute of the stipules found in the perfect leaves of the Marattiaceæ, but they are well developed in the third leaf, where they form two conspicuous appendages clasping the base
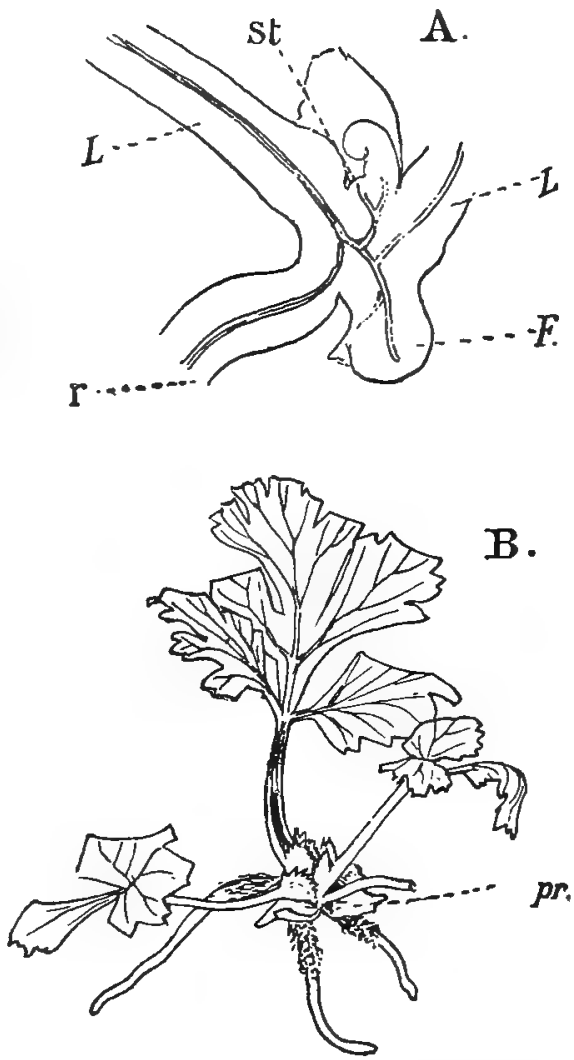

FIG. 159.-Marattia Douglasii. A, Longitudinal section of the young sporophyte, showing the distribution of the vascular bundles, $\times 6 ; l$, leaves; st, stem apex; $r$, a root; $f$, the foot; $B$, young sporophyte with the prothallium $(p r)$, still persisting.

of the next youngest leaf. The edges of these stipules are somewhat serrate, and the edges of the two meet, much like two bivalve shells. The strictly dichotomous character of the cotyledon is gradually replaced in the later leaves by the pinnate 
arrangement, both of the divisions of the leaf and the venation. This is brought about in both cases by an unequal dichotomy, by which one branch develops more strongly than the other, so that the latter appears lateral. With the assumption of the pinnate form the leaf also develops the wings or appendages upon the axis between the pinnæ. In the fully-developed leaves of the mature sporophyte, the last trace of this is seen in the ultimate branching of the veins, which is always dichotomous.

The second root arises close to the base of the second leaf, and at first there seems to be one root formed at the base of each of the young leaves; in the older sporophyte the roots are


FIG. 160.-A, Longitudinal section; B, transverse section of roots from older sporophyte of $M$. Douglasii, showing apparently more than one initial cell, $\times 200$.

more numerous. Holle states that this is not the case in Marattia, where only one root is formed for each leaf, in Angiopteris two. This, however, requires confirmation in the older plants. As the roots become larger it is no longer possible to distinguish certainly a single initial cell. The adjacent segments themselves assume to some extent the function of initials, and thus in place of the single definite apical cell a group of apparently similar initials is formed, which takes its place (Fig. I60). This seems to be in some degree associated with the increase in size of the roots. ${ }^{1}$

${ }^{1}$ It is possible that a single initial may be present even here, but the great similarity of the central group of cells makes this exceedingly difficult to determine. 


\section{The Adult Sporophyte}

According to Holle (1. c. p. 218) the four-sided apical cell found in the stem of the young sporophyte of Marattia is retained permanently, but in Angiopteris this is not the case, as in the older sporophyte a single apical cell is not certainly to be made out. Bower ( ( II) p. 324) comes to the same conclusion

A.
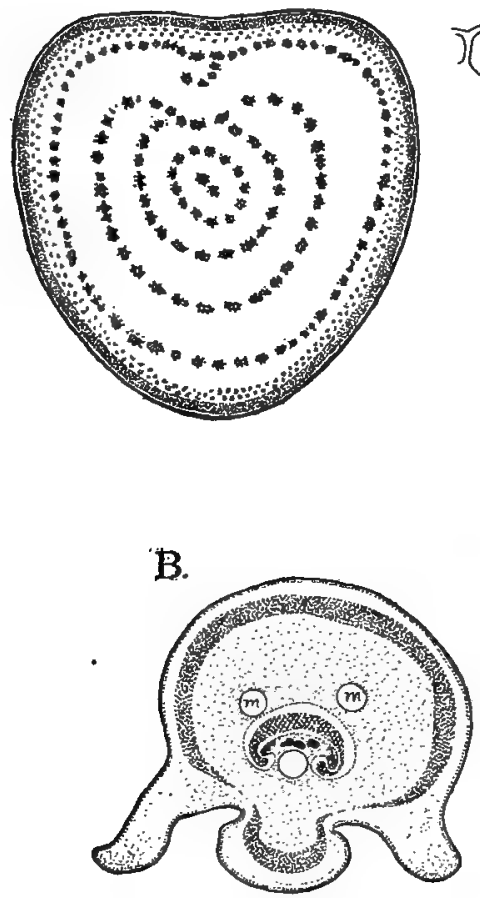

C.
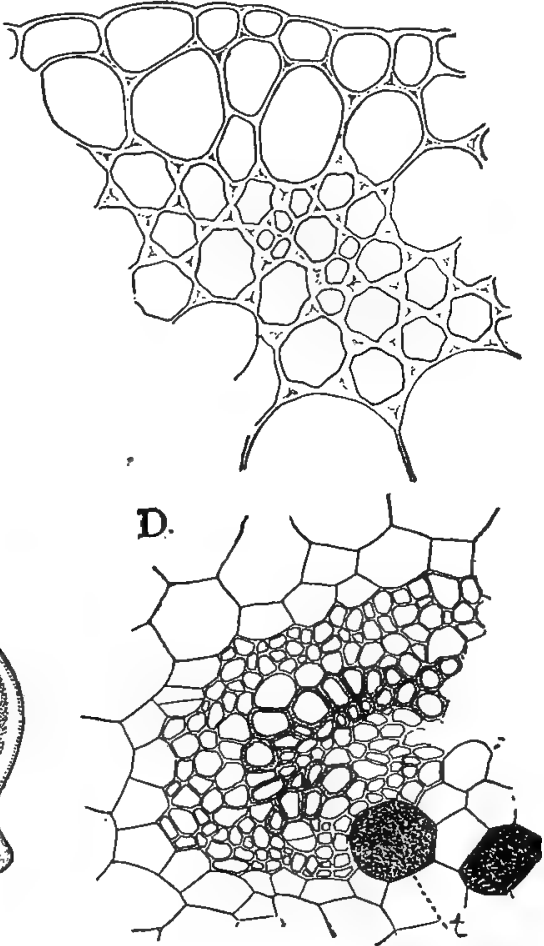

FIG. 161.-A, Section of the stipe of Angiopteris evecta, natural size; B, section of the rachis of the ultimate division of the leaf of Marattia alata, $\times 15 ; m$, mucilage ducis; $C$, collenchyma from the hypodermal layer of the rachis, $\times 250$; $D$, part of the vascular bundle of $B, \times 250 ; t$, tannin cells.

as Holle, although in an earlier paper (2) he attributes a single apical cell to the stem of Angiopteris. The stem in both genera becomes very massive, but its surface is completely covered by. the persistent stipules.

The structure of the stem in Angiopteris has recently been carefully investigated by Miss Shove (I) who has also reviewed 
the earlier literature upon the anatomy of the Marattiaceæ. In the stem of Angiopteris there is a reticulate vascular cylinder like that of Ophioglossum, but within this are three or four similar concentrically arranged "meshed zones," and a single central strand. In the specimen examined by Miss Shove the stem was oblique, and the meshes of the vascular cylinders were much closer upon the dorsal than upon the ventral side.

The majority of the roots originate from the inner zones, but they may also arise from the outer ones. The leaf-traces all come from the outer zone-at least such was the case in the specimen studied by Miss Shove. It is stated that Mettenius (3), found that the leaves also received strands from the second vascular zone. The concentric vascular cylinders are connected by branches ("compensating segments"), which pass out to
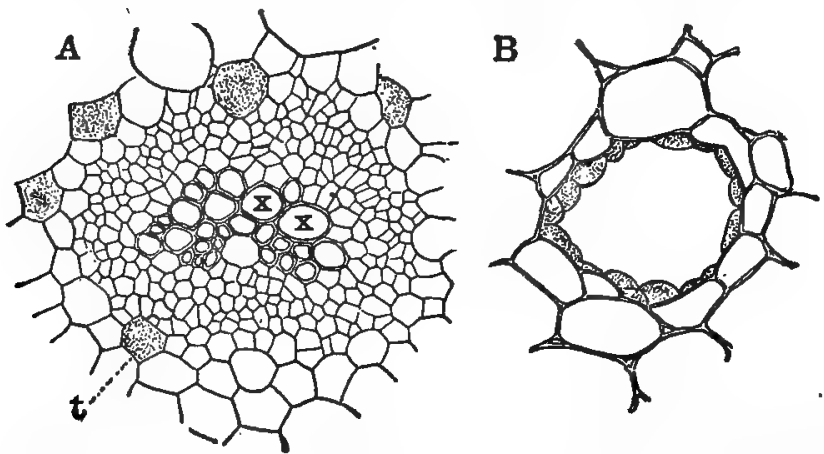

FiG. 162.-Danca alata. A, Transverse section of vascular bundle of the petiole, $\times 175$; $x$, tracheary tissue; $t$, tannin cells, $B$, Cross-section of a mucilage duct, $\times 175$.

the gaps formed by the departure of the leaf-traces. Marattia (Kühn (2)), closely resembles Angiopteris in its stem structure, but it has but two vascular cylinders outside the central strand, while Kaulfussia has but a single one. The bundles, are, according to Holle ( (2), p. 2I7) concentric, but the phloem more strongly developed upon the outer side.

The thick petioles of the full-grown leaves are traversed by very numerous vascular bundles, which at the base give off branches that supply the thick stipules within which they branch and anastomose to form a network. These bundles in Angiopteris (Fig. I6I, A) are arranged in several circles, or according to De Vriese (I) and Harting, the central ones form a spiral. In the rachis of the last divisions of the leaves, how- 
ever, both of Marattia and Angiopteris, there is but a single axial bundle, as in the petiole of the cotyledon.

Fig. I67, B shows a cross-section of a pinnule from a large leaf of $A$. evecta, which has much the same structure as that of Marattia. The central vascular bundle is horse-shoe shaped in section, and shows a central mass of large tracheids with reticulate or scalariform markings, surrounded by the phloem made up of very large sieve-tubes much like those of Botrychium, and with these are the ordinary protophloem cells and bast parenchyma. A distinct bundle-sheath is absent, as, according to Holle, it is from all the bundles in both Marattia and $A n$ giopteris, except those of the larger roots. The bulk of the

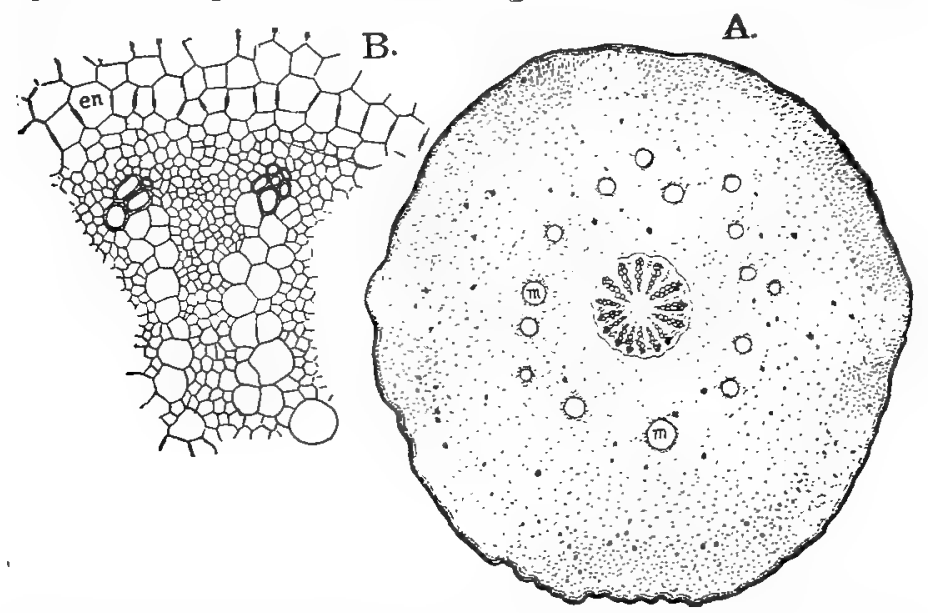

EIG. I63.-A, Section of a large root of Angiopteris evecta, $X_{14} ; m$, mucilage duct; $B$, part of the central cylinder, $X$ about 70 ; en, endodernis.

ground tissue is composed of large parenchyma cells, but on both sides just below the epidermis is a band of colourless cells which resemble exactly the collenchyma of Phanerogams. In the base of the petiole this becomes harder and forms a colourless sclerenchyma, which in Dancea is replaced by brown sclerenchyma like that of the true Ferns. In the lamina of the leaf in Angiopteris too, the arrangement of the tissues is strikingly like that of the typical Angiosperms. A highly-developed palisade parenchyma occupies the upper part of the leaf beneath the epidermis, which bears stomata only on the lower side of the leaf. The rest of the mesophyll is composed of the spongy green parenchyma found in the other Ferns. The smaller veins both here and in Marattia have collateral bundles. 
Short hairs occur upon the young sporophyte, and upon the older plant there may be developed scales (paleæ) similar to those found in the leptosporangiate Ferns.

The base of the stipe, as well as that of the rachis of the leafsegments, is enlarged, closely resembling the "pulvinus" of a leguminous leaf. The stalk breaks at this place, leaving a clean scar. The smaller leaflets separate in the same way from the rachis.

The Marattiaceæ all develop conspicuous mucilage ducts (Figs. I62, I63, m) and gum canals, very much like those occurring in the Cycads (Brebner (2)). These ducts are of two kinds. The first type is "schizogenic," $i$. e., of intercellular origin, the secretory cells surrounding the intercellular canal. The ducts of the second type are formed from the breaking down of rows of tannin-bearing cells, which thus form irregular ducts, not unlike certain milk-tubes of the higher plants.

Upon the stipules and stipe there are often present lenticellike structures ("Staubgrübchen" of German authors). These originate beneath stomata, in much the same way as the ordinary lenticels; but the cells below the opening of the lenticel are not cork-cells, but small, thin-walled cells, which separate and dry up, forming a dusty powder.

Intercellular rod-like organs, composed mainly of calciumpectate, are of common occurrence. There may also occur silicious deposits, and crystals of calcium-oxalate have been observed in Angiopteris (See Bitter (I)).

\section{The Sporangium}

The sporangia of the Marattiaceæ differ most markedly from the Ophioglossaceæ in being borne on the lower side of the ordinary leaves, and not on special segments. Except in Angiopteris, they form synangia, whose development has been especially studied in Marattia. Luerssen ( 7 ) describes the process thus: "In Marattia the first differentiation of the sporangium begins while the young leaf is still rolled up between the stipules of the next older one. The tissue above the fertile vein is more strongly developed than the adjoining parenchyma, and forms an elevated cushion parallel with the vein. This is the receptacle, which develops two parallel ridges, separated by a cleft. These two ridges grow up until they meet, and their edges grow together and completely close the cleft which lies 
between. In each half there are differentiated the separate archesporial groups of cells corresponding to the separate chambers found in the complete synangium." The whole process takes, according to his account, about six months. Luerssen was unable either in Marattia or Angiopteris to trace back the archesporium to a single cell, which Goebel (3) claims is present in the latter.

In Angiopteris the process begins as in Marattia, but at a period when the leaf is almost completely developed and
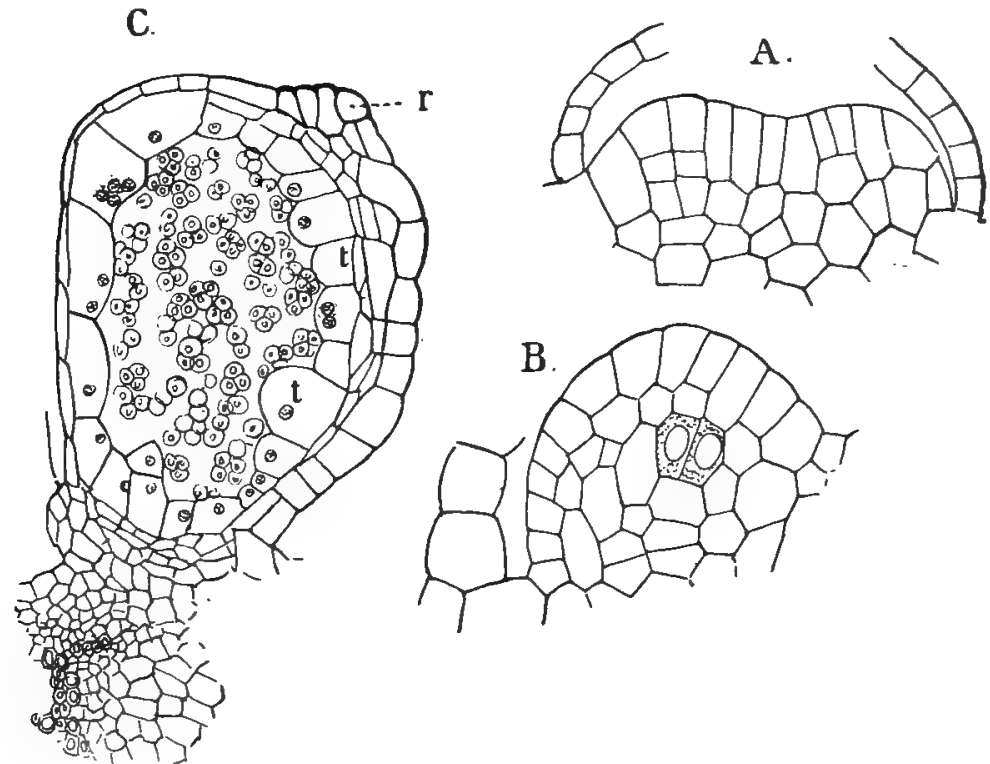

Fig. 164.-Angiopteris cvecta. Development of the sporangium. A, Vertical section of very young receptacle; $B$, similar section of an older sporangium in which the archesporium is already developed (after Goebel); C, longitudinal section of an almost fully-developed sporangium, showing the persistent tapetal cells $(t) ; r$, the annulus, $\times 75$.

unfolded. The first indication of the young sorus is the formation of an oblong depression above a young vein, and about the border of this are numerous short hairs, which as a rule are absent from the epidermis of the leaf (Fig. I64, A). The placenta is formed as in Marattia, but instead of the two parallel ridges that are found in the latter, the young sporangia arise separately, much as in Botrychium. As in the latter too, Goebel states that the archesporium can be traced to a single 
hypodermal cell in the axis of the young sporangium. This cell divides repeatedly, but apparently without any definite order, and the division of the spores follows in the usual way. From the cells about the archesporium tapetal cells are cut off, but these do not disappear, as Goebel (3) asserts, but persist until the sporangium is mature. The growth is greater
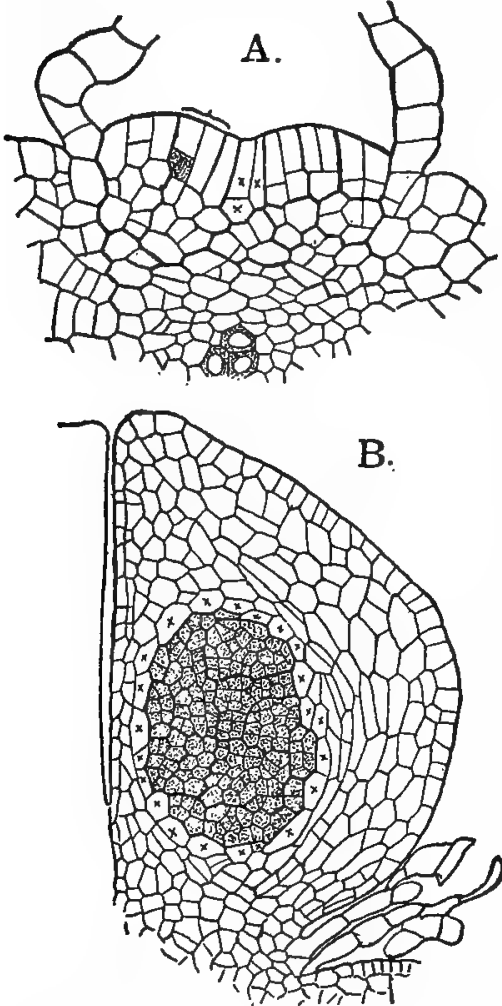

FIG. I65.-Marattia fraxinea. A, Transverse section of young synangium, $\times 225 ; B$, similar section of an older synangium, Xirz; $x, x$, the tapetal cells. (After Bower.) upon the outer side, which is strongly convex, while the inner face is nearly flat.

A section of the nearly full-grown sporangium (Fig. I64,C) shows that the wall upon the outer side is much thicker, and is composed for the most part of three layers of cells, of which the outer in the ripe sporangium have their outer walls strongly thickened. The top of the sporangium and the inner wall are composed of but one layer of cells (exclusive of the tapetum), which are flat and more delicate than those upon the outer side. Near the top on its outer side is a transverse line of cells with thickened darker walls, which project somewhat above the level of the others. This is the annulus or ring, and resembles closely that of $\mathrm{Os}$ munda. Lining the wall is a layer of very large thinwalled cells which form the tapetum. This in Angiopteris remains intact until the spores are divided. Whether it disappears before the dehiscence of the sporangium was not determined. The contents of these cells, which are very much distended, and evidently actively concerned in the growth of the forming spores, contain very few granules, but are multinucleate in many cases. Whether 
this condition is due to a coalescence of originally separate cells, or what seems more likely, arises simply from nuclear division in the young tapetal cells, without the formation of cell walls, was not decided. The young spore tetrads, at this time, are embedded in an apparently structureless mucilaginous matter, which stains uniformly with Bismarck-brown. This mucilage apparently is secreted by the tapetal cells for the nourishment of the spores.

Bower ( I7) has recently made a very complete study of the development of the sporangium in all the genera except
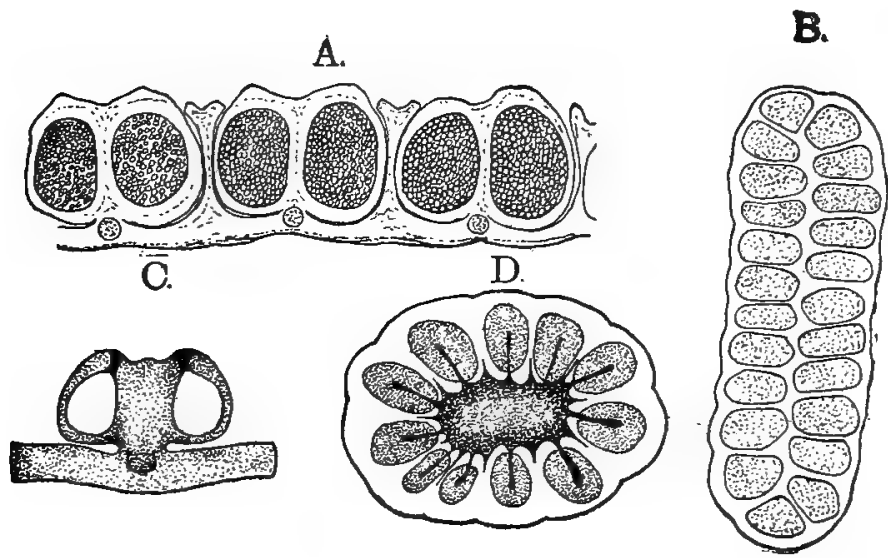

FIG. 166.-A, Transverse section of three synangia of Danca alata, $X_{15} ; \mathrm{B}$, horizontal section of a synangirm, showing the numerous loculi, $X_{15} ; C$, vertical; $D$, horizontal section of a synangium of Kaulfussia esculifolia, $X 15 . \quad$ (C, D, after Bower.)

'Archangiopteris. He finds in all of them that the sporogenous tissue of each sporangium (or loculus), can usually be traced to a single mother-cell, although there may be exceptions to this rule.

In all cases the tapetum arises from the tissue adjacent to the archesporium, and not from the outer cells of the sporogenous complex. In this respect the Marattiaceæ resemble more nearly Helminthostachys or Botrychium than they do Ophioglossum.

In Dancea and Kaulfussia there is no mechanical tissue representing an annulus. The dehiscence is accomplished by a 


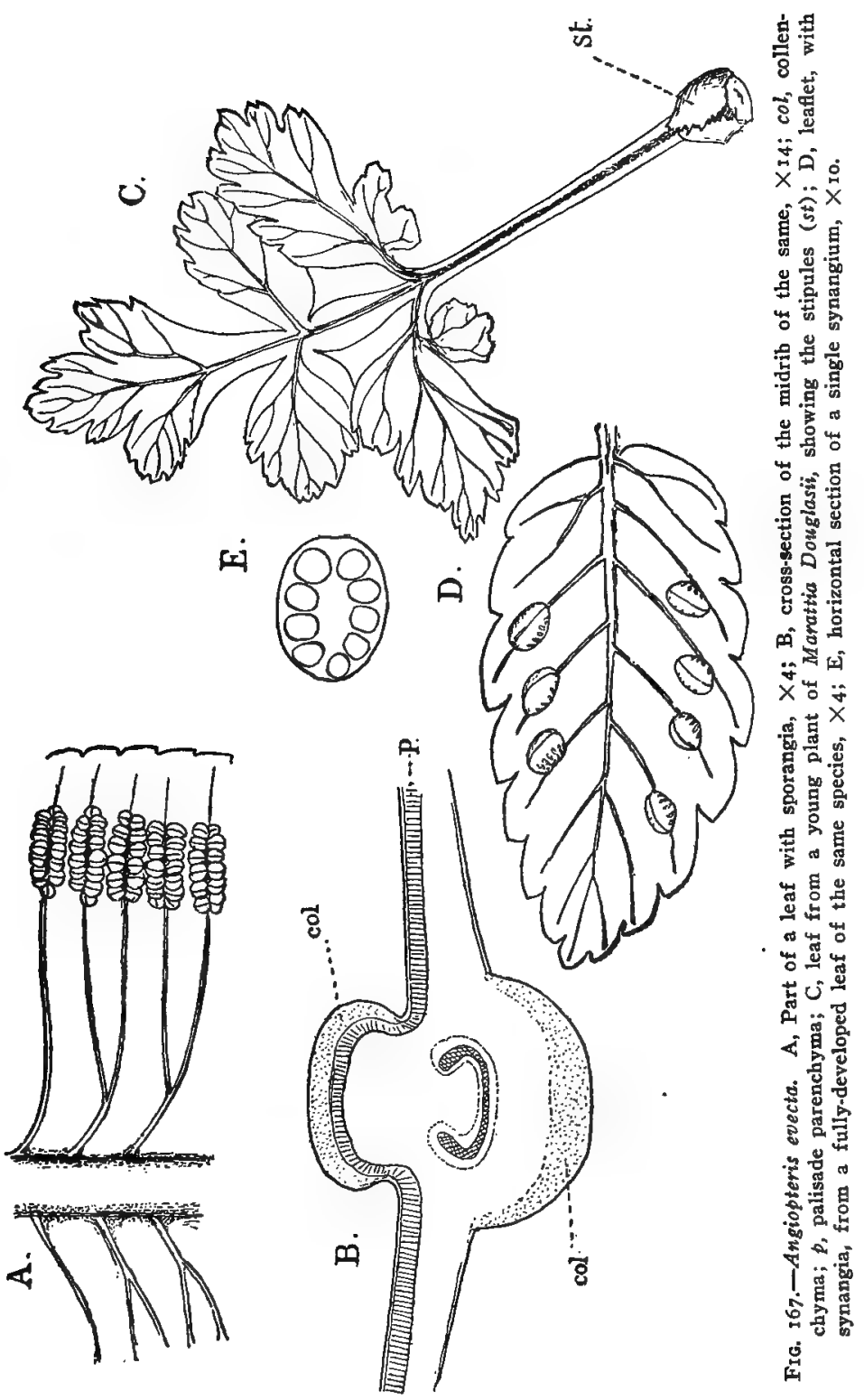


shrinking of the cells on either side of the opening slit. The latter in Danca is short, and finally appears like a circular pore, but is really not essentially different from that in Kaulfussia and Marattia. In the latter there is a mechanical tissue which causes the two valves of the synangium to gape widely at maturity, and the dehiscence of the individual loculi is effected by

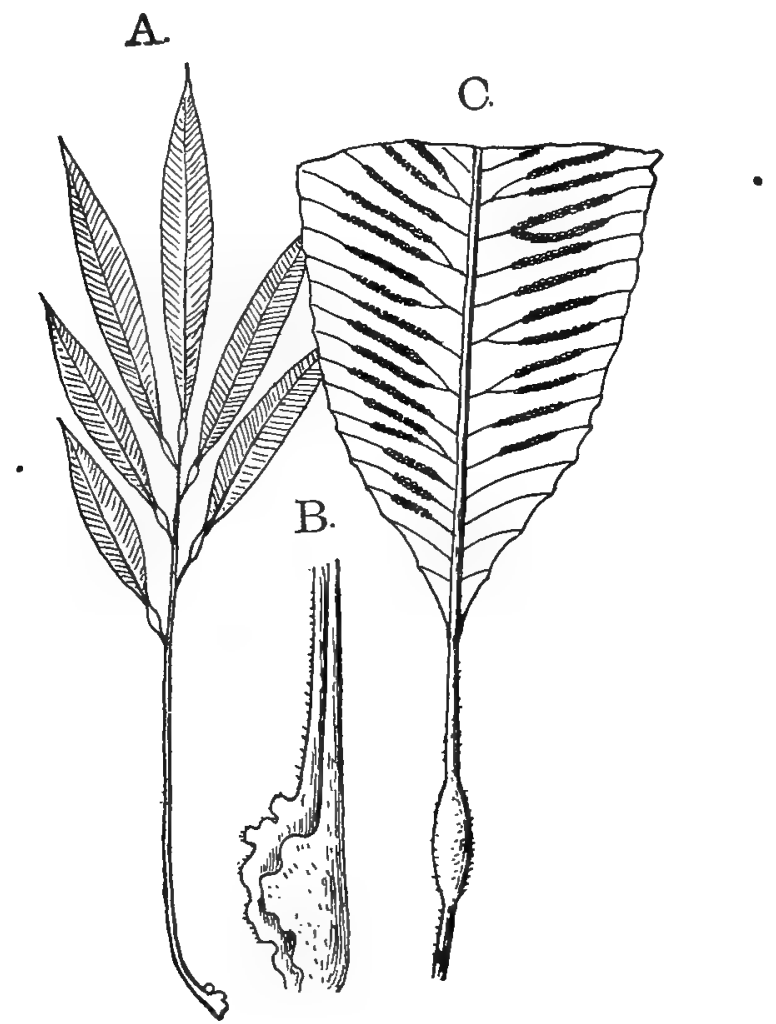

FIG. 168.-Archangiopteris Henryi. A, Entire sterile leaf, reduced; B, base of stipe, showing the stipules; C, part of a fertile pinna, of the natural size. (After Christ \& Giesenhagen.)

the contraction of thinner walled cells surrounded by firmer tissue.

The number of spores produced in each loculus is approximately I750 for Danca, 7500 for Kaulfussia, 2500 for Marattia, and 1450 for Angiopteris.

Bower's account and figures of Angiopteris differ from the specimens examined by the writer in the greater thickness of 
the sporangium wall. This may have been due to different conditions under which the plants were grown, or to a possible difference in the species.

There is frequently found surrounding the synangium, hairs or scales which form a sort of indusium (Fig. 165). In Danca , the leaf tissue between the synangia grows up as a ridge, with expanded top overarching them. This ridge in section appears T-shaped (Fig. I66, A).

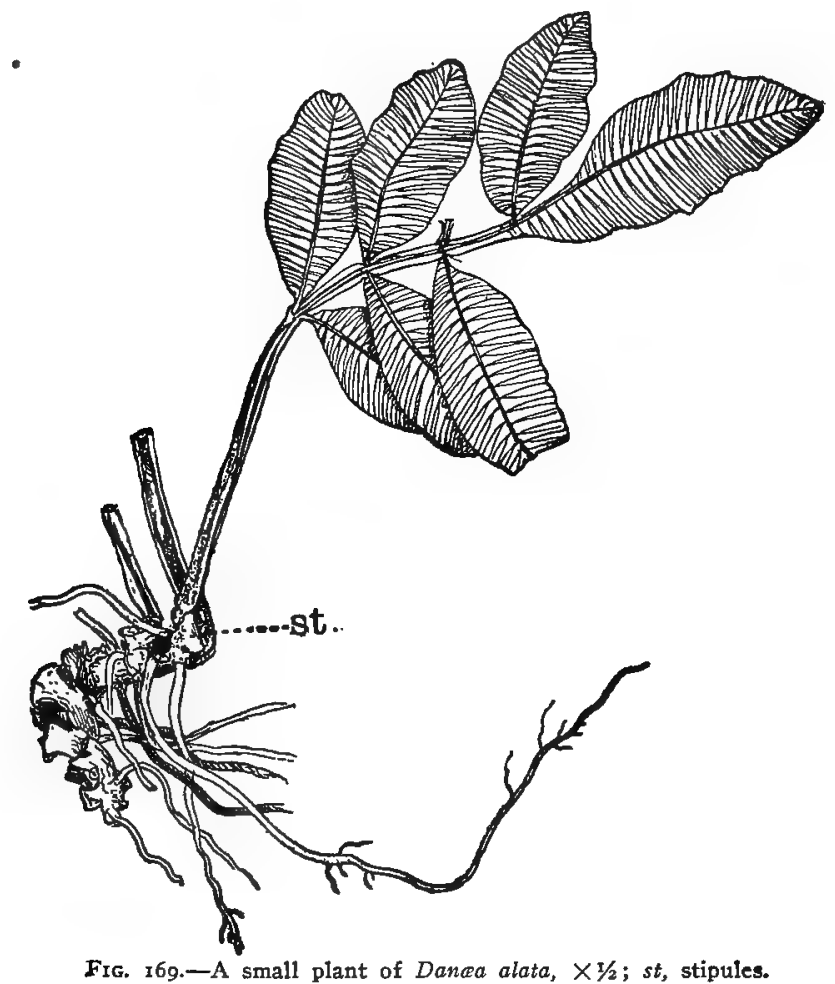

Classification of the Marattiacex

The living Marattiaceæ (Bitter (I)) may be divided into four sub-families, of which the first, Angiopterideæ includes two genera, Angiopteris and Archangiopteris, while the others, Marattieæ, Kaulfussieæ, and Danæaæ, contains each but a single genus. 
Marattia includes about twelve species of tropical and subtropical Ferns, both of the Old World and the New. Kaulfussia includes but a single species, belonging to southeastern Asia. The synangia are scattered over the lower surface of the palmate leaf, and are circular, with a central space into which the separate loculi open by a slit, as in Marattia. Kaulfussia is characterised by very large pores upon the lower side of the leaf. A study of the development of these shows that at first they are perfectly normal in form, and that the large round opening is a secondary formation, the two guard cells of the young stoma being torn apart, and disappearing almost entirely in the older leaf.

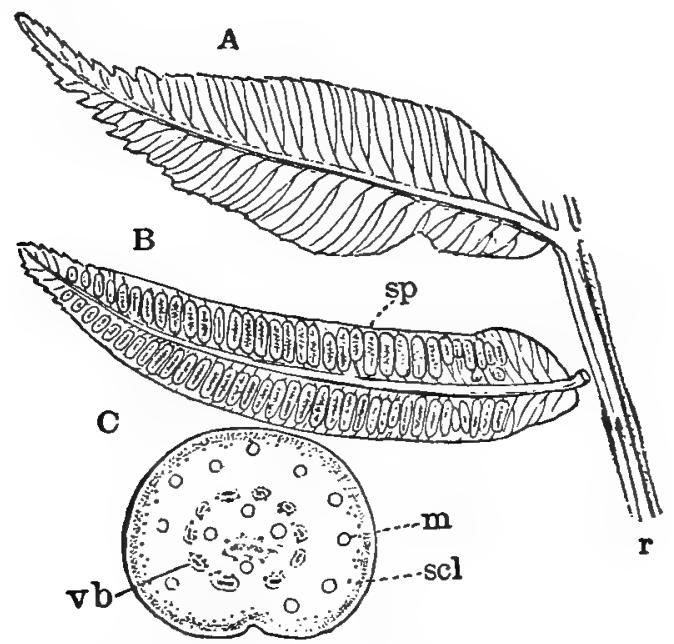

Fig. 170.-Danca alata. A, Sterile; B, fertile pinna, $X_{I} 1 / 2 ; C$, cross-section near the base of the petiole, $\times 6$; sel, selerenchyma; $m$, mucilage ducts; $v b$, vascular bundles.

The genus Dancea is exclusively American and comprises about fourteen species of small or middle-sized Ferns. D. simplicifolia has a simple lanceolate leaf, the others have oncepinnate leaves. The fleshy stipe is often characterised by conspicuous swellings. The venation of the leaves (Fig. I Io) is much like that of Angiopteris and some species of Marattia. .. The fertile pinnæ are decidedly contracted, and the elongated synangia almost completely cover their lower surface.

The stem (Fig. I69) is a horizontal fleshy rhizome, the leaves arranged in two ranks upon the upper side. The leaf- 
base has a pair of conspicuous stipules like those found in the other genera.

Kaulfussia cesculifolia is the sole representative of the family Kaulfussieæ, and differs very much in habit from the other living Marattiacex. The rhizome and leaf arrangement are not unlike those of Dancea, but the leaf is palmately divided, and the venation is reticulate, while the synangia are scattered. The synangium is circular, or broadly oval in outline. (Fig. r66).

The recently discovered Archangiopteris, (Fig. 168) is a small Fern from southern China, which in habit resembles Dance. The sporangia, however, are more like those of 'Angiopteris.

\section{The Affinities of the Eusporangiate Filicinea}

In attempting to determine the affinities of the members of this group, many difficulties are encountered. First, and perhaps most important, is the small number of species still existing, which probably are merely remnants of groups once much more abundant. This is certainly true of the Marattiaceæ, and presumably is the case with the Ophioglossaceæ as well. In the former this is amply proven by the geological record; but in the others the fossil forms allied to them are very uncertain, and as yet poorly understood. In the Ophioglossaceæ the series from Ophioglossum through the simpler species of Botrychium to the higher ones, such as $B$. Virginianum, is complete and unmistakable, but when points of connection between these and other forms are sought, the matter is not so simple:

Our still somewhat incomplete knowledge of the gametophyte of the Ophioglossacer makes the comparison doubly difficult. From the development of chlorophyll in the germinating spore of $B$. Virginianum, as well as from analogy with other Ferns, it seems probable at any rate that the subterranean chlorophylless prothallium is a secondary formation, but this cannot be asserted positively until the development is much better known than at present, and its relation to the green prothallium of the Marattiales and the thallus of the Hepaticæ must remain in doubt. The structure of the sexual organs and development of the embryo point to a not very remote connection with the former order, and in some respects also to the Anthocerotes. 
Ophioglossum beyond question shows the simplest type of sporangium of any of the Pteridophytes, and may be directly compared to a form like Anthoceros. In both cases the archesporium is hypodermal in origin, and is formed without any elevation of the tissue to form separate sporangia. In Anthoeeros, alternating with the sporogenous cells, are sterile cells which divide the archesporium into irregular chambers containing the spores. A direct comparison may be drawn between this and the origin of the archesporium in Ophioglossum, especially in connection with Prof. Bower's discovery of a continuous band of sporangiogenic tissue in the latter. In some species of Ophioglossum, too, the epidermis of the sporangium has stomata as in Anthoccros. A comparison of these remarkable points of similarity in the structure of the sporophyll of Ophioglossum and the sporogonium of Anthoceros, together with the very simple tissues of the former, led the writer (Campbell (7) ) to express the belief that Ophioglossum, of all living Pteridophytes, seemed to be the nearest to the Bryophytes. Subsequent study of the eusporangiate Ferns has strengthened that belief, and from a comparison of these with Ophioglossum on the one hand and the Anthocerotes on the other, it seems extremely likely that the latter represents more nearly than any other group of living plants the form from which the Pteridophytes have sprung, and that in the series of the Filicinea at any rate, Ophioglossum comes nearest to the ancestral type. Of course the possibility of Ophioglossum being a reduced form must be borne in mind, and the saprophytic habit of the prothallium may perhaps point to this; still, whatever may be its real character, there is little doubt that it is the simplest of the Filicinex. The recent discovery of the interesting $O$. simplex strengthens this view.

The resemblances between Ophioglossum and the Anthocerotes are not confined to the sporophyte. The sexual organs -and this is true of all the eusporangiate Pteridophytes-show some most striking similarities that are very significant. It will be remembered that in the Anthocerotes alone among the Bryophytes the sexual organs are completely submerged in the thallus - the antheridia being actually endogenous. It will be further remembered that in the eusporangiate Filicineæ a similar condition of things exists. 
In all the Hepatica the axial row of cells of the archegonitum terminates in the cover cell, which by cross-divisions forms the group of stigmatic cells of the neck. In the Anthocerotes this terminal group of cells is the only part of the archegonium neck that is free, the lateral neck cells being completely fused with the surrounding tissue. This arises from the archegonium mother cell not projecting at all, but we have seen that in crosssection a similar arrangement of the cells is presented to that found in the young archegonium of other Hepaticæ. In the Filicinea a similar state of affairs exists, but the divisions in the mother cell are, as a rule, not so irregular. Still, e. g., Marattia, it is sometimes easy to see that the mother cell (so-called) of the archegonium is triangular when seen in cross-section, and cut out by intersecting walls in exactly the same way as the axial cell in the Bryophyte archegonium. In short, what is ordinarily called the mother cell of the archegonium in the Ferns is really homologous with the axial cell only of the young archegonium of a Liverwort. A comparison of longitudinal sections of the young archegonium of Marattia, for instance, with that of Notothylas, will show this clearly. From this it follows that the four-rowed neck of the Pteridophyte archegonium does not correspond to the six-rowed neck of the Bryophyte archegonium, but only to the group of cells formed from the primary cover cell, and is a further development of this. The relatively long neck of the archegonium in the more specialised forms, e. g., Botrychium Virginianum, and especially the leptosporangiate Ferns, must be regarded as a secondary development connected probably with fertilisation. The shifting of the archegonium to the lower surface of the gametophyte has probably a similar significance. In B. Virginianum, however, the archegonia are borne normally upon the upper side of the thallus, as in the thallose Liverworts.

It is possible that a similar relation exists between the antheridia of the eusporangiate Ferns and that of the Anthocerotes. In both cases the formation of the antheridium begins by the division of a superficial cell into a cover cell and a central one. The former divides only by vertical walls in the Marattiaceæ, but in Botrychium and the Anthocerotes it becomes two-layered. In the latter the central cell may form a single antheridium, or it may produce a group of antheridia, but in the others it divides at once into a mass of sperm cells. By the 
suppression of the wall in the antheridium of an Anthoceros where only one antheridium is formed, there would be produced at once an antheridium of the type found in Botrychinm, and by a further reduction of the division of the cover cell, by which it remains but one cell thick, the type found in Marattia would result.

Such an origin of the antheridium of the Filicineæ is, at any rate, not inconceivable, while not so obvious perhaps as the resemblances in the archegonium, and is simply suggested as a possible solution of a very puzzling problem.

The Marattiaceæ agree closely among themselves, and the structure of the gametophyte is like that of the Ophioglossacex, so far as the latter is known, and also offers most striking resemblances to the Hepaticæ. The long duration of the prothallium, and its persistence after the sporophyte is independent, as well as the long dependence of the latter upon the gametophyte, are all indications of the low rank of this order. The sporophyte, while showing many points of resemblance to the Ophioglossacex, still differs very much also, and in general habit as well as the position of the sporangia comes nearer the leptosporangiate Ferns. Of the Ophioglossaceæ, Helminthostachys on the whole approaches nearest to the Marattiaceæ, so far as the general character of the sporophyte is concerned. The venation of the leaves and dehiscence of the sporangia are very similar to Angiopteris, and the green sterile tips to the sporangial branches hint at a possible beginning of the lamina of the sporophylls in the Marattiaceæ.

The synangia of Dancea show a certain analogy, at least, with the sporangial spike of Ophioglossum, and it is possible that a comparison might be made between the leaf of $O$. palmatum, with its numerous sporangial spikes, and a sporophyll of Danca (see Campbell (26)). Both archegonium and antheridium of Ophioglossum pendulum are strikingly similar to those of the Marattiaceæ.

While any relationship between these orders is necessarily a remote one, nevertheless there are too many agreements in structure to make it at all probable that the Ophioglossaceæ and Marattiacex have had an entirely independent origin.

In seeking a connection with the leptosporangiate Ferns there are two points where this is possible. The higher species of Botrychimm show an unmistakable approach to the leptospo- 
rangiate type. The archegonium neck projects much more than in the other Eusporangiatæ, and the vascular bundles in the petiole are truly concentric. The venation of the leaves also becomes that of the typical Ferns. The sporangia are completely free and smaller and more delicate, although truly eusporangiate in development. In all these respects there is an approach to Osmunda, unquestionably the lowest of the leptosporangiate series. Helminthostachys too may be almost as well compared to Osmunda as to Angiopteris.

On the other hand, in the circinate vernation of the leaf as well as the histology, in the roots and in the sporangia, the Marattiaceæ, especially Angiopteris, approach quite as close or closer to the Osmundaceæ than does Botrychium or Helminthostachys.

We may conclude, then, from the data at our disposal, that the living eusporangiate Filicineæ consist of a few remnants of widely divergent branches of a common stock, which formerly was predominant, but has been supplanted by more specialised modern types. From this primitive stock have arisen on the one hand the leptosporangiate Ferns, and Cycads, on the other, through Isoetes, or some similar heterosporous forms, the Angiosperms. 


\section{CHAPTER IX}

\section{FILICINEA LEPTOSPORANGIAT}

THE Leptosporangiatæ bear somewhat the same relation to the eusporangiate Ferns that the Mosses do to the Hepaticæ, but the disproportion in numbers is much greater in the former case. While the whole number of living Eusporangiatæ is probably less than 50 , the Leptosporangiatæ comprise about 4000 species. In the former the differences between the groups are so great that there is some question as to their near relationship, while all the leptosporangiate Ferns show a most striking similarity in their structure, and except for the presence of heterospory in two families, might all be placed in a single order. Carrying our comparison still further, we may compare the Polypodiacex, which far outnumber all the others, with the Bryales. among the Mosses. Both groups are apparently modern specialised types that have supplanted to a great extent the lower less specialised ones.

The distribution of the leptosporangiate Ferns, too, offers some analogy with the Mosses. While the eusporangiate Ferns are few in number of species, they are for the most part also restricted in numbers of individuals. The Leptosporangiates, on the other hand, occur in immense numbers, especially in the tropics, where they often form a characteristic feature of the vegetation. This is true to a limited extent in temperate regions also, where occasionally a single species of Fern, $e$. g., Pteris aquilina, covers large tracts of ground almost to the exclusion of other vegetation. A somewhat prevalent idea that the Ferns of to-day form merely an insignificant remnant of a former vegetation is hardly borne out by the facts in the case. Any one who has seen the wonderful profusion of Ferns in a 
tropical forest, and the enormous size to which many of them grow, is very quickly disabused of any such notion.

The fossil record is also extremely instructive as bearing on this point. According to Solms-Laubach (2) there is but one certainly authentic case from the Carboniferous rock which can be regarded certainly as a leptosporangiate form, all of the other sporangia discovered being of the eusporangiate type. In the later formations the Leptosporangiates increase in number, but according to Luerssen ( ( 7 ) II, p. 574) undoubted Polypodiaceæ are not found before the Tertiary, where a number of living genera are represented.

Potonié (3) cites several examples of Palæozoic Ferns probably allied to the lower leptosporangiate families, but the number is very small compared to the etusporangiate types.

Except in the few heterosporous forms there is, on the whole, great uniformity in the gametophyte. The most marked exception to this is the filamentous protonema-like prothallium of some species of Trichomanes and Schizaa. Except in these, however, the germinating spore, either directly or after forming a short filament, produces normally a flat, heartshaped prothallium, growing at first by a two-sided apical cell, the prothallium being at first one cell thick, but later producing a similar cushion to that found in Marattia but less prominent, and the wings always remain one cell thick. Upon the lower side of the cushion are produced the archegonia, which have always a projecting neck, sometimes straight, but more commonly bent backward. The antheridia are produced upon the same prothallium as the archegonia in most forms, but a few species of Ferns are diœcious, and usually there are small male prothallia in addition to the large hermaphrodite ones. The antheridia, like the archegonia, always project above the surface of the prothallium.

The first divisions in the embryo always divide it into regular quadrants, and the young members always grow from a definite apical cell, which, with the possible exception of some of the Osmundacer, is also found at the apex of the later roots and always in the stem. In size the sporophyte varies extremely. In some of the smaller Hymenophyllaceæ the creeping stem is not thicker than a common thread, and the fullydeveloped leaves scarcely a centimetre in length. The other extreme is offered by the giant tree-ferns belonging to the Cya- 
theaceæ, e. g., Alsophila, Cyathea, Cibotium. The leaves are in most cases compound, and either firm and leathery in texture, or in the delicate Hymenophyllaceæ have the lamina reduced to a single layer of cells, so that in texture it recalls a moss leaf. With the single exception of the Salviniacex the leaves are always circinate in the bud. The surface of the stem and leaves is frequently provided with various epidermal outgrowths, scales and hairs, which show a strong contrast to the mostly glabrous Eusporangiatz. The vascular bundles are, both in the stem and petioles, of the concentric type with a very distinct endodermis, and in the older parts of both stems and leaves parts of the ground tissue are often changed into thick-walled and dark-coloured sclerenchyma. In the finer veins of the leaf the vascular bundles are reduced in structure and more or less perfectly collateral.

The sporangia are extremely uniform in structure throughout the group. They can be traced back to a single epidermal cell, in most cases developed from the lower side of the unmodified sporophylls, as in the Marattiaceæ. They are always more or less distinctly stalked, and grow for a time from a pyramidal apical cell, whose growth is stopped by the formation of a periclinal wall (Fig. I9o). The central tetrahedral cell has first a layer of tapetal cells cut off from it, and the inner cell then forms the archesporium. No sterile cells are formed in the archesporium, but all the cells (except in the macrosporangium of the Hydropterides) develop perfect spores. The ripe sporangium is provided, except in the Hydropterides, with an annulus or ring of thickened cells, which assists in its dehiscence, and forms the most characteristic structure of the ripe sporangium.

\section{Non-Sexual Reproduction}

In a few of the Ferns special non-sexual reproductive bodies, buds of different kinds, occur upon the prothallium, which thus may have an unlimited growth. Such buds may have the form of ordinary branches, or they are of a special form. Buds of the latter class occur, sometimes in great numbers, in certain Hymenophyllacex, where they are formed upon the margin of the prothallium, to which they are attached by short unicellular pedicels from which they readily become de- 
tached. In this way, as well as by the separation of ordinary branches, the prothallia of some species of Hymenophyllum form dense mats several inches in diameter, which look exactly like a delicate Liverwort. A most remarkable case is that of Anogramme leptophylla, examined by Goebel (I). The prothallium multiplies extensively by buds, some of which form tuber-like resting bodies, by which the prothallium becomes perennial. The sporophyte in this species is annual and dies as soon as the spores ripen. The archegonia are borne on special branches of the prothallium, which penetrate into the ground and lose their chlorophyll. Goebel ((I0) p. 245) suggests

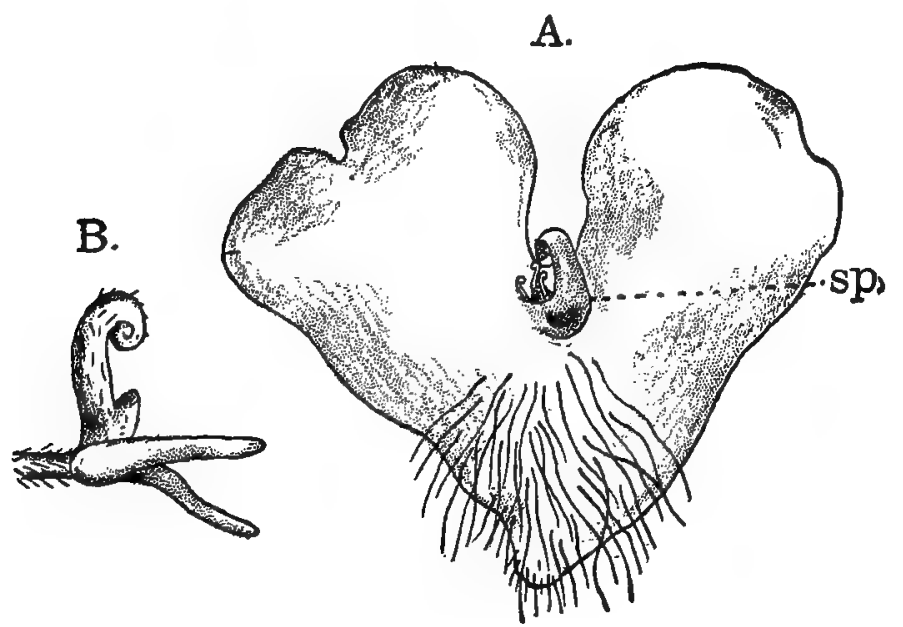

Fig. 171.-A, Prothallium of Pteris cretica, with the sporophyte, $s p$, arising as a vegetative bud; B, apex of the root of Asplenium esculentum, developing into a leafy shoot. (A, after De Bary; B, after Rostowzew.)

what seems very probable, that the subterranean prothallium of the Ophioglossaceæ may be of this nature, and the fact that in Botrychium Virginianum the germinating spore develops chlorophyll would point to this.

\section{Apogamy and Apospory}

Apogamy, or the development of the sporophyte from the prothallium as a vegetative bud, was first discovered by Farlow ( I) and later investigated by De Bary (2), Leitgeb (I3), and Sadebeck (6). It is known at present in Pteris Cretica, As- 
pidium flix-mas var. cristatum, Aspidium falcatum, Todea Africana, and several others. Sometimes archegonia are produced, or they may be absent from the apogamous prothallium, but antheridia usually are found. When archegonia are present they do not appear to be functional. In Pteris Cretica (Fig. I7 I, A), where usually no archegonia are developed, the cushion of tisste which ordinarily produces them is formed as usual; but instead of forming archegonia it grows out into a leaf at whose base is formed the stem apex, which soon produces a second leaf. The first root arises endogenously near the base of the primary leaf, and the young plant closely resembles the sporophyte produced in the normal way. Previous to the development of the bud there is formed in the prothallium itself a vascular bundle which is continued into the leaf, but is entirely absent from normal prothallia.

The opposite state of affairs, where the gametophyte arises directly from the sporophyte without the intervention of spores, is known in a number of species, and has been especially investigated by Bower (6). He found that there were two types of apospory, as he named the phenomenon, one where the pro-

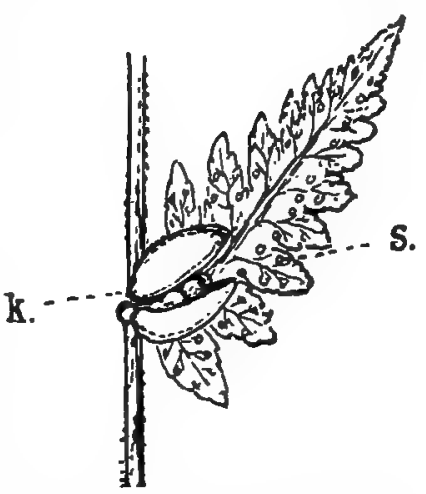
FIG. 172.-Pinna from the leaf of Cystopteris bulbifera, with a bud $(k)$ at the base, $X z ; s$, the sori (after Atkinson). thallium was produced from a sporangium arrested in its normal growth, and by active multiplication of the cells of the stalk and capsule wall forming a flattened structure, which soon showed all the characters of a normal prothallium with sexual organs. In the second case the prothallia grew out directly from the tips of the pinnæ, and there was no trace of sporangia being formed previously. The first observations of these phenomena were made upon two varieties, Athyrium flix-fomina var. clarissima and Polystichum angulare var. pulcherrimum, but since, Farlow (2) has discovered the same phenomenon in Pteris aquilina. In the latter the prothallia were always transformed sporangia. The phenomenon of apospory was first observed by Druery $(1,2)$. 
The production of secondary sporophytes as adventitious buds upon the sporophyte is a regular occurrence in some species. Asplenium bulbiferum and Cystopteris bulbifera are familiar examples of such sporophytic budding. In these large numbers of buds are formed which soon develop all the characters of the perfect sporophyte. Very early a definite apical cell is established from which all the other parts are derived. In Camptosorus rhizophyllus, the "walking fern" of the Eastern United States, a single bud is formed at the tip of the slender leaf which bends over until it takes root. From this terminal bud another leaf grows and roots in the same way.

\section{Classification of the Leptosporangiate}

The Leptosporangiatæ fall into two groups, which may be termed orders, although the two families in the second order (Hydropterides) are not closely related to each other, but each has nearer affinities with certain of the homosporous forms.

I. Homosporous Ferns with large green prothallium, usually in its early stages growing from a single apical cell; more commonly monœecious, but sometimes diœcious. Leaves always circinate in vernation. Sporangia with a more or less developed annulus, either borne upon ordinary leaves or on specially modified sporophylls. Usually, but not always, each group of sporangia (sorus) covered by a special covering, the indusium.

Order I. Filices. (Eufilicineæ. Sadebeck (7)).

Family I. Osmundaceæ.

Family 2. Gleicheniaceæ.

Family 3. Matoniaceæ.

Family 4. Hymenophyllaceæ.

Family 5. Schizæaceæ.

Family 6. Cyatheacex.

Family 7. Parkeriaceæ.

Family 8. Polypodiacex.

II. Heterosporous forms, either aquatic or amphibious; the prothallia are always diøcious, the female prothallium with chlorophyll and capable of more or less independent growth when not fertilised; male prothallium always without chlorophyll, the vegetative part reduced to one or two cells, besides the antheridium. Leaves either circinate (Marsiliaceæ) or 
folded (Salviniaceæ) ; sporangia without an annulus and borne in special "sporocarps," which are either modified branches of ordinary leaves (Marsiliaceæ) or a very highly developed indusium.

Order II. Hydropterides.

Family I. Marsiliaceæ.

Family 2. Salviniaceæ.

\section{Order I. Filices}

The eight families of the Filices form an evidently very natural group, but there has been a good deal of disagreement as to their relative positions. The Osmundaceæ are generally recognised as approaching most nearly the eusporangiate Ferns, and the Gleicheniaceæ come next to these. The Hymenophyllaceæ are usually considered at the other extreme of the series, but there are a number of reasons why this seems doubtful, and I am inclined to assign them an intermediate position. Their structure and development give evidences of their being a specially modified group adapted to living in very damp situations, and they probably cannot be regarded as connecting any of the other families, but rather as a side branch which has developed in a direction away from the type. They come nearest the Gleicheniaceæ and Osmundaceæ in the structure of the sexual organs, and the sporangium shows points in common with the former family. The sporangium, however, also resembles that of the Cyatheacer, and the strongly-developed indusium is much like that of the latter. The Schizæacea also may possibly form a side branch from the ascending series which ends in the Polypodiaceæ.

Professor Bower ( 19), who does not recognize the Ophioglossaceæ as belonging to the Filicineæ, divides the other homosporous Ferns into three suborders, based upon the development of the sporangia. His first suborder, "Simplices,". includes the Marattiaceæ, Osmundaceæ, Schizæaceæ, Gleicheniaceæ, and Matoniaceæ. In these families all the sporangia in a sorus are developed simultaneously, and the output of spores is relatively large. The second suborder, "Gradatæ," comprises the Hymenophyllaceæ (inc. Loxsomaceæ), Cyatheaceæ (inc. Dicksonieæ-in part), and one sub-family, Dennstædtineæ, belonging to the Polypodiaceæ. In these the sporangia arise in 
basipetal succession on the receptacle. The remaining subfamilies of the Polypodiaceæ constitute the suborder, "Mixtæ," in which sporangia of very different ages are mixed together in the same sorus.

The well-known Ostrich-Fern, Onoclea struthiopteris (Struthiopteris Germanica) illustrates very satisfactorily the germination of the spores and the development of the gametophyte and embryo in the Polypodiaceæ, the typical modern Ferns. O. sensibilis, which may probably be better separated generically from Struthiopteris, agrees closely with the latter in the development of the gametophyte.

The large oval spores contain, besides much oil and some starch, numerous small crowded chloroplasts. The three walls of the spore are plainly demonstrable, especially as the brown perinium is often thrown off by the swelling of the spore, and the transparent exospore can then be seen, with the delicate endospore lying close to its inner face. A large nucleus occupies the centre of the spore. Contrary to the statements usually made that spores containing chlorophyll quickly lose their vitality, these will germinate after a year or more, although not so.well as those of the same season, but they normally remain from autumn until spring before they germinate. $O$. sensibilis acts in the same way, and spores of other Ferns containing chlorophyll have been germinated after an equally long period.

The spores germinate promptly, varying from two or three days to about a week, depending upon the temperature. The exospore is ruptured irregularly near one end, and through this a short colourless papilla protrudes and is shut off by a transverse wall (Fig. I73, B). This papilla contains little or no chlorophyll and rapidly lengthens to form the first rhizoid, which undergoes no further divisions. The large green cell alone produces the prothallium. The divisions in the prothallial cell vary somewhat, but in the great majority of cases a series of transverse walls is first formed, and the young prothallium (Fig. I73, C) has the form of a short filament. Sooner or later, in normally-developed prothallia, the terminal cell of the row becomes divided by a longitudinal wall, which may be:straight, but more frequently is oblique and followed by another similar wall in the larger of the two cells, meeting it so as to include a triangular cell, which is the "two-sided" apical : 


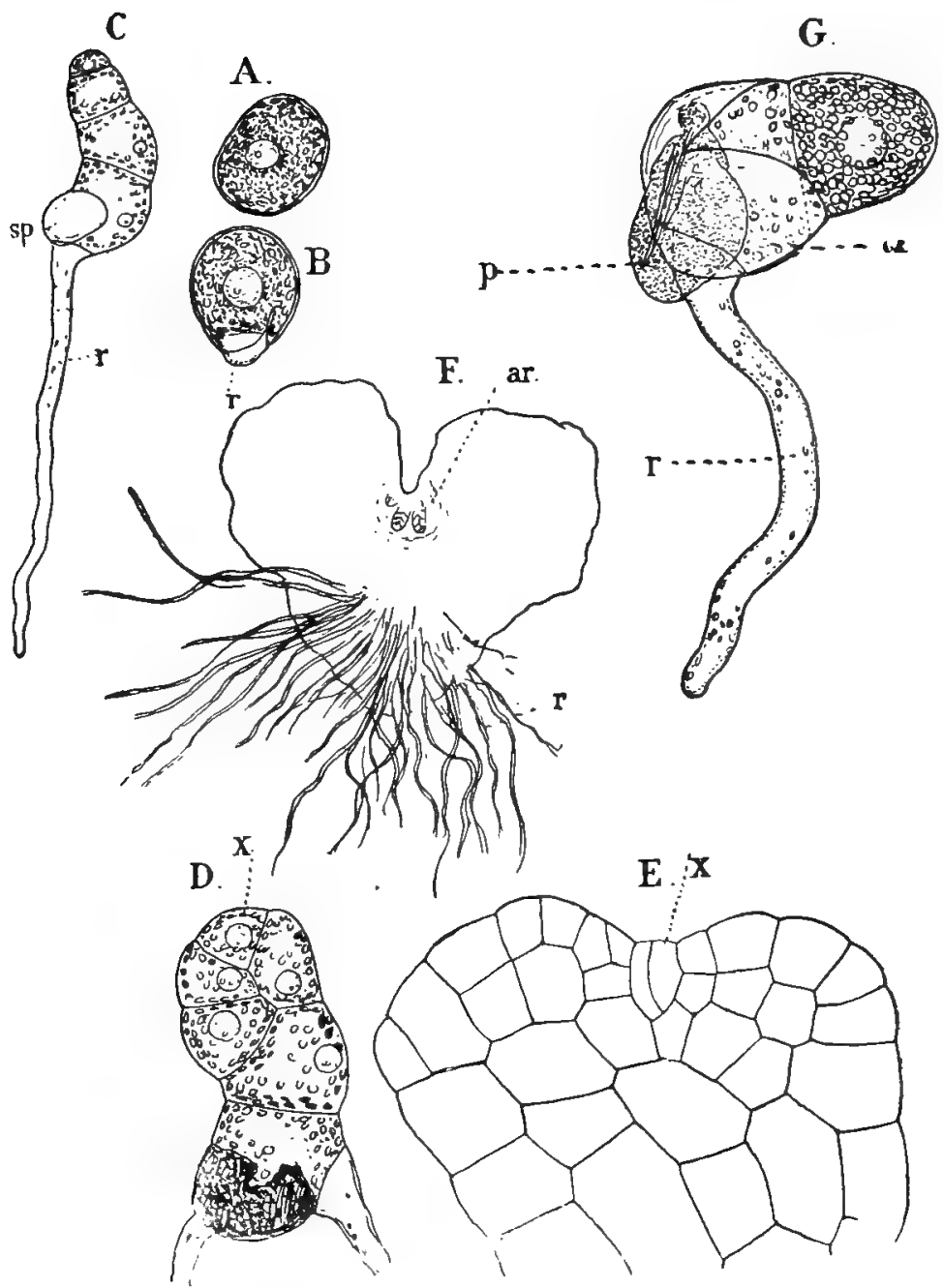

Fic. 173.-Onoclea struthiopteris. A, B, Germinating spores with the perinium removed, $\times 300 ; C$, young prothallium, $\times 100 ; D, E$, older prothallia with two-sided apical cell $(x), \times_{300 ;} \mathrm{F}$, small female prothallium seen from below, $\times_{25} ; \mathrm{G}$, very young protballium with the two outer spore-coats, $X_{300} ; r$, primary rhizoid; $a r$, archegonia; $p$, perinium; $e x$, exospore. 
cell of the next phase of the prothallium's growth. The divisions up to this point correspond exactly with those of Ancura or Metzgeria, and are also much the same as in Marattia, except that in Onoclea the prothallium only in very rare cases assumes the form of a cell mass at first.

By the regularly alternating segments of the apical cell the young prothallium soon assumes a spatulate form, which becomes heart-shaped by the rapid growth of the outer cells of the young segments, which grow out beyond the apical cell. Sooner or later the single apical cell is replaced by two or more initials formed from it in the same way as in the Marattiacea, and from this time on the growth is from a series of marginal initials. This change is connected with the formation of the thickened archegonial cushion, which, so far as I have observed, does not form in Onoclea so long as the single twosided apical cell is present.

As the prothallium grows new rhizoids grow out from the marginal and ventral cells and fasten the prothallium firmly to the ground. These hairs, colourless when first formed, later become dark brown.

In the genus Onoclea, as well as some other Polypodiaceæ, the prothallia are regularly dicecious, and only a part of them develop the archegonial meristem. The others remain onelayered, and are often of very irregular form, and may be reduced to a short row of a few cells. In Athyrium filixfomina these may even be reduced to a single vegetative cell besides the root-hair, and an antheridium. Cornu (I) records similar reduced prothallia in Aspidium flix-mas. All of the "a-meristic" prothallia, as Prantl ( (4), p. 499) calls them, are males. In the majority of the Polypodiacex these occur more or less plentifully, and are often the result of insufficient nutrition; but in Onoclea it is something more than this, as not only the small prothallia are male, but the large ones are exclusively female, and not hermaphrodite, as in most Ferns.

\section{The Sex-Organs}

The first antheridia appear within three or four weeks under favourable conditions, and are formed either from marginal or ventral cells of the prothallium. The very young antheridium is scarcely to be distinguished from a young rhizoid. Like it, 
it arises from a protrusion of the cell which is cut off by a wall, which is usually somewhat oblique. The papilla thus formed enlarges and soon becomes almost hemispherical. It contains a good deal of chlorophyll and a large central nucleus surrounded by dense cytoplasm. The first wall in the young antheridium (Fig. I74, A) is very peculiar. It has usually the form of a funnel, whose upper rim is in contact with the wall of



FIg. I74-Onoclea struthiopteris. Development of the antheridium. A-C, Vertical section, $X 600 ; D$, two nearly ripe sperm cells; $E$, free spermtatozoid, $X$ about I200.

the antheridium cell, and whose base strikes the basal wall of the antheridium. Sometimes this first wall does not reach to the base, in which case it is simply more or less strongly concave, and the basal cell cut off by it from the antheridium is discoid instead of ring-shaped (Fig. I74, B). The second wall is hemispherical, and is nearly concentric with the outer wall of the antheridium. The dome-shaped central cell produces the 
mother cells of the spermatozoids, and has much more dense contents than the outer cells, but all the chloroplasts remain in the latter. A third wall now forms in the upper peripheral cell, much like the first one in form, and cuts off a cap cell at the top. The young antheridium at this stage consists of four cells-a central dome-shaped one surrounded by three others, the two lower ring-shaped, and the terminal one discoid. These outer cells are nearly colourless and contain very little granular contents, except the small chloroplasts, which are mainly confined to the surface of the inner walls.

The divisions in the central cell are at first very regular. The first one is always exactly vertical, and is followed by a transverse wall in either cell which strikes it at right angles, and next a third set of walls at right angles to both of these, so that whether seen in cross-section or longitudinal section, the central cells are arranged quadrant-wise. Successive bipartitions follow in all the cells until the number may be a hundred or more, but the number is ustually much less, about thirty-two being the commonest. The regular arrangement of the sperm cells soon becomes lost, and they form a mass of polyhedral cells with dense granular cytoplasm, and large nuclei. A nucleolus is visible until the last division, after, which it can no longer be distinguished; otherwise the nuclei show no peculiarities. The transformation of the nucleus into the biody of the spermatozoid proceeds here as in other Ferns that have been examined, but I was unable to satisfy myself that so large a part of the forward end of the spermatozoid is of cytoplasmic origin, as Strasburger ( (II), IV, p. II 5). asserts. The fullydeveloped spermatozoid describes about three complete coils within the globular sperm cell, and does not lie coiled in a single plane, as in the Hepaticæ, but in a tapering spiral (Fig. I74, D). The very numerous long cilia are attached at a point a short distance back from the apex, and as Buchtien ( ( I ), p. $3^{8}$ ) showed, cover a limited zone, although hardly so restricted as he figures.

From the investigations of Shaw (2) and Belajeff $(5,6,7)$, it is evident that the cilia arise from a blepharoplast. Belajeff considers the blepharoplast in the Pteridophytes, as well as in the Bryophytes, to be a centrosome; but Shaw believes that the blepharoplast is an organ sui generis, and of quite different nature from the centrosome. 
Mottier (3) has recently examined the structure of the spermatozoid in Struthiopteris. He could detect no cytoplasmic envelope investing the posterior coils, which seemed to be of exclusively nuclear nature. The vesicle showed a fine cytoplasmic reticulum in which the larger granules were imbedded.

The separation of the sperm cells begins at about the time the development of the spermatozoids commences. The mucilaginous walls stain now very strongly, and in a living state appear thick and silvery-looking. The inner layer of the cell wall, however, remains intact, so that when the sperma-
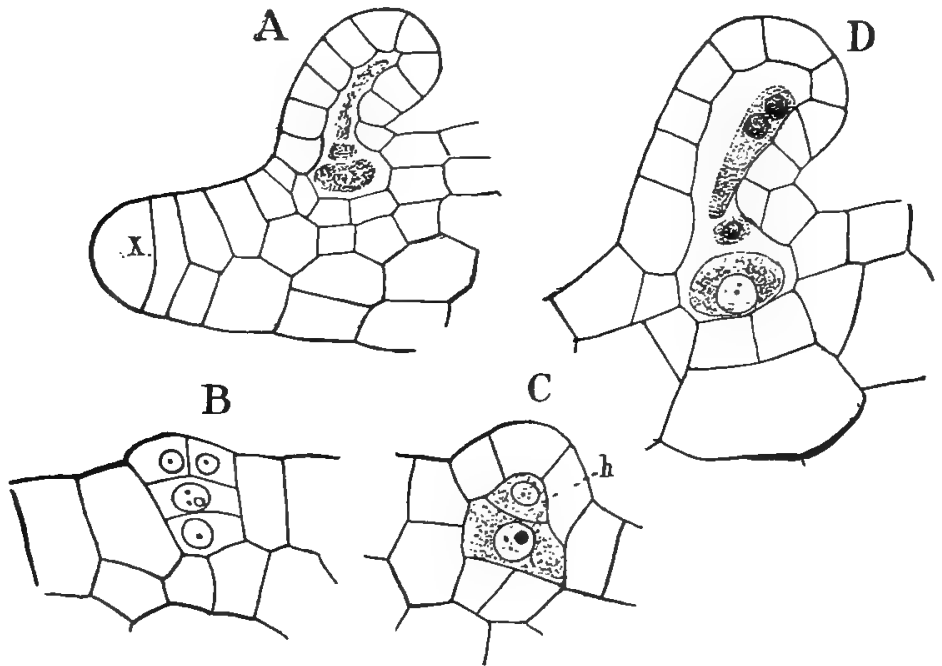

Frg. 175.-Onoclea struthiopteris. A, Longitudinal section of the apex of a female prothallium, showing the apical cell $(x)$ and a nearly ripe archegonium, $\times 215$; B-D, development of the archegonium; longitudinal sections, $\times 430 ; h$, neck canal cell.

tozoids are ejected, they are still enclosed in a delicate cell membrane, which swells up as the water is absorbed and finally dissolves completely. The vesicle derived from the remains of the cytoplasm is very conspicuous here, and the granular contents usually, but not always, show the starch reaction. The body of the free spermatozoid has the form of a flattened band with thickened edges, which tapers to a fine point at the anterior end, but is broader and blunter behind. The peripheral cells of the antheridium become so much compressed by the crowding of the sperm cells that they are scarcely perceptible, 
but after the antheridium is burst open, the two lower ones become so distended that they nearly fill the central cavity. The opening is effected either by a central rupture of the cover cell, or less commonly by a separation of this from the upper ring cell.

The development of the archegonium is intimately connected with the apical growth of the large female prothallium. A soon as the single apical cell has been replaced by the marginal initials, the divisions in the latter become very definite. Comparison of cross and longitudinal sections shows that these are much like those of Marattia or,

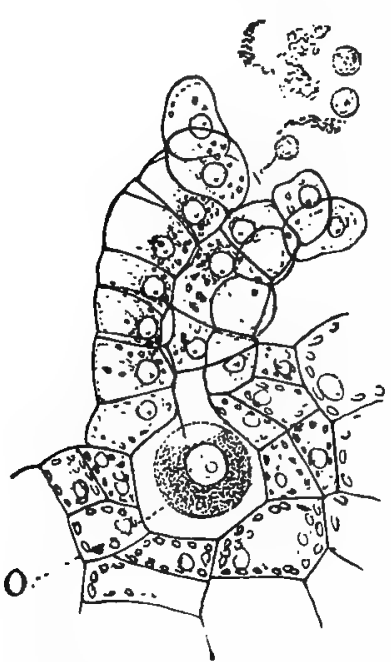

FIG. I76.-Ripe archegonium of

$O$. struthiopteris in the act of opening, $\times 300 ; 0$, the egg. among the Hepaticæ, Dendroceros or Pellia epiphylla. Each initial cell has the form of a semi-disc (Fig. I75, A), and the growth is both from lateral segments, which mainly go to form the wings of the prothallium, and basal, or inner segments, which produce the projecting archegonial cushion. If this begins to form very early, it may develop a midrib extending nearly the whole length of the prothallium; but usually it does not form until relatively late. Each basal segment of the initial cells divides into a dorsal and ventral cell (semi-segment), the latter the larger of the two, and with much more active growth. The latter alone is concerned in the growth of the projecting cushion. Each ventral semisegment is first divided by a wall parallel with the primary segment wall, and from the anterior of these cells, almost exactly as in Notothylas, the archegonium is developed. It is not possible to make out any definite succession of walls by which the axial cell of the archegonium is cut out, but it suon is recognisable by the granular cytoplasm and large nucleus. As in Marattia, the first transverse wall separates the inner cell from the cap cell, and the inner one then divides into the basal and the central cells. The cover cell divides into the four primary neck cells, and the central cell arching up between these 
has the pointed apex cut off by a curved wall from the central cell. The primary neck canal cell, so formed, is noticeably smaller than that of Marattia. The neck cells, which in the eusporangiate forms all grow alike, here show a difference, and the two anterior rows develop faster than the posterior ones, so that these rows are longer and the neck is strongly bent backward. In Onoclea there are usually about seven cells in each anterior row and about two less in the posterior ones. The neck cells are almost colourless, with distinct nuclei, and a few small, pale chloroplasts. From the central cell is now cut off the ventral canal cell, which is quite small, and separated from the egg by a strongly concave wall. The nucleus of the neck canal cell always divides, but no division wall is formed, and the two nuclei lie free in the cell. The basal cell divides by cross-walls into four, and with similar cells cut off from the adjacent prothallial tissue constitutes the venter of the ripe archegonium. The disintegration of the division walls of the canals cells, and the partial deliquescence of the inner walls of the neck cells, offer no peculiarities.

When the archegonium opens, the terminal cells diverge widely and the upper ones are often thrown off.

The opening of the sexual organs and the entrance of the spermatozoids may be easily seen by simply allowing the plants to remain slightly dry for a few days until a number of sexual organs are mature. If these are now placed upon the slide of the microscope in a drop of water, in a few minutes the sexual organs will open, and the spermatozoids will be seen to be attracted to the archegonia in large numbers, and with care some of them may be followed into the neck and down to the centra1 cell. The actual entrance of the spermatozoid into the egg has been observed, but is difficult to demonstrate in the living condition. Pfeffer (3) has shown that the substance which attracts the spermatozoids in the Polypodiaceæ is malic acid, and that an artificial solution of this, of the proper strength, will act very promptly upon the free spermatozoids of these Ferns.

Buller ( $I$ ) has found that in addition to malic acid and its salts, many salts, both organic and inorganic, which occur in the cell-sap, may exert a positive chemotactic stimulus upon the spermatozoids of Ferns. However, none of them react so strongly as malic acid and its salts. 
Buller also showed that the starch which is usually present in the vesicle of the spermatozoid, when it escapes from the antheridium, disappears completely in species where the period of activity is prolonged. Thus in Gymnogramme Mertensii, the swarm-period lasted about two hours, and during this time the starch disappeared completely.

\section{Fertilisation}

Shaw (2) has made a careful study of the fertilisation in Struthiopteris and in Onoclea. He states that before the arche-

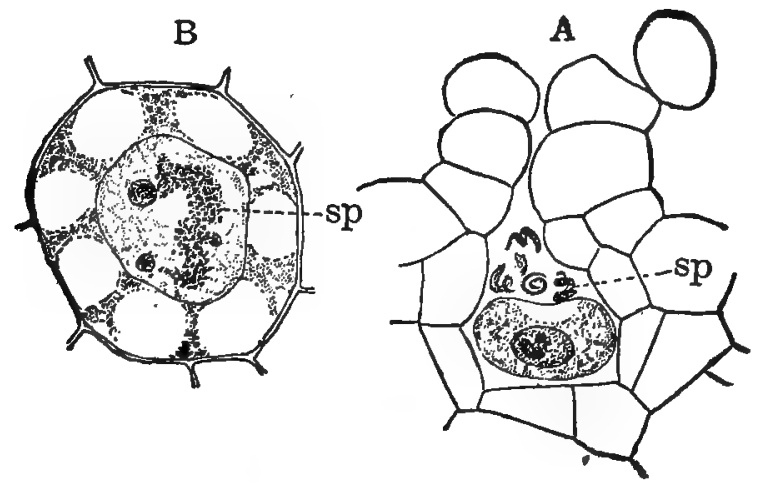

FIo. I77.-A, Osmunda cinnamomea, section of a recently fertilised archegonium, $\times 450$. A spermatozoid has penetrated the nucleus of the $\mathrm{egg}$, and several are in the space above the egg. B, Onoclea sensibilis. Egg fourteen hours after the penetration of the spermatozoid, which is still recognizable within the egg nucleus, Xgoo. (B, after Shaw.)

gonium opens, the egg is depressed above, and the nucleus flattened. As soon as the archegonium opens, and the disorganised contents of the neck cells are expelled, the egg becomes turgid, and the depressed upper part forms the receptive spot. (Fig. I77.)

The mucilaginous matter ejected from the archegonium retards the movements of the spermatozoids, and detaches the vesicle. As the spermatozoid penetrates the neck, it becomes much stretched out, and forces its way through to the central cavity of the archegonium, by a slow screw-like movement. Having penetrated into the ventral cavity, the coils draw together again, and the movements are much more rapid.

After a spermatozoid has entered the egg at the receptive 
spot, Shaw states that the egg then collapses, and suggests that this prevents the penetration of more than one spermatozoid. Mottier ((3) p. I39) expresses some doubt whether the collapsed appearance of the egg, usually found in microtome sections, is really normal.

The spermatozoid soon penetrates into the nucleus of the egg, where for some time it remains with little change of form. Presumably the cilia and the cytoplasmic part of the spermatozoid remain in the egg-cytoplasm as they do in Cycas and Zamia (Ikeno ( I), Webber (I)).

The body of the spermatozoid, after it penetrates the eggnucleus, gradually loses its homogeneous appearance, and the nuclear reticulum becomes more and more apparent. The spiral form becomes less evident, and the nucleus passes through much the same changes, except in reverse order, that are seen in its development from the nucleus of the sperm-cell. Finally the reticulum of the male nucleus becomes indistinguishable from that of the egg-nucleus, and the fusion is complete. During this fusion the egg nucleus retains its original form. The process of fusion is slow. In one instance, sixty hours after fertilisation, the sperm-nucleus was clearly recognisable.

As soon as the egg is fertilised it develops a membrane, and soon after undergoes its first segmentation. The, inner walls of the neck cells almost immediately turn dark brown, and the cells of the ventral part begin to divide actively and form the calyptra, which here, as in the Bryophytes, is formed from the venter alone, and is tipped with the remains of the neck cells.

The position of the archegonium depends largely upon the light. If both sides of the prothallium are about equally illuminated, archegonia will develop from both sides. As soon as an archegonium is fertilised, no new ones form, but it frequently happens that a very large number prove abortive before finally fertilisation is effected.

\section{The Embryo}

The first division wall in all Polypodiaceæ yet investigated is vertical and nearly coincident with the axis of the archegonium. This basal wall (Fig. I78, A) at once divides the 
embryo into the anterior epibasal half and the posterior hypobasal. The former produces the stem and cotyledon, the latter the primary root and foot. The early divisions are extremely regular, and offer a marked contrast to those in the eusporangiate embryo. The second wall is the transverse (quadrant) wall, separating the leaf and stem in the epibasal part, and the root and foot in the hypobasal. The next walls are the median or octant walls, but they do not correspond

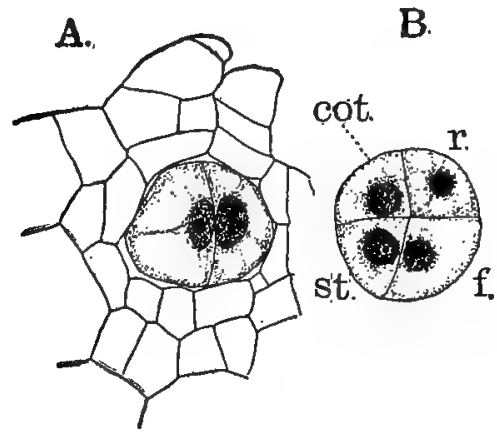

C.
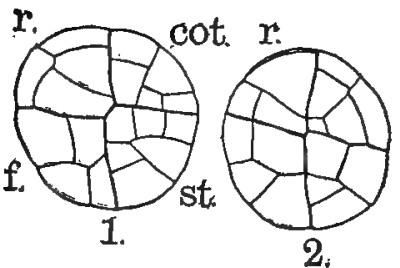

D.

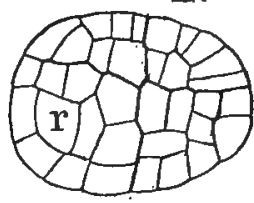

f. E.



F.

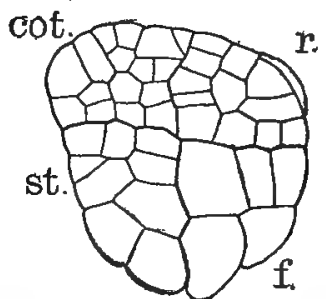

FIG. 178.-Onoclea sensibilis. A, two-celled embryo, $X$ about $500 ; \mathrm{B}$, an eight-celled embryo, longitudinal section; $C$, two longitudinal sections of an older embryo, $X$ about $250 ; \mathrm{D}, \mathrm{E}$, two horizontal sections of a still older embryo; $\mathrm{F}$, longitudinal section of an advanced embryo; the cotyledon is beginning to project beyond the other organs; cot, cotyledon; $r$, root; st, stem; $f$, foot. (All figures drawn from sections made by Dr. W. R. Shaw.)

exactly in all the quadrants. While in the cotyledon and stem they are almost exactly median, in the root especially, the octant wall diverges often a good deal from the median line, and the two resulting octants are unequal in size. The following divisions correspond for a short time in all the octants, but soon show characteristic differences. For a short time each octant shows a definite apical growth, the segments being cut off by walls formed successively parallel to the three primary 
divisions in the embryo, so that each octant may be said to have a three-sided apical cell. When the octant wall in the root quadrant is decidedly oblique this is not always evident in the smaller octant, and the larger one in this case at once becomes the definitive apical cell of the primary root.

The first of these walls is usually parallel to the basal, the second to the quadrant wall. Sometimes this order is reversed, but never, apparently, is the first wall parallel with the octant wall. Before the third segment is cut off from the octant, each of the two first ones divides by a periclinal wall into an inner and an outer cell. Fach octant now consists of five cells, two inner and three outer ones, of which one is the primary octant cell, which still retains its original tetrahedral form. The outer cell of each segment divides by a radial wall, but beyond this the succession in the walls differs. Of the eight original octants, one in each quadrant persists as the apical cell respectively of cotyledon, stem, root, and foot, but in the latter it becomes very early obliterated by the formation of a periclinal wall and further longitudinal divisions, which is the case also with one of the octants in the leaf and root. In the stem both octants persist, one becoming the permanent stem apex, the other forming the apical cell of the second leaf.

Shaw ( (2), p. 280) found in one instance an embryo in which the first wall in the hypobasal part of the embryo was the median wall instead of the usual transverse wall.

\section{The Cotyledon}

Of the two primary octants of the cotyledon, one very early ceases to grow and soon becomes indistinguishable, and the subsequent growth is due almost entirely to the activity of a single octant. The apical cell is at first like that of the other members, tetrahedral, but after about two sets of segments have been cut off from it no more are usually cut off from the side of the apical cell parallel to the basal wall, and the threesided cell thus passes over into a two-sided one with segments cut off alternately right and left. By the suppression of the growth in the sister octant, the apical cell gradually assumes a nearly median position. By the change to the two-sided form of the apical cell, the originally conical leaf rudiment becomes flattened, and a little later this is followed by a dichotomy of 
the growing point and the production of two apical cells like the original one (Fig. I79, C). The division is first brought about by. a nearly central longitudinal division of the apical cell, and on either side of this, by a curved wall running to the outer wall of each cell, two new apical cells, separated by two elóngated central cells, result. Each of these new growing points develops one of the lobes of the cotyledon, which undergo one or more bipartitions before the cotyledon breaks through
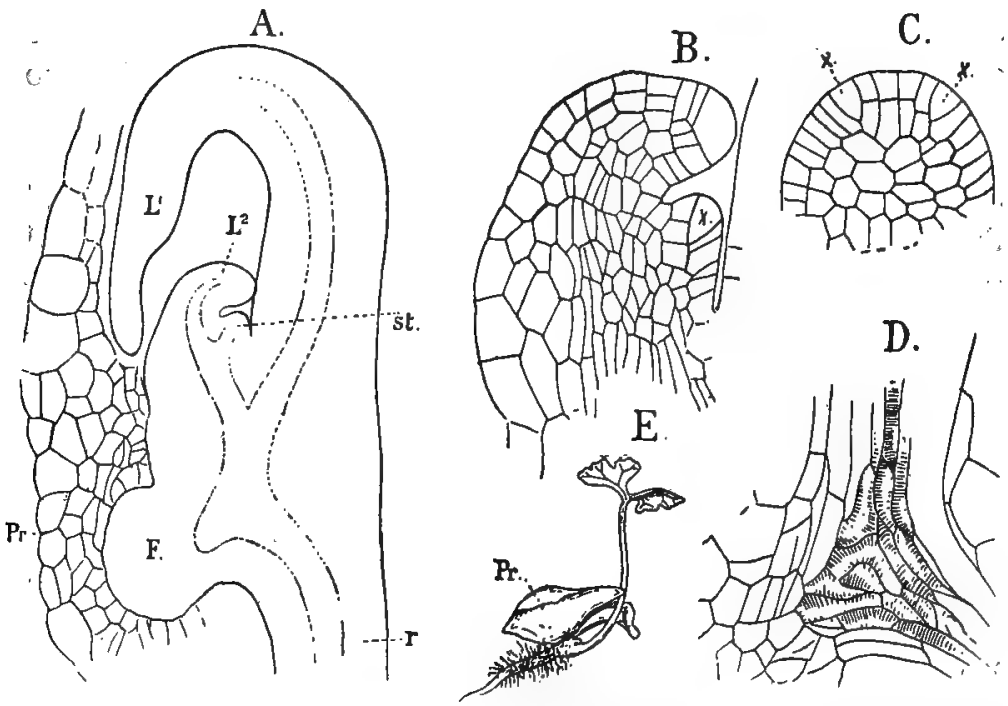

Fig. 179.-Onoclea struthiopteris. A, Longitudinal section of young sporophyte still connected with the prothallium $(P r), \times 60 ; \mathrm{B}$, the apex of same, $\times 180 ; \mathrm{C}$, surface view of the young cotyledon showing the first dichotomy; $D$, central region of $\mathbf{A}$, showing the primary tracheary tissue, $\times_{180} ; E$, young sporophyte with nearly full-grown cotyledon and primary root, $X_{3} ;$ st, stem; $\mathrm{L}^{1}$, cotyledon; $\mathrm{L}^{2}$, second leaf; F, foot; $P r$, prothallium.

the prothallium. As in Marattia the growth is much stronger upon the outer side and the leaf is strongly curved over. It very early grows beyond the stem apex, and the embryo loses its oval form much earlier than is the case with any of the Eusporangiatæ.

\section{The Stem}

The early segmentation of the stem apex is much the same as in the cotyledon; but later the divisions in the segments are somewhat different, and the first wall is a radial one, instead of 
periclinal. The stem is very short at the time the young sporophyte breaks through the prothallium, and its apex more pointed than is afterwards the case.

\section{The Root}

At first the segmentation of the apical cell of the root is almost exactly like that of the stem, and it is not until several lateral segments, usually about two series of them, have been formed that the first periclinal wall, cutting off the first cell of the root-cap, is formed. There is a good deal of difference, however, as to the time this occurs, and there is probably some connection between it and the different period at which the primary root breaks through the calyptra. In most Polypodiaceæ, the root is the first of the organs to penetrate the calyptra, but sometimes in Onoclea it is still short at the time the cotyledon is nearly developed, and in this recalls Marattia, where this is regularly the case. As soon as the first segment of the root-cap is formed, the segmentation of the root is extremely regular, and corresponds essentially to that found in the later roots.

\section{The Foot}

All definite divisions cease very soon in both of the foot octants, and this part of the embryo forms a more or less projecting hemispherical mass of cells, closely appressed to the prothallial cells. As usual in such cases the outer cells are large and distinct.

Shortly before the embryo breaks through the calyptra, which takes place much earlier than in Marattia, the first traces of the vascular bundles are seen as strands of procambium cells occupying the axis of each of the primary organs, and united in the centre, so that the four bundles together form a cross. Of these the one going to the foot is short, and ends blindly within that organ, but the others continue to grow with the elongation of the members to which they belong. The first permanent tissue to be recognised forms, as in Marattia, a bundle of short irregular tracheids at the junction of the young bundles (Fig. I79, D). These primary tracheids in Onoclea are scalariform, but the pits are shorter than in the later ones. Throughout the life of the sporophyte no vessels are formed, but only tracheids, as in nearly all Ferns. In the cotyledon the tracheids 
are all spiral, and occupy the centre of the concentric bundle, and from these growth proceeds centrifugally. The elements of the phloem are poorly differentiated, and in this stage no true sieve-tubes could be detected. While a definite bundlesheath can scarcely be made out, the limits of the bundle are clearly defined. The venation of the cotyledon is dichotomous, corresponding to the dichotomous branching of the lamina.

The vascular cylinder of the young stem is solid, and is mainly composed of short and broad scalariform tracheids, but in the centre of the bundle are some small spiral and reticulate ones. The phloem at this stage is not well developed, and does not show perfect sieve-tubes. The bundle sends a branch to the second leaf, but is continued beyond the point of contact, and develops tracheids above the point of union before the first ones are formed in the leaf. In this early stage the bundlesheath is very poorly differentiated in the stem, but becomes better marked as the plant develops.

The primary root is monarch, and the tracheary tissue composed of short pointed tracheids with irregular scalariform markings. These are surrounded by one or two layers of narrow cells with oblique transverse septa. The calyptra is soon penetrated by the cotyledon, which, instead of growing straight up through the prothallium, as it does in Marattia, breaks through upon the ventral side and then bends upward between the lobes in front (Fig. I79, E). The root bends down and penetrates the earth, and very soon after, the prothallium dies. The epidermis of the cotyledon produces small glandular hairs, and that of the root numerous root-hairs.

The second leaf is directly traceable to one of the primary stem octants, and may be either regarded as one of the primary members of the embryo, or as the first segment of the stem. Its development corresponds exactly to that of the cotyledon, as it does in its fully-developed state. The second root arises endogenously, like all the later ones, and its apical cell is formed close to the point of union of the bundles of the leaf and stem, and probably, as in the later roots, is derived from a cell of the endodermis.

The new leaves arise in regular succession from the segments of the apical cell of the stem and up to the fifth or sixth, and possibly later the first division of the leaf is dichotomous, and the pinnate form of the later leaves is gradually attained, as in 
Marattia. As the stem grows, the central stele, which at first is solid ("protostelic"), becomes a hollow cylinder ("siphonostele"), which, according to Jeffrey (3) in most Polypodiacex shows a concentric structure, $i$. $e$., there is a central mass of wood, with both outer and inner phloem, and an external and internal endodermis. Sometimes, however, e.g., Davallia stricta, both internal endodermis and phloem are absent, and this would seem to be the case also in Struthiopteris (Campbell (I)).

A cross-section of a plant of the latter species with three fully-developed leaves showed the vascular cylinder to be oval in outline, and consisting of the following parts. A central pith of elongated parenchymatous cells, surrounded by a thick ring of short spiral and reticulate tracheids, outside of which was a zone of phloem, the whole enclosed by a distinct endodermis. The latter is continuous, with the endodermis of the bundles going to the leaves and roots, and the xylem of these also connects with that of the stem bundle. The apex of the stem becomes more and more hidden by the development of scales from the epidermis, which finally completely hide it and form a very efficient pro-

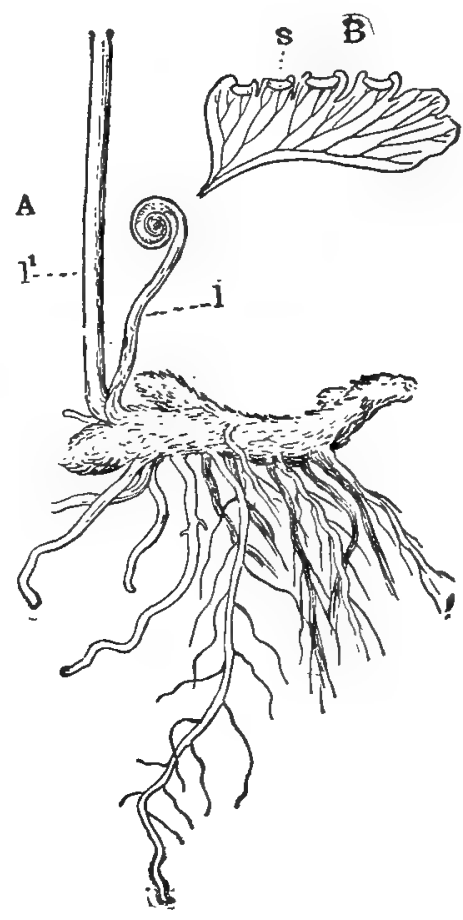

Fig. I80.-Adiantum pedatum. A, Rhizome with young leaf, $l$, and the base of an

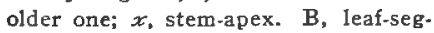
ment, showing venation, and sori, $s$. tection.

The petioles of the first three leaves have a single axial vascular bundle, but in the fourth, as in all subsequent ones, there are two. They separate very soon after leaving the stem bundle, which is deeply cleft where they issue from it. These bundles are typically concentric in structure, and have a welldeveloped endodermis. The number of roots in the young 
plant exceeds the leaves. In a plant with the fourth leaf still unfolded, there were six fully-developed roots.

The gaps in the vascular cylinder become more and more prominent as the sporophyte develops, and there is finally formed the wide-meshed reticulate cylinder found in the adult sporophyte.

In some Ferns, e. g., Pteris aquilina, there are developed medullary steles which arise from the inner surface of the primitive stelar tube. (See Jeffrey (3), Pp. I33, I 34).
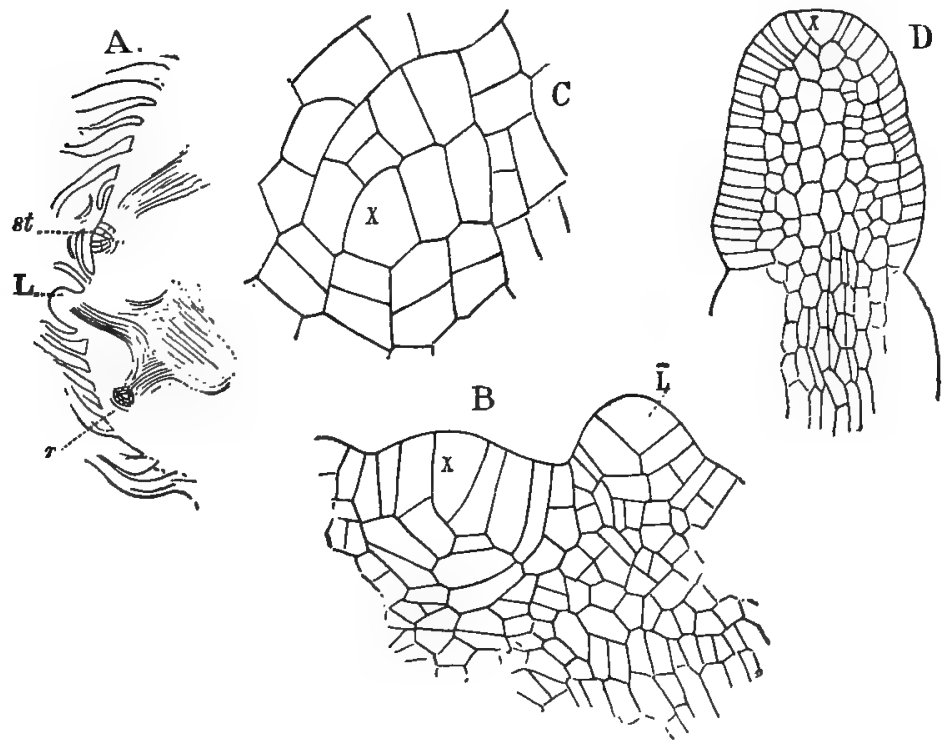

FIG. 181.-A, Vertical longitudinal section of the apex of a rhizome of Adiantumi emarginatum, $X_{25} ; \mathrm{B}$, the central part of the same, $X_{180} ; \mathrm{L}$, a young leaf; $\mathrm{C}$, cross-section of a similar stem apex, $\times 180 ; D$, apex of a young leaf of Onocléa struthiopteris, showing the apical cell $(x)$.

\section{The Mature Sporophyte}

\section{The Stem}

The stem in most of the Polypodiacex is either an erect or creeping rhizome which, unlike that of the Eusporangiatæ, often branches freely. These branches are almost alway's formed monopodially, and are usually of the same structure as the main axis; but in $O$. struthiopteris great numbers of peculiar stolons 
are formed that are quite different at first in appearance from the ordinary shoots. The main axis in this species is an upright rhizome about $2 \mathrm{~cm}$. in diameter, but appearing much larger on account of the thick persistent leaf-bases which cover it. The stolons arise from the bases of these leaves, apparently as adventitious buds. They may remain dormant for a long time, as very many more of the very small ones are found than those that are fully developed. They finally bend upward, and the scattered scale-like leaves give place to the perfect green ones. The main rhizome is occupied by a central cylinder composed of a network of anastomosing bundles. Inside of this cylinder is a medulla made up of large parenchyma cells, and communicating with the cortex by means of the foliar gaps, or spaces between the bundles.

Fig. I8I, A shows a longitudinal section of the apex of a stem of Adiantum emarginatum, which shows the typical appearance in the Polypodiaceæ. The apex of the stem forms a slight cone, whose centre is occupied by the large initial cell, which is deeper than broad. In cross-section it shows much the same form. Divisions occur, evidently, only at comparatively long intervals, and each segment presumably gives rise to a leaf. The first division in each segment is longitudinal and perpendicular to its broad faces. Each of the six semi-segments is then divided into an inner and an outer cell, and the latter again by a longitudinal wall parallel to its inner and outer faces, so that each original segment is divided into two inner cells and four outer ones. From the inner cells the pith and vascular bundles arise, from the outer ones the cortex and epidermis, but after the first divisions there is great irregularity in the succession of the cells. The young vascular bundles can be traced nearly to the apex, and first appear as bundles of procambium cells, which lower down unite and are joined by others from the leaves and roots.

In $O$. struthiopteris characteristic air-chambers are formed in the young medulla at an early period. At certain points the cells become longer and their contents more transparent. These cells divide less rapidly than the surrounding tissue, and large intercellular spaces are formed. The loose cells about these form masses of trichomes, either hairs or scales, which later dry up and leave a large empty space, which may or may not communicate with the exterior through the foliar gaps. 
In Onoclea struthiopteris, as in most leptosporangiate Ferns, the outer cortical cells become changed into sclerenchyma. The sclerenchyma forms several hypodermal layers, distinctly separated from the inner cortical parenchyma. These sclerenchyma cells are much elongated; their lateral walls are somewhat uneven, and in their younger stages swell up more strongly under the action of potassic hydrate than do the cortical cells. Their walls become thick, are first pale yellow, and later a dark reddish brown. The walls are very markedly striate, and the central lamella distinct. Deep pits extend down to the latter.

The bundles in the stems of the Polypodiaceæ are very uniform in structure. They are usually elliptical in section, and the first tracheary tissue formed is a strand of small spiral or reticulate tracheids at the foci of the bundle. From there the formation of the very large scalariform ones, so characteristic of the leptosporangiate Ferns, proceeds towards the centre of the bundle, where the last-formed ones are situated. The young tracheids have thin walls and abundant protoplasm, but as the wall thickens, the contents gradually disappear, and
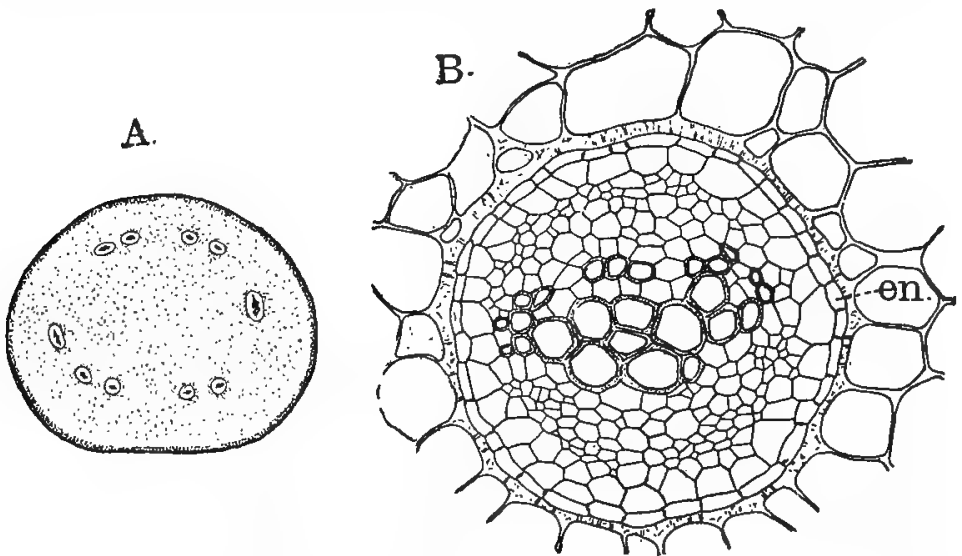

Fig. I82.-Polypodium falcatum; A, Transverse section of the rhizome, $\times 6 ; \mathrm{B}$, a sin: gle vascular bundle, $X I 75$; $e n$, endodermis.

finally no living protoplasm remains in them. Faint elongated transverse pits become evident, and the spaces between these rapidly thicken at the expense of the cell contents until all the protoplasm is used up. The thickened bars between the pits give the characteristic ladder-like appearance to the older 
tracheid (Fig. I84, B). In cross-section these bars are nearly rhomboidal, and give the familiar beaded appearance to sections of the tracheid wall.

Sieve-tubes of very characteristic form are found in the bundles of all the Polypodiacex. In $O$. struthiopteris they occupy an irregular area at each end of the bundle. Their differentiation begins shortly after that of the large scalariform tracheids, and in some respects resembles it. The procambium cells from which they arise are uniform in diameter, and have squarer ends than the young tracheids. Their contents are more colourless and finely granular than those of the tracheids, and the nucleus not so evident. The formation of the sieve-
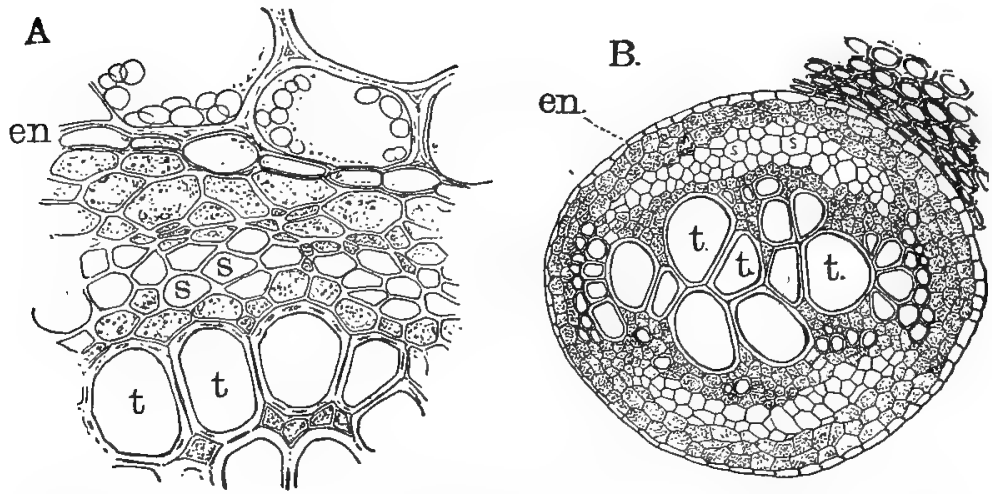

Fig. 183.-Woodwardia radicans. A, Part of a transverse section of a vascular bundle of the rhizome, $X_{400}$ (about); $B$, transverse section of a root, $X_{70} ; t$, tracheids; $s$, sieve-tubes; en, endodermis.

plates begins by transverse thickened bars on the lateral walls, less regular than in the tracheids, and the bars more or less anastomosing so as to enclose thin areas, the sieve-plates (Fig. I84, D, E). These occur all over the lateral walls, as well as the transverse ones. While it could not be positively shown, it is extremely probable that the pores, afterwards formed, penetrate completely the thin membrane of the sieve-plates, and throw the adjacent sieve-tubes into communication.

While it is usually supposed that there are no nuclei in the adult sieve-tubes, in several instances, evidences of the presence of a number of small nuclei were met with. A further investigation of this point is desirable.

With the tracheary tissue is mingled more or less wood- 
parenchyma, and in the phloem the sieve-tubes are accompanied by bast parenchyma.

Outside the phloem is a layer of cells, which may be double in some places, and which usually contain a good deal of starch. According to Strasburger ( ( I I), Vol. 3, p. 446) these cells do not constitute a true pericycle, but belong to the cortex. They are sister-cells of the endodermis, which is thus, not the innermost cortical layer, but the next but one. The endodermal cells show the characteristic thickenings on their radial walls.

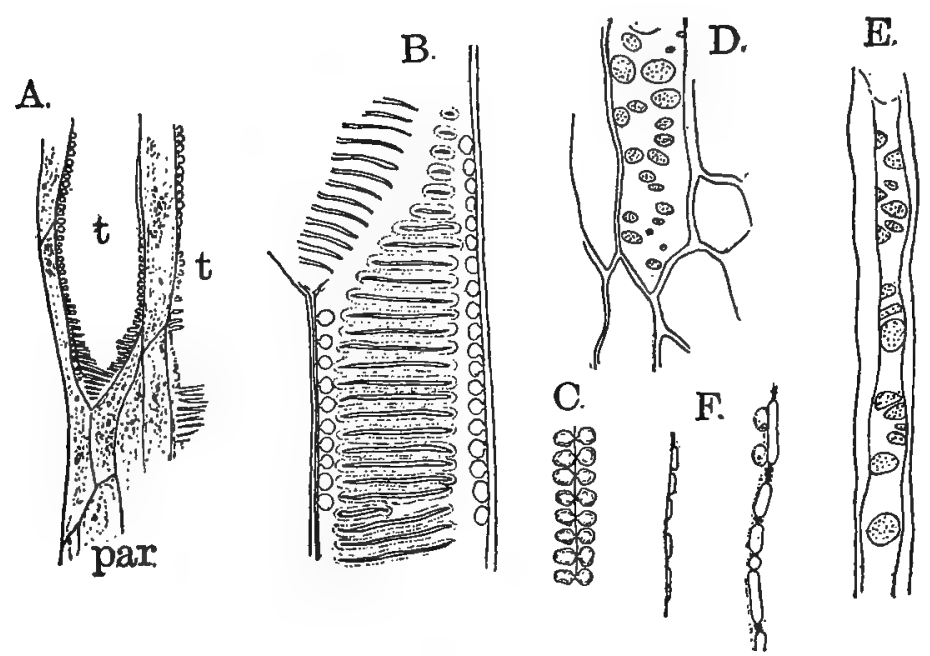

FIG. I84,-Woodwardia rodicans. A, Tracheids, $t$, and wood-parenchyma, par., from the rhizome, $\times 225$ (about); B, longitudinal section of two tracheids, more strongly magnified; $C$, section of the wall between two tracheids; D-F, sieve tubes.

\section{The Leaf}

While the leaf in a few of the Leptosporangiatæ is simple, in much the larger number it is compound, either dichotomously branched (Adiantum pedatum) or more commonly pinnately divided. Owing to the great irregularity of the divisions and slow formation of new segments in the stem apex, it is exceedingly difficult to determine positively whether each segment of the stem apex produces a leaf, but this seems probable: The leaf appears as a blunt conical emergence, whose apex is occupied by a single large apical cell, which in nearly all forms examined is wedge-shaped and forms two rows of segments. As the leaf grows it assumes the form of a flattened cone with a 
broad base, more convex on the outer side, and very soon showing the circinate vernation. The petiole grows much more rapidly than the lamina, which remains small until the close of the season before which it unfolds. In most species of colder climates the development of the leaves is very slow, and may occupy three or four years. The last stage of growth consists merely in an expansion of the leaf, with comparatively little cell division. This latter phase of growth often goes on with great rapidity, in strong contrast to the excessively slow growth during the early stages.

The first wall in the young segment of the apical cell divides it into an inner and an outer cell, and the latter then divides into two by a longitudinal wall, and each of the latter into two more by a transverse wall. Of these five cells, the inner ones, in the lamina of the leaf, produce the rachis, the outer ones the lamina itself. The outer cells of the segments form the pinnæ. Soon after the separation into lamina and petiole, the development of pinnæ begins in those Ferns which, like O.struthiopteris, have pinnate leaves (Fig. I8I, D). Their formation is strictly monopodial, and begins by an increase in growth in the outer cells of the young segment, which thus forms a lobe. The marginal cells divide rapidly by longitudinal walls, so that at first the young pinna does not grow from a single apical cell, but sometimes two of the division walls intersect and an apical cell is formed. Whether this always happens could not be absolutely determined. As each pinna corresponds to a segment of the apical cell of the leaf, it follows that they alternate with each other on opposite sides of the rachis. Where they grow from an apical cell, the divisions follow those in the apex of the leaf. From the inner cells of the segments the rachis of the pinna is developed. The midrib of each lobe of the pinna bears the same relation to it that the rachis does to the pinna itself. The secondary veins arise in acropetal succession, and at first form a strand of procambium reaching from the midrib to the margin. Where dichotomy of the veins occurs, as it so frequently does in their ends, this is connected with a dichotomy of the marginal group of meristematic cells (Sadebeck (6), p. 270). Each marginal cell, like the segment of the apical cell of the leaf, divides into an inner and an outer cell. The latter then divides longitudinally, and the dichotomy is thus inaugurated. These secondary marginal 
cells now repeat the same divisions, and the two diverging rows of inner cells form the beginning of the young veins.

Except the smallest veins, which are collateral, the bundles are typically concentric, and differ only in minor particulars from those of the stem. The ground tissue of the petiole shows much the same structure as that of the rhizome in most Ferns, and usually develops several layers of hypodermal sclerenchyma. In the lamina, the cells of the ground tissue, or mesophyll, as the leaf expands, separate and form large intercellular spaces be-

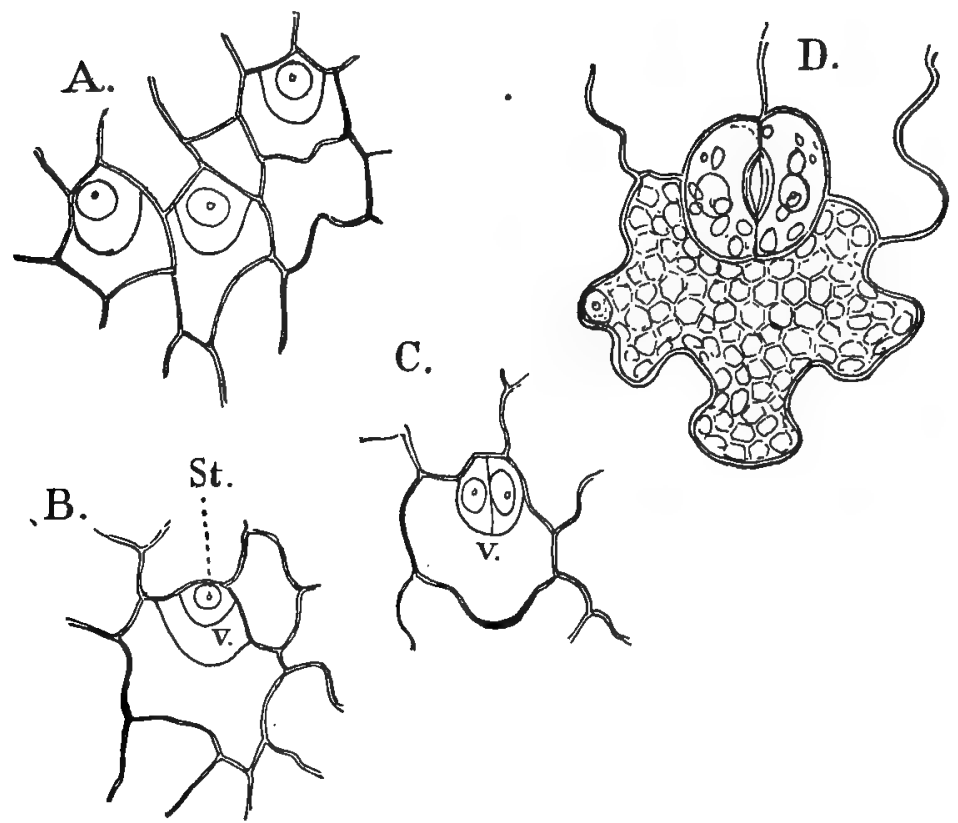

Frg. 185.-Adiantum emarginatum. Development of the stomata, $\times 525 ; v$, accessory cell; st, stoma mother cell.

tween them. The cells are in many places connected by prolongations or protrusions of the wall. On the upper side, in cases where no stomata are developed, an imperfect palisade parenchyma may form, but in none of the forms examined by me was it nearly so distinct as in Angiopteris. The fully-developed epidermal cells are very siruous in outline, and always contain numerous chloroplasts.

In Onoclea struthiopteris stomata are developed only upon the lower side of the lamina, but sometimes these also are found 
upon the upper surface. Usually, but not always, the development of the young stoma is preceded by the formation of a preliminary cell (Fig. I85, '), horse-shoe shaped, and cutting off a small cell from one corner of an epidermal cell. A similar wall forms within this small cell, parallel to the first one (Fig. I $85, \mathrm{~B}, s t$ ), and the cell thus separated is the stoma mother cell. A longitudinal wall next divides this, and then splits in the middle to form the pore of the stoma (Fig. I85, C). This when complete is exactly in structure like those of other vascular plants, and like them communicates with the airspaces of the mesophyll. The accessory cell enlarges very much with the expansion of the leaf, and its walls have the same sinuous outline that the other epidermal cells exhibit. A curious variation of the ordinary form is seen in Aneimia (De Bary (3), p. 42), where the mother cell of the stoma is cut out by a perfectly circular wall, very much like the funnel-shaped one in the antheridium, and the stoma is apparently free in the centre of an epidermal cell. It seems that this also occurs in Polypodium lingua (De Bary, 1. c.).

Most of the Leptosporangiatæ are characterised by numerous epidermal outgrowths, either hairs or scales. These are especially abundant upon the younger parts, and are largely protective. The hairs are either simple or glandular ones. In the latter case the gland is usually a terminal, pear-shaped cell, which secretes mucilaginous matter, or less frequently (Onoclea struthiopteris) this secretion may be resinous. In the common Californian "gold-back" Fern, Gymnogramme triangularis, the yellow powder upon the back of the leaf is a waxy secretion, derived from epidermal hairs. Of similar nature are the large chaffy scales (palex) which occur in such numbers upon the bases of the petioles of so many Ferns. This development of hairs, however, is most marked in the large tree-Ferns, Dicksonia, Cibotium, etc., where the young leaves are completely buried in a thick mass of brown wool-like hairs, which are sometimes utilised as a substitute for wool in stuffing mattresses, etc.

\section{The Root}

The roots arise in large numbers in most Ferns, and apparently bear no definite relation to the leaves. The primary ones are first visible very near the apex of the stem (Fig. I8I, A, r), 
and Van Tieghem (5), who has made a very exhaustive study of the subject, states that they always arise from an endodermal cell. This divides into a basal cell and a terminal one, and by the former the young root is directly connected with the xylem of the stem bundle. In the outer cell the three walls defining the pyramidal apical cell now arise, and the latter at once begins its characteristic divisions.

The segmentation in the apex of the roots of the Leptosporangiata is exceedingly regular.

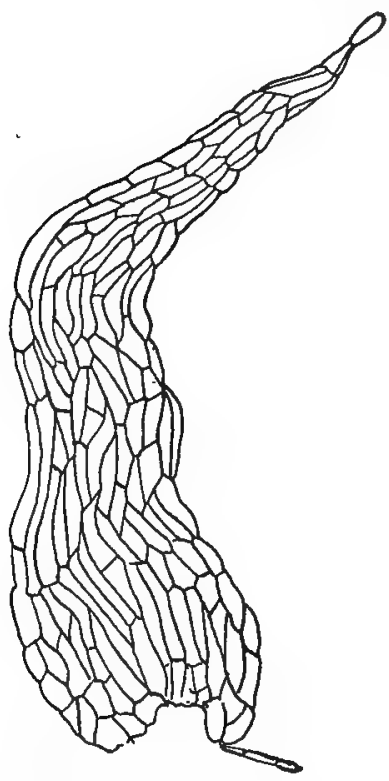

FIG. 186. -Scale from the stipe of Cystopteris fragilis, $\times 25$.

Corresponding to each set of lateral segments an outer segment forms as well. Van Tieghem does not apparently recognise the root-cap as distinct from the epidermis, but all other observers consider the rootcap as a distinct structure. The first division wall in the lateral segments is the sextant wall, which is perpendicular to the broad faces of the segment and curves somewhat so as to strike one of the lateral walls a little above the base, and thus makes the two sextant cells of unequal size (Fig. I88, C). The next wall is transverse and separates an inner from an outer cell, and with this divides the plerome or stele from the cortex. After this in the outer of the primary cells there is a separation of an outer from an inner cell, the former giving rise either directly or by a subsequent division to a single layer of cells upon the outside of the root, which is usually regarded as the epidermis, and the inner cells from the cortex. The inner layer of the cortex, which can be traced back almost to the summit, is the endodermis.

According to Strasburger (IO) in Pteris Cretica the cap cells divide only by perpendicular walls, and the older layers of the cap remain but one cell in thickness. Van Tieghem states ( (5), p. 532) and I have verified this in Adiantum emarginatum and Polypodium falcatum, that with the exception of the 
first-formed cap cell (or "epidermal segment," to use his terminology), there is, in the central part, always a doubling of the cells by periclinal walls, so that each layer of the older root-cap is normally double, except sometimes at the extreme edge.

There is very little displacement of the cells for a long time, and cross-sections of the root, made some distance below the summit, still show the limits of the original sextant walls, which form six radiating lines with periclinal walls arranged with great regularity. In the centre the divisions proceed with great rapidity, and the plerome soon shows the elongated narrow procambium cells. In the centre are four much larger cells, which develop later into tracheids, and three of these can be traced back to the central cells of the three larger sextants (Fig. I88, D); the fourth arises from the inner cell of one of the smaller ones. This central group of cells marks the position of the plate of tracheary tissue, found later in the root. By this time the parts of the complete root are all indicated. The bundle is bounded externally by the endodermis, whose cells are much elongated transversely, and clearly distinguishable from the peri-



FIG. 187.-Pteris cretica. Origin of lateral rootlet from the endodermis of the root; en, endodermis of the main root; $x$, apical cell of the rootlet; p, "digestive pouch." (After Van Tieghem.)

cambium (pericycle), which consists of one or two rows of cells. Inside this is the mass of procambium cells, the large tracheids of the central part of the xylem being very evident (Fig. I88, E). The masses of procambial cells on either side of this central line of cells constitute the young phloem.

The primary tracheids (protoxylem) arise simultaneously at the foci of the section, and consist of a single line of narrow pointed tracheids, with fine spiral markings, very closely set at first, but later pulled apart somewhat with the increase in length of the root. These are formed a long time before any other permanent tissue elements can be distinguished. Around these 
primary tracheids are formed a group of similar ones, and from here the formation proceeds towards the central group of large tracheids, which are the last to have their walls thickened and lignified. The large secondary tracheids are scalariform, like those of the stem. The cells of the pericycle remain nearly unchanged, but in the two phloem masses, according to Poirault (I) sieve-tubes are always present. These tubes are of two types, those with horizontal transverse walls, and those with inclined ones. The perforations in the sieve-plates were

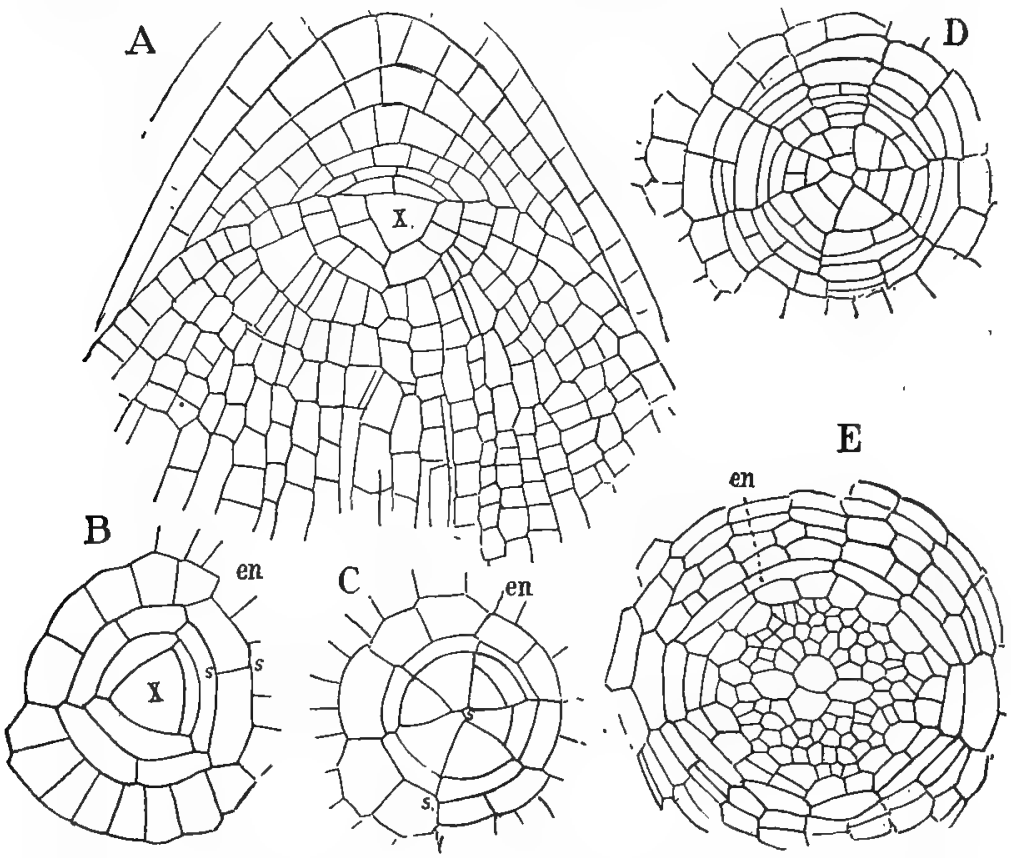

Frg. 188.-Adiantum emarginatum. A, Longitudinal; B-E, a series of transverse sections of the root, $\times 200 ; x$, apical cell; $s-s$, sextant walls; $e n$, endodermis.

demonstrated, and lateral perforations, either isolated or in groups, also occur. His statement that the sieve-tubes have no nuclei requires further proof. The walls of the sieve-tubes are of cellulose, but in the sieve-plates callus is found. The rest of the phloem is composed of conducting cells, with thin walls and oblique septa. The endodermis often becomes dark-coloured and its walls lignified, and when the root dries the vascular cylinder becomes separated from the ground tissue by the transverse splitting of the endodermal cells. 
The secondary roots arise in regular succession in two lines, corresponding to the ends of the xylem plate in the diarch bundle. They themselves generally branch further, and thus very extensive root systems are formed. The origin of the lateral roots of the Ferns has been exhaustively studied by Lachmann (7), but their position seems to be of very little importance systematically, and except in a few cases like Osmunda, where two roots regularly arise from each leaf, there is little relation between roots and leaves. In creeping rhizomes they arise either mainly from the ventral side or from all parts indifferently. As yet the only forms in which complete absence of roots is known among the Leptosporangiatæ are Salvinia, species of Trichomanes, and Stromatoptcris (Poirault (2), p. 147), one of the Gleicheniaceæ. In all of these, however, there are substitutes either in the form of modified leaves (Salinia) or root-like rhizomes.

The formation of buds from the roots, such as occur in Ophioglossum, has been also observed in some Leptosporangiatæ. This was first discovered by Sachs in Platycerimm Wallichii, and later described by Rostowzew (I); and Lachmann (7) also describes it in Anisogonium Sermamporense. In all these cases the apex of the root appears to become transformed directly into the apex of the bud (Fig. I7 I, B).

\section{The Sporangium}

The development of the sporangium of all the Leptosporangiatæ is much the same, but the position of the sporangia, and the character of the indusium when present, vary much, and will be discussed later as the different families are treated separately.

In the Polypodiaceæ the sporangia, as is well known, arise usually in groups (sori) upon the backs of leaves that differ but little from the ordinary ones. Sometimes, however, e. g., Onoclea, they are very different, the sporangia being produced in great numbers, and the lamina of the leaf is much contracted. One of the simplest cases is seen in Polypodium. Here the sporangia develop late upon ordinary leaves, and form scattered round sori, bearing, however, a definite relation to the veins-in this case forming above the free end of one of the 
small veins. Where there are special sporophylls, the development of the sporangia begins before the leaves begin to unfold.

In Polypodium (Fig. I90) the first evidence of the formation of sporangia is a series of minute depressions upon the lower side of the leaf, much as occurs in Angiopteris. The bottom of this depression is occupied by a low elevation, the placenta, and upon this the sporangia form in an analogous
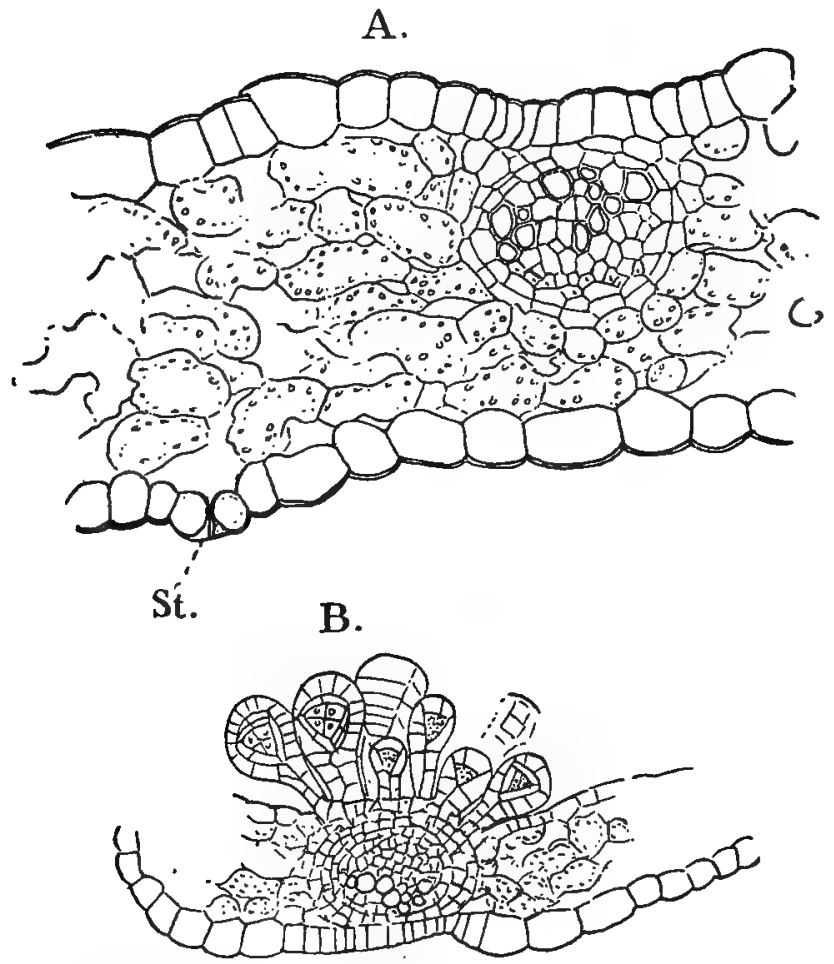

FIG. I89.-Polypodium falcatum. A, Cross-section of a sterile leaf, cutting across one of the smaller veins, $\times 260$; st, section of a stoma; $B$, similar section of a sporophyll, showing the position of the sorus above the vein, $\times 85$.

way, but are not all developed at the same time, so that a single sorus may contain nearly all stages of development. The sporangium here can be readily traced back to a single epidermal cell.

The sporangial cell protrudes until it is nearly hemispherical, when it is cut off by a wall level with the surface of the 
placenta. The basal cell takes no further part in the development of the sporangium, and after a time becomes indistinguishable. The outer cell now divides by a wall, occasionally transverse, but much more commonly strongly inclined (Fig. I90, A), and striking the basal wall. This is now followed by two others, also inclined, and meeting so as to enclose a pyramidal apical cell, from which a varying number of lateral segments are cut off. These form three rows, corresponding to the three rows of cells found in the stalk, which is not sharply separated from the capsule, as stated by Goebel (( IO), p. 218), and formed from the lower of two primary cells, but is merged
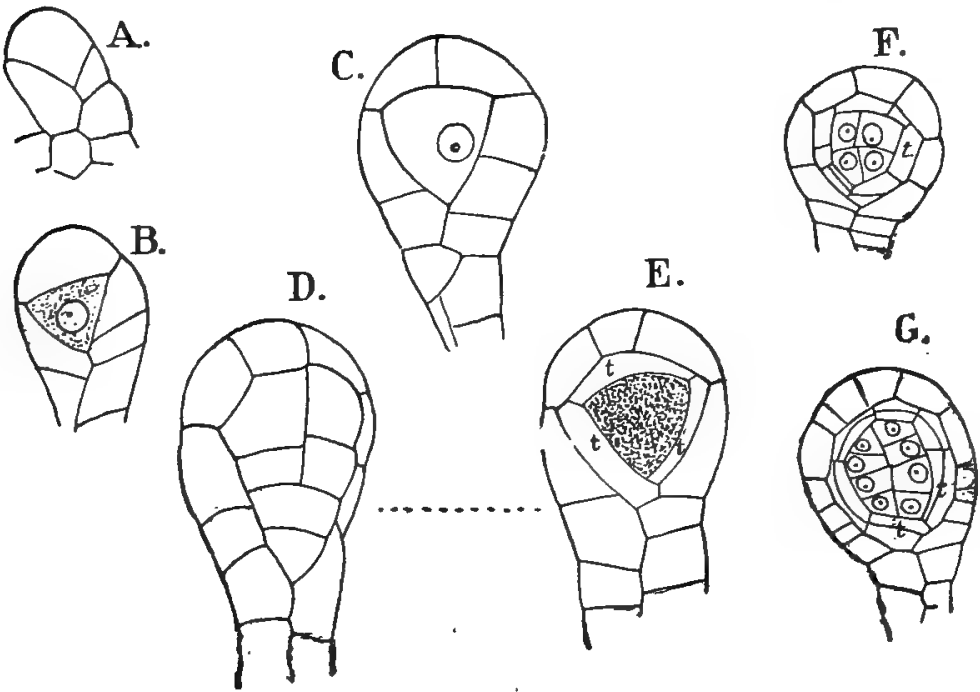

Frg. rgo.-Polypodium falcatum. Development of the sporangium. A-E, from living specimens; F, G, microtome sections; A, B, C, optical sections; D, E, the same sporangium, showing respectively the surface cells and central optical section; $t$, $t$, tapetum. A-E, $\times 400 ; \mathrm{F}, \mathrm{G}, \times 200$.

gradually into the capsule, and owes its three-rowed form to a primary and not a secondary division. The upper part of the young sporangium enlarges, so that it becomes pear-shaped (Fig. I9o, B), and a periclinal wall is then formed in the apical cell. . The cells of the stalk undergo no longitudinal divisions, and it remains permanently composed of three rows.

Kündig ( $\mathrm{I}$ ) first called attention to the real state of affairs, and since, C. Müller (2) has investigated the matter further. 
The central tetrahedral cell of the young sporangium (archesporium) has cut off from it, by periclinal walls, the primary tapetal cells $(t)$, and in the meantime the wall of the capsule forms repeated radial divisions but no periclinal ones, and, unlike that of the eusporangiate Ferns, always remains singlelayered. A surface view of the sporangium at this stage shows the last-formed lateral segment to still retain its triangular form, and the cell divisions in it are very regular. After two or three transverse divisions, a median vertical wall follows, and in each of the resulting cells a transverse wall. Of the two upper cells, one, according to Müller, remains undivided, the other divides again by a vertical wall, and the inner of the two cells thus formed by further transverse divisions forms the stomium or mouth of the sporangium.

The cells of the young sporangium contain but little granular contents, and the divisions are very evident. As soon as the archesporium is formed its contents begin to assume a more granular appearance, and become more highly refractive than those of the surrounding cells. The contrast between the archesporial cells and those of the wall increases as the sporangium grows older.

The first division in the central cell begins soon after the separation of the primary tapetal cells. The direction of this first wall is usually transverse, but may be more or less inclined, or even vertical. In each of these cells a wall is formed at right angles to the first-formed, and the quadrant cells are again divided into equal octants. Each of these eight cells divides once more (Fig. I9O, G), and the sixteen spore mother cells, found in most Ferns, are complete. In Onoclea struthiopteris I found twelve as the ordinary number, but at what point the division is suppressed was not made out. During the division of the central cells the tapetal cells also divide, first by radial walls only, but later by one set of periclinal walls. This doubling of the tapetum, while it occurs in the majority of Polypodiaceæ, does not seem to be universal (Goebel (Io), p. 2 I8). The cells of both sporogenous cells and tapetum have dense granular cytoplasm, and large nuclei. Soon after the divisions in the sporogenous complex are completed, the walls of the tapetal cells become broken down, and their contents dispersed through the large central cavity. The sporangium continues to enlarge rapidly after this, and the spore mother 
cells, still united, float in a large cavity, which in the living sporangium seems to be filled with a structureless mucilaginous fluid, but when fixed and stained is seen to contain the unchanged nuclei of the tapetum, as well as its cytoplasmic contents. Gradually the connection between the sporogenous cells is lost, and the isolated cells, each surrounded by a very delicate membrane, float in the large central cavity. Here they divide into four cells, as usual, and the division may be simultaneous, resulting in tetrahedral spores, or successive (Onoclea), in which case bilateral spores are formed. Strasburger ((I2), p. 239) states that during the division of the spores in Osmunda there is a reduction of the chromosomes to one-half their original number, but in a later paper ( I4) he reports that although there is a reduction in the number of chromosomes, the ratio of twelve to twenty-four, which was first given, is not absolutely constant. Stained microtome sections of sporangia during the formation of the spores show that the spore mother cells, and afterwards the spores themselves, are embedded in a granular matter, evidently the product of the disorganised tapetum, and that the nuclei of the latter are collected about them, evidently intimately associated with the growth of the young spores, and in the later stages, with the formation of the perinium. The latter is rarely smooth, but shows spines, ridges, and folds of characteristic form in different species.

When chlorophyll is present in the ripe spore it only arises at a late period. In Onoclea struthiopteris, about the time that the perinium begins to form, numerous small colourless granules appear near the nucleus, and with the ripening of the spore these increase rapidly in size and number, and an examination shows that the increase in number is the result of division. These are young plastids, and as they enlarge, chlorophyll is formed in them and they become very much crowded, so that the green colour of the ripe spore is very pronounced.

The further history of the sporangium wall is somewhat complicated. The stomium, as we have seen, arises from a special cell of the last-formed lateral segment. The segment on the opposite side (next older but one) shows a quite similar arrangement of cells, and, according to Müller, the cell corresponding to the stomium by two transverse walls forms the first segment of the annulus. The cells immediately below also divide similarly, and give rise to a second section. The rest of 
the annulus arises from the upper or cap segment of the sporangium wall, and extends from the stomium over the top of the sporangium, and joins the part of the annulus upon the other side. The walls of all the cells are at first alike, but those of the annulus begin to thicken, this being confined to their inner and radial walls, the outer walls remaining thin. In most species the cells of the annulus are the same for the whole extent, but in Polypodium falcatum (Fig. I9r), which is figured here, the cells of the annulus immediately above the stomium

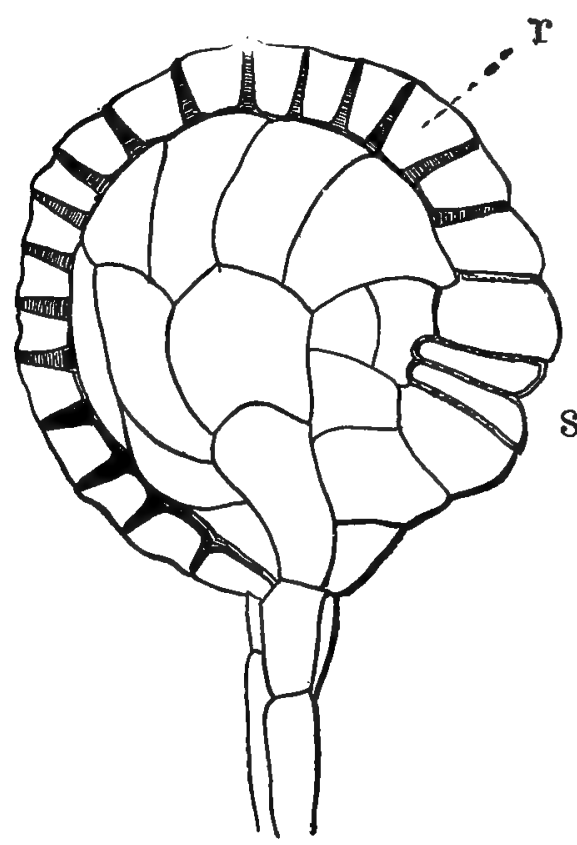

Fic. 191.-Surface view of a nearly ripe sporangium of Polypodium falcatum, $\times 175 ;$ st, stomium; $r$, annulus. are larger and thinnerwalled. The stomium cells are more extended laterally than the other cells of the annulus, and between them the sporangium opens by a wide horizontal cleft

Atkinson ( (3), p. 68) describes the process thus for the Polypodiacea. "While the opening of the stomium between the lip cells is aided by their peculiar form, it seems possible that at maturity the line of union is less firm than between the other cells. The fissure once started proceeds across the lateral walls of the sporan$\mathrm{g}$ i u m, usually in a straight line, thus splitting in half the cells of the middle row, their frailty favouring this. The drying of the annulus brings about the unequal tension of its cell walls. During this process it slowly straightens, carrying between the distal portion of the lateral walls of the sporangium, which remain attached to the free extremity, the greater part of the spores. When straight, it continues to evert, and this usually proceeds until the two ends of the annulus nearly or quite meet, when with a sudden snap it 
throws the spores violently away and returns to nearly its normal position."

Paraphyses, in the form of pointed hairs, often with a glandular terminal cell, sometimes occur with the sporangia. These in some Ferns, e.g., Aspidium filix-mas, are direct outgrowths of the sporangium itself. 


\section{CHAPTER X}

\section{THE HOMOSPOROUS LEPTOSPORANGIAT $Æ$ (FILICES)}

\section{Fam. I. Osmundaceze (Diels $(I)$ )}

The Osmundacex, which in many respects form a transition from the eusporangiate to the leptosporangiate Filicinex, are represented by two genera, Todea (inc. Leptopteris), with four species, mostly confined to Australasia, one species only being found in South Africa; Osmunda, with six or seven species, belonging mainly to the temperate and warm temperate regions of the northern hemisphere. The widely distributed species $O$. regalis is found also in South Africa, but otherwise they belong exclusively to the northern hemisphere. Osmunda has the large sporangia borne on very much modified sporophylls, which recall strongly those of Botrychium or Helminthostachys; Todea, while its sporangia are like those of Osmunda, has them borne upon the backs of ordinary leaves.

\section{The Gametophyte}

The development of the gametophyte is completely known in Osmunda (Kny (5) ; Campbell (I2)) and somewhat less perfectly in Todea (Luerssen (3)), which does not, however, seem to differ essentially from Osmunda. In the latter there is considerable difference in the species examined. In all of them the spores contain chlorophyll at maturity, and quickly lose their power of germination. Sown as soon as ripe, they germinate very promptly, and the first division of the spore often takes place within twenty-four hours. The early stages show great variation, even in the same species, and these seem to be often quite independent of external conditions. The un- 
germinated spore has an exceedingly delicate endospore, which is difficult to demonstrate, but after the exospore bursts along the three ventral ridges, and the endospore is exposed, it becomes very evident.

The first division takes place after the spore has elongated slightly, and is usually transverse, separating the small rhizoid
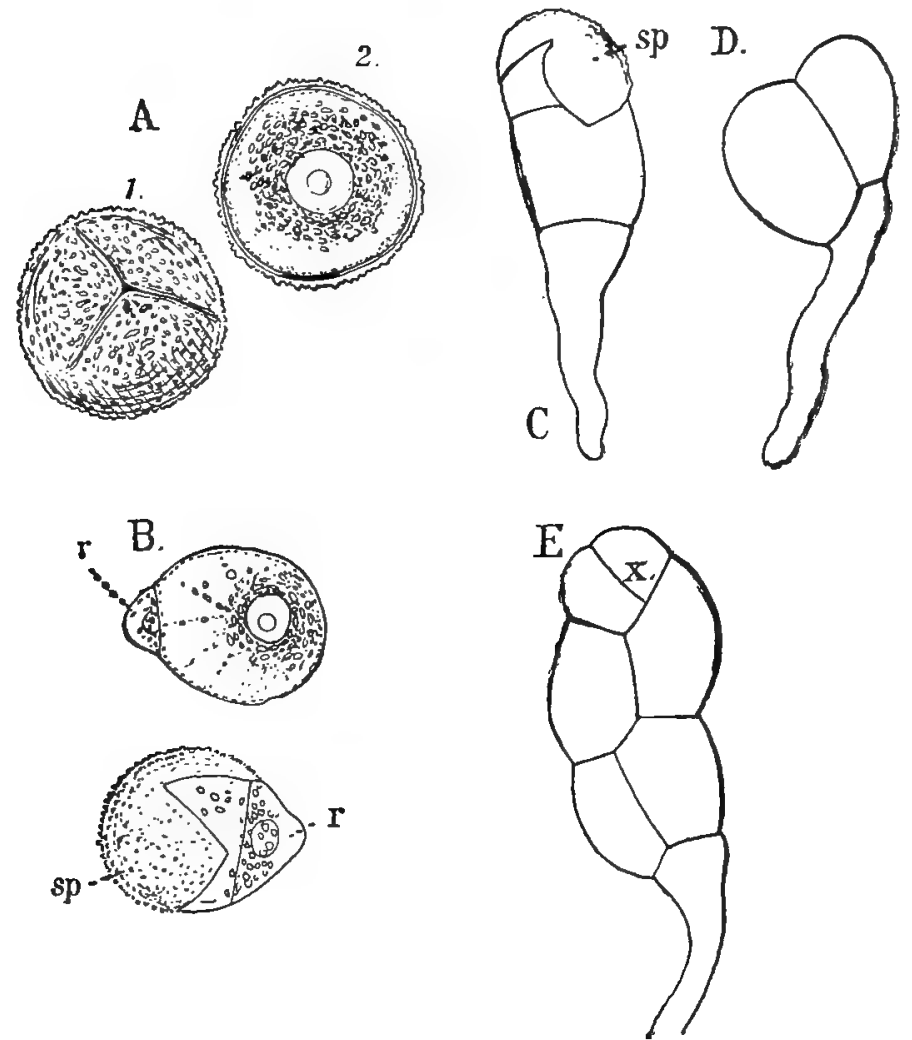

Fig. 191.-Osmunda Claytoniana. A, Ungerminated spore; 1, ventral surface; $\boldsymbol{z}$, optical section, $\times 550 ; \mathrm{B}$, germinating spores, $\times 275 ; r$, primary rhizoid; C-E, older stages, $\times 275 ; s p$, spore membrane; $x$, apical cell.

from the large prothallial cell (Fig. I9I, B). The young rhizoid contains chlorophyll, but not so much as the larger cell. As germination proceeds the chloroplasts separate and increase in size. They are often arranged in lines extending from the large nucleus to the periphery of the cell. As a general thing, 
the growth of the prothallium is exactly opposite to that of the first rhizoid (bi-polar germination), and $\operatorname{Kny}((5), \mathrm{p} . \mathrm{I2})$ lays a good deal of stress upon this, as distinguishing Osmunda from the Polypodiaceæ; but it is not at all uncommon for $O$. Claytoniana, especially, to have the axis of growth of the rhizoid almost or quite at right angles to that of the prothallium, exactly as in the Polypodiaceæ. Where the germination is truly bi-polar the exospore is pushed up with the growing prothallium, and appears like a cap at its apex, but if the rhizoid is lateral, the exospore remains at the base.

- In O. Claytoniana there are usually several transverse walls


FIG. 192.-Osmunda cinnamomea. A, Young prothallia; $B$, an older prothallium, $\mathbf{X}_{2} 60$.

formed before any longitudinal ones, but in $O$. cinnamomea and $O$. regalis it is quite common to have the first transverse wall followed by a longitudinal wall in each cell, so that the four primary cells are arranged quadrant-wise (Fig. ig2, A, $c$ ). Rarely the first wall in the prothallial cell is longitudinal, as is often the case in Equisetum, and sometimes the first divisions are in three planes, so that a cell mass is formed at once, as so often occurs in the Marattiaceæ. Where a filamentous protonema is formed, a two-sided apical cell is soon established in exactly the same way as in Onoclea. Where the four quadrant cells are formed, one of the terminal ones becomes at once the apical cell. 
As soon as the apical cell is established, growth proceeds as in Onoclea, and a heart-shaped prothallium is formed. One difference, however, may be noted. Each segment cut off from the apical cell divides first by a transverse wall into an inner and an outer cell, but the inner cell from the first undergoes divisions by horizontal walls, so that a central midrib is formed, very much as in Metzgeria, and the prothallium becomes more elongated than is common in the Polypodiacer. The single two-sided apical cell persists for a long time, but is finally replaced either by a single cell, much like that of Pellia epiphylla, or more commonly by a series of marginal cells, as in the Marattiacex or Polypodiacex. The subsequent growth of the prothallium is the same as in those forms, but no definite relation could be made out between the archegonia and the segments of the initial cells. Among the Hepaticæ Dendroceros offers almiost an exact analogy in the form of the apical cells and the divisions of the segments.

According to Luerssen (3), in Todea a distinct apical cell is often wanting, and the growth throughout is due to the activity of several similar initials. His figures, however, hardly bear out his statement, and further information is desirable on this point.

As the prothallia grow older the midrib becomes conspicuous, and projects strongly from the ventral surface. In $O$. cinnamomea and $O$. regalis even at maturity it is very little broader where the archegonia are formed; but in 0 . Claytoniana it forms a cushion in front, much like that of Marattia or the Polypodiacer, and in this respect, as well as in the form of the apical cells, seems to approach the latter. In this species the prothallium is lighter coloured, and the rhizoids not so dark, while in its dark green colour and fleshy texture $O$. cinnamomea recalls Anthoceros lavis or Marattia.

Where a cell mass is formed at first, this condition is temporary, and an apical cell is established which gives rise to the ordinary flat prothallium. The small male prothallia, which are produced in large numbers, exhibit various irregularities and quite commonly do not show any definite apical growth, and in $O$. Claytoniana especially often branch irregularly, or in some cases there is a true dichotomy (Fig. I93, A.) Slender filamentous prothallia are especially common in this species (Fig. I94, C), and recall somewhat those of some species of Trichomanes. 
The prothallia of the Osmundaceæ often form adventitious buds, much like those of the Marattiaceæ. These secondary prothallia (Fig. I94, B) generally arise from the margin, but may be produced from the ventral surface. An apical cell is usually early established, and the subsequent growth is closely like that of the primary one.
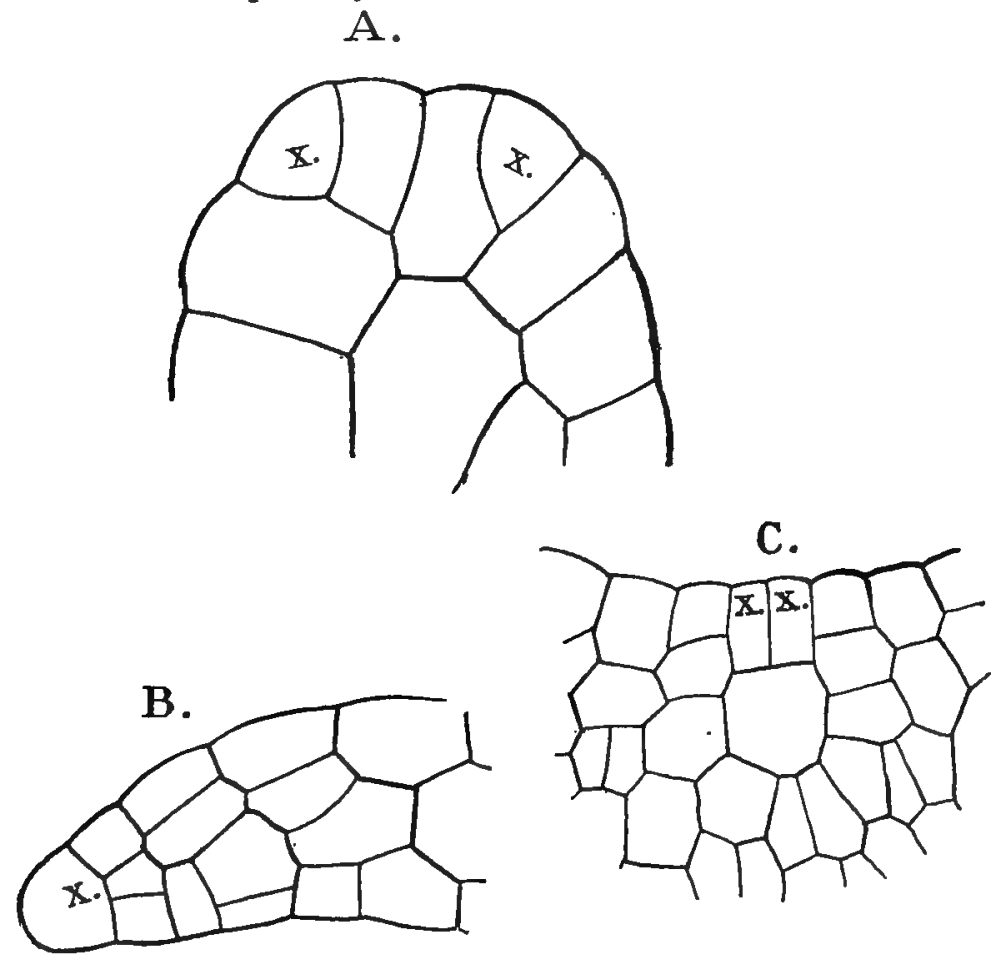

Fig. 193.-A, Apex of a young prothallium of $O$. Claytoniana, with two similar initials, $x, x, \times 560 ; B$, longitudinal section of an advanced prothallium of $O$. cirrramomea, $\times 260$; $C$, horizontal section of a similar one, showing two initials, $\times 260$.

The prothallia are long lived if they remain unfertilised, and Goebel (( I6), p. I99) states that in O. regalis they may reach a length of four centimetres. He also records a genuine dichotomy of the older prothallia of this species.

\section{The Antheridium}

Under favourable circumstances the first antheridia appear after about a month in $O$. Claytoniana, and continue to form 
for a year or more. In $O$. cinnamomea they first appeared about two weeks later. While they are almost always present upon the large female prothallia, ${ }^{1}$ numerous exclusively male plants are always met with. These latter are usually irregular in form, and even filamentous, especially when crowded. Upon the latter the antheridia are either terminal or marginal; in the flattened prothallia they occur mainly upon the margin and

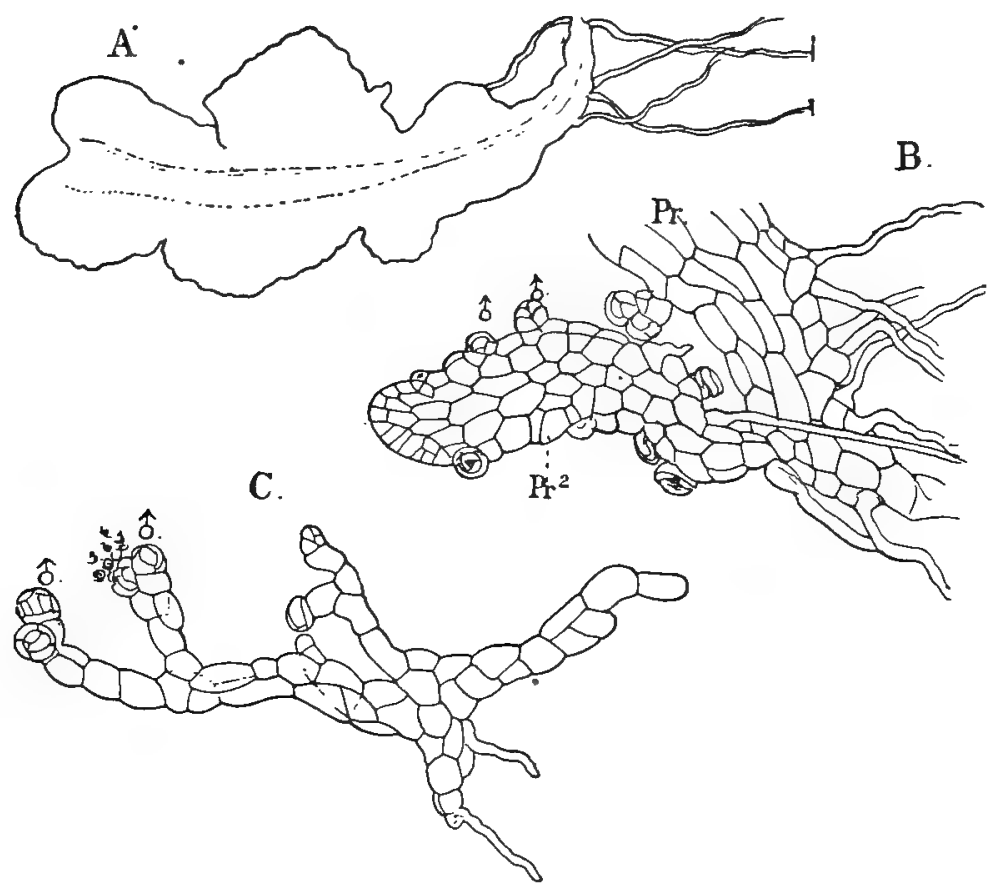

FIG. 194.-A, Protballium of $O$. Claytoniana, about two montbs old, $X$ about 30 ; B, base of an older prothallium of the same species with a secondary prothallium $\left(p r^{2}\right)$ growing from it, $\times 80 ; \delta$, antheridia; $C$, small branching male prothallium of the same species, $\times 75$.

lower surface of the wings. The development corresponds closely in all forms that have been examined, and differs considerably from that of the Polypodiaceæ.

The mother cell is cut off as usual, but the second wall is not funnel-shaped, but plane and inclined, so that it strikes the basal cell. In the larger of the two cells thus formed a vary-

1 Luerssen (l.c. p. 449) states that they are often absent from very vigorous prothallia. 
ing number of divisions occur, cutting off a series of lateral segments, much after the fashion of a three-sided apical cell. The segments thus cut off form the basal part of the antheridium, and when the number is large a pedicel may be formed. When the full number of basal segments is complete, a domeshaped wall arises in the apical cell, as in the Polypodiaceæ, and the central cell has much the same form (Fig. I95, A). This has no chlorophyll, and as usual the large distinct nucleus is embedded in dense highly refractive cytoplasm. There are
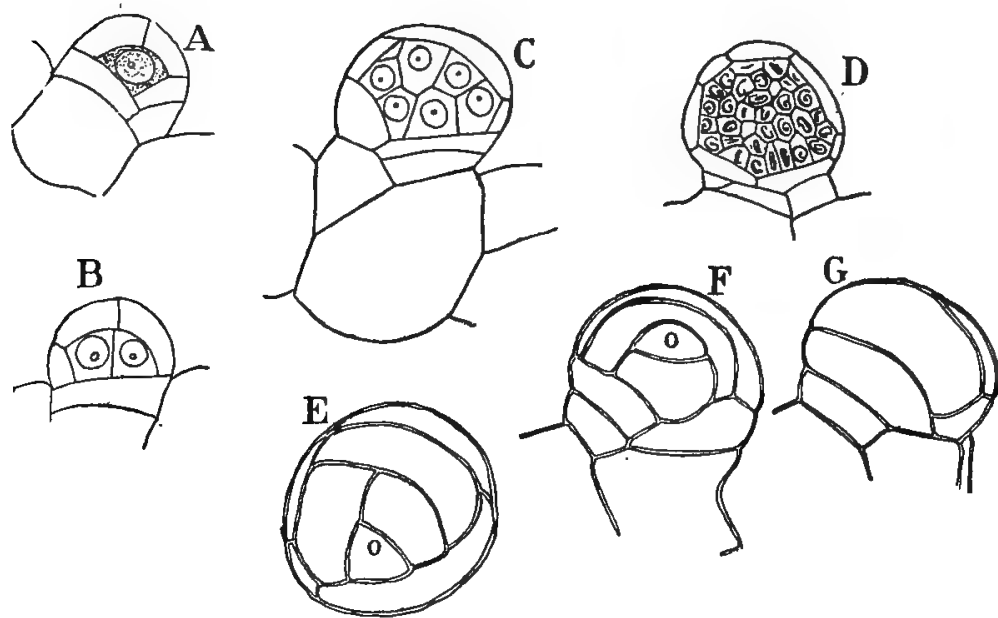

Fig. 195-A-D, Development of the antheridium of $O$. cinnamomea, in longitudinal section, $\times 425 ; \mathrm{E}, \mathrm{F}, \mathrm{G}$, three surface views of ripe antheridia of $O$. Claytoniana; E, from above, the others from the s1ae; 0 , opercular cell, $\times_{425}$.

next developed in the outer dome-shaped cell two or three walls, running more or less obliquely over the apex; either at the top or at one side the last-formed wall encloses a small cell, which is thrown off when the antheridium opens (Fig. 195,o). This opercular cell, both in form and position, recalls strongly that found in the Marattiacer.

The divisions in the central cell correspond closely to those in Onoclea, but the number of sperm cells is larger, being usually Ioo or more. The development is also the same, and will not be entered into here. ${ }^{1} \quad$ After the final division of the sperm cells the nuclei remain slightly flattened in the plane of division,

${ }^{1}$ For details see Campbell (I2), p. 6I. 
as in the Hepaticæ, and the mature spermatozoids are coiled more flatly than in the Polypodiacex. The free spermatozoid recalls that of Marattia or Equisetum rather than that of the Polypodiacex. There are but about two complete coils, and the hinder one relatively larger than in the latter forms. In swimming there is peculiar undulating movement, suggestive of the spermatozoid of Equisctum.

\section{The Archegonium}

The archegonia are only borne upon the large heart-shaped
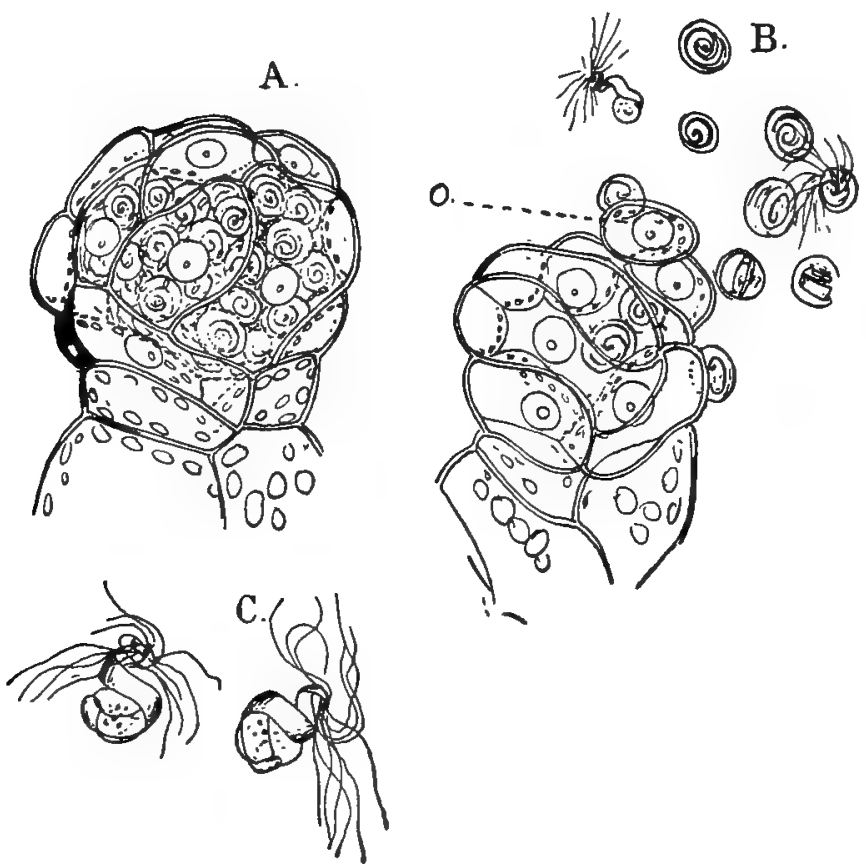

Fig. 196.-A, Ripe antheridium of $O$. Claytoniana, just ready to open; $B$, the same discharging the sperm cells, $\times 600 ; C$, two spermatozoids, $\times 1200 ; 0$, operculum.

prothallia, and occupy the sides of the projecting midrib, where, if the earlier ones are not fertilised, they may continue to form indefinitely; but no correspondence can be made out between them and the initial cells, and while developed for the most part in acropetal order, new ones may arise among the older ones. 
The mother cell of the archegonium is scarcely distinguishable from the neighbouring cells, either in size or contents, and cannot always be identified until after the first transverse divisions. The development is much as in the other Ferns, but there are

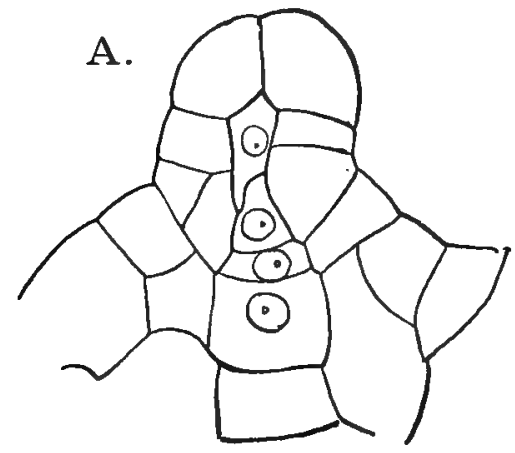

B.

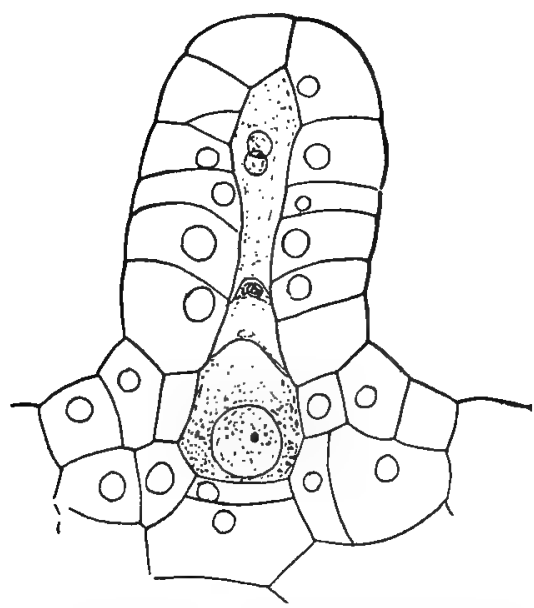

FrG. 197,-A, Young archegonium of $O$. cinnamomea, with the neck canal cell divided by a cell wall; $B$, \& nearly ripe archegonium of the same species, $\times 525$. some differences that may be noted. The first transverse division, as in these, separates the cover cell from the inner cell, and the latter may divide into a basal and central cell, but sometimes this division is omitted, and the basal cell is absent. The cover cell divides by the usual cross-walls into the four primary neck cells, which here all develop alike, and the neck remains straight. The complete neck has about six tiers of cells. The separation of the neck and ventral canal cells follows in the usual manner, but occasionally the former may be divided by a transverse cell wall (Fig. I97, A), although ordinarily the division is confined to the nucleus. The neck cells have small nuclei, and in the living state are almost transparent, with little chlorophyll. Small glistening bodies, apparently of albuminous nature, are often present, and are especially conspicuous in material fixed with chromic acid. Kny and Luerssen both speak of the quantity of starch in the axial row of cells in $O$. regalis, but in neither $O$. cinnamomea nor $O$. Claytoniana was this noticeable. As the egg approaches maturity the nucleus becomes large and distinct, and one or two nucleoli 
are present. The chromosomes are not conspicuous, a condition that we have seen before is not uncommon in the egg nucleus.

A curious appearance was noted several times just before the archegonium seemed about to open, and after the formation of the ventral canal cell. This was the separation from the upper part of the egg of a small body containing what looked like a nucleus. Whether this is something analogous to the "polar body" found in animal ova could not be determined.

When the archegonium opens, the four rows of cells bend strongly outward, and frequently some of the terminal cells become detached. A large receptive spot is present, and the nucleus is smaller than in the younger egg, and contains more chromatin, and usually but a single nucleolus.

\section{Fertilisation}

The horizontal position of the archegonia, as they project from the sides of the midrib, makes it easier to follow the entrance of the spermatozoid than is the case in most Ferns. The spermatozoids collect about the mouth of the freshly-opened archegonium, and soon one finds its way in. With the ciliated end down, it revolves rapidly, not seeming to be much impeded by the mucilage thrown out by the archegonium. Suddenly, with a quick movement, quite unlike the slow worm-like movement seen in most Ferns, it slips through the neck into the central cavity, where its movement is resumed. After about three or four minutes it disappears, and has presumably penetrated the egg. Other spermatozoids may make their way into the central cavity, but only one penetrates the ovum. The lower neck cells now approach, but not enough to prevent the entrance of other spermatozoids. Within a few hours the inner walls of the neck cells begin to show the brown colour that indicates that fertilisation has been accomplished.

The egg quickly secretes a cellulose membrane, which prevents the entrance of the other spermatozoids. The egg nucleus moves towards the receptive spot at the time of fertilisation, where the spermatozoid may be seen but little altered in form. It almost at once comes into contact with the female nucleus, and the two then move toward the centre of the ovum. Here the spermatozoid gradually loses its coiled form and con- 
tracts until it becomes oblong, and in close contact with the egg nucleus, in some cases looking as if it had penetrated the egg nucleus as it does in Onoclea (Shaw (2)). The process is a slow one, and in one case twenty-four hours after the entrance of the spermatozoid the two nuclei were still recognisable. Finally they are completely fused, and a single nucleus, with usually, perhaps always, two nucleoli is seen. No sign of a separation of the chromosomes of the copulating nuclei was observed.

\section{The Embryo}

The first division of the ovum is the same with respect to the archegonium as in Onoclea, i. e., the basal wall is parallel
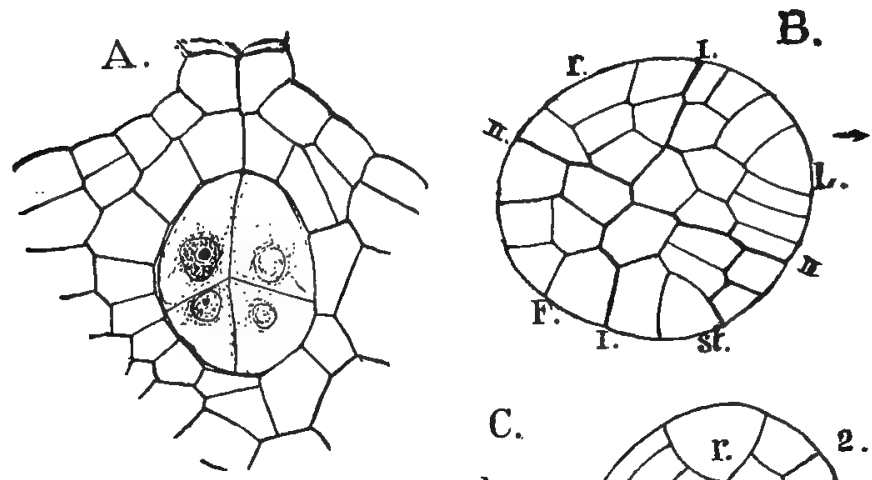

C.

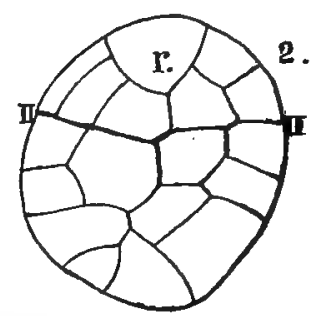

Frc. 198.-A, Vertical section of an eight-celled embryo of $O$. Claytoniana, $\times 260$. Median longitudinal section of an older embryo of the same species, $\times 260 ; C$, two transverse sections of a somewhat younger embryo of $O$. cinnamomea, $\times 260$; st, stem apex; L, cotyledon; $r$, primary root; F, foot.

with its axis; but the quadrant wall is also parallel with this instead of transverse, although its position with reference to the axis of the prothallium is the same; so that the embryo-quadrants, and the organs derived from them, are situated like those of the polypodiaceous embryo, with reference to the prothallium, but not to the archegonium. 
As in Onoclea the primary organs are established by the first two walls, and the next divisions form octants, but there is somewhat less regularity in the later divisions, in which respect Osmunda is intermediate between the Polypodiaceæ and the Eusporangiatæ. As in the former, the two epibasal quadrants develop stem and cotyledon, the hypobasal ones, root and foot. At this stage the cells of the young embryo contain but little granular cytoplasm, and there are large vacuoles. As the embryo grows older the granular cell contents increase in quantity. The subsequent divisions follow very closely those in the embryo of Onoclea, but are less regular, and the embryo retains for a longer time its original nearly globular form.

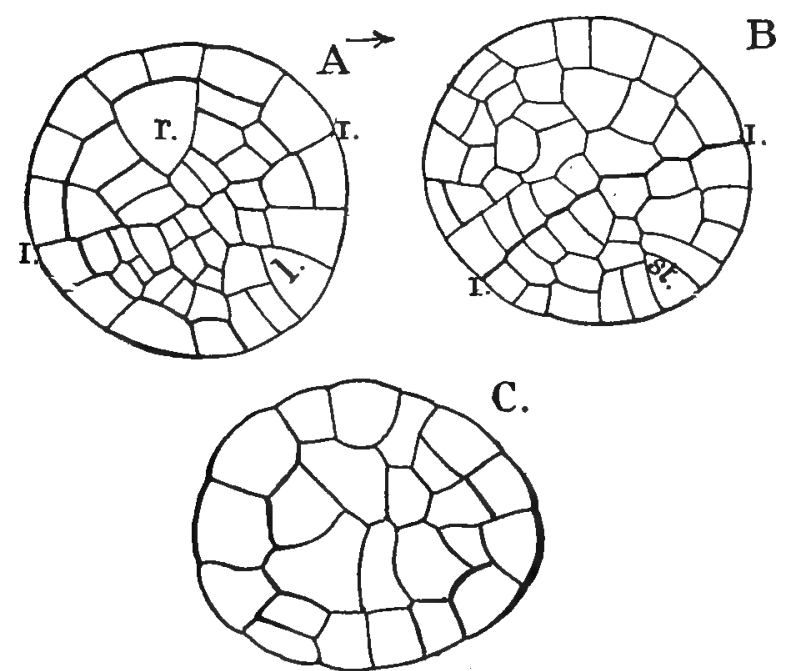

FIG. 199.-Three sections of one embryo of $O$. cinnamomea in which the root $(r)$ is especially well marked, $\times 260$. Lettering as in the last.

The direction of growth of the cotyledon is determined in part by the first walls in its primary octants. The outer octant usually becomes at once its apical cell, and if its first segment is formed on the side next the octant wall, this throws the axis of growth very much to one side, so that the axis of the leaf may be almost at right angles to the median line of the embryo. Otherwise it nearly coincides with this. The original threesided apical cell persists for a long time, and it could not be positively shown whether or not it was afterwards replaced by 
a two-sided one. The further development of the cotyledon corresponds almost exactly with Onoclea. It does not break

B.

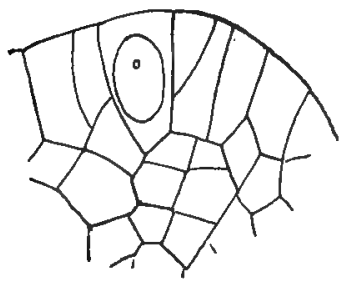

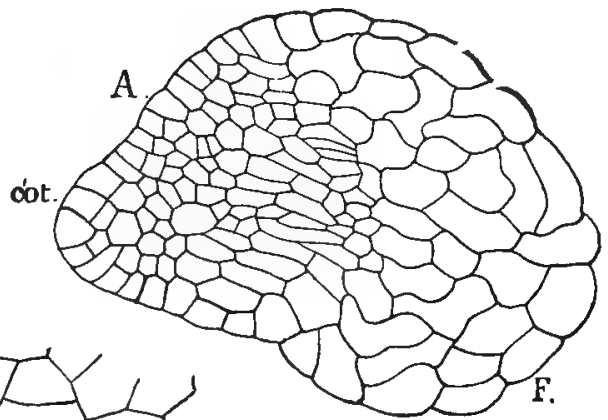

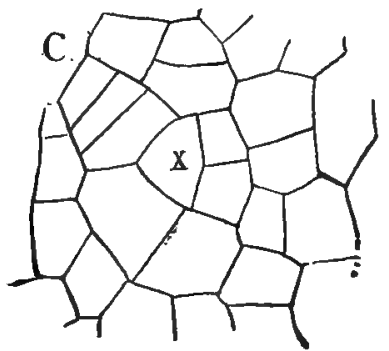

F1c. 200.-A, Horizontal section of an advanced embryo of $O$. Claytoniana, passing through the cotyledon and foot, $X_{23} ; \mathrm{B}$, longitudinal section of the stem apex in a somewhat older embryo of $O$. cinnamomea, $\times 460 ; C$, transverse section of the apex of the primary root of the same, $\times 460$.

through the calyptra until later, and in this respect shows its primitive character. The single vascular bundle of the petiole

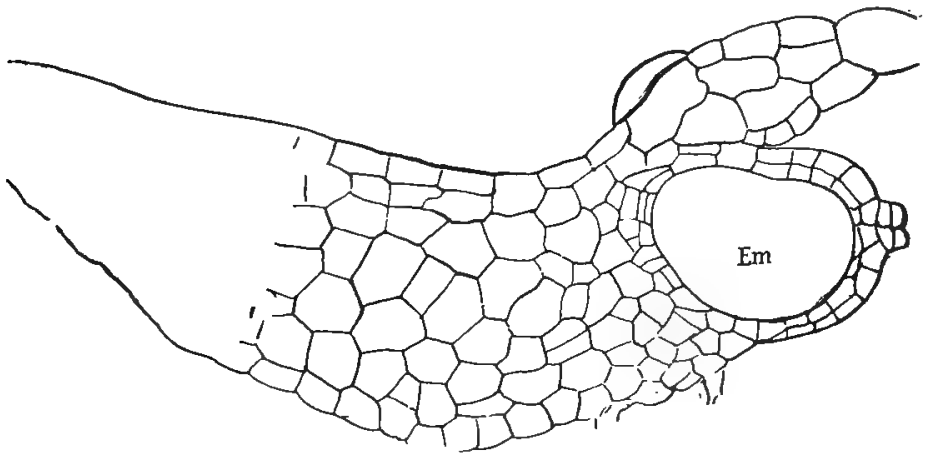

FIG. 20x.-Transverse section of a prothallium of 0 . Claytoniana, showing the lateral position of the embryo $(\mathrm{em}), \times 75$.

approaches the collateral type, and is much like that of the cotyledon of Marattia. Stomata of the usual type occur on 
both sides of the lamina. The development of the stem offers no peculiarities. The apical cell is of the tetrahedral form found in the mature sporophyte.

The root is bulky, and the apical cell relatively small, with large segments, dividing less regularly than in Onoclea, and on the whole approaches most nearly to Botrychium. The form of the apical cell is like that of Onoclea or Botrychium, and is interesting because in the later roots this is replaced by another type, so that this would indicate that the three-sided form found in so many cases is the primitive condition. The vascular bundle is diarch.

The foot is very large, and while formed originally from the upper hypobasal quadrant, it encroaches more or less upon all the others. Very early its cells cease to show any regular order in their divisions, and divide more slowly than the other cells of the embryo, so that they become decidedly larger. The cells lose much of their protoplasm as they increase in size, and serve simply as absorbent organs. They are in close contact with the prothallial cells, and crowd upon them until the foot penetrates deep into the prothallium, whose cells it par-

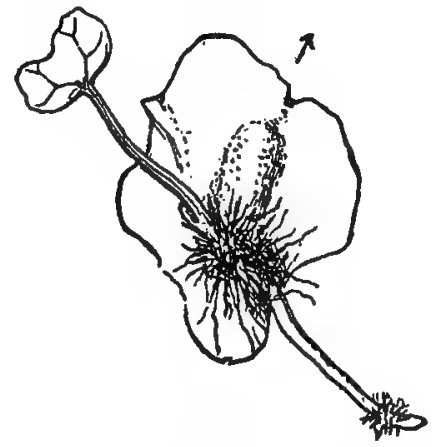

FIG. 202.-Young sporophyte of $O$. Claytoriana, still attached to the prothallium, $\times 6$.

tially destroys. It is upon the large development of the foot, whose outer cells are sometimes extended into root-like extensions like those in Anthoceros, that the young embryo is maintained so long at the expense of the prothallium.

Frequently more than one embryo begins to develop, and sometimes a number of archegonia may be fertilised; but no cases were met with where more than one embryo came to maturity, although it is quite possible that this may occur.

In all the Osmundaceæ the mature stem is a stout rhizome, which in the genus Todea may form an upright caudex, a metre or so in height. The bases of the stipes are broadly winged and these sheathing leaf-bases persist for many years, completely covering the surface of the stem. According to Faull ( I), who has made a very thorough study of the anatomy of 
the Osmundaceæ, the stem usually bifurcates once, into branches of equal size, which may rarely fork once more.



Fic. 203.-Upper part of a sporophyll of 0 . Clay. toniana, $X_{2} ; s p$, sporangia; $\mathrm{B}$, section of the rhizome of $O$. regalis, showing the arrangement of the vascular bundles, $X_{4}$ (after De Bary).

The woody strands form a reticulate cylinder, and in cross-, sections of the stem appear as a circle of horse-shoe shaped masses of wood lying inside the phloem, and separated from each other by the medullary rays. The tracheary tissue con-;
A section of the rhizome (Fig. 203, B), shows a massive cortex composed largely of dark sclerenchyma, but the inner cortex is parenchymatous. The central cylinder is bounded by an endodermis, with in which are from one to four layers of cells constituting the pericycle. Faull ( ( I ), p. 7) was unable to verify Strasburger's statement, that both the endodermis and pericycle in Osmunda, as in the other Ferns examined by the latter ( (II), p. 449), are of cortical origin.

Inside the pericycle is a continuous cylinder of phloem, whose outer cells constitute the protophloem. The phloem proper consists mainly of sieve-tubes of large size a nd with conspicuous sieve-plates upon their lateral faces. The socalled "quergestreckte-, zellen" of Zenetti (Fig. 204, qu) are considered by Faull to be sieve-tubes. 
sists of small ringed and spiral elements constituting the protoxylem, and larger scalariform metaxylem tracheids. In $O$. cinnamomea, Faull found an internal endodermis and traces of internal phloem, which are quite absent in the other species, where the xylem-masses are in direct contact with the pith. Faull considers the condition in $O$. cinnamomea as the primitive condition from which the type found in the other species has been derived by a suppression of the inner phloem and enc'odermis.

A.

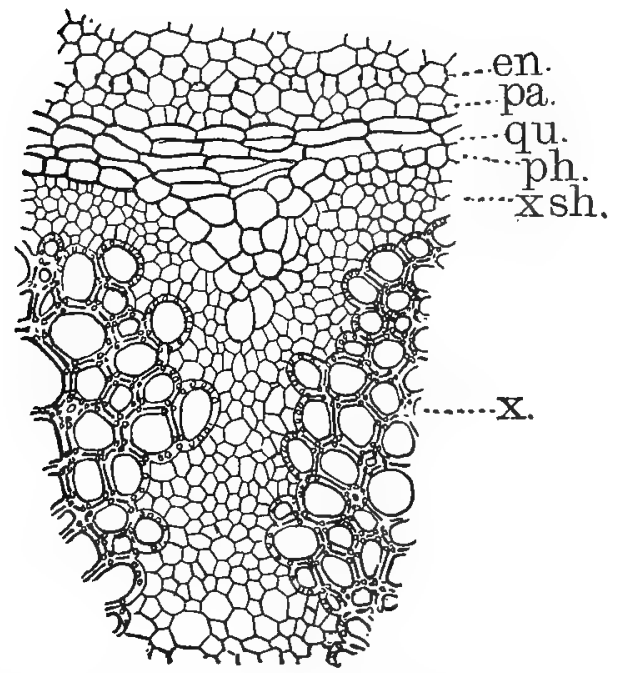

B.

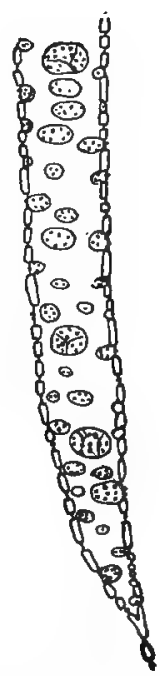

FIG, 204.-Osmunda regalis. A, Part of the central cylinder of the rhizome, '250; B, a sieve-tube, more highly magnified. (After Zenetti.)

The leaf traces (Faull (I), p. 20) pass very obliquely through the cortex into the leaf base. They are concentric in structure. The protoxylem is situated on the inner face of the xylem strand and is continuous with that of the stem. Each leaf trace is surrounded by a sheath of colourless cells.

\section{The Leaf}

The origin of the leaves is the same as in the Polypodiacer, but the young leaf grows from a three-sided apical cell much 
like the stem (Bower (II), Klein (2)), and the young leaf is more conical than in the Polypodiaceæ. In the very young leaf, according to Bower, one side of the apical cell is always directed toward the stem apex, and never one of the angles. In the presence of a three-sided apical cell, as well as its more cylindrical form, there is an approach to Botrychium. The further development of the leaf is like that of the pinnate leaves of the Marattiaceæ or Polypodiaceæ, with which they agree also in the strongly circinate vernation. The leaves are always pinnately divided, and are similar in all the species, and the type of venation is the same. While in all species of Osmunda and in Todea barbara, the structure of the leaf is quite like that of Polypodiacex, the other species of Todea (Leptopteris) have the lamina of the leaf reduced to two or three layers of cells, and there are no stomata. The texture of the leaves in these forms is filmy, like that of Hymenophyllum.

The petiole is traversed by a single large vascular bundle, which in section is crescent-shaped and in structure concentric, with the elements like those of the Polypodiacex, but the endodermis is not so clearly differentiated; and close to the inner side of the bundle are numerous mucilage cells, recalling the tannin ducts of Angiopteris. A further point of resemblance to the Marattiaceæ is the presence of stipular wings at the base of the petiole. The chaffy scales (paleæ) so common in the Polypodiaceæ are quite wanting, but hairs are developed, often in great numbers. Thus in $O$. cinnamomea the young leaves are covered completely with a felted mass of hairs, recalling those in some of the Cyatheaceæ. Some of these are glandular. The sterile leaves and sporophylls are either very much alike, as in Todea, or the sporophylls may be very different. An extreme case is seen in $O$. cinnamomea, where the whole sporophyll is devoted to the development of sporangia. In this species, as well as $O$. Claytoniana, the sporophylls develop first and form a group in the centre of a circle of sterile leaves. In $O$. cinnamomea the sporophylls develop no mesophyll, and die as soon as the spores are scattered.

\section{The Root}

The roots of the mature sporophyte differ very markedly from those of the other Leptosporangiatæ, and have been the 
subject of numerous investigations, but there still is a good deal of diversity of opinion as to their exact method of growth. Bower ( ( II ), p. 3 IO) states that in $O$. regalis there may be a single apical cell, such as exists in the first root of $O$. Claytoniana and $O$. cinnamomea, but that it never shows the regular segmentation of the typical leptosporangiate root, and it may be replaced by two or three similar initials. In Todea barbara he found four similar initials, and in no case a single one, although Van Tieghem and Douliot ((5), p. 378) ascribe to this species a single three-sided apical cell. ${ }^{1}$
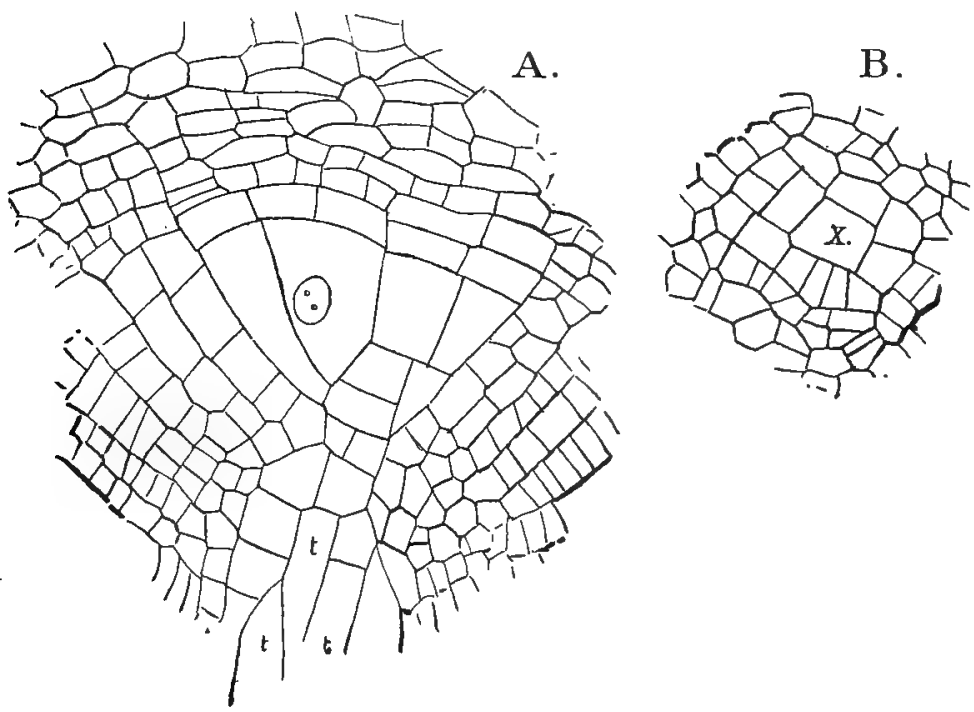

FIG. 205.-A, Longitudinal section through the root apex of $O$. cinnamomea; $t$, young tracheids, $\times 200 ; B$, cross-section of root apex of 0 . Claytoniana, $\times 200$.

Osmunda cinnamomea (Fig. 205, A) shows a single very large initial, more or less triangular in form when seen in profile, but with the point sometimes truncate. Transverse sections show that it is really a four-sided pyramid. The young segments are very large, and it is possible that these may sometimes assume the rôle of initials. Owing to the slowness and irregularity of cell division it is difficult to trace the limits of the segments beyond the youngest ones. They usually form

1 Lachmann (I) asserts, however, that he found a group of initials such as Bower describes. 
a spiral, but cases were sometimes encountered where the segments were apparently cut off in pairs from opposite sides of the initial cell. The root-cap arises in part from special segments cut off from the outer face of the apical cell, but also in part from the outer cells of the lateral segments, as in the Eusporangiatæ. The separation of the tissue system follows much as in Botrychium. The central cylinder is large and oval in section, but with poorly-defined limits, and it is not possible to state positively whether it owes its origin exclusively to the innermost cells of the segments. The large central tracheæ, as in Adiantum, are very early distinguishable. O. Claytoniana agrees on the whole with $O$. cinnamomea, but the divisions

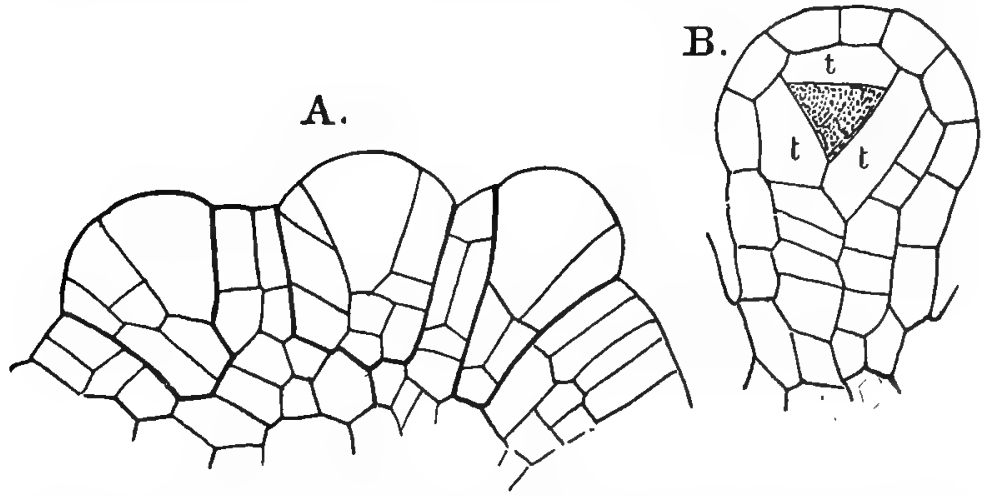

Fic. 206.-Osmunda regalis. A, Section of young sporophyll passing through three very young sporangia; $B$, longitudinal section of an older sporangium; $t$, the tapetum, $\times 325$ (after Bower).

are much more regular, and it approaches nearer the typical leptosporangiate type, both in the arrangement of the young tissues and in the structure of the fully-developed vascular bundle, which closely resembles that of the Polypodiaceæ, and differs from the investigated species of Osmunda and Todea in the better development of the endodermis, and in having the pericycle of but one or two layers. The vascular cylinder of the root is typically diarch like that of the Polypodiaceæ, but exceptionally (Faull (I), p. 22), it may be triarch.

The roots arise regularly, two at the base of each leaf (Lachmann (7), p. I I8), and their bundles connect with those of the stem near the bottom of the elongated foliar gap in its vascular cylinder. 


\section{The Sporangium}

The sporangia in Osmunda are produced upon sporophylls that closely resemble those of Botrychium or Helminthostachys, but in Todea they occur upon the backs of the leaves, as in most Ferns. In structure and development they are intermediate between the true leptosporangiate type and the eusporangiate. So far as they have been investigated they all correspond very closely. The origin of the sporangia is almost identical with that in Botrychium, and more than one cell may take part
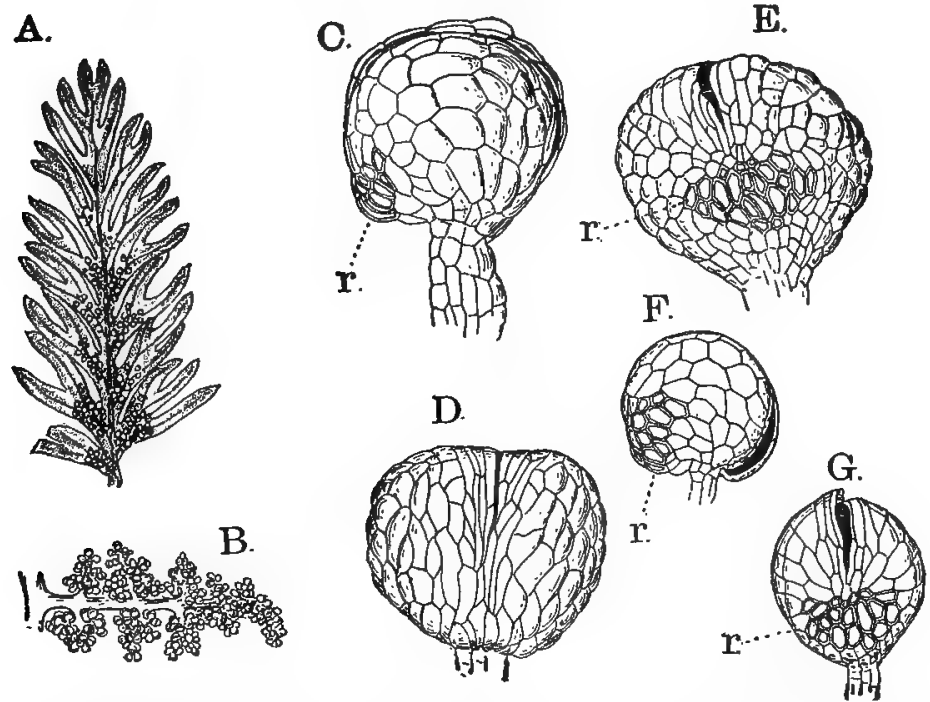

FIG. 207.-A, Pinnule of a fertile leaf of Todea (Leptopteris) hymenophylloides, $X_{2}$; $B$, fertile pinnule of Osmunda Claytoniana, $\times 3$; C-E, three views of the ripe sporangium of $O$. cinnamomea, $\times 40 ; \mathrm{F}, \mathrm{G}$, sporangia of Todea hymenophylloides, $\times 40 ; r$, annulus.

in their formation (Bower (II); Goebel (I7)). Bower says: "In all cases, however, one cell distinctly takes the lead, and this we may call the initial cell (Fig. 206, A); but the arrangement of its division wall does not, as in the true leptosporangiate Ferns, conform to any strict plan; the initial cells are oblong, seen in vertical section, and the first divisions are longitudinal, so as to meet the basal wall : both in the segment thus cut off and in the central cell, periclinal or sometimes oblique divisions may take place, so that a considerable bulk of 
tissue is formed, in the projecting apex of which a single large cell occupies a central position." As in Botrychium the archesporium is derived from a single hypodermal cell, which approaches more or less the tetrahedral form of the true Leptosporangiates, but shows a good deal of variation. As in these the wall of the sporangium is only one-layered, and the tapetum ordinarily two, but occasionally three-layered. The fully-developed sporangium is in shape much like that of Botrychium $V$ irginianum, and has a very short massive stalk. Like $\mathrm{Hel}$ minthostachys and Angiopteris, it opens by a vertical cleft, and like the latter there is a rudimentary annulus consisting of a group of thick-walled cells (Fig. 207,r).

\section{The Gleichentace正}

These comprise about twenty-five species of tropical and sub-tropical Ferns,

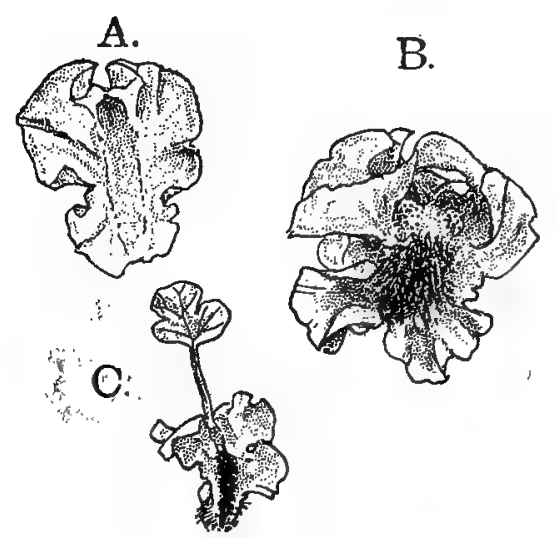

FIG. 208.-Gleichenia pectinata. Prothallia, $X_{4}$; $B$, a large prothallium seen from below, showing a dichotomy of the apex; $C$, the young sporophyte attached to the prothallium. which may be all placed in two genera (Diels (I) ) - Stromatopteris, with a single species $S$. $m$ onilifor $m i s$ and Gleichenia with about 25 species. The best known is $G$. dichotoma, an extremely common Fern of the tropics of the whole world. It has very long leaves, which fork repeatedly, and may be proliferous from the growth of buds developed in the axils of the forked pinnæ.

\section{The Gametophyte}

The development of the prothallium has been studied by Rauwenhoff ( I), and shows some interesting points in which it is intermediate between the Osmundaceæ and the other Leptosporangiatæ. The spores of Gleichenia are usually tetra- 
hedral, and contain no chlorophyll. When the ripe spores are sown, after a few days the oil-drops become much smaller but more numerous, and the first chloroplasts become evident. The latter increase in number and size, and small starch grains are developed. The exospore is ruptured in from two to three weeks from the time the spore is sown, and the spore contents surrounded by the intine project through the opening. The first wall usually separates the first rhizoid, which, like that of Osmunda, often contains a good deal of chlorophyll, from the larger prothallial cell. As a rule the development of the prothallium corresponds closely to that of the Polypodiacex, but
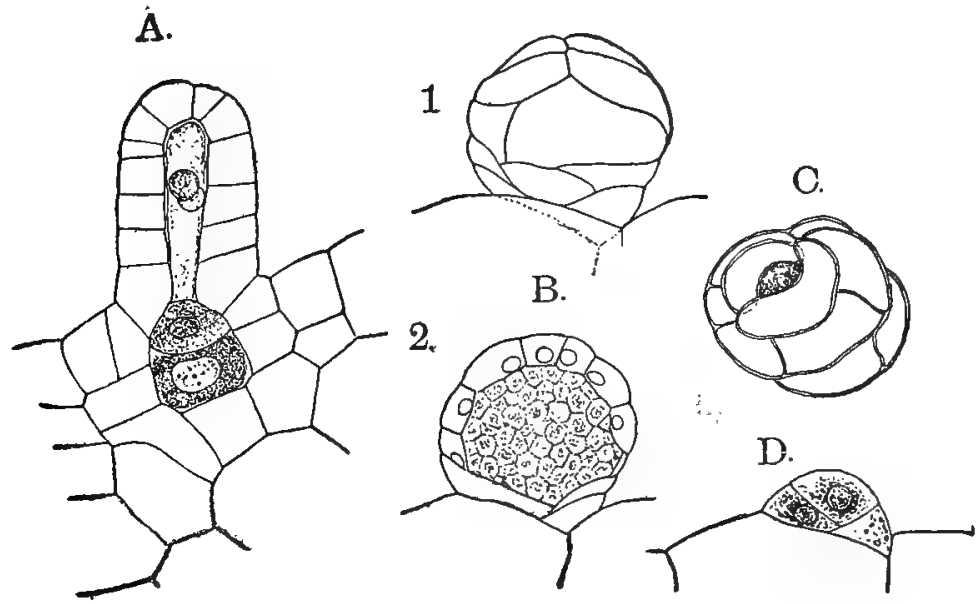

FIG. 209.-Gleichenia pectinata. A, Ripe archegonium; B, nearly ripe antheridium; 1 , surface view; 2, optical section; $C$, apex of open antheridium, showing the method of dehiscence; D, section of very young antheridium. All figures $X$ about $25^{\circ}$.

it may have a midrib like that of Osmunda. The growth is normally from a two-sicled apical cell, which is replaced later by marginal initials. A point of resemblance to Osmunda is the abundant production of adventitious shoots, which are formed in numbers upon the margin or from the ventral surface, and may develop into perfectly normal prothallia.

Rauwenhoff's account of the sexual organs is not as complete as might be wished, but is sufficient to show some interesting points of resemblance to the Osmundaceæ. The first wall in the antheridium cuts off a basal cell, and the next wall is somewhat like the funnel-shaped wall in the Polypodiaceæ. 
The dome-shaped wall next formed is here not so marked, being nearly flat. ${ }^{1}$ No definite cover cell is cut off, but the upper cell appears to divide by a single wall running obliquely over the apex, somewhat as in Osmunda. The divisions in the central cell offer no peculiarities, and the spermatozoids resemble those of other Ferns. The archegonia are formed on the forward part of the midrib, but are not confined to the sides, as in Osmunda. Apparently a basal cell is not always formed, but as to this and the much more important point, the number and character of the canal cells, Rauwenhoff says nothing definite. The neck is long and straight, like that of Osmunda and the Hymenophyllacea.

A.

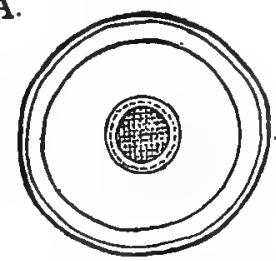

B.

B.
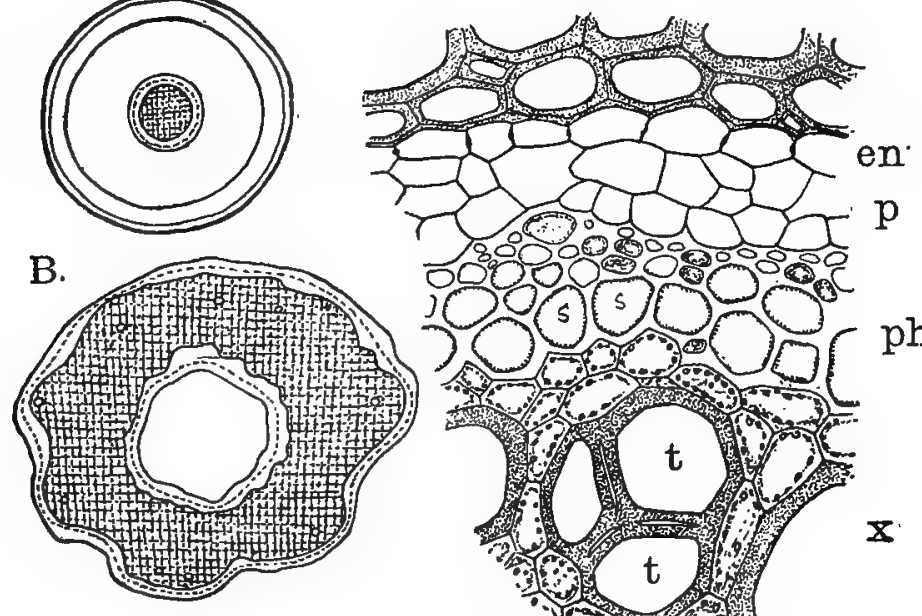

C.

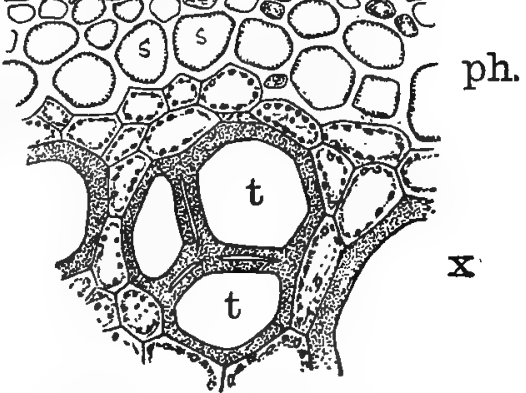

Fig. 210.-A, Diagram of the tissues of the rhizome in Gleichenia flabellata, $\times 8$; section of the stele (somewhat diagrammatic) of $G$. pectinata, $\times 26$; $C$, part of the stele of $G$. dichotoma, $\times 350$. (All figures after Boodle.)

In G. pectinata (Fig. 209) the resemblance of the antheridium to that of Osmunda is much more striking than in the species studied by Rauwenhoff. The archegonium in this species showed a division of the nucleus of the neck canal cell.

'Rauwenhoff's statement that the central cell of the antheridium contains chlorophyll, to judge from his Fig. 58, which illustrates this, is based upon a pathological case. The absence of chlorophyll from the central cells of the antheridium is a very constant character in all Archegoniates. 


\section{The Embryo}

To judge from the few rather vague statements made by Rauwenhoff in regard to the embryo, this more nearly resembles the typical leptosporangiate type than it does Osmunda. The primary root has a large and definite three-sided apical cell, and the divisions in the segments are very regular.

\section{The Adult Sporophyte}

Poirault (I) and Boodle (3) have made a study of the stem of various species of Gleichenia, which differs a good deal from

A.

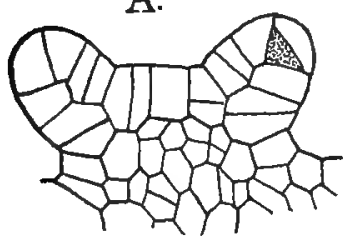

C

B.
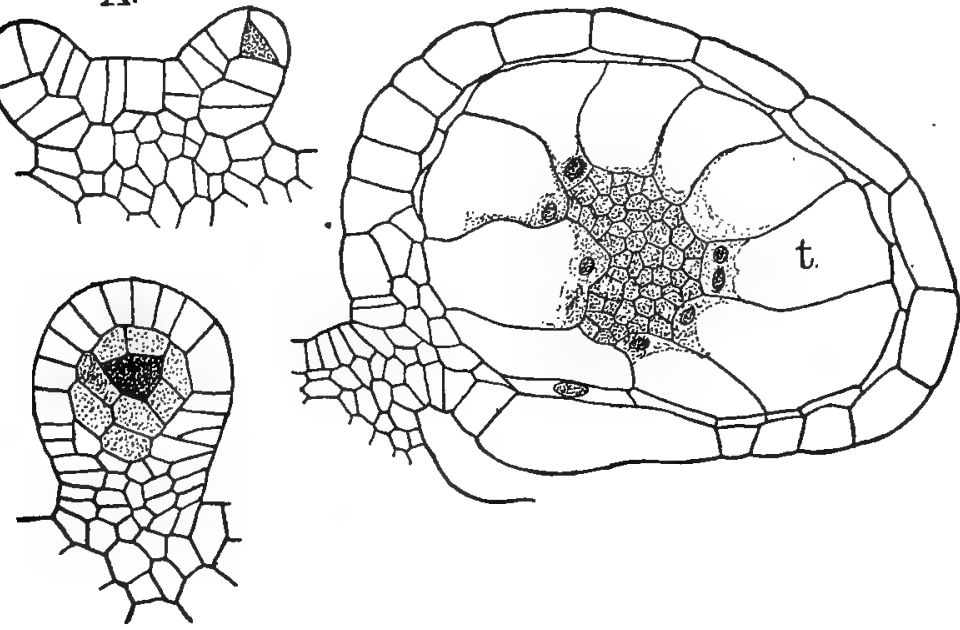

Fig. 211,-Gleichenia fiabellata. Development of the sporangium; A, B, X300; C, $\times$ iso. (After Bower.)

that of Osmunda, and approaches that of the Hymenophyllaceæ and Schizæaceæ. A single axial bundle traverses the stem, and is separated from the sclerenchymatous cortex by a distinct endodermis. Within the latter is a pericycle of several layers of cells, within which is a continuous zone of phloem containing large and small sieve-tubes, and phloem parenchyma. Within the phloem are also secreting cells. The whole central part of the stem, except in $G$. pectinata, is occupied by bundles of large scalariform tracheids separated by parenchyma (Fig. 210, C). The single bundle traversing the petiole is much like that of 
Osmunda, and the lamina of the leaf does not show any peculiarities. In G. pectinata (Boodle (3)), the stele is a hollow cylinder with both internal and external phloem and endodermis (Fig. 210, B).

\section{The Sporangium}

The development of the sporangium has been studied by Bower (19). The young receptacle begins to develop while the leaf is still tightly coiled. From the margin of the circular receptacle, and in some cases also from its upper surface, the

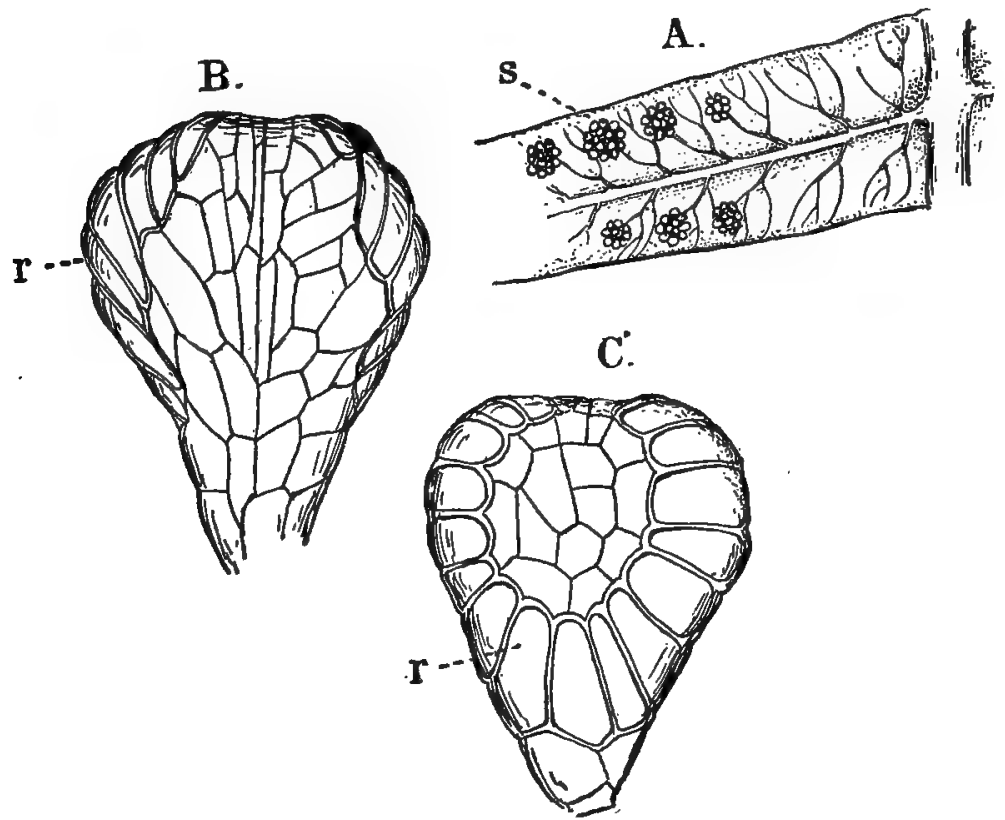

FrG. 212.-A, Pinnule of Gleichenia dichotoma, showing the position of the sori (s), $X_{4}$; $B$, ventral; $C$, dorsal view of the ripe sporangium, $\times 85$.

young sporangia arise as small conical outgrowths. Each sporangial outgrowth undergoes a series of regular segmentations resulting in a central, nearly tetrahedral, sporangial cell, from which successive segments are cut off which give rise to the short, massive stalk of the sporangium. Finally a periclinal wall is formed resulting in the archesporium. The further development is much like that of Osmunda, except that the inner of the two layers of tapetal cells become very large and their nuclei 
may divide (Fig. 2II ). At this stage there is a marked resemblance to the sporangium of Angiopteris, and Bower calls attention to the similarity in form between the sorus of Gleichenia and that of the Marattiacex. The walls of the inner tapetal cells are finally absorbed. The number of sporogenous cells is large, the number of spores in G. Alabellata amounting sometimes to over 800 .

In G. dichotoma (Fig. 212) the sporangia form rounded naked sori above the terminal branch of a lateral vein. They are pear-shaped, with a very short stalk, and upon the outer surface is a nearly complete very distinct annulus composed of
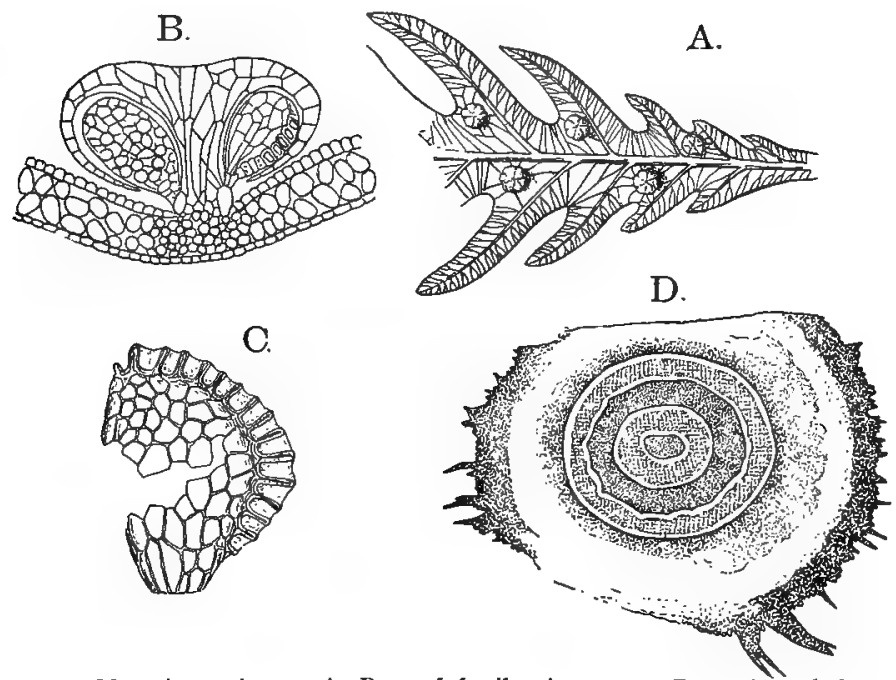

Fig. 213.-Matonia pectinata. A, Base of fertile pinna, $\times_{3} ; \mathrm{B}$, section of the sorus; C, open sporangium, $\times 35 ; D$, section of rhizome, $\times$ Io. (A, B, after Diels; $D$, after Seward.)

a single row of large thick-walled cells. This is interrupted at the top of the sporangium by three or four narrow thinwalled cells, and starting from this point and extending along the median line of the ventral surface are two rows of narrow cells, between which the sporangium opens.

\section{The Matoniace}

The family Matoniacer is represented by the single genus Matonia (Fig. 213), with two species, M. pectinata and M. sar- 
mentosa, both of limited range, and confined to the Malayan region. The affinities of Matonia are probably with the Gleicheniaceæ, rather than with the Cyatheaceæ, with which they were formerly associated. The large flabellate leaves of $M$. pectinata are much like those of some species of Gleichenia, and the arrangement of the sori is much the same. There is, however, a conspicuous umbrella-shaped indusium of firm texture, and in their form and dehiscence the sporangia are more like those of the Cyatheacex. The development of the sporangium, according to Bower (I9), is much like that of Gleichenia.

The structure of the stem in Matonia pectinata (Seward (2)) is very much like that of Gleichenia pectinata, but there is a second and sometimes a third cylindrical stele within the primary stele (Fig. 2I3, D).

Zeiller (I) from a comparison of Matonia with the fossil genus Laccopteris, which occurs in early Jurassic beds, concludes that the two genera are very closely related, if not actually identical, and represent the earliest forms of the Cyatheaceæ, and that Matonia is the last remnant of a family now in process of extinction.

\section{The Hymenophyllace}

The Hymenophyllaceæ have been the subject of much discussion on account of the assumption made by all the earlier writers that they were the most primitive of the Pteridophytes. This was based very largely upon the apparent resemblance between the delicate sporophyte of many of them and the leafy gametophore of the Mosses. More recent study of their development, especially the gametophyte, has led to a modification of this view, although it is still held by many botanists. It seems more probable that the peculiarities of both gametophyte and sporophyte are due to the peculiar environment of these plants, which grow only in very moist places, indeed are almost aquatic at times. They are for the most part extremely delicate Ferns of small size, and with few exceptions are tropical. Many are epiphytes, and these have the roots very poorly developed or even entirely wanting. The leaves are, with few exceptions, reduced to a single layer of cells, except the veins, which gives them a striking resemblance in texture to the leaves 
of some of the larger Mosses, e. g., species of Mnium. Hooker ( I ) reduces them all to three genera, which, however, are often further divided. Of these Loxsoma is represented by but one species, L. Cunninghamii, a form which seems to be intermediate in general characters between the Cyatheacez and the other Hymenophyllaceæ, but its life history and anatomy are not known. Of the other genera Hooker gives seventy-one species to Hymenophyllum and seventy-eight to Trichomanes. ${ }^{1}$

\section{The Gametophyte}

The gametophyte is known more or less completely in several species of both Trichomanes and Hymenophyllum. The
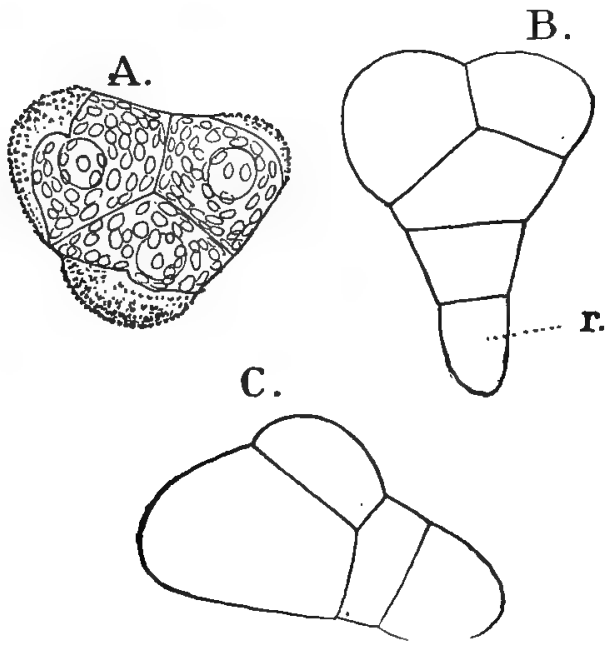

FIG. 214.-Trichomanes Draytonianum. Germination of the spores, $\times 525 ; r$, primary rhizoid.

large spores germinate promptly, but their subsequent development is very slow. They contain chlorophyll and often begin to germinate within the sporangium, where they may often be found divided into three equal cells by walls radiating from the centre (Fig. 2I4). All of the cells begin to grow out into filaments, but usually only one of them develops into the prothallium, the others dividing only once or twice, and forming short brown rhizoids. In some species of Trichomanes, e. $g$.

${ }^{3}$ The number of species known now considerably exceeds this. 
T. pyxidiferum (Bower (8)), the prothallium remains filamentous, and forms a densely branching structure very much like the protonema of some Mosses, but coarser in texture. Other species, however, e. g., T. alatum, produced flattened thalloid prothallia from branches of the filamentous forms, and Hymenophyllum always has a flat hepatic-like prothallium, which in its earlier stages, according to Sadebeck ( (6), p. I6I), always develops a two-sided apical cell, and differs in no wise from that of other Ferns. These prothallia, however, remain single-layered throughout, although they reach an extraordinarily large size, and branch much more freely than those of most other Ferns (Fig. 2I5). The rhizoids are always very short and dark-coloured, and generally occur in

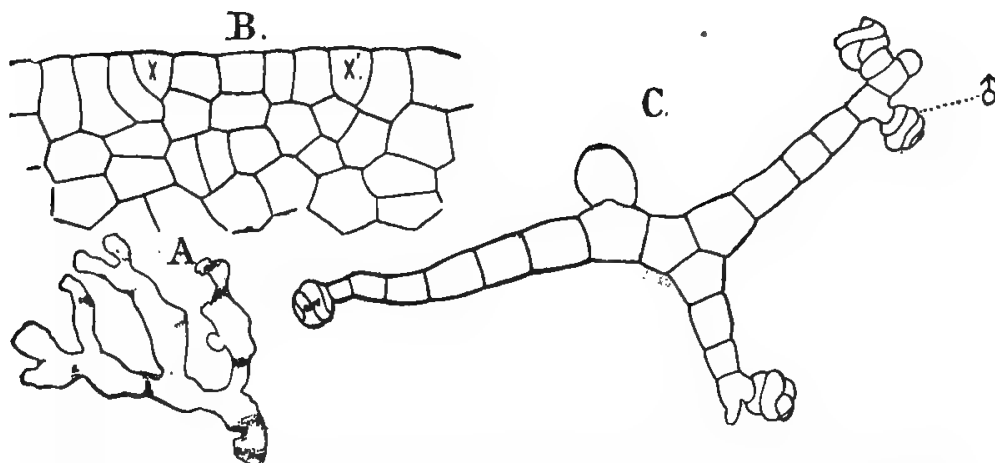

Frc. 2r5.-Hymenophyllum (sp). A, Large prothallium of the natural size; B, part of the margin of one of the growing branches, showing two similar initial cells, $\times 180$; C, a filamentous male prothallium derived from a bud, $\times 60$.

groups upon the margin only. The branching of the prothallia is either monopodial or dichotomous, and the latter method may be repeated a number of times. They may live for an indefinite time apparently. The writer has kept prothallia of both Trichomanes and Hymenophyllum for nearly two years, at the end of which time they showed no diminution of vigour.

They form ordinary adventitious shoots, but there are also special gemmæ developed in many of them, often in great numbers. In an undetermined species of Hymenophyllum collected in the Hawaiian Islands (Fig. 216) these gemmæ occurred very abundantly upon prothallia that had ceased to form sexual organs. A marginal cell grows out and curves upward, 
and the tip is cut off by a transverse wall from the basal cell. In the terminal cell are next formed a series of vertical walls, which transforms it into a row of cells extended at right angles to the axis of the pedicel. One of the central cells now bulges out laterally, and this papilla is cut off by an oblique wall and forms the beginning of a short lateral branch, so that the fullydeveloped bud has somewhat the form of a three-rayed star, and in this condition becomes detached and grows into a new prothallium. The prothallia formed in this way often do not
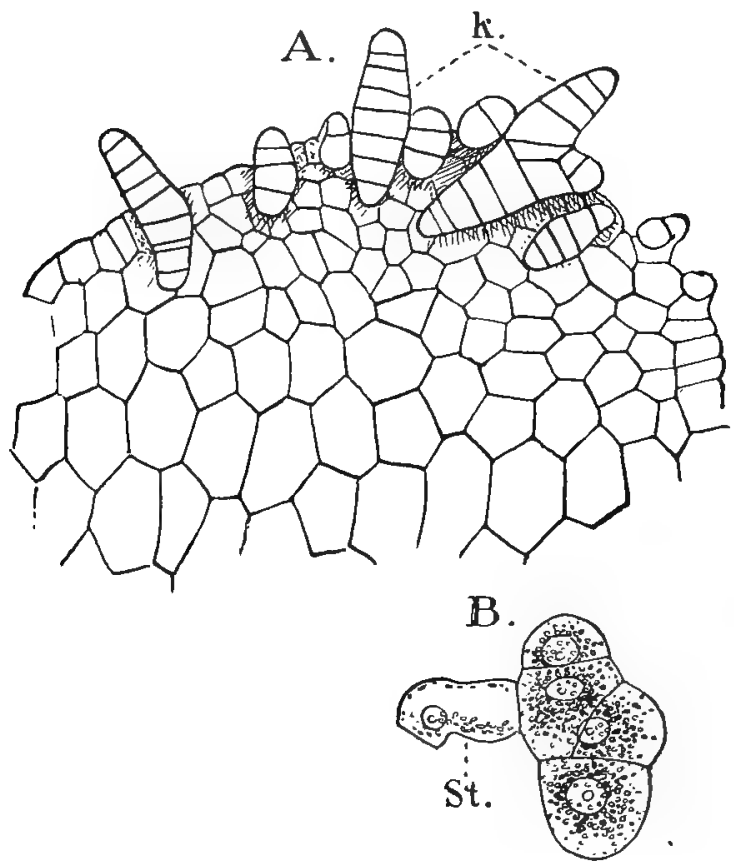

FIG. 216.-Hymenophyllum ( $s p$ ). Margin of a prothallium with numerous gemma $k$; $\times 85 ; B$, a young gemma, $\times 260$; st, its stalk.

develop a flat thallus, but may remain filamentous, and each ray may produce antheridia either terminally or laterally (Fig. $2 \mathrm{I} 5, \mathrm{C}$ ). In case a flat thallus is formed, only one or sometimes two of the rays grow out in this form, the other having only a limited growth, and terminating in a short rhizoid. In short, the process is very similar to that in the germinating spores. 


\section{The Sexual Organs}

Bower (8) has investigated the structure of the antheridium in Trichomanes, and Goebel (IO) in both Trichomanes and Hymenophyllum. My own study of their development has been confined to an undetermined species of Hymenophyllum from the Hawaiian Islands, but the results of my observations agree entirely with those of other observers. The antheridia arise mainly upon the margin of the prothallium, or upon the ends of the filamentous ones. After the mother cell is cut
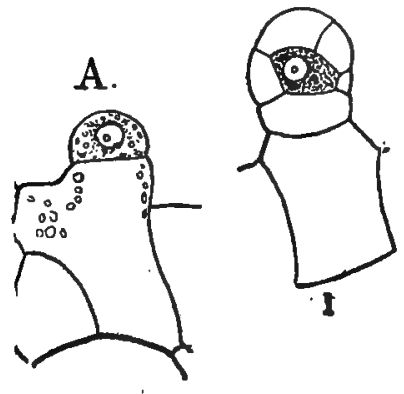

B.


C.

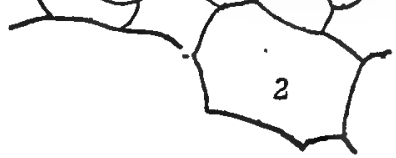

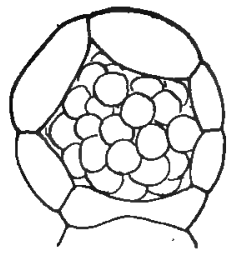

1.

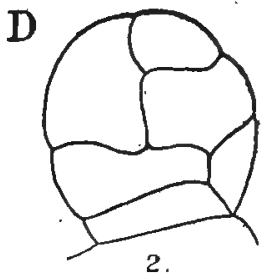

2.

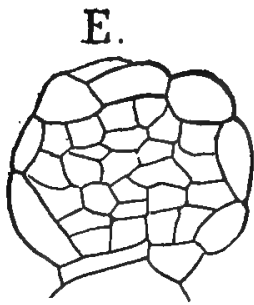

FrG. 2I7.-Hymenophyllum (sp). Development of the antheridium, $\times 260 . A, D$, From living specimens; E, microtome section; $\mathrm{B}_{4}, \mathrm{C}_{2}, \mathrm{D}_{i}$, optical sections; B 2, C 1, D 2, surface view of the same.

off, there is usually formed another transverse wall, by which a short pedicel is produced. A funnel-shaped wall does not ever seem to be formed, but the next division walls are more like those in Osmunda, and extend only part way round the circumference of the mother cell. After a varying number of basal cells are thus formed, a dome-shaped wall arises. separating the central cell. This wall is not so convex, as is usually the case in the Polypodiacer, and in this respect, as well as the form of the wall cells, the antheridium resembles that of Gleich- 
enia. In the Hymenophyllacea no cap cell is formed, but as in Osmunda and Gleichenia, the upper cell is divided by walls running over the apex. The divisions in the central cell and the structure of the spermatozoids, so far as these have been studied, correspond with those of the other Leptosporangiatæ.

A single archegonial cushion is not formed, but the archegonia occur in small groups at different points upon the margin. Goebel (IO) has shown, however, that these archegonial groups arise first near the growing point of the prothallial branch, and that they are simply separated by the intervention of zones of sterile tissue. At the point where they arise the prothallium becomes more than one cell thick, and in all cases where the development could be certainly followed, the archegonium arose from one of the ventral cells, and never directly from a marginal cell. The details of the development have not been

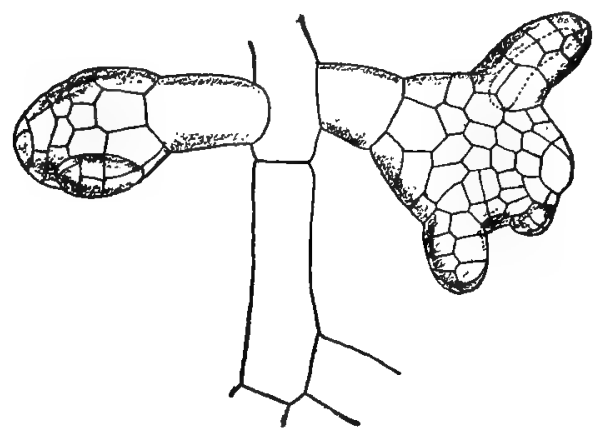

FiG. 218.-Part of the filamentous prothallium and archegoniophores of Trichomanes rigidum. (After Goebel.)

followed, and whether there is any division of the neck canal cell is not known. The neck is straight, as in Osmunda and Gleichenia.

In Trichomanes the archegonial meristem (archegoniophore) may be formed as a short branch, directly upon the filamentous prothallium.

The lateral walls of the prothallial cells are in all the species thicker than is the case in most Ferns, and there are distinct pits in them. In the rhizoids a parasitic fungus is frequently found.

The embryogeny is almost unknown (Janczewski (2)), but the first divisions and the very young sporophyte correspond 
closely with those of the other Leptosporangiatæ. The cotyledon is simple with a single median vein, and a root is present in all species yet examined.

\section{The Mature Sporophyte}

Prantl (I) has given a very complete account of the structure of the mature sporophyte, and Bower (II) has added to this by a careful study of the meristems of the different organs. From the investigations of the latter it seems that here, as in nearly all other Ferns, the stem apex has the usual three-sided

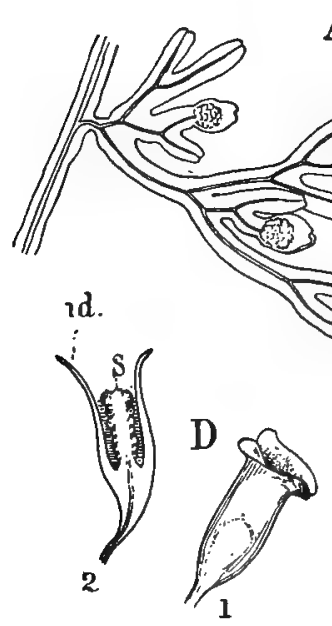

A

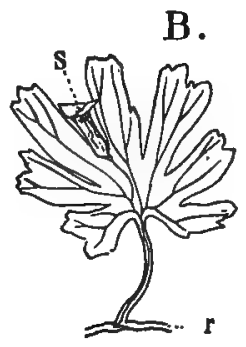

FiG. 219.-Pinna of the leaf of Hymenophyllum recurvum, $\times_{3} ; \mathrm{B}$, part of rhizome (r) and leaf of Trichomanes parvulum, $\times 3$; , pinna of the leaf of Trichomanes cyrtotheca, $X_{3} ; D_{1}$, trumpet-shaped indusium of the same, $X_{4} ; 2$, section of the indusium (id) with the central sorus, $\times 5$; $s$, the sorus.

initial cell, but only a small part of the segments give rise to leaves, which are arranged in two ranks.

The stem in all investigated Hymenophyllaceæ is monostelic, and one leaf-trace passes to each leaf. The cortex is usually largely made up of sclerenchyma, especially the inner cortex. In Hymenophyllum recurvum (Fig. 220), the axial vascular bundle is strictly concentric. Occupying the centre is a curved band of tracheary tissue, the small central tracheids being the protoxylem. Around the xylem is a continuous zone 
of phloem, separated from the endodermis by a broad pericycle. In other species of Hymenophyllum, Boodle (I) found a different arrangement of the xylem and phloem. In some cases, e g., $H$. scabrum, there are two xylem plates, with the protoxylem elements in the conjunctive tissues between them.

In Trichomanes there is also a good deal of variation. Fig. $220, B$, shows the structure in $T$. venosum, a small species from
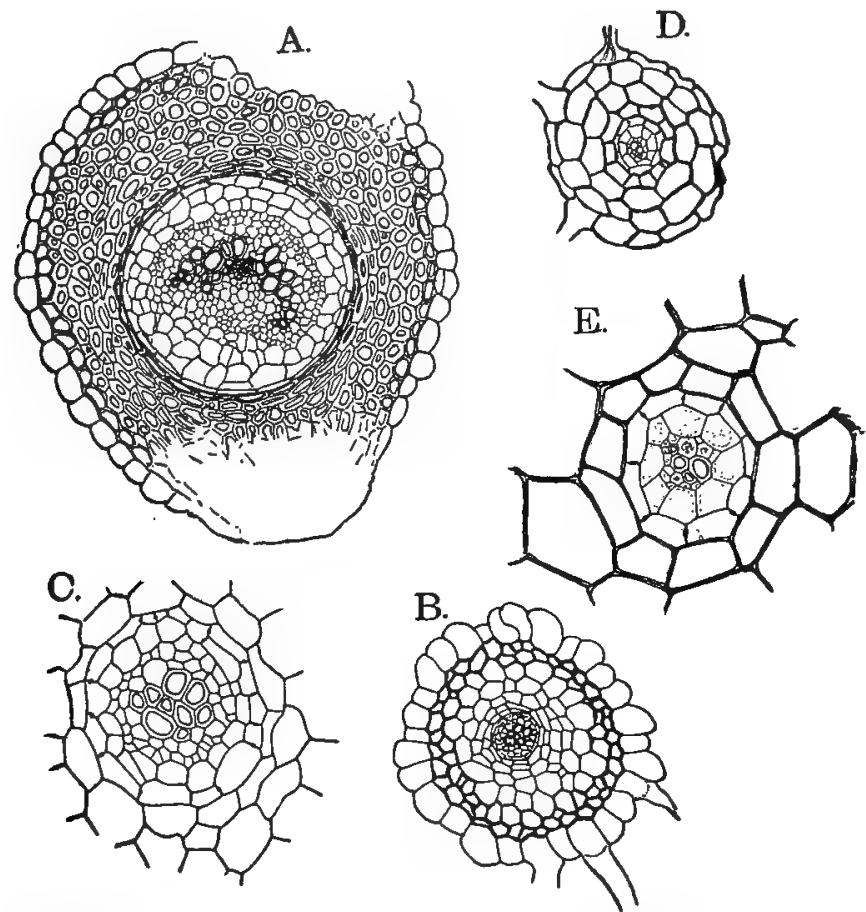

Fig. 220.-A, Section of the rhizome of Hymenophyllum recurvum, $X$ about $40 ; \mathrm{B}$, rhizome of Trichomanes venosum, $X$ about $75 ; \mathrm{C}$, stele of $\mathrm{B}$, more highly magnified; D, root of Hymenophyllum recurvum, $X$ about 75 ; E, stele of the root more highly magnified.

Australia and New Zealand. The structure of the stem differs from that of Hymenophyllum recurvum, mainly in its greater delicacy. The sclerenchyma of the cortical region is less developed, and the concentric axial cylinder corresponding to its much smaller size has both the xylem and phloem reduced in amount.

In the stouter species, like $T$. radicans, the amount of wood 
is much greater. According to Boodle (1. c. Fig. 24), there are two or three protoxylems, accompanied by parenchyma cells, surrounded by a massive ring of large tracheids. There is an approach in this species, and still more in $T$. reniforme, to the form characteristic of Hymenophyllum scabrum and its allies. In the small species, $T$. muscoides, apparently by reduction, the stele becomes collateral, and this, according to Prantl ( ( I) , p. 26), is the rule in the sub-genus Hemiphlebium, where the xylem lies on the ventral side of the stem, the phloem on the dorsal side. The pericycle, at certain points, shows clearly its common origin with the endodermis. Van Tieghem (3) considers that there is a double endodermis, and that no true pericycle is present. In $T$. labiatum ( $T$. microphyllum) Giesenhagen (I) found the bundle reduced to a single tracheid surrounded by four or five parenchyma cells immediately within the endodermis. The reduction is carried still further in $T$. Motleyi, where tracheary tissue has entirely disappeared from both stem and sterile leaf. In the sporophylls, however, tracheary tissue is present (Karsten (2), p. I35).

\section{The Leaf}

The observations on the earliest stages of the leaf are very incomplete, but in some cases at least a two-sided apical cell is present. In those with palmately lobed or entire kidney-shaped leaves, the later growth is marginal, and of the same type found in similar leaves among the Polypodiacex. The venation in these forms is exclusively dichotomous, in those with pinnate leaves, e. g., Trichomanes radicans, this is only true of the last formed veins.

With the exception of a very few species, e. g., T. reniforme, $H$. dilatatum, where the mesophyll of the leaves is three to four cells thick, the whole lamina, with the exception of the veins, is single-layered, and of course stomata are completely absent. The form of the leaf is either pinnate, as in the larger species of Trichomanes and Hymenophyllum (Fig. 219), reniform (T. reniforme), or palmately divided ( $T$. parvulum, Fig. 219 , $B)$. The smaller veins, as in other Ferns, have collateral vascular bundles, and in the smallest ones the xylem may be reduced to a single row of tracheids. The latter may be spiral, reticulated, or scalariform. In the phloem Prantl could not 
distinguish any well-marked sieve-tubes, but it was mainly composed of bast fibres and cambiform cells, and in Hemiphlebium (Trichomanes) Hookeri the phloem is absent from the very much reduced smaller veins. This is possibly an intermediate condition between the normally developed bundles of the veins of most species and the so-called pseudo-veins, in which there is no tracheary tissue developed, but which in their origin correspond to the ordinary veins. The petiole always has a single vascular bundle, usually of typical concentric structure, but in the section Hemiphlebium Prantl states that it is collateral. The ground tissue of the petiole is largely composed of sclerenchyma like that of the stem.

\section{The Roots}

The development of the roots has been studied only in a very few species. Bower (I I) states that in T. radicans and $H$. demissum it "conforms to the normal type for the root of leptosporangiate Ferns, as described by Nägeli and Leitgeb," but does not go into details, and Prantl makes an equally brief statement. While lateral roots are completely wanting in the section Hemiphlebium, where their place is taken by leafless branches, in most of the other forms they are developed in considerable numbers. There is, according to Prantl, great variation in the arrangement of the parts in the vascular cylinder. Thus while all the species of Hymenophyllum have diarch bundles, that of Trichomanes pyxidiferum is monarch, while in one species, $T$. brachypus, as many as nine primary xylem masses are found. The Marattiacex alone, among the other Ferns, show such great variability.

Trichomes occur, but not so abundantly as in most of the Leptosporangiatæ. They have usually the form of hairs, which are either temporary (those formed on the margins of the young leaves) or persistent for a longer time, like those that cover the end of the stem apex and bases of the petioles in many species.

\section{The Sporangium}

All of the Hymenophyllacex agree closely in the position of the sporangia, whose development has, however, been studied in detail only in Trichomanes; but from the close correspond- 
ence in other respects it is not likely that Hymenophyllum differs essentially from the latter. The sorus occupies the free end of a vein, which often continues to grow for a long time in Trichomanes, and forms a long slender placenta or columella, upon which the sporangia arise basipetally. While the
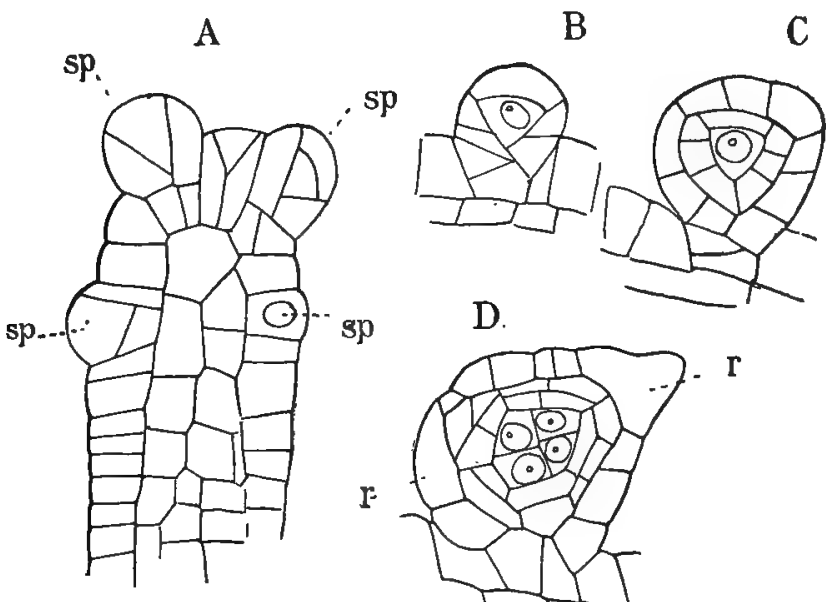

D.
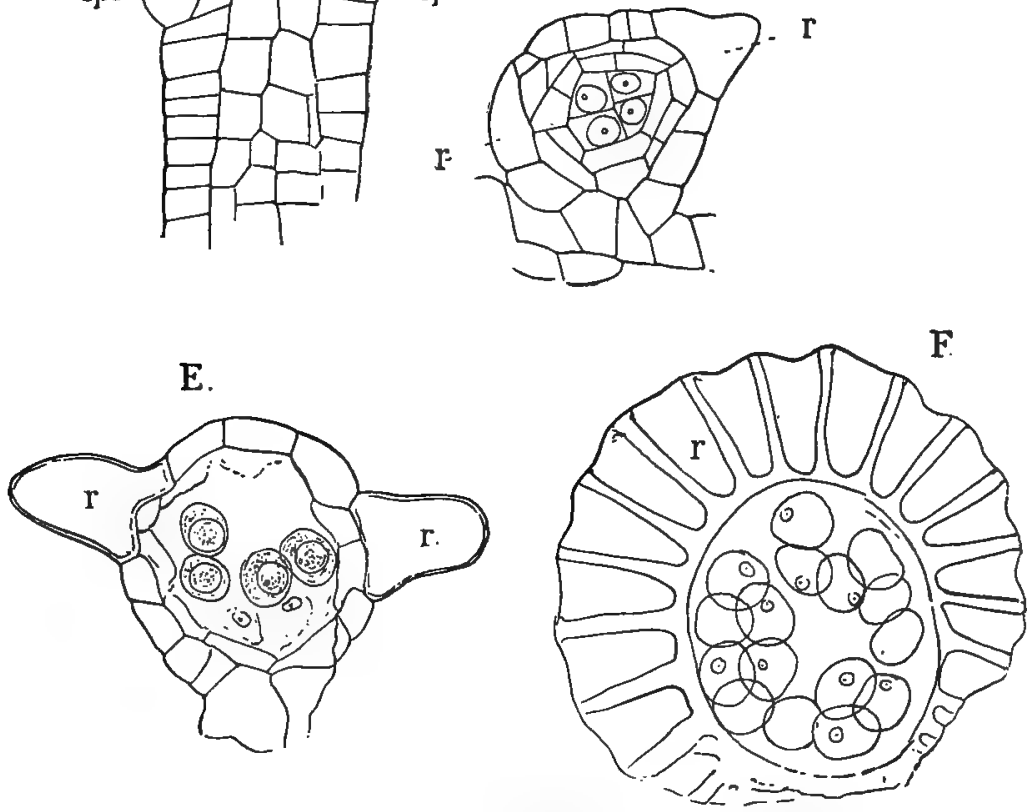

Frg. 221. - Trichomanes cyrtotheca. Development of the sporangium, $\times 225.4$, Longitudinal section of very young receptacle with the first sporangia $(s p)$; B-D, successive stages of development seen in longitudinal section; $F$, horizontal section of nearly ripe sporangium; $r$, the annulus.

receptacle is still very young the tissue of the leaf immediately about it forms a ring-shaped ridge, which grows up in the form of a cup-shaped indusium, which either remains as a tube 
(Trichomanes) or is divided into two valves (Hymenophyllum ). Many species of the former genus, however, show an intermediate condition, with the margin of the indusium deeply two-lipped.

The first sporangia arise at the top of the placenta (Fig. $22 \mathrm{I}$ ), but the apex itself does not usually develop into a sporangium. After the first sporangia have formed, new ones continue to develop. Near the base of the placenta a zone of meristem is formed, which constantly contributes to its growth, and the young sporangia arise from the surface cells formed from this meristem. The mother cell is very easily distinguished by its larger size and denser contents. About every third cell seems to develop a sporangium, but this probably is not absolutely uniform. The first wall is usually nearly vertical, and cuts off a narrow segment from one side of the mother cell (Fig. 22I, A). This in most cases examined was next followed by a wall almost at right angles, separating a small basal cell. After these preliminary divisions, which form the very short stalk, the next divisions are exactly as in the Polypodiaceæ, and give rise to the central tetrahedral cell with the four peripheral ones. Prantl ( ( I), p. 39) -states that the first divisions of the cap cell are also spirally arranged. In T. cyrtotheca (Fig. 22I) the tapetum is massive, and composed throughout of two layers. The archesporium divides into eight cells, whose further history is the same as in other Ferns. The annulus in the Hymenophyllaceæ is large, and situated much as in Gleichcnia. According to Prantl, it arises in part from the cap cell and partly from numbers one and three of the primary peripheral cells. Where the young sporangium is cut longitudinally (Fig. 22I), the annulus cells are at once recognised by their larger size, especially upon the dorsal side. Their radial and inner walls become very thick, and a horizontal section (Fig. 22I, F) shows that the annulus is not complete, but is interrupted on the inner side where the stomium is formed.

\section{Apogamy and Apospory}

Both of these phenomena have been discovered by Bower (8) to occur not infrequently in Trichomanes, and probably further investigations will reveal other instances. Apogamy was common in $T$. alatum, in which species archegonia were 
not seen at all, and the origin of the young sporophyte was unmistakably non-sexual. Prothallia, arising directly from the leaf, or from the sporangial receptacle, were found to be a common phenomenon in the same species.

\section{The Schiz mace}

The Schizæaceæ include about sixty species belonging to five genera. The very characteristic sporangia have a terminal annulus, which forms a sort of crown at the apex. Some of them, like Schizaa pusilla and Trochopteris elegans, are very,
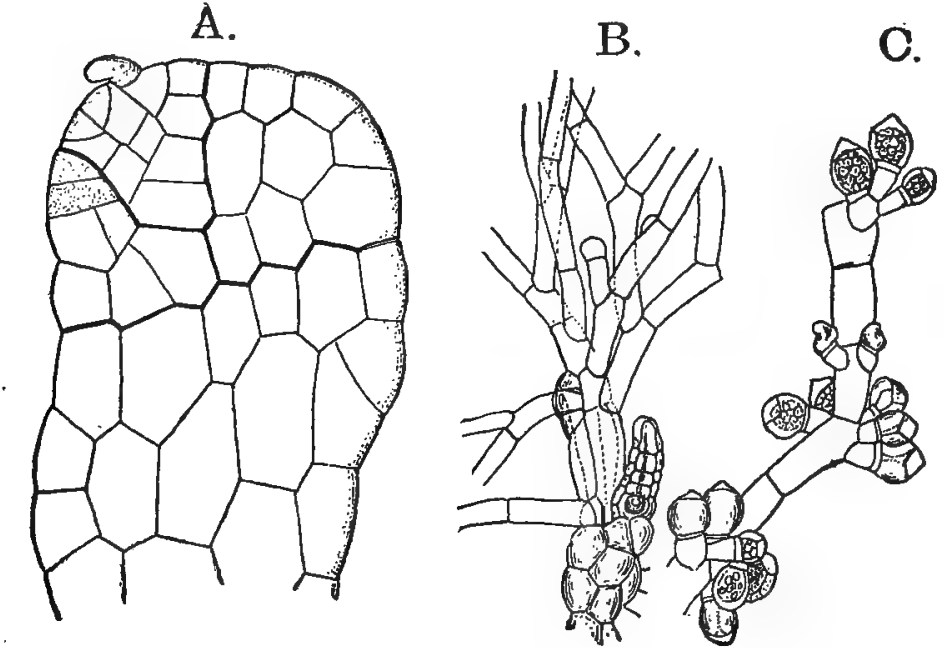

Erg. 222.-A, Prothallium of Aneimia Phyllitidis, $X_{180} ; \mathrm{B}$, female; C, male, prothallia of Schizaea pusilla, $\times_{30}$ (A after Bauke, B, C, after Britton \& Taylor.)

small and delicate plants. In the largest species of Lygodium the slender twining fronds may reach a great length. According to Hooker (2), the New Zealand species L. articulatum, may reach a length of $50-100$ feet.

\section{The Gametophyte}

According to Bauke (2), the prothallium in Lygodium, Aneimia, and Mohria is much like that of the Polypodiaceæ, except that in the two latter genera (Fig. 222), the growing point is at one side. The spores are tetrahedral, and contain no chlorophyll until after germination has begun. The germ- 
ination is like that of the Polypodiacex, and a filament is first formed, after which the flat prothallium grows for a time by a single apical cell, which is finally replaced by a group of marginal cells. In Aneimia and Mohria the growing point lies on one side, so that the prothallium is not heart-shaped. In $L y$ godium, however, the prothallium has the ordinary form.

The development of the antheridia has been studied by Kny (4) in Aneimia hirta. The only difference between this and

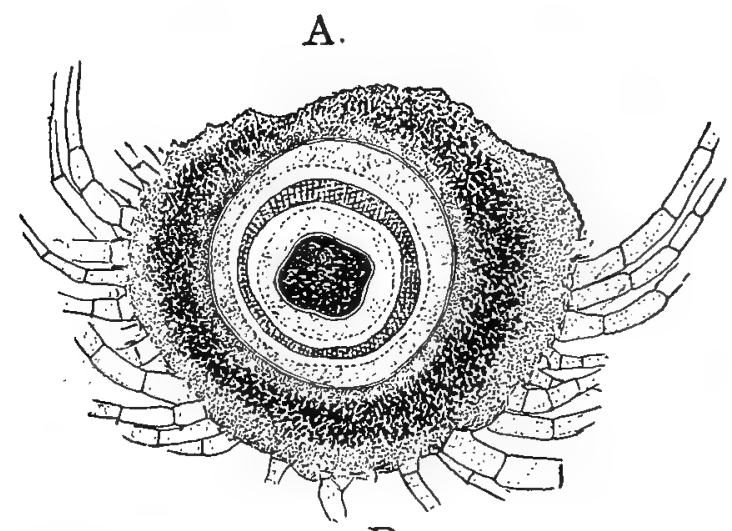

B.



FIG. 223.-Aneimia hirsuta. A, Section of the rhizome, $X_{30} ; \mathrm{B}$, part of the central region, $\times 300$.

the normal antheridium of the Polypodiacex is that in Aneimia the first wall is always flat instead of funnel-shaped, and the basal cell of the antheridium is therefore disc-shaped. The archegonia appear to correspond exactly with those of the Polypodiacex.

The genus Schizaa, to judge from S. pusilla (Britton and Taylor (I)), and $S$. dichotoma (Thomas (I)), differs mark- 
edly from the other genera in the form of the prothallium, which is filamentous and extensively branched, resembling very closely that of certain species of Trichomanes (Fig. 222, B, C). The antheridia resemble those of Aneimia, but the archegonium has the straight neck found in the lower Leptosporangiatæ.

\section{The Sporophyte}

The tissues of the sporophyte in Lygodium and Schizca are much like those of Gleichenia and the Hymenophyllaceæ. As in these the stem as well as the petiole is traversed by a single
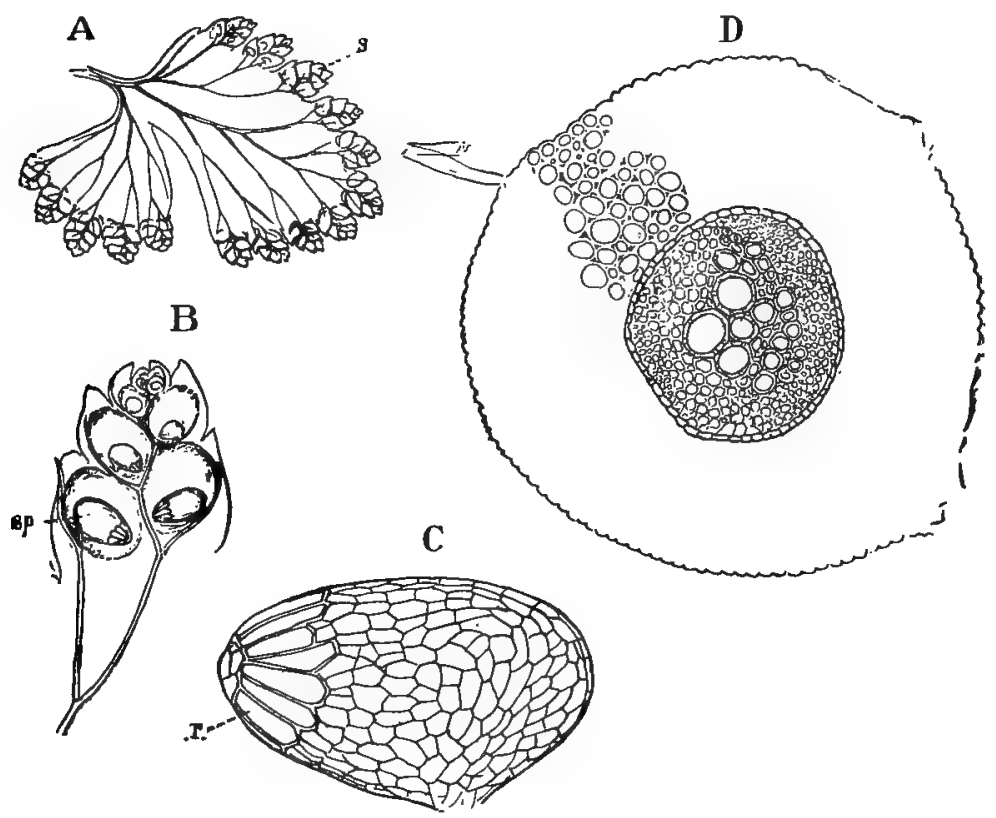

Frc. 224-Lygodium Japonicum. A, Pinnule, $\times_{3} ; s$, the sporangial segments; $\mathbf{B}$, horizontal section of one of the latter showing the sporangia, $s p, X_{14} ; \mathrm{C}$, a single sporangium, showing the terminal annulus $(r), \times 65$; cross-section of the petiole, $\times 65$.

concentric vascular bundle. In most species of Aneimia and Mohria the bundles of the stem form a cylindrical network like that of the Polypodiacex. The stem bundles are concentric, as are those of the petiole and larger veins in all but Schizcea, which Prantl ( (5), p. 23) states has collateral bundles throughout, except in the stem. The small veins have collateral bun- 
dles as in other Ferns. Sclerenchyma is largely developed, especially in the petioles, where the whole mass of ground tissue in Lygodium (Fig. 224) is composed of this tissue.

In one section of Aneimia the stele (Fig. 223) has the form of a continuous tube with both external and internal phloem and endodermis (see also Boodle (2)).

The leaves are pinnate in all the forms except a few species of Schizca. Lygodium, as is well known, shows a continuous growth at the aper of the leaf, something like Gleichenia, but here the primary apex retains its meristematic condition, and the extremely long and slender axis of the leaf twines about its support like the stem of many climbing plants. The sporo-

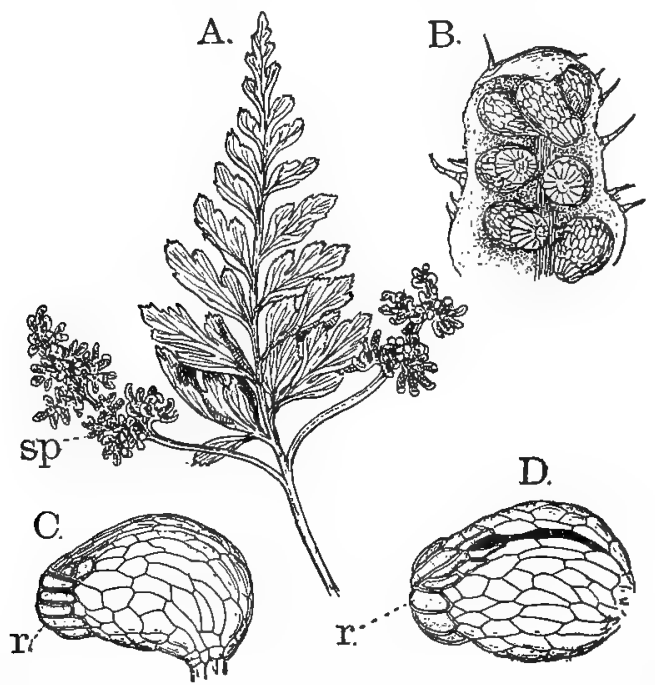

Fig. 225.-Aneimia hirsuta. A, Sporophyll, showing the two fertile pinnæ, $s p . ; \mathrm{B}$, segment of the fertile pinna, enlarged; $C, D$, sporangia, $X$ about 40 .

phylls are usually smaller than the sterile leaves, or where only portions of the leaf are sporiferous these are much contracted. The anatomy of the leaf corresponds closely with that of the other Ferns. The stomata, which are for the most part confined to the lower side of the leaf, are always arranged in two parallel rows in Schizea, and the peculiar stomata of Aneimia have already been mentioned. The trichomes are for the most part hairs. Only in Mohria do scales occur.

In Schisca pusilla the sterile leaves are filiform, without 
any distinct lamina. The fertile leaves are pinnately divided. In other species, e. g., $S$. dichotoma, the leaves are dichotomously divided, but the fertile leaf-segments are pinnate, as they are in S. pusilla (Diels (I)).

In Aneimia (Fig. 225) the two lower pinnæ of the sporophyll are fertile, and in most species become very long-stalked and more divided than the sterile pinnæ. The leaves arise from the dorsal side of the rhizome and in Lygodium, Prantl (5) states that they form but a single row. He also says that the

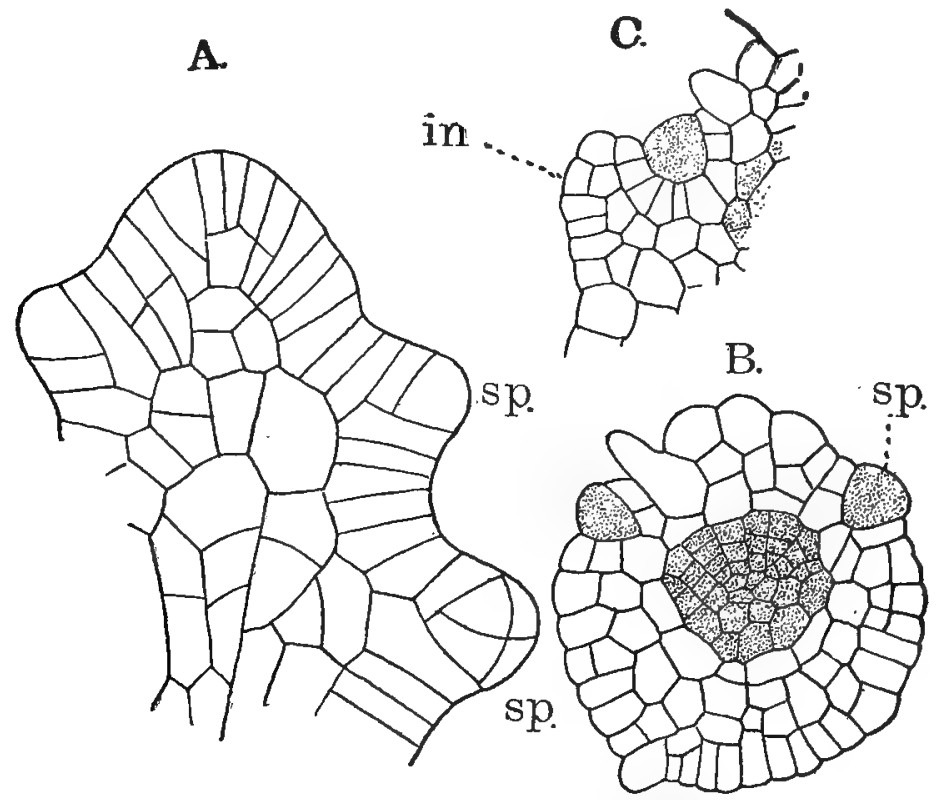

FIG. 226.-A, Apex of a young, fertile leaf-segment of Aneimia Phyllitides, $\times \mathbf{2 0 0}$;

B, transverse section of young fertile leaf-segment of Schizaea Pennula, $\times$ roo;

$C$, part of a similar section ot a somewhat older leaf, $X$ Ioo; $s p$, young sporangia;

in, indusium. (All figures after Crantl.)

roots are always diarch, like the Polypodiaceæ, but gives no further details of their growth or structure.

\section{The Sporangium}

The development of the sporangia has been carefully investigated by Prantl (5) and in origin and arrangement they differ decidedly from the other Leptosporangiates, but approach most nearly Osmunda, and among the eusporangiate Ferns 
show a certain likeness to Botrychimm. The sporangia arise always in acropetal order from the apex of the terminal segments (sorophore) of the sporophyll, and are strictly lateral in origin, not originating from epidermal cells, but from marginal ones. The young sporangium appears as a lateral outgrowth of the margin, exactly like a young pinna upon the main axis, and the young sorophore has the appearance of a young pinnate leaf, and at this stage recalls strongly the similar one in BOtrychium. This is especially marked in Aneimia and Lygo-
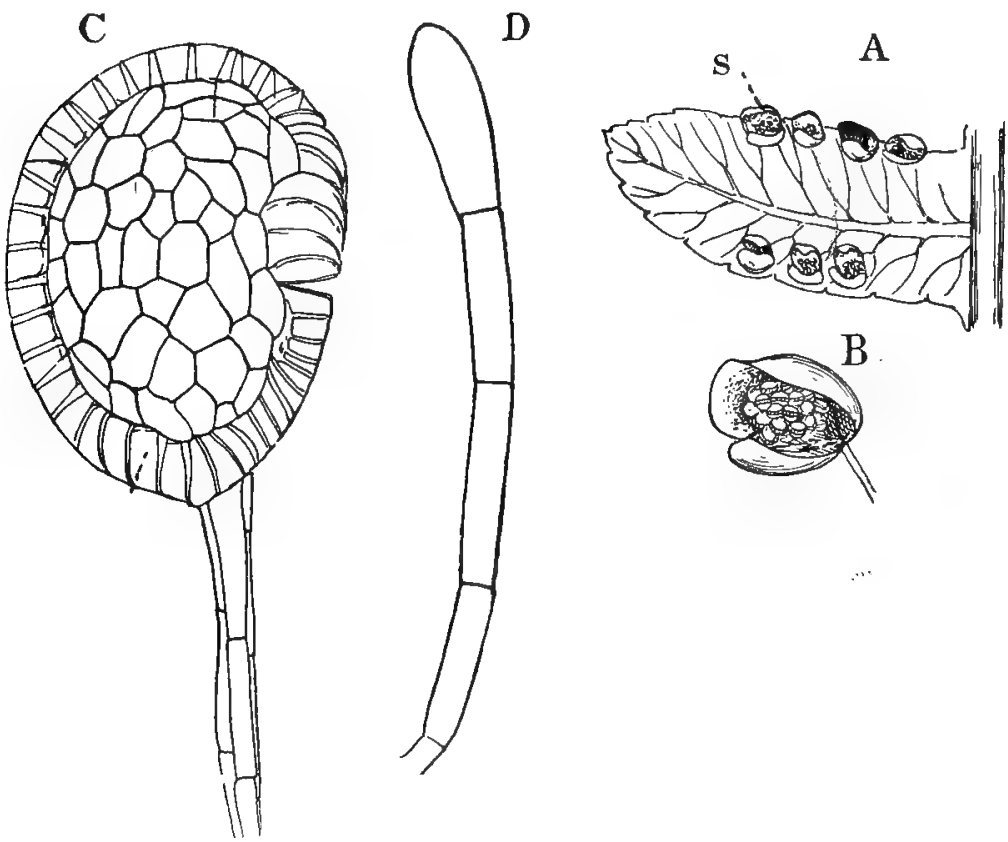

Frg. 227-Cibotium Menziesii. A, Pinnule with the sori ( $s$ ), $\times 3 ; \mathrm{B}$, a single sorus showing the two-valved indusium, $\times_{9} ; \mathrm{C}$, a single sporangium, $\times 80 ; r$, the annulus; $\mathrm{D}$, a paraphysis, $\times 80$.

dium, less so in Schizcea, where the sporangia are smaller, and the mother cells project much more strongly. The early divisions correspond closely with those of the Hymenophyllacer, and as there the tapetum is massive and two-layered, and the stalk of the sporangium very short. The wall is derived in

The divisions in the wall are too complicated to be explained without numerous figures. See Prantl's figures, Plate V.-VIII. 
major part from the cap cell, which in all the forms becomes much more developed than in any other Ferns, and from it alone the apical annulus is derived. In Ancimia and Mohria the tissue of the tip of the leaf adjacent to the sporangia grows into a continuous indusium, which pushes them under to the lower side. In Lygodium (Fig. 224) each sporangium very evidently corresponds to a single lobe of the leaf segment, and has a vein corresponding to this. The pocket-like indusium surrounding each sporangium grows up about it much as the indusium of Trichomanes grows up about the whole sorus.
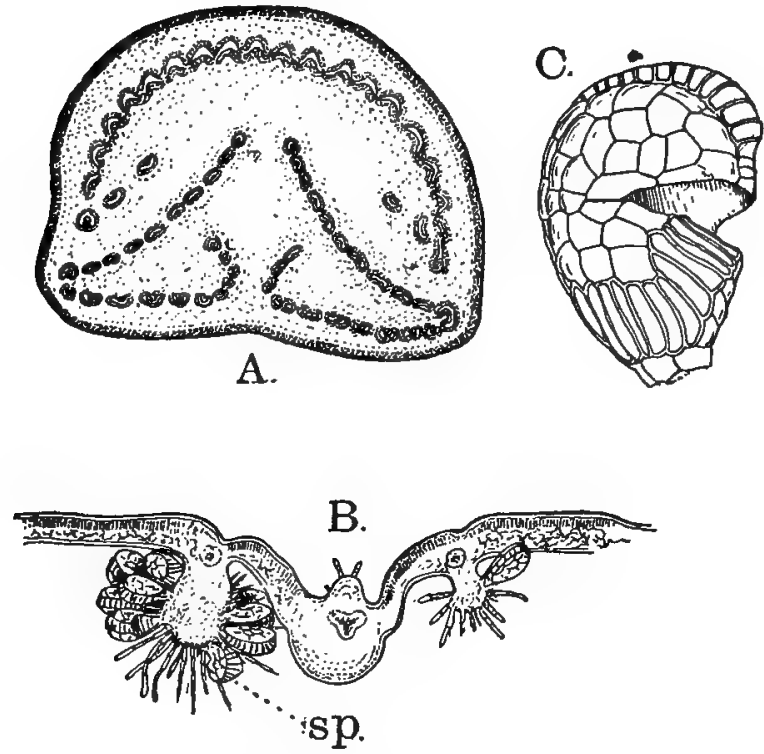

Fig. 228.-Alsophila Cooperi. A, section of the stipe, $X_{11 / 2 ; B}$, cross-section of leaflet, showing the sori, $\times 20 ; C$, open sporangium.

\section{The Cyatheacex}

These are all Ferns of large size, some of them Tree-Ferns, Io metres or more in height. They occur in the tropics of both hemispheres, and some of them, e.g., Dicksonia antarctica, are also found in the extra-tropical regions of the southern hemisphere. They correspond so closely in all respects with the typical Polypodiaceæ that, except for the slightly different annulus, they might be placed in that family. In some forms, 
e. g., Alsophila contaminans, the trunk is quite free from roots, and the leaves fall away, leaving very characteristic scars marked by the vascular bundles. In others, like Dicksonia antarctica, the whole trunk is covered with a thick mat of roots, thicker than the trunk itself.

The prothallium is exactly like that of the Polypodiacea, so far as it has been studied (Bauke (I)), except that in some species of Alsophila there are curious bristle-like hairs upon the upper surface. In the structure of the antheridia the Cyatheaceæ are intermediate in character between the Polypodiaceæ and the Hymenophyllaceæ. The characteristic funnel-formed

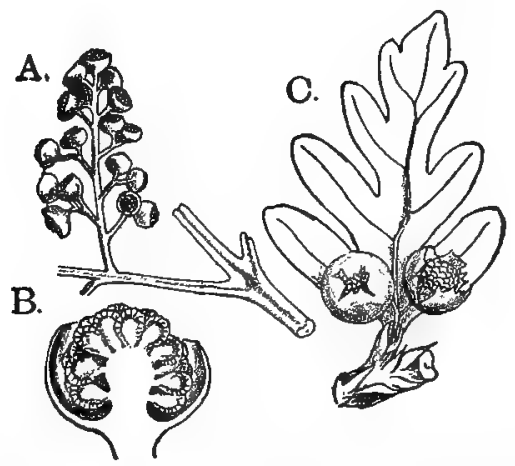

FIG. 229.-A, Part of a sporophyll of Thyrsopteris elegans, $X_{2} ; \mathrm{B}$, section of the sorus, $X \mathrm{ro}$; C, leaflet, with two sori, of Cyathea microphylla. (A, B, after Kunze; C, after Hooker.)

primary wall of the former occurs here, but not until one and sometimes two preliminary basal cells are cut off, as in $O s-$ munda or Hymenophyllum. The following divisions correspond exactly with those of the antheridium of the Polypodiaceæ, except that Bauke states that the cap cell, as well as the upper ring cell, may divide again. The dehiscence is effected either by the separation of an opercular cell or by the rupture of the cap cell. The archegonia are like those of the Polypodiacea. In Cyathea medullaris Bauke figures a specimen, however, where the neck canal cell is divided by a membrane (1. c. Pl. IX, Fig. 8).

The first divisions in the embryo correspond with those of the Polypodiaceæ, but the further development of the young sporophyte is not known. 
The position of the sori is that of the typical Polypodiaceæ, and sometimes a decidedly elevated placenta is present. The indusium is either cup-shaped ( $C$ yathea), or bivalve, e.g., Cibotium (Fig. 229). In the latter the outer valve fits closely over the other like the cover of a box. The sporangia which are either long or short-stalked, although their development has not been followed, correspond so closely in the mature state to those of the Polypodiaceæ that there is little doubt that their development is much the same. The annulus is nearly or quite complete, but above the stomium in Cibotium Menziesii the cells of the annulus are broader but thinner-walled (Fig. 227, C), and Atkinson shows much the same appearance in C.Chamissoi. In the former species the stalk is long and composed of three rows of cells, as in typical Polypodiaceæ. With the sporangia in this species are also numerous long paraphyses (Fig. $227, \mathrm{D})$.

\section{The Parkeriacere (Diels (I), Kny (6))}

This family comprises but a single species, Ceratopteris thalictroides, a peculiar aquatic Fern of wide distribution in the tropics. Unlike most Pteridophytes, Ceratopteris is characteristically annual, although by the formation of adventive buds it may become perennial.

The prothallia are usually diœcious, and the antheridia differ from those of the typical Polypodiaceæ in projecting but little above the surface of the prothallium.

Except for the peculiarities due to its aquatic habit, in which respect it differs from all other homosporous Ferns, the growth of the organs and structure of the tissues is similar to those of the Polypodiaceæ, to which family Ceratopteris is often assigned.

The development of the sporangium is essentially like that of the Polypodiaceæ, but the annulus sometimes shows an incomplete development, probably correlated with the aquatic habit of the plant (Hooker (I), p. I74).

\section{The Polypodiacese}

The Polypodiaceæ may very aptly be compared to the stegocarpous Bryineæ among the Mosses, inasmuch as like that 
group they give evidence of being the most specialised members of the order to which they belong, and comprise a very large majority of the species. Most of them agree closely in their structure, which has been given in detail, and will not be re-
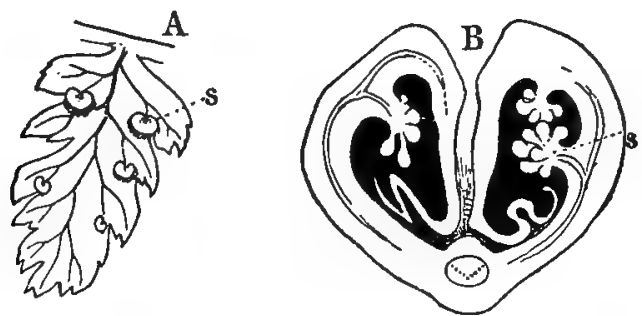

FIG. 230.-A, Pinnule of Aspiditm spinulosum, showing the sori (s) with kidneyshaped indusium, $\times 2^{1 / 2} ; \mathrm{B}$, cross-section of a pinna from a young sporophyll of Onoclea struthiopteris; s, sorus, $\times 25$.

peated here. With very few exceptions the structure of the prothallium and sexual organs is like that of Onoclea, but one or two variations may be mentioned. In Vittaria (Britton and Taylor (2)), is found a type of prothallium recalling that of
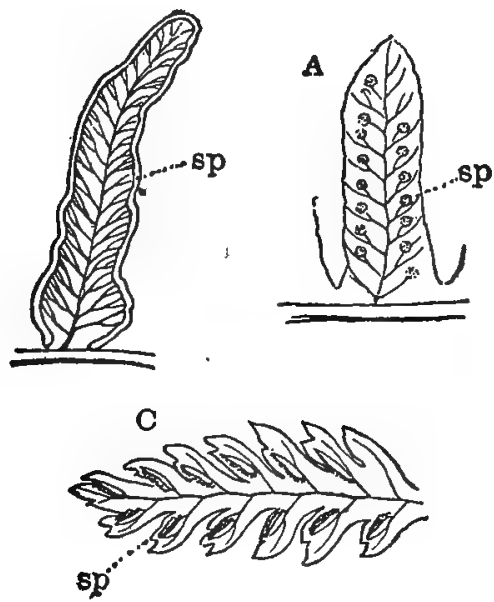

Frg. 23r.-A, Polypodium falcatum. Pinna with sori, sp; natural size. B, Pteris aquilina. C, Asplenium filix-foemina, $\times_{3}$.

Hymenophyllum, both in its large size and extensive branching. Its earlier stages show the ordinary development, but it later branches extensively, and, like Hymenophyllum, numerous groups of archegonia are formed upon one prothallium. Bod- 
ies resembling the oil bodies of Liverworts are also met with in this genus. The sexual organs closely resemble those of the Polypodiacer, but the antheridia have a well-marked stalk, something like that found often in the Hymenophyllaceæ.

Among the many genera and species aside from these, while there is extraordinary variety, the differences are all of secondary importance, and consist mainly in the form and venation of the leaves and the position of the sporangia. The leaves range from the undivided ones of Vittaria or Scolopendrium to the

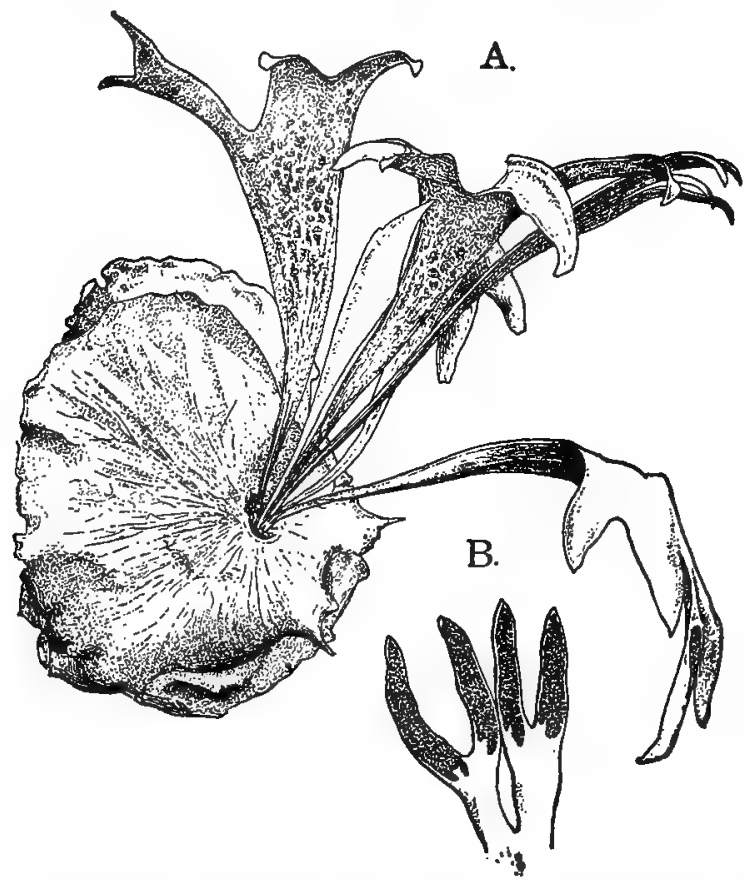

FIG. 232.-Platycerium alcicorne. A, Whole plant, much reduced; $B$, tip of a sporophyll, showing the crowded sporangia. (A, after Coulter; B, after Diels.)

repeatedly divided leaves, usually pinnate, of such forms as Pteris aquilina. In some tropical epiphytic species, such as Asplenium nidus, Platycerium, species of Polypodium, the leaves are arranged so that they form receptacles for collecting humus. In the two latter genera these leaves are very much modified, the two forms of leaves being familiar to all botanists in the common Platycerium alcicorne, where the closely overlapping round basal ones are very highly developed. 
The sporangia may almost completely cover the backs of the sporophylls, as in Platycerium (Fig. 232), or more commonly form definite sori, which may or may not have an indusium. Where the latter is present, it is either formed by the margin of the leaf, as in Adiantum or Pteris, or it may be a special scale-like outgrowth of the lower side of the leaf. In such cases it is a membranaceous covering of characteristic form. Thus in Aspidium (Fig. 230, A) it is kidney-shaped, in Asplenium elongated, and free only along one side. Where, as in Onoclea (Fig. 23o, B), the margins of the sporophyll are involute, so as to completely enclose the sori, the indusium is wanting or very rudimentary. 


\section{CHAPTER XI}

\section{LEPTOSPORANGIATÆ HETEROSPOREÆ (HYDROPTERIDES)}

THE two very distinct families of heterosporous Leptosporangiatæ have obviously but little to do with each other, but, both of them being evidently related to the homosporous forms, they may be placed together for convenience. Each of the two families contains two genera, which in the Marsiliaceæ are closely allied, but in the Salviniaceæ not so evidently so, although possessing many points in common. They are. all aquatic or amphibious plants, and the gametophyte, especially in the Marsiliaceæ, is extremely reduced.

\section{SALViniace $x$}

The two genera, Salvinia and Azolla, contain a number of small floating aquatics which differ very much in the habit of the sporophyte from any of the other Filicineæ, but in the development of the sporangia and the early growth and form of the leaves show affinities with the lower homosporous Leptosporangiatæ, from some of which they are probably derived.

The fully-developed sporophyte is dorsiventral, and the leaves are arranged in two dorsal rows in Azolla, four dorsal and two ventral in Salvinia. The dorsal leaves are broad and overlap, so that they quite conceal the stem. Roots are developed in Azolla, but are quite wanting in Salvinia, where they are replaced physiologically by the dissected ventral leaves (Fig. 233). The sporophyte branches extensively, and these lateral shoots readily separate, and in this way the plants multiply with extraordinary rapidity. The sporangia are enclosed in a globular or oval "sporocarp," which is really an indusium,

'Also known as Rhizocarpex. 

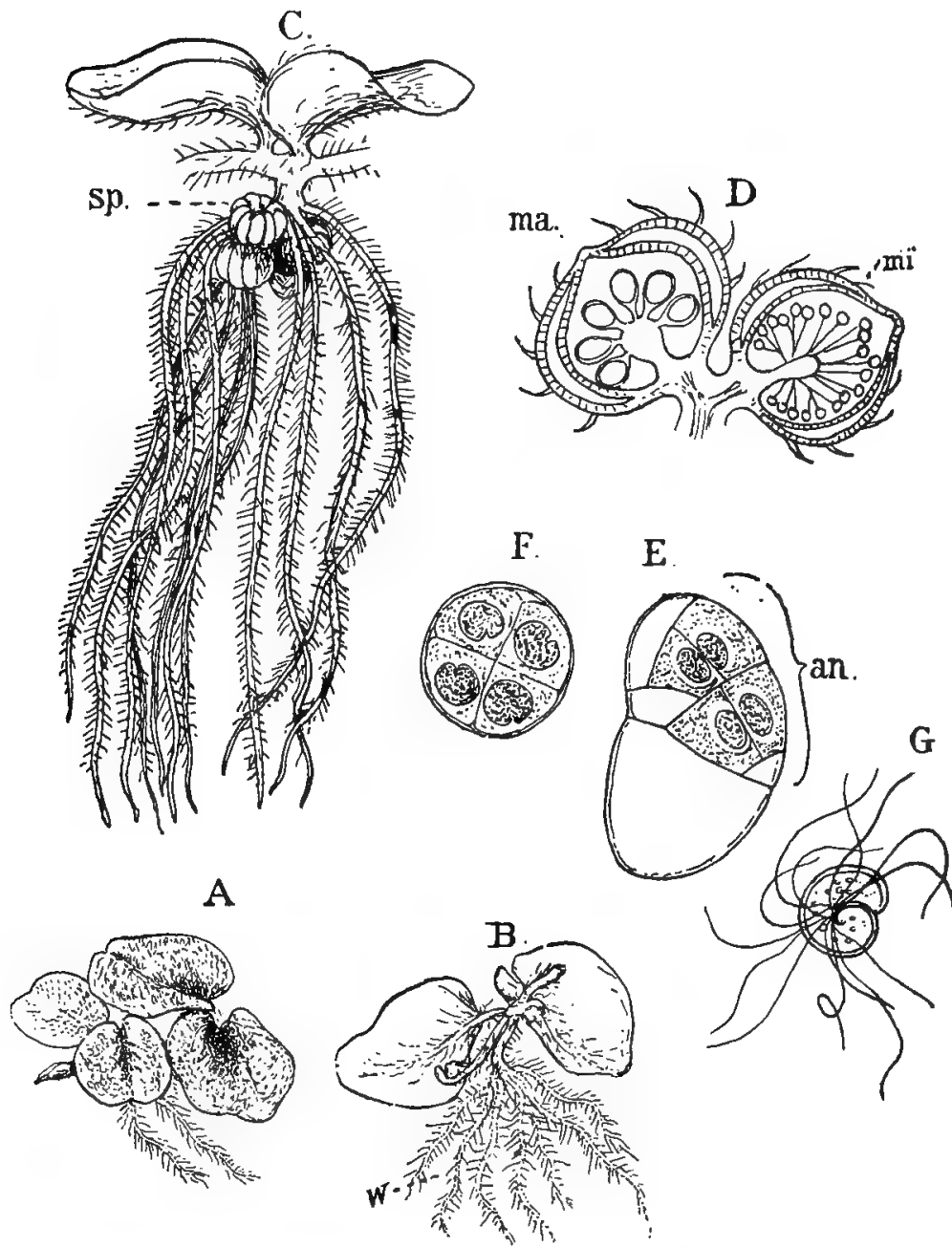

FIG. 233.-Salvinia natans. A, Small plant, $X_{2}$, seen from above; $B$, a similar one from below; $w$, root-like submerged leaf; $C$, fragment of a fruiting plant, $\times 2$; $s p$, sporocarps; D, a macrosporangial ( $m a$ ) and microsporangial ( $m i$ ) sporocarp in longitudinal section (slightly magnified); E, male prothallium with the single antheridium (an) from the side, Xrooo; F, a similar one seen from above; G. spermatozoid (Figs. C, D after Luerssen). 
much like that of some of the Hymenophyllacex and Cyatheaceæ.

\section{The Gametophyte}

The first account of the development of the sexual stage of the Salviniacer that is in the least degree accurate is Hofmeister's ( I ), who made out some of the most important points in the development of the female prothallium. Pringsheim's (I) classic memoir on Salvinia added still more, as well as Prantl (4) and Arcangeli (I), but none of these observers were able to follow accurately the earliest divisions in the germinating macrospores. Berggren's (2) account is the only one on the female prothallium of Azolla, except a paper by the writer, but Belajeff (4) has given an excellent account of the germination of the microspores.

\section{The Male Prothallium}

The microspores at maturity are embedded firmly in a mass of hardened protoplasm, which in Salvinia fills the whole sporangium, but in Azolla is divided into separate masses, "massulæ." The wall of the sporangium in Azolla decays and sets these free in the water, but in Salvinia the wall of the sporangium is still evident when the germination takes place. In the latter the young prothallium grows into a short tube, whose basal part is separated as a large vegetative cell, from whose base later, Belajeff states, a small cell is cut off. The upper cell becomes the antheridium. In it is first formed in most cases an oblique wall, which Belajeff states is always followed by another similar one, which forms a central sterile cell separating the two groups of sperm cells. This cell, however, did not occur in the specimens studied by me, where the two groups of sperm cells were usually in immediate contact (Fig. 233, E). From each of the upper cells peripheral cells are cut off, but they do not completely enclose the sperm cells, which are in contact with the outer wall of the antheridium. A cover cell corresponding to that in the ordinary Fern antheridium is more or less conspicuous. Each of the central cells divides by cross-walls into four, and there are thus eight sperm cells in the ripe antheridium. The spermatozoids of Salvinia have about two complete coils, 
and a smaller number of cilia than is usually the case in the Filicineæ (Fig. 233, G).

In Azolla the contents of the ungerminated microspore, whose wall is thin and smooth, contain but little granular matter. The first indication of germination is the rupturing of the exospore along the three radiating ventral ridges, and the protrusion of a small papilla. This is cut off by a transverse wall near the top of the spore cavity, and forms at once the mother cell of the single antheridium (Fig. 234, C). Belajeff
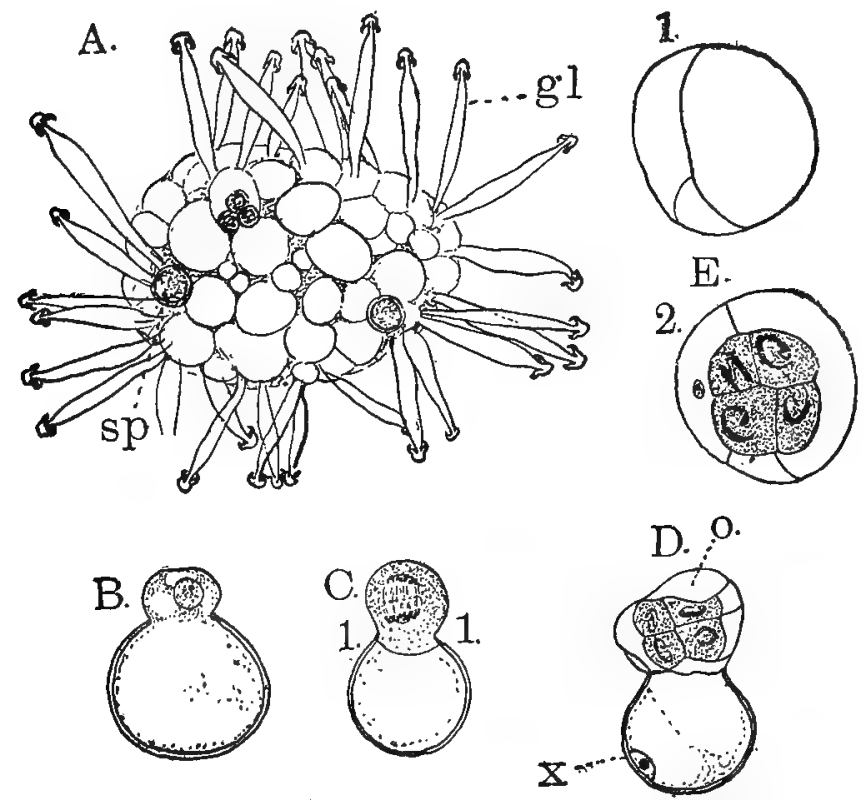

FIG. 234.-Azolla filiculoides. A, Massula with enclosed microspores $(s p), \times 250 ; g l$. glochidia; B-D, development of male prothallium and antheridium, $\times 560$; $v$, opercular cell; E, cross-sections of a ripe antheridium, $\times 750 ; 1$, the top; 2 , nearly median section; $*$, second prothallial cell.

( (3), p. 329) says the next divisions are nearly parallel and divide the antheridium into three cells, one above the other, and of these only the middle ones divide further. For some reason, which is not quite clear from his account, Belajeff does not regard the whole upper cell as an antheridium, but says that the latter is only formed after five vegetative cells have been cut off. It seems much more in accordance with the structure found in the related homosporous Ferns to regard the whole 
upper part of the prothallium as the antheridium. In spite of his statement that the development of the male prothallium has little in common with the true Filices, his figures of Azolla are extraordinarily like the simple male prothallia that sometimes occur among the Polypodiaceæ.

In my earlier studies of the male gametophyte, the second prothallial cell ( $F$ ig. 234, $x$ ), described by Belajeff, was overlooked, but subsequent examination of my preparations showed that it was present.

The subsequent divisions correspond to Belajeff's account. In the middle cell of the antheridium two nearly vertical walls are formed, which with the top cell (cover cell) completely enclose the central one. The cover cell recalls in form and position the same cell in the antheridium of the Polypodiacer, but is formed here previous to the separation of the central cell. In one of the lateral cells a horizontal wall is formed, so that the sperm cells are surrounded by five parietal ones. The central cell now divides by a median vertical wall, and each of the daughter cells twice more, so that eight sperm cells are formed, as in Salvinia. The prothallium remains embedded in the substance of the massula, and the spermatozoids probably escape by the softening of the outer part of the latter. In Salvinia the prothallia project beyond the sporangium wall, and are easily detached.

The antheridium of the Salviniaceæ does not closely resemble that of any other group. Azolla differs less from the homosporous Ferns in this particular, and shows some resemblance to the Hymenophyllaceæ in the arrangement of the parietal cells. Occasionally a triangular opercular cell occurs in Azolla, which recalls that in Osmunda.

\section{The Female Prothallium}

The macrospores of Azolla filiculoides are borne singly in the sporangia. The spores only germinate after they have been set free by the decay of the indusium, the upper part of which, however, persists as a sort of cap. The decay of the sporangium wall and indusium exposes the curious tuberculate epispore, with its filamentous appendages, which serve to hold the massulæ, which are firmly anchored to them by their peculiar hairs (glochidia) with their hooked tips. This is evi- 
dently of advantage in bringing the male and female plants together.

The macrospores germinate most promptly in the early autumn, and in California, where this species is abundant, this is probably the natural time for germination. As the first stages of germination take place within the completely closed spore, it is difficult to tell precisely just when it begins. So nearly as could be determined, the first division may take place within two or three days, and the whole development be completed within a week.

A section of the ripe spore, still within the sporangium, shows its contents to be nearly uniform, and much like that of Isoetes. The nucleus is here at the apex of the spore cavity and not conspicuous. It is somewhat elongated and stains but little. No nucleolus can be seen.

The first sign of germination is an increase in the size of the nucleus, which becomes nearly globular, and a small nucleolus becomes evident. At the same time the cytoplasm about it becomes free from large granules and indicates the position of the mother cell of the prothallium. This upper part of the spore cavity is now cut off by a nearly straight transverse wall, and this small lenticular cell becomes the prothallium. The granules in its cytoplasm are finer than those in the large basal cell, and the nucleus stains strongly and shows a large nucleolus. The nucleus of the lower cell remains in the upper part, and is much like that of the prothallial cell.

The first division wall in the upper cell is vertical and divides it into two cells of unequal size. In a prothallium having but three cells, the second wall was also vertical, but in others it looked as if it were horizontal, which Prantl ((4), p. 427) states is the case in Salvinia. From the upper of the cells formed by the first horizontal wall the first archegonium arises. If the horizontal wall forms early, the primary archegonium is nealy central, but if two vertical walls precede it, its position is nearer the side opposite the first cell cut off. In the few cases where successful cross-sections of the very young prothallium were made, the archegonium mother cell was decidedly triangular, showing that it was formed by three intersecting walls, as in Isoetes. It divides into an outer and inner cell, the latter, as in Isoetes, giving rise at once to egg and canal cells, without the formation of a basal cell. 
Up to this point the exospore remains intact; the central cell of the archegonium is only separated from the spore cavity by a single layer of cells, and the young prothallium agrees closely with Prantl's account of the similar stage of Salvinia (Fig. 235, A, B). Berggren's figures of $A$. Caroiniana, at a stage presumably the same, are too diagrammatic to allow of a satisfactory comparison.

Shortly after the first division in the archegonium a rapid increase takes place in the size of all the cells of the prothaljium, by which it expands and ruptures the exospore, which breaks open by three lobes at the top.
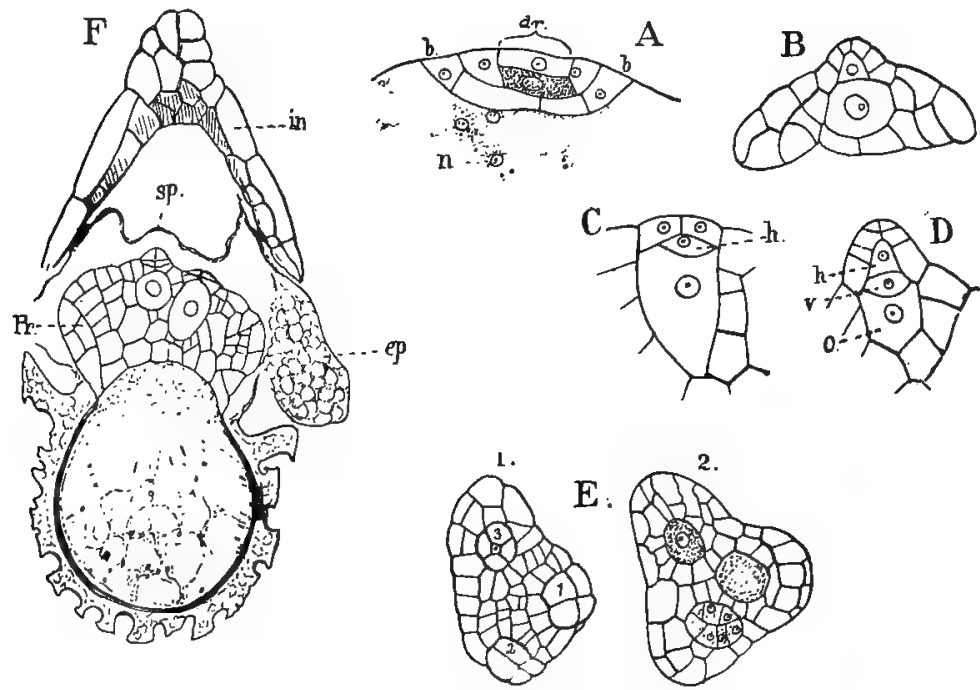

FIG. 235.-Azolla filiculoides. A, Lungitudinal scetion through the upper part of the germinating macrospore, $\times 220 ; b, b$, the basal wall of the prothallium; $a r$, young archegonium; $n$, free nuclei; $\mathrm{B}$, similar section of a nearly developed female prothallium, $\times 220 ; \mathrm{C}, \mathrm{D}$, archegonia, $\times_{375 ;} h$, neck canal cell; $v$, ventral canal cell; $o$, egg; E, two transverse sections of a prothallium with the three first archegonia, $\times 160 ; F$, median section of a macrospore with large prothallium $(p r), \times 65 ; i n$, indusium; $s p$, remains of sporangium wall; $e p$, perinium.

The most remarkable difference between Azolla and the other Hydropterides is the further development of the lower of the two primary nuclei. ${ }^{1}$ In Azolla it undergoes repeated divisions, and the resulting nuclei remain embedded in the protoplasm in close proximity to the lower cells of the pro-

${ }^{2}$ Recently Coker (I) has observed a fragmentation of the nucleus in Marsilia. 
thallium (Fig. 235, A). This nucleated protoplasm is free from the large albuminous granules in the lower part of the spore cavity, and in stained sections presents a finely granular appearance, and is evidently concerned with the elaboration of the reserve food materials in the large spore cavity. In exceptional cases indications of the formation of cell walls between these nuclei were seen, but usually they remained quite free. Whether a similar state of affairs exists in Salvinia remains to be seen.

When the first archegonium is ripe, the prothallium is nearly hemispherical, with the originally convex base strongly concave. The central cell of the archegonium is separated by one, sometimes two, layers of cells from the spore cavity, and the neck projects considerably above the surface of the prothallium. The latter now pushes up between the softened episporic mass at the top of the spore, and the archegonium is exposed. In cross-section the prothallium is more or less triangular (Fig. $235, \mathrm{E}$ ), with one angle longer than the others. This longer arm corresponds to the "sterile third" of the prothallium of Salvinia, and represents the first cell cut off from the prothallium mother cell.

If the first archegonium is fertilised, no others are formed; but usually several secondary ones are present. The second archegonium arises close to the primary one; indeed its central cell is generally separated from it only by a single layer of cells. The third arises near the base of the larger lobe (Fig. $235, \mathrm{E})$. In case all of these prove abortive, others develop between them apparently in no definite order, and to the number of ten or occasionally more. In the older prothallia these later archegonia are sometimes borne in small groups upon elevations between the older ones.

The neck canal cell of the archegonium is formed much earlier than Pringsheim describes in Salvinia, and is cut off from the central cell about the time the first divisions take place in the cover cell. Each row of the neck has four cells, as in Salvinia, and the neck canal cell may have its nucleus divide, as in Isoetes and the homosporous Filicinea. This has not yet been observed in Salvinia.

In Salvinia (Pringsheim ( I), Prantl (4)) the prothallium is large and develops a good deal of chlorophyll. It has a very characteristic appearance, and shows the same triangular form 
that Azolla does, but from two of the corners long wing-like appendages hang down, and the whole prothallium is saddleshaped. The side joining the two wings is the front, and the primary archegonium occupies the highest point, as in Azolla,
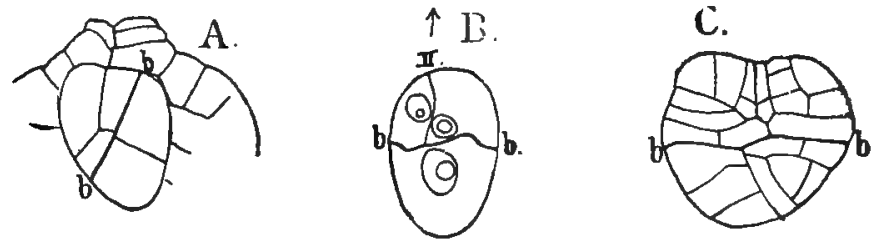

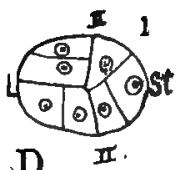

D.
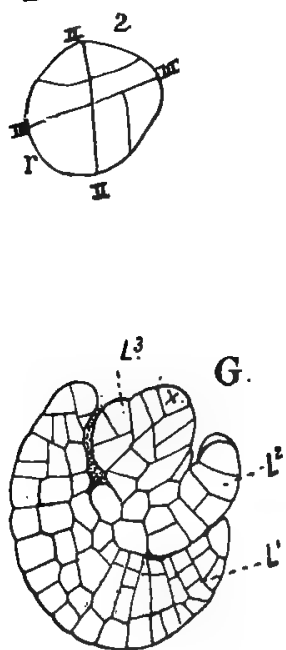
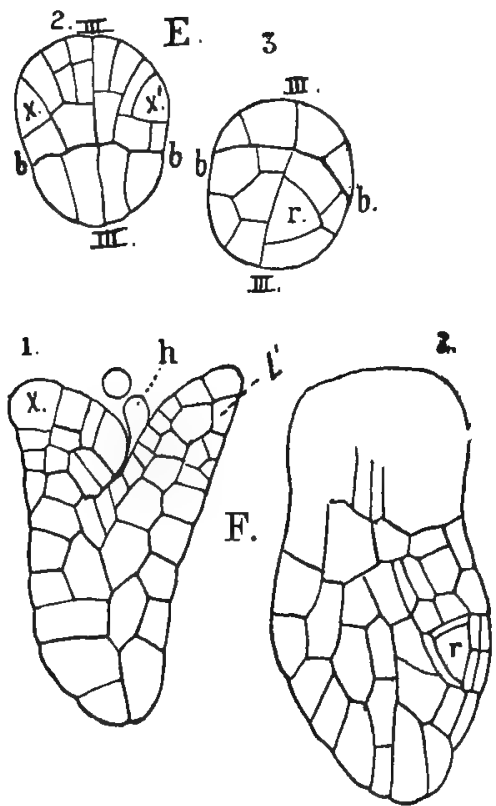

FrG. 236.-Azolla filiculoides. Development of the embryo, $\times 350 . \quad A, B, C, Y o u n g$ embryos in median longitudinal section; D, two horizontal sections of a young embryo; $\mathrm{E}$, three transverse sections of a somewhat older one; $x^{*}, x^{*}$, initial cells of the cotyledon; F, two longitudinal sections of an advanced embryo; G, horizontal section of an older one, with the rudiments of the second and third leaves; $b, b$, basal wall of the embryo; st, stem; $L^{x}$, cotyledon; $r$, root; $h$, hairs; $x$, apical cell of the stem; $\mathrm{L}^{2}, \mathrm{~L}^{3}$, second and third leaves.

and the two secondary ones form a line with it parallel to the forward edge, which develops a meristem and other archegonia in rows parallel to the first ones, in case these fail to be fertilised.

In Azolla the prothallium has but little power of independ- 
ent existence, and even when unfertilised develops but little chlorophyll. No rhizoids occur (this seems to be true of Salvinia also), and the growth only proceeds until the materials in the spore are exhausted. To judge from Berggren's figures A. Caroliniana has a larger prothallium but fewer archegonia than $A$. filiculoides.

\section{The Embryo}

The fertilised ovum, previous to its first division, elongates vertically. The basal wall is usually transverse instead of longitudinal, as in the other Leptosporangiates, although in exceptional cases it may approach this position in Azolla. From the epibasal half in the latter arise, as in the other Leptosporangiatæ, the cotyledon and stem apex; from the hypobasal, foot and root. The quadrant walls do not always arise simultaneously, but as soon as they are formed the primary organs of the embryo are established and are arranged in the same way as in other Ferns. Berggren asserts that the root does not develop until later, and is derived from the foot; but in sections it is very evident from the first, and corresponds in position exactly with that of other Leptosporangiates.

In all but the stem quadrant the octant walls are exactly median, and this may be true of the latter; but in the stem quadrant the octant wall may make an acute angle with the quadrant wall, and the larger of the two cells then forms at once the two-sided apical cell of the stem, and from now on divides alternately right and left. Where the octant wall is median, it is probable, although this. could not be positively proved, that the stem apex forms for a short time three sets of segments instead of two.

In the cotyledon the median octant wall is followed by a vertical wall in each octant, forming two cells that appear respectively triangular and four-sided. The former have larger nuclei and divide for a time after the manner of two-sided apical cells, and perhaps the first division of the leaf quadrant may be of the nature of a true dichotomy, and these cells are the apical cells of the two lobes. In the four-sided cell, the radial and tangential divisions succeed each other with much regularity. By the growth of the two initials (Fig. 236, E, $\left.x, x^{\prime}\right)$ the young cotyledon rapidly grows at its lateral margins 
and bends forward so as to enclose the stem apex. At the same time the upper marginal cells divide rapidly by oblique walls alternately on the inner and outer sides, so that the cotyledon also increases in length, and by this time it is about four cells thick.

As soon as the apical cell of the stem is established, it grows very much as in the mature sporophyte. Each segment divides into a ventral and dorsal half, and each of these into an acroscopic and basiscopic portion. In case the stem octants are equal at first it is not possible to say which is to form the stem apex, but this is determined by the first division in each cell. One of them divides by a vertical wall into equal parts and becomes the second leaf; the other forms the stem apex. If the octants are unequal, the smaller one always forms the leaf. At the base of the cotyledon, between it and the stem, is a group of short hairs (Fig. 236, F, $h$ ).

The primary root of Azolla arises in exactly the same way as that of the typical homosporous Leptosporangiatæ, except that here the two root octants seem to be always equal in size, and as practically only one of them forms the root, the other dividing irregularly and becoming merged in the foot, the root is more or less decidedly lateral (Fig. 236, E). After one complete set of lateral segments has been formed, the primary cap segment is cut off from the outer face, but, unlike the other Ferns, this is the only one formed. The cap cell divides later by periclinal walls, so that there are two layers of cells covering the apical cell, and these are continuous with the epidermis of the rest of the embryo, and continue to grow at the base, so that a two-layered sheath is formed about the young root. The lateral segments are shallow and arranged very symmetrically, and the divisions correspond to those in the other Ferns.

The divisions in the foot are more regular than is usually the case, and this is especially noticeable in sections cut parallel to the quadrant wall (Fig. 236, E). The general arrangement of the cells is quite like that of the cotyledon, but the divisions are fewer and the cells larger. Corresponding to the upward growth of the cotyledon, the foot elongates downwards beyond the base of the root, which thus appears as a lateral growth from it, and no doubt led to Berggren's mistake concerning its origin.

Salvinia in its early stages is much like Azolla, but, accord- 
ing to Leitgeb, ${ }^{1}$ the apical cell of the stem is always three-sided at first, and only later attains its permanent form. The root remains undeveloped, and no later ones are produced, but the first divisions in what corresponds to the root quadrant in Azolla are apparently very similar to those of that plant, and it would perhaps be more correct to say that the primary root remains undeveloped rather than to consider it as completely absent (Dutailly ( I ) ).

The second leaf in the embryo of Azolla arises practically from the first segment of the stem apex, and each subsequent segment also produces a leaf. The early growth in length of
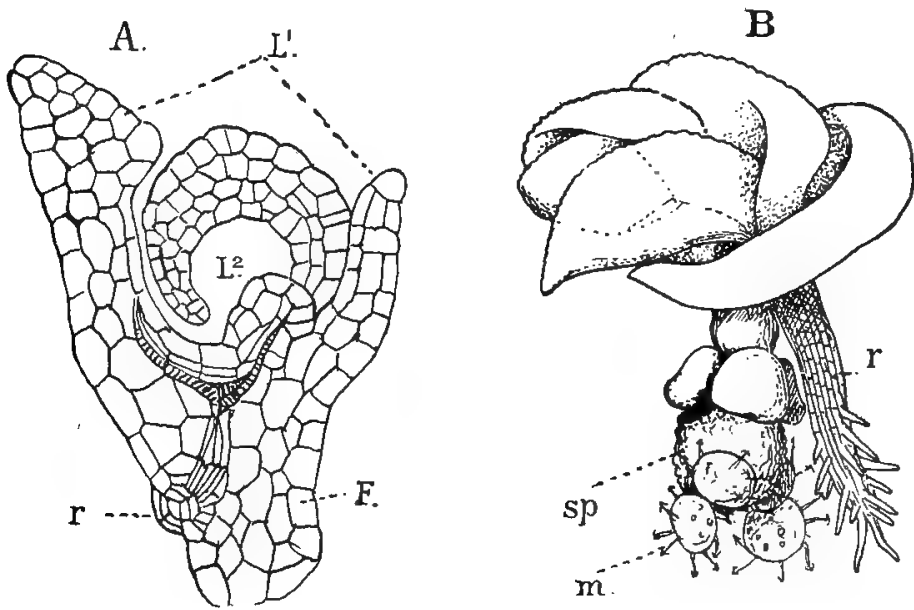

FrG. 237.-Azolla filiculoides. Nearly median section of the young sporophyte after it has broken through the prothallium, $\times 100 ; B$, an older plant with the macrospore $(s p)$ still attached; $m$, massulæ attached to the base of the macrogpore; $r$, the primary root, $\times 40$.

the primary root is slow, and it does not become conspicuous until a late stage. The vascular bundles are poorly developed and arise relatively late. No trace of them can be seen until the second leaf is well advanced. Their origin and development correspond to those in other forms described. The tracheary tissue is composed entirely of small spiral tracheids,

The second root arises close to the base of the second leaf, and like all the later ones is of superficial origin. As the cotyledon grows, large intercellular spaces form in it, and the young

${ }^{2}$ Leitgeb, see Schenk's "Handbuch der Botanik," vol. i. p. 216. 
sporophyte breaks away from the spore or carries the latter with it to the surface of the water. As the embryo breaks though the episporic appendages at the top of the spore, these are forced apart and the cap-shaped summit of the indusium is thrown off. The cotyledon is funnel-shaped, with a cleft on one side, and completely surrounds the stem apex. The root is still inconspicuous, and forms only a slight protuberance upon one side of the foot, which looks like a short cylindrical stalk (Fig. 237).
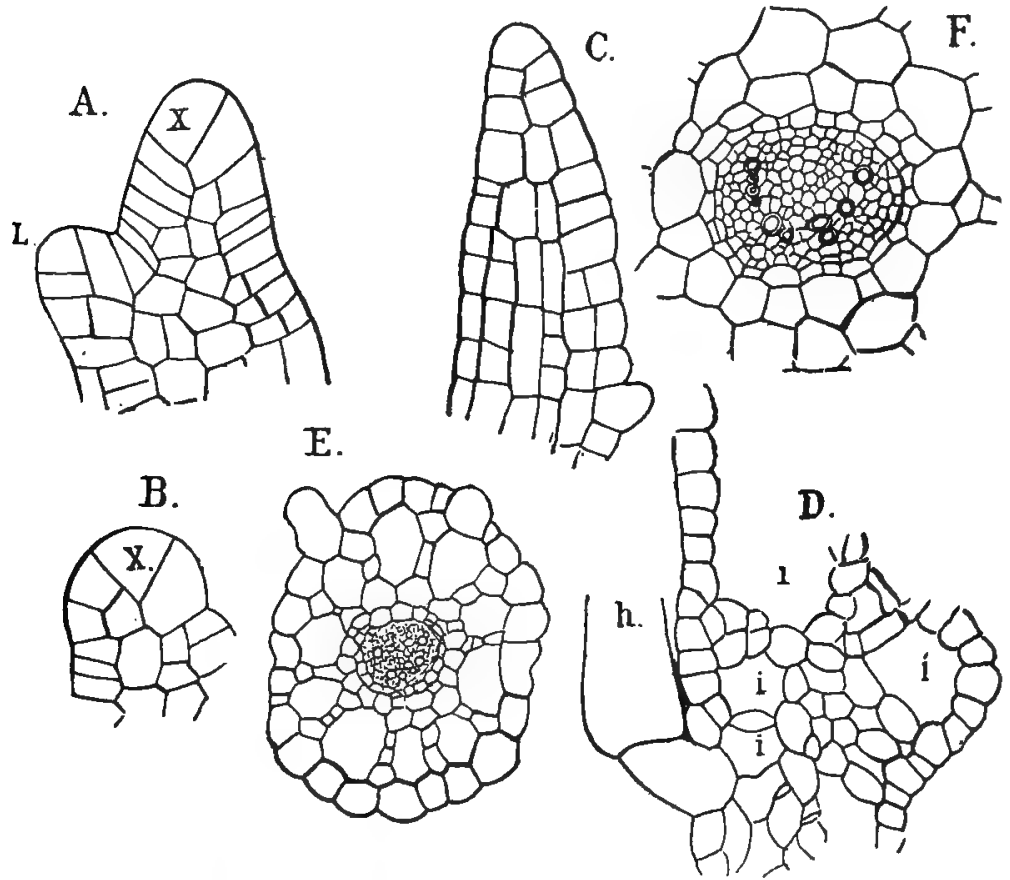

FIG. 238.-Salvinia natans. A, Horizental section of the stem apex, $\times 450 ; \mathrm{L}$, young leaf; $B$, a young leaf, showing the apical cell $(x), X_{450}$ C, longitudinal section of a segment of a ventral leaf, $X_{450} ; \mathrm{D}$, section of a dorsal leaf; $i$, lacunæ; $h$, hair, $X 225 ; E$, cross-section of the stem, $X_{50} ; F$, the vascular bundle, $X 225$.

The growth of the first root is limited, and it differs from the later ones by forming peculiar stiff root-hairs. The later roots, except the second, do not seem to bear any definite relation to the succeeding leaves.

A careful examination of the ripe macrosporangium shows a number of colourless small round bodies occupying the space 
between its upper wall and the indusium. These are the resting cells of a Nostoc-like alga-Anabana Azolla,-which is always found associated with this plant. At the same time that the embryo begins to develop, these cells become active, assume the characteristic blue-green colour of the growing plant, and divide into short filaments that at first look like short Oscillarice. The cells soon become rounded, and heterocysts are formed. Some of these filaments remain entangled about the stem apex of the embryo, while others creep into special cavities which are found in all the leaves except the cotyledon, and here develop into a colony.

The first branch is formed after the plant has developed about eight leaves, but whether its position is constant was not determined

\section{The Mature Sporophyte}

Strasburger (6) has investigated very completely the tissues of the mature sporophyte of Azolla, and Pringsheim (I) has done the same in Salvinia, so that these points are very satisfactorily understood.

The growing point of the stem in Azolla (Fig. 240, A) is curved upward and backward, in Salvinia (Fig. 238, A) it is nearly horizontal. In both genera there is a two-sided apical cell from which segments arise right and left. Each segment divides into a dorsal and ventral cell, and a transverse section just back of the apex shows four cells arranged like quadrants of a circle. In Azolla the dorsal cells develop the leaves, the ventral ones the branches and roots. Each semi-segment is divided into an acroscopic and basiscopic cell, and these are further divided into a dorsal and lateral cell in the upper ones, into a ventral and lateral one in the lower. The leaves arise from one of the dorsal cells, which may be either acroscopic or basiscopic, but is always constant on the same side of the shoot, so that the two rows of leaves alternate. The lateral buds, which do not seem to appear at definite intervals, arise from one of the upper cells of the ventral segment, and alternate with the leaves on the same side of the stem.

The mother cell of a leaf is distinguished by its size and position (Fig. 240, B, III, L), and the first division wall, as in the cotyledon, divides it into two nearly equal lobes. No trace 
of an apical cell can be found in the young leaf, and in this respect, as well as the secondary divisions of the stem segments, Azolla differs from Salvinia, where for a long time the young leaves grow, as in most Ferns, by a two-sided apical cell (Fig. $238, \mathrm{~B}$ ). Each leaf lobe in Azolta is divided into an inner small cell and an outer larger one, and the latter is then divided by a radial wall. This formation of alternating tangential and radial walls is repeated with great regularity, and can be traced

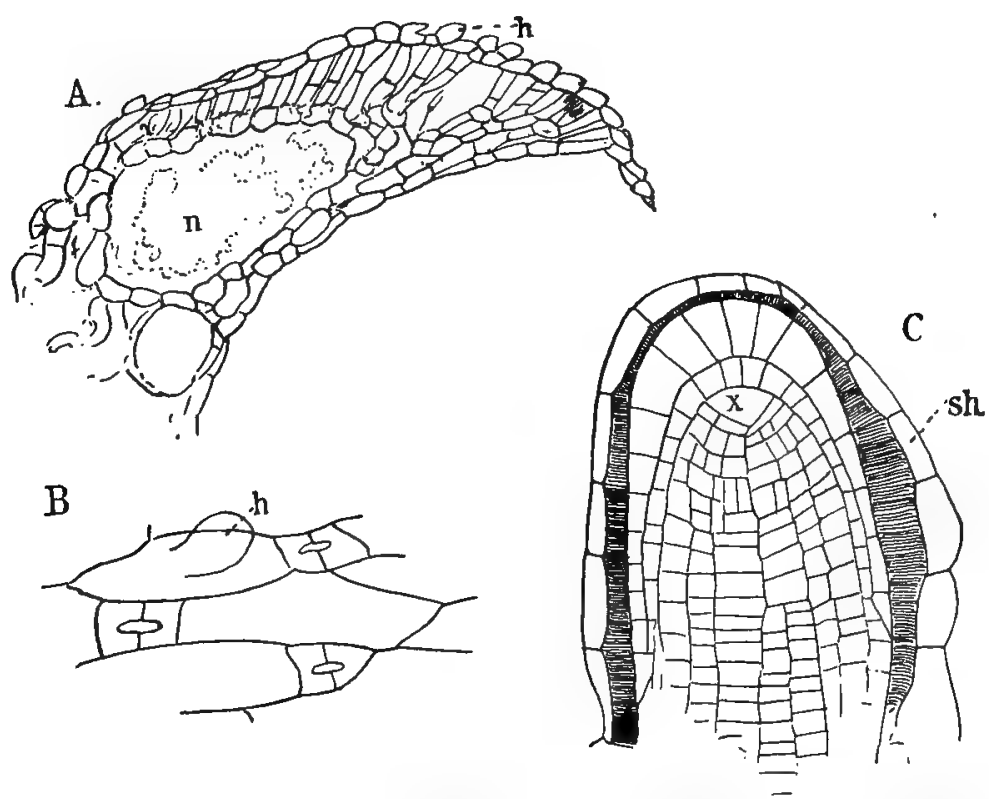

Fig. 239.-Azolla filiculoides. A, Longitudinal section of a dorsal lobe of the leaf, $X$ about $40 ; n$, cavity with colony of Anabcna; $h$, unicellular hairs; B, epidermis with stomata, $\times 150$ (after Strasburger); C, longitudinal section of young root, $\times 225 ; s h$, root-sheath.

for a long time. It is not unlike the arrangement of cells figured by Prantl ( (I), Pl. I, Figs. 2, 3) in some of the Hymenophyllaceæ.

The fully-developed leaves of $A z o l l a$ are all alike. In $A$. filiculoides the two lobes are of nearly equal size, the lower or ventral one, which is submersed, somewhat larger, but simpler in structure. The dorsal lobe shows a large cavity near its base (Fig. 239, A), which opens on the inner side by a small pore. On the outer side the epidermal cells are produced into short 
papillate hairs, which in some species, e.g., A. Caroliniana, are two-celled. Stomata of peculiar form (Fig. 239, B) occur on both outer and inner surfaces. The bulk of the leaf is composed of a sort of palisade parenchyma, and the cavity is partly encircled by an extremely rudimentary vascular bundle. The ventral lobe of the leaf is but one cell thick, except in the middle, where there is a line of lacunar mesophyll, traversed by a simple vascular bundle.

In Salrinia the leaves are of two kinds. The dorsal ones are undivided, and traversed by a single vascular bundle. The mature leaf shows two layers of large air-chambers, separated only by a single layer of cells, whose walls are like those of the epidermis. From both upper and lower surfaces, but especially the former, numerous hairs develop. The ventral leaves are repeatedly divicled, and each segment grows by a definite apical cell; the segments are long and root-like, and covered with numerous long delicate hairs, looking like rhizoids. These submersed leaves doubtless replace the roots. The leaves in Salvinia are arranged in alternating whorls of three, corresponding to the nodes, and this arrangement accounts for the six rows of leaves previously referred to.

The mature stem shows a central concentric vascular bundle (Fig. 238, E, F), whose tracheary tissue is somewhat more compact and the trachere in Azolla than in Salvinia. This is surrrounded by a definite endodermis and one or two layers of larger parenchyma cells, and radiating from the latter are plates of cells separated by large air-spaces, and connecting the central tissue with the epidermis (Fig. 238, E).

The lateral branches arise in acropetal order, but apparently not always at equal intervals. Their development is a repetition of that of the main axis. Like the branches, the roots in Azolla arise acropetally, and their number is very much less than the leaves. They arise from superficial cells and follow exactly in their development the primary root of the embryo. The inner layer of cells of the sheath, however, in these later roots becomes disorganised, and there is a space between this and the root itself. A single root-cap segment only is formed subsequent to the primary one from which the sheath forms, and this secondary cap segment undergoes division but once by periclinal walls (Fig. 239, C).

Iueavitt (I) found in the older roots of both $A$. fliculoides 
and $A$. Caroliniana numerous root-hairs, which arise from definite cells, evident while the "epiblema" or superficial layer of the root is still actively dividing-a condition which also occurs in many other Pteridophytes. "The initials for these root-hairs arise within a belt of actively dividing cells lying immediately under the inner root-cap, not far from the apex, ...... As the root reaches the limit of its development, the hair-forming impulse travels downward until the apical cell itself is split into several parts, each one piliferous." (1. c., p. 4I6, 4I7.)

\section{The Sporangia}

The sporangia in both genera are contained in a so-called sporocarp, which is really a highly-developed indusium. These sporocarps always arise as outgrowths of the leaves, in Salvinia from the submersed leaves, in Azolla from the ventral lobes. In Salvinia several are formed together (Fig. 233, C), in Azolla two, except in $A$. Nilotica, where there are four. Each sporocarp represents the indusiate sorus of a homosporous Fern.

In Azolla filiculoides these sori arise, as Strasburger ( (6), p. 52) showed, from the ventral lobe of the lowest leaf of a branch. My own observations in regard to the origin differ slightly from Strasburger's in one respect. Instead of only a portion of the ventral lobe going to form the sori, the whole lobe is devoted to the formation of these, and the involucre which surrounds them is the reduced dorsal lobe of the leaf, and not part of the ventral one.

The leaf lobe, as soon as its first median division is complete, at once begins to form the sporocarps, each half becoming transferred directly into its initial cell. In this, walls are formed, cutting off three series of segments (Fig. 240, D). Next a ring-shaped projection arises about it, and this is the beginning of the indusium ( $i d$ ) or sporocarp, which bears exactly the same relation to the young sorus that it does in Trichomanes, and Salvinia shows the same thing. From this point the two sorts of sporocarps in Azolla differ. In the macrosporic ones the apical cell develops directly into the single sporangium; in the microsporangial sorus the apex of the receptacle, which probably represents an abortive macrosporangium (Goebel (22), p. 669) forms a columella from whose base the microsporangia develop. (Fig. 24I, A.) 

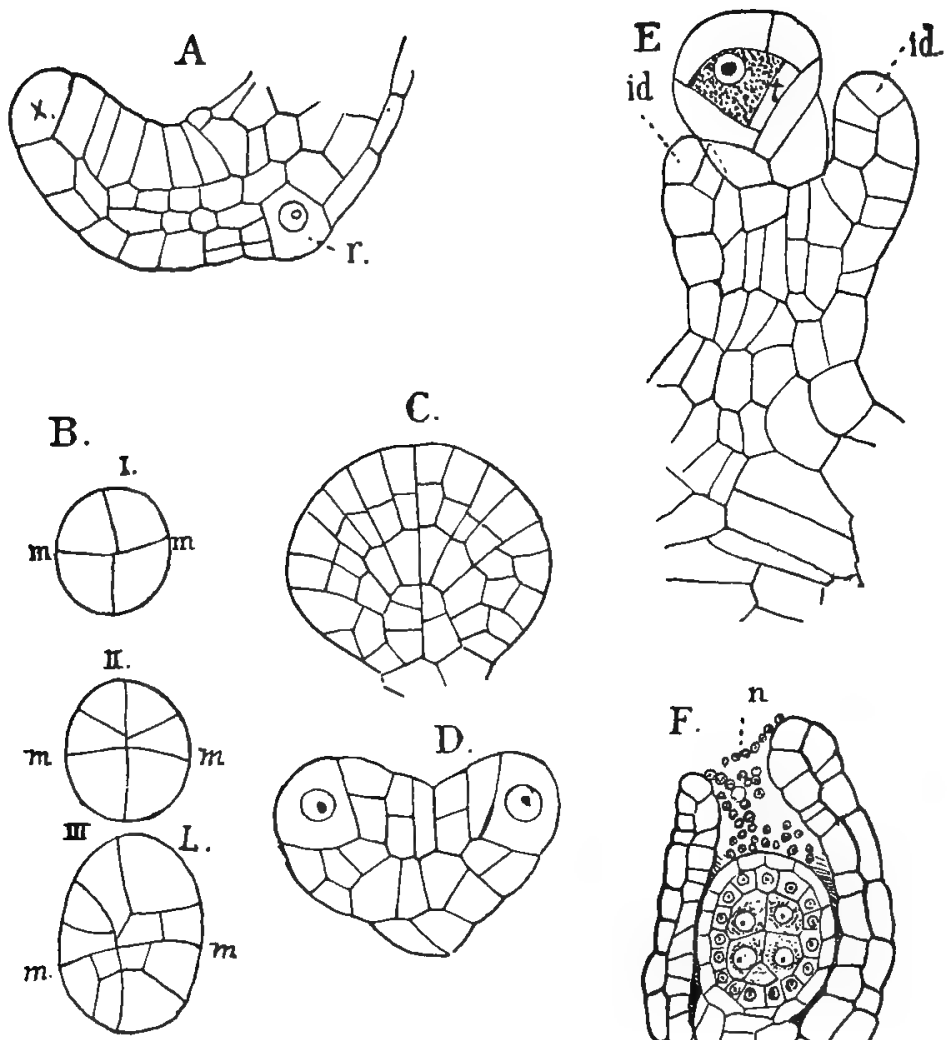

C.
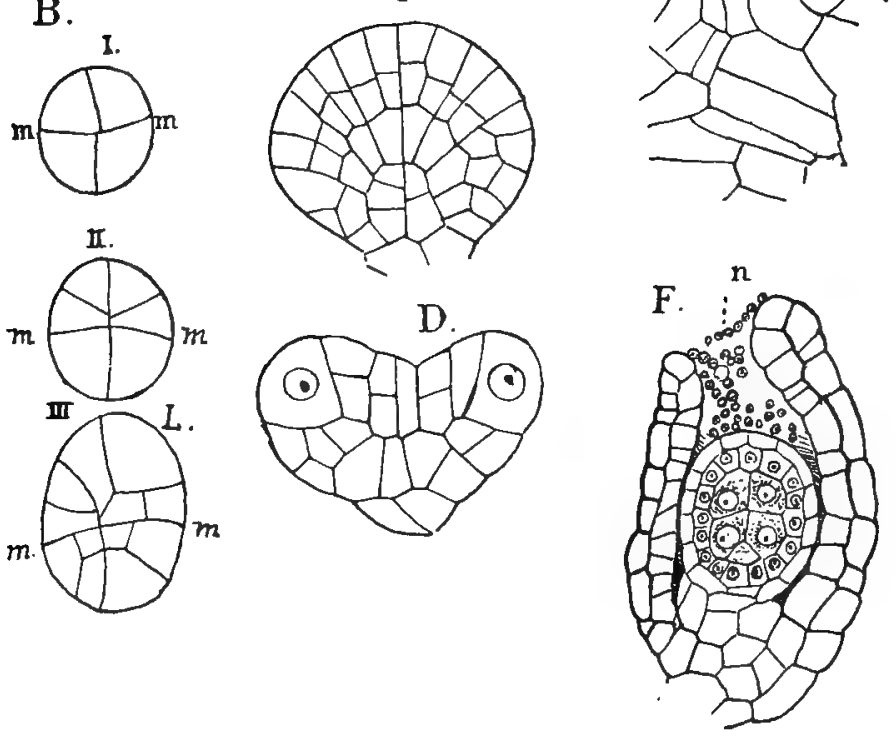

Fig. 240.-Azolla filiculoides. A, Vertical longitudinal section of the stem apex, $\times 600$; $r$, mother cell of a root; $B$, three successive transverse sections just back of the apex; $m$, the median wall; $L$, mother cell of a leaf, $\times 600 ; C$, single lobe of a young sterile leaf, $\times 600 ; D$, fertile leaf segments with two very young sporocarp rudiments, $\times 600 ; \mathrm{E}$, longitudinal section of young macrosporangium, showing the young indusium $(i d), \times 600 ; t$, first tapetal cell; $F$, older macrosporangium completely surrounded by the indisium, $\times 35^{\circ} ; n$, Anabana filaments. 
The development of the sporangium follows closely that of the other Leptosporangiatæ up to the final development of the spores. The tapetum is composed of but a single layer of cells in Azolla, but in Salvinia it usually becomes double (Jurányi (I) ). In both genera the wall remains single-layered, and no trace of an annulus can be detected.

In the macrosporangium of Azolla the archesporium produces eight sporogenous cells, the microsporangium sixteen. In Salvinia, according to Jurányi, both sporangia contain sixteen spore mother cells. ${ }^{1}$ Shortly after the divisions are completed in the central cell and tapetum the cell walls of the latter are dissolved, but for a time the sporogenous cells remain together. Finally, they become isolated and round off before the final division into the young spores takes place. In the macrosporangium only one spore finally develops. This is at first, in Azolla, a thin-walled oval cell lying free in the enlarged cavity of the sporangium. Examination shows it to be surrounded by a thick layer of densely granular nucleated protoplasm derived from the tapetum. As the spore grows the surrounding protoplasm and the abortive spores are used by it as it develops, and through their agency the curious episporic appendages of the ripe spore are deposited upon the outside. The spore itself is perfectly globular and surrounded by a firm yellowish exospore, which in section is almost perfectly homogeneous. The epispore covering this shows over most of the spore a series of thick cylindrical papillæ, from the top of which numerous fine thread-like filaments extend. In section the epispore shows two distinct parts, a central spongy-looking mass and an outer more homogeneous part covering all but the tops of the papillæ. At the top of the spore are three episporic masses, composed entirely of the spongy substance and surrounding a central conical mass from whose summit extend numerous fine filaments like those growing from the rest of the epispore. The name "swimming apparatus," which has been applied to this apical mass, is a misnomer, as the ripe sporangium sinks promptly when freed from the plant.

The indusium rapidly grows above the young macrosporangium, or group of miscrosporangia, and its walls, which become double, converge at the top and finally the opening is com-

${ }^{1}$ Heinricher (2), however, states that in the macrospangium there are but eight, as in Azolla. 
pletely closed. In the former, before this happens, filaments of Anabcena creep in and enter the resting condition. Thus they remain until growth is resumed with the germination of the spore, when the embryo is infected. The upper cells of the indusium become very dark-coloured and hard, and remain after the lower part decays. The wall of the macrosporangium does
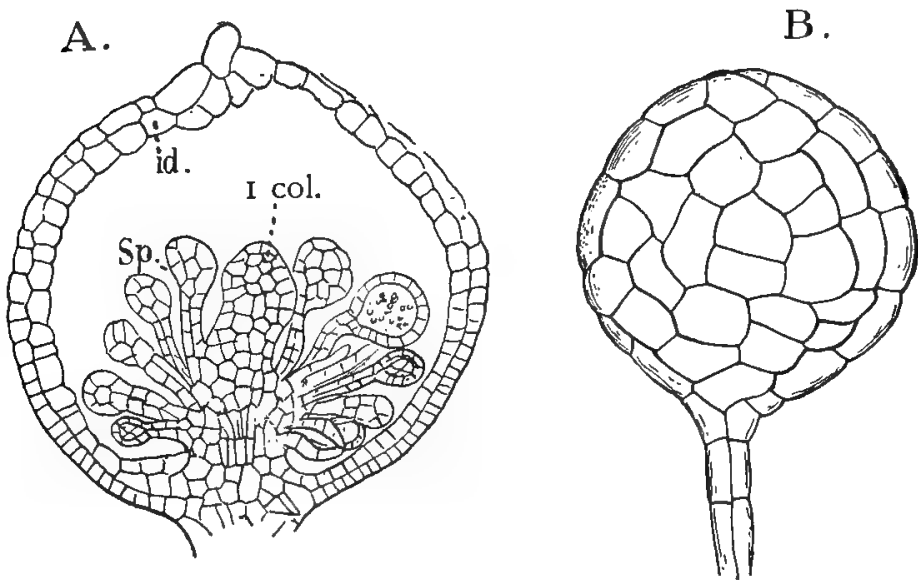

FIG. 24r.-A, Young microsporangial sorus of $A$. filiculoides, $\times 80$; col, columella; id, indusium; $B$, nearly ripe microsporangium, $\times 225$.

not become absorbed, as Strasburger ((6), p. 7I) states, but remains intact, though very much compressed, until the spore is ripe.

The sporocarps of Salvinia are like those of Azolla, but the two layers of cells are separated by a series of longitudinal airspaces which correspond to ridges upon the surface of the sporocarp (Fig. 233, D).

The microsporangia of Azolla have a long stalk, which is composed of usually two, but sometimes three rows of cells. The sixteen sporogenous cells all develop, so that there are normally sixty-four microspores in each sporangium. These have the exospore thin and smooth, and are included in a kind of common epispore, which here too owes its origin mainly to the tapetal cells. This episporic substance is divided into masses (massulæ), which have the foamy structure of the episporic apendages of the macrospore. This appearance is apparently due to the formation of vasuoles, which make these 




B.

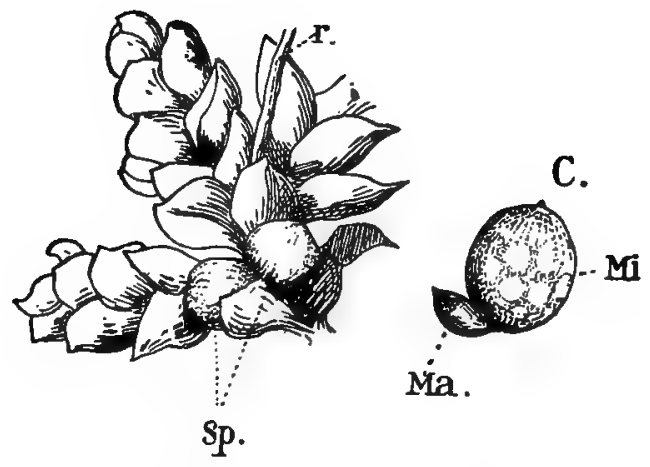

Frg. 242.-Azolla filiculoides. A, Mature sporophyte, $X_{2} ; \mathrm{B}$, lower surface of a branch with two microsporangial sori $(s p), \times 6 ; C$, macrosporangial $(m a)$ and microsporangial $(m i)$ sori, $\times$ Io. 
massulæ look as if composed of cells. The tapetal nuclei are confined to the outside of the massula, and can be detected almost up to the time they are fully developed. Finally, upon the outside of the massulæ are formed the curious anchor-like "glochidia" (Fig. 234, $g l$ ), whose flattened form is due to their formation in the narrow spaces between the massulæ.

In Salvinia the microsporangia arise as branches from sporangiophores which bud out from the columella, so that their number much exceeds that of the macrosporangia, or of the microsporangia of Azolla. There are no separate massula,

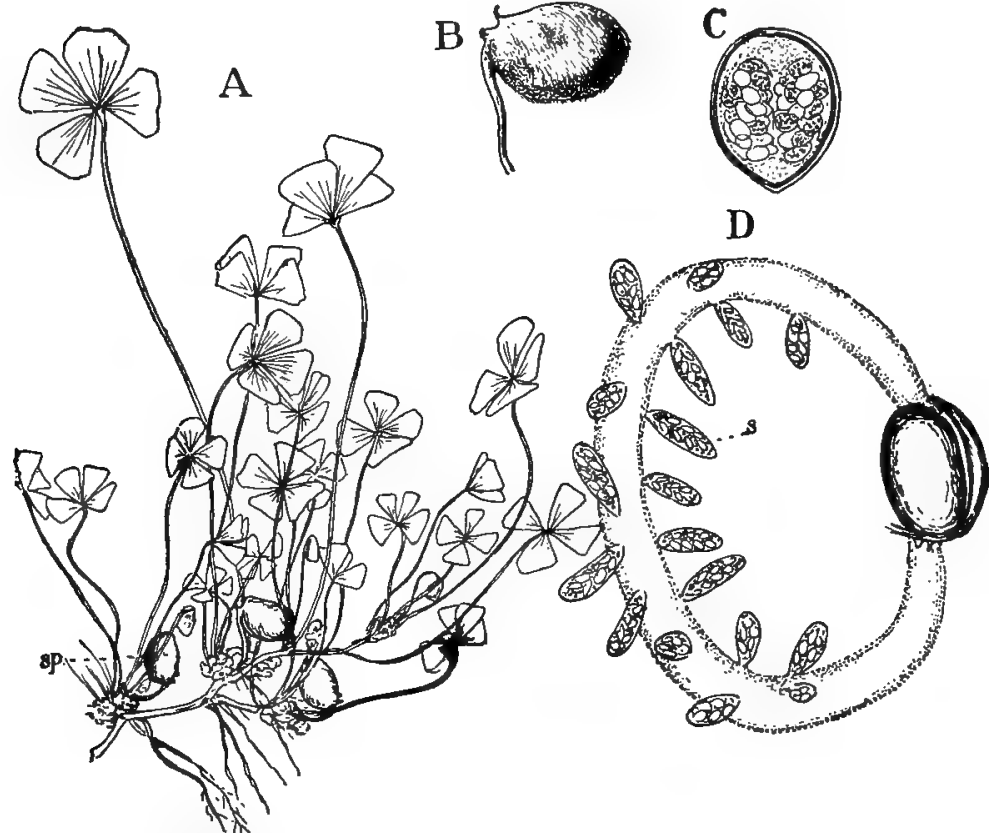

FrG. 243.-Marsilia vestita. A, Fruiting plant of the natural size; $s p$, sporocarps; B, a single sporocarp, $\times_{4} ; \mathrm{C}$, cross-section of the same, $\times_{5} ; \mathrm{D}$, germinating sporo. carp, showing the gelatinous ring by which the sori $(s)$ are carried out, $\times 3$.

and in the macrosporangium the epispore is much less developed than in Azolla.

\section{The Marsiliace}

The two genera of the Marsiliaceæ, Marsilia and Pilularia, are much more closely related than Salvinia and Azolla, and at the same time their resemblance to the homosporous Ferns is 
closer, and of the two genera Pilularia is evidently the nearer to the latter. The development of both gametophyte and sporophyte in the two corresponds very closely.

The sporangia are borne in "sporocarps," which are morphologically very different from those of the Salviniacex, being metamorphosed leaf segments enclosing several sori, and not single sori enclosed simply in an indusium. The spores germinate with extraordinary rapidity, especially in Marsilia, and in $M$. Egyptiaca the writer has found a two-celled embryo developed within thirteen hours from the time the ungerminated spores were placed in water.

The sporocarp of Marsilia is a bean-shaped body, which is attached to the petiole of the leaf by a more or less prominent pedicel. It is very hard, and unless opened artificially may remain a long time unchanged, if placed in water; but if a little of the hard shell is cut away, the swelling of the interior mucilaginous tissue quickly forces apart the two halves of the fruit. As more water is absorbed, this gelatinous inner tissue continues to expand and forms a long worm-shaped body (Fig. $243, \mathrm{D})$, to which are attached a number of sori, each surrounded by a sac-shaped indusium in which the sporangia are closely packed. Macrosporangia and microsporangia occur in the same sorus. The former contain a single large oval white spore, the latter much more numerous small globular ones. The indusium remains intact for several hours, if not injured, but finally, with the sporangium wall, is completely dissolved, and the spores are set free.

\section{The Microspores and Male Prothallium}

The microspores of $M$. vestita (Fig. 244) are globular cells about $.075 \mathrm{~mm}$. in diameter. The outer wall is colourless and sufficiently transparent to allow the contents to be dimly seen. Lying close to the wall are numerous distinct starch granules, and in the centre the nucleus is vaguely discernible. Sections through the ungerminated spore show that the wall is thick, with an inner cellulose endospore, outside of which are the exospore and the epispore or perinium, composed of closelyset prismatic rods. The central nucleus is large and distinct, with usually one or two nucleoli.

The first division takes place at ordinary temperatures, 
about $20^{\circ} \mathrm{C}$, within about an hour after the spores are placed in water. Previous to this the nucleus enlarges and moves to one side of the spore, usually the point opposite the apex, and the granular cytoplasm collects near the centre and is connected with the peripheral cytoplasmic zone only by thin strands. The first wall divides the spore into two very unequal cells, the
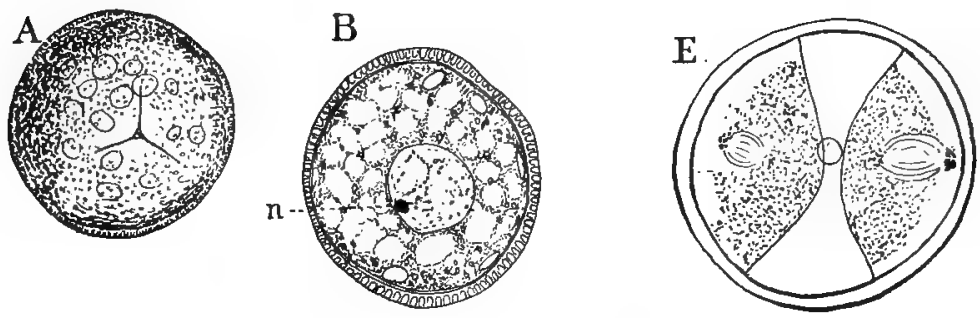

$\mathrm{D}$


FrG. 244.-Marsilia vestita. Germination of the microspores, $\times 450 ; x$, vegetative prothallial cell; $m$, basal antheridial cell; $p$, peripheral antheridial cells; $\mathrm{A}$, an unger. minated spore, ventral aspect; $\mathrm{B}$, section of a similar one-all longitudinal sections except $E$ and $F$, which are transverse. In these the two groups of sperm cells are separated by a large sterile cell.

smaller containing but little granular contents, and representing the vegetative part of the prothallium, while the upper becomes the antheridium. In Pilularia there is subsequently cut off a small cell from the vegetative cell, and Belajeff (4) states that this also is always the case in Marsilia, but it is less conspicuous 
than in Pilularia (Fig. 245, A, y). The next division is not always the same, but is usually effected by a wall nearly parallel to the first one, but more or less concave (Fig. 244, D). Sometimes the antheridial cell divides at once by an oblique wall into two nearly equal cells, from each of which a group of sperm cells is later cut off. In no case was the central cell cut off by a dome-shaped wall, such as is common in the homosporous Ferns, and also in Pilularia. The formation of this wall is apparently suppressed here, perhaps as the result of the extremely rapid development of the antheridium, and the separation of the sperm cells takes place by walls cut off from the periphery of the two upper cells. A cap cell (Fig. 245, d) is almost always present, as in Pilularia and the Polypodiaceæ.

From the two cells of
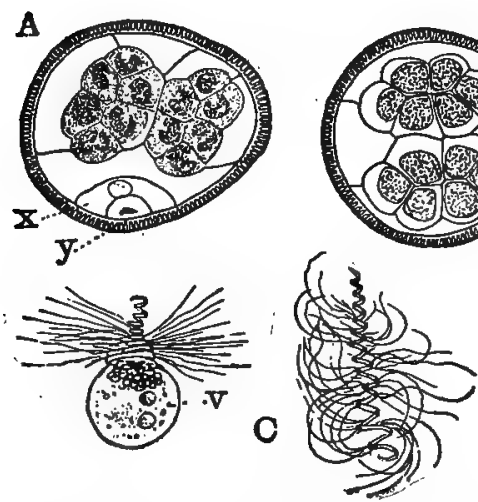

FIG. 245.-Marsilia vestita. A, Longitudinal, B, transverse division of the male gametophyte, $\times 400 ; x, y$, the two vegetative prothallial cells; C, two free spermatozoids, $\times 800 ; v$, vesicle.

$B$ the middle part of the antheridium a varying number of sterile cells are cut off, which are quite transparent, while the contents of the central cells are very densely granular. Not infrequently the two groups of sperm cells are completely separated by one of these sterile cells (Fig. 244, F), and Belajeff considers that each group of sperm cells represents a distinct antheridium. In view of the relationship between the Marsiliaceæ and Schizæaceæ, indicated by recent studies on the structure and development of the two families (Campbell (26)), this view has some support, as there is a cer-. tain resemblance between each of these cell groups and the simple antheridium of Aneimia or Schizaa. The divisions in the central cells are very regular, and the sixteen sperm cells in each group are arranged very symmetrically (Fig. 245). The whole number in $M$. vestita is completed in about seven hours from the time germination begins, and the formation of the spermatozoids commences about an hour later and takes about 
four hours for its completion. Pilularia approaches much nearer to the Polypodiaceæ in the structure of the antheridium (Fig. 246). The first funnel-shaped wall is much more frequently extended to the basal wall, and the two groups of sperm cells are much less distinct than in Marsilia.

The spermatozoids of Marsilia are at once distinguished by a great number of coils, sometimes thirteen or fourteen in $M$. vestita. The cilia are very numerous, but are attached only to the broad lower coils, the upper narrow ones being quite free from them. The vesicle attached to the broad lower coils is very conspicuous and contains numerous starch granules as well as albuminous ones. In Pilularia the long upper part of the spermatozoid is absent, and it apparently corresponds only to the few broad basal coils of that of Marsilia, which are of nuclear origin, like the greater part of the body in the spermatozoid of Pilularia.

Shaw (3) and Belajeff (7) have studied the development of the spermatozoid in Marsilia, Shaw's studies on $M$. vestita being especially complete.

At the close of the second from the last division

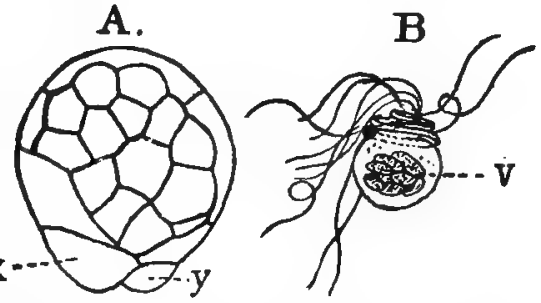

Fig. 246.-Ripe antheridium of Pilularia globuli. fera, showing the two vegetative prothallial cells $(x, y), \times 375 ; \mathrm{B}$, free spermatozoid, showing the large vesicle $(v)$ with the contained starch granules.

of the central tissue of the

antheridium, there appears at either pole of the spindle a small body, the "blepharoplastoid," which seems later to divide, the two halves increasing in size and remaining together near the resting nucleus. These two blepharoplastoids seem to disappear during the early stages of the next mitosis, but shortly afterwards there is seen at either pole of the spindle a small blepharoplast $(b)$. At the close of the mitosis the blepharoplast lies near the nucleus of the cell (the secondary spermatocyte of Shaw ). This blepharoplast divides, and the daughter blepharoplasts increase in size, finally occupying a position near the poles of the nuclear spindle (Fig. 247, B). This division results in the formation of the spermatozoid mother cells, or spermatids.

After the division into the spermatids is complete, the 
blepharoplast increases in size, and shows several granular bodies within it, and it is from these granules that the ciliabearing band is developed.

The blepharoplast becomes much elongated and with the nucleus moves toward one side of the sperm cell (Fig. 247, D). The nucleus also elongates, but the blepharoplast extends far beyond it. The blepharoplast finally forms a funnel-shaped coil of ten or more turns, of which the three posterior coils, which are much wider, are in contact with the slender coiled nucleus, which does not extend beyond this point (Fig. 247, E).

\section{The Macrospore and Female Prothallium}

The macrospores of the Marsiliaceæ are extremely complex in structure, and are borne singly in the sporangia. In Mar-

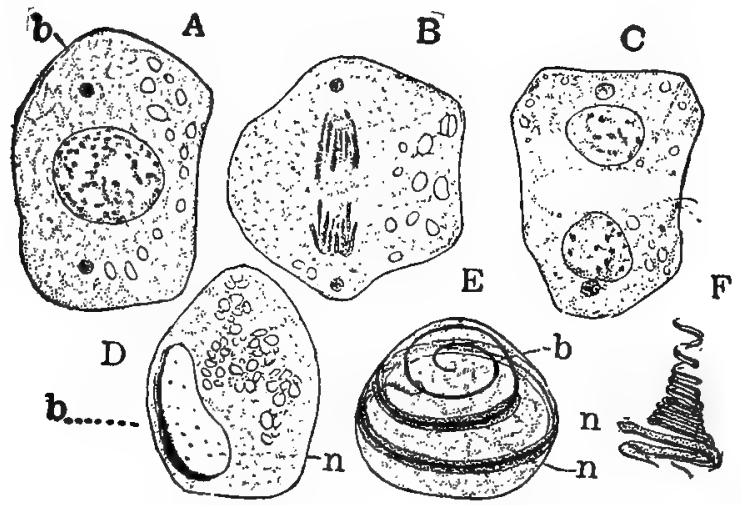

FIG. 247.-Marsilia vestita. Development of the spermatozoid, $\times 1500$. A-C, last division preliminary to the formation of the spermatids; D-F, development of the spermatozoid; $x$, nucleus of spermatid; $b$, blepharoplast (after Shaw).

silia vestita they are ellipsoidal cells about $.425 \times .750 \mathrm{~mm}$. in diameter, ivory-white in colour, and covered with a shiny mucilaginous coating. The upper part of the spore has a hemispherical protuberance covered with a brown membrane, and it is the protoplasm within this papilla that forms the prothallium. The apex of the papilla shows the three radiating ridges like those in the microspores, and indicates that, like them, the macrospore is of the radial or tetrahedral type.

Sections of the ungerminated spore (Fig. 248, A) show a structure much like that of the microspore, but more highly 
developed. A noticeable difference is the segregation of the protoplasm containing the nucleus, which occupies the apical papilla. This is filled with fine granules, but is entirely free from the very large starch grains of the large basal part of the spore. The nucleus is somewhat flattened. A similar arrangement of the spore contents is found in Pilularia, but the apex of the spore does not form a distinct papilla. The epispore is of nearly equal thickness, except at the extreme apex, in Marsilia, but in Pilularia, especially in $P$. globulifera, the epispore

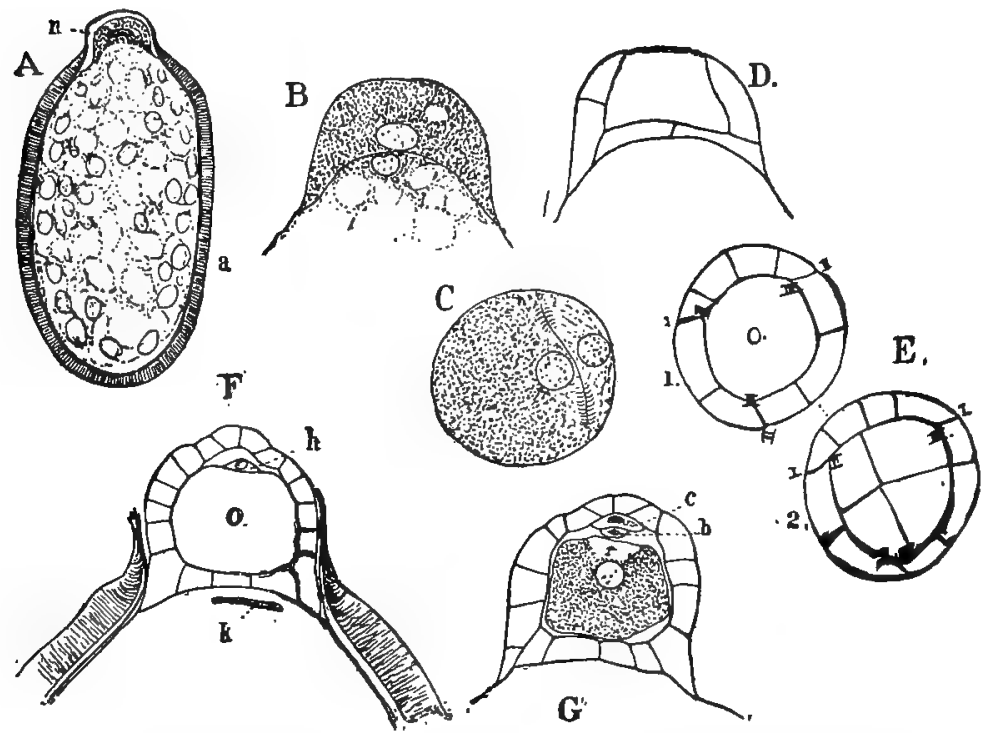

FIG. 248.-Marsilia vestita. Germination of the macrospore; A, longitudinal section of the ripe macrospore, $\times 60 ; n$, nucleus; $\mathrm{B}-\mathrm{G}$, successive stages in the development of the female prothallium and archegonium, $\times 360 ; \mathrm{C}, \mathrm{E}$, transverse sections, the others longitudinal; $n$, neck canal cell; $h$, ventral canal cell; $r$, receptive spot of the egg; $k$, remains of the nucleus of the spore cavity.

of the upper third is much thicker, and from the outside the spore appears somewhat constricted below this.

Previous to the first division, which in $M$. vestita takes place about two hours after the spores are placed in water, the amount of protoplasm at the apex increases, and the nucleus becomes nearly globular and there is an increase in the amount of chromatin. In Pilularia the first wall is always transverse and cuts off the mother cell of the prothallium; but in Marsilia, while this is usually so, occasionally a lateral cell is cut 
off first from the papilla. In Pilularia the next wall is parallel to this transverse primary wall, and this may also occur in Marsilia, but in the latter more commonly the first lateral cell is first cut off by a vertical wall, and this is followed by two others, which intersect it and include a large central cell (Fig. $248, \mathrm{E})$, from which a basal cell is subsequently separated. In Pilularia, besides the formation of the basal cell by the second wall, the central cell is, as a rule, cut out by two, and not three, walls. The basal cell of the archegonitum in Marsilia divides
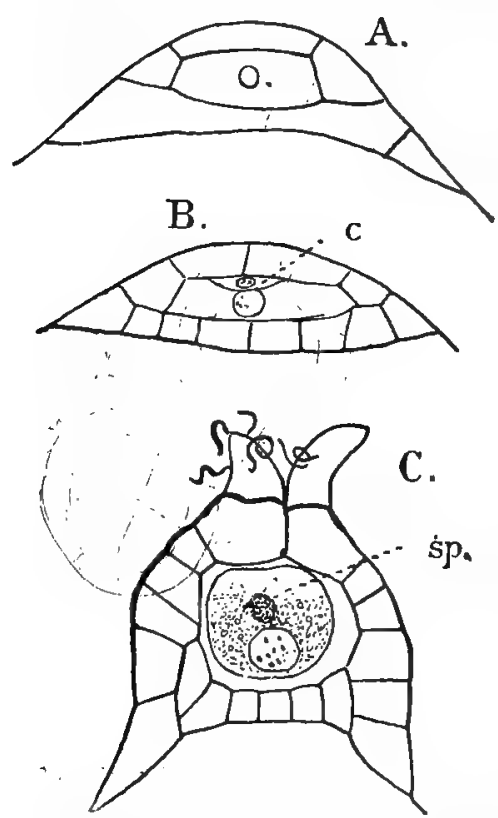

Fig: 249.-Pilularia globulifera. A, B, Young female prothallia, longitudinal section, $\times 300 ; c$, neck canal cell; $C$, section of a recently fer. tilised archegonium, $\times_{300 ;} s p$, spermatozoid within the egg.

by cross-walls into equal quadrants, and the lateral cells divide both by vertical and horizontal walls before any further divisions take place in the archegonium. This finally divides into the cover cell and inner cell. The neck is very short, especially in Marsilia, and each row has but two cells. These in Pitularia (Fig. 249), are much longer. Both neck and ventral canal cells are very small, especially in $M a r-$ silia, and the former has its nucleus undivided. In Marsilia the prothallium grows gradually as the divisions proceed, but in Pilularia (Fig. 249) the young prothallium increases but little in size until the divisions are almost completed, when there is a sudden enlargement. The complete development of the prothallium occupies about twelve to fifteen hours in Marsilia vestita, and in Pilularia globulifera forty to forty-five hours.

Coker (I) states that in Marsilia Drummondii the nucleus in the basal part of the spore subsequently becomes very large and irregular in form and finally divides amitotically in several parts which apparently remain active for some time.

The egg in both genera is large, but in Marsilia it is the larger. In both, the receptive spot is evident. The nucleus 
is unusually small in Marsilia, which otherwise resembles Pilularia.

The phenomena of fecundation are very striking in the Marsiliacex. The mucilaginous layer, about the macrospore attracts and retains the spermatozoids, which collect by hundreds about it. The mucilage above the archegonium forms
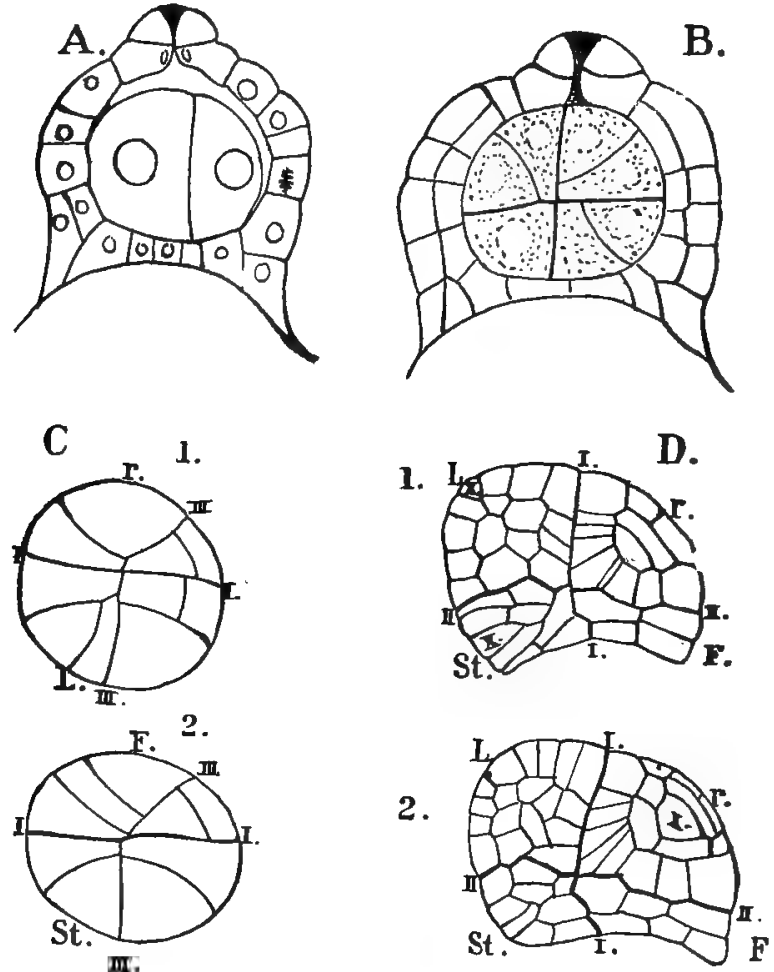

Frc. 250.-Marsilia vestita. Development of the embryo. A, Longitudinal section of archegonium with two-celled embryo; $\mathrm{B}$, similar section of a later stage; $\mathrm{C}$, two transverse sections of a young embryo; D, two longitudinal sections of an older one; I, I, the basal wall; L, cotyledon; st, stem; $r$, root; F, foot. A-C, $\times_{525}$; $\mathrm{D}, \times 260$.

a deep funnel, which becomes completely filled with the spermatozoids. As these die their bodies become much stretched out, so that they look very different from the active ones, with their closely placed coils. The attractive substance here is not confined to the material sent out from the open archegonium, as the 
spermatozoids collect in equal numbers about those which are still closed, and even about spores that have not germinated at all. Marsilia did not prove a good subject for studying the behaviour of the spermatozoid within the egg, owing to the difficulty of differentiating the spermatozoid after its entrance. Pilularia is better in this respect, and shows that the changes are the same as those described in Marattia and Osmunda.

Coincident with the first divisions in the embryo, each of the lateral cells of the prothallium (venter) divides by a periclinal wall, but the basal layer of cells remains but one cell thick. The prothallium grows with the embryo for some time, and in its later stages develops abundant chlorophyll, and its basal superficial cells grow out into colourless rhizoids. In case the archegonium is not fertilised, the prothallium grows for a long time, and reaches considerable size, but never develops any secondary archegonia. In Pilularia, both prothallium and embryo may develop chlorophyll in perfect darkness (Arcangeli ( I), p. 336).

\section{The Embryo (Hanstein (2); Campbell $\left(3,{ }^{1} 3\right)$ )}

The two genera correspond very closely in the development of the embryo, which shows the greatest resemblance to the Polypodiacea. In Marsilia the development of the embryo proceeds very rapidly. The first division of the egg is completed within about an hour after the spermatozoid enters, and in Pilularia after about three hours, as nearly as could be made out. In both the basal wall is vertical and divides the somewhat flattened egg exactly as in Onoclea. The quadrant walls next follow, and then the octant wall, as usual. Of the latter the one in the root quadrant diverges very strongly from the median line (Fig. 250, C), and that in the foot quadrant is much like it. In the others it is nearly or quite median, and it is impossible to say which of the leaf and stem octants is to form the apical cell of those organs. The relative position of the young organs is exactly the same, both with reference to each other and to the archegonium, as in the Polypodiacex.

\section{The Cotyledon}

The cotyledon grows for a time from the regular divisions of one or both of the primary octant cells, but this does not 
usually continue long, and the subsequent growth is purely basal. The cotyledon is alike in both genera, and is a slender cylindrical leaf tapering to a fine point, where the cells are much elongated and almost colourless. Its growth is at first slow, but at a later period (in Pilularia globulifera about the eighth day) it begins to grow with great rapidity and soon reaches its full size. This is largely due to a simple elongation and expansion of the cells, which are separated in places, and form a series of longitudinal air-channels separated by radiating plates of tissue (Fig. 25 $1, i$ ). The simple vascular bundle traversing



FIG. 25r.-Longitudinal section of the young sporophyte of Pilularia globulifera, still enclosed in the calyptra ( $c a l)$, and attached to the macrospore $(s p), X_{75} ; \mathrm{B}$, the lower part of the same embryo, $\times 215 ; r$, apical cell of the root; st, apical cell of the stem; $i$, lacunæ.

the axis is concentric, with a definite endodermis, but the tracheary tissue is very slightly developed. This becomes first visible about the time the leaf breaks through the calyptra.

\section{The Stem}

Of the two octants in the stem quadrant one becomes at once the apical cell of the stem, the other the second leaf, as in other Leptosporangiatx. The first wall in each octant meets octant and quadrant walls, and cuts off a large cell from each 
octant, in contact with the foot. Hanstein and Arcangeli regard these as part of the foot, and physiologically they no doubt are to be so considered, but morphologically they are beyond question segments respectively of the stem and second leaf. At first these are not distinguishable from each other, but the divisions in the latter are usually (in Pilularia) less regular, and the apical cell early lost. It may, however, develop a regular three-sided apical cell, like that of the later leaves. The earlier segments of the stem apex are larger than the subsequent ones, and the broadly tetrahedral form of the primary octant is reduced to the much narrower form found in the older sporophyte.

\section{The Root}

The first wall in the root quadrant strikes the basal wall at an angle of about $60^{\circ}$, so that the octants are of very unequal size (Fig. 250, C), and the larger one, as in other similar cases, becomes at once the initial cell of the root, which in both genera shows the same regular divisions that characterise the Polypodiaceæ. The segments of the root-cap do not form any periclinal walls, and remain single-layered. The root, like the cotyledon, is traversed by regular air-chambers, and its transverse section resembles very closely that of the leaf. These airchambers appear while the root is very young, and at a point between the endodermis and the cortex. The latter is at this stage divided into but two cells, the outermost of 'which by a further tangential division becomes two-layered, the outer forming the epidermis, and the inner by similar divisions becomes three-layered. The two outer layers divide by radial walls, but the inner ones divide only by periclinal walls, and form one-layered lamellæ separating the air-spaces and connecting the endodermis with the outer cortex.

\section{The Foot}

The first divisions in the foot quadrant follow closely those in the root, but this regularity soon ceases, and after the first divisions no definite succession in the walls can be distinguished. The foot remains small, but, as we have seen, the first segments of the lower epibasal octants practically form part of it, and doubtless all the lower cells are concerned in the absorption of 
food from the spore. The volume of the protoplasm in the spore increases as the prothallium grows, but loses more and more its coarsely granular structure. In both Marsilia and Pilularia the nucleus of the spore cavity soon becomes indistinguishable, and in the former is from the first very small. In Pilularia it is larger, and in the later stages bodies were observed that looked as if they might be secondary "endospermnuclei," like those of Azolla, but their nature was doubtful. A further study of Marsilia vestita has shown irregular deeply staining bodies in the protoplasm below the basal prothallial cells, which may perhaps be nuclei like those described by Coker (I) in $M$. Drummondii.

The early leaves are at first alike in both genera, and the earliest ones do not show any trace of the circinate vernation of the later ones. In Pilularia the later leaves are essentially like the cotyledon, but in Marsilia all the later leaves show a distinct lamina. This is at first narrow and undivided, and spatulate in form. In $M$. vestita this is succeeded by five or six similar ones, with constantly broadening laminæ, which finally divide into two narrow wedge-shaped lobes, and these are then succeeded by others with broader lobes, which finally are replaced by four lobes, the central ones being narrower than the outer ones. All of these early lobed leaves are folded flat, and it is not until about ten or twelve leaves have been formed that finally the leaf attains the form and vernation of the fully-developed ones.

The divisions in the stem apex take place slowly, but apparently a complete series of segments is produced in rapid succession, and there is an interval before any more divisions occur, as there is always considerable difference in the ages of any two succeeding sets of segments. The apical cell of Pilularia in cross-section has the form of an isosceles triangle with the shorter face below. Probably each dorsal segment at first gives rise to a leaf, and each ventral one to a root. However, the number of roots exceeds that of the leaves, but the origin of these secondary roots was not further investigated.

\section{The Mature Sporophyte}

In both Marsilia and Pilularia the fully-developed sporophyte is a creeping slender rhizome, showing distinct nodes and 
430

MOSSES AND FERNS

CHAP.

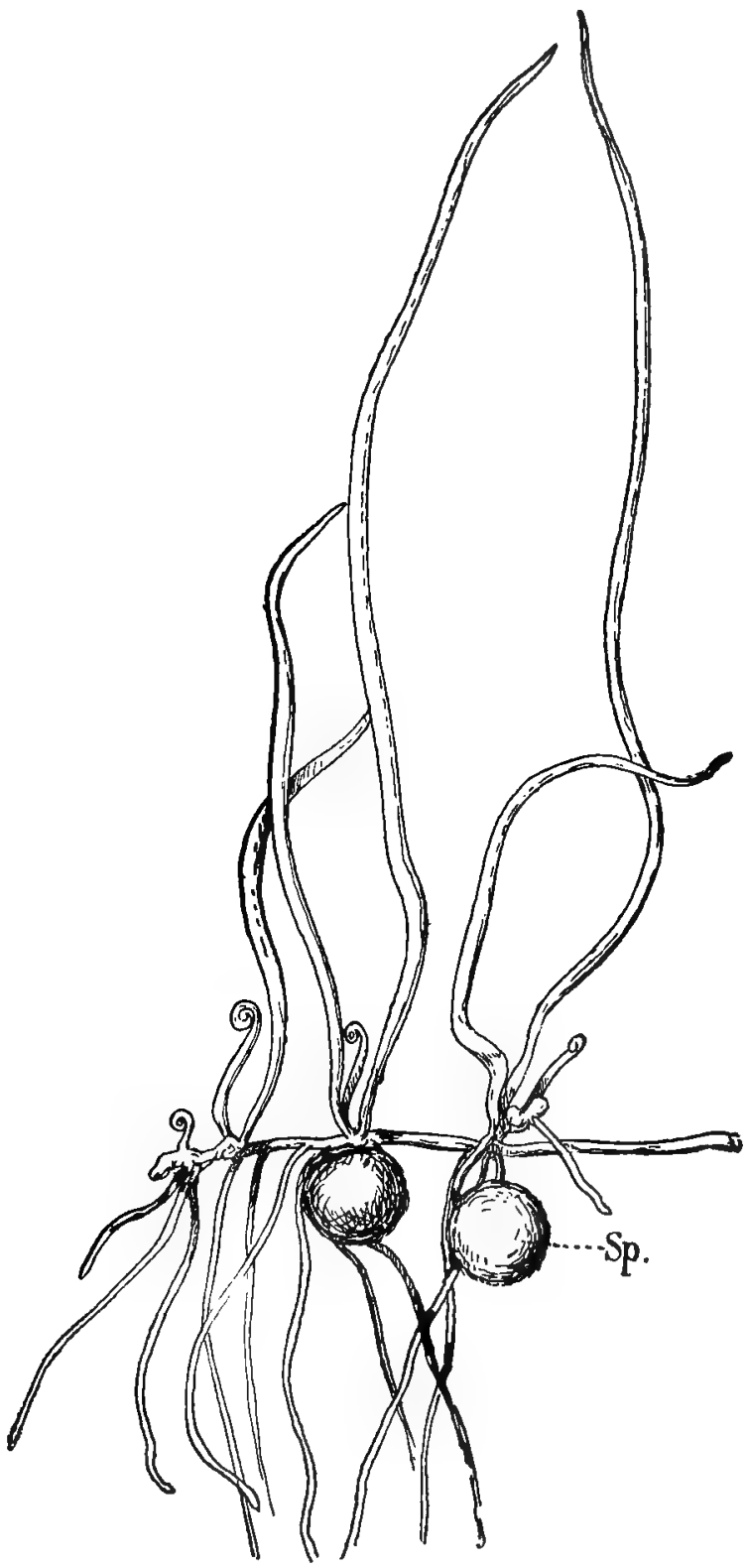

FIG. 252. -Part of a fruiting plant of Pulularia Americana, $X_{4} ; s p$, sporocarps 
internodes. At the nodes are borne the various appendages of the stem, and the elongated internodes are, except for occasional roots, quite destitute of appendages. Leaves and branches arise from the nodes, and in Marsilia are much crowded. The plants are aquatic or amphibious, and the habit of the plant is very different, especially in Marsilia, as it grows completely submerged, or partially or entirely out of water. Some species, like $M$. vestita, which grow where there is a



FrG. 253.-Marsilia vestita. A, Vertical longitudinal section of the stem apex, $\times 80$; $\mathrm{L}$, leaves; st, stem apex; $r$, roots; $\mathrm{B}$, the stem apex, $X_{450} ; \mathrm{C}$, horizontal section of very young leaf, $\times 450 ; \mathrm{D}$, similar section of an older one, $\times 450 ; \mathrm{E}$, cross-section of petiole, $\times 80$.

marked dry season, grow in shallow ponds or pools, which dry up as the end of the growing period approaches, and the ripening of the sporocarps takes place after the water has evaporated. In the first case the petioles are extremely long and weak, and the leaf-segments float upon the surface. In the other case the petioles are much shorter and stouter, and the leaves are borne upright. The young leaves are circinate, as in the ordinary Ferns, and in Pilularia retain the same structure as the coty- 
ledon. In Marsilia they are always four-lobed. The sporocarps are modified outgrowths of the petiole, which are often formed so near the base as to appear to grow directly from the stem. They often are borne singly, but may occur in considerable numbers--twenty or more in $M$. polycarpa-and are globular in Pilularia, bean-shaped in Marsilia. The growth of the stem and the origin of the various appendages are the same in both genera.

A longitudinal section of the stem (Fig. 253, A) shows the decidedly pointed apex occupied by a large and deep apical cell with very regular segmentation. Each segment divides into an inner and an outer cell, the former in all the segments forming the central plerome cylinder, and the outer cells developing the cortex of the stem, and the leaves in the dorsal segments, the roots in the ventral ones. The young leaves are separated by distinct intervals or internodes, and apparently all of the dorsal segments do not give rise to leaves, but just what the relation is between the nodes and internodes was not determined. The roots arise in strictly acropetal order from the ventral segments, but their number does not seem to be constant. In Pilularia Americana the number of roots considerably exceeds that of the leaves, as it does in the young sporophyte of $P$. globulifera.

The single axial vascular bundle is truly cauline, and extends considerably beyond the base of the youngest leaf. The later leaves in Pilularia, both in their growth and complete structure, correspond to the primary ones. They grow for a time from a three-sided apical cell, in which respect they differ from Marsilia. ${ }^{1} \quad$ The development of the leaf of the latter has been carefully studied by Hanstein in $M$. Drummondii, and $M$. vestita corresponds exactly with that species. A section of the very young leaf (Fig. 253, C) parallel with the surface shows a large two-sided apical cell. The leaf-rudiment assumes a somewhat spatulate form, and on either side a projecting lobe is formed, the rudiment of one of the lateral segments of the leaf. The apical cell is now divided by a median wall, after which periclinal walls are formed, and from this time the growth of the leaf can no longer be traced to a single initial cell. The first longitudinal wall in the apical cell establishes the two

${ }^{3}$ Pilularia globulifera, according to Johnson (2) and Meunier ( $t$ ) has the typical two-sided cell found in Marsilia. 
terminal lobes, which at first are not separated (Fig. 253, D). The establishment of the veins follows exactly as in Ferns with a similar venation, and is strictly dichotomous. The stem branches freely in both genera, and the branches arise close to the apex, and below a young leaf somewhat as in Azolla.

The roots correspond closely to those of the higher homosporous Ferns. The segmentation of the apical cell follows the same order as in the Polypodiaceæ. Goebel's figure of $M$. salvatrix ( ( IO), p. 238) differs somewhat from the account given more recently by Andrews ( I) for $M$. quadrifolia. The latter observer states that there are no periclinal walls in the root-cap segments, which remain throughout one-layered, and that the separation of the plerome takes place earlier than Goebel indicates. Van Tieghem's ( $(5)$, p. 535) account of the root of $M$. Drummondii confirms Andrews' observations upon M. quadrifolia. The bundle of the root is diarch, as in the Polypodiaceæ, and the lateral roots arise in the same manner. The endodermal cells from which they spring are distinguished from the others by their shorter and broader form, and are very easily recognisable by this as well as from their position. They form two vertical rows exactly opposite the ends of the xylem plate, and the lateral roots therefore are also strictly two-ranked. Narrow lacunæ are formed in the cortical tissue of the root, and the cells surrounding these are connected by regular series of short outgrowths, which connect them in a way that recalls very strongly the connecting tubes between conjugating filaments of Spirogyra, and produce a similar ladder-like appearance.

The solid vascular cylinder of the young stem is later usually replaced by a tubular one, but its structure is also concentric, with phloem completely surrounding the xylem, and it has both an inner and outer endodermis. When the plants are completely submerged the ground tissue is mainly parenchyma, but in the terrestrial forms sclerenchyma may be developed in the cortex of the stem and petiole. The latter is always traversed by a single axial bundle, which in the lamina in Marsilia divides repeatedly near the base of the wedge-shaped leaflets into numerous dichotomous branches.

Luerssen ( 7$)$, p. 6or) mentions as special reproductive bodies, tubers found in $M$. hirsuta. These are irregular side branches covered with imperfectly-developed leaves, and with 
the cortical tissue strongly developed and full of starch. These are supposed to survive long periods of drought, and to germinate under favourable conditions. A condition somewhat analogous to this appears in $M$. vestita (Fig. 243, A), but whether these short lateral branches are of this nature was not investigated.

The Sporocarp (Sachs (I); Goebel (6); Meunier (I); (Johnson $(I, 2))$

The development of the sporocarp is much the same in the
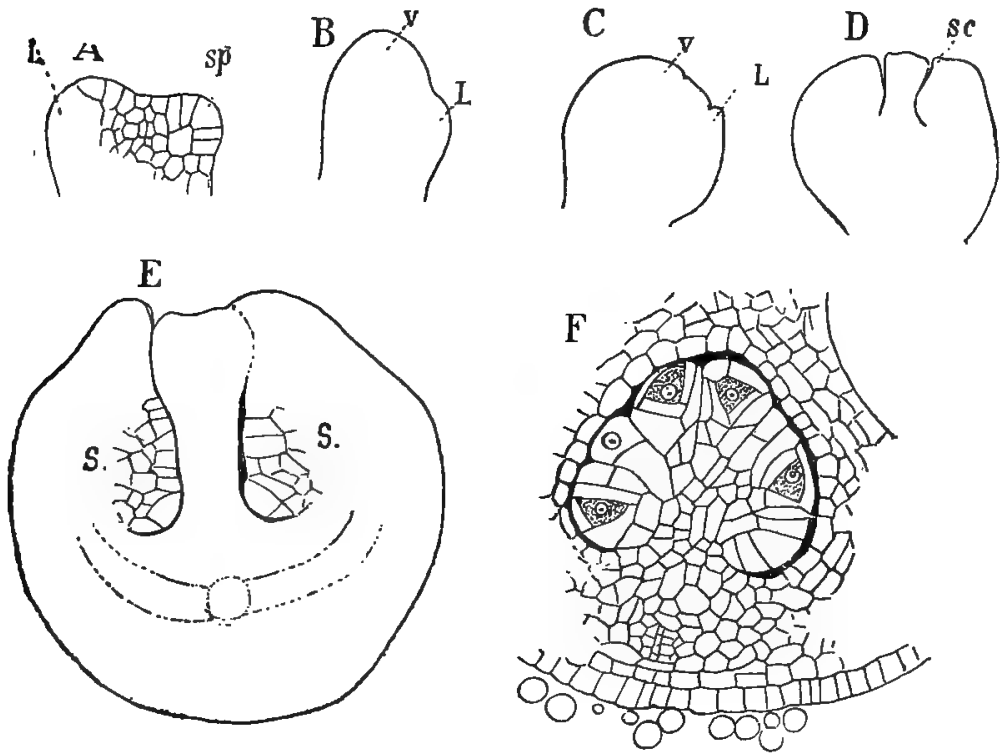

FIG. 254-Pilularia Americana. Development of the sporocarp. A, Very young sporophyll with sporocarp rudiment $(s p)$, showing a distinct apical cell; B-D, longitudinal sections of young stages, showing the formation of the "sorus canals" $(s c), \times 130 ; U$, the original apex of the young sporocarp; $I$, secondary lobes or leaflets; $E$, longitudinal section of an older stage, $X$ about $130 ; s, s$, young sori; $F$, transverse section of an older sorus, $\times 180$.

two genera, but is most easily followed in the simple sporocarp of Pilularia. In $P$. Americana, the young fruit begins to develop almoșt as soon as the leaf can be recognised, and while it is still close to the stem apex. Growth is stronger upon the back of the young leaf, and it very early assumes the circinate 
form. Before this curvature is very pronounced, however, in the sporophyll, a protuberance arises upon its inner face, a short distance above the base (Fig. 254, A). This originates from a single cell, which functions for some time as an apical cell, and causes the young sporocarp to project strongly from the leaf, of which it is simply a branch, somewhat analogous to the spike in Ophioglossum. It may, perhaps, be better compared to a fertile leaf segment of Aneimia, as it has been shown by Johnson (2), that the mother cell of the young sporocarp arises from the margin and not from the face of the leaf.

It has at first the form of a blunt cone, but soon upon the side turned toward the leaf a slight prominence appears (Fig. $254, \mathrm{~B}, \mathrm{~L}$ ), and about the same time two similar lateral ones are formed. As in the sterile part of the leaf growth is stronger on the outside, and the young sporocarp bends in toward the leaf, so that the position of fertile and sterile segments is very like that in the young sporophyll of Ophioglossum. The apex of the sporocarp rudiment, together with the three lobes, enclose a slightly depressed area, which becomes the top of the sporocarp. The four prominences (including the original apex of the fertile segment) are beyond question to be considered leaflets, which remain confluent except at the top. A little later a slight depression or pit forms at the base of each lobe and the central area at the top. These pits are separated laterally by the coherent edges of the leaflets, which extend to the axis of the sporocarp and are continuous with it. As the young fruit enlarges, the depressions deepen owing to the elongation of both leaflets and the axial tissue, which forms a sort of central columella (Fig. 254, D). Thus are formed four deep cavities, separated laterally by the united margins of the leaflets, and corresponding to the much more numerous "canals" described by Russow and Johnson in the fruit of Marsilia; like these they at first open at the summit by a pore, and a study of longitudinal sections shows clearly their strictly external origin.

From his study of $P$. globulifera, Johnson (2) concludes that all four lobes of the sporocarp are of lateral origin. $\mathrm{He}$ was able to trace the origin of each sorus to a single marginal cell in each of the four segments of the young sporocarp. Sections of the young sporocarp of Marsilia at this stage (Johnson (I), Figs. 22, 23) resemble to an extraordinary degree 
the young fertile segment of the leaf of Schizqa, where the relation of the sporangia to the leaf margin is very similar.

$\mathrm{U}_{\mathrm{p}}$ to the time the cavities begin to form, the young fruit is composed of uniform tissue, but shortly after, the tissue systems become differentiated, and the peduncle of the sporocarp is formed. At this time the vascular bundle of the peduncle can be recognised, and joins that of the sterile segment near
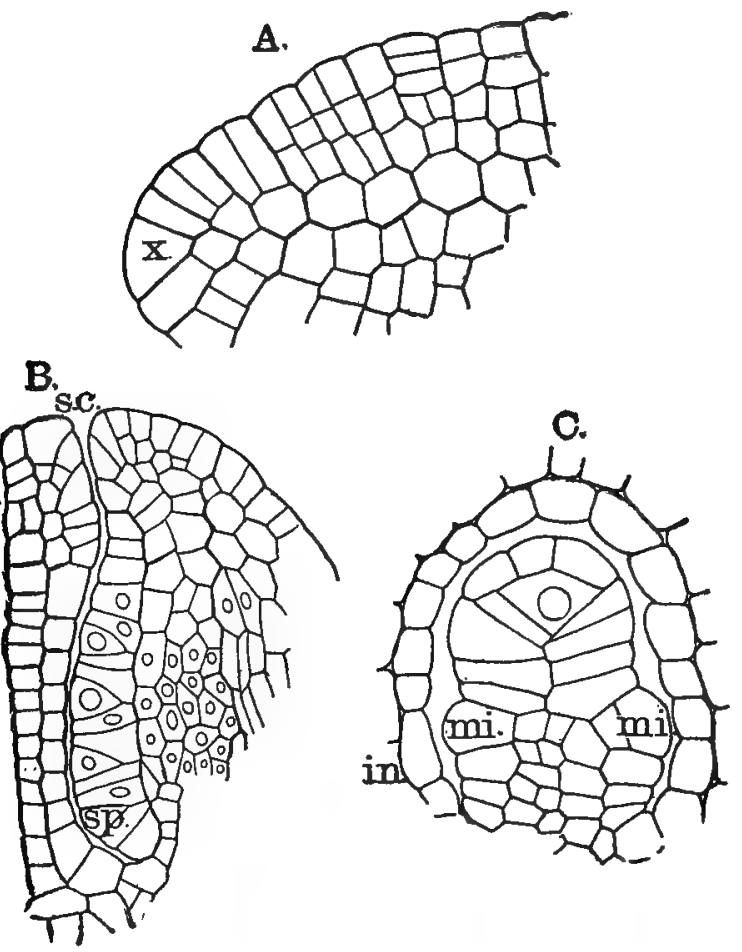

Fig. 255,-Marsilia quadrifolia. A, Horizontal section of very young sporocarp, $\times 500$; $B$, transverse section of an older sporocarp; $s c$, sorus canal; $s p$, young sporangium, $X$ about 340 ; $C$, horizontal section of young sorus showing the large apical macrosporangium, and the lateral microsporangia, $m i$; $i n$, the indusium. (After Johnson.)

its base. The peduncle is much longer in $P$. Americana than in the very similar $P$. globulifera. The circinate coiling of the sterile segment is repeated, though less conspicuously, here, and the body of the sporocarp is bent at right angles to the peduncle. 
The cavities rapidly become larger with the expansion of the growing sporocarp, but the space between the inner surface of the lobes and the columella remains narrow, owing to the growth of the sorus, which almost completely fills it from the first. The sorus forms an elongated cushion, extending nearly the whole distance from the apex to the base of the lobe, along the median line of its inner face. In origin and position it corresponds closely to that of the Schizæaceæ.

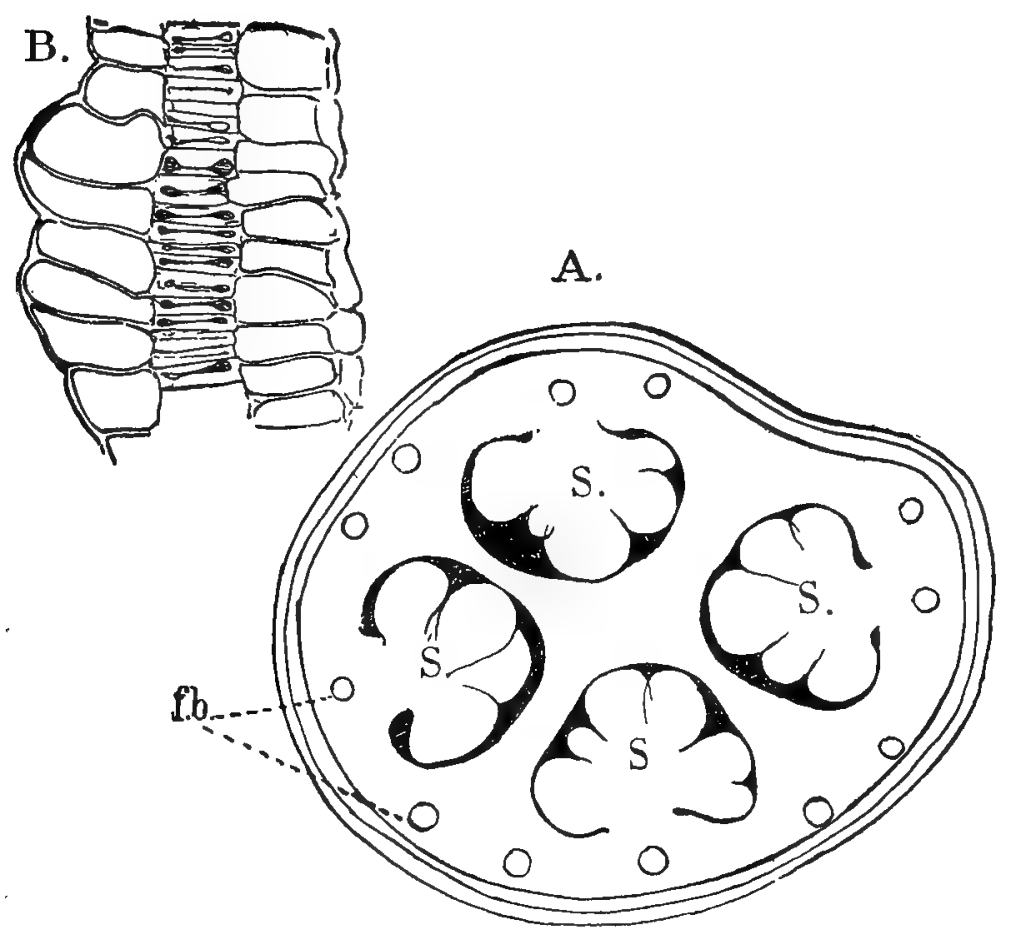

Fic. 256.-Transverse section of an older sporocarp of $P$. Americana, showing the four sori $(s) ; f b$, vascular bundles, $\times 85 ; \mathrm{B}$, section of the wall of a nearly ripe sporocarp, $\times 255$.

The vascular bundle of the peduncle divides into four branches, where it enters the sporocarp, and one branch goes to each lobe, of which it forms the midrib lying below the sortus. From each of these two smaller branches are given off near the base, following the margin of the lobe (Fig. 256, 
A). By this time the outer epidermal cells begin to thicken, the first indication of the hard shell found in the ripe sporocarp.

The development of the sporangia corresponds most nearly to that of the Schizæaceæ. The surface cells of the sorus protrude as papillæ, in which the same divisions arise as in other Leptosporangiata. The first division wall is usually strongly oblique, but may be transverse. The formation of the archesporium is the same, but the apical growth of the sporangia is checked sooner in the earlier ones, which have consequently a very short stalk. In the later ones, which arise between the others, the stalk is longer. The first sporangia are formed at the base of the sorus, and their development proceeds toward the apex; but later secondary ones may arise at any point in the sorus.

The tapetum is well developed, and, as in most homosporous Ferns, consists of two layers, in some places of three. The number of sporogenous cells is usually eight, but some or all of these may divide again, so that the whole number ranges from eight to sixteen. The dissolution of the tapetum walls and subsequent division of the spores follow precisely as in Azolla. In stained sections the nucleated protoplasm of the tapetal cells is very evident after the walls have disappeared. At this point the difference in the two kinds of sporangia becomes manifest. Those in the lower part of the sorus, $i$. e., the oldest ones, form the macrosporangia, the upper ones microsporangia. In the latter all the spores mature; in the former, as in Azolla, one spore grows at the expense of the others, and finally fills the sporangium completely.

It has been generally supposed that no trace of an annulus could be detected in the Marsiliaceæ. The writer has found, however (Campbell (26)), in Pilularia Americana, traces of a terminal annulus like that of the Schizæaceæ. The ripe sporangium, moreover, is strongly oblique like that of Schizaa.

As the sporocarp ripens the outer cells become excessively hard, especially the first layer of hypodermal cells (Fig. 256), whose walls become so thick as to almost obliterate the cell cavity. The second hypodermal layer is also thickened, but not so strongly. At maturity the sporocarp of $P$. Americana forms a globular body about $3 \mathrm{~mm}$. in diameter, covered with hairs, and attached to a long peduncle which bends downward 
and buries the ripe sporocarp more or less completely in the earth. The statement ${ }^{1}$ that this species has but three chambers is incorrect, and except for the longer pedicel of the fruit, and a slightly thinner epispore in the upper part of the macrospore, it corresponds exactly to $P$. globulifera. The sporocarp splits into four parts, corresponding to the four lobes of the young fruit, and the membranaceous margins of the leaf form a tough indusium surrounding the sporangia. This indusium is not, at least in $P$. globulifera, readily pervious to water, and germination does not begin for a long time after the valves separate, unless the indusium is artificially opened. Except for the number and position of the sori, and the relative position of the two sorts of sporangia, Marsilia agrees exactly with Pilularia. The sorus canals form two longitudinal rows along the sides of the elongated fruit rudiment, which may be compared to a pinnate leaf. In Marsilia, occupying the middle line of each sorus, is a row of large tetrahedral cells, which form three sets of segments, like any three-sided apical cell. Each of these cells produces a group of sporangia. The terminal one, derived directly from the apical cell, is a macrosporangium; the smaller lateral ones, derived from its earlier segments, the microsporangia.

\section{Fossil Leptosporangiate}

Sporangia of undoubted Leptosporangiatæ are exceedingly rare in the earlier geological formations. Solms-Laubach (2) cites Hymenophyllites as probably being a genuine leptosporangiate Fern, and Zeiller (I) describes some isolated sporangia that seem to be much like those of the modern Gleicheniacex. Forms like the Osmundaceæ have also been described by various writers, but no traces of Cyatheaceæ or Polypodiaceæ have been yet detected in Palæozoic formations. In the Jurassic, undoubted evidences of Gleicheniacex, Osmundaceæ, and Schizæaceæ are found (Raciborski ( I)), but the Polypodiacex do not seem to have appeared until still later. The existence of the Hydropterides below the Tertiary is doubtful, but in the latter formation occur undoubted remains of the living genera Salvinia, Pilularia, and Marsilia.

${ }^{1}$ Goebel (10), p. 240; Underwood (4), 2nd ed., p. 127; "Botany of California," vol. ii. p. 352 . 


\section{Affinities of the Leptosporangiata}

The Osmundaceæ undoubtedly are intermediate between the Eusporangiatæ and Leptosporangiatæ, but with which order of the former their affinities are closest is difficult to say. Among the Ophioglossacex, the larger species of Botrychium and Helminthostachys show apparent close structural similarity to the Leptosporangiatæ; but, on the other hand, in the distinctly circinate leaves and the character of the sporangia, as well as the histology, the Marattiaceæ are certainly quite as nearly related. Apparently all of these forms are generalised types, springing from a common stock, but no two of them directly related.

Among the Leptosporangiatæ themselves the relationships are evidently much closer. A common type of prothallium and sporangium prevails throughout, even in the heterosporous forms. The four families, Osmundaceæ, Gleicheniaceæ, Cyatheaceæ, and Polypodiaceæ, form a pretty continuous series, of which the Polypodiaceæ are with very little question the latest and most specialised forms. This is evinced both by the geological record, which, so far as yet examined, shows that they were the latest to appear, and by the fact that at present they greatly outnumber the other Ferns, probably including at least 90 per cent. of all living species. The single genus Polypodium has over 400 species, probably as many as all the lower Ferns combined. These facts, together with the specialised character of all the parts, indicate that they are Ferns which have adapted themselves to modern conditions.

The Schizæaceæ and Hymenophyllaceæ do not seem to belong to this main line, but are somewhat peculiar types, apparently belonging near the bottom of the series. The Hymenophyllaceæ, on the whole, approach most nearly the Gleicheniaceæ, with which they agree in many points, both in the sporophyte and gametophyte, but they also recall the Osmundacere, and possibly may form a branch somewhere between the two, but nearer the former. The peculiarities of the gametophyte are probably in large measure the result of environment, and the filamentous prothallium of some species of Trichomanes and Schizea is beyond question a secondary and not a primary condition, and the prothallium is typically like that of the other Leptosporangiatæ. The nearest affinities of the Schizæaceæ 
seem to be with the Osmundaceæ, but in the structure and arrangement of their vascular bundles they are more like the Gleicheniaceæ.

Of the two families of the Hydropterides, the Salviniaceæ shows several points of resemblance to the Hymenophyllaceæ. The development of the leaves is strikingly like those of $\mathrm{Hy}$ menophyllaceæ with reniform or palmate leaves, and the structure of the sori almost identical. The absence of secondary

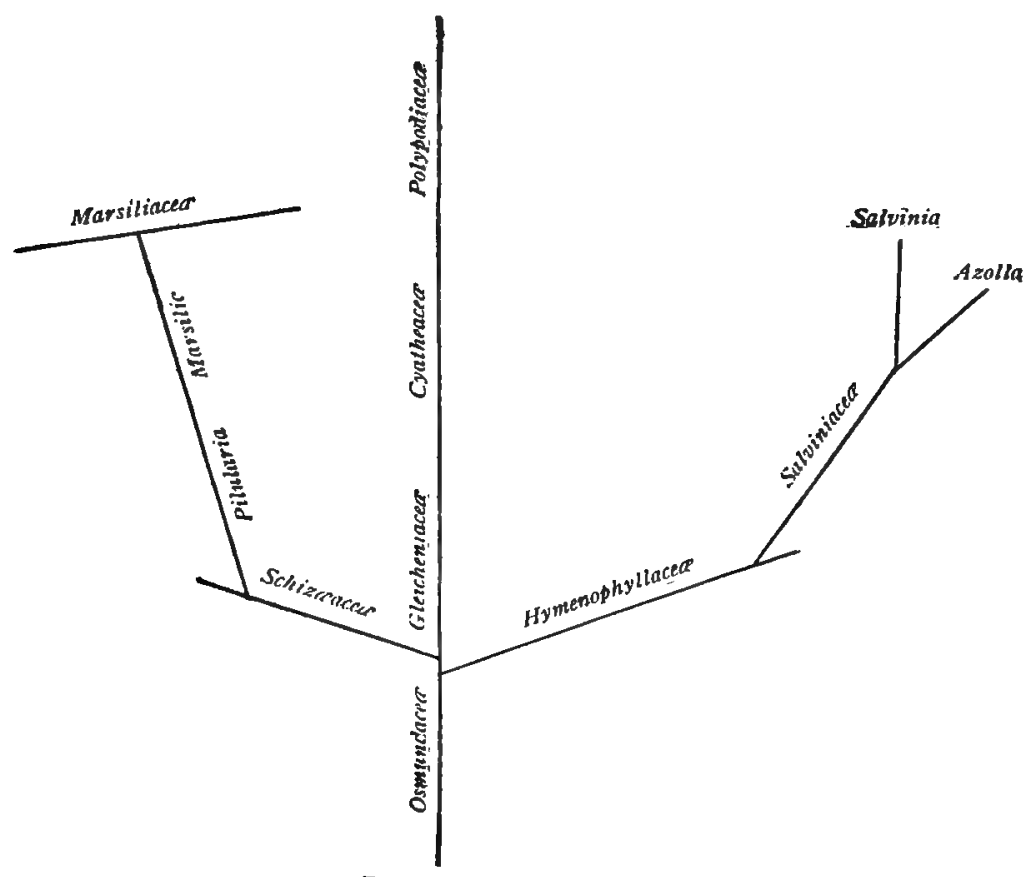

Eusporangigla:

roots in Salvinia is suggestive also of the similar absence in some species of Trichomanes. The two-sided apical cell of the stem is, however, different from that of the few Hymenophyllaceæ examined, which all possess the pyramidal initial, but possibly further examination may show forms with an initial cell similar to that of Azolla or Salvinia.

The Marsiliaceæ, except for their marked heterospory, are typical leptosporangiate forms. The writer has been inclined to assign them a position near the Polypodiaceæ, but recent 
work on these forms has led to a somewhat different conclusion (Campbell (26)). Both the anatomical structure, and the character of the sporocarp and sporangium point to a not very remote affinity with the Schizæaceæ. This view would harmonise better with Belajeff's views as to the structure of the antheridium in Marsilia. The two genera of the Marsiliacex are evidently very closely related, and of these Pilularia approaches nearer the homosporous Ferns. The accompanying diagram shows the relationship assumed here. 


\section{CHAPTER XII}

\section{EQUISETINE压}

All of the living representatives of the second class of the Pteridophytes may without hesitation be referred to the single genus Equisetum, with about twenty-five species, some of which, e. g., E. arvense, are almost cosmopolitan. In the largest species, E. giganteum, the stems reach a height of Io metres or more, but are slender, not more than 2 to $3 \mathrm{~cm}$. in diameter, and supported by the surrounding trees and bushes. The smallest species is E. scirpoides (Fig. 28I, B), whose slender stems are seldom more than 15 to $20 \mathrm{~cm}$. in length, and often one millimetre or less in diameter. In spite of these differences in size, the structure is remarkably uniform, both in gametophyte and sporophyte. The following account is based mainly upon a study of E. telmateia, ${ }^{1}$ but applies to the other species that have been studied.

\section{The Gametophyte}

The ripe spore of Equisetum is globular and shows no trace of the ventral ridges usually evident in tetrahedral spores. Four distinct membranes surround it, the inner one (intine) being exceedingly delicate, but with care showing the cellulose reaction (Buchtien (I)). Outside of this are the exospore and the elaters, between which lies another layer, "Mittelhaut" of Strasburger ( ( I I), p. I99), belonging to the exospore. The well-known elaters (Fig. 257, A) form two strips attached in the middle and terminating in spoon-shaped appendages. The elaters are usually more or less spirally twisted, and when dry show faint oblique striations, except on the expanded ends. They are extremely hygroscopic, and respond instantly to any

${ }^{1}$ E. maximum Lam. 
changes in the moisture of the atmosphere. A careful study of the dehiscence of the sporangium shows that as it dries the expansion of the elaters assists very materially in opening it, and their function is something more than that of keeping the spores together, as has been asserted (Buchtien (I), p. I5). The striation of the elaters is merely the result of wrinkling by drying, and when moistened this disappears completely. The elaters show the cellulose reaction except upon the upper surface, which is cuticularised.

The spores contain much chlorophyll, which in the dry spores appears amorphous and gives them a dark olive-green colour. So soon as the spore is moistened, however, it increases
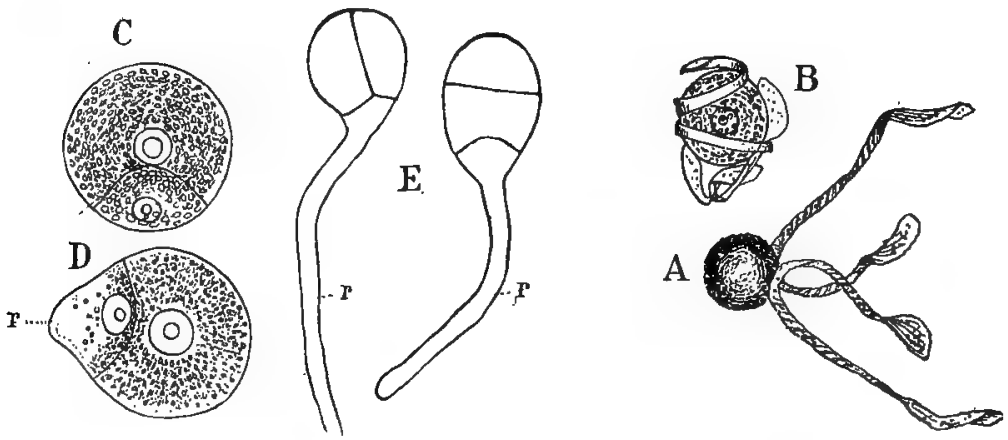

FiG. 257.-In this and all the following figures of Equisetum, the drawings were made from $E$. telmateia (E. maximum, Lam.), unless otherwise indicated. A, ripe, dry spore with expanded elaters, $\times 180 ; B$, a similar spore placed in water, $\times 180 ; C$, $D$, germinating spores, $\times_{3} 60 ; E$, older stages of germination, $X_{1} 80 ; r$, primary rhizoid.

in diameter by about one-half through the absorption of water, and the numerous small round chloroplasts then become very evident. The nucleus is large, and occupies the centre of the spore. After a short time the elaters and the outer layer of the exposore are thrown off, and probably the rest of the exospore, as no trace of this can be seen in the young prothallium.

The spores quickly lose their power of germination, and should be sown as soon as they are discharged. If this is done germination begins almost at once, and within ten to twelve hours the first division wall may be completed. The chloroplasts rapidly multiply by division and often show a distinct radiate arrangement, extending in lines from the nucelus to the periphery. The first division may occur before the spore has 
changed form, and in this case (Fig. $257, \mathrm{C}$ ) a small cell is cut off by a strongly curved wall. Both cells contain chlorophyll, but the nucleus of the smaller cell is smaller than the other. In other spores there is first an elongation, as in Osmunda, and the smaller end, which like that has some chlorophyll, but not so much relatively as the larger, is cut off, and forms the first, rhizoid, and within twenty-four hours, under suitable conditions, this may reach a length considerably exceeding the diameter of the spore. Sadebeck ( (6), p. I77) showed and Buchtien
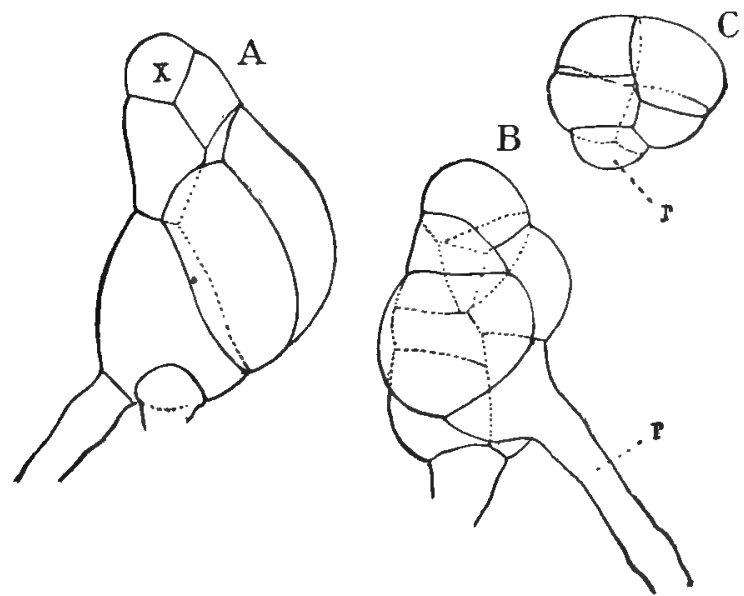

Dre. 258.-Young prothanlia of Equisetum, showing the variation in form, $\times 180$. In $\mathrm{A}$ there is apparently a definite initial cell; $r$, rhizoid.

( ( I ) p. 29) confirmed this, that the first rhizoid is positively heliotropic.

The first divisions in the prothallial cell are extremely various, in this recalling the behaviour of the eusporangiate Filicineæ and the Osmundaceæ. The first wall may be either ver tical or transverse (Fig. 257), and sometimes, but not often, there are several transverse walls, and a short filament is formed. More commonly the first transverse wall is followed by a vertical wall in one or both cells. In case the first wall is vertical it not infrequently happens that the two cells, by repeated transverse divisions, form two parallel rows of cells, which may diverge, so that the young prothallium becomes twolobed. In a number of cases a two-sided apical cell was seen (Fig. 258), but its growth is very limited. Finally, a cell-mass 
occasionally is the first product of germination. As a not infrequent occurrence may be mentioned also the suppression of the first rhizoid (Fig. 258, C). The development for some time is so varied that it is impossible to give any rule for it, but generally the prothallium at this stage, like that of the leptosporangiate Ferns, consists of but one layer of cells, and does not show a midrib. These prothallia also do not have a definite apical growth, and are usually more or less branched. Often,
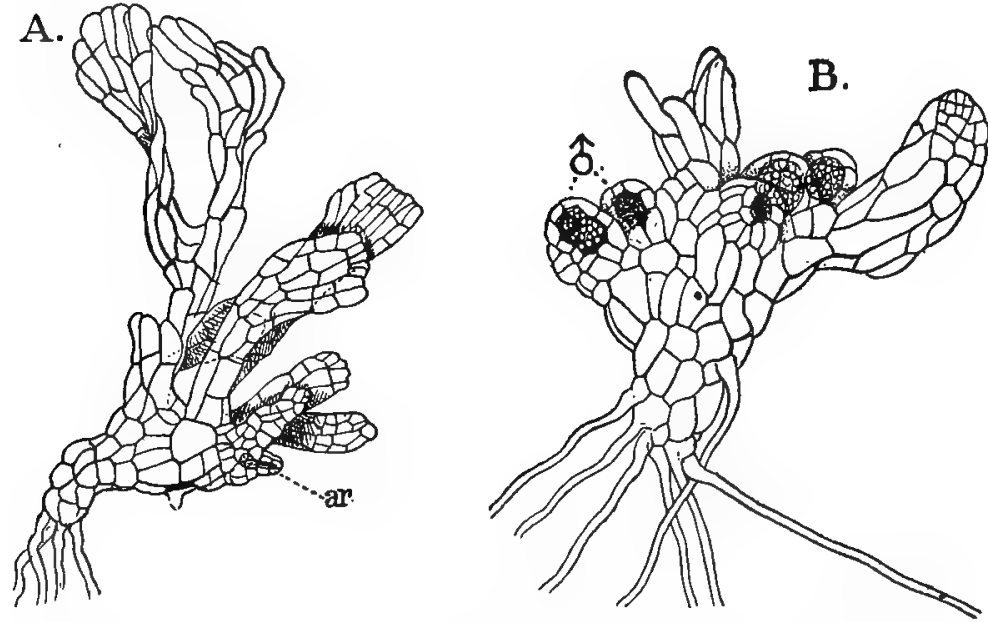

Fug. 259.-A, Female prothallium with the irst archegonium (ar), $\times 70 ; \mathrm{B}$, male prothallium, $\times$ yo.

however, the prothallium while still small has a somewhat cylindrical body composed of several layers of cells, and in these the rhizoids are mainly confined to the base. The chloroplasts which these at first contain are gradually changed into leucoplasts, and may be completely absorbed (Buchtien ( I), p. I 7).

A comparison of the gametophyte with that of Lycopodium cernum has been made (Jeffrey (2), p. I86), but as Goebel has pointed out ( (22), p. 409) there is this radical difference,-in Equisetum the prothallium is dorsi-ventral, as it is in the Ferns, while in Lycopodium it is radially constructed. The more or less evidently upright form assumed by the prothallium in Equisetum is due to the amount of light. Normally the prothallium of E..telmateia is not upright, but more or less decidedly prostrate, as it is in the Ferns. (See Fig. 259, A.) 


\section{The Sexual Organs}

The prothallia of Equisetum are usually diøcious and, as is usual in such cases, the males are smaller and the antheridia develop first. The latter generally appear in about a month. In E. telmateia there is not so much difference in the appearance and size of the male and female plants, and they are not always distinguishable by the naked eye.

The first antheridia in E. pratense (Buchtien (I), p. 2I), may appear within four weeks on vigorous prothallia, and are found at the tip, or upon the forward margin of the prothallium. After the first marginal antheridia are formed, there is inaugurated an active division in the cells immediately adjacent, and a sort of meristem is developed from which new antheridia

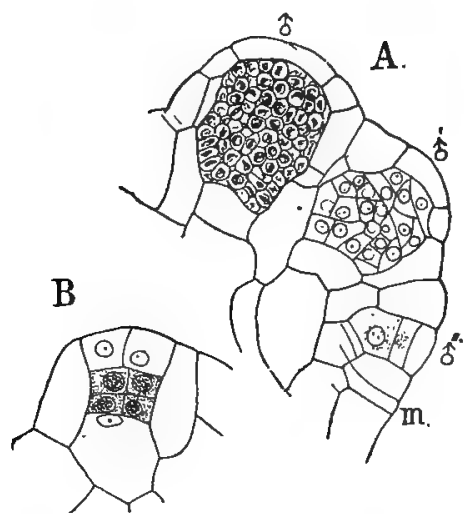

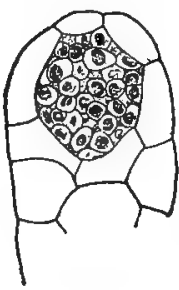

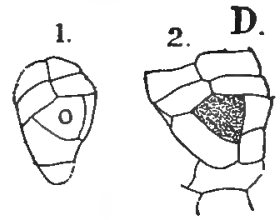

D.
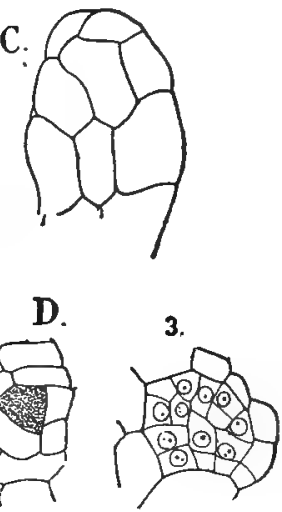

FIG. 260.-Development of the antheridium, $\times$ igo. A, Longitudinal section through the antheridial meristem showing antheridia of different ages; B, longitudinal section of young antheridium, $\times 375 ; \mathrm{C}$, two sections of a terminal, single antheridium, nearly ripe, $X 190 ; D$, three transverse sections of young antheridium, $\times 190$; $o$, opercular cell.

arise, much as is the case in E. telmateia. While in the latter species, as in others, the antheridia may arise at the ends of the prothallial branches, they also may be formed upon a meristem quite like the archegonia, and are usually in groups, so that longitudinal sections show antheridia of very different ages, all evidently derived from the activity of the meristem (Fig. 260, A). The development shows a close resemblance to that of the eusporangiate Ferns, and in connection with the other points in the growth of the gametophyte and sexual organs, suggests 
a nearer connection of these two groups than is usually admitted. As in the eusporangiate Ferns, the antheridium mother cell is divided into an inner and an outer cell of which the inner one forms at once the sperm cells. When the antheridium arises at the end of a filament, the divisions in the terminal cell are very much like those in Osmunda. In the mother cell three intersecting walls enclose a tetrahedral cell, which then has the cover cell cut off by a periclinal wall. In both forms of antheridium the subsequent history is the same. The central cell divides first by a transverse wall, followed by vertical walls in each cell, and subsequently by numerous divisions which show no definite arrangement (Fig. 26o, C), and produce a very large number of sperm cells. In the cover cell only radial walls are formed,

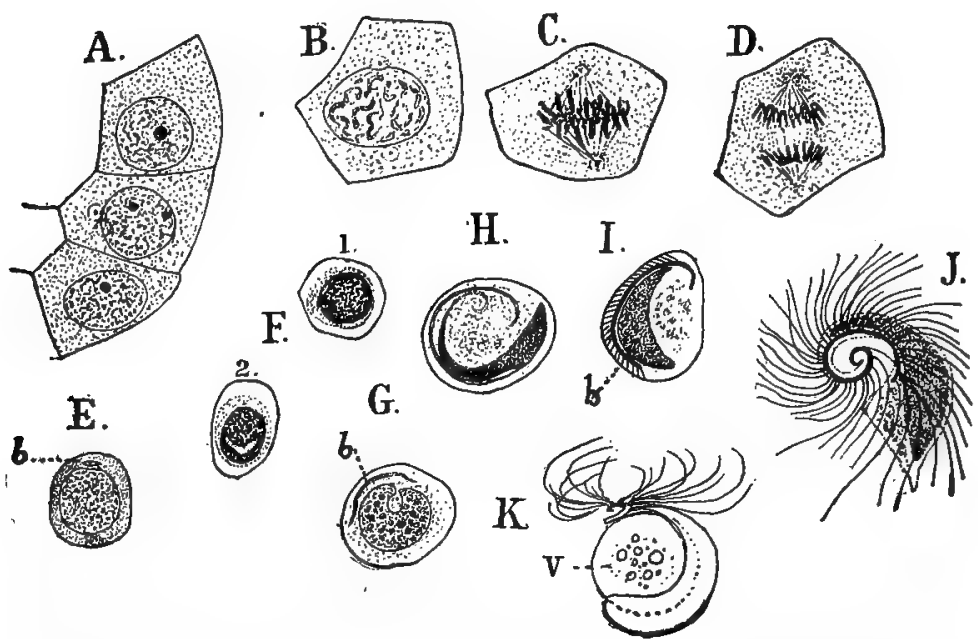

FIG. 261.-Development of the spermatozoids, $X$ rooo. A, Three of the central cells of an antheridium before the final division; B.D, final nuclear divisions in the sperm cells; E-J, development of the spermatozoid from the nucleus of the sperm cell; $K$, two free spermatozoids; $v$, the vesicle; $b$, blepharoplast. (I. J., after Belajeff).

and it thus remains single-layered, as in Marattia and Osmunda. There is often a triangular cell (Fig. 26o, D, o), recalling the opercular cell in these forms.

From the prothallial tissue adjacent to the sperm-cells, there is usually cut off a mantle of tabular cells enclosing the spermcells, much as is the case in Marattia and Botrychium. The dehiscence of the antheridium is caused by the separation of the cells of the outer-wall, but no cells are thrown off. 


\section{Development of the Spermatozoids}

The large size of the spermatozoids of Equisetum makes them especially suitable for the study of their development, and this was traced with some care in E. telmateia. Belajeff (6), more recently, has studied the development of the spermatozoid in $E$. arvense.

The nuclei of the sperm cells previous to their final division are globular and show one, sometimes two, small but distinct nucleoli, and numerous chromosomes. In exceptional cases the two blepharoplasts could also be seen. Previous to the final division the latter take their place on opposite sides of the now somewhat flattened nucleus, whose nucleolus cannot be distinguished and whose chromosomes are very distinct, short, curved bodies. Their number could not with certainty be determined. The nucleus passes through the various karyokinetic phases, and the blepharoplasts occupy the poles of the nuclear spindle. The resting nuclei, as in other cases, show no nucleolus. Fig. $26 \mathrm{I}, \mathrm{F}$, shows the earliest stage in the differentiation of the spermatozoid, and this corresponds exactly with what I have observed in various Ferns, and differs somewhat from Buchtien's figures of corresponding stages. The nucleus, which is not noticeably lateral in position, shows a narrow cleft upon one side. Seen in profile (Fig. 26I, F, I), one side projects somewhat more than the other, and becomes the anterior end, which later becomes thinner than the posterior part. I was unable to see that this forward part behaved differently from the hinder . part with regard to the nuclear stain employed, nor could I satisfy myself of the presence of the cytoplasmic anterior prominence which Strasburger ( ( I I), IV,, Pl. I I ) figures in the Ferns.

In some cases the blepharoplast could be seen (Fig. 26I, EH) and in the older stages this was much elongated, extending beyond the pointed end of the nucleus; but perhaps owing to the fixing agent used-chromic acid-the formation of the cilia from the blepharoplast did not show at all clearly, while Belajeff indicates (Fig. 26I, I) that they are very conspicuous. Perhaps also due to unsatisfactory staining, my preparations did not show at all clearly the cytoplasmic envelope about the nucleus which is so conspicuous in Belajeff's figures. (See Fig. 26I, J.)

The body rapidly elongates and becomes quite homogeneous, 
but this does not occur until a comparatively late stage. The nucleus is here somewhat flattened to begin with, and the coils of the spermatozoid lie nearly in the same plane and resemble a good deal those of Marattia, except that they are larger. The protoplasm enclosed within the coils is conspicuously granular, and forms the large vesicle attached to the posterior coils of the free spermatozoid. The mucilaginous change in the walls of the sperm cells begins about the same time as the differentiation of the spermatozoids.

The free spermatozoids consist of from two to three complete coils, of which the forward one or two are very much smaller than the very large and broad hinder one, which encloses the vesicle. The cilia are much like those of the Fern spermatozoid, but somewhat shorter. The cover cells of the ripe antheridium are forced apart by the swelling of the mucilage from the disorganised walls of the sperm cells, which are forced out of the opening into the water, where the remaining wall of the sperm cell is dissolved and the spermatozoid set free. When in motion a peculiar undulation of the large posterior coil is conspicuous, a phenomenon which has also been observed in the quite similar spermatozoids of Osmunda.

The young female prothallium is always a cylindrical mass of cells with a series of thin lateral lobes. After the archegonia begin to form and a definite apical meristem is established, the formation of these lobes is almost exactly like the similar ones in young plants of Anthoceros fusiformis. The exact relation of the growing point in the older prothallium to the primary one could not be made out. In the former this arises, according to Buchtien ( I), upon the under side of the prothallium, without any apparent relation to the primary growing point. This much is certain, that just before the first archegonium appears, there is formed a cushion not unlike that of the Ferns. In the youngest condition this in profile (Fig. 262, A) shows an evident apical cell (probably one of several), not unlike that of the Ferns; but the great difficulty of obtaining accurate sections through it made it impossible to follow exactly its further development. This much can be stated confidently, however, that at the time when the first archegonia are produced, the structure of the prothallium is essentially that of Osmundd or Marattia, and consists of a central massive midrib and a one-celled lamina, which is not continuous, but composed of 
separate lobes. A similar condition exists in Osmunda, where in the older prothallia similar but much shorter and broader lobes arise alternately from either side of the growing apex.

The development of the archegonium is intimately associated with the formation of the lobes. The archegonium mother cell is formed close to the base of the young lobe upon the ventral side. By subsequent growth of the tissue between it and the apical meristem, it is subsequently forced to the upper side, but its origin is ventral, as in the Ferns. The lobe at whose base

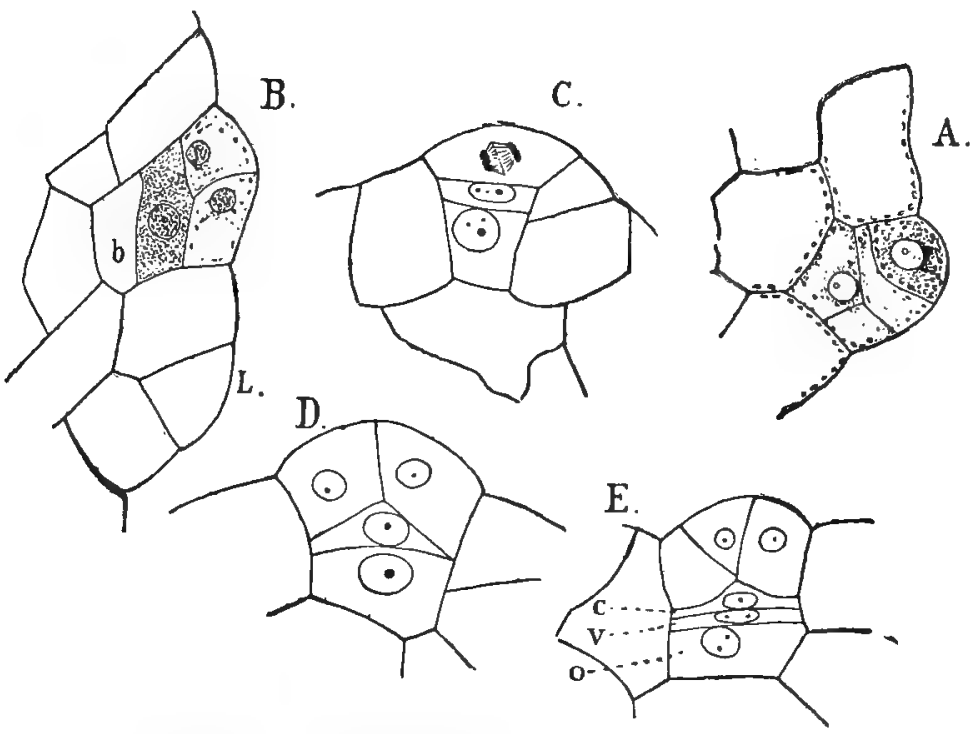

Fig. 262.-Development of the archegonium. A, Optical section of the very young archegonial meristem, $\times 225$; B-E, longitudinal sections of young archegonia, $\times 450$; $c$, neck canal cell; $v$, ventral canal cell; 0 , egg.

it is borne grows for some time by a definite apical cell, which is very evident in horizontal sections (Fig. $263, \mathrm{C}$ ).

The development of the archegonium most nearly resembles that of the eusporangiate Ferns. Usually, but not always, no basal cell is formed, and the first division in the inner cell separates the neck canal cell from the central cell. Both neck and ventral canal cells (Fig. 262, E) equal in breadth the central cell, and in this respect are most like the Marattiacer. The neck canal cell later grows up between the neck cells, but there is usually a space between its summit and the terminal neck 
cells, which here are much longer than the others. It subsequently divides by a transverse wall, as may happen in the Marattiaceæ and occasionally in Osmunda, but whether this always takes place is not certain (Fig. 263, A). The four rows of neck cells are all alike, and consist ordinarily of three cells
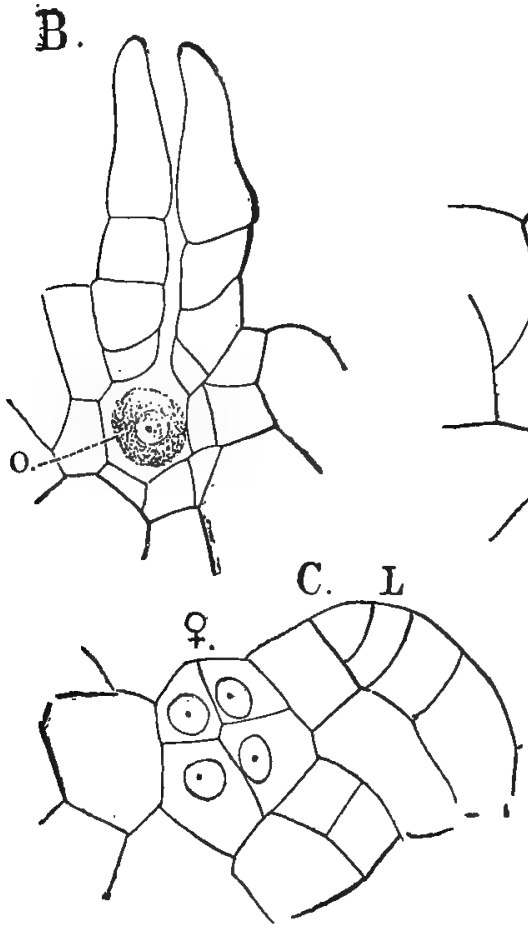
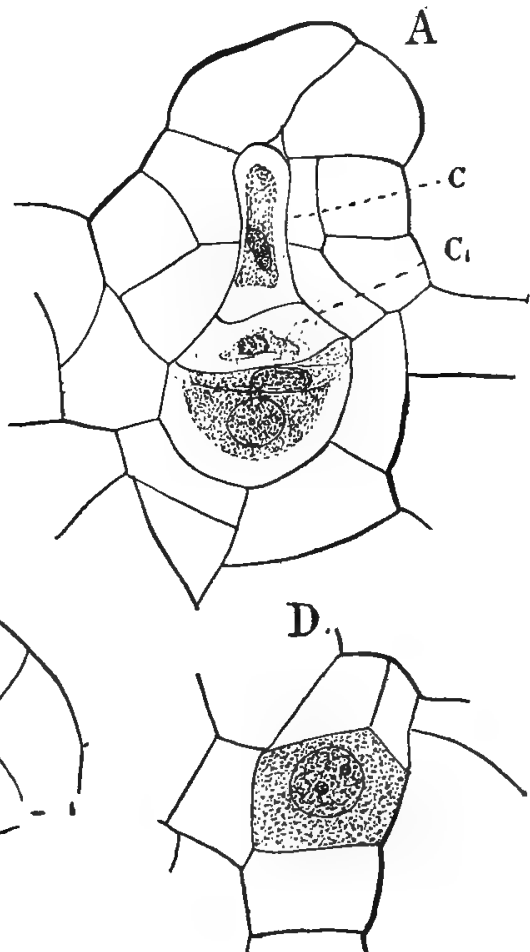

F士G. 263.-A, Longitudinal section of nearly ripe archegonium, with two neck canal cells $(c, c, \times 550 ; \mathrm{B}$, section of an open archegonium, $\times 275 ; \mathrm{C}, \mathrm{D}$, two crosssections of a young archegonium; $L$, the lobe at the base of which the archegonium is formed, $\times 550$.

each, the terminal ones being very long, and when the archegonium opens bending back strongly, but not becoming detached. The central cell is surrounded by a single layer of tabular cells cut off from the adjacent prothallium tissue, but these divisions may extend to the lower neck cells (Fig. 263, A). The egg is globular and shows no peculiarities of structure. Buchtien's ( ( I , p. 24) account of the further development of the meristem, as well as his figures, point to something very much like a repeated dichotomy of the growing point; a further investiga- 
tion of the exact origin of the primary meristem and its relation to the secondary ones found in the branches is much to be desired.

Jeffrey finds in $E$. arvense, $E$. hiemale, and $E$. limosum, that the neck canal cell usually divides longtitudinally, and compares it with the divisions in the archegonium of Lycopodium phlegmaria. This division may take place in E. telmatcia, but is exceptional. It may be mentioned that a similar division has been observed in Marattia Douglasii.

Each archegonium stands between two lobes, the one from whose base it has itself developed, and the next younger one. As these lobes in vigorous prothallia grow to a large size, and branch, this gives the prothallium an extremely irregular outline, recalling very much that of Anthoceros punctatus or $A$. fusiformis. These branching lobes are not to be confounded with the branches of the prothallium body due to the dichotomy of the archegonial meristem. These latter are always short, and project but little compared to the secondary branching lobes produced from them. The entrance of the spermatozoids and the changes subsequent to fertilisation seem to be exactly the same as in Ferns.

The prothallia are normally dicecious, but this is not exclusively the case. To a certain extent the external conditions influence the production of males or females, as in the Ferns, and unfavourable conditions of nutrition tend to increase the proportion of the former.

According to Hofmeister (I) the number of archegonia upon vigorous prothallia varies from twenty to thirty. His statement that this exceeds the number of antheridia in the larger male prothallia is not confirmed by Buchtien, who found as many as $I 20$ of the latter in some cases.

Usually more than one archegonium is fertilised, Hofmeister having found as many as seven embryos upon a single prothallium. He does not state how many of these develop. The embryo corresponds closely to that of the Ferns, and has been carefully described by Sadebeck (6).

\section{The Embryo}

The fertilised egg grows until it completely fills the ventral cavity, and its granular contents become more separated, and 
the nucleus is decidedly larger than before fertilisation. The lower neck cells approach and apparently become grown together, and as the divisions in the lower neck cells here contribute to the calyptra, the young embryo becomes more deeply sunken in the prothallial tissue than is common in the Ferns. The basal wall is transverse, as in the Marattiaceæ, and the formation of the quadrants takes place as usual. The position of the quadrant walls is, however, sometimes slightly different,

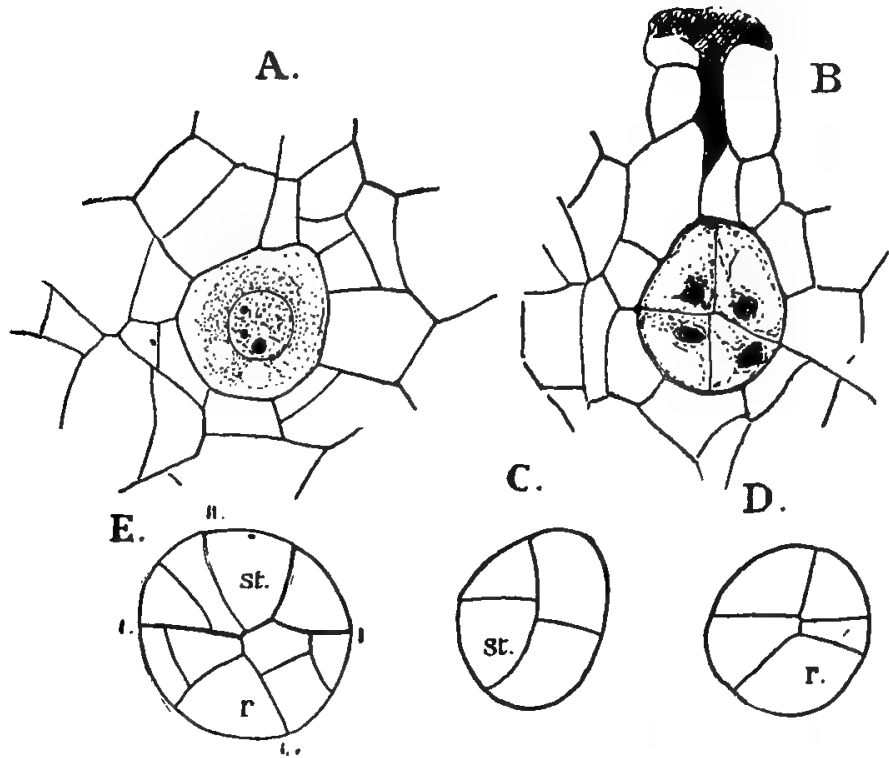

FIG. 264.-A, Longitudinal section of the venter of a recently fertilised archeg'onium, $\times 300 ; \mathrm{B}$, a similar section of an archegonium with the young embryo; C, D, two transverse sections of a somewhat older embryo, $\times 300$; st, apical cell of the stem; $r$, apical cell of the root; $\mathrm{E}$, longitudinal section of an older embryo, $\times 300 ; \mathrm{I}, \mathrm{I}$, the basal wall.

being often decidedly inclined in both epibasal and hypobasal halves (Fig. 264, E). In the former the larger of the two primary cells is the initial for the stem, and its large size, compared to the leaf quadrant, already points to the greater development of the stem in the sporophyte compared to the leaves. Of the hypobasal quadrants the larger becomes at once the root, whose axis is nearly coincident with that of the stem.

Jeffrey ( (2), p. I69) thinks that in E. hiemale the root also may be of epibasal origin, but his figures 7 and 8 are capable of 
a different interpretation, and to judge from them it is quite as likely that the root is hypobasal as in the other species examined. The first two divisions in the stem quadrant establish the definitive apical cell, which occupies nearly the centre of the epibasal part of the embryo, and is surrounded by a circle of four cells, two of which belong to the leaf quadrant (Fig. 225, C), and two are segments of the stem quadrant, the first one corresponding morphologically to the second leaf of the Fern embryo. This
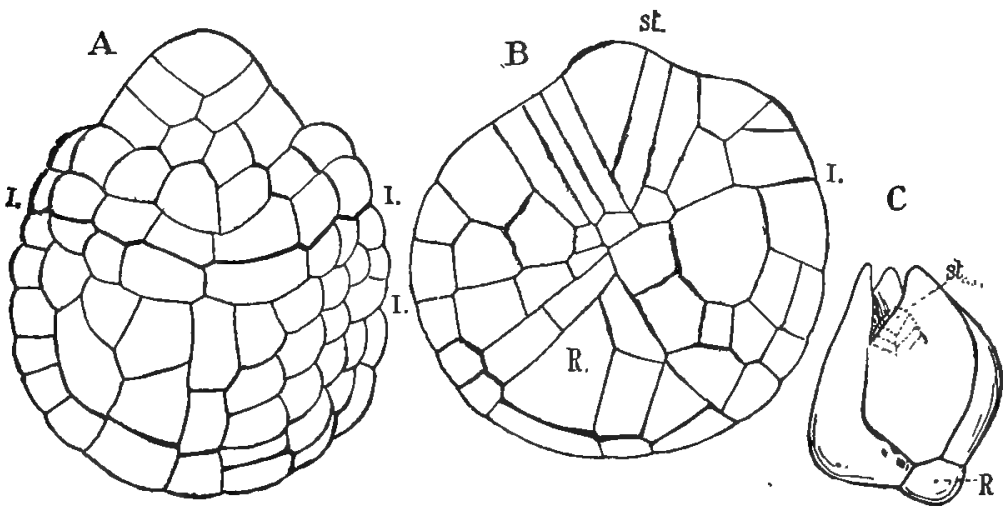

Fig. 265.-A, An advanced embryo of $E$. arvense, surface view, $\times 360 ; B$, optical section of a similar stage of $E$. palustre, $\times 360$; older embryo of $E$. arvense, $\times 160$; st, stem; R, root (all the figures after Sadebeck).

circle of cells forms the first sheath about the stem of the young sporophyte. After one set of lateral segments has been cut off from the root quadrant, the primary cap cell is formed as in the Ferns. Unlike the latter, the divisions in the stem apex proceed rapidly, and it soon projects in the centre of the embryo as a broad conical prominence, terminating in the large tetrahedral apical cell.

The three parts of which the primary leaf-sheath is composed remain distinct and form the three teeth (Fig. 265, C), which grow rapidly until they are about on a level with the apex of the stem. This growth is mainly due to the activity of the marginal cells. The root grows less actively at first than either stem or leaves, and at the time the latter is nearly fully developed forms but a small protuberance at the base of the embryo (Fig. 265, C). The foot at this time is not conspicu- 
ous, but later enlarges more. Its cells are in close contact with the prothallial cells. The root now grows rapidly downward, penetrating through the prothallium until it reaches the ground. The stem apex rapidly elongates and grows upward through the calyptra. The embryo thus perforates the prothallium both above and below, as in Marattia, although owing to the position of the archegonium in the former, the relation of the embryo to the archegonium is not the same.

The root in $E$. hiemale and $E$. arvense (Jeffrey (2), p. 169) penetrates the earth before the shoot breaks through the calyptra, but in $E$. limosum, the emergence of the root occurs at a much later period. At the time the shoot emerges from the calyptra, there is already developed the rudiment of the bud that is to form the second shoot. This bud is formed above the origin of the primary root, between two of the primary leaftraces. At this time there are already developed three or more leaf-whorls about the shoot-axis. The second shoot does not develop its first root until its first foliar sheath is well developed.

In most species that have been studied, the primary shoot has the leaves of the whorls in threes, but in $E$. variegatum (Buchtien (I), p. IIO) there are regularly but two leaves in each whorl, and Jeffrey found that this was sometimes the case in E. limosum.

The development of the primary axis, unlike that of the Filicineæ, is limited, and it ceases growing after producing ten to fifteen sheaths, which, like the first one, are three-toothed. The stem remains very slender, but shows the marked division into nodes and internodes found in the later ones. This primary stem has irregular lacunæ in the cortex, but does not show the cavity so conspicuous in the central part of the older plant, and in E. telmateia, according to Buchtien, this is quite solid. In this species he figures four vascular bundles, whose xylem is relatively much better developed than in the later stems. The bundles, like all of those in the stem and leaves, are collateral, and the whole group is surrounded by a well-marked endodermis. From the base of this primary shoot a second stronger one develops. This second shoot is much more vigorous, and its leaf-sheaths have four teeth. From the base of this others arise in the same way and in rapid succession. Sometimes the third, or one or more of the later formed basal shoots, bends downward and penetrates the earth, producing the first of the 
characteristic thizomes. The first of these have also fourtoothed sheaths, but the branches produced from them gradually assume the characters of the fully-developed shoots, some of which ultimately bear sporangia. The first shoots of the sporophyte, even in such species as later branch very freely, produce only an occasional branch, which breaks through the base of the sheath.

In E. hiemale, there is found, according to Jeffrey, a gradua! transition from the typical arrangement of the tissues of the root, to those in the base of the young shoot. There is first developed in the latter an unbroken tube of reticulate tracheids, which Jeffrey considers to be a reversion to an originally cylindrical stele. However, as this same arrangement is repeated in the succeeding nodes, it seems much more likely that this ring of tracheary tissue merely represents the basal node. Within the ring of tracheary tissue is a mass of parenchyma, and outside a zone of phloem bounded by a typical endodermis. The rudiment of the second shoot causes a break in the vascular ring above its point of origin. In the internode there are three vascular strands, corresponding to the three teeth of the foliarwhorl. In short, the structure of the primary shoot is essentially the same as that of the stouter shoots developed subsequently. Although Jeffrey speaks of a "central-cylinder," there is nothing in his account to show that the vascular bundles do not originate from the primary cortical tissue, as they do in the adult shoots.

\section{The Mature Sporophyte}

On comparing the sporophyte of Equisetum with that of most Ferns, the greatest contrast is in the relative importance of stem and leaves. The stem in all the Equisetineæ is extraordinarily developed, while the leaves are rudimentary, in strong contrast to their great size and complexity in most Ferns. All species of Equisetum produce a more or less developed underground rhizome, which often grows to a great length and ramifies extensively. This, like the aerial branches developed from it, shows a regular series of nodes and internodes. The latter are marked by longitudinal furrows, and about each node is a sheath whose summit is continued into a number of teeth, varying with the size of the stem. Corresponding to each tooth 

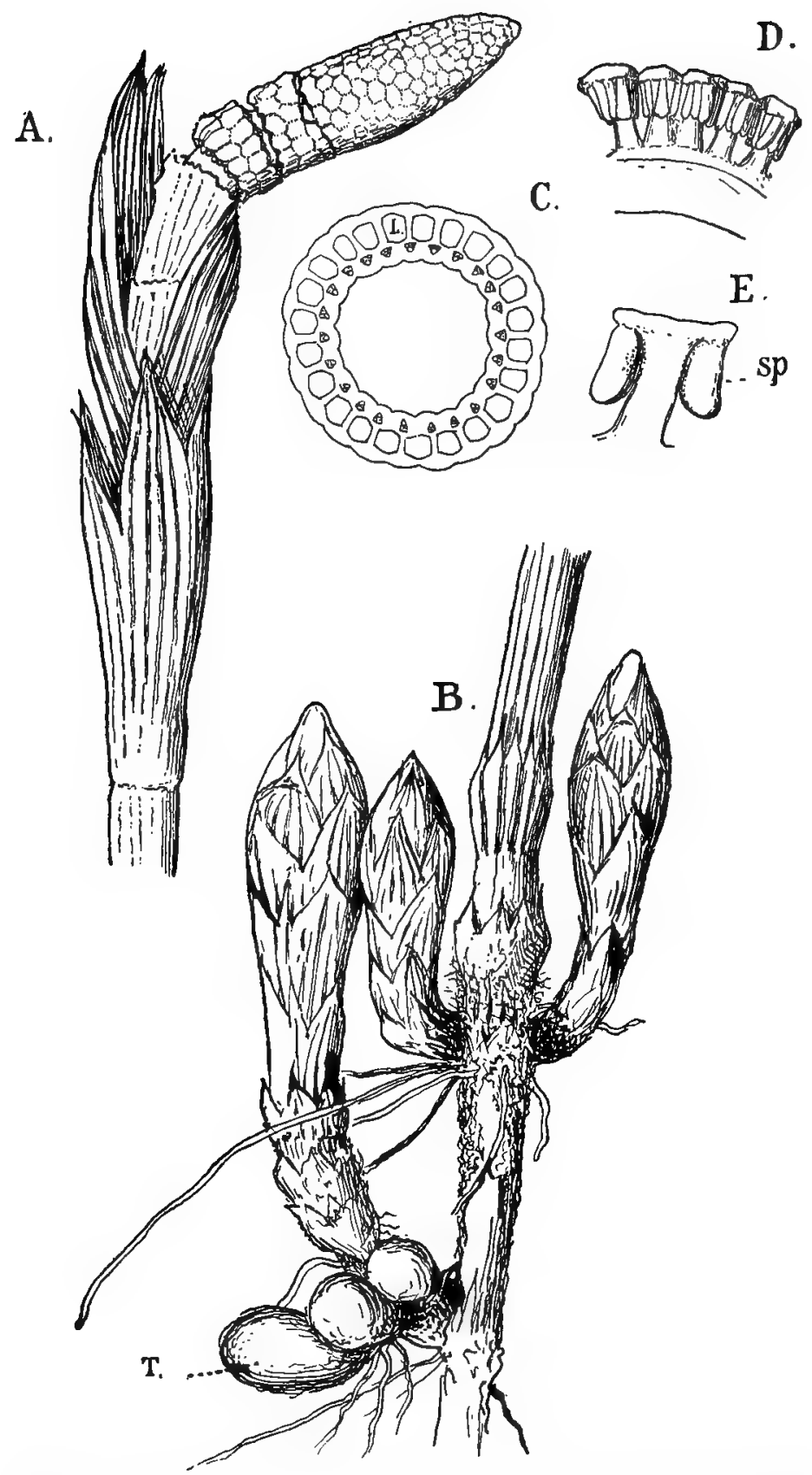

FIG. 266.-A, Upper part of a fertile shoot of E. telemateia, $X_{I}$; B, lower part of a vegetative shoot, with young branches for the next season's growth, $X_{I} ; T$, tubers; $C$, cross-section of an internode of the fertile shoot, $X_{4} ; \mathrm{L}$, cortical lacunæ; $\mathrm{D}$, sporangiophores, $X_{4} ; E$, median section of a single sporangiophore, $X_{6} ; s p$, sporangia. 
of the sheath there is developed an axillary bud, which may either at once develop into a shoot, subterranean or aerial, or these buds may remain dormant for an indefinite period, being capable of growing, however, under favourable conditions. The surface of the rhizome in E. telmateia, especially at the nodes, is covered with a dense dark-brown felt of matted hairs, and a whorl of roots occurs at each node, corresponding in number to the number of axillary buds, from whose bases the roots really grow. Sometimes the buds become changed into tubers (Fig. 266), which are especially common in E. telmateia and $E$. arvense. These tubes are protected by a hard brown sclerenchymatous rind, within which is a mass of starchy parenchyma, traversed by the slender vascular bundles. In some cases these buds form in chains and are then seen to be the swollen internodes of short branches.

The aerial stems are of two kinds, sporiferous and sterile. In one group the only difference between the two is that the former bear at the apex the sporangial strobilus; in the second, of which E. telmateia is an example, the sporiferous branches are almost entirely destitute of chlorophyll and quite unbranched, while the green sterile shoots are extensively branched. In such forms the fertile shoots die as soon as the spores are shed, and usually appear before the green shoots are developed.

The Stem (Rees (2); Sachs (I); Janczewski (3); Jeffrey (2))'

A longitudinal section of one of the numerous subterranean buds (Fig. 267) shows that the conical apex of the stem is occupied by a large pyramidal cell whose segmentation is exceedingly regular. The youngest of the foliar sheaths is separated from the apex by several segments, but below, the next older sheath is very close to it, and the internode, which in the older stem is so conspicuous, is scarcely perceptible. The closely-set sheaths grow very rapidly, so that all but the youngest ones extend beyond the stem apex, which is thus very completely protected. They form a compact, many-layered covering about it, presenting very much the appearance of the leafbuds of many Spermaphytes. The apical cell shows the usual three series of lateral segments. These are arranged in three rows, but owing to a slight displacement in the younger ones, 
the teeth of the sheaths alternate. Each cycle of three segments comes to lie practically in the same plane, and constitutes a disc which later forms a node and internode of the stem. Each segment is first divided by a wall nearly parallel to the wall by which it was cut off from the apical cell, into two overlying cells. The upper cells or semi-segments give rise to the nodes, the lower to the internodes.

The next walls are like the sextant walls in the roots of the Ferns, and a cross-section just below the apex presents exactly the same appearance. Each cell now divides by walls,

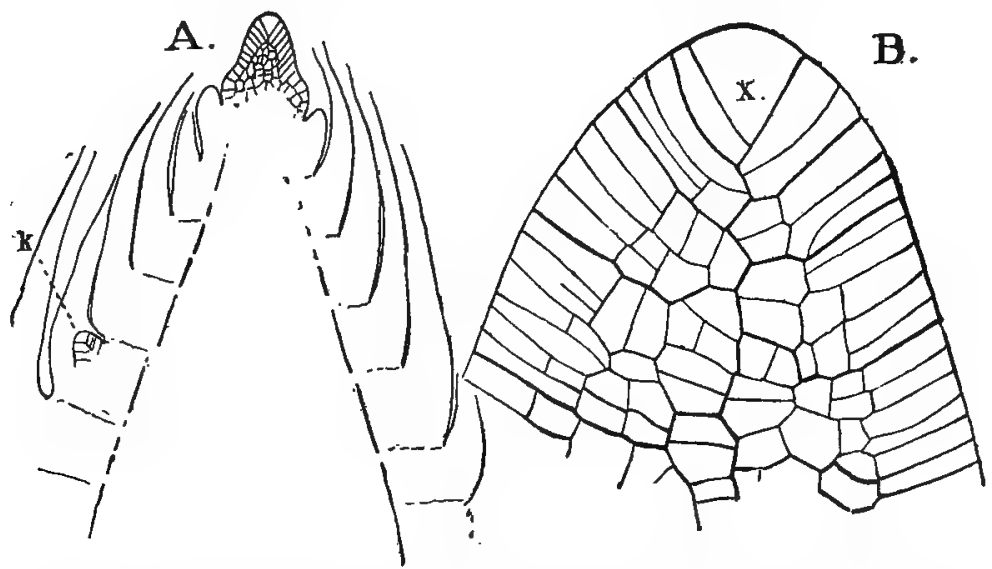

FIG. 267.-A, Median section of a strong subterranean (vegetative) bud, $X_{3} 0 ; k$, lateral bud; $B$, the apex of the same section, $\times 200$.

apparently not always in the same order, parallel with the primary and lateral walls, and very soon there are periclinal divisions by which an inner cell is cut off from each segment cell that extends to the centre. This primary group of central cells is the pith, which later in the internodes is usually torn apart and destroyed, leaving the large central hollow met with in all the larger species of Equisetum. From the outer cells are developed the leaves, the vascular bundles, and cortex.

The annular leaf-sheaths begin as outgrowths of the superficial nodal cells of each cycle of segments, and these form a -circular ridge or cushion running round the base of the apical cone. The summit of this ridge is occupied by a row of marginal cells, which are the initial cells, and from these segments are cut off alternately upon the inner and outer sides (Fig. 272, 
A). The growth is stronger at certain points, which, according to Rees, have a definite relation to the early divisions. Thus in E. scirpoides the teeth are always three, and correspond to the

A.

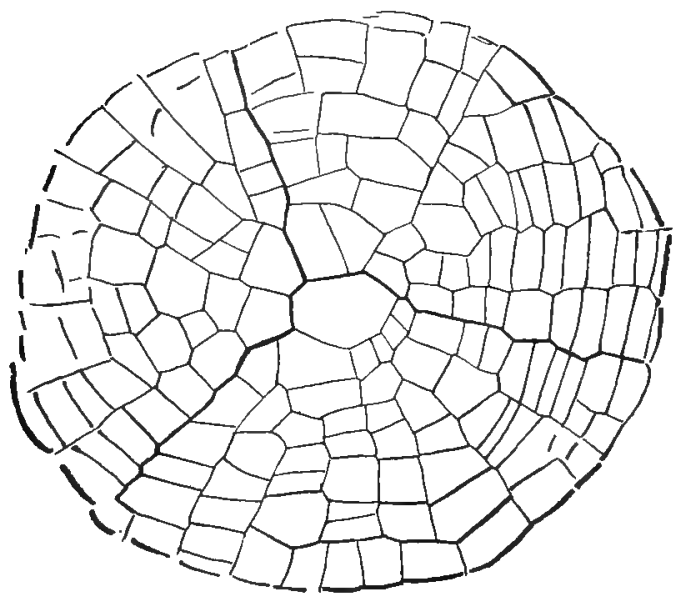

B.
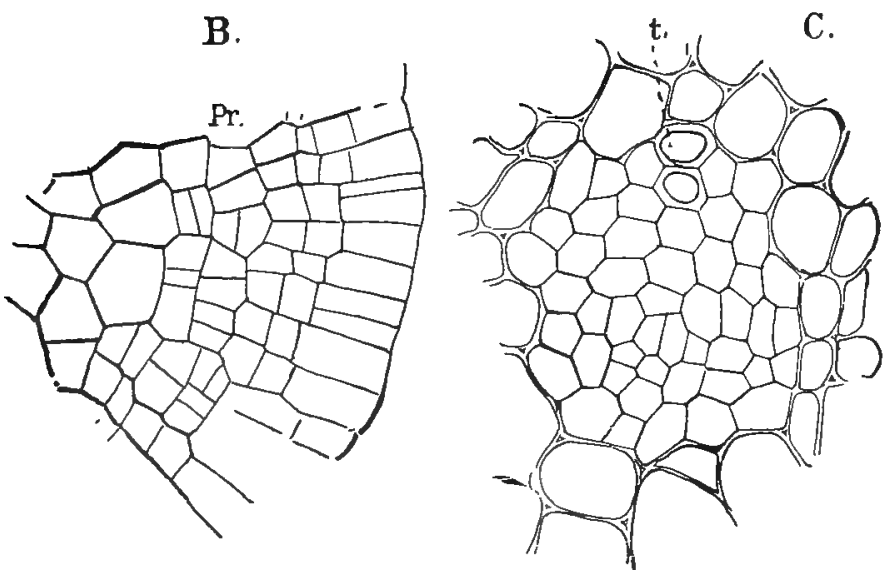

FIG. 268.-Transverse section of a young vegetative shoot just below the apex, $\times 260 ; B$, outer part of a section lower down, $\times 260 ; p r$, procambial zone; $C$, young vascular bundle, $\times 520 ; t$, primary tracheids.

primary nodal cells; in $E$. arvense there are six or seven, in the first case corresponding to the sextant cells, in the latter to the sextant cells plus the first division in one of them. In the 
large species, like E. telmateia, it is difficult to trace any such relation. In most forms, by subsequent dichotomy of some or all of the primary teeth, others are formed, so that the number in the fully-developed sheath exceeds that first formed. As soon as the young sheath begins to project, a section through one of the teeth shows that it is divided into an upper and lower tier of cells, the apical cell terminating the upper one. This division no doubt corresponds to the first horizontal division in the outer nodal cell from which the leaf-tooth originally comes. In one a little older (Fig. 272, B), in this upper tier of cells a line of cells occupying the axis is evident $(f b)$, extending from the base of the leaf nearly to the summit, and growing at its outer end by the addition of cells derived from the inner part of the youngest upper segments of the terminal cell of the leaf. ${ }^{1}$ This is the beginning of the single vascular bundle found in each leaf.

Shortly after this first indication of the vascular bundle of the leaf can be seen, the cells of the cortex immediately outside the central pith begin to divide rapidly by longitudinal walls and form a zone of cambiform cells completely surrounding the medulla. In the primary central row of cells in the leaves similar divisions occur, and a very evident procambium cylinder is formed, bending in and joining the procambium zone of the cortex. At the point of junction the cells are shorter and broader, and the cortical cells lying outside are also much broader, so that the cortical procambium is very conspicuous. If cross-sections are examined about this time, in the procambium zone are found a number of groups of cells where the divisions are more rapid, and the resulting cells narrower than the surrounding ones. These are the separate vascular bundles, and are continuous with those in the leaves (Fig. 269). The first permanent tissue consists of one or two small annular tracheids upon the inner side of the bundle (Fig. 268, C). These are followed by several others. They first form in the internodal part of the bundle and only later in the foliar portion. The nodal tracheids joining the xylem of the foliar and internodal bundles are very irregular short cells with annular thickenings upon their walls. Later two small groups of larger spiral tracheæ are formed at the sides of the xylem, but the

${ }^{1}$ Each tooth is here regarded as a leaf, the sheath as a circle of confluent leaves. 
greater part remains but little changed. By this time, in E. telmateia, numbers of cells with peculiar contents are noticed scattered through the pith and cortex (Fig. 269). The contents of these are dense, and stain deeply, indicating the presence of mucilaginous matter, and probably tannin, their appearance and behaviour being very much like the tannin cells of Angiopteris or Marattia.

In the older parts of the section the nodal cells remain short, while the internodal cells elongate very much and separate the nodes with their attached foliar sheaths. With this growth is associated the formation of the characteristic lacunæ. In all

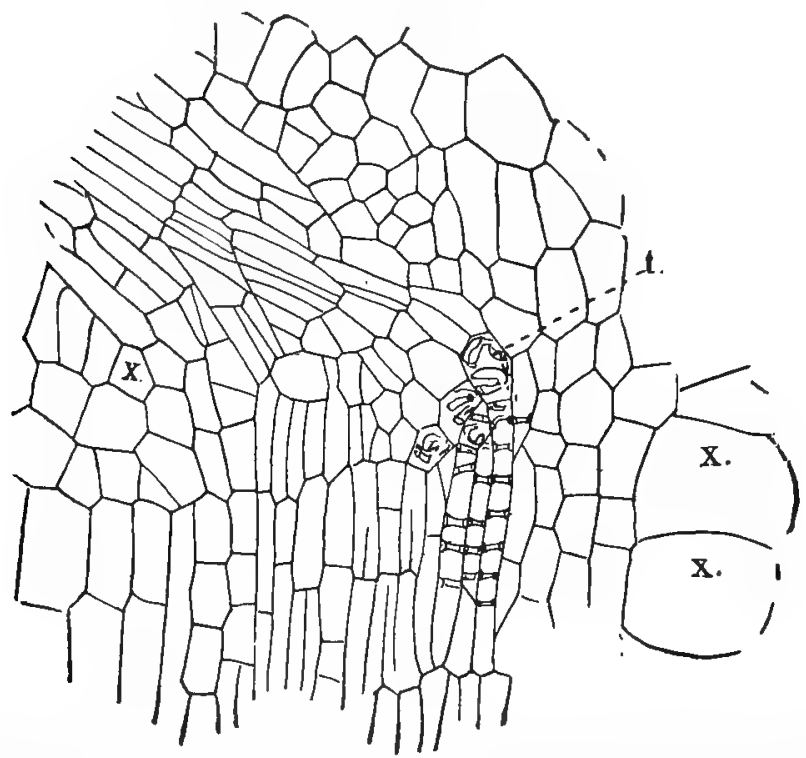

Frg. 269.-Longitudinal section of the young stem, showing the junction of the foliar and internodal bundies; $t r$, the primary tracheids; $x, x$, tannin-bearing cells.

the large species the growth of the medullary cells very soon ceases to keep up with the expansion of the stem, and they are torn apart and almost completely disappear, leaving a great central cavity in each internode separated from the neighbouring ones by a thin diaphragm,-all that is left of the medulla in the fully-developed stem. The leaves of successive sheaths alternate, and a study of the course of the vascular bundles shows that at each node the alternating bundles of successive internodes are connected by short branches. Corresponding to the 
vascular bundles are ridges upon the surface of the internodes and foliar sheaths, due to greater growth at these points, as a result of which a regular series of cortical lacunæ (vallecular canals) is formed, alternating with them (Fig. 266, C), and lying just outside of the cortical zone containing the vascular bundles. In some of the small species of Equisetum, as in the primary shoot; the central lacuna is absent.

A cross-section of the fully-developed stem of $E$. telmateia (Fig. 266, C) shows this very regular arrangement of the vascular bundles and lacunæ. In addition to the large cortical ones, each vascular bundle has, on the inner side, a large airspace, which like the other is formed by the tearing apart of the tissues of the bundle. In this way the primary tracheids are torn apart and often destroyed, so that all that remains of them are the isolated thickened rings adhering to the sides of the canal. The bundle is strictly collateral in structure, and very much resembles that of many grasses and other simple Monocotyledons. The phloem is composed of sieve-tubes, which, according to Russow (I), have only horizontal sieve-plates, and no lateral ones as in the Ferns. These are mingled with cambiform cells. In the species in question there is in addition a zone of bast fibres at the outer limit of the phloem.

Surrounding the whole circle of bundles in $E$. telmateia, $E$. arvense, and several other species, there is a common endodermis (Fig. 270, en ). In others the arrangement is different (Pfitzer (I) ; Van Tieghem (6)). Thus in E. limosum, each separate bundle has its own endodermis; in $E$. hiemale there is a common inner as well as an outer endodermis in the aerial stems, while the bundles of the rhizome are like those of $E$. limosum. Inside the endodermis lies the single pericycle.

There has been some controversy as to the nature of the vascular system in Equisetum. Van Tieghem $(6,8)$ describes the stem of Equisetum as "astelic"; Strasburger ( ( I I ), vol.' 3) considers it as monostelic. Jeffrey has attempted to reduce the structures to his "siphonostelic" type, $i$. e., he would compare the complex of vascular bundles to the cylindrical stele of the Ferns and Lycopods. The spaces between the vascular strands of the internodes he considers as "gaps" comparable to the foliar gaps in the stele of the Ferns, or the ramular gaps in the stele of the Lycopods. He is, moreover, of the opinion that the solid stele ("protostele") found in the fossil Sphenophyllales is the 
prototype of the "siphonostele," which he thinks is the condition found in Equisetum. He seems, however, to have overlooked the fact that in the adult shoot, at least, of Equisetum, the whole vascular system of the stem originates from the primary cortex or periblem, the original central tissue-cylinder giving rise only to the pith. Moreover, his assumed "ramular gaps" are found equally developed whether branches are developed or not, and are obviously related to the leaf-traces of the internode.

All the cortical cells are separated by small intercellular spaces, which are very conspicuous in the soft tissue of the

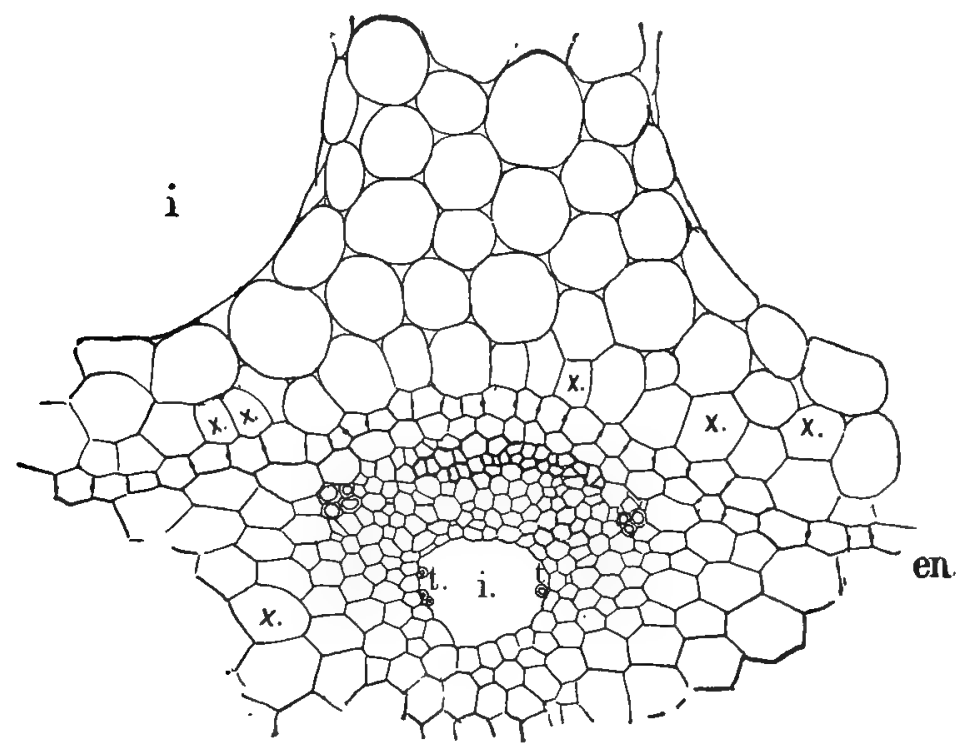

FIG. 270.-Transverse section of the vascular bundle of a fully-developed vegetative shoot, $\times 75 ; i, i$, lacunx; $x, x$, tannin cells; $t, t$, remains of the primary tracheids; en, endodermis.

fertile stems of $E$. telmateia and $E$. arvense. In all of the internodes of the main axes of $\dot{E}$. telmateia chlorophyll is absent, but in most species the principal assimilative tissue is situated here. It consists usually of isolated masses of transversely extended green cells separated by strands of colourless sclerenchymatous fibres, which form the ridges so prominent upon the internodes and foliar sheaths. Seen in cross-section the masses of 

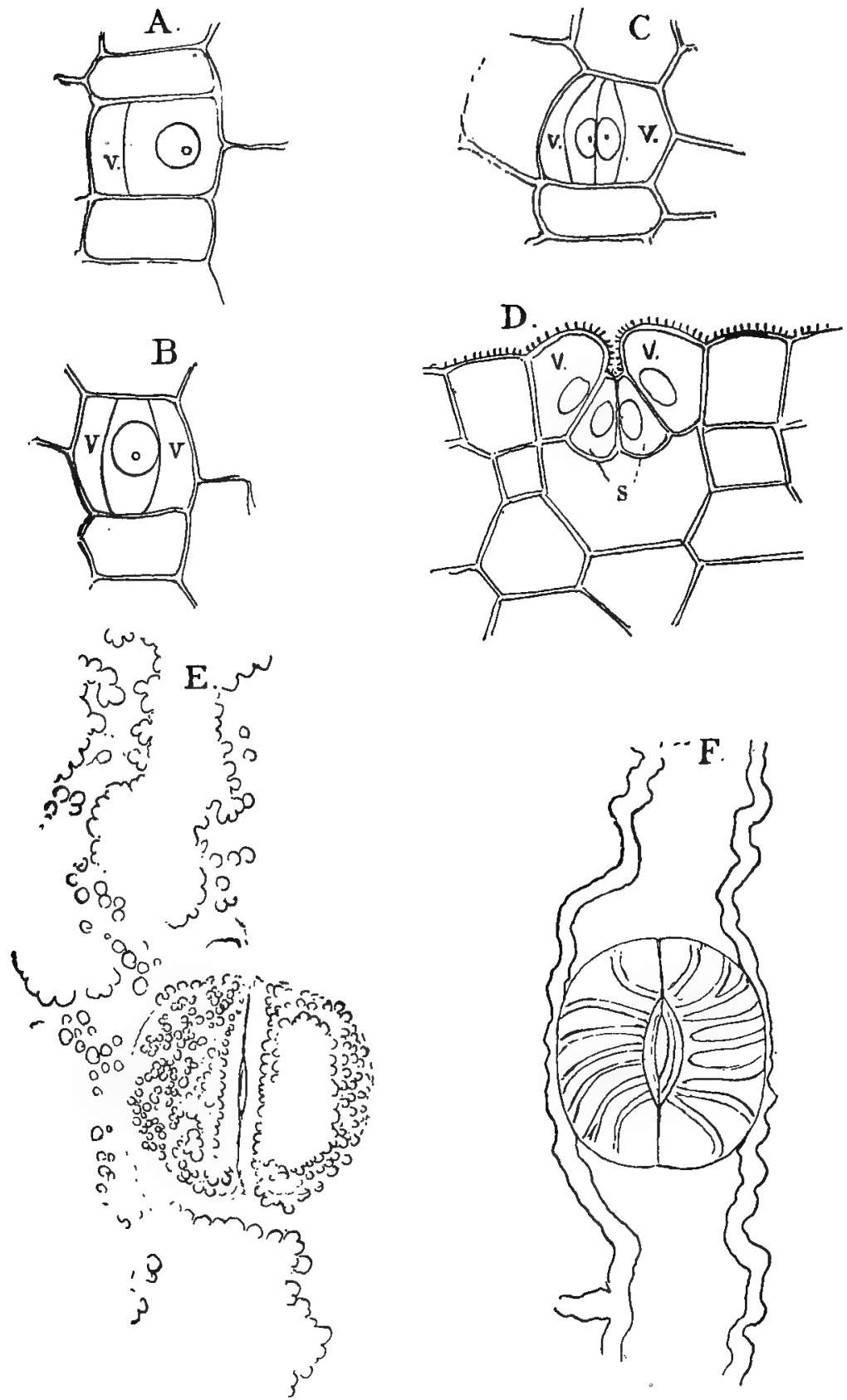

FIG. 271.-Development of the stomata. A-C, Surface views of very young stornata of E. telmateia, $\times 600 ; \mathrm{D}$, section of an older stoma of $E$. limosum, $\times 700$ (after Strasburger); E, outer surface of a complete stoma of E. telmateia, showing the silicious nodules upon the epidermal cells; F, inner side of the same, showing the silicious bars upon the inner walls of the guard cells; $v, v$, accessory cells; $s$, guard cells. 
green cells are concave outwardly and lie beneath the ridges. In secondary branches the amount of this tissue is much greater and the lacunæ less conspicuous, or indeed even wanting.

The epidermis, as is well known, contains great quantities of silica, which gives it its very rough and harsh surface. This is deposited either uniformly, as is usually the case in the lateral cell walls, or in tubercular masses. Upon the inner surface of the guard cells of the stomata it forms regular transverse bars (Fig. 27I). Upon the outer walls of the epidermal cells the masses form either isolated bead-like projections or these are more or less completely confluent.

The stomata are peculiar in structure, and their development was first correctly described by Strasburger (I). In E. telmateia these only occur usually upon the foliar sheaths, but in species with green internodes they are found principally upon the sides of the furrows over the green hypodermal tissue. ${ }^{1}$ Before the stoma proper is formed, the cell divides twice by longitudinal walls (Fig. 27I), and the original cell is thus divided into a central one (the real stoma mother cell) and two narrow lateral accessory cells. The central cell now divides again, and the division wall splits in the centre as usual. A cross-section of the young stoma (Fig. 27 I, D) shows that the walls by which the accessory cells are cut off are inclined, so that the stoma cell is broader at the bottom than at the top, and as development proceeds the accessory cells completely overarch the stoma, and in the older ones look as if they had arisen by horizontal divisions in the primary guard cells. The accessory cells show the same tuberculate silicious nodules upon their outer walls as the other epidermal cells, and upon the inner face of the real guard cells only are formed the regular bars. Stomata are quite absent from the rhizome, and also from the colourless fertile branches of $E$. telmatcia. Compared with the aerial stems, the rhizome shows a smaller number of vascular bundles, and a corresponding reduction in the number of the lacuna.

\section{The Branches}

Until the researches of Janczewski (3) and Famintzin (I) it was supposed that the lateral branches arose endogenously.

1 Miss E. A. Southworth (I) found that in E. arvense they occur upon the ridges, and upon the fertile as well as the sterile shoots. 
Their researches, however, showed conclusively that this was not the case, but that the origin is exogenous. In most species they are produced abundantly, and a bud is formed in the axil of each leaf, although it frequently happens that some of them do not develop fully. In E. telmateia they do not occur at all, as a rule, upon the colourless sporiferous shoots, but are regularly formed from all but the lowest nodes of the sterile stems.
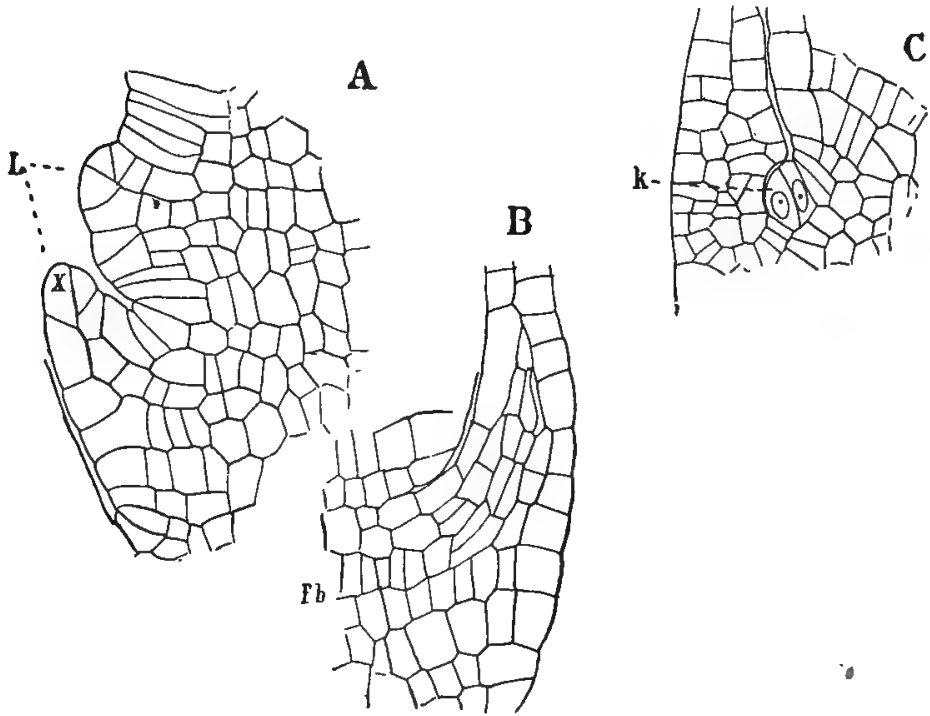

FIG. 272.-Longitudinal section of a young vegetative shoot showing two young leaves (L.), $\times 200 ; B$, section passing through the base of a somewhat older leaf; $f b$, vascular bundle; C, section passing through a young bud. $(k)$.

In $E$. scirpoides they are absent from all the aerial stems, but whether rudiments of them are formed does not seem to have been investigated.

Their development may be readily traced in a series of median longitudinal sections through a vigorous sterile stem of $E$. telmateia or $E$. arvense before it appears above ground. The young bud (Fig. 272, C) originates from a single epidermal cell just above the insertion of the leaf. This cell enlarges and is easily recognisable. In it are formed three intersecting walls cutting out the apical cell, which at first is somewhat irregular, but soon assumes its definite form, and the subsequent growth of the branch resembles in all essential points that of the main 
shoot. Very early the cells of the leaf-base immediately above the young bud grow around it like a sheath, and finally become grown together with the epidermal cells of the axis above the bud, which thus lies in a completely closed cavity. As the bud grows it gradually destroys the tissue surrounding the cavity, and finally breaks through the base of the leaf, appearing from the outside as if it had developed from below and not from the axil of the leaf. In most species these branches remain simple,

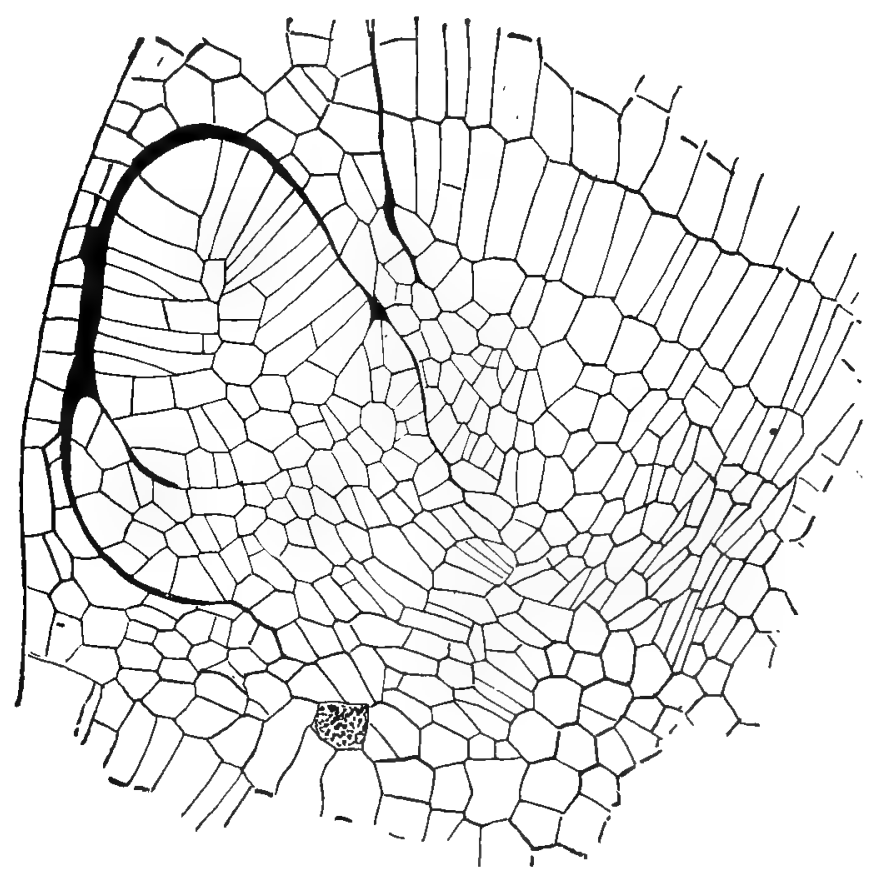

FIG. 273.-Section of a lateral bud, enclosed within the sheath formed by the leaf-base, $\times 175$.

but in E. sylvaticum and E. giganteum the secondary branches also ramify.

\section{The Roots}

The formation of the roots is intimately connected with that of the lateral buds. Each bud normally produces a single root below the first foliar sheath, which in the buds derived from the rhizome all develop, whether the buds themselves grow further 
or not. According to Janczewski, certain of these rhizogenic buds of the rhizome produce several roots, but the buds remain otherwise undeveloped. In the aerial stems the roots remain normally undeveloped, but may often be stimulated into growth by keeping the stem moist and dark.

Van Tieghem ( (5), p. 55 I) describes the roots of E. palustre as being exogenous, and says they can be traced to a definite cell of one of the young segments. Janczewski ( (3), p. 89), however, was unable to recognise the young root until the first
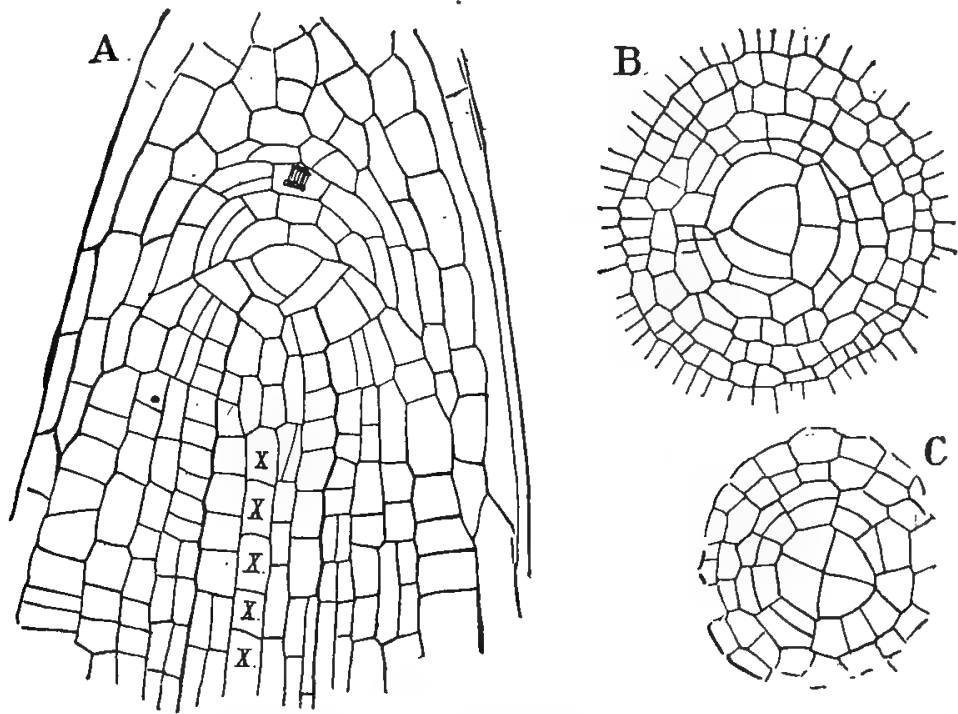

FIG. 274.-A, Longitudinal section of the root apex, $\times 200 ; x, x$, the large central vessel of the vascular bundle; $B, C$, two transverse sections passing through the apex, $\times 200$. In $\mathrm{C}$ is shown the first divisions of the cap cell.

foliar sheath was well developed, and in E. telmateia I could see no trace of the root in still older buds, and they were apparently always of endogenous origin, although this point was not specially investigated.

The structure of the apical meristem is much like that of the leptosporangiate Ferns, the main difference being the greater development of the root-cap, in which periclinal walls are frequent, so that the older layers, especially in the middle, are several cells thick, and not clearly limited.

After the sextant walls are formed, each semi-segment is 
divided at once into an inner and an outer cell, the former giving rise directly to the plerome or central cylinder. The next division (seen in longitudinal section) separates the epidermis initials from the cortex. A cross-section of the young plerome immediately after the first divisions have taken place (Fig. 275, A) shows that the three primary cells are of unequal size, and that the two smaller ones divide first. From the larger one, the first periclinal wall separates a central cell, which occupies almost exactly the middle of the section, and this stands immediately above the corresponding one in the older segments, so that in longitudinal sections (Fig. 274) these form a very conspicuous axial row of cells $(x, x)$, which together constitute
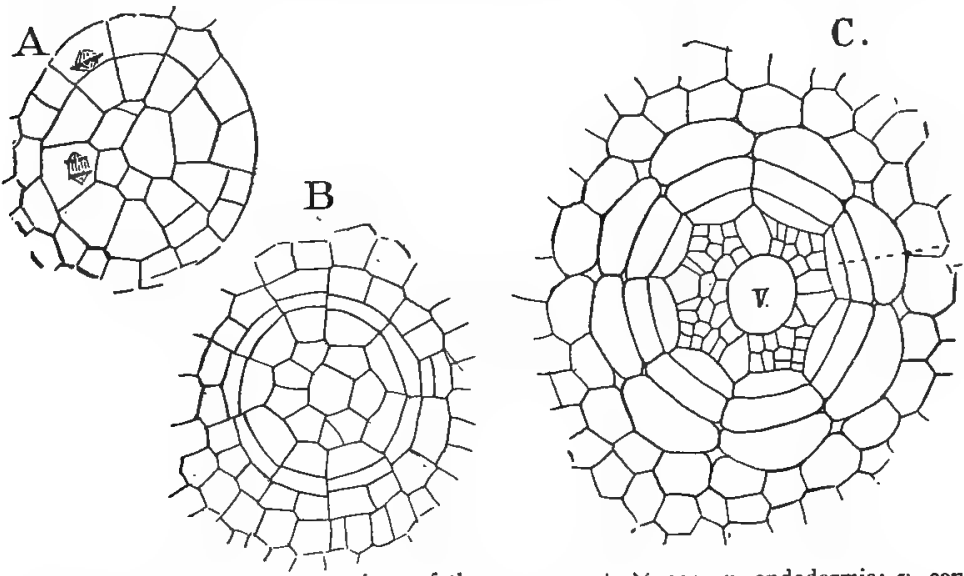

Fig. 275.-Three transverse sections of the young root, $X 200 ; \iota n$, endodermis; $v$, central vessel.

the single large vessel which occupies the centre of the older bundle. The endodermis becomes separated by this time, and a little lower down divides by periclinal walls into the two layers found in the completely developed root. The tissues of the central part of the young root are very regularly disposed (Fig. $275, \mathrm{~B}, \mathrm{C}$ ). In the centre is the large vessel already described, around which are arranged at first a single row of usually six or eight cells (Fig. 275, B). By these first divisions the separation of the xylem and phloem of the bundle is complete. If there are six of these primary cells the bundle will be triarch, if eight, tetrarch. In somewhat older sections of a tetrarch bundle (Fig. 275, C) four of the primary cells are still recognisable and have divided but little. These form the four groups 
of tracheids of the older bundle. The intermediate cells divide much more rapidly and constitute the phloem. The number of endodermal cells in a cross-section corresponds generally to, the number of xylem and phloem masses. The peripheral groups of trachex early develop spiral thickenings upon their walls, and sometimes there is but a single row of tracheæ in each xylem mass. Each of the three phloem masses of $E$. variegatum has three narrow sieve-tubes in contact with the inner endodermis surrounded by thin-walled cambiform cells. The thickenings upon the walls of the large central vessel form only at a late period.

Intercellular spaces arise at the angles of the outer endodermal cell, and similar ones also between the outer cells of the cortex, which becomes very spongy in the older roots. Numerous brown root-hairs, like those upon the rhizome, cover the surface of the root. A pericycle is quite absent, and the secondary roots arise from the inner endodermis in direct contact with the tracheids. The latter, as will be seen from the figure, lie between two endodermal cells, and the young root lies therefore not directly opposite, but to one side of the corresponding xylem mass. The young roots may arise from either of these endodermal cells, and consequently there is formed a double row of rootlets corresponding to each xylem mass of the bundle. Shortly after the rootlet is formed, the endodermal cell outside it divides by a tangential wall, and this develops into a double layer of cells completely enclosing the young rootlet (Van Tieghem (5), p. 395). A similar "digestive pouch" is formed, according to Van Tieghem, in the roots of many Ferns, but is in these derived from the cortex outside the endodermis. The double endodermis of the bundle of the older root shows the characteristic foldings of the radial walls only upon the outer cells.

Cormack ( I) has recently published a paper showing that in E. maximum (telmateia) there is a slight secondary increase in thickness in the nodes of the stem, due to the presence of a genuine cambium, not unlike that in the stem of Botrychium.

\section{The Sporangium (Bower (I5))}

In all species of Equisetum the sporangia are formed upon the under side of peltate sporophylls arranged in closely-set 
circles about the upper part of the axis of the fertile shoots (Figs. 266, 28I ). A section through the apex of the young shoot shows much the same structure as a sterile one, but the apical cell is smaller and the leaves do not arise so near the summit. Circular foliar sheaths are formed in the same way, but the leaves form rounded elevations, either entirely separated or but slightly joined (Fig. 276). These are at first nearly hemispherical, but soon become constricted at the base, and about the same time the first trace of the sporangia can be seen. A section of the young sporophyll shows that the centre of the promi-
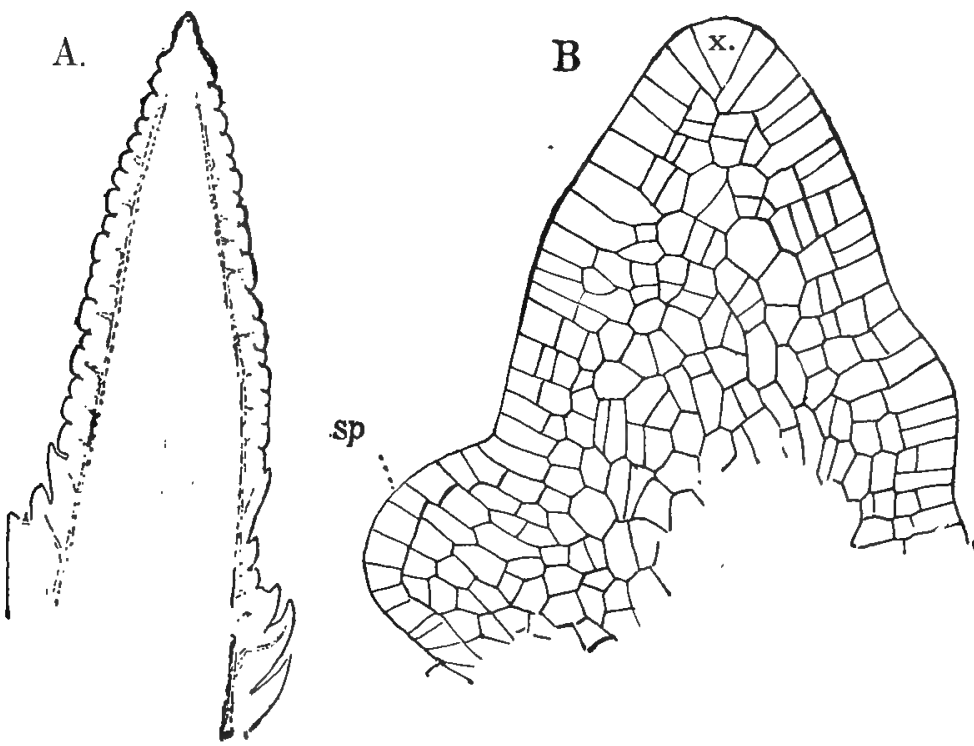

Fic. 276.-A, Longitudinal section of the apex of a young fertile shoot, $\times 16 ; B$, apex of the same, $X 160 ; s p$, young sporangiophore; $i$, apical cell.

nence already has formed the young plerome which, as in the ordinary leaves, joins that of the internode beneath. Just above the base a cell may sometimes be detected, which is larger than its fellows, and has a larger nucleus. From a comparison with slightly older stages there is no doubt that this is the sporangium mother cell, or more correctly the axial sporangial cell, as the adjacent tissue also takes part in its further growth. This axial cell now becomes separated into an inner and outer cell, as in Botrychium. The outer cell divides again. The inner- 
most cell of the axial row is the archesporium, and gives rise to the sporogenous cells by repeated divisions, at first at right angles to each other, later in all directions. Bower ( ( I5), p. 497) thinks that all the sporogenous cells are not to be traced back to the single archesporial cell, but that the inner of the two cover cells also takes part in spore-formation. The exact limits of the archesporium are difficult to follow, as the contents of the sporogenous cells are not strikingly different from the
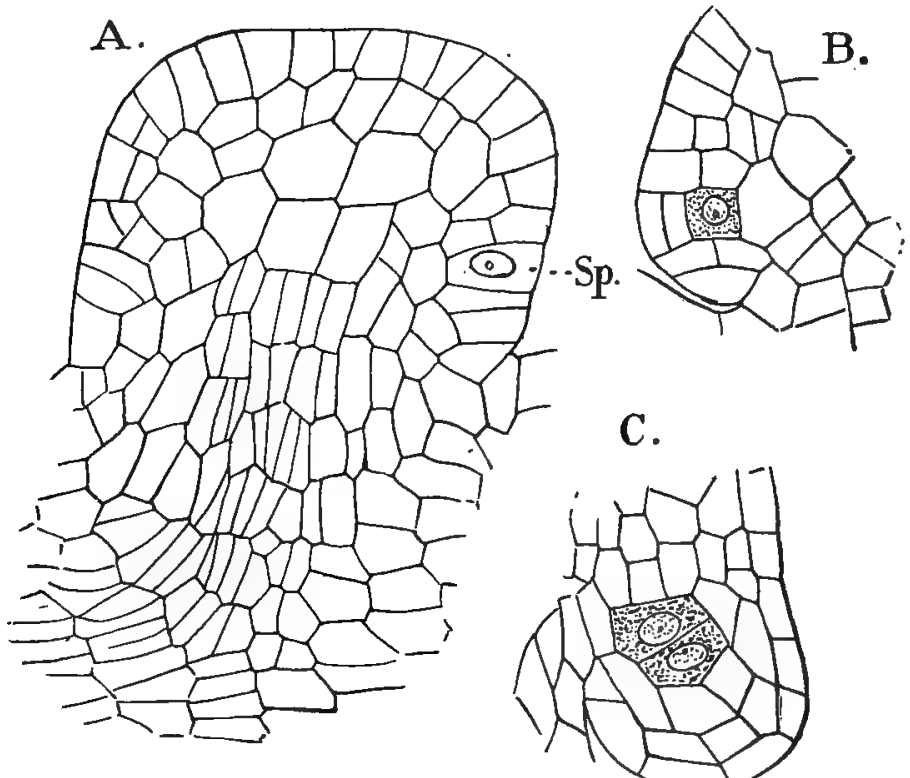

C.

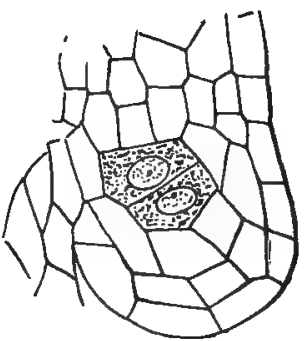

Fig. 277.-A, Longitudinal section of young sporangiophore, showing the primary sporangial cell $(s p), \times_{2} 60 ; \mathrm{B}, \mathrm{C}$, longitudinal sections of young sporangia, $\times 260$. The archesporial cells are shaded.

inner tapetal ones. These are derived from the cells adjacent to the axial row, and from the cells of the latter just outside the archesporium. The wall of the sporangium is mainly formed from the cells adjacent to the axial row of cells. All the cells grow and divide rapidly, so that the sporangium soon projects strongly from the margin of the sporophyll, whose upper part becomes broad and flattened, while the stalk increases but little in diameter. The wall of the sporangium at first is three or four cells thick, Finally it is reduced to but a single complete 
layer by the absorption of the others, but the remains of a second layer can be made out in stained sections of the ripe sporangium (Fig. 28o, E). The vascular bundles of the sporophyll divide, one branch running to each sporangitum.

Of the two species studied by Bower, E. arvense and $E$. limosum, the latter showed more slender and strongly projecting sporangia, but otherwise they were alike. E. telmateia has even more massive sporangia than $E$. arvense. The sporophylls

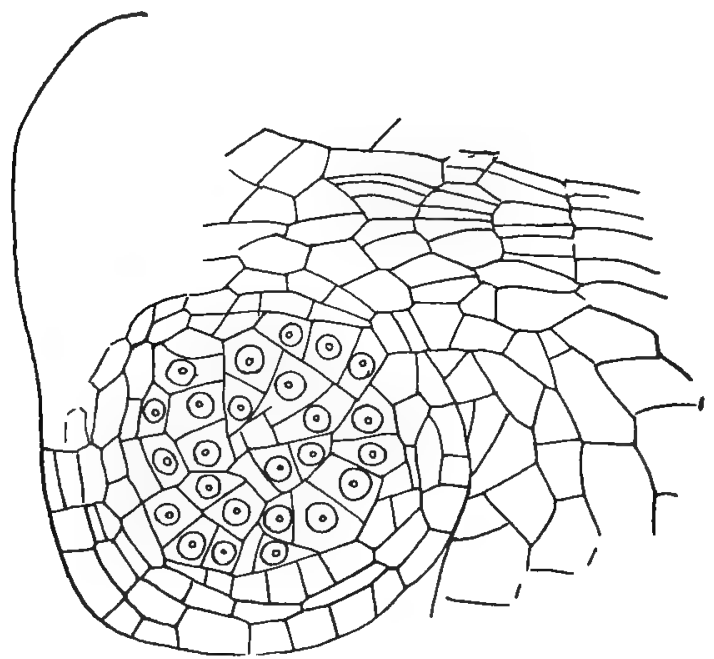

Fig. 278.-Longitudinal section of an older sporangium, $\times 260$. The nuclei are shown in the archesporial cells.

form a regular cone at the apex of the fertile branch, and are arranged in regular whorls, which vary in number in proportion to the size of the cone. The top of the sporophyll is always polygonal in outline, owing to the lateral pressure of its neighbours, and very often they are regularly hexagonal, but this bears no relation to the number of sporangia, which usually exceed in number the angles of the sporophyll.

\section{Development of the Spores}

The development of the spores in Equisetum, while agreeing in many respects with that of the eusporangiate Ferns, shows some peculiarities that are noteworthy, and as this offers one of the best cases for studying spore-formation, it was somewhat 
carefully followed in E. telmateia. After the complete number of cells has been formed in the archesporium, and before the tapetal cells are broken down, the sporogenous cells are divided into groups which begin to separate from each other. With the enlargement of the sporangium and the breaking down of the inner tapetal cells these masses become isolated, and are very easily removed from the sporangium (Fig. 240, A). They usually consist of four cells, which in water swell up somewhat. In a fresh condition they appear quite colourless, but the cytoplasm is densely granular. The nucleus is very large and appears quite transparent with one or two distinct nucleoli. In microtome sections of about the same age the numerous rodshaped chromosomes were very evident, but their number could not be determined. The nucleolus is conspicuous, and on one side, in a slight depression in the nuclear membrane were seen, in some cases what were taken to be two centrospheres. The latter were not always very evident, and the radiations which are usually present about centrospheres, were not seen. From the later investigations of Osterhout ( I) upon E. limosum, it is probable that the interpretation of these bodies as centrospheres was not warranted, as he failed to find centrospheres in that species, and their presence in many other cases, where it was supposed they existed, has been disproved.

Osterhout has also shown that the bipolar spindle, observed in E. talmateia is a secondary condition. In E. limosum, he found that about the time the spirem-filament had completely separated into the individual chromosomes, a change was observable in the cytoplasm surrounding the nucleus. Up to this time the cytoplasm in material treated with the Flemming triple stain shows the characteristic orange or brownish coloration. The cytoplasm immediately around the nucleus now stains a violet color, and is supposed to assume the character of kinoplasm. This kinoplasmic zone increases in size, and gradually assumes more and more the appearance of a dense net of delicate fibresthe future spindle-fibres. These begin to extend outward into the orange cytoplasm and converge at numerous points, so as to form a number of conical bundles radiating from the nucleus. There is thus developed a multi-polar spindle, and as the nuclear membrane gradually disappears, the free ends of these spindle fibres penetrate into the nuclear cavity and come in contact with the chromosomes, which gradually arrange themselves into the 
characteristic nuclear plate. The separate nuclear spindles finally converge more and more, until finally they unite into a more or less definite large bipolar spindle with the nuclear plate at the equator (Fig. 279, C). Before the final division takes place, the sporogenous cells become completely rounded off, and are embedded in a mass of nucleated protoplasm (Fig. 280 , A) derived from the tapetal cells, but also in part from some of the archesporial cells which do not develop into spores.

Fig. 279 shows the successive stages in the process. During

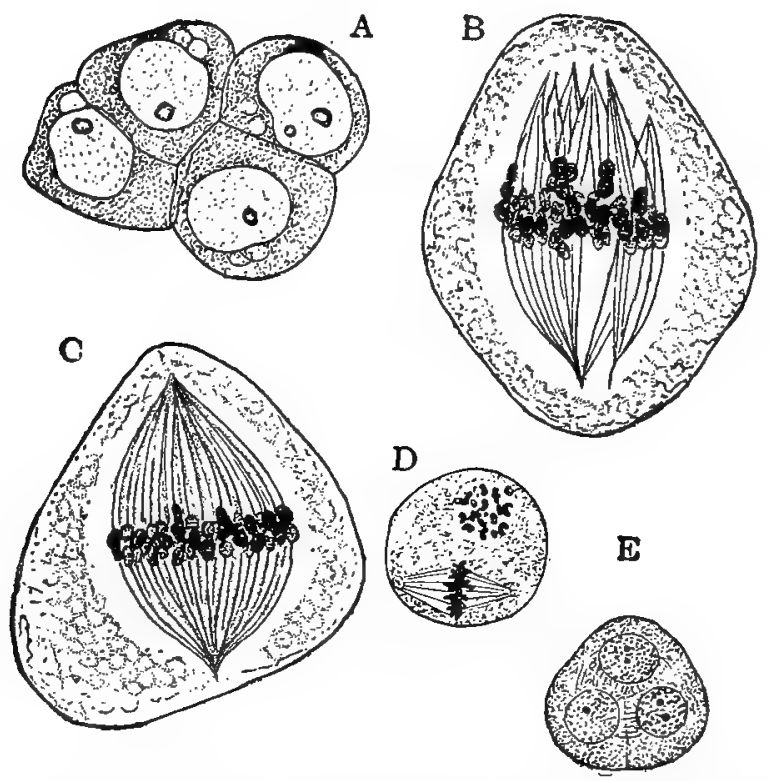

FIG. 279.-A, Group of four sporogenous cells of E. telmateia, $\times_{400} ; \mathrm{B}, \mathrm{C}$, first mitosis in $E$. limosum (after Osterhout); B, shows the multipolar spindle; D, E, second mitosis in E. telmateia.

the division of the primary nucleus there is an evident cell plate formed, but no division wall. During this first division there is probably a reduction in the number of the chromosomes, as in Osmunda. At any rate the number is evidently much smaller during the metaphases of the second nuclear divisions (Fig. $279, D)$. The second divisions are the same as the primary one, and the planes of the two nuclear spindles may either be parallel or at right angles (Fig. 279, D). In either case the resulting nuclei arrange themselves at equal distances from the 
centre of the cell, and the connecting filaments are formed between them. In the connecting spindles there is formed between each pair of nuclei a cell plate, which soon develops into a definite cellulose membrane, and the spores separate completely.

It is probable that the definitive cell-wall is formed in the same way as in the spore-formation of other plants (Mottier (3), p. 32). The cell-plate formed at the equator of the spindle in the later stages of division, is split into two layers which thus
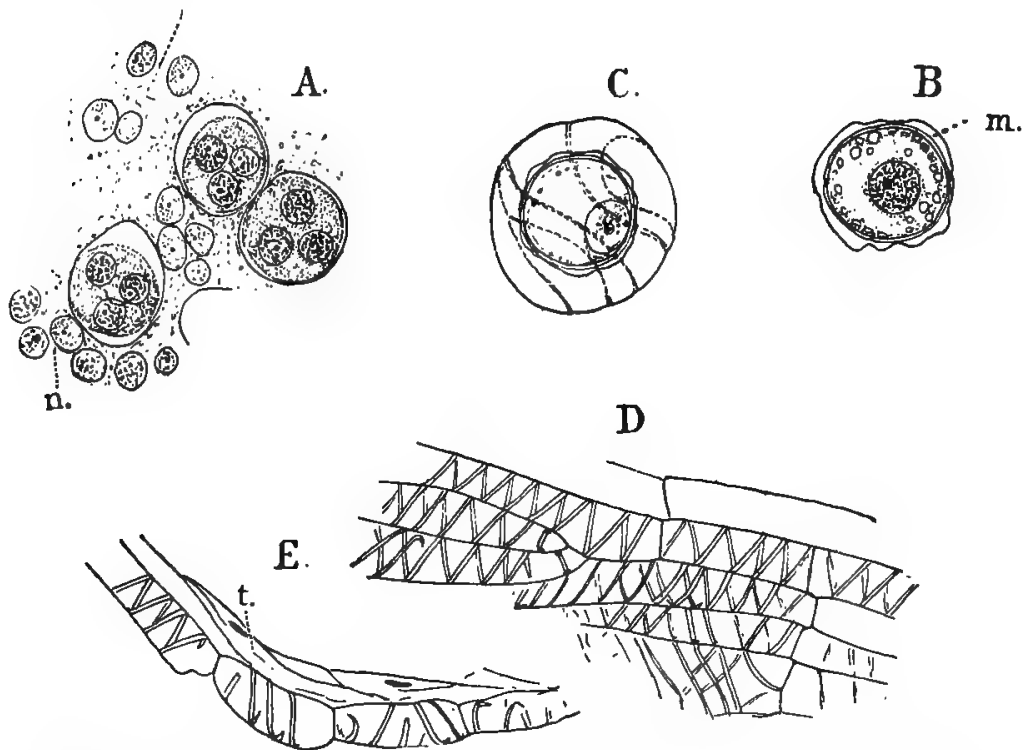

FIG. 280.-A, Group of sporogenous cells, just before the final division into the spores, embedded in the nucleated protoplasm formed from the disintegrated tapetum, and sterile archesporial cells, $\times 500 ; B$, optical section of young spore, showing the three membranes; $m$, the middle lamella, $\times 500 ; \mathrm{C}$, an older spore, showing the splitting of the outermost coat to form the elaters, $\times 500 ; D$, surface view of the dorsal cells of the wall of a ripe sporangium, $\times 150 ; E$, section of the wall, showing the remains of the inner layers of cells $(t), \times 250$.

separate completely the two protoplasts. In the space between the protoplasts, the new cell-wall is then laid down.

The young spore has at first a very delicate cellulose membrane, which thickens, and later has separated from the outside the "middle layer" (Fig. 280, B, $m$ ), which in spores placed in water lifts itself in folds from the underlying endospore. The outer perinium seems to be unquestionably formed through the agency of the nucleated protoplasm, in which the young spores 
lie. It is at first a uniform membrane, closely applied to the middle coat, but when placed in water it swells up and separates completely from the exospore, or remains attached to it at one point only, which marks the point of attachment of the elaters in the ripe spores. The elaters arise from the epispore by its splitting spirally into four bands (Fig. $280, C$ ), due apparently to thickening along these bands, leaving thin places between, which are finally absorbed. The outside of the elaters becomes cuticularised. The ripe spores contain numerous chloroplasts, which only are evident in the latest stages of development. In $E$. arvense the formation of the sporangia begins nearly a year before the spores are shed, and they are completely developed during the preceding autumn. The growth of the fertile branch and the scattering of the spores take place very soon after growth begins in the spring. Whether in cold climates E. telmateia behaves the same way I cannot state; but in California, where growth continues all the winter, the development of the sporangia is gradual, and the fertile stems grow up and scatter the spores as soon as they are ripe. The ripe sporangia are oblong sacs, whose wall is composed for the most part of a single layer of elongated cells, marked with spiral thickened bands upon the dorsal surface and rings upon the ventral cells, where the longitudinal slit by which the sporangium opens is placed (Fig. 280, D, E). The internodes in the strobilus are very little developed, but as the spores ripen there is a slight elongation, by which the sporophylls are separated.

\section{Classification}

Milde ( I) divides the genus into two, Equisetum ${ }^{1}$ (Equiseta phanopora), in which the accessory cells of the stoma are on a level with the surface of the epidermis; and Hiptrochcete ( $E$. cryptopora), in which the stomata are sunk in depressions of the epidermis. In the former group are two divisions, those which, like $E$. arvense and $E$. telmateia, have the fertile and sterile branches different, and those where they are alike, e. g., E. limosum (Fig. 280, A). Some species, e. g., E. pratense, have the fertile stems at first colourless, but afterwards forming chlorophyll and developing branches. In Hippochate, which includes among American species E. hiemale, E. robustum, E. variega-

${ }^{2}$ Euequisetum, Sadebeck. 


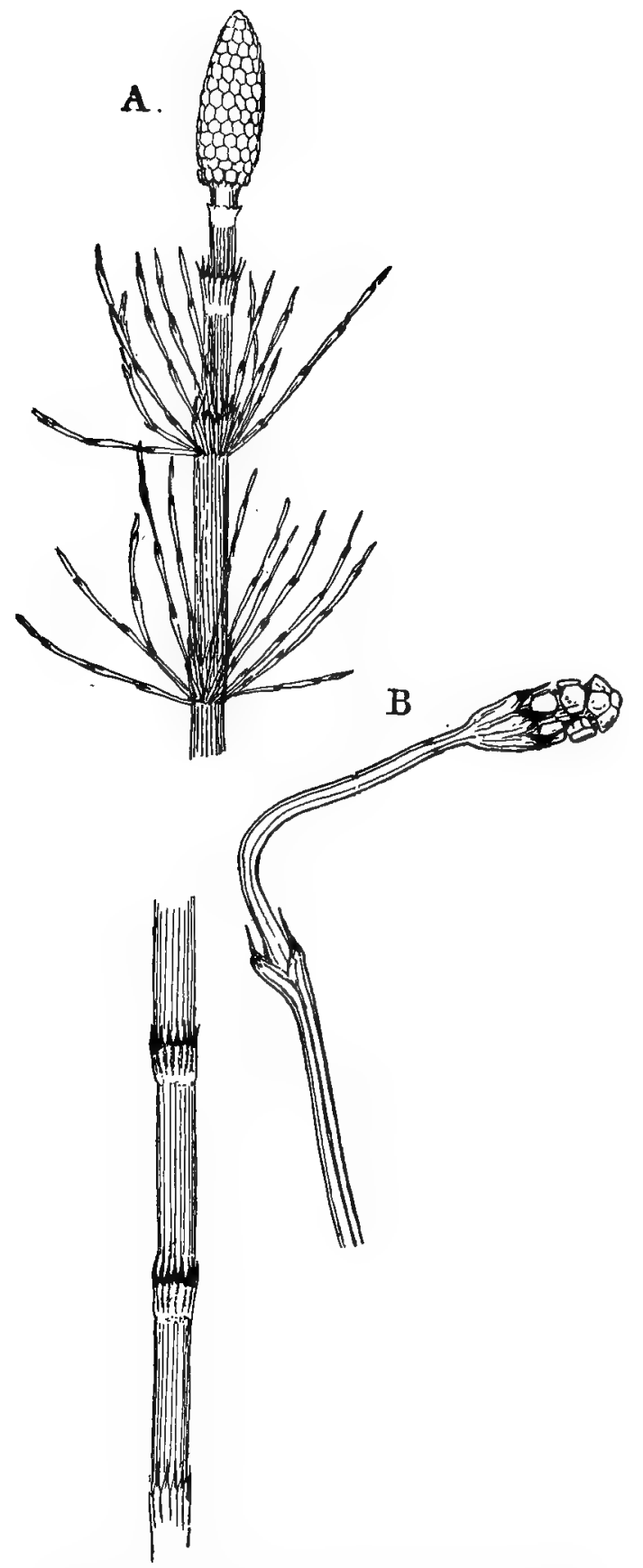

FrG. 281.-A, Equisetum limosum, $X 1 / 2 ; B, E$. scirpoides, $X \mathbf{2}$ 
tum and E. scirpoides (Fig. 28I, B), the aerial branches are all similar and often are quite unbranched. The foliar sheaths show considerable variation. In the fertile stems of $E$. $t e l$ mateia (Fig. 266) they are extremely large and the ribs very prominent, but the separate leaves are not all distinct at the apex, but the sheath splits into a few very deeply cleft pointed lobes. In the sterile shoots, however, and in all the stems of most species, the teeth are very distinct and the foliar sheath much shorter. The number of teeth varies from three in E. scirpoides, to thirty or forty, or even more, in E. telmateia and $E$. robustum. In $E$. sitvaticum the branches produce whorls of secondary branchlets.

Sadebeck (8) recognises 24 species of Equisetum. The largest forms occur in tropical America, where some species, e. g., E. giganteum, reach a height of 3 to I2 metres, but are relatively slender, the stem usually not exceeding two or three centimetres in diameter, and requiring support from the shrubs and trees among which it grows. E. Schaffneri is described as having a stem about two metres in height with a thickness of Io centimetres, but with a very large central cavity, so that it is not very strong. In some of the larger species, e. g., E. giganteum, cones may be borne at the end of the lateral branches, as well as at the apex of the main shoot.

\section{Fossil Equisetinece}

The living genus Equisetum is represented in a fossil condidition by a number of closely allied forms, perhaps generically identical, and usually united under the name Equisetites. Besides these, there are several types differing materially from Equisetum, but nevertheless undoubtedly related to the living forms. The most important of these fossil forms are the characteristic Palaeozoic fossils belonging to the Calamitaceæ and Sphenophyllacex. A further discussion of these forms will be left for a later chapter.

\section{Affinities of the Equisetinece}

The Equisetinex, as will be seen from the account of the fossil forms, are a very ancient group, and their relation to the other Pteridophytes somewhat problematical. The modern 
forms being so restricted in number and type, offer but partial means of comparison; still a comparison of these with the simpler Filicineæ does indicate some affinity between the two groups, although, as might be expected, a very remote one. Van Tieghem (6) has shown that the structure and arrangement of the vascular bundles in the stem of Ophioglossum and Equisetum have much in common. As we have seen, the prothallium is not essentially different in Equisetum and the eusporangiate Ferns, and the spermatozoids are closely like those of the latter, and not at all like those of the Lycopodinea. This latter point I believe to be one of great importance.

If the Equisetinea do come from a common stock with the Ferns, they must have branched off at a very remote period, long before the latter had become completely differentiated. The very different importance relatively of the stem and leaves in the two groups points to this, as well as the extremely dissimilar character of the sporophylls. The genus Equisetum is evidently but a reduced remnant of a once predominant type of plants which has been crowded out by the more specialised Ferns and Spermatophytes. The presence of heterospory in some fossil forms is interesting, but from what we know at present it never developed to the same extent as in the other groups of Pteridophytes. 


\section{CHAPTER XIII}

\section{LYCOPODINE压}

THE Lycopodinex, though far exceeding in number the species of Equisetum, are inferior in number to the Ferns. Baker (2) enumerates 432 species, of which 334 belong to one genus, Selaginella, while another, Lycopodium, has 94. A more recent enumeration of the two genera (Pfitzer (2), Hieronymus (I)) indicates a considerably larger number of species, Selaginella alone possessing approximately 500 species. Like the Equisetineæ they are abundant in a fossil condition, and it is very evident that these ancient forms were, many of them, enormously larger than their living representatives, and more complicated in structure. The living species are mainly tropical in their range, but Lycopodium has a number of species common in northern countries, and a few species of Selaginella, e. g., S. rupestris, have a wider range; but the great majority of the species are found only in the moist forests of the tropics. The gametophyte of the homosporous forms is known best in Lycopodiumn. Our knowledge of it was based mainly upon the important researches of Treub (2), but these have been added to by Goebel ( 18 ) in the case of $L$. inundatum, and more recently Bruchmann (5) and Lang (I) have succeeded in finding prothallia of several European species, and we now have a very satisfactory account of all but their earliest stages.

The gametophyte in its earliest condition, so far as is certainly known, develops chlorophyll, and this condition may be permanent, e. g., L. cernutm, but other forms have a chlorophylless prothallium, and are saprophytic in habit, like Ophioglossum. The germination of these forms is at present unknown.

The sporophyte has the axis strongly developed, and the 


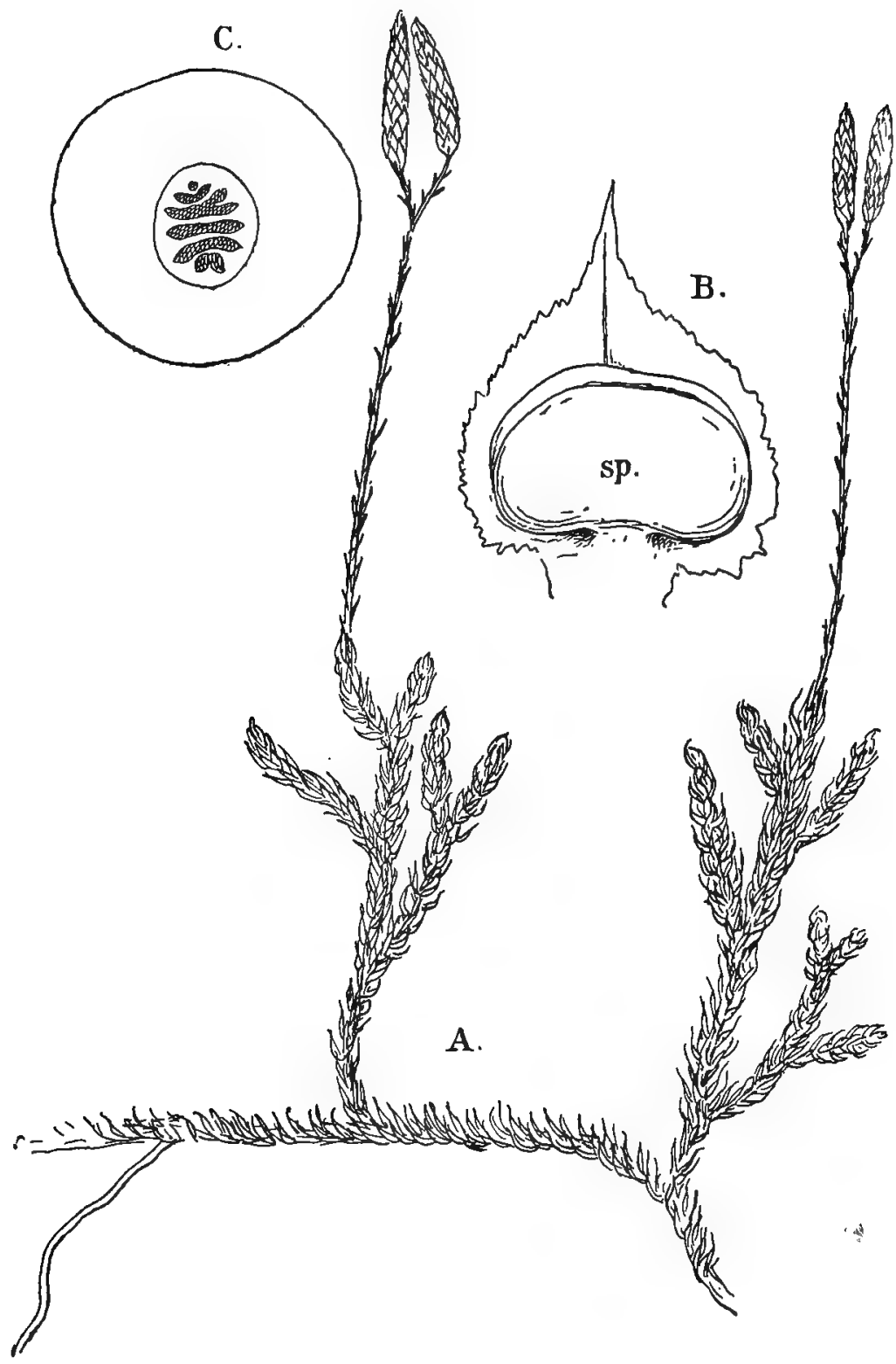

FiG. 282. Part of a fruiting plant of Lycopodium clavatum, $\times \frac{4}{8} ; \mathrm{B}$, sporophyll, with sporangium $(s p)$ of $L$. dendroideum, $X \mathrm{I2} ; \mathrm{C}$, cross-section near the base of an aerial shoot of $L$. dendroideum, $\times 12$. 
leaves, though usually numerous, are simple in structure and generally small. The genera are all homosporous except Selaginella, which is very markedly heterosporous, and has the gametophyte very much reduced and projecting but little beyond the spore wall.

\section{CLASSIFICATION \\ Order I. Lycopodiales}

\section{A. Homosporece}

I. Roots always present; sporangia alike, simple, in the axils of more or less modified leaves, which may form a distinct strobilus, or may be but little different from the ordinary ones both in form and position; prothallia either green or colourless, monocious.

\section{Family I. Lycopodiace}

Genera 2.-(I) Lycopodium; (2) Phylloglossum

II. Roots absent; vegetative leaves much reduced or well developed; sporophylls petiolate, bilobed; sporangia plurilocular; gametophyte unknown.

\section{Family II. Psilotace e}

Genera 2.-(I) Psilotum; (2) Tmesipteris

B. Heterosporece

Characters those of Family I., but spores always of two kinds.

Family III. Selagineldaceze

Genus $I$. Selaginella

\section{THE LYCOPODIACE平}

\section{The Gametophyte}

The Lycopodiacex include the two genera Lycopodium and Phylloglossum, the latter with a single species, $P$ Drummondii. The gametophyte is known in a number of species of Lycopodium, and recently (Thomas (I)), has also been 
described for Phylloglossum. The first investigator who succeeded in obtaining the germination of the spores was De Bary ( I), who studied the earliest stages in the germination in $L$. inundatum, but was unable to obtain the later ones. About fifteen years later Fankhauser found the old prothallia of $L$. annotinum (I), but our first complete knowledge of the prothallium and embryo is due to the labours of Treub (2), who examined most thoroughly several tropical species of $L y c o-$ podium. Goebel ( 18 ) succeeded in finding a number of prothallia of $L$. inundatum which correspond very closely to $L$. cernunim, the first species examined by Treub. Other European species have more recently been investigated by Bruchmann (5) and Lang (I).

The germination of the spores in L. cernuum and $L$. inundatum is much like that of the homosporous eusporangiate Ferns. The tetrahedral spores contain no chlorophyll, but it develops before the first division wall is formed. This may be either vertical or horizontal, or more or less inclined. The two primary cells are nearly equal in size, but one of them appears to normally remain undivided. The other enlarges and becomes divided by an oblique wall (Fig. 283 , A), and functions for some time as an apical cell, from which segments are cut off alternately right and left. Usually each segment is then divided by a periclinal wall into a central and a peripheral cell. $\mathrm{Up}_{\mathrm{p}}$ to this point the germination of $L$. cernuum corresponds exactly with De Bary's observations upon L. inundatum. The ovoid body formed at first Treub calls the "primary tubercle," and this does not develop directly into the complete prothallium, but the apical cell ceases to form two rows of segments and elongates so as to produce a filament in which for a time only transverse walls are formed (Fig. $283, \mathrm{~B}$ ). The base of this filamentous appendage, however, later develops longitudinal walls and forms a thickened cylindrical mass, which is the beginning of the prothallium body. Sometimes, but not usually, a second filamentous outgrowth is formed from the primary tubercle, which may produce a second prothallial body.

The growth of the prothallium proper does not seem to show a definite meristem, but at the summit are produced a number of leaf-like lobes which seem to arise in acropetal succession, and the growth may be considered, in a general way at least, as apical. The individual lobes are usually two cells 
thick, and like those of Equisetum show a definite two-sided apical cell. This apical growth later disappears and all trace of it is lost in the older lobes. Rhizoids are produced only in small numbers from the cylindrical prothallium body, and are usually entirely absent from the primary tubercle, whose peripheral cells are always occupied by an endophytic fungus which Treub refers probably to the genus Pythium. We have seen that similar fungus mycelia occur in the chlorophylless
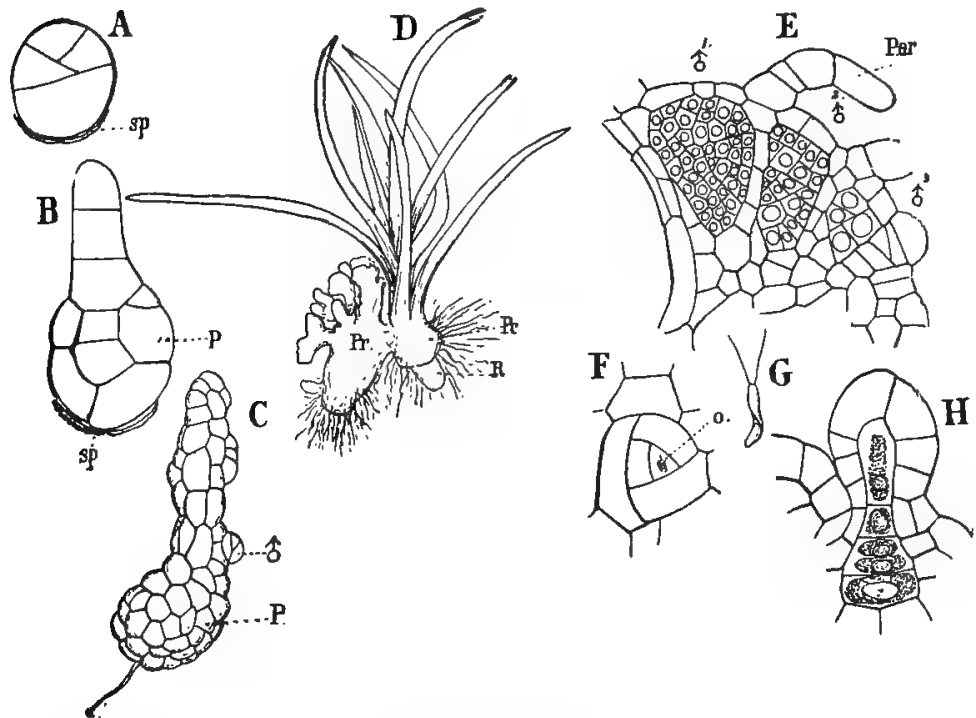

FIG. 283.-A, B, very young prothallia of Lycopodium cernum. A, X250; B, $\times 200$. $\mathrm{P}$, Primary tubercle; $\mathrm{C}$, an older prothallium of the same species with the first antheridium $\left(\delta^{3}\right), \times 75 ; \mathrm{D}$, a fully-developed prothallium $(p r)$ with the young sporophyte attached, $X_{I 2} ; p c$, protocorm; $R$, primary root; $E$, section through an antheridial branch of the prothallium of $L$. phlegmaria, showing antheridia $\left(\delta^{\prime}\right)$ in different stages of development; par, a paraphysis, $\times 180 ; \mathrm{F}$, surface view of the top of an antheridium of the same species; 0 , opercular cell, $\times 180$; $G$, a spermatozoid, $X_{410} ; H$, section of the archegonium of the same species, $X_{180}$ (all the figures after Treub).

prothallium of Botrychium, and Goebel found the same in $L$. inundatum. While in the primary tubercle the fungus occupies the lumen of the cells, as it penetrates into the body of the prothallium it confines itself mainly to the intercellular spaces, where its growth causes more or less displacement of the cells. It does not, however, seem to penetrate into the meristematic tissues at the summit.

The fully-grown prothallium of $L$. cernuum is a small up- 
right cylindrical body, seldom, apparently, exceeding about two mm. in height. The base is more or less completely buried in the ground, and contains but little chlorophyll. The summit is surrounded by the lobes already spoken of, and these have somewhat the appearance of leaves crowning a short stem. The whole structure of the prothallium recalls in some respects that of Equisetum, but differs in the important particular that it is radially constructed, and is not dorsi-ventral.

2) Besides the type of prothallium found in L. cernuum, with which $L$. inundatum closely agrees, Treub has also studied the very different prothallium of $L$. phlegmaria, and others of similar habit. These are only known in their mature condition, in which they are saprophytes, growing in the outer decayed layers of bark upon the trunks of trees. In this condition they are extremely slender branched structures, totally different from those of $L$. cernum, both in form and in the complete absence of chlorophyll. Like the prothallia of many Hymenophyllaceæ, they multiply by special gemmæ and apparently may live for a long time. Like those of $L$. cernuum they are always infected by an endophytic fungus.

Bruchmann (4) finds that there is a good deal of difference among the European species. L. clavatum (Fig. 284, A) and $L$. annotinum represent one type. The gametophyte is subterranean, and in appearance not very different from that of Botrychium, although its manner of growth is of an entirely different type. In the earliest stages observed, it was an upright, top-shaped body, the upper surface of which was somewhat depressed below the margin, which forms an elevated rim about the central area. There is no proper apical growth, but a zone of cells between the rim and the central area is meristematic, and to the growth of this zone the future development of the gametophyte is due. The whole of the central area is devoted to the formation of the reproductive organs, and constitutes the "generative tissue," and like the similar tissue in $B O$ trychium, its cells are almost destitute of granular contents. Outside the colourless generative tissue is a layer of dense storage-cells, and outside of these a layer of tissue in which is an endophytic fungus. Unicellular rhizoids occur in considerable numbers upon the under surface.

The gametophyte of $L$. complanatum (Fig. 284, C) is also subterranean, but quite different in form from that of L. clav- 
atum, although the essential structure is much the same. It is a fusiform structure, with a terminal mass of short, irregular lobes covered with the reproductive organs. Between the terminal generative portion and the sterile fusiform body of the prothallium, there is a meristematic zone, corresponding to that in $L$. clavatum. The oldest reproductive organs are at the centre of the generative area, the youngest are next the zone of meristematic tissue.

$L$. Selago closely resembles $L$. phlegmaria in the structure of the gametophyte, and there are similar paraphyses formed among the reproductive organs.

L. inundatum, as was previously shown by Goebel,.belongs to the type of $L$. cernuum, and Phylloglossum (Thomas (I)) seems to be very much like $L$. cernuum, in the structure of the gametophyte.

The gametophytes of all species are normally diœcious, but the antheridia usually develop first.

\section{The Sexual Organs}

The sexual organs of all investigated species of $L y c o-$ podium are very similar, and resemble those of the euspor

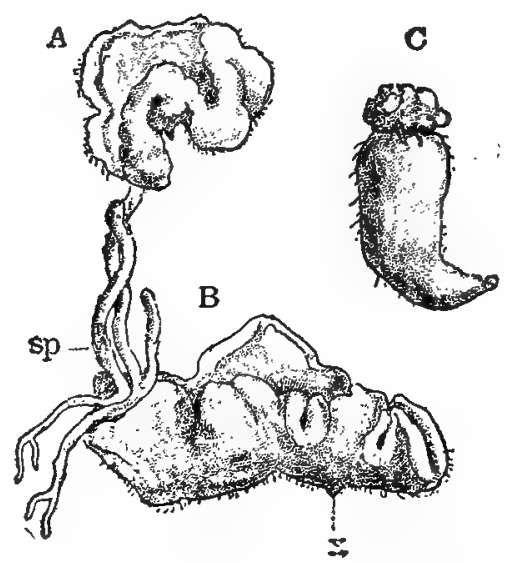

FrG. 284.-A, Lycopodium clavatum, gametophyte, $X_{3} ; \mathrm{B}, L$. annotinum, old gametophyte, with young sporophytes, $s p$, attached, $\times 3 ; C$, gametophyte of $L$. com. planatum, $\times_{3}$ (after Bruchmann). As in these forms the antheridium mother cell divides first by a periclinal wall into an outer and inner cell, the latter giving rise immediately to the sperm cells. In the outer cell the divisions are much like those in Marattia, but the opercular cell does not become detached as in these, but is broken through as in the Polypodiacer. In L. phlegmaria the outer wall is often in places double, as not unfrequently is the case in the Ophioglossaceæ. The spermatozoids are almost straight oblong bodies with two cilia, like those of the Bryophytes (Fig. $283, \mathrm{G})$. The vesicle, which usually remains attached to the spermatozoids of most Archegoniates, here is almost always 
free and often remains within the sperm cell after the escape of the spermatozoids.

The archegonium in most species of Lycopodium differs a good cleal from that of the other Pteridophytes, especially in the large number of neck canal cells that are usually found. The cells of the axial row may be as many as ten in L.annotinum, and in L. complanatum Miss Lyon (3) found I4-I6 cells, which in some cases had two nuclei in each cell, a condition which is also found in L. phlegmaria. L. cernuum, however, according to Treub, has but a single neck canal cell.

In the remarkably large number of canal cells, as well as in the occasional development of five instead of four outer cellrows in the neck (Bruchmann (4), p. 34), Lycopodium undoubtedly resembles more nearly the typical Bryophytes than does any other of the Pteridophytes.

\section{The Embryo (Treub (2); Bruchmann (4))}

Treub has traced the development of the embryo in $L$. phlegmaria through all its stages, and has shown that $L$. cernuum corresponds closely to it, and Goebel's investigations upon $L$. inundatum show that this species does not differ essentially from the others. The first division in the embryo is transverse, and of the two primary cells the one next the archegonium remains undivided, or divides once by a transverse wall and forms the suspensor, which is characteristic of all investigated Iycopodineæ, while the lower cell alone gives rise to the embryo proper. In the embryonal cell the first wall is a somewhat oblique transverse one, which divides it into unequal cells. In the larger of these a wall forms at right angles to the primary wall (Fig. 285, A), and this is soon followed in the smaller cell by a similar one, so that the embryo is divided into quadrants. Of these the two lower form the foot, while of the upper ones in L. phlegmaria, the one formed from the larger of the two primary cells (moitie convexe of Treub) produces the cotyledon, the other the stem apex. The primary root, which in Lycopodium arises very late, originates from the same quadrant as the cotyledon.

In $L$. cernuum, while the early divisions correspond exactly with those of $L$. phlegmaria, the further development of the embryo shows some noteworthy differences. As - in that 
species, the two lower quadrants form the foot, which here remains completely buried within the prothallium. From the upper part of the embryo is next developed what Treub calls the "protocorm." This is a tuber-like organ (Fig. 283, D,
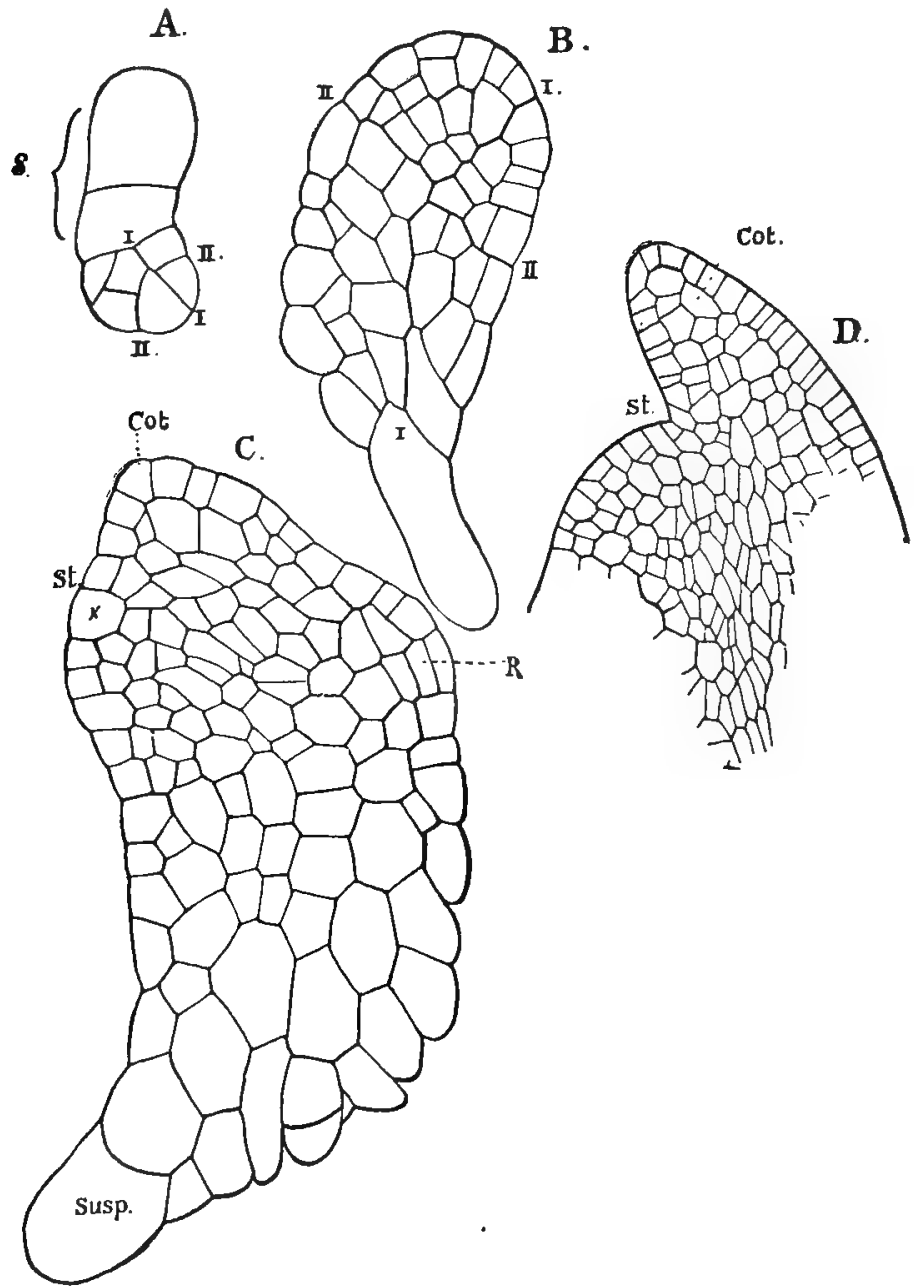

F1G. 285.-Embryogeny of Lycopodium phlegmaria (after Treub). st, Stem; cot, cotyledon; susp, suspensor. A, $\times_{315} ; \mathrm{B}, \times_{235} ; \mathrm{C}, \times_{235} ; \mathrm{D}, \times_{175}$.

pc), from which the leaves and stem apex are subsequently developed. The cotyledon arises from the summit of the protocorm, and is followed by a number of secondary leaves which 
förm successively from a group of meristematic cells, which usually develop into the permanent apex of the stem. About the time that the stem apex becomes recognisable as such, the first root appears as a surface outgrowth of the protocorm, and strictly exogenous in origin. Not infrequently the end of the primary root gives rise to a tubercle similar to the protocorm.

An interesting case was seen by Treub, where, apparently by a longitudinal division of the young embryo, two embryos were formed, much as is normally the case in some Gymnosperms.

On comparing the two types of embryo found in $L$. phlegmaria and $L$. cernum, the main differences are the almost complete absence of the protocorm and greater development of the suspensor in the former. L. inundatum, as might be expected, corresponds closely in the structure of the young sporophyte to $L$. cernuum.

Corresponding with the late appearance of the roots is the late development of the vascular bundles, which, according to Treub, are often quite absent from the cotyledon and, even occasionally from the second leaf. The protocorm of $L$. cernuum and $L$. inundatum Treub regards as the remains of a primitive structure originally possessed by the Pteridóphytes, which replaced the definite leafy axis found in the more specialised existing forms.

Phylloglossum, which has sometimes been regarded as the most primitive of existing Pteridophytes, resembles closely the young sporophyte of Lycopodium cernuum.

Bruchmann states $\left((4)\right.$, p. $\left.3^{8}\right)$ that the fertilised egg enlarges very much before the first division wall is formed, differing in this respect from Selaginella, and more resembling $M a-$ rattia or Botrychium. The first division is transverse. The larger of the two cells, lying next the archegonium-neck, forms the suspensor, and the smaller one develops into the embryo itself.

Both $L$. clavatum and $L$. annotinum differ from the species studied by Treub in the late development of the leaves (Bruchmann (4), p. 46). Moreover, in these species there are two opposite cotyledons as in Selaginella.

The development of the young sporophyte is extraordinarily slow, and Bruchmann states that it sometimes does not 
appear above the surface of the earth until several years have elapsed. The leaves developed upon these subterranean shoots are rudimentary. Sometimes more than one sporophyte is borne by the prothallium (Fig. 284, B). The differentiation of the vascular cylinder begins about the time that the root breaks through the prothallial tissue. The hypocotyledonary part of the stele is diarch, but higher up four or five protoxylem groups are developed.

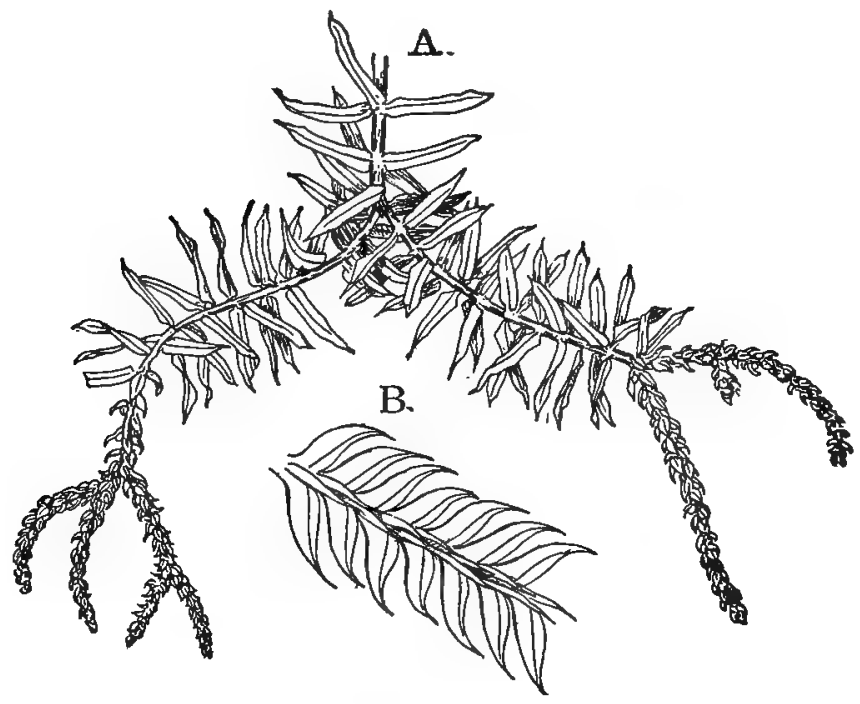

FIG. 286.-A, Lycopodium pachystachyon, $\times 3 / 4 ; B, L$. volubile, showing the two forms of leaves, $\times 2 \frac{3}{4}$.

\section{The Adult Sporophyte}

In all species of Lycopodium the sporophyte possesses an extensively branched stem, which may be upright, as in $L$. cernuum, or extensively creeping, as in L. clavatum and other species, where the main axis is a more or less completely subterranean rhizome with upright secondary branches. In the tropics some species are epiphytes. The leaves are always. simple, and of small size. Each leaf has a single median vascular bundle, which does not extend to the apex. The arrangement of the leaves is usually spiral, and they are uniformly distributed about the stem, and all alike; but in a few species, e. g., L. complanatum and L. volubile, they are of two 
kinds and arranged in four rows, as in most species of Selaginella. The branching of the stem is either dichotomous or monopodial. The roots, which are borne in acropetal succession (Bruchmann found also in L. inundatum adventive roots), branch dichotomously, like those of Isoetes. The sporangia are borne singly, in the axils of the sporophylls, which may differ scarcely at all from the ordinary leaves ( $L$. selago, $L$. lucidulum), (Fig. 287), or the sporophylls are different in form and size from the other leaves and form distinct strobili,
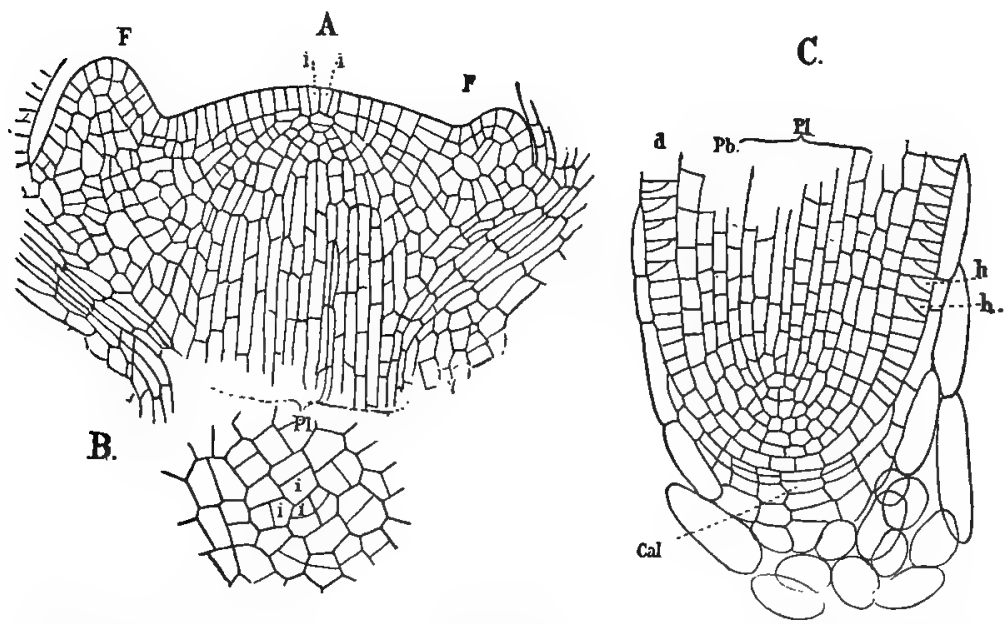

FIG. 287.-Lycopodium selago. A, Longitudinal section of the stem apex, $X_{120 ;}$ F, F, young leaves; $i, i$, initial cells; $P l$, plerome; $B$, surface view' of the stem apex, showing the group of initial cells, $\times 260 ; \mathrm{C}$, longitudinal section of the root-tip; $d$, dermatogen; $P b$, periblem; $P l$, plerome; Cal, calyptrogen; $h, h$, root-hair initials, $\times 120$ (all the figures after Strasburger).

which are often borne at the end of almost leafless branches (Fig. 282).

None of the investigated species of Lycopodium show a definite initial cell at the apex of the stem, and Treub ( (2), V) was unable to determine positively whether such a one exists in the embryo. In L. phlegmaria he describes and figures embryos, where a single prismatic apical cell is apparently present, but in others the presence of such a cell was doubtful, and in $L$. cernuum in no case did he find any evidence of a single initial.

The vegetative cone of the mature sporophyte is usually 
broad (Fig. 287) and only slightly convex. Its centre is occupied by a group of similar initial cells, which in L. selago, according to Strasburger (( IO), p. 240), usually show two initials in longitudinal section (Fig. 287, $i$ ). From these initials are cut off lateral segments which, by further periclinal and anticlinal walls, produce the epidermis and cortex, and secondarily the leaves. Periclinal walls also are formed from time to time in the initial cells, by which basal segments are cut off, which produce the large central plerome cylinder.

The leaves arise as conical outgrowths near the stem apex, and owe their origin to the three or four outer cell layers of the growing point. The separation of the epidermis does not occur until the leaf has formed a conspicuous conical protuberance. The differentiation of the procambium in the young leaf begins early, and the strand joins the central procambial cylinder of the stem, which, however, is quite independent of the leaf-traces. Each young leaf-trace joins an older one at the point of junction with the stem cylinder, and thus the complete stem possesses two systems of vascular bundles, the strictly cauline central cylinder, and the system of common bundles formed by the united leaf-traces.

The first elements of the vascular bundles to become recognisable are spiral tracheids, both in the stem and leaves, and these are followed in the former by the much wider scalariform tracheids that occupy the central part of the tracheary plates in the fully-developed bundles.

The fully-developed central cylinder of the stem (Russow ( I), p. I 28 ; De Bary (3), p. 28 I ; Strasburger ( I I), vol. iii., p. 458; Strasburger, l. c., p. 46o; Van Tieghem (5), p. 553) is undoubtedly to be considered as a group of confluent vascular bundles or as gamostelic. The oval or nearly circular crosssection (Fig. 288, A) is sharply separated from the surrounding ground tissue by a clearly-marked endodermis, within which is a pericycle which may be only one cell thick, but is usually several-layered. According to Strasburger this pericycle does not properly belong to the central cylinder, but is of cortical origin. The cutinised band ("radial folding") of the endodermal cells is only observable in the younger stages, as later the whole wall of the endodermal cells become cutinised. This cutinisation extends also through a number of the succeeding cortical layers. The rest of the cortical region is 
in most species occupied by elongated sclerenchyma cells, with no intercellular spaces.

The central vascular cylinder contains, as is well known, several, usually transversely placed, tracheary plates, alternating with phloem masses, and surrounding these a varying amount of parenchyma. In upright species the tracheary plates are often more or less completely confluent, and in crosssection have a somewhat star-shaped outline. In the dorsiventral stems the tracheary plates are quite separate and perfectly transverse in position. Their outer angles are occupied



Fig. 288.-A-D, Lycopodium volubile; A, transverse section of the stem, $\times 18 ; l$, leafbase; $B$, tissues of the central part of the stem, $X$ about 200 ; , sieve-tube showing lateral sieve-plates, $X$ about $600 ; \mathrm{D}$, section of the wall of a sieve-tube; $E$, section of the leaf of L. lucidulum, $\times 35$.

by the small primary spiral or annular tracheids, from which the centripetal formation of the large scalariform elements proceeds exactly as in the leptosporangiate Ferns. The mass of tracheary tissue is compact, and contains no parenchymatous elements. According to Strasburger the oblique end walls of the large tracheids show the same elongated pits as the lateral walls, but in no cases could any communication between adjacent tracheids be demonstrated. Each tracheary mass is 
surrounded by a single layer of parenchyma, whose inner cell walls show bordered pits, like those of the adjacent tracheids.

The phloem masses are, in the arrangement and development of the parts, very like the xylem, and the formation of the sieve-tubes begins at the outer angles and proceeds centripetally. The large sieve-tubes in L. volubile (Fig. 288, C) are conspicuous, appearing nearly empty, and with delicate, colourless walls. Upon their lateral faces are numerous sieve-plates, which in the smaller species are not easily demonstrated.

Where the branching is monopodial, the young branches arise laterally close to the growing point, but without any relation to the leaves. Where, however, as in L. selago (Strasburger ( IO), p. 242), there is a genuine dichotomy, it is inaugurated by an increase in the number of initial cells, which is then followed by a forking of the apex of the plerome cylinder, and the two resulting branches are exactly alike. Intermediate conditions between a perfect dichotomy and true monopodial branching occur. In these there is a true dichotomy, but one branch is stronger than the other, and continues as the main axis, while the weaker one is pushed to one side and looks like a lateral shoot. Bruchmann has described certain "pseudo-adventive" buds, which are young branches arrested in their development at a very early stage, which may later develop. Strasburger (7) has found adventive buds in $L$. aloifolium, $L$. verticillatum, $L$. taxifolium, and $L$. reflexum, which possibly may be of the same nature.

\section{The Leaf}

The leaves of all species of Lycopodium are relatively small, and are usually lanceolate in outline with broad sessile base. The margins of the leaves are often serrate, and in all cases the leaf is traversed by a simple midrib, which, as already stated, does not reach to the apex. Their arrangement varies, even in the same species, and upon the same shoot. Thus in L. alpinum (Hegelmaier ( I), p. 8I5) the leaves are regularly arranged in pairs which arise simultaneously; in $L$. selago they are usually in true whorls of four or five. The latter, however, often shows a spiral arrangement of the leaves, with a divergence of two-ninths, less often two-sevenths. In other species, e.g., L. complanatum, L. volubile (Fig. 286, B), the 
leaves are dimorphous and arranged in four ranks, like those of most species of Selaginella.

The structure of the vascular bundle of the leaf is simple. It is concentric in structure, with the central part composed of a small number of spiral and annular tracheids, and the peripheral portion made up of parenchyma, with a circle of scattered narrow sieve-tubes. A definite endodermis cannot be demonstrated. In the species with the leaves all alike both surfaces bear stomata, but in those with decussate leaves the greater part of the upper surface is destitute of them.

\section{The Root}

The roots of Lycopodium arise, as in other Pteridophytes, in acropetal succession, but with no relation to the position of the other organs. According to Bruchmann adventive roots may arise in L. inundatum, but they have not been observed in other forms. L. selago (Strasburger (Io), p. 259) may serve to show the characters of the root in the genus. The meristem of the apex is clearly differentiated into the initials of the different primary tissues (Fig. 287, C). The dermatogen $(d)$ completely covers the apex of the growing point as a single layer. The periblem $(p b)$ is three cells thick; the plerome $(p l)$ terminates in a group of special initials. As in the stem, the plerome alone forms the central cylinder, the periblem giving rise only to the cortex, and the structure of the mature root corresponds closely to that of the stem, except for the presence of the root-cap, which has its own initial group of cells (calyptrogen, $c a l$ ). From the older dermatogen cells are derived, by special walls, the mother cells of the root-hairs $(h)$.

Van Tieghem ( (5), p. 553) states that the secondary roots arise from the pericycle instead of from the endodermis, as in other Pteridophytes; but Strasburger claims that the so-called pericycle of Lycopodium is really cortical, and does not belong properly to the central cylinder, so that this difference is only apparent. The endodermis itself is not readily recognisable on account of the complete cutinisation of the walls.

The origin of the root-hairs is somewhat peculiar. From the base of each dermatogen cell a wedge-shaped cell is cut off (Fig. $287, \mathrm{C}, h$ ), and this afterwards is divided into two similar cells, each of which grows out into a unicellular hair. Thus the root-hairs are found in pairs. 
The roots always normally branch dichotomously, as in Isoetes, and the successive divisions usually are in planes at right angles to each other. As in Isoetes, the process is inaugurated by a broadening of the apex of the root, which is followed by a forking of the plerome and a subsequent division of the other histogenic tissues.

The structure of the mature root (Russow (I)) in $L$. clavatum, L. alpinum, and most species examined, is much like the stem. The hexarch to decarch fibrovascular cylinder is radial in structure, the xylem plates often united at the centre, so that in cross-section they present a more or less regular stellate form. In $L$. selago and L. inundatum, according to Russow, the xylem is diarch and the two masses united into a single one, which is crescent-shaped in section, with the phloem occupying the space between the extremities. As in the stem the primary tracheids are narrow annular and spiral ones, and the large secondary ones scalariform.

\section{Gemme}

Special bulblets or gemmæ are formed regularly in a number of species of $L y$. copodium, and have been the subject of several special
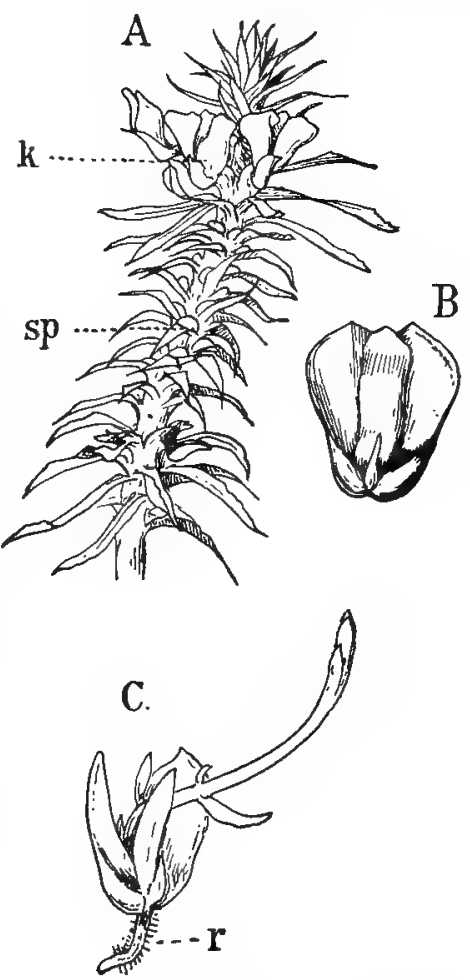

Fig. $289 .-A$, End of a shoot of Lycopodium lucidulum, with gemmx (k) and sporangia (sp), $X_{2} ; \mathrm{B}$, a single bulblet, $\times_{4} ; \mathrm{C}$, germinating bulblet of $L$. selago (after Cramer), $X_{4} ; r$, the primary root. investigations (Cramer (I); Hegelmaier (I) ; Strasburger (7)). These in L. lucidulum (Fig. 289, A, $k$ ) are flattened, heart-shaped structures composed of several thickened fleshy leaves, and formed apparently in the axils of somewhat modi- 
fied stem leaves, from which they readily separate when fully grown. The axillary origin of the bulblets is only apparent; they are really, so far as can be determined, similar in origin to the ordinary branches, and formed withotit any relation to the leaves. Before the bulblet becomes detached, the rudiment of a root can be made out at the base, and as soon as it falls off and comes in contact with the earth the root begins to grow and fastens the bulblet to the ground (Fig. 289, C). The axis of the bulblet, which at first is very short, rapidly elongates, and the leaves formed up it have the characters of the ordinary ones. As the leafy axis develops the fleshy leaves of the bulblet lose their chlorophyll completely and finally decay.

Hegelmaier describes mucilage ducts in the stem and leaves of $L$. inundatum and some other species, which are not unlike those found in Angiopteris.

\section{The Sporangium}

The most recent and accurate account of the structure and development of the sporangia of the Lycopodinex is that given by Professor Bower in his memoir upon this subject ( I5). His investigations include a number of species of Lycopodium, and the following account is taken mainly from his memoir. The results of his investigations show that there is much more variety shown than was before supposed, both in the form of the sporangium itself and in the mode of origin and number of the archesporial cells.

In $L$. selago the sporangium originates upon the upper surface of the sporophyll close to its base, and in radial section the young sporangium appears to originate from a single cell; but this is really only one of a transverse row of cells, all of which participate in its formation. Each cell of this primary row divides first into a large central cell (Fig. 290, C, $x$ ) and (in radial section) two peripheral ones. The central cell next by successive periclinals forms a row of three cells, of which the middle one is the archesporium, which, judging only from radial sections, seems to consist only of a single cell; but comparing with the radial section a tangential one, it is seen that the archesporium really consists of a row of similar cells (Fig. $290, F)$. The growth in the upper part of the sporangium is stronger than below, so that a distinct, although short stalk is 
B.
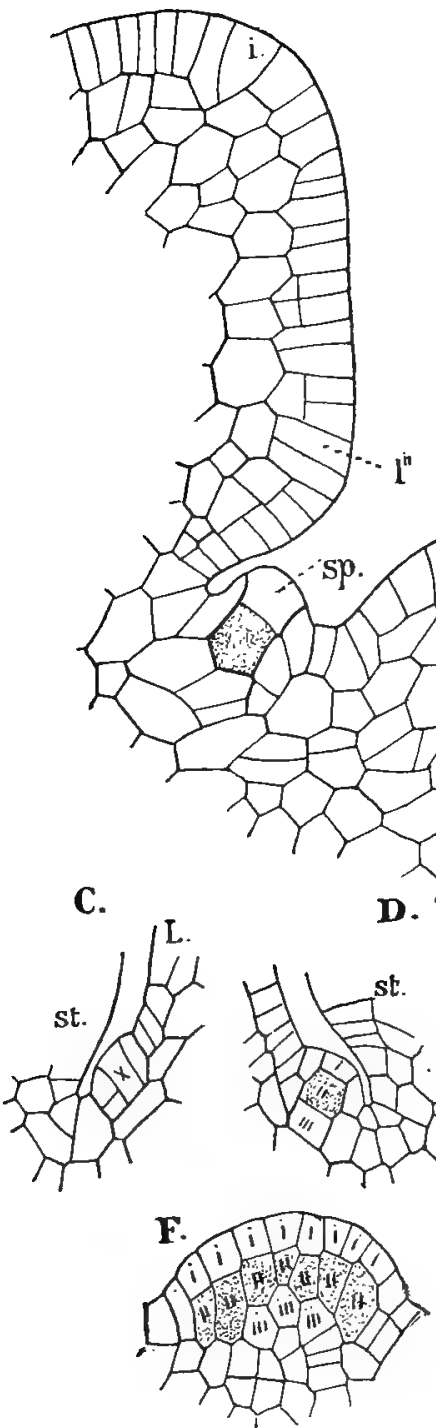

D.

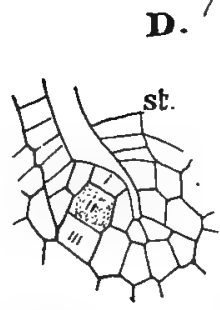

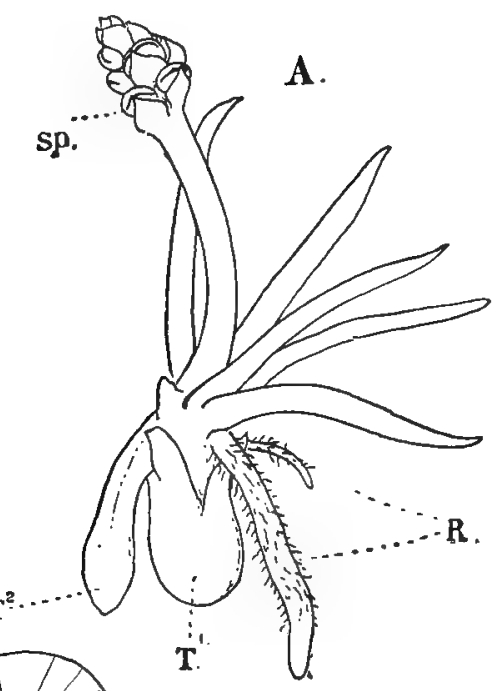

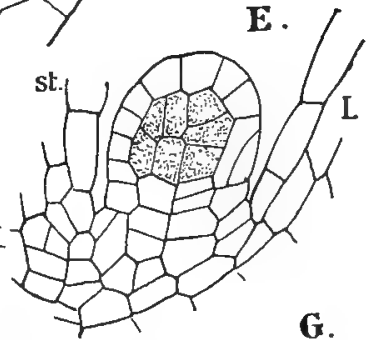

E

G.

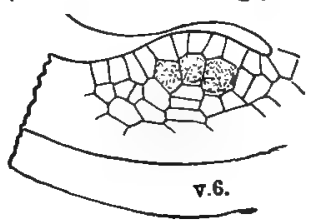

Fig. 290.-A, Plant of Phylloglossum Drummondii, $X$ about 3 (after Bertrand). st, Sporangia; $R$, roots; $T^{1}$, protocorm; $T^{2}$, secondary protocorm; $B$, longitudinal section of the young strobilus of the same, showing the initial cell (i), young leaves $\left(l^{\prime}, l^{\prime \prime}\right)$, and young sporangium $(s p), \times 240 ; \mathrm{C}-\mathrm{E}$, young sporangia of Lycopodium selago, radial sections, $\times 225 ; F$, tangential section of the same; $G$, radial section of young sporangium of $L$. clavatum (Figs. B-G after Bower). 
formed. The archesporial cells rapidly divide, but show little regularity in the divisions. All of the resulting cells separate and produce four spores in the usual manner. The wall of the mature sporangium consists regularly of three layers of cells, of which the innermost is the tapetum. The tapetum bounding the lower part of the archesporium is derived from the cushion-like group of cells below it, to which Bower gives the name "sub-archesporial pad." The tapetum does not become disorganised, as in most Ferns and Equisetum, but remains as part of the sporangium wall. The fully-grown sporangium, as in all species of Lycopodium, is kidney-shaped.

Among the numerous other species investigated by Professor Bower, $L$. clavatum represents the type most widely removed from $L$. selago. The differences between the two are summarised by Professor Bower as follows :

"I. The sporangium is similar in position and in general form to that of $L$. selago, but its body is more strongly curved.

"2. The archesporium here consists of three rows of cells, each row being composed of a large number (about twelve) of cells; thus the extent of the archesporium is much greater than in L. selago, occasional additions to it seem to be made by cells cut off periclinally from the superficial cell at an early stage.

"3. The tapetum is similar in origin to that in L. selago.

"4. The sub-archesporial pad is much more developed, and is at times extended as processes of tissue which penetrate the sporogenous mass for a short distance.

" 5 . The stalk of the sporangium is much shorter and thicker than in L. selago.

"6. Arrested sporangia are frequently present, and may be found either at the base or apex of the strobilus.

"7. L. inundatum may be looked upon as an intermediate link between the type of sporangium of $L$. selago and that of $L$. clavatum, both as regards form of the sporangium and complexity of the archesporium."

\section{Phylloglossum}

The other genus of the Lycopodiacex contains but the single species $P$. Drummondii, from Australia and New Zealand. This curious and interesting little plant has been carefully in- 
vestigated by Bower (5) and Bertrand (3), and the former regards it as the most primitive in structure of all the living Pteridophytes.

The sporophyte resembles in an extraordinary degree the young sporophyte of Lycopodium, especially L. cernumm. It grows from a small tubercle (protocorm), which is regarded as homologous with the same structure in the embryo of Lycopodium. This protocorm in small plants produces only sterile leaves-from four to twenty-and a small number of roots, often only a single one. In more vigorous plants a smaller number of sterile leaves is formed, but the apex of the protocorm grows into an elongated axis, bearing a single small strobilus at the apex (Fig. 290, A). The structure of the latter is essentially as in Lycopodium. The roots are produced exogenously, as in the Lycopodium embryo, and are in structure much the same. All of the tissues are very simple, and none of the organs show a single apical cell, except possibly the apex of the strobilus, where such a single initial seems to be sometimes present (Fig. 290, B, $i$ ). At the end of the growing season a new protocorm is formed. This arises directly from the apex of the old one, where no strobilus is developed, but in the latter case grows out upon a sort of peduncle from near the base of one of the leaves. The development of the sporangia is essentially the same as in L. selago (Fig. 290, B).

The anatomy of the vegetative organs has been carefully studied by Bertrand, and corresponds closely to that of Lycopodium, but the tissues are simpler. In the axis which bears the strobilus there are about six xylem masses arranged in a circle, but there is no definite endodermis limiting the central cylinder. The root-bundle is diarch.

Recently the gametophyte of Phylloglossum has been discovered and described by Thomas (I). In its main features it agrees with that of Lycopodium cernuum, having abundant chlorophyll, and having much the same general structure. The sexual organs and embryo also resemble those of $L$. cernuum.

Bertrand states that M. L. Crié found that the spores germinated readily, and produced a colourless prothallium like that of the Ophioglossacex, both in form and in the structure of the sexual organs, but that the spermatozoids are biciliate.

These observations do not agree with the results of Thomas's investigations. The latter observer thinks that per- 
haps Crié may have obtained only the early stages of the primary tubercle. The differences between Phylloglossum and Lycopodium do not seem sufficient to warrant the establishment of a separate family, the Phylloglosseæ, as Bertrand proposes.

\section{The Psilotacex (Pritzel $(I)$ )}

The Psilotaceæ include the two evidently related genera Psilotum and Tmesipteris, the former with two extremely variable species (Baker (I)), the latter with but a single one. All the species are tropical or sub-tropical, Psilotum being found in all the warmer parts of the world; but Tmesipteris is confined to Australia, New Zealand, and parts of Polynesia. The prothallium is quite unknown in both genera, but the development and anatomy of the sporophyte of both are now pretty well known. The sporophyte (Bertrand (I, 2); Bower (I5); Solms-Laubach (I)), which in its mature condition is quite destitute of roots, grows either upon earth rich in humus (Psilotum triquetrum), and is evidently more or less saprophytic, or it may be an epiphyte. Tmesipteris grows upon the trunks of tree-Ferns, and Bertrand states that it is a true parasite, which, however, like Viscum or Phorodendron, has not entirely lost its chlorophyll. The plant always consists of two parts, a lower portion consisting of branched root-like rhizomes, which take the place of roots, and aerial green branches which ramify dichotomously. The branching is especially marked in Psilotum, much less so in Tmesipteris. The leaves are small and scale-like in Psilotum, larger and lanceolate in Tmesipteris. The sporangia (or synangia) are bilocular in the latter, trilocular in Psilotum and in both cases borne upon a smaller bilobed sporophyll.

The development of the sporophyte has been carefully studied by Solms-Laubach (I), who discovered that it multiplied rapidly by means of small gemmæ (Fig. 292, $k$ ) produced in great numbers upon the subterranean shoots. These buds or bulblets are small oval bodies, but one cell in thickness, and showing usually a definite two-sided apical cell. Their cells are filled with starch, and they sometimes remain a long time dormant. These buds may produce others, but usually from each one is produced one, or sometimes more, elongated shoots, - which develop into subterranean branches like those from 
which the bud was originally produced. The young plant arising from the gemma is at first composed of uniform parenchyma, but in the later formed portions a simple vascular bundle is finally developed. No definite apical cell can be detected in

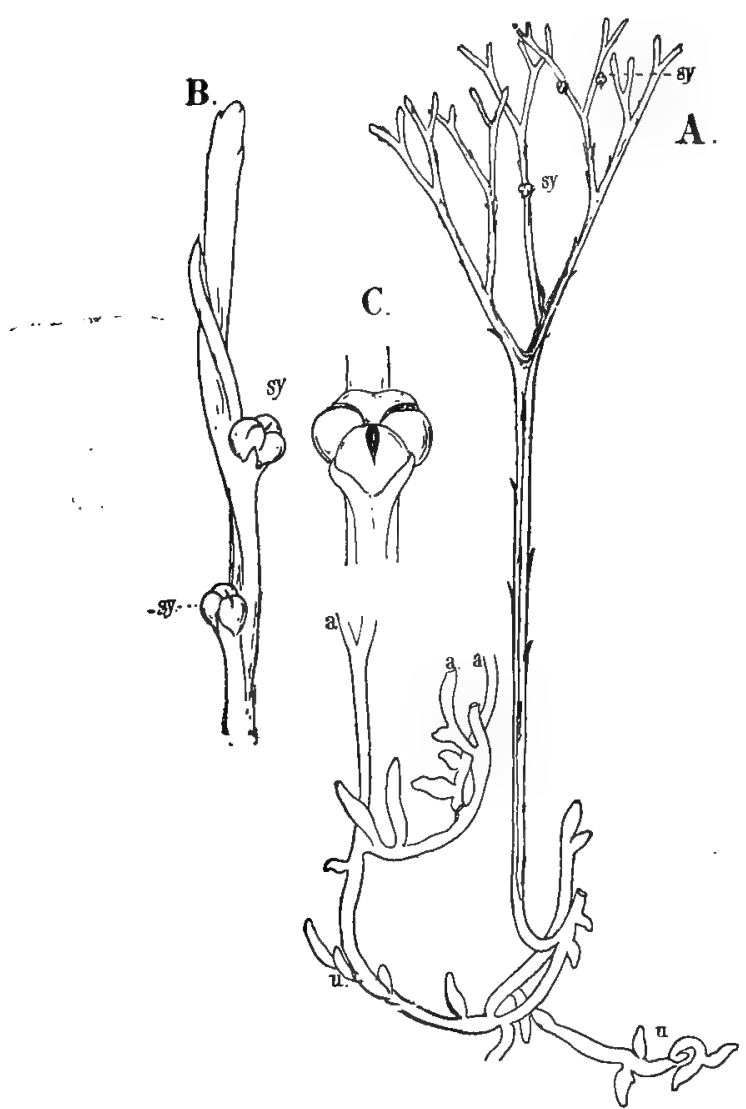

FIG. 291.-Part of a vigorous plant of Psilotum triquetrum, about $1 / 6 ; u, u$, Subterranean shoots; $a, a$, the bases of aerial branches; sy, synangia; $\mathrm{B}$, branch with two mature synangia, slightly enlarged; $C$, a single opened synangium, showing the two lobes of the sporophyll below it (after Bertrand).

the earlier stages, but later each branch of the rhizome shows a pyramidal initial cell, much like that in the Ferns, but less regular in its divisions, and it is not possible to trace back all the tissues with certainty to this single cell. The branching is. a true dichotomy, but is not brought about by the division of 
the original apical cell, but this becomes obliterated previous to the formation of the two branches, and two new initial cells are formed quite independently of it.

The tissues of the Psilotacere are quite simple (Russow (I), Pritzel (I), Ford (I)). The most recent account is by Miss Ford, who has made a very complete study of the tissues of Psilotum triquetrum.

The surface of the aerial shoot is strongly ribbed (Fig. 293, A) in the stouter portions, but nearly triangular in section

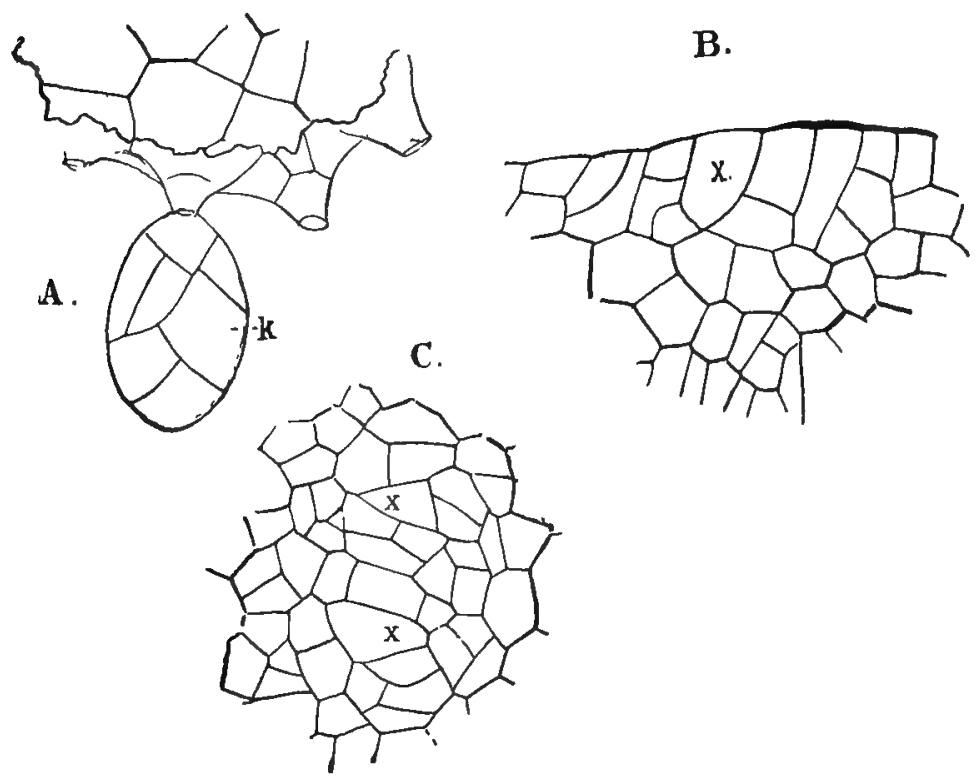

FrG. 292-Psilotum triquetrum. A, Fragment of a subterranean, shoot with a young gemma $(k), \times 120 ; \mathrm{B}$, longitudinal section of the apex of a subterranean shoot, $\times 185 ; C$, transverse section of the apex of a subterranean shoot in the act of forking, $x, x$, the apical cells of the two branches, $\times 185$ (all figures after Solms-Laubach).

nearer the apex. Within the epidermis, in which are numerous stomata, there is a zone of outer cortical cells, containing numerous chloroplasts, and constituting the principal assimilating tissue. The cells of this zone are irregular in outline, with numerous intercellular spaces, like the mesophyll of many leaves. Inside this assimilative cortex is a zone of sclerenchyma forming the principal mechanical tissue of the shoot. Within this zone is a mass of thin-walled parenchyma, bounded 
internally by the endodermis which limits the central cylinder. Miss Ford finds that with proper treatment, the endodermis can be readily differentiated, although ordinarily its presence is not evident.

The central cylinder, or stele, has its axis composed of a mass of sclerenchyma about which the radiating xylem-masses form a more or less regular star-shaped mass, when seen in transverse section. The number of xylem masses varies from 3 to Io. The protoxylem, composed as usual of narrow spiral tracheids, occupies the points of the star-shaped section, the larger secondary tracheids being developed centripetally. The latter are scalariform. The phloem is very poorly differentiated, and its boundaries are impossible to determine exactly. Larger elements, probably representing sieve-tubes, are present

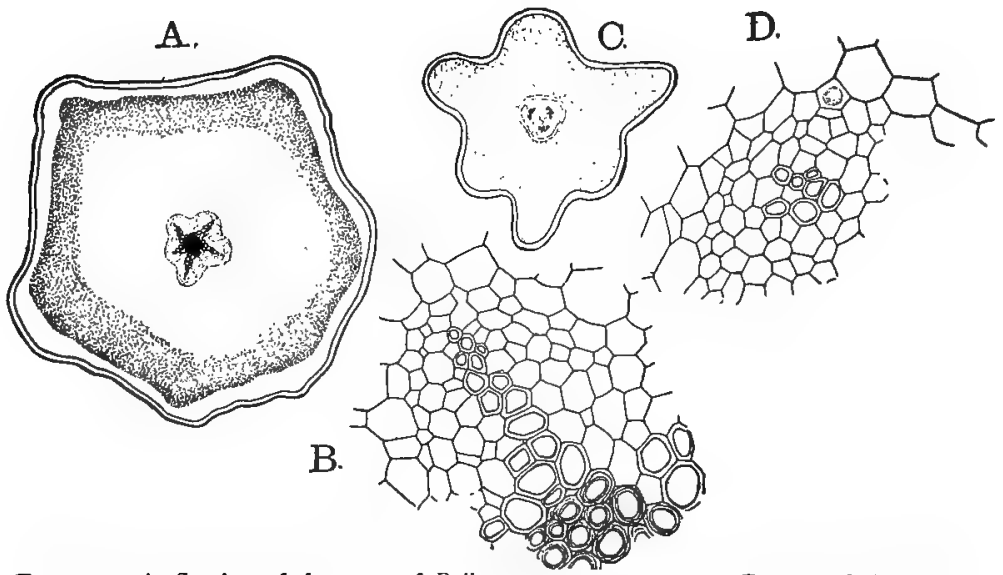

Fic. 293.-A, Section of the stem of Psilotum triquetrum, $\times 20 ; B$, part of the central cylinder, $\times \mathrm{I}_{50}$; $\mathrm{C}$, section of the stem of Tmesipteris tannensis, $\times 20 ; D$, part of the central cylinder, $X I 50$.

but neither well-defined sieve-plates nor callus could be demonstrated. Between the endodermis and protoxylem are several layers of pericycle cells. In Psilotum the leaves have no vascular bundle; in Tmesipteris a single bundle traverses the leaf, as in Lycopodium.

The structure of the stem in Tmesipteris (Fig. 293, C) is much like that of Psilotum, but is simpler. There are 3 to 5 xylem-masses which are much less symmetrically arranged than in Psilotum. The leaves, however, possess a well-devel- 
CHAP.

oped vascular bundle, which is continued into the stem as a leaf-trace, and joins the axial cylinder.

\section{The Sporangium (Bower (I5))}

There has been much disagreement as to the morphological nature of the sporangiophores of the Psilotaceæ. The two chief views are the following: (I) That the whole sporangiophore is a single foliar member; (2) that it is a reduced axis

A.

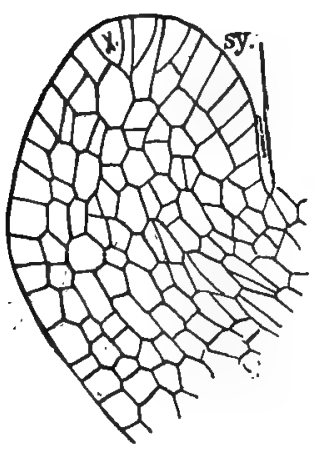

B.

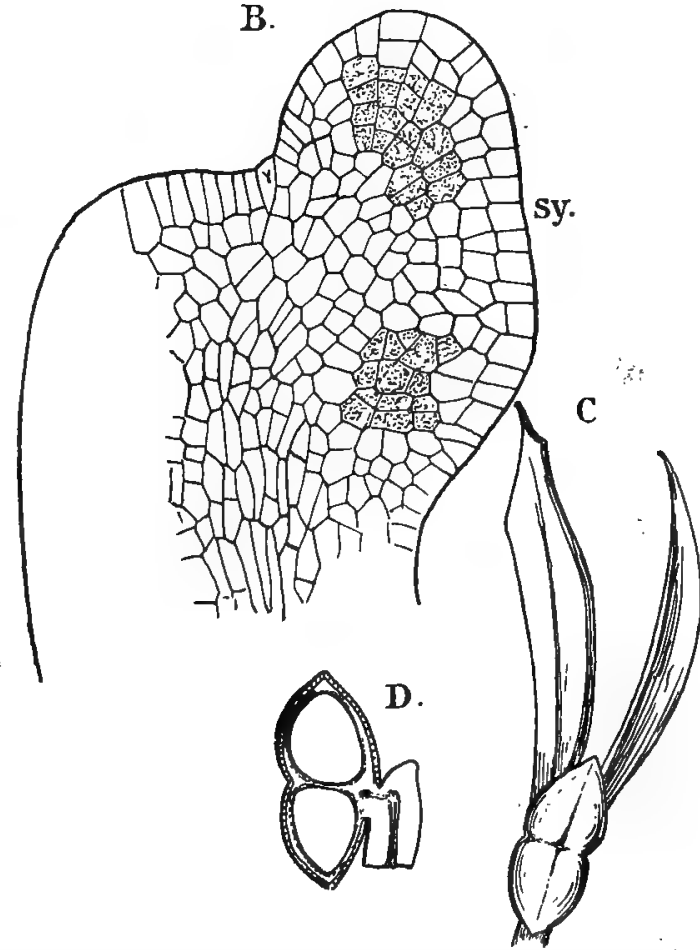

Fig. 294.-Tmesipteris tannensis. A, Radial section of the young sporangiophore, $X I 12 ; s y$, the young synangium; $B$, similar section of an older sporangiophore, $X_{I 12}$. The archesporial cells are shaded. C, Fully-developed synangium, showing its position between the two lobes of the sporophyll, $\times_{3} ; \mathrm{D}$, a longitudinal section of the synangium, showing the two loculi (all the figures after Bower).

bearing a terminal synangium and two leaves. The recent very careful researches of Bower upon the origin of the sporangiophore and synangium confirm the former view. He describes the development in Tmesipteris as follows: "The apical cone 
of the plant is very variable in bulk. ... In the large as well as the small specimens a single initial is usually present, but its segmentation does not appear to be strictly regular, and it is difficult to refer the whole meristem to the activity of one parent cell. ... When a leaf or sporangiophore is about to be formed, certain of the superficial cells increase in size, and undergo both periclinal and anticlinal divisions so as to form a massive outgrowth, the summit of which is occupied, as seen in radial section, by a single larger cell of a wedge-like or prismatic form. . . . In these early stages I find it impossible to say whether the part in question will be a vegetative leaf or a sporangiophore, and even when older it is still a matter of uncertainty. . . Those which are to develop as sporangiophores soon show an increase in thickness, while they grow less in length; an excrescence of the adaxial surface soon becomes apparent (Fig. 294, A, sy), in which the superficial cells are chiefly involved. . . . The superficial cells at first form a rather regular series, which mäy be compared with the cells which give rise to the sporangia in Lycopodium clavatum, or in Isoetes: they undergo more or less regular divisions, which, however, I have been unable to follow in detail : a band of tissue some four or more layers in depth is thus produced. About this period certain masses of cells assume the characters of a sporogenous tissue: but though they can be recognised as such by the character of the cells, it is extremely difficult to define the actual limits of these sporogenous masses."

In Tmesipteris there are normally two masses of sporogenous tissue corresponding to the two loculi in the mature synangium; in Psilotum, which correspond closely with Tmesipteris in other respects, there are three. Whether additions are made to the sporogenous tissue from cells outside the original archesporium was not determined with certainty, but Professor Bower thinks it not improbable. In Psilotum the young archesporium is more clearly defined than in Tmesipteris, and it seems not unlikely that each sporogenous mass is referable to the division of a single primary archesporial cell. In both genera some of the sporogenous cells do not develop spores, but simply serve for the nourishment of the others, as in Equisetum.

The fully-developed synangium has the outer walls of the loculi composed of a single superficial layer of large cells, beneath which are several layers of smaller ones (Fig. 294, D). The cells composing the septa are narrow tabular ones, with 
firm woody walls marked by numerous pits. Occasionally the septum is partially absent and the loculi are thus thrown more or less completely into communication. The spores are usually of the bilateral form, like the microspores of Isoetes, but may also be of the tetrahedral type.

Bower regards the whole synangium as homologous with the single sporangium of Lycopodium, and also calls attention to its resemblance to the sporangium of Lepidodendron, with which the Psilotaceæ also show resemblances in the structure of the stem.

\section{The Affinities of the Psilotacea (Bower (2I), Ford (I), $S \operatorname{cott}(I))$}

While the Psilotacea are usually united with the Lycopods, there has been of late a tendency to remove them from this class, and to assume a somewhat near affinity with the fossil Sphenophyllales, whose relationships are usually considered to be with the Equisetales. The undoubted anatomical resemblances between the Psilotaceæ and Lycopodiaceæ cannot be overlooked, and the question then remains whether these resemblances are anything more than analogies.

The anatomy of the smaller shoots of the Psilotaceæ undoubtedly recall the stem-structure of Sphenophyllum, and there seems to be also important points of resemblance in the sporangial structures. (Bower (2I), Thomas (3)).

Miss Ford ( ( 1 ), p. 603), whose work on Psilotum is the most recent, considers the Psilotaceæ to be much reduced forms, probably owing to their saprophytic habit. They are "somewhat closely allied to the fossil group of the Sphenophyllales."

\section{The Selaginellace}

Unlike the Filicineæ, the heterosporous Lycopodineæ outnumber very much the homosporous forms, but all of the former may be reduced to a single genus, Selaginella, which contains nearly five hundred species, and, except for the presence of heterospory, approaches closely the genus Lycopodium, to which it is clearly not very distantly related. The great majority of the species of Selaginella belong to the tropics, and form a 
characteristic feature of the forest vegetation of those regions. A few belong to the more temperate parts of Europe and America, and a small number, e. g., S. rupestris, S. lepidophylla, grow in dry situations.

\section{The Gametophyte}

Hofmeister ( I) included Selaginella among the other Pteridophytes he studied, but he was unable to make out the earlier

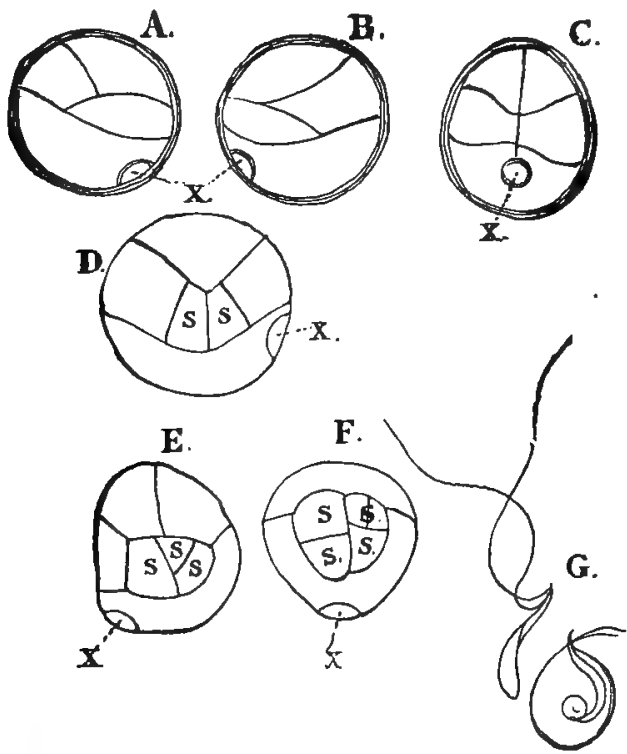

FIG. 295.-A, B. C, Three views of the young antheridium of Selaginella Kraussiana, $\times 450 ; D$, an older stage of the same, $\times 480 ; E, F$, two views of an older antheridium of $S$. stolonifera, $\times 480 ; \mathrm{G}$, spermatozoids of $S$. cuspidata, $X_{11}{ }^{2} ; x$, vegetative prothallial cell; $s$, central cells (after Belajeff).

stages of development of the prothallium. Later Millardet (I) and Pfeffer ( I ) made further investigations upon the same subject, and added much to Hofmeister's account, but were also unable to determine the earliest phases of germination.

Belajeff (I) has since given an accurate account of the germination of the microspores, and during the past ten years the development of the macrospores and female gametophyte has been very thoroughly investigated. 


\section{The Microspores and Male Prothallium}

The microspores of all species of Selaginella are small and of the tetrahedral type. According to Belajeff (I) they may show either a distinct perinium, or the latter is not clearly separated from the exospore. The spores contain no chlorophyll, but include much oil as well as solid granular contents. At the time that the spores are shed each one has already divided into two very unequal cells, a very small lenticular cell (Fig. 295, $x$ ) and a much larger one which, as in Isoetes, becomes the single antheridium.

The first wall in the antheridium divides it into two equal cells, each of which then divides into two others, a basal and an apical cell. The latter divides twice more, forming three segments, so that the young antheridium at this stage consists of eight cells arranged in two symmetrical groups. Of the three segments formed in each apical cell, the first and sometimes the second form periclinal walls, so that a central cell (or two cells) is formed in each half of the antheridium, not unlike what obtains in Marsilia, and the young antheridium consists now of two (or four) central cells and eight peripheral ones. Belajeff states that the cell walls do not show the cellulose reaction, and that they are later absorbed. Where there are four primary central cells, these by further divisions produce a single cell-complex, which, after the disintegration of the peripheral cell walls, floats free in the cavity of the spore. Where but two primary central cells are formed, each produces a separate hemispherical cell mass. Belajeff does not state the number of sperm cells formed. The spermatozoids (Fig. 295, G) are extremely small and closely resemble those of many Bryophytes, as well as Lycopodium. Like these they are always biciliate.

Miss Lyon (2) has given a very different account of the male gametophyte in $S$. apus. She states that in this species the cytoplasm of the germinating spore contains large vacuoles separated by bands of cytoplasm, which radiate from the central "generative" nucleus. The latter, with its envelope of protoplasm, then divides into "two cells," but how the membranes about these free cells are formed is not stated. These two cells give rise to the two masses of sperm-cells, and in the radiating vacuoles are formed granular masses which, to judge from the 
figures, are astonishingly cell-like in appearance. Until it can be conclusively shown that these are not really cells, the statement must be accepted with a certain amount of reservation.

A recent examination by the writer of some of the germinating stages of the microspore of S. Kraussiana has shown beyond question that in this species at least, Belajeff's statement as to the formation of a peripheral layer of cells about the sperm cells is correct. There was no trace of any vacuoles; the granular cytoplasm filling the spore completely and the walls separating the peripheral cytoplasm from the central area were clear and unmistakable. No attempt was made to verify the exact succession of the division walls.

\section{The Macrospore and Female Prothallium}

The formation of the female prothallium begins while the spore is still within the sporangium, and long before it has reached its full size.

At an early period, shown first by Fitting (I), but later verified by Miss Lyon (2) and Campbell (25), the protoplast of the young macrospore separates from the inner spore membrane (Fig. 296, A), and the outer spore-membrane increases rapidly in size, so that a wide space separates the protoplasmic vesicle from the inner spore-membrane. The minute globular protoplast was mistaken by all the earlier observers for the primary nucleus of the macrospore, as it is very evident through the transparent membrane at this time. The real nucleus is very small and divides very soon, but the cytoplasmic layer remains extremely thin. As the spore develops, the cytoplasmic vesicle rapidly increases in diameter and finally comes again into close contact with the endospore, or inner cellulose membrane (Fig. 296, B). There is a middle lamella or mesospore $(m)$, which is very conspicuous in the early stages, as it is also, except at the apex of the spore, quite free from the thick outer coat, the exospore. The space between the mesospore and exospore is filled with a substance which stains faintly, and undoubtedly contains material which is used by the growing membranes.

The nuclei $(n)$ are small, and while the cytoplasmic layer remains thin, are flattened. Later they increase rapidly in number, and with the thickening of the cytoplasmic layer, become globular in form. At first they are pretty uniformly distributed, but later are more numerous at the apex of the spore; but 
at no time in S. Kraussiana are they confined to this apical region, as Miss Lyon states is the case in $S$. apus.

With the increase in the amount of protoplasm, the very large central vacuole becomes reduced in size, and finally, but this does not occur until after the germination of the spore, is
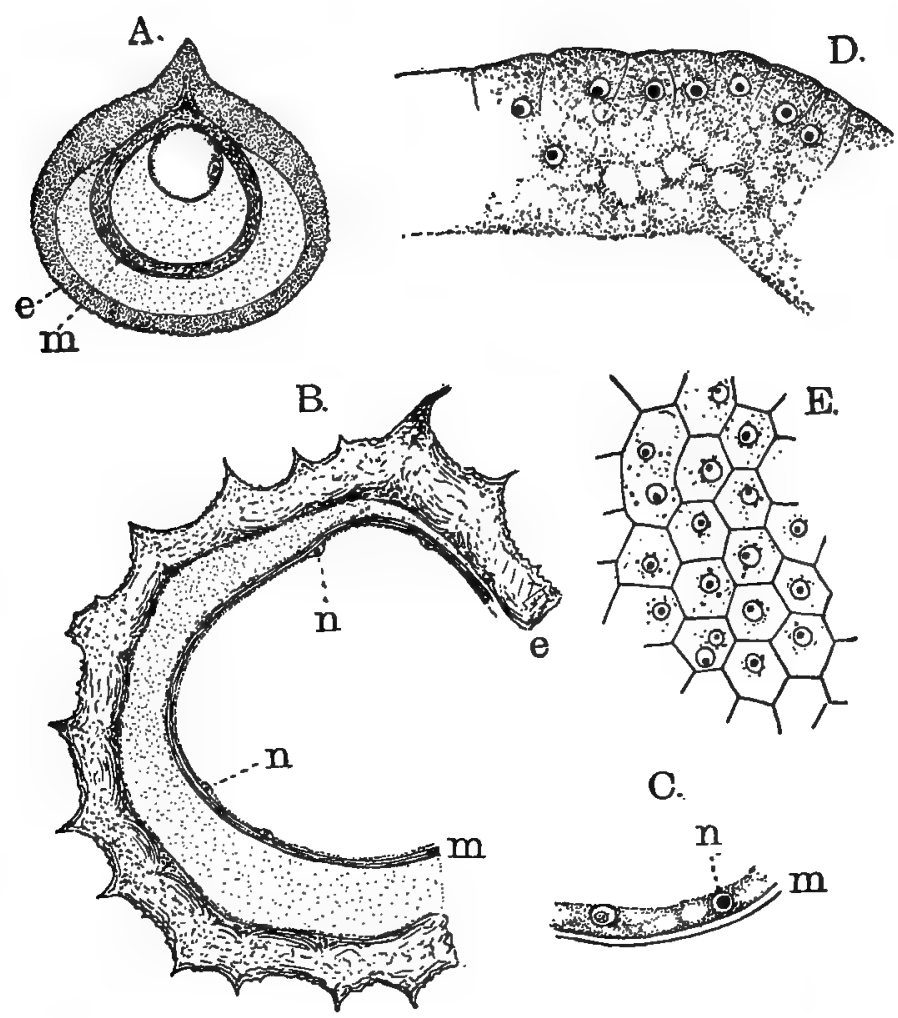

Fig. 296.-A, Young macrospore of Selaginella helvetica. The vesicular protoplast, with the primary nucleus, is much smaller than the spore membranes, $X_{400} ; \mathrm{B} \cdot \mathrm{E}$, $S$. Kraussiana, sections of the older macrospore, showing the development of the gametophyte; $\mathrm{B}, \times$ about 200 , the others more highly magnified; $e$, exospore; $m$, mesospore; $n$, nuclei; $\mathrm{D}, \mathrm{E}$, show the first. cell-formation; $\mathrm{D}$, vertical; $\mathrm{E}$, horizontal section of spore-apex. (A, after Fitting).

completely obliterated. In microtome sections it appears entirely empty, but Heinsen (I) states that in the living. state it is occupied by great quantities of fatty oil. Whether this is the case in $S$. Kraussiana was not investigated. 
The protoplasmic layer is somewhat thicker at the apex, and here begins the first cell-formation (Fig. 296, D, E). There is but a single layer of nuclei at this point in $S$. Kraussiana. In $S$. apus there may be, according to Miss Lyon, six or seven layers; but none at all in the basal region of the spore.

Cell-division begins in $S$. Kraussiana by the simultaneous appearance of delicate cell-walls between the nuclei at the apex of the spore. These walls cut out cells (areoles), each, at least in the central region, containing but a single nucleus. These

B.

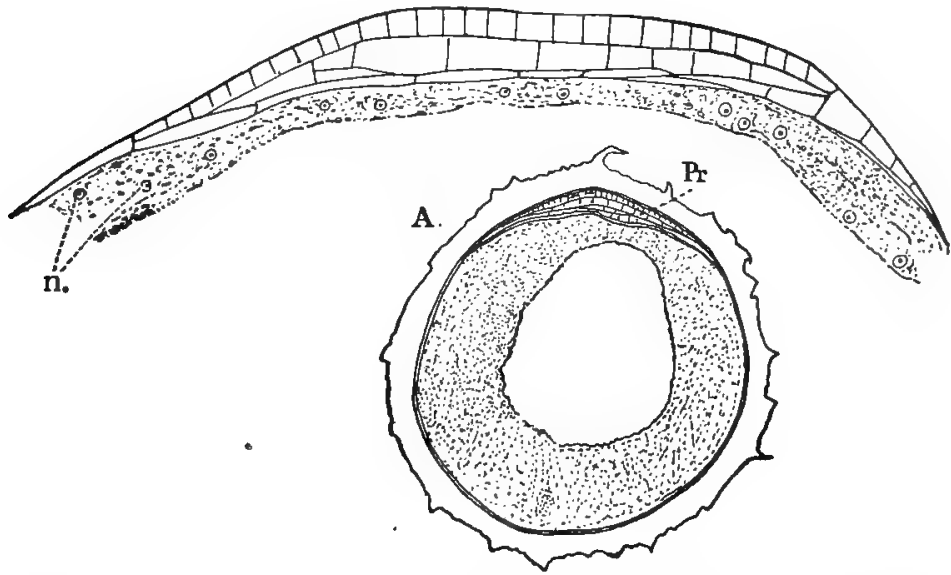

FrG. 297.-Selaginella Kraussiana. A, Longitudinal section of a nearly ripe macrospore, with the primary prothallium $(P r)$ complete, but still showing a large vacuole in the centre of the spore, $\times 65 ; \mathrm{B}$, similar section of a younger stage, before the diaphragm has been differentiated, $\times_{400} ; \mathrm{rl}$, free nuclei.

areoles are at first open upon their inner side, and the first cellformation resembles to a remarkable degree the typical endosperm formation in the Spermatophytes. Fig. 296, E shows a cross-section of the apex of the spore shortly after the first cell walls are complete. The extremely regular hexagonal form of the cells toward the centre of the prothallium is very noticeable. At the margin, and below, the cells are larger, and often contain several nuclei.

The cell-formation does not extend at this stage to the base of the spore, as in Isoetes, but is confined to the apex, where a definite cellular body is formed. This is three-layered in the middle, but at the margins but one cell in thickness. The lower cells have the walls which are in contact with the spore-cavity 
much thickened at a later stage, and thus is formed the diaphragm which is so conspicuous in most species, and which led Pfeffer to suppose that the first division in the young prothallium proper from the lower part of the spore, in which later the "secondary endosperm" is formed.

Scattered through the protoplasm of the spore-cavity below the diaphragm are numerous nuclei. The protoplasmic layer becomes rapidly thicker (Fig. 297, A), and finally completely fills the cavity of the spore. The thickenings upon the outer spore-coat are very evident even before the primary nucleus divides, and they increase rapidly in size, as the spore develops. A very casual examination suffices to show that the tapetal cells of the sporangium here play a most important part, not only in the development of the spore-coat, but also in the growth of the prothallium. The rapid increase in the amount of protoplasm in the spore during the growth of the prothallium, as well as the growth of the spore itself, can only be accounted for by the activity of these cells, which are in close contact with the spore, and show every evidence of being active cells, through whose agency the materials are conveyed to the spore for its further development.

The first archegonia begin to form shortly before the spores are shed, and soon after, the exospore splits along the three ventral ridges and exposes the central part of the prothallium. This, like that of Isoetes, is quite destitute of chlorophyll, and is entirely dependent upon the food materials in the spore for its further development. About this time also begins the cellformation in the part of the spore below the diaphragm (Fig. 298). This is simply a continuation of the same process by which the apical tissue was developed, but the cells are larger and more irregular.

The archegonia are produced in considerable numbers, and apparently in no definite order. Their development corresponds with that of Lycopodium, but the neck is very short, like that of the Marsiliaceæ, each row of neck cells having but two cells. No basal cell is formed, and the central cell is separated from the diaphragm only by a single layer of cells. The neck canal cell (Fig. 298) is broad, like that of Isoetes, but the nucleus does not, apparently, divide again. The egg (Fig. 298, E) shows a distinct receptive spot, and the nucleus is clearly defined. At this stage the diaphragm is very evident and much 
thickened, so that the archegonial tissue of the prothallium is very sharply separated from the nutritive tissue below.

Sometime after germination begins, the vacuole completely disappears, and sometimes a spongy-looking mass was seen filling it before it finally disappeared. In the later stages, the nuclei in the cytoplasm immediately below the diaphragm are much more numerous and correspondingly smaller than those in the much more coarsely granular cytoplasm of the basal region. The finely granular protoplasm and numerous nuclei

A.
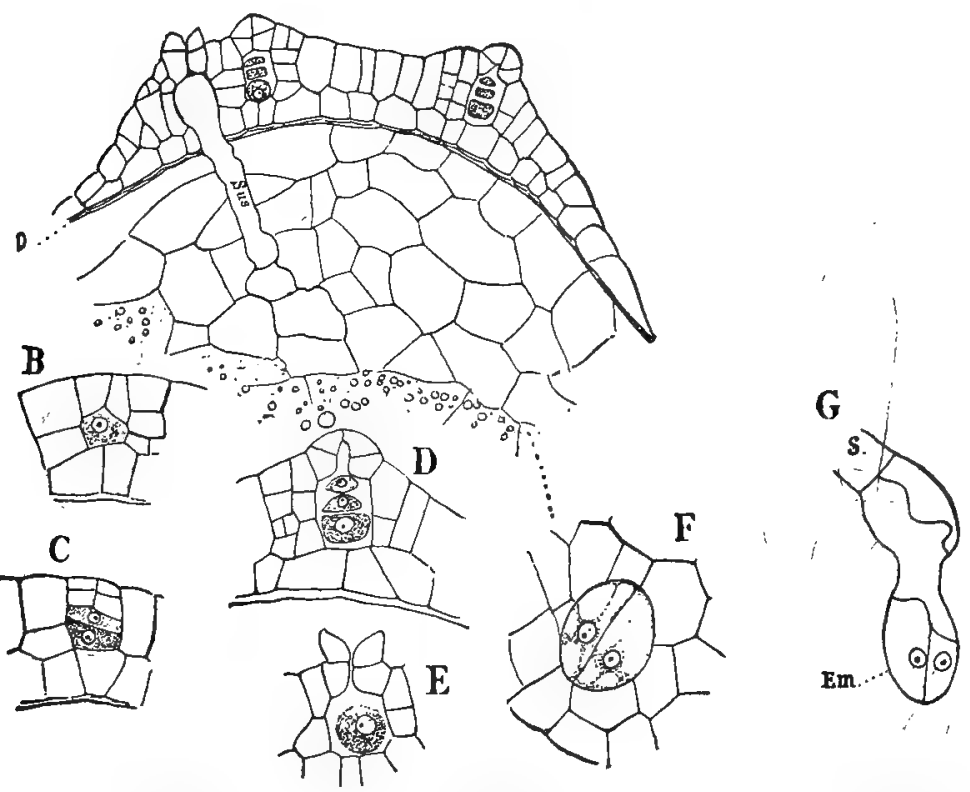

FrG. 298.-Selaginella Kraussiana. A, Nearly median section of a fully-developed female prothallium, showing the diaphragm $(d), \times 180$. One of the archegonia has been fertilised, and the suspensor (sus) has penetrated through the diaphragm into the tissue below it; $\mathrm{B}-\mathrm{E}$, development of the archegonium, $\times 360 ; \mathrm{F}$, twocelled embryo, belonging to the suspensor shown in $A, \times 360$; $G$, end of a suspensor with two-celled embryo (em), $\times_{3} 60$.

show the region where the cell-formation begins which results in the secondary prothallial tissue.

Arnoldi ( $\mathrm{I}$ ) states that in S. cuspidata there is a single large primary nucleus near the apex of the spore which is completely filled with cytoplasm. It looks very much, however, as if he had mistaken the protoplasmic vesicle of the young 
spore for the nucleus-if his statement is correct, $S$. cuspidata differs very remarkably from other investigated species in the development of the gametophyte.

Miss Lyon (2) found in both $S$. apus and $S$. rupestris a much greater development of the primary prothallial tissue than is found in S. Kraussiana. To judge from her figures 54 and 55 , there are two types of prothallium in $S$. apus, one in which the base of the primary prothallium is sharply delimited, and the other without any clear boundary between the primary and secondary prothallial tissues.

\section{The Embryo}

The first division in the fertilised ovum is transverse, and as in Lycopodium, the cell next the archegonium neck becomes
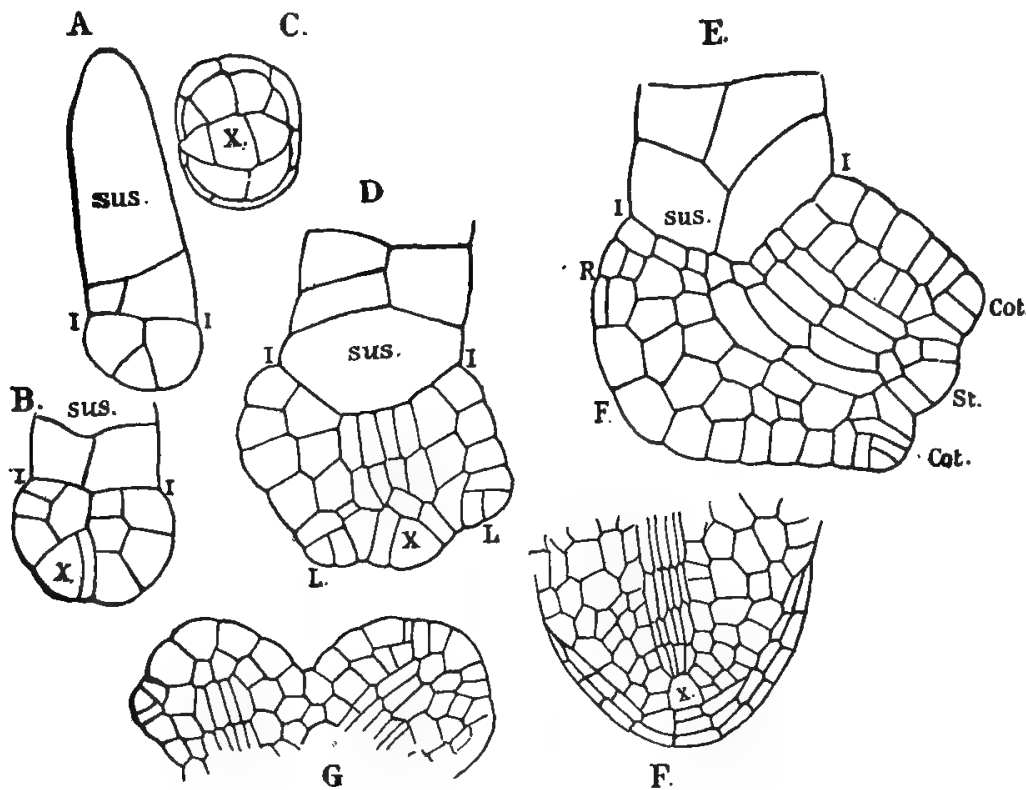

FIG. 299.-Selaginella Martensii. Development of the embryo (after Pfeffer). A, B, $D, E$, Successive stages in longitudinal section, $\times 340 ; C$, apical view of a young embryo with four-sided apical cell $(x), \times 340 ; \mathrm{F}$, longitudinal section of the primary root, $\times 205 ; \mathrm{G}$, apex of the young sporophyte, showing the first dichotomy, $\times 340$.

the suspensor. This in Selaginella is much more developed, however, and grows at first more actively than the lower cell from which the embryo proper arises. The upper part of the 
suspensor enlarges somewhat, and forms a bulbous body, which completely fills the venter of the archegonium. The suspensor grows rapidly downward, penetrating the diaphragm and pushing the young embryo down into the mass of food cells which occupy the space below it. The suspensor is very irregular in form, and undergoes several divisions (Fig. 298, G).

The first division in the embryo proper is almost vertical (Fig. 298, F), and divides it into nearly equal parts. Beyond this the early stages of the embryo were not followed by the writer, but to judge from the later stages, they correspond to those of $S$. Martensii, which has been most carefully studied by Pfeffer (I), the substance of whose work may be given as follows. After the first wall is formed in the embryo, there arises in one of the cells a second, somewhat curved one, which strikes the primary wall about half-way up. The cell thus cut off, seen in longitudinal section, is triangular, and is the apical cell of the stem (Fig. 299, A). The two other cells (leafsegments) now undergo division by a vertical wall, which divides each into equal parts, and each of these pairs of cells develops into a cotyledon. The apex of the young cotyledon is occupied by a row of marginal cells in which divisions are formed, like those in the apical cell of the stem, and in longitudinal section the apex of the cotyledon seems to have a single apical cell, much like the stem (Fig. 299, E). From the larger of the leaf-segments, by a more active growth of the cells next the suspensor, the foot is formed, and by its growth the stem apex is pushed to one side, and its axis becomes almost at right angles to that of the suspensor. Each cotyledon develops upon its inner side, near the base, an appendage, the ligula (Fig. $300, l)$, which is a constant character of all the later leaves.

The primary root, as in Lycopodium, forms late, and no trace of it can be seen until the other parts are evident. It arises in the larger leaf-segment, close to the suspensor, and therefore is separated from the cotyledon by the foot. The root-cap arises from a superficial cell, which divides early by both periclinal and anticlinal walls, and thus becomes two layered. From a cell immediately below is derived the single apical cell to which the subsequent growth of the root is due. The further divisions in the primary root were not followed.

The axes of the stem and root soon develop a strand of procambium which is continuous in the two, but to judge from 
Pfeffer's figures, the cotyledons do not develop their vascular bundles until later. The early growth in length of the root is mainly intercalary, as the divisions in the apical cell for some time are not very rapid, and for a long time the root-cap consists only of the two original layers.

With the growth of the embryo the cell-formation in the lower part of the spore continues until it is filled with a continuous large-celled tissue, the contents of whose cells are much less granular than the undivided regions of the spore, and as the embryo develops, the foot crowds more and more upon them

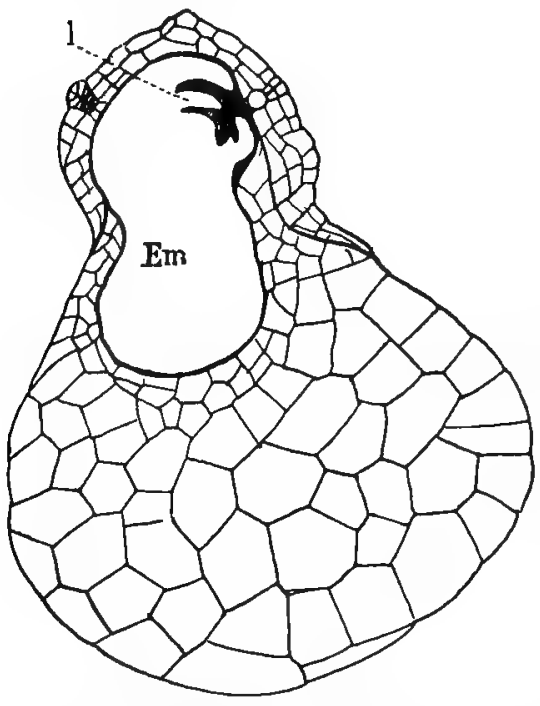

FIG. 30o.-Longitudinal section of a fullydeveloped prothallium of $S$. Kraussiana, with an advanced embryo (em), X77; $l$, ligula. until it nearly fills the spore cavity.

On comparing Pfeffer's account of $S$. Martensii with my own observations upon S. Kraussiana, the main differences consist first in the smaller development in the latter of the primary prothallium, $i$. e., the prothallial tissue formed before the spores are shed, the archegonia being only separated from the diaphragm by a single layer of cells instead of by three or four, as in $S$. Martensii. L. apus, which was also examined by the writer, is intermediate in this respect between the two. A second difference is the later period at which the cell division in the lower part of the prothallium is completed in $S$. Kraussiana. In this species, too, no rhizoids were seen, while Pfeffer observed them in $S$. Martensii. Finally, in the latter the suspensor is much shorter and straighter than in S. Kraussiana. Miss Lyon (2) found that in $S$. apus no suspensor was formed, but the development of the embryo is not described.

In $S$. Martensii, almost as soon as the cotyledons are established, the two-sided apical cell of the stem is replaced by a 
four-sided one, from which are then produced two similar ones by the formation of a median wall, and a true dichotomy of the primary axis thus takes place at once, the two new branches growing out at right angles to the cotyledon. While this may also occur in S. Kraussiana (Fig. $301, D$ ), it is not always the case, and frequently the young plant remains unbranched until it has reached a length of a centimetre or more, and has produced numerous leaves.

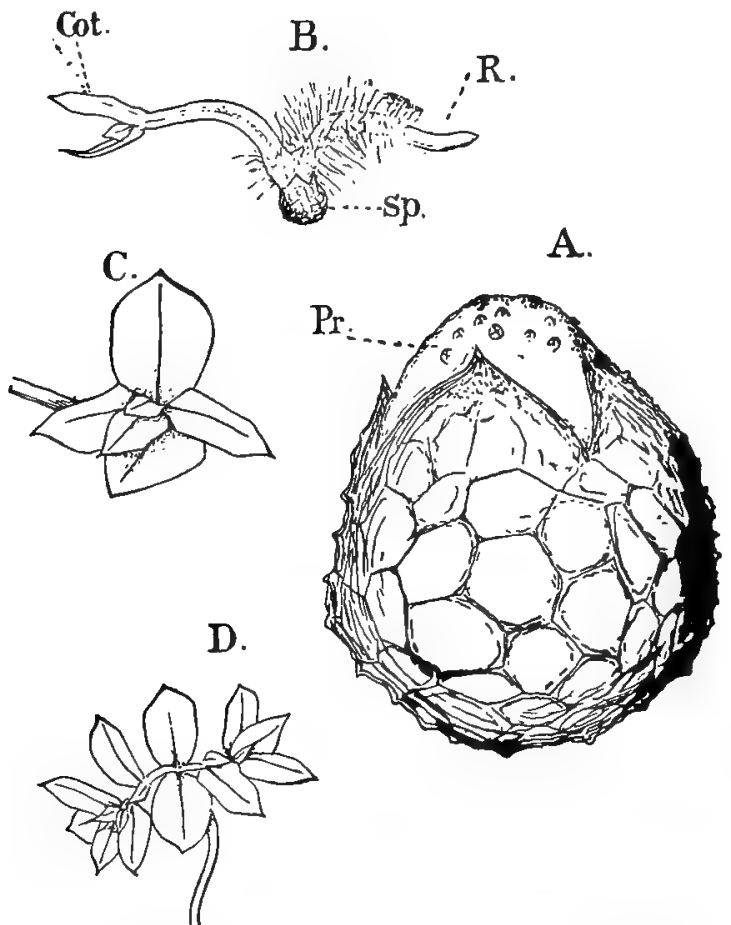

FrG. 301.-Selaginelle Kraussiana. A, Macrospore with the prothallium ( $p r), \times 50 ; \mathrm{B}$, young sporophyte still attached to the spore $(s p), \times 8$; cot, cotyledons; $\mathrm{R}$, root; $\mathrm{C}$, upper part of an older stage, $\times 6 ; \mathrm{D}$, a still older one showing the first dichotomy, $\times 4$.

The embryo of S. spinulosa (Bruchmann (4)) has a short and massive suspensor, and no foot is developed.

Miss Lyon (2) found that in both $S$. apus and $S$. rupestris, fertilisation occurred while the spores were still within the sporangium, and the sporangium attached to the strobilus. "The strobilus of $S$. rupestris retains its physiological connection 
with the plant until the embryo has produced the cotyledons and root." (l. c., p. I83).

In $S$. apus, the strobili are shed in the early autumn, whether fertilisation has occurred or not. S. rupestris retains the strobili through the winter, and fertilisation is effected in the spring.

From some partial observations made by the writer upon spores of a species (probably L. Bigelovii) from the dry region of southern California, it looks very much as if, in this species, the spores became completely dried up after the embryo had already attained some size, and that the spores remained in this condition through the dry season, the embryo resuming its growth again in the autumn.

\section{The Adult Sporophyte}

The genus Selaginella is a very large one, but there is some difference of opinion as to the number of species. Hieronymus ( I ) enumerates 559 species, while Underwood (4) says the genus contains "about 335 " species. The genus is usually divided into two subgenera, Euselaginella (Homoophyllum. of Hieronymus) and Stachygynandrum (Heterophyllum, Hieronymus). In the first are included those species in which the leaves are all alike and arranged radially about the shoot, which is generally more or less completely upright. S. rupestris, S. selaginoides and S. Bigelovii are examples. In Stachygynandrum, which comprises the majority of the species, the shoot is dorsiventral, and often prostrate. The leaves are four-ranked, those of the two dorsal rows being much smaller than the others (Fig. 302). The first type suggests the species of Lycopodium of the type of L. annotinum, the second that of $L$. complanatum or $L$. volubile. In many species there is a creeping stem from which upright branches grow, much as in many species of Lycopodium, but in others there is no clear distinction between these parts. The roots may arise directly from the ordinary branches, but in many species, e. g., $S$. Kraussiana, they are borne at the end of peculiar leafless branches or rhizophores (Fig. 305, A). These, like the stem, show an apparently regular dichotomous branching, which, however, is really monopodial. The leaves, like those of Lycopodium, are small, more or less lanceolate in outline, and with a single median vein. In the homophyllous forms the sporo- 
phylls differ but little in appearance from the ordinary leaves, but in the heterophyllous ones they are smaller than the other leaves, and form a strobilus much like that of Lycopodium, but usually less conspicuous.

The strobilus (Hieronymus (I), p. 653) may be either erect or horizontal; much more rarely it is pendent, and there appears to be a certain relation between the arrangement of the sporophylls and the position of the strobilus. Where it is upright the sporophylls are all alike, and disposed radially about the axis. Where the strobilus is horizontal it is more or less markedly dorsiventral in structure. In $S$. selaginoides and $S$. deflexa there is a more or less perfect spiral arrangement of the

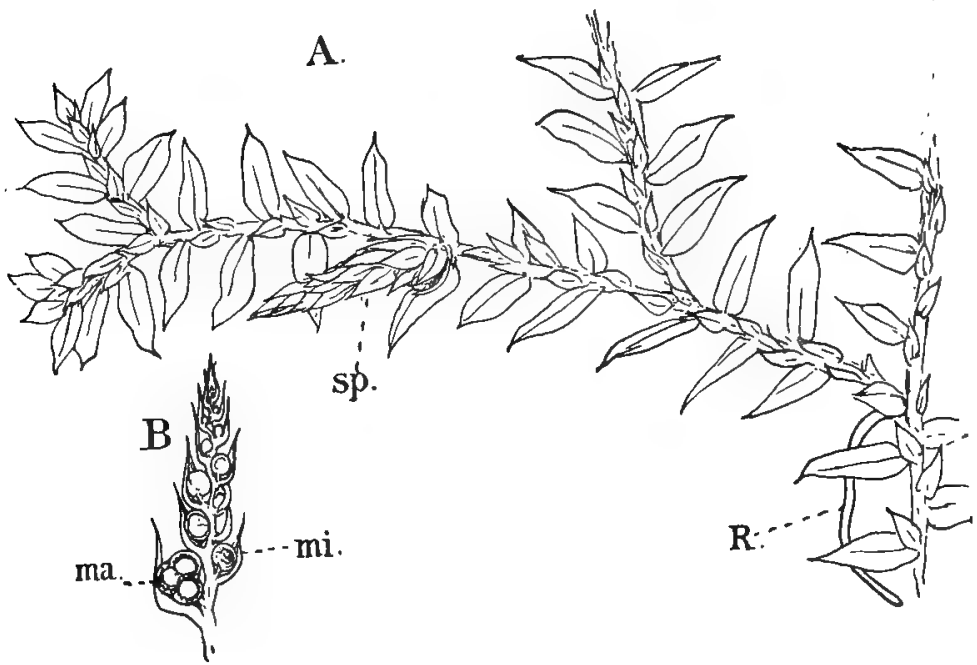

FIg. 302.-A, Part of a fruiting plant of Selaginella Kraussiana, $\times 3$; sp, sporangial strobilus; R, young rhizophore; B, longitudinal section of the strobilus, $\times 5 ; m a$, macrosporangium; mi, microsporangium.

sporophylls, but in all the other species they are four-ranked. Usually in the latter case the sporophylls are alike, but there may be the same difference in the dorsal and ventral leaves of the dorsi-ventral strobili that is found in the sterile shoots of the same species.

The basal leaves of the strobilus may be sterile, but usually each sporophyll subtends a sporangium. In S. Kraussiana, and many other species of the same section of the genus, there is but a single macrosporangium developed-the first formed 
sporangium of the strobilus. This is much larger than the microsporangia, and the sporophyll correspondingly large. In other species, e. g., S. apus, there may be several macrosporangia. According to Hieronymus the position of the strobilus conditions to some extent the development of macrosporangia, which are either basal, or in that part of the strobilus

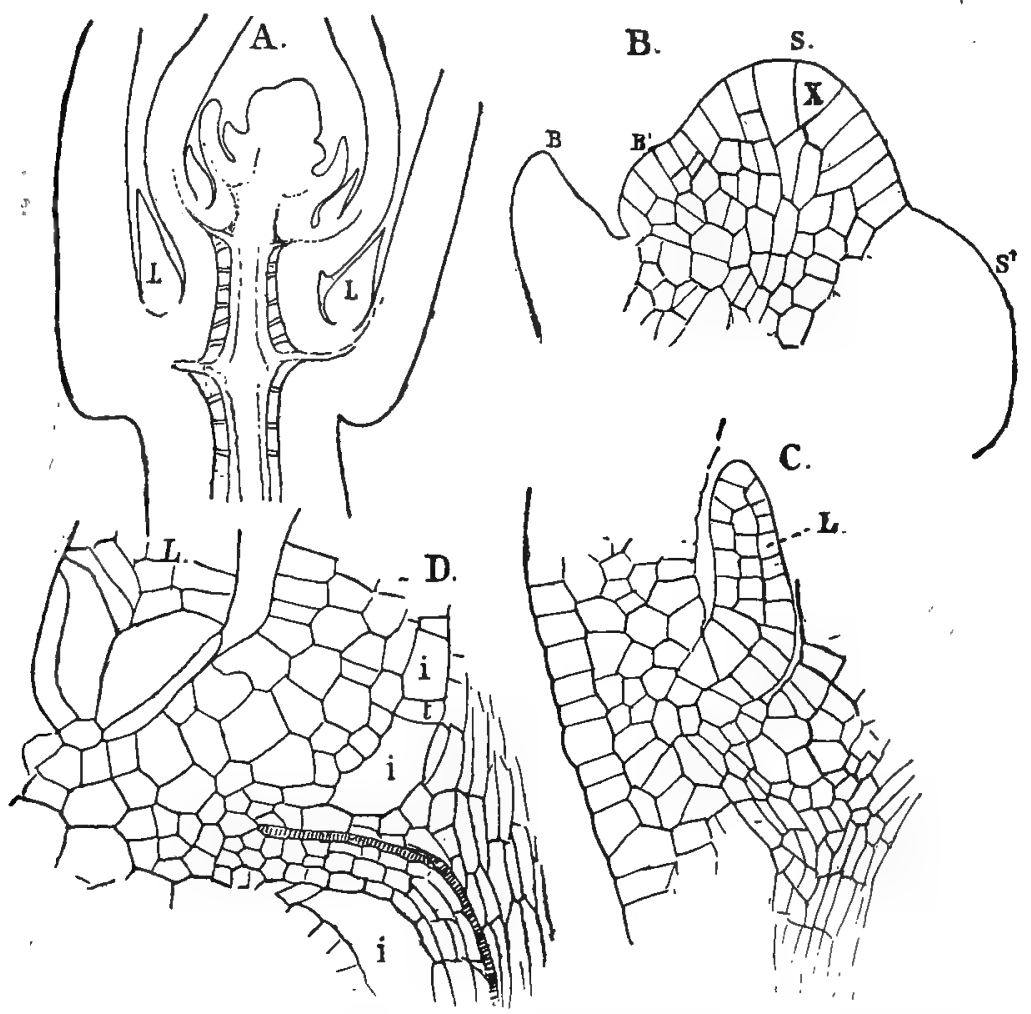

Frc. 303.- Selaginella Kraussiana. Horizontal section of the apex of the stem, $\times 77 ; B$, the apical meristem of the same, $\times 450 ; s$, the apex of the main axis; $s^{\prime}$, a young lateral branch; B, B, young leaves; L, ligula of the leaf; C, D, longitudinal sections of the base of older leaves, $\times 450 ; i$, lacuna surrounding the vascular bundles of the stem; $t$, one of the trabecula.

nearest the ground. Thus in dorsiventral strobili they are developed on the ventral side; in pendent ones they may form at the apex of the strobilus. Miss Lyon made some interesting observations upon the development of the sporangia in $S$. apus and $S$. rupestris. In the latter species the strobili begin to de- 
velop in the late summer and autumn, producing at this time only macrosporangia. In the spring the growth of the strobilus is resumed, and microsporangia are developed, the gametophytes produced from the macrospores of the previous year being fertilised by spermatozoids developed from the microspores developed in the spring. In $S$. apus there was evidence that the embryos formed in the autumn passed through the winter within the macrospore, completing their development in the spring.

The leaves arise much in the same way that the branches do, but do not develop a single apical cell. The growth is
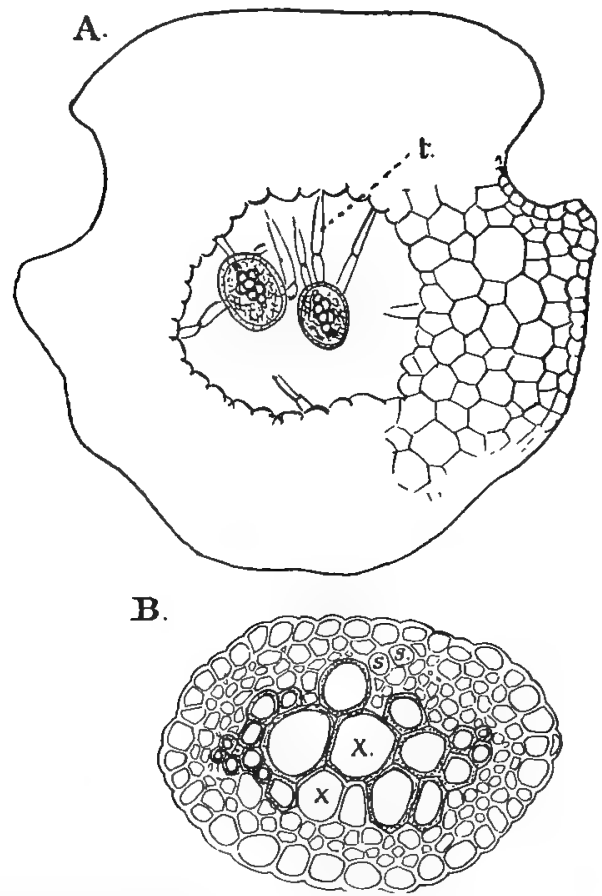

Fig. 304.-Cross-section of a fully-developed stem of S. Kraussiana, showing the two vascular bundles suspended in the large central lacuna by means of the trabecula $(t), \times 75 ; \mathrm{B}, \mathrm{a}$ single vascular bundle, $\times_{450} ; x, s$, scalariform tracheids; $s, s$, sieve-tubes.

much the same as in the first leaves of the embryo, and as in these the early growth is due mainly to a row of marginal initial cells from which segments are cut off alternately above and below. 
If we examine a longitudinal section of the stem a short distance below the apex (Fig. 303, A), we find a regular intercellular space formed between the central stele (or steles), which completely surrounds it, and becomes very conspicuous as the section is examined lower down. The formation of this lacuna is similar to that in the capsule of the Bryales, and, as there, the central mass of tissue is connected by rows of cells with the outer tissue. These rows of cells (trabeculæ) are at first composed of but a single cell, but later by tangential walls become slender filaments by which the vascular cylinders are suspended in the large lacuna which occupies the centre of the stem (Fig. 304, $t$ ). According to Strasburger $((7)$, p. 457$)$ both the trabeculæ, which are usually regarded as endodermal, and the pericycle, are of cortical origin.

The fully-developed bundle in S. Kraussiana (Fig. 304, B) shows a pericycle composed of a single layer of rather large cells, within which lies the phloem, which completely surrounds the xylem, as in the Ferns. The sieve-tubes in this species form a single circle just inside the pericycle, but according to Gibson ( (2), p. I76) are absent opposite the protoxylem. He states that there is but a single group of protoxylem elements here, but my own observations lead me to think that there are two, as Russow affirms is the case. The origin of the protoxylem was not traced, but the appearance of the mature bundle in the specimens examined (Fig. 304, B) points to this conclusion. The protoxylem is made up of small spiral and annular tracheids, the metaxylem (secondary wood) of larger scalariform elements, as in Lycopodium. The sieve-tubes have delicate walls and numerous, but poorly developed, sieveplates upon their lateral walls.

While in the main the anatomicai characters are essentially the same in all species examined, there are a number of differences to be noted (Gibson $(I, 2)$ ). Thus the stem may be monostelic (S. Martensii), bistelic (S. Kraussiana), polystelic (S. levigata). In the former species the presence of silica in the inner cortex has been demonstrated by Strasburger, and Gibson has shown the same thing in other species. In this species, too, besides the simple trabeculæ found in $S$. Kraussiana, others occur in which the outer cells undergo divisions in more than one plane, and form a group of cells with which the endodermal cell is articulated. In all species examined these 
cells show more or less marked cutinisation. The number of protoxylems in most species is two, but there may be accessory ones.

The cortex is composed in most species of delicate parenchyma, with few or no intercellular spaces, and most of the cells contain chlorophyll. In species like $S$. lepidophylla, which grow in dry localities, the cortical cells are sclerenchymatous, with deeply-pitted walls and no lacunæ are present in the stem. In the creeping stems, even in polystelic species, there is but a single stele, which gradually passes over into the separate steles of the upright stems.

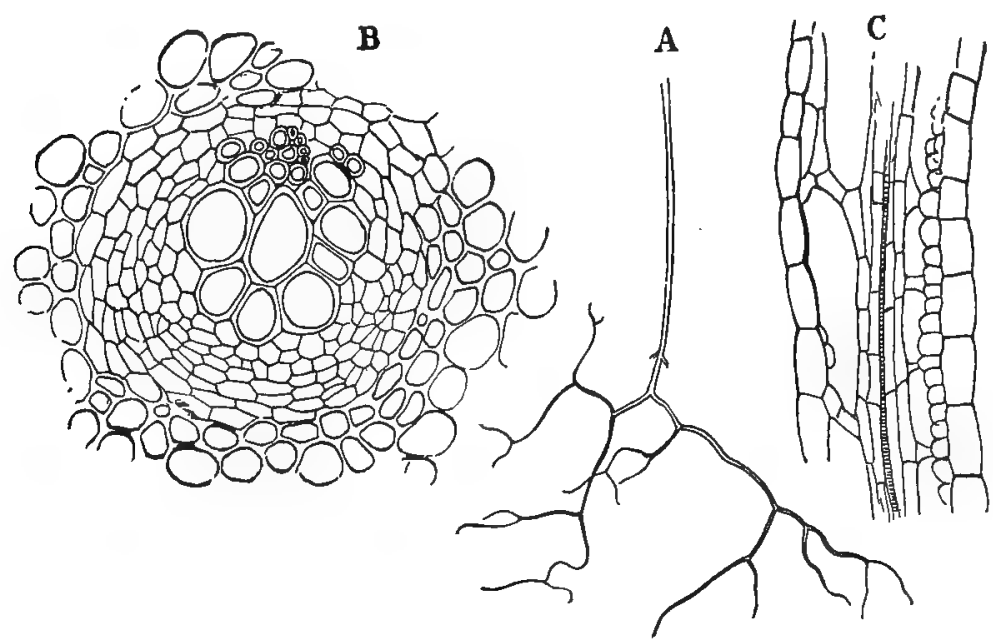

FIG. 305.-A, Rhizophore, with roots of $S$. Kraussiana, $\times I 1 / 2 ; \mathrm{B}$, cross-section of the vascular bundle of a root, $\times 430 ; C$, median longitudinal section of the leaf, $X_{215}$.

\section{The Leaf (Gibson $(4,5)$; Hieronymus $(I)$ )}

The leaves of Selaginella are always of simple structure, much like those of Lycopodium. Gibson $(4,5)$ has made an exhaustive study of their structure, and the following account is based upon his studies.

The leaf may be perfectly symmetrical in outline, or may have one side more developed than the other. In some species there are characteristic basal appendages, or auricles.

A section of the leaf (see also Fig. 303) in most species shows a definite upper and lower epidermis, which may be com- 
posed of similar cells, e. g., S. rupestris, or of cells of somewhat different form on the two surfaces of the leaf, e. g., S. Martensii. Some of the epidermal cells may have the form of sclerenchymatous fibres (S. suberosa). The mesophyll is composed of a loose network of cells, which may be all alike ( $S$. rupestris) or less frequently, there is developed below the upper epidermis, a palisade parenchyma (S. Lyallii). As a rule stomata are formed only upon the lower epidermis, but there are some exceptions.

The single median vascular bundle is concentric in structure, and the leaf-traces join the vascular cylinder of the stem, as they do in Lycopodium. The xylem consists of a single row of annular tracheids, and three or four spiral ones. The phloem is mainly composed of elongated parenchyma cells, but one or two sieve-tubes can usually be demonstrated. Surrounding the bundle is a pericycle consisting of a single layer of cells, or in some cases more, but no definite endodermis is present.

There is always developed at the base of the leaf the characteristic ligula (Fig. 303, l). This develops at an early period, and seems to be an organ for retaining moisture, as its young cells develop abundant mucilage. In its fully developed condition it shows a basal portion (glossopodium) composed of large cells which are surrounded by a sort of sheath which is continuous with the epidermis of the leaf. It varies in form in different species. Thus in S. Vogelii it is tongue-shaped; in S. Martensii, fan-shaped; in S. cuspidata, fringed (for further details of its structure and development see Gibson (4)).

Simple hairs are of frequent occurrence in various parts of the sporophyte.

\section{The Chloroplasts}

The chloroplasts of Selaginella are peculiar, on account of their large size and small numbers. A careful study has been made of these by Haberlandt (9), who found that in each of the meristematic cells of the stem apex a single plastid was present. This in the assimilative cells of the leaves either remains undivided (S. Martensii), or it may become more or less completely divided into two ( $S$. Kraussiana). In $S$. Willdenowii there may be as many as eight. In the cortical paren- 
chyma of the stem the chloroplasts are apparently of the ordinary form, but a careful examination shows that they are all connected, and are directly referable to the divisions of the primary plastid in the young cell. In all cases the nucleus is in contact with the chloroplast or group of chloroplasts (Fig. 306). The character of the chloroplasts here has its nearest analogy in Anthoceros, where occasionally a division of the chloroplasts is met with, especially in the elongated cells of the sporogonium.
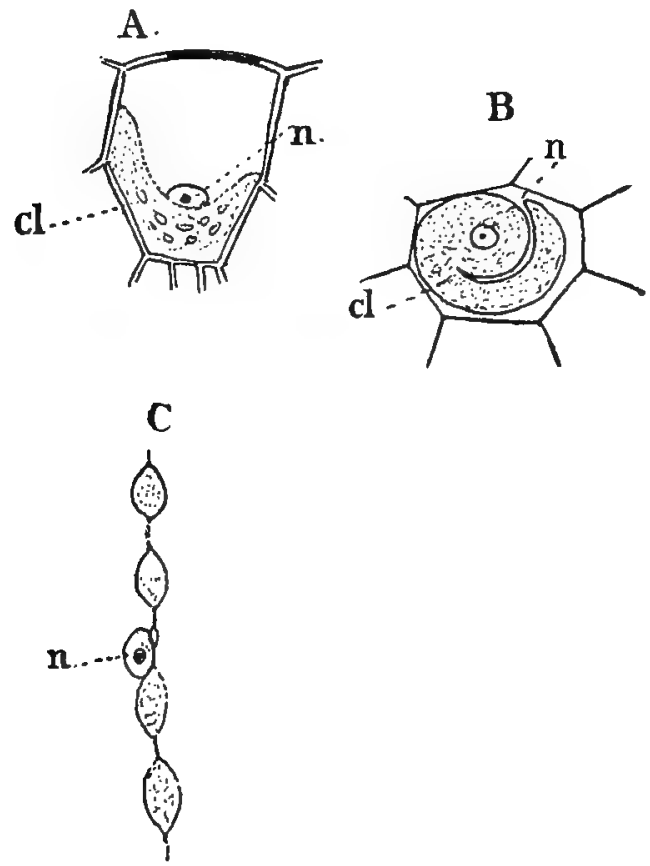

FIG. 306.-A, B, Cells of the mesophyll of Selaginella Martensii showing the single chloroplast $(c l)$ and the nucleus $(n)$; C, chain of connected oval chloroplasts from the inner cortex of the stem of $S$. Kraussiona, $\times 640$ (after Haberlandt).

\section{The Roots}

The roots in S. Kraussiana are borne upon the special leafless branches or rhizophores, which in structure are much like the stem. Previous to the formation of the first roots upon the rhizophore (Sadebeck (6)), the apical cell is obliterated and replaced by a group of initial cells. The apical cells of the (usu- 
ally two) roots formed arise secondarily, and quite independently of each other, from cells lying below the surface, and covered with one or two layers of cells. These cells soon assume a tetrahedral form, and become the apical cells of the primary roots. The branching of the roots, like that of the stem, is really monopodial, although apparently a true dichotomy.

The vascular bundle of the root is monarch (Fig. 305, B), and does not show a distinct endodermis. The phloem surrounds the xylem completely, but apparently sieve-tubes are
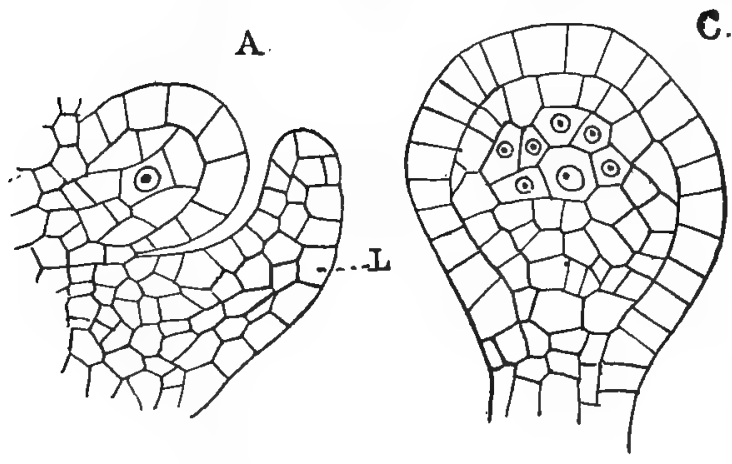

D.
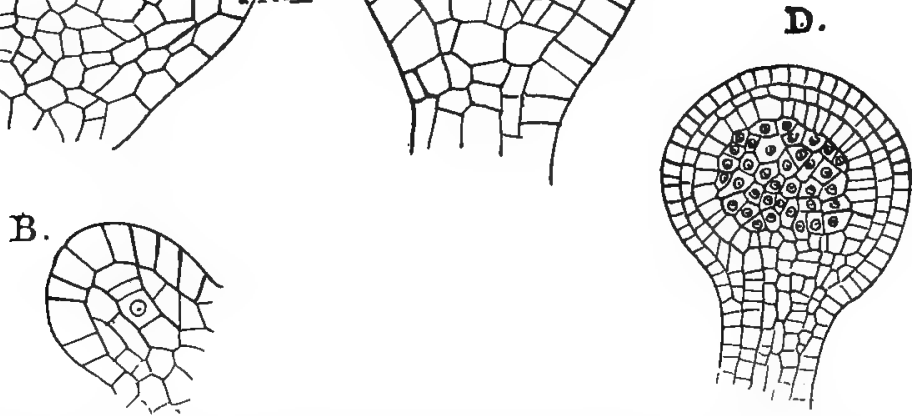

Fxa. 307.-Selaginella Kraussiana. Development of the microsporangium, radial sections. A-C, $\times 500 ; D, \times 235$. The nuclei of the archesporial cells are shown. L, The leaf subtending the sporangium.

not developed opposite the protoxylem. The elements of the bundle are in structure like those of the stem-bundles.

\section{The Sporangium (Goebel (I6); Bower (I5))}

The development of the sporangium is much like that of $L y$ copodium, and has been studied by Goebel and Bower in $S$. spinosa, and by the latter in $S$. Martensii also. In $S$. Kraussiana (Fig. 307, A) a radial section of the young sporangium shows a very regular arrangement of the cells, with a single central archesporial cell (the nucleated cell of the figure). This evidently has arisen from a hypodermal cell of the central row, and from it is already cut off by a periclinal, an outer cell. 
The whole closely resembles Goebel's figures of $S$. spinosa. A comparison with older stages indicates that from this central cell alone the sporogenous cells are produced, as in Lycopodium selago. The outer row of cells does not divide by periclinal walls, and from the first forms an extremely distinct layer. The first cell cut off from the archesporium divides again by a periclinal wall (Fig. $307, \mathrm{~B}$ ), and the inner cell forms probably the first tapetal cell, although in some cases it looks as if this cell took part in the formation of spores. The arche-
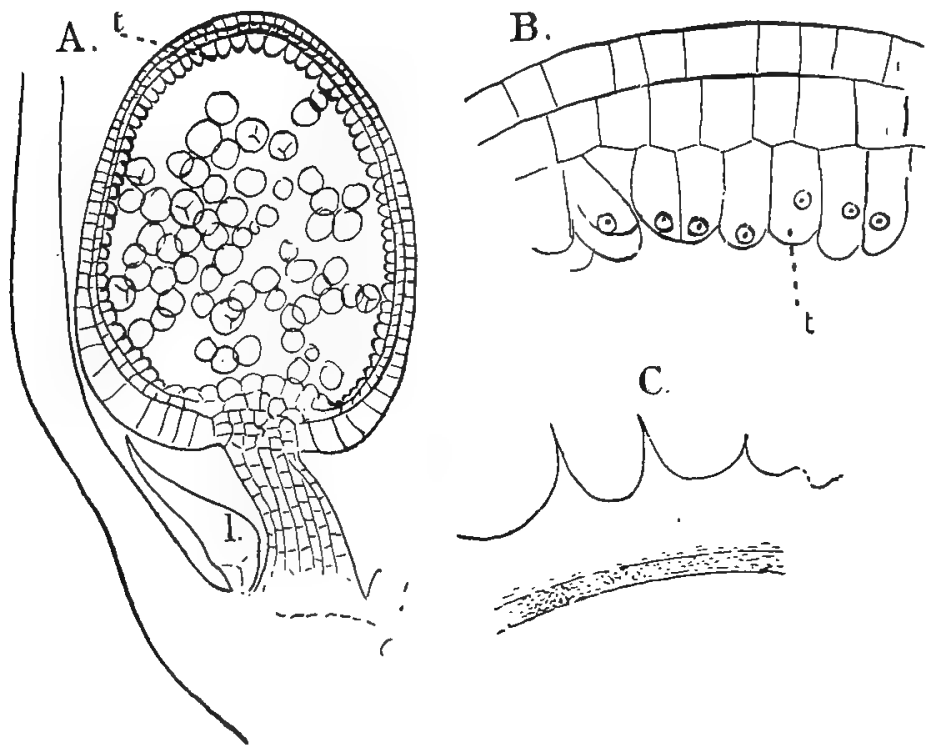

FIG. 308.-Selaginella Kraussiana. A, Radial section of a nearly tipe microsporangium, $\times$ Ioo; $l$, ligula of the subtending leaf; $t$, tapetum; $B$, section of young macrosporangium (about half grown), showing the papillate tapetal cells $(t), \times 600$; , section of the wall of a young macrospore from the same sporangium, $\times 600$.

sporium undergoes repeated divisions to form the sporogenous tissue, and finally the layer of cells between this and the primary wall divides by periclinal walls to form the tapetum, which here remains intact until the spores are nearly or quite mature. The formation of the stalk is the same as in Lycopodium.

It is quite possible that the apparently single archesporial cell of $S$. Kraussiana may be one of a transverse row of archesporial cells, like those of $S$. Martensii. 
Miss Lyon (2) thinks that in both S. apus and S. rupestris the whole sporangium may be traced back to a single superficial cell, which she calls the archesporium.

Bower (I5) considers it probable that in S. spinosa and $S$. Martensii the sporogenous tissue cannot be traced back always to a single cell (in radial section), and has also shown that when tangential sections are examined, as in Lycopodium, the archesporium always is a row of cells.

In all species of Selaginella yet examined, the sporangium is not of foliar origin, but originates from the axis above the insertion of the leaf by which it is subtended.

As in Lycopodium the tapetal cells do not become disorganised, but remain intact as the inner layer of cells of the threelayered sporangium wall. They form an epithelium-like layer of papillate cells, distinguished by their dense granular contents, and it is evident that they are actively concerned in the elaboration of nutriment for the growth of the young spores (Fig. 308).

As in the other heterosporous Pteridophytes, the two sorts of sporangia are alike in their earlier stages, and this in Selaginella continues up to the time of the final division of the spore mother cells. In the microsporangium, all of the sporogenous cells undergo the usual tetrad division; but in the macrosporangium only a single one normally divides. Occasionally one of the divisions is suppressed so that but two macrospores result. In the microsporangium all of the spores mature, and the spores remain small. The single tetrad of macrospores increases enormously in bulk, and finally completely fills the macrosporangium, which is itself much larger than the microsporangia, and by the crowding of the enclosed spore-tetrad, assumes a four-lobed form. The cells of the wall remain green and fresh up to the time that the macrospores are ripe, and sections show that the tapetal cells are in close contact with the wall of the spores. The episporic ridges are very evident before the spore has reached half its final diameter, and sections of the spore wall at this time (Fig. 308, C) show the spine-like section of the surface ridges. The wall rapidly increases in thickness as the spores grow, and this increase is evidently due almost entirely to the activity of the tapetal cells, as the spore at this stage contains very little protoplasm. The first nuclear division in the macrospore takes place when the spore is about 
half-grown, and by the time it has reached its full size the cell divisions in the apical region are complete and the archegonia have begun to form. (For details of the spore-development in Selaginella see Fitting ( $\mathrm{I}$ )).

The ripe sporangium opens by a vertical cleft, as in Lycopodium. Goebel (22) has recently described in detail the mechanism involved in the dehiscence of the sporangium.

\section{The Affinities of the Lycopodinece}

Among the living Lycopodinex there are two well-marked series, one including the Lycopodiaceæ and Selaginellacex, the other the Psilotacex. In the first, beginning with Phylloglossum, the series is continued through the different forms of Lycopodium to the Selaginellacex. The relation of the Psilotacex to this series is doubtful, and must remain so until the sexual generation of the former is known. The probable saprophytic or parasitic life of these plants makes it impossible to determine just how far their simple structure is a primitive character rather than a case of degradation.

Of the first series, it seems probable that of the forms whose life history is known, the type of $L$. cernum represents the most primitive form of the gametophyte. It is reasonable to suppose that in all these forms the prothallium was green, and that the saprophytic prothallia, like those of $L$. phlegmaria and $L$. annotinum, are of secondary origin. The prothallium, of the type of $L$. cernuum, may be directly connected with the Bryophytes and resembles them also in the small biciliate spermatozoids, in which latter respect all the Lycopodinex yet examined agree. This latter point is perhaps the strongest reason for assuming that the Lycopods represent a distinct line of development, derived directly from the Bryophytes, and not immediately related to either of the other series of Pteridophytes. The character of the archegonium, as well as the long dependence of the embryo upon the prothallium and the late appearance of the primary root, point to the genus Lycopodium as a very primitive type, even more closely related to the Bryophytes than are the eusporangiate Ferns. Phylloglossum, at least so far as the sporophyte is concerned, is the simplest living Pteridophyte.

The close relation of Selaginella to Lycopodium is suf- 
ficiently obvious. It is, however, interesting to note that Selaginella seems to have retained certain characters that are apparently primitive. These are the presence of a definite apical cell in the stem and root of most species, and the peculiar chloroplasts, which are especially interesting as a possible survival of the type found in so many Confervacex, e. g., Coleochate, from which it is quite likely that the whole archegoniate series has descended. This form of chloroplast occurs elsewhere among the Archegoniatæ only in the Anthocerotes.

In the characters of the sporangium and the early development of the prothallium, Selaginella undoubtedly shows the closest affinity to the Spermatophytes, especially the Gymnosperms, of any Pteridophyte. The strobiloid arrangement of the sporophylls and the position of the sporangia are directly comparable to the strobilus of the Coniferæ. The wall of the sporangium is here not only morphologically, but physiologically comparable to the nucellus of the ovule, and the macrospore grows, not at the expense of the disorganised sporogenous cells and tapetum alone, but is nourished directly from the sporophyte through the agency of the cells of the sporangium stalk and wall, until the development of the enclosed prothallium is far advanced. The latter, both in its development while still within the sporangium, as well as in all the details of its formation, shows a close resemblance to the corresponding stages in certain Conifers. The formation of a "primary" and "secondary" prothallium is, as we have seen, only apparent, and the diaphragm in the prothallium of Selaginella is not a true cell wall, marking a primary division of the spore contents, but only a secondary thickening of the lower walls of certain cells, indicating a temporary cessation in the process of cell-formation. It is by no means improbable that this cell-formation may sometimes go on uninterruptedly, in which case no diaphragm would be formed, and, as in Isoetes, there would be no distinct line of demarcation between the archegonial tissue at the apex and the large-celled nutritive tissue below.

The presence of a suspensor in all investigated Lycopodinea is a character which distinguishes them at once from the other Pteridophytes, and has its closest analogy again among the Conifers.

The possibility that the Psilotaceæ may not be directly re-

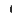


lated to the other Lycopodinex has been referred to. As nothing is known at present of the gametophyte and embryo, this point must, for the present, remain open.

\section{Fossil Lycopodinece}

Many fossil remains of plants undoubtedly belonging to the Lycopodineæ are met with, especially in the Coal-measures, where the Lepidodendrea were especially well developed. Of homosporous forms, it seems pretty certain that the fossils described under the name Lycopodites are related to the living genus Lycopodium, and certain fossils from the Coal-measures have even been referred to the latter genus, some of these being homophyllous, others heterophyllous. Solms-Laubach thinks it somewhat doubtful whether the plants described by various writers, and belonging to older formations, really are Lycopodineæ.

In regard to the Psilotacea he says: "The statements respecting fossil remains of the family Psilotace are few and uncertain, nor is this surprising in such simple and slightly differentiated forms. If Psilotites . . . does really belong to this group, a point which I am unable to determine from the figures, we should be able to follow the type as far down as the period of the Coal-measures."

A discussion of some of the numerous characteristic fossil Lycopods will be left for a special chapter. 


\section{CHAPTER XIV}

\section{ISOETACE $\mathbb{E}$}

THE genus Isoetes, the sole representative of the family Isoetaceæ, differs so much from the other Pteridophytes that there has been a good deal of difference of opinion as to where it should be placed. Isoetes is most commonly associated with Selaginella, and there are undoubtedly marked resemblances between the two genera in certain anatomical details, and in the development of the spores and gametophyte. On the other hand, the embryo and the spermatozoids are much more like those of the lower Ferns, with which they have sometimes been associated. Whether the Isoetacea are assigned to the Filicineæ or Lycopodineæ, they are sufficiently distinct to warrant the establishment of a separate order, Isoetales.

According to Sadebeck (8), there are 62 species of Isoetes. Of these sixteen are found in the United States.

Isoetes has been the subject of repeated investigation, Hofmeister ( $\mathrm{I}$ ) being the first to study its development in detail. The sporophyte is in most species either aquatic or amphibious, but a few species are terrestrial. They are very much alike in appearance, having a very short stem whose upper part is completely covered with the overlapping broad bases of the leaves, which themselves are long and rush-like, so that the plant in general appearance might be readily taken for an aquatic Monocotyledon. The roots are numerous and dichotomously branched. The stem grows slowly in diameter, and the older ones show two or three vertical furrows that unite below, and as the stem continues to grow these furrows deepen, so that the old stem is strongly two or three lobed. In the furrows the roots are formed in acropetal succession. The leaves are closely set and expanded at the base (Fig. 309) into a broad sheath, 
with membranaceous edges. Just above the base of each perfectly-developed leaf is a single very large sporangium, sunk more or less completely in a cavity (fovea), which in most



Fig. 3og.-A, Plant of Isoetes Bolanderi, $\times 1 ; B$, base of a leaf with macrosporangium, $X_{4} ; l$, ligula; $v$, velum.

species is covered wholly or in part by a membranaceous indusium (velum), and above the fovea is a scale-like outgrowth of 
the leaf, the ligula. The spores are of two kinds, borne in separate sporangia. The outer leaves of each cycle produce microspores, the inner ones macrospores, many times larger than the former. The innermost leaves, which are not usually perfectly developed, are sterile, and separate one year's growth from the next. In some of the land forms, e. g., I. hystrix, these sterile leaves are very much reduced, and form spine-like structures.

\section{The Gametophyte}

The germination of the microspores was studied by Hofmeister (I), and later by Millardet (I) and Belajeff (I), the

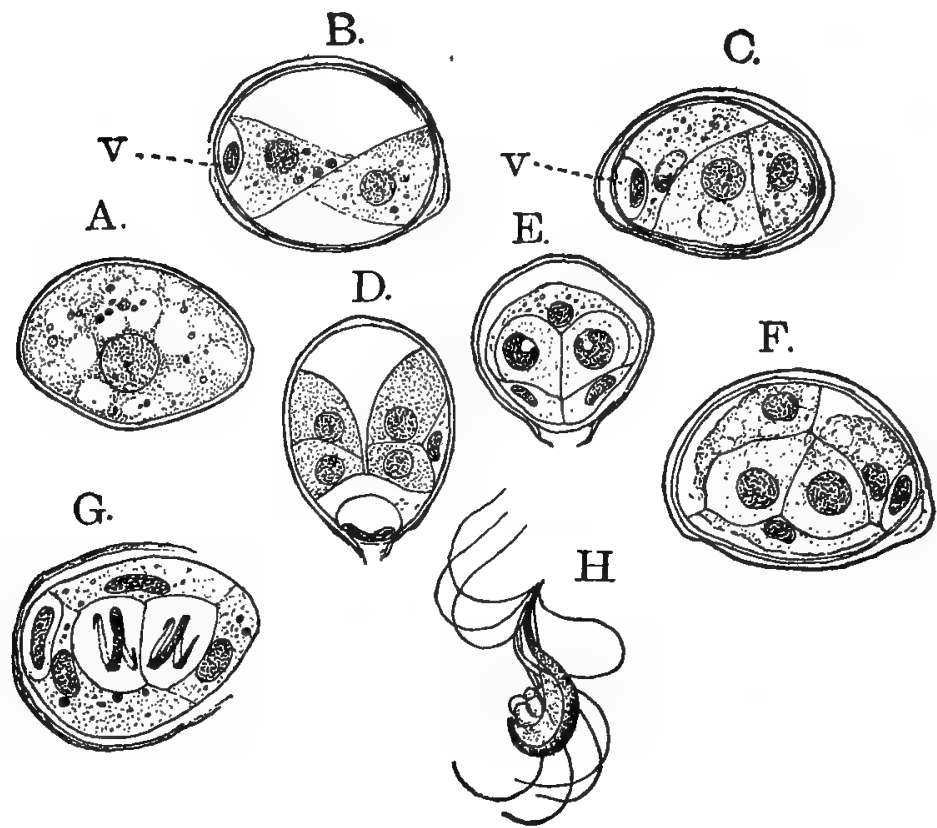

FIG. 3ro.-A-G, Isoetes echinospora, var. Braunii. Development of the antheridium, $X$ about rooo. $H$, Spermatozoid of $I$. Malinverniana ( $H$, after Belajeff).

later writer differing in some essential particulars from the earlier observers. The two former studied I. lacustris, the latter, I. setacea and I. Malinverniana, which do not seem to differ, however, from I. echinospora, which was investigated by the writer. The microspores of all the species are bilateral, and are small bean-shaped cells with thick but in most species nearly colourless walls. The epispore sometimes has spines upon it, 
but in $I$. echinospora var. Braunii the surface of the spore is nearly smooth. In this species the spores begin to ripen in the early autumn, and continue to do so as long as the conditions permit of growth. The spores are set free by the decay of the sporangium wall, which probably in nature is not completely the case until winter or early spring, which seems to be the natural time for germination. If they are set free artificially, however, they will germinate promptly, especially if this is done late in the autumn or during the winter. Thus spores sown in December produced free spermatozoids in two weeks. The spores do not all germinate with equal promptness, and all stages of development may be met with in the same lot. The ripe spore has no chlorophyll, but contains besides the nucleus, albuminous granules, small starch grains, and oil.

The first division wall cuts off a small cell from one end, which undergoes no further development, and represents the vegetative part of the prothallium, which is here absolutely rudimentary. The rest of the spore forms at once the single antheridium. In the latter two, walls are formed so inclined to each other as to include two upper cells and one lower one (Fig. $3^{\text {IO }}, \mathrm{C}$ ). This latter next divides into two by a vertical longitudinal wall, and each of the resulting cells is further divided by a periclinal wall, so that the antheridium consists of four peripheral cells and two central ones. The latter finally divide again, by vertical walls, making four central cells, which become at once the sperm cells. According to Belajeff the walls of the peripheral cells become dissolved finally, so that the sperm cells float free within the spore cavity. Each sperm cell forms a single coiled spermatozoid, which is more slender than that of Marattia, but like it is multiciliate.

In microtome sections of the germinating spores of $I$. echinospora, the walls of the peripheral cells were evident after the spermatozoids were completely formed, and there seems some doubt whether they are absorbed at all. Occasionally (Fig. 3 IO, D) the sperm-cells were divided into two separate groups as in Marsilia.

The macrospores are very many times larger than the microspores, and are of the tetrahedral type instead of bilateral. They are nearly globular in form and show plainly the three converging ridges on the ventral surface. If the fresh spore is crushed in water, its contents appear milky, and microscopic 
examination reveals numerous oil-drops and some starchgranules, mingled with roundish bodies of albuminous nature. The latter absorb water and swell up so that they look like free cells.

The wall of the spore is very thick. The perinium is thick

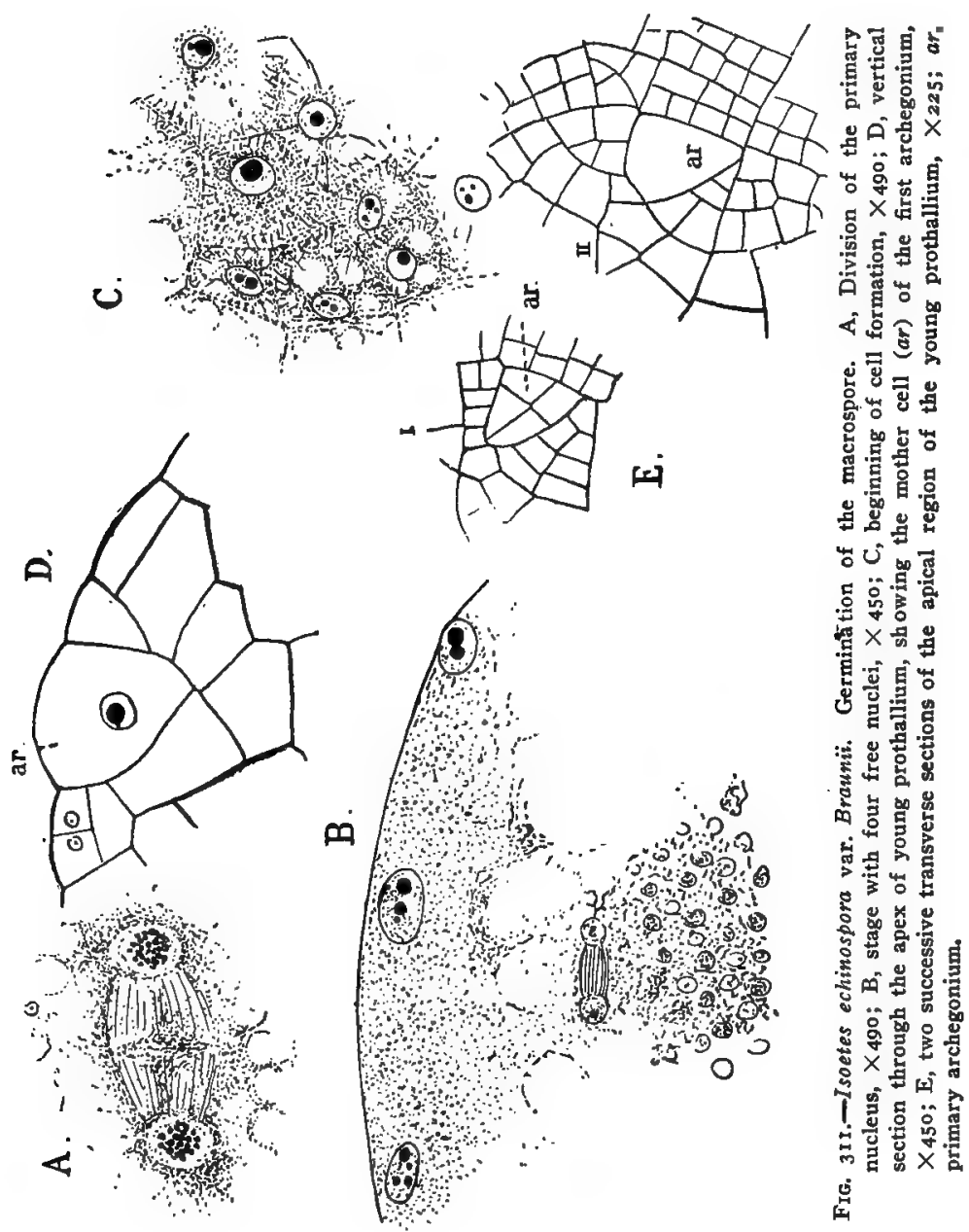

and transparent in appearance, and in the species under consideration provided with short recurved spinules. The interior, in microtome sections, is filled with coarsely granular cytoplasm, which often appears spongy, owing no doubt to the dissolving 
out of the oil. Scattered through the cytoplasm are round starch granules with a central hilum. The large nucleus lies in the basal part of the spore. It is broadly oval in outline, and the cytoplasm immediately about it is nearly free from large granules. Before germination begins there are few chromosomes, and the nucleolus does not stain readily.

In I. lacustris (Farmer (2)) the primary nucleus is at the apex of the spore, and this is also the case in I. Malinverniana (Arnoldi ( I ) ).

After the spores have lain a few days in water, the nucleus increases in size, and then the nucleolus stains very intensely and the chromosomes become more conspictuous. The nucleus divides while still in its original position, and undergoes division in the usual way. A very evident cell plate is formed in the equator of the nuclear figure (Fig. 3 I I, A), but no cell wall is found, and the result of the division is two large free nuclei. The next youngest stage observed (Fig. 3 I I, B) had four free nuclei, which now had moved to the ventral side of the spore. These are very much smaller than the primary one, but are relatively richer in chromatin. They continue to divide until there are from about thirty to fifty free nuclei, but as yet no trace of cell division can be seen. Most of the nuclei lie in the ventral part of the spore, close to the outer wall; but an occasional one may be detected elsewhere.

Cell division begins at the apex (ventral part) of the spore. At this time the cytoplasm stains more deeply than before, and sometimes extremely delicate threads may be detected, radiating from the nuclei and connecting adjacent ones (Fig. 3I I, C). The first traces of the division walls appear simultaneously between the nuclei in the form of cell plates composed of minute granules, probably of cellulose, which quickly coalesce and form a continuous membrane. In this way the upper part of the spore becomes transformed into a solid tissue (Fig. 3I2).

The formation of the cell walls closely resembles that in Selaginella. The primary cells, or areoles, are open in their inner faces, and it is not until the second nuclear division takes place that the inner cell wall is developed. (Arnoldi (I), Figs. $5,6)$.

The cell formation proceeds quickly toward the base of the spore, following the spore wall, so that for a time the central space remains undivided. The whole process recalls most 
vividly the endosperm formation of most Angiosperms. On account of the extremely thin walls and dense contents of the

A.

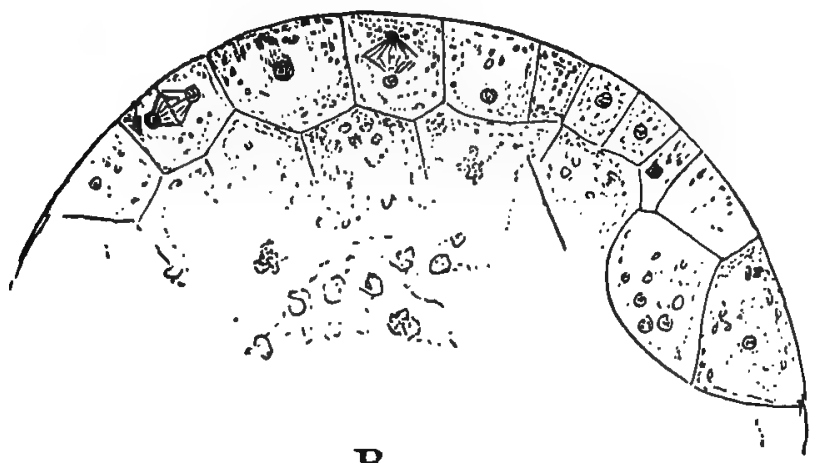

B.

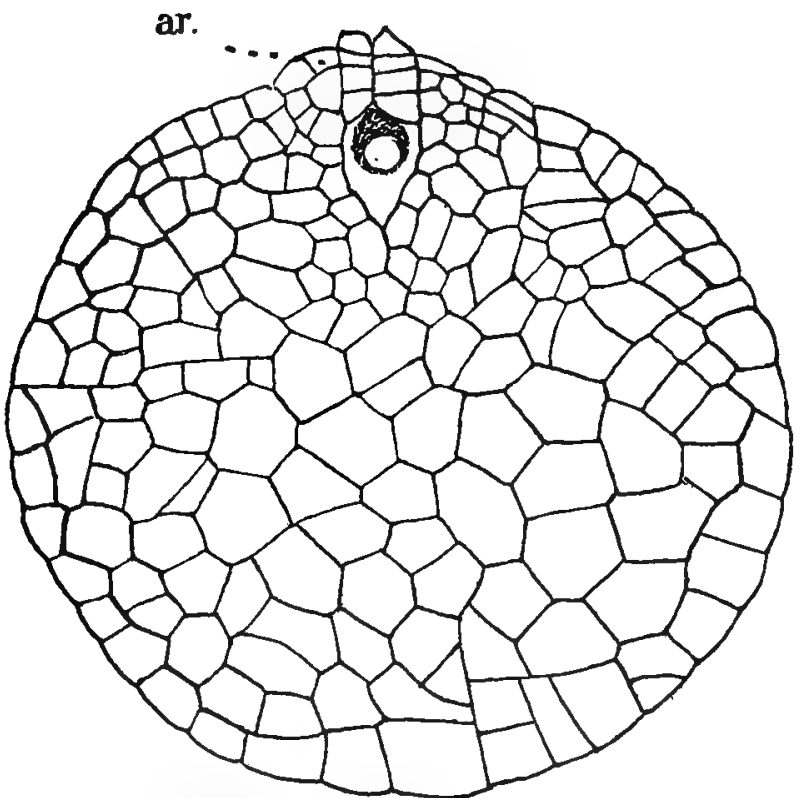

FrG. 312.-Isoetes echinospora var. Braunii. A, Longitudinal section through the apex of the female prothallium, showing the first cell formation, $X_{300} ; \mathrm{B}$, similar section of a prothallium with the divisions completed and the first archegonium (ar) already opened.

young prothallial cells it is not easy to determine exactly when the whole spore cavity becomes filled up with cellular tissue. 
Because of the greater number of free nuclei in the upper part of the spore, and their consequent close proximity, the cells are smaller than those in the central and basal parts of the prothallium. Sometimes the transition from this small-celled tissue to the large-celled tissue of the basal part is quite abrupt and the more noticeable as the upper cells are more transparent; but there was nothing to indicate that this was in any way connected with the early divisions of the primary nucleus, and more often no such sudden transition was seen.

Hofmeister's account of the coalescence of previously separate cells to form the prothallium was obviously based upon incorrect observation, and is not borne out by a study of sections of the germinating spore.

The first archegonium is very early evident, generally before the cell division is complete in the lower part of the spore. It occupies the apex of the prothallium, and the mother cell is distinguished by its large size and dense granular contents. It is simply one of the first-formed cells that soon ceases to divide, and as its neighbours divide rapidly the contrast between them becomes very marked. Whether seen from above or in longitudinal section, it generally is triangular, or nearly so. In the structure of the mature archegonium, Ophioglossum shows strong points of resemblance, as do the Marattiaceæ, but the egg cell is much larger in Isoetes.

The development of the archegonium corresponds almost exactly with that of Marattia, but the basal cell is always wanting, and the first transverse wall separates the central cell from the cover cell. The first division in the inner cell is parallel with the base of the cover cell, and divides it into the primary canal cell and central cell. The contents of the three cells of which the archegonium is now composed are similar, and the nuclei large and distinct. The cover cell next divides into four by transverse walls (Fig. 3 I I, E), and from these, as in Marattia, the four rows of cells of the neck are formed. The number in each row is usually four in the mature archegonium. The ventral canal cell, which like that of Marattia extends the whole breadth of the central cell, is separated almost simultaneously with the appearance of the first transverse divisions in the neck cells. The neck canal cell has at first a single nucleus, which later divides, but there is no division wall formed. Although the number of cells in each row of the neck is usually greater 
than in Marattia, the neck canal cell is shorter and extends but little between the neck cells (Fig. $3{ }^{\mathrm{I}} 3, \mathrm{~B}$ ).

The egg is very large, round or oval in form, and the nucleus contains a large nucleolus that stains very intensely, but otherwise shows little chromatin. The receptive spot is of unusual size, and occupies about one-third of the egg. It is
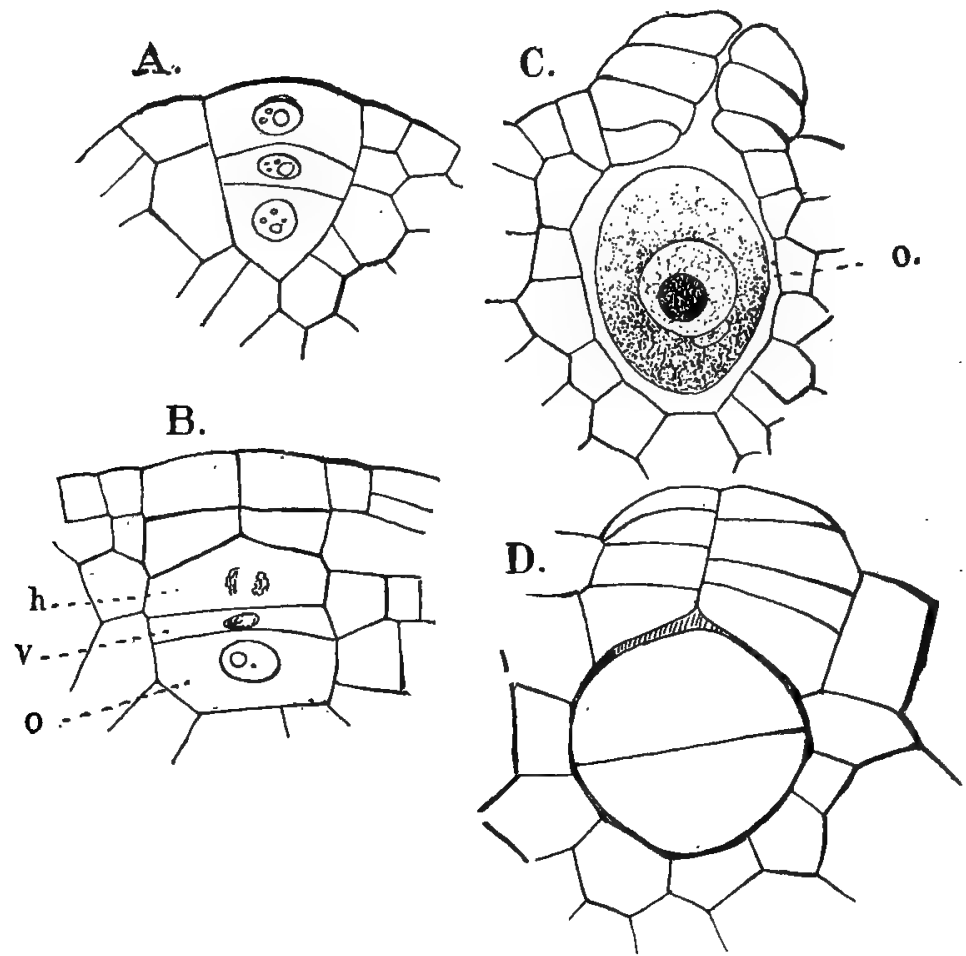

FIG. 313.-Isoetes echinospora var. Braunii. Development of the archegonium, $\times 500$; 0 , the egg; $v$, ventral canal cell; $h$, neck canal cell; $\mathrm{D}$, shows a two-celled embryo within the archegonium.

almost hyaline, showing, however, a faint reticulate arrangement of fine granules; the lower portion of the egg is filled with granules that stain strongly.

In $I$. lacustris, according to Hofmeister, only one archegonium is formed at first, and if this is fertilised, no others are produced; but in $I$. echinospora, even before the first archegonium is complete, two others begin to develop and reach maturity shortly after the first, whether the latter is fertilised or 
not. In case all of these primary archegonia prove abortive, a small number, apparently not more than five or six, may be formed subsequently; but so far as my observations go, the production of archegonia is limited, as is the growth of the prothallium itself. ${ }^{1}$

The development of the prothallium goes on without any increase in size, until the first archegonium is nearly complete, about which time the spore opens along the line of the three ventral ridges, and the upper part of the enclosed prothallium is exposed, but projects but little beyond the opening. In case all the archegonia prove abortive, the prothallium continues to grow until the reserve food material is used up, but then dies, as no chlorophyll is developed in its cells, and only in very rare instances are rhizoids formed.

Miss Lyon (3) figures a longitudinal division of the neck canal cell in $I$. lacustris, and Arnoldi ( I) states that a similar division may occur in I. Malinverniana.

\section{The Embryo}

Besides the earlier account of Hofmeister, Kienitz-Gerloff (6) and Farmer (2) have made some investigations upon the embryogeny of $I$. lacustris, which correspond closely, so far as they go, with my own on $I$. echinospora.

The youngest embryos seen by me had the first division wall complete (Fig. 3 $3, \mathrm{D}$ ). This is transverse, but more or less inclined to the axis of the archegonium. The nuclei of the two cells are large and contain several chromatin masses. The second division in the epibasal and hypobasal cells does not always occur simultaneously, the lower half sometimes dividing before the upper one, and at times the second walls are at right angles instead of in the same plane. Of the quadrants thus formed, the two lower form the foot, and the two upper ones the cotyledon and primary root. The stem apex arises secondarily at a later period, and probably belongs to the same quadrant as the root; but as it does not project at all, and is not certainly recognisable until after the boundaries between the quadrants are no longer evident, this cannot be positively asserted.

Sometimes the quadrants divide into nearly equal octants,

'In old prothallia of $I$. lacustris according to Kienitz-Gerloff (6), there may be 20 to 30 archegonia. 
but in several young embryos examined, no definite octant walls were present, at least in the upper octants, but whether this is a common occurrence would be difficult to say. The next divisions in the embryo resemble those in Marattia, and as in the latter it may be said that the young members of the embryo grow for a short time from an apical cell, inasmuch as the tetrahedral octants at first have segments cut off parallel with the basal, quadrant, and octant walls, leaving an outer cell (Fig. 3 I 4 , A) that still retains its original form; but very soon peri-



Frg. 314-A, An embryo of I. echinospora var. Braunii, with unusually regular divisions, $X_{450} ; B$, a much older one, still enclosed within the prothallium, $X_{150}$; ar, archegonia.

clinal walls arise in this cell in each quadrant, and it is no longer recognisable as an apical cell, and from this time the apex of the young member grows from a group of initial cells.

Up to this time the embryo has increased but little in size, and retains the globular or oval form of the egg. It now elongates in the direction of the basal wall, and soon after, the cotyledon and primary root become differentiated. The axis of the former coincides with the plane of the basal wall, and it 
approaches more or less the vertical as the latter is more or less inclined. Occasionally the basal wall is so nearly vertical that the cotyledon grows upright and penetrates the neck of the archegonium at right angles to its ordinary position. At the base of the leaf at this stage a single cell, larger than its neighbours, may often be seen (Fig. 3I5, A, l). This is the mother cell of the ligule, found in all the leaves. This cell projects,





1.


D.

B.
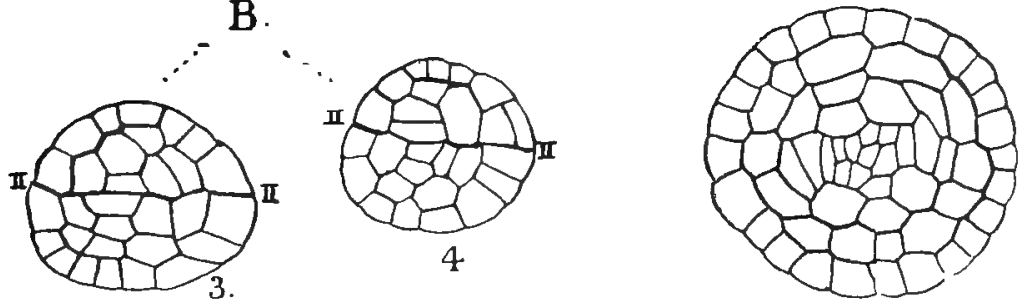

FIG. 315.-Development of the embryo in I. echinospora var. Braunii. A, Median longitudinal section of a young embryo; B, four horizontal sections of a younger one; $C$, two vertical transverse sections of an older embryo; $l$, the ligula, $\times_{300}$.

and as the leaf grows divides regularly by walls in a manner compared by Hofmeister to the divisions in the gemmæ of Marchantia. It finally forms a scale-like appendage about twelve cells in length by as many in breadth.

Almost coincident with the first appearance of the ligule a depression is evident, which separates the bases of the cotyledon and root. The base of the latter, which now begins also to 
grow in length, projects in the form of a semi-circular ridge that grows rapidly and forms a sheath about the ligule and the base of the cotyledon (Fig. 3I,$v$ ). The growth of this sheath is marginal, and continues until a deep cleft is formed. A number of cells at the bottom of the latter between the sheath and the leaf base constitute the stem apex. As they differ in appearance in no wise from the neighbouring cells, it is quite impossible
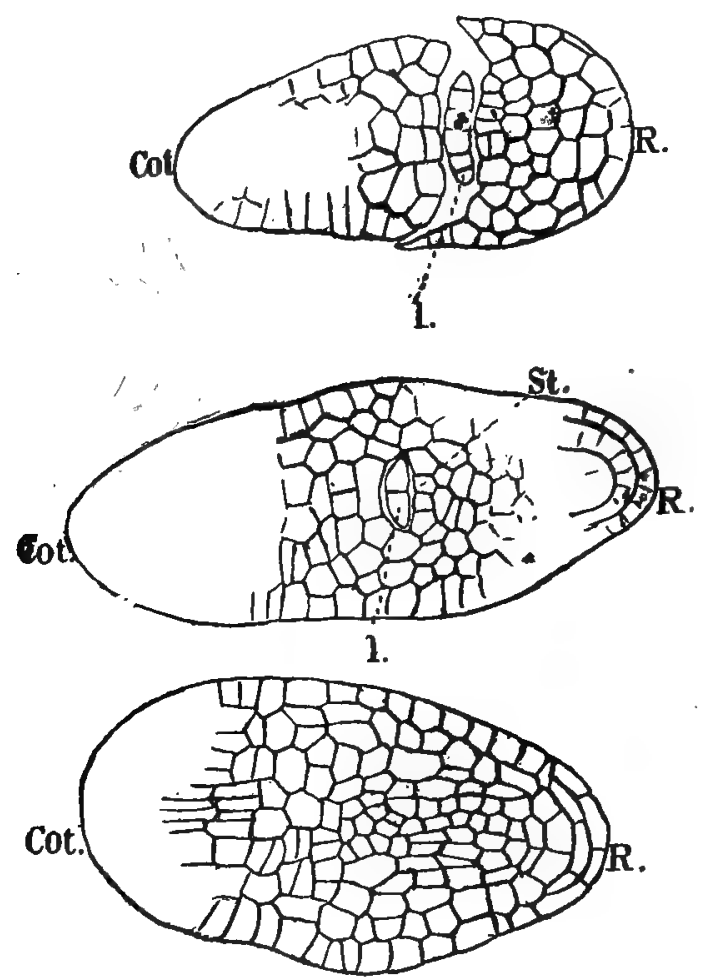

Fic. 316.-Three successive horizontal sections of a somewhat advanced embryo of $I$, echinospora var. Braunii, $\times 260 ; \mathrm{R}$, root; cot, cotyledon; st, stem; $l$, ligula.

to say just how many of them properly belong to the stem. So far as can be judged, the origin of the growing point of the stem is strictly secondary, and almost exactly like that of many Monocotyledons. ${ }^{1}$

Longitudinal sections of the embryo, when root and leaf are

${ }^{3}$ See Hanstein's figures of Alisma, for example, in Goebel's Outlines, Fig. 332 . 
first clearly recognisable, show that the foot is not clearly defined, as the basal wall early becomes indistinguishable from the displacement due to rapid cell division in the axis of the embryo. It projects but little, and the cells are not noticeably larger than those of the cotyledon and root.

As the cotyledon lengthens it becomes somewhat flattened, and in the later stages its increase in length is due entirely to basal growth. Even in very young embryos a distinct epidermis is evident in the leaf, and about the time that the ligule is formed the first trace of the vascular tissue appears. This consists of a bundle of narrow procambium cells, which lie so near the centre of the embryo that it is impossible to assign it

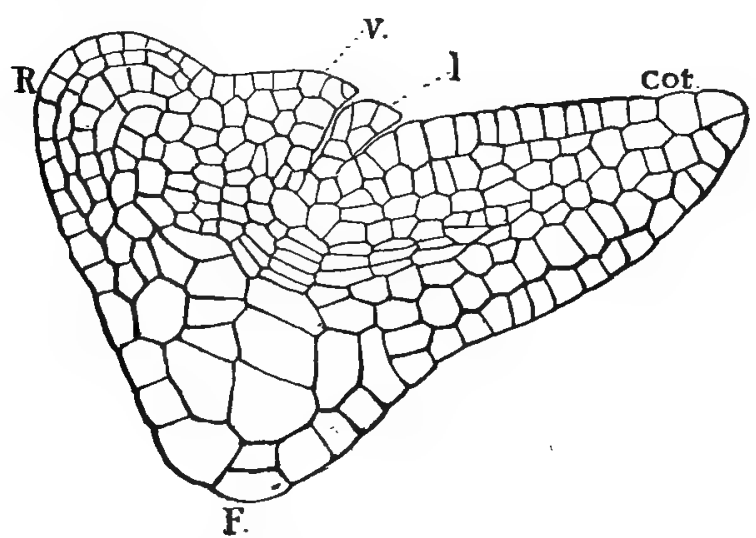

Frc. 317.-Median longitudinal section of an embryo" of the same species shortly before the cotyledon breaks through the prothallium; lettering as in the preceding, $\times{ }_{3} 00$.

certainly to either root or leaf; indeed it sometimes seems to belong to one quadrant, sometimes to the other. From it the development of the axial bundles of cotyledon and root proceeds, and by it they are directly united. The section of the central cylinder of the leaf is somewhat elliptical, and it does not extend entirely to the end. Its limits are clearly defined from the periblem, in which the divisions are mainly transverse and the cells arranged in regular rows.

The primary xylem consists of small spiral and annular tracheids at the base of the leaf, and from these the formation of similar ones proceeds towards the tip. Their number is small, even in the full-grown leaf, and they are the only differ- 
entiated elements, the rest of the bundle showing only elongated parenchyma, much like the original procambium cells.

The axis of growth of the primary root usually coincides with that of the cotyledon, but this is not always the case. In
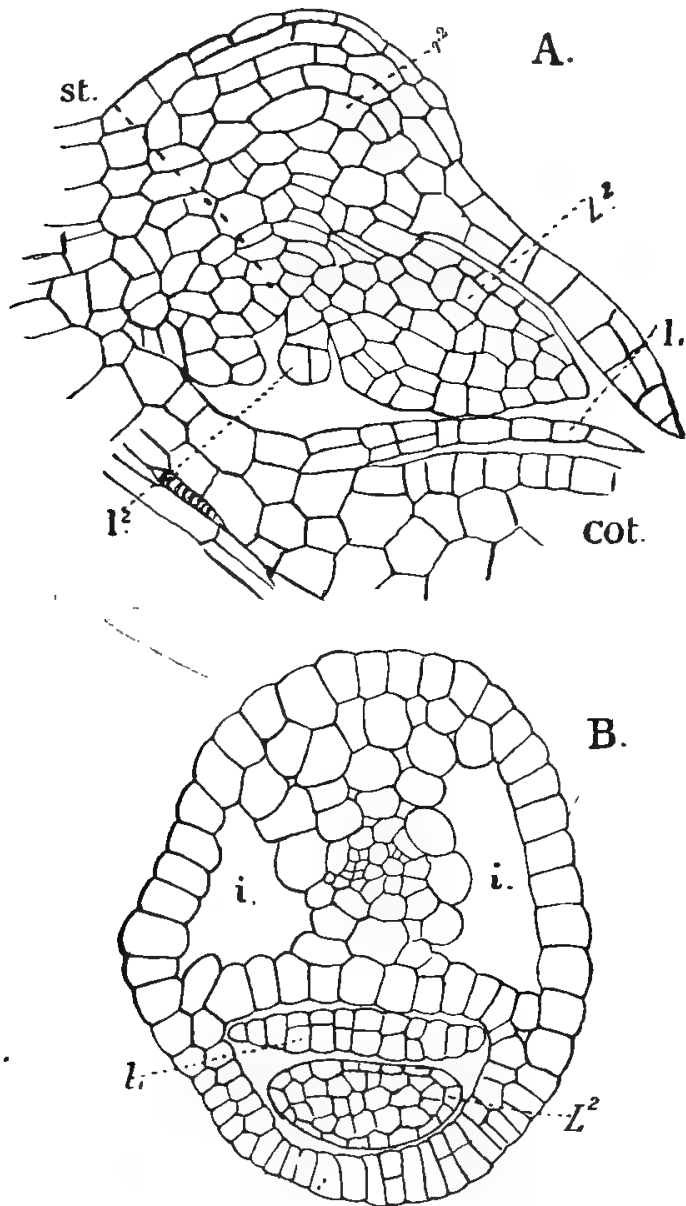

FrG. 318.-A, Median section of a young sporophyte with the second leaf $L^{2}$ already formed; $r^{2}$, second root; st, stem-apex, $X_{150} ; \mathrm{B}$, cross-section near the base of the cotyledon, showing the intercellular spaces $i$ and the second leaf $\mathrm{L}^{2}$ surrounded by the sheath $v$ at the base of the cotyledon; $l$, the ligule of the cotyledon, $\times 300$.

the very young root (Fig. $3 r 7, R$ ) the end is covered with a layer of cells continuous with the epidermis of the rest of the embryo. Beneath are two layers of cells concentric with the 
epidermis. From the inner one arises the initial cell (or cells?) of the plerome, which soon becomes well defined and connected with the primary strand of procambium in the axis of the embryo. It is quite possible that here, as in the older roots, a single initial cell is present in the plerome, but this is not certain. The layer of cells immediately below the primary epidermis is the initial meristem for all the tissues of the root except the plerome. The primary epidermis later divides into two concentric layers which take no further part in the growth of the root except as they join the outer layers of the root-cap.

From the layer above the plerome initial, additions are made at regular intervals to the root-cap, and these layers remain one cell thick, so that the stratification is very marked. At the apex of the root there is no separation of dermatogen and periblem, which are first differentiated back of the apex. The primary xylem consists of very delicate spiral tracheids formed at the base of the root at the same time that the first ones appear in the leaf.

The foot increases much in size as the leaf and root develop, and its superficial cells become much enlarged and encroach upon the large cells of the prothallium, whose contents are gradually absorbed by it.

The cotyledon is at first composed of compact tissue, which during its rapid elongation separates in places, and forms a system of large intercellular spaces. There are two rows of very large ones, forming two broad air-chambers extending the whole length of the leaf, but these are interrupted at intervals by imperfect partitions composed of single layers of cells. In the root there are similar lacunæ, but they are smaller and less regularly arranged.

The growing embryo is for a long time covered by the prothallial tissue, which in the upper part continues to grow with it; but finally cotyledon and root break through, the former growing upward, the root bending down and anchoring the young sporophyte in the mud. Owing to the large air-spaces the cotyledon is lighter than the water, and always stands vertically, whether the original position was vertical or horizontal. In the latter case the plant appears to be attached laterally to the prothallium, and the stem apex, which when first formed stands almost vertically, now assumes the horizontal position which it has in the older sporophyte. 
About the time that the young sporophyte breaks through the prothallium, the second leaf begins to develop. The growing point (Fig. 3I8, st) now lies in the groove between the base of the root and the cotyledon, and its nearly flat surface is at right angles to the axis of the latter. The second leaf $\left(\mathrm{L}^{2}\right)$ arises as a slight elevation on the side of the stem directly opposite the cotyledon. From the first it is multicellular, and its growth is entirely like that of the cotyledon, which it otherwise resembles in all respects. Almost as soon as the leaf is evident at all, a strand of procambium cells is formed running from the junction of the cotyledon and first root, and is continued into the second leaf as its plerome.

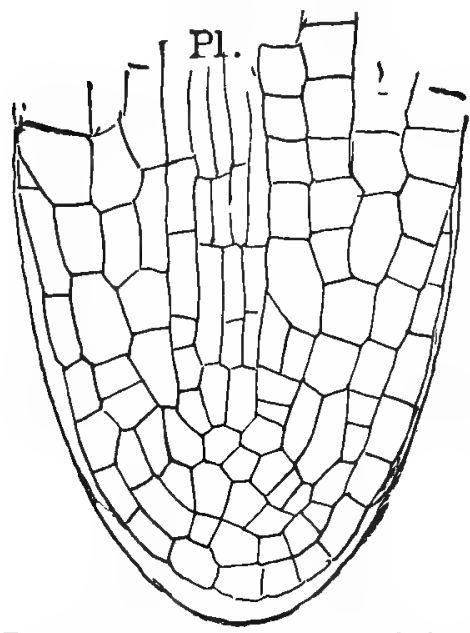

FIG. 319.-Longitudinal section of the second root, $\times 525 ; \mathrm{Pl}$, plerome.

The second root develops from the base of the second leaf in the immediate vicinity of the common fibrovascular bundle, and is formed about the time that the leaf begins to elongate. A group of cells here begins to multiply actively, and very soon shows a division into the initials of the tissue systems of the young root. From this time the growth proceeds as in the primary root, and it finally breaks through the overlying tissues.

The stem has no vascular bundle apart from the common bundle formed from the coalescence of the bases of the bundles from the leaves and roots. In all the later-formed leaves and roots there is but a single axial bundle. In the leaves this is decidedly collateral in form with the poorly-developed xylem upon the inner (upper) side. Except for their larger size, and their having usually four instead of two air-channels, the later leaves resemble in all respects those first formed.

The development of the young plant was not followed beyond the appearance of the third leaf, but it probably in its later history corresponds to $I$. lacustris. In the latter, according to Hofmeister (( I), p. 354), the opposite arrangement of the 
leaves continues up to about the eighth, when the $\frac{1}{2}$ divergence is replaced successively by $\frac{1}{3}, \frac{2}{5}, \frac{3}{8}, \frac{5}{13}$, and $\frac{8}{21}$, which is the condition in the fully-developed sporophyte.

\section{The Adult Sporophyte (Sadebeck (9))}

The structure of the mature sporophyte has been the subject of repeated investigations, among the most recent being

B.
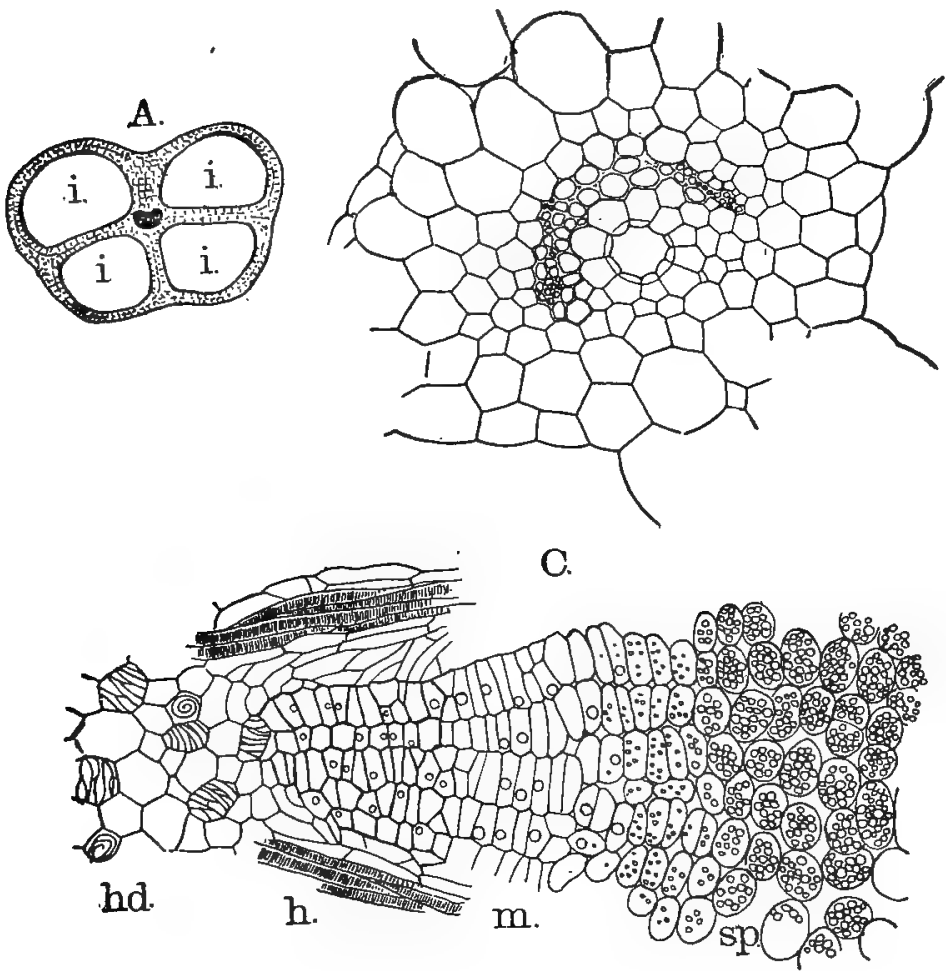

FIG. 320.-A, B, Isoetes echinospora. A, Section of fully developed leaf, XI5; B, vascular bundle of the leaf, $X$ about 200 ; $C$, part of a transverse section of the stem of $I$, lacustris; $s p$, starch-bearing cortical cells; $m$, meristematic zone; $h$, tracheids; $h d$, tissue of the central region ( $\mathrm{C}$ after Potonié).

those of Farmer (2) and Scott (2), who made a most careful examination of the vegetative organs in I. lacustris and I. hystrix. The thick, very short stem has a central vascular bundle, which as in the young plant is made up of the united leaf-traces, and there is no strictly cauline portion, as Hegelmaier ( I) and 
Bruchmann (I) assert. Scott (2), however, states that in $I$. hystrix, there is a short, cauline stele distinct from the leaf traces.

This central cylinder is composed of very short tracheids, with spiral and reticulate markings, mixed with similarlyshaped cells with thin walls. Surrounding this xylem cylinder is a layer of cells, which Farmer calls the "prismatic layer." This, according to Russow ((I), p. I39), is continuous with the phloem of the leaf-traces, and he regards it as the phloem of the stem bundle. Outside of this prismatic layer is a zone of meristematic cells, which form the "cambium." The cells of this zone are like those of the cambium of Boytrychium or of the Spermatophytes, and like these new cells are formed on both sides; but those formed upon the outside remain parenchymatous and are gradually thrown off with the dead outer cortex. Those upon the inner side develop into the prismatic cells, mingled with which are cells very like the tracheids, except that they retain to some extent their protoplasmic contents. These cells are arranged in more or less well-marked zones, and possibly mark the limits of each year's growth. It will be seen from what has been stated that while a true secondary thickening of the stem occurs in Isoetes, it is quite different from that in Botrychium, which closely resembles the normal thickening of the coniferous or dicotyledonous stem. It has been compared to that found in Yucca or Draccena, and this perhaps is more nearly like it. However, as the development of cambium and secondary thickening have evidently occurred independently in very widely separated groups of plants, it is quite likely that we have here one more instance quite unconnected with the same phenomenon elsewhere.

The leaves, as already stated, differ but little from those of the young plant. The vascular bundle is somewhat better developed, but remains very simple, with only a few rows of tracheids fully developed. The vascular bundle of the leaf is better developed at the base of the leaf, and especially behind the sporangium (Smith (I)).

The phloem remains undifferentiated, and no perfect sievetubes can be detected. The phloem lies upon the outer side of the xylem, but shows a tendency to extend round toward the upper side. Of the Filicineæ, Ophioglossum comes the nearest to it in the structure of the bundles. The air-channels are four 
in number in the fully-developed leaf, and the diaphragms across them more regular and complete. Instead of being throughout but one cell thick, as in the first leaves, they are thicker at the edges, so that in section they appear biconcave. In the older leaves the broad sheath at the base is much better developed, and the over-lapping leaf bases give the whole stem much the appearance of the scaly bulb of many Monocotyledons.

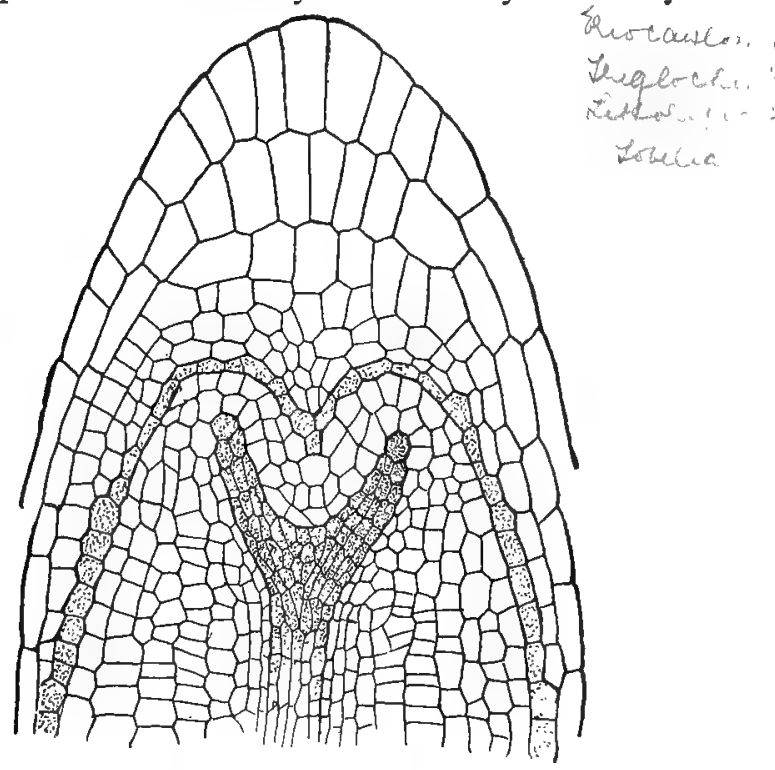

Fic. 321.-Isoetes lacustris. Section of root-apex, showing dichotomy, $X$ about Igo (after Bruchmann).

In all the terrestrial species, and those that are but partially immersed, the leaves are provided with numerous stomata of the ordinary form; but in some of the submersed species these are partially or entirely wanting. The development of the ligule also varies, being very much greater in the terrestrial species, where it may possibly be an organ of protection for the younger leaves.

The ligule in its fully developed condition (Smith (I)) shows four portions: I, a sheath of glandular appearing cells at its base ; 2 , the "glossopodium," consisting of a band of large empty cells, above which is (3) the main portion of the ligule, composed of small cells containing protoplasm; 4 , the apex, composed of dead cells. 
Hofmeister states that in I. lacustris the first sporangia are not developed until the fourth year from the time the young sporophyte is first formed. The sporophylls begin to form in the third year, but it is a year more before the sporangia are complete. From this time on, the regular succession of sporophylls and sterile leaves continues.

There has been much disagreement as to the method of growth in the root. The earlier observers attributed to it a single apical cell, not essentially different from that of the true Ferns; this was shown to be incorrect by Bruchmann (I) and Kienitz-Gerloff (6), but Farmer (2) claims that none of these have correctly described the structure of the larger roots, which differs somewhat from that of the earlier ones. According to the latter observer there is always a single initial for the plerome, and above this two layers of meristem, one giving rise to the inner cortex, the other to the outer cortex, as well as to the epidermis and root-cap. The fibrovascular bundle is monarch, like that of Ophioglossum vulgatum, and the phloem becomes differentiated before the xylem elements are evident.

The later roots arise much as the second one does in the young plant, but the rudiment is more deeply seated. The roots are arranged in $I$. lacustris in four rows, two corresponding to each furrow (Van Tieghem (5)). According to Bruchmann the first evidence of a forming root is a single cell of the cortical tissue lying a short distance outside of the leaftrace. This, however, cannot be looked upon as the apical cell, as it only gives rise to calyptrogen and dermatogen. The periblem and plerome arise from the cells lying immediately below it.

The branching of the roots is a genuine dichotomy, and has also been carefully studied by Bruchmann (Fig. 32I). He states that the process begins by a longitudinal division of the plerome initial, and each of the new initials at once begins to form a separate plerome. The overlying tissues are passive, and their divisions are governed by the growth of the two plerome strands.

\section{The Sporangium}

The development of the sporangium has been studied by Goebel (3), and more recently by Bower (I5), and WilsonSmith (I). Each leaf, except the imperfect ones that sepa- 
rate the sporophylls of successive years, bears a single very large sporangium, situated upon the inner surface of the expanded base.

According to Goebel (3) the young sporangium consists of an elongated elevation composed of cells which have divided by periclinal walls; but both Bower (I 5 ) and Smith (I) state that it can be traced back to a small group of strictly superficial cells which later undergo periclinal divisions.

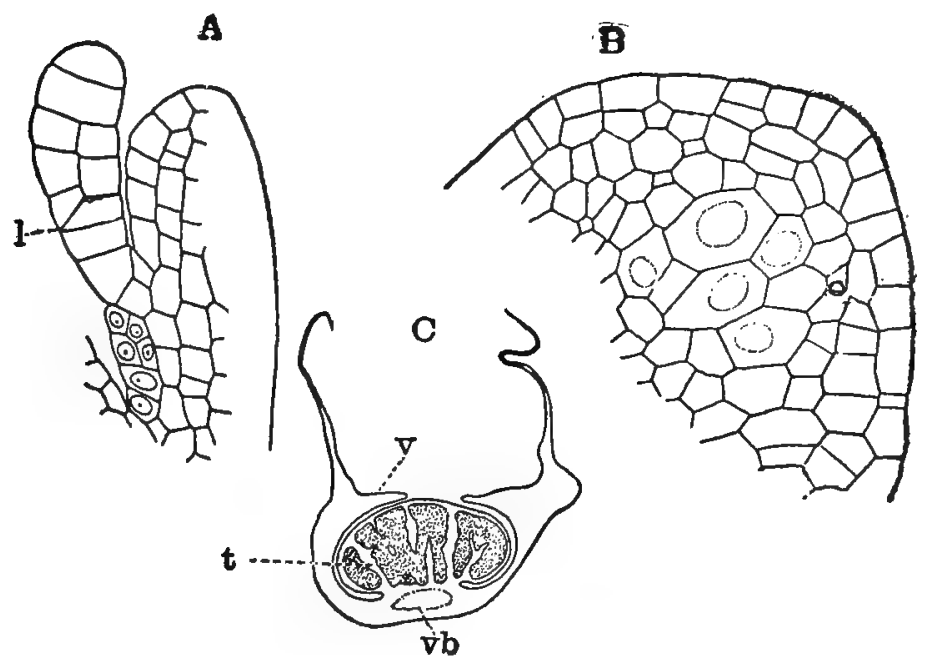

FIG. 322.-Isoetes echinospora. A, section of young sporophyll, $\times 325 ; l$, ligule; the sporangial cells have the nuclei shown. B, section of part of a young macrosporangium, $\times 325$; the sporogenous cells have the nuclei shown. $\mathrm{C}$, cross-section of the base of a young sporophyll, with microsporangium, $\times 25 ; v$, the velum; $v b$, vascular bundle; the trabecula are left unshaded. (After Wilson-Smith).

The very complete account of the development of the sporangium of $I$. echinospora made by Wilson-Smith ( I) differs in some important details from that of Goebel. The first periclinal division, while it may separate a definite parietal layer, does not, as a rule, do this; but there are further periclinal divisions in the superficial layer of cells which add to the sporogenous tissue, much as is the case in Equisetum and Ophioglossum. There is not, therefore, the early and definite segregation of the archesporium described by Goebel, nor do the archesporial cells remain independent, as Goebel states is the case in I. lacustris.

Wilson-Smith finds a complete absence of the regular 
arrangement of the cells described by Goebel. He says (1. c., p. 24I ), "I am forced to conclude that the sporangium of Isoetes (at least of $I$. echinospora and $I$. Engelmanni) just as the microsporangium of Angiosperms, grows as a unit, and not as a number of individual segments."

The velum appears very early and is apparently developed directly from a part of the sporangium-fundament-indeed it looks as if in some cases it actually contributed to the sporogenous tissue. The velum reaches its full development before the rest of the sporangium does. In certain species, some of its cells, as well as those of the adjacent leaf-tissues, may become lignified and show spiral and annular thickenings.

In their early stages, there is no difference between microand macrosporangia. Wilson-Smith could find no indication in the species investigated by him, of the early differentiation of the two.kinds of sporangia described by the early investigators. In both macro- and microsporangia, divisions occur in all directions, resulting in a very large mass of potential sporogenous tissue. There is later, however, a differentiation of the archesporial tissue into fertile and sterile areas, the latter forming later the "trabeculæ."

About the time that the last cell-divisions are taking place in the archesporial tissue, certain regions divide less actively and react less strongly to stains. These relatively inactive regions are the sterile ones, and from them are developed the sporangium wall, the trabeculæ and tapetum, while the rest of the archesporial tissue, at least in the microsporangium, develops spores.

The trabeculæ are more or less irregular masses of tissue, not forming definite partitions, although they may anastomose more or less freely (Fig. 322, C). The cells of the trabecula become flattened and extended by the subsequent growth of the sporangium, and lose to a great extent their protoplasmic contents, so that they soon become clearly separated from the intervening sporogenous cells. The trabeculæ later undergo a further differentiation into a layer next the sporogenous cells, this outer layer constituting the tapetum, and an inner mass of much larger and more colourless cells, the trabecular proper.

The young tapetal cells do not stain strongly, but later, when they presumably become active in supplying the young spores with food, they stain even more strongly than the spo- 
rogenous cells. As in Lycopodium and Selaginella, the tapetal cells remain intact, instead of being broken down as they usually are in the Ferns and Equisetum.

In the microsporangium all the sporogenous cells divide, the divisions being successive and usually resulting in spores of the "bilateral" type, although tetrahedral spores are sometimes formed. The number of spores in each sporangium is very great. In I. echinospora, it ranges from I 50,000 to 300,000.

\section{The Macrosporangium}

The earliest stages of both types of sporangium are alike, but the macrosporangia are recognisable as such earlier than the microsporangia. In the former, before any distinction of fertile and sterile tissue is evident, certain cells become noticeably larger than their neighbours, and enter into competition, as it were, to become the spore mother cells. There is apparently no rule as to either the number or position of these potential mother cells; but sooner or later some of them outstrip their competitors, become very large, and ultimately divide into the four macrospores.

The formation of the trabectula and tapetum is essentially the same as in the microsporangium; but the trabeculæ are fewer and more massive, and the tapetum is several cells in thickness. The unsuccessful sporogenous cells probably are used up in the further development of the growing spores.

The further development of the macrospore has been studied in I. Durieni by Fitting (I). Preliminary to the first nuclear division in the mother cell, whose membrane consists of a pectose-compound and not cellulose, there is a division of the starch granules into two groups which divide again, and the four starch masses arrange themselves tetrad-wise in a way that recalls the behaviour of the cell contents in the dividing spore mother cells of Anthoceros. The four nuclei resulting from the repeated division of the primary nucleus are in close contact with the four starch masses, and there then follows the simultaneous formation of cell plates between the nuclei. The cell plates are replaced by the cell walls which separate the four young tetrahedral macrospores.

The protoplast of each young spore secretes about itself a special membrane from which is later developed the characteris- 
tic perispore. Within the special membrane is developed a second membrane-exospore-which later shows a division into three layers. Within the exospore the mesospore and endospore arise very much as in Selaginella, which Isoetes further resembles in the separation of the mesospore from the protoplast and from the exospore, although this is less conspicuous than in Selaginella.

As the sporangium develops, the surrounding leaf tissue grows up about it, somewhat as the integument of an ovule invests the nucellus. Goebel calls attention to the resemblance between the sporangium of Isoetes, sunk in the fovea and partially covered by the velum, and an ovule with a single integument.

Bower finds in the sporangium of Lepidodendron, structures which resemble the trabeculæ of Isoetes, and he is inclined to consider the two genera as really related.

In $I$. lacustris the sporangium is sometimes replaced by a leafy bud which may develop into a perfect plant. (Goebel: "Ueber Sprossbildung aus Isoetesblätter," Bot. Zeit., I879).

The relationship of Isoetes to the other Pteridophytes is not entirely clear, and there has been a good deal of difference of opinion on this point. In many respects it shows a nearer affinity to the eusporangiate Ferns, than to the Lycopodinea, in which the genus is usually included. The archegonium closely resembles that of Ophioglossum or Marattia, and the spermatozoids are multiciliate, which is never the case in any known Lycopod, but is universal among the Ferns. The anatomy of the sporophyte is quite peculiar, but may, perhaps be quite as aptly compared to the Fern-type, as to that of the Lycopodinea. The dichotomous branching of the roots has a parallel in Ophioglossum, although it must be admitted that it closely resembles the forking of the root in Lycopodium. The sporangium may perhaps as well be compared to the spike of Ophioglossum or the synangium of Dancea as to the single sporangium of Lycopodium or Lepidodendron. It would be rash to assert positively that the trabeculæ correspond to the partitions between the sporangia of Ophioglossum, and that the sporangium is really compound, but this is not inconceivable. The position and origin of the large sporangium of Isoetes are certainly not very unlike those of the sporangiophore of Ophioglossum. 
The development of the spores and the early stages of the female gametophyte certainly resemble those of Selaginella, and form the strongest argument for assuming a relationship between the two genera. The embryo, however, is very much more like that of the eusporangiate Ferns, resembling, perhaps, most nearly that of Botrychium, and in connection with the structure of the mature gametophyte and sexual organs, makes it not improbable that there is a real, but extremely remote relationship between Isoetes and the Eusporangiatæ.

As to the affinities of Isoetes with the Spermatophytes, it more nearly resembles them in the formation of the female prothallium than any other Pteridophyte except Selaginella, and the reduction of the antheridium is even greater than there. The embryo resembles very much that of a typical Monocotyledon, and the histology of the fully-developed sporophyte, the leaves with their sheathing bases surrounding the short bulblike stem, and the structure of the roots, all suggest a possible relation to the Monocotyledons directly rather than through the Gymnosperms.

There is, however, a great interval between the flower of the simplest Angiosperm and the sporophylls of Isoetes, and more evidence must be produced on the side of the former before it can be asserted that this relationship is anything more than apparent. 


\section{CHAPTER XV}

THE NATURE OF THE ALTERNATION OF GENERATIONS

THE origin and significance of the phenomenon of the alternation of generations, so characteristic of the Archegoniates, and its bearing upon the origin of the leafy sporophyte of the higher plants, have been the subject of much discussion.

Among the lower plants the phenomenon is not uncommon, but it is in none of these so prominent as it is among the Archegoniates. If the views of Oltmanns (2) are accepted, the cystocarp of the Rhodophyceæ represents a neutral generation, comparable in a way to the sporophyte of the Archegoniates, and like the sporophyte of the Muscinex is parasitic upon the gametophyte. The fruiting body resulting from the fertilisation of a carpogonium or archicarp in many Ascomycetes also is very similar to the cystocarp of the Rhodophycex, and might perhaps with equal propriety be denominated the sporophyte.

The method of development of the sporophyte in these forms, however, is very different indeed from that of the Archegoniates, and does not suggest even a remote homology.

Among the Chlorophyceæ, the alternation of generations is not conspicuous, but it is nevertheless in this group and not among the Rhodophyceæ that we are to seek the progenitors of the Archegoniates.

The presence of sexual and non-sexual plants among the Green Algae is in no way comparable to the alternation of gametophyte and sporophyte in the Archegoniates. The same individual in Oedogonium or Vaucheria may produce either zoöspores or gametes, and the production of sexual or non-sexual cells is largely due to external conditions. (See Klebs (I)). The product of the fusion of the gametes in these plants is a resting spore, which on germination, either directly or by the 
preliminary formation of zoöspores, gives rise to the new generation. The primary function of the resting spore (zygote) is to carry the plant over a period of stress-drought or cold.

The Confervoidex among the Green Algx are for good reasons considered to be among living forms the nearest to the progenitors of the Archegoniates. The germinating zygote in these plants usually develops several zoöspores, each of which gives rise to a new plant, thus quickly increasing the number of individuals resulting from a single fertilisation. This is obviously an advance upon the condition where the zygote gives rise to but one plant, and this preliminary division of the zygote probably was the first step in the evolution of the sporophyte or neutral generation which becomes so conspicuous in the Archegoniates.

Among the Confervoidex, Coleochcete most nearly approx1mates the condition found in the lower Bryophytes. Alone among the Algx the germinating zygote forms a cellular body or embryo directly comparable to that of Riccia, for example. Each cell of this embryo-sporophyte then produces a zoöspore which develops into a new plant (gametophyte).

Whether the protective envelope formed about the fertilised oögonium of Coleochate may be considered to be in any way comparable to the outer cells of an archegonium is doubtfulat best the resemblance is very remote-and in the character of the sexual organs there is a very great gap between Coleochcete and the simplest Liverwort.

The zygote of the Green Algæ is evidently a provision for carrying the plant over periods of cold and especially droughtthat is, it is in a sense an adaptation to terrestrial conditions which the growing plant cannot withstand. From this dormant unicellular sporophyte (oöspore) there has gradually been evolved the complex, independent sporophyte of the vascular plants.

The first step in the elaboration of the sporophyte was the production of several zoöspores. The next step is that shown in Coleochate, where there is marked growth of the germinating zygote and its trarisformation into a cellular body, or embryo, previous to the formation of the zoöspores. No form is known among the Chlorophycex in which the development of the sporophyte is carried any further.

The transition from the typically aquatic life of the algal 
ancestors of the lower land plants to the terrestrial mode of life was probably very gradual. We may still find forms among the simpler Algæ which are to a greater or less degree adapted to a terrestrial life. Such types as Pleurococcus, Botrydium, and species of Vaucheria may be cited. In Pleurococcus no special organs for water absorption are developed, and the cells simply vegetate as long as the surrounding atmosphere is sufficiently moist, becoming dried up and dormant when the necessary moisture is lacking. Botrydium, however, is provided with a relatively extensive system of roots, which penetrate the moist earth and enable the plants to live for a considerable time as a genuine land plant, since the loss of water due to transpiration is made good so long as there is an adequate supply of water in the soil. These Algæ, however, have no efficient check against the loss of water in the parts exposed to the air, and very quickly die when the supply of water from the earth is suspended.

Such Schizophyceæ as Nostoc and similar.terrestrial forms, by the development of the massive gelatinous or mucilaginous envelope, are protected against rapid loss of water. The gelatinous tissues of many sea-weeds, which are exposed for short intervals to the air, no doubt serve a useful purpose in holding water. None of these forms, however, can be considered as very well equipped for a strictly terrestrial existence.

To judge from the life-history of certain aquatic Liverworts, such as Ricciocarpus, it seems not unlikely that the primitive Archegoniates arose from some aquatic Algæ, probably not very unlike Coleochate. These may have become stranded upon the mud by the subsiding water, and by the development of rhizoids which are often induced by such contact with a solid medium, the activity of the plant would be prolonged until the rhizoids were unable to extract sufficient moisture from the soil to supply the needs of the plant. To judge from the analogy of Ricciocarpus, this contact with the soil is a stimulus to a much more vigorous growth than is the case when the plant is floating, and we can conceive that the vegetative vigour of the Alga might have been enhanced by its new terrestrial mode of life.

The direct origin of the simple gametophyte of such a Liverwort as Aneura or Anthoceros, from some confervoid type is readily conceivable, but the very great difference in the complexity of the reproductive organs between even the simplest 
Liverwort and any known Alga forbids the assumption of any but a very remote connection between them.

In all typical Liverworts which are characteristically terrestrial plants, in addition to the rhizoids for absorbing water, there is also a more or less perfect cutinisation of the superficial cells which materially checks the loss of water from transpiration. In addition to this there are often special provisions for protecting the plants from injury by drought. Most species have mucilage secreting organs of some kind, and the hairs and scales frequently developed upon the plant are usually associated with water storage. Like some Algæ, certain Liverworts can become dried up without injury, reviving promptly when supplied with water. Less frequently special tubers are formed, these being especially marked in some species from dry regions, like those about the Mediterranean or in Southern California.

In passing from an aquatic to a terrestrial habitat, another change of structure must be noted, namely, the development of mechanical tissues for giving the plant body the necessary support in the much rarer medium of the atmosphere. In studying the evolution of the gametophyte in the Bryophytes, it becomes at once evident that the development of mechanical tissues is largely obviated in the lower types by their never attempting to stand upright, but they lie prostrate upon the ground as we may assume was done by their algal prototypes. This prostrate position, while doing away with the necessity for skeletal tissues also has the advantage of offering a much larger surface for the development of the rhizoids, and also exposes a smaller surface directly to the air and consequently reduces the loss of water by evaporation. Most of the lower Hepaticæ and all the Anthocerotes have retained this primitive type of gametophyte. In the Mosses, however, the prostrate thallus is replaced by a definite leafy axis, which is often upright and may develop a fairly complete system of skeletal tissues. This type realises its most perfect expression in such large Mosses as Polytrichum and Dawsonia. We find in these that in addition to the mechanical elements, there are also water-conducting tissues, comparable to the tracheary tissue of the vascular plants, although in one case we have to do with gametophytic structures, in the other with sporophytic ones. In these large Mosses, the rhizoids are multicellular, and may be twisted into 
cable-like strands, which simulate true roots, but are less efficient than these.

The size to which the gametophyte may grow depends largely upon the water supply, which must be regarded as the most potent factor governing the development of the plant body. It is evident that the delicate rhizoids alone are insufficient to supply with water a plant of any but the most modest dimensions. Indeed, in many Bryophytes, the rhizoids play but a minor part in supplying water, as the whole plant may absorb water much as an Alga does. So also we find very few Bryophytes in which the development of mechanical tissues is sufficient to make the plants (except small ones) stand firmly upright. Either the plant is prostrate, or it maintains its upright position by virtue of the mutual support offered by its neighbours, most of the large Mosses growing in dense tufts or mats.

It is evident that the size to which a terrestrial gametophytic structure can grow is necessarily limited, owing to its inadequate means of obtaining water. Either the plant must grow where there is a permanent and abundant water supply, or else it must dry up and completely cease its activity during periods of drought. It would seem as if the originally aquatic gametophyte could never adapt itself perfectly to terrestrial conditions, and upon the sporophyte devolved the development of a different plant-type adapted from the first to life in the air. As the sporophyte assumed the character of an independent plant, it gradually replaced the gametophyte as the predominant structure of the higher plants.

The origin of the sporophyte of the Archegoniates, as we have seen, is to be sought in the zygote of some Green Alga. This in its simplest form is a single thick walled resting spore, adapted to resisting drought, and changes of temperature which are fatal to the growing plant. From its very nature, it is primarily the terrestrial phase, so to speak, of these typically aquatic organisms. The embryo-like cell mass developed in Coleochate may very properly be compared to the embryosporophyte of Riccia, or of any Liverwort. However, each cell of the rudimentary sporophyte of Coleochcete produces but a single spore, and this is a zoöspore like those of other Algæ, and is clearly associated with the normally aquatic habit of these plants. 
In the simplest sporophyte of the Liverworts as illustrated by Riccia, there is first the separation of the superficial layer of sterile cells, about the central mass of sporogenous tissue, and each cell of the latter produces four thick-walled resting spores, corresponding physiologically to the single resting spore of the Alga. The retention of the zygote within the archegonium and the parasitic habit of the embryo developed from it enables the sporophyte to reach a much larger size than is possible where the germination is entirely at the expense of the food-materials stored up within the spore, as is necessarily the case where the zygote becomes free before germination, as it does in all the Chlorophycex. When to this is added the division of each sporogenous cell into four spores, it is clear that the output of spores resulting from a single fertilisation is very much increased, a great advantage for a terrestrial plant in which the conditions for fertilisation may not occur very often.

The formation of the spores in tetrads is common to all Archegoniates, and it is preliminary to this division that there occurs the reduction in the number of the chromosomes which has been observed in a number of cases. While this reduction is not always strictly definite, it is found that the spore has approximately one-half the tumber of chromosomes which are found in the vegetative cells of the sporophyte, and this reduced number, of course, is transferred to the tissues of the gametophyte which arises from the germination of the spore. When the gametes fuse, the zygote-nucleus receives the combined chromosomes of the gametes, and the sporophytic cells descended from it contain the double number of chromosomes.

We must assume that in its primitive form the sporophyte of the first Archegoniates was composed exclusively of sporogenous tissue, as it is in Coleochate. Riccia shows the first indication of the sterilisation of the outer layer of sporogenous tissue. Professor Bower ( I6) has called attention to the great importance of the principle of sterilisation of potentially sporogenous tissue in the evolution of the sporophytic structures among the Archegoniates

The next step in the evolution of the sporophyte, as it is seen in the Liverworts, is one of great importance in the further evolution of the sporophyte. This is the sterilisation of the whole of the basal part of the sporophyte, which assumes the important rôle of a special organ of absorption, or haustorium. 
The foot is an absorbent organ of great efficiency, and through it the growing embryo is nourished at the expense of the gametophyte, upon which the embryo lives much as a parasitic Fungus does upon its host. This development of a special absorbent organ at once allows a longer period of growth for the embryo, and a correspondingly greater development of sporogenous tissue.

The next evidence of progressive sterilisation in the tissues of the sporophyte is the development of an intermediate region, the seta, and the sterilisation of some of the sporogenous tissue to form elaters. Both of these developments, however, are concerned solely with the dissemination of the spores. In the more advanced sporophytes of most Liverworts, the cells develop more or less chlorophyll, and to this extent the sporophyte is capable of self-support. The sporophyte, however, remains dependent to a great extent upon the gametophyte, from which, by means of the massive foot, it receives most of its nourishment.

The first marked evidences of a capacity for independent existence in the sporophyte are found among the-Anthocerotes and the Mosses. In these classes, the sterilisation of the sporogenous tissue is carried much further than in any of the Hepaticæ, and much the greater part of the sporophyte is composed of sterile tissue. In such forms as Anthoceros and Funaria, the sporogenous tissue forms but a small fraction of the whole sporophyte, which grows for several months and develops an extensive and efficient system of tissues for photosynthesis. Conducting tissues are also present, and in the Mosses the seta and capsule have conspicuous mechanical tissues as well. The sporophyte, nevertheless, receives its water supply from the gametophyte through the foot, as it does in the Liverworts.

With the establishment of a true root putting the sporophyte into direct communication with the earth, the independence of the sporophyte is completed. Whether the direct contact with the earth acted as a stimulus to vegetative activity, as it seems to have done in the case of the transference of the gametophyte from water to land, of course we can only conjecture; but the extraordinary complexity of the sporophyte which is found in all Pteridophytes indicates that this is not improbable. With the establishment of the sporophyte as an independent, typically. 
terrestrial plant, the gametophyte becomes more and more subordinated, finally serving merely to develop the reproductive organs and to nourish the young sporophyte until it can take care of itself.

While it must remain conjectural just how the first true root arose, the most probable explanation is that it was a modification of part of the foot. The foot is from its first inception peculiarly an absorbent organ, acting much as the haustorium of a parasite would do, and taking from the gametophyte the water and food necessary for the growth of the sporophyte. The foot, like the true roots developed later in the history of the sporophyte, is a very.different organ from the delicate rhizoids of the gametophyte, and much more efficient for supplying a massive structure like the sporophyte with the water necessary for its growth. Moreover, as soon as a true root was established, provided with an apical meristem for prolonged growth, it could keep pace with the increasing size of the sporophyte, and by the subsequent development of similar secondary roots of increasing size and complexity, a root system was established, to whose further development there was no apparent limit.

So soon as the sporophyte was emancipated from its dependence upon the gametophyte, a new plant-type, essentially terrestrial in its nature, was established. This was not a transformed aquatic organism, like the gametophyte, but the elaboration of a structure essentially adapted to an aerial existence from the beginning. To the zygote of some Alga, a resting spore developed to carry the plant over a period of drought, can be traced, step by step, by growth and specialisation, the complex sporophyte as it exists among the vascular plants.

This view of the origin of the leafy sporophyte from the zygote of some aquatic algal ancestor is the so-called Antithetic theory of alteration of generations. It assumes that the two generations are essentially distinct, the gametophyte representing the primitive aquatic phase, the sporophyte the secondary terrestrial condition, arising from the germinating zygote. The sporophyte in its earliest condition was simply a 1 spore-bearing structure for the multiplication of the gametophyte; later is gradually assumed the character of an independent plant, of essentially terrestrial habit.

Opposed to this view is the theory of Homologous Alternation. This theory was first championed by Pringsheim (3), 
but more recently has been advocated by Scott (3), Coulter (I), and others. This view maintains that the sporophyte arose as a modification of the gametophyte, and not as an essentially new structural type. The homologous theory of alternation is based largely upon the phenomena of apospory and apogamy, and also, to a lesser extent, upon experiments in regeneration. Pringsheim showed that the protonema of a Moss might arise from the cut end of the seta, as well as from the tissues of the gametophyte, a case of apospory, but as yet there are no instances known of the converse, $i$. $e$, the origin of the sporophyte in the Mosses by apogamy. Pringsheim believed that the protonema is not essentially different from the vegetative tissues of the sporophyte from which it might be made to develop, and that therefore no line can be drawn between strictly gametophytic and sporophytic structures. It must be remembered, however, that the protonema normally develops from certain sporophytic cells (spores), and its development under abnormal conditions from other sporophytic tissue is not inexplicable. It is, moreover, a significant fact that the cells of the seta, from which the protonemal filaments arise, a fact which Pringsheim himself recognises, correspond in position to the sporogenous tissue of the capsule, and are probably homologous with them. The phenomenon of apospory in certain Ferns is comparable to that in the Mosses, and recently Lang (4) has been able to induce in Anthoceros a development of structures which seem to be rudimentary gametophytes. The origin of these in all cases was not clear, but they seemed usually to arise from the outer tissues of the sporophyte, and not from the sporogenous layer. Stahl (I) also found that protonemaformation might arise from the parietal region of the capsule in Ceratodon.

The strongest argument in favor of homologous alternation is the phenomenon of apogamy, or the origin of the sporophyte as a vegetative bud upon the gametophyte, and apospory, or the origin of the gametophyte by budding from the sporophyte. Apogamy has been observed in a number of species of Ferns belonging to the Polypodiaceæ, Hymenophyllaceæ, and Osmundaceæ. How far apogamy may be considered a natural phenomenon, and how far it is a pathological condition induced by artificial means, needs further elucidation. It undoubtedly in some species like Pteris cretica entirely super- 
sedes the sexually formed sporophyte, as in this species, apparently, archegonia are never formed. (Sadebeck (8), p. 34.) In other cases, both apogamous and normal sporophytes are known. Lang (3) has found that exposure to strong sunlight will sometimes induce apogamy. Apospory (Bower (6)) may consist of the transformation of sporangia into prothallia, or in some cases the latter may arise from sterile leaf-tissue, even from leaves which bear no sporangia.

Bower has pointed out that all known cases of apogamy occur among the leptosporangiate Ferns, admittedly the most recent and specialised members of the class. If apogamy is to be looked upon as a reversion to a primitive condition, it is hard to understand why it should be absent in the other more primitive Pteridophytes. It must be admitted, of course, that these forms have not received the same amount of study as the higher Ferns, and it is quite possible that apogamy may be shown to occur in some of them.

Lang (1. c.) has suggested that the origin of the sporophyte, assuming the homologous theory of alternation, may have been something as follows: The primitive gametophyte of the Pteridophytes was probably a flat thallus that under stress of circumstances, owing to an insufficient water supply, may have given rise to spores, the spore stage following the sexual stage, but being an integral part of the gametophyte, and not produced from the ovum. In connection with this special spore-producing function, the structure gradually assumed the character of a leafy shoot, and later became replaced by a similar structure which arose from the fertilised egg.

It is not made clear, however, how the originally apogamous sporophyte came to be transferred to the archegonium, nor why the spores produced from it should so exactly resemble those developed from the sexually produced sporophyte of the Bryophytes, which according to the homologous theory of alternation has nothing to do with the sporophyte of the Ferns.

Although many Bryophytes normally are subjected to all the conditions which should, according to Lang's theory, induce apogamy, no instances are known among them of such apogamous production of spores, or anything resembling in the remotest degree the normal sporophyte. Either the whole gametophyte dries up and revives when water is applied, or else special tubers are developed which survive the dry period. 
In the few Ferns in which perennial prothallia are formed, $e$. g., Gymnogramme triangularis, $G$. (Anogramme) leptophylla, the behaviour of the gametophyte is precisely the same as in the Liverworts.

Coulter has suggested that the determining factor in the development of the leafy sporophyte has been photosynthesis or "chlorophyll work." He sees no reason why such a structure as the leafy sporophyte may not have arisen non-sexually in response to the need for increased chlorophyll activity, quite apart from the production of spores. The spores would find more favourable conditions upon a leafy shoot than upon the thallus.

It is doubtless true that the production of a large leafy shoot would be advantageous in increasing the output of spores; but why this leafy shoot should not have developed gradually from the sexually produced sporophyte of some bryophytic prototype, as there is the strongest evidence that it has done, is not made clear. The development upon the leaves of the sporophyte of spores of the same type as those of the lower Archegoniates is entirely comprehensible if it is admittted that the sporophyte of the Fern is descended from the leafless sporophyte of some ancestral Bryophyte; but it is very hard to explain if we assume that there is no genetic connection between the spores of Bryophytes and Pteridophytes.

According to Coulter's hypothesis, the leafy sporophyte originated by budding comparable to that of the leafy shoot of a Moss from the protonema, or the apogamously produced sporophyte of a Fern. The leaves were originally purely vegetative organs, and the development of sporangia was secondary. The germination of the asexual spores and the zygote are assumed to have been the same, each giving rise to a thallus upon which arose secondarily the leafy shoot.

If such were really the course of development, it is strange that no trace of the thallus-stage has persisted in the embryosporophyte. The only structure which could possibly be so interpreted is the suspensor in Lycopodium and Selaginella, which most morphologists would hesitate to consider of such nature.

The statement (Coulter (I), p. 56), "Perhaps such a tendency ( $i$. $e$, the elimination of the thallus portion of the zygote product) is no more difficult to understand than the fact that 
the spore produces a gametophyte .... and a zygote produces a sporophyte.....," can hardly be admitted. The spores of all Archegoniates, if we admit the antithetic theory of alternation, are the direct descendants of those produced by the germinating zygote of the ancestral form, where also the product of germination is not directly a new gametophyte, but spores from which the latter arises secondarily, as is the case, in the Archegoniates. This is readily demonstrable, while on the other hand, the development of any type of spore in the least resembling those of the sporophyte is absolutely unknown in any gametophytic structure.

If it is admitted that the leafy sporophyte originally arose as an apogamous bud, it would necessarily follow that the foliage leaves are more primitive than the sporophylls, and that there is no genetic connection between Bryophytes and Pteridophytes; at present, however, it seems to the writer that the weight of evidence is very much against such a supposition.

That chlorophyll activity has been a very potent factor in the evolution of the plant-body is of course beyond dispute, but its bearing upon the origin of the higher land plants is not so clear. All green plants, whether aquatic or terrestrial, must provide for photosynthesis, and we find the arrangements for the most favorable exposure of the green tissue brought about in various ways. Leaves are by no means confined to land plants, many Algæ, especially the large Laminariaceæ and Fucaceæ having large and perfect foliar organs, which, although of simple structure, are very efficient organs for photosynthesis. The independent development of the leaves in several groups of Bryophytes shows no evident connection with adaptation to a terrestrial environment.

If one were seeking among the Bryophytes a structure which most nearly simulated the leafy Fern-sporophyte, it would be found in such thallose Liverworts as Symphyogyna or Hymenophyton, whose repeatedly forked thallus resembles superficially to an extraordinary degree the fan-shaped leaf of a small Fern. It is conceivable that when the sporophyte first developed a leaf, the latter might tend to assume the dichotomously branched form so common in the gametophyte of the lower Liverworts and of the Ferns also which presumably have arisen from similar forms.

Looking at the evidence from all sides, it seems to the writer 
that the weight of evidence is very much in favour of the antithetic theory of the alternation of generations, and that there is a real genetic connection between Bryophytes and Pteridophytes. The sporophyte of the latter is directly descended from some bryophytic ancestral form, although it is quite probable that the existing Pteridophytes may have been derived from more than one ancestral type. All of the Archegoniates agree closely in their most important structural details. The sexual organs and method of fertilisation, and the early divisions of the embryo, are very much alike in all of them. There is evident in all of the higher Bryophytes a tendency to a subordination of the sporogenous function to the vegetative existence of the sporophyte, with the development of conducting and assimilating tissues comparable to those in the sporophyte of the vascular plants. Finally, the spores produced by the sporophyte are identical in structure in the two series of archegoniate plants.

The really weighty argument on the other side is the occurrence of apogamy and apospory. As to the significance of these phenomena, they may probably be compared to the adventitious budding, so common in many of the higher plants. In both Pteridophytes and Spermatophytes, the whole sporophyte may arise by budding from almost any portion of the plantbody. Thus in Camptosorus or Cystopteris bulbifera, the young sporophyte arises from the leaf, as it does in Begonia or Bryophyllum among the Spermatophytes. In Ophioglossum it may arise from the root-apex, a condition paralleled among the Spermatophytes by the production of root-buds or suckers in Populus or Anemone. Certain supposed cases of parthenogenesis in the Spermatophytes have been shown to be rather cases of budding from the nucellar (sporangial) tissue, and many other instances could be cited showing similar conditions.

No morphologist has ever regarded such adventitious origin of the sporophyte as indicating in any sense of the word a reversion to a primitive condition. It is not argued that because the sporophyte may arise as a bud from a root, that therefore the sporophyte originated first as a modification of a root. In the same way, it does not seem reasonable to argue from the doubtfully normal phenomenon of apogamy that the sporophyte developed in the first place as a vegetative modification of the gametophyte. 
Farmer's recent remarkable studies on apogamy (Farmer (I0)), show that nuclear fusions occur, indicating that a stimulus, equivalent to fertilisation, is necessary for the development of apogamous structures.

It would seem then, that the adaptation to strictly terrestrial conditions, and the consequent necessity for providing an adequate water supply, is the real clue to the causes for the development of the leafy sporophyte. All Bryophytes retain to some extent the character of aquatic plants, most of them being able to absorb water at all points, and relying only to a limited extent upon the rhizoids. Moreover, the latter are entirely inadequate to supply a plant-body of large size, which could not, of course, absorb sufficient water for its growth from the atmosphere. Nature has apparently made numerous attempts to adapt the essentially aquatic gametophyte to an aerial existence, with only partial success.

The sporophyte, at first purely a spore-producing structure, was from its inception essentially an aerial organism. Its water supply from a very early period was furnished through the agency of the massive foot, which drew upon the gametophyte for its supply, and formed a much more efficient haustorium than the rhizoids of the gametophyte. Later was developed a true root, probably a modification of the foot, but unlike the latter, connecting the sporophyte with the earth.

With the appearance of the first true root, the emancipation of the sporophyte is complete, and as the root system develops to keep pace with the aerial parts of the sporophyte, a true terrestrial type of plant is encountered for the first time. The appearance of the first genuine green land plants may be considered the most momentous epoch in the whole history of the Plant Kingdom. 


\section{CHAPTER XVI}

\section{FOSSIL ARCHEGONIATES}

WHILE the geological record is necessarily very incomplete, nevertheless a study of the fossil forms has been of great assistance in understanding the relationships of the existing Archegoniates.

Unfortunately the simpler, and presumably the older, types are too delicate in structure to have left any recognisable fossil remains, except in a very few cases; and this is true also of the more perishable structures, such as the gametophyte of the higher forms.

In spite of the very fragmentary nature of the fossil remains, some of these are so complete that our knowledge, even of the internal structure of some of the extinct types, is extraordinarily accurate, and the researches of the past two decades have thrown much light upon the geological history of the higher Archegoniates.

The fossil remains are of two kinds-casts and petrifactions. The former, of course, can give information only as to the external characters, but these impressions are in many instances beautifully clear, and the nature of the plants unmistakable. True petrifactions are of much rarer occurrence, but where they do occur, the internal structure of the petrified plant can often be made out with great exactness. The infiltration of mineral substances completely replaces the cell walls, and thin sections of such petrifactions show most beautifully the character of the tissues. Silica, calcium-carbonate, iron pyrites among other substances are the causes of these petrifactions. This petrifaction may take place on a large scale, as is seen in the petrified forests of Arizona and California. For a full account of the conditions under which fossils have been formed, 
the reader is referred to Professor Seward's "Fossil Plants" (Seward (I), Chap. IV). By grinding thin slices of these petrified tissues, they may be examined microscopically with as much ease as sections taken from living plants, and it is largely to a critical study of such petrified tissues that the affinities of many doubtful forms have been determined.

In some of the later formations delicate plants, like Mosses and Liverworts, have been preserved in amber, and of course in these cases, there is no question of the nature of the plants; but no such fossils occur in the older formations, and none of those discovered are essentially different from their existing relatives, and of course throw no light upon the early history of the Archegoniates.

The fossil remains of the lower plants are for the most part extremely meagre, and throw little light upon the evolution of the Archegoniates. Presumably the progenitors of the lower Archegoniates were simple Green Algæ, but such extremely perishable organisms can hardly be expected to have left recognisable remains in the older rocks. Some of the calcareous Algæ like the Characex, certain Siphoneæ and Corallines, are known from very old strata, and there is every reason to believe that the less specialised Confervoidex, which probably are nearer the lower Archegoniates, were also abundantly represented in the earlier geological epochs, although they have left no recognisable fossil traces. The delicate nature of the primitive Hepaticæ fully explains their absence from the earlier strata, and the same is true of the gametophyte of the Pteridophytes.

\section{Fossil Muscinex (Seward (I), Chap. VIII)}

The fossil remains of Bryophytes are too scanty in number and of too doubtful authenticity in most cases to be of much value in determining the geological history of the group. Liverworts are too delicate to leave fossil traces except under most exceptional conditions. In the Tertiary and later formations they are occasionally met with, but all the forms discovered are closely aliied to existing species, and throw no light upon the origin of the Hepaticæ. Of the few unmistakable fossil Hepaticæ, may be mentioned Marchantites Sezannensis, of Oligocene Age. This is evidently close to the living genus 
Marchantia-perhaps identical with it. From the amber of North Germany, also of the Oligocene, a number of Liverworts have been described, all being referred to living genera, e. $g$., Frullania, Jungermannia.

The higher Mosses might be expected to leave more evident traces than the more delicate Liverworts; but although many moss-like fragments have been described, the real nature of most of them is doubtful, as they are for the most part merely impressions and might very well belong to other plants than Mosses. While it is extremely probable that some of the species of "Muscites" are real Mosses, and that Mosses were present in the Palæozoic formations, it cannot be said that our knowledge of these forms is very satisfactory.

Some of the larger Mosses, like Polytrichum and Hypnum, might very well be preserved fossil; but unfortunately their resemblance to the shoots of small Lycopods, or even of some Conifers, is so close that their identification from impressions is practically impossible. Except in the later formations no trace of the characteristic sporogonium has been found, and even in the few instances from the later formations, the real nature of the fossils is not beyond question. While it is reasonable to suppose that both Liverworts and Mosses occurred in the Palæozoic formations, there is no certain evidence of this from the geological record, and such fragments as do occur in the Palæozoic rocks are too uncertain to throw any light upon the origin of the Muscineæ.

\section{Fossil Pteridophytes}

The firm tissues of the sporophyte in the Pteridophytes are much more resistant than the soft tissues of most Bryophytes, and consequently far better fitted to be preserved in a fossil condition. Remains of undoubted Pteridophytes occur from the Silurian, and in the Devonian and the succeeding Palæozoic formations they constitute the predominant plant types. It is evident from a study of the fossil remains that all the existing classes were well differentiated as far back as the record extends; but in addition to these, there were a number of types which have become extinct, the exact affinities of some of which are not entirely clear. 


\section{Filicinece (Potonié (3); Scott (I))}

The great majority of the fossil remains of Ferns are in the forms of impressions, but these are frequently of great clearness, the numerous Carboniferous. fossils being especially beautiful, and showing all the external characters most perfectly. As these impressions are usually of sterile leaves, the first attempts to classify them were based upon the venation. While the venation is a diagnostic character of importance, it cannot be relied upon exclusively, as it sometimes happens that two nearly related forms, e. g., Onoclea sensibilis and O. struthiopteris, have a very different type of venation. On the other hand, the Cycad, Stangeria, has a venation so much like that of a Fern that the sterile plant was at first described as a species of Lomaria.

The more recent students of fossil plant remains have relied much more upon a study of the sporangia and of the tissues as disclosed by sections of petrifactions, and the results of these studies have added very materially to our knowledge of the affinities of the Ferns as gathered from a study of the structure of the living species, and have thrown much light upon the history of the fossil forms.

The earliest undoubted remains of Ferns occur in the Silurian. Of the few fossils of this age which can with reasonable certainty be assigned to the Filicinex may be cited the genus Rhodea, a Fern with finely dissected leaves, not closely resembling any existing type. In the Devonian a number of characteristic genera occur. Among these may be mentioned Cardiopteris, Sphenopteridium, Adiantites and Archeopteris (Palceopteris.)

During the Carboniferous the Ferns increase rapidly in number and variety, and constitute with the other Pteridophytes the predominant vegetation of the period. In the Secondary and Tertiary formations, they become less prominent, giving way to the rapidly increasing Spermatophytes; but they have persisted to the present time in large numbers, and have held their own much better than the other two classes.

In studying the venation of the earliest Ferns, especially the Archæopteridæ of Potonié, it is found that they all correspond to a type found at present in comparatively few Ferns 
The leaflets show no midrib, and are usually more or less fanshaped with radiating, dichotomously branched veins.

A similar type of leaflet is found in some existing species of Botrychium, e. g., B. lunaria, and also in species of Schizca, Trichomanes, Aneimia, and Adiantum. This type of venation occurs in the cotyledon of most Ferns, and is probably to be considered a more primitive one than the pinnate venation of the typical Ferns. Two other characteristic types are the " $P e$ copteris" and the "Sphenopteris" types, which are represented in many recent Ferns. The first, which differs from the others in having the pinnules sessile, by a broad base, is especially common in the Cyatheaceæ, which includes most of the living tree-Ferns.

The netted venation seems to be the most recent type of all, and Potonié states that it is first met with in Mesozoic fossils.

The dichotomous branching of the leaf itself also seems to be a primitive condition, and is relatively more common among the Palæozoic types than in those of the present. There are, however, many examples among existing species, and it is the usual form in the cotyledon. Gleichenia, Schizcea, Trichomanes, Matonia, Adiantum, are among the modern genera in which this occurs. The Palæozoic Ferns also show not infrequently a condition intermediate between dichotomous and pinnate leaves.

Another peculiarity of these ancient Ferns is the frequent development of subsidiary pinnæ between the ordinary ones. These are rare in modern Ferns, but are known in a few cases, e. g., Gleichenia gigantea, Hemitelia capensis.

In the oldest fossils in which the sporangia have been detected, these are confined to special leaves, or leaf-segments, as they are in the living Ophioglossacer and Osmundaceæ. These fertile leaf-segments are quite destitute of a lamina, and are completely covered by the sporangia. This condition of things is an interesting confirmation of the view which considers the Ophioglossacea as the most primitive existing type of Ferns. This view holds that the primitive Fern type must have developed the sporangial portion of the leaf before the lamina appeared, a condition now known to exist in the curious Ophioglossum simplex.

The Devonian genus Archeopteris, for example, closely resembles Botrychium, except that the fertile part of the leaf is 
terminal instead of arising from the face of the leaf. In Ophioglossum, however, a study of the earlier stages of the fertile leaf makes it not improbable that the spike may be interpreted as a truly terminal organ, and the sterile segment as a lateral appendage of it, comparable to the condition in Archeopteris. Dimorphic leaves are of common occurrence also in the later Palæozoic Ferns.

From the numerous studies that have recently been made upon the stem-structure of the fossil Ferns, it appears (Scott ( I), p. 303) that the monostelic stem is relatively commoner among the Palæozoic Ferns than it is at present. Among the existing Ferns, monostelic stems are especially characteristic of the Gleicheniaceæ, Hymenophyllaceæ, and most Schizæaceæ. There were, however, many Palæozoic Ferns in which the stemstructure closely resembled that prevailing among living Ferns. Some stems closely resembling those of modern tree-Ferns have been described under the name Psaronius. A study of the leaves and sporangia of these shows that their affinities were with the Marattiaceæ rather than with the Cyatheaceæ, to which family belong nearly all the living tree-Ferns.

The characteristic sporangia of Ferns are the most certain means of determining their affinities, and unless these are known, the identification of the fossils must be more or less doubtful. While fossil sporangia are of comparatively rare occurrence, still enough has been made out concerning the nature of the sporangia of the fossil Ferns to make perfectly clear the affinities of many of these with the living forms.

As might be expected from a comparative study of the existing Filicinex, it is found that the Eusporangiatæ, while showing every indication of being more primitive than the Leptosporangiatæ, are really much older geologically. While at the present time these constitute probably less than two per cent. of the living Ferns, among the Palæozoic fossils they far outnumber all others, if they do not actually include all Palæzoic Ferns.

Of the two living families, Ophioglossaceæ and Marattiacea, it is the latter which is especially abundant in a fossil condition. Whether the scarcity of the Ophioglossacea as fossils is due to their lack of firm tissues in the leaf, or whether the living forms have become more modified than the Marattiaceæ, it is not possible to decide. The former view seems to 
the writer the more probable, as there are very strong reasons for considering the type of sporangium found in Ophioglossum as the most primitive occurring in the Filicinex.

Very few fossils have been found that can be referred without hesitation to the Ophioglossaceæ. The early Palæozoic genera Rhacopteris and Archcopteris were apparently very much like Botrychium, but it is by no means agreed by all Palaobotanists that they really were related to the Ophioglossaceæ. There are also other Palæozoic genera, which perhaps are quite as much like Botrychium as they are like the Marattiacex, with which they are usually associated, but all of these forms are very doubtful. Ophioglossites antiqua from the Permian is said to resemble closely the spike of Ohiloglossum, and Chiropteris digitata from the upper Triassic has been compared to O. palmatum. In a later formation (Eocene) there has been found a species of Ophioglossum, O. cocenum (Potonié (3), P. 9I).

If the existence of the Ophioglossacea during the earlier geological epochs is somewhat doubtful, this cannot be said of the second family of the Eusporangiatæ, the Marattiaceæ. These evidently comprised the greater part of the Palæozoic Ferns, and many of them were very much like their living descendants. The few existing Marattiaceæ are mostly tropical Ferns, some of great size, such as most species of Marattia and Angiopteris.

The Marattiaceæ have much firmer leaves than the Ophioglossaceæ, with distinct and conspicuous venation, admirably fitted to leave a clear impress in the rocks, and indeed the casts of these, in many cases, might almost have been made from leaves of the living species. The close relationship of many of these fossil Marattiaceæ with the living ones is perfectly evident. Of these undoubted Marattiaceæ may be mentioned the following genera: Ptychocarpus, Asterotheca (Scott (I) Figs. 91, 92), Scolecopteris and Dancites (Potonié, (3), Figs. 76, 79). The two former genera resemble in the form of the sori (synangia) the living genus Kaulfussia. ,Danaites resembles so closely the genus Danea that it may very well be considered identical. All of the genera mentioned occur in the Carboniferous rocks, but also are found in the early Mesozoic. The recent genus Marattia has been found in the latter formations, and of about the same age are Dance-like forms which have 
been described under the name Dancopsis. The other living genera are not known as fossils, although certain fossil genera seem to be related to them. Thus Asterotheca and Scolecopteris have been placed in the Angiopteridex, Ptychocarpus in the Kaulfussieæ.

Besides the forms which are unquestionably to be referred to the Marattiales, there are a good many types of Palæozoic Ferns which show apparent resemblances to the true Marattiaceæ in the structure of the sporangium, but which have the individual sporangium entirely distinct, instead of more or less united with its neighbours as in the typical synangium of most Marattiaceæ. This free sporangium is structurally like that of such forms as Angiopteris, in which the sporangia are nearly separate, and not improbably represents a Marattiaceous type in which this tendency is carried further than in any of the living genera. In still other forms of supposed Marattiaceous affinity, e. g., Urnatopteris (Potonie (3), Fig. 68), the sporangia are borne upon sporophylls, which are completely covered with them, as in the fertile fronds of Osmunda or Botrychium. In all of the living Marattiacer except Danca, the synangia are borne upon unmodified leaves. In Danca, however, the segments of the sporophyll are much contracted, and the large synangia almost completely cover the lower surface of the pinnæ, and in this respect it suggests an approach to those Palæozoic types in which the lamina of the fertile leaves is entirely wanting.

It is not unlikely that some of the Carboniferous Marattiales were more or less synthetic types, connecting the typical Marattiaceæ with the later developed Leptosporangiates. The genus Senftenbergia (Potonié (3), Fig. 86), for example, seems to resemble to a certain extent both Marattiaceæ and Schizæaceæ, while Renaultia (Sturiella) has been compared with both the Osmundaceæ and Schizæaceæ.

The Marattiaceæ seem to have maintained their ascendency well into the Mesozoic. Raciborski (see Scott ( I), p. 303) found in upper Triassic beds about 70 per cent. of the Ferns to be Marattiaceæ; but in lower Jurassic beds there was a remarkable falling off in their number, only about 4 per cent. being referable to the Marattiacea. At the present time their number is less than one per cent. of the living species of Ferns.

While there is some evidence of the presence of leptospo- 
rangiate Ferns during the Palaozoic, none of these forms are beyond dispute. That there were Ferns whose sporangia possessed a well-marked annulus seems certain, but the character of these sporangia is somewhat doubtful. Of forms perhaps allied to the Gleicheniaceæ, may be mentioned the genus Oligocarpia (Scott (I), Fig. 92). Sporangia have also been found with a transverse annulus not unlike that of the Hymenophyllaceæ, and described as Hymenophyllites, and not infrequently sporangia are encountered which suggest the Osmundaceæ, and there is also evidence for the existence of forms allied to the Schizæaceæ.

While the Marattiaceæ were still predominant at the beginning of the Mesozoic, by the time the Jurassic formations are encountered, they are largely replaced by the lower leptosporangiate Ferns. Osmundaceæ and Cyatheaceæ appear to have been the predominant families at this period (Scott (I), p. 304). There were also Schizæaceæ, Gleicheniaceæ, and perhaps Hymenophyllaceæ, but no true Polypodiaceæ have been found in the earlier Mesozoic formations.

A characteristic family of the Mesozoic is that of the Matoniaceæ, which combines characters of the Gleicheniaceæ and Cyatheacere and was represented by very many forms. At present only two species of Matonia survive, rare Ferns of the Malayan region.

The Polypodiacex first appear in the later secondary formations, and from that time have formed the prevailing Fern type.

The remains of the Hydropterides, the heterosporous Ferns, are too meagre and uncertain to throw much light upon their origin.

\section{Cycadofilices (Scott (I), Potonié (3))}

One of the most important results of the work of Palæbotanists during the last decade has been the discovery that many of the supposed Ferns of the Palæozoic were really forms which were intermediate between the true Ferns and Cycads, and hence they have very appropriately been named Cycadofilices. Some of the Cycadofilices were evidently nearer to the Ferns than to the Cycads. Of these may be cited the genera Lyginodendron and Heterangium, which have been very fully 
studied by Scott (I). These had Fern-like foliage, and the structure of the stem was also like that of the Ferns, but there was a marked secondary thickening of the stem, such as is rare in living Ferns, but is known in the larger species of Botrychium. The structure of the stem in Lyginodendron has been compared to that of Osmunda and the Gymnosperms (Scott, l. c., p. 314).

Heterangium has a monostelic stem, which agrees closely with that of Gleichenia, except for the secondary thickening. Both Lyginodendron and Heterangium had leaves like those of a typical Fern. Unfortunately practically nothing is known about their sporangia.

Of the more Cycad-like forms may be mentioned $C y c a d o-$ xylon and Medullosa. While the sporangia of these forms is not certainly known, it is possible that they may have been heterosporous, or even seed-bearing. (For a full account of these important forms, the reader is referred to Prof. Scott's work (Chap. X, XI).

During the past few years there have been found associated with the Fern-like leaves of the "Neuropteris" and "Alethopteris" types, structures which appear to be real seeds, showing that some, at least, of the Cycadofilices were seed-bearing plants. For this reason it has been suggested that the name Pteridospermea be applied to the Cycadofilices (Grand 'Eury (I )).

The peculiar genus Noggerathia (Potonié (3), Fig. I 58) is one of the few spore-bearing fossils, which has been referred to the Cycadofilices.

\section{Equisetineæe $(\operatorname{Scott}(I) ; \operatorname{Seward}(I))$}

To this class are usually assigned two groups of fossil plants, one belonging to the Equisetaceæ, and represented by the genus Equisetites, which evidently was very close to the genus Equisetum, if not identical with it. The other group, the Calamariaceæ, differed in some respects from the living forms, and there is much diversity of opinion about their real affinities. The best known members of this order are the Calamiteæ, whose anatomical structure is well known. Cormack (I) has made a comparison of the structure of these with Equisetum, and comes to the conclusion that the type of structure is essen- 
tially the same. The general points of difference are the completely separate leaves of the Calamites, the frequent absence of diaphragms at the nodes, and the marked secondary thickening of the vascular bundles. Cormack has shown that a slight thickening of the same character occurs in the nodes of Equisetum maximum, and in the Calamites this thickening seems to begin in the nodes and to extend later to the internodes. $\mathrm{He}$ concludes that all the Calamites possessed this secondary thickening of the stem. The two groups Annulariex and Asterophylliteæ, which have slender stems with regular whorls of leaves at the nodes, have been found to be to some extent, at least the smaller branches, of indubitable Calamiteæ; but it is questionable whether this is always so.

The most important remains of this group are the fossils known under the name Calamostachys. These are cone-shaped structures, whose close affinity with Equisetum is beyond question. The whorls of sporophylls, which are peltate, like those of Equisetum, and bear four sporangia upon the lower surfaces, are separated by alternating whorls of sterile leaves. Through the kindness of Dr. D. H. Scott I have had an opportunity of examining a beautiful series of sections of $C$. Binneyana. The structure of the axis and sporangia correspond in the closest manner to those of Equisetum, but a most interesting difference is the fact that this genus was heterosporous. Macrosporangia and microsporangia occurred in the same strobilus, but the difference in the size of the spores is much less than in the living heterosporous Ferns and Lycopods.

The oldest known fossil belonging to the Equisetineæ is Asterocalamites (Archcocalamites), which has been made the type of a special family Protocalamariaceæ. Asterocalamites was structurally very much like Equisetum, from which it differed, however, in the leaves, which were much better developed, and not united into a sheath. The leaves were repeatedly forked, and of considerable size (Scott ( I ), Figs. 28, 29). The cones are not certainly known, but a cone quite similar to that of Equisetum has been found which perhaps belongs to Asterocalamites, and has been attributed to that genus.

The name Equisetites has been given to those fossil Equisetaceæ which closely resemble the living genus Equisetum. In the Triassic and Jurassic were numerous arborescent Equisetaceæ which closely resembled the living genus Equisetum, but 
showed a secondary growth in thickness which is almost entirely wanting in all the living species. These great horsetails rapidly disappear from the later formations.

The genus Equisetites has also been reported from the later Palæozoic formations, but there seems some question whether these are not more nearly allied to the Calamariaceæ.

Two other Mesozoic genera have been described, which probably are allied to the Equisetaceæ, but they are too imperfectly known to make this at all certain. These are Phyllotheca and Schizoneura. Both had the characteristic jointed stems with the leaves more or less completely united into sheaths about the nodes, as in Equisetum, but the leaves were better developed than in that genus. (See Seward (I), Figs. 68, 69).

The oldest known member of the class, Asterocalamites, has been found in the middle Devonian. In the later Devonian the true Calamites appear and increase rapidly in numbers durthe Carboniferous, disappearing before the Trias, when their place is taken by forms closely allied to the living Equisetacer.

\section{Sphenophyllales}

The Sphenophyllales comprise a small number of extremely peculiar fossils, belonging mainly to the Palæozoic, but extending into the earlier Mesozoic also. Aside from the fructifications which have been attributed to them, and some of which have been described under other generic names, they have all been referred to a single genus, Sphenophyllum. They were plants with slender, jointed stems, resembling more nearly those of the Equisetaceæ than any other living Pteridophyte. About the nodes were whorls of wedge-shaped leaves, in some cases dichotomously divided, and not unlike those of Archeocalamites. (Potonié (3), Figs. I72-75).

The anatomy of the stem is very different from that of the true Equisetales, having a single central vascular cylinder, in some respects like that of the typical Lycopods. It has been compared to that of Psilotum or Tmesipteris. (Scott (I), Figs. 34, 35).

The fructifications of undoubted species of Sphenophyllum have been found, and the fossils described under the names Bowmanites and Cheirostrobus are supposed to have been the 
cones of Sphenophyllaceæ. These cones (Scott, (I), Figs. 33, 39-44) on the whole most nearly resemble those of the Calamariacex, having whorls of sterile bracts between the whorls of sporangiophores. Prof. Scott, to whose researches is due the account of the very peculiar Cheirostrobus, thinks that this combines the characters of the Equisetinex and Lycopodinex, and indeed looks upon the Sphenophyllales as a synthetic group, intermediate between Equisetineæ and Lycopodineæ.

Potonié ( (3), p. 204) considers that the Sphenophyllacex represents an off-shoot from the Protocalamariacex, and are in no way allied to the Lycopods.

According to Potonié (l. c., p. I82) it is probable that Sphenophyllum existed for the Silurian, but Seward ( ( I), p. 4I3) says that all of the fossil Sphenophylla of pre-Carboniferous age, are of doubtful authenticity, although he thinks they probably date from the Devonian.

\section{Lycopodineas (Potonié (3); Scott (I); Solms-Laubach (2))}

Many fossils undoubtedly belonging to the Lycopodinex are found in Palæozoic formations, being especially abundant in the Coal Measures, where many arborescent types are conspicuous features of the flora. Of the smaller fossil forms, it seems pretty certain that several described under the generic name Lycopodites are closely related to the living genus $L y c o$ podium. Like the living species, some of these fossil forms are homophyllous, others heterophyllous. In many instances, these fossil Lycopodiacea have the strobili preserved, so that there is no doubt of their real nature, although it cannot be certainly shown whether they were homosporous or heterosporous, and it therefore is doubtful in many cases whether they are more nearly allied to Lycopodium or Selaginella. It is quite possible (Potonié (3), p. 259) that Lycopodites Stockii, from the lower Carboniferous, and $L$. elongatus, for example, may be properly referred to the genus Lycopodium.

The arborescent Lycopods, belonging to the families Lepidodendraceæ and Sigillariaceæ are among the most characteristic of all fossils, and occur in great numbers, especially in the Coal-measures.

The Lepidodendraceæ were plants of large size, which must 
have closely resembled, except for their much greater dimensions, such species of Lycopodium as L. cernum or $L$. dendroideum. The branching was prevailingly dichotomous, and the shoots thickly set with acicular leaves of a size corresponding to the dimensions of the shoots. Sigillaria seems to have been much less freely branched than Lepidodendron, and it has even been supposed that in some species branching was entirely suppressed. Of the living species of Lycopodium, $L$. inundatum or L. saururus may be compared in habit to Sigillaria. Trunks of Lepidodendron a hundred feet in length have been found, showing the genuine tree-like proportions of these giant Club-mosses.

The base of the stem in both Lepidodendron and Sigillaria is often found connected with forking structures, which were originally described as distinct fossils under the name Stigmaria. It is clear, however, that these were the underground parts of Lepidodendron and Sigillaria, probably rhizomes rather than true roots. The name Stigmaria is given them because of the very regular scars upon the surface, and these have been shown to be the points of attachment for roots-or rootlets, if the main Stigmaria branches are true roots and not rhizomes (see Scott (I), Fig. 82).

The slender pointed leaves were often of considerable length, I 5 centimetres or more, and resembled those of Selaginella rather than Lycopodium in having a ligule near the base. (See Scott (I), Figs. 48, 58).

The internal structure is well known in a good many forms, especially among the Lepidodendraceæ (Scott ( $\mathrm{I})$ ), and it is evident that there was a good deal of difference among them, especially in the degree of secondary thickening which occurred.

In all known species of Lepidodendron (Scott ( I ), p. I23) there is always a single stele with centripetally developed primary wood. There may or may not be a central pith. In the larger stems there is usually a central medulla about which the primary wood forms a ring. Probably the phloem, which is rarely well preserved, formed a ring outside the xylem. The cortex is relatively very thick, as it is in the living Lycopodineæ, and through it passed obliquely the leaf-trace bundles, one being given off from the central stele of the stem to each leaf-base.

While in some species, e.g., L. paroulum, there was appar- 
ently no formation of secondary wood, in the majority of the known species a zone of cambium arose outside the primary wood, and from this were developed zones of secondary xylem and phloem, precisely as in the Conifers and Dicotyledons. The structure of the secondary wood, with the conspicuous medullary rays, is strikingly like that of the wood of the Conifers ( Scott (I), Figs. 53, 56).

In addition to the secondary increase in thickness in the stem due to the activity of the cambium, there was also a secondary thickening in the cortical region due to the formation of a periderm, or cortical cambium. This mode of thickening has been compared to that in Isoetes, and it also is not unlike that in arborescent Monocotyledons, such as Dracana and Yucca.

In Sigillaria, whose stem structures are seldom well preserved, there was in most cases a ring of separate vascular bundles and a large central pith, and in the former respect the typical Sigillaria stem is even more like that of the Conifers than is that of Lepidodendron.

In both Lepidodendron and Sigillaria the structure of the leaves was more complicated than that of the living Lycopods, and in certain respects they recall those of the Conifers (Scott ( I), Pp. I48,.204).

The sporophylls of the Lepidodendracea were arranged in cones or strobili, closely resembling those of their living relations. (Scott ( I ), Figs. 47, 48, 65). The strobili have been described under the name of Lepidostrobus. The sporangia were very much larger than those of any living Pteridophytes, in Lepidostrobus Brownii reaching a length of two centimetres. In their large size and. sessile position, they suggest the sporangium of Isoetes, with which they agree also, according to Bower (I5) in the development of partial trabeculæ. The structure of the sporangia has in many cases been preserved with wonderful perfection, and the spores themselves are often encountered. In some species, e. g., L. Oldhamius, spores of only one kind are known ; in others heterospory is very evident. Whether the former type is really homosporous, or whether, as yet, only microspores have been found, is not certain.

Another type of lycopodiaceous cone has been found and has received the name Spencerites (Scott (I), Fig. 7I). The sporangia in Spencerites were short-stalked, and evidently not very 
different in form from those of Lycopodium. The spores are very peculiar in having a sort of wing, suggesting the appendages of the pollen-spores of Pinus.

It seems extremely probable that in some of the Palæozoic Lycopodinea seeds were developed. The fossil seed described as Cardiocarpon has been shown to be borne upon a cone which is almost identical with Lepidostrobus.

\section{Psilotace $x$}

Certain fossil remains have been classed with the Psilotaceæ, but there is much doubt as to the accuracy of these conclusions. Solms-Laubach (2) says: "The statements respecting fossil remains of the family Psilotacex are few and uncertain, nor is this surprising in such simple and slightly differentiated forms. If $P$ silotites .... does really belong to this group, a point which I am unable to determine from the figures, we should be able to follow the type as far down as the period of the Coalmeasures."

The genus Psilophyton, which has been found in the upper Silurian, is regarded by Dawson as related to the Psilotacex, but there seems to be much question about the accuracy of his conclusions. 


\section{CHAPTER XVII}

\section{SUMMARY AND CONCLUSIONS}

\section{The Interrelationships of the Archegoniate}

IT is pretty generally conceded that the origin of the whole archegoniate series is to be sought somewhere among the green Algæ, and that on the whole Coleochate is, perhaps, the form which is nearest to the simplest Muscineæ. While the Characeæ, as we have seen, approach the latter more nearly in the structure of the sexual organs, yet the character of the vegetative parts is so different from that of any of the Muscinex, and the sporophyte is so simple, that any close relationship of the two groups is hardly probable. At best, the connection bebetween any known Alga and the Muscineæ is a very remote one.

From a study of the facts presented in the foregoing pages, the conclusion has been reached that the Liverworts are not only the most primitive of the existing Archegoniatæ, but are also the forms from which all the other groups have descended. When, however, the question arises as to which of the existing groups of Liverworts is the most primitive, the matter is not so easy to settle. Thus while Riccia undoubtedly has the most primitive sporophyte, the gametophyte shows a much higher degree of differentiation than is found in most anacrogynous Jungermanniaceæ or in the Anthocerotes. The latter group, while retaining an extremely simple type of gametophyte, has the sporophyte developed beyond that of any other Liverworts.

It will be remembered that in the germination of most thallose Liverworts (and occasionally in the foliose forms as well) the occurrence of a single two-sided apical cell is quite general, although this may be absent from the fully-developed 
gametophyte. This suggests the possibility of a derivation of all of them from some type in which this two-sided apical cell was permanent. Aneura and Metzgeria, among living genera, have retained this condition, and in this respect are possibly to be considered as representing the simplest type of the thallus. The peculiar gemmæ of the former, which may properly be compared to the zoöspores of Coleochate, strengthen this view.

The peculiar chromatophores of the Anthocerotaceæ, as well as the structure of the sporophyte, make it conceivable that they have originated independently from forms lower than any existing Liverworts. It is quite possible, however, that the Hepaticæ and Anthocerotes represent two branches from a common stock, the multiple chromatophores of the true Hepaticæ being secondary, while Anthoceros has retained the primitive single chromatophore, which has been replaced by the multiple type in the other Archegoniates.

Starting from the primitive type, found in Aneura or Metzgeria, we have endeavoured to show that development proceeded along two lines-the Marchantiales and the Jungermanniales. In the first one the differentiation consists mainly in the specialisation of the tissues, while the gametophyte retains its strictly thallose character; in the Jungermanniacex it is rather in the direction of the development of appendicular organs, while the tissues remain nearly uniform. In both of these groups the sporogophyte is comparatively simple, in strong contrast to the Anthocerotes. The great preponderance of the foliose Liverworts indicates that they are comparatively modern types, which have adapted themselves to present conditions, and show no indications of being connected directly with any higher forms.

Whether the Anthocerotes are considered to have been derived from the lower Hepatica, or whether they have originated independently of these, the differences are too great to consider the group merely an order of the Hepaticæ, coördinate with the Marchantiales or Jungermanniales. Aside from the peculiarities of the gametophyte, especially the primitive type of chromatophore, the structure of the sporophyte of all the Anthocerotes is radically different from that of the true $\mathrm{He}$ paticæ, and forbids a direct association with any of them.

Just as the simplest Jungermanniales may have served as a starting-point for the two main lines of development in the 
Liverworts, so the Anthocerotes suggest the course of development which resulted in two other lines, the Mosses and the Pteridophytes. Whether the former class constitutes a continuous series, beginning with Sphagnum, or whether the Sphagnaceæ and the higher Mosses represent two branches from a common stock, it seems extremely likely that the thalloid protonema of Sphagnum is the primitive condition derived from some Liverwort-like form similar to Anthoceros, and that the alga-like protonema of the higher Mosses is a secondary development from it. The extensively branched protonema is probably an adaptation associated with the rapid propagation of the gametophyte, as the number of leafy shoots produced from such a protonema, is far greater than is possible from a thallose protonema like that of Sphagnum.

In tracing the gradual evolution of the sporophyte among the Muscineæ we have seen how, starting with the simple sporogonium of Riccia, which, physiologically, is only a sporefruit and quite incapable of independent growth, it gradually becomes more and more independent by the development of a special system of assimilative tissues, which reaches its extreme in Anthoceros. It is true that the sporogonium always remains to some extent parasitic upon the gametophyte, but this parasitism is very slight in Anthoceros, where the formation of a root would make the sporogonium quite self-supporting. This increase in the vegetative tissues of the sporophyte is at the expense of the sporogenous tissue, which becomes more and more subordinated to the assimilative and conductive tissue of the sporogonium, as is seen in the Bryales among the Mosses, and in Anthoceros.

In most of the Liverworts the sterile tissues of the sporogonium are mainly concerned with the protection and dissemination of the spores. Only the foot, usually, can be properly considered as an organ concerned in the nourishment of the growing embryo. The seta, capsule wall, and elaters are merely adaptations for facilitating the dispersal of the ripe spores. In all of the Hepaticæ, the whole of the central tissue of the capsule constitutes the archesporium, all of whose cells are devoted to the formation of spores or elaters. In the Anthocerotes, however, the origin of the archesporium is quite different, and it arises not from the central cells, but by a secondary division of the parietal ones. As yet there is no clear 
evidence of a direct connection with either of the series of the Hepaticæ, and it is probable that the Anthocerotes should form a class coördinate with all the other Liverworts on the one hand, and the Mosses on the other. It is possible that the axial bundle of sterile cells found in the capsule of Pellia and Aneura may be homologous with the columella of the Anthocerotes, and the latter therefore to be considered as derived directly from some simple form among the anacrogynous Jungermanniaceæ; but as the sporogonium in all the Anthocerotes that have been thoroughly investigated shows absolutely the same type of structure, and in no case a secondary formation of the columella, this is hardly probable. In the higher Anthocerotes, also, the wall of the capsule, instead of simply serving for the protection of the spores, becomes a massive spongy green tissue communicating with the atmosphere by means of perfectlydeveloped stomata of exactly the same type as those of the vascular plants. This similarity in the assimilative system, together with the basal growth of the sporophyte and the central strand of conductive tissue, has of course suggested a relationship with the vascular plants. Indeed the sporogonium of Anthoceros is much more like the spike of a small Ophioglossum, for example, than it is like the sporogonium of Riccia.

The Mosses, like the foliose Liverworts, seem to represent a modern, extremely specialised type, with no direct connection with higher forms. Probably related to the Anthocerotes through Sphagnum, their further development has diverged farther and farther away from the other Archegoniatæ, until in the Bryinex both gametophyte and sporophyte have little in common with them. In both cases, an extreme specialisation is attained which has no parallel among the Hepaticæ; but whether it is the highly developed leafy gametophoric shoot of Polytrichum or Dawsonia, or the equally complex sporogonium of the same forms, the resulting structures are very different from the corresponding ones in the vascular plants.

The complete emancipation of the sporophyte is first attained in the Pteridophytes. The development of a true root at once establishes the independence of the sporophyte, and inaugurates a new era in the history of the Plant Kingdom, as there is at last developed a plant type, essentially terrestrial in its habit. Throughout the Pteridophytes it is the sporophyte, 
or neutral generation, which claims our principal attention, and not the much reduced gametophyte.

The three classes of the Pteridophytes, while they differ strongly in the form of the sporophyte, are yet so much alike in the essential characters of the sexual generation, as to make it inconceivable that they can have originated from very widely divergent ancestors. The more closely the gametophyte is studied in all of them, the more evident becomes the strong resemblance to the Anthocerotes, whose sporogonium has always been recognised as the nearest approach to the sporophyte of the vascular Archegoniates. This is notably the case when we consider the structure and development of the sexual organs, which in the Anthocerotes differ so remarkably from those of the other Muscinex. Whether the submersion of the archegonia and antheridia in the thallus is the result of the cohesion of an envelope, such as is formed about these in Spharocarpus or Riccia, it is impossible to say, but there is no trace of any such process in the development of the sexual organs in any of the investigated species.

The probable homology of the four-rowed neck of the archegonium of the Pteridophytes with the cover cells only of the Liverwort archegonium, has already been discussed at length in a preceding chapter. It is quite possible that a similar correspondence may exist between the antheridium in the lower Pteridophytes and the Anthocerotes. It will be remembered that in the latter the single antheridium, or group of antheridia, arises from the inner of two cells formed from the division of a superficial cell of the thallus, and that the inner cell may either give rise to a single antheridium, or more commonly, by repeated longitudinal divisions, a group of antheridial mother cells is formed. The whole process is strikingly different from the development of the superficial antheridia in the other groups of Liverworts. In all of the homosporous Pteridophytes except the leptosporangiate Ferns, however, the first division in the antheridial cell is exactly as in the Anthocerotes; but instead of the inner cell developing into a distinct antheridium, the whole of it is devoted to the formation of sperm cells. It seems not improbable that this type of antheridium may have been derived from one like that of the Anthocerotes by the suppression of the parietal cells of the antheridium.

Aside from the forms without chlorophyll, which are prob- 
ably all secondary, the Pteridophytes show four types of gametophyte. The first, represented by most homosporous Ferns, is the familiar heart-shaped prothallium, which strongly recalls the simpler anacrogynous Jungermanniaceæ or Dendroceros; the second is the lobed prothallium of Equisetum, which resembles most nearly among the Liverworts such forms as Anthoceros fusiformis, but has an analogy also in the lobed prothallia sometimes met with in Osmunaia. In some species of Trichomanes and Schizcea there occur the branched filamentous prothallia, which some authors look upon as an indication of direct relationship with forms intermediate between Algæ and Muscineæ. As other species of Trichomanes have the same type of prothallium as the other Ferns, and this is always true of the closely related genus Hymenophyllum, this view is open to question. The green prothallium of Lycopodium cernum differs from the somewhat similar one of Equisetum, in the essential point that in the former we have to do with a radial structure, in the latter with a dorsiventral one. The upright gametophyte of Lycopodium, with its terminal circle of leaf-like lobes, might be compared to a leafy Moss-shoot, although it is hardly probable that this resemblance is more than superficial.

As far as the form and growth of the prothallium are concerned, all forms except Lycopodium could be traced back to the Anthocerotes; the Fern type to forms like Dendroceros or Anthoceros lavis, the Equisetum type more resembling $A$. fusiformis. The difference in the character of the chromatophores is a very important one, and at present must forbid the assumption of any immediate connection between the Anthocerotes and existing Pteridophytes. Whether the occasional appearance of very large plate-like chromatophores in the prothallium of Osmunda cinnamomea (Campbell (I2)) is a reversion to a primitive condition retained in the Anthocerotes, it is, of course, impossible to say, but it is not inconceivable, especially as the same thing is found again normally in the sporophyte of Selaginella. The regular doubling of the chromatophores in the sporophyte of Anthoceros also suggests that the multiple chromatophores of most Archegoniates are secondary.

In the Anthocerotes the origin of the archesporium is different from that of the other Hepatica, being hypodermal, as in the lower Pteridophytes. The columella is in position similar to the primary vascular bundles in the embryo of the Pterido- 
phytes, and in all probability is to be regarded as its homologue. This central strand of conducting tissue, together with the massive assimilative tissue system of the larger species of $A n$ thoceros, would make the sporogonium independent of the gametophyte, were a root or some similar. structure present by which it could be connected with the earth. The alternation of sporogenous and sterile cells in the archesporium, by which the latter is divided into imperfect chambers containing the spores, is, perhaps, the first indication of the separate sporangia of the Pteridophytes. The most striking difference, then, between the sporogonium of Anthoceros and the sporophyte of the simpler Pteridophytes, such as Ophioglossum and Phylloglossum, aside from the absence of roots, which are, physiologically, replaced by the massive foot, is the absence of a definite axis with its lateral appendages (leaves) and sporangia. In Anthoceros the assimilative tissue forms a uniform layer over the whole upper portion of the sporophyte, instead of being restricted mainly to the special organs of assimilation or leaves, and the archesporium is continuous instead of being divided into definite sporangia. It has been claimed by Bower, however, that in Ophioglossum also there is originally a continuous layer of sporogenous tissue, and the formation of the sporangia is secondary.

Many attempts have been made to explain the origin of the leafy axis of the sporophyte of the vascular Archegoniates from the Bryophyte sporogonium. The latest theory is that of Professor Bower ( I6), who has brought forward much important evidence to show that the simpler strobiloid Pteridophytes, especially Phylloglossum, are the primitive forms from which the others have sprung. His conclusions are based largely upon a comparison of Phylloglossum with the embryonic condition of Lycopodium, where the long dependence of the embryo upon the prothallium, the rudimentary vascular bundles, and the late appearance of the root are very striking, and certainly indicate a very low rank for these forms in the pteridophytic series. Another evidence of the close relation of the Lycopodineæ to the Bryophytes is the character of the spermatozoids, which closely resemble those of the Liverworts, both in their small size and the two cilia. Professor Bower's theory as to the origin of the sporophytes is that these arose "by a process of eruption from a hitherto smooth surface." In this way 
he conceives that the smooth cylindrical sporogonium became transformed into a structure directly comparable to the strobilus of Phylloglossum. The sterile leaves, as well as the root, are supposed to be outgrowths of the protocorm, which latter is directly comparable to the massive foot in Anthoceros, whose upper limit is the meristematic zone of cells at the base of the capsule. Bower summarises his conclusions as follows: "The chief points which have been recognised thus far, and are believed to have been the important factors in advance, are: (I) sterilisation of potential sporogenous tissue; (2) formation of septa; (3) relegation of the spore-producing cells to a superficial position; and (4) eruption of outgrowths (sporangiophores) on which the sporangia are supported."

Professor Bower's explanation of the origin of the Lycopodineæ is certainly the most satisfactory that has yet been given, and we may accept without much question his conclusion, that Phylloglossum is on the whole the simplest known Pteridophyte; but his further conclusion that the Ferns are also probably reducible to a strobiloid type is ky no means convincing.

The conclusion reached by the author, after considerable study of the subject, is that in the Ferns, and probably also the Equisetineæ, we have to deal with entirely distinct lines of development. That is, while all three groups of the existing Pteridophytes may perhaps be traced back to a common stock, closely allied to the Anthocerotes, the three lines became differentiated at a very early period, and the differences are so great that it is difficult to see how any one of them could have been derived directly from either of the others. In the Lycopodineæ and Equisetineæ the axis is developed much more strongly than the leaves, and the sporophylls are usually aggregated into a more or less definite strobilus. The origin of the strobilus in the Equisetinea may have been similar to that in Lycopodium; but the sporangia themselves, as well as the structure of the tissues and the prothallium, are more like those of the Ferns, and make it extremely improbable that the strobilus is homologous with that of the Lycopodineæ. In the very definite apical growth of the stem and root, as well as in the structure and arrangement of the vascular bundles, Equisetum approaches much more nearly the condition found in Ophioglossum than that of the Lycopodineæ; and the large multiciliate spermatozoids, and the early divisions of the embryo, are also 
suggestive of the Ferns rather than of the Lycopods. Of course the fact that our knowledge of the Equisetinea is largely based upon the single genus Equisetum, makes it unsafe to lay too much stress upon conclusions drawn from a study of this single type. However, such of the fossil forms as show unmistakable evidence of belonging to the Equisetineæ, conform closely in their structure, so far as it is known, to the living types. The relatively large dichotomously branched leaves of 'Archcocalamites, the oldest known member of the class, indicate that the extremely reduced leaves of the later forms are secondary. The form of the leaves in these ancient Equisetineæ is suggestive of filicinean rather than lycopodinean affinity.

In the Filiciner the development of the leaves is usually much greater than in either of the other classes, and the origin of the sporophyll is probably different. Bower considers the sporophyll of Ophioglossum, for example, as the homologue of a single sporophyll of Lycopodium, and the whole sporangial spike as equivalent to a single sporangium. With this view the author feels that he cannot agree, and it seems to him more likely that the origin of the Fern-type of sporophyte was quite different from that of the Lycopodineæ, and that there is, nothing among the Ferns comparable to the strobilus of the latter.

If we could imagine the meristem at the base of the sporogonium of Anthoceros to produce a lateral flattened appendage or leaf, and the foot to develop into a root penetrating the thallus into the earth, we should have a structure not very unlike a small Ophioglossum. In this case the sporangial spike would represent, not a single sporangium of Phylloglossum. but the whole strobilus, and the sterile segment of the leaf would then be comparable rather to the sterile leaves (protophylls) than to a single sporophyll. That the sporophyte in the Bryophytes can develop a special assimilatory organ comparable to a leaf, is seen in the apophysis of many Bryales. This is especially conspicuous in some species of Splachnum, where it might almost be compared to a perfoliate leaf.

The recent discovery of the remarkable Ophioglossum simplex (Bower (20)) is especially important in this connection. In this species there is no sterile segment to the leaf, and the sporogenous spike must be considered a terminal structure. A comparison of the younger stages of $O$. pendulum with $O$. sim- 
plex, shows that in the former also it is not improbable that the spike is really terminal, and the lamina of the leaf a lateral appendage of it as it is assumed it must have been in the ancestral form.

While the Lycopodineæ correspond closely to the Bryophytes in the form of the spermatozoids, these in the other Pteridophytes are large and multiciliate. Whether these peculiarities have arisen independently in the Filicinex and Equisetineæ, or whether they are inherited from some common ancestor, there is no means of deciding, but the latter view is probably the correct one, and it is likely that the two classes have a common, but extremely remote origin. None of the Muscinea, so far as is known, depart from the biciliate type, but among Algæ CEdogonium offers a similar exception to the usual biciliate form.

The Lycopodiacex and Selaginellex constitute a sufficiently direct series, but the exact affinity of the Psilotacex to these is by no means clear. Our complete ignorance of the sexual stage of the latter, as well as their parasitic habit, makes it impossible to judge just how far their simple structure is primary and how much is due to reduction. More evidence also is required in regard to their assumed affinity with the Sphenophyllaceæ.

The reasons for regarding the eusporangiate Ferns as the lowest of the Filicineæ have already been given at length, but may be summarised as follows: (I) The structure of the gametophyte and sexual organs corresponds more nearly to that of the Liverworts than do those of the Leptosporangiatæ, and the prothallium is larger and longer lived than in the latter; (2) the embryo remains much longer dependent upon the gametophyte, and the latter may live for a long time after the sporophyte becomes independent; (3) the differentiation of the organs and tissues of the embryo takes place later than in the Leptosporangiates, and the tissues of the mature sporophyte are also simpler than in most of the latter; (4) the sporangia of the Eusporangiatæ, especially Ophioglossum, are of a much less specialised type than in the typical leptosporangiate Ferns, and approximate more nearly the condition found in Anthoceros; (5) the small number of species of the Eusporangiata, but the wide divergence of type shown, especially by the two groups of the Ophioglossaceæ and Marattiaceæ, indicate that these are remnants of formerly more predominant forms. Finally, the 
strong evidence of the geological record that the Eusporangiatre were the prevailing types in the earlier formations, and have been supplanted by the more specialised Leptosporangiatæe in more recent times, is reasonably conclusive.

Owing to the very small number of living Eusporangiatæ, the relationships of these among themselves and to the Leptosporangiatæ are difficult to determine. From the frequent occurrence of dimorphic leaves among the older fossil types of Ferns, as well as on grounds of comparative morphology, the type of leaf in the Ophioglossaceæ is probably to be considered a more primitive one than that of the living Marattiaceæ. Of the existing genera of Marattiaceæ, Danca is the only one in which the sporophylls differ in form from the sterile leaves, and this dimorphism probably indicates that on the whole it is the most primitive of the living genera. Whether the extreme type of synangium found in Dancea is older than the nearly free sporangia such as those of Angiopteris, has been questioned, as both types are found among the Palæozoic Marattiaceæ; but the greater specialisation shown in the latter type indicates that it is of more recent origin. There is a possibility that the two types represent two lines of development originating from different stocks comparable to Ophioglossum and Helminthostachys among the Ophioglossacex. The occurrence of Ferns of unmistakable Marattiaceous affinity, but with fertile leaf segments completely covered with free sporangia like those of Botrychium or Osmunda supports this view.

While in such species of Botrychium as $B$. Viginianum, there is a strong resemblance in the tissues to the lower leptosporangiate Ferns, it is not so marked, on the whole, as those in the Marattiaceæ, which probably are nearer the Leptosporangiatæ, and probably have given rise directly to them.

The homosporous Leptosporangiatæ or Filices constitute a very natural order. The Osmundaceæ are without much question the most primitive members of the order, this being indicated both in the gametophyte and sporophyte. While they show certain points of resemblance to Helminthostachys and Botrychium, their affinities seem to be rather with the Marattiaceæ, and presumably they have arisen from some Palæozoic Marattiaceæ with free sporangia borne upon special leaf segments. It is not impossible that two others of the lower families the Schizæaceæ and Gleicheniaceæ, may have originated 
separately from forms like the Marattiaceæ, and not from the Osmundaceæ as is usually assumed, although there is evidence of a not remote relationship with the latter.

The affinities of the Gleicheniacer Cyatheacer and Polypodiaceæ are very apparent. The Hymenophyllaceæ, while probably of pretty ancient origin, form an aberrant group which has become a good deal changed on account of its peculiar habit of life. The Polypodiacex are par excellence the modern Fern type.

The two heterosporous families, the Marsiliaceæ and Salviniaceæ, are independent developments. The former are probably allied to the Schizæaceæ, the latter to Cyatheaceæ or Hymenophyllaceæ.

The development of heterospory in the different groups of the Pteridophytes is of especial interest, from its bearing upon the question of the origin of the Spermatophytes. That heterospory arose in a number of widely remote groups is unquestionable. While among the living Pteridophytes it is confined to the Ferns and Lycopods, the very perfect fossil remains of Calamostachys show that heterospory was also developed in the Equisetineæ, although apparently the difference between the two sorts of spores was less marked than obtains in the other two classes. In the leptosporangiate families, the Marsiliaceæ and Salviniacex, although there is great reduction in the size of the prothallium, its development is essentially the same as in their homosporous relatives, and the female prothallium, if unfertilised, usually develops chlorophyll, and is capable of independent growth; but in the Isoetacer and Selaginellacex the formation of the female prothallium is much more like that in the Spermatophytes, and makes it extremely likely that from some such forms the latter have been derived.

The microsporangia of the Spermatophytes do not differ essentially from those of the heterosporous Pteridophytes, and the microspores (pollen spores) are shed before germination. The macrospore (embryo-sac), however, is retained within the macrosporangium (ovule), where it remains during the whole period of germination. Among the Pteridophytes Selaginella approaches this condition, as the macrospore is retained within the sporangium until germination is far advanced. The integument of the ovule is, with very little question, homologous with the indusium. The young macrosporangium of Azolla is 
extraordinarily like a developing ovule, and the closely investing indusium has all the appearance of an ovular integument. The velum of Isoetes is possibly of the same nature.

The development of heterospory in several unrelated groups of Pteridophytes at once suggests the possibility of a multiple origin for the Spermatophytes. The radical differences between Gymnosperms and Angiosperms, and the absence of any truly intermediate forms, make it extremely probable that these two great divisions have originated independently of one another, probably from different stocks, and it is by no means unlikely that the same may be said of the Cycads, Conifers, and Gnetacex.

The discovery of motile spermatozoids in Cycads and Ginkgo (Ikeno ( 1,2 ) ; Hirase (I); Webber (I)), and the recent studies upon Palæozoic seed-bearing plants all make it certain that the seed-habit has developed quite independently in several widely separated groups.

Except for their siphonogamic fertilisation, the Gymnosperms really are much nearer the Pteridophytes than they are to the Angiosperms. As both the pollen tube and the seedformation are but further developments of heterospory, it is quite conceivable that these might have arisen independently more than once. The close resemblance between the Conifers and the Lycopods, especially Selaginella, probably points to a real relationship. The strobiloid arrangement of the sporophylls, as well as the development of the prothallium and embryo, are extraordinarily similar, and it is not unreasonable to suppose that this is something more than accidental. The strong resemblance between the method of the secondary thickening of the stem in the arborescent fossil Lycopodineæ, and that of the Conifers, as well as the anatomy of the leaves suggests a real affinity. It is known that some of these bore seeds, which in structure and position may very well be compared to those of typical Conifers. The prevailingly dichotomous branching of Lepidodendron, however, is very different from the type of branching in the typical Conifers.

Recent studies on the Cycadofilices, and the discovery of spermatozoids in the living Cycads, proves beyond a doubt the origin of the latter from Fern-like ancestors.

The most recent evidence seems to support the old view that Isoetes belongs in the series of the Lycopodineæ; nevertheless 
the gametophyte and embryo show characters that are more like those of the Ferns, and the exact position in the system of Isoetes must still remain somewhat doubtful.

The Angiosperms are in all probability all members of a common developmental series, but just what is their relation to one another and to the other vascular plants is not so evident. It is usually held that they have been derived from the Gymnosperms through the Gnetaceæ, but it has also been suggested that one or both of the divisions may have originated directly from the Pteridophytes. Attention has been called more than once to the close resemblance between the embryos of the Filicinex and those of typical Monocotyledons, and this is especially the case in Isoetes, where, in addition, the structure of the mature sporophyte is much like that of the Monocotyledons. It is possible that the surrounding of the sporangium by the base of the sporophyll may be the first indication of the ovary of the Angiosperms, but as this applies to the microsporangia as well, much stress cannot be laid upon it. It is quite as easy to trace back the embryo-sac of the Angiosperms to the macrospore of Isoetes as to the embryo-sac of the Gymnosperms; and when the great similarity between the sporophyte of the former and the Monocotyledons is considered, the probability of the origin of the latter from aquatic or semi-aquatic ancestors resembling Isoetes is certainly considerable.

The essential similarity in the structure of the embryo-sac in all Angiosperms yet examined, as well as the structure of the flower, makes it almost inconceivable that the two branches, Monocotyledons and Dicotyledons, could have arisen from different stocks. Strasburger's suggestion that the Dicotyledons were derived directly from the Gymnosperms, and that the Monocotyledons are a reduced branch of the former, is open to objections both on morphological and palæontological grounds, and we believe that the evidence we have at present points to the Monocotyledons as the more primitive of the two divisions of the Angiosperms, from which later the Dicotyledons branched off. It is true that the researches of the past ten years (Coulter (4)) show that there is less uniformity in the structure of the embryo-sac than was supposed to be the case; but there is no question as to the essential similarity in structure in all Angiosperms. It is also becoming evident that the dicotyledonous habit may have developed more than once. 
To summarise briefly: the conclusion reached is that the Spermatophytes represent not one single line of development, but at least two, and perhaps more, entirely independent ones, having their origin from widely separated stocks. The Gymnosperms (at least the Conifers) are probably direct descendants of some group of Lycopods allied to the Selaginellaceæ, or Lepidodendraceæ, while the origin of the Cyads and Angiosperms is to be looked for among the eusporangiate Filicineæ.

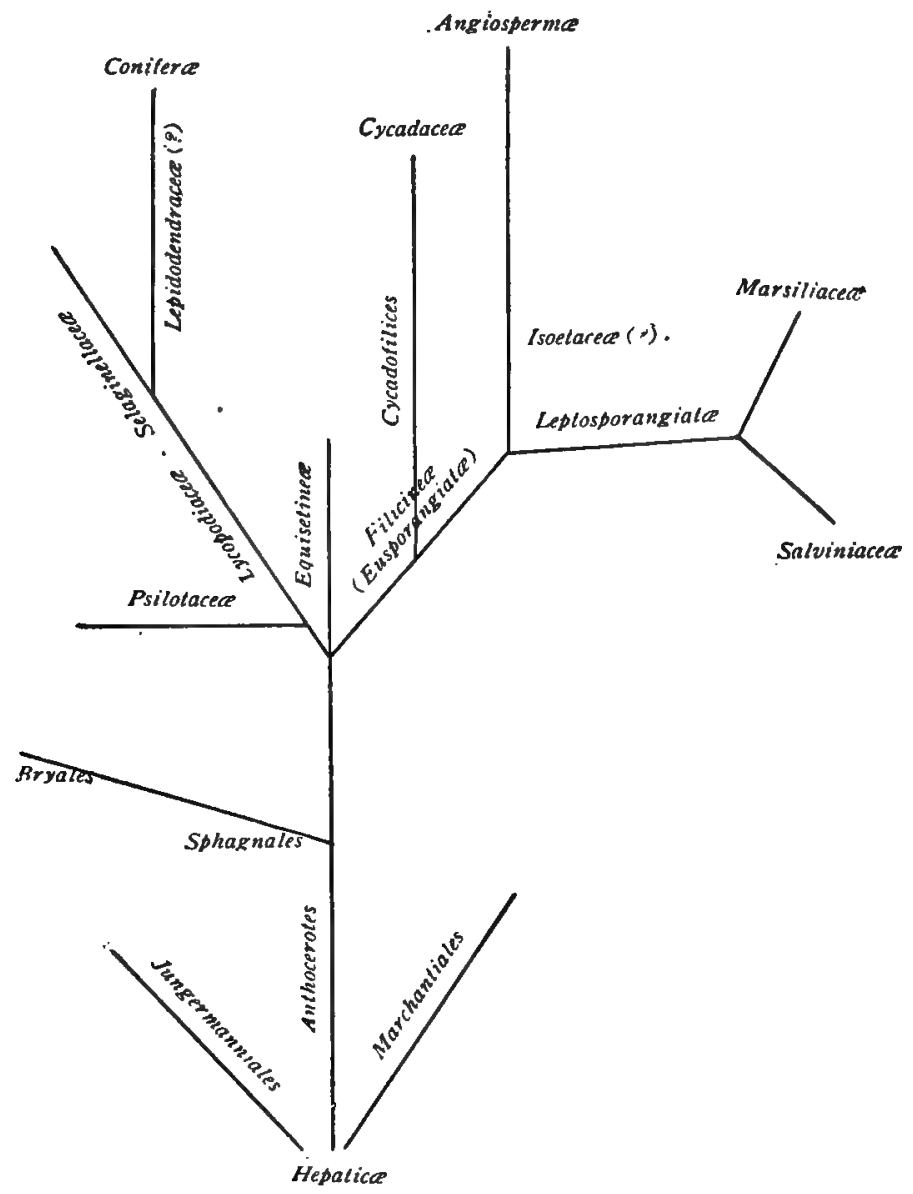




\section{APPENDIX}

\section{CHAPTER II}

P. 9. The occurrence of gemmæ of endogenous origin has also been observed in other species of Aneura, and the multicellular gemmæ of Metzgeria have been found to originate also in much the same manner. (Goebel (8), Cavers (9), Evans (3).) Recently Buch (I) has described unicellular gemmæ of endogenous origin in a leafy liverwort, Haplozia caspitica.

P. Io. A recent study of Sphagnum (Bryan (I)) shows that in this Moss the apical growth of the archegonium is very limited. The terminal cell (cap cell), early undergoes a vertical division, and no basal segments are cut off from it. In a number of Liverworts, on the other hand, there is a limited apical growth (Campbell $(37,39)$ ), although none of the canal cells arise from the terminal cell. It is thus clear that the differences between the archegonium in the Liverworts and Mosses are less marked than has hitherto been supposed.

P. I2. The origin of the sexual organs of the Archegoniates is very obscure. In some respects they resemble most nearly those of the Characeæ, but it is doubtful whether these resemblances indicate any real relationship.

Perhaps the most plausible explanation of the origin of these organs from those of the Algæ is that of B. M. Davis (3), who thinks that they most nearly resemble the plurilocular "gametangia" of certain Brown Algæ. He does not think that there is any genetic connection between the latter and the Archegoniates, but rather that the connection is to be sought with some Green Algæ which had gametangia similar to those of the Phæophyceæ. There are still in existence species of Schizomeris and Draparnaldia which show an approach to these structures, but presumably the direct ancestors of the Archegoniates are no longer in existence.

Davis thinks that the outer cells of the gametangium through sterilization became the wall of the antheridium or archegonium, 
while each cell of the inner tissue gave rise to a gamete. In the archegonium the fertile tissue formed a single axial row, only one cell of which, the egg, normally was functional.

Schenck (I) has come to much the same conclusion as Davis, but believes the Archegoniates have come directly from Brown Algæ marine Phæophyceæ.

In view of the many other obvious points of resemblance between the Archegoniates and the fresh-water Green Algæ it is highly improbable that there should be any genetic connection between them and the strictly marine Phæophyceæ.

It has been argued by Goebel among other writers, that the archegonium and antheridium of the Archegoniates are essentially homologous organs, which would of course agree with the theory of their derivation from some type of plurilocular gametangium. This view is strengthened by work of Holferty (I) and others, who have shown that in certain Mosses structures combining the characters of archegonium and antheridium may occur.

P. I3. There may be some question as to the desirability of removing the Anthocerotaceæ from the Hepaticæ. Thus Cavers (9), who has made a very careful study of the inter-relationships of the Bryophytes, believes that the differences between the Anthocerotaceæ and the other Liverworts are not sufficient to warrant the establishment of a separate class, but thinks that they merely represent an order of Hepaticæ, Anthocerotales, coördinate with the Marchantiales and Jungermanniales.

P. I7. The development of the spermatozoid of the Hepaticæ has been the subject of numerous investigations during the past ten years and while there is general agreement as to certain points, there is a decided difference in others.

In all cases that have been recently examined, the final division of the spermatogenous cells results in the formation of a pair of "spermatocytes," or sperm-cells, which may be separated by a delicate division wall, e.g. Pallavicinia, Calycularia - or the division wall may be suppressed, as in Marchantia and Fossombronia.

All authorities agree that after the final division into the spermatocytes, there is always present a small body, the "blepharoplast,": but as to the nature of this body, the statements are not at all in accord.

Ikeno (4), who studied the spermatogenesis especially in Marchantia polymorpha, believes that the blepharoplast is a centrosome, and that it is of nuclear origin. Schaffner (I) supports this view, but other 
writers (e.g., Woodburn, Escoyez) deny the presence of centrosomes and consider the blepharoplast to be an organ of cytoplasmic origin. Ikeno also describes a peculiar body to which he gives the name "Nebenkörper," whose nature is problematical.

Humphrey (I) has studied the spermatogenesis of Fossombronia, where he decided that the blepharoplast arose de novo in the cytoplasm. In Fossombronia the final division of the sperm-cells is diagonal, as it is in Marchantia, and the spermatids appear triangular in shape. In Fossombronia there is a structure suggestive of the "Nebenkörper," but Humphrey states that in this case it forms part of the spermatozoid. In other Hepaticæ, e.g., Calycularia, Pellia, the spermatids are nearly hemispherical.

In a recent paper, Wilson (2) states that he believes the blepharoplast in Pellia to be derived from a centrosome, and he also describes a globular body "limosphere," and an "accessory body," as present in the spermatid, but was not able to determine their origin.

All agree that the cilia arise from the blepharoplast, which very early assumes a position at the periphery of the spermatid. Most authors state that the elongated thread which connects the cilia with the nuclear portion of the spermatozoid is formed by the elongation of the blepharoplast itself; but Wilson thinks that the greater part of the thread does not belong properly to the blepharoplast.

The bulk of the body of the spermatozoid is undoubtedly formed from the nucleus of the spermatid which becomes homogeneous in appearance and elongates to form a more or less coiled body.

P. 20. In his résumé of the inter-relationships of the Bryophytes, Cavers (9) proposes the establishment of a third order of Hepaticæ (exclusive of Anthocerotales), the Sphærocarpales, which is to a certain extent intermediate in character between the Marchantiales and the Jungermanniales. Spharocarpus (see Chap. III) is on the whole the simplest known Liverwort, and Cavers' view is that the family Sphærocarpaceæ is sufficiently different from the other two orders to warrant the establishment of a third order, Sphærocarpales, which is more primitive than the other two.

P. 2I. It has been proposed to recognize two other families intermediate between the Corsiniaceæ and the Marchantiaceæ, viz. the Targioniaceæ, comprising Targionia and Cyathodium, and the Monocleaceæ with the single genus Monoclea. The cifierences between these genera and the typical Marchantiaceæ are probably sufficient to warrant the establishment of these families. (See Cavers (9).) 
P. 23. Recent studies on Targionia (Deutsch (I)), (O'Keefe (I)) have shown the presence of a single apical cell, and it is by no means unlikely that this will prove to be the case generally in the Marchantiales.

P. 25. Barnes (2), after an examination of a number of Marchantiales, states that invariably the formation of the air-chambers begins by the separation of the cells below the superficial layer, and thus the pits between the latter are secondary, being formed by a splitting of the cell-wall. He examined only Riccia natans and $R$. fluitans, neither of which conforms to the type found in most terrestrial species. The papers by Miss Hirsch (I) and Miss O'Keefe (I) show that Leitgeb's account of the formation of the air spaces in Riccia glauca, and other allied species, is entirely correct.

P. 32. The spermatogenesis in Riccia Frostii has been studied in detail by Miss Black ( $\mathrm{I}$ ). It corresponds closely with that of other Marchantiaceæ. The final division of the sperm-cells is a diagonal one without the formation of a division wall, and results in a pair of triangular spermatids. There is no evident connection between blepharoplast and a polar granule that might be considered to be a centrosome. Eight chromosomes were noted in the sperm-nucleus.

P. 35. Beer (I) has made a critical study of the spore division in Riccia glauca. His results agree entirely with the writer's studies in this species, and in $R$. trichocarpa, so far as the details were examined. In both of these species, the spore mother cells, previous to the final division into the spores, completely fill the cavity of the sporogonium. The walls between them are very delicate, but are readily demonstrable by Bismarck-brown. The protoplasts are usually more or less contracted in microtome sections, and where the division walls are not stained, look as if they were completely isolated, but probably in most cases the contraction is due in part to the effect of reagents.

Beer states that the division walls do not show the cellulose reaction. Sooner or later these walls become disintegrated and the nearly globular protoplasts, which have developed new membranes, become entirely isolated. No evidence of any intercellular nutritive substance, such as Garber (I) and Lewis (I) describe in $R$. natans, can be demonstrated for either $R$. glauca or $R$. trichocarpa.

The nucleus of the spore mother cell contains a conspicuous deeply staining body (see text, Figs. 6, 7), which Beer states is a nucleolus; but from his description and figures of the early stages of mitosis it looks as if this might be really composed of the closely united chromosomes. The latter, according to Beer, are probably seven or eight in 
R. glauca, while Garber and Lewis give but four chromosomes in the spores of $R$. natans.

The primary division walls separating the young spores, according to Beer, are a pectose-cellulose compound, while the secondary thickening of the walls shows the presence of callose.

The spore coat is composed of three parts, an outer coat which very early shows cutinization; a middle coat, also more or less cutinized, and itself showing a differentiation into three laminæ; and finally the inner coat, or endospore, which arises late in the development of the spore, and which shows pectose and cellulose reactions.

Beer thinks that the materials necessary for the development of the spore membranes is derived mainly from the disintegration of the outer sterile cells of the sporophyte, and the inner cells of the calyptra, but that there is probably a certain amount of nutritive matter transferred from the vegetative tissues of the gametophyte.

P. 39. The more recent studies of Ricciocarpus (see Cavers (9)) indicate that this genus should be united with Riccia, as was originally done.

P. 40. Tesselina has recently been discovered in the Southern United States (Howe (6)).

P. 4I. Corsinia marchantioides occurs in the south of Europe and in the Canary Islands and Madeira. Stephani (I) states that it has also been reported from Louisiana. Boschia Weddellii is known only from Brazil.

P. 42. Barnes and Land (2) have made an extended study of the origin of the air-chambers in the Marchantiales, and conclude that in all cases these begin by the formation of an intercellular space just beneath the epidermis, and that the superficial pores, or stomata, are formed secondarily by the subsequent extending of the intercellular space to the surface. From Deutsch's study of Targionia, however (Deutsch (I)), as well as from the writer's studies on Fimbriaria, it appears that sometimes, at any rate, as in Riccia, the first evidence of the air-chamber is a pit between the epidermal cells, which later extends to the underlying tissue.

There are two well-marked types of air-chambers. In Fimbriaria Californica, for example (see Fig. 14), through the rapid enlargement of the thallus, the air-chambers become very large and irregular in form, and there is not a sharp distinction between this lacunar tissue of the dorsal region and the solid tissue of the ventral region.

In the second type, which is seen in Targionia and Marchantia, as well as in most other Marchantiaceæ, the lacunar tissue consists of a 
single tier of well-defined chambers, each opening at the surface by a pore. In most of these (see Fig. I8) the green tissue consists for the most part of short filaments growing from the floor of the air-chamber. The free ends of these filaments, especially immediately under the pore, are often colorless, and more or less enlarged. This is especially conspicuous in Fegatella (Cavers $(6,9)$ ).

The epidermal cells surrounding the pores keep pace with the growth of the thallus, so that the pores remain of nearly their original size.

P. 49. Ernst (2) has more recently described the structure of the thallus in Dumortiera trichocephala, collected in Java, and also of a second species, $D$. velutina, in which the remains of the dorsal lacunæ are conspicuous. Wiesnerella is a genus evidently related to Dumortiera, but having a well-developed epidermis with pores opening into the air-chambers.

P. 56. Cavers has made a careful comparative study of the carpocephalum in several genera of the Marchantiaceæ and concludes that in all of them, except Clevea and Plagiochasma, the carpocephalum is of the composite type. He believes, however, that the Astroporæ of Leitgeb represent a natural group, and to a lesser extent this is true of the Operculatæ, although the limits between the latter and the Compositæ are not at all definite.

P. 58. Cryptomitrium also occurs in the Himalayas.

P. 60. In a recent paper by Miss O'Keefe (I), the young embryo Targionia is described as having two transverse divisions before any longitudinal ones were formed - i.e., there was not the quadrant formation typical of the Marchantiales. The writer's preparations of the young embryos showed the normal quadrant division (see Fig. 23), and it would be interesting to know whether Miss O'Keefe's specimens were abnormal, or whether possibly they were specifically different from the California plant. Meyer (4) shows that in Plagiochasma the young embryo consists of a row of four cells.

P. 65. In Dumortiera trichocephala, and in the allied genus Wiesnerella, there is a very evident seta, and in Monoclea it is very much elongated.

P. 69. Cyathodium is represented by several species in the warmer parts of the world. The largest and least reduced species is $C$. fotidissimum, widely distributed through the Malayan region, where it occurs sometimes in great abundance in shallow caves, or on deeply shaded rocks. The delicate thallus appears to glow with a green phosphorescence when seen at a certain angle, this being apparently due to the form of the superficial cells, which reflect the light strongly. 
This species receives its specific name from its peculiar strong odor when handled.

The archegonia occupy the same position as in Targionia, but the envelope about the sporogonium is much less developed than in the latter.

The antheridia are formed on very short ventral branches; on the same plants that bear archegonia.

Lang (6) has made a careful study of this species as well as of a second one which he refers provisionally to $C$. cavernarum.

The thallus consists mainly of a single layer of larger air-chambers, bounded below by a single layer of cells, and opening above by welldefined pores like those of Targionia, but there is no trace of the green assimilating filaments found in the latter. In C. foetidissimum there are several layers of ventral cells in the region of the midrib. The cells of the superficial layer contain a few relatively large chromatophores, and this is the principal photo-synthetic tissue.

The archegonia and antheridia closely resemble those of Targionia. As already surmised (see text, p. 70), Leitgeb's suggestion that the antheridium is a single cell has proved incorrect. The early stages of the embryo, as shown by Lang's investigations, resemble the Jungermanniales rather than the Marchantiales. The first two divisions are transverse (as Miss O'Keefe found in Targionia), and the lowermost cells form a sort of haustorium, instead of the massive globular foot found in Targionia. There is a slender but short seta, as in Spherocarpus, and except for the presence of a small thickened disc at the summit, the sporogonium more nearly resembles that of Spharocarpus than it does Targionia. The wall cells, however, develop thickenings like those found in Targionia, and true elaters are present.

P. 7o. Occasionally receptacles have been found which bear both archegonia and antheridia (see Ernst (I), Cutting (I)).

P. 70. Stephani (I) records 200 species of Marchantiaceæ, and since his summary was published a number of new species have been described, including several new genera. The Himalayan region is especially rich in these new types (see Kashyap (2)).

P. 70. Schiffner, in a recent paper (4), still asserts that Monoclea should be referred to the Jungermanniales; but the arguments he offers are not very convincing. It may be said, however, in view of the recent work on the Targioniaceæ and Pellia (Hutchinson (I)), that there is a possibility that Monoclea may be in a sense intermediate between the thallose Jungermanniales of the Pellia type, and the 
Targioniaceæ. The characteristic lobing of the spore mother cells, found in the Jungermanniales, is conspicuous in Monoclea, but occurs also in Targionia, though not so markedly. The long seta of the sporophyte can be explained by the semi-aquatic habit of Monoclea (see Cavers (9)).

P. 71. Goebel (27) has recently described a very remarkable Marchantiaceous type, Monoselenium, which shows some striking indications of reduction, comparable to those in Monoclea and Dumortiera. Like these, there is a complete disappearance of the air-chamber, but evidences of reduction are also shown in the reproductive parts. The sexual organs are similar to those of the higher Marchantiaceæ, and are borne on special receptacles of the same type; but the sporophyte is much simpler, approaching in structure that of Corsinia or Boschia. The sterile cells may show the character of true elaters, or they may be undifferentiated nutritive cells like those of Spharocarpus.

P. 7I. Cavers (6) thinks that Leitgeb's division of the Marchantiaceæ into the three groups, Astroporæ, Operculatæ and Compositæ, is to some extent a natural one. The sporogonium wall in the first and third groups shows (usually) fibrous thickenings of the cell-wall, these thickenings being absent in the Operculatæ. The apical cap, or lid, found in the Operculatæ, does not, however, seem to be essentially different from the similar apical cap which is formed in many of the Compositæ, e.g. Wiesnerella, Marchantia.

\section{CHAPTER III}

P. 73. Recent investigations have shown that the differences between the antheridia of the Marchantiales and Jungermanniales are less marked than has been assumed. Thus in Fossombronia (Humphrey (I)), the early divisions in the antheridium resemble those of the Marchantiales, and in Pellia (Hutchinson (I)) this is also sometimes the case, although usually the divisions follow those of the typical Jungermanniales.

P. 75. The classification of the Jungermanniales is still far from satisfactory. Cavers (9) has proposed to remove the "Anelatereæ" from their association with the other Anacrogynæ, and to establish a distinct order, Sphærocarpales, intermediate between the Jungermanniales and the Marchantiales; and there is a good deal to be said for this suggestion. 
P. 75. As to the Elatereæ, there is great difficulty in dividing these into distinct families. Cavers recognizes four families, viz., Aneuraceæ (= Metzgerieæ), Blyttiaceæ (= Leptotheceæ), Codoniaceæ, and Calobryaceæ (= Haplomitreæ). Of these the first two are almost inextricably interrelated, and it will probably be best to combine them into a single family. The family Codoniaceæ contains a number of genera which are very doubtfully related, e.g., Pellia, Fossombronia, and it will probably be necessary to remove some of the members now included in the family, and perhaps to establish a new one.

The Calobryaceæ, comprising the genera Calobryum and Haplomitrium, is a very natural one, but its relation to the other Jungermanniales is somewhat problematical.

Stephani (I) states that he examined the original material of Thallocarpus, and found it to be a Riccia. See also McAllister (I).

P. 75. A recent revision of the genus Sphcrocarpus (Haynes (I)), shows that $S$. terrestris does not occur in the United States. The plant from the Atlantic states hitherto regarded as this species is apparently identical with $S$. Texanus, which in turn is not distinguishable from $S$. Californicus, which is united with that species. A third species, $S$. hians, has been discovered in Washington. See also Douin (I).

P. 86. Evans (3) has shown that in Metzgeria the gemmæ arise in essentially the same way as in Aneura, but the gemma remains attached to the thallus until it has formed a multicellular body of considerable size.

P. 88. The genus Aneura, which is the largest among the Anacrogynæ, shows a good deal of variation in the form of shoot. Some of the species, e.g., A. maxima, have a quite undifferentiated thallus rivalling in size the larger Marchantiales. Other species show a more or less definite midrib, and still others, e.g., A. Tjibodensis, have muchbranched upright shoots arising from a prostrate rhizome, as in Hymenophyton (Umbraculum); but the branching is monopodial instead of dichotomous.

P. 88. In Pallavicinia the central portion of the midrib is occupied by elongated fibre-like cells with markedly thickened cell walls.

P. 89. The antheridia in Pallavicinia (Mittenia) Zollingeri are borne on the midrib, each one being covered by a scale. In other species, e.g., $P$. radiculosa, $P$. Levieri, they are in a row on either side of the midrib, and are covered by a shelf-like outgrowth, which is more or less continuous. (Campbell and Williams (37).) Calycularia 
and Podomitrium (Campbell $(34,39)$ ) closely resemble Pallavicinia Zollingeri in the arrangement of the antheridia; but in Podomitrium they occur on special ventral branches. In Makinoa the antheridia are in chambers, very much as in Aneura. (Miyake (2).)

P. 94. The archegonium of Fossombronia (Humphrey (I)) sometimes regularly shows six neck canal cells. In Pallavicinia radiculosa the writer found usually five or six, and in Calycularia radiculosa and Podomitrium Malaccense the number is about the same, but may probably in some cases be eight. Eight neck canal cells were also found in Trewbia, although Grün states that he found sixteen in the full-grown archegonium. (Grün (I), Campbell (40).)

In Pallavicinia radiculosa the cap cell of the young archegonium sometimes has several lateral segments cut off before the final quadrant division occurs. There may be thus a limited apical growth of the archegonium, somewhat as in the true Mosses, but such growth is confined entirely to the outer cells. Podomitrium Malaccense may show the same phenomenon. (See Gayet (I).)

The archegonial receptacle in most Anacrogynæ, e.g., Pallavicinia, Calycularia, Podomitrium, is surrounded by an involucre composed of several usually laciniated scales. Sometimes, however, as in Symphyogyna and Makinoa, the archegonial group is subtended by a single scale.

Within the involucre there may be developed a second envelope, the perianth (see Fig. 4I, A. per.), which forms a tubular sheath often very conspicuous. The perianth does not form until after fertilisation. It arises as a ring-shaped ridge about the group of archegonia, and elongates rapidly with the growth of the young sporophyte which it encloses. The perianth has evidently been developed quite independently in a number of genera, while it is wanting in others.

P. 94. Aneura has been the subject of several embryological investigations in later years. (Bower (22), Goebel (2I), Clapp (I).) Miss Clapp studied the earliest stages of the embryo and found they agreed with Leitgeb's account. The very much enlarged basal cell is a true haustorium.

P. 95. The wall of the capsule in Aneura is two-layered throughout.

P. 96. The apical mass of sterile tissue is known as an elaterophore.

P. 96. The spore mother cells in Aneura become strongly fourlobed before the nuclear division takes place. This is generally characteristic of the Jungermanniales. 
P. 98. The writer has investigated the development of the sporophyte in Pallavicinia, Podomitrium, Calycularia, and Treubia. (Campbell $(34,37,39,40)$.)

In Pallavicinia (Campbell and Williams (37)) the young embryo develops a very conspicuous haustorium, which is composed of several cells instead of being unicellular as in Aneura, and in Podomitrium (Campbell (39)) and Treubia (Campbell (40)) the haustorium forms a large mass of cells below the foot. In none of these genera is the separation of the sporogenous area so early differentiated as in Aneura.

There is a good deal of variation shown in the development of the sporophyte in different species of Pallavicinia. Thus in P. Zollingeri, which belongs to the section Mittenia, the sporogenous area in the young capsule is quite limited and forms a convex disc, which in vertical section appears as an arc composed of narrow cells arranged in vertical rows, the tissue below forming a sort of columella, which later disappears with the increased growth of the sporogenous tissue.

$P$. radiculosa and $P$. Levieri show a larger amount of sporogenous tissue in the young sporophyte and the capsule becomes very much elongated, especially in the former species. These species belong to the section Eupallavicinia. P. Zollingeri has a shorter capsule, which is more clearly separated from the seta than is the case in any species of Eupallavicinia that were examined ; and there is a distinct somewhat bulbous foot developed, while in Eupallavicinia the foot is much less developed. In both respects Mittenia comes nearer to the genus Mörkia.

In all of the species of Pallavicinia the apical portion of the capsule wall is thicker than the lateral walls, this being most marked in Eupallavicinia, where the apex is pointed and forms a beak some six or eight cells deep, while the lateral walls of the capsule are composed of but three or four layers of cells.

Podomitrium Malaccense (Campbell (39)) much resembles Pallavicinia in the development of the sporophyte, but there is a small apical elaterophore like that of Aneura, and the foot is clearly marked by a constriction as it is in Mörkia or Calycularia. (See Campbell (34).)

P. 98. In many cases, e.g., Pallavicinia Levieri, the calyptra is not wholly derived from the venter of the archegonium, but the tissue below the archegonium is involved so that with its growth the unfertilised archegonia are carried up to the summit of the calyptra. 
The outer cells of the capsule have their cell-walls thickened, sometimes uniformly, e.g., Pallavicinia, Podomitrium; sometimes with thickened bars or partial spirals, e.g., Calycularia radiculosa, Pellia. In the latter genus there is a well-marked basal elaterophore, which is perhaps represented in some other genera by the presence of a few attached elaters at the base of the capsule.

A quadripolar spindle, very much like that in Pallavicinia decipens, occurs in Calycularia radiculosa, but sometimes a bipolar spindle is formed, followed by two others, and this is also the case in Pallavicinia radiculosa and $P$. Levieri (Campbell (37)). In the latter there is no evidence of a quadripolar spindle.

P. 99. The dehiscence of the capsule may be by a fragmentation of the wall, e.g., Fossombronia, or by splitting longitudinally into more or less regular (usually four) valves. In Aneura and Metzgeria this splitting includes the elaterophore, which with the adherent elaters forms four tufts at the free ends of the valves. In Pallavicinia the valves are united at the tip, and the spores escape through four slits between the valves. Cavers (9) states that in Podomitrium the valves are also adherent at the apex, but the writer's studies on $P$. Malaccense indicate that in this species the splitting extends to the apex of the capsule, but there are only two valves instead of four. Calycularia radiculosa (Campbell (34)) sometimes has these valves adherent at the apex, but occasionally separated completely. As in the case of Podomitrium Malaccense there are but two valves, each of which, however, is clearly formed of two coherent valves. According to Schiffner the other species of Calycularia have the wall broken up irregularly on dehiscence, as in Fossombronia, and he thinks they should not be associated, generically, with C. radiculosa.

P. 100. For Goebel (I3), read (I5).

P. I00. Cavers (9) has proposed the name Calobryaceæ as a substitute for Haplomitreæ. The best-known species of the family is Calobryum Blumei, a very beautiful Liverwort, occurring in the Indo-Malayan region. For details see Goebel (I5).

P. ror. It seems almost impossible to clear up the relationships of the Anacrogynæ. Cavers recognises two main lines of development, which he thinks have diverged from the Spharocarpus type. These he calls the Pellia line (comprising the Codoniaceæ and Calobryaceæ) and the Blyttia line (Aneuraceæ and Blyttiaceæ). In both of these there has been the development of leaves, and the question arises as to which of these leafy Anacrogynæ is nearer to the leafy acrogynous Liverworts. 
Two theories have been advanced. Cavers believes all of the Acrogynæ have arisen from the same type, and of the existing Anacrogynæ he thinks Fossombronia represents most nearly this hypothetical ancestor.

Spruce (2) has argued that there is good reason to separate the Acrogynæ into two series, one Jubuloideæ (= Lejeuneaceæ), which perhaps arose from Metzgeria-like ancestors; and the Jungermanneæ (including all the other Acrogynæ), which have been derived from forms like Fossombronia.

Fossombronia differs a good deal from the typical Codoniaceæ, and shows some suggestive resemblances to the Sphærocarpales, especially to Geothallus. Petalophyllum is another genus, usually referred to the Codoniaceæ, which is also perhaps related to Geothallus. It is possible that there is a distinct series of related genera leading from Geothallus, through Petalophyllum and Fossombronia, to Treubia. The latter, on the whole, probably comes nearest to the typical Acrogynæ.

P. IoI. The archegonia are not necessarily confined to special branches, but in some genera, e.g., Plagiochila, Gottschea, are borne at the apex of the main axis. In most genera several archegonia are formed before the apical cell is transformed into an archegonium, but in Lejeunia a single archegonium only is present, and in Frullania usually two.

The archegonial group is usually surrounded by an outer sheath (perichætium) composed of a whorl of more or less concrescent leaves, within which is developed the second envelope, or perianth.

P. I06. The early divisions in the antheridium of Pallavicinia and Podomitrium agree exactly with those in Porella, and further investigation will probably show that this method of division, in the antheridium, is more common than has been supposed to be the case.

P. I07. The spermatogenesis of Porella has been recently described in detail by Woodburn (I).

P. II2. There is a second layer of cells in the wall of the capsule in Porella, which is not clearly indicated in Fig. 57.

P. II2. The embryo of Frullania is so different from that of most of the Acrogynæ, that Spruce (2) has removed the family Lejeuneaceæ, to which it belongs, from the other Acrogynæ and established a special order, Jubuloideæ.

P. II3. For Goebel (I2), read (I4).

P. II4. For Goebel (I3), read (I4).

P. II7. Evans (4) has recently made an exhaustive study of the branching in the Acrogynæ. 
P. IIg. The following classification of the Acrogynæ is taken with some slight changes from Cavers' recent résumé of the Bryophytes (Cavers (9)). It is based upon Spruce's work (Spruce (2)).

A. Leaves various as to form and insertion; capsule usually longstalked; elaters various but never attached or extending from the apex to the base of the capsule; each elater with two or more spiral fibres; archegonia always four or more in a group.

Families - Lophoziaceæ (Epigonantheæ), Cephaloziaceæ (Trigonantheæ), Ptilidiaceæ, Scapaniaceæ, Radulaceæ, Porellaceæ.

B. Leaves typically divided into a large upper and a small lower lobe, the latter usually rolled up or saccate; under leaves (amphigastria) usually present; elaters few, with a single spiral fibre, all fixed by the upper end to the apex of the capsule and extending to the base of the capsule cavity; archegonia from one to four (rarely more) in a group. Fam. I - Lejeuneaceæ.

Cavers considers the Lophoziaceæ to be the lowest forms, connecting the other Acrogynæ with Anacrogynæ of the type of Fossombronia ; the Lejeuneaceæ he places at the top of the acrogynous series.

Spruce, however, as already stated, regards the Lejeuneaceæ (Jubuloideæ) as entirely unrelated to the other families of the Acrogynæ.

\section{CHAPTER IV}

P. I20. A fourth genus, Megaceros, is based upon material collected by the writer in Java. (Campbell (30).)

P. I2I. In Megaceros there are several chromatophores in each cell, sometimes a dozen or more in the large inner cells of the thallus.

In Anthoceros Pearsoni, which resembles Megaceros, also, in having solitary antheridia, there are usually two chromatophores in the inner cells.

P. I28. Peirce (2) concludes from a study of Anthoceros grown upon sterilized soil, and therefore free from Nostoc, that the presence of the latter in the thallus is rather detrimental than otherwise.

P. I28. For Waldner (2), read (I).

P. I32. For Janczewski (2), read (I); for Waldner (2), read (I).

P. I4I. The species of Anthoceros with spiral elaters should be transferred to the genus Megaceros.

P. I45. For Goebel (22), read (2I).

P. I45. The genus Megaceros was established by the writer, to include a number of species which had been included in Anthoceros, but which differ from that genus in certain important particulars. 
The species of Megaceros are mostly tropical, and they are especially common in certain parts of the Malay Archipelago. The writer has collected them at various stations in Java, Sumatra, Borneo, and Luzon. Some of the species are very large and conspicuous, and occur in masses covering the rocks in stream-beds and similar localities. Others grow on rotten logs, and less commonly on the ground.

The thallus usually closely resembles that of the larger species of Anthoceros, and the apical growth in the species investigated by the writer is exactly the same. The most obvious difference is the presence of several chromatophores in the cells, sometimes as many as twelve having been observed in the inner cells. Usually no pyrenoid can be recognized, and the chromatophores are much like those of the higher plants.

The antheridia are large, and borne singly as in Dendroceros or Anthoceros Pearsoni.

The sporophyte in its earlier stages is most like that of Dendroceros, but there is a much larger development of the sporogenous tissue, which suggests the condition found in Notothylas. The spores at maturity contain chlorophyll, a condition found also in Dendroceros, but not in Anthoceros, and the elaters have spiral thickenings as in Dendroceros. Like the latter, stomata are absent.

Megaceros is thus a sort of synthetic type, combining characters found in all three of the other genera. (See Campbell (30).)

P. 148. The writer has investigated two species of Dendroceros from Java (Campbell (30, II)), which agree closely with the other species that have been examined.

P. I56. Lang (7) states that in a species of Notothylas from Singapore (probably $N$. Breutelii), while the early stages of the embryo agree with the other Anthocerotaceæ, and the primary sporogenous tissue originates from the amphithecium, the upper portion of the columella develops spores, so that the latter arise in part from the endothecium. A similar condition, but less marked, was found by the writer in N. Javanicus. (Campbell (30, II).)

P. I59. While there are certain similarities between the young sporophyte of the Anthocerotacex and such Liverworts as Spharocarpus, Cyathodium and especially Fossombronia, the fact that the primary sporogenous tissue in the Anthocerotales always arises from the amphithecium, while in all other Liverworts it is developed from the endothecium, would seem to be a radical difference. Cavers, however, thinks that the differences between the Anthocerotaceæ and the other Liverworts are not sufficient to warrant removing the Antho- 
cerotaceæ from the Hepaticæ, and he regards the order Anthocerotales simply as an order of Hepaticæ co-ordinate with the Marchantiales and Jungermanniales.

P. I6I. For Leitgeb (2), read (4).

\section{CHAPTER V}

P. I66. Cavers (9), in his review of the Musci, divides the Bryales into four groups, which he thinks should have the rank of orders, viz., Tetraphidales, Polytrichales, Buxbaumiales, and Eu-Bryales.

P. I7o. In submerged plants the whole stem consists of uniform tissues, all the cells except the innermost ones having chlorophyll.

P. I73. Oltmanns (I) has made a careful study of the mechanism by which water is taken up by Sphagnum. In most species this is effected by capillary action, due to the numerous pendant branches, which are closely appressed to the stem, and between which the water ascends by capillarity. In species like $S$. cymbifolium, however, in which the cortical cells contain pores and fibres on their walls, these cortical cells play an important rôle in the absorption and conduction of water.

P. I77. The development of the archegonium has been carefully studied by Bryan (I). It shows some interesting suggestions of the Liverwort-archegonium in having the apical growth much less marked than in most Mosses, and in having all of the neck canal-cells formed from the division of a primary canal-cell. There are eight or nine canal-cells. "Abnormalities, such as double venters, multiple eggs, etc., are of common occurrence."

P. I82. For (Ruhland (2)), read (I)).

\section{CHAPTER VI}

P. 195. The statement that Funaria is diœcious is incorrect. The antheridial shoots develop first, and later, as lateral branches from these, the shoots bearing archegonia arise. (See Boodle (7).)

P. 197. The spermatogenesis of the Mosses has received a good deal of attention in recent years. The latest contributions are those of Woodburn (3) and Allen (2), who investigated the spermatogenesis in Mnium affine and Polytrichum juniperinum.

The development of the spermatozoid is much like that of other Bryophytes that have been examined. In Mnium there are six 
chromosomes in the nucleus of the sperm-cell, and there is often present a vacuole, whose contents it is thought contribute to the growth of the spermatozoid.

P. I99. For Goebel (22), read (21).

P. 203. The relation of the protonema to the spores in dicecious mosses has been carefully investigated by Marchal (I, 2), in three species, viz., Barbula unguiculata, Byrum argenteum, and Ceratodon purpureus. The results obtained were the same in all species and may be summarized as follows:

I. The spores in a capsule are of two kinds, as to their sexual character.

2. The spores are "unisexual," i.e., some produce a protonema of which all the shoots are male, while the protonema developed from the others bear only female branches.

3. The sexual character is perfectly transmitted through the medium of secondary protonemal filaments, and by buds of different sorts, some of these giving rise to shoots of a different sex.

4. The action of environmental factors, within a single generation, is incapable of changing the sex-character of the protonema.

P. 203. Bryan (2) has recently examined the development of the archegonium in Catherinea angustata, which does not differ materially from other species that have been investigated.

P. 2I4. The division of the Bryales into Cleistocarpæ and Stegocarpæ is not a natural one, and probably should be abandoned. The same may be said of the "Acrocarpi" and "Pleurocarpi," which do not represent a natural division, both acrocarpous and pleurocarpous forms sometimes occurring in the same genus, e.g., Fissidens.

P. 216. For Goebel (22), read (2I).

P. 218. Tetraphideæ $=$ Tetraphidales (Cavers (9)).

P. 22I. Polytrichaceæ $=$ Polytrichales.

P. 225. Buxbaumiaceæ $=$ Buxbaumiales.

\section{CHAPTER VII}

P. 234. The writer, in I906, discovered in Java the gametophytes of several species of Ophioglossum, including O. Moluccanum (probably identical with $O$. pedunculosum) and $O$. pendulum. In the former species the gametophyte is subterranean, and apparently lives but one season; in the second, as Lang already found, it is buried in the mass of humus collected between the leaf-bases of epiphytic ferns (in this case 
Asplenium nidus). From the position of the older gametophytes, it was clear that they had been growing for many years, and Bruchmann (5), in his study of the prothallium of $O$. vulgatum, found this was also true in that species.

The spores of $O$. Moluccanum germinate in a few days, and divide into three or four cells, growing at the expense of the food materials in the spore, which is destitute of chlorophyll. Faint traces of chlorophyll were noted in a few cases, but after exhausting the food matter in the spore, the young gametophyte, in all cases, finally died.

In $O$. pendulum, where the early divisions occur later than in $O$. Moluccanum, in several cases the young gametophyte associated itself with a fungus, as a result of which its growth was stimulated. It is pretty certain that this association with the fungus is a necessary condition for the further development of the gametophyte. (Campbell $(29,33)$.)

The fully grown gametophytes of $O$. Moluccanum are very delicate, slender, cylindrical bodies, 5-Io millimetres in length. None of those found by the writer were branched, and they were much smaller than those of $O$. pedunculosum, figured by Mettenius; but otherwise they were very similar. In $O$. vulgatum, also, the gametophyte is larger, and may be branched (Bruchmann (5)). Bruchmann found that when the gametophyte in $O$. vulgatum was exposed to the light it developed chlorophyll. The writer was unable to induce the formation of chlorophyll in the gametophyte of $O$. pendulum.

The gametophyte of $O$. pendulum is much more massive than that of the other species, and is very variable in form. Usually there are several stout branches radiating from a common centre. The largest specimen found was about fifteen millimetres in breadth. The form is determined by the position of the numerous roots of the host-fern, among which the branches of the Ophioglossum gametophyte ramify. The branches are very easily broken off, but at once enter upon an independent existence, and this power of reproduction accounts for the very great age (probably more than twenty years) which some of the prothallia show. Under special conditions buds may develop which further facilitate the multiplication of the prothallia.

P. 235. The endophytic fungus, or "mycorrhiza," is especially conspicuous in $O$. pendulum, where it is found in all but the youngest parts of the branches of the prothallium. A cross-section of a branch shows a broad zone of infected tissue, which lies between a central pith and several layers of peripheral cells, which are nearly or quite free from the fungus. 
As the mycorrhiza invades the cells of the young tissue, their contents are mostly destroyed, except the nucleus, which remains intact. In the earlier stages the hyphæ are nearly uniform in thickness, but later they undergo a sort of degenerative process, forming vesicular thin-walled masses, which seem to be finally destroyed by the action of the prothallium cells. "Symbiosis" thus would seem to be a case of mutual parasitism, the fungus being active in the earlier stages, but later being destroyed by the activities of the host-cells.

P. 236. The sex-organs in both $O$. Moluccanum and $O$. pendulum arise in acropetal succession, the youngest ones being close to the apex of the branch. There is no definite relation of antheridia and archegonia, the two being irregularly intermingled.

P. 237. For details of the development of the antheridium, see Campbell $(29,33)$.

P. 237. The spermatozoids are probably the largest known among the Pteridophytes. Those of $O$. pendulum are larger than those of O. Moluccanum, but the nuclear portion is less elongated.

Just before the final division of the sperm-cells, the nucleus shows a small but distinct nucleolus, and in favorable preparations two small rounded bodies, the blepharoplasts, can be distinguished. The chromosomes are very numerous, but the number could not be determined.

After the final mitosis is completed, the nucleus shows a coarse reticulum, but no nucleolus can be seen. Before any evident change occurs in this nucleus, the blepharoplast becomes elongated, and forms a delicate thread which stains strongly with gentian-violet.

The nucleus next elongates slightly, and the reticulate appearance becomes very conspicuous. In the reticulum are large strongly staining chromatin masses, which apparently arise from the coalescence of several chromosomes. The nucleus now becomes indented on one side and in profile appears crescent shaped. As it elongates it assumes the form of a curved thickened band, tapering at the forward end, which is sharply pointed. The chromatin masses become more and more coalescent, until finally the elongated curved nucleus appears almost perfectly homogeneous.

The blepharoplast now becomes a spiral band, which connects with the nucleus, and with it forms the body of the spermatozoid. The central part of the cell contents is enclosed in the coil of the spermatozoid, and probably, as in other Ferns, forms a vesicle attached to the free-swimming spermatozoid.

The cilia begin to appear as short outgrowths of the blepharoplast, 
before the nucleus has changed its form. They increase much in length, and are very numerous.

P. 237. The writer found in $O$. pendulum that the neck canal-cell not infrequently became completely divided into two cells. The ventral canal-cell is difficult to demonstrate, and it often looks as if no ventral canal-cell were formed. Probably it is formed just before the dehiscence of the archegonium, and is very transient.

P. 238. Bruchmann (6) has given a very complete account of the gametophyte of $B$. Lunaria, which closely resembles the younger stages of $B$. Virginianum. The archegonia are on the dorsal surface, as in B. Virginianum, and not on the ventral side, as Hofmeister states is the case.

P. 242. The writer collected the older prothallia of Helminthostachys in Ceylon at the same station where Lang secured his material. They were in forest land, which was subject to annual flooding, and it is probable that this is necessary for the germination of the spores. The gametophyte appears to be annual, dying after the establishment of the sporophyte.

P. 242. The development of the embryo was investigated by the writer in Ophioglossum Moluccanum and O. pendulum. (Campbell $(29,33)$.) In both of these the first division is approximately transverse and divides the embryo into two nearly equal cells, an "epibasal" and "hypobasal." From the hypobasal cell, in both species, a large hemispherical mass of tissue is developed, the foot, while from the epibasal half the other organs of the young sporophyte ultimately develop.

Both species show an unexpected deviation from the usual ferntype. In O. Moluccanum the epibasal portion develops into a conical body, with a definite apical cell, and this later expands at the summit into the lamina of the spatulate cotyledon, or primary leaf.

In the middle region, deep in the tissue near the base of the foot (probably from the epibasal tissue), there arises a group of cells which begin to divide actively, and form the beginning of the primary root, which grows downward in the same plane as the cotyledon, and pushing through the tissue of the foot, breaks through it and the overlying gametophytic tissue, and penetrates into the ground.

The root grows from a tetrahedral apical cell, and there is soon evident an axial strand of elongated cells, the "stele" or young vascular bundle, and this continues without interruption into the corresponding stele of the young cotyledon. All that remains of the foot is a slight enlargement in the middle of the young sporophyte, 
which now shows a markedly bipolar structure, the young plant consisting of only the leaf and root, whose tissues are perfectly continuous. At this stage, absolutely no trace of any stem-structure is present.

In $O$. pendulum the hypobasal part of the embryo, as in $O$. Moluccanum, gives rise to the large foot; but the epibasal portion, instead of developing into the cotyledon either at once grows out into a single root, or, after a vertical division, each half may form an independent root. These roots (or root) grow for a long time, and may branch without any evidence of a leaf being seen. The development of the leafy shoot is not known, but it is highly probable that the first leaf arises from an endogenous bud upon the root. Bruchmann (5) has studied the embryo in 0 . vulgatum, but was unable to find the youngest stages. It resembles more nearly that of $O$. pendulum, than $O$. Moluccanum, in the early development of the root, which makes up the greater part of the embryo before any trace of a leaf or stem-apex can be recognized. The stem-apex, according to Bruchmann, arises near the base of the root, and is of superficial origin; but his figures suggest the possibility of an endogenous origin similar to that of $O$. Moluccanum. In $O$. vulgatum the first leaves are rudimentary, and remain permanently underground. It is several years (8-1o according to Bruchmann) before the first green leaf appears above ground.

In $O$. Moluccanum, at the time the first leaf is completely developed, the young sporophyte consists simply of this leaf, whose lamina shows the characteristic netted venation of the older plant and the root. The slender petiole is continued directly into the root, it being impossible to determine where the petiole ends and the root begins.

In the stele of the leaf the single protoxylem arises on one side, and the bundle at maturity has the "collateral form." The single xylem of the leaf-stele is continued into the root as the single xylem of its "monarch" bundle.

Mettenius's account of the development of the embryo in $O$. pedinculosum agrees closely with the writer's studies on $O$. Moluccanum. Mettenius describes the origin of the stem-apex as a bud upon the root, but did not investigate its exact origin, but it no doubt is the same as in O. Moluccanum.

In the latter the first evidence of the permanent growing-point of the sporophyte is the formation of a group of meristematic cells close to the stele of the root, very much, indeed, like the origin of a secondary root. From this meristem there are differentiated a leaf and the stem-apex, apparently quite independently of each other. The 
leaf grows quite rapidly, and soon ruptures the overlying tissues, and appears on the outside of the root. It develops a vascular bundle which joins directly with that of the primary root.

The stem-apex consists of a shallow mass of tissue with a conspicuous apical cell, but no indications of any vascular bundles, and throughout the life of the sporophyte there are no cauline bundles, the whole vascular system being composed of the united leaf and root traces.

P. 243. The writer's later studies on Botrychium make it probable that, as in Ophioglossum, there is no proper stele in the stem of Botrychium, but that all of the vascular tissue of the axis belongs to the leaf-traces and roots. (See Campbell (33).)

P. 243. Fourth line, for epibasal, read hypobasal.

P. 244. Lyon (2) found in B. obliquum a well-marked suspensor, and Lang (9) states that a suspensor is also developed in Helminthostachys. The early development of the latter is only imperfectly known, but to judge from later stages (Campbell (33)), it is more like Botrychium than like Ophioglossum.

For a detailed account of the development of the vascular system in the young sporophyte of the Ophioglossaceæ see Campbell (33).

P. 245. A full account of the general morphology of the Ophioglossales has been given by Bower (22).

P. 245. The genus Ophioglossum has been divided into three subgenera, perhaps better considered as distinct genera. Euophioglossum includes the great majority of species, Cheiroglossa has but one species, O. palmatum, while Ophioderma has three: $O$. pendulum, $O$. simplex, and $O$. intermedium.

P. 248. The apical cell in $O$. Moluccanum and $O$. reticulatum is either a three-sided or four-sided prism, the apex of which is smaller than the base.

P. 250. In O. Moluccanum, and probably in all species of Ophioglossum, the whole vascular system of the adult sporophyte (except the root) is made up of the leaf traces, which join so as to make a largemeshed hollow cylinder. There is no proper cauline stele.

The bundle from each young leaf can be traced to a junction with a root-stele, and from the point of junction it extends through the tissue of the axis, running almost horizontally until it joins the trace from the next older leaf. In this way is built up the open, large-meshed vascular cylinder. So far as could be determined, in $O$. Moluccanum only one root is formed for each leaf. The tissues of the root-base are continued upward to connect with the young leaf, and downward to join the stele from an older one. 
No endodermis can be seen in O. vulgatum or O. Moluccanum, but in some other species, e.g., O. Bergianum, there is, according to Poirault (3), both an inner and an outer endodermis in the older part of the rhizome.

For details of the stem-structure see Campbell (33).

P. 250. In O. Moluccanum (see Campbell (33)) the sporangiophore arises very early in the development of the sporophyll, and there is virtually a dichotomy of the young sporophyll resulting in the sporangiophore and the sterile lamina. Bruchmann (6) found much the same state of affairs in Botrychium Lunaria.

P. 252. In all species of Euophioglossum there is given off from the vascular system of the rhizome a single leaf-trace, which divides at the base of the petiole into two strands, each of which may divide, or only one of them. In the larger species there are further divisions so that a section of the petiole shows a ring of several bundles. In some species there are large air-spaces in the petiole, while in others these are absent. (For details see Campbell (33).)

In $O$. pendulum the leaf-trace is composed of a number of strands where it joins the vascular cylinder of the rhizome.

P., 254. For Goebel (I 7), read (9).

P. 254. In large roots of $O$. pendulum there may be three or four, or even five, xylem masses, arranged radially.

P. 257. The tapetum is derived, not from the archesporium, but entirely from the inner cells of the wall of the sporangium (Burlingame (r) ). Bower, in a later study of the spore-formation, found that all of the sporogenous cells developed spores.

P. 258. Specimens of $O$. pendulum collected by the writer in Ceylon and Java, were much larger than the Hawaiian plants, sometimes upward of 1.5 meters in length. These usually had the lamina, and sometimes the spike, dichotomously branched.

P. 270. For Goebel (22), read (21).

P. 272. It is probable that all of the sporogenous cells undergo the normal tetrad-division in all the Ophioglossaceæ. (See Bower (22), p. 457.)

\section{[ CHAPTER VIII}

P. 273. A sixth genus, Macroglossum, has been recently described. (Copeland (r).)

P. 274. The writer has also investigated the gametophytes of several species of Danca, Kaulfussia, and Macroglossum. (Campbell $(33,36)$.) 
P. 276. The prothallium of Angiopteris (see Campbell (33)) not infrequently has the usual heart-shape, or may even be considerably elongated. Where fertilization is prevented, it may reach a very large size. Gametophytes of three centimeters or more in length have been observed by the writer in Dancea, and almost as large ones in Kaulfussia and Macroglossum. These large prothallia are often branched, four growing points being noted in one case. (For details see Campbell (3.3).)

P. 280. The archegonium of the other genera closely resembles that of Marattia. In Kaulfussia it is rather larger, and in Dancea the ventral canal-cell is very difficult to demonstrate, indeed, it looks as if it were absent in many cases. In this respect, Dancea recalls the behaviour of Ophioglossum.

P. 281. The writer has investigated the development of the embryo in all of the genera except Archangiopteris. (See Campbell $(33,36)$.) There are some marked differences shown in the different genera. In all cases the primary (basal) wall is transverse, and in Marattia, Kaulfussia, and Angiopteris the whole of the egg takes part in the development of the embryo; but in Dancea and Macroglossum there is a suspensor formed. In the former the fertilised egg elongates before the basal wall is formed, and the cell next the opening of the archegonium, i.e., the lower or hypobasal cell, develops into a short suspensor, while the whole of the embryo proper is derived from the epibasal portion of the two-celled embryo.

In Macroglossum (Campbell (36)) the suspensor is much larger, but its origin is not quite clear.

P. 282. In Marattia, Angiopteris, and Kaulfussia the basal wall divides the embryo into two nearly equal parts, the hypobasal cell (that next the archegonium neck) giving rise to a large, nearly hemispherical foot; from the inner or-epibasal cell the cotyledon is developed, and later the stem-apex. The young embryo is decidedly flattened at first, but later becomes almost globular, and then elongated vertically. At this stage the embryo is bi-polar, as it is in Ophioglossum.

No trace of a root can be recognised until the embryo has reached a considerable size. Then there may be seen near the junction of the foot and cotyledon, near the centre of the embryo, a group of active cells, which it is soon evident constitute the growing point of the primary root, which is thus seen to originate in exactly the same way as it does in Ophioglossum Moluccanum. A single apical cell is present, which is somewhat variable in form. The root finally pushes 
through the foot, which thus becomes practically obliterated, and breaking through the overlying prothallial tissue penetrates into the earth.

From the epibasal region there is developed the cotyledon, whose axis is almost coincident with that of the primary root. Close to the base of the cotyledon, which comprises the major part of the epibasal half of the embryo, a second inconspicuous prominence arises, the stem-apex. A single apical cell is probably present in all cases. It is somewhat variable in form, usually four-sided in cross-section, but sometimes triangular. The base is usually, but not always truncate.

Both cotyledon and root elongate rapidly, and the young sporophyte now closely resembles the corresponding stage of Ophioglossum Moluccanum, except for the presence of the stem-apex, which however, is very inconspicuous. As in Ophioglossum the primary vascular bundle extends as an uninterrupted strand from the cotyledon into the root, and there is no stele developed in the stem region. In Dancea the vascular bundle of the cotyledon is collateral as in Ophioglossum, but in the other genera it is concentric, although the phloëm is less developed on the inner side, and the bundle may approximate the collateral type.

As the second leaf develops it also shows an axial bundle which is continued downward as the second leaf-trace, and unites with the primary bundle to form the beginning of the vascular system of the axis. No stelar tissue is developed in the stem region above the junction of the leaf-traces.

P. 286. The cotyledon in Kaulfussia closely resembles that of Ophioglossum, being oval in form and with reticulate venation. The cotyledon in Danaa is similar in form to that of Kaulfussia, but the venation is more or less completely dichotomous, with free veins. In the other genera, the cotyledon is usually fan-shaped, with dichotomous venation, but in Angiopteris and Macroglossum the venation may be more or less pinnate in character.

P. 287. The statement that the primary root of Marattia is tetrarch is erroneous. It is usually diarch in all the genera, but may be, exceptionally, triarch.

P. 288. The development of the vascular system was critically studied by the writer in Dancea and Kaulfussia, and to some extent also in Marattia and Angiopteris (see Campbell (33)). All of the genera agree as to the essential points of development.

The vascular system of the young sporophyte begins as a single axial strand which is continuous through the cotyledon and root. At 
a very early period a second vascular bundle or stele is formed in the second leaf, and this stele joins the primary axial bundle of the young sporophyte. In Danea, which was especially studied, a similar single stele is formed in each succeeding leaf, up to about the seventh. Up to this time, except for the steles of the secondary roots, the whole vascular system is built up of united leaf-traces, and there is no cauline stele in the strict sense of the word, although one may speak of the bundle or stele of the stem, as soon as there is a solid central strand formed by the junction of the early leaf-traces. This primary stele never has the character of a true protostele, as the xylems belonging to the component leaf-traces can be clearly recognized, and the compound nature of the stele is unmistakable.

At a later stage, about the time the seventh leaf is formed, there arises a single axial ("commissural") strand, which is really of cauline origin, and the only part of the vascular system which strictly belongs to the stem. The leaf-traces formed subsequent to the appearance of the commissural strand are double.

In the older sporophyte the vascular system of the axis has the form of an open wide-meshed cylinder ("Dictyostele"), within which is the commissural strand (or strands).

P. 290. The "meshed zones," are really built up of the very complicated leaf-traces from the gigantic leaves, which sometimes measure 5-6 metres in length.

P. 29I. The statement of Holle (2), that sclerenchyma is present in the stem of Danca, was based upon an error, the plant examined by him not being a Dancea, or any Marattiaceous fern. Danca, like all the other Marattiaceæ, has no sclerenchyma in the stem.

P. 292. For Brebner (2), read (1); for Luerssen (7), read (6).

P. 292. Archangiopteris and Macroglossum, like Angiopteris, have separate sporangia.

P. 297. An examination, by the writer, of sections of sporangia of several forms of Angiopteris, showed a structure corresponding to that given by Professor Bower.

P. 298. In Macroglossum (Campbell (36)) the elongated sori are separated by an elevated ridge, not unlike that found in Dancea.

P. 298. Probably the four sub-families given may better be considered as families, viz., Angiopteridaceæ, Marattiaceæ, Kaulfussiaceæ, Danæaceæ. The Angiopteridaceæ now includes also Macroglossum.

P. 299. Kaulfussia=Christensenia. A second species, C. Cumingiana, has recently been discovered in the Philippines. 
P. 298. All of the forms of Angiopteris have been referred by some writers to a single species, $A$. evecta, but there is no question that there are a number of well-marked species, although probably some of the species recognised by De Vriese ( $\mathrm{I}$ ), should be eliminated.

P. 300. The genus Macroglossum was first described by Copeland (I), from material sent from Sarawak in Western Borneo, where it has been collected at several points. A form of this, probably a second species, has been cultivated in the Botanical Garden at Buitenzog, Java, under the name Angiopteris Smithii. Macroglossum has also recently been reported from Sumatra. Macroglossum, unlike Angiopteris, has simply pinnate leaves, and the structure of the sporangium is more like that of Archangiopteris, to which it is more nearly related than it is to Angiopteris. (See Campbell $(35,36)$.) The type, $M$. Alide, is a large fern with leaves sometimes nearly four metres in length.

P. 300. Some species of Danaa, e.g., D. elliptica, have an upright rhizome, and the leaves arranged spirally.

P. 300. Chlorophyll may develop under certain conditions in the gametophyte of Ophioglossum (see Bruchmann (5), Mettenius (2)).

P. 30I. The young embryo of Ophioglossum Moluccanum, resembles very closely that of Anthoceros.

P. 303. The recent studies of the writer on the embryology of the Marattiaceæ and Ophioglossaceæ show a much greater similarity between them than was supposed to be the case. (See Campbell (33).)

P. 304. The reasons for the assumption of a direct relationship between the Ophioglossaceæ and Marattiaceæ have been given at length elsewhere. (See Campbell (33).) The conclusions reached may be briefly summarised. "From some form allied to the existing species of Ophioglossum the whole Fern-series is descended. In this series the leaf is the predominant organ, the stem, at first, being of quite subordinate importance. This ancestral Fern was monophyllous and the original leaf was a sporophyll, perhaps without any definite sterile segment.

From this central type it may be assumed that several divergent lines of development arose, of which only isolated fragments have persisted to the present time.

The Marattiaceæ, as they now exist, probably do not represent a single unbroken line of descent, but show evidences of a multiple derivation from the primitive stock. The point of contact with the 
Ophioglossales is probably in the neighbourhood of Helminthostachys, which, on the whole, most nearly resembles the Marattiales; but it is improbable that the solid synangium which characterises most of the living Marattiaceæ was derived from a group of distinct sporangia like those of Botrychium or Helminthostachys; and it is more likely that it originated from some structure more nearly resembling the spike of Ophioglossum.

Angiopteris is, with little question, the most specialised of the Marattiales, and has apparently departed furthest from the ancestral type; while, on the other hand, Kaulfussia is probably the most primitive of the existing genera.

On the whole, the Marattiales are nearer the Leptosporangiatæ than the Ophioglassales are, and it is likely that the Leptosporangiates are derived directly from some ancient Fern-types, related to the living Marattiales, but differing from any of the existing forms."

\section{CHAPTER IX}

P. 305. The number of species of the Eusporangiatæ is much larger than the figure given. Christensen (I) recognises 192 species of Ophioglossaceæ and Marattiaceæ, but probably some of these should be reduced.

P. 306. For Luerssen (7), read (6).

P. 308. A very careful study of Apogamy and Apospory has been made by Farmer and Digby (12). It was shown that where gametophytes arose by apospory, the nuclei contained approzimately the same chromosome number as the sporophytic tissues. In such cases, the young sporophyte developed either as an apogamous bud or else arose from an egg-cell which had not been fertilised.

In cases where the gametophyte arises in the normal way, i.e., from the germination of a spore having half the chromosome-number of the sporophyte tissues, the formation of an apogamous sporophyte is preceded by a migration of nuclei from one cell to another with subsequent fusions of the nuclei, so that in this way the cells of the apogamous sporophyte receive the double chromosome-number.

P. 3II. Pilularia Americana shows traces of a terminal annulus like that of the Schizæaceæ (see Campbell (26)).

P. 3I4. Mottier states that in Onoclea monœcious prothallia are found occasionally, although diocism is the rule (see Mottier (4)).

P. 326. The origin of the stele of the young axis needs further investigation. It is not at all unlikely that in the Leptosporangiate 
Ferns, as well as the Eusporangiatæ, the vascular system of the axis is composed entirely of united leaf-traces. Should this be so, the bundle found in the stem-quadrant of the embryo would belong to the second leaf and not to the stem itself.

P. 328. A very elaborate study of the vascular system of the Ferns has been published recently by Tansley (2). This, like all of the similar work of late years, is based on the assumption that the stelar structures of the axis are of cauline origin.

P. 342. 'For "Goebel (IO)," read "(9)."

\section{CHAPTER $\mathrm{X}$}

P. 346. Boodle (8) has observed much reduced male prothallia of Todea, developed from spores which germinated within the closed sporangium, where the latter were prevented from opening on account of excessive moisture.

P. 360. The most recent study of the structure of the vascular system in the Osmundaceæ has been made by Sinnott (I). This is principally concerned with the question of the formation of foliar gaps. These were found to be present in all cases, although often inconspicuous.

P. 366. The writer has investigated the gametophyte in several species of Gleichenia, i.e., G. polypodioides, G. pectinata, G. dichotoma (G. linearis), and G. lavigata. The first species belongs to the section Eugleichenia, the others to Mertensia. $G$. polypodioides, which was collected near Cape Town, has a smaller prothallium than the other species, and one which more nearly resembles that of the Polypodiaceæ in form; while the other species have the prothallium often much elongated, or with a conspicuous midrib, much as in Osmunda. In these species, too, there are more or less conspicuous leaf-like lobes, so that the prothallium closely resembles such a Liverwort as Fossombronia. The larger prothallia are sometimes dichotomously branched.

The antheridia are usually confined to the ventral surface of the gametophyte, but in $G$. lavigata they may also occur upon the dorsal surface of the midrib.

In the older gametophytes there was always found an endophytic fungus, like that occurring in the Marattiaceæ and Ophioglossaceæ.

The antheridium of Gleichenia polypodioides was found to correspond most nearly with that of the species studied by Rauwenhoff; in the other species the antheridium is very much larger, and closely re- 
sembles that of Osmunda. In G. lavigata the antheridium may reach a diameter of $100 \mu$, and contain several hundred sperm-cells.

P. 369. The cotyledon in G. pectinata, G. dichotoma, and $G$. lavigata shows a prolonged apical growth like that of the leaves of the adult sporophyte. The early roots are diarch.

P. 372. Compton's work on $M$. sarmentosa (Compton (I)) shows that the anatomy of this species is somewhat simpler than that of $M$. pectinata, but is not essentially different.

P. 372. Shreve (I) has made a special study of the physiology of the Hymenophyllacex.

P. 379. For Boodle (I), read (2).

P. 383. See the recent paper by Georgevitch (I).

P. 384. In a recent paper by Miss Twiss (I), it is stated that in Aneimia Phyllitidis the two lobes of the heart-shaped prothallium are of equal size.

P. 385. For Thomas (I), read (3).

P. 388. The sterile leaves of the majority of the species of Schizcea are simple, as they are in $S$. pusilla.

P. 388. The development of the sporangium in Aneimia and Lygodium have been examined by Stevens (I), and Binaford (I). Their results confirm the work of Prantl, but add some details to the structure of the tapetum and spore-division. In both genera the tapetum is two-layered. In Lygodium the cells often show two nuclei, and only the inner layer of tapetal cells is broken down. In Aneimia Phyllitidis, Stevens found that the whole tapetum becomes broken down.

P. 395. The relationships of the families of the Filices to each other, and especially the interrelationships of the Polypodiaceæ, are still by no means settled. Among the recent contributions to this subject, may be mentioned especially the important series of papers by Professor Bower on the phylogeny of the Filicales $(27-3 I)$.

\section{CHAPTER XI}

P. 398. Two important contributions on the gametophyte of Salvinia have recently been published: (Arnoldi (2); Yasui (I)).

P. 398. Yasui's account of the development of the male gametophyte confirms Belajeff's statement. He considers that there are two antheridia formed, each containing four sperms. The results of Arnoldi's investigation also confirm Belajeff's conclusions. Arnı'di 
studied the development of the spermatozoid, which does not differ essentially from that of other Filicinex.

P. 403. Both Arnoldi and Yasui found that the nucleus of the spore cavity in Salvinia divides very much as in Azolla.

P. 407. Yasui (I) states that a primary root is present but it is not functional, and soon ceases to be recognisable, becoming merged with the foot.

P. 4I4. Yasui (I) confirms Heinricher's statement that the tapetum in Salvinia is composed of a single layer of cells as in Azolla. Like the latter there are but eight macrospore mother cells, instead of sixteen as Jurányi states. According to Yasui there are sixteen chromosomes in the spore mother cells, and the reduced number in the spore is eight.

P. 4I4. For Jurányi (I), read (2).

P. 4I4. Footnote - "Macrospangium," should be "macrosporangium."

P. 426. For Arcangeli (I), read (2).

P. 435. The marginal position of the sporocarp is especially evident in $M$. polycarpa (see Allison ( $\mathrm{r}$ )).

P. 442. Some interesting experiments bearing on the origin of heterospory have been made by Shattuck (I) on Marsilia.

P. 446. For Goebel (22), read (2I).

\section{CHAPTER XII}

P. 446. The prothallium of Equisetum debile is described by Kashyap (I) as being radial in structure, and resembling that of Lycopodium cernuum; but the figures and descriptions are not very convincing, and it is quite as likely that a more careful investigation would show no radical difference between $E$. debile and the other species that have been studied. The early stages resemble closely those of E.telmateia, where (see text, Fig. 258) the young prothallium sometimes shows a condition corresponding to what Kashyap calls a "primary tubercle."

P. 447. In E. debile (Kashyap (I)) archegonia are formed first, and later, on the same prothallium, the antheridia.

P. 447. The development of the spermatozoids has been very exhaustively studied by Sharp ( $\mathrm{r}$ ). He states that the blepharoplast at one stage becomes broken up into a series of bead-like fragments, which later fuse into a continuous thread. He also states his belief that the blepharoplast is a further development of a centrosome. 
P. 453. The extensive but interrupted marginal meristem noted by Kashyap in $E$. debile, is probably the result of the repeated dichotomy of the primary apex. E. debile has but a single neck canal-cell.

P. 454. Jeffrey's conclusions as to the origin of the root in the embryo of $E$. hicmale and $E$. limosum are interesting, as they indicate a resemblance to the Eusporangiate Ferns, especially Ophioglossum and the Marattiales.

P. 457. E. debile agrees closely with $E$. hiemale in the early development of the young sporophyte.

P. 459. For more recent investigations in the stem structure of Equisetum see Eames (I), Sykes (I), Plant (I), Campbell (27).

P. 462. The development of the xylem in Equisetum has been carefully examined by Eames (I).

P. 462. Miss Sykes (I) has described the presence of very large reticulately pitted tracheids at the nodes in E. maximum. These extend into the carinal canal of the internodal bundles, and it is thought that their function is to conduct water from one internodal bundle to another, as the carinal canals are interrupted at the nodes.

P. 464. The lacuna in the vascular bundle is known as the carinal canal.

P. 467. The most elaborate study of the tissues of Equisetum, recently published, has been made by Plant (I).

P. 472. For Bower (I5), read (I4).

P. 476. Fig. 240 should be 279 .

P. 478. Beer (3) states that the "middle layer" is formed through the activity of the tapetal plasmodium. The membrane first formed about the young spore is the exospore within which is later formed the endospore. The middle layer is first deposited by the tapetal protoplasm, and later, outside of it is formed the perinium, from which, by splitting, the elaters arise.

P. 482. For a further discussion of the relationships of the Equisetales, see Campbell (27).

\section{CHAPTER XIII}

P. 483. For Goebel (18), read (10); for Bruchmann (5), read (4).

P. 483. Bruchmann (9) has succeeded in germinating the spores of several European species of Lycopodium. See also Chamberlain (3), Hollaway (2).

P. 485. It seems probable, from the more recent studies on the Psilotaceæ, that the family should be made the type of a distinct 
order, Psilotales, and perhaps should even be removed entirely from the Lycopodineæ, and associated with the fossil order Sphenophyllales. (See Lawson $(I, 2)$.)

P. 486. Bruchmann succeeded in germinating the spores of three European species, L. clavatum, L. annotinum, and L. Selago. A remarkable feature is the long period necessary for germination. In L. Selago, the first signs of germination were seen in three to five years after the spores were sown, while in the other species, six to seven years passed before the spores began to germinate. Full-grown gametophytes were first found in L. Selago, in six to eight years, in the other species, twelve to fifteen years.

In all the species examined, the first division-wall cuts off a small cell, which is apparently a rudimentary rhizoid. This is soon followed by other walls, resulting in a globular or oval body composed of five cells. There is then a long period of rest. This preliminary stage, or "primary tubercle," is reached at the expense of the food materials in the spore, since the spores are without chlorophyll and the development takes place underground.

As in the case of Ophioglossum, the further development is dependent upon the symbiotic association of the young gametophyte with a fungus. This takes place in the manner already described in Ophioglossum. (See note to p. 234.)

P. 489. For diøecious, read moncecious.

P. 492. Wernham (I), however, thinks that Phylloglossum "far from being a primitive form is highly specialised."

P. 495. Hollaway (I) has recently made an anatomical study of several New Zealand species of Lycopodium.

P. 499. In a considerable number of species of Lycopodium numerous roots are formed, which instead of emerging at once, grow downward for a long distance through the cortical tissues of the stem, emerging finally near the base. These were described by Strasburger in $L$. Selago, and he enumerates about twenty species in which such roots occur. They are especially conspicuous in $L$. pithyoides, an epiphytic species.

P. 500. For Bower (I 5), read (I4).

P. 502. The sporangium does not always, apparently, arise directly from the leaf-base, but may be of axial origin. (Stokey (2), Sykes (2).)

P. 503. The most recent work in Phylloglossum (Wernham (I)) gives a detailed account of the structure. Wernham considers Phylloglossum to be a much reduced form, and not a primitive 
one. He calls attention to certain resemblances in its anatomy to that of Isoetes and believes that the latter and Phylloglossum are related.

P. 504. The gametophytes of both Psilotum and Tmesipteris have recently been discovered (Lawson, I, 2). The gametophytes are much alike, resembling in form that of Lycopodium Phlegmaria; but the sexual organs are much more like those of the Ferns. The spermatozoids are multiciliate. Lawson is inclined to accept the view that the Psilotacex are related to the Sphenophyllales.

P. 504. A study of the anatomy of $P$. flaccidum (Stiles (I)) shows a general agreement with $P$. triquetrum. In both species there is a trace of secondary xylem in the stem-bundle. (See Boodle (6).)

P. 506. It is likely that Tmesipteris is saprophytic rather than parasitic. As in other humus-saprophytes, there is always associated with the plant a mycorrhizal fungus, similar to that found in the Ophioglossaceæ, and the subterranean gametophyte of Lycopodium.

P. 507. The literature on Tmesipteris has been carefully reviewed by Miss Sykes (3), who also made a study of the structure of the sporophyte. She considers the sporangiophore to be a branch having two leaves, and terminated by a synangium composed of one or two spongenous masses that have fused over the apex of the shoot. This contradicts the view held by Bower.

P. 5IO. For Bower (2I), read (20).

P. 510. Miss Sykes concludes that the evidence for associating the Psilotales with either the Sphenophyllales or Lycopodiales is inconclusive. "They are better retained alone in the cohort Psilotales."

P. 518. There is a good deal of difference in different species as to the time of development of the gametophyte within the macrospore. (See Bruchmann (8).) Thus, in S. spinulosa and S. Helvetica the gametophyte is mostly developed after the spores are shed; while in S. rupestris the whole development of the gametophyte is completed while the spores are still within the sporangium. Fertilisation may even occur while the spore is still within the sporangium (e.g., S. apus), thus very closely approximating the condition found in seed-bearing plants.

Bruchmann also asserts that in some species the germination does not begin until after the spores are shed. He gives no figures of sections of the spores, so that it is not quite clear whether or not he implies that the spore when shed had but a single nucleus. This seems highly improbable. 
Bruchmann also found that in some species, e.g., S. Martensii, $S$. spinulosa, no diaphragm is developed, but that there is a gradual transition from the small-celled archegonial tissue at the apex to the larger-celled tissue of the basal region. In $S$. Galeottei the cells are arranged in concentric layers, but there is no diaphragm.

P. 518. Bruchmann's recent studies on the embryo show much variation. In $S$. denticulata the first or basal wall divides the embryo into a hypobasal and epibasal cell, as in S. Martensii, but from the former is developed not only the multicellular suspensor, but also the foot and later the first rhizophore. In S. rubricaulis the foot is also of hypobasal origin, but the suspensor is very short.

P. 520. Bruchmann figures a prothallium of S. Kraussiana, showing rhizoids. These are, however, much less conspicuous than in some other species, e.g., S. Galeottei, where there are large prominences with a bunch of long rhizoids at the outer angles of the prothallium. He states that rhizoids occurred in all the species examined.

$S$. Galeottei shows a marked difference. A membrane is formed about the fertilised egg, which then contracts and forms another membrane, after which it divides into two cells. The young embryo thus lies within a membrane, which now elongates and carries the young embryo down into the endosperm, part of which has become disintegrated. In a later paper (IO) he states that this is also the condition in S. Kraussiana. The elongated "suspensor," therefore, figured in the text (Fig. 298, A. sus.) is this tube which bears within it the young embryo shown in Fig. 298, F.

In two species, $S$. spinulosa and S. rubricaulis, Bruchmann found embryos developed parthenogenetically.

P. 524. A detailed study of the strobilus of Selaginella has been made by Sykes (4) and Mitchell (I). From these investigations it appears that there is a good deal of variation in several respects in different species. The sporophyll itself may be quite simple, or it may be provided with a dorsal flap, which acts as a protection for the sporangium belonging to the next older sporophyll. This is especially marked in S. pumila (Sykes and Stiles (4), p. 524).

The distribution of the two sorts of sporangia, also, shows much variation (Mitchell (I)). In S. spinosa, S. rupestris, S. Helvetica, among others, are found several basal macrosporangia, followed by numerous microsporangia. In $S$. atroviridis, S. gracilis, and others, the cones are wholly macrosporangiate or microsporangiate. In another category, e.g., S. Martensii, S. caulescens, etc., there is an indiscriminate mingling of macrosporangia and microsporangia. 
The difference in size between the two sorts of sporangia is most marked in those where the macrosporangia are confined to the basal portion of the cone.

P. 529. For a detailed discussion of the morphological nature of the rhizophore see Worsdell (I).

P. 530. For Goebel (I6), read (9); for Bower (I5), read (I4).

P. 532. There is considerable variation in the number of megaspores that may be formed (Mitchell (I)). While in most cases there are four, the number may be reduced to two, e.g., S. rupestris, or even a single one, e.g., S. sulcata.

Conversely, cases have been observed where more than one mother cell divides so that the number exceeds four. Miss Mitchell observed twelve in a specimen of $S$. Vogelii, and eight in one of $S$. involvens. In $S$. Helvetica Kainradt (I) found that not infrequently two sporetetrads were formed, and in one case four complete spore-tetrads were seen in a macrosporangium.

\section{CHAPTER XIV}

P. 534. For Sadebeck (8), read (9).

P. 536. See Wernham's paper on Phylloglossum (1), for a comparison of that genus with Isoetes.

P. 553. One of the recent accounts of the anatomy of Isoetes is by Miss Stokey ( $\mathrm{r}$ ), who examined four species. Her account agrees essentially with that of other observers. Her conclusion as to the systematic position of Isoetes is that it should be placed in the Lycopodiales. Lang (14) has still more recently made an elaborate study of the general morphology of the stock of $I$. lacusiris.

P. 554. The type of secondary wood in Isoetes has been compared to that of the fossil Lepidodendreæ. (See Stokey (I), p. 332.)

\section{CHAPTER XV}

P. 563. See Allen ( 1 ).

P. 569. The embryo of certain species of Ophioglossum (e.g., $O$. Moluccanum) probably resembles that of the ancestral Fern. It consists at first simply of the large foot and the young primary leaf. At this stage the embryo bears a marked resemblance to the young sporophyte of Anthoceros. The root arises somewhat later, deep down in the tissue near the junction of the leaf and foot. As this 
endogenous root develops, it penetrates the tissues of the foot and also the overlying tissue of the gametophyte, and emerging, grows downward into the ground.

P. 569. Tenth line from bottom; "alteration" should read "alternation."

P. 570. For Scott (3), read (4).

P. 571. For Lang (3), read (2).

P. 57I. A doubtful case of apogamy has been noted by Jeffrey in Botrychium, one of the Eusporangiate Ferns. (Jeffrey (I).)

\section{CHAPTER XVI}

P. 576. Among the many contributions to a knowledge of the fossil Archegoniates that have appeared in the last ten years, the following may be noted:

Stopes (I), Scott (5, 6), Browne (I), Coulter (5), Kidston (I), Seward (5), Bower (22), Chodat (I), Oliver (I), Jeffrey (4). 



\section{BIBLIOGRAPHY}

Aввот, James. - Scalariform ducts in Prothalli. Quarterly Journal of Microscopical Science, new ser., xiv: 40I, I874.

Abrams, L. R. - Structure and Development of Cryptomitrium tenerum. Bot. Gazette, xxviii : IIO-I 2 I, I899.

AKerman, AKe. - Uber die Chemotaxis der Marchantia-spermatozoiden. Zeitschr. f. Botanik, II : 94-ro3, I9Io.

Allen, Charles E. - I. Die Keimung der Zygote bei Coleochæte. Ber. der deutsch. bot. Gesellsch., xxiii : 285, I905.

2. The Spermatogenesis of Polytrichum juniperinum. Ann. Bot., xxxi: $269-290$, I9I 7 .

Allison, H. E. - Notes on the vascular connections of the Sporocarp of Marsilia polycarpa. New Phytologist, $\mathrm{x}$ : 204-206, I9I I.

Ambronn, H. - Ueber Poren in den Aussenwänden der Epidermiszellen. Pringsheims Jahrb. für wiss. Botanik, xiv: 82-I09, I884.

Andreas, J. - Ueber den Bau der Wand und die Oeffnungsweise des Lebermoossporogons, Flora, xxxvi : I6I-2I3, I899.

ANDREws, W. M. - Apical growth of the roots in Marsilia quadrifolia and Equisetum arvense. Botanical Gazette, xv: I74, I89o.

Arber, E. A. Newell. - The Past History of the Ferns. Ann. Bot., $\mathrm{Xx}: 2 \mathrm{I} 5^{-232,}$ I906.

ARCANGeli, G. - I. Studi sul Lycopodium selago. Livorno, I874.

2. Sulla Pilularia e Salvinia. Nuovo Giornale Botanico Italiano, viii : 320,1876 .

Arcter, JAMES. - Prothalli with scalariform ducts. Q.J.M.S., new ser., $\mathrm{XV}: \mathrm{IO6}, \mathrm{I} 875$.

ARNoldi, W. - Die Entwickelung des weiblichen Vorkeims bei den heterosporen Lycopodiaceen. Bot. Zeit., liv : 1 59-I68, I896.

2. Beiträge zur Kenntniss der Keimung von Salvinia natans, Flora, C: I2I-I39, I9IO.

Ashworth, J. H., On the Structure and Contents of the Tubers of Anthoceros tuberosus. Mem. and Proc. Manchester Literary and Philosophical Society, xli, No. 2, I8g6.

Bancroft, N. - On the xylem elements of the Pteridophyta. Ann. Bot., xxv: $745-760$, I9II.

BarNes, C. R. - Artificial keys to the genera and species of Mosses. Trans. Wisconsin Acad. of Sciences, Arts and Letters, viii : I89o. 
Barnes, C. R., and Land, W. J. - 2. The origin of Air-chambers, Bot. Gaz., xliv: $189-197$, I907. 3. The origin of the cupule of Marchantia. Bot. Gaz., xlvi : 40I-409, I908.

De Bary, A. - r. Sur la germination des Lycopodes. Ann. des Sci. naturelles, ser. 4 , vòl. ix : p. 30,1858 .

2. Ueber apogame Farne und die Erscheinung der Apogamie im Allgemeinen. Bot. Zeit., r878, p. 449.

3. Comparative Anatomy of the vegetative organs of the Phanerogams and Ferns. Oxford, I884.

Bastit, E. - Comparison entre le rhizome et la tige feuillée des Mousses.

Bul. de la Soc. bot. de France, xxxvi: 295, I889.

BAUKE, H. - I. Entwickelungsgeschichte des Prothalliums bei den

Cyatheaceen. Pringsheims Jahrb. für wiss. Botanik, x : 49, I876.

2. Beiträge zur Keimungsgeschichte der Schizæaceen. Pringsh. Jahrb. für wiss. Botanik, xi : 603,1878 .

3. Das Prothallium von Platycerium grande. Bot. Zeit., I879, p. 433.

4. Einige Bemerkungen über das Prothallium von Salvinia natans. Flora, Ixii : 209, 1879 .

5. Aus dem botanischen Nachlass von H. Bauke. Bot. Zeit. (Beilag.), I880.

Beck, G. - Einige Bemerkungen über den Vorkeim von Lycopodium.

Oesterreichische botanische Zeitschrift, I880, p. 34I.

Becquerel, P. - Germination des spores d'Atrichum undulatum et d'Hypnum velutinum. Rev. gen. Bot.: 49-66, I906.

Beer, R. - I. On the Development of the Spores of Riccia glauca. Ann. Bot., xx: 293-300, I906.

2. On the Development of the Spores of Helminthostachys Zeylanica. Ann. Bot., $\mathrm{xx}$ : $177^{-186, \text { I906. }}$

3. The Development of the Spores of Equisetum. New Phytologist, viii : $26 \mathrm{I}-266$, I909.

BeHrens, J. - Ueber die Regeneration bei den Selaginelleen. Flora, Ergänzungsb., lxxxiv : 1.59-166, I879.

Belajefr, W. - I. Die Antheridien und Spermatozoiden der heterosporen Lycopodineen. Bot. Zeit., I885, p. 793.

2. Ueber Bau und Entwickelung der Spermatozoiden der Gefässkryptogamen. Ber. der deutschen bot. Gesellschaft, vii : I22, I888.

3. Ueber Bau und Entwickelung der Spermatozoiden der Pflanzen. Flora, lxxix: Ergänzsb., I-48, 1894.

4. Ueber den Nebenkern in spermatogenen Zellen und die Spermatogenese bei den Farnkräuter. Ber. der deutsch. bot. Gesell., xv: $337, \mathbf{1 8 9 7}$.

5. Ueber die Cilienbildner in den spermatogenen Zellen. Ber. der deutsch. bot. Gesell., xvi : I40, I898.

6. Ueber die männlichen Prothallien der Wasserfarne (Hydropterides). Bot. Zeit., lvi : I4I-I94, I898. 
7. Ueber die Centrosomen in den spermatogenen 'Zellen. Ber, der deutsch. botan. Gesell., xvii : 199-205, 1899.

Benedict, R. C. - I. Fern leaves, ferns, and fern-allies. American Fern Journal, 1: igro.

2. The origin of New Varieties of Nephrolepis by orthogenetic saltation. I. Progressive Variations. Bull. Torrey Bot. Club, xliii: $207-234,1916$.

BENGT, L. - Ueber die Reizbewegungen der Marchantiaspermatozoiden.

Pringsh. Jahrb. für wiss. Botanik, xli : $65-87$, r,904.

Benson, Margaret J. - I. The Sporangiophore, a unit of structure in the Pteridophytes. New Phytologist, vii: I43-I49, I908.

Berggren, S. - I. Entwickelung und Bau des Proembryo von Diphyscium und Edopodium. Botaniska Notiser af Nordstedt, I873, p. Io9.

2. Om Azollas prothallium och Embryo. Lund's Univer. Arsskrift, vol. xvi.

3. Apogamie in Notochlæna. Botaniska Notiser, I888. Bot. Centralblatt, $\mathrm{xxxv}: \mathrm{I} 83, \mathrm{I} 888$.

BERTHOLd, G. - Studien über Protoplasmamechanik. Leipzig, t886.

Bertrand, C. E. - I. Recherches sur les Tmésipteridées. Arch. bot. du Nord de la France, I882.

2. Le Type Tmésipteridée. Bull. de la Soc. bot. de France, xxx.: p. I $57, \mathrm{I} 883$.

3. Phylloglossum Drummondii. Archives botaniques du Nord de la France, I885, Nos. 30-33; also I886, 34.

4. (and CornaIlle, F.) - Les Charactéristiques des Traces foliaires Osmondéennes et Cyathéacéennes. Extr. des Procés Verbaux de la Société d'Histoire Naturelle d'Autun, IgO2.

Bessey, C. E. - r. A Synopsis of Plant Phyla. University Studies, vii : 99 pp., Lincoln, I907.

BINFoRd, R. - I. Development of the Sporangia of Lygodium. Bot. Gaz., xliv: 2I 4-224, I907.

Bitter, G. - I. Marattiaceæ. Engler and Prantl, Die Natürlichen Pflanzenfamilien, I Th. iv Abt., 422-444, I900.

2. Ophioglossaceæ. Ibid., 449-472.

Black, C. A. - I. The Morphology of Riccia Frostii. Ann. Bot., xxvii : 5II-532, I9I3.

Blackman, V. H. - I. Alternation of Generations and Ontogeny. New Phytologist, viii : $207-218$, I909.

Blakeslee, A. E. - r. Sexual condition in Fegatella. Bot. Gaz., xlvi : $384-385$, I 908 .

Blasius, W. - Ueber die americanische "Auferstehungspflanze" (Selaginella lepidophylla, Spr.). Jahresb. d. Ver. f. Naturw. zu Braunschweig, I879, I880. Bot. Centralblatt, ii: 966, I880.

Bolleter, Edgen. - I. Fegatella conica, eine morphologisch-physiologische Monographie. Bot. Centrlbl. Beihefte, xviii, Abt., I: 327-408, I905. 
Boodle, L. A. - I. On some points in the Anatomy of the Ophioglossaceæ. Ann. of Bot., xiii : $377-394$, 1899 .

2. Comparative Anatomy of the Hymenophyllaceæ, Schizæaceæ and Gleicheniaceæ.

I. On the Anatomy of the Hymenophyllacex. Ann. of Bot., xiv: $455-496$, 1900 .

3. II. On the Anatomy of the Schizæaceæ. Ann. of Bot., xv : 35942 I, I9OI.

4. III. On the Anatomy of the Gleicheniaceæ. Ibid.: 703-747.

5. IV. Further Observations on Schizæa. Ann. of Bot., xvii : 5II537, I903.

6. Secondary tracheids in Psilotum. Ann. of Bot., xviii: 505-517, I904.

7. The Monceism of Funaria hygrometrica. Ann. Bot., xx: 32I, I906.

8. On the production of dwarf male Prothalli in the sporangia of Todea. Ann. Bot., xxii : 23I-243, I908.

Bower, F. O. - I. Note on the gemmæ of Aulacomnium palustre. Journal of Lin. Soc., xx: $465, \mathrm{r} 884$.

2. Comparative Morphology of the leaf of the Vascular Cryptogams and Gymnosperms. Proc. of the Roy. Soc., xxxvii : 61, I884. Phil. Trans., clxxv: 565, 1884 .

3. Preliminary note on the apex of the root and leaf in Osmunda and Todea, Proc. Roy. Soc., xxxvi : 442, I884.

4. Apex of the root in Osmunda and Todea. Q. J. Mic. Sci, new ser., $x x v$ : 75,1885 .

5. Phylloglossum Drummondii. Royal Soc. Phil. Transactions, clxxvi: Part II, 665, I885.

6. Apospory and allied phenomena. Trans. of the Linnæan Soc. Second ser., Bot., vol. ii : 301,1887 .

7. Preliminary note on the formation of gemmæ in Trichomanes alatum. Ann. of Botany, i: I83, I887.

8. On some normal and abnormal developments of the Oöphyte in Trichomanes. Ann. of Botany, i: 269, 1888.

9. Antithetic as distinct from homologous alternation of generations in plants. Annals of Botany, iv : $347, \mathrm{I} 890$.

10. Attempts to induce aposporous development in Ferns. Annals of Botany, iv: r68, I889.

II. The comparative examination of the Meristems of Ferns as a phylogenetic study. Annals of Botany, iii : 305, I889.

12. Is the Eusporangiate or the Leptosporangiate the more primitive type of Fern? Annals of Botany, vol. v: I09, I89I.

13. On the structure of Lepidostrobus Brownii Sch. Annals of Botany, vii : 329,1893 .

I4. Studies in the Morphology of the spore-producing members. 
Equisetineæ and Lycopodineæ. Roy. Soc. Phil. Trans., vol. clxxxv: 1894, 473 .

I5. A Theory of the Strobilus in Archegoniate Plants. Ann. of Bot., viii : 343,1894 .

16. Studies in the Morphology of Spore-producing Members, ii : Ophioglossacex, London, I8g6.

17. Studies in the Morphology of Spore-producing Members, iii : Marattiaceæ. Phil. Trans. Roy. Soc., series B, vol. I89 : 35-81, I897.

I8. Address before Section $\mathrm{K}$, British Association, Bristol, I898. Nature, lix : 66-88-II2, I898.

I9. Studies in the Morphology of Spore-producing Members, iv. The Leptosporangiate Ferns. Phil. Trans., ser. B, vol. I92 : 29I38, I899.

20. Studies in the Morphology of Spore-producing Members, v. General Comparisons and Conclusions. Phil. Trans., ser. B, vol. 196: 191-257, 1903.

21. Ophioglossum simplex, Ridley. Ann. of Bot., xviii : 205, r904.

22. The Origin of a Land Flora, London, $\mathbf{I} 908$.

23. Studies in the Phylogeny of the Filicales. I. Plagiogyria. Ann. Bot., xxiv: 423-450, I910.

24. Notes on the Morphology of Ophioglossum palmatum. Ann. Bot., XXv: $277-298$, I9r.

25. On the primary xylem and the origin of medullation in the Ophioglossaceæ. Ann. Bot., xxv: 537-553, rgrr.

26. On Medullation in the Pteridophyta. Ann. Bot., xxv: 555574, I9II.

27. Studies in the Phylogeny of the Filicales, ii. Lophosoria, and its relation to the Cyatheoidex. Ann. Bot., xxvi: 269$324,1912$.

28. Studies in the Phylogeny of the Filicales, iii. On Metaxya and certain other relatively primitive ferns. Ann. Bot., xxvii : $443-477$, I913.

29. Studies in the Phylogeny of the Filicales, iv. Blechnum and allied genera. Ann. Bot., xxviii: 363-43I, I9I4.

3o. Studies in the Phylogeny of the Filicales, v. Ann. Bot., xxix: $495-529$, I9I 5 .

3I. Studies in the Phylogeny of the Filicales, vi. Ann. Bot., xxxi : I-39, I9I 7.

Brebner, G. - . . On the Mucilage-canals of the Marattiaceæ. Journ. Lin. Soc., London, $x x x: 444,1895$.

2. On the Prothallus and Embryo of Dancea simplicifolia, Rudge. Ann. of Bot., $x$ : I09, 1896 .

3. On the Anatomy of Danæa and other Marattiaceæ. Ann. of Bot., xvi : 5 I $7-55^{2}, 1902$. 
Breeves, J. - On the development of the stem and leaves of Physiotium giganteum. Trimen's Journal of Botany, xxxii : 33, I894.

Britton, E. G., and TAYLOR, A. - I. The Life History of Schizca pusilla.

Contributions from the N. Y. Bot. Garden, No. II, I90I. Also Bull.

Torrey Bot. Club, xxviii : I-I9, IgOI.

2. The Life History of Vittaria lineata. Mem. Torrey Bot. Club, viii: No. 3, I902.

Brotherus, V. F. - Bryales. Engler and Prantl, Die Nat. Pflanzenf. Theil i, Ab. 3: 288-II7 $\mathrm{I}^{+}$, I902-I909.

Browne, IsABeL. - I. The Phylogeny and Interrelationships of the

Pteridophyta. New Phytologist, vii, viii: Ig08-rgog.

2. A second contribution to our knowledge of the Anatomy of the Cone and fertile stem of Equisetum. Ann. Bot., xxix: 23I264 , I9r 5 .

Bruchmann, H. - I. Wurzeln von Isoetes und Lycopodium. Jenaische Zeitschrift für Naturwissenschaften, 1874 .

2. Die vegetativen Verhältnisse der Selaginelleen. Giebel's Zeitschrift für die gesammten Naturwissenschaften, 1877 .

3. Untersuchungen über Selaginella spinulosa, A. Br. Gotha, I897.

4. Ueber die Prothallien und die Keimpflanzen mehrerer Europäischer Lycopodien. Gotha, I898.

5. Ueber das Prothallium und die Keimpflanze von Ophioglossum vulgatum L. Bot. Zeit., lxii : 227-247, I904.

6. Uber das Prothallium und die Sporenpflanze von Botrychium Lunaria, Flora, xcvi: 203-230, 1906.

7. Das Prothallium von Lycopodium complanatum. Bot. Zeit., lxvi : I69-I8I, rgo8.

8. Vom Prothallium der grossen Spore und der Keimesentwickelung einiger Selaginella-Arten. Flora, xcviii: I2-5I, 1908.

9. Die Keimung der Sporen und die Entwickelung der Prothallien von Lycopodium clavatum, L. annotinum und L. Selago. Flora, ci: 220-267, I9ro.

Io. Zur Reduction des Embryotragers bei Selaginella. Flora, civ: 237-246, I913.

Bryan, G. S. - The Archegonium of Sphagnum. Bot. Gaz., lix: 4056, I9I5.

2. The Archegonium of Catherinea angustata Brid. (Atrichum angustatum). Bot. Gaz., lxiv: I-20, I9I7.

Bucr, H. - 7. Uber die Brutorgane der Lebermoose. Helsingfors, I9I I. Buchtien, O. - Entwickelungsgeschichte des Prothallium von Equisetum. Bibliotheca botanica, vol. viii., Cassel, I887.

Buller, A. H. R. - Contributions to our Knowledge of the Physiology of the Spermatozoa of Ferns. Ann. of Bot., xiv: 543, 1900.

Buenger, E. - Beiträge zur Anatomie der Laubmooskapsel. Botanisches Centralblatt, vol, xlii, I89o, p. 193. 
Buesgen, M. - Untersuchungen über normale und abnormale Marsilienfrüchten. Flora, lxxiii : I69, I8go.

Burck, W. - I. Das Prothallium von Aneimia. Bot. Zeit., I875, p. 499. 2. Sur la développement du prothalle d'Aneimia comparé a celui des autres fougères. Archives Néërlandaises des Sciences exactes et naturelles, t. $\mathrm{x}:$ 4I $7, \mathrm{I} 875$.

Burlingame, L. L. - The Sporangium of the Ophioglossales. Bot. Gaz., lxiv: $34-56,1907$.

CAMPBell, D. H. - $\mathrm{x}$. The structure and development of the Ostrich Fern. Mem. Boston Society of Natural History, I887.

2. Zur Entwickelungsgeschichte der Spermatozoiden. Berichte der deutsch. bot. Gesellschaft, vi : I20, 1887.

3. The development of Pilularia globulifera L. Annals of Botany, ii: 233,1888 .

4. Einige Notizen über die Keimung von Marsilia Ægyptiaca. Ber. der deutsch. bot. Gesellschaft, v: 340, 1888 .

5. The systematic position of the Rhizocarpex. Bulletin of the Torrey Bot. Club, xv: 258, r888.

6. A study of the apical growth of the prothallium of Ferns. Ibid., xviii : 73, I89I.

7. On the affinities of the Filicinex. Bot. Gazette, xv: I, I8go.

8. Die ersten Keimungsstadien der Macrospore von Isoetes echinospora Durieu. Berichte der deutsch. bot. Gesellschaft, viii : 97, I89o.

9. Notes on the apical growth in the roots of Osmunda and Botrychium. Botanical Gazette, xvi: 37, r89r.

ro. Contributions to the Life History of Isoetes. Annals of Botany, $\mathrm{v}:$ 231, I891.

Ir. On the relationships of the Archegoniatæ. Botanical Gazette, xvi : 323, I89r.

12. On the Prothallium and Embryo of Osmunda Claytoniana L. and O. Cinnamomea L. Annals of Botany, vi: 49, I892.

I3. On the Prothallium and Embryo of Marsilia vestita. Proceedings of the California Acad. of Sciences, 2nd Ser. vol. iii : I83, April, 1892.

14. The development of the sporocarp of Pilularia Americana. Bul. Torrey Bot. Club, xx: I4I, r893.

15. On the development of Azolla filiculoides, Lam. Annals of Botany, vii : I 55, I893.

16. Observations on the development of Marattia Douglasii, Baker. Annals of Botany, viii : I, I894.

I7. Notes on Sphærocarpus. Erythea, iv: 73, I896.

18. The Development of Geothallus tuberosus, Campbell. Ann. of Bot., ix : 489 , 1896 . 
19. The systematic position of the Genus Monoclea. Bot. Gaz., xxv: 272,1898 .

20. On the Structure and Development of Dendroceros, Nees. Jour. Linn. Soc., London, xxxiii : 467,1898 .

2I. Recent work upon the Development of the Archegonium. Bot. Gaz., xxvi : 428-43I, I898.

22. Studies on the Gametophyte of Selaginella. Ann. of Bot., xvi: 419-428, I902.

23. The Origin of Terrestrial Plants. Proc. A. A. A. S., lii : $463-484$, I903.

24. Antithetic versus Homologous Alternation. American Naturalist, xxxvii : I 53, I903.

25. Resistance of Drought by Liverworts. Torreya, iv : 8I-86, I904.

26. Affinities of the Ophioglossaceæ and Marsiliaceæ. Am. Naturalist, xxxviii : $76 \mathrm{I}-775$, I904.

27. Affinities of the Genus Equisetum. Am. Naturalist, xxxix: $273-285,1905$.

28. Studies on the Ophioglossaceæ. Am. Naturalist, xli: r39-r 59, 1907.

29. Studies on the Ophioglossaceæ. Ann. du Jardin Bot. de Buitenzorg, 2d Ser., vi : 138-r94, 1907.

30. Studies on some Javanese Anthocerotaceæ.

I. Ann. Bot., xxi: 467-486, 1907 .

II. Ann. Bot., xxii : 9I-I02, 1908 .

3r. Symbiosis in Fern Prothallia. Am. Naturalist, xlii: r 54-ז65, I908.

32. The Prothallium of Kaulfussia and Gleichenia. Ann. du Jardin Bot. de Buitenzorg, 2d Ser., viii: 69-102, I908.

33. The Eusporangiatæ; the Comparative Morphology of the Ophioglossaceæ and Marattiacex. Carnegie Institution of Washington, Publication No. I4I, pp. vi.-224, rgrI.

34. The Morphology and Systematic Position of Calycularia radiculosa (Steph.). Dudley Memorial Volume. Stanford University: 33-6r, I9r3.

35. The Genus Macroglossum Copeland. Philippine Journ. Sci. ix. No. 3. Sec., Bot.: 219-223, I9r4.

36. The Structure and affinities of Macroglossum Alida Copeland. Ann. Bot., xxviii : 65I-669, I9I4.

37. (and Williams, Frorence). - A Morphological Study of some members of the Genus Pallavicinia. Stanford University Press: 44, pp. I9I4.

38. Die Verbreitung gewisser Lebermoose der Malaischen Region. Pfeffer Festschrift. Jahrbücher für wissenschaftliche Botanik, lvi : $365-373$, 1915.

39. The Morphology and systematic Position of Podomitrium. Am. Journ. Bot., v: I99-210, I9I 5. 
40. The Archegonium and Sporophyte of Treubia insignis, Goebel. Am. Journ. Bot., vi : 26I-273, IgI6.

CARDifF, I. D. - The Development of the Sporangium in Botrychium. Bot. Gaz, xxxix : 340-347, I905.

Cavers, F.- r. Explosive discharge of Antherozoids in Fegatella conica. Annals of Botany, xvii: 270-274, 1903.

2. On Saprophytism and Mycorrhiza in Hepaticæ. New Phytologist, ii: $30-35,1903$.

3. Some points on the biology of Hepaticæ. "The Naturalist": I-I 5, May, June, rgo3.

4. Notes on Yorkshire Bryophytes, i. Petalophyllum Ralfsii. "The Naturalist": 327-334, Sept., Ig03.

5. Notes on Yorkshire Bryophytes, ii. Pallavicinia Flotowiana. "The Naturalist": Nov., Dec., I903.

6. On the Structure and Biology of Fegatella conica. Annals of Botany, xviii : $87-120$, 1904 .

7. Contributions to the Biology of the Hepaticæ. Part I. Targionia, Reboulia, Preissia, Monoclea. Leeds and London, March, I904.

8. Notes on Yorkshire Bryophytes, iii. Reboulia hemispherica. "The Naturalist": I-I 5, July, Aug., I904.

9. The Interrelationships of the Bryophyta. Reprint No. 4, New Phytologist: pp. 203, I9r.

Celakovsky, L. - Untersuchungen über die Homologien der generativen Produkte der Fruchtblätter bei den Phanerogamen und Gefässkryptogamen. Pringsheims Jahrb. für wiss. Botanik, xiv : 29I, I884.

Chamberlain, C. J. (see also "Coulter") - I. Winter Characters of certain Sporangia. Bot. Gaz., xxv: $124-128,1898$.

2. Mitosis in Pellia. Bot. Gaz., xxxvi: 28-5I, 1903.

3. Prothallia and Sporelings of three New Zealand species of Lycopodium. Bot. Gaz., lxiii : 5I-65, I9I7.

Chanderer, S. E. - I. On the Arrangement of the Vascular Strands in the "Seedlings" of certain Leptosporangiate Ferns. Ann. Bot., xix: 365-410, I905.

Charles, Grace M. - The Anatomy of the Sporeling of Marattia alata. Bot. Gaz., 2I : 8r-IoI, I9II.

Chodat, R. - Les Pteropsides des temps paléozoiques. Arch. des Sciences physiques et naturelles, xxv : 44 pp., Geneva, I908.

Christ, H. - Die Farnkräuter der Erde. Jena, I897.

(and Giesenhagen, K.) - Pteridographische Notizen. Flora, lxxxvi: $72-85, \mathrm{I} 899$.

Christensen, C. - Index Filicum, Copenhagen, igo6.

Chrysler, M. A. - I. The nature of the fertile spike in the Ophioglossacer. Ann. Bot., xxiv: I-I8, I910.

2. Is Ophioglossum palmatum anomalous? Bot. Gaz., lii: $\mathbf{I}_{5} \mathbf{I}-\mathbf{I} 53$, I9IO. 
Crapp, G. L. - The life history of Aneura pinguis. Bot. Gaz., liv: r77I93, I9I 2.

Coker, W. C. - On the occurrence of two egg cells in the Archegonium of Mnium. Bot. Gaz., xxxv: 136, 1903. The nucleus of the spore cavity in Prothallia of Marsilia. Bot. Gaz., xxxv: I37, 1903 .

2. Selected Notes, ii. Liverworts. Bot. Gaz., xxxvi: 225, 1903.

Compton, R. H. - The anatomy of Matonia sarmentosa. New Phytologist, viii : $299-307,1909$.

Conard, H. S. - The Structure and life history of the Hay-scented Fern. Carnegie Inst. of Wash. Publ. No. 94: Wash., rgo8.

Copeland, E. B. - Ferns of the Malay Asiatic Region. Philippine Jour. Science, Sec. C. Bot., iv. Igog.

Cormack, B. G. - On a cambial development in Equisetum. Annals of Botany, vii : 63,1893 .

CoRnu, M. - Note on two-celled male prothallia of Nephrodium filix-mas. Bull. de la Soc. bot. de France, t. xxi : I6I, I874.

Coulter, J. M. - I. The Origin of the Gymnosperms and the Seed Habit. Bot. Gaz., xxvi : I 53-I68, I898.

2. The Origin of the Leafy Sporophyte. Bot. Gaz., xxviii : 46-59; I899.

3. (and Chamberlain, C. J.) - Morphology of Spermatophytes, Part I, Gymnosperms, New York, IgoI.

4. Morphology of Spermatophytes, Part II, Angiosperms, New York, Ig03.

5. (and Chamberlain, J. C.) - Morphology of Gymnosperms : Chicago, I9Io.

Cramer, C. - I. Ueber Lycopodium Selago. Pflanzenphysiologische Untersuchungen von Carl Nägeli und Carl Cramer, vol. iii : p. Io.

2. Vorläufige Mittheilung über geschlechtloses Fortpllanzen des Farnprothalliums, namentlich mittels Conidien resp. Gemmen. Bot. Centralb., Bd. i: 476 , I880.

Cutring, E. M. - On androgynous receptacles in Marchantia. Ann. Bot., xxiv : $349-357$, I910.

Czaper, F. - Zur Chemie der Zellmembranen bei den Laub- und Lebermoosen. Flora, lxxxvi: 36I-38I, I899.

DachnowsKi, A. - Zur Kenntniss der Entwickelungsphysiologie von Marchantia polymorpha. Jahrb. der Wissenschftl. Botanik, xliv: 254-286, I907.

DANGEARD, P. A. - Essai sur l'anatomie des cryptogames vasculaires. Le Botaniste, first series, I889, p. 2 II.

2. Mémoire sur la morphologie et l'anatomie des Tmésipteris. Le Botaniste, second series, p. I63, I89I.

Davenport, G. E. - Vernation in Botrychium. Bulletin of the Torrey Botanical Club, viii : 100, I88I. 
Davis, B. M. - I. The Spore-mother-cell of Anthoceros. Bot. Gaz., xxviii : 89-108, I899.

2. Nuclear Studies on Pellia. Ann. of Bot., Xv: I47-I80, I90r.

3. The Origin of the Archegonium. Ann. of Bot., xvii : 477-492, 1903, Davis, R. C. - The Structure and Affinities of Peranema and Diacalpe. Ann. Bot., xxvi: 245-268, I9 2 .

Deutsch, H. A. - A Study of Targionia hypophylla. Bot. Gaz., liii: 492-503, I9I2.

De Vriese, W. H., and Harting, P. - Monographie des Marattiacées, 1853.

Diels, L. - Cyatheaceæ, Polypodiaceæ. Engler and Prantl, Die Nat. Pflanzenfamilien, Th. I, Abt. iv : I1 2-336, I899.

2. Polypodiaceæ, Parkeriaceæ, Matoniaceæ, Gleicheniaceæ, Schizæaceæ, Osmundaceæ. Ibid., 337-380, I900.

Dourn, CH. - I. Nouvelles observations sur Sphærocarpus. Rev. Bryol., xxxvi : 37-4I, r909.

2. Le pedicelle de la capsule des Hépatiques. Bull. Soc. Bot. de France, lv: 194-202; 270-277, I908.

Druery, C. T. - I. Observations on a Singular Mode of Development in the Lady-fern (Athyrium Filix-famina). Jour. Linn. Soc. Lond. Botany, xxi : $354-358, \mathrm{r} 884$.

2. On a new instance of Apospory in Polystichum angulare var. pulcherrimum. Ibid, xxii : 437-440, I887.

3. Notes on an Aposporous Lastraa (Nephrodium). Ibid., xxix : 479482,1893 .

4. Notes upon Apospory in a Form of Scolopendrium vulgare, var. crispum, and a new Aposporous Athyrium; also an additional phase of Aposporous Development in Lastrca pseudo-mas, var. cristata. Ibid., $\mathrm{xxx}$ : $28 \mathrm{I}-284, \mathrm{I} 894$.

Durand, E. J. - The development of the sexual organs and Sporogonium of Marchantia polymorpha. Bull. Torrey Bot. Club, xxxv: $3^{2} \mathrm{I}-335$, I908.

Dutatuly, G. - Sur l'interpretation des différentes parties de l'embryon de Salvinia. Comptes rendues des séances de la Soc. botanique de Lyon, I88I.

Duval-Jouve, J. - Histoire naturelle des Equisetum de France. Paris, I864.

EAMES, A. J. - On the occurrence of centripetal Xylem in Equisetum. Ann. Bot., xxiii : 587-612, I909.

Eaton, D. C. - Ferns of North America. Coloured plates by J. H. Emerton and C. E. Faxon.

Erstrand, E. V. - Brutknospenbildung bei den foliosen Lebermoose. Botaniska Notiser af Nordstedt, I879, No. 2.

ERnst, A. - I. Über androgyne Inflorescenzen bei Dumortiera. Ber. Deutsch. bot. Gesellsch., xxv: 455-464, Igo6. 
2. Untersuchungen über Entwickelung Bau und Verteilung der Inflorescenzen von Dumortiera. Ann. Jard. Bot. Buitenzorg, ser. 2, vii: I 53-223, I908.

Evans, A. W. - I. A provisional list of the Hepatica of the Hawaiian Islands. Trans. Conn. Acad., viii : 253, ז89x.

2. An arrangement of the genera of the Hepaticæ. Ibid., p. 262, I892.

3. Vegetative reproduction in Metzgeria. Ann. Bot., xxiv: 27I303, I9Io.

4. Branching in the Leafy Hepaticæ. Ann. Bot., xxvi: I-37, I9I2.

5. (and HookeR, H. D. Jr.) - Development of the Peristome in Ceratodon purpureus. Bull. Torrey Bot. Club, xl: 97-Io9, I9I3.

Famintzin, A. - Knospenbildung bei Equisetum. Mélanges biologiques tirés du bulletin de l'Académie impériale de St. Pétersbourg, t. ix: 573,1876 .

Fankhauser, J. - Ueber den Vorkeim von Lycopodium. Bot. Zeit., i873, p. I.

FarLow, W. G. - r. Ueber ungeschlechtliche Erzeugung von Keimpflanzen auf Farnprothallien. Bot. Zeit., I874, p. I80; also Quarterly Journal of Mic. Science, new ser., xiv: p. 266, I874.

2. Apospory in Pteris aquilina. Annals of Botany, ii : 383, 1889.

Farmer, J. Bretland. - I. On Isoetes lacustris. Proc. Royal Soc., vol. xlv: p. 306, I889.

2. On Isoetes lacustris. Annals of Botany, v: 37, 189o.

3. The Embryogeny of Angiopteris evecta, Hoffm. Ann. of Botany, vi: 1892,265 .

4. Studies in Hepatica. On Pallavicinia decipiens, Mitten. Ann. of Botany, viii : 35, I 894 .

5. (and ReEves, J.) - On the occurrence of Centrospheres in Pellia epiphylla, Nees. Ann. of Botany, viii: 219-224, I894.

6. On Spore-formation and Nuclear Division in the Hepaticæ. Ann. of Bot., ix : 469-523, 1895 .

7. Spore-formation in Fegatella conica. Ann. of Bot., ix: 666-668, I895.

8. The Quadripolar Spindle in the Spore Mother-cell of Pellia epiphylla. Ann. of Bot., xv: 43I, I9or.

9. (and HILL, T. G.) - On the Arrangement and Structure of the Vascular Strands in Angiopteris evecta and some other Marattiaceæ. Ann. of Bot., xvi : 371-402, I902.

Io. (with Moore, J. E. S., and Digby, L.) - On the Cytology of Apogamy and Apospory, i. Preliminary note on Apogamy. Proc. Roy. Soc., lxxi : 453-457, 1903. 
II. Sporogenesis in Pallavicinia. Bot. Gaz., xli : 67-70, I906.

12. Studies in Apospory and Apogamy in Ferns. Ann. Bot., xxi: I6I-I99, I907.

Faull, J. H. - The Anatomy of the Osmundacex. Bot. Gaz., xxxii : $38 \mathrm{I}-$ $420, \mathrm{rgor}$.

2. The Stele of Osmunda cinnamomea. Trans. Canadian Instit, vii : 5I5-534, I9ro.

Fellner, Ferd, - Ueber die Keimung der Sporen von Riccia glauca. Jabresber. der Akad. des naturwiss. Vereins in Graz, I875.

FIRTSCH, G. - Ueber einige mechanische Einrichtungen in anatomischen Bau von Polytrichum juniperinum. Berichte der deutschen botanischen Gesellschaft, i: 83, 1883 .

Fitring, H. - I. Bau und Entwickelungsgeschichte der Macrosporen von Isoëtes und Selaginella, und ihre Bedeutung für die Kenntniss des Wachstums pflanzlicher Zellmembranen. Bot. Zeit., lviii: I07-165, Ig00.

Ford, MIss S. O. - I. The Anatomy of Ceratopteris thalictroides. Ann. of Bot., xvi: 95-I20, I902.

Garber, J. F. - The Life History of Ricciocarpus natans. Bot. Gaz., xxxvii : I6I-r77, I904.

Gardner, W., and ToKutaro, Ito. - On the structure of the mucilage-secreting cell of Blechnum occidentale, L., and Osmunda regalis, L. Ann. of Botany, i: 27, August, 1887.

Garjeanne, A. J. M. - I. Die Oelkörper der Jungermanniales. Flora, xcii : $457-482$, I903.

GAYET, L. A. - Recherches sur le développement de l'archégone chez les Muscinées. Ann. des Science naturelles, Bot., ser. 8, 3: I6I-258, I897.

Georgevitch, P. - Preliminary note on Apospory and Apogamy in Trichomanes Kaulfussii. Ann. Bot., xxiv: 233-234, I910.

GeraRd, R. - Recherches sur le passage de la racine à la tige. Ann. des Sciences naturelles, sixth series, xi : 279, I88I.

Grbson, R. J. Harvey. - I. On the silicious deposit in certain species of Selaginella. Ann. Bot., vii : 355 , I893.

2. Contributions towards a knowledge of the anatomy of the genus Selaginella. Ibid., viii : I33, I894.

3. Note on the diagnostic characters of the subgenera and species of Selaginella, Spr. Transactions Biol. Soc. Liverpool, vol. viii., I894.

4. Contributions toward a Knowledge of the Anatomy of the Genus Selaginella, i. The Stem. Ann. of Bot., viii : 355, Ig04.

5. The Anatomy of Selaginella, ii. The Ligule. Ann. of Bot., $x$ : 76-88, 1896.

6. The Anatomy of Selaginella, iii. The Leaf. Ann. of Bot., xi: I $23-$ I 55, I 897 . 
Gresenhagen, C. - (See also Christ.) - Die Hymenophyllaceen. Flora, lxxiii : $4 \mathrm{II}$, I890.

Gittay, E. - Ueber eine eigenthümliche Form des Stereoms bei gewissen Farne. Bot. Zeit., 1882, p. 694.

Glueck, G. - Die Sporophyllmetamorphose. Flora, Ixxx: 303-387, I895.

Goebeler, E. - Die Schutzvorrichtungen am Stammscheitel der Farne.

Flora, lxix: 45I, I886.

Goebel, K. - I. Das Prothallium von Gymnogramme leptophylla. Bot. Zeit., I877, p. $67 \mathrm{I}$.

2. Wachsthum von Metzgeria und Aneura. Arbeiten des bot. Instituts, Würzburg, ii : 285, I879.

3. Beiträge zur vergleichenden Entwickelungsgeschichte der Sporangien. Bot. Zeit., I880, p. 545, I88I, p. 68I.

4. Zur Embryologie der Archegoniaten. Arbeiten des bot. Instituts in Würzburg, ii : 437,1880 .

5. Zur vergleichenden Anatomie der Marchantiaceen. Ibid., p. 529.

6. Beiträge zur vergleichenden Entwickelungsgeschichte der Sporangien. Pilularia globulifera. Bot. Zeit., I882, p. 77 I.

7. Ueber die Antheridienstände von Polytrichum. Flora, lxv : 323, I882.

8. Die Muscineen. Schenks Handbuch der Botanik, vol. ii., I882.

9. Vergleichende Entwickelungsgeschichte der Pflanzenorgane. Schenks Handbuch der Botanik, vol. iii., I884.

1o. Das Prothallium von Lycopodium inundatum. Bot. Zeit., I887, p. 16 r.

II. Morphologische und biologische Studien, I, I I. Annales du Jardin botanique de Buitenzorg, vii : I-II9, I887.

I2. Outlines of Classification and special Morphology. (Translation of the German Edition.) Oxford, Clarendon Press, I887.

13. Ueber die Fruchtsprosse der Equiseten. Ber. d. deutsch. bot. Gesell., iv : $184,1886$.

I4. Ueber die Jugendstände der Pflanzen. Flora, lxxii : I, I889.

I5. Morphologische und biologische Studien, iv. Ann. du Jardin botanique de Buitenzorg, ix : I-40, I89r.

16. Archegoniatenstudien. Flora, Ergänzungsband, 1892, Bd. lxxvi : 92. Also Flora, Bd. lxxvii : 82, 1893.

17. On the simplest form of Moss. Ann. of Botany, vol. vi: 355, 1892.

18. Ueber Function und Anlegung der Lebermooselateren. Flora, lxxx: 1-37, I895.

I9. Ueber die Sporenausstreuung bei den Laubmoosen. Flora, lxxx: 459-486, I895.

20. Hecistopteris, eine verkannte Farngattung. Flora, lxxxii: 67$75, \mathrm{I} 896$. 
2I. Organographie der Pflanzen. Four Parts. Jena, I898-Igor. 2d Edit., I9I 3-I 5.

22. Sporangien, Sporenverbreitung und Blütenbildung bei Selaginella. Flora, lxxxviii : 207-228, 1901.

23. Ueber Homologien in der Entwickelung männlicher und weiblicher Geschlechtsorgane. Flora, xc: 279-305, 1902.

24. Archegoniatenstudien, $x$. Beiträge zur Kenntniss australischer und neuseeländischer Bryophyten. Flora, xcvi : 95-202, 1906.

25. Archegoniatenstudien, xi. Weitere Untersuchungen über Keimung und Regeneration von Riella und Sphærocarpus. Flora, Xcvii: I92-2I5, 1907 .

26. Archegoniatenstudien, xii. Über die Brutknospenbildung und über die systematische Stellung von Riella. Flora, xcviii: $308-323,1908$.

27. Archegoniatenstudien, xiii. Flora: 43-97, 1910.

28. Archegoniatenstudien, xv. Die Homologie der Antheridien und Archegonien bei den Lebermoosen. Flora, cv: 53-70, I9I3.

Golenkin, M. - Die Mycorhizaähnlichen Bildungen der Marchantiaceen.

Flora, xc: 209-220, 1902.

Gordon, W. T., On the Prothallus of Lepidodendron Veltheimianum. Trans. Bot. Soc. Edinb., xxiii, Ig08.

GotTsche, C. M. - I. Anatomisch-physiologische Untersuchungen über Haplomitrium Hookeri. Acta Acad. Caes. Leopold. Car. Nat. Cur., t. $x x$, pars i, p. 267,184 r.

2. Uebersicht und kritische Würdigung der Leistungen in der Hepaticologie. Bot. Zeit. (Supplement), I858, p. 49.

Graham, Margaret. - The development of the Sporogonium and adjacent tissues of the Gametophyte of Conocephalum conicum. Bull. Torrey Bot. Club., xxxvi: 61 5-623, I909.

Groentand. - Mémoire sur la germination de quelques Hépatiques. Ann. des Sci. nat., series iv., t. $x: 5$, I8 54 .

Guignard, Leon. - I. Développement et constitution des anthérozoides. Révue générale de botanique, I889, t. i. liv. I-4.

2. Sur les anthérozoides des Marsiliacées et Equisetacées. Bul. de la Soc. bot. de France, xxxvi : 378 , r889.

3. Sur la constitution du noyau sexuel chez les végétaux. Comptes rendus, Paris, t. cxii : I074, I89I.

Gwynne-Vaughn, D. T. - I. Observations on the Anatomy of Solenostelic Ferns, I. Loxsoma. Ann. of Bot., xv : 7I-98, IgoI.

2. Observations on the Anatomy of Solenostelic Ferns, Part II. Ann. of Bot., xvii: 689-742, I903.

3. On the real nature of the tracheæ of Ferns. Ann. Bot., xxii : 40I4I3, I908. (See also Kidston.)

4. On the Anatomy of Archangiopteris Henryi and other Marattiaceæ. Ann. Bot., xix: 259-27I, I905. 
Haberlandt, G. - I. Vergleichende Anatomie des assimilatorischen Gewebesystems der Pflanzen. Pringsheims Jahrb. für wiss. Bot., xiii : 74, I882.

2. Ueber die physiologische Function des Centralstranges im Laubmoosstämmchens. Ber. der deutschen bot. Gesellschaft, i: $263, \mathrm{I} 883$.

3. Ueber Wasserleitung im Laubmoosstämmchen. Ibid., ii: 467 , I884.

4. Beiträge zur Anatomie und Physiologie der Laubmoosen. Pringsheims Jahrb. für wiss. Botanik, xvii : 359 , 1886 .

5. Das Assimilationssystem der Laubmoosen. Flora, lxix: 45, I886.

6. Ueber Collaterale Gefässbündel im Laube der Farne. Sitzb. der k. Akad. der Wiss. Wien, Ixxxiv., I Abt., p. I2r, r88r.

7. Ueber das Assimilationssystem. Ber. der deutschen bot. Gesellschaft, iv : 206, I886.

8. Zur Kenntniss des Spaltöffnungsapparat. Flora, Lxx: 97, I887.

9. Die Chlorophyllkörper der Selaginelleen. Flora, lxxi : 29r, I888. Halft, F. - Die Schliesshaut der Hoftüpfel im Xylem der Gefässkryptogamen. Inaug. Dissert., 3 I pp., Bonn, Igro.

Hannig, E. - Ueber die Staubgrübchen an den Stämmen und Blattstielen der Cyatheaceen und Marattiaceen. Bot. Zeit., lvi : 9-33, I898.

Hansel, V. - I. Keimung von Preissia commutata. Sitzungsberichte der kais. Akademie der Wissenschaften, Wien, lxxiii, I Abtheilung: $89,1876$.

Hanstein, J. - I. Pilulariæ globuliferæ generatio cum Marsilia comparata. Bonn, I866.

2. Befruchtung und Entwickelung der Gattung Marsilia. Pringsheims Jahrbücher für wiss. Botanik, iv : I97, I865.

Hawkins, L. A. - The Development of the Sporangium of Equisetum hiemale. Ohio Naturalist, vii : I22-I26, I907.

Haynes, Caroline C. - Sphærocarpos hians, Sp. Nov., with a revision of the Genus - and illustrations of the Species. Bull. Torrey Bot. Club, xxxvii : 2I 5-230, I9IO.

Heald, F. D. - I. Conditions for the Germination of the Spores of Bryophytes and Pteridophytes. Bot. Gaz., xxvi: $25-45$, I898.

2. A Study of Regeneration as exhibited by Mosses. Ibid., I69-210, I 898 .

Hegelmaier. - Zur Morphologie der Gattung Lycopodium. Bot. Zeit., $1872,773$.

HeIm, CARL. - Untersuchungen über Farnprothallien. Flora, lxxxii : 329-386, 1896 .

Heinricher, E. - I. Die jüngsten Stadien der Adventivknospen an der Wedelspreite von Asplenium bulbiferum. Sitzber. der kais. Akad. der Wissenschaften, Wien, lxxxiv, r Abt.: I I5, I88I. 
2. Die näheren Vorgänge bei der Sporenbildung der Salvinia natans verglichen der übrigen Rhizocarpeen. Sitzber. der. $k$. Akad. der Wiss., Wien, lxxxvii, I Abt. : 494, 1882.

HeInsen, E. - Die Makrosporen und weibliches Prothallium von Selaginella. Flora, lxxviii: 466, I 894 .

Hieronymus, G. (and Sadebeck, R.). - Selaginellaceæ. Engler and Prantl, Nat. Pflanzenfam. I Abt., iv : 62I-7I5, I90I.

HiLdebrand, F. - Brutkörper von Bryum annotinum. Flora, Ivi: $5^{1} 3$, I874.

Hirase, S. (see also "Ikeno"). - - I. Études sur la fécondation et l'émbryogénie du Ginkgo biloba. Journal Coll. Sci. Imp. University, Tokyo, xii : I03-I491, I898.

Hirsch, Pauline E. - The Development of Air-chambers in the Ricciaceæ. Bull. Torrey Bot. Club, xxxvii : 73-77, rgro.

Hobkirk, C. P. - On some points in the development of Osmunda regalis. Journal of Botany, xi: 97, 1882.

HofmeIster, W. - I. The Higher Cryptogamia. Ray Society, I862. This contains a translation of the "Vergleichende Untersuchungen," as well as the later papers upon the Archegoniatæ.

2. Über die Zellenfolge im Achsenscheitel der Laubmoose. Bot. Zeit., xxviii : 44I, 457, 473-1870.

Holferty, G. M. - The Development of the Archegonium of Mnium cuspidatum. Bot. Gaz., xxxvii : 106-г 26, r904.

Holle, J. G. - I. Ueber Bau und Entwickelung der Vegetationsorgane der Ophioglosseen. Bot. Zeit., I875, 24I.

2. Vegetationsorgane der Marattiaceen. Bot. Zeit., 1876, 215.

Holloway, J. E. - I. A comparative Study of the Anatomy of six New Zealand species of Lycopodium. Trans. and Proc. New Zealand Institute. New Issue, xlii : $356-370$, I909.

2. Studies in the New Zealand Species of the Genus Lycopodium.

Part I. Wellington, N. Z., Igi6.

Holtzman, C. L. - On apical growth of the stem, and the development of the sporangium of Botrychium Virginianum. Bot. Gazette, xvii: 214, 1892 .

Hooker, Sir J., and Baker, J. G. - Synopsis Filicum. London, I874.

HorNe, A. S. - Discharge of Antherozoids in Fossombronia and Haplomitrium. Ann. Bot., xxiii : I59-I60, Ig09.

Howe, M. A. - т. Gyrothyra, a new genus of Hepaticæ. Bull. Torrey Bot. Club, xxiv : 20I-205, 1897 .

2. Anthocerotaceæ of North America. Bull. Torrey Bot. Club, xxv: $\mathrm{I}-24, \mathrm{I} 898$.

3. Hepaticæ and Anthocerotes of California. Mem. Torrey Bot. Club, vii: 1899 .

4. (and UnDERWood, L. M.). - The Genus Riella, with Descriptions of 
new species from North America and the Canary Islands. Bull. Torr. Bot. Club, xxx: 2I4-224, I903.

5. Exogenous Origin of the Antheridium in Anthoceros. Torreya, iv : 175, November, 1904 .

6. Oxymitra (Tesselina) in the United States. Bryologist, xvii : 7275, 1914 .

Humphrey, H. B. - I. The Development of Fossombronia longiseta. Ann. Bot., xx: 83-108, 1906.

2. Studies in the Physiology and Morphology of some Californian Hepaticæ. Proc. Wash. Acad. Sciences, xix : I-50, 1908.

Hutchinson, A. H. - Gametophyte of Pellia epiphylla. Bot. Gaz., lx: I34-I 43, IgI 5 .

Hy, F. - I. De la structure de la tige des mousses de la famille des Polytrichacées. Bull. de la Soc. bot. de France, t. xxvii : Io6, I880.

2. Recherches sur l'archégone et le développement du fruit des Muscinées. Ann. des Sciences Naturelles, series 6, t. 18: 105, I884.

IKeno, S. - I. The Spermatozoids of Cycas revoluta (Japanese). Bot. Mag., Tokyo: 10, 1896.

2. (and HIRASE). - Spermatozoids of Gymnosperms. Ann. of Bot., xi : 344, r 897 .

3. Untersuchungen über die Entwickelung der Geschlectsorgane und den Vorgang der Befruchtung bei Cycas revoluta. Pringsh. Jahrb. f. wiss. Bot., xxxii : $557-602$, I898.

4. Die Spermatogenese von Marchantia polymorpha. Beiheft z. Bot. Centralbl., xv : 65-88, 1903.

Janchen, E. - Neuere Vorstellungen über die Phylogenie der Pteridophyten. Mitteil. Naturwiss. Ver., Wien, ix., IgI I.

JANCZEWSKI, ED. DE. - I. Vergleichende Untersuchungen über die Entwickelungsgeschichte des Archegoniums. Bot. Zeit., I872, p. 37.7 .

2. (and Rostafinsi, J.). - Note sur le prothalle de l'Hymenophyllum Tunbridgense. Mém. de la Soc. nationale des Sciences naturelles de Cherbourg, t. xix, 1875 .

3. Recherches sur le développement des bourgeons dans les prêles. Mém. de la Soc. nationale des Sciences naturelles de Cherbourg, t. $x x ., 1876$.

4. Etudes comparées sur les tubes cribreux. Ann. Sci. Nat, Bot., ser. 6, xiv : 50, 1882 .

Janse, J. M. - Les Endophytes radicaux de quelques Plantes Javanaises. Ann. du Jard. Bot. de Buitenzorg, xiv: 53-201, 1897.

JEFrrey, E. C. - I. The Gametophyte of Botrychium Virginianum. Proc. Canad. Inst., v., I898.

2. The Development, Structure and Affinities of the Genus Equisetum. Mem. Boston Soc. Nat. Hist., v. No. 5, I 899 :

3. The Structure and Development of the Stem in Pteridophytes_and 
Gymnosperms. Phil. Trans. Roy. Soc., ser. B, vol. I95: II9I46, 1902 .

4. The Pteropsida. Bot. Gaz., l: 40I-4r4, r910.

Jornson, D. S. - I. On the Development of the Leaf and Sporocarp in Marsilia quadrifolia, L. Ann. of Bot., xii : II9-I45, I8g8.

2. On the Leaf and Sporocarp of Pilularia. Bot. Gaz., xxvi: I-24, I8g8.

3. The Development and Relationship of Monoclea. Bot. Gaz., xxxviii : I85-205, I904.

Jonkman, H. F. - I. La génération sexuée des Marattiacées. Arch. Néerlandaises, etc., t. xv: 199, I880. Also in Bot. Zeit., I878, p. I 29.

2. Over de Keimung van Kaulfussia æsculifolia. Nederland. Kruidkdg. Archief, ser. 2, deel. 3, stuck 2, p. 262, 1879.

3. L'Embryogénie de l'Angiopteris et du Marattia. Archiv. Néerland. t. $x x x: 213-230$. (Separate, not dated.)

JUEL, O. - Über den anatomischen Bau von Riccia Bischoffii. Svensk Bot. Tidskr., I60-I66, I9I0.

JURANYI, L. - r. Ueber den Bau und die Entwickelung des Sporangiums von Psilotum triquetrum Sw. Bot. Zeit., I87I, p. I76.

2. Ueber die Entwickelung der Sporangien und Sporen von Salvinia natans, Berlin, I873.

3. Ueber die Gestaltung der Frucht bei Pilularia globulifera. Review, Bot. Centralb., I : 207, I880.

KAINRAdT, E. - Über ein Makrosporangium mit mehreren Sporentetraden von Selaginella helvetica, und entwickelungsgeschichtliche Untersuchungen über die Makrosporangien unserer einheimischen Selaginelleen. Sitzungsber. K. Ak. Wiss., Wien, I9I2.

Kamerling, Z. - Zur Biologie und Physiologie der Marchantiaceen. Flora, lxxxiv: I-68, I897, Ergänzungsb.

Karsten, G. - I. Beiträge zur Kenntniss von Fegatella conica. Botanische Zeitung, 1887, p. 649.

2. Morphologische und biologische Untersuchungen über einige Epiphytenformen der Molukken. Ann. du Jard. Bot. de Buitenzorg, xii: II7-I95, I895.

Kashyap-SHIv, R. - I. The Structure and Development of the Prothallus of Equisetum debile. Ann. Bot., xxviii: I63-I8I, I9I4.

2. Morphological and Biological Notes on new and little known Himalayan Liverworts. I. New Phytologist, xiii : 206-225, I9I4. II. New Phytologist, xiii : 208-723, I9I4. III. New Phytologist, xiv : I-I8, I9I5.

Kmston, R., and Gwynne-Vaughn, D. T. - On the Fossil Osmundaceæ. Trans. Roy. Soc. Edinb., xlvii : I9Iо.

KIEntT-GerLoff, F. - r. Vergleichende Untersuchungen über die Entwickelungsgeschichte des Lebermoossporogons. Bot. Zeit., I874, I6I ; I875, 777 . 
2. Untersuchungen über die Entwickelungsgeschichte der Laubmooskapsel, und die Embryoentwickelung einiger Polypodiaceen. Bot. Zeit., xxxvi : 33, 49, I878.

3. Morphologische Bedeutung der Laubmooskapsel in Vergleich zur Lebermoosfrucht. Sitzungsberichte der Gesellschaft. naturf. Freunde, Berlin, $x 876$.

4. Genetische Zusammenhang von Moose und Gefässkryptogamen. Botanische Zeitung, 1876,705 .

5. Ueber Wachsthum und Zelltheilung in der Entwickelung des Embryos von Isoetes lacustris. Bot. Zeit., i88r, 76r.

6. Ueber die Bedeutung der Paraphysen im Anschluss an H. Leitgeb's "Wasserausscheidung an den Archegonienstande von Corsinia." Botanische Zeitung, I886, 248.

King, C. A. - Explosive Discharge of Antherozoids in Conocephalum. Torrya, iii : 60, Ig03.

KLEBS, G. - Die Bedingungen der Fortpflanzung bei einigen Algen und Pilzen, Jena, 1896.

KleIN, J. - Sprossung an den Inflorescenzstielen von Marchantia polymorpha. Botanisches Centralblatt, v: 26, I88I.

Kuein, L. - I. Bau und Verzweigung einiger dorsiventralgebauter Polypodiaceen. Nova Acta Acad. Caes. Leop. Carol. Nat. Cur. T. xlii : 335, I881. Review, Bot. Zeit., I882, 9гі.

2. Vergleichende Untersuchungen über Organbildung und Wachsthum am Vegetationspunkte dorsiventraler Farne. Bot. Zeit., I884, 577 .

KNy, L. - I. Beiträge zur Entwickelungsgeschichte der laubigen Lebermoosen. Pringsheims Jahrb. für wiss. Botanik, iv: $64,1865$.

2. Ueber Bau und Entwickelung der Riccien. Ibid., v: 364 .

3. Entwickelung des Vorkeims der Polypodiaceen und Schizæaceen. Sitzber. d. Gesellschaft. naturf. Freund., Berlin, I868.

4. Ueber Bau und Entwickelung des Farnantheridiums. Monatsber. d. Berlin. Akad., I869, p. 4 I6.

5. Beiträge zur Entwickelungsgeschichte der Farnkräuter. I. Osmunda regalis. Pringsh. Jahrb. f. wiss. Bot., viii : I, 1872.

6. Treppengefässe in Farnprothallien. Verhandl. des bot. Vereins der Prov. Brandenburg, Jahrg., xvi : 7I, I874.

7. Entwickelung der Parkeriaceen dargestellt an Ceratopteris thalictroides. Nova Acta Acad. Caes. Leop. Carol. Nat. Cur., T. xxxvii : No. 4, 1875 .

8. Durchwachsung an dem Wurzelhaare zweier Marchantiaceen. Verhandl. des bot. Vereins der Prov. Brandenburg, Jahrgang 2I, I879, p. 2.

9. Entwickelung von Aspidium filix-mas., I Theil. Berlin, I895.

Kосн, L. - Ueber Bau und Wachstum der Wurzelspitze von Angiopteris evecta. Pringsh. Jahrb. f. wiss. Botanik, xxvii : 369 , 1895 . 
$\mathrm{K}_{\mathrm{RUCH}}, \mathrm{O}$. - I. Istolog a ed istogenia del fascio conduttore delle foglie di Isoetes. Malpighia, An. iv.: 56, I8go.

2. Appunti sullo sviluppo degli organi sessuali e sulla fecondazione della Riella Clausonis. Malpighia, vol. iv : 403 ; Genoa, I89o, I89I.

KuHN, R. - I. Zur Entwickelungsgeschichte der Andreæaceen. Schenk und Luerssen, Mitthl. aus dem Gesammtgebiete d. Botanik, vol. i.

2. Untersuchungen über die Anatomie der Marattiaceen und anderen Gefässkryptogamen. Flora, lxxii : 457, 1889.

3. Ueber den anatomischen Bau von Danæa. Flora, lxxiii: I47, I 890 .

Kundig, J. - Beiträge zur Entwickelungsgeschichte des Polypodiaceensporangiums. Hedwigia, xxvii, Heft I : r, I888.

Kund, A. - Die Entwickelung der Micro- and Makrosporangien von Salvinia natans. Beiheft. Bot. Centralbl., xxvii: Abt. I, 26-5I, rgrI. KUPPER, W. - Über Knospenbildung an Farnblätter. Flora, xcvi : $337-$ $408,1906$.

Kurssanow, L. - Eine Notiz zur Frage über die Phylogenie des Archegoniums. Bull. Soc. Nat. Moskva, xxii : 39-43, 1910.

KÜsTER, W. - Die Oelkörper der Lebermoose und ihr Verhältniss zu den Elaioplasten, Basel, r894.

LAAGe, A. - Bedingungen der Keimung von Farn- und Moossporen. 44 pp., Halle, I9o6.

Lachmann, P. - I. De l'accroissement terminale de la racine de Todea barbara. Bul. de la Soc. botanique de Lyon, I884, p. 42.

2. Sur l'origine des racines chez les fougères. Bul. de la Soc. bot. de France, $\mathrm{xxx}:$ 33, 1884 .

3. Sur le système libéro-ligneux des fougères. Bul. de la Soc. bot. de Lyon, p. 35, I884.

4. Recherches anatomiques sur les Davallia. Bul. de la Soc. botanique de Lyon, I886.

5. Sur la structure de la racine des Hyménophyllacées. Ibid., I886.

6. Structure et croissance de la racine des fougères, et l'origine des radicelles. Bul. de la Soc. bot. de Lyon, 1887.

7. Insertion des Racines. Ann. de la Soc. bot. Lyon, I889.

Lamothe, A. - Le gametophyte des Marchantiales. De l'importance de ses charactères anatomiques. Compt. rend. Paris, clv: I093-Iog6, I9I 2.

LAMPA, Emma. - I. Untersuchungen an einigen Lebermoosen. Sitzungsber. der Kais. Akad. der Wiss., Wien, cxi : 477-489, Igo2.

2. Über die Beziehung zwischen dem Lebermoosethallus und dem

Farnprothallium. Osterr. Bot. Zeitschr., lix : 409-4I4, Igog.

LAND, W. J. S. (See also, BARNeS). - A protocorm of Ophioglossum. Bot. Gaz., lii : 478-479, I9II. 
LANG, W. H. - I. Alternation of Generations in the Archegoniates. Ann. of Bot., xii: $583-592,1898$.

2. On Apogamy and the Development of Sporangia upon Fern-prothalli. Phil. Trans. Roy. Soc., ser. B, vol. I9o, I898.

3. On Apospory in Anthoceros loevis. Ann. of Bot., sv: 503-510, Igor.

4. On the Prothalli of Ophioglossum pendulum and Helminthostachys zeylanica. Ann. of Bot., xvi : 23-56, I902.

5. On a Prothallus provisionally referred to Psilotum. Ann. of Bot., xviii : 57 I-577, I904.

6. On the Morphology of Cyathodium. Ann. Bot., xix : 4II-426, I905.

7. On the Sporogonium of Notothylas. Ann. Bot., xxi : 201-21I, I907.

8. A theory of Alternation of Generations, based on Ontogeny. New Phytologist, viii : I-2, I909.

9. On a Suspensor in Helminthostachys. Ann. Bot., xxiv: 6II, I9IO.

Io. On the Interpretation of the Vascular Anatomy of the Ophioglossaceæ. Mem. Proc. Manchester Liter. and Phil. Soc., lvi : Part II. No. I2, rgi2.

II. Studies in the Anatomy of the Ophioglossaceæ. I. On the Branching of Botrychium Lunaria. Ann. Bot., xxvii: 203242, I9I3.

12. The Embryo of Helminthostachys. Ann. Bot., xxviii: I9-37, I9I4.

13. The Anatomy and Branching of the Rhizome of Helminthostachys.

Ann. Bot., xxix: I-54, I9I5.

I4. Studies in the Morphology of Isoetes, I. The Stock of Isoetes lacustris. Mem. and Proc. Manchester Lit. and Phil. Soc., lix: 28 pp., rgr 5 .

Lawson, A. A.- I. The Prothallus of Tmesipteris Tannensis. Trans. Royal Soc. Edinb., li, Part III : 785-794, I9r7.

2. The Gametophyte Generation of the Psilotacex. Ibid., lii, Part I: $93-\mathrm{II} 3$, I9ז7.

Leaviti, R. G. - I. The Root-hairs, Cap and Sheath of Azolla. Bot. Gaz., xxxiv : 414-4I8, I902.

2. Trichomes of the Roots in Vascular Cryptogams and Angiosperms.

Proc. Boston Soc. Nat. Hist., xxxi : 273-313, 1904.

Leclerc du Sablon. - I. Sur le sporogone des Hépatiques et le rôle des élatères. Bulletin de la Soc. bot. de France, t. xxxii, pt. I : 30, I885.

2. Sur la développement du sporogone de Frullania dilatata. Bul. de la Soc. bot. de France, t. xxxii, pt. 4: p. I87, I885.

3. Recherches sur la développement du sporogone des Hépatiques. Ann. des Sci. naturelles, ser. vii, t. ii : I26-I80, 1885 . 
4. Recherches sur le dissémination des spores chez les cryptogames vasculaires. Ann. des Sci. naturelles, ser. vii, t. ii : 5, I 885 .

5. Sur les anthérozoides du Cheilanthes hirta. Bul. de la Soc. bot. de France, t. xxxv: $238,1888$.

6. Reviviscence de Selaginella lepidophylla. Ibid., p. Iog.

7. Sur l'endoderme de la tige des Selaginelles. Journal de Botanique, I889, 207.

8. Recherches anatomiques sur la formation de la tige des fougères. Annales des Sci. naturelles, ser. vii, t. xi : I, I890.

9. Sur les tubercules des Equisetacées. Rév. géneralé de Botanique, t. iv: $1892,97$.

ro. Sur le développement du sporogone des Mousses. Rév. génér. Bot., xvii : No. 197, I93-I97, I905.

Leitgeb, Hubert. - I. Wachsthum des Stämmchens von Fontinalis und Sphagnum. Sitzb. d. kais. Akad. d. Wissenschaften, Wien, Bd. Ivii, Abt. i : 308, r 868.

2. Entwickelung der Antheridien bei Fontinalis antipyretica. Sitzber. der k. Akad. d. Wiss., Wien, lviii, Abt. i : 525, I868.

3. Ueber Schistostega. Mittheilung des naturwiss. Vereines, Graz, I874.

4. Zur Kenntniss des Wachsthums von Fissidens. Sitzungsberichte der kaiserlichen Akademie der Naturwissenschaften, Wien, Bd. lxix, Abt. i : 47, I874.

5. Verzweigte Moossporangien. Naturwissenschaftliche Verein für Steiermark, 1876 .

6. Ueber Zoöpsis. Naturwissenschaftliche Verein für Steiermark, 1876.

7. Untersuchungen über die Lebermoose, I874-I88I, 6 volumes. Vol. i, Blasia pusilla; vol. ii, Die foliosen Jungermannieen; vol. iii, Die frondosen Jungermannieen; vol. iv, Die Ricceen; vol. v, Die Anthoceroteen; vol. vi, Die Marchantieen.

8. Das Sporogon von Archidium. Sitzber. der kais. Akad. der Wiss., Wien, lxxx, Abt. i : 447, 1879.

9. Ueber Bilateralität der Prothallien. Flora, 1xii : 317, I879.

ro. Die Antheridienstände der Laubmoose. Flora, lxv: 467, I882.

Ir. Ueber Bau und Entwickelung einiger Sporen. Ber. der deutsch. bot. Gesellschaft, Bd. i: 246, r883.

I2. Ueber Bau und Entwickelung der Sporenhäute und deren Verhalten bei der Keimung. Graz, I884.

13. Wasserauscheidung an den Archegonienstände von Corsinia. Flora, lxviii : 327 , I885.

14. Sprossbildung an apogamen Farnprothallien. Ber, der deutschen bot. Gesellschaft, iii : 169 , I885. 
I5. Die Stellung der Fruchtsäcke bei den geocalycen Jungermannieen.

Sitzber. der kais. Akad. der Wissenschaften, Wien, Bd. lxxxiii, I Abt.: 5I5, I88ז.

Lesage, P. - I. Croissance du sporogone en dehors de la plante-mère de Pellia epiphylla. Extr. du Bull. Soc. scientif. et med. de l'Ouest., xix : Rennes, Igro.

2. Croissance comparée du sporogone de Polytrichum formosum sur la plante-mère et en dehors de la plante-mère.

LEwIs, C. E. - The Embryology and Development of Riccia lutescens and $R$. crystallina. Bot. Gaz., xli: 1 10-138, 1906.

Lieuwen-ReijnvaAN, W. and J. VAN. - Über die Spermatogenese der Moose, speciell mit Berücksichtigung der Zentrosomen- und Reductionsteilungfragen. Ber. Deutsch. Bot. Gesell, xxvi : 30I-309, 1908. LIGNIER, O. - I. Equisetales et Sphénophyllales. Leur origine filicinéenne commune. Bull. de la Soc. Linn. de Normandie, ser. 5, vol. 7. Caen, I903.

2. Sur l'origine des Sphenophyllales. Bull. Soc. Bot. de France, lv: 278,1908 .

LILIENFELd, F. - Beiträge zur Kenntniss der Art Haplomitrium Hookeri. Bull. int. Ac. Sc. Cracou, Ser. B : 3r5-339, I9ri.

Limpricht, G. - I. Ueber Tüpfelbildung bei Laubmoosen. Schlesische botanische Gesellschaft, I884, 289.

2. Ueber die Porenbildung in der Stengelrinde von Sphagnum. Ibid., I99, I885.

LorCH, W. - Die Polytrichaceen. Eine biologische Monographie. Abhandl. Kgl. Bayer. Akad. d. Wissensch. 2 Kl., xxiii : 445-546, Igo8.

Lotșy, J. P. - Vorträge über botanische Stammesgeschichte. Band II. Jena, I909.

Luerssen, C. - I. Spaltöffnungen von Kaulfussia. Bot. Zeit., I873, 625.

2. Dickenwachsthum innerer Parenchymzellen der Marattiaceen. Botanische Zeitung, 1873, 641.

3. Zur Keimungsgeschichte der Osmundaceen, vorzüglich der Gattung Todea. Mittheilungen aus dem Gesammtgebiete der Botanik, Schenk und Luerssen, Bd. I : 460.

4. Ueber Farnsporangien. Ibid., Bd. ii : I.

5. Ueber die Entwickelungsgeschichte des Marattiaceenvorkeims, Bot. Zeit., 535, 1875 .

6. Handbuch der systematischen Botanik. Bd. i., Kryptogamen. Leipzig, 1879 .

7. Die Farnpflanzen oder Gefässbündelkryptogamen (Rabenhorst, Kryptogamenflora). Leipzig, I884-I889.

Lutz. - Sur l'origine des canaux gommifères des Marattiacées. Jour. de Botanique, xii : I33-35, I898. 
Lyon, Miss F. M. - I. A Study of the Gametophytes of Selaginella apus. and S. rupestris. Bot. Gaz., xxxii : I24-I4I, I70-I94, I9or.

2. The Evolution of the Sex-organs of Plants. Bot. Gaz., xxxvii : 28I-293, 1904 .

Lyon, H. L. - I. Polyembryony in Sphagnum. Bot. Gaz., xxxix : 365366, I905.

2. A New Genus of Ophioglossacex. Bot. Gaz., xl: 455-458, 1905 . MacMilian, C. - I. On the casting off of parts of the Aquatic Hairs of Azolla. Quart. Bull. Univ. of Minn., I895.

2. Some Considerations on the Alternation of Generations in Plants. Lincoln, Neb., I896.

McAllister, F. - The Morphology of Thallocarpus Curtisii. Bull. Torry. Bot. Club, xliii : I I 7-I 26, I9I 5 .

McCormick, Florence A. - A study of Symphyogyna aspera. Bot. Gaz., lviii : 4r9-43r, rgr4.

McFadden, Efrie B. - The Development of the Antheridium of Targionia hypophylla. Bull. Torr. Bot. Club, xxiii : 242-244, I896.

McNIcol, Marx. - On Cavity-parenchyma and Tyloses in Ferns. Ann. Bot., xxii : 40I-4I3, I908.

Manning, Florence L. - Life history of Porella platyphylla. Bot. Gaz., Xlvii : $320-322$, I9I4.

Marchal, El. and Em. - r. Recherches experimentales sur la sexualité des spores chez les mousses. Mem. couronnés, Cl. Sc. Acad. RoyBelgiques. 2. ser. t. i, Igo6.

2. Aposporie et sexualité chez les Mousses. Bull. Acad. RoyBelgique, $1907: 765-789$.

3. Marchal, Em. Recherches cytologiques sur le genre Amblystegium. Bull. Soc. Roy-Belgique, li: pp. I5, rgi2.

- Marquette, W. - Concerning the Organization of the spore mother-cells of Marsilia quadrifolia. Trans. Wiscon. Acad. Sc. Arts and Letters, xvi : 8I-T06, I908.

Mathuschek, Franz. - Die Adventivknospen an den Wedeln von Cystopteris bulbifera. Oesterreichische botanische Zeitschrift, I894, I2II $24 ; 177-178$.

Mettenius, Georg. - I. Beiträge zur Kenntniss der Rhizocarpeen. Frankfurt-am-Main, 1846 .

2. Filices Hort. bot. Lips., I856.

3. Ueber Phylloglossum. Bot. Zeit., 1867, p. 97.

MeunIer, AlPh. - La Pilulaire. Etude anatomico-génétique du sporocarpe chez la Pilularia globulifera - La Cellule, iv : 319, r887.

Meyer, K. - I. Untersuchungen über den Sporophyt der Lebermoose. Bull. Soc. Imp. Nat. Moscow, IgII.

2. Entwickelung des Sporogons der Corsinia marchantioides. Bull. Soc. Imp. Nat. Moscow: 263-286, I9I2.

3. Zur Frage von der Homologie der Geschlechtsorgane und der 
Phylogenie des Archegoniums. Biol. Zeitschr., xi: I77-187, I9I2.

4. Untersuchungen über den Sporophyt der Lebermoose II. Die Entwickelungsgeschichte des Sporogons bei Plagiochasma. Bull. de la Soc. imper. des Nat. de Moscou. 597-615, I9I3.

5. A Study of the Sporophyte in the Liverworts of the Group of the Marchantiales. Moscow, I916. (Russian.)

MiLde, J. - I. Monographia Equisetorum. Nova Acta Acad. Cæs. Leopold Carol., Nat. Cur., xxxii, pars ii : p. x, 1867.

2. Monographia generis Osmundæ. Bot. Zeit., I868, 800, and Flora, lii : $54, \mathrm{I} 869$.

3. Monographia Botrychiorum. Verhandl. d. zool. bot. Gesell., Wien. Bd. xix: p. 55, I869.

MillaRdet, A. - Le prothallium male des cryptogames vasculaires. Strassburg, I869.

Mitchell, G. - Contributions toward a knowledge of the genus Selaginella. Part V. The Strobilus. Ann: Bot., xxiv: I9-32, Igro.

Mryake, K. - I. . On the spermatozoid of Ginkgo. Bot. Mag., Tokyo, xii: $337-339, \mathbf{1} 898$.

2. Makinoa, a New Genus of Hepaticæ. Bot. Mag., Tokyo, xiii : I-4, r899.

Monteverde, N. A. - Ueber krystallinische Ablagerungen bei Marattia. Arbeiten der St. Petersburg Naturforscher-Gesellschaft, t. xvii., I886. Moore, A. C. - I. The Mitoses in the Spore Mother-Cell of Pallavicinia. Bot. Gaz., xxxvi : $384-388$, I903.

2. Sporogenesis in Pallavicina. Bot. Gaz., $\mathrm{xl}: 8 \mathrm{I}-96, \mathrm{Ig05}$.

Morin, F. - Anatomie comparée et expérimentale de la Famille des Muscinées. Review, Botanisches Centralblatt, lviii: I64, I894.

Mottier, D. M. - I. Notes on the apical growth of Liverworts. Bot. Gazette, xvi : I4I, I89I.

2. Contributions to the Life-History of Notothylas. Ann. of Bot. viii : 39 I, I894.

3. Fecundation in Plants. Carnegie Institute, Ig04.

4. Notes on the sex of the Gametophyte of Onoclea Struthiopteris. $\therefore$ Bot. Gaz., l: 209-213, I9Iо.

Muller, Carl. - I. Ueber den Bau der Commissuren der Equisetumscheiden. Pringsheims Jahrb. für wiss. Botanik, xix : 497, 1888 .

2. Zur Kenntniss der Entwickelungsgeschichte des Polypodiaceensporangiums. Berichte der deutsch. botan. Gesellschaft, xi: 54, I893.

Müller, Carl (and RuHland, W.). - 3. Die Laubmoose. Engler and Prantl, Die Nat. Pflanzenf., Theil i, Abt. iii : I 52-243, I898-Igor.

Müller, HermanN. - Sporenvorkeim und Zweigvorkeime der Laubmoose.

Arbeiten des botanischen Instituts zu Würzburg, Bd. i : 475 .

MülleR, N. J. C. - I. Das Wachsthum des Vegetationspunktes von 
Pflanzen mit decussirter Blattstellung. Pringsh. Jahrb. f. wiss. Botanik, v : 247, I866-67.

2. Die Entwickelungsgeschichte der Kapsel von Ephemerum. Pringsh. Jahrb. für wiss. Bot., vi : 237, I867-68.

NAWASchin, S. - Was Sind eigentlich die sogenannten Microsporen der Torfmoosen? Bot. Centralblatt, xliii., p. 289, 189o.

Nemec, B. - I. Die Induktion der Dorsiventralität bei einigen Moosen.

Bull. international de l'Académie des Sciences de Bohème, ix, I904.

2. Die Symmetrieverhältnisse und Wachstumsrichtungen einiger Laubmoose. Jahrb. f. Wissensch. Botanik, xliii: 50I-579, I906.

3. Die Induction der Dorsiventralität bei einiger Moose. II. Bull. internat. de l'Acad. Sc. Bohème, xi : r-7, rgo7.

4. Das Problem der Befruchtungsvorgänge und andere cytologische Fragen. Berlin, I9ro.

Newcomb, F. C. - Spore Dissemination of Equisetum. Bot. Gazette, xiii : I73, I888.

O'KEEFE, LiLLIAN. - Structure and Development of Targionia hypophylla. New Phytologist, xiv: I05-I16, I9I5.

OtIver, F. W. - Pteridosperms and Angiosperms. New Phytologist, v: 232-242, I906.

Oltmanns, F. - I. Zur Entwicklungsgeschichte der Florideen. Bot. Zeit., lvi : $154, \mathrm{I} 898$.

2. Morphologie und Biologie der Algen. Jena, rgo4.

Osterhout, W. J. V. - Ueber Entstehung der Karyokinetischen Spindel bei Equisetum. Pringsh. Jahrb. f. wiss. Botanik, xxx : I59-I68, I897.

Pedersen, R. - Entwickelungsgeschichte des Polypodiaceenvorkeims. Mittheilungen aus dem Gesammtgebiete der Botanik. Schenk und Luerssen, Bd. ii, p. I30, I875.

PeIrce, G. J. - I. Forcible Discharge of Antherozoids in Asterella Californica. Bull. Torr. Bot. Club, xxix: 374-382, 1902.

2. Anthoceros and its Nostoc Colonies. Bot. Gaz., xlii : 55-59, rgo6.

3. Studies of Irritability in Plants. The formative influence of light. Ann. Bot. xx: 449-465, 1906 .

Perrin, G. - Sur les prothalles d'Equisetum. C. R. Acad. Sc. Paris, cliii : I97-I99, I9II.

Petrx, Loren C. - The Anatomy of Ophioglossum pendulum. Bot. Gaz., xlvii : $169-\mathrm{rg2}$, IgI4.

Pfeffer, W. - r. Die Entwickelung des Keimes der Gattung Selaginella. Botanische Abhandlungen, etc., herausgegeben von Dr. Johannes Hanstein. Bonn, $187 \mathrm{I}$.

2. Die Oelkörper der Lebermoose. Flora, lvii : 2, 1874 .

3. Locomotorische Richtungsbewegungen durch chemische Reize. Untersuch. aus dem bot. Institute zu Tübingen, Bd. i. I884, 363. 
Pfitzer. - Ueber die Schutzscheide der deutschen Equisetaceen. Pringsh. Jahrb. f. wiss. Bot., vi : 292, I867-68.

Prccone, A. - Notizie e osservazioni sopra l' Isoetes Durieui. Nuovo Giornale Botanico Italiano, viii : 1876 .

Picketr, F. L. - The Development of the Prothallium of Camptosorus rhizophyllus. Bot. Gaz., xlvii: 228-238, I914.

PIEtch, W. - Entwickelungsgeschichte des vegetativen thallus, insbesondere der Luftkammern der Riccien. Flora, ciii : $247-284$, I9r r.

Plant, M. - Untersuchungen über die physiologischen Scheiden der Gymnospermen, Equisetaceen und Bryophyten. Pringsh. Jahrb. wiss. Bot., xlvii : I2I-I85, I 909 .

Poirault, G. - I. Recherches d'histogénie végétale. Developpement des tissus dans les organes végétifs des cryptogames vasculaires. Mém. de l'Acad. imp. des sciences de St. Pétersbourg, ser. vii., t. xxxvii, I890.

2. Sur l'Ophioglossum vulgatum. Journal de Botanique, vi, I89r.

3. Recherches anatomiques sur les cryptogames vasculaires. Ann. des

Sciences naturelles, ser. vii, t. xviii : II 3, I893.

Potonie, H. - I. Anatomie der Lenticellen der Marattiaceen. Jahrb. des bot. Gartens, Berlin, I88I, p. 307, Bd. I.

2. Ueber den Bau der Leitbündel der Polypodiaceen und über den Begriff des Leitbündels bei den Gefässkryptogamen. Verhandl. des Verreins für Naturwiss. der Prov. Brandenburg, Jahrg. xxiv: $77,1882$.

3. Lehrbuch der Pflanzenpalæontologie. Berlin, r89g.

4. Fossil Pteridophytes in Engler and Prantl, Die natürlichen Pflanzen familien. Theil i, Abt. iv.

Prantl, K. - I. Die Hymenophyllaceen. Untersuchungen zur Morphologie der Gefässcryptogamen, vol. i. Leipzig, I875.

2. Morphologische Studien. Flora, lviii: 537,1875 .

3. Ueber die Anordnung der Zellen in flächenförmigen Prothallien der Farne. Flora, xxxvi : 497-5II, 530-543, 545-556, I878.

4. Zur Entwickelungsgeschichte des Prothalliums von Salvinia natans. Bot. Zeit., I879, p. 425 .

5. Die Schizæaceen. Untersuchungen zur Morphologie der Gefässkryptogamen, vol. ii : Leipzig, I88I.

6. Die Farngattungen Cryptogramme und Pellæa. Engler's botanisches Jahrbuch, ii : 403, I882.

7. Helminthostachys Zeylanica in ihre Beziehung zu Ophioglossum und Botrychium. Ber. der deutsch. bot. Gesellschaft, i : I 55, I883.

8. Systematisches Uebersicht der Ophioglosseen. Ibid., 348 .

9. Beitrag zur Systematik der Ophioglosseen. Jahrbuch des bot. Gartens, Berlin, Bd. iii : 297, I884.

ro. Die Mechanik des Rings am Farnsporangium. Ber. deutsch. botan. Gesellsch., iv : 42, 1886 . 
Prescher, R. - Die Schleimorgane der Marchantien. Sitzungsber. der Kais. Akad. der Wiss., Wien, lxxxvi: I32-I58, I882.

Pringsherm, N. - I. Zur Morphologie der Salvinia natans. Pringsh. Jahrb. für wiss. Botanik, iii : 484, I863.

2. Vegetative Sprossung/ der Moosfrüchte. Monatsbericht der königlichen Akademie der Wissenschaften zu Berlin, 1876, p. 425 .

3. Sprossung der Moosfrucht und Generationswechsel der Thallophyten. Pringsheims Jahrbücher für wiss. Botanik, Bd. xi: I, I8 88 .

Pritzel, E. - Lycopodiaceæ, Psilotaceæ. Engler and Prantl, Nat. Pflanzenf., I Th. Abt. iv : 563-619, I900.

Quelle, F. - Bemerkungen über die Rhizoideninitialen in der Ventralschuppen der Marchantiaceen. Hedwigia, xli : I 76, I902.

Raciborski, M. - Ueber die Osmundaceen und Schizæaceen der Juraformation. Engler, Jahrbuch für Systematik-Pflanzengeschichte und Pflanzengeographie, xiii : I, I89I.

RAUWENHOFF, N. W. P. - I. Einiges über die ersten Keimungserscheinungen der Kryptogamensporen, Bot. Zeit., I879, p. 44I.

2. La génération sexuée des Gleichéniacées. Archives Néerlandaises

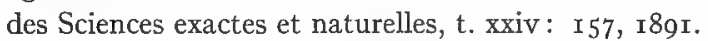

Reess, M. - I. Zur Entwickelungsgeschichte des Polypodiaceen-Sporangiums. Pringsh. Jahrb. für wiss. Botanik, vol. v: p. 217, I866-67.

2. Zur Entwickelungsgeschichte der Stammspitze von Equisetum. Pringsh. Jahrb. für wiss. Botanik, vi : 209, 1867-68.

RöLL, J. - Ueber die Veränderlichkeit der Stengelblätter bei den Torfmoosen. Bot. Centralblatt, xli : 24I, I8go.

Rostowzew, S. - I. Beiträge zur Kenntniss der Gefässkryptogamen. I. Umbildung von Wurzeln in Sprosse. Flora, lxxiii: I 55, I8go.

2. Recherches sur l'Ophioglossum vulgatum. Botanisches Centralblatt, I: 364,1892 .

3. Die Entwickelungsgeschichte und die Keimung der Adventivknospem bei Cystopteris bulbifera. Ber. der deutschen bot. Gesellschaft, 45, I 894 .

Roze, E. - Observations sur le prothalle des Fougères. Bull. de la Soc. bot. de France, xxviii : I35, I88I.

RUGE, G. - Beiträge zur Kenntniss der Vegetationsorgane der Lebermoose. Flora, lxxvii : 279-312, I893.

RUHLAND, W. (and WARnstorf, C.). - Sphagnales, Andreæales, and Archidiaceæ. Engler and Prantl, Die nat. Pflanzenf., Theil I, Abt. 3: 244288, т9от.

Russow, E. - r. Vergleichende Untersuchungen, betreffend die Histiologie der vegetativen und sporenbildenden Organe und die Entwickelung der Sporen der Leitbündelkryptogamen. Mém. de l'Acad. imp. des Sciences de St. Pétersbourg, ser. 7, xix: No. I, I872. 
2. Betrachtungen über das Leitbundel und Grundgewebe aus vergleichend morphologischem und physiologischem Gesichtspunkte. Dorpat, I875.

3. Ueber die Verbreitung der Callusplatten bei den Gefässpflanzen. Review, Bot. Zeit., I88 I, p. 723.

4. Développement des tubes cribreux. Ann. des Sci. naturelles, ser. 6, xiv: 167, I882.

5. Zur Anatomie resp. Physiologie und vergleichenden Anatomie der Torfmoosen. Dorpat, I887.

SADEBEck, R. - I. Ueber die Marchantiaceen. Verhandlungen des botanischen Vereins der Prov. Brandenburg, 1873 .

2. Wachsthum der Farnwedel. Verhandl. des bot. Vereins der Prov. Brandenburg, Jahrgang I5, I16, I873.

3. Die Entwickelung des Farnblattes, Berlin, I874.

4. Wachsthumsverhältnisse von Osmunda regalis. Bot. Zeit., I875, p. 638 .

5. Der Embryo von Equisetum. Bot. Zeit., 1877, p. 44. Also Pringsheims Jahrb. für wiss. Botanik, xi : 575,1878 .

6. Die Gefässkryptogamen. Schenks Handbuch der Botanik, vol. i, I882.

7. Pteridophyta, Hymenophyllaceæ. Engler and Prantl, Nat. Pflanzenf., I, Abt. iv: I-II2, I899.

8. Hydropteridineæ. Ibid., $38 \mathrm{I}-42 \mathrm{I}, \mathrm{I} 900$.

9. Equisetaceæ. Ibid., 520-548, I900.

10. Isoetaceæ. Ibid., 756-779, I902.

SATter, A. - I. Beiträge zur Entwickelungsgeschichte des Lebermoosantheridiums. Sitzber. der kais. Akad. der Wissenschaften, Wien, Bd. 86, Abt. i: July, r882.

2. Zur Kenntniss der Antheridienstände einiger Laubmoose. Ber. deutsch. bot. Gesellsch. ii: I3, r884.

Schafrner, J. H. - The Centrosomes of Marchantia polymorpha. Ohio Naturalist, ix : $383-388$, I 908 .

SchellenberG, H. C. - Zur Entwickelungsgeschichte der Equisetenscheide. Ber. deutsch. bot. Gesellsch., xiii : I65, I895.

Schenk, H. - Uber die Phylogenie der Archegoniaten und der Characeen.

Bot. Jahrb. f. Systematik, xxxii: Heft. I, I-37, 1908.

Schiffner, V.- r. Hepaticæ. In Engler and Prantl, Die nat. Pflanzenf., I Th., 3 Abt., I-I4I, I893-95.

2. Morphologische und biologische. Untersuchungen über die Gattungen Grimaldia und Neesiella. Hedwigia, xlvii: 306-320, 1908.

3. Untersuchungen über die Marchantiaceengattung Bucegia. Beih. 3. Bot. Centrlbl., xxiii, 2 Abt.: 273-290, I908.

4. Ibid. Phylogenetische Studien über die Gattung Monoclea. Oesterr-Bot. Zeitschr., lxiii, I9I3. 
Schmper, A. F. W. - I. Ueber Bau und Lebensweise der Epiphyten West Indiens. Bot. Centralblatt, xvii: p. 192, I884.

2. Untersuchungen über die Chlorophyllkörper und die ihnen homologen Gebilde. Pringsh. Jahrb. f. wiss. Botanik, xvi: I-247, I885.

Schrmper, PH. W. - Versuch einer Entwickelungsgeschichte der Torfmoose (Sphagnum) und einer Monographie der in Europa vorkommenden Arten dieser Gattung. Stuttgart, 1858.

SCHNEIDER, F. - Beiträge zur Entwickelungsgeschichte der Marsiliaceen. Berlin, I9I2.

SchoeNaU, Kard von. - Zur Verzweigung der Laubmoose. Hedwigia, li : $\mathrm{r}-56, \mathrm{rgII}$.

Schovte, J. C. - Die Stelartheorie. Gröningen, rgo2.

SCHotTränder, P. - Beiträge zur Kenntniss des Zellkerns und der Sexualcellen bei Kryptogamen. Cohn's Beiträge zur Biologie der Pflanzen, Bd. vi : 267,1892 .

Schostakowitsch, W. - Ueber die Reproductions- und Regenerationserscheinungen bei den Lebermoosen. Flora, lxxix, Ergänzungsband: $350-384,1894$.

Schrenk, J. - The dehiscence of Fern-sporangia. Bulletin of the Torrey Botanical Club, xiii: I68, I886.

Schrodt, J. - Neue Beiträge zur Mechanik der Farnsporangien. Flora, lxx: p. I77, I887.

ScHulze, H. - Ein Beitrag zur Kenntniss der vegetativen Vermehrung der Laubmoosen. Bot. Centralblatt, xxxi: 382,1887 .

ScotT, D. H. - I. Present Position of Morphological Botany. Presidential address before Sec. K, B. A. A. S., 1896 .

2. Studies in Fossil Botany. London, Igoo. (Also many monographs on fossil plants.)

3. (and Hill, T. G.). - The Structure of Isoetes hytrix. Ann. of Bot., xiv: 413-454, I900.

4. On the Origin of Seed-bearing Plants. Lecture before the Roy. Inst. of Great Britain, London, I903.

5. The Present Position of Palæozoic Botany. Progressus Rei Botanicae, i: Heft. I, I907.

6. Ibid. Studies in Fossil Botany, 2d Edit., Igog.

Seward, A. C. - I. Fossil Plants. Vol. I, Cambridge, I897.

2. On the Structure and Affinities of Matonia pectinata. Phil. Trans., ser. B, vol. I9I : I7 I, I899.

3. (and DaLE, E.).- On the Structure and Affinities of Dipteris. Phil. Trans., Ser. B, vol. I94: 487-513, I901.

4. (and Ford, S. O.). - The Anatomy of Todea, with Notes on the Geological History and Affinities of the Osmundaceæ. Trans. Linn. Soc. Lond., 2d ser., Botany, vol. vi, pt. 5 : 237-260, 1903.

5. Fossil Plants, vol. ii., I9IO. 
Sharp, L. W. - r. Spermatogenesis in Equisetum. Bot. Gaz., liv: 89II9, I9I2.

2. Spermatogenesis in Marsilia. Bot. Gaz., lviii : 4I9-43I, I9I4.

Shatruck, C. H. - The origin of Heterospory in Marsilia. Bot. Gaz., xlix: I9-40, I910.

SHAw, W. R. - I. Parthenogenesis in Marsilia. Bot. Gaz., xxiv: II4II 7, I897.

2. The Fertilization of Onoclea. Ann. of Bot., xii : 26I-285, I898.

3. Ueber die Blepharoplasten bei Onoclea und Marsilia. Ber. deutsch. bot. Gesellsch., xvi : I77-I84, I898.

Shreve, F. - Physiology of the Hymenophyllaceæ. Carnegie Inst. of Wash. Yearbook, No. 9.

Sinnott, E. W. - I. Foliar Gaps in the Osmundaceæ. Ann. Bot., xxiv : IO7-II8, I9IO.

2. The Evolution of the Filicinean Leaf-trace. Ann. Bot., xxv: I67-I9I, I9II.

Smith, R. WiLson. - The Structure and Development of the Sporophylls and Sporangia of Isoetes. Bot. Gaz., xxix : $225^{-258}, 323-346$, Igoo.

Solms-Laubach, H. Graf zU. - I. Der Aufbau des Stockes von Psilotum triquetrum und dessen Entwickelung aus der Brutknospe. Ann. du Jardin botanique de Buitenzorg, iv: 139, I884.

2. Fossil Botany. Oxford, Clarendon Press, i89r.

3. Ueber Exormotheca, eine wenig bekannte Marchantiaceengattung. Bot. Zeitung, lv: $\mathrm{I}-\mathrm{r} 6$, 1897 .

Sonntag, P. - Ueber Dauer des Scheitelwachsthums und Entwickelungsgeschichte des Blattes. Pringsheims Jahrb. für wiss. Botanik, xviii : 236, 1887 .

Southworth, EFfie A. - Structure, development, and distribution of the stomata of Equisetum arvense. American Naturalist, xvii : October, I884. Spring, A. - Monographie de la famille des Lycopodiacées. Mem. de l'Acad. roy. de Belgique, t. xxiv: pt. i., I842; pt. ii., I849.

Spruce, R. - I. The Morphology of the leaf of Fissidens. Trimen's Journal of Botany, xix: p. 98.

2. Hepaticæ of the Amazon and of the Andes of Peru and Ecuador. Trans. Bot. Soc., Edinburgh, vol. xv, I885.

Stahl, E. - Künstlich hervorrufene Protonemabildung. Hallesche Bot. Zeitung, p. 689, I876.

Starr, Anna M. - A Mexican Aytonia. Bot. Gaz., lxi: 48-58, Igr6.

Stephan, F. - Species Hepaticarum. Bull. de l'Herbier Boissier. Ser. I, vi-viii : Ser. 2, i-viii, Geneva, I898-Igo8.

Stephenson, B. G. - Young Stages of Dicksonia and Cyathea. Tr. and Proc. New Zealand Instit., xl : I-I6, I907.

Sterns, E. E. - Bulblets of Lycopodium lucidulum. Bulletin of the Torrey Botanical Club, xv: 3I 7, I888. 
Stevens, W. C. - On the Development of the Sporangia and Spores of Aneimia Phyllitidis. Ann. Bot., xxv: I059-1068, I911.

Strles, W. - The Structure of the ærial shoots of Psilotum flaccidum Wall.

Ann. Bot., xxiv : $373-387$, rgro.

Stokey, Alma G. - I. The Anatomy of Isoetes. Bot. Gaz., xlvii : 3II335, I909.

2. The Sporangium of Lycopodium pithyoides. Bot. Gaz., 1: 218219, I910.

Stopes, M. C. - Ancient Plants. London, igio.

Strasburger, E. - I. Ein Beitrag zur Entwickelungsgeschichte der Spaltöffnungen. Pringsh. Jahrb. f. wissen. Bot., v: 297, I866-67.

2. Die Geschlechtsorgane und die Befruchtung bei Marchantia polymorpha. Pringsh. Jahrb. f. wissen. Bot. vii : 409.

3. Die Befruchtung bei den Farnkräutern. Ibid., 390 .

4. Die Befruchtung bei den Coniferen. Jena, I869.

5. Die Coniferen und Gnetaceen. Jena, 1872.

6. Ueber Azolla. Jena, I873.

7. Einige Bemerkungen über Lycopodiaceen. Bot. Zeit., I873, p. 81 .

8. Die Angiospermen und die Gymnospermen. Jena, 1879 .

9. Zellbildung und Zelltheilung. Third edition, Jena, I880.

I0. Das botanische Practicum, second edition, Jena, 1887.

II. Histologische Beiträge, 6 vols., I888-Igoo.

I2. The periodic reduction of chromosomes in living organisms. Ann. of Bot., viii : 28I, 1894 .

I3. Die Pflanzlichen Zellhäute. Pringsh. Jahrb. f. wiss. Bot., xxxi: 5II-596, I 898 .

I4. Ueber Reductionsteilung. Sitzungsber. der Königl. Preuss. Akad. der Wissensch., xviii., IgO4 (Sep. 28 p.).

I 5. Zeitpunkt der Bestimmung des Geschlechts, Apogamie, Parthenogenese und Reductionsteilung. Histologische Beiträge, Heft. 7, Jena, Igog.

16. Über Geschlechtsbestimmende Ursachen. Jahrb. wiss. Bot., xlviii : 427-520, I910.

Sykes, M. G. - I. Tracheids in the nodal region of Equisetum maximum. New Phytologist, v: I29-I32, I906.

2. Notes on the Morphology of the Sporangium-bearing Organs of the Lycopodiacex. New Phytologist, vii : 4I-60, I908.

3. The Anatomy and Morphology of Tmesipteris. Ann. Bot., xxii: 63-89, I908.

4. (and Stiles, W.). - The Cones of the Genus Selaginella. Ann. Bot., xxiv: $523-536$, I910.

Tansley, A. G., and Chick, E. - On the Structure of Schizca Malaccana. Ann. Bot., xvii : 493-310, I903.

Tansley, A. G. - Lectures on the Evolution of the Filicinean Vascular System. (Reprint from New Phytologist.) Cambridge, I909. 
Terletzki, P. - Anatomie der Vegetationsorgane von Struthiopteris Germanica, und Pteris aquilina. Pringsheims Jahrbücher für wiss. Botanik, $x v: 452,1884$.

Thistleton-Dyer, W. F. - Morphology of Selaginella. Nature, 1877, p. 489 .

Тномєе K. - Die Blattstiele der Farne. Pringsheims Jahrb. für wiss. Botanik, xvii : 99, I886.

Thomas, A. P. W. - I. Preliminary Account of the Prothallium of Phylloglossum. Proc. Roy. Soc., lxix : 285-29I, I9or.

2. The affinities of Tmesipteris with the Sphenophyllales. Ibid., lxix: I902.

3. An Alga-like Fern-prothallium. Ann. of Bot., xvi: I65, I902.

Thuret, G. - I. Discharge of Antherozoids in Fegatella. Mem. de la Soc. des Sciences Nat. de Cherbourg, t. iv: $[216,1856$.

Tilden, Josephine E. - On the Morphology of Hepatic Elaters, with special reference to branching elaters of Conocephalus conicus. Minnesota Botanical Studies, Bulletin 9: 43-53, I894.

Towle, Phebe M. - Notes on the Life-history of the Mniums. The Bryologist, ix : $54-56$, 1906 .

TreUb, M. - I. Recherches sur les organes de végétation de Selaginella Martensii Spr. Musée botanique de Leide, t. ii.

2. Etudes sur les Lycopodiacées. Annales du Jardin botanique de Buitenzorg, iv., v., vii., I884-I89o.

Twiss, E. M. - The Prothallia of Aneimia and Lygodium. Bot. Gaz., xlix : I68-I8I, I9ro.

UNDERWOod, L. M. - I. Hepaticæ. In Gray, Manual of Botany of North Eastern United States, sixth edition, I890.

3. Index Hepaticarum, part I. Bibliography. Memoirs of the Torrey Botanical Club. Vol. iv., No. I, I893.

4. The Evolution of the Hepaticæ. Bot. Gazette, xix : 347,1894 .

5. Our native Ferns and their Allies. Sixth edition, New York, I 900. Vaizey, J. Reynolds. - I. Transpiration of the sporophore of the Musci. Annals of Botany, I: 73, 1887 .

2. On the anatomy and development of the sporogonium of the Mosses. Journal of the Linn. Society, xxiv: 262, I888.

3. Preliminary note on the root of Equisetum. Annals of Botany, ii.: I23, 1888 .

4. On the morphology of the sporophyte of Splachnum luteum. Annals of Botany, v: I, I8go.

Van Treghem, Ph. - I. Sur quelques points de l'anatomie des cryptogames vasculaires. Bull. de la Soc. bot. de France, xxv: I69, I883.

2. (et Dovliot). - Sur la Polystélie. Ann. des Sci. naturelles, ser. 7, t. $3: 275,1886$.

3. Sur le dédoublement de l'endodermis dans les cryptogames vasculaires. Journal de Botanique, r888, p. 404. 
4. Sur la limite du cylindre centrale et de l'écorce dans les cryptogames vasculaires. Journal de Botanique, r888, p. 369 .

5. (et DULIOT). Recherches comparatives sur l'origine des membres endogènes dans les plantes vasculaires. Ann. des Sc. naturelles, ser. 7 , t. viii : I, I888.

6. Remarques sur la structure de la tige des prêles. Journal de Botanique, I89o, p. 365 .

7. Remarques sur la structure de la tige des Ophioglossées. Ibid., p. 405.

8. Traité de Botanique, second edition. Paris, I892.

Vaughn-Jennings, A. (and Hall, K. M.). - Notes on the structure of Tmesipteris. Proc. Roy. Irish Acad., I8gr.

VINES, S. H. - I. On the homologies of the suspensor. Q. J. Mic. Sci., xvii : 58,1878 .

2. The Systematic position of Isoetes. Annals of Botany, ii: II7, I888.

Vöchting, H. - Ueber die Regeneration der Marchantiaceen. Pringsheims Jahrb. für wiss. Bot., xvi : 367, I885.

VoIGHT, A. - Vergleichende Anatomie der Marchantiaceen. Botanische Zeitung, 1879, p. 729.

Vouk, F. - I. Das Sporogonium von Orthotrichum. Sitzungsber. der kais. Akad. der Wissenschaften, Wien, lxxiii : 385 , I876.

2. Die Entwickelung des Embryos von Asplenium Shepherdii. Sitzber. der kais. Akad. der Naturwissenschaften, Wien, Bd. lxxvi., Abt. I : 27I, I877.

Waldner, M. - I. Entwickelung des Antheridium von Anthoceros. Sitzber. der k. Akad. der Wiss., Wien, Bd. lxxv., Abt. I: 8r, I877.

2. Die Entwickelung der Sporogone von Andrexa und Sphagnum. Leipzig, I887.

Warson, W. - Xerophytic adaptations of Bryophytes. New Phytologist, xiii : $149-169$, I914.

Webrer, H. J. - The Development of the Antherozoids of Zamia. Bot. Gaz., xxiv: 22, 1897 .

Wernham, H. F. - The Morphology of Phylloglossum Drummondii. Ann. Bot., xxiv: 335-347, 1910.

West, CYRIL. - I. On the Structure and Development of the Secretory Tissues of the Marattiaceæ. Ann. Bot., xxix: 409-422, I9I5.

2. On Stigeosporium Marattiacearum and the Mycorrhiza of the Marattiacer. Ann. Bot., xxxi : 77, I9I 7.

Williamson, W. C. (and Scotr, D. H.). - Further observations on the Organization of the Fossil Plants of the Coal Measures. Roy. Soc. Phil. Trans., vol. clxxxv: 863, I894.

Willis, J. C. - Flowering Plants and Ferns. Cambridge, I904.

WILson, M. - т. On spore-formation and nuclear division in Mnium hornum. Ann. Bot., xxiii: I4I-I 57, I909. 
2. Spermatogenesis in the Bryophyta. Ann. Bot., xxv: 4r5-457, I9II.

WoJENowic. - Beiträge zur Morphologie, Anatomie und Biologie der Selaginella lepidophylla. Inaugural Dissertation, Breslau, I8go.

Woopburn, W. L. - r. Spermatogenesis in certain Hepaticæ. Ann. Bot., XXV: 299-3I3, I9II.

2. Spermatogenesis in Blasia pusilla. Ann. Bot., xxvii : 93-1or, I9r3.

3. Spermatogenesis in Mnium affine, var. ciliaris (Grev.) C. M. Ann. Bot., xxix : 44I-456, I9I 5 .

Worsdelt, W. C. - The Rhizophores of Selaginella. New Phytologist, ix: $242-253$, 1910.

WuIST, E. D. - The physiological condition for the development of monœcious prothallia in Onoclea Struthiopteris. Bot. Gaz., xlix: 216-219, 1910.

Yamanouchi, SH. - Spermatogenesis, Oogenesis and Fertilization in Nephrodium. Bot. Gaz., xlv: 145-175, I908.

YAPP, R. H. - I. On Two Malayan Myrmecophilous Ferns. Ann. Bot., xvi : 185-230, 1902.

2. Apogamy in Nephrodium. Bot. Gaz., xlv: 289-3I8, 1908 .

Ibid. Chromosomes in Osmunda. Bot. Gaz., xlix: I-I2, I9Io.

YASUI, K. - On the Life-history of Salvinia natans. Ann. Bot., xxv : 470483 , I9I I.

Yeates, H. R. - The means of distribution of Hepatica. New Phytologist, vii : I67-I7I, I908.

Zacharias, E. - I. Ueber die Spermatozoiden. Bot. Zeit., I88r, p. 827. 2. Ueber den Nucleolus. Bot. Zeit., r885, p. 289.

3. Beiträge zur Kenntniss des Zellkerns in den sexuellen Zellen. Bot. Zeit., I887, p. 28 r.

ZeIller, R. - Affinités du Genre Laccopteris. Bull. de la Soc. bot. de France, 1885 , p. $2 x$.

Zenerti, P. 一 Das Leitungssystem im Stamm von Osmunda regalis, L. Bot. Zeit., liii : $53-78$, I895.

ZreurNSKI, F. - Beiträge zur Biologie des Archegoniums und der Haube der Laubmoose. Flora, c: I-36, r909.

Zimmerman, A. - I. Scheitelzellen an den Adventivknospen einiger Farne. Bot. Centralblatt, vi: r75, r88r.

2. Ueber die Einwirkung des Lichtes auf dem Marchantieenthallus. Arbeiten des bot. Instituts in Würzburg, Bd. ii., Heft iv., p. 665 . 


\section{INDEX}

Acrocarpæ, 218, 623

Acrogynæ, 73, 74, 99, I00, IOI, I70, $6 \mathrm{Ig}, 620$

asexual reproduction, II 8

branching, I04, II7

classification, I I 9

distribution, II 9

gemmæ, II 8

germination of spores, II3

leaves, II 6

traps in leaves, $\mathbf{I} \mathbf{7}$

epiphytic, II 6

Adiantites, 579

Adiantum, 364, 395, 580 emarginatum, 329, 336 ; Figs. I8I, I85, I 88

pedatum, 332 ; Fig. 180

Adventitious budding, 574

of gametophyte, 277,350

Adventitious buds, 258

Adventive shoots, 497

Ricciaceæ, 27

Air-chambers,

Marchantiaceæ, 23, 42, 48, 6ro, 6II, 6I2

Ricciocarpus, 39, 40, 610

Struthiopteris, 329

Air-space (see Lacunæ), 206, 207, 216

Alethopteris, 585

Algæ, I, 2, 9, I4, 121, 227, 230, 564, $565,566,569,573,592$

Alisma, 548

Alsophila, 307

prothallium, 39r

contaminans, $39 \mathrm{I}$

Cooperi, Fig. 228
Alternation of generations, 2, 562 antithetic, 569, 574 homologous, 569, 570, $57 \mathrm{r}$

Amber, 577, 578

Amblystegium, I93, 194

apical growth, IgI

leaf, I92

riparium var. fluitans, 190; Figs. 98,99

Ameristic prothallia, 3 I4

Amphigastrium, I4, I I 4

Porella, I02

Amphithecium, I3, I79, I85, I86, 205, 206, 2I 4

Anabæna Azollæ, 409, 4I 5

Anacrogynæ, 73, 74, 75, 85, 100, I09, I57, I 58, 592, 595, 597, 6I4, 6I8, 6I9

calyptra, 98

elaters, 96,99

germination of spores, 99

spore-division, 98

spores, 99

sporophyte, 94,95

Andreæa, I6I, I65, I87, 196, 20r, $202,203,209,219,226$, 227

leaves, $\mathrm{I} 82$

sex-organs, $\mathrm{r} 84$

sporophyte, I84, I85

stem, I82

crassinerva, Fig. 95

Spetrophila, Figs. 94, 95

Andreæaceæ, I6I, I65

Andreæales, I60, I66, I8I

Androgynous receptacles,

Marchantiaceæ, 6 I3 
Aneimia, 335, 384, 385, 386, 387, $388,389,390,420,580,636$ antheridium, 385

hirsuta, Figs. 223, 225

hirta, 385

phyllitidis, 636; Figs. 222, 226

Anelatereæ, 73, 75, 6I4

Anemone, 574

Aneura, 2, 9, I4, I5, I6, 72, 85, 86, $88,89,92,94,96,97,98,99$, I09, II 4 , I 2 I, I32, I 57 , I 58, $274,314,564,593,595,607$, $6 \mathrm{I} 7,6$ I 8

antheridia, 89

archegonia, 92, 93

embryo, 6I 6

multifida, $12,86,95,98$; Fig. 45 gemmæ, 86, 607, 6r 8

palmata, 99 ; Fig. 48

pinguis, 95, 99 ; Fig. 45

pinnatifida, 87,88 , 90; Figs. 39 , $40,4 \mathrm{I}$

Tjibodensis, 6I 5

Aneuracex, 615, 618

Angiopteridaceæ, 632

Angiopterideæ, 298, 583

Angiopteris, 271, 274, 276, 277, 279, $284,286,289,290,29 I, 292$, $293,297,298,299,300,304$, $334,340,362,366,371,582$, $583,602,630,631,632,634$

leaf, 290, 29I

stem-structure, 289

stipules, 290

vascular system, 290, 63I, 632

evecta, 273, 29r ; Figs. 149, I57, I6I, I63, I64, I67

Smithii, 633

Angiosperms, 291, 304, 558, 604, 605,606

Anisogonium seramporense, 339

Annulariæ, 586

Annulus, 165, 209, 210, 213, 294, $307,343,366,37$ I, 383, 392, 438,584
Anogramme leptophylla, 308, 572

Antheridium,

Aneimia, 385

Anthoceros, I29, I30, I3 I

Azolla, 399

Botrychium, 240

Cyatheaceæ, 39I

dehiscence, 53, I07, I99, 3 I8

Dendroceros, 146

Equisetum, 447, 448

Funaria, 196, 197, 199

Gleichenia, 368, 635

Hepaticæ, I6

intermediate structures, 203

Jungermanniales, 73, 6r 4

Lycopodium, 489

Marchantiaceæ, 5I, 6I4

Marsilia, 420

Muscineæ, Io

Notothylas, I49, I 50

Onoclea, 3 II 5

Ophioglossum, 236

Osmunda, 351, 352

Pallavicinia, 6r 5

Pellia, 92

Pilularia, 42 I

Porella, I05, I06

Riccia, 3I, 33

Salvinia, 398

Selaginella, 5I 2, 5I3

Sphærocarpus, 80

Sphagnum, I75, I76

thallose Hepaticæ, I2

Figs. 5, I5, 16, 30, 33, 35, 40, 52, $53,67,68,80,102,103$, I04, I25, I26, I28, I74, 195, I96, $217,234,244,245,246,259$, $260,283,295,310$

Antheridia, exogenous, I3I

Antheridial receptacle,

Fimbriaria, 49

Marchantia, 53

Anthoceros, I4, 53, I2O, I2I, I 22, I46, I47, I48, I49, I50, I 5 I, I 52,153, I 55, I 56,165, I 79 , 
I87, 2II, 227, 229, 30I, 303, $359,529,564,568,570,593$, $594,598,599,600,601,620$, $621,633,642$

antheridium, I29, I 30

apical growth, I25

archegonium, I32, I33, I34

archesporium, $\mathrm{I} 36$

basal wall, 242

chloroplasts, I42, I 58

dichotomy of thallus, 145

gametophyte, I 23

germination of spores, I43, I44

mucilage-clefts, I 25

sex-organs, I 28

spore-development, I39

spore-division, I4I

sporophyte, I34, I35, I36

stomata, I32

structure of thallus, I 28

dichotomus, 145

fusiformis, I3, I23, I25, I28, I34,

I39, I4I, I42, I43, I44, I45,

I49, I 50, 45o, 597; Figs. 64,

$65,66,69,73,76,77$

lævis; I23, I33, I34, I39, I4I, I $43,276,349,597$

Pearsoni, I 23, I29, I32, I33, I34, I38, I39, I40, I42, I43, 620, 62I; Figs. 67, 70, 7x, 72, 74,75

phymatodes, 145

punctatus, I 23

tuberosus, I45

Anthocerotaceæ, 593, 608

Anthocerotales, 609, 622

Anthocerotes, 8, I0, I2, I3, I6, 74, I $20, \mathrm{I}_{4} 8, \mathrm{I}_{5} 6, \mathrm{I}_{5} 8, \mathrm{I}_{59}, 227$, 229, 23I, 280, 300, 30I, 302, $534,565,568,592,594,595$, 596

archegonium, I3

chloroplast, I3, I 2 I

columella, I 37

evolution of, 156
Anthocerotes - Cont.

gametophyte, I3, I20

sexual organs, I 2 I

sporophyte, I 22

Antithetic alternation of generations, 569,574

Apical cell, 8I, I57

Anacrogynæ, 89

Hepaticæ, 15

Jungermanniaceæ, I5, I02

Marchantiaceæ, 67

Muscineæ, 9

Riccia, 38

root, 253, 266, 284, 325, 359

Sphærocarpus, 82

Apical growth,

Amblystegium, I9I

Aneura, 85

Anthoceros, 125

archegonium of Funaria, 202

Bryales, I9o

embryo, 203

Jungermanniales, 72

Marchantiaceæ, 47

Porella, 102, 103

prothallium, 3I4, 3I8

Sphagnum, I 70

sporophyte of Mosses, I65

stem, IgO, 459, 494

Apogamy, 233, 243, 308, 383, 57o, $57 \mathrm{I}, 573,574,634,643$

Apophysis, 207, 21I, 213, 220, 224, 229,600

Apospory, 233, 308, 309, 383, 570, $57 \mathrm{I}, 574,634$

Aquatic mosses, I60

Aquatic plants, 575

Archæocalamites, 600 (see Asterocalamites)

Archæopterideæ, 574

Archæopteris, 580, 581, 582

Archæopteris (Palæopteris), 579

Archangiopteris, 273, 295, 298, 300, $630,632,633$

Henryi, Fig. I68 
Archegonial receptacle, 56, 57

Marchantiaceæ, 48, 58, 6I3

Archegoniatæ, I, I2I

fossil, 576

interrelationships, 592

Archegonium, I, 5, 6, II, I7, 57, II3, I28, I32, I58, I64, I84, 203, 227, 279, 302, 309, 318, 3I9, 450, 45I, 452, 533, 544

Aneura, 92, 93, 94

Anthoceros, I32, I33, I34

Anthocerotes, I3

Azolla, 403

Botrychium, 240, 24I

Dendroceros, 147

Funaria, 199, 200, 201

Gleichenia, 368

Haplomitriex, IoI

Hepaticæ, I6

Hymenophyllaceæ, 377

Isoetes, 543

Jungermanniales, 73,74

Lycopodium, 490

Marattia, 280

Marchantiaceæ, 46, 70

Mninum cuspidatum, 202

Notothylas, I 50

Ophioglossum, 237, 238, 626

Osmunda, 353, 354

Pellia epiphylla, 94

Porella, I07, I08

Pteridophytes, 232, 596

Riccia, 29, 30, 3 I

Selaginella, 5 I 6

Sphærocarpus, 76

Sphagnum, I77, I78, I81

thallose Hepaticæ, I2

Targionia, 53, 55

Archesperma, I

Archesporium, 5, I2, 13, I8, 21, 62, 80, 95, III, I 22, I35, I36, I37, I38, I5I, 165, I79, I85, $205,207,209,214,254,255$, $256,269,272,293,301,307$, $342,474,500,531$
Archidium, 166, I85, 214, 228 spore-formation, 187 spores, 185,187 sporophyte, I86

Ravenelii, Fig. 96

Areoles, 5I 5, 54I

Ascomycetes, 562

Aspidium, 395

falcatum, 309

filix-mas, 3I4, 345 (var. cristatum), 309

spinulosum, Fig. 230

Asplenium, 395

bulbiferum, 310

esculentum, Fig. I $7 \mathrm{I}$

filix-fœmina, Fig. 23I

nidus, 394,624

Assimilating tissue, I22, 165, 227, $229,465,568,594,595$

Astelic structure, 464

Asterocalamites, 586, 587 (Archæocalamites)

Asterophylliteæ, 586

Asterotheca, 582, 583

Astroporæ, 59, 6I4

Athyrium filix-fœmina, 3I4 (var. clarissima) 309

Atrichum, I64

undulatum, I6I

Azolla, 233, 396, 398, 400, 409, 4I 7, 603,637

antheridium, 399

archegonium, 403

embryo, 405

female prothallium, 400, 40I, 402

leaf, 409,410

primary root, 406

roots, 4II, 4I 2

sporangium, 4I 2, 4I4

sporocarp, $4 \mathrm{I} 2$

stem-apex, 406

stem-structure, 4 II

stomata, 4I I

Caroliniana, 402, 405, 412 
Azolla - Cont.

filiculoides, 405, 410; Figs. 235, $236,237,239,240,24$ I, 242

Barbula fallax, Fig. I I9 unguiculata, 623

Bast fibres, 464

Bazzania, I 9

Begonia, 574

Bellincinioideæ, I 19

Blasia, 9, I2, 14, 72, 74, 99, I 58 gemmæ, I00

pusilla, 9o; Fig. 4I

Blepharoplast, $5 \mathrm{I}, 52,279,3 \mathrm{I} 6,42 \mathrm{I}$, $422,449,608,609,625$

Blepharoplastoid, 42 I

Blyttia, 618-(see also Pallavicinia)

Blyttiaceæ, 6I 5, 6r8

Boschia, 42, 59, 60, 6II, 6r4

Botrychium, 233, 235, 237, 238, $245,249,258,272,273$, $277,284,285,293,295$, $300,303,346,359,364$, $365,440,554,56 \mathrm{r}, 564$, $580,582,583,602,626$, $628,629,634,643$

antheridium, 240 apical growth of stem, 262 archegonium, 240 cotyledon, 243, 244

development of first root, 244 embryo, 242, 243, 628 gametophyte, 239,626

leaf, 264 root, 259,266 secondary thickening, 262

sex-organs, 239 sieve-tubes, 266 spermatozoids, 240 sporangiophore, 259 sporangium, 268, 269 tracheids in prothallium, 243 vascular bundle of stem, 244 vascular bundles, 26r, 265 venation of leaf, 259
Botrichium - Cont.

lunaria, 238, 245, 264, 267, 268, $269,580,626$; Fig. I4I

obliquum, 628

rutæfolium, 262, 270

simplex, 258, 259, 26I, 266, 268; Fig. $14 \mathrm{I}$

ternatum, 26I, 264, 266, 267, 268 ;

Fig. I4I

Virginianum, 234, 259, 261, 262, $267,268,269,27 \mathrm{I}, 300,302$, 304; 308, 366, 602, 626; Figs. I 26, I 27, I 28, I 29, I30, I4I, I42, I44, I45, I46, I47, I 48

Bowmanites, 587

Branching,

Acrogynæ, I4, II7, 6I9

Lycopodium, 494

Porella, ror

prothallium, 374

root, 499

stem, 497

Brown Algx, 607, 608

Bryales, 70, I6I, I65, I66, I8I, I82, I83, I85, I88, 2 I $3,2 \mathrm{I} 6,220$, $226,228,305,594,595,600$, 622,623

apical growth, I9o

branching, I93, I94

classification, 214

gametophyte, 188

germination of spores, 188

peristome, 220

stem-structure, I94

Bryinex, I84, I85, I86, I9I, 205

Bryophyllum, 574

Bryophytes, I, 3, 4, 5, 8, I 2 I, 229, $230,257,301,32 \mathrm{I}, 490,563$; $566,572,575$

effect of drought, $57 \mathrm{I}$

gametophyte, 533

relation to Pteridophytes, 574

Bryoziphion, 2I 7

Bryum argenteum, 623 
Budding, r6 r, 560 adventitious, 574 adventitious of gametophyte, 277,350

from roots, 339 sporophyte, 3 Iо

Buds, 233, 307, 308 see also Gemmæ

Bulblets, 499

Buxbaumia, 8, I60, 162, 163, 166, 220,228

indusiata, Fig. 123

Buxbaumiaceæ, 225

Buxbaumiales, 622, 623

Calamariaceæ, $48 \mathrm{I}, 585,587$

Calamiteæ, 585,586

Calamostachys, 586, 603

Calcareous Algæ, 577

Callus, 265

Calobryaceæ, 6I 5, 6I8

Calobryum, I2, 72, IOO, IOI, 6I 5

Blumei, 6I8

Calycularia, 608, 609, 6I 5

radiculosa, 6ז6, 6ז8

Calyptra, I8, 63, I42, 2I3, 2I4, 243, 284,321

Cambium, 262, 263, 554, 590

Camptosorus, 310,574

rhizophyllus, 3 I0

Carboniferous, $306,582,583$

Carboniferous ferns, 579

Cardiocarpon, 59I

Cardiopteris, 579

Carpocephalum, 56

hairs, 58

scales, 58

Carpogonium, $5^{62}$

Catharinia, 199, 623 angustata, 623

Centrosome, 5I, 3I6, 608, 609

Centrospheres, 476

Pellia, 99

Cephalozia bicuspidata, II4

Cephaloziaceæ, 620
Ceratodon, 570

Ceratopteris, 233

thalictroides, $39^{2}$

Characeæ, I, 2, 8I, 577, 592, 607

Cheiroglossa palmata, 258,628

Cheirostrobus, 587,588

Chemotropism, 3 I9

Chiloscyphus, II 4

Chlorophyceæ, 562, 567

Chlorophyll,

in spores, 312,343

Chlorophyll work, 572

Chloroplast, ז39, 529, 593

Anthoceros, 158

Anthocerotes, I3, I21

Selaginella, 528, 534

Chromatophores, I0, I97, I98; See also, Chloroplast antheridium of Hepaticæ, I7 Osmunda, 597

Chromosomes, reduction, $343,477,567$

Cibotium, 307, 335

Chamissoi, 392

Menziesii, 392 ; Fig. 227

Cleistocarpæ, I66, I85, 214, 216, 228,623

Clevea, 56, 61 2 ; Fig. 20

Climacium, I63, I94

Americanum, Fig. 86

Coal measures, $535,59 \mathrm{r}$

Codoniacex, 6I5, 6I8, 6I9

Codonieæ, 75

Collateral bundies, 262, 334

Collenchyma, 29I

Coleochæte, I4, I21, I 59, 534, 563, $564,566,567,592,593$

Cololejeunia Gœbelii, II8; Fig. 60

Columella, I 22, I35, I38, I5I, I53, I 58, I79, I85, 209, 2I4, 2I6, 595

Completoria, 239

Composita, 58, 618

Concentric bundles, 284, 286, 29r, 334 
Conductive tissue, I62, 568, 595

Cones, 590

Confervoideæ, 563,577

Coniferæ, 262, 534

Conocephalus, I5, 2I, 42, 43, 47, $53,58,69,148$ multicellular spores, I9, 47;

Fig. I

Corallines, 577

Cork, 263

Corsinia, 4I, 42, 46, 59, 60 marchantioides, $6 \mathrm{II}, 6 \mathrm{I}_{4}$ sexual organs, $4 \mathrm{I}$ sporophyte, 4I ; Fig. 22

Corsiniaceæ, 2I, 4I, 46, 47, 59, 609 sporophyte, 60

Corsinieæ, 62, 7I, (see Corsiniaceæ)

Cortex, I7O, I73, 223, 253, 262, 263

Cotyledon, 4, 243, 282, 287, 323, $357,358,405,426,491,519$, $547,548,549,55 \mathrm{I}$

Cristensenia, see Kaulfussia

Cumingiana, 632

Cronisia, 4I

paradoxa, 4I

Cryptomitrium, 58, 6I2 tenerum, 67

Crystals, 292

Cupuliferæ, 270

Cyathea, 307 medullaris, $39 \mathrm{I}$

microphylla, Fig. 229

Cyatheaceæ, 307, 310, 31I, 372, $373,390,439,440,580,581$, 584,603

antheridium, 39r

indusium, 392

Cyathodium, 69, 609, 6I2, 62I

cavernarum, 613

fotidissimum, 6I2, 6I3

Cyathophorum, 217

pennatum, Fig. I I 7

Cycadofilices, 584, 604

Cycadoxylon, $5^{8} 5$
Cycads, 304, 579, 584, 585, 604 spermatozoids, 604

Cycas, $32 \mathrm{I}$

Cystopteris bulbifera, 233, 310, 574; Fig. 172

fragilis, Fig. I 86

Danæa, 271, 273, 274, 276, 279, $284,285,286,29$ I, 295, 297, 298, 299, 300, 303, 560, 582, $602,629,630,631,632,633$

alata, 286; Figs, 162, 166, I69, I 70

elliptica, 633

simplicifolia, 285, 299; Fig. I57

Danæaceæ, 632

Danæites, 582

Danæopsis, 583

Darlingtonia, 117

Davallia stricta, 327

Dawsonia, 565, 595

superba, stem of, 222 ; Figs. I 20, I 22

Dehiscence

antheridium, 53, 107, 199, 318

capsule, 74,6 r 8

sporangium, 257, 270, 297, 344,

444

sporogonium, 18,65 , 143

Dendroceros, I3, I20, I4I, I45, I53, I56, 318, 349, 597, 621

antheridium, $\mathbf{1 4 6}$

archegonium, 147

embryo, I47

spores, I48

structure of thallus, 146

Breutelii; Figs. 78, 79

cichoraceus, $\mathbf{I} 46$

crispus, $\mathrm{I}_{4} 8$

Javanicus, 123, I46 ; Fig. 64

Dennstædtineæ, 3 I I

Devonian, $578,579,587,588$, 59r

Diaphragm, 5I6

Diatoms, $\mathbf{I} 28$ 


\section{Dichotomy}

Anacrogynæ, 86, 87

Anthoceros, I45

leaf, 580

Marchantiales, 22

prothallium, 350, $45^{2}$

Riccia, 27

root, 258,556

stem-apex, $52 \mathrm{I}$

Dicksonia, 335

antarctica, 390, 39I

Dicksonieæ, 3 II

Dicotyledons, 26r, 263, 270, 590, 605

Digestive pouch, 472

Dimorphic leaves, $580,58 \mathrm{I}$

Diøecism, 314, 453

Diphyscium, 188

Dracæna, 554, 590

Draparnaldia, 607

Dumortiera, 2I, 23, 42, 43, 48, 49, $7 \mathrm{I}, 6 \mathrm{I} 2,6 \mathrm{I} 4$

apical cell, 49

irrigua, 48,49

trichocephala, 49, 6I 2

velutina, 6r 2

Elatereæ, 75, 85, 6I 5

Elaters, I2, 18, 20, 21, 47, 60, 63, 65,73, III I I 22, I38, I4I, I 55, 166, 443, 479, 568, 594

Anacrogynæ, 96, 99

Fimbriaria, 64, 65

Notothylas, 156

Elaterophore, $6 \mathrm{I} 7$

Embryo, 3, 6, 7, II, I3, I8, 20, 73, ז34, т35, 136, เ79, I85, เ86, 203, 214, 230, 23I, 322, 356, $39 \mathrm{I}, 454,519,533,545,56 \mathrm{I}$, 563,566

apical cell, 203

Azolla, 405

Botrychium, 242, 243, 628

Dendroceros, 147

Equisetum, 453, 455
Embryo-Cont.

Funaria, 203, 204, 205

Gleichenia, 369

Hymenophyllaceæ, 377

Isoetes, $545,546,547,548$

Leptosporangiatæ, 306

Lycopodium, 490

Marattia, 28I

Marsilia, 426

Notothylas, I5I

Onoclea, 32 I

Ophioglossum, 245, 626, 627

Osmunda, 356

Pilularia, 426

Polypodiaceæ, 32 I

Porella, rog

Riccia, 33

Selaginella, 5r8, 64I

Sphærocarpus, 7.8

Sphagnum, 178

Embryo-sac, 603, 605

Endodermis, 244, 249, 262, 332, $337,338,360,361,464,495$

Endogenous branches, II 7

Endophytic fungus, 487

Endosperm, 515, 542 secondary, 516

Endospore, 5, 19, 35, 64, 513, 560

Endothecium, 179, 185, 186, 205, $206,214,216$

Eocene, 582

Ephemerum, I63, 188, 214; 216, 228

sex organs, 214

phascoides, Fig. I 5

Epiblema, 412

Epidermis, 223, 334

Epigoniantheæ, I19, 620

Epiphragm, 225

Epiphytes, 372

Epiphytic Acrogynæ, II6

Epiphytic ferns, 233

Epispore, 5, 19, 64, 414

Equisetaceæ, 6, 585

classification, 479 
Equiseta cryptopora, 479 phanopora, 479

Equisetineæ, 232, 443, 585, 588, $599,600,601,603$

affinities, $48 \mathrm{r}$

fossil, $48 \mathrm{I}$

Equisetites, 48r, 585, 586, 587

Equisetum, 5, I44, 231, 267, 268, $272,348,353,443,483,557$,

$585,586,597,600,637,638$ antheridium, 447,448

archegonium, 45 I

branching, $457,467,468,469$

embryo, 453, 455

epidermis, 467

gametophyte, 443

leaf, 460,462

neck-canal cells, 453

rhizome, 457

roots, 470

secondary thickening, 472

spermatozoids, 449,637 .

sporangium, 473

spore, $443,444,476,478$

stem, 460

stem-structure, 459,464

tuber, 459

vascular bundle, 462

arvense, $443,449,453,456,46 \mathrm{r}$, $465,467,468,479$; Fig. 265

debile, 637,638

giganteum, 443, 469, 48I

hiemale, 453, 454, 456, 457, 464, 479,638

limosum, 453, 456, 464, 476, 479, 638 ; Figs. 279, 28I

maximum (see E. telmateia), $472,586,638$

palustre, 470; Fig. 265

pratense, 479

robustum, $479,48 \mathrm{I}$

Schaffneri, $48 \mathrm{r}$

scirpoides, $443,46 \mathrm{I}, 468,48 \mathrm{r}$;

Fig. $28 \mathrm{I}$
Equisetum - Cont. sylvaticum, 469, 48I telmateia, $443,447,449,456$, 459, 464, 465, 472 ; Figs. $257,258,259,260,26 \mathrm{I}, 262$, $263,264,266,267,268,269$, $270,272,273,274,275,276$, $277,278,279,280$

variegatum, 479

Eu-Bryales, 622

Euequisetum, 479

Eufilicineæ, 3 I0

Euophioglossum, 628, 629

Eupallavicinia, 6 I 7

Eurynchium prælongum, I60

Euselaginella, 522

Eusporangiatæ, 234, 301, 304, 305, $307,3 \mathrm{II}, 328,357,440,482$, $560,56 \mathrm{I}, 58 \mathrm{I}, 60 \mathrm{I}, 602,634$

affinities, 300

Eustichia, 2I7

Exine, 5, I9

Exogenous antheridia, I3I

Exogenous roots, 470

Exospore, 5, r9, 35, 36, 64, 443, 5 I 4,560

Fegatella, 58, 61 2 (see also Conocephalus)

Fern, I4, I8, II6, 232, 233, 483, 599 development of leaf, 332, 333 development of root, 335,337 epiphytic, 233

fossil, 306,602

gold-back; 335

heterosporous, 306, 603

homosporous, 597

leaves, 233

ostrich, 3 I 2

stem, 233

tree, 335,390

Fertilization, 2, II, 319, 321, 567, 604

Marattia, 28I

Marsiliacex, 425 
Fertilization - Cont

Onoclea, 320

Osmunda, 356

Selaginella rupestris, 525

Filicales, 233, 636

Filices, 234, 3 I0, 31 I , 346, 636

Filicinea, 229, 232, 233, 482, 536, $579,600,601$

Fimbriaria, 16, 18, 42, 48, 51, 56, 67,71

antheridial receptacle, 49

archegonial receptacle, 58 elaters, 65

Bolanderi, 50

Californica, 24, 47, 49, 53, 54, 56,

$58,59,60,65,66,67,69$, 277,6 II

elaters, 64; Figs. I, II, I4, I5, I6, 2I, 25, 26, 29

Fissidens, 161, 217, 623

Foliar gaps, 329, 464

Foliose Hepaticæ, II 2, Ir 3

Foliose Jungermanniaceæ, I I 7

Foliose Liverworts, 595

Fontinalis, 8, 160, 163, 190, I93, 194, 196, 200, 218, 220

antipyretica, I90; Fig. I 19

Foot, 3, 18, 137, 179, 230, 231, 233, $325,357,359,428,568,569$

Fossil Archegoniates, 576

Equisetineæ, 48I

Ferns, 273, 306, 602

Leptosporangiatæ, 439

Lycopodinex, 535

Muscineæ, 226, 577

Pteridophytes, 578

Fossombronia, 14, 72, 74, 83, 92, 94, $96,97,100,145,158,608$, $609,61_{4}, 635$

longiseta, 90, 92, 96, 97; Figs. 4I, $43,44,46,47$

Fovea, 537

Frullania, II2, 578, 619

dilatata; Fig. 58

Fucaceæ, 573
Funaria, 190, 192, 193, 194, 203, $216,218,220,221,568$

antheridium, 196, $197,199,622$ archegonium, 199, 200, 201, 202 embryo, 203, 204, 205

leaf, 193

spore-formation, 2 ro

sporophyte, 203, 206, 207

hygrometrica, I6I, I66, I90, 218;

Figs. 97, IOO, IOI, I02, $\mathrm{IO}_{3}$, 104, 105, 106, 107, 108, 109, IIO, II , II3, II4

Funicularia, 4r, see also Boschia

Gametangium, 608

Gametophore, 2, 3, 8, I2, I3, 20, 37, $74,116,161,162,163,189$, I9O, 214, 2I6, 22I, 227

branching of, $\mathrm{I}_{3}$

Gametophyte, 2, 3, 4, 5, 6, 8, I2, I4, I2I, I 57, I6I, 225, 226, 229, $300,306,56 \mathrm{r}, 563,566$

adventitious budding, 350

Anthoceros, I 23

Anthocerotes, 13, I 20, 621

apical growth, 276

Archegoniates, 229

Botrychium, 239, 626

Botrychium Virginianum, 238

Bryales, 188

Bryophytes, 533

Equisetum, 443, 637

Gleichenia, 366, 635

Helminthostachys, 24I

Hymenophyllaceæ, 373

Jungermanniales, 72

Lycopodiaceæ, 485

Lycopodium, 486, 638, 639

Marattiaceæ, 274, 275, 630

Marchantiales, 20

Muscinex, 9

Ophioglossum, 234, 624

Osmundaceæ, 346

Phylloglossum, 503

Psilotales, 504, 640 
Gametophyte - Cont.

Pteridophytes, 230, 597

Salviniaceæ, 398

Schizæaceæ, 384

Selaginella, 5I I, 5I3, 640, 64I

Trichomanes, 374

Gamostelic bundles, 495

Gemma-cups, 44

Gemmx, 9, I 2, 13, 23, 46, 69, 74, 86, II8, I62, 219, 374, 499, $500,504,593,607,6$ I 5 .

Aneura multifida, 9, 86, 607, 615

Blasia, 9, 100

Haplozia, 607

Hymenophyllum, 375

Lunularia, 44

Marchantia, 9, 44, 45

Marchantia polymorpha, 45

Metzgeria, 607, 6 5

Psilotum, 504

Tetraphis, IO, 2 I9

Treubia, Ioo

Georgia, 2I8 - see also Tetraphis

Geothallus, 73, 75, 82, 92, 6ro tuberosus, 82, 83; Figs, 34, 35

Germination

Acrogynæ, II4

Anacrogynæ, 99

Anthoceros. I43, I44

Bryales, I 88

Gleichenia, 367

Marchantiaceæ, 66

Marsilia, 7, 4I8

Ophioglossaceæ, 234, 235, 624

Osmunda, 347

Sphærocarpus, 8I

Riccia, 36

Germ-tube, I9, 37, 66, 8I, I44

Gingko,

spermatozoids, 604

Glandular hairs, 72, I 71,335

Gleichenia, 366, 369, 370, 580, 635, 636
Gleichenia - Cont.

antheridium, 368

archegonium, 368

embryo, 369

gametophyte, 366,635

germination of spores, 367

sporangium, 370

spores, 37 I

stem-structure, 369

dichotoma, 366, 37I, 635, 636;

Figs. 210, 2ฐ̄2

flabellata, 37I; Figs. 210, 2 I I

gigantea, 580

lævigata, 635, 636

linearis, see G. dichotoma

pectinata, $368,370,372,635,636$;

Figs. 208, 209, 210

polypodioides, 635,636

Gleicheniacex, 3 Io, 3 I I , 339, 366,

$372,439,440,58 \mathrm{I}, 584,603$

Glochidia, 400, 4I7

Glossopodium, 528, 555

Gnetaceæ, 604, 605

Gold-back fern, 335

Gonidium, 2, I 2

Gottschea, 6Ig (see also Schistochila)

Gradatæ, 3II

Green Algæ, I4, 86, I58, 562, 563, $566,577,607,608$

Grimaldia, 56, 6I, 65

Gum canals, 292

Gymnogramme triangularis, 335, 572

Gymnospermæ, I, 26I, 534, 56I $604,605,606$

Gymnostomium, 218

Hairs, $178,223,286,292,307,335$, $362,38 \mathrm{I}, 4 \mathrm{II}, 565$

Haplomitrieæ, 74, 75, 100 archegonium, I0I

Haplomitrium, I2, 72, 100, 10I, I58, 615

Haplozia cæspitica, 607 
Helminthostachys, 234, 270, 295, $303,304,346,365,366,440$, $602,626,634$

gametophyte, 24I, 626

sex-organs, 242

sporangiophore, 272

sporophyte, $27 \mathrm{I}$

Zeylanica, 270; Figs. I26, I4I

Hemiphlebium, 380, 38I (see also Trichomanes)

Hemitelia capensis, 580

Hepaticæ, 8, 9, 10, II, I3, I4, 33,

44,72, I 20 , I 2 I, I 22 , I I I,

I32, I $38, I_{42}$, I 59, I6o, I64,

I66, I78, I87, 20I, 202,226 ,

$227,229,24 \mathrm{I}, 300,302,303$,

$305,316,565,577,592,593$,

594,595

antheridium, I2, I6

apical cell, 15

archegonium, I2, I6

chromatophores of antheridium, 17

classification, 20

germination of spores, I9

interrelationships, 157

mucilage cells, 15

sex-organs, 15

spermatozoid, I7

spores, I9

spore-formation, 19

sporophyte, I8

Hepaticæ foliosæ, II 2

Heterangium, 584, 585

Heterophyllum, 522

Heterosporous ferns, 306, 396, 603

Heterosporous Lycopodineæ, 510

Heterosporous Pteridophytes,

gametophyte, $6 \circ 3$

Heterospory, 6, 7, 396, 585, 586,

$$
590,604
$$

Hippochæte, 479

Homcoophyllum, 522

Homologous alternation of generations, $569,570,57 \mathrm{I}$
Homosporeæ, 485

Homosporous ferns, 597

Homosporous Leptosporangiatæ, 346

Hydropterides, 234, 307, 310, 3II, $396,441,584$

Hygroscopic movements, 213, 344, 443

Hymenophyllaceæ, 306, 307, 310, 3 II, 369, 372, 373, 440, 44I, $570,58 \mathrm{I}, 584,603,636$

archegonium, 377

embryo, 377

gametophyte, 373

leaf, 380

root, $38 \mathrm{I}$

sexual-organs, 376

sporangium, $38 \mathrm{I}, 382$

stem-structure, 378,379

vascular bundles, 380

Hymenophyllites, 439, 584

Hymenophyllum, 308, 362, 373, 374, $376,383,597$; Figs. 21 5 , 2I6, 217

gemmæ, 375

demissum, $38 \mathrm{I}$

dilatatum, 380

recurvum, 379; Figs. 219, 220

scabrum, 379,380

Hymenophyton, 87, 573, 636

flabellatum, Fig. 38

Hymenostomum, 218

Hypnum, 161, 578

Hypoderma, 223, 330, 334

Incubous leaves, II 6

Indusium, 298, 392, 395, 439

Intercalary branches, 117

Intine, 5, I9, 443

Involucre, 77, 98

Iron Pyrites, 576

Isoetaceæ, 536

Isoetales, 233,536

Isoetes, 304, 40I, 534, 536, 590, $604,605,642$ 
Isoetes - Cont.

affinities, 560

archegonium, 543

embryo, 546

gametophyte, 538

Bolanderi, 537, Fig. 309

echinospora, var. Braunii, 538, $539,544,545,557,558,559$;

Figs. 3IO, 3II, 3I 2, 3I3, 3I4,

$315,316,317,318,320,322$

Engelmanni, $55^{8}$

hystrix, $538,553,554$

lacustris, $538,54 \mathrm{I}, 544,553,556$, 557, 560, 642; Figs. 320, $32 \mathrm{I}$

malinverniana, 538,545 ; Fig. 3 Io setacea, 538

Jubuloideæ, II9, 619, 620

Jungermannia, I I $2,116,578$

bicuspidata, I09, II 2, II4

Jungermanniacex, I2, I4, 47, 65, I 26, I $28, I_{43}, I_{4} 8$, I 55, I 57 , I82, I97, 227

apical cell, I5, IO4

foliose, II 7

thallose, 74,89 , 99, II 4

Jungermanniales, $19,20,21,70,72$, $78,8 \mathrm{r}, \mathrm{I} 20, \mathrm{r} 58, \mathrm{I} 59,593$, $608,609,6 \mathrm{I}_{3}, 6 \mathrm{I}_{4}$

Jurassic, $439,583,584,586$

Kaulfussia, 273, 274, 290, 295, 297, 299, 582, 629, 630, 631, 632, 633,634

pores, 299

synangium, 300

æsculifolia, 300 ; Fig. 166

Kaulfussieæ, 298, 300, 583

Laccopteris, 372

Lacunæ (air-spaces), 47, 216, 464, $526,55 \mathrm{I}$

Laminariaceæ, 573
Leaf, $3,4,6$, I4, I70, 23I, 454, 455, $456,497,498,525,555,598$ Acrogynæ, II 6

Amblystegium, I92

Andreæa, I82

Angiopteris, 290

Azolla, 409, 4 IO

Botrychium, 264

development (Ferns), 333

dichotomy, 580

dimorphic, 580, $58 \mathrm{I}$

Equisetum, 460, 462

Fern, 233

Funaria, I93

Hymenophyllaceæ, 380

Lepidodendron, 589

Leptosporangiatæ, 332

Liverworts, 73

Lycopodium, 493, 495

Marattia, 287, 288, 29I

Marsilia, 429, 432

Mosses, I62, 218

Ophioglossum, 250, 251, 257

origin of, 598

Osmundaceæ, 36r, 362

Pleuridium, 2 I6

Porella, IO2

Salvinia, 4I I

Schizæaceæ, 387

Selaginella, 523, 527

Sphagnum, 172

succubous, II 6

traps (in Acrogynæ), I I 7

vascular bundles, 247, 252, 327 venation, 258, 27I, 286, 299, $300,333,579$

Leaf traces, $162,222,223,290,36 \mathrm{I}$, 495

Leafy sporophyte, $23 \mathrm{I}$

origin of, 572

Lejeunia, II4, 6I9; sp. Fig. 62 metzgeriopsis, I16, II8; Fig. 60 serpyllifolia, Fig. 59

Lejeuneaceæ, 6I9, 620

Lenticels, 292 
Lepidodendraceæ, 588,606

Lepidodendron, 510, 560, 589, 590, 604

leaves, 589

parvulum, 589

Lepidostrobus, 590 , $59 \mathrm{r}$

Brownii, 590

Oldhamius, 590

Leptome, 213

Leptopteris, 346,362

Leptosporangiatæ, 234, 267, 292, $302,304,305,57 \mathrm{r}, 58 \mathrm{I}, 583$, $601,602,634$

affinities, 440

classification, 3 10

embryo, 306

fossil, 439

Homosporous, 346

leaf, 336

non-sexual reproduction, 307

sporangium, 339

Leptotheceæ, 75, 6. 5

Leucobryum, 218; Fig. I $2 \mathrm{I}$

Ligula, 5I9, 528, 538, 547, 555

Limosphere, 609

Liverworts (see also Hepaticæ), 2, 3, 6,

8, I 4, I 7, I 8, I 2 2, II 9, I 29, I 56,

I 57, I 59, I 60, I $76,202,565$

acrogynous, $\mathrm{I} 7 \mathrm{O}$

foliose, 595

thallose, 226

Loculus, 295

Lomaria, 579

Lophocolea, II3, II4

Lophoziaceæ, 620

Loxsoma, 373

. Cunninghamii, 373

Loxsomacex, 3 II

Lunularia, 23, 44, 65

gemmæ, 44

Lycopodiaceæ, 485, 510, 523

gametophyte, 486

Lycopodiales, $485,640,642$

Lycopodinex, 232, 482, 483, 536, $560,588,599,60$ I
Lycopodinex - Cont.

affinities, 533

fossil, 535

heterosporous, 5 I I

Lycopodites, 535, 588

elongatus, 588

Stockii, 588

Lycopodium, 483, 485, 5II, 535, 572,600

antheridium, 489

archegonium, 490

branching, 494

embryo, 490

gametophyte, $483,638,639$

leaves, 493,495

stem structure, 495

aloifolium, 497

alpinum, 497, 499

annotinum; 486, 490, 492, 533, 639; Fig. 284

cernuum, 446, 483, 486, 487, 488, 489, 490, 492, 493, 494, 533, $589,597,637$; Fig. 283

clavatum, 488, 492, 493, 499,

502, 639; Figs. 282, 284, 290 complanatum, 490, 493, 497;

Fig. 284

dendroideum, 589; Fig. 282

inundatum, 483, 486, 487, 488, $489,492,494,498,499$, 500, 502,589

lucidulum, 494, 499 ; Figs. 288, 289

pachystachyon, Fig. 286

phlegmaria, 453, 489, 490, 492, $494,533,640$; Figs. 283,285 pithyoides, 639

reflexum, 497

saururus, 589

selago, 489, 494, 497, 498, 499, $500,502,639$, Figs. 287 , 289,290

verticillatum, 497

volubile, 493, 497; Figs. 286, 288

Lyginodendron, 584, 585 
Lygodium, 384, 386, 388, 389, 390, 636

articulatum, 384

Japonicum, Fig. 224

Macroglossum, 629, 630, 63I, 632, 633

Alidæ, 633

Smithii, 633

Macrosporangium, 7, 4I4, 438, 524, $532,556,559$

Macrospore, 400, 422, 513, 538, 539, 559

germination, 4 or, $423,513,54 \mathrm{I}$ Madotheca, see. Porella

Makinoa, 92, 6ェ6

Malic acid, 3 I9

Marattia, 237, 273, 274, 277, 284, $289,290,291,292,293,297$, 299, 302, 303, 306, 3파, 318, $325,353,358,448,450,560$, $582,630,63$ I

apical growth of root, 288

archegonium, 280

cotyledon, 283,286

embryo, 28I, 282

fertilization, $28 \mathrm{I}$

leaf, 288

sex-organs, 278

spermatozoids, 279

a atata, Fig: I6r

Douglasii, 276; 278, 279, 453 ;

Figs. I50, I 51 I I 52, I 53, I 54 ,

I 55, I 56, I 58, I 59, I 60,167

fraxinea, Fig. 165

Marattiaceæ, 6, 23I, 238, 273, 303, $304,307,311,348,350,352$, $362,37 \mathrm{I}, 440,581,582,583$,

$601,602,603,630$

classification, 298

gametophyte, 274, 275, 285

sporangium, 292, 294

spores, 297

sporophyte, 289

vascular system, $63 \mathrm{I}, 6_{32}$
Marattiales, 233, 234, 273

Marattieæ, 298

Marchantia, 9, I2, I5, I6, 23, 42, $44,53,55,59,6 \mathrm{I}, 65,67,7 \mathrm{O}$; $7 \mathrm{I}, 74, \mathrm{I00}, \mathrm{II} 8,578,608$, $6 \mathrm{II}, 6 \mathrm{I} 4$

antheridial receptacle, 53

gemmæ, 44, 45

spermatozoids, 52

geminata, 53

polymorpha, $24,47,50,58,65$, 608 ; Figs. I2, 13, I7

gemmæ, 45

spermatozoid, $5 \mathrm{I}$

Marchantiaceæ, 2, 9, 14, 16, I8, 28, 40, 4I, 59, 60, 6I, 64, 7I, 72, $73,78,80,94,96,99,123$, I $25, \mathrm{I28}, \mathrm{I} 57, \mathrm{I} 58, \mathrm{I74}, 23 \mathrm{O}$, $609,6 \mathrm{I}_{2}, 6 \mathrm{I}_{3}, 6 \mathrm{I} 4$

air-chambers, 42, 48, 6II antheridium, 5 I apical cell, 67

apical growth, 47 archegonial receptacle, $48,5^{8}$ archegonium, 46

biology, 67 branching of thallus, 46 dehiscence of antheridium, 53 germination of spores, 66,67 mucilage cells, 43,69

oil-bodies, 44

pores, 42

receptacles, $47,6 I_{2}, 6 I_{3}$

regeneration, 69

rhizoids, 42

sexual organs, 49

spores, 47

sporophyte, $47,59,65$

transpiration in, 69

water conservation, 69

xerophytic, 67

Marchantiales, $8,20,21,24,74,78$, I $20,158,159,593$

air-chambers, 23

dichotomy, 22 
Marchantiales - Cont. gametophyte, 20 rhizoids, 23

Marchantieæ, 69

Marchantites, Sezannensis, 577

Marsilia, 5, 4I7, 4I8, 4I9, 423, 435, 439, 442, 637

antheridium, 420

embryo, 426

germination of spores, $4 \mathrm{I} 8$

leaf, 429,432

macrospore, 422

microspores, $4 \mathrm{I} 8$

stem-structure, 432

tubers, 433

vascular bundle of stem, 433

Egyptiaca, 4I8

Drummondii, 424, 429, 432, 433

hirsuta, 433

polycarpa, 432

quadrifolia, 433 ; Fig. 255

salvatrix, 433

vestita, 4I8, 42I, 422, 424, 429,

432, 434 ; Figs. 243, 244, 245,

$247,248,250,253$

Marsiliaceæ, 7, 234, 3 I0, 3 II , 396, $4 \mathrm{r} 7,44 \mathrm{r}, 603$

embryo, 426

female prothallium, 422, 423,424

fertilization, 425

germination of spores, $7,4^{18}$

roots, 433

sporocarp, 434

Massula, 398, 4I 5

Mastigobryum, II 7

trilobatum, Fig. 6I

Matonia, 371, 580, 584, 636

affinities, 372

stem-structure, 372

pectinata, 371, 372; Fig. 213

sarmentosa, $37 \mathrm{I}$

Matoniaceæ, 3IO, 3II, 37I, 584

Mechanical tissues, 565,566

Medullary rays, 26r, 263, $59 \circ$

Medullary steles, 328
Medullosa, 585

Megaceros, 620, 62I

Megasporangium, see Macrosporangium .

Megaspore, see Macrospore

Mesophyll, 266, 334, 528

Mesospore, 513, 560

Mesozoic, 582, 583, 584, 587

Mesozoic fossils, 580

Metaxylem, 244

Metzgeria, I4, 72, 85, 88, 95, 99, II4, II6, I2I, 3I4, 349, 593, 607,6 I 5,618

furcata, 87,94

pubescens, 85 ; Fig. 37

-Metzgeriaceæ, 74, 6 5

Metzgerieæ, 75

Microsporangium, 4I4, 4I 5 , 4I 7 , $438,524,532,558,559$

Microspores, $\mathrm{I} 79,538$

Marsilia, 4I8

Middle lobe, 58

"Mittelhaut," 443

Mittenia, 6r5, 6r7

Mixtæ, 3 I2

Mnium, r6r, 373

archegonium, 202

affine, 622

cuspidatum, I64, 202

Mohria, 384, 385, 386

Monoclea, 2I, 23, 42, 48, 70, 7I, $609,6 \mathrm{I}_{3}, 6 \mathrm{I}_{4}$

Forsteri, 70

Gottschei, 70

Monocotyledons, I42, 548, 56I, 590, 605

Monoselenium, 614

Monostelic stem, 526, 58I

Mörkia, 6I7

Mosses, 2, 3, 8, 9, IO, II, I2, I4, 20, 3I, 60, 74, 103, I09, II6, II9, I20, I3I, I57, I60, I6I, I78, I82, I88, I90, I93, 229, 230, $23 \mathrm{I}, 305,372,565,566,568$, $570,577,578,594,595$ 
Mosses - Cont.

aquatic, I6o

cleistocarpous, I66, I88

leaves, $\mathrm{I} 62,2 \mathrm{I} 8$

non-sexual reproduction, $\mathrm{I}_{6} 2$

saprophytic, I60

sporophyte, 165

stem, I62

stegocarpous, I66, I88

Mucilage cells, 362

Hepaticæ, 15

Marchantiaceæ, 43, 69

Mucilage clefts, I2I, I25, I26, I28, I $44,145,146$

Mucilage ducts, $43,292,500$

Multicellular spores, I9, 99, I48

Multipolar nuclear spindle, 476

Musci, 8, I3, I60

affinities, 226

Muscineæ, 8, 9, I59, I60, 229, 23I, $562,592,601$

antheridium, Io

apical cell, 9

archegonium, Io

asexual reproduction, 9

classification, I 2

fossil, 226, 577

gametophyte, 9

rhizoids, 9

sex-organs, II I I64

sporophore, I 2

sporophyte, I2, 594

Muscites, 578

Mycorhiza, 238, 239, 270, 624, 625, 635

Nanomitrium, 216

Nebenkörper, 52, 609

Neck-canal cells

Equisetum, 453

Isoetes, 545

Neuropteris, 585

Nœggerathia, 585

Nostoc, I00, I21, I23, I25, I28, 145, 146,564
Notothylas, I20, 122, 146, 147, 148, I 58, I 59, I79, I87, 228, 302, 318,621

antheridium, 149,150

archegonium, $5_{5 \circ}^{\circ}$

embryo, I5I, I 52

spore-development, I 55

spores and elaters, ${ }_{5} 6$

sporophyte, I 53

thallus, 149

Breutelii, 62I

Javanicus, 621

melanospora, I 56

orbicularis, I48; Figs. $64,80,8 \mathrm{I}$, $82,83,84,85$

valvata (orbicularis), I $22, \mathrm{I} 28, \mathrm{I} 48$

Octant wall, 322

Edogonium, 562, 60I

Oil-bodies, 40, 394

Marchantiaceæ, 44

Oligocarpia, 584

Oligocene age, 578

Onoclea, 281, 319, 339, 343, 348, $352,357,358,359,395,634$ antheridium, 315

cotyledon, 323

embryo, $32 \mathrm{I}$

fertilization, 320

primary root, 325

prothallium, 3I2, 3 I4

sex-organs, 3 I4

spermatozoid, 3 I 6

sensibilis, 312, 579; Figs. 177, I 78

struthiopteris, 3I2, 327, 328, 33I, 333, 334, 342, 579; Figs. I73, I74, I75, I76, I79, I8r, 230

air-chambers in, 329

stem, 329

Oögonium, I

Oöspore, $5^{6} 3$

Opercular cell, 237, 278, 352

Operculatæ, 69, 6I4 
Operculum, 13, I65, 180, 207, 209, $210,21 \mathrm{I}, 2 \mathrm{I} 3,2 \mathrm{I} 6,217,218$, 220

Ophioderma, see Ophioglossum pendulum, 245,628

Ophioglossaceæ, 229, 280, 284, 300, $303,308,440,580,581,582$, $601,602,633$

gametophyte, 234, 624, 625

germination of spores, 234,235 , 624

Ophioglossales, 233, 234

Ophioglossites antiqua, 582

Ophioglossum, 4, 232, 233, 235, 240, 24I, 259, 26I, 262, 266, 270, $272,278,284,286,290,295$, $300,301,302,339,482,554$, $557,560,574,582,598,599$, $600,601,602,623,624,625$, $628,629,634,639$

antheridium, 236, 625 archegonium, 237, 238, 626 embryo, 626, 627

leaf, $250,25 \mathrm{I}$ root, 252, 253, 254

sex-organs, 236 sporangium, $247,254,255,256$ sporophyte, 245 stem-apex, 247, 248 stem-structure, 249 vascular bundle, $245,247,250$, 628,629

Bergianum, 258, 629

intermedium, 628

Lusitanicum, 247

Moluccanum, 623, 624, 625, 626, $627,628,629,630,631$, 633

embryo, 626

gametophyte, 624

palmatum, 258, 303, 628

pedunculosum, 234, 238, 245, $623,627,628,629$; Fig. 125 embryo, 245 prothallium, 236
Ophioglossum - Cont.

pendulum, 234, 235, 238, 25\%, $254,257,258,27 \mathrm{I}, 303,600$;

Figs. I 24, I25, I31, 133, I34, $\mathrm{I}_{35}, \mathrm{I}_{3} 6, \mathrm{I}_{37}, \mathrm{I}_{3} 8, \mathrm{I} 39, \mathrm{I} 40$

prothallium, 235, 624

simplex, 258 , 30r, 580,600 œocenum, 582

vulgatum, 249, 250, 254, 257, 27I, 624

leaf, 257

Fig. 132

Oscillariæ, 128

Osmunda, 5, 259, 304, 343, 346, 348, $362,367,376,448,583,597$, 636

antheridium, 351,352

archegonium, 353, 354

chromatophores, 597

embryo, 356

fertilization, 356

germination of spores, 347

primary root, 359

spermatozoids, 353

cinnamomea, 348, 349, 35I, 362, 363,364 ; Figs. I77, 192, I93, I95, I97, I98, I99, 200, 205,207

Claytoniana, 272, 348, 349, 363, 364; Figs. I91, 193, I94, 195, 196, 198, 200, 201, 202, $203,205,207$

regalis, $346,348,349,350,363$;

Figs. 203, 204, 206

Osmundaceæ, 304, 306, 310, 3II, $346,439,440,570,580,584$, $602,603,635$

gametophyte, 346

leaf, 361,362

root, 362

sporangium, 365

stem, 359

stem-structure, $360,36 \mathrm{r}$

Ostrich fern, 3 I2 (see Onoclea)

Ovule, $7,560,603$ 
Palæopteris, see Archæopteris, 579

Palæozoic seed-plants, 604

Palæozoic formations, 578

Paleæ, 292, 335

Palisade parenchyma, 29, 528

Pallavicinia, 14, 87, 89, I25, 608, 618,619

cylindrica, 89, 90; Figs. 4r, 42

decipiens, 98,618

Levieri, $6 \mathrm{I} 7,6 \mathrm{I} 8$

Lyellii, 98

radiculosa, $6 \mathrm{I} 5,6 \mathrm{I} 6,6 \mathrm{I} 7,6 \mathrm{I} 8$

Zollingeri, 6I 5, 6I6, 6I 7

Paraphyses, II, I99, 345, 392, 489

Parasitism, 533

Parkeriaceæ, 3 10, 392

Parthenogenesis, 574

Peat-bogs, I6o

Peat-mosses, 166

Pellia, 9, I9, 73, 99, то8, I09, I48, I55, I 58, I83, 595, 609, 6I3, 614,618

antheridium, 92

centrosomes, 99

spermatozoids, I7, 92

calycina, 88, 90, 99; Figs. 40, 48 .

epiphylla, I7, 90, 98, 99, I46, 318,

349 ; Fig. 42

archegonium, 94 seta, 98

Perianth, 65, I09, II3, 6I6

Periblem, 253

Perichætium, I I, I 2

Pericycle, 332, 337, 360

Pericyclic sector, 223

Perinium, 5, 19, 64, 343

Perispore, 560

Peristome, 165, 210, 2I I, 213, 216, 218,220

Bryales, 220

hygroscopic movements, I66

Polytrichaceæ, 225

Permian, 582

Petalophyllum, 6r9
Petrifactions, $576,577,579$

Phanerogams, 29I

Phascaceæ, I6r, 166, 188

Phascum, 216

archesporium, 216

cuspidatum,

embryogeny, 2I6; Fig. II5

Phloëm, 26r, 265, 268, 29I, 326, $332,360,369,379,387,464$, $497,507,526,554$

Phorodendron, 504

Photosynthesis, 572, 573

Phylloglossex, 504

Phylloglossum, 485, 486, 492, 502, $503,533,598,599,639,640$, 642

gametophyte, 503

Drummondii, 502 ; Fig. 200

Phyllotheca, 587

Physiotium, I04

Pilularia, 233, 4I7, 4I8, 4I9, 442

antheridium, $42 \mathrm{I}$

embryo, 426

female prothallium, 424

sporangium, 438

sporocarp, 435, 436, 437, 439

Americana, 432, 434, 436, 438, 634 ; Figs. 252, 254

globulifera, 423, 424, 432, 435, 436, 439; Figs. 246, 249, 25I, 256

Pinus, 59I

Placenta, 340

Plagiochasma, 56, 6I 2

Plagiochila, 6I9

Platycerium, 394, 395

alcicorne; Fig. 232

Wallichii, 339

Plerome, 253

Pleuridium, 216

leaves, 216

subulatum, Fig. II 5

Pleurocarpæ, 218, 623

Pleurococcus, 564

Pleurozioideæ, II9 
Podomitrium, 6I6, 6I 7, 6I8

Malaccense, 6I6, 6I7, 6I8

Pollen-spores, 4, 58r, 603

Pollen-tube, 604

Polyembryony, 492

Polypodiaceæ, 305, 306, 310, 3II, 3I 2, 3I4, 33I, 339, 349, 357, $362,367,392,439,440,570$, 584,603

embryo, 321

sporangia, 395

stem, 328

stem-apex and structure, 329

structure of primary stele, 327

vascular bundles of stem, 330

Polypodium, 339, 34I, 394, 440 development of sporangium, 340

falcatum, 336, 344; Figs. I82, I89, I90, I9I, 231

lingua, 335

Polystelic stem, 526

Polystichum angulare var. pulcherrimum, 309

Polytrichaceæ, I62, I63, I65, 2I8, $220,22 \mathrm{I}$

male inflorescence, 224

Peristome, 225

shoot, 222

stem, 222

Polytrichales, 622, 623

Polytrichum, I62, I64, I99, 203, $222,229,565,578,595$

calyptra, 225

leaves, $22 \mathrm{I}$

sporogonium, 224

stem, 22 I

commune, 218, 22I ; Figs. Ir9, I 2 I

formosum, 218

juniperinum, 223, 622

Populus, 574

Porella, II3, II 5, I76, 6I9

amphigastria, 102

antheridium, I05, I06

apical growth, I02, I03
Porella - Cont.

archegonia, 107, 108

branching, IOI

embryo, ro9

perianth, Iog

sex-organs, I04

spermatozoids, To7, 619

spores, III

sporophyte, IIo

Bolanderi, IOI ; Figs. 49, 50, 52,

$53,54,55,56,57$

platyphylla, Iог

Porellacex, 620

Pores, 40,48

Fimbriaria Californica; Fig. II

Kaulfussia, 299

Marchantiaceæ, 42, 59

Preissia, 14, 44, 58, 59, 6r, 70

sclerenchyma, 44

commutata, 44, 54

Primary root, 326, 492

Azolla, 406

Botrychium, 243

Marattia, 284

Onoclea, 325

Osmunda, 359

Primary tubercle, 236, 486

Prismatic layer, 554

Prosenchyma, I73

Prothallium, see also Gametophyte, 4, 5, 6

Alsophila, 39I

ameristic, 3 I4

apical growth, 3I4, 3 I8

branching, 277, 374

dichotomy, $45^{2}$

diœcism, 453

secondary, 534

Protocalamariaceæ, 586, 588

Protocephalozia, 74

ephemeroides, i 16

Protocorm, 49I, 492, 503, 599

Protonema, 2, 3, 8, 12, I3, 20, 37,

74, II4, II5, II6, I6I, I62, I63, I68, I82, I83, I88, I89, 
214, 216, 219, 226, 227, 570, Ptychocarpus, 582 594,623

Protophyll, 600

Protostele, 327, 464

Protoxylem, 244, 337

Psaronius, 58I

Pseudoperianth, 65

Pseudopodium, I80, I82

Pseudo-veins, 38I

Psilophyton, 59r

Psilotaceæ, 485, 504, 510, 533, 535, $59 \mathrm{r}, 60 \mathrm{I}, 638$

affinities, 510

sporangium, 508, 509

spores, 5 IO

vascular bundles, 507

Psilotales, 639, 640

Psilotites, 535, 59r

Psilotum, 23I, 485, 504, 507, 510, 587

gemmæ, 504

rhizome, 505

structure, 506

flaccidum, 640

triquetrum, 504, 640; Figs. 29I, 292, 293

Pteridophytes, I, 3, I4, I20, I2I, I 57, x 59, 229, 572, 594

archegonium, 232, 596

fossil, 576

gametophyte, 230, 597, 603

homosporous, 7

relation to Bryophytes, 574

sporangium, 598

spore-formation, 232

sporophyte, 595

strobiloid, 598

Pteridospermeæ, 585

Pteris, 395 medullary steles, 328

aquilina, 305, 309, 394; Fig. $23 \mathrm{I}$ Cretica, 308, 309, 336, 570; Figs.

$$
\text { I7I, } 187
$$

Ptilidiaceæ, 620

Ptilidioideæ, IIg
Pulvinus, 292

Pyrenoid, I3, I 2 I

Pythium, 239, 487

Quadrant wall, 322

Quadripolar spindle, 98

Radula, III, II2, II4, I83; Fig. 59

Radulaceæ, 620

Reboulia, 42, 56, 58

hemisphærica, Fig. 20

Reduction of chromosomes, 343, 477,567

Regeneration, 570

Marchantiaceæ, 69

Renaultia, 583

Resting spore, $563,5^{67}$

Rhacopteris, 582

Rhizocarpex, 234, 396, (see also Hydropterides)

Rhizogenic buds, 470

Rhizoids, I4, 19, 20, 27, 37, 39, $66,67,69,72,86$, 102, I21, I23, $444,160,161,162,168$, I70, I82, 183, I88, I90, I94, $221,230,276,314,347,374$, $564,565,566,569,575$

Bryales, 188

Danæa, 277

Marchantiaceæ, 42, 70

Marchantiales, 23

Muscineæ, 9

Riccia, 28

Rhizome

Psilotum, $5 \circ 5$

Struthiopteris, 329

Rhizophore, $5^{22}$

Rhodea, 579

Rhodophyceæ, 562

Rhyncostegium murale, I6o

Riccia, I2, I4, I5, I8, 2I, 24, 42, 46, $47,49,50,53,54,55,59,60$, $66,67,7 \mathrm{I}, 76,77,78,8 \mathrm{I}, 90$, I $57,158,563,566,567,592$, 596 
Riccia - Cont.

antheridium, 3I, 33

apical cell, 38

archegonium, 29, 3 I

calyptra, 36

dichotomy, 27

embryo, 33

rhizoids, 28

sex-organs, 28

spermatozoids, 33,6 10

spore-division, 35, 610, 6II

sporophyte, 33,34

thallus, 24, 25, 28

ventral lamellæ of thallus, 26

Bischoffii, 30

crystallina, 27

fluitans, 24, 27, 39, 610

Frostii, 6ro

glauca, 23, 29, 36, 610; Figs. I, $2,3,4,5,6$

trichocarpa, 24, 29, 30, 36, 67, 610; Figs. 4, 5, 6, 7, 8, 9

hairs, 39

Ricciaceæ, I7, I8, 24, 4I, 46, 47, $59,7 \mathrm{I}, 75$

adventive buds, 27

classification, 39

germination, 36

Ricciocarpus, 8, 40, 41, 42, 564, 610, 6 II

air-chambers, 39, 40, 610

monœcious reproduction, 40

sexual organs, 40

terrestrial form, 40

ventral lamellæ, 40

natans, 39, 6ro; Fig. Io

Riella, 8, 73, 75, 83

structure, 84

Americana, 84 ; Fig. 36

helicophylla, 84 ; Fig. 36

Root, 3, 4, 6, 9, 157, 230, 243, 257, $27 \mathrm{I}, 284,287,288,290,323$, $335,357,428,454,455,469$, 472, 498, 519, 530, 552, 556, $566,568,575$
Root - Cont.

adventive, 498

apical cell, 359

apical growth, 363

Azolla, 4II

Botrychium, 259, 266

branching, 499

budding from, 258,339

development, 336, 337

dichotomy, 258, 556

Equisetum, 469

exogenous, 470

Hymenophyllacea, 38 I

Marattiaceæ, 288, 630

Marsiliaceæ, 433

Muscinex, 9

Ophioglossum, 252, 253, 254, $626,627,629$

origin, 569

Osmundaceæ, $362,363,364$

primary, 456, 492

primary (Azolla), 406

primary (Onoclea), 325

primary (Osmunda), 359

secondary, 339, 472, 498

Selaginella, 529

sieve-tubes, 338

Stigmaria, 589

vascular bundle, 254, 287, 337,

$47 \mathrm{I}, 499,530,629,63 \mathrm{I}$

Root-buds, 574

Root-hairs, 286, 412, 498

Salvinia, 339, 396, 398, 400, 401, 402, 403, 406, 409, 417, 439, 636,637

antheridium, 398

leaves, 4 II

prothallium, 403

sporocarp, 4I 2, 4I 5

natans; Figs. 233, 238

Salviniaceæ, 234, 307, 3II, 396, $44 \mathrm{I}, 603$

gametophyte, 398

stem-structure, 409 
Saprophytic mosses, I6o, 226

Sarracenia, II 7

Sauteria, 43

Scalariform tracheids, 330

Scales, 69, 223, 307, 335, 565 carpocephalum, $5^{8}$

Scapaniacex, 620

Scapanioideæ, II9

Schistochila, I I 9 appendiculata; Fig. 63

Schistostega, 218

Schizæa, 306, 386, 387, 389, 420, 440, 580,597

dichotoma, $385,388,636$

pennula ; Fig. 226

pusilla, 384, 385, 388, 636; Fig. 222

Schizæaceæ, 310, 3II, 369, 384, $420,438,440,442,58 \mathrm{I}, 583$, $584,603,634$

gametophyte, 384

leaf, 387

sporangium, 388

stem-structure, 386

stomata, 387

Schizogenic ducts, 292

Schizomeris, 607

Schizoneura, 587

Schizophyceæ, 564

Sclerenchyma, 222, 291, 307, 330, $334,387,465,496$

Scolecopteris, 582,583

Scolopendrium, 394

Secondary endosperm, $5^{16}$

Seed, $7,585, .59$ I

Selaginella, $7,483,5 \mathrm{II}, 5 \mathrm{Ig}, 56 \mathrm{I}$, $572,588,603,640,64 \mathrm{I}$, 642

antheridium, $5 \mathrm{I} 2,5 \mathrm{I} 3,640,64 \mathrm{I}$ archegonium, 516

chloroplasts, 528, 534

embryo, 518, 64I

female gametophyte, 5I4, 640, $64 \mathrm{r}$

leaves, 523,527
Selaginella-Cont.

male gametophyte, 512

roots, 529

spermatozoids, 512

stem-structure, 526

apus, 512, 514, 518, 520, 521, 522, $524,532,640$

atroviridis, $64 \mathrm{I}$

Bigelovii, 522

caulescens, 64I

cuspidata, $517,518,528$; Fig. 295

deflexa, 523

denticulata, 64I

Galeottii, 64I

Gracilis, 64I

helvetica, 640, 641, 642 ; Fig. 296 Kraussiana, 5I3, 5I4, 520, 64I ;

Figs. 295, 296, 297, 298, 300, 301, 302, 303, 304, 305. 306, 307,308

lævigata, 526

lepidophylla, 5II, 527

Lyallii, 528

Martensii, 520, 526, 528, 530, 53I, 532, 64I ; Fig. 299

rubricaulis, $64 \mathbf{I}$

rupestris, 483 , $5 \mathrm{II}, 5 \mathrm{I} 8,52 \mathrm{I}, 522$, $524,528,532,640,641,642$ selaginoides, 522, 523 spinosa, 530, 532, 64I

spinulosa, 521, 64I stolonifera; Fig. 295

suberosa, 528

sulcata, 642

Vogelii, 528,642

Selaginellaceæ, $485,51 \mathrm{I}, 533,60 \mathrm{I}$, 606

Senftenbergia, 583

Seta, I2, I8, 74, I65, 207, 213, 2I6, 568

Sieve-tubes, $252,263,265,27 \mathrm{I}, 326$, $33 \mathrm{I}, 360,464,472,497$

Sigillaria, 589,590

Sigillariaceæ, 588 
Silica, 467,576

Silurian, 578, 588, 59I

Simplices, 3 II

Siphoneæ, 577

Siphonostele, 327, 464, 465

Sorophore, 389

Sorus, 339, 395

Spencerites, 590

Spermatid, I7, 5I, 52

Spermatocyte, 608

Spermatophytes, 4, 7, 262, 482, $534,56 \mathrm{r}, 574,579,603,604$, 606

Spermatozoids, 2, ro, II $32,5 \mathrm{r}, 8 \mathrm{I}$, I3I, I97, I99, 232, 278, 316, $398,420,42 \mathrm{I}, 450,482,539$, $560,598,601$

Botrychium, 240

Cycads, 604

Equisetum, 449, 637

Gingko, 604

Hepaticæ, I7, 608, 609

Jungermanniales, 73

Lycopodium, 489

Makinoa, 92

Marattia, 279

Marchantia, 52

Marchantia polymorpha, 5I

Marsilia, 42I

Onoclea, 317

Ophioglossum, 625, 626

Osmunda, 353

Pellia, I7, 92

Porella, 107, 6r9

Psilotaceæ, 640

Salvinia, 398

Selaginella, $5^{13}$

Sphærocarpales, 609, 6r3, 6I4, 62I

Sphærocarpus, I2, I5, I6, 17, I8, $73,75,83,90,92,94$, I5I, I 57, I 58, I $59,596,6 \mathrm{I}_{4}, 6$ I 5 , 6I9; Figs. 30, 3I, 32, 33

Californicus, 75, 6r5; Fig. 30 cristatus, 75,82

hians, 6I 5
Sphærocarpus - Cont.

terrestris, 75, 80, 8I, 82, 6I 5

Texanus, 615

Sphagnaceæ, I56, I6r, I65, I84, 228,594

Sphagnales, I60, I66, I8I

Sphagnum, I60, I6r, I62, I64, I65, I79, I80, I82, I83, I84, I85, I88, I90, I9I, I94, I99, 200, $203,209,218,219,226,227$,

$594,595,607,622$

antheridia, 175,176

apical growth, I 70

archegonium, 177, I78, I8I, 607,622

branching, I67, I73, I74

embryo, 178

germination, $\mathrm{I} 68$

leaf, I67, I68, I69, I 72

sex-organs, I 74

spermatozoids, $I 76$

stem-structure, I 72, I73

acutifolium, I78; Figs. I9, 92, 93 cymbifolium, 173,622 ; Figs. 89, 9o, 9 I

squarrosum; Fig. 88

Sphenophyllacex, 48I, 588, 60I

Sphenophyllales, $587,639,640$

Sphenophyllum, 51 2, 587

Splachnum, 220, 229, 600

Sporangiogenic band, 254

Sporangiophore, 250, 25I, 258, 26r, 27I, 508, 599

Botrychium, 259

Helminthostachys, 272

Psilotacex, 508

Sporangium, 4, 7, 271, 272, 273, 303, $304,307,389,412,472,473$ $475,479,500,524,530,53 \mathrm{I}$ $534,556,557,584,600,64 \mathrm{I}$

Botrychium, 268, 269

Cyatheaceæ, 392

dehiscence, 257, 270, 297, 344, 444

eusporangiate, 232 
Sporangium - Cont .

Gleichenia, 370

Hymenophyllaceæ, 38r, 382

Isoetes, 556

Leptosporangiatæ, 232, 339

Lycopodium, 500

Marattiaceæ, 292, 294

Marsiliaceæ, 438

Ophioglossum, 247, 254, 255, 256,257

origin of, 598

Osmundaceæ, 365

Pilularia, 438

Polypodiaceæ, 395

Psilotaceæ, 508, 509

Pteridophytes, 598

Schizæaceæ, 388

Selaginella, 530, 641, 642

Spores, 4, 5, I2, 20, 2I, 36, 60, 64, $74,80,84,96$, III, I 22 , I4I, I 55, I $79,182,185,213,257$, 295, 475, 559

Anacrogynæ, 99

Archidium, 185, I 87

Dendroceros, I 48

Equisetum, 443, 444, 476

germination, 5, I9, 47, 99, II3, I43, 188, 274, 312, 346, 367, $373,4 \mathrm{I} 8,444,486,539$

Gleichenia, 37 I

Hepaticæ, I9

Marattiaceæ, 297

Marchantiaceæ, 47

Notothylas, ${ }_{5} 6$

Porella, III

Psilotacex, 5 IO

Spore-division, 96, 343, 567, 618

Anacrogynæ, 98, 618

Anthoceros, I4I

Porella, III

Riccia, 35

Targionia, 63

Spore-fruit, 14

Spore-membrane, r9, 35, 64, 343, 414, 479
Spore-sac, 179, 205, 206, 210, 213, $2 \mathrm{I} 6,224$

Sporocarp, 4I8, 432

Azolla, 4I2

Marsiliaceæ, 434

Pilularia, 435, 436, 437, 439

Salvinia, 4I 2, 4I 5

Sporogenous cells, 63,342

Sporogenous tissue, 255,37 I

Sporogonium, 5, 20, 187, 203, 221, 225 (see also Sporophyte)

Archidium, I85

Buxbaumia, 225

Funaria, 209

Jungermanniales, 74

Marchantiaceæ, 47, 65

Muscinex, I2

Polytrichum, 224

Riccia, 34

Tetraphis, 220

Sporophore

Muscineæ, I2

Sporophyll, 340, 362, 387, 494, 523, $556,573,583,590,600$

Sporophyte, 3, 4, 5, 6, 8, I2, I3, I4, 2I, 23, 70, 73, IO9, I2I, I23, I $57,227,229,230,562,566$, 575

Anacrogynæ, 94, 95

Andreæa, I84, I85

Anthoceros, I34, I35, I36

Anthocerotes, I 22

apical growth, I65

Archidium, I86

budding, 3 Io

Calycularia, 6I7

Corsinia, 4I

Funaria, 203

Helminthostachys, $27 \mathrm{I}$

Hepaticæ, I8

leafy, 569

Marattiaceæ, 289

Muscineæ, I 2, 594

Notothylas, I 53

Ophioglossum, 245 
Sporophyte - Cont.

origin of, 566,572

Pallavicinia, $6 \mathrm{I} 7$

Pellia epiphylla, 97

Podomitrium, 6I7

Porella, Io9

Pteridophytes, 595

Riccia, 33

Sphærocarpus, 78,79

Targionia, 60

Treubia, 617

Stachygynandrum, 522

Stangeria, 579

"Staubgrübchen," 292

Stegocarpæ, 216, 217, 227, 623

Stele, 464

medullary (Pteris), 328

primary (Polypodiaceæ), 327

Stem, 3, 223, 243, 323, 324, 357, 454, 455,519

Andreæa, 182

apical growth, 190, 247, 248, $262,284,459,494$

Bryales, I94

Dawsonia superba, 222

development of vascular bundles, 327

Equisetum, 459, 460

Ferns, 233

Lycopodium, 495

monostelic, $526,58 \mathrm{I}$

Osmundaceæ, 359

Polypodiaceæ, 328

Polystelic, 526

Polytrichaceæ, 222

Polytrichum, 22I

secondary growth, 263

secondary thickening, 262, 585, 586

Sphagnum, I 72, I73

Structure of,

Angiopteris, 289

Azolla, 4r I

Equisetum, 464

fossil Ferns, 587
Stem-Cont.

Gleichenia, 369

Hymenophyllacex, 378, 379

Isoetes, 553

Marsilia, 432

Matonia, 372

Ophioglossum, 249, 628

Osmundaceæ, 360

Salviniaceæ, 409

Schizæaceæ, 386

Selaginella, 526

Struthiopteris, 329

vascular bundle, $244,250,285$, $326,330,369,496$

Stephaninoidex, I I 9

Sterilization, $5^{6} 7,599$

Stigeoclonium, I 2 I

Stigmaria, 589

Stipules, $273,287,362$

Angiopteris, 290

Stolon, I63, 329

Stomata, I3, I22, I25, I43, I56, I65, I80, 2II, 2I $2,2 \mathrm{I} 3$, $227,25 \mathrm{I}, 266,286,334$, $335,358,467,498,528,555$, 595

Anthoceros, ${ }^{42}$

Azolla, 4II

Schizæaceæ, 387

Stomium, 343

Strobiloid Pteridophytes, 598

Strobilus, 494, 599, 64I

Stromatopteris, 339

moniliformis, 366

Struthiopteris Germanica (see Onoclea), 3I 2

Sturiella, 583

Subsidiary pinnæ, 580

Succubous leaves, II6

Suspensor, 490, 492, 519, 520, 534, $572,64 \mathrm{I}$

Symphyogyna, 87, 573; Fig. 38

Synangium, 273, 292, 297, 300, 303, 508

Synthetic types, 583,588 
Tannin cells, 286, 292

Tapetum, 257, 270, 272, 294, 295, $307,342,343,366,383,438$, $502,53 \mathrm{I}, 532,558,559$

Targionia, 22, 42, 43, 44, 46, 48, $52,58,65,66,67,70,7 \mathrm{I}, 6 \mathrm{ro}$, 6 II

antheridium, 50

archegonium, 53, 55

spore-division, 63

sporophyte, 60

hypophylla, 24, 50; Figs. I, I8, I9, $23,24,27,28$

Targioniaceæ, 609, 6I 2, 6I 3

Targionieæ, 69, 7I

Terrestrial plants, $230,569,575$

Terrestrial sporophyte, 230

Tertiary, 306, 577

Tertiary formations, 439

Tesselina (Oxymitra), 40, 42, 7I, 6 II

pyramidata, 40

Tetraphideæ, 218

Tetraphidales, 622,623

Tetraphis, I6I, I88, 2I8, 226, 227

gemmæ, IO, 219

sporogonium, 220

pellucida, I62, 2I9; Fig. II8

Thallocarpus, 75, 6I5

Theca, 2II, 2I3

Thuidium, I6I, I94

Thyrsopteris elegans; Fig. 229

Tmesipteris, 485, 504, 507, 509, 587,640

tannensis; Figs. 293, 294

Todea, $346,349,359,362,364,635$

Africana, 309

barbara, 362,363

Hymenophylloides; Fig. 207

Trabeculæ, 526, 558, 559

Tracheary tissue, 222, 263, 285, 36I, 472,496

Tracheids, 325,338

prothallium of Botrychium, 243 scalariform, 330
Transpiration, Marchantiaceæ, 69

Traps, leaves (Acrogynæ), II7

Tree-fern, 335, 390, 58I

Treubia, I00, IOI, I 58, 6I 6

gemmæ, 100

insignis, 100

Triassic, $582,583,586$

Trichomanes, $306,339,349,373$, $376,377,380,383,580,597$

gametophyte, 374

alatum, 374

brachypus, 38 I

cyrtotheca; Figs. 219, 22I

Draytonianum; Fig. 2 I4

Hookeri, $38 \mathrm{I}$

labiatum, 380

Motleyi, 380

muscoides, 380

parvulum, 380; Fig. 219

pyxidiferum, 374, $38 \mathrm{r}$

radicans, $379,380,38 \mathrm{I}$

reniforme, 380

rigidum; Fig. 218

venosum, 379; Fig. 220

Trigonantheæ, II9, 620

Trochopteris elegans, 384

Tubers, 69, I3I, I45, 433, 565

Equisetum, 459

Geothallus, 83

Marsilia, 434

Umbraculum, 6I 5

Urn (see Theca), 2 I I

Urnatopteris, 583

Vaginula, I80

Vallecular canals, 464

Vascular bundles, I22, 245, 247, $249,250,252,26 \mathrm{I}, 265,285$, $287,307,325,327,330,357$, $380,433,462,464,471,492$, $496,507,526,528,549,552$, $556,628,629,63 \mathrm{r}, 632,635$ 
Vascular Cryptogams, 23I

Vascular gaps, 465

Vascular plants, I 22, I65, 222

Vaucheria, 562, 564

Veins,

development, 333

pseudo-, $38 \mathbf{I}$

structure, 334

Velum, 537, 558, 604

Venation,

cotyledon, 326

Ferns, 580

Pecopteris type, 580

Sphenopteris type, 580

Ventral hairs,

$$
\text { Metzgeria, } 86
$$

Ventral lamellæ,

Marchantiaceæ, 43

Ricciocarpus, 40

Viscum, 504

Vittaria, 233, 393, 394
Walking fern, 3 ro (see also Camptosorus)

Water-absorption, 565, 566

Water-conducting cells, 222

Water-conduction, 565

Water-conservation, Marchantiaceæ, 69

Water supply, 229, 568

Webera nutans, I60

Weisia, 2 r 8

Wiesnerella, 6I2, 6I4

Woodwardia radicans; Figs. I83, I84

Xerophytes, 230

Xerophytic Marchantiacex, 67

Yucca, 554, 590

Zamia, $32 \mathrm{I}$

Zoöspores, 9, 86, 563, 593

Zygote, 563, 566, 569 
THE following pages contain advertisements of books by the same author or on kindred subjects 



\title{
A University Text-Book of Botany
}

\author{
By DOUGLAS H. CAMPBELL, Ph.D.
}

Professor of Botany in the Leland Stanford Jr. University, California

With many illustrations. Cloth, $8 v 0, \$ 4.00$

"It seems to me that it will form an admirable handbook for university work where one wishes in brief form a treatment of the subject to cover all phases of the subject. The illustrations are excellent, and the matter is presented with the forcefulness which is characteristic of its author."-G. F. Atkinson, Professor of Botany, Cornell University.

This is a new and revised edition of a standard work of reference - not a laboratory manual - for the use of students in American colleges and universities. Professor Campbell is one whose position and experience have equipped him with a thorough acquaintance with university requirements; he writes in a style that impresses his knowledge on the reader.

\section{THE MACMILLAN COMPANY Publishers 64-66 Fifth Avenue New York}




\title{
A Text-Book of Botany for Colleges
}

\section{By WILLIAM FRANCIS GANONG,}

\author{
Professor of Botany in Smith College
}

Part I, The Structures and Functions of Plants. Illustrated

$$
\text { Cloth, } x i i+604 \text { pp., Index, Ill., I2mo, } \$ 2.50
$$

This work embodies the results of the author's well-known interest in educational problems, and his long practical experience in botanical teaching. It is intended for college students in the general or introductory courses in botany. While a clear exposition of the fundamental facts of the science is the first aim, the effort is also made to keep prominent the idea of interpretation or explanation of the principles of botanical phenomena, particularly those which are frequently met with. The economic aspects of botany receive careful consideration in conjunction with the scientific phenomena which respectively underlie them. In order that the professor who is using the book may be enabled to continue the type of laboratory work which he has found adapted to his particular situation, the book is prepared in the form of semi-independent sections, each of which deals with a leading topic. This method of treatment will also make the book desirable for the general reader who is interested in the subject of botany and who finds the prevailing form of text inconvenient for reference.

\section{THE MACMILLAN COMPANY}

Publishers 64-66 Fifth Avenue New York




\section{Plant Breeding}

474 pp., Ill., I2mo, $\$ 2.00$

By L. H. BAILEY, formerly Director of the New York State Agricultural College. New Edition revised by A. W. GilberT, formerly Professor of Plant Breeding in the New York State College of Agriculture.

As the text is now issued, the material in the old edition has been thoroughly revised and brought down to date. New discussions of mutations, Mendelism, heredity, and the recent applications of the breeding of plants are all included.

\section{Trees in Winter}

$446 \mathrm{pp}$., Ill., I2mo, $\$ 2.00$

By ALBERT F. BLAKESLEE, formerly Professor of Botany and Director of Summer School at the Connecticut Agricultural College, and CHESTER D. JARVIS, formerly Horticulturist of the Storrs Agricultural Experiment Station.

Gives the needed information in regard to the kinds of trees to select for different purposes, where to locate them, when and how to plant them, how to take care of them and protect them from insects, fungus, and other injuries.

\section{Plant Physiology} 516 pp., I2mo, $\$ 1.60$

\section{With Special Reference to Plant Production}

By BENJAMin M. DUGGaR, Ph.D., Professor of Plant Physiology in Washington University and Director of the Missouri Botanical Gardens.

Discusses the life relations of plants and crops from a fundamental point of view. The important physiological activities of the plant are demonstrated experimentally, and the practices of the crop-grower are reviewed from this standpoint.

\section{The Fungi Which Cause Plant Disease $77_{3}$ pp., Ill., $8 v 0, \$ 4.00$}

By F. L. STEVENS, Professor of Plant Pathology in the University of Illinois.

It introduces the student to the more important cryptogamic parasites affecting economic plants in the United States and provides adequate keys and descriptions for their identification. Technical description of each division, order, family, genus and species is given.

\section{THE MACMILLAN COMPANY}

\section{Publishers 64-66 Fifth Avenue New York}




\section{The Principles of Plant Culture}

295 pp., Ill., I $2 m o, \$ 1.25$

By the late Professor E. S. GOFF, of the University of Wisconsin. Revised by Professors L. R. Jones and J. G. MOORE, of the University of Wisconsin.

A text-book for beginners in agriculture and horticulture. It explains the cycle of plant life from seed to flower and fruit; the influence of environment on plants, as also of temperature, unfavorable water supply, of weather and food supply; the destructiveness of weeds, insects and diseases. It discusses propagation, pruning, transplanting and plant breeding.

\section{The Teaching Botanist}

439 pp., I2mo, $\$ 1.25$

By WILLIAM F. GANONG, Professor of Botany in Smith College.

A manual of information upon botanical instruction, together with outlines and directions for a comprehensive elementary course. This work consists of a series of descriptive essays upon matters important in botanical education, together with suggested outlines, with full practical directions, for a general or introductory course in accordance with the results of the best recent experience.

\section{Diseases of Economic Plants}

400 pp., Ill., I2mo, $\$ 2.00$

By F. L. STEVENS, Professor of Plant Pathology, University of Illinois, and J. G. HALL, formerly Professor of Plant Pathology, Washington State College.

Designed for those who wish to recognize and treat diseases without the burden of long study as to their causes. It indicates the chief prominent characters of the most destructive diseases of plants, caused by bacteria or fungi, in the United States, in such a way that in most cases reliable diagnoses may be made. Information is given regarding the best methods of prevention or cure for these diseases.

\section{THE MACMILLAN COMPANY \\ Publishers 64-66 Fifth Avenue New York}









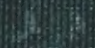
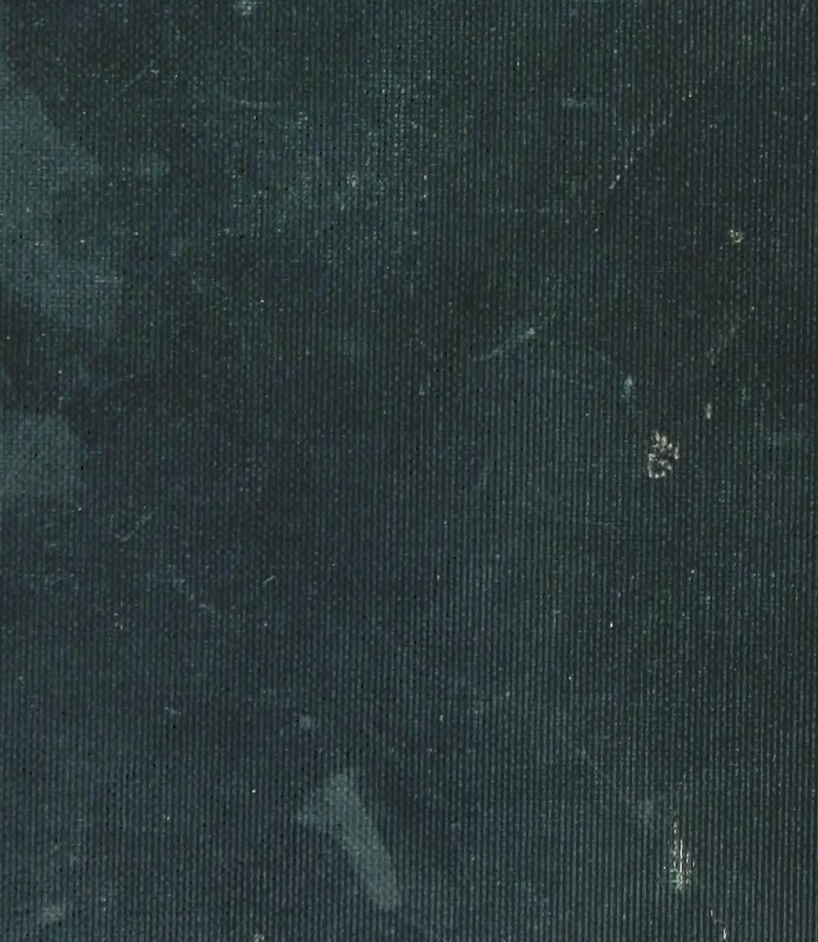